\title{
DEVELOPMENT AND APPLICATION OF OPTIMAL DESIGN CAPABILITY FOR COAL GASIFICATION SYSTEMS
}

Technical Documentation:

Oxygen-based Combustion Systems (Oxyfuels) with

Carbon Capture and Storage (CCS)

Final Report of

Work Performed Under Contract No.: DE-AC21-92MC29094

Reporting Period Start, October 2003

Reporting Period End, May 2007

Report Submitted, May 2007

to

U.S. Department of Energy

National Energy Technology Laboratory

626 Cochrans Mill Road, P.O. Box 10940

Pittsburgh, Pennsylvania 15236-0940

by

Edward S. Rubin (P.I.)

Anand B. Rao

Michael B. Berkenpas

Carnegie Mellon University

Center for Energy and Environmental Studies

Department of Engineering and Public Policy

Pittsburgh, PA 15213-3890 



\section{Contents}

Objective

Literature Review $\quad 2$

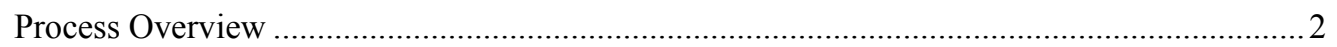

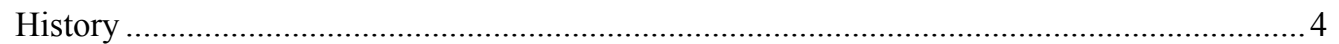

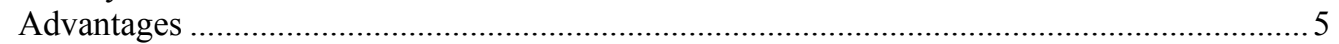

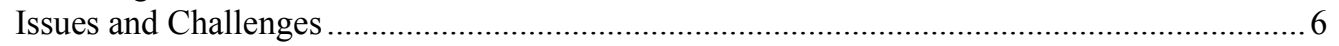

$\begin{array}{ll}\text { Performance Model } & 8\end{array}$

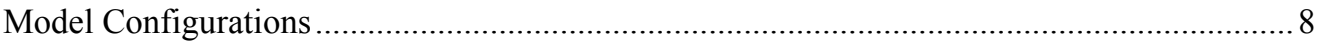

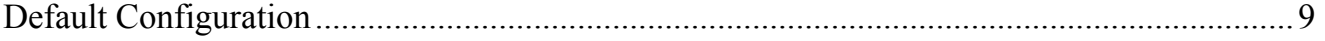

Key Model Parameters.............................................................................................. 9

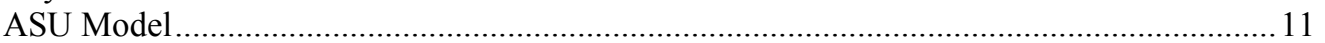

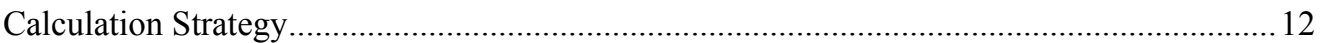

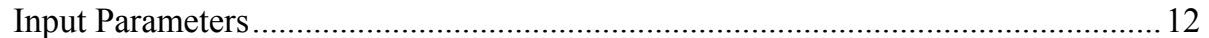

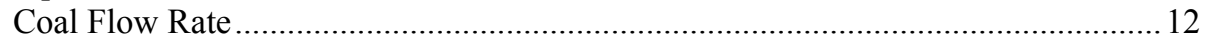

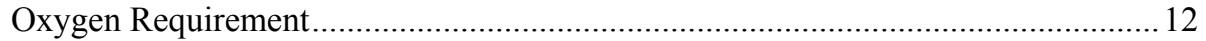

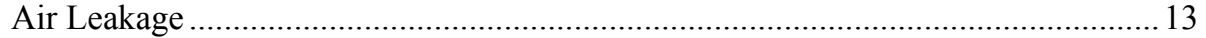

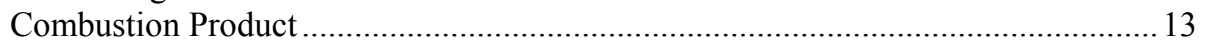

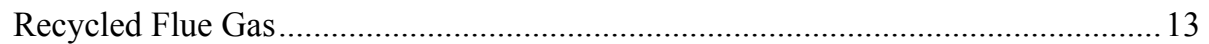

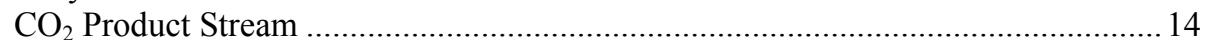

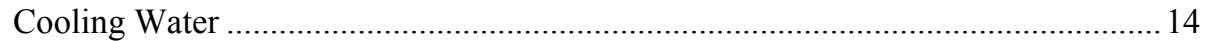

Power Requirement ………………….............................................................. 14

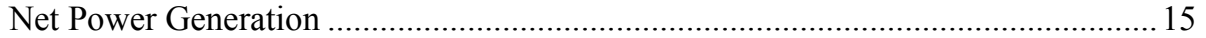

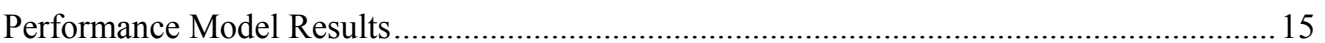

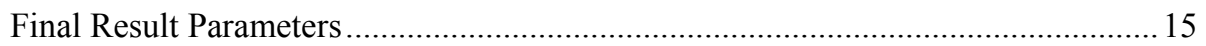

Intermediate Result Parameters ................................................................................ 16

$\begin{array}{ll}\text { Cost Model } & 17\end{array}$

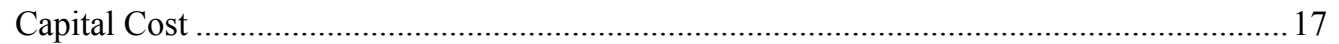

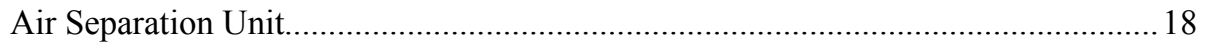

Flue Gas Recycle Fan........................................................................................ 19

Flue Gas Recycle Ducting .................................................................................... 19

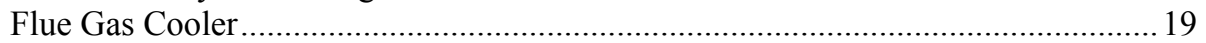

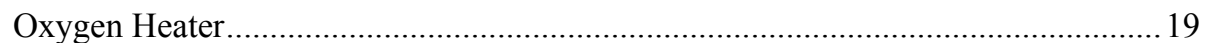

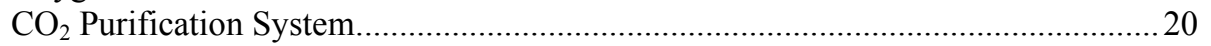

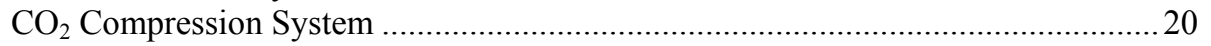

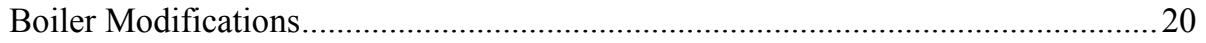

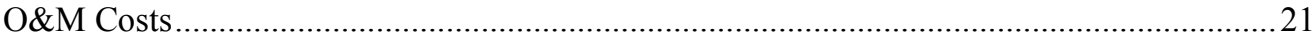

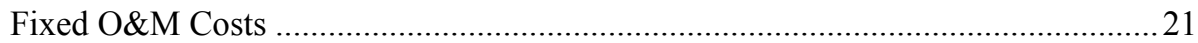

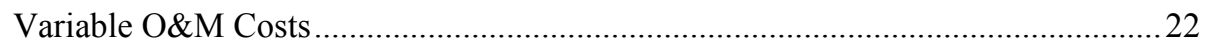




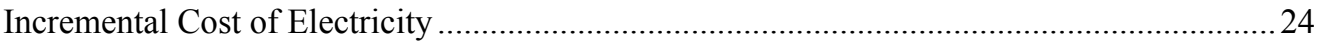

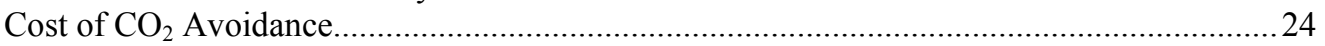

$\begin{array}{ll}\text { Case Study } & 26\end{array}$

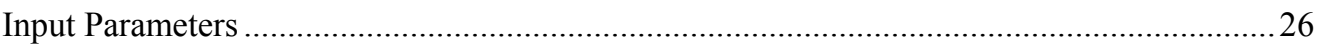

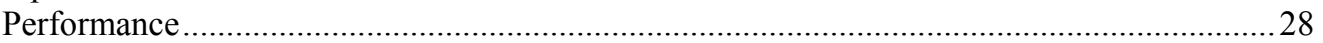

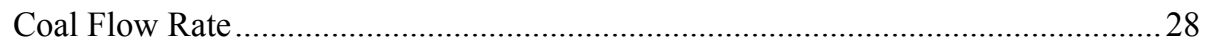

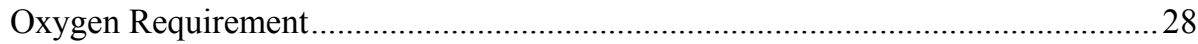

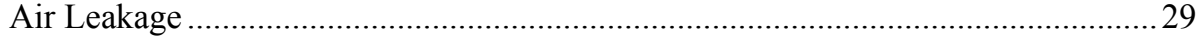

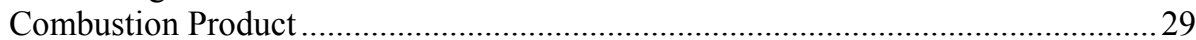

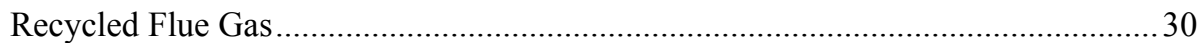

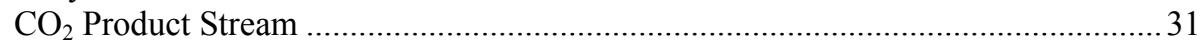

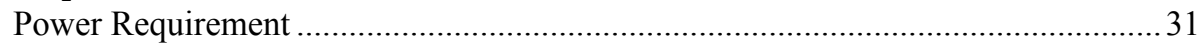

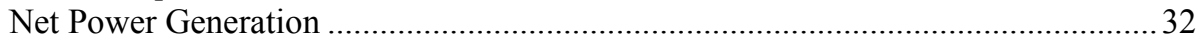

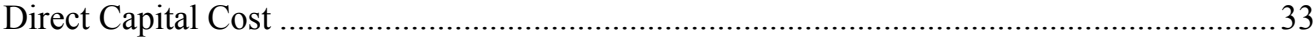

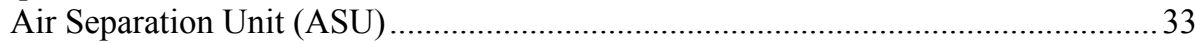

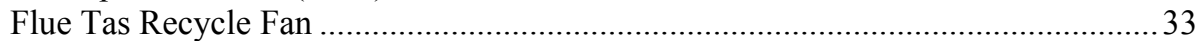

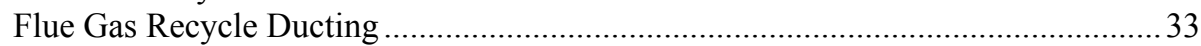

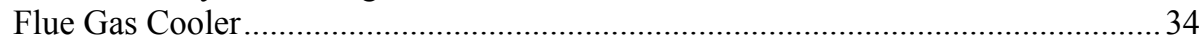

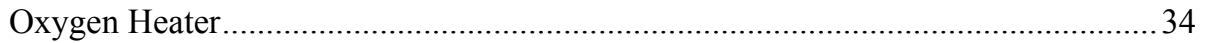

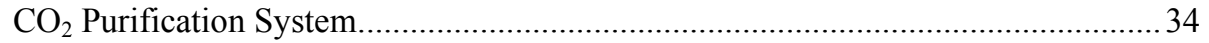

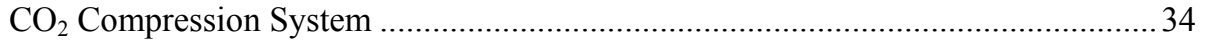

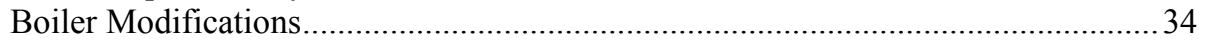

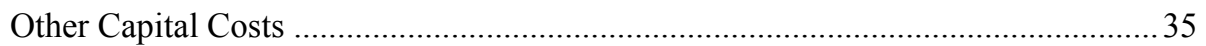

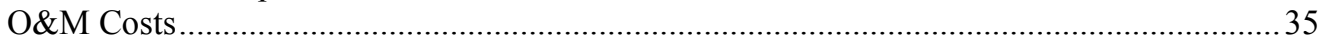

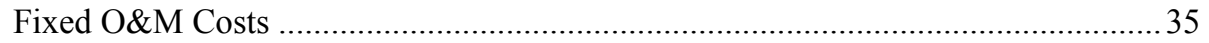

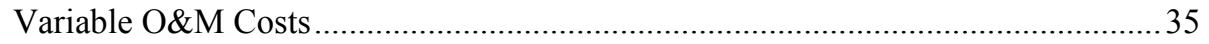

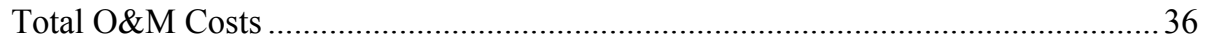

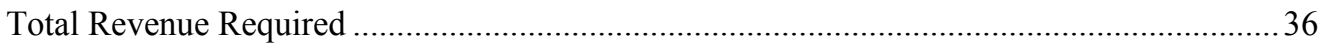

$\begin{array}{ll}\text { References } & 37\end{array}$ 


\section{List of Figures}

Figure 1. Oxyfuel combustion $(\mathrm{O} 2 / \mathrm{CO} 2)$ system configuration in IECM-CS model.......................................................

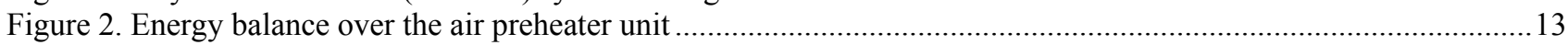




\section{List of Tables}

Table 1. Summary of oxyfuel plant configurations assumed by various studies (data not available is represented by a blank entry in the table).

\section{.3}

Table 2. Summary of the key process parameter values assumed by various studies (data not available is represented by a blank entry in the table).

Table 3. Key process parameter values in IECM-CS oxyfuel model ........................................................................11

Table 4. Plant cost index (PCI) as a function of the costing year ................................................................................ 18

Table 5. Oxyfuel combustion system capital cost model parameters and nominal values ............................................2

Table 6. Oxyfuel combustion system O\&M cost model parameters and nominal values .............................................22

Table 7. Design parameters for case study of a pulverized coal plant with $\mathrm{CO}_{2}$ control using $\mathrm{O}_{2} / \mathrm{CO}_{2}$ recycle (oxyfuel

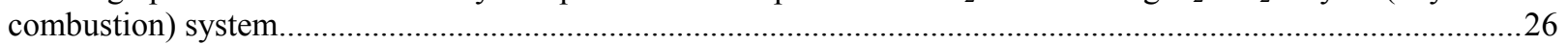

Table 8. Coal properties and associated oxygen requirements for stoichiometric combustion. …..................................28

Table 9. Combustion products of the flue gas stream. All values are in units of $\mathrm{lb}-\mathrm{mole} / \mathrm{hr}$.........................................29

Table 10. Oxidant and recycled flue gas composition. All values are in units of lb-mole/hr.........................................30

Table 11. Final oxidant and recycled flue gas composition All values are in units of $\mathrm{lb}-\mathrm{mole} / \mathrm{hr}$...................................30 


\section{Disclaimer}

This report was prepared as an account of work sponsored by an agency of the United States Government. Neither the United States Government nor any agency thereof, nor any of their employees, makes any warranty, express or implied, or assumes any legal liability or responsibility for the accuracy, completeness, or usefulness of any information, apparatus, product, or process disclosed, or represents that its use would not infringe privately owned rights. Reference herein to any specific commercial product, process, or service by trade name, trademark, manufacturer, or otherwise does not necessarily constitute or imply its endorsement, recommendation, or favoring by the United States Government or any agency thereof. The views and opinions of authors expressed herein do not necessarily state or reflect those of the United States Government or any agency thereof. 


\section{Acknowledgements}

This report is an account of research sponsored by the U.S. Department of Energy's National Energy Technology Center (DOE/NETL) under Contract No. DE-AC2192MC29094. 


\section{Objective}

The basic objective of this research is to develop a model to simulate the performance and cost of oxyfuel combustion systems to capture $\mathrm{CO}_{2}$ at fossil-fuel based power plants. The research also aims at identifying the key parameters that define the performance and costs of these systems, and to characterize the uncertainties and variability associated with key parameters. The final objective is to integrate the oxyfuel model into the existing IECM-CS modeling framework so as to have an analytical tool to compare various carbon management options on a consistent basis [1]. 


\section{Literature Review}

\section{Process Overview}

Oxyfuel combustion for $\mathrm{CO}_{2}$ capture was first proposed in 1981 by researchers at the Argonne National Laboratory. The basic approach is to use pure oxygen for combustion, rather than air, so as to produce a flue gas stream consisting mainly of $\mathrm{CO}_{2}$ and water vapor. The water is then easily removed, leaving a concentrated $\mathrm{CO}_{2}$ stream for disposal. To prevent excessively high temperatures in the boiler, a portion of the flue gas stream is recycled back to the boiler to dilute the oxygen and maintain temperatures similar to conventional air-blown designs.

A review of recent studies reveals that different organizations employ substantially different design assumptions regarding the plant configuration. Table 1 summarizes the configuration options defining the scope of an oxyfuel plant model assumed by various studies [2-15]. These studies also use different assumptions for various process parameters, as indicated in Table 2. 
Table 1. Summary of oxyfuel plant configurations assumed by various studies (data not available is represented by a blank entry in the table)

\begin{tabular}{|c|c|c|c|c|c|c|c|c|c|}
\hline $\begin{array}{l}\text { Studyl } \\
\text { Reference }\end{array}$ & Year & $\begin{array}{l}\text { Plant type } \\
\& \text { size } \\
\left(M_{\mathrm{g}}\right)^{1}\end{array}$ & $\begin{array}{l}\text { Flue gas } \\
\text { recycle }^{2}\end{array}$ & $\begin{array}{l}\text { Particle } \\
\text { removal }^{3}\end{array}$ & FGD $^{4}$ & $S R^{5}$ & $\begin{array}{l}\text { Flue } \\
\text { gas } \\
\text { cooler }^{6}\end{array}$ & $\begin{array}{l}\text { Dry } \mathrm{CO}_{2} \\
\text { refining }\end{array}$ & $\begin{array}{l}\text { Other } \\
\text { units }^{8}\end{array}$ \\
\hline Dillion et al. [2] & 2004 & New, 740 & Dry & ESP & No & No & Yes & Distill & No \\
\hline AAL [3] & 2004 & New, 533 & Wet & ESP, out & Yes $^{*}$ & No & No & No & $\mathrm{ACI}$ \\
\hline AAL [4] & 2003 & $\begin{array}{l}\text { Retrofit, } \\
\text { multiple }\end{array}$ & Wet & ESP, out & Yes $^{*}$ & $\begin{array}{l}\text { Option } \\
\mathrm{al}^{*}\end{array}$ & No & No & ACI \\
\hline AAL [4] & 2003 & $\begin{array}{l}\text { New, } \\
\text { multiple }\end{array}$ & No & ESP & Yes & No & No & No & ACI \\
\hline ANL [4] & 2003 & Retrofit & Wet & ESP & Yes & No & No & No & $\begin{array}{l}\mathrm{APH}, \\
\mathrm{O}_{2} \mathrm{htr}\end{array}$ \\
\hline U Waterloo [6] & 2003 & $\begin{array}{l}\text { Retrofit, } \\
400\end{array}$ & Wet & & & & Yes & Distill & $\begin{array}{l}\text { Aux } \\
\text { power }\end{array}$ \\
\hline \begin{tabular}{|l} 
Chalmers/ \\
Vattenfall $[7,8]$
\end{tabular} & 2002 & New, 933 & Wet & Cyclone & No & & No & Distill & No \\
\hline $\begin{array}{l}\text { ALSTOM/ } \\
\text { ABB/AEP [9] }\end{array}$ & 2001 & $\begin{array}{l}\text { Retrofit, } \\
463\end{array}$ & Wet & ESP & Yes & No & Yes & Distill & No \\
\hline $\begin{array}{l}\mathrm{AP} / \mathrm{BP} / \mathrm{Babcock} \\
{[10]}\end{array}$ & 2000 & New & Wet & & No & No & Yes $^{*}$ & Distill & No \\
\hline Simbeck [11] & 2000 & New, 575 & Dry & Baghouse & No & No & No & No & No \\
\hline Simbeck [11] & 2000 & $\begin{array}{l}\text { Retrofit, } \\
318\end{array}$ & Wet & ESP & No & No & No & No & $\begin{array}{l}\text { Aux } \\
\text { power }\end{array}$ \\
\hline $\begin{array}{l}\text { McDonald \& } \\
\text { Palkes [12] }\end{array}$ & 1999 & $\begin{array}{l}\text { Retrofit, } \\
318\end{array}$ & Wet & ESP & No & No & Yes & Distill & $\begin{array}{l}\mathrm{APH}, \\
\mathrm{O}_{2} \mathrm{htr}\end{array}$ \\
\hline $\begin{array}{l}\text { Babcock et al. } \\
{[13]}\end{array}$ & 1995 & 660 & Dry & ESP & No & No & Yes & Distill & Claus \\
\hline Air Products [14] & 1992 & $\begin{array}{l}\text { Retrofit, } \\
572\end{array}$ & Wet & & & & & Distill & No \\
\hline Japanese [15] & 1992 & New, 1000 & Wet, Dry & ESP & No & No & Yes $^{*}$ & No & No \\
\hline
\end{tabular}

${ }^{1}$ Gross plant size (MW)

${ }^{2}$ Recycled flue gas may be wet (retaining the moisture) or dry (dried and then recycled)

${ }^{3}$ Removal of particulate matter in the flue gas can be achieved using an Electro-static precipitator (ESP) or a Cyclone or a Bag house

${ }^{4}$ Flue gas desulfurization system for $\mathrm{SO}_{2}$ control

${ }^{5}$ Selective catalytic reactor for $\mathrm{NO}_{\mathrm{x}}$ control

${ }^{6}$ Flue gas cooling is generally required and is achieved using a direct contact cooler

${ }^{7}$ In order to achieve high purity $\mathrm{CO}_{2}$ product, distillation (Distill) is commonly used to remove inerts

${ }^{8}$ Some of the studies mention other additional units such as: Activated carbon injection (ACI) system for mercury control, Air pre-heater (APH) and oxygen heater for better heat integration, Auxiliary power generation (Aux power), and Claus plant (Claus) to recover sulfur from $\mathrm{SO}_{2}$ stream

*All these units are located outside the recycle loop, else they are located inside the recycle loop by default

- Multiple plant sizes: 500, 200, 100 and $30 \mathrm{MW}_{\mathrm{g}}$ 
Table 2. Summary of the key process parameter values assumed by various studies (data not available is represented by a blank entry in the table)

\begin{tabular}{|c|c|c|c|c|c|c|c|c|c|c|}
\hline $\begin{array}{l}\text { Studyl } \\
\text { Reference }\end{array}$ & Year & $\begin{array}{l}\text { FGR } \\
\text { ratio }^{1}\end{array}$ & $\begin{array}{c}\text { Oxygen } \\
\text { purity (mole } \\
\%)^{2} \\
\end{array}$ & \begin{tabular}{|c}
$\begin{array}{c}\text { Excess } \\
\text { air } \\
(\%)^{3}\end{array}$ \\
\end{tabular} & $\begin{array}{c}\text { Air } \\
\text { leakage } \\
(\%)^{4}\end{array}$ & $\begin{array}{l}\text { FGR } \\
\text { temp } \\
\left({ }^{\circ} \mathrm{C}\right)^{5}\end{array}$ & $\begin{array}{l}\mathrm{CO}_{2} \text { purity } \\
(\text { mole \%) }\end{array}$ & $\begin{array}{c}\eta_{\cos ^{\circ}} \\
(\%)^{7}\end{array}$ & $\begin{array}{l}\% \text { change } \\
\text { in } \eta_{\text {boiler }}^{8}\end{array}$ & $\begin{array}{l}\text { \% change } \\
\text { in } \mathrm{NO}_{\mathrm{x}}^{9}\end{array}$ \\
\hline Dillion et al. [2] & 2004 & $\begin{array}{l}0.67, \\
\text { w/w }\end{array}$ & 95 & 19 & & 35,330 & 96 & $\sim 91$ & & \\
\hline AAL [3] & 2004 & $\begin{array}{l}0.75 \text { to } \\
0.8\end{array}$ & 99 & & $\sim 5$ & & 95 & $\sim 100$ & & -70 \\
\hline AAL [4] & 2003 & & & & & & & & & $?$ \\
\hline AAL [4] & 2003 & 0.0 & & & & & & & & $\begin{array}{l}-53 \text { to }- \\
76\end{array}$ \\
\hline ANL [4] & 2003 & & & & & & & & & \\
\hline U Waterloo [6] & 2003 & 0.71 & 99.5 & 3 & 1 & 40 & 95 & 90 & & \\
\hline $\begin{array}{l}\text { Chalmers/ } \\
\text { Vattenfall }[7,8]\end{array}$ & 2002 & $\begin{array}{l}0.64 \\
w / w\end{array}$ & 95 & 1.5 & & 340 & $98, \mathrm{w} / \mathrm{w}$ & $\sim 100$ & & -67 \\
\hline $\begin{array}{l}\text { ALSTOM/ } \\
\text { ABB/ AEP [9] }\end{array}$ & 2001 & $\sim 0.67$ & 95,99 & 15 & 1 & 38 & 98 & 94 & +2.7 & \\
\hline $\begin{array}{l}\mathrm{AP} / \mathrm{BP} / \\
\text { Babcock [10] }\end{array}$ & 2000 & $\sim 0.67$ & 95 & & & 31 & $\sim 97$ & 93 & & \\
\hline Simbeck [11] & 2000 & $\begin{array}{l}0.71 \\
\mathrm{w} / \mathrm{w}\end{array}$ & 95 & 0 & & & & 100 & 0 & \\
\hline Simbeck [11] & 2000 & $\begin{array}{l}0.73, \\
\mathrm{w} / \mathrm{w}\end{array}$ & 99.5 & 6.5 & 1 & & 85 & & +3.5 & -31 \\
\hline $\begin{array}{l}\text { McDonald \& } \\
\text { Palkes [12] }\end{array}$ & 1999 & $\sim 0.67$ & 99 & & 1 & 38 & 98 & & +3.5 & \\
\hline $\begin{array}{l}\text { Babcock et al. } \\
{[13]}\end{array}$ & 1995 & $\begin{array}{l}0.65 \\
0.75 \\
0.85\end{array}$ & $95,99.5$ & $\begin{array}{l}10,15 \\
17\end{array}$ & $0,1,3,5$ & 45 & 85 to 99 & $\begin{array}{l}95 \text { to } \\
100\end{array}$ & +4 to +6 & -60 \\
\hline $\begin{array}{l}\text { Air Products } \\
{[14]}\end{array}$ & 1992 & & 99.5 & 2 & & & & 98 & & \\
\hline Japanese [15] & 1992 & & 97.5 & & & & $95+$ & 90 & +3 & \\
\hline
\end{tabular}

\section{History}

The fact that oxygen is required for sustaining a combustion reaction has been known for centuries. The name "oxygen" comes from the Greek words "oxy genes" meaning "acid former." Although oxygen was prepared by several researchers by the late $18^{\text {th }}$ century, it was not recognized as an element until identified by Joseph Priestley, an English chemist, who is generally credited with the discovery of oxygen in 1774. Swedish researcher Carl Wilhelm Scheele had independently discovered oxygen and studied its properties during 1771-3, but his work was published later in 1777. Oxygen was liberated by intensely heating mercury oxide, which is a common laboratory procedure to produce oxygen even today [16-18].

\footnotetext{
${ }^{1}$ Flue gas recycle (FGR) ratio is the fraction of the total flue gas being recycled to the boiler

${ }^{2}$ Purity of the oxygen used in the oxyfuel combustion process

${ }^{3}$ Excess air is the fraction of theoretical air (or oxidant), and is used to ensure complete combustion

${ }^{4}$ Undesired air infiltration into the boiler, expressed as a fraction of theoretical air

${ }^{5}$ The temperature at which the recycled flue gas stream is introduced back into the boiler

${ }^{6}$ The percentage of $\mathrm{CO}_{2}$ present in the product stream

${ }^{7}$ The overall $\mathrm{CO}_{2}$ capture or removal efficiency of the system

${ }^{8}$ Boiler efficiency is the fraction of energy in combustion that is converted to steam energy; this column represents the relative efficiency of oxygen-firing to air-firing

${ }^{9} \mathrm{NO}_{\mathrm{x}}$ emission rate (lb/MBtu) for oxygen-firing, relative to air-firing
} 
It took more than a hundred years after the discovery of oxygen for a large-scale production of oxygen. Air, which is an abundant source of oxygen, could not be used to produce pure oxygen until the end of $19^{\text {th }}$ century. Carl von Linde obtained a patent for the world's first modern refrigerator in 1877, an essential component of modern cryogenic systems. He was among the first in the world to produce large volumes of liquid air (1895), and in 1902 began constructing his first air separation unit $[19,20]$. Oxygen production plants using air separation technology became commercially available in another decade or two, and many more companies entered this field. Air Products, Inc. built its first oxygen generator in the 1940s and is now one of the leading manufacturers of oxygen plants [21].

Oxygen was being produced for various industrial uses and also for use in the health care sector. High temperature flames using oxyfuel combustion (e.g., using acetylene) became popular in welding and other metal processing applications. Large amounts of oxygen are also consumed in various petrochemical industries to produce a large array of chemicals and polymers.

The idea of using oxyfuel combustion for $\mathrm{CO}_{2}$ capture in a coal-fired furnace is much more recent. It was first proposed by Horne and Steinberg in 1981, and was also being studied by Wolsky and others at Argonne National Laboratory at that time [14]. There was a growing interest in capturing $\mathrm{CO}_{2}$ during the 1970 s, not because of greenhouse gas concerns, but due to its potential use in enhanced oil recovery. In 1982, Abraham et al claimed that oxyfuel combustion was $20 \%$ cheaper than an MEA process for $\mathrm{CO}_{2}$ capture [22]. Later, as the oil crisis of the late 1970s subsided, and real oil prices fell, the interest in capturing $\mathrm{CO}_{2}$ also diminished. Some experimental work continued at ANL and a few other places through the 1980s and early 1990s [23]. Many more research groups started looking into this technology in late 1990s, when greenhouse gas control emerged as a global environmental issue.

Oxyfuel technology is now being promoted as a promising option for $\mathrm{CO}_{2}$ capture from power plants. However, it is still in the early stages of development. Although various parts of this system (such as oxygen production and flue gas treatment) are commercially available today, only laboratory-scale studies of oxyfuel combustion for coal-fired power generation have been conducted so far, with some pilot plant studies also in progress. Recently, Vattenfall has announced a plan to build a 40MWt demonstration plant using oxyfuel combustion technology.

\section{Advantages}

A number of features make oxyfuel combustion technology a potentially attractive option for capturing $\mathrm{CO}_{2}$ from power plants [24-26].

- Use of steam cycle technology: Oxyfuel combustion systems use conventional boiler technology, which the power plant community is familiar with. This also makes it a potential candidate for $\mathrm{CO}_{2}$ retrofits to existing steam plants. As it does not use any major chemical processes (like gasification, water-gas shifting, etc.), it is perceived as a more reliable system. More importantly, independent of greenhouse gas concerns, there are on-going efforts to improve the steam cycle efficiency. Oxyfuel combustion systems would benefit from these developments as well.

- Nitrogen-free combustion: When air is used in conventional combustion, it introduces a large amount of nitrogen which is inert (does not help the combustion reaction). When pure oxygen is used in place of air, the quantity of flue gas generated reduces substantially. 
This leads to reductions in equipment sizes and heat losses, and to savings in the cost of flue gas treatment.

- Lower emissions: Use of oxyfuel combustion technology with $\mathrm{CO}_{2}$ capture opens up the possibility of a zero-emission (or close to zero emissions) coal power plant. Almost all the $\mathrm{CO}_{2}$ from the plant can be captured using this process, whereas other $\mathrm{CO}_{2}$ capture technologies become increasingly expensive as the $\mathrm{CO}_{2}$ capture efficiency approaches $100 \%$. Various experimental studies using $\mathrm{O}_{2} / \mathrm{CO}_{2}$ recycle show significant reduction in $\mathrm{NO}_{\mathrm{x}}$ formation, as part of the $\mathrm{NO}_{\mathrm{x}}$ in the recycle stream is believed to get dissociated to form nitrogen [27-30]. Thus, the $\mathrm{NO}_{\mathrm{x}}$ levels in these boilers may fall significantly. Some studies have also reported substantial reduction in mercury emissions as well as enhanced $\mathrm{SO}_{2}$ removal efficiency in FGD units [31, 32]. Finally, there is a possibility of co-capture of other pollutants (especially $\mathrm{SO}_{2}$ ) along with $\mathrm{CO}_{2}$, if co-disposal becomes feasible and acceptable.

- Potential cost savings: At present, oxyfuel configurations assume an externally recycled flue gas stream, required to control temperature in the boiler in order to avoid ash melting problems. However, better materials and boiler designs may help eliminate (or substantially cut down) the need for recycled flue gas. This would lead to very compact boilers and flue gas cleanup devices, which cost substantially less. Further cost savings are also expected from improved efficiency, elimination of certain flue gas cleanup devices (e.g. SCR) and improvements or new developments in oxygen production technology (e.g. use of ion transport membranes).

\section{Issues and Challenges}

Several key issues or challenges need to be addressed in order to make oxyfuel capture systems feasible and competitive [24-26].

- Boiler design: Today there is lack of fundamental knowledge in order to design a boiler using pure oxygen for combustion. For example, how much excess oxygen would be required? What kind of oxygen distribution system needs to be used to ensure complete combustion of the fuel into $\mathrm{CO}_{2}$ and water (and avoiding $\mathrm{CO}$ formation)? There is a need for more experimental and modeling work, as well as for verification and validation of reliable heat transfer models. Use of pure oxygen for combustion leads to very high flame temperature. This may lead to problems such as ash melting and high-temperature $\mathrm{NO}_{\mathrm{x}}$ formation. Also required are new materials that can be used to fabricate the high temperature boilers, especially if flue gas is not recycled. Another potential problem with the boiler design is air leakage. The main reason for using pure oxygen for combustion is to obtain a flue gas which is almost all $\mathrm{CO}_{2}$ when dried. However, air leakage may lead to significant amount of nitrogen in the flue gas. Designing an air-sealed boiler is a challenge.

- Large-scale oxygen production: For a typical power plant, the oxygen requirement would be very large, several multiples of other current industrial applications. Current air separation technology (cryogenic) has a very large energy requirement and capital cost. 
Determining the optimum level of oxygen purity is another challenge, and is dependent on the $\mathrm{CO}_{2}$ product purity requirements.

- Co-capture and co-disposal: Although it is commonly assumed that $\mathrm{CO}_{2}$ could be disposed of along with $\mathrm{SO}_{2}$ and $\mathrm{NO}_{\mathrm{x}}$, it is not clear yet, if this would be technically feasible (e.g., because of potential problems in compression of this mixture, as well as corrosion issues in pipeline transport). Economic viability and environmental acceptability are other key factors. Depending upon the $\mathrm{CO}_{2}$ purity requirement as dictated by regulation or the end user, further purification of the flue gas may be required.

- Other environmental emissions: An oxyfuel combustion system, especially if it uses near-stoichiometric or low excess oxygen, may have higher $\mathrm{CO}$ emissions, and may also leave some unburned carbon. Secondly, the condensate from this process has higher amounts of dissolved acidic gases and hence needs treatment. Also, it is possible that trace toxic substances might be introduced to storage sites (e.g. geologic formations) through co-capture and co-disposal. 


\section{Performance Model}

A preliminary model has been developed to simulate the performance of oxyfuel combustion system for $\mathrm{CO}_{2}$ capture. It is designed to yield mass and energy flows across the various units such as the ASU (oxygen generator), boiler, air preheater, oxygen preheater, flue gas recycle fan and other plant components. The model has been built and integrated with the existing IECM-CS modeling framework [1].

In order to determine the most suitable configuration, it is necessary to consider the following questions:

- Is the recycled flue gas dried (dry recycle) or is it recycled along with its moisture content (wet recycle)?

- Is it necessary to cool the flue gas prior to recycle?

- What type(s) of particulate control unit should be used (cyclone, baghouse or cold ESP)? If ESP is used, how would the performance get affected because of different flue gas composition (as compared to conventional system)?

- Is the recycled flue gas stream treated for particulate control?

- Should the flue gas be treated for $\mathrm{SO}_{\mathrm{x}}$ and $\mathrm{NO}_{\mathrm{x}}$ control?

- If the flue gas is treated for $\mathrm{SO}_{\mathrm{x}}$ and $\mathrm{NO}_{\mathrm{x}}$ control, where would these units be placed with respect to the recycle point?

- If the $\mathrm{CO}_{2}$ product is disposed with $\mathrm{SO}_{\mathrm{x}}$ and $\mathrm{NO}_{\mathrm{x}}$ content, how might it affect the performance of the compression system and the cost of transport and storage?

We have attempted to address each of these questions based on a review of the literature. In defining the scope of an oxyfuel system model, we have also considered tradeoffs between the number of configuration options and the resulting data requirements and complexity added to the model.

\section{Model Configurations}

The following menu system configuration options are included in the current model:

- Plant type: New or Retrofit

- Steam cycle: Sub-critical or supercritical

- Oxygen generator: Cryogenic or ITM (advanced) 
- Flue gas recycle: Wet recycle or dry recycle

- Particulate removal: ESP/cyclone/baghouse

- Flue gas cooler: Yes (within recycle loop) or No

- If FGR and FG cooler: Where should it be located?

- FGD - optional

- SCR - optional

- $\mathrm{CO}_{2}$ purification system - optional

- Heat integration features: APH, $\mathrm{O}_{2}$ heater, use of $\mathrm{N}_{2}$

\section{Default Configuration}

The default model configuration for the oxyfuel combustion system for $\mathrm{CO}_{2}$ capture in IECM-CS is as follows:

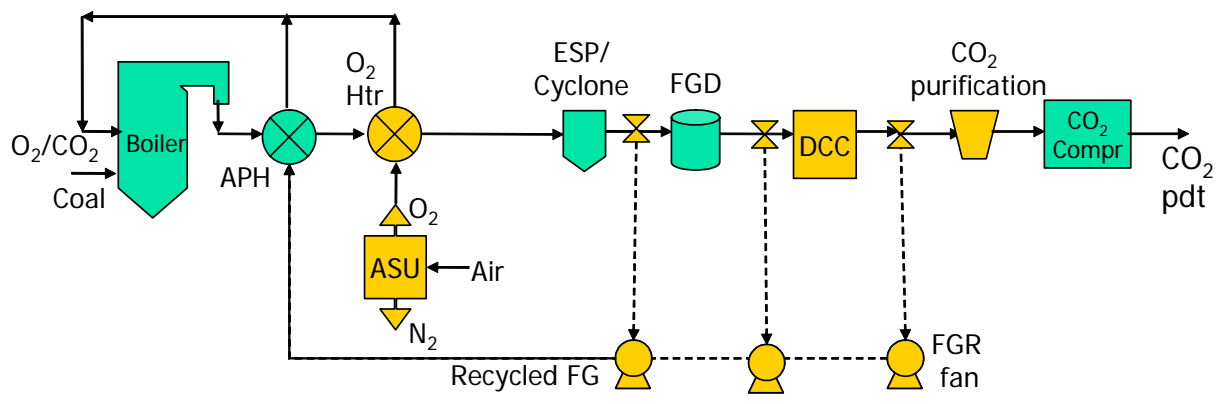

Figure 1. Oxyfuel combustion (O2/CO2) system configuration in IECM-CS model

\section{Key Model Parameters}

The key model parameters defining the performance of the oxyfuel combustion system for $\mathrm{CO}_{2}$ capture are as follows:

- Oxygen purity: Air contains about $21 \%$ oxygen on molar basis. The oxygen product obtained from an air separation unit (ASU) is typically in excess of $90 \%$. It may be noted that the energy penalty (and the cost of separation) increases sharply with higher product purity. However, at higher oxygen purity there are less non-condensable impurities in the $\mathrm{CO}_{2}$ product obtained from the system. Many studies have reported that $95 \%$ is an optimal level of oxygen purity. This value has been used as a model default. Argon is the main impurity in the oxygen product, with some traces of nitrogen.

- Oxygen pressure: This is the pressure at which the oxygen product is delivered from the air separation unit. The total energy requirement for the ASU also depends on this pressure.

- Excess oxygen: Excess oxidant is generally provided to ensure complete combustion of the fuel and to avoid formation of carbon monoxide. Conventional coal combustion is carried out using about $15-20 \%$ excess air. Since pure oxygen is an expensive commodity as compared to air, it is necessary to minimize the use of excess oxygen. 
The optimum level of excess oxygen needed to ensure complete combustion is not yet clear. Various studies assume values in the range $0-19 \%$, the majority of them being on the lower side. Hence a default value of $5 \%$ is used.

- Air leakage: Ideally, the oxyfuel system aims at using only pure oxygen for combustion. However, it may not be practically feasible to seal the boiler and flue gas ductwork completely to avoid air ingress. Such air infiltration into the system is termed as air leakage. It is crucial to keep it at minimum level. Values in the range of $1-5 \%$ have been assumed by various studies, while many others tend to ignore this parameter and assume zero air leakage. In a conventional air-fired boiler, the amount of air leakage is typically $15-20 \%$ of the theoretical air requirement. It is expected that oxyfuel systems would be better sealed and the default value for air leakage is thus assumed to be $2 \%$ of theoretical (stoichiometric) oxygen.

- Flue gas recycle ratio: Oxyfuel combustion systems with flue gas recycle are also commonly referred to as " $\mathrm{O}_{2} / \mathrm{CO}_{2}$ combustion systems". The flue gas recycle ratio (FGRR) is the fraction of total flue gas generated that is recycled back into the boiler. Higher FGRR implies a lower oxygen mole fraction in the $\mathrm{O}_{2} / \mathrm{CO}_{2}$ oxidant entering the boiler, whereas zero FGRR is the case of pure oxygen combustion with no flue gas recycle.. Studies using flue gas recycle assume FGRR values in the range $0.6-0.85$. The IECM-CS uses a nominal value of 0.7 .

- Recycled flue gas temperature: The temperature of the recycled flue gas would decide the temperature of oxidant stream (after mixing with pure oxygen) entering the boiler, and hence affect the working of the air preheater and the boiler efficiency. It is recommended that the flue gas be cooled down to near ambient temperature (say $40 \operatorname{degC}$ ), especially in the retrofit applications, in order to make use of the existing air preheater. Not all the studies use flue gas cooler, and the FGR temperature is quite high in those configurations.

- FGR fan pressure head: A fan is used to provide a small pressure head for the recycled flue gas stream going back to the boiler. This FGR fan pressure head along with the recycled flue gas flow rate, determine the energy used by the fan. The nominal (default) value for this pressure head is 0.14 psi.

- Flue gas moisture removal: The recycled flue gas may be sent back to the boiler with or without moisture. The flue gas moisture removal level is the fraction of moisture removed from the recycled flue gas stream. It would be zero in case of a wet recycle system (the more prevalent assumption), and close to one in case of dry recycle. IECM$\mathrm{CS}$ uses the value of zero (wet recycle) as default value.

- $\mathrm{CO}_{2}$ product purity: The flue gas from oxyfuel combustion is a mixture of $\mathrm{CO}_{2}$ with other compounds. Even after drying (i.e. removal of $\mathrm{H}_{2} \mathrm{O}$, which is the second largest component in the flue gas), the concentrated $\mathrm{CO}_{2}$ stream may contain various non-condensable gases (e.g. $\mathrm{N}_{2}, \mathrm{O}_{2}, \mathrm{Ar}$ ) and pollutants $\left(\mathrm{SO}_{2}, \mathrm{NO}_{\mathrm{x}}, \mathrm{HCl}\right.$ ), depending on the combustion conditions and various parameters discussed before. Some studies assume that the $\mathrm{CO}_{2}$ product may be compressed and disposed together with all these impurities (co-disposal), while other studies propose schemes for $\mathrm{CO}_{2}$ product purification. The $\mathrm{CO}_{2}$ product purity 
is a parameter that would dictate the kind of post-treatment required for the $\mathrm{CO}_{2}$ stream. It would also affect the energy requirement for $\mathrm{CO}_{2}$ purification and compression. A nominal purity of $97.5 \%$ is assumed in the IECM-CS.

- $\mathbf{C O}_{2}$ capture efficiency: Under ideal conditions, oxyfuel combustion system with flue gas recycle should be able to capture all the $\mathrm{CO}_{2}$ present in the flue gas, i.e. the theoretical capture efficiency of this system is $100 \%$, as assumed by some studies $[3,7,8,11]$. However, $\mathrm{CO}_{2}$ emissions do occur while operating this plant, especially during drying and purification of the concentrated $\mathrm{CO}_{2}$ stream. Accounting for these undesired and unavoidable losses, the $\mathrm{CO}_{2}$ capture efficiency of this system as reported by various studies is in the range of $90-98 \%$ $[2,6,9,10,13-15]$.

- $\mathbf{C O}_{2}$ product pressure: This is the final pressure at which the $\mathrm{CO}_{2}$ product is delivered at the plant boundary. A typical value is about 2000 psig (13.7 MPa). This parameter, along with the $\mathrm{CO}_{2}$ compression efficiency, determines the total energy requirement for $\mathrm{CO}_{2}$ compression, which is a major energy penalty item second only to that of the air separation unit.

- $\mathrm{CO}_{2}$ compressor efficiency: Based on our previous studies a nominal (default) value of $80 \%$ is assumed for the $\mathrm{CO}_{2}$ compressor.

Table 3 summarizes the nominal parameter values for the oxyfuel model, along with the ranges employed in the IECM-CS.

Table 3. Key process parameter values in IECM-CS oxyfuel model

\begin{tabular}{||l|l|l|l||}
\hline Parameter & Units & Default value & Range \\
\hline \hline Oxygen purity & $\%$ mole & 95 & $90-100$ \\
\hline Oxygen pressure & $\mathrm{MPa}$ & 0.1 & 0.1 \\
\hline Excess oxygen & $\%$ theor. & 5 & $0-19$ \\
\hline Air leakage & $\%$ theor. & 2 & $0-5$ \\
\hline Flue gas recycle ratio & fraction & 0.7 & $0.6-0.85$ \\
\hline Flue gas recycle temperature & degC & 38 & $35-40$ \\
\hline FGR fan pressure head & psi & 0.14 & 0.14 \\
\hline FG moisture removal & $\%$ & 0 (wet recycle) & $0-100$ \\
\hline $\mathrm{CO}_{2}$ product purity & $\%$ mole & 97.5 & $90-100$ \\
\hline $\mathrm{CO}_{2}$ product pressure & MPa & 13.8 & $7.6-15.2$ \\
\hline $\mathrm{CO}_{2}$ compression efficiency & $\%$ & 80 & $75-85$ \\
\hline \hline
\end{tabular}

\section{ASU Model}

The oxyfuel system model nominally assumes a conventional cryogenic air separation unit. The ASU performance and cost models previously developed for the IGCC plant systems [33] also is used for the oxyfuel model. 


\section{Calculation Strategy}

The IECM-CS is an integrated modeling framework that simulates the performance and cost of fossil-fuel power generation systems with environmental controls. All major plant components and multi-pollutant interactions are taken into consideration. The following sub-sections describe the algorithm used to estimate the performance of the oxyfuel combustion system. The algorithm is illustrated in the Case Study section later in this document.

\section{Input Parameters}

To begin, the following parameters are specified by the user (or the model defaults):

1. ASU product composition (as an elemental volume percent)

2. Coal composition (as an elemental weight percent, plus ash and water weight percent)

3. Excess oxygen to boiler (as a percent of the stoichiometric oxygen)

4. Air leakage to flue gas (as a percent of the stoichiometric oxygen)

5. Flue gas recycle ratio (as a percent of the total flue gas produced)

6. Gross size of plant (as megawatts of internal power produced)

7. Gross plant heat rate (as a combination of the steam cycle heat rate and the boiler efficiency)

\section{Coal Flow Rate}

Calculate the coal flow rate based on $\mathrm{MW}_{\mathrm{g}}$, heat rate and coal properties (heating value). The relationship in Equation (1) can be used to determine the coal flow rate required to generate the desired (or actual) gross power, given the coal properties and gross heat rate.

$$
M_{\text {coal }}=\frac{M W_{g} \times H R_{\text {steam }}}{2 \times \eta_{\text {boiler }} \times H H V_{\text {coal }}}
$$

where,

$$
\begin{aligned}
& M_{\text {coal }}=\text { mass flow rate of coal (ton } / \mathrm{hr} \text { ) } \\
& M W_{g}=\text { gross cumulative power produced by the entire power plant; this does } \\
& \text { not consider power used by equipment in the power plant (MW) } \\
& H R_{\text {steam }}=\text { heat rate of the steam cycle, which excludes the effects of the boiler } \\
& \text { efficiency }(\mathrm{Btu} / \mathrm{kWh}) \\
& \eta_{\text {boiler }}=\text { boiler efficiency (fraction) } \\
& H H V_{\text {Coal }}=\text { higher heating value of the coal on a wet basis }(\mathrm{Btu} / \mathrm{lb})
\end{aligned}
$$

\section{Oxygen Requirement}

The oxygen flow rate required by the air separation unit is done through the following steps. 
1. Calculate the stoichiometric $\mathrm{O}_{2}$ requirement based on the coal flow rate, coal composition, and emission factors for incomplete combustion reactants

2. Calculate the total $\mathrm{O}_{2}$ requirement based on the excess oxygen specified

3. Calculate the total oxygen product (i.e., oxidant) flow rate based on the oxygen purity and total $\mathrm{O}_{2}$ requirement

\section{Air Leakage}

The air leakage stream is calculated based on air composition and air leakage input parameter.

\section{Combustion Product}

The combustion product is referred to as a flue gas stream. Given the coal and oxygen flow rates into the boiler, the composition and flow rate of the flue gas stream can be calculated.

\section{Recycled Flue Gas}

For the next iteration, part of the flue gas is recycled back to the boiler. The recycled flue gas is then added to the coal and oxygen streams described above. The flow rate of the recycled stream is calculated using FGRR and the total flue gas flow rate; this amount is then included in the estimation of the total flue gas combustion product.

The calculation is repeated until a steady state is achieved. Once the mass flow rates are balanced (it may take few iterations), the temperatures of various streams are estimated through heat balance over each unit (boiler, air preheater, $\mathrm{O}_{2}$ heater). The temperature of the oxidant stream (mixture of recycled flue gas and pure oxygen) is estimated through simple energy balance over the air preheater (APH) unit.

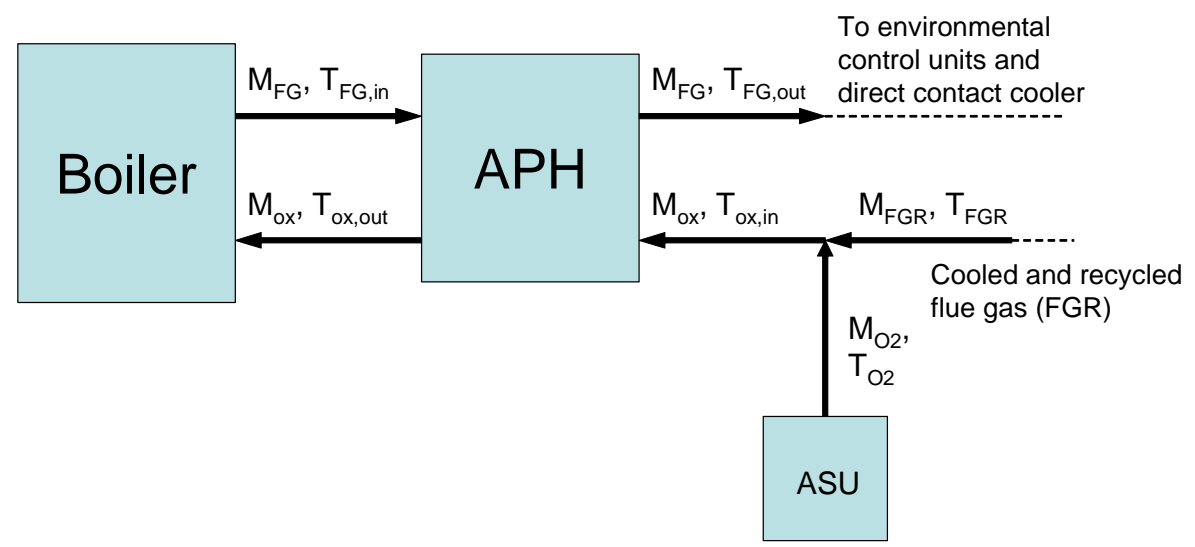

Figure 2. Energy balance over the air preheater unit

The energy balance equations yields:

$$
T_{o x, i n}=\frac{M_{O 2} \times c_{p, O 2} \times T_{O 2}+M_{F G R} \times c_{p, F G R} \times T_{F G R}}{M_{o x} \times c_{p, o x}}
$$




$$
T_{o x, \text { out }}=T_{o x, \text { in }}+\frac{M_{F G} \times c_{p, F G} \times\left(T_{F G, \text { in }}-T_{F G, \text { out }}\right)}{M_{o x} \times c_{p, o x}}
$$

where,

$c_{p, F G}=$ average specific heat of the flue gas (FG)

$C_{p, F G R}=$ average specific heat of the recycled flue gas (FGR)

$c_{p, O 2}=$ average specific heat of pure oxygen $\left(\mathrm{O}_{2}\right)$

$c_{p, o x}=$ average specific heat of the combined oxidant (ox)

\section{$\mathrm{CO}_{2}$ Product Stream}

The $\mathrm{CO}_{2}$ product composition and flow rate calculation is based on the $\mathrm{CO}_{2}$ capture efficiency and $\mathrm{CO}_{2}$ purity requirement.

\section{Cooling Water}

The cooling water requirement is based on the flue gas flow rate and the desired temperature difference. The reference case study reports a cooling water requirement of 93,200 gpm for a plant treating a flue gas flow rate of 809,763 $\mathrm{ft}^{3} / \mathrm{min}$, the flue gas being cooled from $144^{\circ} \mathrm{F}$ to $100^{\circ} \mathrm{F}$. So, the cooling water requirement is obtained as $3.3(10)^{-3} \mathrm{gpm} \mathrm{per}^{3} / \mathrm{min}^{3} \mathrm{per}^{0} \mathrm{~F}$.

$$
M_{\text {cooling }}=3.3(10)^{-3} \times V_{f g} \times \Delta T
$$

where,

$M_{\text {cooling }}=$ cooling water requirement (gpm)

$V_{f g}=$ flue gas flow rate (actual $\mathrm{ft}^{3} / \mathrm{min}$ ) at $100{ }^{\circ} \mathrm{F}$

$\Delta T=$ desired temperature difference $\left({ }^{\circ} \mathrm{F}\right)$.

\section{Power Requirement}

The energy requirements must be calculated for the flue gas recycle fan, the air separation unit, the $\mathrm{CO}_{2}$ purification unit, and the $\mathrm{CO}_{2}$ compression unit. The following expressions derived in other studies are used to estimate these power requirements [33, 34]:

\section{ASU Unit Power}

$$
\begin{aligned}
& \mathrm{MACP}=0.0049 * \varphi+0.4238, \text { for } \varphi \leq 97.5 \% \\
& \mathrm{MACP}=0.0736 /(100-\varphi)^{1.3163}+0.8773, \text { for } \varphi>97.5 \%
\end{aligned}
$$

where,

$$
\begin{aligned}
& \mathrm{MACP}=\mathrm{kWh} / 100 \mathrm{ft}^{3} \mathrm{O}_{2} \text { product } \\
& \left.\varphi=\mathrm{O}_{2} \text { product purity (mole } \%\right)
\end{aligned}
$$

\section{ASU Total Power}

$$
\mathrm{MW}_{\mathrm{ASU}}=3.798(10)^{-3} \times \mathrm{MACP} \times \mathrm{M}_{\mathrm{O} 2}
$$

where, 
$\mathrm{M}_{\mathrm{O} 2}=$ Total oxygen requirement from ASU (lbmole/hr)

FGR Fan

$\mathrm{MW}_{\mathrm{FGR}}=3.255(10)^{-6} \times \mathrm{V}_{\mathrm{FG}} \times \Delta \mathrm{P}_{\mathrm{FGRF}} / \eta_{\text {fgrf }}$

where,

$\mathrm{V}_{\mathrm{FG}}=$ flue gas flow rate $\left(\mathrm{ft}^{3} / \mathrm{min}\right)$

$\Delta \mathrm{P}_{\mathrm{FGRF}}=\mathrm{FGR}$ fan pressure head (psi)

$\eta_{\text {fgrf }}=$ fan efficiency (\%), usually $75 \%$

\section{Flue Gas Cooling}

$$
\mathrm{MW}_{\mathrm{FGcooling}}=4.7(10)^{-5} \times \mathrm{M}_{\text {cooling }}
$$

where,

$\mathrm{M}_{\text {cooling }}=$ cooling water flow rate (gpm)

$\mathrm{CO}_{2}$ Purification and Compression

$\mathrm{MW}_{\text {compr_purif }}=\left(\mathrm{e}_{\text {comp }} / 1000+\mathrm{e}_{\text {purif }}\right) \times \mathrm{M}_{\mathrm{CO} 2}$

where,

$\mathrm{M}_{\mathrm{CO} 2}=$ total mass of $\mathrm{CO}_{2}$ captured (ton/hr)

$\mathrm{e}_{\text {purif }}=0.109 \mathrm{MWh} /$ ton, for high purity product (purity $>97.5 \%$ )

$=0.0018 \mathrm{MWh} /$ ton, for low purity product [13]

$\mathrm{e}_{\text {comp }}=\left[-51.632+19.207 \times \ln \left(\mathrm{P}_{\mathrm{CO} 2}+14.7\right)\right] /\left(1.1 \times \eta_{\text {comp }} / 100\right), \mathrm{kWh} / \mathrm{ton}$

$\mathrm{P}_{\mathrm{CO} 2}=\mathrm{CO}_{2}$ product pressure $(\mathrm{psig})$

$\eta_{\text {comp }}=\mathrm{CO}_{2}$ compression efficiency (\%), usually $80 \%$

\section{Net Power Generation}

Finally, calculate the net power generation based on user-specified gross output and calculate energy requirements for all environmental control units, including the oxyfuel combustion system.

\section{Performance Model Results}

The oxyfuel system model is able to estimate the key intermediate and final results.

\section{Final Result Parameters}

These are the results a user is most likely to be interested in. They include:

- $\mathrm{CO}_{2}$ product flow rate

- Environmental emissions

- Total energy penalty

- Net power output

- Plant heat rate 


\section{Intermediate Result Parameters}

These additional parameters, which are estimated based on other user-specified input parameters, are crucial in calculating the key result parameters. They include:

- Boiler efficiency

- Oxygen product flow rate from ASU

- Flue gas recycle flow rate 


\section{Cost Model}

The cost model for the oxyfuel system for $\mathrm{CO}_{2}$ capture is directly linked to the performance model, and follows the framework used elsewhere in the IECM [35] to ensure consistency in economic calculations. There are four types of costs calculated by this model based on available data: capital cost, operating and maintenance (O\&M) cost, incremental cost of electricity (COE), and cost of $\mathrm{CO}_{2}$ avoidance.

A conventional pulverized coal plant consists of a base plant (consisting of boiler, steam turbine, air preheater), and environmental control units such as ESP, FGD and SCR system. All these process areas have their own capital and O\&M costs associated with them, and IECM calculates each of them. The oxyfuel combustion system for $\mathrm{CO}_{2}$ control requires special equipment/process units in addition to the units mentioned above. The cost model described here reports the costs associated with only the additional units required for the oxyfuel system. The costs of the remainder of the plant are calculated by the IECM model, depending on the new plant versus retrofit application case as explained later in this chapter.

\section{Capital Cost}

The total capital requirement (TCR) of a system is calculated as the sum of the installed equipment costs (called the process facilities capital, PFC, which depends on one or more performance variables that determine the size or capacity of each component), plus various indirect costs that are typically estimated as fractions of the process facilities cost following the EPRI cost estimating guidelines [36].

The PFC of the oxyfuel combustion system for $\mathrm{CO}_{2}$ capture consists of several cost areas, most of which are scaled using a 0.6 cost scaling index and adjusted using the plant cost index as follows:

$$
\mathrm{C}_{\mathrm{i}}=\mathrm{C}_{\mathrm{i} \text {,reference }} \times\left(\mathrm{X}_{\mathrm{i}} / \mathrm{X}_{\mathrm{i} \text {,reference }}\right)^{0.6} \times\left(\mathrm{PCI} / \mathrm{PCI}_{\text {ref }}\right),
$$

where:

$\mathrm{C}_{\mathrm{i}}=$ installed capital cost of cost area (i) for a case study of interest

$\mathrm{C}_{\mathrm{i}, \text { reference }}=$ reference cost for cost area (i), for a particular reference case

$\mathrm{X}=$ scaling parameter relevant to the cost area, such as the flue gas flow rate, gross plant size, or $\mathrm{CO}_{2}$ product flow rate

$X_{i}=$ value of the relevant scaling parameter (i) for the case study of interest

$\mathrm{X}_{\mathrm{i}, \text { reference }}=$ value of the corresponding scaling parameter (i) for the reference case study

$\mathrm{PCI}=$ Plant cost index for the year in which the capital cost is being calculated 
$\mathrm{PCI}_{\text {ref }}=$ Plant cost index for the year in which the reference cost was reported

The plant cost indices are listed in Table 4.

Table 4. Plant cost index (PCI) by year (Chemical Engineering magazine)

\begin{tabular}{||l|l|l|l|l|l||}
\hline Year & Cost Index & Year & Cost Index & Year & Cost Index \\
\hline \hline 1977 & 204.1 & 1987 & 323.8 & 1997 & 386.5 \\
\hline 1978 & 218.8 & 1988 & 342.5 & 1998 & 389.5 \\
\hline 1979 & 238.7 & 1989 & 355.4 & 1999 & 390.6 \\
\hline 1980 & 261.1 & 1990 & 357.6 & 2000 & 394.1 \\
\hline 1981 & 297.0 & 1991 & 361.3 & 2001 & 394.3 \\
\hline 1982 & 314.0 & 1992 & 358.2 & 2002 & 395.6 \\
\hline 1983 & 316.9 & 1993 & 359.2 & 2003 & 402.0 \\
\hline 1984 & 322.7 & 1994 & 368.1 & 2004 & 444.2 \\
\hline 1985 & 325.3 & 1995 & 381.1 & 2005 & 468.2 \\
\hline 1986 & 318.4 & 1996 & 381.7 & 2006 & 499.6 \\
\hline
\end{tabular}

The oxyfuel system cost areas may be broadly categorized into three categories, namely those related to oxygen production (air separation unit), those related to flue gas recirculation and heat integration (flue gas cooler, flue gas recycle fan, flue gas recycle ducting, and oxygen heater), and those related to $\mathrm{CO}_{2}$ processing $\left(\mathrm{CO}_{2}\right.$ compressors and $\mathrm{CO}_{2}$ purification system). In addition to these, some cost will be associated with boiler modifications required in case of retrofit applications. The cost model for each of these cost areas are described below:

\section{Air Separation Unit}

The model is taken from Frey and Rubin [39]. This paper documents mathematical models of coal gasification combined cycle power plants. The cost model is the result of a statistical study of several oxygen plants that are incorporated into power plants. The cost equation is stated below. It gives the process facilities cost of the air separation unit in thousands of 1989 dollars [37].

$$
C_{\text {ASU, ref }}=\frac{14.35 \times N_{t} \times T_{a}^{0.067}}{(1-\phi)^{0.073}}\left(\frac{M_{o x}}{N_{o}}\right)^{0.852}
$$

where,

$\mathrm{T}_{\mathrm{a}}=$ Ambient air temperature $\left({ }^{\circ} \mathrm{F}\right)$

$\mathrm{N}_{\mathrm{t}}=$ Total number of production trains

$\mathrm{N}_{\mathrm{o}}=$ Number of operating production trains

$\mathrm{M}_{\mathrm{ox}}=$ Molar flow rate of output oxygen (not oxygen product) (lb-mole/hr)

$\phi=$ Purity of oxygen product

$20^{\circ} \mathrm{F} \leq T_{a} \leq 95^{\circ} \mathrm{F}$

$625 \leq\left(\frac{M_{o x}}{N_{o}}\right) \leq 11,350 \mathrm{lbmole} / \mathrm{hr}$

$0.95 \leq \phi \leq 0.995$ 
So, the capital cost equation for the air separation unit is as follows:

$$
\begin{aligned}
& \mathrm{C}_{\mathrm{ASU}}=\mathrm{C}_{\mathrm{ASU}, \mathrm{ref}} \times\left(\mathrm{PCI} / \mathrm{PCI}_{\mathrm{ref}}\right) \\
& \mathrm{C}_{\mathrm{ASU}}=\mathrm{C}_{\mathrm{ASU}, \text { ref }} \times\left(\mathrm{PCI} / \mathrm{PCI}_{1989}\right)
\end{aligned}
$$

where,

$\mathrm{C}_{\mathrm{ASU}, \text { ref }}$ is calculated using equation (4-2).

\section{Flue Gas Recycle Fan}

The cost of the fan required for recycling part of the flue gas is scaled on the basis of the flow rate of the flue gas being recycled $\left(\mathrm{V}_{\mathrm{FGR}}, \mathrm{ft}^{3} / \mathrm{min}\right)$. The reference cost for the fan is $2 \mathrm{M} \$$, corresponding to a flue gas flow rate of $6.474(10)^{5} \mathrm{ft}^{3} / \mathrm{min}$ (actual) [38].

$$
\begin{aligned}
& \mathrm{C}_{\mathrm{FGR} \_ \text {fan }}=\mathrm{C}_{\mathrm{FGR} \_ \text {fan,ref }} \times\left(\mathrm{V}_{\mathrm{FGR}} / \mathrm{V}_{\mathrm{FGR}, \text { ref }}\right)^{0.6} *\left(\mathrm{PCI} / \mathrm{PCI}_{\mathrm{ref}}\right) \\
& \mathrm{C}_{\mathrm{FGR} \_ \text {fan }}(\mathrm{SM})=2.0 \times\left[\mathrm{V}_{\mathrm{FGR}} / 6.474(10)^{5}\right]^{0.6} *\left(\mathrm{PCI} / \mathrm{PCI}_{1998}\right)
\end{aligned}
$$

\section{Flue Gas Recycle Ducting}

Additional ducting is necessary to recycle part of the flue gas in the oxyfuel combustion system. The cost of this ducting is assumed to be a function of the flow rate of recycled flue gas. The reference cost is $10 \mathrm{M} \$$, corresponding to a flue gas flow rate of $6.474(10)^{5} \mathrm{ft}^{3} / \mathrm{min}$ (actual) [9].

$$
\begin{aligned}
& \mathrm{C}_{\mathrm{FGR} \_ \text {ducting }}=\mathrm{C}_{\mathrm{FGR} \_ \text {ducting,ref }} \times\left(\mathrm{V}_{\mathrm{FGR}} / \mathrm{V}_{\mathrm{FGR}, \mathrm{ref}}\right)^{0.6} \times\left(\mathrm{PCI} / \mathrm{PCI}_{\mathrm{ref}}\right) \\
& \mathrm{C}_{\mathrm{FGR} \_ \text {ducting }}(\mathrm{SM})=10.0 \times\left[\mathrm{V}_{\mathrm{FGR}} / 6.474(10\}^{5}\right]^{0.6} \times\left(\mathrm{PCI} / \mathrm{PCI}_{2001}\right)
\end{aligned}
$$

\section{Flue Gas Cooler}

The cost of the flue gas cooler is scaled on the basis of the flow rate of the flue gas assuming the desired flue gas temperature similar to that used in the reference study. The reference cost for the direct contact cooler is $17.6 \mathrm{M} \$$, corresponding to a plant size of $500 \mathrm{MW}$ gross, and treating a flue gas flow rate of $809,763 \mathrm{ft}^{3} / \mathrm{min}$ (actual) entering the cooler at $144^{\circ} \mathrm{F}[9]$.

$$
\begin{aligned}
& \mathrm{C}_{\mathrm{FG} \_\mathrm{DCC}}=\mathrm{C}_{\mathrm{FG} \_ \text {DCC,ref }} \times\left(\mathrm{V}_{\mathrm{FG}} / \mathrm{V}_{\mathrm{FG}, \text { ref }}\right)^{0.6} \times\left(\mathrm{PCI} / \mathrm{PCI}_{\mathrm{ref}}\right) \\
& \mathrm{C}_{\mathrm{FG}_{-} \mathrm{DCC}}(\mathrm{SM})=17.6 \times\left(\mathrm{V}_{\mathrm{FG}} / 809,763\right)^{0.6} \times\left(\mathrm{PCI} / \mathrm{PCI}_{2001}\right)
\end{aligned}
$$

\section{Oxygen Heater}

In addition to the air preheater that exists in a conventional PC plant, the oxyfuel combustion system includes an additional heat exchanger called the "oxygen heater" for better heat integration. The cost of this heat exchanger is scaled on the basis of the gross plant size. The reference cost is $12 \mathrm{M} \$$, corresponding to a plant size of $500 \mathrm{MW}$ gross [9].

$$
\begin{aligned}
& \mathrm{C}_{\mathrm{APH} \_\mathrm{OH}}=\mathrm{C}_{\mathrm{APH} \_\mathrm{OH}, \text { ref }} \times\left(\mathrm{MW}_{\text {gross }} / \mathrm{MW}_{\text {gross,ref }}\right)^{0.6} \times\left(\mathrm{PCI} / \mathrm{PCI}_{\text {ref }}\right) \\
& \mathrm{C}_{\mathrm{APH} \_\mathrm{OH}}(\mathrm{SM})=12 \times\left(\mathrm{MW}_{\text {gross }} / 500\right)^{0.6} \times\left(\mathrm{PCI} / \mathrm{PCI}_{2001}\right)
\end{aligned}
$$




\section{$\mathrm{CO}_{2}$ Purification System}

The cost of the $\mathrm{CO}_{2}$ purification system depends on the desired purity level of the $\mathrm{CO}_{2}$ product, and the total $\mathrm{CO}_{2}$ product flow rate. The cost of a system yielding a high purity product ( $>99.9 \%$ ) is estimated to be about $\$ 181,818$ per ton $\mathrm{CO}_{2}$ product $/ \mathrm{hr}$, corresponding to a reference product flow rate of $550 \mathrm{ton} / \mathrm{hr}$. It is assumed that this cost would be applicable for purity range above $97.5 \%$. In case of applications where such high product purity is not required, a cheaper system giving a low purity product may be used. Such systems are estimated to cost about $\$ 18,182$ per ton $\mathrm{CO}_{2}$ product $/ \mathrm{hr}$, corresponding to a reference product flow rate of $660 \mathrm{ton} / \mathrm{hr}$ [13].

$$
\mathrm{C}_{\mathrm{CO} 2 \text { _purif }}=\mathrm{C}_{\mathrm{CO} 2 \text { purif,ref }} \times \mathrm{M}_{\mathrm{CO} 2 \_ \text {dt }} \times\left(\mathrm{M}_{\mathrm{CO} 2 \_ \text {pdt }} / \mathrm{M}_{\mathrm{CO} 2 \_ \text {pd, }, \text { ref }}\right){ }^{0.6} *\left(\mathrm{PCI} / \mathrm{PCI}_{\mathrm{ref}}\right)
$$

where,

$$
\mathrm{M}_{\mathrm{CO} 2 \text { pdt }}=\mathrm{CO}_{2} \text { product flow rate, ton } / \mathrm{hr}
$$

So, for the high purity $\mathrm{CO}_{2}$ product:

$$
\mathrm{C}_{\mathrm{CO} 2 \text { _purif }}(\mathrm{SM})=0.2 \times\left(\mathrm{M}_{\mathrm{CO} 2 \_ \text {dt }} / 1.1\right) \times\left(\mathrm{M}_{\mathrm{CO} 2 \_ \text {pdt }} / 550\right)^{0.6} \times\left(\mathrm{PCI} / \mathrm{PCI}_{1995}\right)(
$$

And for the low purity $\mathrm{CO}_{2}$ product:

$$
\mathrm{C}_{\mathrm{CO} 2 \text { _purif }}(\mathrm{SM})=0.02 \times\left(\mathrm{M}_{\mathrm{CO} 2 \_ \text {pdt }} / 1.1\right) \times\left(\mathrm{M}_{\mathrm{CO} 2 \text { pdt }} / 660\right)^{0.6} \times\left(\mathrm{PCI} / \mathrm{PCI}_{1995}\right)
$$

\section{$\mathrm{CO}_{2}$ Compression System}

The multi-stage compression unit with inter-stage cooling and drying yields the final $\mathrm{CO}_{2}$ product at the specified pressure (about $2000 \mathrm{psig}$ ) that contains only acceptable levels of moisture and other impurities (e.g. $\mathrm{N}_{2}$ ). Multiple trains will be required if the total $\mathrm{CO}_{2}$ product flow rate is larger than $300 \mathrm{ton} / \mathrm{hr}$. The size (and cost) of this unit will be a function of the $\mathrm{CO}_{2}$ product compression power, and may be estimated as follows [38]:

$$
\begin{aligned}
& \mathrm{C}_{\mathrm{CO} 2 \text { _compr }}=\mathrm{C}_{\mathrm{CO} 2 \text { _compr,ref }} \times\left(\mathrm{hp}_{\mathrm{CO} 2 \text { comp }} / \mathrm{hp}_{\mathrm{CO} 2 \text { _comp,ref }}\right)^{0.7} \times\left(\mathrm{PCI} / \mathrm{PCI}_{\mathrm{ref}}\right) \\
& \mathrm{C}_{\mathrm{CO} 2 \text { _compr }}=16.85 \times\left(\mathrm{hp}_{\mathrm{CO} 2 \text { _comp }} / 51,676\right)^{0.7} \times\left(\mathrm{PCI} / \mathrm{PCI}_{1998}\right)
\end{aligned}
$$

where,

$$
\mathrm{hp}_{\mathrm{CO} 2 \text { comp }}=\mathrm{CO}_{2} \text { product compression power requirement (hp). }
$$

In addition to the above mentioned cost areas, there will be cost of boiler modifications required in case of a retrofit application, discussed later in this section.

\section{Boiler Modifications}

In case of a pre-existing $\mathrm{PC}$ plant being retrofitted for $\mathrm{CO}_{2}$ capture, the boiler must be modified to suit the new oxyfuel combustion system. The cost for these modifications has been estimated to be about $4 \%$ of the cost of the boiler [9].

$$
\begin{aligned}
& \mathrm{C}_{\text {boiler_mod }}=0.04 \times \mathrm{C}_{\text {boiler }} \times\left(\mathrm{PCI} / \mathrm{PCI}_{2001}\right) \text {, for retrofit application } \\
& \mathrm{C}_{\text {boiler_mod }}=0, \text { for new plant case (default) }
\end{aligned}
$$

The sum of these individual process area equipment costs gives the total process facilities capital (PFC). The various indirect costs are then estimated as fractions of the PFC following the EPRI cost estimating guidelines [36]. Table 5 lists the elements of total capital cost. Because of data limitations some of the indirect cost factors for the amine system are estimated based on other similar technologies. 
The total plant cost (TPC) is the sum of the process facilities capital (PFC), general facilities capital, engineering and home office fees, and contingencies (project and process). The project contingency is a capital cost factor covering the cost of additional equipment or other costs that would result from a more detailed design at an actual site. The process contingency is a capital cost factor (added cost) applied to a technology to reflect its level of maturity. TPC is developed on the basis of instantaneous ("overnight") construction occurring at a single point in time, and is generally expressed in mid-year dollars of a (user-specified) reference year.

The total capital requirement (TCR) includes all the capital necessary to complete the entire project, including interest during construction (AFUDC, allowance for funds during construction) and owner costs, which include royalties, startup costs, and inventory capital.

Table 5. Oxyfuel combustion system capital cost model parameters and nominal values

\begin{tabular}{||l|l|l||}
\hline & Capital Cost Elements & Value \\
\hline \hline A & Process Area Equipment Costs & (See Eqns (12) to (29) above \\
\hline B & Total Process Facilities Capital (PFC) & $\Sigma C_{i}$ \\
\hline C & Engineering and Home Office & $7 \%$ PFC \\
\hline D & General Facilities & $10 \%$ PFC \\
\hline E & Project Contingency & $15 \%$ PFC \\
\hline F & Process Contingency & $5 \%$ PFC \\
\hline G & Total Plant Cost (TPC) $=$ sum of above & B+C+D+E+F \\
\hline H & AFUDC (interest during construction) & Calculated \\
\hline I & Royalty Fees & $0.5 \%$ PFC \\
\hline J & Pre-production & 1 month's fixed O\&M cost \\
\hline K & Pre-production & 1 month's variable O\&M cost \\
\hline L & Inventory (startup) Cost & $0.5 \%$ TPC \\
\hline M & Total Capital Requirement (TCR) & G+H+I+J+K+L \\
\hline
\end{tabular}

\section{O\&M Costs}

The major operating and maintenance (O\&M) cost consists of the fixed costs and variable cost elements listed in Table 6.

\section{Fixed O\&M Costs}

The fixed $O \& M(\mathrm{FOM})$ costs in the model include the costs of maintenance (materials and labor) and labor (operating labor, administrative and support labor). They are estimated on annual basis $(\$ / y r)$ as follows:

$$
\begin{aligned}
& \mathrm{FOM}=\mathrm{FOM}_{\text {labor }}+\mathrm{FOM}_{\text {maint }}+\mathrm{FOM}_{\text {admin }} \\
& \mathrm{FOM}_{\text {labor }}=\text { labor } \times \mathrm{N}_{\text {labor }} \times 40(\text { hrs } / \text { week }) \times 52(\text { weeks } / \mathrm{yr}) \\
& \mathrm{FOM}_{\text {maint }}=\Sigma \mathrm{i}\left(\mathrm{f}_{\text {maint }}\right) \mathrm{i} \times \mathrm{TPC}_{\mathrm{i}} \text { where } \mathrm{i}=\text { process area } \\
& \mathrm{FOM}_{\text {admin }}=\mathrm{f}_{\text {admin }} \times\left(\mathrm{FOM}_{\text {labor }}+\mathrm{f}_{\text {maintlab }} \times \mathrm{FOM}_{\text {maint }}\right)
\end{aligned}
$$

where,

labor $=$ the hourly wages to the labor $(\$ / \mathrm{hr})=\$ 24.82 / \mathrm{hr}$ 


$$
\begin{aligned}
& \begin{array}{l}
\mathrm{N}_{\text {labor }}=\text { number of operating labor required }=2 \\
\left(\mathrm{f}_{\text {maint }}\right)_{\mathrm{i}}=\text { total annual maintenance cost expressed as the fraction of the total } \\
\text { plant cost }(\mathrm{TPC})=0.04 \text { for all areas }
\end{array} \\
& \mathrm{f}_{\text {maintlab }}=\text { fraction of maintenance cost allocated to labor }=0.4 \\
& \mathrm{f}_{\text {admin }}=\text { the administrative labor cost expressed as the fraction of the total labor } \\
& \quad \text { cost }=0.3
\end{aligned}
$$

\begin{tabular}{|c|c|}
\hline O\&M Cost Elements & Typical Value \\
\hline \multicolumn{2}{|l|}{ Fixed O\&M Costs } \\
\hline Total Maintenance Cost & $4 \%$ TPC \\
\hline Maintenance Cost Allocated to Labor ( $f_{\text {maintlab }}$ ) & $40 \%$ of total maint. Cost \\
\hline Admin. \& Support Labor Cost $\left(f_{\text {admin }}\right)$ & $30 \%$ of total labor cost \\
\hline Operating Labor $\left(\mathrm{N}_{\text {labor }}\right)$ & 2 jobs/shift \\
\hline \multicolumn{2}{|l|}{ Variable O\&M Costs } \\
\hline Chemicals Cost & $\$ 0.26 /$ ton $\mathrm{CO}_{2}$ \\
\hline Waste Water Treatment Cost & $\mathrm{n} / \mathrm{a}$ \\
\hline $\mathrm{CO}_{2}$ Transport Cost & $\$ 0.03 /$ ton $\mathrm{CO}_{2}$ per mile [33] \\
\hline $\mathrm{CO}_{2}$ Storage/Disposal Cost & $\$ 4.55 /$ ton $\mathrm{CO}_{2}[33]$ \\
\hline
\end{tabular}

Table 6. Oxyfuel combustion system O\&M cost model parameters and nominal values

\section{Variable O\&M Costs}

The variable O\&M (VOM) costs include costs of chemicals consumed (if any, in $\mathrm{CO}_{2}$ purification and drying), utilities (water, power), and services used (waste water treatment, $\mathrm{CO}_{2}$ transport and storage). These quantities are determined in the performance model. The unit cost of each item (e.g., dollars per ton of reagent, or dollars per ton of $\mathrm{CO}_{2}$ stored) is a parameter specified as a cost input to the model. The total annual cost of each item is then calculated by multiplying the unit cost by the total annual quantity used or consumed. Total annual quantities depend strongly on the plant capacity factor.

The individual components of the variable O\&M cost are a function of the annual hours of operation (HPY). The following equation describes this value:

$$
\mathrm{HPY}=(\mathrm{PCF} / 100) \times 365 \times 24(\mathrm{hrs} / \mathrm{yr})
$$

\section{Chemicals}

A small quantity of chemicals is used in this process, including the ASU chemicals, desiccant and lubricants. The aggregate cost of these chemicals is calculated from the reference study by normalizing the total cost of chemical consumption reported ( $\$ 613,400 / \mathrm{yr}$ ) over the flow rate of $\mathrm{CO}_{2}$ captured (400 ton/hr) [9].

$$
\mathrm{VOM}_{\text {chemicals }}=\mathrm{UC}_{\text {Chemicals }} \mathrm{M}_{\mathrm{CO} 2} \times \mathrm{HPY}
$$

where

$\mathrm{UC}_{\text {Chemicals }}=$ unit cost of the chemicals used, averaged at $\$ 0.26 /$ ton $\mathrm{CO}_{2}$ captured and $\mathrm{M}_{\mathrm{CO} 2}$ is the flow rate of $\mathrm{CO}_{2}$ captured (ton $/ \mathrm{hr}$ ). 


\section{Wastewater Treatment}

It is not clear if the moisture condensed from the flue gas needs to be treated in a wastewater treatment plant. If yes, the cost would be based on the quantity estimated in the performance model as:

$$
\mathrm{VOM}_{\text {wastewater }}=\mathrm{M}_{\text {wastewater }} \times \mathrm{UC}_{\text {wastewater }} \times \mathrm{HPY}
$$

where,

$\mathrm{UC}_{\text {wastewater }}=$ unit cost of wastewater treatment.

\section{$\mathrm{CO}_{2}$ Transport}

Transportation of $\mathrm{CO}_{2}$ product is assumed to take place via pipelines. The cost of $\mathrm{CO}_{2}$ transport is estimated on the basis of two user-specified parameters namely transportation distance $(\mathrm{TD}$, in $\mathrm{km})$ and unit cost of transport $\left(\mathrm{UC}_{\text {transport }}, \$ \mathrm{~km}\right.$ per tonne $\mathrm{CO}_{2}$ ), plus the $\mathrm{CO}_{2}$ product flow rate (calculated result from performance model).

$$
\mathrm{VOM}_{\text {transport }}=\mathrm{M}_{\mathrm{CO} 2} \times \mathrm{UC}_{\text {transport }} \times \mathrm{TD} \times \mathrm{HPY}
$$

\section{$\mathrm{CO}_{2}$ Storage}

Depending upon the method of $\mathrm{CO}_{2}$ disposal or storage, either there may be some revenue generated (as in enhanced oil recovery, or enhanced coal bed methane), or an additional cost (all other disposal methods). The total cost or revenue of $\mathrm{CO}_{2}$ disposal/storage is estimated from the unit cost and $\mathrm{CO}_{2}$ product flow rate $\left(\mathrm{UC}_{\text {disp }}\right)$.

$$
\mathrm{VOM}_{\text {disposal }}=\mathrm{M}_{\mathrm{CO} 2} \times \mathrm{UC}_{\text {disp }} \times \mathrm{HPY}
$$

\section{Power}

By default, all energy costs are handled internally in the model by de-rating the overall power plant based on the calculated power requirement. The $\mathrm{CO}_{2}$ capture unit is charged for the total electricity production foregone because of $\mathrm{CO}_{2}$ capture and compression $\left(\mathrm{E}_{\mathrm{CO} 2, \mathrm{tot}}\right)$.

For power plants with multi-pollutant controls the desire to quantify costs for a single pollutant requires an arbitrary choice of how to charge or allocate certain costs. This is especially relevant for energy-intensive processes like $\mathrm{CO}_{2}$ capture systems.

The unit cost of electricity $\left(\mathrm{COE}_{\text {noctt }}\right)$ is estimated by the base plant module, or may be overridden by a user-specified value if this energy is assumed to be supplied from an external source. Since energy cost is one of the biggest O\&M cost items for the $\mathrm{CO}_{2}$ unit, the way in which it is accounted for is important when calculating the mitigation cost.

$$
\mathrm{VOM}_{\text {energy }}=\mathrm{E}_{\mathrm{CO} 2 \text {,tot }} \times \mathrm{HPY} \times \mathrm{COE}_{\text {noctl }}
$$

The total variable O\&M (VOM, $\$ / \mathrm{yr})$ cost is obtained by adding all these costs:

$$
\begin{gathered}
\mathrm{VOM}=\mathrm{VOM}_{\text {chemicals }}+\mathrm{VOM}_{\text {wastewater }}+\mathrm{VOM}_{\text {transport }}+\mathrm{VOM}_{\text {disposal }}+ \\
\mathrm{VOM}_{\text {energy }}
\end{gathered}
$$

Finally, the total annual O\&M cost (TOM, $\$ / \mathrm{yr})$ may be obtained as:

$$
\mathrm{TOM}=\mathrm{FOM}+\mathrm{VOM}
$$




\section{Incremental Cost of Electricity}

Once the total capital requirement and the total O\&M costs are known, the total annualized cost of the power plant may be estimated as follows:

Total annual revenue requirement, TRR $(\$ / y r)=(\mathrm{TCR} \times \mathrm{CRF})+\mathrm{TOM}$

where,

$\mathrm{TCR}=$ Total capital requirement of the power plant $(\$)$

$\mathrm{CRF}=$ Capital recovery factor (fraction)

The capital recovery factor, or fixed charge factor (FCF), is the factor that annualizes the total capital requirement of the plant. It depends on the applicable interest rate (or discount rate) and useful lifetime of the plant. The details of the capital recovery factor can be found elsewhere [36].

It can be seen that a higher value of this factor (e.g. from assumptions of shorter plant life and/or higher interest rate) leads to a higher overall annualized cost. Hence the assumption about this factor (a user-defined parameter) is crucial in the overall economics of the plant.

The IECM framework calculates the cost of electricity (COE) for the overall power plant by dividing the total annualized plant cost $(\$ / y r)$ by the net electricity generated $(\mathrm{kWh} / \mathrm{yr})$. Results are expressed in units of $\$ / \mathrm{MWh}$ (equivalent to mills $/ \mathrm{kWh}$ ).

Cost of electricity, $\mathrm{COE}(\$ / \mathrm{MWh})=\mathrm{TRR} /\left(\mathrm{MW}_{\text {net }} \times \mathrm{HPY}\right)$

where,

$\mathrm{TRR}=$ Total annual revenue requirement $(\$ / \mathrm{yr})$

$\mathrm{MW}_{\text {net }}=$ Net power generation capacity (MW)

$\mathrm{HPY}=$ Annual hours of operation (hrs/yr)

Note that the COE includes the cost of all environmental control systems, not just the $\mathrm{CO}_{2}$ control system. Thus, by running two scenarios of the power plant model, one without $\mathrm{CO}_{2}$ capture (reference plant) and one with $\mathrm{CO}_{2}$ capture $\left(\mathrm{CO}_{2}\right.$ capture plant), the incremental capital costs, O\&M costs, and total annualized costs attributed to $\mathrm{CO}_{2}$ capture are obtained. The addition of a $\mathrm{CO}_{2}$ capture and sequestration system increases the $\mathrm{COE}$ for the plant; this incremental cost of electricity is attributed to $\mathrm{CO}_{2}$ control.

\section{Cost of $\mathrm{CO}_{2}$ Avoidance}

Analysts often express the cost of an environmental control system in terms of the cost per unit mass of pollutant removed. However, for energy-intensive $\mathrm{CO}_{2}$ controls there is a big difference between the cost per tonne $\mathrm{CO}_{2}$ "removed" and the cost per tonne "avoided" based on net plant capacity. Since the purpose of adding a $\mathrm{CO}_{2}$ unit is to reduce the $\mathrm{CO}_{2}$ emissions per net $\mathrm{kWh}$ delivered, the "cost of $\mathrm{CO}_{2}$ avoidance" is the economic indicator that is widely used in this field. It can be calculated as:

Cost of $\mathrm{CO}_{2}$ Avoided $(\$ / \mathrm{t})=$

$$
\frac{(\$ / k W h)_{\text {after }}-(\$ / k W h)_{\text {before }}}{\left(\text { tonne } \mathrm{CO}_{2} / \mathrm{kWh}\right)_{\text {before }}-\left(\text { tonne } \mathrm{CO}_{2} / \mathrm{kWh}\right)_{\text {after }}}
$$


In contrast, the cost per unit of $\mathrm{CO}_{2}$ removed or captured is simply the additional expenses incurred in the capture of $\mathrm{CO}_{2}$, divided by the total quantity of $\mathrm{CO}_{2}$ captured. This can be calculated as the difference between the total annualized cost of the plant (TRR, $\mathrm{M} \$ / \mathrm{yr}$ ) with and without $\mathrm{CO}_{2}$ control, divided by the total quantity of $\mathrm{CO}_{2}$ captured (tonne $\mathrm{CO}_{2} / \mathrm{yr}$ ), with the net power generated by the two plants remaining the same. Hence, the $\mathrm{CO}_{2}$ avoidance cost, as calculated in equation $4-33$, is quite different from the cost per unit of $\mathrm{CO}_{2}$ captured. In case of $\mathrm{CO}_{2}$ control using an energy-intensive technology like amine-scrubbing, the cost of $\mathrm{CO}_{2}$ avoidance may be substantially higher than cost of $\mathrm{CO}_{2}$ capture. 


\section{Case Study}

The application of the performance and cost model may be illustrated using a case study of a power plant. Let us consider the case of an existing conventional coalfired power plant, and impact of modifying it to oxyfuel combustion plant to obtain a concentrated $\mathrm{CO}_{2}$ product stream.

\section{Input Parameters}

The basic assumptions and input parameters are listed in Table 7. These can be entered into the IECM [1].

Table 7. Design parameters for case study of a pulverized coal plant with $\mathrm{CO}_{2}$ control using $\mathrm{O}_{2} / \mathrm{CO}_{2}$ recycle (oxyfuel combustion) system

\begin{tabular}{|c|c|c|c|}
\hline Parameter & Value & Parameter & Value \\
\hline Gross plant size $(\mathrm{MW})$ & 500 & Emission standards & 2000 NSPS $^{1}$ \\
\hline Base plant steam cycle type & $\mathrm{SC}^{2}$ & $\mathrm{NO}_{\mathrm{x}}$ Controls & $\mathrm{LNB}^{3}$ \\
\hline $\begin{array}{l}\text { Gross plant heat rate } \\
(\mathrm{kJ} / \mathrm{kWh})\end{array}$ & $9325^{4}$ & Particulate Control & $\mathrm{ESP}^{5}$ \\
\hline Plant capacity factor $(\%)$ & 75 & $\mathrm{SO}_{2}$ Control & FGD $^{6}$ \\
\hline \multicolumn{2}{|l|}{ Coal characteristics } & $\mathrm{CO}_{2}$ Control & $\mathrm{O}_{2} / \mathrm{CO}_{2}{ }^{7}$ \\
\hline Rank & Bit. & $\mathrm{CO}_{2}$ product purity $(\%)$ & 97.5 \\
\hline $\mathrm{HHV}(\mathrm{kJ} / \mathrm{kg})$ & 30,776 & $\mathrm{CO}_{2}$ capture efficiency $(\%)$ & 90 \\
\hline$\% \mathrm{~S}$ & 2.13 & $\mathrm{CO}_{2}$ product pressure $(\mathrm{kPa})$ & 13,790 \\
\hline$\% \mathrm{C}$ & 73.81 & Distance to storage $(\mathrm{km})$ & 165 \\
\hline Delivered cost (\$/tonne) & 37.10 & $\begin{array}{l}\text { Cost year basis (constant } \\
\text { dollars) }\end{array}$ & 2000 \\
\hline Delivered cost (\$/GJ) & 1.203 & Fixed charge factor & $0.15^{8}$ \\
\hline
\end{tabular}

${ }^{1} \mathrm{NO}_{\mathrm{x}}=65 \mathrm{ng} / \mathrm{J}, \mathrm{PM}=13 \mathrm{ng} / \mathrm{J}, \mathrm{SO}_{2}=81 \%$ removal (assumed to be the same as that of the reference plant case)

${ }^{2}$ Nominal case is a sub-critical unit

${ }^{3} \mathrm{LNB}=$ Low- $\mathrm{NO}_{\mathrm{x}}$ Burner

${ }^{4}$ Gross heat rate of the plant improves to $8,841 \mathrm{~kJ} / \mathrm{kWh}$ after switching to oxyfuel combustion mode, due to higher boiler efficiency

${ }^{5} \mathrm{ESP}=$ Electrostatic Precipitator

${ }^{6} \mathrm{FGD}=$ Flue Gas Desulfurization

${ }^{7} \mathrm{O}_{2} / \mathrm{CO}_{2}=$ Oxyfuel combustion system with flue gas recycle

${ }^{8}$ Corresponds to a 30 -year plant lifetime with a $14.8 \%$ real interest rate (or, a 20 -year life with $13.9 \%$ interest) 
The reference plant (without $\mathrm{CO}_{2}$ control unit) is a New Source Performance Standard (NSPS) compliant coal-fired power plant and the complete plant with multi-pollutant environmental controls is simulated using IECM. Wyoming Powder River Basin coal has been assumed to be used. The model outputs are presented later in Table 5.2 in comparison with the estimates for the $\mathrm{CO}_{2}$ capture plant.

In case of the $\mathrm{CO}_{2}$ capture plant, the following changes have been assumed as compared to the reference plant:

- Pure oxygen (95\% purity) mixed with recycled flue gas is used as oxidant, in place of air.

- Excess air (or oxygen) level is reduced to 5\% (reference plant uses the default value which is about $20 \%$ ).

- Air leakage has been reduced to $2 \%$ (reference plant uses the default value which is about $19 \%$ ).

- The boiler efficiency improves to $94.03 \%$ in case of oxyfuel combustion system, as compared to $89.16 \%$ for the reference plant using air.

- $\mathrm{CO}_{2}$ handling system including $\mathrm{CO}_{2}$ product purification, compression, transport and storage has been added.

The values for other parameters are listed in Table 3, Table 4, Table 5 and Table 6 in previous sections. 


\section{Performance}

\section{Coal Flow Rate}

The required coal flow rate for this illustration is calculated using Equation (1):

$$
\begin{aligned}
\mathrm{M}_{\text {coal }} & =M_{\text {coal }}=\frac{M W_{g} \times H R_{\text {steam }}}{2 \times \eta_{\text {boiler }} \times H H V_{\text {coal }}} \\
& =\frac{500 M W \times 7,880 \mathrm{Btu} / \mathrm{kWh}}{2 \times 0.9404 \times 13,260 \mathrm{Btu} / \mathrm{lb}} \\
& =158 \mathrm{ton} / \mathrm{hr} \text { (or } 143.3 \mathrm{tonne} / \mathrm{hr})
\end{aligned}
$$

\section{Oxygen Requirement}

\section{Stoichiometric Oxygen}

The stoichiometric $\mathrm{O}_{2}$ requirement is calculated on the basis of the coal flow rate and coal composition. The results are shown in Table 8.

Table 8. Coal properties and associated oxygen requirements for stoichiometric combustion.

\begin{tabular}{|l|l|l|l|l|l||}
\hline Coal component & Mol. Wt. & wt $\%$ & ton/hr & $\mathbf{O}_{\mathbf{2}}$ ton/ton & $\mathbf{O}_{\mathbf{2}}$ req. ton/hr \\
\hline \hline $\mathrm{C}$ & 12 & 73.81 & 116.6 & 2.7 & 331.0 \\
\hline $\mathrm{H}$ & 2 & 4.88 & 7.7 & 8.0 & 61.7 \\
\hline $\mathrm{O}$ & 32 & 5.41 & 8.5 & -1 & -8.5 \\
\hline $\mathrm{S}$ & 32 & 2.13 & 3.4 & 1 & 3.4 \\
\hline $\mathrm{N}$ & 28 & 1.42 & 2.2 & $0.095^{1}$ & 0.2 \\
\hline Total & & & & & 367.7 \\
\hline
\end{tabular}

So, the theoretical $\mathrm{O}_{2}$ requirement is $367.7 \mathrm{ton} / \mathrm{hr}$, or about $22,970 \mathrm{lbmole} / \mathrm{hr}$.

\section{Required Oxygen}

With $5 \%$ excess oxygen, the total amount of $\mathrm{O}_{2}$ required can be calculated.

$$
M_{O 2, \text { req }}=1.05 \times 367.7=386 \mathrm{ton} / \mathrm{hr}
$$

\section{Required Oxidant}

The oxygen product is $95 \%$ pure. Hence, the total amount of oxygen product or oxidant supplied by the ASU can be calculated.

$$
\begin{gathered}
M_{o x}=386 / 0.95=406.4 \text { ton } / \mathrm{hr} \\
=369 \text { tonne } / \mathrm{hr}
\end{gathered}
$$

\footnotetext{
${ }^{1}$ Estimated on the basis of $\mathrm{NO}_{\mathrm{x}}$ emission rate of $0.1885 \mathrm{lb} / \mathrm{MBtu}$ and assuming $95 \%$ of $\mathrm{NO}_{\mathrm{x}}$ is $\mathrm{NO}$
} 


\section{Air Leakage}

Air leakage stream is defined on the basis of theoretical air (oxygen) requirement. It is assumed that the air leakage is $2 \%$ which means the air leakage stream contains oxygen equivalent to $2 \%$ of theoretical oxygen requirement for combustion. So, the amount of oxygen in air leakage stream $=0.02 * 367.7=7.4 \mathrm{ton} / \mathrm{hr}$. Air contains about $22.8 \% \mathrm{w} / \mathrm{w}$ of oxygen. So, the air leakage stream is estimated to be $=7.4 \mathrm{f}$ $0.228=32.3 \mathrm{ton} / \mathrm{hr}$.

\section{Combustion Product}

The combustion products and composition of the flue gas stream is estimated on the basis of combustion reaction stoichiometry, and other known input streams.

Table 9. Combustion products of the flue gas stream. All values are in units of lb-mole/hr.

\begin{tabular}{||l|r|r|r|r|r||}
\hline Component & $\begin{array}{l}\text { Combustion } \\
\text { Products }\end{array}$ & Oxidant & Sub-total & Air Leakage & \multicolumn{1}{l||}{ lotal } \\
\hline \hline $\mathrm{N}_{2}$ & 134.4 & 194.4 & 328.8 & $1,712.1$ & $2,040.9$ \\
\hline $\mathrm{O}_{2}$ & $-22,967.9$ & $24,116.3$ & $1,148.4$ & 459.4 & $1,607.8$ \\
\hline $\mathrm{H}_{2} \mathrm{O}$ & $7,710.4$ & 0.0 & $7,710.4$ & 63.2 & $7,773.6$ \\
\hline $\mathrm{CO}_{2}$ & $19,436.6$ & 0.0 & $19,436.6$ & 0.0 & $19,426.6$ \\
\hline $\mathrm{CO}$ & 0.0 & 0.0 & 0.0 & 0.0 & 0.0 \\
\hline $\mathrm{HCl}$ & 0.0 & 0.0 & 0.0 & 0.0 & 0.0 \\
\hline $\mathrm{SO}_{2}$ & 208.7 & 0.0 & 208.7 & 0.0 & 208.7 \\
\hline $\mathrm{SO}_{3}$ & 1.7 & 0.0 & 1.7 & 0.0 & 1.7 \\
\hline $\mathrm{NO}$ & 25.0 & 0.0 & 25.0 & 0.0 & 25.0 \\
\hline $\mathrm{NO}_{2}$ & 0.9 & 0.0 & 0.9 & 0.0 & 0.9 \\
\hline $\mathrm{NH}_{3}$ & 0.0 & 0.0 & 0.0 & 0.0 & 0.0 \\
\hline $\mathrm{Ar}$ & 0.0 & $1,074.8$ & $10,74.8$ & 20.5 & $1,095.3$ \\
\hline Total & $\mathbf{4 , 5 4 9 . 7}$ & $\mathbf{2 5 , 3 8 5 . 5}$ & $\mathbf{2 9 , 9 3 5 . 2}$ & $\mathbf{2 , 2 5 5 . 1}$ & $\mathbf{3 2 , 1 9 0 . 3}$ \\
\hline \hline
\end{tabular}




\section{Recycled Flue Gas}

The flue gas is then passed through the ESP and FGD units to remove particulate matter and sulfur oxides respectively. Next, it is cooled down and most of the water is condensed out. A part of the flue gas is then recycled back into the boiler along with oxygen from ASU.

So, for the next iteration, the oxidant is a mixture of oxygen and recycled flue gas. The oxidant and flue gas streams are estimated assuming that part of the oxygen requirement comes from the leakage air and the oxygen content in the recycled flue gas. For $75 \%$ flue gas recycle ratio, we get:

Table 10. Oxidant and recycled flue gas composition. All values are in units of lb-mole/hr.

\begin{tabular}{|c|c|c|c|c|c|c|}
\hline Component & FGR & $\mathrm{O}_{2}$ (theory) & $\mathrm{O}_{2}$ (corr.) & Oxidant & Total & FG Out \\
\hline N2 & $1,530.7$ & 194.4 & 181.0 & $1,711.6$ & $3,558.1$ & 889.5 \\
\hline $\mathrm{O} 2$ & $1,205.8$ & $24,116.3$ & $22,451.2$ & $23,657.0$ & $1,148.4$ & 287.1 \\
\hline $\mathrm{H} 2 \mathrm{O}$ & $1,275.3$ & 0.0 & 0.0 & $1,275.3$ & $9,048.9$ & $2,262.2$ \\
\hline $\mathrm{CO} 2$ & $14,577.5$ & 0.0 & 0.0 & $14,577.5$ & $34,014.1$ & $8,503.5$ \\
\hline $\mathrm{CO}$ & 0.0 & 0.0 & 0.0 & 0.0 & 0.0 & 0.0 \\
\hline $\mathrm{HCl}$ & 0.0 & 0.0 & 0.0 & 0.0 & 0.0 & 0.0 \\
\hline $\mathrm{SO} 2$ & 156.5 & 0.0 & 0.0 & 156.5 & 365.1 & 91.3 \\
\hline $\mathrm{SO} 3$ & 1.3 & 0.0 & 0.0 & 1.3 & 2.9 & 0.7 \\
\hline NO & 18.8 & 0.0 & 0.0 & 18.8 & 43.8 & 10.9 \\
\hline $\mathrm{NO} 2$ & 0.6 & 0.0 & 0.0 & 0.6 & 1.5 & 0.4 \\
\hline $\mathrm{NH} 3$ & 0.0 & 0.0 & 0.0 & 0.0 & 0.0 & 0.0 \\
\hline AR & 821.5 & $1,074.8$ & $1,000.6$ & $1,822.1$ & $1,842.5$ & 460.6 \\
\hline Total & $19,587.9$ & $25,385.5$ & $23,632.7$ & $43,220.6$ & $50,025.4$ & $12,506.4$ \\
\hline
\end{tabular}

After several iterations, we get the following stable solution:

Table 11. Final oxidant and recycled flue gas composition All values are in units of lbmole/hr.

\begin{tabular}{||l|r|r|r|r|r|r||}
\hline Component & \multicolumn{1}{l|}{ FGR } & O $_{2}$ (req.) & \multicolumn{1}{l}{ Oxidant } & \multicolumn{1}{l}{ Total } & \multicolumn{1}{l|}{ FG Out } & \multicolumn{1}{l|}{ FGR } \\
\hline \hline $\mathrm{N} 2$ & $6,093.4$ & 184.7 & $6,278.1$ & $8,124.6$ & $2,031.1$ & $6,093.4$ \\
\hline $\mathrm{O} 2$ & $1,205.8$ & $22,910.5$ & $24,116.3$ & $1,607.8$ & 401.9 & $1,205.8$ \\
\hline $\mathrm{H} 2 \mathrm{O}$ & $1,525.7$ & 0.0 & $1,525.7$ & $9,299.2$ & $2,324.8$ & $1,525.7$ \\
\hline $\mathrm{CO} 2$ & $58,309.3$ & 0.0 & $58,309.3$ & $7,7745.9$ & $19,436.5$ & $58,309.3$ \\
\hline $\mathrm{CO}$ & 0.0 & 0.0 & 0.0 & 0.0 & 0.0 & 0.0 \\
\hline $\mathrm{HCl}$ & 0.0 & 0.0 & 0.0 & 0.0 & 0.0 & 0.0 \\
\hline $\mathrm{SO} 2$ & 29.7 & 0.0 & 29.7 & 39.6 & 9.9 & 29.7 \\
\hline $\mathrm{SO} 3$ & 0.2 & 0.0 & 0.2 & 0.3 & 0.1 & 0.2 \\
\hline $\mathrm{NO}$ & 75.0 & 0.0 & 75.0 & 100.0 & 25.0 & 75.0 \\
\hline $\mathrm{NO} 2$ & 2.6 & 0.0 & 2.6 & 3.4 & 0.9 & 2.6 \\
\hline $\mathrm{NH} 3$ & 0.0 & 0.0 & 0.0 & 0.0 & 0.0 & 0.0 \\
\hline $\mathrm{Ar}$ & $3,124.6$ & $1,021.1$ & $4,145.7$ & $4,166.2$ & $1,041.5$ & $3,124.6$ \\
\hline Total & $70,366.3$ & $24,116.3$ & $94,482.6$ & $101,087.0$ & $25,271.8$ & $70,366.3$ \\
\hline
\end{tabular}




\section{$\mathrm{CO}_{2}$ Product Stream}

The $\mathrm{CO}_{2}$ product flow rate is estimated as follows:

Total $\mathrm{CO}_{2}$ captured $=0.90 \times 19,436.5=17,492.9 \mathrm{lbmole} / \mathrm{hr}=384.8 \mathrm{ton} / \mathrm{hr}$

At $97.5 \%$ purity level, the total product flow rate would be about $17,942 \mathrm{lbmole} / \mathrm{hr}$ or $394 \mathrm{ton} / \mathrm{hr}$.

\section{Power Requirement}

The energy requirement for various items are calculated in the following subsections.

\section{ASU Unit Power}

$\mathrm{MACP}=0.0049 * \varphi+0.4238$, for $\varphi \leq 97.5 \%$

$$
=0.0736 /(100-\varphi)^{1.3163}+0.8773, \text { for } \varphi>97.5 \%
$$

where,

$$
\mathrm{MACP}=\mathrm{kWh} / 100 \mathrm{ft}^{3} \mathrm{O}_{2} \text { product }
$$

Here,

$$
\varphi=\mathrm{O}_{2} \text { product purity }(\mathrm{mole} \%)=95 \%
$$

So,

$$
\mathrm{MACP}=0.0049 \times 95+0.4238=0.8893 \mathrm{kWh} / 100 \mathrm{ft}^{3} \mathrm{O}_{2} \text { product }
$$

\section{ASU Total Power}

$$
\mathrm{MW}_{\mathrm{ASU}}=3.798(10)^{-3} \times \mathrm{MACP} \times \mathrm{M}_{\mathrm{O} 2}
$$

Where,

$$
\mathrm{M}_{\mathrm{O} 2}=\text { Total oxygen requirement from } \mathrm{ASU}=22,911 \mathrm{lbmole} / \mathrm{hr}
$$

So,

$$
\mathrm{MW}_{\mathrm{ASU}}=3.798(10)^{-3} \times 0.8893 \times 22,911=77.38 \mathrm{MW}
$$

\section{FGR Fan}

$$
\mathrm{MW}_{\mathrm{FGR}}=3.255(10)^{-6} \times \mathrm{V}_{\mathrm{FG}} \times \Delta \mathrm{P}_{\mathrm{FGRF}} / \eta_{\text {fgrf }}
$$

where,

$$
\begin{aligned}
& \mathrm{V}_{\mathrm{FG}}=\text { flue gas flow rate }\left(\mathrm{ft}^{3} / \mathrm{min}\right) \\
& \Delta \mathrm{P}_{\mathrm{FGRF}}=\text { FGR fan pressure head (psi) } \\
& \eta_{\text {fgrf }}=\text { fan efficiency (\%), usually } 75 \%
\end{aligned}
$$

Here,

recycled flue gas flow rate $=70,366 \mathrm{lbmole} / \mathrm{hr}$

At $100 \operatorname{deg} F$, the volumetric flow rate of this stream would be about $438,620^{1}$ $\mathrm{ft}^{3} / \mathrm{min}$. So,

$$
\mathrm{MW}_{\mathrm{FGR}}=3.255(10)^{-6} \times 438,620 \times 0.14 / 0.75=0.27 \mathrm{MW}
$$

\footnotetext{
${ }^{1} \mathrm{~V}=22.4\left(\mathrm{~m}^{3} / \mathrm{kgmole}\right) \times 70,366(\mathrm{lbmole} / \mathrm{hr}) \times(\mathrm{kg} / 2.2 \mathrm{lb}) \times(311 / 298) \times(\mathrm{hr} / 60 \mathrm{~min}) \times\left(\mathrm{ft}^{3} / 0.02832 \mathrm{~m}^{3}\right)=438,620$
} $\left(\mathrm{ft}^{3} / \mathrm{min}\right)$ 


\section{Flue Gas Cooling}

$$
\mathrm{MW}_{\text {FGcooling }}=4.7(10)^{-5} \times \mathrm{M}_{\text {cooling }}
$$

Now,

$$
\mathrm{M}_{\text {cooling }}(\mathrm{gpm})=3.3(10)^{-3} \times \mathrm{V}_{\mathrm{fg}} \times \Delta \mathrm{T}
$$

So,

$$
\mathrm{M}_{\text {cooling }}=3.3(10)^{-3} \times 438,620 \times 40=57,900 \mathrm{gpm}
$$

Hence,

$$
\mathrm{MW}_{\mathrm{FGcoling}}=4.7(10)^{-5} \times 57,900=2.7 \mathrm{MW}
$$

\section{$\mathrm{CO}_{2}$ Purification and Compression}

$$
\mathrm{MW}_{\text {compr_purif }}=\left(\mathrm{e}_{\text {comp }}+\mathrm{e}_{\text {purif }}\right) \times \mathrm{M}_{\mathrm{CO} 2}
$$

where,

$$
\begin{aligned}
& \left.\mathrm{M}_{\mathrm{CO} 2}=\text { total mass of } \mathrm{CO}_{2} \text { captured (ton } / \mathrm{hr}\right)=384.8 \mathrm{ton} / \mathrm{hr} \\
& \mathrm{e}_{\text {purif }}=0.0018 \mathrm{MWh} / \text { ton, for low purity product } \\
& \mathrm{P}_{\mathrm{CO} 2}=\mathrm{CO}_{2} \text { product pressure }(\mathrm{psig})=2000 \\
& \eta_{\text {comp }}=\mathrm{CO}_{2} \text { compression efficiency }(\%)=80 \%
\end{aligned}
$$

So,

$$
\begin{aligned}
\mathrm{e}_{\text {comp }} & =[-51.632+19.207 \times \ln (2,000+14.7)] /(1.1 \times 80 / 100), \mathrm{kWh} / \mathrm{ton} \\
& =107.39 \mathrm{kWh} / \mathrm{ton}
\end{aligned}
$$

So,

$$
\mathrm{MW}_{\text {compr_purif }}=(0.1074+0.0018) \times 384.8=42.02 \mathrm{MW}
$$

\section{Net Power Generation}

The net power generation is calculated by summing the power requirements in the subsections described above and subtracting that power from the gross power generated in the power plant. This is the power that is available for export and use outside the power plant.

The energy consumption from the subsections above is as follows:

$$
\mathrm{MW}_{\text {use }}=77.38+0.027+2.7+42.02=122.13 \mathrm{MW}
$$

The net power output of the plant can be estimated based on the gross output (500 $\mathrm{MW}$ ) and the energy requirements for all environmental control units.

$$
\mathrm{MW}_{\text {net }}=500-122.13=377.83 \mathrm{MW}
$$




\section{Direct Capital Cost}

The capital costs are estimated using the equations in the Capital Cost section discussed earlier. Please refer to those previous sections for the governing equations, references, and explanations. Each process area in the power plant and the associated capital costs are given in the following subsections.

Note also that all costs are reported in \$M for year 2000 US \$ for illustration purposes. To convert costs to other years, please refer to Table 4 and substitute the appropriate cost index for the year of interest for the "PCI" term in each cost equation.

\section{Air Separation Unit (ASU)}

Maximum train capacity $=11350 \mathrm{lbmole} / \mathrm{hr}$

Hence, three operating trains would be required.

$$
C_{A S U, r e f}=\frac{14.35 \times N_{t} \times T_{a}^{0.067}}{(1-\phi)^{0.073}}\left(\frac{M_{o x}}{N_{o}}\right)^{0.852}
$$

where,

$$
\begin{aligned}
& 20^{\circ} \mathrm{F} \leq T_{a} \leq 95^{\circ} \mathrm{F} \\
& 625 \leq\left(\frac{M_{o x}}{N_{o}}\right) \leq 11,350 \text { lbmole } / \mathrm{hr} \\
& 0.95 \leq \phi \leq 0.995
\end{aligned}
$$

So,

$$
C_{\text {ASU, ref }}=\frac{14.35 \times 3 \times 59^{0.067}}{(1-0.95)^{0.073}}\left(\frac{22,911}{3}\right)^{0.852}=\$ 143,168,000(1989 \$)
$$

So, the capital cost equation for the air separation unit is as follows:

$$
\begin{aligned}
\mathrm{C}_{\mathrm{ASU}} & (\$ \mathrm{M})=\mathrm{C}_{\mathrm{ASU}, \mathrm{ref}} \times\left(\mathrm{PCI} / \mathrm{PCI}_{1989}\right) \\
& =143.2 \times(394.1 / 355.4) \mathrm{M} \$ \\
& =\$ 158.8 \mathrm{M}
\end{aligned}
$$

\section{Flue Tas Recycle Fan}

$$
\mathrm{C}_{\mathrm{FGR} \_ \text {fan }}(\$ \mathrm{M})=2.0 \times\left[\mathrm{V}_{\mathrm{FGR}} / 6.474(10)^{5}\right]^{0.6} \times\left(\mathrm{PCI} / \mathrm{PCI}_{1998}\right)
$$

So,

$$
\begin{aligned}
\mathrm{C}_{\mathrm{FGR} \_ \text {fan }}(\$ \mathrm{M}) & =2.0 \times\left[438,620 / 6.474(10)^{5}\right]^{0.6} \times\left(\mathrm{PCI} / \mathrm{PCI}_{1998}\right) \\
& =1.58 \times(394.1 / 389.5)=\$ 1.6 \mathrm{M}
\end{aligned}
$$

\section{Flue Gas Recycle Ducting}

$$
\mathrm{C}_{\mathrm{FGR} \_ \text {ducting }}(\$ \mathrm{M})=10.0 \times\left[\mathrm{V}_{\mathrm{FGR}} / 6.474(10)^{5}\right]^{0.6} \times\left(394.1 / \mathrm{PCI}_{2001}\right)
$$

So, 


$$
\begin{aligned}
\mathrm{C}_{\mathrm{FGR} \_ \text {ducting }}(\$ \mathrm{M}) & =10.0 \times\left[438,620 / 6.474(10)^{5}\right]^{0.6} *\left(\mathrm{PCI} / \mathrm{PCI}_{2001}\right) \\
& =7.9 \times(394.1 / 394.3)=\$ 7.9 \mathrm{M}
\end{aligned}
$$

\section{Flue Gas Cooler}

$\mathrm{C}_{\mathrm{FG} \_\mathrm{DCC}}(\$ \mathrm{M})=17.6 \times\left(\mathrm{V}_{\mathrm{FG}} / 809,763\right)^{0.6} \times\left(\mathrm{PCI} / \mathrm{PCI}_{2001}\right)$

So,

$$
\begin{aligned}
\mathrm{C}_{\mathrm{FG} \_\mathrm{DCC}}(\$ \mathrm{M}) & =17.6 \times(438,620 / 809,763)^{0.6} \times\left(\mathrm{PCI} / \mathrm{PCI}_{2001}\right) \\
& =17.6 \times(0.692) *(394.1 / 394.3)=\$ 12.2 \mathrm{M}
\end{aligned}
$$

\section{Oxygen Heater}

$$
\mathrm{C}_{\mathrm{APH} \_\mathrm{OH}}(\mathrm{SM})=12 \times\left(\mathrm{MW}_{\text {gross }} / 500\right)^{0.6} \times\left(\mathrm{PCI} / \mathrm{PCI}_{2001}\right)
$$

So,

$$
\begin{aligned}
\mathrm{C}_{\mathrm{APH} \_ \text {OH }}(\$ \mathrm{M}) & =12 \times(500 / 500)^{0.6} \times\left(\mathrm{PCI} / \mathrm{PCI}_{2001}\right) \\
& =12 \times(394.1 / 394.3)=\$ 12.0 \mathrm{M}
\end{aligned}
$$

\section{$\mathrm{CO}_{2}$ Purification System}

For the low purity $\mathrm{CO}_{2}$ product:

$$
\mathrm{C}_{\mathrm{CO} 2 \text { _purif }}(\$ \mathrm{M})=0.02 \times\left(\mathrm{M}_{\mathrm{CO} 2 \text { pdt }} / 1.1\right) \times\left(\mathrm{M}_{\mathrm{CO} 2 \text { pdt }} / 660\right)^{0.6} \times\left(\mathrm{PCI} / \mathrm{PCI}_{1995}\right)
$$

So,

$$
\begin{aligned}
\mathrm{C}_{\mathrm{CO} 2 \text { _purif }}(\$ \mathrm{M}) & =0.02 \times(394 / 1.1) \times(394 / 660)^{0.6} \times\left(\mathrm{PCI} / \mathrm{PCI}_{1995}\right) \\
& =5.3 \times(394.1 / 381.1)=\$ 5.5 \mathrm{M}
\end{aligned}
$$

\section{$\mathrm{CO}_{2}$ Compression System}

$$
\mathrm{C}_{\mathrm{CO} 2 \text { _compr }}(\$ \mathrm{M})=16.85 \times\left(\mathrm{hp}_{\mathrm{CO} 2 \_ \text {comp }} / 51,676\right)^{0.7} *\left(\mathrm{PCI} / \mathrm{PCI}_{1998}\right)
$$

where,

$\mathrm{hp}_{\mathrm{CO} 2 \text { _omp }}=\mathrm{CO}_{2}$ product compression power requirement (hp).

So,

$$
\begin{aligned}
\mathrm{C}_{\mathrm{CO} 2 \_ \text {compr }}(\$ \mathrm{M}) & =16.85 \times\left(55,394^{1 /} / 51,676\right)^{0.7} *\left(\mathrm{PCI} / \mathrm{PCI}_{1998}\right) \\
& =17.7 \times(394.1 / 389.5)=\$ 17.9 \mathrm{M}
\end{aligned}
$$

\section{Boiler Modifications}

In case of a pre-existing $\mathrm{PC}$ plant being retrofitted for $\mathrm{CO}_{2}$ capture, the boiler must be modified to suit the new oxyfuel combustion system. The cost for these modifications has been estimated to be about $4 \%$ of the cost of the boiler [9].

$$
\begin{aligned}
& \mathrm{C}_{\text {boiler_mod }}(\$ \mathrm{M})=0.04 \times \mathrm{C}_{\text {boiler }} \times\left(\mathrm{PCI} / \mathrm{PCI}_{2001}\right) \text {, for retrofit application } \\
& \mathrm{C}_{\text {boiler_mod }}(\$ \mathrm{M})=0, \text { for new plant case (default) }
\end{aligned}
$$

\footnotetext{
${ }^{1} \mathrm{hp}_{\text {CO2_comp }}=107.4(\mathrm{kWh} / \mathrm{ton}) \times 384.8($ ton $/ \mathrm{hr}) \times(\mathrm{hp} / 0.746 \mathrm{~kW})=55,394 \mathrm{hp}$
} 
So,

$$
\mathrm{C}_{\text {boiler_mod }}(\$ \mathrm{M})=0
$$

So, the total process facilities cost (PFC) is sum of the individual costs estimated above, which is $\$ 221.3 \mathrm{M}$.

\section{Other Capital Costs}

Next, the indirect capital costs are estimated using Table 5, and hence the total capital requirement (TCR) of the $\mathrm{O}_{2} / \mathrm{CO}_{2}$ recycle system is estimated.

$$
\begin{aligned}
& \mathrm{PFC}=\$ 221.3 \mathrm{M} \\
& \mathrm{TPC}=\$ 303.2 \mathrm{M} \\
& \mathrm{TCR}=\$ 337.9 \mathrm{M}
\end{aligned}
$$

\section{O\&M Costs}

The O\&M costs for this system are estimated, as in the O\&M Costs section previously discussed.

\section{Fixed O\&M Costs}

The fixed O\&M (FOM) costs in the model include the costs of maintenance (materials and labor) and labor (operating labor, administrative and support labor). They are estimated on annual basis ( $\$ / y r)$ for a $\$ 2000$ year basis as follows:

$$
\begin{aligned}
\mathrm{FOM}= & \mathrm{FOM}_{\text {labor }}+\mathrm{FOM}_{\text {maint }}+\mathrm{FOM}_{\text {admin }} \\
\mathrm{FOM}_{\text {labor }}= & \text { labor } \times \mathrm{N}_{\text {labor }} \times 40(\mathrm{hrs} / \text { week }) \times 52(\text { weeks } / \mathrm{yr}) \\
& =\$ 24.82 / \mathrm{hr} \times 2 \times 40 \mathrm{hr} / \mathrm{wk} \times 52 \mathrm{wk} / \mathrm{yr} \\
& =\$ 103,251 / \mathrm{yr} \\
\mathrm{FOM}_{\text {maint }} & =\Sigma_{\mathrm{i}}\left(\mathrm{f}_{\text {maint }}\right) \times \mathrm{TPC}_{\mathrm{i}} \text { where } \mathrm{i}=\text { process area } \\
& =0.04 \times \mathrm{TPC}=0.04 \times \$ 303.2 \mathrm{M}=\$ 12,128,000 / \mathrm{yr} \\
\mathrm{FOM}_{\text {admin }} & =\mathrm{f}_{\text {admin }} \times\left(\mathrm{FOM}_{\text {labor }}+\mathrm{f}_{\text {maintlab }} \times \mathrm{FOM}_{\text {maint }}\right) \\
& =0.3 \times(103,251+0.4 \times 12,128,000)=\$ 1,486,335 / \mathrm{yr}
\end{aligned}
$$

So,

$$
\begin{aligned}
& \mathrm{FOM}=103,251+12,128,000+1,486,335 \\
& =\$ 13.72 \mathrm{M} / \mathrm{yr}
\end{aligned}
$$

\section{Variable O\&M Costs}

The variable O\&M (VOM) costs are estimated on the basis of Table 6 and the Variable O\&M Costs section previously discussed, as follows:

\section{Chemicals}

$$
\begin{aligned}
\mathrm{VOM}_{\text {chemicals }} & =\mathrm{UC}_{\text {Chemicals }} \times \mathrm{M}_{\mathrm{CO} 2} \times \mathrm{HPY} \\
& =\$ 0.26 / \text { ton } \mathrm{CO}_{2} \text { captured } \times 384.8 \mathrm{ton} / \mathrm{hr} \times 6575 \mathrm{hr} / \mathrm{yr}
\end{aligned}
$$


$\mathrm{CO}_{2}$ transport

$$
\begin{aligned}
\mathrm{VOM}_{\text {transport }} & =\mathrm{M}_{\mathrm{CO} 2} \times \mathrm{UC}_{\text {transport }} \times \mathrm{TD} \times \mathrm{HPY} \\
& =394 \mathrm{ton} / \mathrm{hr} \times \$ 0.03 / \text { ton.mile } \times 100 \mathrm{mile} \times 6,575 \mathrm{hr} / \mathrm{yr} \\
& =\$ 7,771,650 / \mathrm{yr}
\end{aligned}
$$

\section{$\mathrm{CO}_{2}$ Storage}

$$
\begin{aligned}
& \mathrm{VOM}_{\text {disposal }}=\mathrm{M}_{\mathrm{CO} 2} \times \mathrm{UC}_{\text {disp }} \times \mathrm{HPY} \\
& \quad=394 \mathrm{ton} / \mathrm{hr} \times \$ 4.55 / \mathrm{ton} \times 6,575 \mathrm{hr} / \mathrm{yr} \\
& \quad=\$ 11,787,003 / \mathrm{yr}
\end{aligned}
$$

\section{Power}

$$
\begin{aligned}
\mathrm{VOM}_{\text {energy }} & =\mathrm{E}_{\mathrm{CO} 2, \text { tot }} \times \mathrm{HPY} \times \mathrm{COE}_{\text {noctl }} \\
= & 119.67 \mathrm{MW} \times 6,575 \mathrm{hr} / \mathrm{yr} \times \$ 37.5 / \mathrm{MWh} \\
= & \$ 29,506,134 / \mathrm{yr}
\end{aligned}
$$

\section{Total Variable O\&M Cost}

The total variable O\&M (VOM, \$/yr) cost is obtained by adding these particular costs just calcuated:

$$
\begin{aligned}
\mathrm{VOM}= & \mathrm{VOM}_{\text {chemicals }}+\mathrm{VOM}_{\text {transport }}+\mathrm{VOM}_{\text {disposal }}+\mathrm{VOM}_{\text {energy }} \\
& =0.658+7.772+11.787+29.506=\$ 49.723 \mathrm{M} / \mathrm{yr}
\end{aligned}
$$

\section{Total O\&M Costs}

So, the total O\&M cost for the $\mathrm{CO}_{2}$ capture unit is:

$$
\mathrm{TOM}=\mathrm{FOM}+\mathrm{VOM}=\$ 13.72 \mathrm{M} / \mathrm{yr}+\$ 49.723 \mathrm{M} / \mathrm{yr}=\$ 63.44 / \mathrm{yr}
$$

\section{Total Revenue Required}

Finally, the overall annualized cost of the $\mathrm{CO}_{2}$ capture system using $\mathrm{O}_{2} / \mathrm{CO}_{2}$ recycle technology can be estimated. The total revenue required is calculated as follows:

$$
\operatorname{TRR}(\$ M / y r)=(T C R \times C R F)+\mathrm{TOM}
$$

where,

$$
\mathrm{CRF}=\text { Capital recovery factor }(\text { fraction })=0.148
$$

So

$$
\mathrm{TRR}=337.9 \times 0.148+63.44=\$ 113.5 \$ \mathrm{M} / \mathrm{yr}
$$

So, the total annualized cost of capturing $\mathrm{CO}_{2}$ using oxyfuel combustion based $\mathrm{O}_{2} / \mathrm{CO}_{2}$ recycle system has been estimated to be about $\$ 113.5 \mathrm{M} / \mathrm{yr}$. 


\section{References}

1. Berkenpas, M.B., et al, User Documentation: Integrated Environmental Control Model (IECM) with Carbon Capture and Storage (CCS), 2007, Final Report of Work Performed Under Contract No DE-AC21-92MC29094 for US Department of Energy, National Energy Technology Laboratory by the Center for Energy and Environmental Studies, Carnegie Mellon University, Pittsburgh, PA (available at www.iecm-online.com).

2. Dillon, D.J., et al. Oxy-combustion for $\mathrm{CO}_{2}$ capture from advanced supercritical PF and NGCC power plant. in E.S. Rubin, D.W. Keith and C.F. Gilboy (Eds.), Proceedings of 7th International Conference on Greenhouse Gas Control Technologies, Volume 1: Peer-Reviewed Papers and Plenary Presentations. 2004: IEA Greenhouse Gas Programme, Cheltenham, UK.

3. Varagani, R., et al. Oxycombustion in pulverized coal-fired boiler: a promising technology for $\mathrm{CO}_{2}$ capture. in the Third Annual Conference on Carbon capture and sequestration, May 3-6. 2004. Alexandria, VA, USA.

4. Marin, O., et al. Economic analysis of oxygen-fired coal boilers. in Twenty-eighth International Technical Conference on Coal Utilization and Fuel Systems. 2003. Clearwater, FL.

5. Doctor, $\mathrm{R}$., $\mathrm{CO}_{2}$ capture for PC-boiler using flue-as recirculation: Evaluation of $\mathrm{CO}_{2}$ capture/utilization/disposal options. 2003, Project facts - Sequestration, USDOE/NETL.

6. Singh, D., et al., Techno-economic study of $\mathrm{CO}_{2}$ capture from an existing coal-fired power plant: MEA scrubbing vs. $\mathrm{O}_{2} / \mathrm{CO}_{2}$ recycle combustion. Energy Conversion and Management, 2003. 44: p. 3073-3091.

7. Andersson, K., et al. An $865 \mathrm{MW}$ lignite fired $\mathrm{CO}_{2}$ free power plant - a technical feasibility study. in Sixth Greenhouse Gas Control Technologies. 2002. Kyoto, Japan.

8. Birkestad, H., Separation and compression of $\mathrm{CO}_{2}$ in an $\mathrm{O}_{2} / \mathrm{CO}_{2}$-fired power plant, in Department of Energy Conversion. 2002, Chalmers Univ of Technology: Goteborg, Sweden.

9. ALSTOM, et al., Engineering feasibility and economics of $\mathrm{CO}_{2}$ capture on an existing coal-fired power plant. 2001, Final report prepared by ALSTOM Power Inc., ABB Lummus Global Inc., ALSTOM Power

Environmental Systems and American Electric Power (AEP). Report no. (PPL-01-CT-09) submitted to Ohio Department of Development, Columbus, OH and US Department of Energy/ NETL, Pittsburgh, PA. p. 163.

10. Wilkinson, M.B., et al. A study on the capture of carbon dioxide from a large refinery power station boiler by conversion to oxyfuel operation. in Fifth Greenhouse Gas Control Technologies. 2000. Cairns, Australia.

11. Simbeck, D. and M. McDonald. Existing coal power plant retrofit $\mathrm{CO}_{2}$ control options analysis. in presented at the Fifth International Conference on Greenhouse Gas Control Technologies, 13-16 August. 2000. Cairns, Australia.

12. McDonald, M.M. and M. Palkes, A design study of the application of $\mathrm{CO}_{2} / \mathrm{O}_{2}$ Combustion to an existing 300 MW coal fired power plant. 1999.

13. Babcock, et al., Pulverised caol combustion system for $\mathrm{CO}_{2}$ capture: Final Report, JOULE II Programme, Clean Coal Technology R\&D, Contract No. JOU2-CT92-0062. 1995, Commission of the European Communities, Directorate General XII for Science, Research and Development. p. 52.

14. Allam, R.J. and C.G. Spilsbury, A study of the extraction of $\mathrm{CO}_{2}$ from the flue gas of a $500 \mathrm{MW}$ pulverized coal fired boiler. Energy Conversion and Management, 1992. 33(5-8): p. 373-378.

15. Nakayama, S., et al., Pulverized coal combustion in $\mathrm{O}_{2} / \mathrm{CO}_{2}$ mixtures on a power plant for $\mathrm{CO}_{2}$ recovery. Energy Conversion and Management, 1992. 33(5-8): p. 379-386.

16. Periodic Table: Scholar edition: oxygen : History, http://www.webelements.com/webelements/scholar/elements/oxygen/history.html. 2004.

17. Oxygen, http://www.mtsinai.org/pulmonary/papers/ox-hist/ox-hist1.html. 2004. 
18. Oxygen: History, http://nautilus.fis.uc.pt/st2.5/scenes-e/elem/e00810.html. 2004.

19. Linde Gas LLC, History of innovation, http://www.us.lindegas.com/International/Web/Lg/US/Likelgus.nsf/DocByAlias/nav history. 2004.

20. Linde AG, Air seperation history, http://www.linde-process-engineering.com/en/p0001/p0036/p0037/p0037.jsp. 2004.

21. Air Products, History of innovation, http://www.airproducts.com/Technology/innovation.htm. 2004.

22. Abraham, B.M., et al., Coal-oxygen process provides $\mathrm{CO}_{2}$ for enhanced oil recovery. Oil and Gas Journal, 1982. March 15: p. 68-75.

23. Payne, R., et al., $\mathrm{CO}_{2}$ recovery via coal combustion in mixtures of oxygen and recycled flue gas. Combustion Science and Technology, 1989. 67: p. 1-16.

24. Jordal, K., et al. Oxyfuel combustion for coal-fired power generation with $\mathrm{CO}_{2}$ capture - Opportunities and challenges. in E.S. Rubin, D.W. Keith and C.F. Gilboy (Eds.), Proceedings of 7th International Conference on Greenhouse Gas Control Technologies, Volume 1: Peer-Reviewed Papers and Plenary Presentations. 2004: IEA Greenhouse Gas Programme, Cheltenham, UK.

25. Simbeck, D. Overview and insights on the three basic $\mathrm{CO}_{2}$ capture options. in the Third Annual Conference on Carbon capture and sequestration, May 3-6. 2004. Alexandria, VA, USA.

26. Stromberg, L., $\mathrm{CO}_{2} / \mathrm{O}_{2}$ (Oxyfuel) combustion for coal-fired power generation with $\mathrm{CO}_{2}$ capture - Opportunities and challenges. 2003.

27. Bool, L. and H. Kobayashi. NOx reduction from a 44-MW wall-fired boiler utilizing oxygen enhanced combustion. in Twenty-eighth International Technical Conference on Coal Utilization and Fuel Systems. 2003. Clearwater, FL.

28. Bool, L., et al. Oxygen for NOx control - A step change technology. in The 19th Annual International Pittsburgh Coal Conference. 2002. Pittsburgh, PA, USA.

29. Wilkinson, M.B., et al. $\mathrm{CO}_{2}$ capture via oxyfuel firing: Optimisation of a retrofit design concept for a refinery power station boiler. in First National Conference on Carbon Sequestration. 2001. Washington, DC.

30. Croiset, E. and K.V. Thambimuthu, Nox and $\mathrm{SO}_{2}$ emissions from $\mathrm{O}_{2} / \mathrm{CO}_{2}$ recycle coal combustion. Fuel, 2001. 80: p. 2117-2121.

31. Chatel-Pelage, F., et al. A pilot-scale demonstration of oxy-combustion with flue gas recirculation in a pulverized coal-fired boiler. in Twenty-eighth International Technical Conference on Coal Utilization and Fuel Systems. 2003. Clearwater, FL.

32. Marin, O., et al. Low-oxygen enrichment in coal-fired utility boilers. in Twenty-eighth International Technical Conference on Coal Utilization and Fuel Systems. 2003. Clearwater, FL.

33. Rubin, E.S., et al, Technical Documentation: Integrated Gasification Combined Cycle Systems (IGCC) with Carbon Capture and Storage (CCS), 2007, Final Report of Work Performed Under Contract No. DE-AC2192MC29094 for the US Department of Energy, National Energy Technology Laboratory by the Center for Energy and Environmental Studies, Carnegie Mellon University: Pittsburgh, PA (available at www.iecmonline.com).

34. Rao, A.B., A Technical, Economic, and Environmental Assessment of Amine-based Carbon Capture Systems for Greenhouse Gas Control, in Ph.D. Thesis: Engineering and Public Policy. 2003, Carnegie Mellon University: Pittsburgh. p. 175.

35. Rubin, E.S., et al., Integrated environmental control modeling of coal-fired power systems. Journal of Air and\& Water Management Association, 1997. 47: p. 1180-1188.

36. TAG, Technical Assessment Guide. 1999, EPRI TR 102276, EPRI: Palo Alto, CA.

37. Frey, H.C. and E.S. Rubin, Stochastic modeling of coal gasification combined cycle systems: cost models for selected integrated gasification combined cycle (IGCC) systems. 1990, U.S. Department of Energy: Morgantown, WV.

38. Fluor, Evaluation of technologies for the removal of CO2 from coal fired power plant flue gas. 1998, Report prepared by Fluor Daniel Canada Inc., Calgary, Alberta, Canada: for TransAlta, November 1998.

39. Frey, H.C. et al. Stochastic Modeling of Coal Gasification Combined Cycle Systems : Cost Models of Selected Integrated Gasification Combined Cycle (IGCC) Systems. Task 2 Topical Report prepared by Carnegie Mellon University for the U.S. Department of Energy, Morgantown Energy Technology Center, Morgantown, WV, DOE/MC-24258-2901, NTIS DE90015345, June 1990. 


\section{DEVELOPMENT AND APPLICATION OF OPTIMAL DESIGN CAPABILITY FOR COAL GASIFICATION SYSTEMS}

Technical Documentation:

Integrated Gasification Combined Cycle Systems (IGCC) with Carbon Capture and Storage (CCS)

Final Report of

Work Performed Under Contract No.: DE-AC21-92MC29094

Reporting Period Start, October 2003

Reporting Period End, May 2007

Report Submitted, May 2007

to

U.S. Department of Energy

National Energy Technology Laboratory

626 Cochrans Mill Road, P.O. Box 10940

Pittsburgh, Pennsylvania 15236-0940

by

Edward S. Rubin (P.I.)

Michael B. Berkenpas

H. Christopher Frey

Chao Chen

Sean McCoy

Constance J. Zaremsky

Carnegie Mellon University

Center for Energy and Environmental Studies

Department of Engineering and Public Policy

Pittsburgh, PA 15213-3890 



\section{Contents}

DISCLAIMER

ACKNOWLEDGEMENTS

Gasification

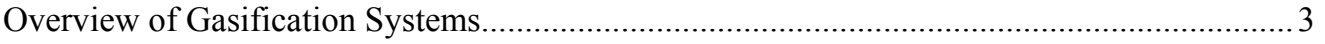

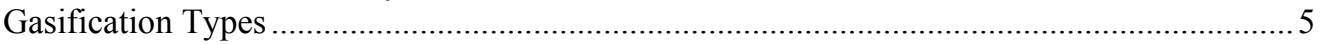

Moving-Bed or Counter-Current Reactors ……………....................................... 5

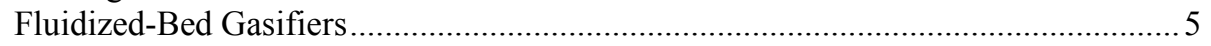

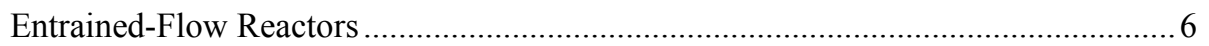

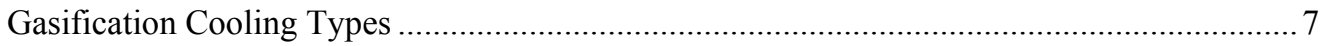

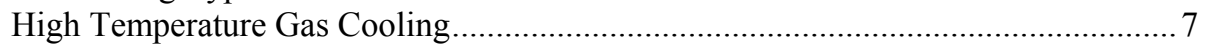

Radiant and Convective Syngas Cooling Design ......................................................

Radiant Only Syngas Cooling Design .................................................................... 8

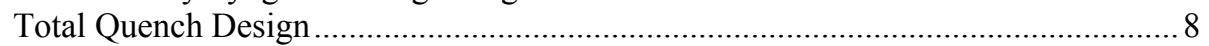

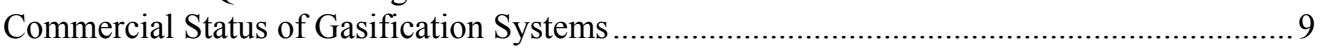

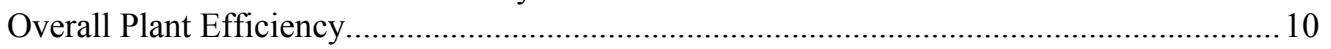

Net Power Output and Plant Efficiency.................................................................. 10

Economics

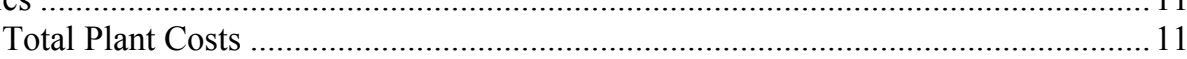

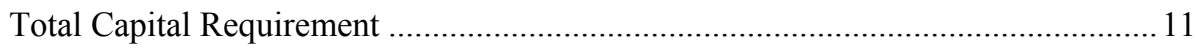

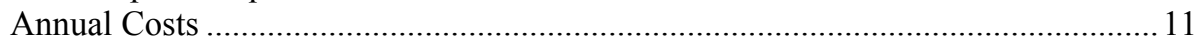

Levelized Costs ....................................................................................... 11

$\begin{array}{ll}\text { Oxidant Feed } & 13\end{array}$

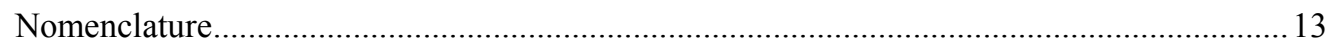

Oxidant Feed Process Description .................................................................................... 13

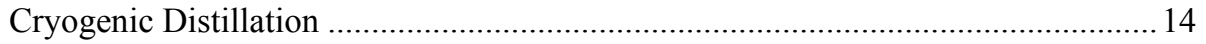

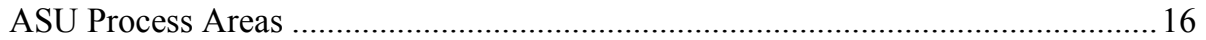

Oxidant Feed Performance Model ................................................................................. 18

Gas Flow - Gasification ................................................................................... 18

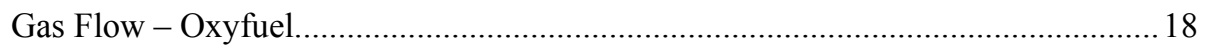

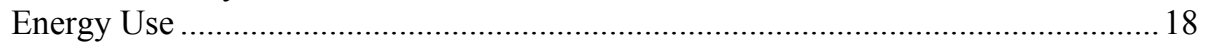

Oxidant Feed Cost Model ............................................................................................. 20

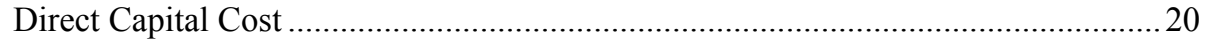

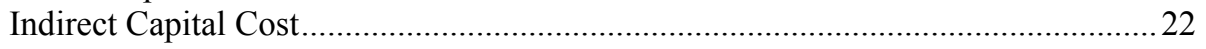

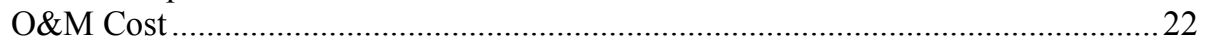

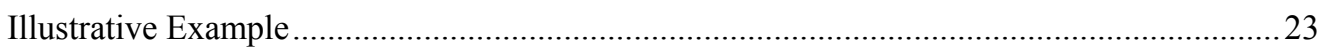

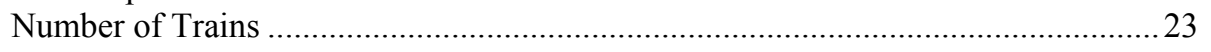

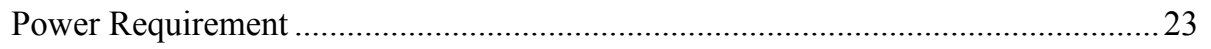

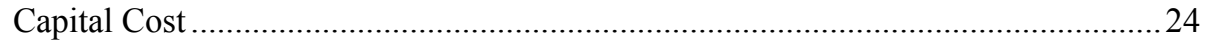

Operating and Maintenance Cost ................................................................ 24

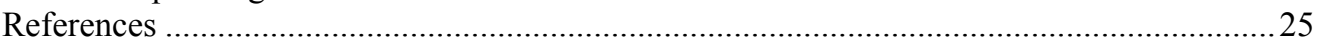




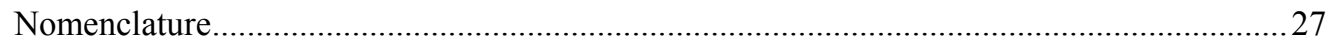

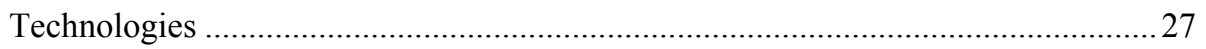

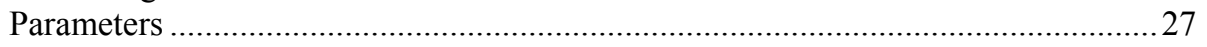

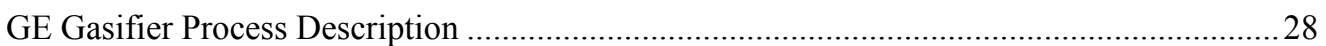

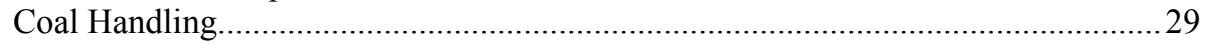

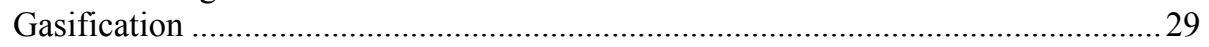

Syngas Quenching ......................................................................................... 31

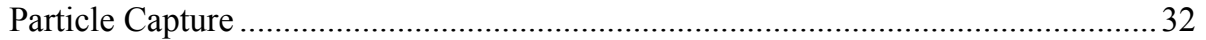

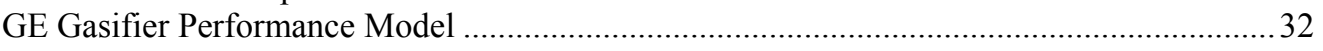

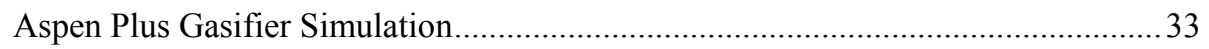

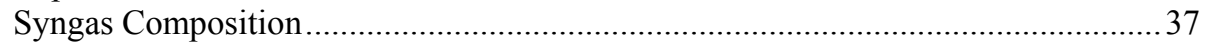

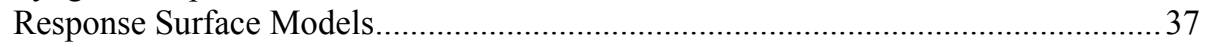

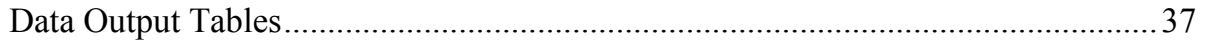

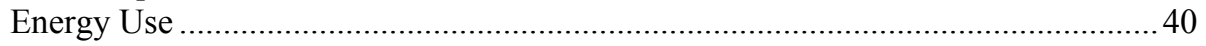

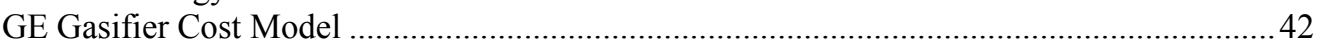

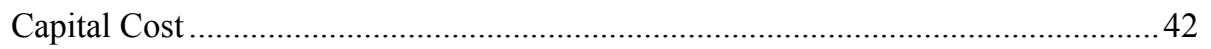

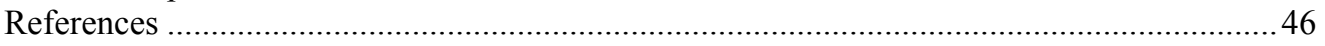

Water Gas Shift System $\quad 49$

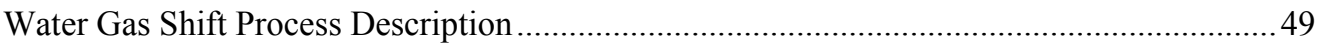

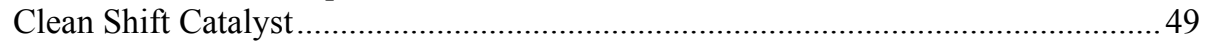

Sulfur Tolerant Shift Catalysts ..............................................................................5 50

Water Gas Shift Performance Model................................................................................... 51

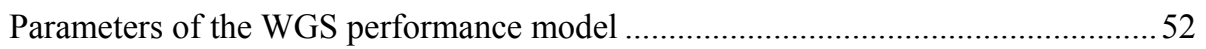

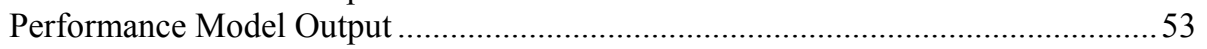

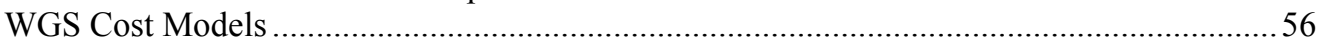

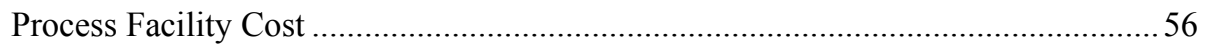

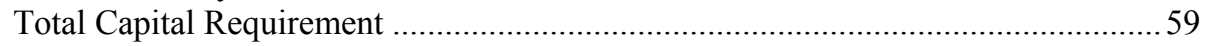

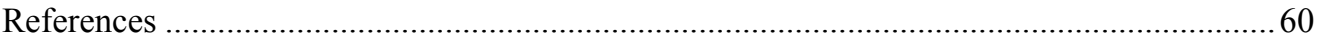

Sulfur Removal and Recovery (Cold-Gas Cleanup) 61

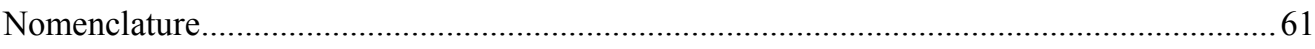

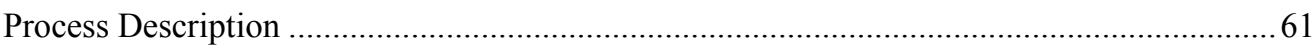

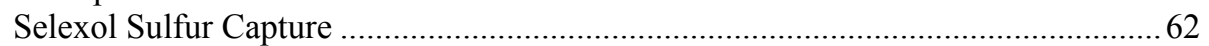

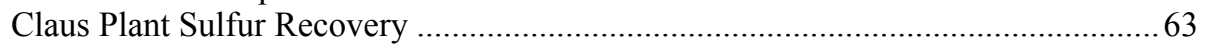

Beavon-Stretford Tail Gas Treatment ................................................................... 63

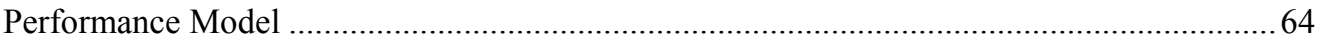

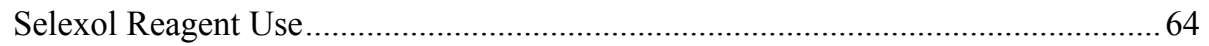

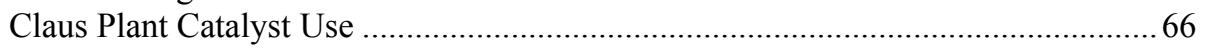

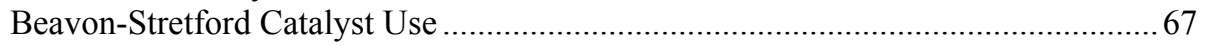

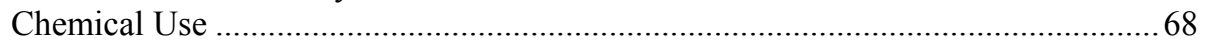

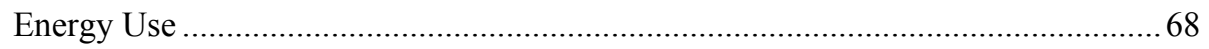

Sulfur Removal and Recovery Cost Model ....................................................................... 70

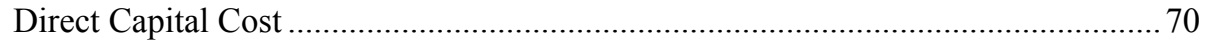

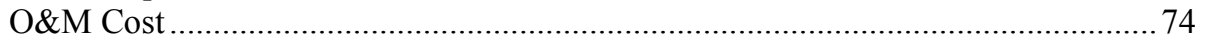

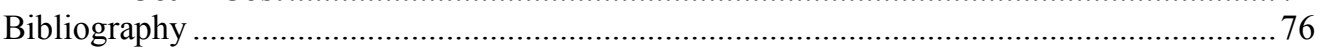

$\begin{array}{ll}\text { Selexol System } & 79\end{array}$

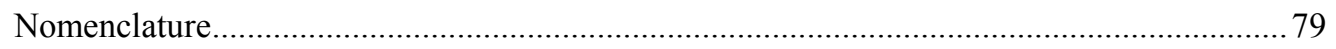

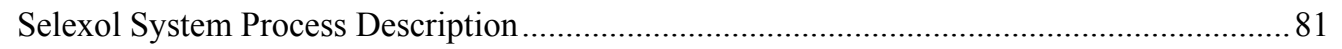

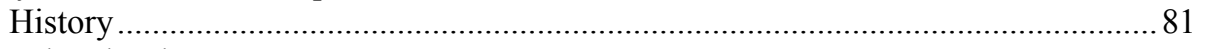

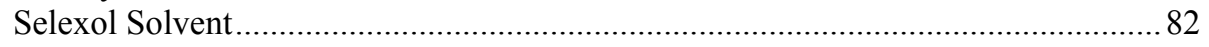




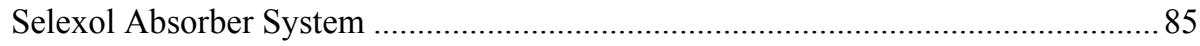

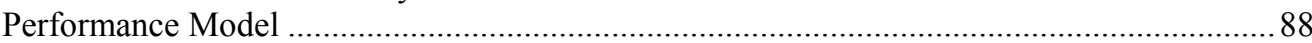

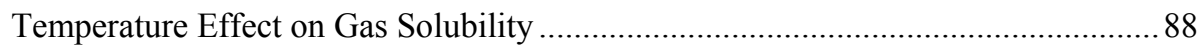

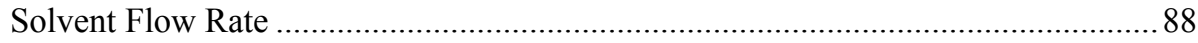

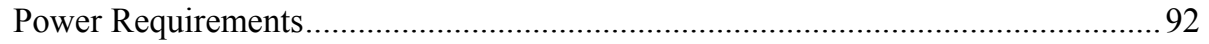

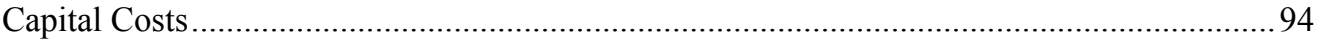

Process Facility Costs........................................................................................... 94

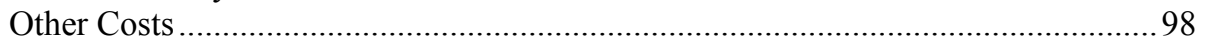

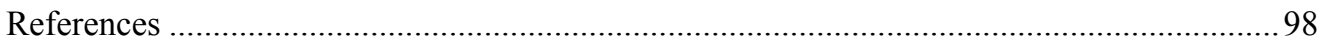

$\begin{array}{ll}\text { Power Block } & 101\end{array}$

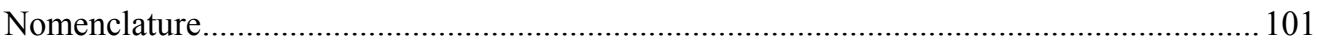

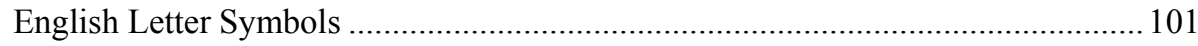

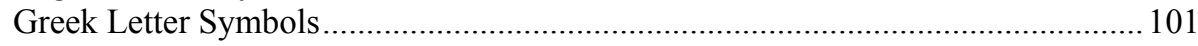

Power Block Process Description................................................................................. 101

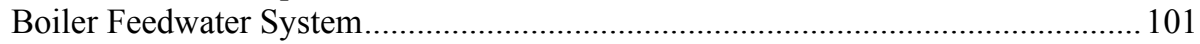

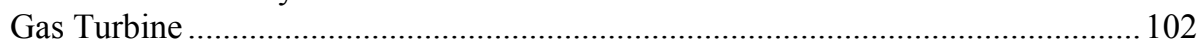

Heat Recovery Steam Generator .......................................................................... 103

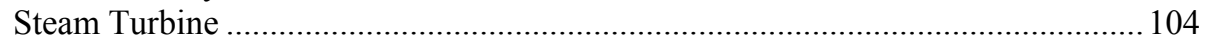

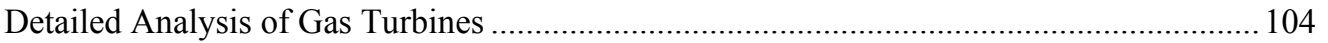

Commercial Offerings for $2,300^{\circ} \mathrm{F}$ Gas Turbines .................................................. 104

Operating Strategies for Coal Gas Firing ................................................................. 106

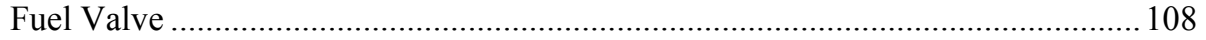

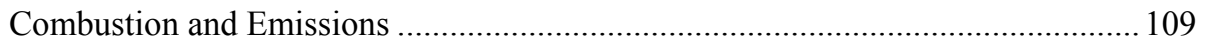

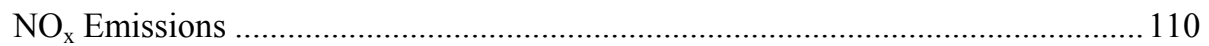

Combustion Efficiency and CO Emissions ............................................................ 114

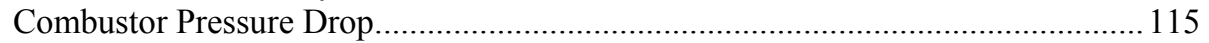

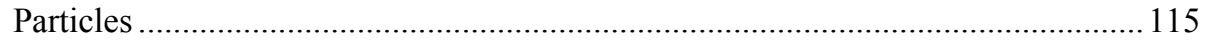

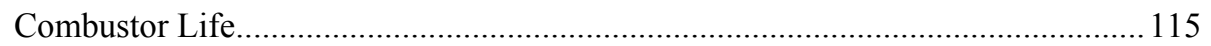

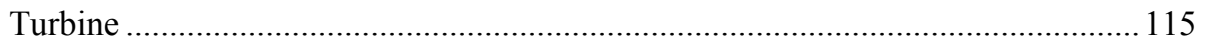

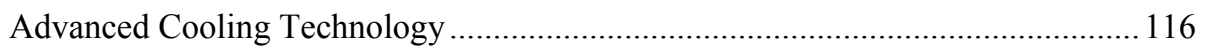

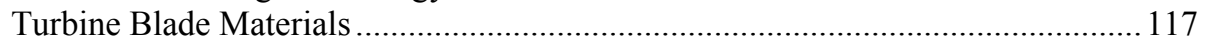

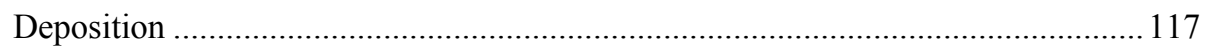

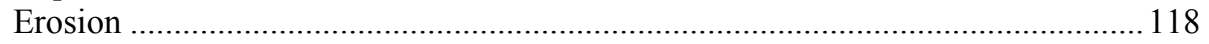

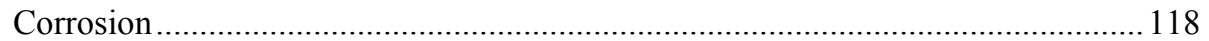

Power Block Performance Model............................................................................... 119

Simple Cycle Gas Turbine: Mass and Energy Balance ............................................ 119

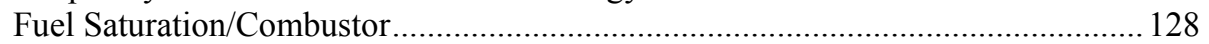

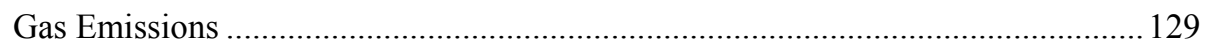

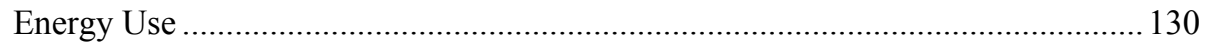

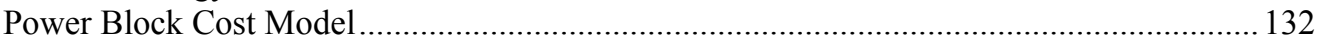

Power Block Capital Cost ………….................................................................. 132

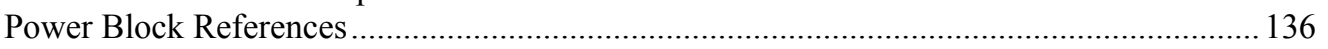

$\mathrm{CO}_{2}$ Transport $\quad 141$

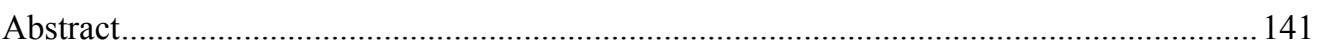

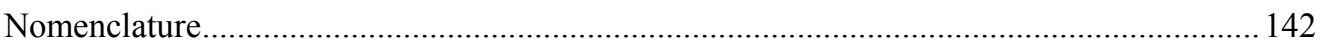

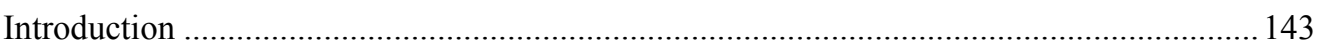

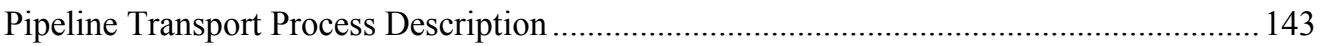

Physical Properties of Carbon Dioxide.................................................................. 144

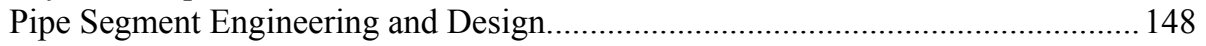

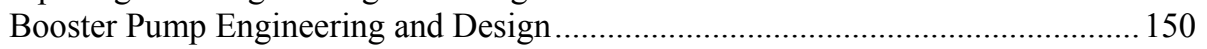

Illustrative Performance Model Results ................................................................. 151

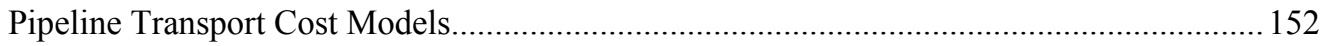




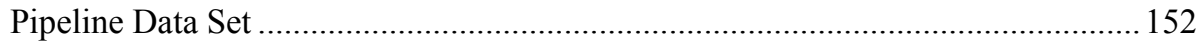

Capital Cost Models ................................................................................................. 155

Operating \& Maintenance Cost Model.................................................................... 162

Pipeline Routing Considerations ..................................................................... 163

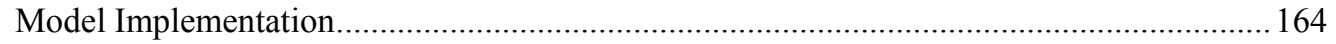

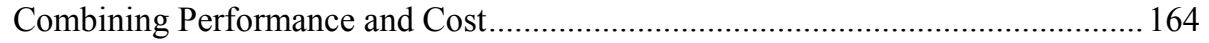

Sensitivity Analysis Tools ............................................................................ 166

Illustrative Results ......................................................................................... 167

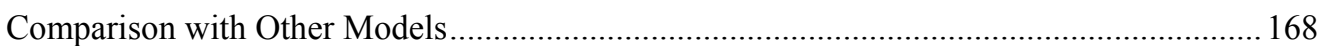

Performance Model Comparison............................................................................ 168

Cost Model Comparison .................................................................................. 169

Overall Model Comparison ........................................................................... 170

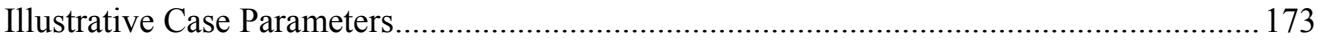

Illustrative Results ................................................................................................... 173

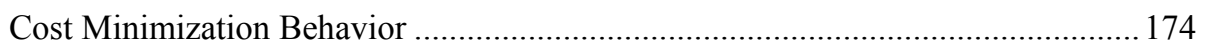

Model Sensitivity Analysis Results ............................................................................... 175

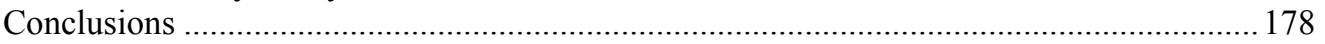

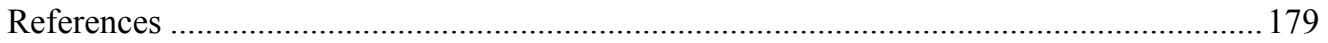

Appendix: Properties of $\mathrm{CO}_{2}$ and Fluids of Interest ................................................. 182

Regression Analysis $\quad 183$

Overview of Multivariate Linear Least Squares ........................................................... 183

Standard Error ......................................................................................... 186

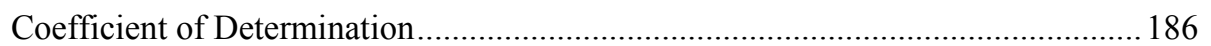

Statistical Significance of the Model................................................................. 187

Application of Regression Analysis to Model Development............................................ 188

Number of Observations....................................................................... 188

Transformation of Variables............................................................................ 189

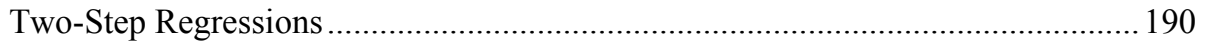

Selection of Predictive Variables ................................................................ 191

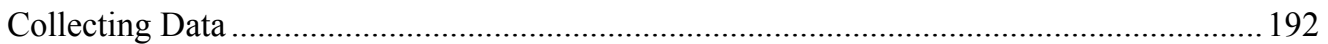

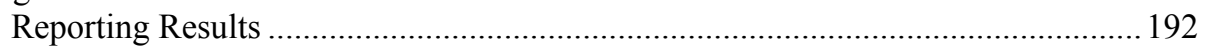

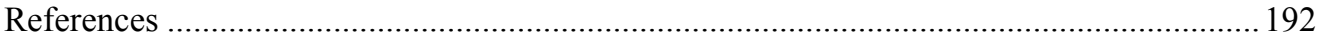




\section{List of Figures}

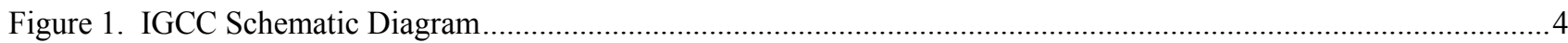

Figure 2. Radiant and Convective High Temperature Syngas Cooling Design ............................................................ 8

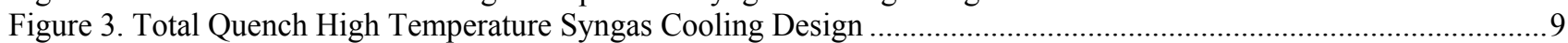

Figure 4. Equilibrium diagram with stage separation (Baukal, 1998) ….................................................................. 15

Figure 5. Air Separation Unit Process Flow Diagram (Alstom, 2003) ...................................................................... 16

Figure 6. Effect of oxygen purity on ASU power (McKetta, 1990) ........................................................................19

Figure 7. Oxygen flow rate vs. oxidant feed section cost ........................................................................................2

Figure 8. GE entrained gasifier schematic (taken from Eastman Gasification Services Company, 2005)....................28

Figure 9. Temperature Variation in an Entrained Gasifier (Based on Simbeck et. al., 1983)...........................................30

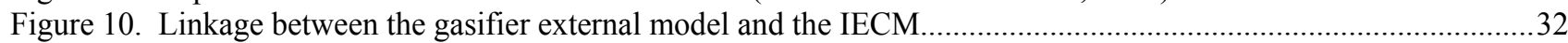

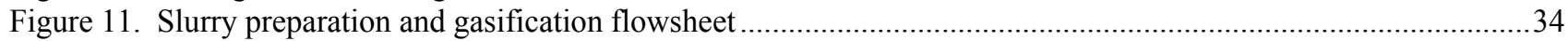

Figure 12. Flow diagram to generate data tables from Aspen Plus simulations ............................................................36

Figure 13. Power Requirement for the Coal Slurry Preparation Unit .........................................................................4

Figure 14. Power Requirement for the Gasification Section for Total Quench ............................................................41

Figure 15. Direct Cost for the Coal Handling and Slurry Preparation Process $($ Cost Year $=2000) \ldots \ldots \ldots \ldots \ldots \ldots \ldots \ldots \ldots \ldots \ldots . . . .43$

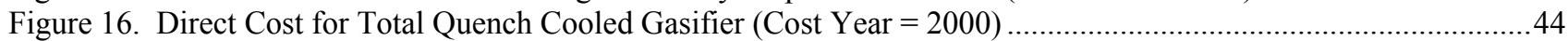

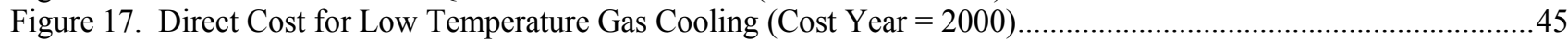

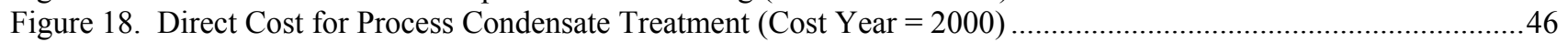

Figure 19: Coal gasification system with a clean water gas shift reaction .....................................................................50

Figure 20: Schematic process of a gasifier system with a sour shift..........................................................................50

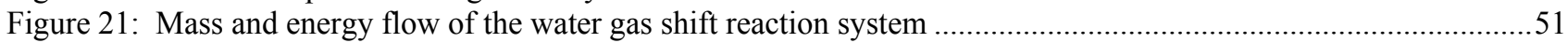

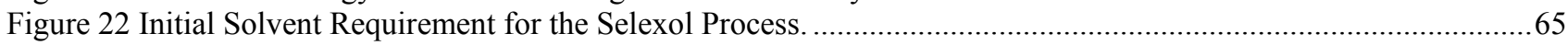

Figure 23: Annual Solvent Requirements for the Selexol Process .........................................................................65

Figure 24 Initial Catalyst Requirement for Two-Stage Claus Plant. ...............................................................................6 66

Figure 25: Annual Makeup Catalyst Requirement for Two-Stage Claus Plant ............................................................67

Figure 26 Initial Catalyst Requirement for the Beavon-Stretford Process.......................................................................67

Figure 27: Annual Catalyst Requirement for the Beavon-Stretford Process ..................................................................68

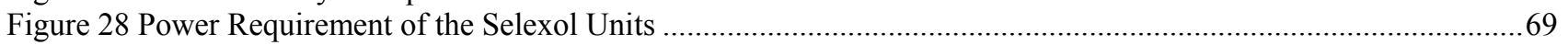

Figure 29 Power Requirement for Two-Stage Claus Plants ...................................................................................69

Figure 30 Power Requirement for the Beavon-Stretford Process ....................................................................................70

Figure 31 Predicted vs. Actual Costs for Selexol Acid Gas Removal .......................................................................72

Figure 32 Predicted vs. Actual Costs for 2-Stage Claus Plants .................................................................................. 73

Figure 33 Predicted vs. Actual cost of the Beavon-Stretford Section.............................................................................74

Figure 34: Initial Stretford Chemical Cost for the Beavon-Stretford Process. ...............................................................75

Figure 35: Annual Chemical Cost for the Beavon-Stretford Process .........................................................................76

Figure 36 Characteristics for Chemical and Physical Solvents [Sciamanna, 1988] .......................................................83

Figure 37 Selexol Process for Sulfur and $\mathrm{CO}_{2}$ Removal [Kohl, 1985] .................................................................. 85

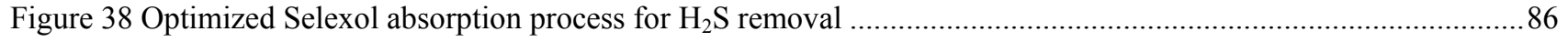

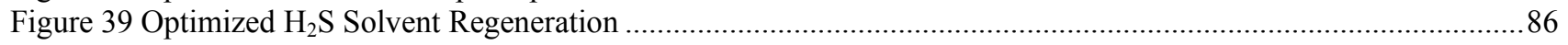

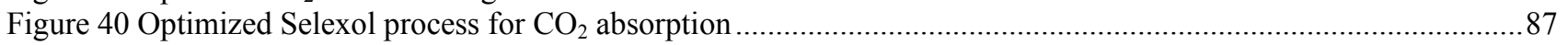

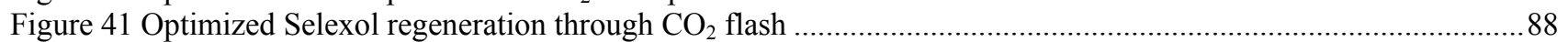

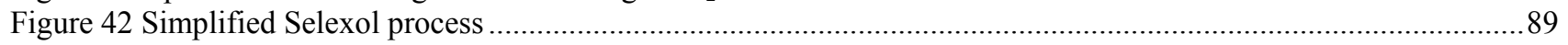

Figure 43 Calculation process for the flow rate of Selexol................................................................................... 91

Figure 44 Calculation process for the operating pressure of the sump tank .................................................................92

Figure 45 Simple Schematic of Gas Turbine Mass Balance with Compressor Air Extraction........................................102

Figure 46 Simplified Schematic Diagram of a Simple Cycle Gas Turbine ….............................................................119

Figure 47 Regression Results for Entropy as a Function of Temperature for Air ......................................................121 
Figure 48 Regression Results for Temperature as a Function of Entropy for Air .......................................................122

Figure 49 Regression Results for Enthalpy as a Function of Temperature for Air.......................................................122

Figure 50 Regression Results for Temperature as a Function of Enthalpy for Air......................................................122

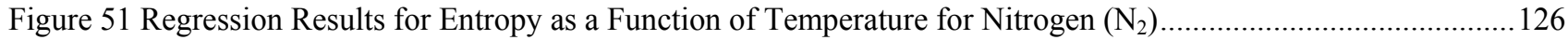

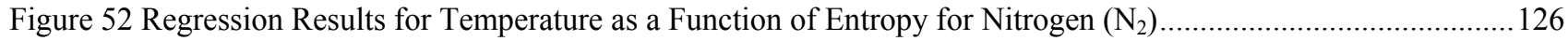

Figure 53 Regression Results for Enthalpy as a Function of Temperature for Nitrogen $\left(\mathrm{N}_{2}\right)$....................................126

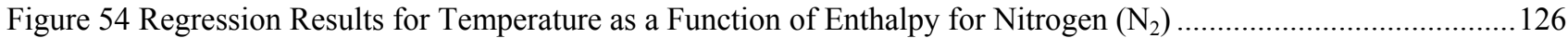

Figure 55 Exhaust Gas Temperature versus Gas Turbine Compressor isentropic Efficiency .........................................127

Figure 56 Simple Cycle Efficiency versus Gas Turbine Compressor isentropic Efficiency ..........................................127

Figure 57 Output versus Gas Turbine Compressor Isentropic Efficiency. Note: ET = Gas Turbine Expander Isentropic

Efficiency......

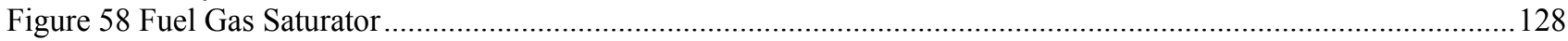

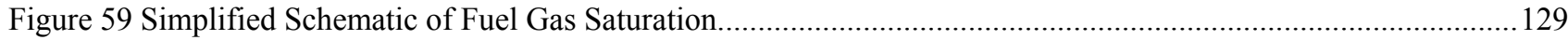

Figure 60 Power Requirement for Boiler Feed Water Treating............................................................................... 131

Figure 61 Power Requirement for Process Condensate Treatment .........................................................................131

Figure 62 Predicted vs. Actual Cost for Heat Recovery Steam Generators..............................................................134

Figure 63 Direct Cost for the Steam Turbine-Generator Section ........................................................................... 135

Figure 64 Predicted vs. Actual Direct Costs for the Boiler Feedwater Section ..........................................................136

Figure 65. The boundaries, inputs, and output from the pipeline model ..................................................................144

Figure 66. The density of carbon dioxide as a function of temperature for several isobars in the transport range...........145

Figure 67. Phase diagram for $\mathrm{CO} 2$ showing the sublimation, melting, and boiling curves as well as the triple point and the critical point.

Figure 68. Relative error between the density of $\mathrm{CO}_{2}$ calculated by the Peng-Robinson equation of state and the density of $\mathrm{CO}_{2}$ as predicted by the Span and Wagner equation of state in the range of pressures and temperatures of interest for the transport model.

Figure 69. Relative error between the viscosity calculated by the Chung et al method and the viscosity predicted by the model of Vesovic et al (modified by Fenghour et al) for the range of temperatures and pressures of interest in the transport model.

Figure 70. Pipeline diameter as a function of length for several flow rates in $\mathrm{Mt} / \mathrm{y}$ for isothermal flow at $12^{\circ} \mathrm{C} \ldots \ldots \ldots \ldots . . .151$

Figure 71. The breakdown of states in each EIA natural gas pipeline region.............................................................153

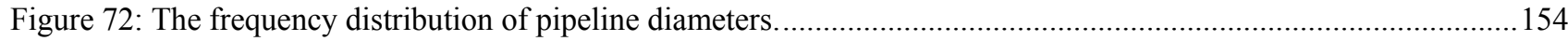

Figure 73: The frequency distribution of projects by region ...................................................................................154

Figure 74: The histogram of pipeline lengths, which excludes one $1400 \mathrm{~km}$ project for clarity .................................155

Figure 75. Total pipeline capital cost as a function of pipeline length, showing the clustering of variables at relatively low costs and short lengths

.156

Figure 76. The logarithm of total pipeline construction cost and pipeline length showing a reduction in clustering of data

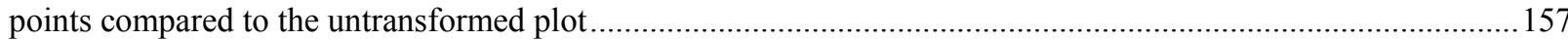

Figure 77. The capital cost of a 16 inch pipeline located in the Midwest over varying lengths ...................................161

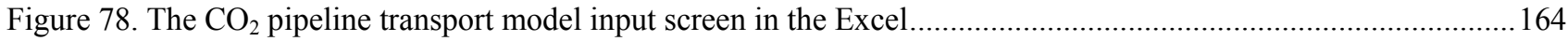

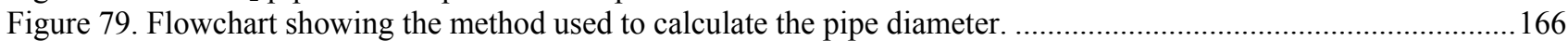

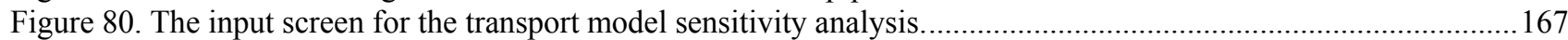

Figure 81. Cost per tonne of $\mathrm{CO} 2$ transported across the US Midwest via pipeline as estimated by the model for varying

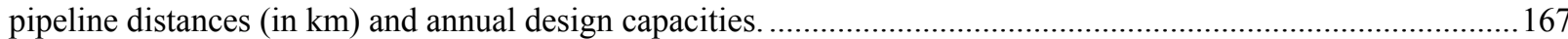

Figure 82. A comparison between the MIT model and the CMU model, showing that the CMU model generally predicts

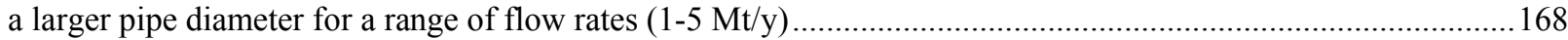

Figure 83. The range of capital costs possible from the CMU cost models, depending on region, compared with the capital costs possible from the MIT and IEA models for a 16" NPS pipeline.

Figure 84. A comparison of results from the CMU pipeline transport model and the MIT pipeline transport model......170

Figure 85. Comparison of results from the CMU model (top) and results presented in Figure 4.2 of the IPCC Special Report (bottom)

Figure 86. The transport cost surface for a coal fired plant with no booster stations. .................................................174

Figure 87. The transport cost as a function of length for amounts of CO2 transported for cases with no booster stations (solid line), and the cost minimizing optimum number of booster stations (dotted line).....................................175

Figure 88. The CDF generated from the Monte Carlo sensitivity analysis on the transport model................................177

Figure 89. Rank-order correlation between the input parameters and the output parameters, showing the relative importance of variability in the input parameters to the cost of transport 



\section{List of Tables}

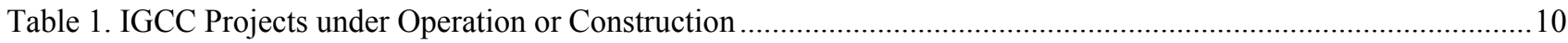

Table 2. Coal composition and its corresponding input in Aspen Plus.................................................................33

Table 3. Approach temperatures used in Aspen Plus to characterize non-equilibrium ([Altafini, 2003; Zaimal, 2002, Zhu, 2003)

Table 4. Volume fraction of syngas components exiting the gasifier using the Appalachian (Low Sulfur) coal as a function of carbon in slag and gasifier temperature.

5. Volume fraction of syngas components exiting the gasifier using the Appalachian (Medium Sulfur) coal as a function of carbon in slag and gasifier temperature. 38

Table 6. Volume fraction of syngas components exiting the gasifier using the Illinois \#6 coal as a function of carbon in slag and gasifier temperature.

Table 7. Volume fraction of syngas components exiting the gasifier using the WPC Utah coal as a function of carbon in

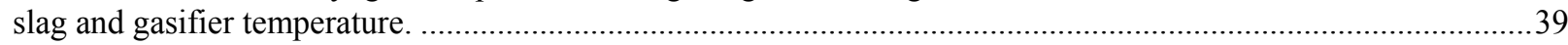

Table 8. Summary of Design Studies used for Coal Handling and Slurry Preparation Auxiliary Power Model

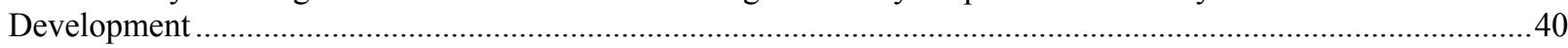

Table 9: Range of model parameter values for the WGS reaction system …….........................................................52

Table 10: Input and output parameters of the WGS reaction system.........................................................................53

Table 11: Water gas shift reactor cost data adjusted to the dollar value in 2000 [Doctor, 1996] ..................................57

Table 12: Gas-liquid heat exchanger cost data adjusted to the dollar value in 2000 [Doctor, 1996]..............................57

Table 13: Gas-gas heat exchanger cost data adjusted to the dollar value in 2000 [Doctor, 1996].................................58

Table 14: Cost parameters of water gas shift process ...........................................................................................59

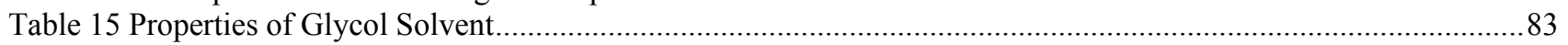

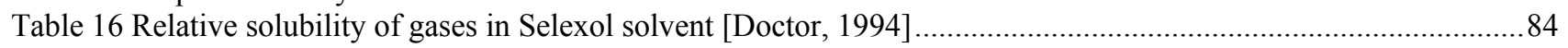

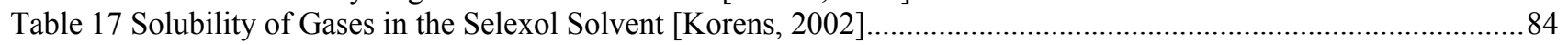

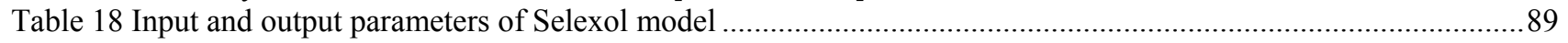

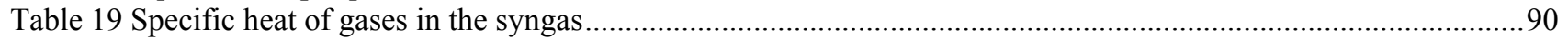

Table 20 Solution heat (Btu/lb-solute) of gases in the Selexol.......................................................................................90

Table 21 Absorber cost data adjusted to the dollar values in 2000 [Doctor, 1996] ..........................................................95

Table 22 Power recovery turbine cost data adjusted to the dollar value in 2000 [Doctor, 1996] ....................................95

Table 23 Sump tank cost data adjusted to the dollar value in 2000 [Doctor, 1996] .....................................................95

Table 24 Recycle compressor cost data adjusted to the dollar value in 2000 [Doctor, 1996] ........................................96

Table 25 Selexol pump cost data adjusted to the dollar value in 2000 [Doctor, 1996] ...................................................96

Table $26 \mathrm{CO}_{2}$ compressor cost data adjusted to the dollar value in 2000 [Doctor, 1996] ..............................................96

Table $27 \mathrm{CO}_{2}$ final compressor cost data adjusted to the dollar value in 2000 [Doctor, 1996] ......................................97

Table 28 Flash tank cost data adjusted to the dollar value in 2000 [Doctor, 1996] ........................................................97

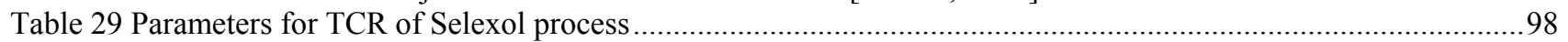

Table 30 Representative 2,300 ${ }^{\circ} \mathrm{F}$ Firing Temperature Heavy-Duty Gas Turbine Commercial Offerings....................... 104

Table 31. Conversions between NPS and maximum inner pipe diameter (Mohitpour, 2003) …...................................152

Table 32. Parameter estimates for Equation (129), and their standard errors, t-values, and p-values............................ 158

Table 33. Parameter estimates for Equation (130), and their standard errors, t-values, and p-values. ...........................158

Table 34. Parameter estimates for Equation (131), and their standard errors, t-values, and p-values. ........................... 160

Table 35. Parameter estimates for Equation (132) and their standard errors, t-values, and p-values............................160

Table 36. The cost of construction of a $100 \mathrm{~km}, 16$ inch pipeline in the Midwest, and the regional differences relative to

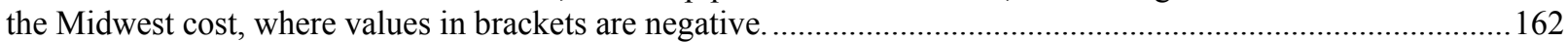

Table 37. Parameters used by Skovholt to determine rules of thumb for pipe diameter ............................................. 168

Table 38. The pipe diametrs proposed by Skholvolt compared with those calculated by the CMU model (all diameters in

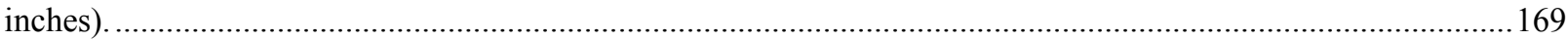

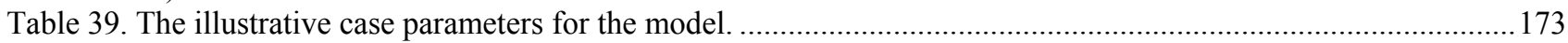




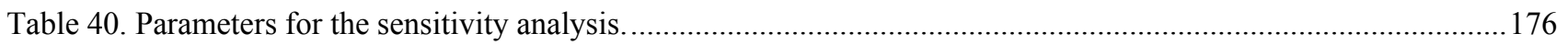

Table 41. Physical properties of $\mathrm{CO}_{2}$ and other fluids relevant to the transport model ..............................................182

Table 42. Binary interaction parameters for the Peng-Robinson equation used in the transport model ...........................182 


\section{DISCLAIMER}

This report was prepared as an account of work sponsored by an agency of the United States Government. Neither the United States Government nor any agency thereof, nor any of their employees, makes any warranty, express or implied, or assumes any legal liability or responsibility for the accuracy, completeness, or usefulness of any information, apparatus, product, or process disclosed, or represents that its use would not infringe privately owned rights. Reference herein to any specific commercial product, process, or service by trade name, trademark, manufacturer, or otherwise does not necessarily constitute or imply its endorsement, recommendation, or favoring by the United States Government or any agency thereof. The views and opinions of authors expressed herein do not necessarily state or reflect those of the United States Government or any agency thereof. 


\section{ACKNOWLEDGEMENTS}

This report is an account of research sponsored by the U.S. Department of Energy's National Energy Technology Center (DOE/NETL) under Contract No. DE-AC2192MC29094. 


\section{Gasification}

This chapter provides a description of the coal-based power generation and integrated environmental control systems selected for case studies in this research. An advanced system was selected on the basis of promising costs, plant performance, and emission reductions. A baseline system, representative of conventional technology, was also selected for the purpose of comparative analysis. The engineering performance, emissions, and cost models of each system are also described.

\section{Overview of Gasification Systems}

Gasification systems are a promising approach for clean and efficient power generation as well as for polygeneration of a variety of products, such as steam, sulfur, hydrogen, methanol, ammonia, and others (Philcox and Fenner, 1996). As of 1996, there were 354 gasifiers located at 113 facilities worldwide. The gasifiers use solid fuels (petroleum residuals, petroleum coke, refinery wastes, coal, and other fuels) as inputs, and produce a synthesis gas containing carbon monoxide (CO), hydrogen $\left(\mathrm{H}_{2}\right)$, and other components. The syngas can be processed to produce liquid and gaseous fuels, chemicals, and electric power. In recent years, gasification has received increasing attention as an option for repowering at oil refineries, where there is currently a lack of markets for low-value liquid residues and coke (Simbeck, 1996).

A general category of gasification-based systems is Integrated Gasification Combined Cycle (IGCC) systems. IGCC is an advanced power generation concept with the flexibility to use coal, heavy oils, petroleum coke, biomass, and waste fuels to produce electric power as a primary product. IGCC systems typically produce sulfur as a byproduct. Systems that produce many co-products are referred to as "polygeneration" systems. IGCC systems are characterized by high thermal efficiencies and lower environmental emissions than conventional pulverized coal fired plants (Bjorge, 1996).

A generic IGCC system is illustrated schematically in Figure 1. In an IGCC power plant, the feedstock to the gasifier is converted to a syngas, composed mainly of hydrogen and carbon monoxide, using a gasification process. After passing through a gas cleanup system, in which particles and soluble gases are removed via wet scrubbing and in which sulfur is removed and recovered via a selective removal process, the syngas is utilized in a combined cycle power plant. Different variations of IGCC systems exist based upon the type of coal gasifier technology, oxidant (e.g., oxygen or air), and gas cleanup system employed. 


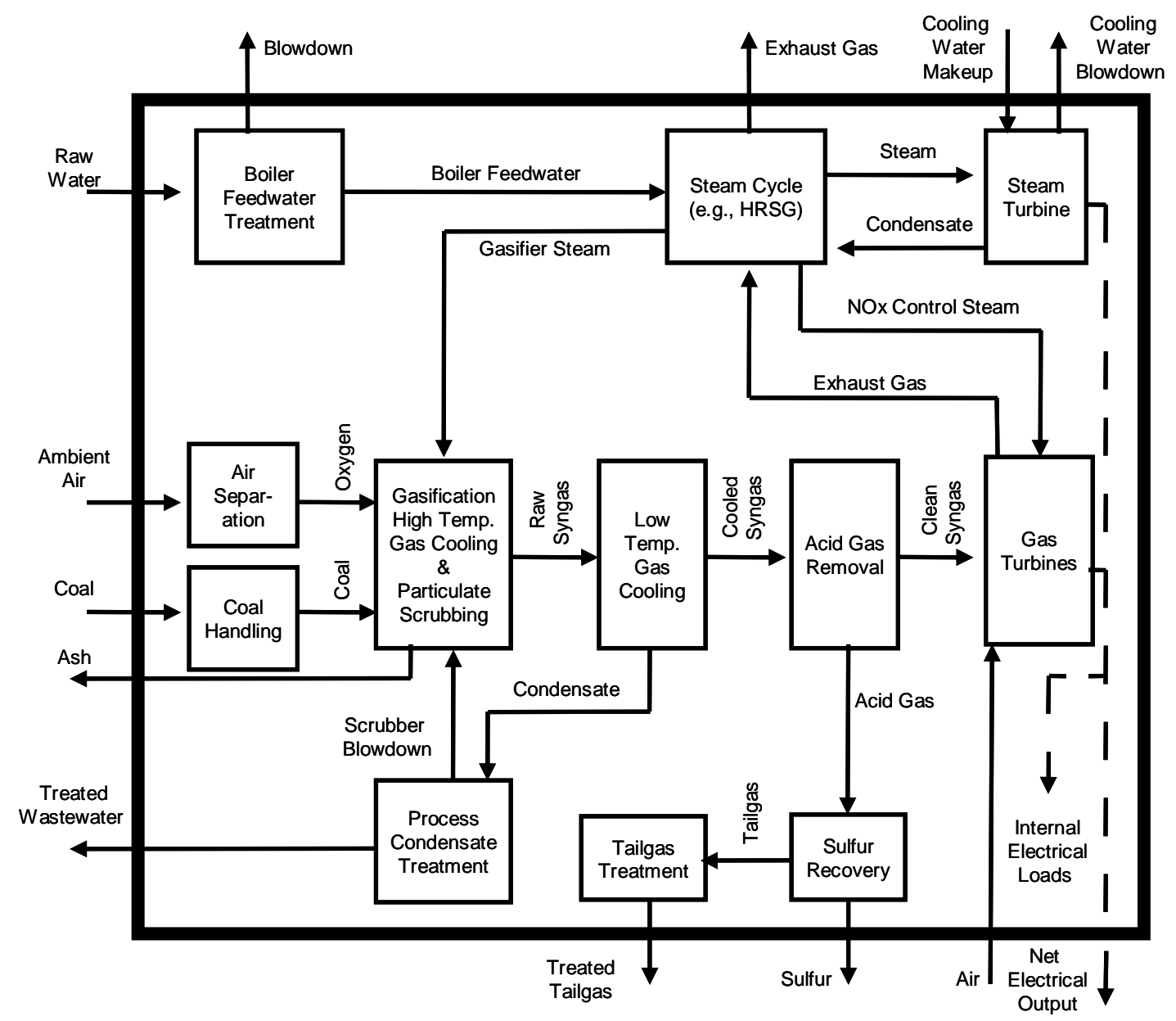

Figure 1. IGCC Schematic Diagram

A typical IGCC system includes process sections of

- Fuel Handling

- Gasification

- High-Temperature Gas Cooling

- Low Temperature Gas Cooling and Gas Scrubbing

- Acid Gas Separation

- Fuel Gas Saturation

- Gas Turbine

- Heat Recovery Steam Generator

- Steam Turbine

- Sulfur Byproduct Recovery

The specific design of each of the process sections such as gasification and hightemperature gas cooling varies in different IGCC systems. 


\section{Gasification Types}

Three generic designs of gasification are typically employed in IGCC systems, each of which is described below. In all types of reactors, the feedstock fuel is converted to syngas in reactors with an oxidant and either steam or water. The oxidant is required to partially oxidize the fuel. The exothermic oxidation process provides heat for the endothermic gasification reactions. Water or steam is used as a source of hydrolysis in the gasification reactions. The type of reactor used is the primary basis for classifying different types of gasifiers.

\section{Moving-Bed or Counter-Current Reactors}

Moving bed reactors feature counter-current flow of fuel with respect to both the oxidant and the steam. For example, in the case of coal gasification, coal particles of approximately $4 \mathrm{~mm}$ to $30 \mathrm{~mm}$ (Simbeck et al., 1983) in diameter are introduced at the top of the reactor, and move downward. Oxidant is introduced at the bottom of the reactor. A combustion zone at the bottom of the reactor produces thermal energy required for gasification reactions, which occur primarily in the central zone of the reactor. Steam is also introduced near the bottom of the gasifier. As the hot gases from combustion and gasification move upward, they come into contact with the fuel introduced at the top. The heating of the fuel at the top of the reactor results in devolatilization, in which lighter hydrocarbon compounds are driven off and exit as part of the syngas. Because the gases leaving the gasifier contact the relatively cool fuel entering the gasifier, the exit syngas temperature is relatively low compared to other types of reactors. The counter-current flow of fuel with the oxidant and steam can result in efficient utilization of the fuel, as long as the residence time of the fuel is long enough for even the larger particles to be fully consumed. Ash and unconverted fuel exit the bottom of the gasifier via a rotating grate.

A typical syngas exit temperature for a moving bed gasifier is approximately 1,100 ${ }^{\circ} \mathrm{F}$. At this temperature, some of the heavier volatilized hydrocarbon compounds, such as tars and oils, will not be cracked and can easily condense in downstream syngas cooling equipment. Because fuel is introduced at the top of the gasifier where the syngas is exiting, this type of gasifier cannot handle fine fuel particles. Such particles would be entrained with the exiting syngas and would not be converted to syngas in the reactor bed. Cyclones are typically used to capture fine particles in the syngas, which are often sent to a briquetting facility to form larger particles and then recycled to the gasifier for another attempt at conversion.

An overall measure of gasifier performance is the cold gas efficiency. The cold gas efficiency is the ratio of the heating value of "cold" syngas, at standard temperature, to the heating value of the amount of fuel consumed/required to produce the syngas. The cold gas efficiency does not take into account recovery of energy in the gasifier such as through steam generation or associated with sensible heat of the syngas at high temperatures. Moving bed gasifiers tend to have very high cold gas efficiencies, with values in the range of 80 to 90 percent.

Typical examples of such reactors are Lurgi dry bottom gasifiers and the British Gas/Lurgi slagging gasifiers.

\section{Fluidized-Bed Gasifiers}

Fluidized bed reactors feature rapid mixing of fuel particles in a $0.1 \mathrm{~mm}$ to $10 \mathrm{~mm}$ size range with both oxidant and steam in a fluidized bed. The feedstock fuel, oxidant and steam are introduced at the bottom of the reactor. In these reactors, backmixing of incoming feedstock fuel, oxidant, steam, and the fuel gas takes place 
resulting in a uniform distribution of solids and gases in the reactors. The gasification takes place in the central zone of the reactor. The coal bed is fluidized as the fuel gas flow rate increases and becomes turbulent when the minimum fluidizing velocity is exceeded.

The reactors have a narrow temperature range of $1800^{\circ} \mathrm{F}$ to $1900{ }^{\circ} \mathrm{F}$. The fluidized bed is maintained at a nearly constant temperature, which is well below the initial ash fusion temperature to avoid clinker formation and possible defluidization of the bed. Unconverted coal in the form of char is entrained from the bed and leaves the gasifier with the hot raw gas. This char is separated from the raw gas in the cyclones and is recycled to the hot ash agglomerating zone at the bottom of the gasifier. The temperature in that zone is high enough to gasify the char and reach the softening temperature for some of the eutectics in the ash. The ash particles stick together, grow in size and become dense until they are separated from the char particles, and then fall to the base of the gasifier, where they are removed.

The processes in these reactors are restricted to reactive, non-caking coals to facilitate easy gasification of the unconverted char entering the hot ash zone and for uniform backmixing of coal and fuel gas. The cold gas efficiency is approximately 80 percent (Supp, 1990). These reactors have been used for Winkler gasification process and High-temperature Winkler gasification process. A key example of fluidized gasification design is the KRW gasifier.

\section{Entrained-Flow Reactors}

The entrained-flow process features a plug type reactor where the fine feedstock fuel particles (less than $0.1 \mathrm{~mm}$ ) flow co-currently and react with oxidant and/or steam. The feedstock, oxidant and steam are introduced at the top of the reactor. The gasification takes place rapidly at temperatures in excess of $2300{ }^{\circ} \mathrm{F}$. The feedstock is converted primarily to $\mathrm{H}_{2}, \mathrm{CO}$, and $\mathrm{CO}_{2}$ with no liquid hydrocarbons being found in the syngas. The raw gas leaves from the bottom of the reactor at high temperatures of $2300^{\circ} \mathrm{F}$ and greater. The raw gas has low amounts of methane and no other hydrocarbons due to the high syngas exit temperatures.

The entrained flow gasifiers typically use oxygen as the oxidant and operate at high temperatures well above ash slagging conditions in order to assure reasonable carbon conversion and to provide a mechanism for slag removal (Simbeck et al., 1983).

Entrained-flow gasification has the advantage over the other gasification designs in that it can gasify almost all types of coals regardless of coal rank, caking characteristics, or the amount of coal fines. This is because of the relatively high temperatures which enable gasification of even relatively unreactive feedstocks that might be unsuitable for the lower temperature moving bed or fluidized bed reactors. However, because of the high temperatures, entrained-flow gasifiers use more oxidant than the other designs. The cold gas efficiency is approximately 80 percent (Supp, 1990). Typical examples of such reactors are GE gasifiers and E-Gas gasifiers.

The advantage of adopting entrained flow gasification over the above mentioned reactors is the high yield of synthesis gas containing insignificant amounts of methanol and other hydrocarbons as a result of the high temperatures in the entrained-flow reactors.

GE gasification is a specialized form of entrained flow gasification in which coal is fed to the gasifier in a water slurry. Because of the water in the slurry, which acts as heat moderator, the gasifier can be operated at higher pressures than other types of entrained-flow gasifiers. Higher operating pressure leads to increased gas production capability per gasifier of a given size (Simbeck et al., 1983) 
In this study, we focus on modeling assessment of entrained flow gasification. Assessments of moving bed and fluidized bed gasifier based systems have been done in previous work (Frey and Rubin, 1992a, 1992b, Frey et al., 1994, Frey, 1998).

\section{Gasification Cooling Types}

\section{High Temperature Gas Cooling}

The design of the high temperature syngas cooling process area depends on the type of gasifier used. The gas cooling requirements for entrained flow gasification systems are more demanding than for other gasification systems as the former produce syngas at higher temperatures. Typically, the gas cooling process for systems employing entrained flow gasification systems either use heat exchangers to recover thermal energy and generate steam or use water quenching. The former design can be radiant and convective or radiant only, while the latter is known as total quench high temperature gas cooling. The former is more efficient as it can produce high temperature and pressure steam, whereas the latter is much less expensive (Doering and Mahagaokar, 1992).

\section{Radiant and Convective Syngas Cooling Design}

The design of a radiant and convective gasification system is shown in Figure 2. Each gasifier has one radiant cooler and one convective cooler. The hot syngas is initially cooled in a radiant heat transfer type of heat exchanger. High pressure steam is generated in tubes built into the heat transfer surface at the perimeter of the cylindrical gas flow zone. The molten slag drops into a slag quench chamber at the bottom of the radiant gas cooler where it is cooled and removed for disposal. The gas leaves the radiant cooler at a temperature of approximately $1500^{\circ} \mathrm{F}$.

The syngas from the radiant heat exchanger flows into a convection type of heat exchanger. In the convective heat exchanger, the syngas flows across the boiler tube banks. These tubes help remove the entrained particles in the syngas that are too fine to drop out in the bottom of the radiant cooler. High pressure steam is generated in these tubes. The cooled gas leaves the convective chamber at a temperature of approximately $650^{\circ} \mathrm{F}$. 


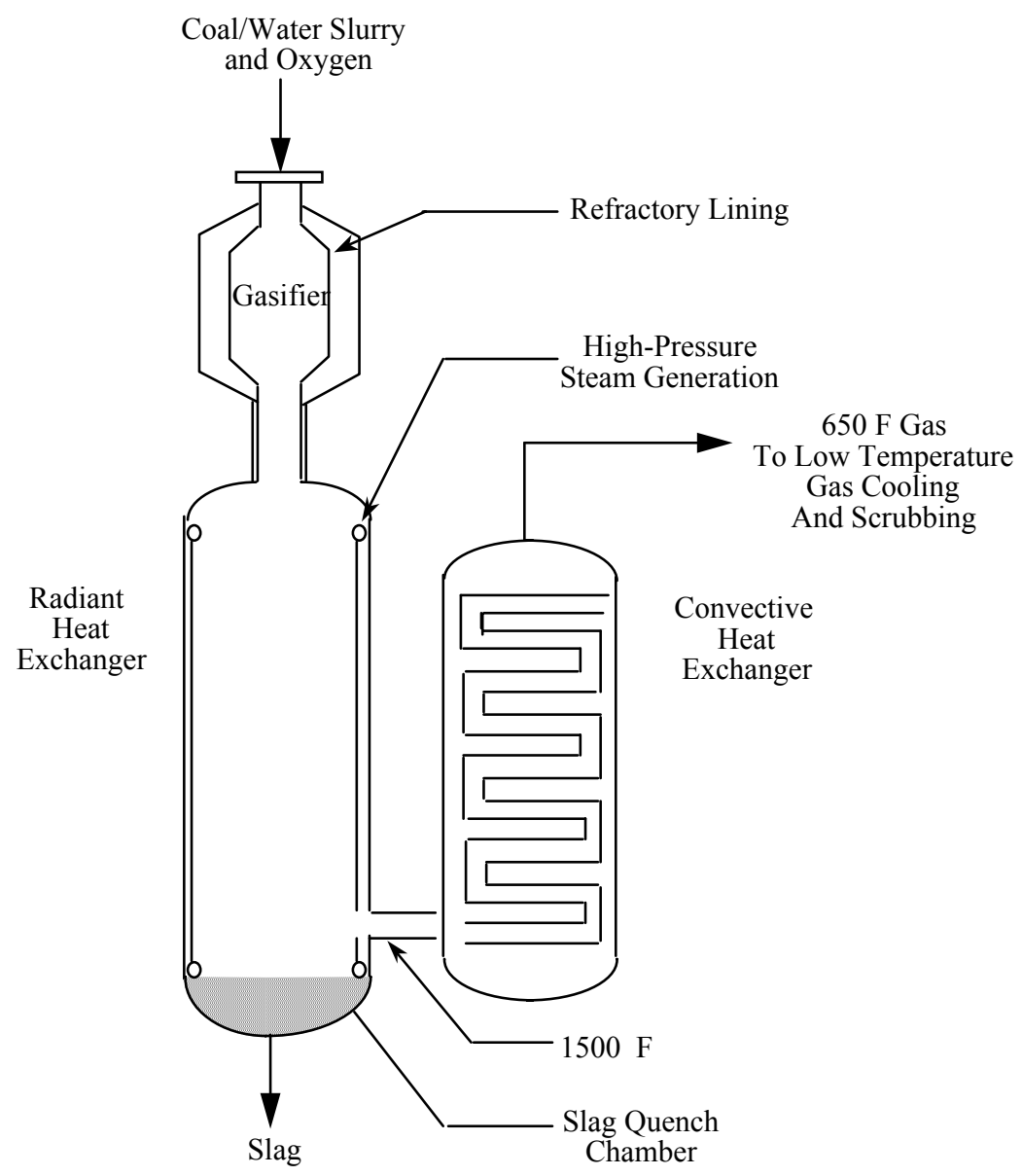

Figure 2. Radiant and Convective High Temperature Syngas Cooling Design

\section{Radiant Only Syngas Cooling Design}

The hot syngas is cooled initially in the radiant cooler and high pressure steam is generated as in the radiant and convective design. However, in this case both the molten slag and the raw gas are quenched in the water pool at the bottom of the radiant cooler. The cooled slag is removed from the cooler for disposal. The raw gas, saturated with moisture, flows out of the radiant cooler at a temperature of approximately $400{ }^{\circ} \mathrm{F}$.

\section{Total Quench Design}

The total quench design is depicted in Figure 3. In this design, the hot syngas and the molten slag particles flow downward through a water spray chamber and a slag quench bath. Water is sprayed just beneath the partial oxidation chamber to cool the hot syngas. The entrained slag is separated from the syngas in the slag quench bath (Nowacki, 1981). There is no high pressure steam generation in this method as in the previous two designs since there is no heat recovery. The raw gas saturated with moisture flows to the gas scrubbing unit at a temperature of $430{ }^{\circ} \mathrm{F}$. 


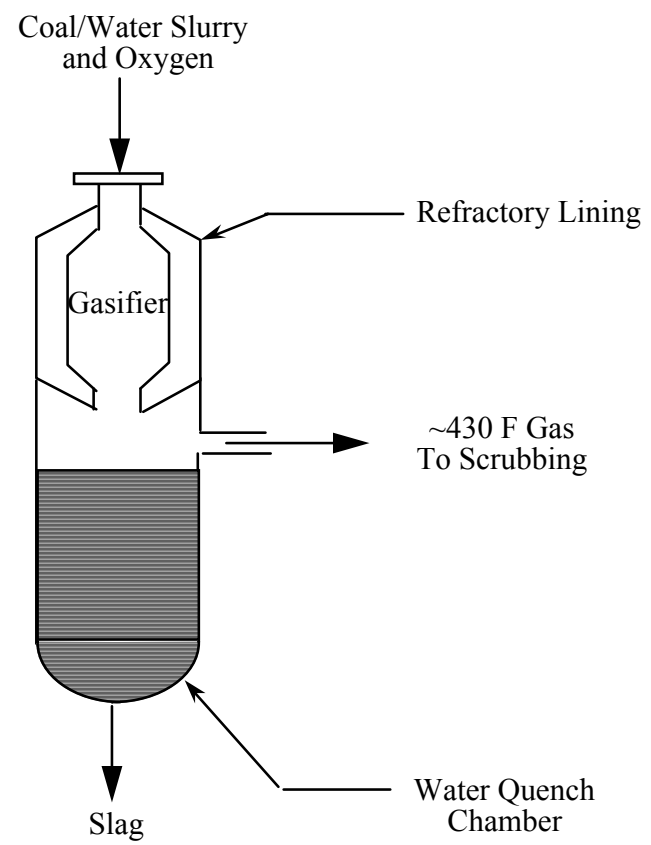

Figure 3. Total Quench High Temperature Syngas Cooling Design

In this study, both the radiant and convective and the total quench high temperature syngas cooling designs are evaluated. The radiant and convective design has the advantage over total quench syngas cooling of a higher plant efficiency. However, the cost of the radiant and convective design is higher than that of the total quench design. The total quench design results in increased moisturization of syngas, which can prove effective in terms of preventing $\mathrm{NO}_{\mathrm{X}}$ formation in the gas turbine combustor and in terms of augmenting power production from the gas turbine. In a water quench system, large quantities of water are used and thus contaminated by the slag, requiring complex primary and secondary treatment facilities. Hence total quench design has additional operating problems such as those caused due to increased water treating facilities, increased discharge water permitting issues, and added operating and maintenance costs when compared to radiant and convective design (Doering and Mahagaokar, 1992).

\section{Commercial Status of Gasification Systems}

The IGCC concept has been demonstrated commercially. Table 1 lists the IGCC plants currently in operation or undergoing construction. The GE coal gasification process has been successfully used in a number of chemical plants since the early 1980s for the production of synthesis gas from coal. A GE-based 95 MW IGCC power plant was operated successfully from 1984 to 1988 in California (Simbeck et al., 1996). API Energia, a joint venture of Asea Brown Boveri and API, adopted GE gasification to gasify visbreaker residue from an API refinery to produce steam and power. Tampa Electric Company's Polk Power station also utilizes GE gasification, gasifying about 2,000 tons of coal per day to produce $250 \mathrm{MW}$ of power. The El Dorado gasification project demonstrates that hazardous waste streams can be converted by gasification to valuable products. (Farina et al., 1998).

An E-Gas gasifier-based IGCC power plant at Wabash River Station is currently under operation (Simbeck et al., 1996). A 335 MW IGCC demonstration plant for European electricity companies is operating at Puertollano, Spain (Mendez-vigo et al., 1998). The GE gasifier-based El Dorado plant, the Shell-Pernis plant in The 
Netherlands, and the Sarlux plant in Italy use low pressure (38 barg) GE gasification to produce hydrogen and/or steam along with power (Bjorge et al., 1996).

Table 1. IGCC Projects under Operation or Construction

\begin{tabular}{||l|l|l|l|l|l|l||}
\hline Project & Location & $\begin{array}{l}\text { Start-up } \\
\text { Date }\end{array}$ & $\begin{array}{l}\text { Plant } \\
\text { Size }\end{array}$ & Products & Gasifier & Fuel \\
\hline \hline $\begin{array}{l}\text { Cool Water } \\
\text { IGCC }\end{array}$ & $\begin{array}{l}\text { Barstow, } \\
\text { California }\end{array}$ & 1984 & $120 \mathrm{MW}$ & Power & GE & Coal \\
\hline $\begin{array}{l}\text { PSI Wabash } \\
\text { River }\end{array}$ & $\begin{array}{l}\text { Terre } \\
\text { Haute, } \\
\text { Indiana }\end{array}$ & 1996 & $262 \mathrm{MW}$ & Power & E-Gas & Coal \\
\hline $\begin{array}{l}\text { Tampa } \\
\text { Electric }\end{array}$ & $\begin{array}{l}\text { Polk, } \\
\text { Florida }\end{array}$ & 1996 & $250 \mathrm{MW}$ & Power & GE & Coal \\
\hline $\begin{array}{l}\text { Pinon Pine } \\
\text { Sierra Pacific }\end{array}$ & $\begin{array}{l}\text { Sparks, } \\
\text { Nevada }\end{array}$ & 1996 & $100 \mathrm{MW}$ & Power & KRW & Coal \\
\hline $\begin{array}{l}\text { GE } \\
\text { El Dorado }\end{array}$ & $\begin{array}{l}\text { El Dorado, } \\
\text { Kansas }\end{array}$ & 1996 & $40 \mathrm{MW}$ & $\begin{array}{l}\text { Co-generation } \\
\text { Steam and } \mathrm{H}_{2}\end{array}$ & GE & $\begin{array}{l}\text { Pet } \\
\text { Coke }\end{array}$ \\
\hline Shell Pernis & Netherlands & 1997 & $120 \mathrm{MW}$ & $\begin{array}{l}\text { Co-generation } \\
\mathrm{H}_{2}\end{array}$ & $\begin{array}{l}\text { Shell/ } \\
\text { Lurgi }\end{array}$ & Oil \\
\hline Sarlux & $\begin{array}{l}\text { Sarroch, } \\
\text { Italy }\end{array}$ & 1998 & $550 \mathrm{MW}$ & $\begin{array}{l}\text { Co-generation } \\
\text { Steam }\end{array}$ & GE & Oil \\
\hline API Energia & $\begin{array}{l}\text { Falconara } \\
\text { Marittima }\end{array}$ & 1999 & $234 \mathrm{MW}$ & Power & GE & Oil \\
\hline Puertallano & & 1997 & $335 \mathrm{MW}$ & Power & Prenflo & Coal \\
\hline
\end{tabular}

\section{Overall Plant Efficiency}

\section{Net Power Output and Plant Efficiency}

The net plant power output is the total power generated from the gas turbines and steam turbines less the total auxiliary power consumption. The gas and steam turbines have been modeled as a series of compressors and turbines. This unit operation block requires outlet pressure and isentropic efficiencies as parameters. The power consumed by the compressors and the power generated by the turbines are calculated by the performance model. The net power output in MW is given by

$\mathrm{MW}_{\text {net }}=\mathrm{MW}_{\mathrm{GT}}+\mathrm{MW}_{\mathrm{ST}}-\mathrm{W}_{\mathrm{e}, \mathrm{AUX}}$

The net plant efficiency on a higher heating value basis is given by

$\eta=3.414 \times 10^{6} \frac{M W_{n e t}}{M_{c f, C H, i} \times H H V}$

where,

$\eta=$ net plant efficiency.

$\mathrm{M}_{\mathrm{cf}, \mathrm{CH}, \mathrm{i}}=$ Coal feed rate, $\mathrm{lb} / \mathrm{hr}$.

$\mathrm{HHV}=$ Higher heating value of fuel, BTU/lb. 


\section{Total Plant Costs}

The total plant costs of an IGCC power plant include the process facilities capital costs, indirect construction costs, engineering and home office fees, sales tax, allowances for funds used during construction (AFUDC), project contingency, and total process contingencies.

The equations for the plant cost model are the same as those given in Frey and Rubin (1990) and are not repeated here. However, the model is briefly described.

Indirect construction costs include worker benefits, supervision and administrative labor, purchased and rented construction equipment, and construction facilities. Engineering and home office fees include the costs associated with engineering, office expenses, and fees or profit to the engineer. Sales tax cost is specific to the state where the power plant is constructed and is estimated as the tax on material costs. AFUDC is the estimated debt and equity costs of capital funds necessary to finance the construction of new facilities. Startup costs include one month of fixed operating costs and one month of variable costs based on full plant capacity.

Process contingency is used in deterministic cost estimates to quantify the expected increase in the capital cost of an advanced technology due to uncertainty in performance and cost for the specific design application. Project contingency is used in deterministic cost estimates to represent the expected increase in the capital cost estimate that would result from a more detailed estimate for a specific project at a particular site.

\section{Total Capital Requirement}

The total capital requirement (TCR) includes the total plant investment, prepaid royalties, spare parts inventory, preproduction (or startup) costs, inventory capital, initial chemicals and catalyst charges, and land costs. The methodology for calculating TCR is given in detail in Frey and Rubin (1990).

\section{Annual Costs}

The annual costs of an IGCC plant consists of fixed and variable operating costs. The fixed operating costs are annual costs including operating labor, maintenance labor, maintenance materials, and overhead costs associated with administrative and support labor. The variable operating costs include consumables, fuels, slag and ash disposal, and byproduct credits. For more details on the annual cost models, please refer to Frey and Rubin (1990).

\section{Levelized Costs}

The total capital requirement, fixed operating cost, and operating variable cost are used to calculate the cost of producing electricity that is available for sale from the power plant, based on the net electrical output from the power plant. The calculated cost of electricity is also known as total annualized cost and is the levelized annual revenue requirement to cover all of the capital and operating costs for the economic life of the plant. 
$C_{\text {elec }}=\frac{\left[1,000 f_{c r} T C R+f_{\text {vclf }}(F O C+V O C)\right]\left(\frac{1,000 \text { mills }}{\text { dollar }}\right)}{M W_{\text {net }} 8,760 c_{f}}$

where,

$$
\begin{aligned}
& \mathrm{C}_{\text {elec }}=\text { cost of electricity }(\text { mills } / \mathrm{kWh}) \\
& \text { TCR }=\text { Total capital requirement in } \$ 1,000 \\
& \text { FOC }=\text { Fixed operating costs in dollars } \\
& \text { VOC = Variable operating costs in dollars } \\
& \mathrm{MW}_{\text {net }}=\text { Net power output }(\mathrm{MW}) \\
& \mathrm{f}_{\text {cr }}=\text { Fixed charge factor } \\
& \mathrm{f}_{\text {vclf }}=\text { Variable levelization cost factor } \\
& C_{\mathrm{f}}=\text { Capacity Factor }
\end{aligned}
$$




\section{Oxidant Feed}

Nomenclature

$\eta_{\mathrm{ox}}=$ oxygen purity (vol\%)

$\eta=$ isothermal efficiency of the compressor (fraction)

$\mathrm{M}_{\mathrm{O}, \mathrm{G}, \mathrm{i}}=$ oxygen flow rate into gasifier (lb-mole/hr)

$\mathrm{N}_{\mathrm{O}, \text { OF }}=$ number of operating trains in oxidant feed system

$\mathrm{N}_{\mathrm{T}, \text { OF }}=$ total number of trains in oxidant feed system (operating and spare)

$\mathrm{P}_{\mathrm{i}}=$ input pressure to compressor $(\mathrm{kPa})$

$\mathrm{P}_{\mathrm{o}}=$ product pressure to gasifier $(\mathrm{kPa})$

$\mathrm{T}_{\mathrm{a}}=$ ambient air temperature $\left({ }^{\circ} \mathrm{F}\right)$

$\mathrm{V}=$ volumetric flow rate $\left(\mathrm{m}^{3} / \mathrm{sec}\right)$

\section{Oxidant Feed Process Description}

Cryogenic air separation units (ASU) are used over a wide range of flow rates and purities. Cryogenic plants are capable of producing oxygen at purities exceeding $99.5 \%$. They are used exclusively for large-scale oxygen production, ranging from 600 tons per day to over 8000 tons per day.

Historically, most gasifier systems have used high purity oxygen instead of atmospheric air. Japanese development, however, has concentrated on air blown systems.

The basic advantages of oxygen blown gasification are:

- reduced gasifier size and subsequent lower cost;

- higher syngas heating value;

- smaller gas handling and cleanup equipment due to lower syngas volume and subsequent lower cost;

- smaller heat exchangers to recover sensible heat from the syngas prior to cleanup.

The disadvantage of using high purity oxygen as an oxidant is the higher complexity of plant integration required. Hence, controlling and operating a power plant 
becomes more closely associated with running a chemical plant. Matching the requirements for availability, reliability and flexibility of operation (for example, to load follow) at a competitive cost over a long period are the major challenges. Auxiliary power consumption in oxygen blown systems is estimated to be $10-15 \%$, twice that of an air-blown system.

The oxidant feed section modeled is applicable to oxygen-blown gasification systems or advanced combustion systems (e.g., oxyfuel). A typical air separation plant consists of two parallel operating trains. There are typically no spare trains because product availability is greater than $99 \%$ from large plants (Alstom, 2003). Each train includes an air compression system, air separation unit and an optional oxygen compression system. The oxygen plants produce an oxidant feed to the gasifier containing typically 95 to 98 percent oxygen on a volume basis. It is possible to recover argon as a saleable byproduct from high purity oxygen plants operating at a purity rate of 99.5 percent oxygen or greater; however, the available data are not for the oxygen purity levels and plant designs required to do this. The oxygen plants used to determine costs are commercially available.

This process section typically has an air compression system, an air separation unit, and an oxygen compression system per train. The oxygen compression system is not treated for power plant types that operate at or near atmospheric pressure. The minimum number of operating trains is two and there are no spare trains. The number of trains depends on the total mass flow rate of oxygen.

\section{Cryogenic Distillation}

The heart of the cryogenic distillation process is the distillation column. It is in this column that air is separated into its components. The difference in the boiling points of the components of air is the driving principle behind the operation of the column. This is illustrated by Figure 4. This figure shows the temperature versus composition of air, treated as a binary mixture of nitrogen and oxygen. The upper line is the dewpoint line, when liquid drops start to form in gas as air is cooled. The lower line is the bubble line, when gas bubbles first form in liquid as air is warmed. The boiling point of pure oxygen ( $0 \%$ nitrogen) is shown by the top left point on the graph, at $-292^{\circ} \mathrm{F}$. The boiling point of pure nitrogen is shown by the bottom right point on the graph, at $-316^{\circ} \mathrm{F}$. Atmospheric air contains $0.93 \%$ argon by volume, which has a boiling point of $303^{\circ} \mathrm{F}$. As this is much closer to the boiling point of oxygen than nitrogen, most of the argon in air will go with the oxygen through the main distillation column. Thus air can be treated as $78 \%$ Nitrogen and $22 \%$ oxygen for the purposes of this discussion. 


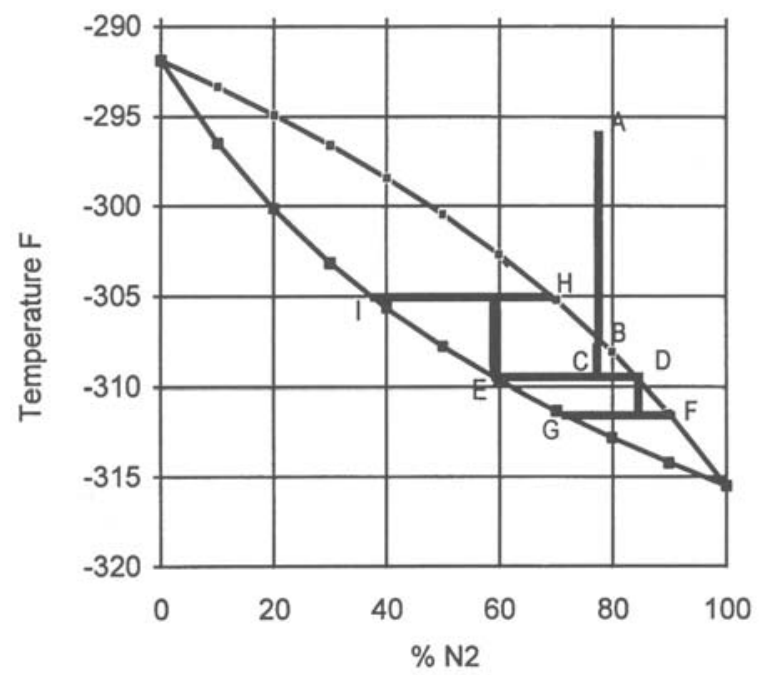

Figure 4. Equilibrium diagram with stage separation (Baukal, 1998)

Following the dark, lettered line shows how the separation process occurs. Ambient air (A) is cooled below the dew point (B) to a temperature between the bubble point and the dew point (C). The air is now a mixture of liquid and gas, and is pumped into a column. The mixture is allowed to settle on a tray in the distillation column until it reaches thermal equilibrium and the liquid and vapor phases separated. The liquid phase (E) is now richer in oxygen and the gas phase (D) is richer in nitrogen.

The oxygen-rich liquid is now removed and heated slightly until it is at a temperature between the liquid and bubble lines. As a result of the heating the liquid becomes a froth of vapor and liquid. This mixture is allowed to cool until it reaches thermal equilibrium and the vapor $(\mathrm{H})$ and liquid (I) phases separate. The liquid, which is now richer in oxygen than both points (A) and (E), is removed and heated again. The cycle continues until the desired purity of oxygen is reached. The vapor $(\mathrm{H})$ is mixed with another "batch" of liquid from (E), providing the heat to turn the liquid into foam.

The nitrogen-rich vapor (D) is cooled slightly until is a foam again. It is then allowed to reach equilibrium, where it separates into vapor $(\mathrm{F})$ and liquid $(\mathrm{G})$ phases. The vapor, now richer in nitrogen then both (A) and (D), is removed and cooled again. The cold liquid $(\mathrm{G})$ is recycled back into the vapor (D), providing the cooling for that stream.

In the distillation column, each separation and equilibrium occurs on a sieve tray. These are metal trays with many small holes that allow vapor to bubble through them into liquid on the tray. When the foam on a tray separates into vapor and liquid, the vapor will rise up to the tray above, and bubble through into the liquid. The liquid that forms will overflow a short wall and fall to the next tray downward. In a column, there is a constant flow of rising vapor and a counter flow of descending liquid. As the vapor moves upwards through the trays it becomes colder and richer in nitrogen. As the liquid flows downward through the trays it becomes warmer and richer in oxygen. The number of trays in the column determines the purity of the products. 


\section{ASU Process Areas}

The ASU can be separated into several steps, each important in efficiently separating oxygen from the air. Figure 5 shows a diagram of the entire cryogenic process. The sections that follow will describe the various sub-sections.

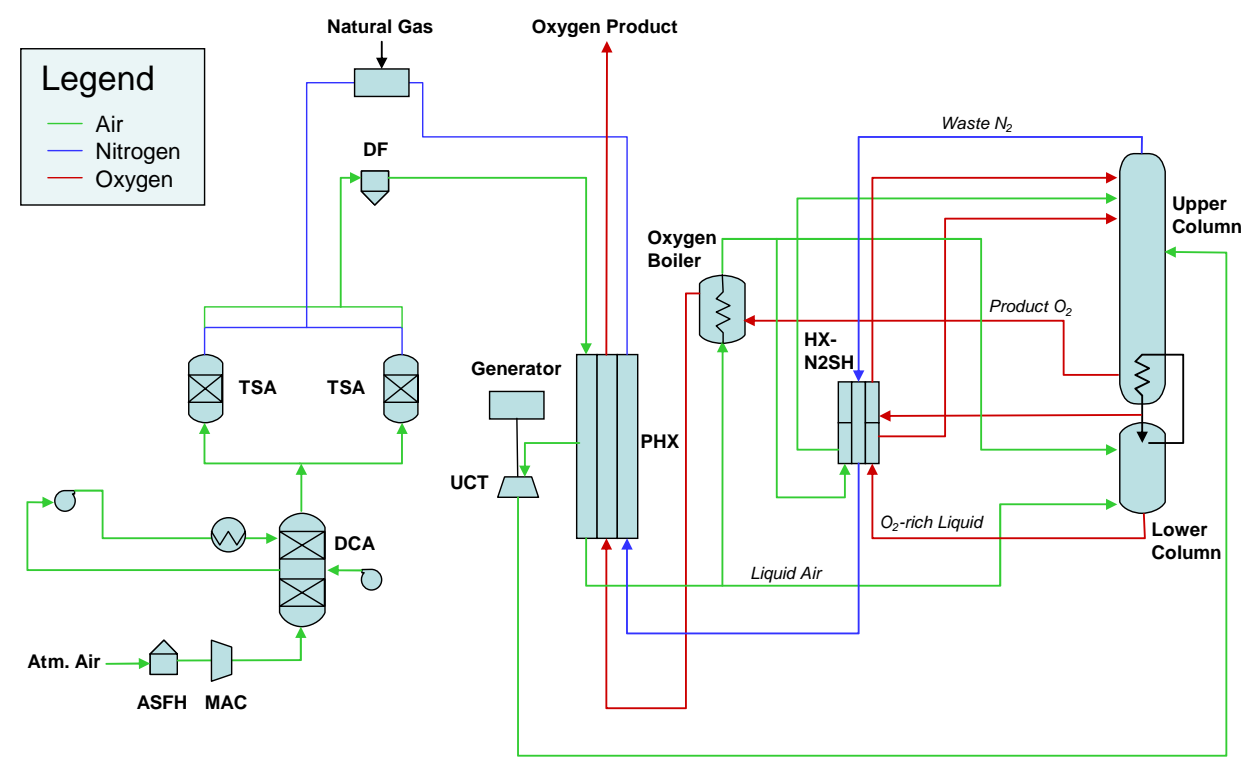

Figure 5. Air Separation Unit Process Flow Diagram (Alstom, 2003)

\section{Air Compression}

Ambient air is drawn through an air separation filter house (ASFH) for the removal of dust and large airborne particles prior to entering the three stage main air compressor (MAC). The compressor can be treated as isothermal. The filtered air is compressed in the MAC to approximately $550 \mathrm{kPa}(65 \mathrm{psig})$ and then flows through the two-stage direct contact after-cooler (DCA). Air is cooled by exchanging heat with cooling water in the first stage and with chilled water provided by a mechanical chiller in the second stage.

\section{Pre-purification}

The after-cooled air is then passed through the pre-purification system. The prepurification system uses a two bed temperature-swing adsorption (TSA) process that allows continuous operation. One bed purifies the feed air while the other bed is being regenerated with first hot then cool waste nitrogen. A natural gas regeneration heater provides regeneration energy. The pre-purifier beds utilize a split adsorbent design (molecular sieve and alumina) to remove water, carbon dioxide, and most of the hydrocarbons from the air stream. Since water and carbon dioxide have boiling points well above that of nitrogen and oxygen, they would freeze in the main heat exchanger and eventually block air flow. The hydrocarbons would be an extremely dangerous impurity in an oxygen stream. After pre-purification, the air stream is passed through a dust filter to remove any solid particles.

\section{Air Feed Streams}

The treated air enters a large, heavily insulated building containing the distillation columns and all of the cryogenic equipment. For larger plants this building can be 10 stories tall. This building is called the cold box as the temperature inside is always 
below $-250 \mathrm{~F}$. There are also conventional refrigeration systems to compensate for heat leaks and other non-idealities in the cold box.

The cold box requires one air feed stream. This stream is sent through the Primary Heat Exchanger (PHX) and then split into three streams. One stream is fed to the oxygen boiler. A second air stream (turbine air) is cooled partially in the PHX and fed to the upper column turbine (UCT). Adjusting the turbine airflow can modulate the total amount of refrigeration generated by the cold box. A third air stream is fed to the bottom of the lower column. These three streams are described in the next section.

\section{Cold Box}

Early cryogenic designs had a single distillation column and were inefficient and incapable of producing oxygen at very high purities. The two column design, as shown in Figure 5 , solved both problems. The two columns are thermally linked by a reboiler, a heat exchanger that prohibits mixing of fluids. The double column design has not changed since its introduction in the 1930's. The upper column is under low pressure and the lower column is under high pressure.

The air stream to the oxygen boiler is cooled and condensed against product oxygen and waste nitrogen streams. The outgoing product oxygen stream and waste nitrogen stream are heated from cryogenic temperatures up to approximately ambient temperature. The cooled air stream is sent to both the upper and lower columns.

The turbine air stream is also cooled against warming nitrogen and oxygen streams. It is drawn from an intermediate location between the warm leg and the cold leg of the PHX. It is then expanded and cooled in the upper column turbine (UCT). The UCT drives a generator that provides power for the plant. The UCT air stream enters two-thirds of the way down the upper (low-pressure) distillation column. Injecting this stream directly into the low-pressure column increases mixing and thus the effectiveness of the column.

The cooled air stream entering the lower column is separated into nitrogen at the top and oxygen-enriched air (kettle liquid) at the bottom. The crude liquid oxygen at the bottom is approximately $45 \%$ pure. Argon is removed at this point to allow oxygen product purity of greater than $97 \%$ later. The nitrogen at the top of the column is condensed in the main condenser against boiling oxygen from the upper column. A portion of the condensed nitrogen from the main condenser is used as reflux for the lower column. The remainder is sub-cooled in the cross flow passages in the nitrogen superheater section of the PHX against warming gaseous nitrogen streams from the upper column. This sub-cooled liquid nitrogen stream then enters the top of the upper column as reflux. The kettle liquid is sub-cooled in the cross flow passes of the nitrogen superheater section of the PHX and then enters the upper about $2 / 3$ of the way down the column.

The upper column also produces waste nitrogen from the top. This nitrogen may be further purified in the upper column and sold as a by-product. The gaseous nitrogen stream is the coldest stream in the plant and is often used to subcool other streams within the coldbox, as illustrated in Figure 5. The nitrogen is warmed in all sections of the PHX to near-ambient temperatures. The product oxygen is boiled in the oxygen boiler against the condensing air stream and exits as product.

The upper column produces high purity liquid oxygen. The liquid oxygen falls to the bottom of the column. Unlike the high-pressure column, this liquid is high purity product. When LOX product is desired, it can be taken from this pool. However, this results in a loss of plant efficiency and a lower gaseous oxygen output. Since oxyten needed for combustion is usually gaseous, it is assumed that large quantities of LOX are not needed. The liquid at the bottom of the column is sent through the reboiler, 
where it is boiled by the heat of the condensing nitrogen in the high-pressure column. This high purity gas is piped out of the low-pressure column and sent through the main heat exchanger (PHX), where it cools the incoming air. The product oxygen exits near ambient temperature and $115 \mathrm{kPa}(2 \mathrm{psig})$. If high-pressure product is desired, the oxygen is compressed by oxygen compressors.

\section{Oxidant Feed Performance Model}

\section{Gas Flow - Gasification}

IGCC systems operate at high pressures and require a pressurized oxidant feed. The IGCC power plant is modeled to consist of 95 percent pure oxygen at $250{ }^{\circ} \mathrm{F}$ and 734 psia. The mass flow rate of oxidant is set to match the molar flow rate of oxygen required by the gasifier model. The oxidant is assumed to be combined with the coal slurry. The only impurities in the oxidant are nitrogen and argon.

\section{Gas Flow - Oxyfuel}

Advanced combustion systems (e.g., oxyfuel) operate at near-atmospheric pressures and do not require a pressurized oxidant fee. First generation Oxyfuel systems will likely adapt a standard boiler design by mixing recycled flue gas with high-purity oxygen. Future designs will likely avoid externally recycled flue gas and use highpurity oxygen directly in the boiler. This type of system is modeled to consist of 95 percent pure oxygen at $59^{\circ} \mathrm{F}$ and atmospheric pressure. The mass flow rate of oxidant is set to match the molar flow rate of oxygen required by the boiler model. The only impurities are nitrogen and argon.

\section{Energy Use}

The oxygen plant consumes significant amounts of electric power, thereby reducing the saleable electrical output of the power plant. When reporting costs on a normalized basis (e.g., $\$ / \mathrm{kW}$ or mills $/ \mathrm{kWh}$ ), it is important to use an accurate estimate of the net electrical production available for sale. The performance model does not estimate the internal electrical load, hence a simple regression model of power consumption versus key flow rates has been developed for the oxygen plant. This model provides an accurate estimate of the plant electrical requirements. It replaces the previous regression models (Frey, 1990 and Frey, 2001).

There are three main factors that affect the required power input to an ASU:

1. the volume or amount of oxygen product to be produced,

2. the purity of the product, and

3. the delivery pressure of the product.

While there are other factors that affect plant performance, such as the ratio of liquid versus gaseous oxygen produced, they are not considered in this model.

The power required to operate an oxygen plant can be divided into four sections: (1) the main air compressor (MAC), (2) the refrigeration system to compensate for heat losses in the cold box, (3) auxiliary and control systems, and (4) the final oxygen product compressor (if required). The first three sections will be combined together into one component of the energy model and referred to as the MAC power. Since the delivery pressure, and thus the amount of power needed to compress the oxygen 
product, is independent of the separation process, it will be treated as a separate component of the energy model.

Figure 6 shows the power required by an oxygen plant as a function of the oxygen purity of the product stream (McKetta, 1990). This figure shows a characteristic shape that is a result of the interaction of two factors, namely the input air stream compression (not a function of oxygen purity) and power generated from exhaust air expansion (decreasing with oxygen purity).

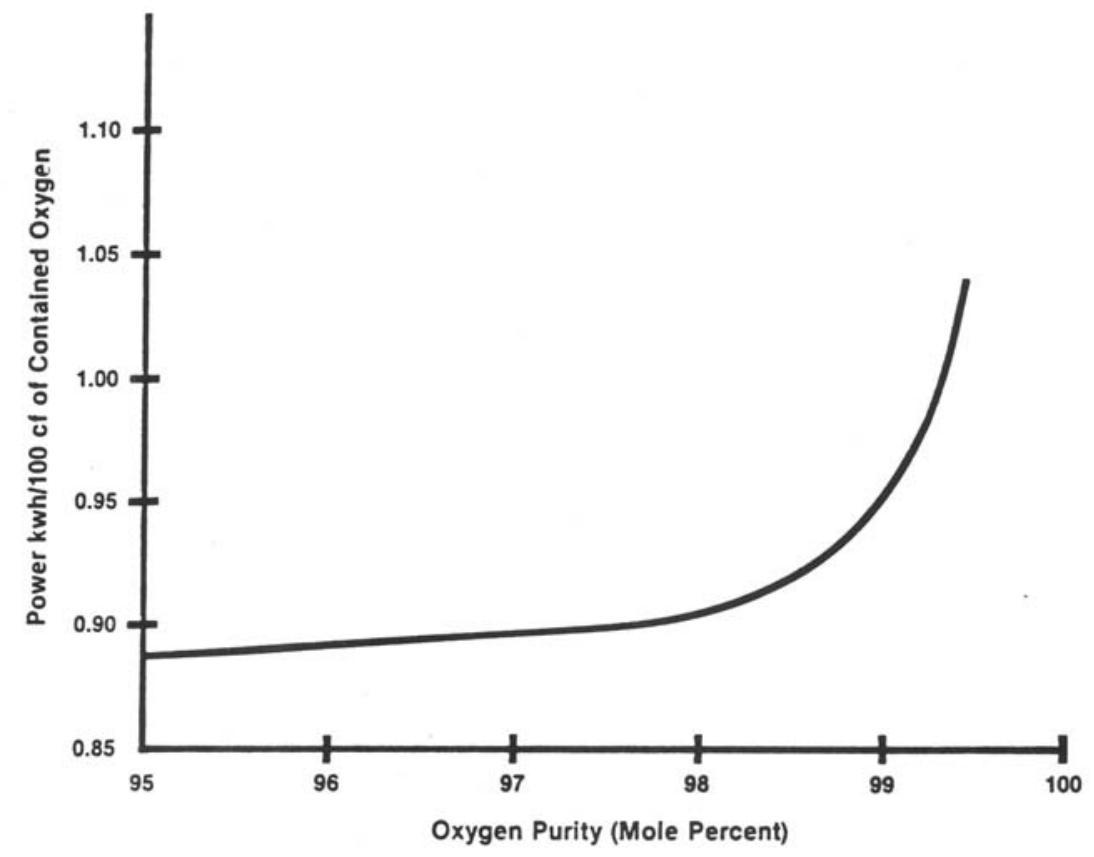

Figure 6. Effect of oxygen purity on ASU power (McKetta, 1990)

The input air stream must be compressed to approximately $550 \mathrm{kPa}$ (79.8 psi), regardless of the product purity. This requires around $1.05 \mathrm{~kW} / 100$ cubic feet of oxygen product. This assumes a compressor efficiency of $75 \%$, which is a typical value for current commercial applications in large-scale plants. After the air stream is compressed, it is later expanded in the plant to cool the air stream. The process is called a Joule-Thompson expansion.

The air stream is expanded through a turbo expander, which generates power that can be fed back into the oxygen separation plant. This expansion creates a power credit. As the purity requirement increases, the fraction of the air stream that can be expanded in this way decreases exponentially. This is because the air stream is expanded in the low-pressure column rather than going through the high-pressure column first. This air will avoid the numerous distillation stages in the high-pressure column, and therefore will decrease the purity of the product. This dilution effect becomes more pronounced as the desired purity increases. The overall result is a decrease in the power credit from about $0.16 \mathrm{~kW} / 100$ cubic feet of oxygen at $95 \%$ purity to approximately zero at $99.5 \%$, even though the required power input remains constant at $1.05 \mathrm{~kW} / 100$ cubic feet of oxygen product.

The MAC power as summarized in Figure 6 is given in units of kilowatts per 100 cubic feet of oxygen product as a function of the oxygen purity. The relationship can be divided into two regimes with a purity of $97.5 \%$ separating them. Each region is represented by a regression curve to fit the relationship. 


$$
\begin{array}{ll}
\text { MAC Power }=4.88 e^{-3} \eta_{o x}+0.4238 & \eta_{\mathrm{ox}}<97.5 \\
\text { MAC Power }=\frac{7.361 e^{-2}}{\left(100-\eta_{o x}\right)^{1.316}}+0.8773 & \eta_{\mathrm{ox}}>97.5
\end{array}
$$

where,

$$
\begin{aligned}
& 0.85 \leq \text { MAC Power } \leq 1.05 \mathrm{~kW} / 100 \mathrm{cf} \text { of oxygen } \\
& 95 \leq \eta_{\text {ox }} \leq 99.5
\end{aligned}
$$

In Equations (4) and (5), MAC Power has a range from 0.85 to $1.05 \mathrm{~kW} / 100$ cubic feet of oxygen. The oxygen purity range specified above is typical for a cryogenic ASU.

The oxygen product exits at $115 \mathrm{kPa}(16.7 \mathrm{psi})$. If higher pressure oxygen is desired, the product is fed through inter-cooled oxygen compressors. The model for this process utilizes the ideal gas law and is stated below in Equation (6)

$$
\text { PC Power }=P_{i} \times \dot{V} \ln \left(\frac{P_{o}}{P_{i}}\right) \times \frac{1}{\eta}
$$

PC Power is the required power input to the oxygen product compressor in $\mathrm{kW}$. A typical value for the efficiency is 0.75 .

\section{Oxidant Feed Cost Model}

Cost data for 31 cryogenic oxygen plants were taken from 14 studies of oxygenblown IGCC systems, all prepared for EPRI. These plants all include electric motordriven compressors. Data from coal-to-syngas systems were not included because many of these use steam-driven, rather than motor-driven, compressors. Electric motor-driven systems offer advantages in terms of plant operation, although steamdriven systems may be more energy efficient. These plants produced between 625 and $11,350 \mathrm{lb}$ mole/hr of oxygen per train. A typical plant consists of two parallel operating trains with no spare trains. Each train includes an air compression system, air-separation unit and an oxygen compression system. For more detail on the oxygen plant design, see Fluor (2003). The oxygen plants represented in the database are considered commercially available.

\section{Direct Capital Cost}

This process section typically has an air compression system, an air separation unit, and an oxygen compression system. The direct cost of oxygen plants is expected to depend mostly on the oxygen feed rate to the gasifier, because the size and cost of compressors and the air separation systems are proportional to this flow rate. The oxygen purity of the oxidant feed stream is expected to affect the cost of the air separation system. As oxygen purity increases, It is expected that the cost of the oxygen plant will increase because the size of equipment in the air separation plant (e.g., high pressure column) increases. The ambient temperature determines the volume flow rate of air entering the inlet air compressor; as ambient temperature increases, the volume flow rate increases for a given mass flow, thereby requiring an increased compressor size.

A number of regression models were considered in which alternative combinations of predictive parameters and functional forms were assumed. These regressions were 
based on nonlinear variable transformations using the natural logarithm. A single variant regression of cost and oxygen flow rate, using an exponential scaling formulation yielded excellent results $\left(\mathrm{R}^{2}=0.9\right)$. The scaling exponent in this case was 0.9 . The addition of terms for ambient temperature and oxidant purity yielded a marginal improvement in the summary statistics for the model. From an engineering viewpoint, the inclusion of these additional predictive terms significantly improves the utility of the model, allowing costs to be sensitive to both primary and secondary factors. A multivariate regression is assumed for the oxidant feed process area direct capital cost (Frey, 2001). The direct cost model for the oxidant feed section is given in Equation (7):

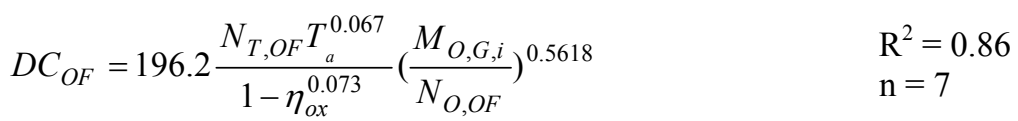

where,

$$
\begin{aligned}
& 20 \leq T_{a} \leq 95 \\
& 625 \leq \frac{M_{O, G, i}}{N_{O, O F}} \leq 17,000 \\
& 0.95 \leq \eta_{o x} \leq 0.98
\end{aligned}
$$

The regression form used in Equation (7) is based on the regression form developed by Frey (Frey, 1990). Frey developed the regression equation based on 31 data points, resulting in a variance of 0.94 . The Frey regression form was modified to fit data from recently published reports (Chase and Kehoe, 2003; Foster et al, 2003; IEA, 2003; Brdar and Jones, 2003). Figure 7 shows the data points used for this regression. Costs are provided in December 2000 dollars and can be scaled to other years using the Chemical Engineering Plant Cost Index.

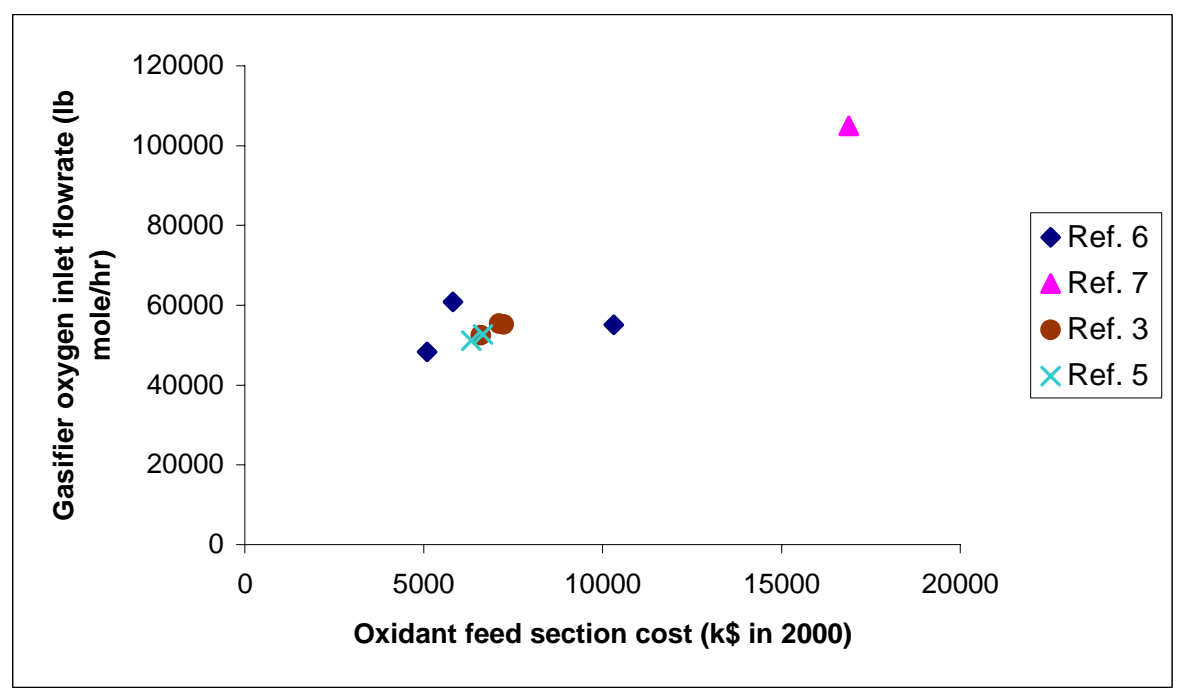

Figure 7. Oxygen flow rate vs. oxidant feed section cost

The robustness of the exponential scaling relationship between oxygen flow rate and direct capital cost is indicated by the similarity of the exponent for oxygen flow rate in the single and multi-variable regression models. In the single variable model previously described, the exponent was 0.9 , while for the multivariate model above it is 0.86 . The limits for each parameter indicated above represent the ranges for which the regression model is valid. While to obtain accurate results these ranges should 
not be violated, it is not a severe violation to exceed the range for the oxygen flow rate per train, particularly on the high side, because the model reasonably captures the expected relationship between oxygen flow rate and cost. An alternative to extrapolating the model for oxygen flow rate per train, however, is to alter the number of trains so that the flow rate per train is within the limits given above. The ambient temperature and oxygen purity parameters should not be extrapolated.

\section{Indirect Capital Cost}

Indirect capital costs are directly related to direct capital costs (referred here as process facilities capital or PFC) and often expressed as a fraction of the plant facilities capital. There are several categories of indirect costs that are specified in the model.

The general facilities section includes cooling water systems, plant and instrument air, potable and utility water, and electrical systems. Engineering and home office fees include the costs associated with engineering, office expenses, and fees or profit to the engineer. Process contingency is used to determine cost estimates for expected increase in the capital cost of an advanced technology due to uncertainty in performance. Project contingency is used to determine cost estimates for expected increase in the capital cost resulting from a more detailed estimate for a specific project at a particular site. Miscellaneous capital includes equipment needed to bring the system to full capacity. Inventory capital includes raw materials and spare parts available in storage.

\begin{tabular}{||l|l||}
\hline Indirect Cost Category & Cost \\
\hline \hline General Facilities & $15 \%$ PFC \\
\hline Engineering \& Home Office Fees & $10 \%$ PFC \\
\hline Project Contingency & $15 \%$ PFC \\
\hline Process Contingency & $5 \% \mathrm{PFC}^{1}$ \\
\hline Royalty Fees & $0.5 \%$ PFC \\
\hline Miscellaneous Capital & $2 \% \mathrm{TPI}$ \\
\hline Inventory Capital & $0.5 \% \mathrm{TPC}$ \\
\hline \hline
\end{tabular}

PFC = Plant Facility Cost (direct capital only); TPC $=$ Total Plant Cost (direct and indirect costs ignoring finance and escalation costs); TPI = Total Plant Investment (direct and indirect costs including finance and escalation costs)

\section{O\&M Cost}

The annual costs of the ASU consist of fixed and variable operating costs. The fixed operating costs are annual costs including operating labor, maintenance costs ( $2 \%$ of the total plant cost) of which a portion is allocated to maintenance labor, and overhead costs associated with administrative and support labor. These are defined by the following equations:

$$
\text { Oper. Labor }=\left(\frac{\$}{h r}\right) \times\left(\frac{\text { jobs }}{\text { shift }}\right) \times\left(\frac{\text { shifts }}{\text { day }}\right) \times\left(\frac{40 h r}{w k}\right) \times\left(\frac{52 w k}{y r}\right)
$$

Maint. Labor $=0.4 \times$ Total Maint. Cost

\footnotetext{
${ }^{1}$ This level of contingency is associated with a well-defined plant that has been demonstrated commercially.
} 
The variable operating costs include consumables, fuels, and byproduct credits. For the ASU process area, these costs are assumed to be negligible.

\section{Illustrative Example}

Suppose an IGCC plant requires a maximum production of 2,500 standard tons per day of $97.5 \%$ purity oxygen. The required pressure at the gasifier is $700 \mathrm{kPa}$. In order to provide this amount of oxidant, the number of ASU production trains, the power requirements, capital cost, and operating costs need to be determined. The following sections detail the calculations to determine these values. The costs are reported in December 2000 dollars, but may be adjusted to other years using the Chemical Engineering Plant Cost Index.

\section{Number of Trains}

Equation (4) includes a maximum size limit of 11,375 lbmole/ $\mathrm{hr}$ of oxygen for one ASU train. Because we wish to compare the required flow rate to the maximum flow rate, we need the actual flow rate of oxygen:

$$
\begin{aligned}
& 2,500 \text { stpd } *\left(\frac{1,000 s c f h}{1 s t p d}\right)=2,500,000 \text { scfh product } \\
& (2,500,000 \text { scfh product }) * 0.975=2,437,500 \text { scfh } O_{2} \\
& 2,437,500 \text { scfh } O_{2} *\left(\frac{0.00255 \text { lbmole }}{1 \text { scf }}\right)=6,220 \text { lbmole } / \mathrm{hr} \mathrm{O}_{2}
\end{aligned}
$$

This required flow rate is below the maximum flow rate for one ASU train $(11,375$ $\mathrm{lbmole} / \mathrm{hr}$ ). Hence, only one ASU train is required to transport the $6,220 \mathrm{lbmole} / \mathrm{hr}$ of oxygen required by the IGCC plant.

\section{Power Requirement}

The IGCC requires oxygen pressure of $700 \mathrm{kPa}$ to be delivered, higher than the 115 $\mathrm{kPa}$ threshold of the main air compressor. Additional compression will be required of the product stream, so both Equation (4) and Equation (6) will be used to determine the total power requirement. The main air compressor power can be calculated from either Equation (4) or equation (5) (97.5\% purity is the cutoff value). Equation (4) is used to calculate the main air compressor power requirement below:

$$
\begin{aligned}
& 2500 s t p d *\left(\frac{1000 s c f h}{1 s t p d}\right)=2,500,000 s c f h \\
& \text { MAC Power }=4.88 * 10^{-3} *(97.5)+0.4238 \\
& =0.8996 \mathrm{kWh} / 100 \mathrm{scf} \\
& \text { MAC Power }=(0.8996 \mathrm{kWh} / 100 \mathrm{scf}) *(2,500,000 \mathrm{scfh}) \\
& =22,490 \mathrm{~kW}=22.49 \mathrm{MW}
\end{aligned}
$$

The additional power to compress the product stream from $115 \mathrm{kPa}$ to $700 \mathrm{kPa}$ is calculated from Equation (6). Assume the efficiency of the compressor is $75 \%$. 


$$
\begin{aligned}
& 2,500,000 s c f{ }^{*}\left(\frac{1 m^{3}}{35.31 f t^{3}}\right) *\left(\frac{1 h}{3600 s}\right)=19.66 m^{3} / s \\
& \text { PC Power }=(115 \mathrm{kPa}) *\left(19.66 \mathrm{~m}^{3} / \mathrm{s}\right) * \ln \left(\frac{700 \mathrm{kPa}}{115 \mathrm{kPa}}\right) * \frac{1}{0.75} \\
& =5,450 \mathrm{~kW}=5.45 \mathrm{MW}
\end{aligned}
$$

The total power required to produce the maximum flow rate of oxygen product is 27.9 MW. This is the power that must be supplied to the air separation unit from an outside source or from the plant directly.

\section{Capital Cost}

The average ambient temperature surrounding the plant is $65^{\circ} \mathrm{F}$. For this example, only one ASU train is required as shown in the previous sections. We will assume that this train operates continuously (i.e., no spare train).

$$
\begin{aligned}
& 2,500 \text { stpd } *\left(\frac{1,000 s c f h}{1 \text { stpd }}\right)=2,500,000 \text { scfh product } \\
& (2,500,000 \text { scfh product }) * 0.975=2,437,500 \text { scfh oxygen } \\
& 2,437,500 \text { scfh } O_{2} *\left(\frac{0.00255 \text { lbmole }}{1 s c f}\right)=6,220 \text { lbmole } / \mathrm{hr} O_{2} \\
& \text { PF Cost }=\frac{15.91 *(1 \text { train }) *\left(65^{\circ} \mathrm{F}\right)^{0.067}}{(1-0.975)^{0.073}}\left(\frac{6,220 \mathrm{lbmole} / \mathrm{hr}}{1 \text { train }}\right)^{0.852} \\
& \text { PF Cost }=\$ 47,032(\$ 1,000)=47.0 \mathrm{M} \$ \\
& \text { General Facilities }=0.15 \times 47.0=7.05 \mathrm{M} \$ \\
& \text { Eng'r \& Home Office }=0.10 \times 47.0=4.7 \mathrm{M} \$ \\
& \text { Project Contingency }=0.15 \times 47.0=7.05 \mathrm{M} \$ \\
& \text { Process Contingency }=0.05 \times 47.0=2.35 \mathrm{M} \$ \\
& \text { Royalty Fees }=0.005 \times 47.0=0.24 \mathrm{M} \$ \\
& \text { Total Plant Cost }=47.0+7.05+4.7+7.05+2.35+0.24 \\
& =68.39 \mathrm{M} \$
\end{aligned}
$$

The costs are reported in December 2000 dollars, but may be adjusted to other years using the Chemical Engineering Plant Cost Index.

\section{Operating and Maintenance Cost}

There are only fixed variable costs associated with the air separation unit, as mentioned above. The total maintenance cost combines materials and labor costs and is taken to be $2 \%$ of the total plant cost calculated in the previous section. The maintenance cost is:

$$
\text { Maint } . \text { Cost }=0.02 \times \$ 68.39=\$ 1.37 \mathrm{M} \$
$$


Maintenance labor is $40 \%$ of the total maintenance cost, or $0.55 \mathrm{M} \$$. The operating labor assumes $6.67 \mathrm{jobs} / \mathrm{shift}$ and $4.75 \mathrm{shifts} /$ day. With a labor rate of $25 \$ / \mathrm{hr}$, the operating labor cost is:

$$
\begin{aligned}
& \text { Oper. Labor }=25 \times 6.67 \times 4.75 \times\left(\frac{40 h r}{w k}\right) \times\left(\frac{52 w k}{y r}\right)=1.65 \mathrm{M} \$ \\
& \text { Maint. Labor }=0.4 \times 1.37=0.55 \mathrm{M} \$ \\
& \text { Adm. \& Support Labor }=0.3 \times(1.65+0.55)=0.66 \mathrm{M} \$ \\
& \text { Fixed } O \& M \text { Cost }=1.37+1.65+0.66=3.68 \mathrm{M} \$
\end{aligned}
$$

These costs are given in December 2000 dollars (the cost year basis for the total plant cost).

\section{References}

Alstom (2003). Volume 1: Evaluation of Advanced Coal Combustion \& Gasification Power Plants with Greenhouse Gas Emission Control and Volume 2: Bench-scale Fluidized Bed Combustion Testing. Final Report prepared by Alstom Power, Inc. to Department of Energy National Energy Technology Center. Pittsburgh, PA. PPL03-CT-09. May, 2003.

Baukal, C.E. (1998). Oxygen-Enhanced Combustion, CRC Press, LLC, Boca Raton, FL. 1998.

Brdar R.D., and R.M. Jones (2003): GE IGCC Technology and Experience with Advanced Gas Turbines, GE Power Systems, GER-4207, 2003.

Chase, D.L., and P.T. Kehoe (2003). GE Combined-Cycle Product Line and Performance. GE Power Systems, GER-3574G, 2003.

Foster A.D., H.E. Doering, and M.B. Hilt M.B.(2003): Fuel flexibility in heavy-duty gas turbines, GE Company, Schenectady, New York, 2003.

Frey, H.C. and E.S. Rubin (1990). Stochastic Modeling of Coal Gasification Combined Cycle Systems: Cost Models of Selected Integrated Gasification Combined Cycle (IGCC) Systems. Task 2 Topical Report prepared by Carnegie Mellon University for the U.S. Department of Energy, Morgantown Energy Technology Center, Morgantown, WV. DOE/MC/24248-2901, NTIS DE90015345. June 1990.

Frey, H.C., and N. Akunuri (2001). Probabilistic Modeling and Evaluation of the Performance, Emissions, and Cost of Texaco Gasifier-Based Integrated Gasification Combined Cycle Systems Using ASPEN. Prepared by North Carolina State University for Carnegie Mellon University and U.S. Department of Energy, National Energy Technology Center, Pittsburgh, PA. January 2001.

IEA (2003). Potential for improvement in gasification combined cycle power generation with $\mathrm{CO}_{2}$ capture, IEA Greenhouse Gas R\&D Program, report number PH4/19, 2003.

McKetta, J. (1990). Encyclopedia of Chemical Processing and Design, Vol. 31, pg. $214,1990$. 



\section{GE Entrained-Flow Gasifier}

Nomenclature

\section{Technologies}

LTGC $=$ Low temperature gas cooling area (gas quench)

$\mathrm{CH}=$ Coal handling and slurry preparation

$\mathrm{G}=$ Gasifier area

$\mathrm{PG}=$ Process condensate treatment

\section{Parameters}

$\mathrm{W}_{\mathrm{e}, \mathrm{CH}}=$ Coal handling auxiliary power, $\mathrm{kW}$

$\mathrm{W}_{\mathrm{e}, \mathrm{G}}=$ Gasification auxiliary power, $\mathrm{kW}$

$\mathrm{W}_{\mathrm{e}, \mathrm{LT}}=\mathrm{LTGC}$ auxiliary power, $\mathrm{MW}$

$\mathrm{W}_{\mathrm{e}, \mathrm{PC}}=$ Process condensate auxiliary power, $\mathrm{kW}$

$\mathrm{m}_{\mathrm{cf}, \mathrm{G}, \mathrm{i}}=$ Coal feed rate to gasifier, tons/day

$\mathrm{m}_{\mathrm{syn}, \mathrm{LT} \mathrm{i}}=$ Syngas flowrate into LTGC, lbmole $/ \mathrm{hr}$

$\mathrm{m}_{\text {syn,LT o }}=$ Syngas flowrate from LTGC, lb/hr

$\mathrm{m}_{\mathrm{SBD}}=$ Scrubber blowdown flowrate, $\mathrm{lb} / \mathrm{hr}$

$\mathrm{N}_{\mathrm{O}, \mathrm{G}}=$ Number of operating gasifier trains

$\mathrm{N}_{\mathrm{T}, \mathrm{G}}=$ Total number of gasifier trains (operating and spare)

$\mathrm{N}_{\mathrm{O}, \mathrm{LT}}=$ Number of operating LTGC trains

$\mathrm{N}_{\mathrm{T}, \mathrm{LT}}=$ Total number of LTGC trains (operating and spare)

$\mathrm{DC}_{\mathrm{CH}}=$ Direct capital cost of coal handling section, $\$ 1000$

$\mathrm{DC}_{\mathrm{G}}=$ Direct capital cost of gasification section, $\$ 1000$

$\mathrm{DC}_{\mathrm{LT}}=$ Direct capital cost of LTGC section, $\$ 1000$ 


\section{GE Gasifier Process Description}

This report describes a GE entrained-flow gasifier-based IGCC system with total quench high temperature syngas cooling using coal. The GE entrained-flow gasifier (originally developed by Texaco) has been used since 1956 for chemical and power applications. Although primarily used for chemical production in the past, a prototype gasifier was built in 1984 (Clearwater Project) and the first full-scale plant was built in 1995 (Polk Station).

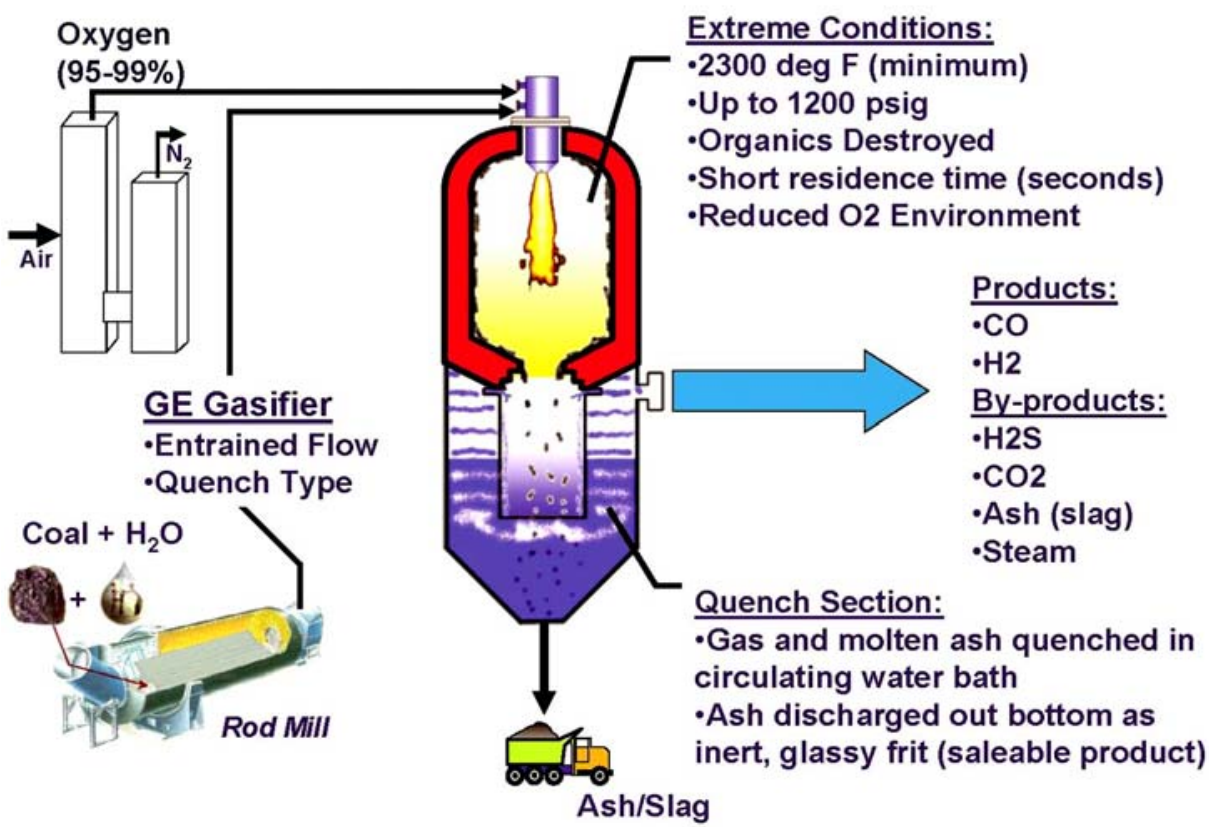

Figure 8. GE entrained gasifier schematic (taken from Eastman Gasification Services Company, 2005).

The GE gasifier is an entrained flow gasifier, as are the Shell gasifiers and ConocoPhillips E-Gas gasifiers (originally developed by Dow). Entrained flow gasifiers have high outlet temperatures and operate in the slagging range (the ash is fully liquid with low viscosity). The GE gasifier has the benefit of being able to handle a large variety of coal types, produce a syngas free of oils and tars, exhibit a high carbon conversion, produce low concentrations of methane, and produce a high throughput (due to the high reaction rates at elevated temperatures). A detraction of the GE gasification system is the higher oxygen requirement to achieve the higher temperature, resulting in higher auxiliary electrical requirements. Also associated with the higher temperature is the increased coal oxidation, resulting in a lower cold gas efficiency.

The GE gasification system uses a coal in water slurry in a single-stage down flow reactor configuration, as shown in Figure 8. The dry solids concentration in the slurry is typically around $65 \%$. A pump delivers the slurry to the gasifier at pressures in the range of 500-1,000 psi. The gasifier is refractory lined and typically operates in the range of $2250-2,900 \mathrm{~F}$. Oxygen is used to combust only a portion of the feedstock in order to provide thermal energy needed by endothermic gasification reactions. The hot raw syngas leaves the gasifier and is cooled either by a series of radiant and convective heat exchangers to a temperature of $650^{\circ} \mathrm{F}$ or by contact with water to a temperature of $433^{\circ} \mathrm{F}$. The syngas passes through a wet scrubbing system to remove particulate matter and water soluble gases such as $\mathrm{NH}_{3}$. 
The details of the major process areas are briefly described below.

\section{Coal Handling}

Coal handling involves unloading coal from a receiving vessel (train, truck or barge), storing the coal, moving the coal to the grinding mills, and feeding the gasifier with positive displacement pumps. A typical coal handling section contains one operating train and no spare train. A train consists of a bottom dump railroad car unloading hopper, vibrating feeders, conveyors, belt scale, magnetic separator, sampling system, deal coal storage, stacker, reclaimer, as well as some type of dust suppression system.

Slurry preparation trains typically have one to five operating trains with one spare train. The typical train consists of vibrating feeders, conveyors, belt scale, rod mills, storage tanks, and positive displacement pumps to feed the gasifier. All of the equipment for both the coal handling and the slurry feed are commercially available.

The feed coal is crushed and slurried in wet rod mills. The coal slurry containing about 66.5 weight percent solids is fed into the gasifier, which is an open refractorylined chamber, together with a feed stream of oxidant. The slurry is transferred to the gasifier at high pressure through charge pumps. The water in the coal slurry acts as a temperature moderator and also as a source of hydrogen in gasification (Simbeck et al., 1983).

\section{Gasification}

GE entrained-flow gasification can handle a wide variety of feedstocks including coal, heavy oils, and petroleum coke (Preston, 1996). The current study focuses on IGCC systems using coal feed. Oxygen is assumed as the oxidant for the IGCC systems evaluated in this study. The oxidant stream contains $95+$ percent pure oxygen. The oxygen is compressed to a pressure sufficient for introduction into the burner of the GE entrained-flow gasifier (Matchak et al., 1984). Operation under high pressure is beneficial to increase the capacity of the gasifier reactor volume and thereby reduce capital cost. It is also beneficial to downstream processes because of increased partial pressures. 


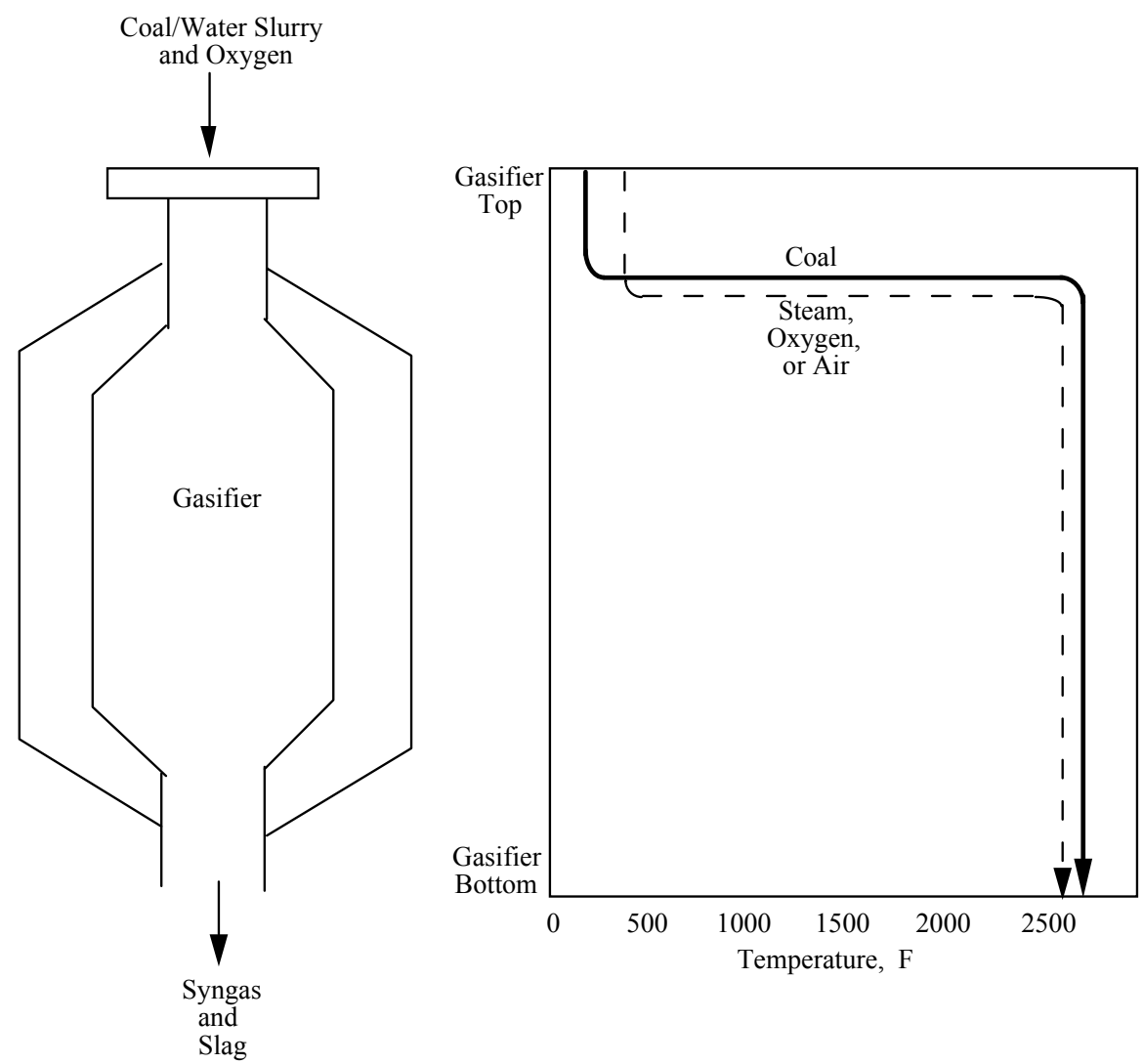

Figure 9. Temperature Variation in an Entrained Gasifier (Based on Simbeck et. al., 1983)

The coal slurry and oxidant feed are delivered to the gasifier burners. Gasification takes place rapidly at temperatures exceeding $2,300^{\circ} \mathrm{F}$. Coal is partially oxidized at high temperature and pressure. Figure 9 demonstrates the temperature variation across the gasifier (Simbeck et al., 1983). The combustion zone is near the top of the reactor, where the temperature in the gasifier changes from approximately 250 to $2500{ }^{\circ} \mathrm{F}$. The operating temperature is sufficiently higher than the ash fusion temperature of $2,300{ }^{\circ} \mathrm{F}$ to cause the ash to become molten and separate out easily from the raw gas. A portion of the coal feed burns, providing heat for the endothermic gasification reactions that result in the formation of $\mathrm{CO}, \mathrm{CO}_{2}, \mathrm{H}_{2}, \mathrm{CH}_{4}$, and $\mathrm{H}_{2} \mathrm{~S}$.

The syngas leaves the gasifier at temperatures in the range of $2300{ }^{\circ} \mathrm{F}$ to $2700{ }^{\circ} \mathrm{F}$. Because of the high temperatures characteristic of entrained-flow gasifiers, the syngas contains smaller amounts of methane than other types of gasifiers and is free of tars and other hydrocarbons (Simbeck et al., 1983).

\section{Chemical Reactions}

The chemical reactions modeled in the equilibrium gasifier reactor model are:

$$
\begin{aligned}
& \mathrm{C}+2 \mathrm{H}_{2} \rightarrow \mathrm{CH}_{4} \\
& \mathrm{C}+\mathrm{H}_{2} \mathrm{O} \rightarrow \mathrm{CO}+\mathrm{H}_{2} \\
& \mathrm{CO}+\mathrm{H}_{2} \mathrm{O} \rightarrow \mathrm{CO}_{2}+\mathrm{H}_{2} \\
& \mathrm{CH}_{4}+1.5 \mathrm{O}_{2} \rightarrow \mathrm{CO}+2 \mathrm{H}_{2} \mathrm{O}
\end{aligned}
$$




$$
\begin{aligned}
& 2 \mathrm{CO}+\mathrm{O}_{2} \rightarrow 2 \mathrm{CO}_{2} \\
& \mathrm{~S}+\mathrm{H}_{2} \rightarrow \mathrm{H}_{2} \mathrm{~S} \\
& \mathrm{~N}_{2}+3 \mathrm{H}_{2} \rightarrow 2 \mathrm{NH}_{3} \\
& \mathrm{CO}+\mathrm{H}_{2} \mathrm{~S} \rightarrow \mathrm{COS}+\mathrm{H}_{2} \\
& \mathrm{Ar} \rightarrow \mathrm{Ar}
\end{aligned}
$$

Equations ( $(8),(9)$, and (10), are the primary gasification reactions. Equation $(\underline{8)}$ is an exothermic reaction and is known as methanation. The formation of methane increases the heating value of the product gas. Equation (9) is an endothermic reaction, more generally known as the "water gas reaction". Equation $(10)$ is an exothermic reaction, more generally known as the "water gas shift reaction." Equations $(9)$ and $(10)$ together lead to the formation of hydrogen. Equation (11), in series with Equation (8), represents the partial combustion of coal and Equation (12) in sequence with Equations (8) and (9), models the complete oxidation of coal.

\section{Sulfur Compounds}

Over $90 \%$ of the sulfur in the feedstock is converted to hydrogen sulfide $\left(\mathrm{H}_{2} \mathrm{~S}\right)$ and the rest is converted to carbonyl sulfide (COS). Compounds such as $\mathrm{SO}_{2}$ and $\mathrm{SO}_{3}$ are absent in the syngas. Because COS is difficult to capture, a hydrolysis unit or shift reactor is required to convert the $\mathrm{COS}$ to $\mathrm{H}_{2} \mathrm{~S}$ prior to acid gas removal.

\section{Nitrogen Compounds}

Nitrogen enters the gasifier both as a molecule (an impurity from the air separation unit) and as fuel-bound nitrogen. Gasifiers produce primarily ammonia $\left(\mathrm{NH}_{3}\right)$ with negligible amounts of $\mathrm{NO}$ or $\mathrm{NO}_{2}$, because of the reducing conditions in the gasifier.

\section{Chlorine Compounds}

Most of the chlorine in the coal is converted to hydrogen chloride gas $(\mathrm{HCl})$.

Chlorine compounds from the coal may also react with ammonia to form ammonium chloride $\left(\mathrm{NH}_{4} \mathrm{Cl}\right)$. Most of the chlorides are removed in a water scrubber.

\section{Solid carbon and ash}

Some char (unconverted carbon) and ash will always be entrained in the gas flow exiting the gasifier. The quench removes a majority of the solid particles, preventing fouling occurrences downstream. After capture, the particles may be recycled to the gasifier to increase the carbon conversion efficiency.

\section{Syngas Quenching}

The temperature of the syngas exiting the gasifier is typically around 2,300 $\mathrm{F}$ and the fly ash or slag exists in liquid form. To protect downstream components from fouling, a quench is needed to solidify the slag.

A water quench uses sensible heat from the syngas to vaporize water. This quench drives the water gas shift reaction to increase the $\mathrm{H} 2 / \mathrm{CO}$ ratio, a benefit in the case of $\mathrm{CO}_{2}$ capture performed downstream. 
The scrubbed gas enters various heat exchangers in the low temperature gas cooling section. The heat removed from the syngas is utilized to generate low-pressure steam to heat feed water or as a source of heat for fuel gas saturation.

\section{Particle Capture}

Dry solids still entrained in the syngas are removed by a wet scrubbing system. The scrubbers operate at a temperature below the dew point of the gas so that the particles can serve as nuclei for condensation and result in more efficient removal. The particle-laden water is sent to a water treatment plant and the clarified water used again as quench water.

\section{GE Gasifier Performance Model}

The Integrated Environmental Control Model (IECM) is a desktop model developed by Carnegie Mellon University as a tool for assessing the technical performance, cost and environmental effectiveness of different fossil fuel power generation technologies. The broad framework of the model consists of a base power plant, with options to add modules for meeting environmental regulations with respect to emissions of $\mathrm{NO}_{\mathrm{x}}, \mathrm{SO}_{\mathrm{x}}$, particulates, mercury and $\mathrm{CO}_{2}$. The user is thus able to determine the performance and cost of the overall plant equipped with one or several of the above modules. The IECM has recently been expanded to include Integrated Gasification Combined Cycle (IGCC) process in addition to the combustion-based systems.

IGCC is a promising technology for power generation from coal. It offers several advantages as compared to the conventional $\mathrm{PC}$ boiler including higher process efficiency, lower emissions of $\mathrm{SO}_{2}$ and $\mathrm{NO}_{\mathrm{x}}$ and easier capture $\mathrm{CO}_{2}$ for sequestration. Because of the differences between different types of gasifiers, it is important to have a gasifier model that accurately predicts the syngas composition, which in turn determines the power output of the downstream gas turbine and steam cycle blocks. However, there are trade-offs involved because of the complexity associated with modeling the gasification process. Detailed gasifier models that employ computational fluid dynamics (CFD) are time consuming, data intensive and costly to run. A less complex (but still time consuming) approach is to model the gasifier using a commercial process simulator like ASPEN Plus, and then "import" the results into the IECM by developing suitable output data tables (Figure 10).

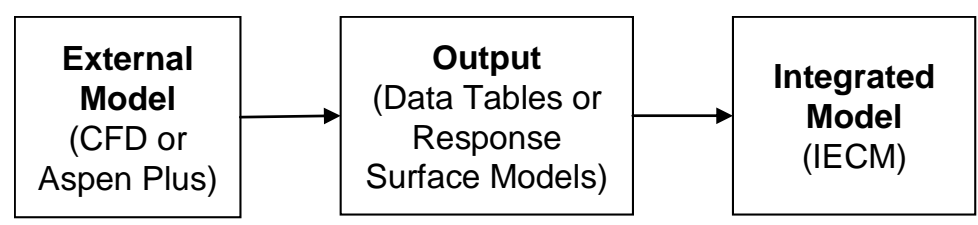

Figure 10. Linkage between the gasifier external model and the IECM

We have taken this approach in modeling the gasifier. This report summarizes the development of data tables for performance assessment of a coal gasifier in IGCC power plants. The major objective of this evaluation is to identify the key thermodynamic and process variables in a gasifier and to study the impact on the composition of synthesis gas. Our modeling approach was an extension of the Aspen Plus model previously developed by the National Energy Technology Laboratory (NETL). These models were modified to run as a stochastic simulation. This capacity provides a powerful and efficient way to generate model response to 
simultaneous changes in several key input variables. The output results are then used to develop an output data table and a response surface model of the gasifier.

\section{Aspen Plus Gasifier Simulation}

The next several sections briefly describe the Aspen Plus flowsheet components used to generate the output data tables and response surface models.

\section{Oxidant Feed}

The reaction temperature and heat loss in the gasifier, which is assumed to be $1 \%$ of the total low heating value of the inlet coal flow, in the gasification reactor is maintained by adjusting the inlet flow rate of oxygen.

The gasifier oxidant feed was fixed at a value of $95 \%$ purity. The Aspen Plus gasifier model adjusted the flow of oxidant required such that the heat loss from the gasifier is less than or equal to one percent of the total heat input to the gasifier. Thus, the Aspen Plus model calculates the oxygen flow required obtaining the user specified gasifier outlet temperature and overcoming this heat loss. The coal slurry and oxidant feed are mixed and sent to the gasification unit model.

\section{Coal Slurry Preparation and Gasification}

Coal from the coal grinding system is continuously fed to the grinding mill. Grey water from waste water treatment facility is used for slurrying the coal feed. The coal slurry with a desired slurry concentration is pumped into the gasifier. In this section, the methodology used to model coal preparation is presented.

Coal is a type of non-conventional solid, and its composition has to be input in a form suitable to Aspen Plus. In Aspen Plus, the component attributes of coal are specified in three forms: (1) a proximate analysis, (2) an ultimate analysis, and (3) a sulfur analysis. Table 2, as an example, gives the typical compositions of Pittsburgh \#8 coal and its input values for the Aspen Plus model. Aspen Plus estimates the heat of coal combustion based on these tables unless the heat of combustion is provided directly.

Table 2. Coal composition and its corresponding input in Aspen Plus

\begin{tabular}{||l|l|l|l|l|l|l|l||}
\hline $\begin{array}{l}\text { Coal composition } \\
\text { (wet basis) }\end{array}$ & \multicolumn{4}{|l|}{ Ultimate } & \multicolumn{3}{l||}{ Sulfur Analysis } \\
\hline \hline Element & Value & Element & Value & Element & Value & Element & Value \\
\hline Ash & 7.24 & Moisture & 5.05 & Ash & 7.63 & Pyritic & 1.23 \\
\hline Carbon & 73.81 & Fixed Carbon & 49.855 & Carbon & 77.74 & Sulfate & 0 \\
\hline Hydrogen & 4.88 & Volatile Matter & 42.515 & Hydrogen & 5.14 & Organic & 1 \\
\hline Nitrogen & 1.42 & Ash & 7.63 & Nitrogen & 1.5 & & \\
\hline Chlorine & 0.06 & & & Chlorine & 0.06 & & \\
\hline Sulfur & 2.13 & & & Sulfur & 2.23 & & \\
\hline Oxygen & 5.41 & & & Oxygen & 5.7 & & \\
\hline \hline
\end{tabular}

Figure 11 illustrates the mass and heat flows in the coal slurry preparation process and gasification units. The coal slurry is compressed through a slurry pump. The gasification simulation calculates the Gibbs free energy of the coal. However, the Gibbs free energy of coal cannot be calculated because it is a non-conventional component with regard to Aspen Plus. Hence, a coal decomposition unit operation, which simulates a reactor with a known yield and does not require the reaction 
stoichiometry and kinetics, decomposes the coal into its constituent elements based on the ultimate composition analysis of coal.

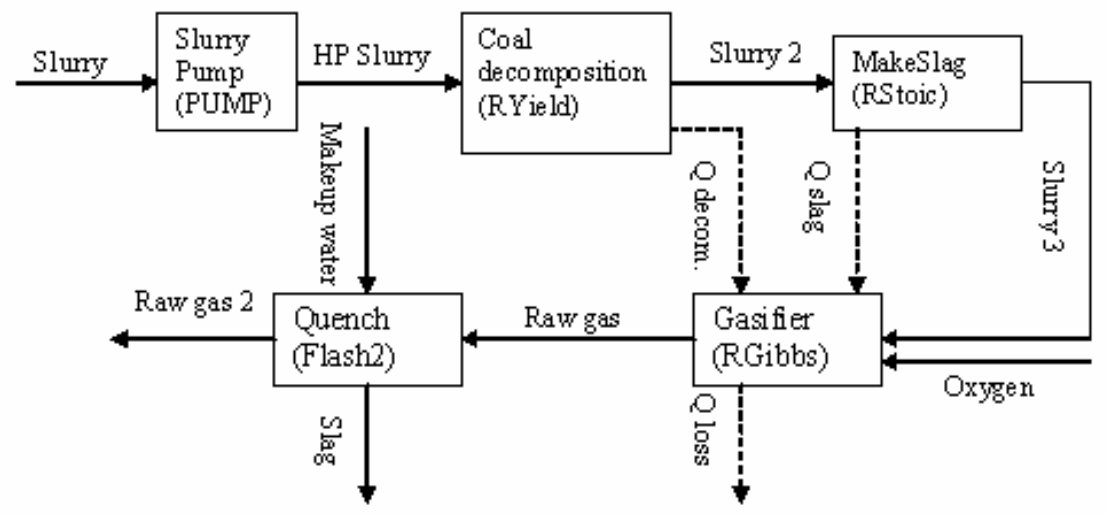

Figure 11. Slurry preparation and gasification flowsheet

The gasifier unit converts coal slurry into syngas. The coal slurry and oxygen from the air separation unit react in the gasifier at high temperature (approximately 2450 ${ }^{\circ} \mathrm{F}$ ), high pressure (approximately 620 psia in this study) and under the condition of insufficient oxygen to produce syngas. Chemical reactions and their approach temperatures ${ }^{2}$ modeled in this equilibrium gasifier reactor are shown in Table 3. The syngas produced consists primarily of hydrogen and carbon monoxide with lesser amounts of water vapor, carbon dioxide, hydrogen sulfide, methane, and nitrogen. Traces of carbonyl sulfide and ammonia are also formed.

Table 3. Approach temperatures used in Aspen Plus to characterize non-equilibrium ([Altafini, 2003; Zaimal, 2002, Zhu, 2003)

\begin{tabular}{|l|l||}
\hline Chemical Reaction & Approach Temperature \\
\hline \hline $\mathrm{C}+2 \mathrm{H}_{2} \rightarrow \mathrm{CH}_{4}$ & $300^{\circ} \mathrm{F}$ \\
\hline $\mathrm{C}+\mathrm{H}_{2} \mathrm{O} \rightarrow \mathrm{CO}+\mathrm{H}_{2}$ & \\
\hline $\mathrm{C}+\mathrm{O}_{2} \rightarrow \mathrm{CO}$ & \\
\hline $2 \mathrm{CO}+\mathrm{O}_{2} \rightarrow 2 \mathrm{CO}_{2}$ & $550^{\circ} \mathrm{F}$ \\
\hline $\mathrm{CH}_{4}+2 \mathrm{O}_{2} \rightarrow \mathrm{CO}_{2}+2 \mathrm{H}_{2} \mathrm{O}$ & $500^{\circ} \mathrm{F}$ \\
\hline $\mathrm{S}+\mathrm{H}_{2} \rightarrow \mathrm{H}_{2} \mathrm{~S}$ & $500^{\circ} \mathrm{F}$ \\
\hline $\mathrm{N}_{2}+3 \mathrm{H}_{2} \rightarrow 2 \mathrm{NH}_{3}$ & $500^{\circ} \mathrm{F}$ \\
\hline $\mathrm{CO}+\mathrm{H}_{2} \mathrm{~S} \rightarrow \mathrm{COS}+\mathrm{H}_{2}$ & $500^{\circ} \mathrm{F}$ \\
\hline $\mathrm{Cl}{ }_{2}+\mathrm{H}_{2} \rightarrow 2 \mathrm{HCl}$ & $300^{\circ} \mathrm{F}$ \\
\hline \hline
\end{tabular}

Ash present in the coal melts into slag. Hot syngas and molten slag from the gasifier flow downward into a quench chamber, which is filled with water, and is cooled into medium temperature (approximately $450^{\circ} \mathrm{F}$ ). The slag solidifies and flows to the bottom of the quench chamber.

Third, raw syngas and molten slag discharge from the reactor into the quench chamber, which is simulated by the quench unit. This unit performs rigorous vaporliquid equilibrium calculations to determine the thermal and phase conditions of

\footnotetext{
${ }^{2}$ The approach temperature is a pseudo-temperature used in Aspen Plus to adjust calculated equilibrium concentrations to actual (observed) values under non-equilibrium conditions.
} 
syngas saturation process. In this quench unit, molten slag is cooled down and separated from the syngas.

\section{Modeling Approaches}

\section{Computational Fluid Dynamics}

There are two main approaches to modeling a gasifier. A detailed Computational Fluid Dynamics (CFD) based approach involves solving two sets of coupled equations. The first set of equations consists of the gas-phase Eulerian equations of the flow, transport and energy in the gasifier (essentially the turbulent Navier-Stokes equations modified for volatile combustion). The second set of equations consists of the discrete particle equations modeled in a Lagrangian frame. These equations involve particle's heating, devolatilization and char combustion. These two sets of equations are solved simultaneously with an appropriately defined grid. This approach is useful if one is interested in obtaining the temperature profiles in the gasifier, volatile combustion contours, kinetics of pollutant formation and carbon conversion. This approach is extremely time consuming and costly; the setup and run time of a typical simulation can take anywhere from days to weeks. This makes it difficult to identify and explore the critical variables and do sensitivity analysis.

\section{Chemical Equilibrium}

A second approach is to use the basic thermodynamics of carbon/char gasification based on a chemical equilibrium approach. This is the approach implemented in ASPEN. It can be accomplished much faster than CFD and hence is more convenient for sensitivity analysis. This approach is appropriate if one is interested only in the syngas composition and heating value, which is the primary need of the Integrated Environment Control Model (IECM). Thus, we have taken this approach in modeling the gasifier.

\section{Input Parameters}

DOE's National Energy Technologies Laboratory (NETL) previously developed flowsheets for IGCC power plants in ASPEN for four different types of gasifiers: Shell, KRW, GE (previously Texaco) and E-Gas (previously Destec), all fed with nominal Illinois \# 6 coal characteristics. These models were used to develop suitable data output tables for seven different types of coals:

4. Appalachian (Low Sulfur),

5. Appalachian (Medium Sulfur),

6. Illinois \# 6,

7. North Dakota (Lignite),

8. WPC Utah (Bituminous),

9. Wyoming (PRB), and

10. Wyodak.

For each gasifier, there are several key design variables that are of interest such as temperature, pressure, oxidant flow rate, carbon conversion and the relative amounts of coal, oxidant and steam or water inputs to the gasifier. Perturbations in these quantities have an impact on the resulting syngas composition and heating value. We used NETL's ASPEN models to reflect this functionality by incorporating a stochastic variation of key gasifier variables as explained below. 
The overall framework of the IECM for IGCC power plants is carried out as follows:

1. The user selects a gasifier technology from the four options mentioned above.

2. The user chooses a coal variety from several available options.

3. For each gasifier, there are several process variables that the user can vary within a specified range about the nominal (NETL specified) default value as will be discussed in a following section.

4. The model then calculates the composition and heating value of the syngas corresponding to the coal type and the process variables defined above. The syngas may consist of $\mathrm{CO}, \mathrm{H}_{2}, \mathrm{CO}_{2}, \mathrm{CH}_{4}, \mathrm{H}_{2} \mathrm{O}, \mathrm{N}_{2}, \mathrm{NH}_{3}$, $\mathrm{COS}, \mathrm{Ar}$, and $\mathrm{H}_{2} \mathrm{~S}$.

5. The syngas composition along with user-specified plant size and other parameters is then utilized for mass and energy balance calculations for the overall plant.

As shown in Figure 10, an external model of the different gasifiers was used in Aspen Plus. A stochastic block developed at Carnegie Mellon University was added to the model to allow the model to vary parameters automatically and produce multiple output tables. Figure 12 shows the flow diagram for these simulations.

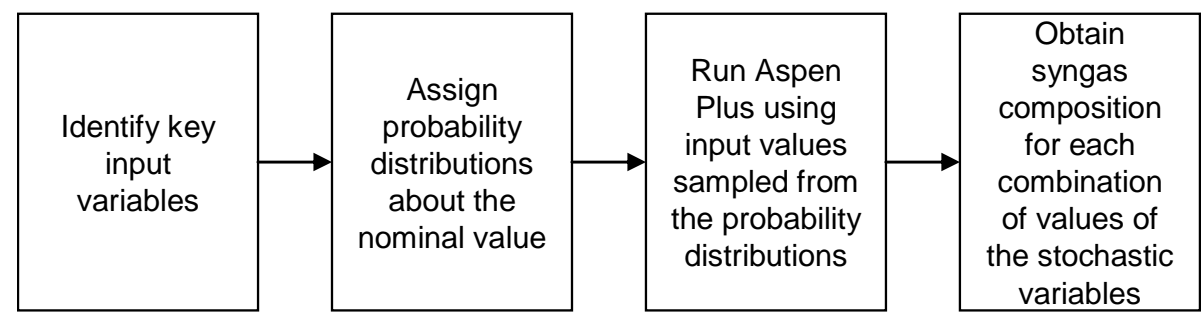

Figure 12. Flow diagram to generate data tables from Aspen Plus simulations

\section{Running the Simulation}

Running the Aspen Plus simulation involves the following steps:

1. First, a few key input variables are identified, which are critical in modeling the process and whose values are likely to fluctuate within a range, such as gasifier temperature, steam flow rate, carbon lost in slag etc.

2. The user then specifies a probability distribution for each of the above variables. In this case, a uniform distribution was used to reflect a range of values (typically $\pm 10 \%$ ) around the nominal value. The distributions could be uniform, normal, logarithmic or lognormal etc. The user also decides on the number of samples (in this case 100 iterations).

3. Each of the probability distributions is sampled to obtain one set of random variables corresponding to the uncertain variables. The sampling technique used was Latin Hypercube Sampling.

4. The random variables are then propagated through the Aspen Plus flowsheet to obtain the syngas composition or mole fractions of the various constituents.

5. The above process is repeated for the chosen number of samples.

6. The above procedure was then repeated for different coal compositions. 


\section{Syngas Composition}

In this section we discuss the two main options for modeling a coal gasifier to quantify the syngas being produced and justify the approach taken in our model (IECM).

\section{Response Surface Models}

The output of ASPEN is used to obtain the partition factors. The partition factor of an element $i$ into a syngas constituent $j$ is defined as the fraction of the total element $i$ which is contained in $\mathrm{j}$. For instance, partition factor of $\mathrm{C}$ into $\mathrm{CO}$ is obtained as follows: First we consider the total mass of carbon entering the gasifier. (This is obtained from the coal flow rate and the coal composition data). Then we obtain the total mass of carbon contained in the $\mathrm{CO}$ exiting the gasifier. The ratio of the latter to the former gives the partition factor of $\mathrm{C}$ into $\mathrm{CO}$. Similarly we define the partition factors of $\mathrm{H}_{2}$ into $\mathrm{H}_{2} \mathrm{O}$. We obtain the partition factor for each of the possible option as follows: $\mathrm{C}$ to $\mathrm{CO}, \mathrm{C}$ to $\mathrm{CO}_{2}, \mathrm{C}$ to $\mathrm{CH}_{4}, \mathrm{~S}$ to $\mathrm{H}_{2} \mathrm{~S}, \mathrm{~S}$ to $\mathrm{COS}, \mathrm{H}$ to $\mathrm{H}_{2}, \mathrm{H}$ to $\mathrm{H}_{2} \mathrm{O}$ and $\mathrm{H}$ to $\mathrm{NH}_{3}$. The above set of partition factors completely specifies the composition of the syngas if the inlet flow rates are completely known. We obtain these partition factors for each combination of the random variables, hence for a number of samples. The partition factors are the independent variables and the gasifier process variables are the dependent variables. A linear regression is fitted to obtain each of the partition factors as a function of the uncertain process variables. These regression models can then implemented in IECM.

NOTE: This method was implemented and found to be numerically unstable. Hence, the data output table approach below was used.

\section{Data Output Tables}

In this approach, we take all the outputs generated by the stochastic ASPEN flowsheet and select discrete data points of the syngas composition by the component to build up a table, which is then used in the IECM. The carbon content in the slag and the gasifier temperature were the two variables varied in this approach. We selected 3 discrete values for each variable: two extreme points of the range and the mid point nominal value. Therefore the data table will have all possible combinations of the discrete values of all these variables.

The data for the four bituminous coals available in the IECM are shown in Table 4, Table 5, Table 6, and Table 7. Although sub-bituminous and lignite coals can successfully be gasified in a GE entrained-flow gasifier, the optimal temperature is much different, the efficiency is much lower, and the water content into the gasifier is much harder to control. Due to these issues, non-bituminous coal runs were not included in the IECM. 
Table 4. Volume fraction of syngas components exiting the gasifier using the Appalachian

(Low Sulfur) coal as a function of carbon in slag and gasifier temperature.

\begin{tabular}{|c|c|c|c|c|c|c|c|c|c|}
\hline \multirow{2}{*}{$\begin{array}{l}\text { Carbon } \\
\text { in Slag } \\
\text { Temp. (F) }\end{array}$} & \multicolumn{3}{|c|}{$1 \%$} & \multicolumn{3}{|c|}{$3 \%$} & \multicolumn{3}{|c|}{$5 \%$} \\
\hline & 2350 & 2450 & 2550 & 2350 & 2450 & 2550 & 2350 & 2450 & 2550 \\
\hline $\mathrm{H}_{2}$ & 0.35306 & 0.35503 & 0.35724 & 0.35360 & 0.35488 & 0.35608 & 0.34656 & 0.34722 & 0.34779 \\
\hline $\mathrm{CO}$ & 0.39475 & 0.38761 & 0.37917 & 0.40142 & 0.39328 & 0.38505 & 0.40458 & 0.39659 & 0.38850 \\
\hline $\mathrm{CO}_{2}$ & 0.13889 & 0.14155 & 0.14463 & 0.13191 & 0.13495 & 0.13797 & 0.12824 & 0.13119 & 0.13413 \\
\hline $\mathrm{H}_{2} \mathrm{O}$ & 0.07556 & 0.07886 & 0.08289 & 0.08674 & 0.09090 & 0.09525 & 0.09853 & 0.10302 & 0.10770 \\
\hline $\mathrm{N}_{2}$ & 0.00883 & 0.00886 & 0.00890 & 0.00883 & 0.00887 & 0.00891 & 0.00889 & 0.00893 & 0.00897 \\
\hline $\mathrm{CH}_{4}$ & 0.01878 & 0.01796 & 0.01703 & 0.00727 & 0.00687 & 0.00648 & 0.00282 & 0.00266 & 0.00250 \\
\hline $\mathrm{C}_{2} \mathrm{H}_{6}$ & - & - & - & - & - & - & - & - & - \\
\hline $\mathrm{C}_{3} \mathrm{H}_{8}$ & - & - & - & - & - & - & - & - & - \\
\hline $\mathrm{H}_{2} \mathrm{~S}$ & 0.00178 & 0.00180 & 0.00182 & 0.00174 & 0.00176 & 0.00178 & 0.00172 & 0.00174 & 0.00176 \\
\hline $\mathrm{NH}_{3}$ & 0.00011 & 0.00011 & 0.00012 & 0.00009 & 0.00009 & 0.00009 & 0.00007 & 0.00007 & 0.00007 \\
\hline $\mathrm{COS}$ & 0.00009 & 0.00009 & 0.00009 & 0.00009 & 0.00009 & 0.00009 & 0.00009 & 0.00009 & 0.00009 \\
\hline $\mathrm{HCl}$ & 0.00018 & 0.00019 & 0.00019 & 0.00018 & 0.00018 & 0.00018 & 0.00018 & 0.00018 & 0.00018 \\
\hline $\mathrm{Ar}$ & 0.00795 & 0.00794 & 0.00792 & 0.00814 & 0.00813 & 0.00811 & 0.00832 & 0.00831 & 0.00830 \\
\hline $\mathrm{O}_{2}$ & - & - & - & - & - & - & - & - & - \\
\hline
\end{tabular}

Table 5. Volume fraction of syngas components exiting the gasifier using the Appalachian (Medium Sulfur) coal as a function of carbon in slag and gasifier temperature.

\begin{tabular}{|c|c|c|c|c|c|c|c|c|c|}
\hline \multirow{2}{*}{\begin{tabular}{||l} 
Carbon \\
in Slag
\end{tabular}} & \multicolumn{3}{|c|}{$1 \%$} & \multicolumn{3}{|c|}{$3 \%$} & \multicolumn{3}{|c|}{$5 \%$} \\
\hline & 2350 & 2450 & 2550 & 2350 & 2450 & 2550 & 2350 & 2450 & 2550 \\
\hline $\mathrm{H}_{2}$ & 0.35306 & 0.35503 & 0.35724 & 0.35360 & 0.35488 & 0.35608 & 0.34656 & 0.34722 & 0.34779 \\
\hline $\mathrm{CO}$ & 0.39475 & 0.38761 & 0.37917 & 0.40142 & 0.39328 & 0.38505 & 0.40458 & 0.39659 & 0.38850 \\
\hline $\mathrm{CO}_{2}$ & 0.13889 & 0.14155 & 0.14463 & 0.13191 & 0.13495 & 0.13797 & 0.12824 & 0.13119 & 0.13413 \\
\hline $\mathrm{H}_{2} \mathrm{O}$ & 0.07556 & 0.07886 & 0.08289 & 0.08674 & 0.09090 & 0.09525 & 0.09853 & 0.10302 & 0.10770 \\
\hline $\mathrm{N}_{2}$ & 0.00883 & 0.00886 & 0.00890 & 0.00883 & 0.00887 & 0.00891 & 0.00889 & 0.00893 & 0.00897 \\
\hline $\mathrm{CH}_{4}$ & 0.01878 & 0.01796 & 0.01703 & 0.00727 & 0.00687 & 0.00648 & 0.00282 & 0.00266 & 0.00250 \\
\hline $\mathrm{C}_{2} \mathrm{H}_{6}$ & - & - & - & - & - & - & - & - & - \\
\hline $\mathrm{C}_{3} \mathrm{H}_{8}$ & - & - & - & - & - & - & - & - & - \\
\hline $\mathrm{H}_{2} \mathrm{~S}$ & 0.00178 & 0.00180 & 0.00182 & 0.00174 & 0.00176 & 0.00178 & 0.00172 & 0.00174 & 0.00176 \\
\hline $\mathrm{NH}_{3}$ & 0.00011 & 0.00011 & 0.00012 & 0.00009 & 0.00009 & 0.00009 & 0.00007 & 0.00007 & 0.00007 \\
\hline COS & 0.00009 & 0.00009 & 0.00009 & 0.00009 & 0.00009 & 0.00009 & 0.00009 & 0.00009 & 0.00009 \\
\hline $\mathrm{HCl}$ & 0.00018 & 0.00019 & 0.00019 & 0.00018 & 0.00018 & 0.00018 & 0.00018 & 0.00018 & 0.00018 \\
\hline $\mathrm{Ar}$ & 0.00795 & 0.00794 & 0.00792 & 0.00814 & 0.00813 & 0.00811 & 0.00832 & 0.00831 & 0.00830 \\
\hline $\mathrm{O}_{2}$ & - & - & - & - & - & - & - & - & - \\
\hline
\end{tabular}


Table 6. Volume fraction of syngas components exiting the gasifier using the Illinois \#6 coal as a function of carbon in slag and gasifier temperature.

\begin{tabular}{|l|l|l|l|l|l|l|l|l|l||}
\hline $\begin{array}{l}\text { Carbon } \\
\text { in Slag }\end{array}$ & \multicolumn{3}{|c|}{$1 \%$} & \multicolumn{3}{|c|}{$3 \%$} & \multicolumn{3}{c||}{$5 \%$} \\
\hline \hline Temp. (F) & 2350 & 2450 & 2550 & 2350 & 2450 & 2550 & 2350 & 2450 & 2550 \\
\hline \hline $\mathrm{H}_{2}$ & 0.33966 & 0.33996 & 0.34011 & 0.32948 & 0.32915 & 0.32878 & 0.31631 & 0.31558 & 0.31487 \\
\hline $\mathrm{CO}$ & 0.30680 & 0.29917 & 0.29264 & 0.31395 & 0.30638 & 0.29989 & 0.31888 & 0.31137 & 0.30493 \\
\hline $\mathrm{CO}_{2}$ & 0.19004 & 0.19257 & 0.19469 & 0.18268 & 0.18520 & 0.18732 & 0.17757 & 0.18005 & 0.18212 \\
\hline $\mathrm{H}_{2} \mathrm{O}$ & 0.12800 & 0.13314 & 0.13767 & 0.14314 & 0.14856 & 0.15334 & 0.15802 & 0.16371 & 0.16871 \\
\hline $\mathrm{N}_{2}$ & 0.00854 & 0.00857 & 0.00860 & 0.00861 & 0.00864 & 0.00868 & 0.00870 & 0.00874 & 0.00877 \\
\hline $\mathrm{CH}_{4}$ & 0.00767 & 0.00721 & 0.00683 & 0.00279 & 0.00261 & 0.00247 & 0.00105 & 0.00099 & 0.00093 \\
\hline $\mathrm{C}_{2} \mathrm{H}_{6}$ & - & - & - & - & - & - & - & - & - \\
\hline $\mathrm{C}_{3} \mathrm{H}_{8}$ & - & - & - & - & - & - & - & - & - \\
\hline $\mathrm{H}_{2} \mathrm{~S}$ & 0.00976 & 0.00986 & 0.00995 & 0.00965 & 0.00975 & 0.00984 & 0.00959 & 0.00970 & 0.00979 \\
\hline $\mathrm{NH}_{3}$ & 0.00010 & 0.00010 & 0.00011 & 0.00008 & 0.00008 & 0.00008 & 0.00006 & 0.00006 & 0.00006 \\
\hline $\mathrm{COS}$ & 0.00040 & 0.00039 & 0.00039 & 0.00041 & 0.00041 & 0.00040 & 0.00043 & 0.00043 & 0.00042 \\
\hline $\mathrm{HCl}$ & 0.00048 & 0.00049 & 0.00049 & 0.00048 & 0.00048 & 0.00048 & 0.00047 & 0.00048 & 0.00048 \\
\hline $\mathrm{Ar}$ & 0.00854 & 0.00853 & 0.00853 & 0.00873 & 0.00872 & 0.00872 & 0.00892 & 0.00891 & 0.00891 \\
\hline $\mathrm{O}_{2}$ & - & - & - & - & - & - & - & - & - \\
\hline \hline
\end{tabular}

Table 7. Volume fraction of syngas components exiting the gasifier using the WPC Utah coal as a function of carbon in slag and gasifier temperature.

\begin{tabular}{|l|l|l|l|l|l|l|l|l|l||}
\hline $\begin{array}{l}\text { Carbon } \\
\text { in Slag }\end{array}$ & \multicolumn{3}{|c|}{$1 \%$} & \multicolumn{3}{c|}{$3 \%$} & \multicolumn{3}{c||}{$5 \%$} \\
\hline \hline Temp. (F) & 2350 & 2450 & 2550 & 2350 & 2450 & 2550 & 2350 & 2450 & 2550 \\
\hline \hline $\mathrm{H}_{2}$ & 0.32304 & 0.32257 & 0.32195 & 0.30986 & 0.30888 & 0.30777 & 0.30984 & 0.29373 & 0.29228 \\
\hline $\mathrm{CO}$ & 0.27961 & 0.27206 & 0.26446 & 0.28704 & 0.27950 & 0.27191 & 0.28701 & 0.28492 & 0.27736 \\
\hline $\mathrm{CO}_{2}$ & 0.21830 & 0.22077 & 0.22319 & 0.21068 & 0.21317 & 0.21561 & 0.21071 & 0.20759 & 0.21001 \\
\hline $\mathrm{H}_{2} \mathrm{O}$ & 0.15346 & 0.15928 & 0.16534 & 0.16983 & 0.17591 & 0.18222 & 0.16985 & 0.19200 & 0.19856 \\
\hline $\mathrm{N}_{2}$ & 0.00896 & 0.00900 & 0.00904 & 0.00904 & 0.00909 & 0.00913 & 0.00904 & 0.00918 & 0.00923 \\
\hline $\mathrm{CH}_{4}$ & 0.00502 & 0.00468 & 0.00436 & 0.00179 & 0.00166 & 0.00155 & 0.00179 & 0.00062 & 0.00058 \\
\hline $\mathrm{C}_{2} \mathrm{H}_{6}$ & - & - & - & - & - & - & - & - & - \\
\hline $\mathrm{C}_{3} \mathrm{H}_{8}$ & - & - & - & - & - & - & - & - & - \\
\hline $\mathrm{H}_{2} \mathrm{~S}$ & 0.00165 & 0.00167 & 0.00169 & 0.00164 & 0.00166 & 0.00168 & 0.00164 & 0.00165 & 0.00167 \\
\hline $\mathrm{NH}_{3}$ & 0.00010 & 0.00010 & 0.00010 & 0.00008 & 0.00008 & 0.00007 & 0.00008 & 0.00006 & 0.00006 \\
\hline $\mathrm{COS}$ & 0.00006 & 0.00006 & 0.00006 & 0.00007 & 0.00007 & 0.00007 & 0.00007 & 0.00007 & 0.00007 \\
\hline $\mathrm{HCl}$ & 0.00003 & 0.00003 & 0.00003 & 0.00003 & 0.00003 & 0.00003 & 0.00003 & 0.00003 & 0.00003 \\
\hline $\mathrm{Ar}$ & 0.00977 & 0.00977 & 0.00978 & 0.00995 & 0.00996 & 0.00997 & 0.00995 & 0.01015 & 0.01017 \\
\hline $\mathrm{O}_{2}$ & - & - & - & - & - & - & - & - & - \\
\hline \hline
\end{tabular}




\section{Energy Use}

\section{Coal Handling}

The GE gasifier system uses a coal slurry with typically 66.5 weight percent of solids as feed to the gasifier. Coal handling involves coal unloading, stacking, reclamation, and conveying equipment followed by three operating and one spare train of wet grinding equipment.

To estimate the auxiliary power requirements of the coal handling unit, a predictive model was developed by Rocha and Frey (1997) using 14 data points (one column) obtained from the sources listed in Table 8 . The coal feed rate was chosen as the independent variable for development of an auxiliary power model. Two models were selected for consideration: power consumed per slurry train vs. coal feed rate per slurry train; and total power consumed by the slurry preparation process area vs. total coal flow to slurry preparation. The power consumed per slurry train vs. coal feed rate per slurry train produced a standard error of $1,183 \mathrm{~kW}$ per train and a $\mathrm{R}^{2}$ of 0.716 , whereas the standard error for the other model is $2,949 \mathrm{~kW}$ for the entire plant and the $\mathrm{R}^{2}$ value is 0.807 . Because of the higher $\mathrm{R}^{2}$ value, the latter model was selected.

Table 8. Summary of Design Studies used for Coal Handling and Slurry Preparation Auxiliary Power Model Development

\begin{tabular}{||l|l|l|l|l|l|l||}
\hline $\begin{array}{l}\text { Report } \\
\text { No. }\end{array}$ & Company & Authors & Year & Sponsor & Gasifier & Coal \\
\hline \hline AP-3109 & $\begin{array}{l}\text { Synthetic Fuels } \\
\text { Associates }\end{array}$ & Simbeck et al. & 1983 & EPRI & Texaco & Illinois \#6 \\
\hline AP-3486 & Fluor Engineers & Matchak et al. & 1984 & EPRI & Texaco & Illinois \#6 \\
\hline AP-4509 & $\begin{array}{l}\text { Energy Conversion } \\
\text { Systems }\end{array}$ & $\begin{array}{l}\text { McNamee and } \\
\text { White }\end{array}$ & 1986 & EPRI & Texaco & $\begin{array}{l}\text { Illinois \#6 } \\
\text { Lignite }\end{array}$ \\
\hline AP-5950 & Bechtel Group & Pietruszkiewicz & 1988 & EPRI & Texaco & Illinois \#6 \\
\hline GS-6904 & Fluor Daniel & $\begin{array}{l}\text { Hager and } \\
\text { Heaven }\end{array}$ & 1990 & EPRI & Dow & $\begin{array}{l}\text { Eastern } \\
\text { Bituminous }\end{array}$ \\
\hline $\begin{array}{l}\text { TR- } \\
100319\end{array}$ & Fluor Daniel & $\begin{array}{l}\text { Smith and } \\
\text { Heaven }\end{array}$ & 1991 & EPRI & Destec & Illinois \#6 \\
\hline $\begin{array}{l}\text { MRL } \\
\text { Texaco }\end{array}$ & $\begin{array}{l}\text { Mentebello } \\
\text { Texach Lab, }\end{array}$ & Robin et al. & 1991 & DOE & Texaco & Pittsburgh \#8 \\
\hline
\end{tabular}

$\mathrm{W}_{\mathrm{e}, \mathrm{CH}}=1.04 \mathrm{~m}_{\text {cf, G. } \mathrm{i}} \quad \mathrm{R}^{2}=0.807$

where,

$$
3,300 \leq m_{c f, G . i} \leq 20,000 \text { tons/day (as received) }
$$

The model and data are shown in Figure 13. The model fit is greatly influenced by the data point that is at 6,500 tons/day gasifier coal feed rate (McNamee and White, 1986). A much better fit could occur if this value was removed from the power consumption model consideration. The data point was not removed because no reason could be found to exclude the value from the development of the power consumption model. 


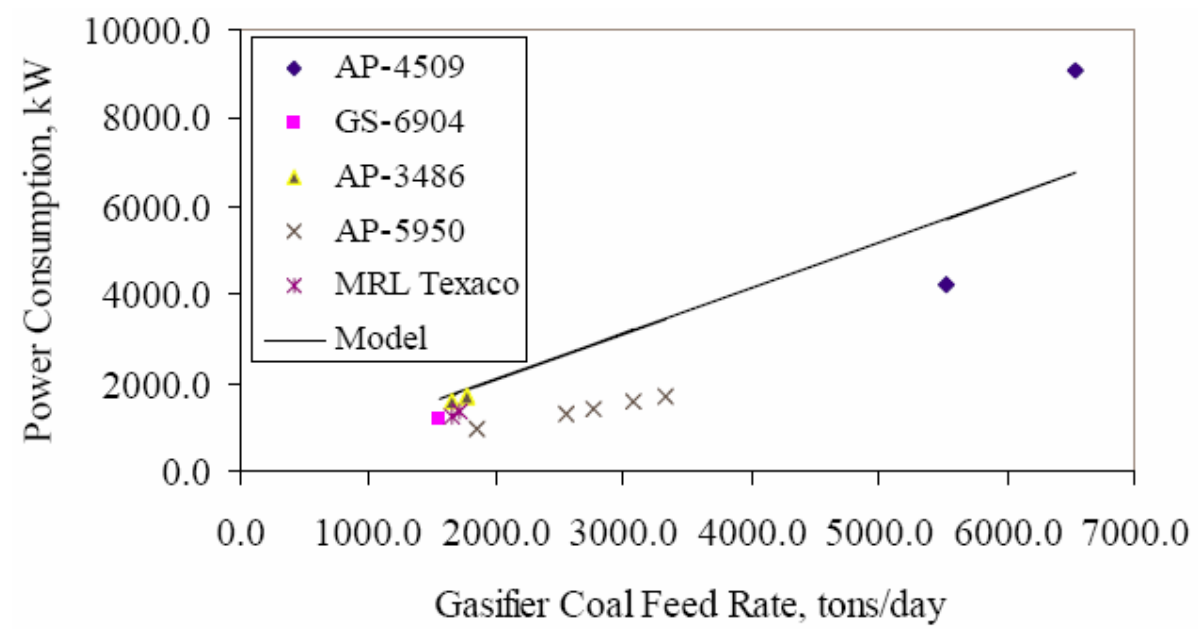

Figure 13. Power Requirement for the Coal Slurry Preparation Unit

\section{Gasification}

Only two data points were available for the determination of the auxiliary power consumption model for the gasification section based upon water quench high temperature syngas cooling. The two data points were obtained from studies by Matchak et al. (1984) and Robin et al. (1993). A linear model with zero intercept was developed based upon the coal flow rate (as-received basis) per gasifier train and is shown in Figure 14. The auxiliary model developed has a standard error of $16 \mathrm{~kW}$ for the entire plant and $\mathrm{R}^{2}$ of 0.970 . The $\mathrm{R}^{2}$ variable is very high because only two data points were available.

$\mathrm{W}_{\mathrm{e}, \mathrm{G}}=0.111 \mathrm{~N}_{\mathrm{T}, \mathrm{G}}\left(\mathrm{m}_{\mathrm{cf}, \mathrm{i}} / \mathrm{N}_{\mathrm{O}, \mathrm{G}}\right)$

$\mathrm{R}^{2}=0.970$

where,

$1300 \leq \mathrm{m}_{\mathrm{cf}, \mathrm{G}, \mathrm{i}} \leq 2400$ tons/day per train (as received)

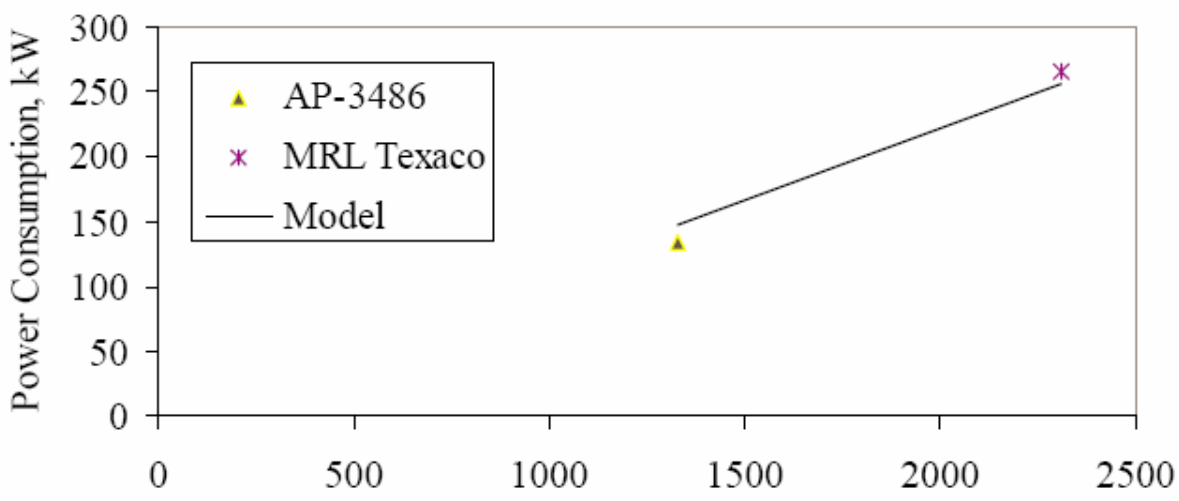

Gasifier Coal Feed Rate, tons/day (as-received basis)

Figure 14. Power Requirement for the Gasification Section for Total Quench 


\section{Low Temperature Gas Cooling}

The auxiliary power consumption model for the low temperature gas cooling (LTGC) section was developed using a single data point from the study by Matchak et al. (1984) and is given in MW by:

$\mathrm{W}_{\mathrm{e}, \mathrm{LT}}=3.211 \times 10^{-5} \mathrm{~m}_{\mathrm{SN}, \mathrm{LT}, \mathrm{O}}$

\section{Process Condensate Treatment}

The process condensate treatment plant has the following auxiliary power consumption model, which is developed for the present GE gasification system using a single data point from the study Matchat et al., (1984) and is given in MW by the equation:

$\mathrm{W}_{\mathrm{e}, \mathrm{PC}}=9.289 \times 10^{-7} \mathrm{~m}_{\mathrm{S}, \mathrm{BD}}$

\section{GE Gasifier Cost Model}

\section{Capital Cost}

This section documents the cost model developed for the GE gasifier-based IGCC plant with total quench high temperature gas cooling. New direct capital cost models for major process sections are presented here. For the purpose of estimating the direct capital costs of the plant, the gasifier is divided into four process areas. The direct cost of a process section can be adjusted for other years using the appropriate cost index. The capital costs are provided in December 2000 dollars and can be scaled to other years with the Chemical Engineering Plant Cost Index.

\section{Coal Handling}

Coal handling involves unloading coal from a train, storing the coal, moving the coal to the grinding mills, and feeding the gasifier with positive displacement pumps. A typical coal handling section contains one operating train and no spare train. A train consists of a bottom dump railroad car unloading hopper, vibrating feeders, conveyors, belt scale, magnetic separator, sampling system, deal coal storage, stacker, reclaimer, as well as some of type of dust suppression system. Two studies (McNamee and White, 1986; Matchak et al., 1984) assumed a double boom stacker and bucket wheel reclaimer system. The studies by Smith and Heaven (1992) and Hager and Heaven (1990) assumed a combined stacker reclaimer. Pietruszkiewicz et al. (1988) specified conveyors to perform the stacking operation and a rotary plow feeder for the reclaim system.

Slurry preparation trains typically have one to five operating trains with one spare train. The typical train consists of vibrating feeders, conveyors, belt scale, rod mills, storage tanks, and positive displacement pumps to feed the gasifiers. All of the equipment for both the coal handling and the slurry feed are commercially available. This typical train design is assumed in two reports (McNamee and White, 1986; Matchak et al., 1984).

A regression model was developed for the direct capital cost of coal handling and slurry preparation using the data collected for possible independent variables affecting direct capital cost. Figure 15 shows the data points. A regression was developed, based on the equation developed by Frey (2001) and revised with additional data (Chase 2003, IEA 2000, Foster 2003, and Brdar 2003). Coal feed rate to gasifier on as-received basis is the most common and easily available independent variable. The direct cost model for the coal handling is based upon the overall flow 
to the plant rather than on per train basis. This is because a better value of $\mathrm{R}^{2}$ was obtained in the former case. The regression model derived is:

$$
D C_{C H}=9.92 m_{c f, G, i} \quad \mathrm{R}^{2}=0.8
$$

where,

$$
2,800 \leq \mathrm{m}_{\mathrm{cf}, \mathrm{G}, \mathrm{i}} \leq 25,000 \text { tons/day }
$$

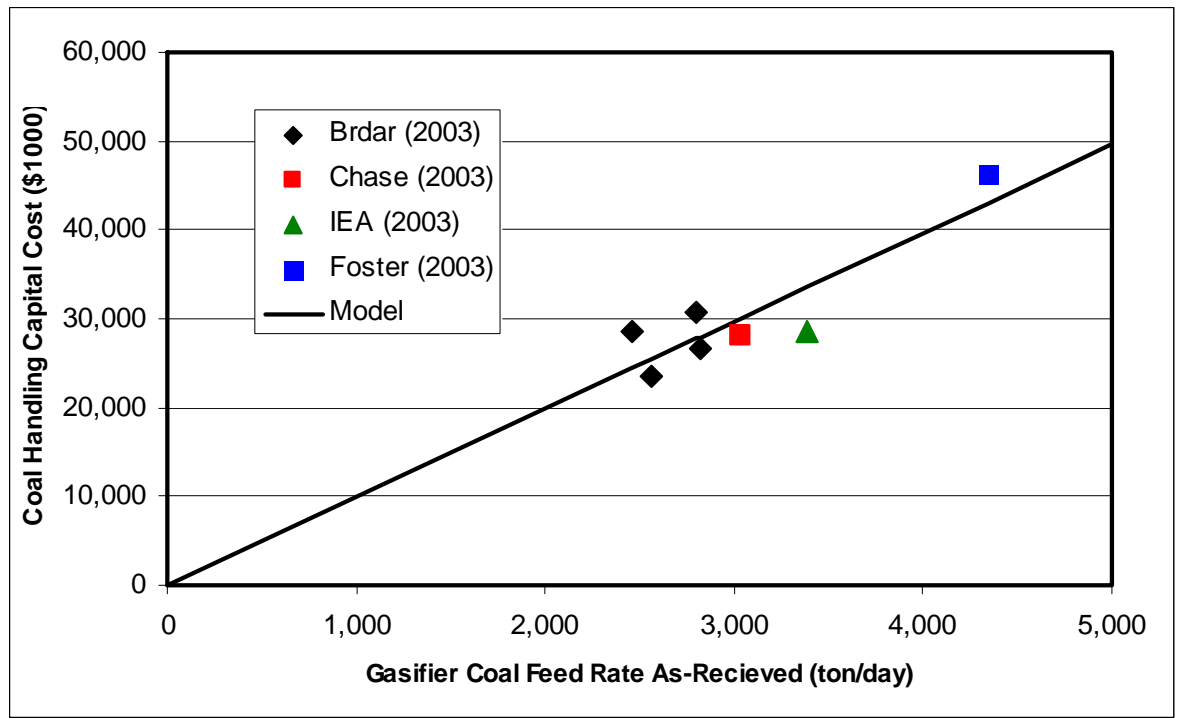

Figure 15. Direct Cost for the Coal Handling and Slurry Preparation Process (Cost Year = 2000)

\section{Gasification}

The GE gasification section of an IGCC plant contains gas scrubbing, gas cooling, slag handling, and ash handling. For IGCC plants of $400 \mathrm{MW}$ to $1100 \mathrm{MW}$, typically four to eight operating gasification trains are used along with one spare train (Matchak et al., 1984). The direct capital cost model is a function of the asreceived coal flow rate. The data is shown in Figure 16. The regression as shown in Equation (22) is based on data from IEA (2003) and Chase (2003).

$D C_{G}=15.88 * M_{C G, G, i}{ }^{0.943}$

where,

$$
1,300 \leq \mathrm{m}_{\mathrm{cf}, \mathrm{G}, \mathrm{i}} \leq 3,300 \text { tons/day }
$$




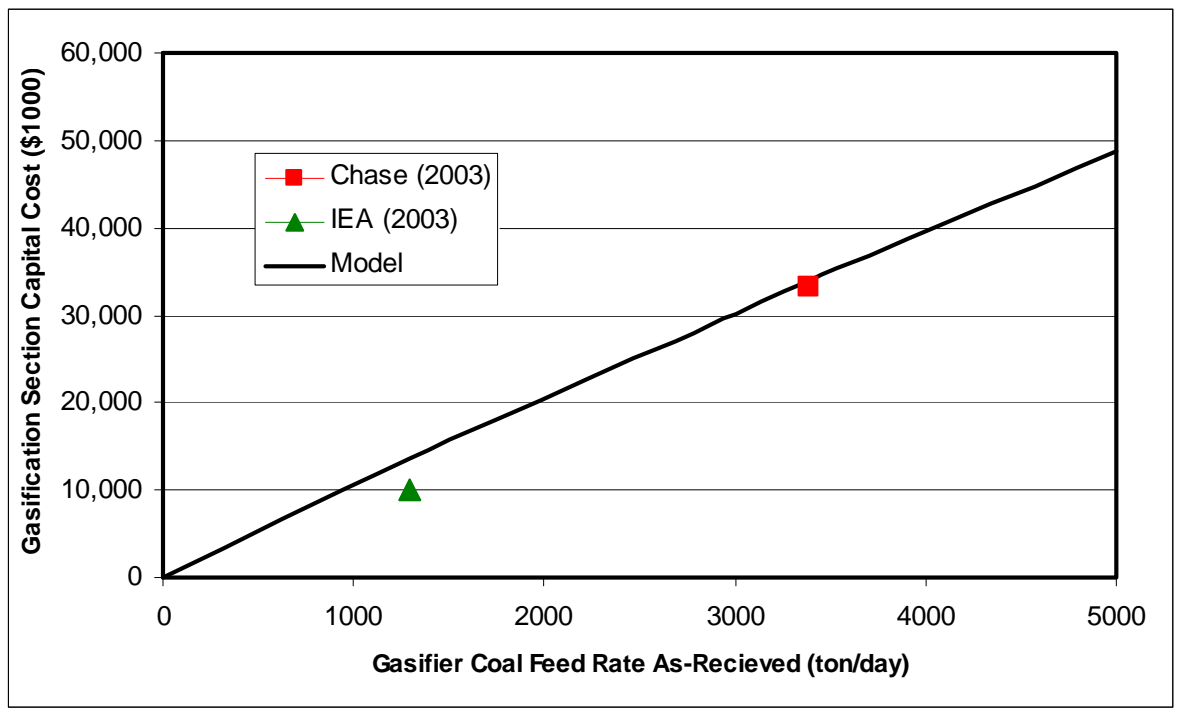

Figure 16. Direct Cost for Total Quench Cooled Gasifier (Cost Year = 2000)

\section{Low Temperature Gas Cooling}

In IGCC systems featuring "cold gas cleanup," the syngas is cooled to about $100 \mathrm{~F}$ before entering the acid gas removal plant section. Additionally, in many IGCC designs, moisture is added to the fuel gas in a fuel gas saturator to reduce $\mathrm{NO}_{\mathrm{x}}$ formation during syngas combustion in the gas turbine.

The low temperature gas cooling section consists primarily of a series of shell and tube heat exchangers. The fuel gas saturator is a vertical column with sieve trays in which fuel gas is contacted counter-currently with hot water flowing downward.

Data for this particular plant section design was available from three studies (Chase 2003, IEA 2003, and Foster 2003). Although all "cold gas" IGCC systems have a fuel gas cooling process area, not all IGCC system designs are based on fuel gas moisturization. Alternatively, many are based on direct steam injection into the gas turbine. Equation (23) shows the regression results from the data. See Figure 17 for the data and regression results.

$$
D C_{L T}=0.0156 N_{O, L T}\left(\frac{M_{s y n, L T, o}}{N_{O, L T}}\right)^{1.0} \quad \quad \mathrm{R}^{2}=0.99
$$

where,

$$
650,000 \leq\left(\frac{M_{s y n, L T, o}}{N_{O, L T}}\right) \leq 1,300,000 \mathrm{lb} / \mathrm{hr}
$$




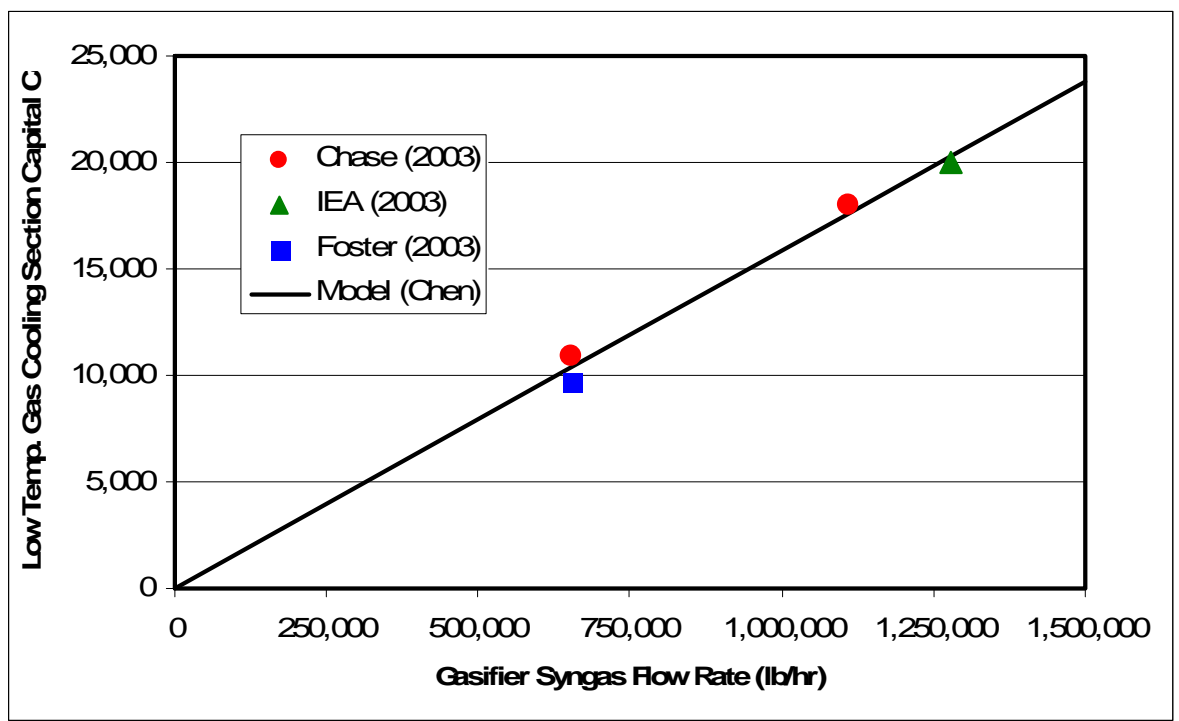

Figure 17. Direct Cost for Low Temperature Gas Cooling (Cost Year = 2000)

\section{Process Condensate Treatment}

The process condensate treatment section is used to treat blowdown from the particulate scrubber and process condensate from gas cooling (Fluor, 1983b; 1985). These streams contain ammonia, carbon dioxide, and hydrogen sulfide, and the scrubber blowdown also has high chlorides content. The blowdown and condensate stream are treated in separate strippers. The overhead vapor streams from both strippers are cooled in air-cooled heat exchangers and then they flow through knockout drums prior to feed to the Claus plant sulfur furnace. The stripped bottoms product from the blowdown water stripper is cooled by the incoming process condensate water and then sent to a water treatment plant for biological treatment prior to flow to the cooling tower. The bottoms from the process condensate water stripper are sent as make up to the gas scrubbing unit.

Because the treated process condensate is used as make-up to the gas scrubbing unit, and because blowdown from the gas scrubbing unit is the larger of the flow streams entering the process condensate treatment section, it is expected that process condensate treatment direct cost will depend primarily on the scrubber blowdown flow rate. Because only two cost studies were identified with similar designs and sufficient detail for regression analysis, a single variate regression analysis was used and scaled to $2000 \$$ :

$D C_{P C}=9814\left(\frac{m_{S B D}}{300000}\right)^{0.6}$ 


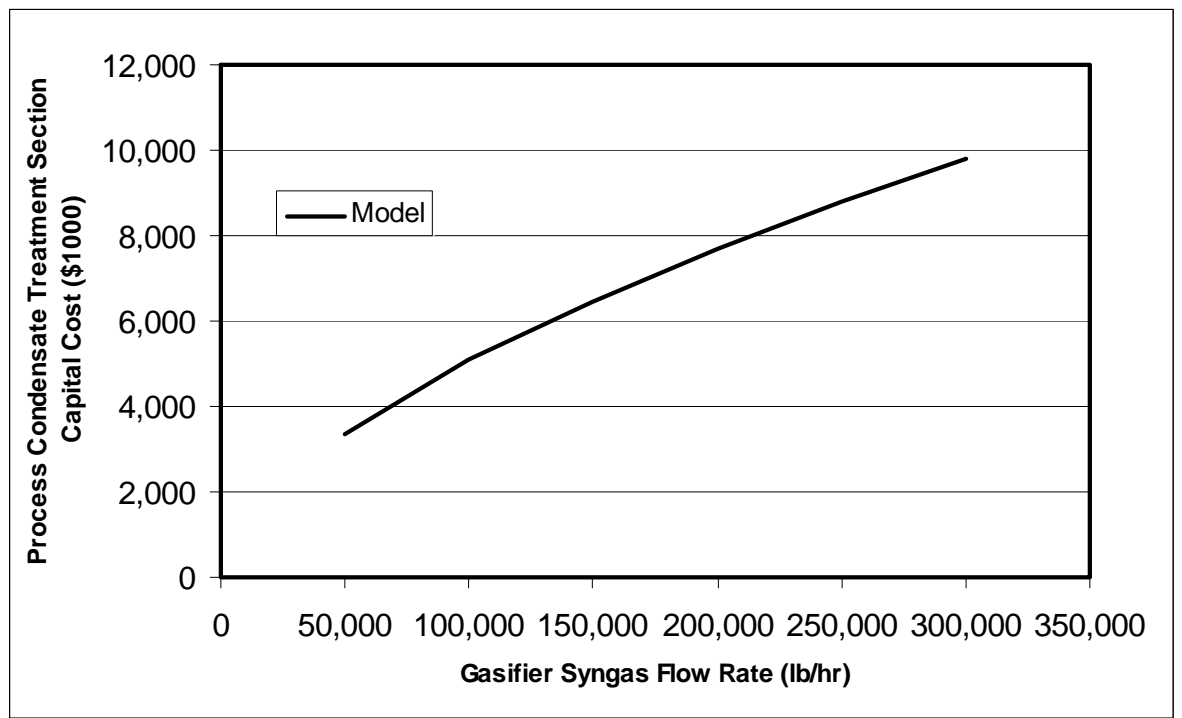

Figure 18. Direct Cost for Process Condensate Treatment (Cost Year = 2000)

\section{References}

Brdar R.D., Jones R.M., 2003: GE IGCC Technology and Experience with Advanced Gas Turbines, GE Power Systems, GER-4207

Chase D.L., Kehoe P.T., 2003: GE Combined-Cycle Product Line and Performance, GE Power Systems, GER-3574G

Fluor(1983b). Shell-Based Gasification-Combined-Cycle Power Plant Evaluations. Prepared by Fluor Engineers, Inc. for Electric Power Research Institute, Palo Alto, CA. EPRI AP-3129. June 1983.

Fluor (1985). Cost and Performance of Kellogg Rust Westinghouse-based Gasification-Combined-Cycle Plants. Prepared by Fluor Engineers, Inc. for Electric Power Research Institute, Palo Alto, CA. EPRI AP-4018. June 1985.

Foster A.D., Doering H.E., and Hilt M.B., 2003: Fuel flexibility in heavy-duty gas turbines, GE Company, Schenectady, New York

Frey, H.C., and N. Akunuri, "Probabilistic Modeling and Evaluation of the Performance, Emissions, and Cost of Texaco Gasifier-Based Integrated Gasification Combined Cycle Systems Using ASPEN," Prepared by North Carolina State University for Carnegie Mellon University and U.S. Department of Energy, Pittsburgh, PA, January 2001.

Hager, R.L., and D.L. Heaven (1990). Evaluation of a Dow-Based GasificationCombined-Cycle Plant Using Bituminous Coal. Prepared by Fluor Daniel for the Electric Power Research Institute. Palo Alto, CA. EPRI GS-6904.

IEA, 2000: Modeling and simulation for coal gasification, IEA Coal Research 2000, ISBN 92-9029-354-3

IEA Greenhouse Gas R\&D Program, 2003: Potential for improvement in gasification combined cycle power generation with $\mathrm{CO}_{2}$ capture, IEA report, report number PH4/19 
Matchak, T.A., A.D. Rao, V. Ramanathan et al. (1984), "Cost and Performance for Commercial Applications of Texaco-Based Gasification-Combined-Cycle Plants," AP-3486. Prepared by Flour Engineers, Inc for EPRI, Palo Alto, CA.

McNamee, G.P., and G.A. White (1986), "Use of Lignite in Texaco GasificationBased-Combined-Cycle Power Plants,” AP-4509. Prepared by Energy Conversion Systems, Inc for EPRI, Los Angeles, CA.

Pietruszkiewicz, Milkavich, Booras et al. (1988), “An Evaluation of IGCC and PCFS plants, ” AP-5950. Prepared by Bechtel Group, Inc for EPRI, Palo Alto, CA.

Robin et al. (1993)

Rocha, M. F., and H.C. Frey (1997), “Cost Modeling of a Texaco Coal Gasification Combined Cycle System, ” Prepared by North Carolina State University for Carnegie Mellon University and U.S. Department of Energy, Morgantown, WV, August.

Simbeck D. R., R.L. Dickenson, and E.D. Oliver (1983), "Coal Gasification Systems: A Guide to Status, Applications, and Economics," AP-3109 Prepared by Synthetic Fuel Associates, Inc for Electric Power Research Institute, Palo Alto, California.

Smith, J., and D. Heaven (1992), "Evaluation of a 510-Mwe Destec GCC Power Plant Fueled With Illinois No. 6 Coal," TR-100319. Prepared by Flour Daniel, Inc for EPRI, Irvine, CA 



\section{Water Gas Shift System}

\section{Water Gas Shift Process Description}

\section{Clean Shift Catalyst}

Gases used in water gas shift reactors often contain sulfur components, such as $\mathrm{H}_{2} \mathrm{~S}$ and COS. These sulfur components have a detrimental effect on the activation of some shift catalysts, which will be poisoned and lose activation in the presence of sulfur components. On the other hand, sulfur components are necessary to maintain the activation of some other shift catalysts. For the former type of shift catalysts, sulfur components must be removed from reaction gases before the water gas shift reaction. Hence this type of catalysts is so-called "clean shift catalyst". A schematic flowsheet of coal gasification system with a clean water gas shift reaction is given in Figure 19. The raw syngas from the gasifier is cooled down, and fed to the soot scrubber to remove the bulk of the air-borne particulates. Then the scrubbed syngas is further cooled prior to passing through a sulfur removal process. Before passing to the shift reactors, steam is added to the clean syngas to meet requirements of a steam-to-carbon ratio. There are two shift reactors, one operating at a higher temperature and a second operating at a lower temperature. Together these form a water gas shift process. A feed/effluent heat exchanger exists between the high and lower temperature shift reactors to assure a proper lower inlet temperature to the second shift reactor.

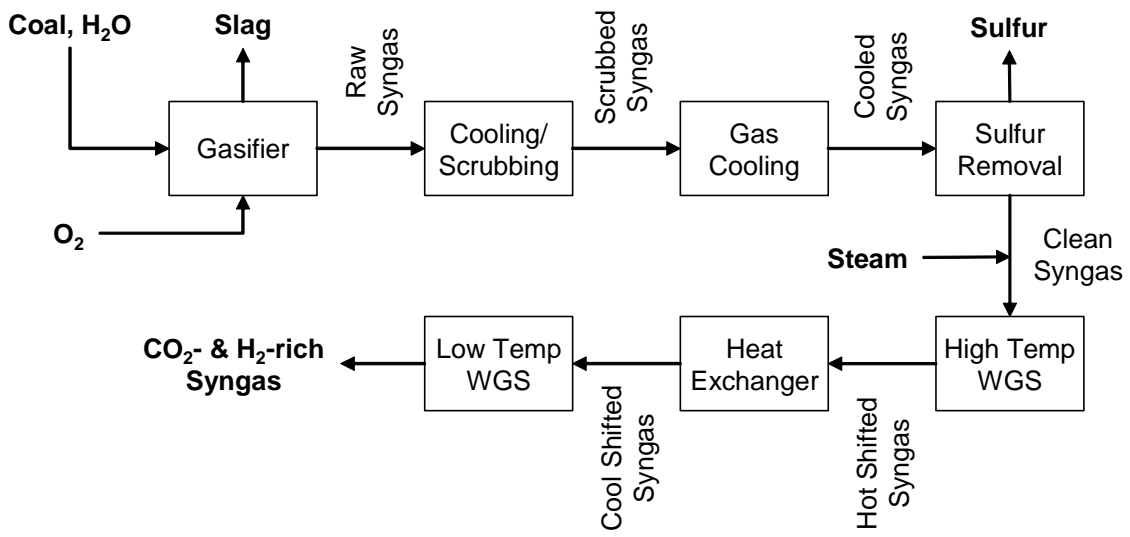


Figure 19: Coal gasification system with a clean water gas shift reaction

For a two-stage shift reaction with clean shift catalysts, the iron-based catalyst is the common commercially available high temperature catalyst. The commonly used low temperature clean shift catalysts are copper-based. Both high temperature and low temperature catalysts require activation by in situ pre-reduction steps. Since both catalysts burn up when exposed to air (pyrophoric), they must be sequestered during system shutdown when only air flows through the system [Frank 2003a].

The lifetimes of Cu-based catalysts and Fe-based catalysts are determined by the poison-absorbing capacity of the catalysts. These poisons are inevitably present in the process gas, such as syngas from coal gasification, or introduced with steam. As mentioned above, the key poison in syngas is sulfur. Hence a sulfur removal process is required upstream of the water gas shift reaction.

\section{Sulfur Tolerant Shift Catalysts}

The so-called sour shift catalysts are sulfur tolerant, and sulfur is required in the feed gas to maintain the catalyst in the active sulphided state. This type of catalyst is usually cobalt-based.

Figure 20 shows the schematic process of a gasifier system with a sour shift reaction. The process draws its name from the acidic or "sour" gases that remain present in the syngas through the water gas shift process before being removed. The syngas from the gasifier is quenched, and then the raw syngas is fed to the soot scrubber, removing the bulk of particulates before passing to the sour shift reactors. Before passing to the shift reactors, steam is added to the scrubbed syngas to meet the requirements of a steam-to-carbon ratio. The first shift reactor operates at high temperature and the hot shifted syngas must be cooled by a heat exchanger prior to entering the second shift reactor. After heat recovery, the cool shifted syngas from the second shift reactor and the final shifted syngas is further cooled prior to being passed to the sulfur removal system.

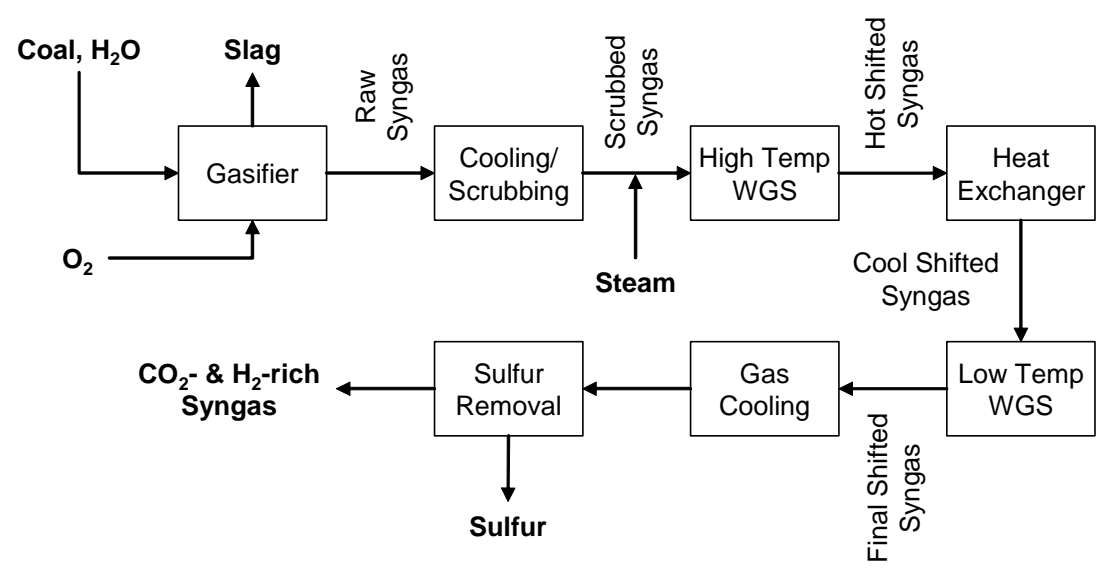

Figure 20: Schematic process of a gasifier system with a sour shift

The sour shift catalyst has demonstrated it's high and low temperature performance, ranging from $210^{\circ} \mathrm{C}$ to $480^{\circ} \mathrm{C}$, and works properly up to a pressure as high as 1160 psia [Frank, 2003b]. Because the catalyst is not impregnated with a water-soluble promoter it can be operated closer to the dew point and will not lose activity when wetted occasionally. 
In a gasification plant, the average catalyst life in the first stage shift reactor was 2.5 years, and 5-8 years in the second reactor [Frank, 2003b]. The difference in catalyst life in the two reactors is highly influenced by the gas quality. These data of catalysts' lifetime are adopted for the estimation of the operation and maintenance cost of the water gas shift reaction system.

\section{Water Gas Shift Performance Model}

This section presents the performance model developed for the WGS reaction process. This is a general performance model for a two-stage shift system with either clean shift catalysts or sulfur tolerant shift catalysts. The purpose of the performance model is to characterize the change in syngas composition and flow rate as a function of inlet condition to the WGS reactor and key design parameters of the WGS system. The performance model also characterizes the heat integration between the shift reaction system and the steam cycle system.

A general water gas shift reaction process model is illustrated in Figure 21. The black box in this figure includes a high temperature reactor, a low temperature reactor and several heat exchangers for heat recovery. The performance of the shift reaction was first modeled in the Aspen Plus. In this model, the syngas from a gasifier is mixed with steam or quenched at a given temperature and pressure, and then fed into the high temperature reactor. Most of the $\mathrm{CO}$ in the syngas is converted to $\mathrm{CO}_{2}$ in the high temperature reactor at a fast reaction rate. Because the water gas shift reaction is exothermic, the syngas from the high temperature reactor has to be cooled before being fed into the low temperature reactor. Further $\mathrm{CO}$ conversion is achieved in the low temperature reactor. The shifted syngas from the low temperature reactor is cooled down again for subsequent $\mathrm{CO}_{2}$ capture in a Selexol process. Part of the heat from syngas cooling is used to heat the fuel gas from Selexol process, and the other part of the heat is integrated into the steam cycle.

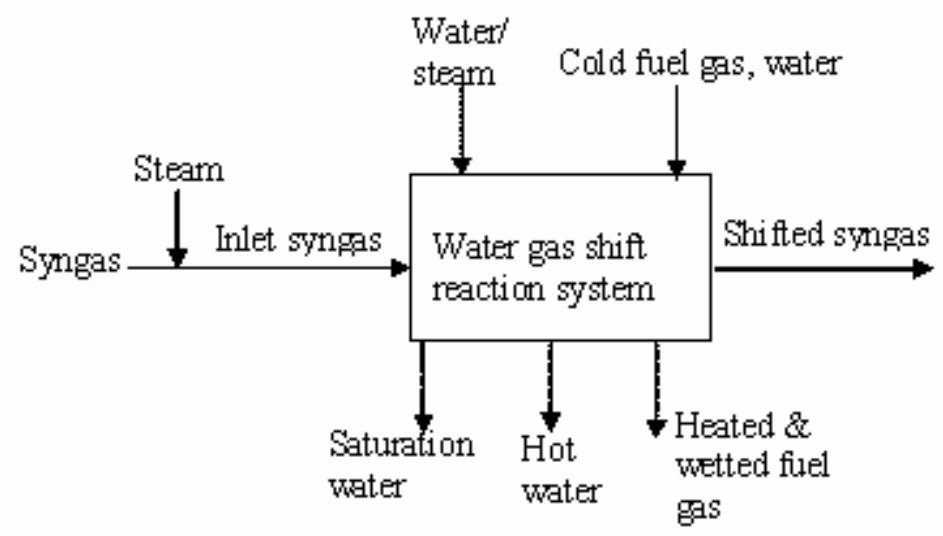

Figure 21: Mass and energy flow of the water gas shift reaction system

In this model, the reactions in the two reactors are assumed to achieve equilibrium states. On the other hand, the shift reaction in a real reactor only approaches an equilibrium state. In order to compensate for the difference between the equilibrium state assumption and the real state in a reactor, the approach temperature method is used to adjust the model equilibrium temperatures. The difference between the model temperature and the design reaction temperature is referred to as the approach temperature. The approach temperature is determined through comparing model outputs with practical data from shift reactors in the industry field. Thus, with the approach temperature, the reactor model is assumed to reach an equilibrium state at a 
higher temperature than the design temperature, which makes the $\mathrm{CO}$ conversion efficiency in the model to match the realistic situation.

The Aspen model had been executed thousands of times with varying the inlet temperature, pressure and syngas composition. The value ranges of these parameters are given in Table 9, which covers the possible ranges of gasification operation. The inlet temperature was varied in a step of $30 \mathrm{~F}$, and the inlet pressure was varied by a step of $100 \mathrm{psia}$. At the same time, 50 different syngas compositions were used. A total of 9000 cases were run. Based on the Aspen simulation results, statistical regression methods were then used to develop relationships between the inlet conditions and the final products of the WGS reaction. Using these regression relationships, the entire water gas shift reaction system can be treated as a "black box" when it is used in the IECM framework.

Table 9: Range of model parameter values for the WGS reaction system

\begin{tabular}{||l|l|l|l|l|l|l|l||}
\hline \multirow{2}{*}{ Parameter } & \multirow{2}{*}{$\begin{array}{l}\text { Inlet } \\
\text { temp. (F) }\end{array}$} & $\begin{array}{l}\text { Inlet } \\
\text { pres. } \\
\text { (psia) }\end{array}$ & & \multicolumn{5}{|c|}{ Volume in the syngas (vol\%) } \\
\cline { 5 - 9 } & & $\mathbf{C O}$ & $\mathrm{H}_{2}$ & $\mathrm{CO}_{2}$ & $\mathrm{H}_{2} \mathrm{O}$ & $\mathrm{CH}_{4}$ \\
\hline Range & $440-755$ & $150-1500$ & $20-60$ & $15-55$ & $5-30$ & $5-30$ & $0.5-20$ \\
\hline
\end{tabular}

\section{Parameters of the WGS performance model}

The input and outlet parameters of this model include the temperature, pressure, and flow rates of the inlet and the outlet syngas as shown in Table 10. The input parameters are used to calculate reaction rates and the composition changes after the reaction. 
Table 10: Input and output parameters of the WGS reaction system

\begin{tabular}{|c|c|c|c|}
\hline \multicolumn{2}{|c|}{ Input parameter } & \multicolumn{2}{|c|}{ Output parameter } \\
\hline \multirow{4}{*}{$\begin{array}{l}\text { Syngas } \\
\text { from } \\
\text { gasifier }\end{array}$} & Temperature $(\mathrm{F})$ & \multirow{4}{*}{$\begin{array}{l}\text { Shifted } \\
\text { syngas }\end{array}$} & Temperature $(\mathrm{F})$ \\
\hline & Pressure (psia) & & Pressure (psia) \\
\hline & Flow rate (lb-mole/hr) & & Flow rate $(\mathrm{lb}-\mathrm{mol} / \mathrm{hr})$ \\
\hline & $\begin{array}{l}\text { Molar concentrations of } \mathrm{CO} \text {, } \\
\mathrm{CO}_{2}, \mathrm{H}_{2} \mathrm{O}, \mathrm{H}_{2}, \mathrm{~N}_{2}, \mathrm{CH}_{4}\end{array}$ & & $\begin{array}{l}\text { Molar concentrations of } \mathrm{CO} \text {, } \\
\mathrm{CO}_{2}, \mathrm{H}_{2} \mathrm{O}, \mathrm{H}_{2}, \mathrm{~N}_{2}, \mathrm{CH}_{4}\end{array}$ \\
\hline \multicolumn{2}{|c|}{ Steam/carbon molar ratio } & \multicolumn{2}{|c|}{ Reaction rate \& Catalyst volume $\left(\mathrm{ft}^{3}\right)$} \\
\hline \multirow{2}{*}{$\begin{array}{l}\text { Feed } \\
\text { water }\end{array}$} & Pressure (psia) & \multirow{2}{*}{$\begin{array}{l}\text { HP \& IP } \\
\text { steam }\end{array}$} & Temperature $(\mathrm{F})$ \\
\hline & Temperature $(\mathrm{F})$ & & Flow rate $(\mathrm{lb}-\mathrm{mol} / \mathrm{hr})$ \\
\hline
\end{tabular}

\section{Performance Model Output}

This section discusses the performance outputs of this model. In this section, the $\mathrm{CO}$ to $\mathrm{CO}_{2}$ conversion is defined and calculated using the chemical equilibrium constant. The outlet temperatures and syngas composition of the two shift reactors are regressed from Aspen model simulation results. The heat released from the syngas cooling is also quantified for the energy balance calculation of the whole IGCC system.

\section{Shifted Syngas Composition}

The water gas shift reaction is a method for further enhancing the yield of hydrogen from gasification. Syngas mixtures containing mostly hydrogen and carbon monoxide are typically generated at elevated temperatures via the combustion of coal, bio-mass, petroleum and organic wastes [Wender, 1996]. Steam is then added to the $\mathrm{CO}-\mathrm{H}_{2}$ feed mixture prior to being introduced to water-gas shift reactors to convert the $\mathrm{CO}$ to $\mathrm{CO}_{2}$ and additional $\mathrm{H}_{2}$. However, thermodynamic equilibrium favors high conversion of $\mathrm{CO}$ and steam to hydrogen and carbon dioxide at low temperatures. Therefore, the water-gas shift reaction is commonly conducted at low temperature in the presence of catalysts that enhance the reaction rate. The water-gas shift reation is reversible and given by Equation $\underline{(25)}$.

$$
\mathrm{CO}+\mathrm{H}_{2} \mathrm{O} \leftrightarrow \mathrm{CO}_{2}+\mathrm{H}_{2} \quad \Delta \mathrm{H}=-41 \mathrm{~kJ} / \mathrm{mol}
$$

The water gas shift reaction occurring in both the high and low temperature reactors changes the concentration of syngas species and the temperature of the syngas. The $\mathrm{CO}$ conversion efficiency $(\xi)$ can be used to show how much $\mathrm{CO}$ is converted into $\mathrm{CO}_{2}$ in one reactor or in two reactors.

$$
\xi=\frac{C O \text { flow in }(\mathrm{lb} \cdot \mathrm{mol} / \mathrm{hr})-\mathrm{CO} \text { flow out }(\mathrm{lb} \cdot \mathrm{mol} / \mathrm{hr})}{C O \text { flow in }(\mathrm{lb} \cdot \mathrm{mol} / \mathrm{hr})}
$$

A numerical model is set up to calculate the $\mathrm{CO}$ conversion in a shift reactor for given inlet parameters. Based on the definition of the $\mathrm{CO}$ conversion and stoichiometric factors of the reaction, the $\mathrm{CO}$ concentration of syngas exiting the high temperature reactor is given by,

$$
[\mathrm{CO}]_{h, o}=[\mathrm{CO}]_{0} \cdot\left(1-\xi_{h}\right)
$$

where 
$[\mathrm{CO}]_{h, o}=$ molar concentration of $\mathrm{CO}$ in the syngas exiting the high temperature reactor

$[\mathrm{CO}]_{0}=$ molar concentration of $\mathrm{CO}$ in the syngas entering the high temperature reactor

$\xi_{h}=\mathrm{CO}$ conversion in the high temperature reactor

Based on the shift reaction shown in Equation (25) and the definition of $\mathrm{CO}$ conversion, the molar concentrations of $\mathrm{H}_{2}, \mathrm{CO}_{2}$ and $\mathrm{H}_{2} \mathrm{O}$ after the high temperature reactor are given by,

$$
\begin{aligned}
& {\left[\mathrm{CO}_{2}\right]_{h, o}=\left[\mathrm{CO}_{2}\right]_{0}+[\mathrm{CO}]_{0} \cdot \xi_{h}} \\
& {\left[\mathrm{H}_{2}\right]_{h, o}=\left[\mathrm{H}_{2}\right]_{0}+[\mathrm{CO}]_{0} \cdot \xi_{h}} \\
& {\left[\mathrm{H}_{2} \mathrm{O}\right]_{h, o}=\left[\mathrm{H}_{2} \mathrm{O}\right]_{0}-[\mathrm{CO}]_{0} \cdot \xi_{h}}
\end{aligned}
$$

Using the $\mathrm{CO}$ conversions definition and Equation (26), the $\mathrm{CO}$ concentration of shifted syngas after the low temperature reactor is to be given by,

$[C O]_{l, o}=[C O]_{0} \cdot\left(1-\xi_{t o t}\right)$

where

$[\mathrm{CO}]_{l, o}=$ molar concentration of $\mathrm{CO}$ in the syngas exiting the low temperature reactor

$$
\xi_{\text {tot }}=\text { the total } \mathrm{CO} \text { conversion in the high and low temperature reactors }
$$

Then the concentrations of $\mathrm{H}_{2}, \mathrm{CO}_{2}$ and $\mathrm{H}_{2} \mathrm{O}$ after the low temperature reactor are given by,

$$
\begin{aligned}
& {\left[\mathrm{H}_{2}\right]_{l, o}=\left[\mathrm{H}_{2}\right]_{0}+[\mathrm{CO}]_{0} \cdot \xi_{\text {tot }}} \\
& {\left[\mathrm{CO}_{2}\right]_{l, o}=\left[\mathrm{CO}_{2}\right]_{0}+[\mathrm{CO}]_{0} \cdot \xi_{\text {tot }}} \\
& {\left[\mathrm{H}_{2} \mathrm{O}\right]_{l, o}=\left[\mathrm{H}_{2} \mathrm{O}\right]_{0}-[\mathrm{CO}]_{0} \cdot \xi_{\text {tot }}}
\end{aligned}
$$

\section{Flow rate of high pressure saturation steam}

In the following two sections, temperature changes and flow rates of water and syngas are calculated, and then used for the following cost model.

Syngas from the high temperature reactor is cooled down to a temperature which is determined by the dew point of syngas before it is fed into the low temperature reactor. According to the heat integration design, heat from the exothermic reaction is recovered to generate high pressure saturated steam for the steam cycle.

The temperature of the saturation steam is determined by the high pressure steam cycle in the power block. Using the data from the ASME steam and water table (1967), the temperature is given by the following regression equation:

$$
\begin{array}{ll}
T_{w, s a t}(F)=328.34+0.3565 P_{s c}-0.0002 P_{s c}^{2}+6 \cdot 10^{-8} P_{s c}^{3} & \mathrm{R}^{2}=0.99 \\
-7 \cdot 10^{-12} P_{s c}^{4} &
\end{array}
$$

where

$$
P_{s c}(\mathrm{psia})=\text { pressure of steam cycle, }(300 \sim 3000 \mathrm{psia})
$$


The heat released by the syngas after the high temperature reactor is determined by,

$$
Q_{H E 1}(B t u / h r)=q_{H E 1} \cdot f_{S G, 0}
$$

where

$f_{S G, 0}=$ total molar flow rate of syngas entering the high temperature reactor (lb-mole/hr);

$q_{H E 1}=$ heat released per lb-mole syngas after the high temperature reactor, which is regressed and given by (Btu/lb-mole),

$$
\begin{aligned}
& q_{H E 1}\left(\frac{B t u}{l b m o l}\right)=P_{0}^{0.0360} T_{0}^{1.2874}[C O]_{0}^{1.14347}\left[\mathrm{CO}_{2}\right]_{0}^{-0.4734} \quad \mathrm{R}^{2}=0.95 \\
& {\left[\mathrm{H}_{2} \mathrm{O}\right]_{0}^{0.3150}\left[\mathrm{H}_{2}\right]_{0}^{0.0003}\left[\mathrm{~N}_{2}\right]_{0}^{0.0139}}
\end{aligned}
$$

where

$P_{0}=$ the pressure of syngas entering the high temperature reactor (psia)

$T_{0}=$ the temperature of syngas entering the high temperature reactor $(\mathrm{F})$

$[i]_{0}=$ the molar concentration of species $\mathrm{i}$ entering the high temperature reactor

Based on the total heat available and the saturation temperature, the flow rate of the saturation high pressure steam $\left(f_{H P S}, \mathrm{lb}-\mathrm{mole} / \mathrm{hr}\right)$ can be calculated by the following equation,

$$
f_{H P S}=\frac{Q_{H E 1}}{\left(h_{T_{w, s a t}}-h_{T_{0}}\right)}
$$

where

$$
\begin{aligned}
& h_{T_{w, s a t}}=\text { enthalpy of steam at saturated temperature (Btu/lb-mole) } \\
& h_{T_{0}}=\text { enthalpy of high pressure feed water at inlet temperature (Btu/lb-mole). }
\end{aligned}
$$

\section{Intermediate Pressure Steam}

The syngas from the low temperature reactor is cooled to $100 \mathrm{~F}$ for sulfur removal, and the heat is recovered to generate the intermediate pressure steam. The total heat $Q_{\text {tot }}(\mathrm{Btu} / \mathrm{hr})$ released when the syngas from the low temperature reactor is cooled down to $100{ }^{\circ} \mathrm{F}$ is given by,

$Q_{\text {tot }}=f_{l, o}\left(9.255 \cdot T_{l, o}-0.316 \cdot P_{l, o}-1386.1 \cdot[C O]_{l, o}\right.$

$-297.779 \cdot\left[\mathrm{CO}_{2}\right]_{l, o}-1485.34 \cdot\left[\mathrm{H}_{2}\right]_{l, o}+17595.87 \cdot\left[\mathrm{H}_{2} \mathrm{O}\right]_{l, o} \quad \mathrm{R}^{2}=0.95$

$\left.-1439.29 \cdot\left[\mathrm{N}_{2}\right]_{l, o}-331.533 \cdot\left[\mathrm{CH}_{4}\right]_{l, o}\right)$

where

$f_{l, o}=$ molar flow rate of syngas exiting low temperature reactor (lb-mole/hr);

$T_{l, o}=$ syngas temperature at the outlet of the second reactor

$P_{l, o}=$ syngas pressure at the outlet of the second reactor

$[i]_{l, o}=$ molar concentration of species $\mathrm{i}$ at the outlet of the second reactor 
In order to meet the approach temperature requirement in the superheater, the final temperature of the intermediate pressure steam $\left(T_{H P S}\right)$ is set to be $10 \mathrm{~F}$ lower than the outlet temperature of the syngas from the second shift reactor, and the feedwater temperature is set to be $59 \mathrm{~F}$. Hence the flow rate of the intermediate pressure steam $\left(F_{I P S}, \mathrm{lb}-\mathrm{mole} / \mathrm{hr}\right)$ is given by,

$$
\left(f_{H P S}+f_{I P S}\right) \cdot\left(h_{I P_{s a t}}-h_{F W}\right)+f_{I P S} \cdot\left(h_{I P S}-h_{I P_{s a t}}\right)=Q_{t o t}
$$

where

$f_{\text {HPS }}=$ flow rate of the high pressure saturation steam (lb-mole/hr)

$h_{I P_{s a t}}=$ enthalpy of the intermediate pressure saturation water at the inlet temperature (Btu/lb-mole)

$h_{F W}=$ enthalpy of the feedwater (Btu/lb-mole)

$h_{I P S}=$ enthalpy of the final intermediate pressure steam (Btu/lb-mole)

\section{WGS Cost Models}

This section presents the economic model developed for the water gas shift reaction process. The cost model is comprised of the capital cost model and the annual operating and maintenance (O\&M) cost model. The capital cost of the WGS reaction system includes the following major process areas: the first stage shift reactor, the second shift reactor and the cooling units. For each of these major areas, its process facilities cost model is developed at first.

\section{Process Facility Cost}

The process facility cost of the reactor includes the reaction vessel, structural supports, dampers and isolation valves, ductwork, instrumentation and control, and installation costs. The reactor vessels are made of carbon steel. The process facility costs of the shift reactors are estimated based on the reactor volumes, which is assumed to be 1.2 times the catalyst volume [Doctor, 1994].

\section{Shift Reactor Vessels}

The process facility costs of the high and low temperature shift reactors are regressed as a function of reactor volume and operation pressure using the data in Table 11. Any of the process facility costs can be expressed for a different year using the Chemical Engineering Plant Cost Index.

$$
P_{R} C_{R}=0.9927 \cdot N_{T, R}\left[17.6487\left(\frac{1.2 V_{\text {cat. }}}{N_{O, R}}\right)^{0.4883} P_{R}^{2.028}\right] \quad \quad \mathrm{R}^{2}=0.9
$$

where

$$
\begin{aligned}
& P F C_{R}=\text { the process facility cost of the reactor (US\$ in 2000) } \\
& N_{T, R}=\text { the total number of the reactor trains } \\
& N_{O, R}=\text { the number of the reactor operating trains } \\
& V_{c a t .}=\text { the volume of catalyst }\left(\mathrm{m}^{3}\right)
\end{aligned}
$$




$$
P_{R}=\text { the operation pressure of the reactor (atm) }
$$

Table 11: Water gas shift reactor cost data adjusted to the dollar value in 2000 [Doctor, 1996]

\begin{tabular}{||l|l|l||}
\hline Cost (\$ in 2000) & Reactor volume $\left(\mathbf{m}^{\mathbf{3}}\right)$ & Pressure(atm) \\
\hline \hline 82864.8 & 22.6 & 31.1 \\
\hline 38692.2 & 34 & 18.7 \\
\hline 59189.0 & 9.684 & 31.0 \\
\hline 21495.0 & 11.553 & 18.7 \\
\hline
\end{tabular}

\section{Heat Exchangers}

In this model, two types of heat exchangers are used, which are the gas-liquid type, and the gas-gas type. Generally, the cost of a heat exchanger depends on its heat exchange surface, which is determined by the heat load of the exchanger and the temperature difference between the hot and cold flows. To allow for variations in these parameters, the process facility cost of the gas-liquid type heat exchanger was regressed using the data in Table 12,

$$
\begin{array}{rlr}
P F C_{H E 1}= & 1.0064 \cdot N_{T, H E} \cdot\left[13.7528\left(d T_{H E}\right)^{-0.6714}\right. & \\
& \left.\times\left(\frac{Q_{H E}}{N_{O, H E}}\right)^{0.6855}\right] & \mathrm{R}^{2}=0.91
\end{array}
$$

where

$P F C_{H E 1}=$ process facility cost of the gas-liquid heat exchanger (US $\mathrm{k} \$$ in 2000)

$N_{T, H E}=$ number of total train of the heat exchanger

$N_{O, H E}=$ number of the operating train of the heat exchanger

$Q_{H E}=$ heat load of the heat exchanger $(\mathrm{kW})$

$d T_{H E}=\log$ mean temperature difference (C)

Table 12: Gas-liquid heat exchanger cost data adjusted to the dollar value in 2000 [Doctor, 1996]

\begin{tabular}{|l|l|l|l||}
\hline $\begin{array}{l}\text { Cost } \\
(\mathrm{K} \$ \text { in 2000) }\end{array}$ & Pressure (atm) & $\begin{array}{l}\text { Log mean } \\
\text { temperature } \\
\text { difference (C) }\end{array}$ & $\begin{array}{l}\text { Heat load } \\
(\mathbf{k W})\end{array}$ \\
\hline \hline 625.4 & 30.7 & 68.2 & 16421.6 \\
\hline 615.0 & 30.7 & 90.8 & 21052.4 \\
\hline 210.2 & 18.7 & 190.4 & 9298.0 \\
\hline 168.2 & 19.4 & 148.6 & 5036.0 \\
\hline 472.9 & 19.4 & 121.0 & 19534.9 \\
\hline
\end{tabular}




\begin{tabular}{||l|l|l|l||}
\hline 315.3 & 19.4 & 13.7 & 1293.1 \\
\hline 210.2 & 18.7 & 190.4 & 9298.0 \\
\hline 99.8 & 19.4 & 153.5 & 2407.3 \\
\hline 210.2 & 20.4 & 190.4 & 9298.0 \\
\hline 634.6 & 68.1 & 52.0 & 12119.7 \\
\hline 210.2 & 157.8 & 190.4 & 9298.0 \\
\hline
\end{tabular}

Based on the data in Table 13, the process facility cost of the gas-gas type heat exchanger is given by,

$$
\begin{array}{rlr}
P F C_{H E 2}= & 0.9927 \cdot N_{T, H E 2}\left[24.4281 \cdot P_{H E 2}^{0.2804}\left(d T_{H E 2}\right)^{-0.1143}\right. & \\
& \left.\times\left(\frac{Q_{H E 2}}{N_{O, H E 2}}\right)^{0.3881}\right] & \mathrm{R}^{2}=0.94
\end{array}
$$

where

$P F C_{H E 2}=$ process facility cost of gas-gas heat exchanger (US k\$ in 2000)

$N_{T, H E}=$ total train number of the heat exchanger

$N_{O, H E}=$ operating train number of the heat exchanger

$Q_{H E}=$ heat load of the heat exchanger $(\mathrm{kW})$

$d T_{H E}=\log$ mean temperature difference in the heat exchanger

The process facility cost can be given in another year basis by using the Chemical Engineering Plant Cost Index.

Table 13: Gas-gas heat exchanger cost data adjusted to the dollar value in 2000 [Doctor, 1996]

\begin{tabular}{||l|l|l|l||}
\hline Cost (k\$ in 2000) & $\begin{array}{l}\text { Pressure } \\
\text { (atm) }\end{array}$ & $\begin{array}{l}\text { Log mean } \\
\text { temperature (C) }\end{array}$ & Heat load (kW) \\
\hline \hline 1757.3 & 30.7 & 98.0 & 17319.5 \\
\hline 1757.3 & 30.7 & 90.7 & 16776.2 \\
\hline 2205.4 & 19.4 & 10.0 & 42480.7 \\
\hline 3131.2 & 30.7 & 318.4 & 100832.3 \\
\hline 2606.0 & 31.6 & 340.4 & 95833.1 \\
\hline 897.1 & 68.1 & 17.2 & 1223.6 \\
\hline 2193.5 & 18.7 & 31.8 & 25641.0 \\
\hline 1294.8 & 18.7 & 19.4 & 4034.0 \\
\hline 644.3 & 20.4 & 69.1 & 2407.3 \\
\hline 849.9 & 20.4 & 71.4 & 5036.0 \\
\hline 692.1 & 20.4 & 57.5 & 2407.3 \\
\hline 966.5 & 18.7 & 51.2 & 5036.0 \\
\hline
\end{tabular}




\section{Total Capital Requirement}

The total process facilities cost of the water gas shift reaction system is the summation of the individual process facility costs above plus the cost of initial catalyst charge. This is added because it is also a large and integral part of the reaction system. Following the EPRI Technical Assessment Guide (1993), the total capital requirement and O\&M cost of the WGS reaction system is given in Table 14 .

Table 14: Cost parameters of water gas shift process

\begin{tabular}{|c|c|}
\hline Capital cost elements & Value \\
\hline Total process facilities cost & Sum of the PFC of each equipment \\
\hline Engineering and home office & $10 \% \mathrm{PFC}$ \\
\hline General facilities & $15 \% \mathrm{PFC}$ \\
\hline Project contingency & $20 \% \mathrm{PFC}$ \\
\hline Process contingency & $5 \% \mathrm{PFC}$ \\
\hline \multicolumn{2}{|c|}{$\begin{array}{l}\text { Total plant cost }(\mathrm{TPC})=\mathrm{PFC}+\text { Engineering fee }+ \text { General facilities }+ \text { Project } \& \text { Process } \\
\text { contingency }\end{array}$} \\
\hline $\begin{array}{l}\text { Allowance for funds during construction } \\
\text { (AFDC) }\end{array}$ & $\begin{array}{l}\text { Calculated based on discount rate and } \\
\text { construction time }\end{array}$ \\
\hline Royalty fees & $0.5 \%$ PFC \\
\hline Preproduction fees & 1 month of VOM\&FOM \\
\hline Inventory cost & $0.5 \%$ TPC \\
\hline \multicolumn{2}{|c|}{$\begin{array}{l}\text { Total capital requirement }(\mathrm{TCR})=\mathrm{TPC}+\mathrm{AFDC}+\text { Royalty fees }+ \text { Preproduction fee+Inventory } \\
\text { cost }\end{array}$} \\
\hline \multicolumn{2}{|l|}{ Fixed $O \& M$ cost (FOM) } \\
\hline Total maintenance cost & $2 \% \mathrm{TPC}$ \\
\hline Maintenance cost allocated to labor & $40 \%$ of total maintenance cost \\
\hline Administration \& support labor cost & $30 \%$ of total labor cost \\
\hline Operation labor & 1 jobs/shift \\
\hline \multicolumn{2}{|l|}{ Variable O\&M cost (VOM) } \\
\hline High temperature catalyst & $\$ 250 / \mathrm{ft}^{3}$, replaced every 2.5 years \\
\hline Low temperature catalyst & $\$ 250 / \mathrm{ft}^{3}$, replaced every 6 years \\
\hline
\end{tabular}


Campbell, J.S., (1970): Influences of catalyst formulation and poisoning on activity and die-off of low temperature shift catalyst, Industrial \& engineering chemistry process design and development, 9(4): 588, 1970.

Davis, R.J., (2003): All That Glitters Is Not AuO, Science, 301(5635), 2003.

Dmitrievich, A., (2002): Hydrodynamics, mass and heat transfer in chemical engineering. Taylor \& Francis Press, New York, NY, 2002.

Doctor, R.D., (1994): Gasification combined cycle: carbon dioxide recovery, transport, and disposal, ANL/ESD-24, Argonne National Laboratory, Energy Systems Division, Argonne, IL, 1994.

Doctor, R.D., (1996): KRW oxygen-blown gasification combined cycle carbon dioxide recovery, transport, and disposal, ANL/ESD-34, Argonne National Laboratory, Energy Systems Division, Argonne, IL. 1996.

Enick, R.M. and Busfamante F., (2001): Very High-Temperature, High-Pressure Homogenous Water Gas Shift Reaction Kinetics, 2001 AIChE Annual Meeting, Reno, NV, 2001.

Frank, P., (2003a): Low Temperature Shift Catalysts for Hydrogen Production, Johnson Matthey Group, 2003.

Frank, P., (2003b): Sulfur Tolerant Shift Catalyst-Dealing with the Bottom of the Barrel Problem, Johnson Matthey Group, 2003.

Newsome, D.S., Kellogg P., (1980): The Water-Gas Shift Reaction, Cat. Rev. Sci. Eng., 21(2), 1980.

Park, J.N., Kim J.H., and Ho-In Lee, (2000): A Study on the Sulfur-Resistant Catalysts for Water Gas Shift Reaction IV. Modification of CoMo/g- $\mathrm{Al}_{2} \mathrm{O}_{3}$ Catalyst with K, Bull. Korean Chem. Soc. 21(12), 2000.

NIST/ASME (2007), NIST/ASME Steam Properties Database Program, Version 2.21, National Institute of Standards and Technology, http://www.nist.gov/srd/nist10.htm, 2007.

Twigg, M.V., (1989): Catalyst handbook, second edition, Wolfe publishing Ltd., Wender, I., (1996): Reactions of Synthesis Gas, Fuel Processing Technology, Vol. 48, 189, 1996. 


\section{Sulfur Removal and Recovery (Cold-Gas Cleanup)}

\section{Nomenclature}

$c_{f}=$ Capacity Factor (fraction)

$\mathrm{M}_{\mathrm{syn}, \mathrm{S}, \mathrm{i}}=$ Molar flow rate of syngas entering Selexol process (lbmole/hr)

$\mathrm{M}_{\mathrm{S}, \mathrm{C}, \mathrm{o}}=$ Molar flow rate of sulfur exiting Claus process ( $(\mathrm{bmole} / \mathrm{hr})$

$\mathrm{M}_{\mathrm{HS}, \mathrm{S}, \mathrm{i}}=$ Molar flow rate of hydrogen sulfide entering Selexol process (lb-mole/hr)

$\mathrm{m}_{\mathrm{s}, \mathrm{C}, \mathrm{o}}=$ Mass flow of sulfur from Claus plant $(\mathrm{lb} / \mathrm{hr})$

$\mathrm{m}_{\mathrm{s}, \mathrm{BS}, \mathrm{o}}=$ Mass flow of sulfur from Beavon-Stretford plant (lb/hr)

$\mathrm{f}_{\mathrm{HS}}=$ Fraction of hydrogen sulfide (by volume)

$\mathrm{N}_{\mathrm{T}, \mathrm{S}}=$ Total number of Selexol trains (integer)

$\mathrm{N}_{\mathrm{O}, \mathrm{S}}=$ Number of operating Selexol trains (integer)

$\mathrm{N}_{\mathrm{T}, \mathrm{C}}=$ Total number of Claus trains (integer)

$\mathrm{N}_{\mathrm{O}, \mathrm{C}}=$ Number of operating Claus trains (integer)

$\mathrm{N}_{\mathrm{T}, \mathrm{BS}}=$ Total number of Beavon-Stretford trains (integer)

$\mathrm{N}_{\mathrm{O}, \mathrm{BS}}=$ Number of operating Beavon-Stretford trains (integer)

$\eta_{\mathrm{HS}}=$ Removal efficiency of hydrogen sulfide from Selexol system (fraction)

\section{Process Description}

A number of different sulfur removal and recovery systems have been studied in IGCC and coal-to-SNG plant designs. The most common configuration is the Selexol process for sulfur removal from the raw syngas, a two-stage Claus plant for recovery of elemental sulfur, and the Shell Claus off-gas treating (SCOT) process for treatment of the tailgas from the Claus plant. However, a number of alternative designs have also been considered. These include integration of the Selexol and SCOT processes in the LONGSCOT design, as well as the use of alternative processes including the Dow GAS/SPEC MDEA and Selectox processes. The design basis assumed here is a Selexol unit for sulfur removal, a two-stage Claus plant for 
sulfur recovery, and either a SCOT or a Beavon-Stretford unit for Claus plant tail gas treatment. In this section, the development of a cost model for the Selexol process is discussed.

\section{Selexol Sulfur Capture}

The proprietary Selexol process selectively removes hydrogen sulfide from the raw syngas. Typically, about 95 percent of the hydrogen sulfide is removed through counter-current contact of the syngas with Selexol solvent. The Selexol process also removes approximately 15 percent of the carbon dioxide in the flue gas. Typically only about one third of COS in the syngas will be absorbed. $\mathrm{H}_{2} \mathrm{~S}$ and COS stripped from the Selexol solvent, along with sour gas from the process water treatment unit is sent to the Claus sulfur plant for recovery of elemental sulfur.

The composition of the acid gas stream which is sent from the Selexol unit to a sulfur recovery plant is typically over 50 percent carbon dioxide (Bechtel , 1983a; Bechtel, 1988; Cover et al, 1985a, 1985b; Fluor, 1983a, 1983b, 1984, 1985; Parsons, 1982). The studies cited here include both IGCC and coal-to-SNG systems based on a variety of gasifiers, including KRW, Texaco, and Shell designs. From these studies, 28 individual data points were developed. Thus, the database for the Selexol cost model represents a variety of coal gas compositions.

From the available performance and cost information for the Selexol process applied to gasification systems, a database containing total direct cost, syngas inlet flow rate, syngas composition (e.g., carbon dioxide, hydrogen sulfide, carbonyl sulfide, water vapor), removal efficiency of syngas components, acid gas flow rate and composition, and syngas temperature and pressure was developed. The inlet crude syngas temperatures for these data ranged from 95 to $120^{\circ} \mathrm{F}$ and the inlet pressures ranged from 315 to 557 psia.

The inlet syngas is contacted counter-currently in a packed bed with Selexol solvent. For a more detailed discussion of this process area, the reader is referred to any of the design studies used as a basis for cost model development, and in particular Fluor (1985). The absorption occurring in the absorber reduce the temperature of the syngas. The treated syngas flows through a knock-out drum to remove solvent mist and is then heated in a heat exchanger by the incoming fuel gas. The cost of the Selexol section includes the acid gas absorber, syngas knock-out drum, syngas heat exchanger, flash drum, lean solvent cooler, mechanical refrigeration unit, lean/rich solvent heat exchanger, solvent regenerator, regenerator air-cooled overhead condenser, acid gas knock-out drum, regenerator reboiler, and pumps and expanders associated with the Selexol process.

The absorption of hydrogen sulfide by the solvent is influenced by the liquid to gas molar ratio in the absorption tower, the partial pressure of the hydrogen sulfide in the syngas, the contact temperature, the number of absorption stages or trays in the tower, and the amount of residual hydrogen sulfide left in the regenerated solvent (EPA, 1983). The absorption tower must be sized based on the syngas volume flow rate and the number of trays required for contacting solvent with the syngas. The solvent circulation rate depends on both the syngas molar flow rate and the desired removal efficiency for hydrogen sulfide. As the removal efficiency is increased, the solvent circulation rate must be increased (EPA, 1983). The solvent circulation rate affects the cost of most of the process equipment in the Selexol process. However, data for the circulation rate are not reported in the design studies. Therefore, to a first order approximation, the cost of the Selexol process is assumed to depend on the syngas flow rate for the syngas temperature and pressure range of the database. The hydrogen sulfide removal efficiency is expected to have a secondary effect on cost, because it also influences the solvent circulation rate. Other parameters such as 
syngas temperature or the concentration of hydrogen sulfide in the syngas may also have secondary effects on the process area cost.

\section{Claus Plant Sulfur Recovery}

In most IGCC cost studies, sulfur recovery is assumed to be achieved using a Claus plant to produce elemental sulfur. This section presents an overview of the design features of a Claus plant in the IGCC process environment. For additional detail see (Fluor, 1985) or any of the other detailed design studies of IGCC or coal-to-SNG systems used to develop this process area cost model.

The inlet stream to the Claus plant is the acid gas from the sulfur removal section. In this study, only data for Claus plants that process the acid gas from a Selexol unit are considered. The acid gas typically contains primarily carbon dioxide and hydrogen sulfide. In order to produce elemental sulfur, a 2:1 ratio of hydrogen sulfide and sulfur dioxide is required. Therefore, a portion of the incoming acid gas is combusted in a two-stage sulfur furnace. The furnace temperature is high enough in the first stage (typically $2,500^{\circ} \mathrm{F}$ ) to destroy any ammonia in the acid gas. Intermediate pressure steam (e.g., 350 psia) is generated from the waste heat produced in the sulfur furnace, cooling the feed gas to the Claus converters to about $600^{\circ} \mathrm{F}$. Further cooling to $350^{\circ} \mathrm{F}$ occurs in a sulfur condenser, generating low pressure steam (e.g., 55 psia). Sulfur flows to a gravity sump, and is kept molten by condensing low pressure steam that flows through coils in the bottom of the sump.

Some of the furnace gas is used to heat the feed gas from the first condenser to approximately $450^{\circ} \mathrm{F}$ prior to entering the sulfur converter, where hydrogen sulfide and sulfur dioxide react in the presence of a catalyst (e.g., Kaiser S-501) to produce elemental sulfur and water. This reaction is exothermic, and the outlet temperature of the gas is approximately $630^{\circ} \mathrm{F}$. The conversion rate is limited by thermal equilibrium. Gaseous sulfur is recovered in a second condenser. The cooling may be accomplished by heating water for fuel gas saturation. The feed gas then is mixed with remaining combustion gases and then enters the second converter. A third condenser, in which water for fuel gas saturation may be heated, is used for final sulfur recovery. The effluent gas from the Claus plant then passes through a coalescer and then on to tail gas treatment.

\section{Beavon-Stretford Tail Gas Treatment}

In this section, an overview of the performance and design of the Beavon-Stretford process is presented as background information for the development of a regression cost model. See (Fluor, 1983a) or (Fluor, 1983b) for a more detailed discussion of this process.

The Beavon-Stretford process is a modification of the Stretford process, which is designed to remove hydrogen sulfide from atmospheric pressure gas streams and convert it to elemental sulfur. However, the Stretford process is not appropriate for handling effluent gases containing sulfur dioxide, carbonyl sulfide, or elemental sulfur. Therefore, a Beavon unit is used to catalytically reduce or hydrolize these species to hydrogen sulfide in the presence of a cobalt molybdate catalyst.

Because hydrogen is required for the reactions occurring in the Beavon unit, flash gas from the acid gas removal section is used as a feed stream. The flash gas is partially combusted in a reducing gas generator, mixed with the Claus plant tail gas, and the total gas stream then enters the Beavon hydrogenation reactor. The hot gas from the reactor is cooled in a waste heat boiler where intermediate pressure (e.g., $100 \mathrm{psia}$ ) steam is generated. The gas stream is further cooled in the desuperheater section of a thermally integrated desuperheater/absorber vessel. The cooling of the 
gas stream is accomplished by heat transfer with cooling water, which is recirculated through an air-cooled heat exchanger. The gas stream then enters the absorber portion of the vessel, where over 99 percent of the hydrogen sulfide is removed by contact with a Stretford solution containing sodium carbonate. The treated gas is vented to the atmosphere.

The Stretford solution flows to a soaker/oxidizer, where anthraquinone disulfonic acid (ADA) is used to oxidize the reduced vanadate in the Stretford solution. The ADA is regenerated by air sparging, which also provides a medium for sulfur flotation. The sulfur overflows into a froth tank, and the underflow from the oxidizer/soaker is pumped to a Stretford solution cooling tower and then to a filtrate tank.

The sulfur from the froth tank is pumped to a primary centrifuge, where the wet sulfur cake product is reslurried and sent to a second centrifuge, after which the sulfur is again reslurried. The slurry is then pumped through an ejector mixer, where the sulfur is melted and separated in a separator vessel. The sulfur goes to a sump.

\section{Performance Model}

\section{Selexol Reagent Use}

\section{Initial Solvent}

The initial requirement for Selexol solvent is expected to depend primarily on the mass flow of hydrogen sulfide, the primary sulfur species in raw syngas, and on the concentration of the hydrogen sulfide. A multivariate regression yielded the following result for the initial solvent requirement, expressed in pounds:

$$
\text { CHEM }_{i, S}=-25,200+16.6\left(\frac{M_{H S, S, i}^{0.935}}{f_{H S}^{1.04}}\right) \quad \begin{aligned}
& \mathrm{R}^{2}=.959 \\
& \mathrm{n}=12
\end{aligned}
$$

where,

$$
\begin{aligned}
& 50 \leq \mathrm{M}_{\mathrm{HS}, \mathrm{S}, \mathrm{i}} \leq 900 \mathrm{lbmole} / \mathrm{hr} \\
& 0.004 \leq \mathrm{f}_{\mathrm{HS}} \leq 0.012
\end{aligned}
$$

The solvent requirement estimated from the regression model is compared to the reported solvent requirement in Figure 22. 


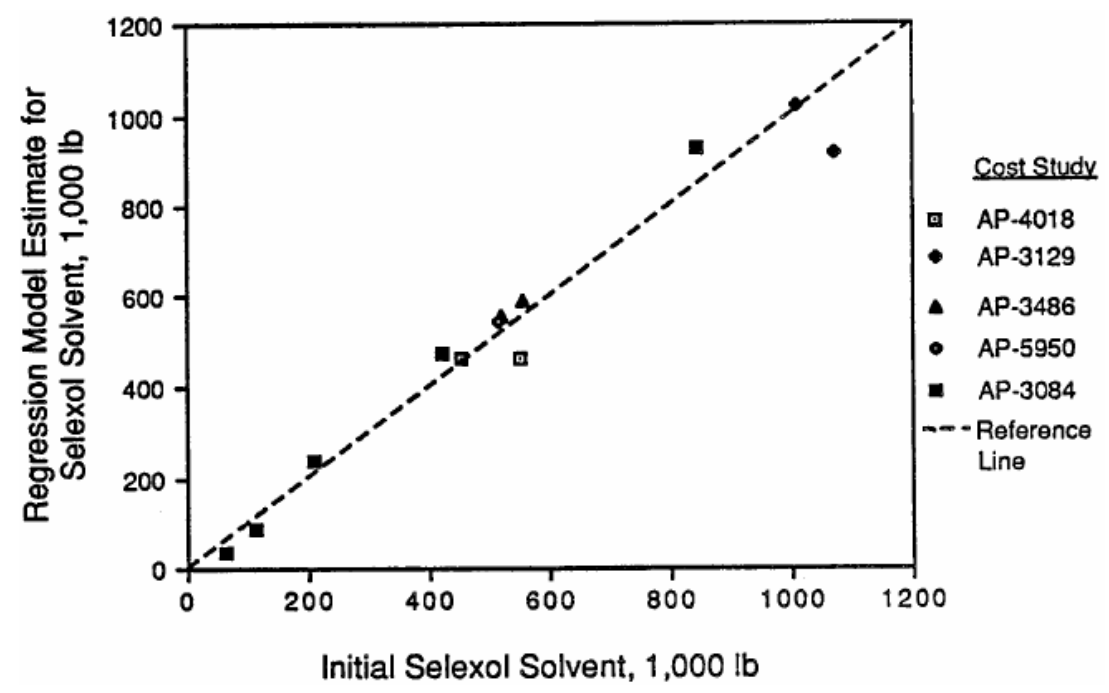

Figure 22 Initial Solvent Requirement for the Selexol Process.

\section{Makeup Solvent}

Selexol solvent is lost during the process and must be replenished. It is a function of the syngas flow rate, not the acid gas flow rate or capture rate. The makeup Selexol solvent flow rate is expressed in units of pounds per year. The regression shown is taken from (Frey, 2001). The regression model is shown graphically in Figure 23 and in equation form as:
$\mathrm{m}_{\mathrm{solv}, \mathrm{S}, \mathrm{i}}=\mathrm{c}_{\mathrm{f}}\left(-350+1.58 \mathrm{M}_{\mathrm{syn}, \mathrm{S}, \mathrm{i}}\right) \mathrm{lb} / \mathrm{yr}$
$\mathrm{R}^{2}=0.989$
$\mathrm{n}=11$

where,

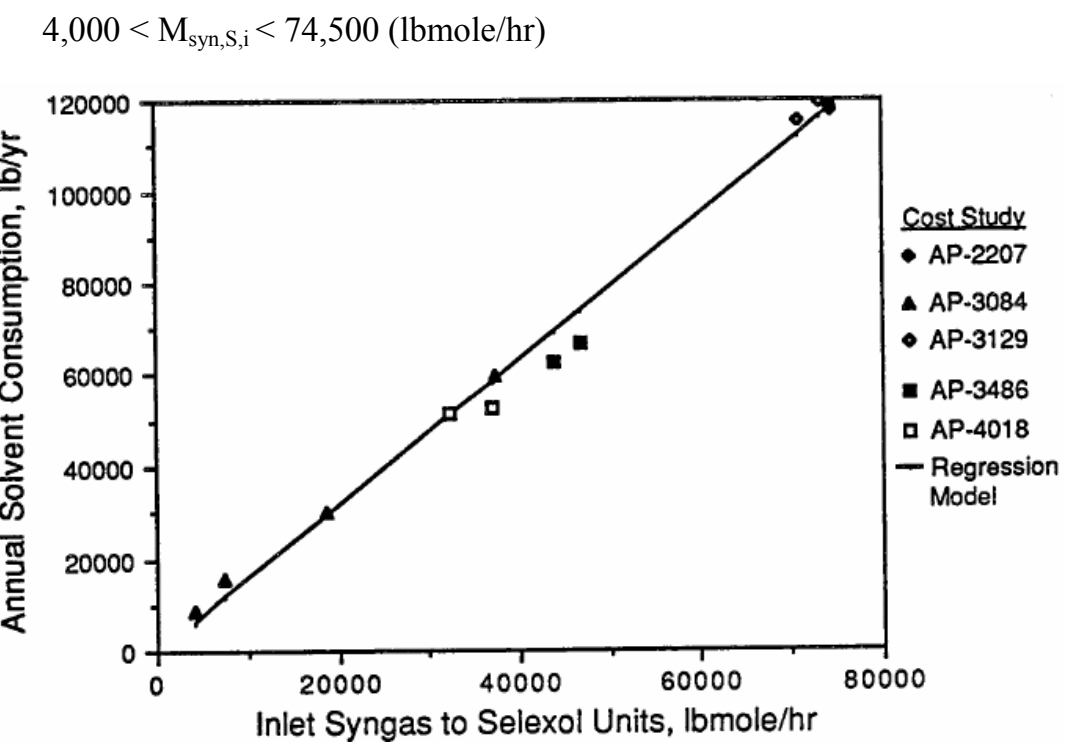

Figure 23: Annual Solvent Requirements for the Selexol Process 


\section{Claus Plant Catalyst Use}

\section{Initial Catalyst}

The initial catalyst requirement for two-stage Claus plants was found to depend on the recovered sulfur mass flow rate. The initial catalyst requirement, in tons, is given by:

$$
\begin{array}{ll}
C A T_{i, C}=5.03 * 10^{-3} m_{s, C, o} & \mathrm{R}^{2}=.959 \\
\mathrm{n}=12
\end{array}
$$

where,

$$
1,000 \leq \mathrm{m}_{\mathrm{s}, \mathrm{C}, \mathrm{o}} \leq 30,800 \mathrm{lb} / \mathrm{hr}
$$

The regression model is shown graphically in Figure 24.

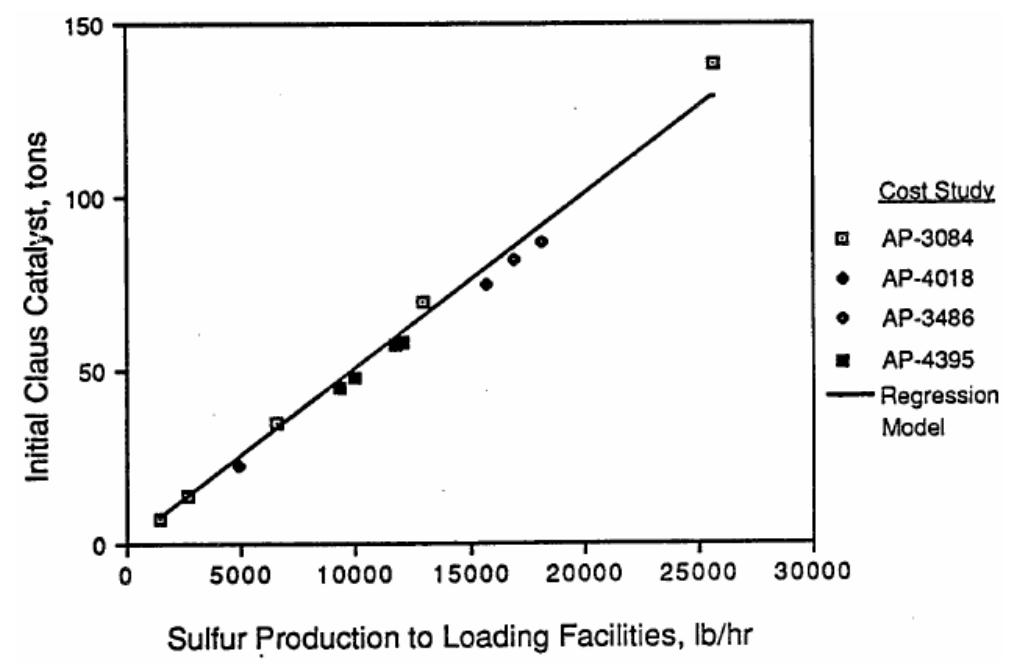

Figure 24 Initial Catalyst Requirement for Two-Stage Claus Plant.

\section{Makeup Catalyst}

The makeup Claus plant catalyst requirement is expressed in units of tons per year. This is the amount of catalyst that must be replaced in an average year. It is based on a regression done by (Frey, 1990).

$m_{c a t, C, i}=0.000961 \cdot c_{f} \cdot m_{s, C, o}$

$$
\begin{aligned}
& \mathrm{R}^{2}=0.843 \\
& \mathrm{n}=13
\end{aligned}
$$

where,

$$
1,000<<m_{s, C, o}<, 26,000 \mathrm{lb} / \mathrm{hr}
$$

The regression model is shown graphically in Figure 25. 


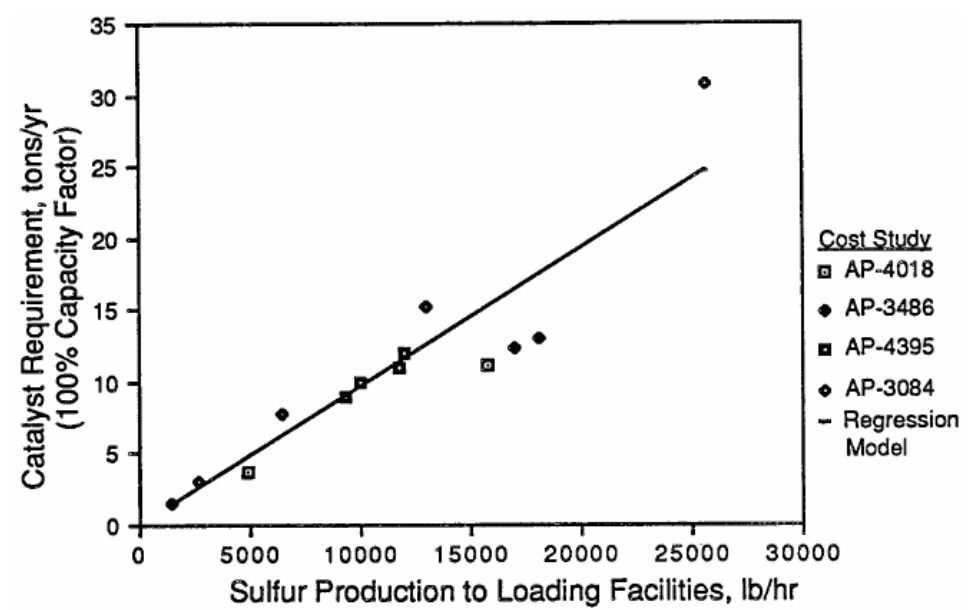

Figure 25: Annual Makeup Catalyst Requirement for Two-Stage Claus Plant

\section{Beavon-Stretford Catalyst Use}

\section{Initial Catalyst}

The Beavon-Stretford process requires a catalyst for the Beavon unit and a special chemical for the Stretford unit. The initial catalyst and chemical requirements for the Beavon-Stretford process were estimated from the values reported in (Fluor, 1983a), which includes data for a range of plant sizes. From these data, a simple linear relationship of catalyst and chemical requirements as a function of the sulfur recovered in the Beavon-Stretford unit was identified.

In the case of the Beavon catalyst, the mass requirement as a function of sulfur flow rate can be estimated. In the case of the Stretford chemicals, the mass requirement is not given. However, the cost of the initial Stretford chemicals as a function of the recovered sulfur flow rate was developed. The resulting regression models for the initial catalyst requirement $\left(C A T_{i, B S}\right)$, in cubic feet is:

$$
\begin{array}{ll}
C A T_{i, B S}=-1.3+0.641 \cdot m_{s, B S, o} & \mathrm{R}^{2}=1.00 \\
\mathrm{n}=5
\end{array}
$$

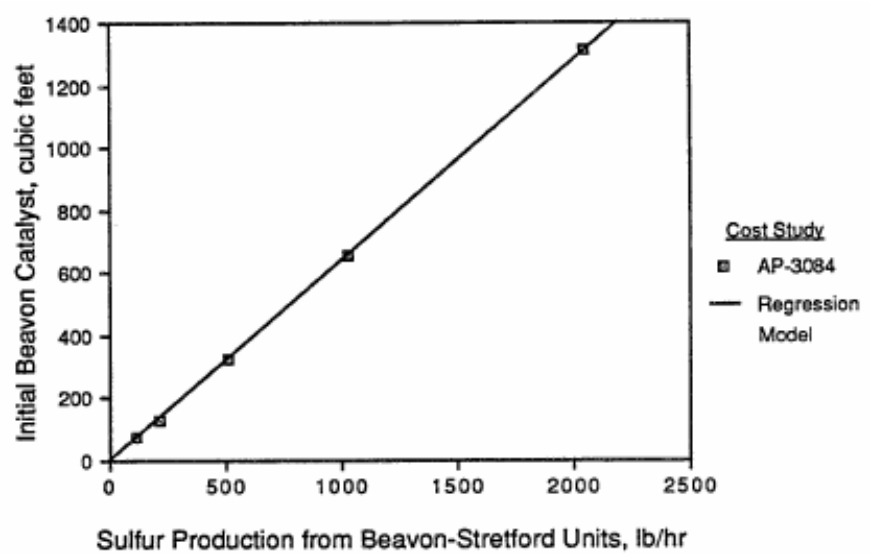

Figure 26 Initial Catalyst Requirement for the Beavon-Stretford Process. 


\section{Makeup Catalyst}

This is the amount of catalyst that must be replaced in an average year. It is based on a regression done by (Frey, 1990). The makeup catalyst requirement is expressed in units of cubic feet per year. The data and regression are shown in Figure 27. Two outlier data points were excluded from the analysis, as indicated in the figure. These points, both from the same study (Fluor, 1983b), appear inconsistent with the more extensive set of data from the other study (Fluor, 1983a).

$$
\begin{array}{ll}
m_{c a t, B S, i}=0.0856 \cdot c_{f} \cdot m_{s, B S, o} & \mathrm{R}^{2}=1.00 \\
\mathrm{n}=5
\end{array}
$$

where:

$100<m_{s, B S, o}<, 2,000 \mathrm{lb} / \mathrm{hr}$

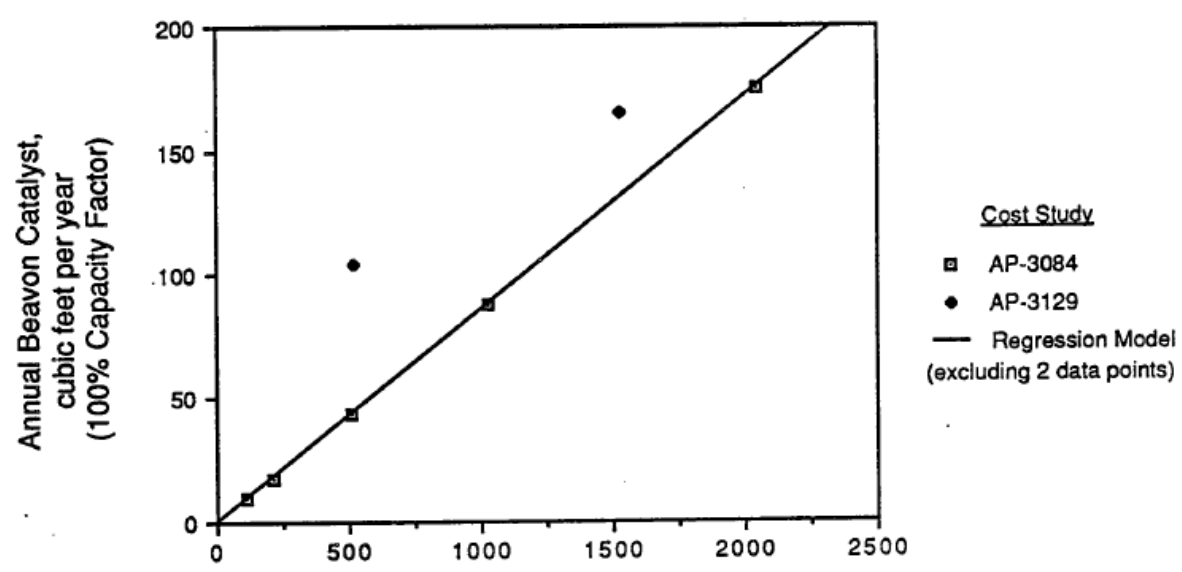

Sulfur Production from Beavon-Stretford Units, lb/hr

Figure 27: Annual Catalyst Requirement for the Beavon-Stretford Process

\section{Chemical Use}

Unlike the consumable catalysts, data are not available regarding the makeup mass flow rate for the Stretford chemicals. However, data are available regarding the cost of the Stretford chemicals. These calculations are provided later in this chapter with the operating and maintenance costs.

\section{Energy Use}

\section{Sulfur Removal (Selexol)}

The auxiliary power consumption model for the Selexol process in MW was developed by (Frey and Rubin, 1990) using 18 data points and is given by

$$
W_{e, S}=0.348+0.000478 \cdot\left(M_{s y n, S, i}\right)^{0.839} \quad \begin{aligned}
& \mathrm{R}^{2}=0.881 \\
& \mathrm{n}=18
\end{aligned}
$$

where,

$$
4,000 \leq \mathrm{M}_{\mathrm{syn}, \mathrm{S}, \mathrm{o}} \leq 74,500 \mathrm{lb}-\mathrm{mole} / \mathrm{hr}
$$

The regression model is shown graphically in Figure 28. 


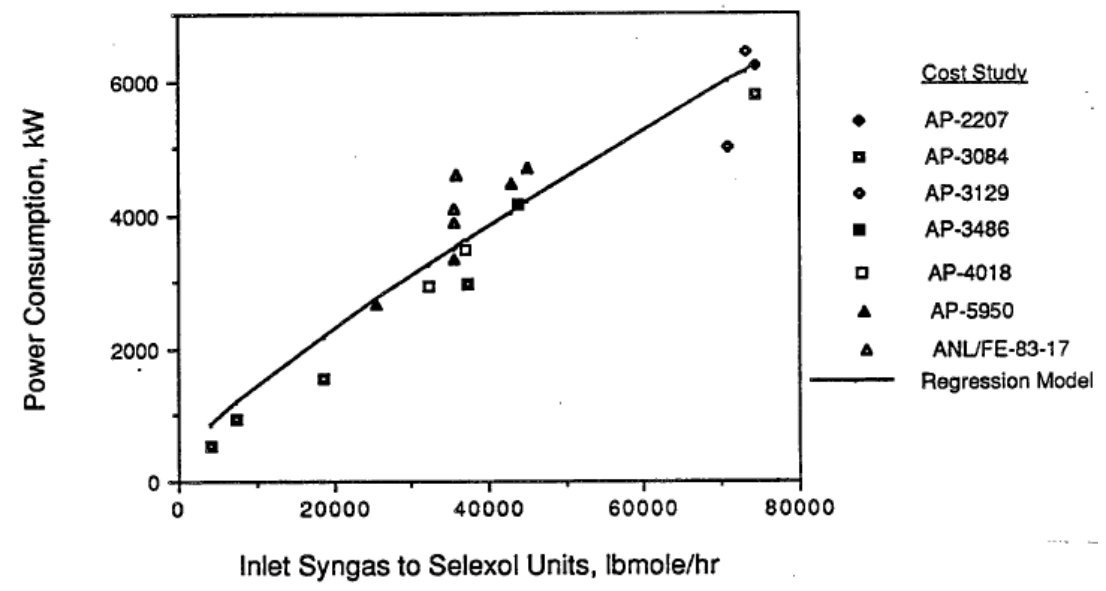

Figure 28 Power Requirement of the Selexol Units

\section{Claus Plant}

The auxiliary power consumption model for Claus plant in MW was developed by (Frey, 1990) using 20 data points is given by:

$$
W_{e, C}=0.000021 \cdot m_{s, C, o} \quad \mathrm{R}^{2}=0.87
$$

where,

$$
1,000 \leq \mathrm{m}_{\mathrm{s}, \mathrm{C}, \mathrm{o}} \leq 30,800(\mathrm{lb} / \mathrm{hr})
$$

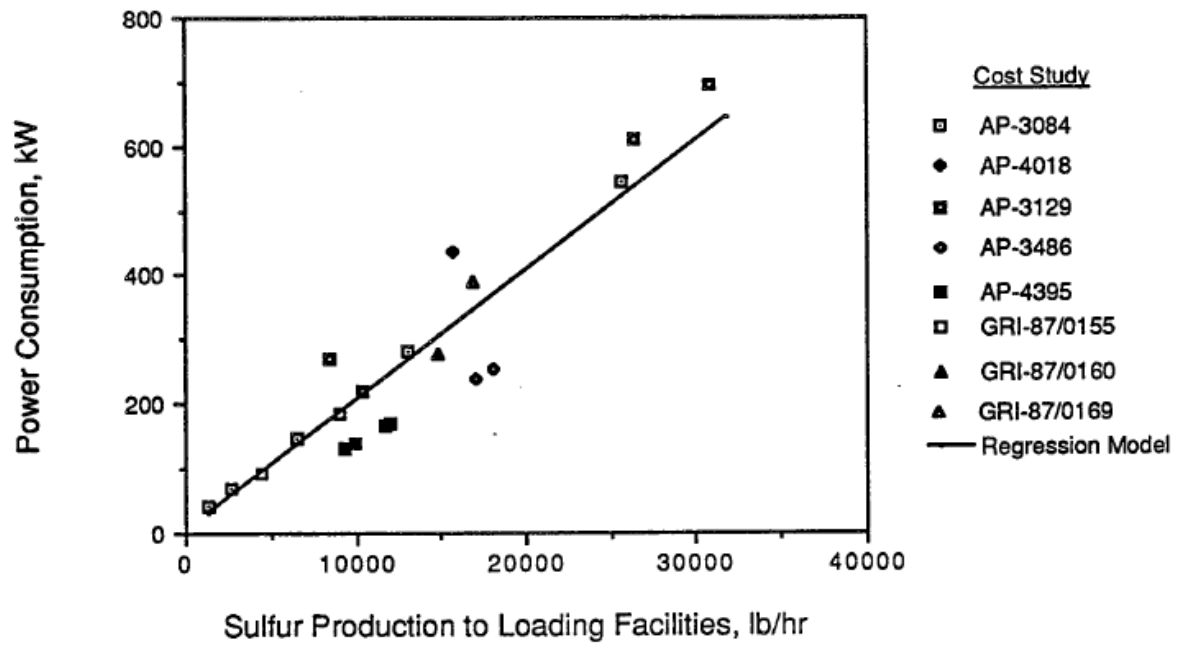

Figure 29 Power Requirement for Two-Stage Claus Plants

\section{Beavon-Stretford Unit}

The auxiliary power consumption model for Beavon-Stretford plant in MW was developed by (Frey, 1990) and is given by:

$W_{e, B S}=0.0445+0.00112 \cdot m_{s, B S, o}$

$\mathrm{R}^{2}=0.990$

where,

$\mathrm{n}=7$

$$
100 \leq \mathrm{m}_{\mathrm{s}, \mathrm{BS}, \mathrm{o}} \leq 2,000(\mathrm{lb} / \mathrm{hr})
$$


The regression model is shown graphically in Figure 30.

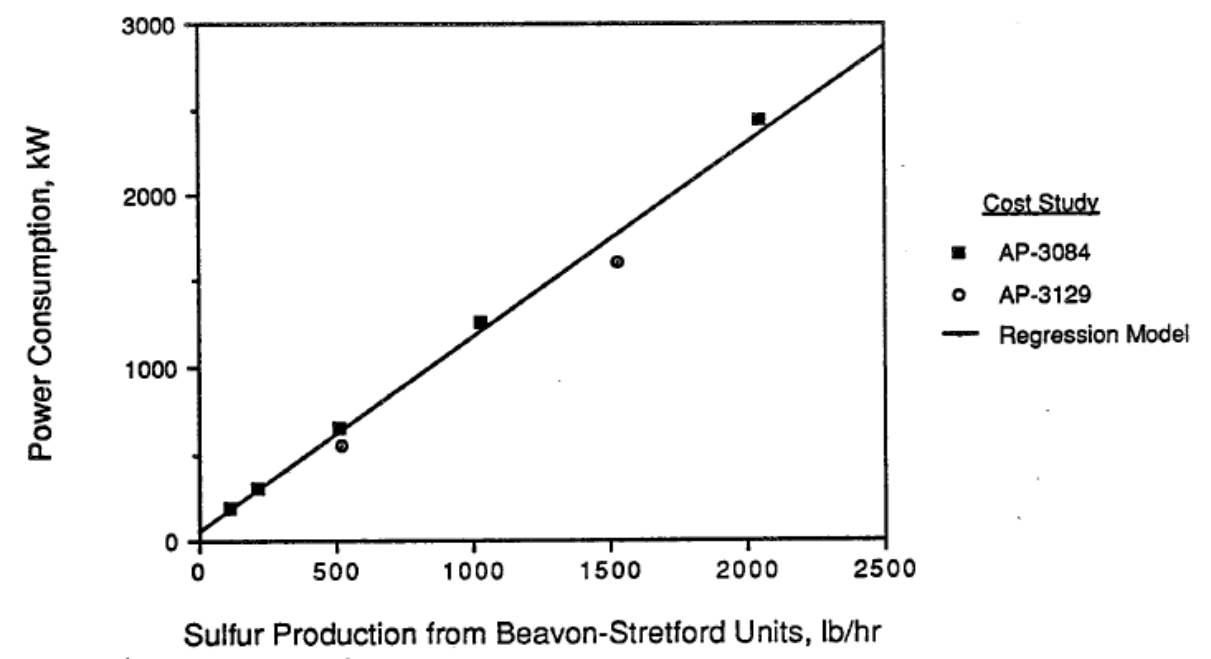

Figure 30 Power Requirement for the Beavon-Stretford Process

\section{Sulfur Removal and Recovery Cost Model}

\section{Direct Capital Cost}

Direct capital cost correlations for each process area are described in the following sections of this report. While some of the process area models may be applicable to a variety of IGCC or coal-to-SNG systems, the models are intended for the specific purpose of estimating the direct cost of the cold gas cleanup systems for capturing and recovering sulfur. The purpose here is not to recapitulate each detail of the process area design basis, but rather to document the development of the cost models. Therefore, the reader may wish to read this report in conjunction with some of the performance and cost studies cited here to obtain more detail about specific process areas.

Capital costs are given for a particular basis year. To provide the costs using a different year, the reader is encouraged to use the Chemical Engineering Plant Cost Index.

\section{Sulfur Removal (Selexol)}

Several alternative regression model formulations were attempted based on syngas flow rate, temperature, pressure, hydrogen sulfide concentration, and the removal efficiency for hydrogen sulfide. The cost of the Selexol process was found to depend primarily on the syngas flow rate entering the acid gas absorber. The cost is also influenced to a much smaller degree by the hydrogen sulfide removal efficiency. Other parameters had less significant or statistically insignificant effects in explaining the cost of the system. Therefore, these additional parameters were excluded from the model.

Hydrogen sulfide in the syngas is removed through counter-current contact with the Selexol solvent. The cost of the Selexol section includes the acid gas absorber, syngas knock-out drum, syngas heat exchanger, flash drum, lean solvent cooler, mechanical refrigeration unit, lean/rich solvent heat exchanger, solvent regenerator, regenerator air-cooled overhead condenser, acid gas knock-out drum, regenerator 
reboiler, and pumps and expanders associated with the Selexol process. The cost model is same as the one developed by (Frey, 1990) for a gasifier-based IGCC system with cold gas cleanup. The number of operating trains is calculated based on the syngas mass flow rate and the limits for syngas flow rate per train used to develop the regression model as given below. A minimum of two operating trains and no spare trains are typically assumed.

IGCC systems with hot gas cleanup produce a hotter gas that requires a modified selexol system to be installed. The direct capital cost model for the Selexol section for a hot gas cleanup system in 2000 dollars is:

$$
D C_{S}=\frac{0.4657 N_{T, S}}{(1-\eta)^{0.059}}\left(\frac{M_{s y n, S, i}}{N_{O, S}}\right)^{0.980} \quad \begin{aligned}
& \mathrm{R}^{2}=0.909 \\
& \mathrm{n}=28
\end{aligned}
$$

where,

$$
\begin{aligned}
& \left.2,000 \leq\left(\frac{M_{s y n, S, i}}{N_{O, S}}\right) \leq 67,300 \text { (lb-mole } / \mathrm{hr}\right) \\
& 0.835<\eta_{\mathrm{HS}}<0.997
\end{aligned}
$$

The same direct cost model for Selexol section is used as that in the radiant and convective design except for a small modification of the coefficient in the equation. This modification was done to match a data point obtained from the study by (Matchak et al, 1984). The direct capital cost model for the cold gas cleanup Selexol section in 2000 dollars is:

$$
D C_{S}=\frac{0.3045 N_{T, S}}{(1-\eta)^{0.059}}\left(\frac{M_{s y n, S, i}}{N_{O, S}}\right)^{0.980}
$$

where,

$$
\begin{aligned}
& 2,000 \leq\left(\frac{M_{s y n, G, i}}{N_{O, S}}\right) \leq 67,300(\text { lbmole } / \mathrm{hr}) \\
& 0.835 \leq \eta_{H S} \leq 0.997 \\
& 200 \leq W_{S T, E} \leq 550(\mathrm{MW})
\end{aligned}
$$

The range for the syngas molar flow rate per train indicates the size range for a single train. Because the scaling exponent for the syngas flow rate term is within the range typically expected for chemical process plants, extrapolation above this range may yield satisfactory results. However, the range for syngas molar flow per train is actually quite large, implying that extrapolation is unlikely in practice. Moreover, the preferred alternative to extrapolation is to adjust the number of trains so that the molar flow rate per train is within the given range. The range for the hydrogen sulfide removal efficiency should not be extrapolated. A graph comparing the regression model estimates of direct cost with the costs reported in the literature is given in Figure 31. 


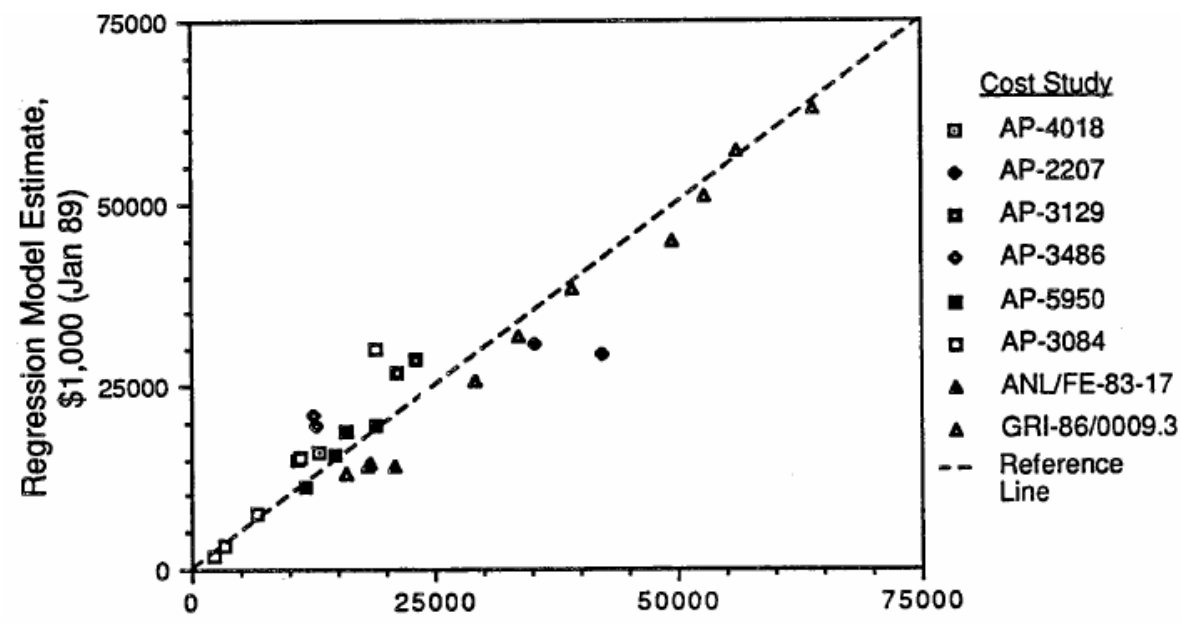

Figure 31 Predicted vs. Actual Costs for Selexol Acid Gas Removal

\section{Sulfur Recovery (Claus Plant)}

A direct cost correlation was developed for two-stage Claus plants based on data from a number of gasification plant studies. A number of data points are not included in this correlation because they represent either three-stage Claus plants or two-stage Claus plants with tail gas incineration and no tail gas treatment, with the incinerator costs included in the direct cost.

The cost of a Claus plant is known to scale primarily with the recovered sulfur mass flow rate capacity using the standard exponential scaling model with an exponent of approximately 0.6 (EPA, 1983b). It appears that this scaling rule may have been the basis for developing the cost estimates of Claus plants used in the design studies, because an excellent goodness-of-fit was found for a single variable regression based on sulfur recovered. The scaling exponent that was obtained in the single variate analysis was 0.668 .

The regression model was further developed to represent the number of operating and spare trains for each data point in the database. The Claus plant contains a twostage sulfur furnace, sulfur condensers, and catalysts. The cost model is same as the one developed by (Frey, 1990). The number of trains is estimated based on the recovered sulfur mass flow rate and the allowable range of recovered sulfur mass flow rate per train used to develop the regression model. The number of total trains is the number of operating trains and one spare train. Typically, one or two operating trains are used. The direct capital cost model as developed by (Frey, 1990) and scaled to 2000 dollars is:

$$
D C_{C}=6.96 N_{T, C}\left(\frac{M_{s, C, o}}{N_{O, C}}\right)^{0.668} \quad \begin{aligned}
& \mathrm{R}^{2}=0.994 \\
& \mathrm{n}=21
\end{aligned}
$$

where,

$$
695 \leq\left(\frac{M_{s, C, o}}{N_{O, C}}\right) \leq 18,100(\text { lbmole } / h r)
$$

The regression model is shown graphically in Figure 32. 


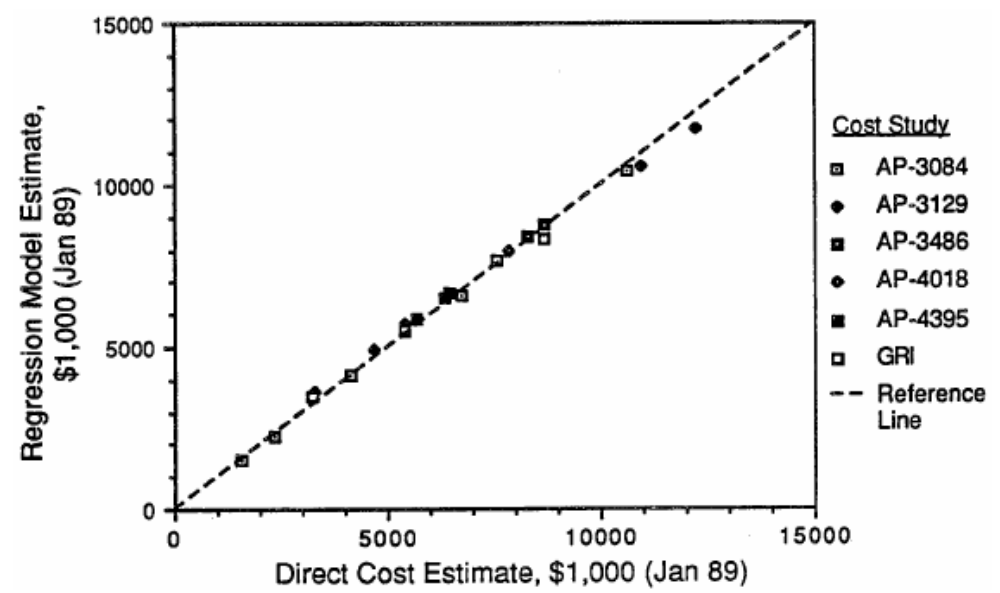

Figure 32 Predicted vs. Actual Costs for 2-Stage Claus Plants

As indicated above, the capacity of a single train varies by a factor of over 20 . Typically, one or two operating trains and one spare train are used, each with equal capacity. Because there was a prior expectation that the cost of the Claus plant should be modeled using an exponential scaling relationship based on recovered sulfur capacity, with a coefficient near 0.6 , this model can be extrapolated at the high end of the range. However, as with all other models, it is recommended that the number of trains be selected so that extrapolation is not required.

\section{Tail Gas Treatment (Beavon-Stretford)}

The process is considered commercially available. The capital cost of a BeavonStretford unit is expected to vary with the volume flow rate of the input gas streams and with the mass flow rate of the sulfur produced. Data from two EPRI-sponsored studies were used to develop a regression cost model (Fluor, 1983a; 1983b). An additional two studies were reviewed for inclusion in the database, but information regarding key process parameters (e.g., recovered sulfur flow rate) was not reported. The two EPRI studies report limited performance and cost data for nine different Beavon-Stretford unit sizes. For example, there is incomplete information about inlet gas streams flow rates. Because of the limited availability of performance data, a regression analysis based only on the sulfur produced by the Beavon Stretford process was developed. However, this regression yielded an excellent fit to the data. The direct capital cost model as developed by (Frey, 1990) and scaled to 2000 dollars is:

$$
D C_{B S}=63.76+73.1 N_{T, B S}\left(\frac{m_{s, B S, o}}{N_{O, B S}}\right)^{0.645} \quad \begin{aligned}
& \mathrm{R}^{2}=0.998 \\
& \mathrm{n}=7
\end{aligned}
$$

where,

$$
75 \leq m_{s, B S, o} \leq 1,200 \mathrm{lb} / \mathrm{hr}
$$

The high coefficient of determination indicated for this model implies either that an exponential cost model is an excellent predictor of the costs of Beavon-Stretford units, or that the costs developed in the EPRI studies were based on a simple scaling model as an approximation. Therefore, it is not immediately clear if this model merely represents an accepted industry practice for developing preliminary cost estimates, or if it accurately reflects the cost of Beavon-Stretford units.

Typically, two operating and one spare train are assumed. Although the regression model is an excellent fit to the data, it is recommended that the number of trains be 
adjusted so that the recovered sulfur flow rate per train does not exceed the limits given above. As a default, the number of operating and total trains for this process area is assumed to be the same as for the Claus plant process area. The regression model is shown graphically in Figure 33 .

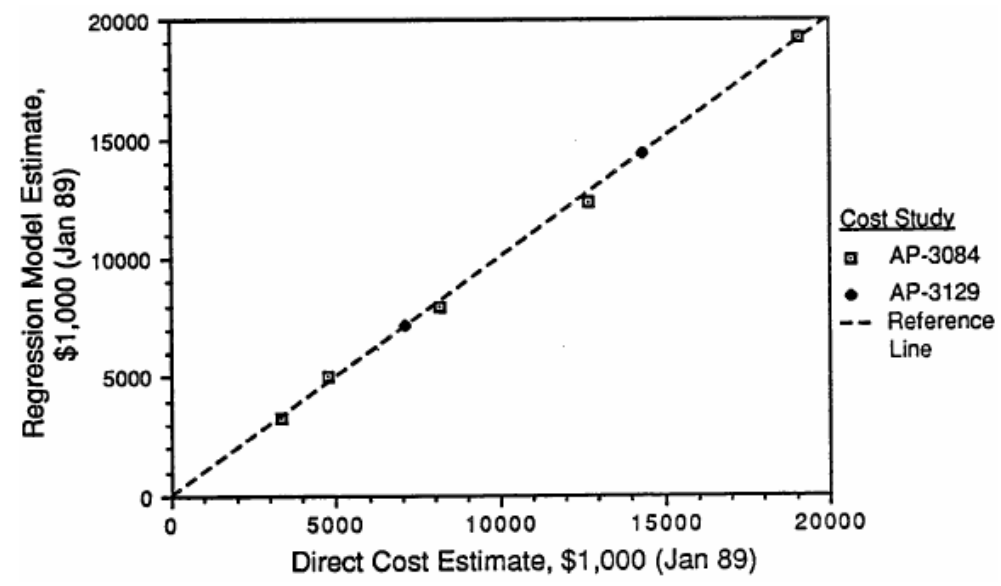

Figure 33 Predicted vs. Actual cost of the Beavon-Stretford Section

\section{Hydrolyzer}

A hydrolyzer may be required to convert $\mathrm{COS}$ to $\mathrm{H}_{2} \mathrm{~S}$ prior to the Selexol unit. At present, no detailed study has been performed. Until one is completed, the cost is assumed to be $5 \%$ of the sulfur capture system.

\section{O\&M Cost}

Makeup chemicals or catalysts are required for the sulfur removal and recovery systems in all IGCC designs. For cold gas cleanup systems, the makeup requirements include Selexol solvent, Claus plant catalyst, Beavon-Stretford catalyst and chemicals. For the hot gas cleanup system with off-gas recycle, the only requirement is for makeup zinc ferrite sorbent. For a hot gas cleanup system with sulfuric acid recovery, makeup sulfuric acid catalyst is also required. The operating material requirements for these systems are summarized below.

To estimate the total variable operating cost, the annual material requiremernts appropriate to the given system must be multiplied by their respective unit costs. In the Beavon-Stretford chemical case, the unit costs are based on a process flow rate (i.e., sulfur recovered in the Beavon-Stretford unit) because the material requirements of the consumables themselves are not reported.

The total variable cost is then:

$$
V O C=O C_{\text {consumables }}=\sum m_{i} \cdot U C_{i}
$$

\section{Selexol Makeup Solvent Cost}

The makeup solvent cost in units of M\$yr in 2000 dollars is calculated as follows:

$$
U C_{s o l v, S}=1.96 \$ / 1 \mathrm{~b} \text { solvent }
$$

$$
V O M_{s o l v, S}=U C_{s o l v, S}\left(\frac{\$}{l b}\right) \cdot \mathrm{m}_{\text {solv }, \mathrm{S}, \mathrm{i}}\left(\frac{l b}{y r}\right) \cdot 1.0 e^{-6}\left(\frac{M \$}{\$}\right)
$$




\section{Claus Makeup Catalyst Cost}

The makeup solvent cost in units of M\$yr in 2000 dollars is calculated as follows:

$$
\begin{aligned}
& U C_{c a t, C}=478.08 \$ / \text { ton catalyst } \\
& V O M_{c a t, C}=U C_{c a t, C}\left(\frac{\$}{t o n}\right) \cdot \mathrm{m}_{\text {cat }, \mathrm{C}, \mathrm{i}}\left(\frac{t o n}{y r}\right) \cdot 1.0 e^{-6}\left(\frac{M \$}{\$}\right)
\end{aligned}
$$

\section{Beavon-Stretford Makeup Catalyst Costs}

The makeup solvent cost in units of M\$yr in 2000 dollars is calculated as follows:

$$
U C_{c a t, B S}=184.71 \$ / \text { ton catalyst }
$$

$$
V O M_{c a t, B S}=U C_{c a t, B S}\left(\frac{\$}{t o n}\right) \cdot \mathrm{m}_{\text {cat }, \mathrm{BS}, \mathrm{i}}\left(\frac{t o n}{y r}\right) \cdot 1.0 e^{-6}\left(\frac{M \$}{\$}\right)
$$

\section{Beavon-Stretford Makeup Chemical Costs}

The Beavon-Stretford process requires a catalyst for the Beavon unit and a special chemical for the Stretford unit. The chemical requirements for the Beavon-Stretford process were estimated from the values reported in (Fluor, 1983a), which includes data for a range of plant sizes. From these data, a simple linear relationship of chemical requirements as a function of the sulfur recovered in the Beavon-stretford unit was identified, as shown in Figure 34. In the case of the Stretford chemicals, the mass requirement is not given. However, the cost of the initial Stretford chemicals as a function of the recovered sulfur flow rate was developed. The resulting regression models for the chemical requirement, in 2000 dollars, is:

$$
\begin{array}{ll}
C_{i, B S, \text { Chem }}=85.8 \cdot m_{s, B S, o} & \mathrm{R}^{2}=1.00 \\
\mathrm{n}=5
\end{array}
$$

where,

$100 \leq m_{s, B S, o} \leq 2,100(\mathrm{lb} / \mathrm{hr})$

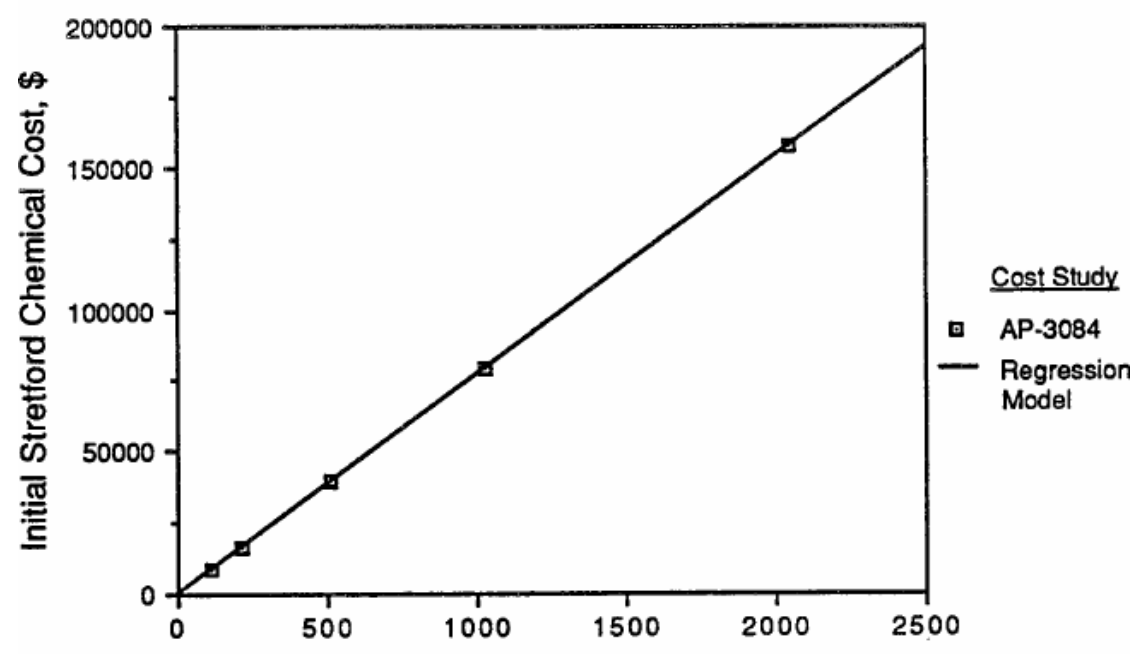

Sulfur Production from Beavon-Stretford Units, $\mathrm{lb} / \mathrm{hr}$

Figure 34: Initial Stretford Chemical Cost for the Beavon-Stretford Process. 


\section{Beavon-Stretford Makeup Chemical Costs}

The regression shown below is the cost of the Stretford chemicals, in 2000 dollars, as a function of the sulfur recovered in the Beavon-Stretford process. The model is shown graphically in Figure 35.

$$
C_{i, B S, \text { Chem }}=170 \cdot c_{f} \cdot m_{s, B S, o} \quad \mathrm{R}^{2}=1.00
$$

where,

$100 \leq m_{s, B S, o} \leq 2,000(\mathrm{lb} / \mathrm{hr})$

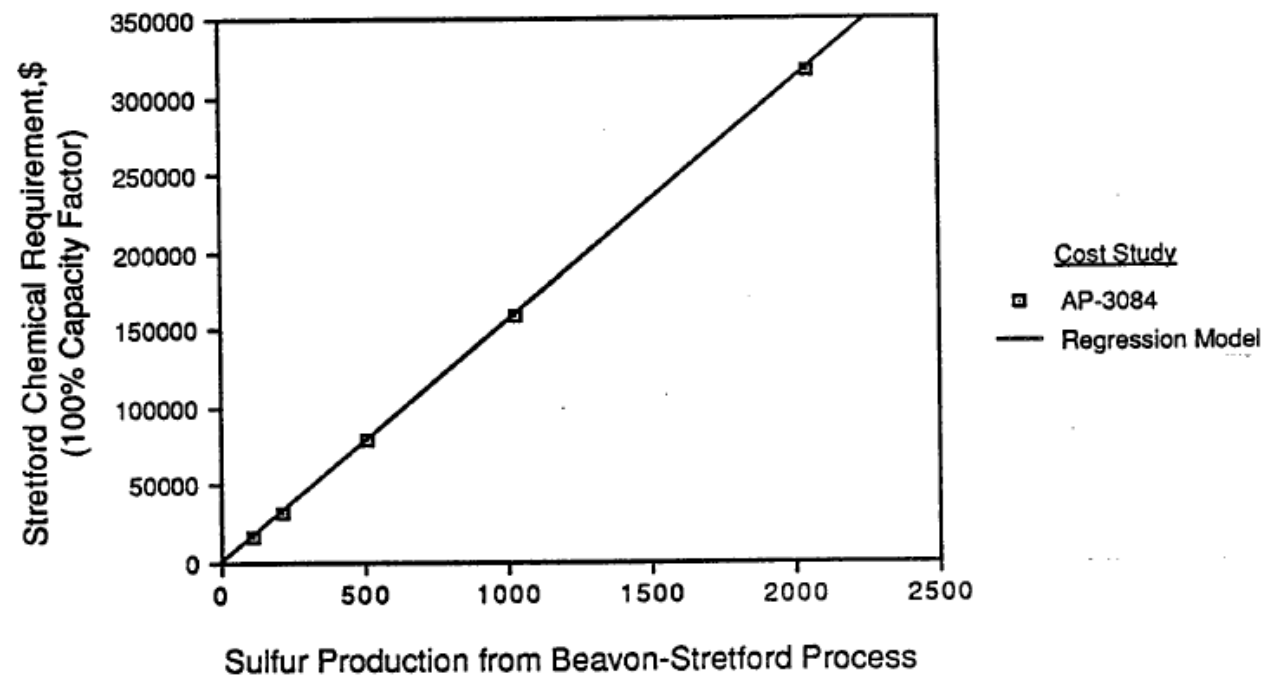

Figure 35: Annual Chemical Cost for the Beavon-Stretford Process

\section{Bibliography}

EPA (1983). Control Technology Appendices for Pollution Control Technical Manuals. U.S. Environmental Protection Agency, Washington, DC. EPA-600/883-009. April 1983.

Bechtel (1983a). Design of Advanced Fossil Fuel Systems (DAFFS), A Study of Three Developing Technologies for Coal-Fired, Base-Load Electric Power Generation: Integrated Gasification Combined Cycle Power Plant With BGC/Lurgi Gasification Process. Prepared by Bechtel Group, Inc., and Burns and Roe/Humphreys-Glasgow Synthetic Fuels, Inc. for the U.S. Department of Energy Argonne National Laboratory. Argonne, Illinois. ANL/FE-83-16. June.

Cover, A.E., D.A. Hubbard, S.K. Jain, E.W. Wong, and C.T. Baker (1985a). Design and Economics of a Lignite-to-SNG Facility Using Westinghouse Gasifiers, in Advanced Coal Gasification Technical Analysis, Final Report. Volume 3-

Technical/Economic Evaluations. Prepared by Kellogg Rust Synfuels, Inc. for Gas Research Institute. Chicago, IL. GRI-86/0009.3. June 1985.

Cover, A.E., D.A. Hubbard, S.K. Jain, P.B. Koneru, and C.T. Baker (1985b). Design and Economics of a Lignite-to-SNG Facility Using Lurgi Gasifiers, in Advanced Coal Gasification Technical Analysis, Final Report. Volume 3-Technical/Economic Evaluations. Prepared by Kellogg Rust Synfuels, Inc. for Gas Research Institute. Chicago, IL. GRI-86/0009.3. November 1985. 
Fluor (1983a). Economic Assessment of the Impact of Plant Size on Coal

Gasification Combined Cycle Plants. Prepared by Fluor Engineers, Inc. for Electric Power Research Institute. Palo Alto, CA. EPRI AP-3084. May.

Fluor(1983b). Shell-Based Gasification-Combined-Cycle Power Plant Evaluations. Prepared by Fluor Engineers, Inc. for Electric Power Research Institute, Palo Alto, CA. EPRI AP-3129. June 1983.

Fluor (1984). Cost and Performance for Commercial Applications of Texaco-Based Gasification-Combined-Cycle Plants: Volume 1, Summary and Discussion of Results, and Volume 2, Design Details. Prepared by Fluor Engineers, Inc. for Electric Power Research Institute, Palo Alto, CA. EPRI AP-3486. April 1984.

Fluor (1985). Cost and Performance of Kellogg Rust Westinghouse-based Gasification-Combined-Cycle Plants. Prepared by Fluor Engineers, Inc. for Electric Power Research Institute, Palo Alto, CA. EPRI AP-4018. June 1985.

Parsons (1982). Evaluation of Coal Gasification-Combustion Turbine Power Plants Emphasizing Low Water Consumption. Prepared by Ralph M. Parsons Company for Electric Power Research Institute. Palo Alto, CA. EPRI AP-2207. January 1982.

Frey, H.C. and E.S. Rubin (1990), Stochastic Modeling of Coal Gasification Combined Cycle Systems: Cost Models for Selected IGCC Systems, Report No. DOE/MC/24248-2901 (NTIS No. DE90015345). June. Prepared by Carnegie Mellon University for U.S. Department of Energy, Morgantown, WV.

Frey, H.C. and N. Akunuri (2001), Probabilistic Modeling and Evaluation of the Performance, Emissions, and Cost of Texaco Gasifier-Based Integrated Gasification Combined Cycle Systems Using ASPEN, Prepared by North Carolina State Univesity for Center for Energy and Environmental Studies, Carnegie Mellon University, Pittsburgh, PA. 



\section{Selexol System}

\section{Nomenclature}

$M W_{\text {Sel }}=$ molar weight of Selexol (280 lb/lb-mol)

$C_{p, s}=$ specific heat of Selexol $\left(0.49 \mathrm{Btu} / \mathrm{lb}{ }^{\circ} \mathrm{F}\right)$

$C_{p, i}=$ specific heat of species $i\left(\mathrm{Btu} / \mathrm{lb}{ }^{\circ} \mathrm{F}\right)$

$S V_{\text {sel }}=$ specific volume of Selexol (32.574 gallon/lb-mol)

$S V_{\mathrm{CO}_{2}}=$ specific volume of $\mathrm{CO}_{2}(377.052 \mathrm{SFC} / \mathrm{lb}-\mathrm{mol})$

$v_{i}=$ specific volume of $\mathrm{CO}_{2}(\mathrm{SFC} / \mathrm{lb}-\mathrm{mol})$

$p_{i}=$ partial pressure of species $\mathrm{i}$ in the syngas (psia)

$p_{1}=$ pressure of syngas at the inlet of absorber (psia).

$p_{\mathrm{CO}_{2}}=$ partial pressure of $\mathrm{CO}_{2}$ psia)

$P_{o, 1}=$ outlet pressure of power recovery turbine 1 (psia)

$P_{i, 1}=$ pressure of the $\mathrm{CO}_{2}$-rich Selexol at the inlet of turbine 1 (psia)

$P_{o, 2}=$ outlet pressure of power recovery turbine 2 (psia)

$P_{i, 1}=$ pressure of the $\mathrm{CO}_{2}$-rich Selexol at the inlet of turbine 1 (psia)

$T_{S G, i}=$ syngas temperature at the inlet of the absorber $\left({ }^{\circ} \mathrm{F}\right)$

$T_{S G, o}=$ syngas temperature at the outlet of the absorber $\left({ }^{\circ} \mathrm{F}\right)$

$\Delta T=$ temperature increase of solvent in the absorber $\left({ }^{\circ} \mathrm{F}\right)$

$\Delta T_{1}=$ solvent temperature increase caused by the heat transfer $\left({ }^{\circ} \mathrm{F}\right)$

$\Delta T_{2}=$ solvent temperature increase due to the solution heat of gases $\left({ }^{\circ} \mathrm{F}\right)$

$\chi_{i}=$ solubility of species $i$ in Selexol at temperature of $30+\Delta T{ }^{\circ} \mathrm{F}$

$\chi_{\mathrm{CO}_{2}}=\mathrm{CO}_{2}$ solubility in the Selexol (SCF/gallon-psia) 
$\chi_{\mathrm{CO}_{2,1}}=$ solubility of $\mathrm{CO}_{2}$ in Selexol at temperature $30+\Delta T\left({ }^{\circ} \mathrm{F}\right)$

$\chi_{\mathrm{CO}_{2,4}}=$ solubility of $\mathrm{CO}_{2}$ in Selexol at temperature $30+\Delta T_{1}\left({ }^{\circ} \mathrm{F}\right)$

$Q_{1}=$ heat released by the syngas

$f_{S G, i}=$ molar flow rate of syngas at the inlet of the absorber (lb-mole/hr)

$f_{S G, i}=$ total flow rate of syngas entering the absorber (lb-mole/hr)

$[i]_{1}=$ molar concentration of species $\mathrm{i}$ in syngas at the inlet of the absorber

$\alpha=\mathrm{CO}_{2}$ removed from the syngas (\%)

$\omega=$ Selexol flow rate (lb-mole/hr)

$V_{i}=$ volume flow rate of species i captured in the Selexol (lb-mole/hr)

$V_{C_{2}, \text { res }}=$ volume flow rate of residual $\mathrm{CO}_{2}$ in the lean solvent (lb-mole/hr)

$V_{\mathrm{CO}_{2}, a b s}=$ volume flow rate of $\mathrm{CO}_{2}$ captured in the absorber (lb-mole/hr)

$\left[\mathrm{CO}_{2}\right]_{1}=\mathrm{CO}_{2}$ molar concentration at the inlet of absorber

$\psi_{\mathrm{CO}_{2}}=$ solution heat of $\mathrm{CO}_{2}$ in Selexol (Btu/lb-solute)

$h p_{\text {tur }}=$ power recovered through the power turbine (hp)

$H_{S e l}=$ total dynamic head $\left(\mathrm{lb} / \mathrm{in}^{2}\right)$

$f_{\mathrm{Sel}_{2}}=$ flow rate of $\mathrm{CO}_{2}$ rich Selexol entering the turbine ( $\left.\mathrm{gal} / \mathrm{min}\right)$

$\eta_{t u r}=$ efficiency of the turbine

$d T_{\text {tur }}=$ decreased temperature of the Selexol in the power recovery turbine $\left({ }^{\circ} \mathrm{F}\right)$

$d P_{t u r}=$ decreased pressure of the Selexol in the power recovery turbine $\left({ }^{\circ} \mathrm{F}\right)$

$h p_{\text {comp. }}=$ power consumption of the $\mathrm{CO}_{2}$ compressor (hp)

$\eta_{\text {comp. }}=$ overall efficiency of the compressor

$V F_{\text {gas }}=$ inlet rate of the $\mathrm{CO}_{2}$ stream $\left(\mathrm{ft}^{3} / \mathrm{min}\right)$

$P_{\text {comp }, i}=$ inlet pressure of the compressor (psia)

$P_{\text {comp.,o }}=$ outlet pressure of the compressor (psia)

$k_{\text {gas }}=\frac{C_{p, \text { gas }}}{C_{v, \text { gas }}}$

$H_{s}=$ total dynamic head (psia)

$f_{\text {Sel }}=$ flow rate of $\mathrm{CO}_{2}$ lean Selexol (gal $\left./ \mathrm{min}\right)$

$\eta_{\text {pump }}=$ efficiency of the pump

$W_{\text {ref. }}=$ power consumption of the solvent refrigeration process $(\mathrm{kW})$ 
$T_{\text {evap }}=$ evaporation temperature of the refrigerant $\left({ }^{\circ} \mathrm{F}\right)$

$N_{T, a b s}=$ total train number of absorbers

$P_{a b s, i}=$ inlet pressure of absorber (atm)

$f_{\text {Sel }}=$ flow rate of the Selexol(lb-mole/hr)

$f_{\text {gas }}=$ flow rate of the syngas $(\mathrm{lb}-\mathrm{mole} / \mathrm{hr})$

$h p_{t u r}=$ power output of the turbine (hp)

$P_{t u r, o}=$ outlet pressure of the turbine (atm)

$N_{T, \text { sump }}=$ total train number of sump tanks

$N_{O \text {,sump }}=$ operating train number of the sump tanks

$f_{S e l}=$ flow rate of Selexol entering a vessel $(\mathrm{kg} / \mathrm{s})$

$h p_{R C}=$ power consumption of the recycle compressor (hp)

$h p_{S P}=$ power consumption of the Selexol pump (hp)

$h p_{\text {comp }}=$ power consumption of the compressor (hp)

$N_{T, r e f t}=$ total train number of the refrigeration unit

$N_{O, \text { reft }}=$ operating train number of the refrigeration unit

$\Delta T_{\text {Sel }}=$ Selexol temperature difference between the inlet and outlet of the refrigeration unit $\left({ }^{\circ} \mathrm{C}\right)$

$N_{T, \tan k}=$ total train number of the flash tank

$N_{O, \tan k}=$ operating train number of the flash tank

\section{Selexol System Process Description}

The Selexol process uses a physical solvent to remove acid gas from the streams of synthetic or natural gas. It is ideally suited for the selective removal of $\mathrm{H}_{2} \mathrm{~S}$ and other sulfur compounds, or for the bulk removal of $\mathrm{CO}_{2}$. The Selexol process also removes COS, mercaptans, ammonia, HCN and metal carbonyls [Epps, 1994].

In this section, the technical background information of Selexol process is reviewed. This information provides the basis for the development of a performance model of Selexol systems to control $\mathrm{CO}_{2}$ emissions from IGCC plants.

\section{History}

The Selexol process, patented by Allied Chemical Corp., has been used since the late 1960s. The process was sold to Norton in 1982 and then bought by Union Carbide in 1990 [Epps, 1994]. The Dow Chemical Co. acquired gas processing expertise, including the Selexol process, from Union Carbide in 2001. The process is offered for license by several engineering companies, such as UOP [UOP, 2002]. 
The Selexol process has been used commercially for 30 years and has provided reliable and stable operations. As of January 2000, over 55 Selexol units have been put into commercial service [Kubek, 2000], which cover a wide variety of applications, ranging from natural gas to synthetic gas. By now, Selexol process has been the dominant acid-gas removal system in gasification projects. Moreover, increasing interests to control $\mathrm{CO}_{2}$ emission in the world may lead to Selexol application widely, particularly for coal gasification plants. Actually, the use of the Selexol solvent has a long history in gasification process, and was chosen as the acid-gas removal technology for the pioneering work in this area. Due to its outstanding record, the Selexol process continues to be the preferred choice for acidgas removal today, and has recently been selected for several large projects around the world [Breckenridge, 2000]. Relevant experiences for gasification are as follows [Kubek, 2000].

- About 50 Selexol units have been successfully commissioned for steam reforming, partial oxidation, natural gas, and landfill gas. Of these, 10 have been for heavy oil or coal gasifiers.

- The $100 \mathrm{MW}$ Texaco/Cool Water (California) 1,000 t/d coal gasifier plant for IGCC demonstration was operated continuously for about five years in the 1980s. The Selexol unit performed extremely well. The process delivered $\mathrm{H}_{2} \mathrm{~S}$-enriched acid gas to a Claus plant while removing 20 to $25 \%$ of the $\mathrm{CO}_{2}$ and treating a high $\mathrm{CO}_{2} / \mathrm{H}_{2} \mathrm{~S}$ ratio feed gas.

- The TVA/Muscle Shoals (Alabama) $200 \mathrm{t} / \mathrm{d}$ coal gasifier demonstration plant was operated continuously for about five years in the early 1980s. It employed a Texaco gasifier, a COS hydrolysis unit, and a Selexol unit to convert coal to clean synthesis gas, and $\mathrm{CO}_{2}$ as an alternative feed to an existing ammonia-urea plant. The COS hydrolysis and Selexol units were stable and had a high on-stream factor. The Selexol unit delivered an $\mathrm{H}_{2} \mathrm{~S}$-enriched acid gas to elemental sulfur production, a pure $\left(<1\right.$ ppmv total sulfur) synthesis gas to $\mathrm{NH}_{3}$ synthesis, and removed part of the $\mathrm{CO}_{2}$ to provide high-purity $\mathrm{CO}_{2}$ for urea production.

\section{Selexol Solvent}

\section{Properties}

The Selexol acid gas removal process is based on the mechanism of physical absorption. The solvent used in the Selexol acid removal system is a mixture of dimethyl ethers polyethylene glycol with the formulation of $\mathrm{CH}_{3}\left(\mathrm{CH}_{2} \mathrm{CH}_{2} \mathrm{O}\right)_{\mathrm{n}} \mathrm{CH}_{3}$, where $\mathrm{n}$ is between 3 and 9 [Epps, 1994]. The general properties of the glycol solvent is given in Table 15 [Sciamanna, 1988; Newman, 1985]. 
Table 15 Properties of Glycol Solvent

\begin{tabular}{||c|l||}
\hline Property & Value \\
\hline \hline Viscosity $@ 25 \mathrm{C}, \mathrm{cp}$ & 5.8 \\
\hline Specific gravity@25C,kg/m^3 & 1030 \\
\hline Mole weight & 280 \\
\hline Vapor pressure @ $25 \mathrm{C}, \mathrm{mmHg}$ & 0.00073 \\
\hline Freezing point C & -28 \\
\hline Maximum operating Temp., C & 175 \\
\hline Specific heat@25C Btu/lb F & 0.49 \\
\hline
\end{tabular}

\section{Solubility of Acid Gases}

The performance of a physical solvent can be predicted by its solubility. The solubility of an individual gas follows the Henry's law - the solubility of a compound in the solvent is directly proportional to its partial pressure in the gas phase.

Selexol is a physical solvent. Therefore, the performance of the Selexol process enhances with increasing acid gas partial pressures. As shown in Figure 36, chemical solvents have a higher absorption capacity at relatively low acid gas partial pressures. However, their absorption capacities plateau at higher partial pressures. The solubility of an acid gas in physical solvents increases linearly with its partial pressure. Therefore, chemical solvent technologies are favorable at low acid gas partial pressures and physical solvents are favored at high acid gas partial pressures.

Physical solvents are more efficient to regenerate, a second advantage for high acid gas partial pressure applications. The physical absorption allows for the solvent to be partially regenerated by pressure reduction, which reduces the energy requirement compared to chemical solvents.

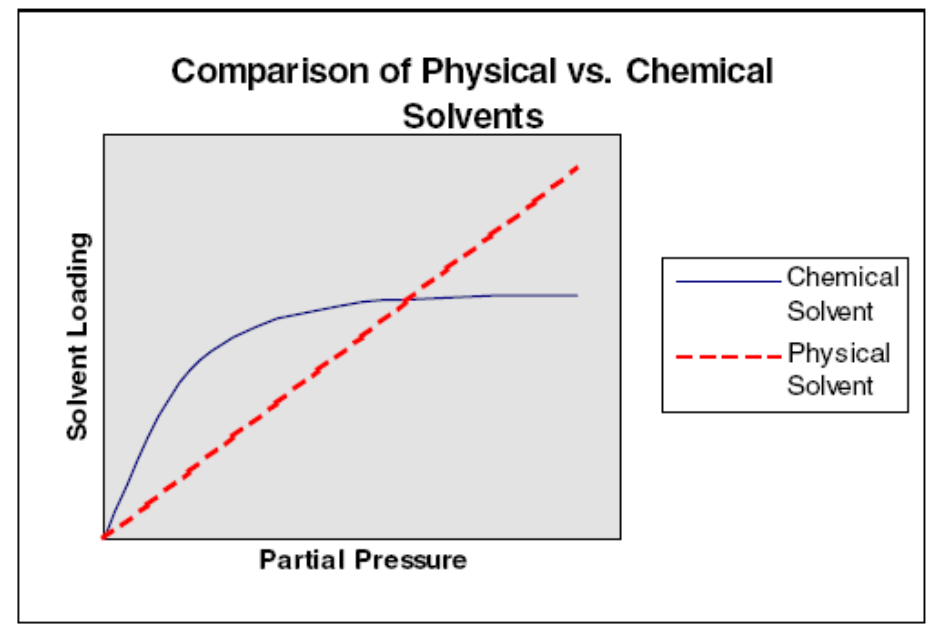

Figure 36 Characteristics for Chemical and Physical Solvents [Sciamanna, 1988] 
Higher partial pressure leads to higher solubility in physical solvents of all components of a gas stream, so another attractive feature of the Selexol system is that it has a more favorable solubility for the acid gases versus other light gases. Compared to acid gases, $\mathrm{H}_{2}$ and $\mathrm{CO}$ have much lower solubility in the solvent. For instance, as shown in Table 16, $\mathrm{CO}_{2}$ is 75 times more soluble than $\mathrm{H}_{2}$, and $\mathrm{H}_{2} \mathrm{~S}$ is 670 times more soluble than $\mathrm{H}_{2}$ in Selexol.

Table 16 Relative solubility of gases in Selexol solvent [Doctor, 1994]

\begin{tabular}{|l|l|l|l|l|l|l|l|l|l|l||}
\hline \hline Gas & $\mathrm{CO}_{2}$ & $\mathbf{H}_{\mathbf{2}}$ & $\mathrm{CH}_{\mathbf{4}}$ & $\mathrm{CO}$ & $\mathrm{H}_{\mathbf{2}} \mathbf{S}$ & $\mathrm{COS}$ & $\mathbf{S O}_{2}$ & $\mathrm{NH}_{\mathbf{3}}$ & $\mathbf{N}_{\mathbf{2}}$ & $\mathbf{H}_{\mathbf{2}} \mathrm{O}$ \\
\hline \hline Solubility & 1 & 0.01 & 0.0667 & 0.028 & 8.93 & 2.33 & 93.3 & 4.87 & 0 & 733 \\
\hline
\end{tabular}

Table 17 shows the actual solubility of various gases at $25^{\circ} \mathrm{C}$ in the Selexol solvent. The solubility data in Table 17 are based on single component solubility. It would be expected that these values should be approximately the same for non-polar components even in acid gas loaded solvents [Korens, 2003].

Table 17 Solubility of Gases in the Selexol Solvent [Korens, 2002]

\begin{tabular}{|l|l|l|l|l|l|l|l|l|l|l||}
\hline \hline Gas & $\mathrm{CO}_{2}$ & $\mathrm{H}_{2}$ & $\mathrm{CH}_{4}$ & $\mathrm{CO}$ & $\mathrm{H}_{2} \mathrm{~S}$ & $\mathrm{COS}$ & $\mathrm{HCN}$ & $\mathrm{C}_{6} \mathrm{H}_{6}$ & $\mathrm{CH}_{3} \mathrm{SH}$ & $\mathrm{H}_{2} \mathrm{O}$ \\
\hline \hline Solubility & 3.1 & 0.03 & 0.2 & 0.08 & 21 & 7.0 & 6600 & 759 & 68 & 2200 \\
\hline Ncm2/g.bar $@ 25^{\circ} \mathrm{C}$ \\
\hline
\end{tabular}

The solvent may be regenerated by releasing the absorbed sour gases. The regeneration step for Selexol can be carried out by either thermally, or flashing, or stripping gas. In addition to its solubility, the Selexol solvent has some other positive advantages to gasification applications [Kubek, 2000].

- A very low vapor pressure that limits its losses to the treated gas

- Low viscosity to avoid large pressure drop

- High chemical and thermal stability (no reclaiming or purge) because the solvent is true physical solvent and does not react chemically with the absorbed gases [Shah, 1988]

- Non-toxic for environmental compatibility and worker safety

- Non-corrosive for mainly carbon steel construction: the Selexol process allows for construction of mostly carbon steel due to its non-aqueous nature and inert chemical characteristics

- Non-foaming for operational stability

- Compatibility with gasifier feed gas contaminants

- High solubility for $\mathrm{HCN}$ and $\mathrm{NH}_{3}$ allows removal without solvent degradation

- High solubility for nickel and iron carbonyls allows for their removal from the synthesis gas. This could be important to protect blades in downstream turbine operation.

- Low heat requirements for regeneration because the solvent can be regenerated by a simple pressure letdown 


\section{Selexol Absorber System}

This section presents a technical overview of Selexol absorption processes for acid gases removal, with particular focus on the effects of the acid gas removal requirements on the design of the Selexol process.

\section{Standard Configuration}

Although a Selexol process can be configured in various ways, depending on the requirements for the level of $\mathrm{H}_{2} \mathrm{~S} / \mathrm{CO}_{2}$ selectivity, the depth of sulfur removal, the need for bulk $\mathrm{CO}_{2}$ removal, and whether the gas needs to be dehydrated, this process always includes the following steps:

- Sour gas absorption

- Solvent regeneration/ \& sour gas recovery

- Solvent cooling and recycle

Through taking advantage of the high $\mathrm{H}_{2} \mathrm{~S}$ to $\mathrm{CO}_{2}$ selectivity of Selexol solvent, Selexol solvent processes can also be configured to capture $\mathrm{H}_{2} \mathrm{~S}$ and $\mathrm{CO}_{2}$ together with high levels of $\mathrm{CO}_{2}$ recovery. This is usually accomplished by staging absorption for a high level of $\mathrm{H}_{2} \mathrm{~S}$ removal, followed by $\mathrm{CO}_{2}$ removal. Figure 37 shows a Selexol process layout for synthesis gas treating where a high level of both sulfur and $\mathrm{CO}_{2}$ removal are required. $\mathrm{H}_{2} \mathrm{~S}$ is selectively removed in the first column by a lean solvent, and $\mathrm{CO}_{2}$ is removed from the $\mathrm{H}_{2} \mathrm{~S}$-free gas in the second absorber. The second-stage solvent can be regenerated with air or nitrogen if very deep $\mathrm{CO}_{2}$ removal is required.
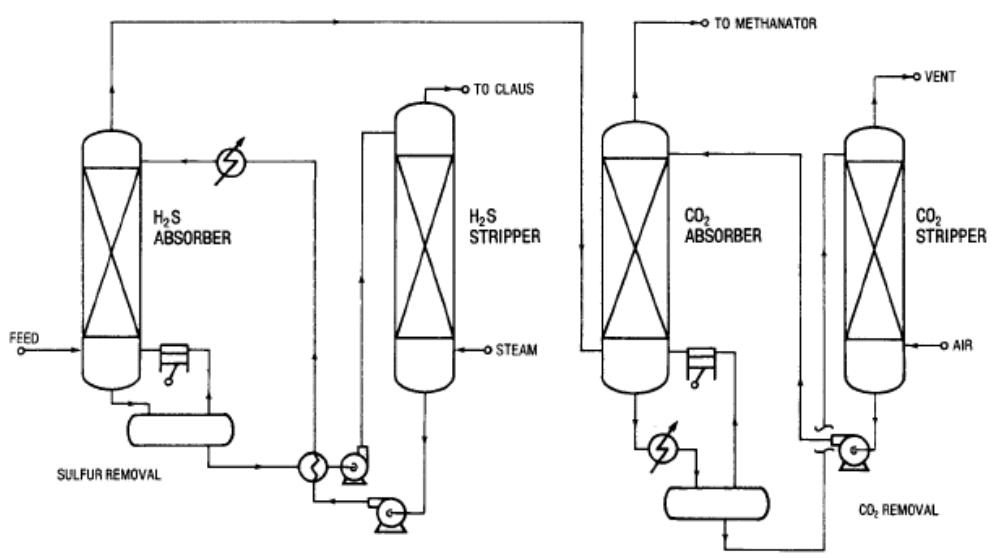

Figure 37 Selexol Process for Sulfur and $\mathrm{CO}_{2}$ Removal [Kohl, 1985]

A COS hydrolysis unit may be added to the configuration shown in Figure 37 to achieve a higher level of removal of $\mathrm{H}_{2} \mathrm{~S}$ and COS. At the Sarlux IGCC plant in Italy, which gasifies petroleum pitch, the Selexol unit allows a COS hydrolysis step and gives an acid gas that is $50-80$ vol. $\% \mathrm{H}_{2} \mathrm{~S}$ to the Claus plant. This acid gas composition is the result of an $\mathrm{H}_{2} \mathrm{~S}$ enrichment factor of about 2 to 3 through the Selexol unit. The $\mathrm{H}_{2} \mathrm{~S}$ content of the purified gas from the Selexol absorber at that plant is about 30 ppmv [Korens, 2002].

\section{Optimized Configurations}

A variety of flow schemes of Selexol processes permits process optimization and energy reduction. The following is a description of an optimal design of a Selexol process which removes sulfur and $\mathrm{CO}_{2}$ from syngas from IGCC systems. This 
optimal design is based on revising a Selexol process, originally designed by UOP, for $\mathrm{H}_{2} \mathrm{~S}$ and $\mathrm{CO}_{2}$ removal from syngas for the production of ammonia (UOP, 2002).

The $\mathrm{H}_{2} \mathrm{~S}$ Absorption flowsheet for the optimized configuration is shown in Figure 38. Syngas from the gas cooling section of the gasification process enters the $\mathrm{H}_{2} \mathrm{~S}$ absorber where it is contacted with $\mathrm{CO}_{2}$-saturated Selexol solvent from the $\mathrm{CO}_{2}$ removal portion of the facility. The pre-saturated solvent from the $\mathrm{CO}_{2}$ removal area is chilled with refrigeration before being fed into the absorber, which can increase the $\mathrm{CO}_{2}$ and $\mathrm{H}_{2} \mathrm{~S}$ loading capacity of the solvent. The use of pre-loaded solvent prevents additional $\mathrm{CO}_{2}$ absorption in the $\mathrm{H}_{2} \mathrm{~S}$ absorber, and it also minimizes the temperature rise across the tower, which negatively affects the $\mathrm{H}_{2} \mathrm{~S}$ solubility and the selectivity of the solvent. $\mathrm{H}_{2} \mathrm{~S}$ is removed from the syngas.

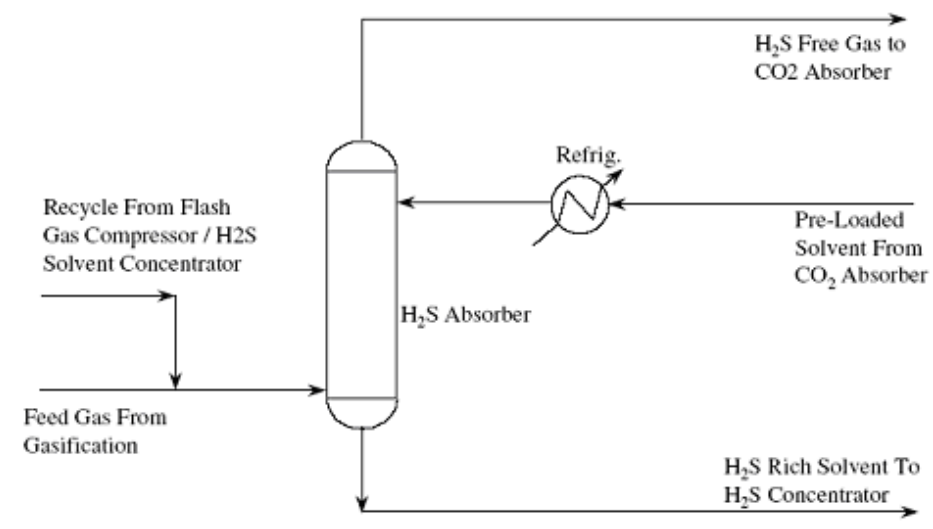

Figure 38 Optimized Selexol absorption process for $\mathrm{H}_{2} \mathrm{~S}$ removal

The $\mathrm{H}_{2} \mathrm{~S}$ absorber overhead stream is mixed with the entire solvent stream from the $\mathrm{CO}_{2}$ absorber. Therefore, bulk $\mathrm{CO}_{2}$ is removed in this pre-contacting stage which reduces the loading in the $\mathrm{CO}_{2}$ absorber. The rich solvent from the $\mathrm{H}_{2} \mathrm{~S}$ absorber is next fed into the $\mathrm{H}_{2} \mathrm{~S}$ solvent regeneration facility.

Figure 39 presents a process flow diagram for the optimized $\mathrm{H}_{2} \mathrm{~S}$ solvent regeneration section. The rich solvent from the $\mathrm{H}_{2} \mathrm{~S}$ absorber is pumped to high pressure and heated in the lean / rich exchanger. The solvent then enters the $\mathrm{H}_{2} \mathrm{~S}$ solvent concentrator, which operates at a pressure higher than the $\mathrm{H}_{2} \mathrm{~S}$ absorber, thus the recycle gases can be recycled to the $\mathrm{H}_{2} \mathrm{~S}$ absorber without compression.

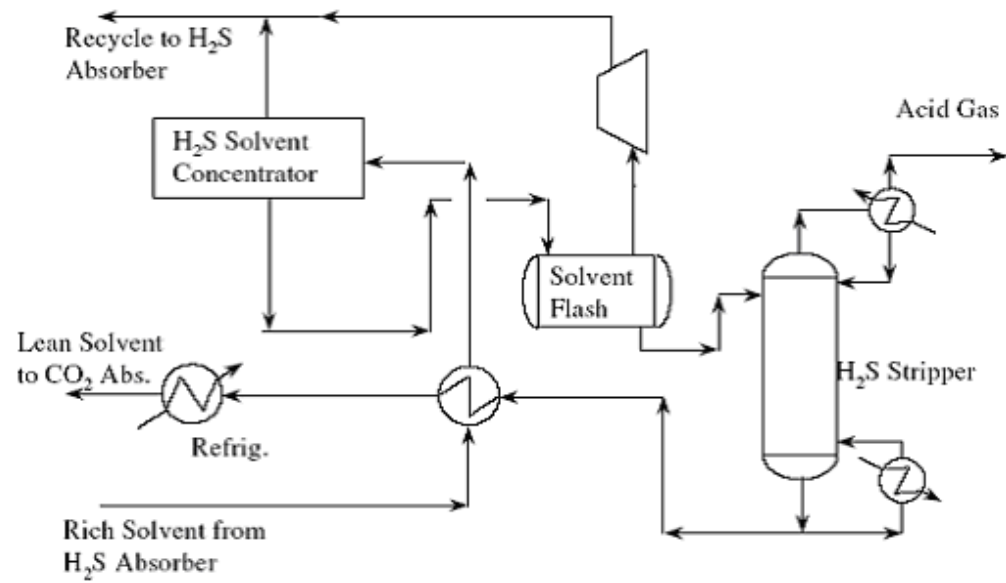

Figure 39 Optimized $\mathrm{H}_{2} \mathrm{~S}$ Solvent Regeneration 
Due to the relative difference in solubility of $\mathrm{CO}_{2}$ and $\mathrm{H}_{2} \mathrm{~S}$ in Selexol solvents, $\mathrm{CO}_{2}$ is removed from solution preferentially over $\mathrm{H}_{2} \mathrm{~S}$, which results in an enriched $\mathrm{H}_{2} \mathrm{~S}$ concentration in the solvent. The $\mathrm{CO}_{2}$ removed in the $\mathrm{H}_{2} \mathrm{~S}$ solvent concentrator is the majority of the recycle gases back to the $\mathrm{H}_{2} \mathrm{~S}$ absorber.

The enriched solvent from the $\mathrm{H}_{2} \mathrm{~S}$ solvent concentrator is flashed down to lower pressure. The flash gas again contains a higher proportion of $\mathrm{CO}_{2}$ than $\mathrm{H}_{2} \mathrm{~S}$. This stream is also recycled back to the $\mathrm{H}_{2} \mathrm{~S}$ absorber. This recycle stream is relatively small because much of the $\mathrm{CO}_{2}$ was removed at high pressure. The solvent from the flash drum enters the Selexol stripper for regeneration.

The optimized $\mathrm{CO}_{2}$ absorption flowsheet is shown in Figure 40. In this optimization design, the entire $\mathrm{CO}_{2}$ solvent flow is contacted with the $\mathrm{H}_{2} \mathrm{~S}$ absorber overhead stream in the pre-contacting stage. The heat of absorption is removed from this precontacting stage in a refrigeration chiller. The relatively high temperature of this stream allows setting high temperature refrigeration, which reduces the power consumption of the refrigeration system. The solvent is cooled to optimum absorption temperatures when the pressure is reduced in the flash regeneration portion of the facility.

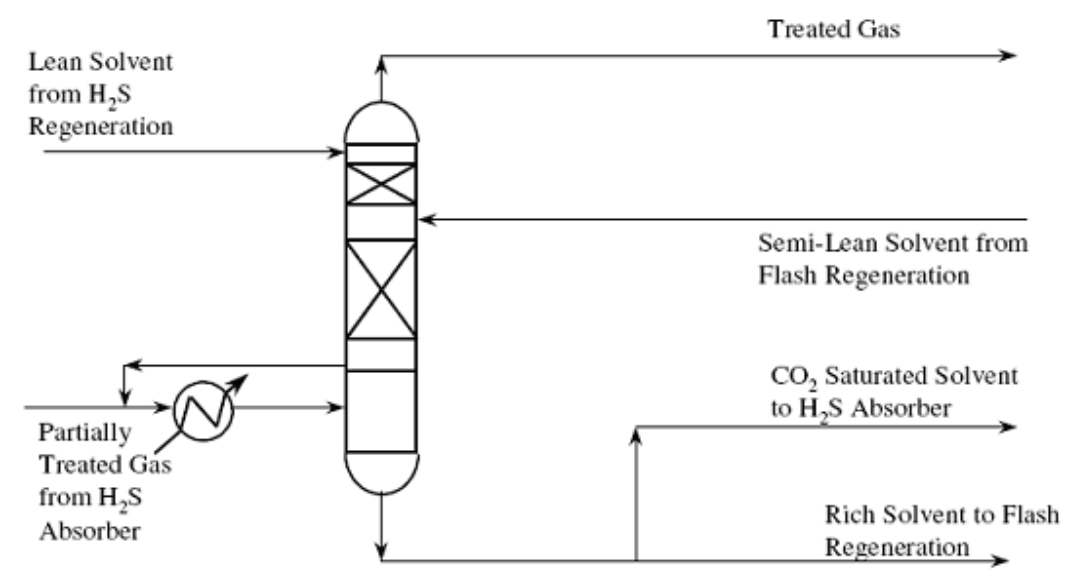

Figure 40 Optimized Selexol process for $\mathrm{CO}_{2}$ absorption

A portion of the rich $\mathrm{CO}_{2}$ solvent is returned to the $\mathrm{H}_{2} \mathrm{~S}$ absorber as pre-saturated solvent. The remainder of the solvent is flash regenerated and will be presented below. The top bed of the tower uses lean solvent from the $\mathrm{H}_{2} \mathrm{~S}$ regeneration facility to contact the syngas. This allows the $\mathrm{CO}_{2}$ to be removed to levels lower than could be achieved using only flash regenerated (semi-lean) solvent.

Rich $\mathrm{CO}_{2}$ is flash regenerated as shown in Figure 41. The flash regeneration uses one sump tank, one or two power recovery turbines, and three stages of flash. The $\mathrm{CO}_{2}$ rich solvent leaving the bottom of the $\mathrm{CO}_{2}$ absorber enters the sump tank at a reduced pressure, where most $\mathrm{H}_{2}$ and a small amount of $\mathrm{CO}_{2}$ captured in the Selexol are released and recycled back to the pre-contacting stage. 


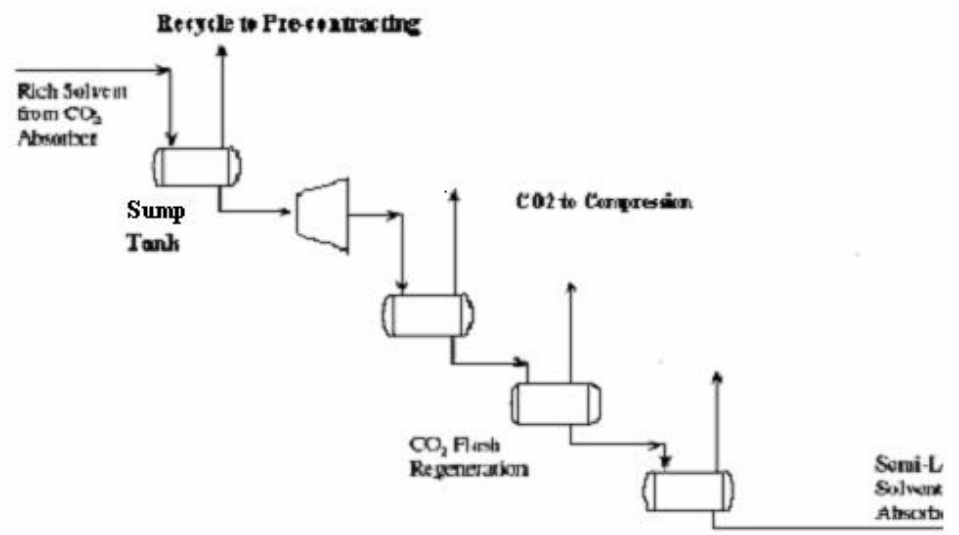

Figure 41 Optimized Selexol regeneration through $\mathrm{CO}_{2}$ flash

The $\mathrm{CO}_{2}$ rich solvent with high pressure is delivered to one or two hydraulic power recovery turbines to recover the pressure energy before it is fed into three flash drums, where $\mathrm{CO}_{2}$ is released at staged pressures to reduce the power consumption of $\mathrm{CO}_{2}$ compression later.

A key limitation of Selexol systems is the operating temperature requirement. The operating temperature for Selexol systems is typically approximately $100^{\circ} \mathrm{F}$. Hence a reasonable location of Selexol process in an IGCC system is down stream of the syngas cooling section.

\section{Performance Model}

As a patented commercial solvent, the detailed characteristics of the Selexol solvent are not available. Hence in this section, a semi-analytical, semi-regression performance model of Selexol systems for $\mathrm{CO}_{2}$ capture is presented. This section discusses the methodology of setting up a performance model of Selexol process for $\mathrm{CO}_{2}$ capture. A cost model of the Selexol process, shown later, is based on this performance model.

\section{Temperature Effect on Gas Solubility}

The solubility of a gas in Selexol depends on its partial pressure and temperature. The solubility of $\mathrm{CO}_{2}$ as a function of temperature is regressed based on published data [Doctor 1996, Black 2000] and given in Equation (43),

$$
\chi_{\mathrm{CO}_{2}}=0.0908-0.0008 T \quad \mathrm{R}^{2}=0.95
$$

where

$$
\mathrm{T}=\text { solvent temperature with a range of } 30 \sim 77^{\circ} \mathrm{F}
$$

The solubility of other gases at different temperature is not available. Here the relative solubility of other gases to $\mathrm{CO}_{2}$ at different temperature is assumed to be constant.

\section{Solvent Flow Rate}

The input and output parameters of this model are given in Table 18. For the performance simulation, the first step is to calculate the flow rate of the solvent. In 
order to determine the solvent flow rate, the examination of the entire Selexol process can be reduced to a simpler model, as shown in Figure 42.

Table 18 Input and output parameters of Selexol model

\begin{tabular}{|c|c|c|c|c|c|}
\hline \multicolumn{3}{|c|}{ Input parameter } & \multicolumn{3}{|c|}{ Output parameter } \\
\hline \multirow{11}{*}{$\begin{array}{l}\text { Syngas } \\
\text { input }\end{array}$} & Flow rate $(\mathrm{mole} / \mathrm{s})$ & $f_{1}$ & \multirow{11}{*}{$\begin{array}{l}\text { Fuel gas } \\
\text { output }\end{array}$} & Flow rate (mole/s) & $f_{2}$ \\
\hline & Pressure & $\mathrm{p}_{1}$ & & Pressure & $\mathrm{p}_{2}$ \\
\hline & Temperature & $\mathrm{T}_{1}$ & & Temperature & $\mathrm{T}_{2}$ \\
\hline & \multirow{8}{*}{$\begin{array}{l}\text { Molar } \\
\text { concentrations }\end{array}$} & {$[\mathrm{CO}]_{1}$} & & \multirow{8}{*}{$\begin{array}{l}\text { Molar } \\
\text { concentrations }\end{array}$} & {$[\mathrm{CO}]_{2}$} \\
\hline & & {$\left[\mathrm{CO}_{2}\right]_{1}$} & & & {$\left[\mathrm{CO}_{2}\right]_{2}$} \\
\hline & & {$\left[\mathrm{H}_{2}\right]_{1}$} & & & {$\left[\mathrm{H}_{2}\right]_{2}$} \\
\hline & & {$\left[\mathrm{CH}_{4}\right]_{1}$} & & & {$\left[\mathrm{CH}_{4}\right]_{2}$} \\
\hline & & {$\left[\mathrm{H}_{2} \mathrm{~S}\right]_{1}$} & & & {$\left[\mathrm{H}_{2} \mathrm{~S}\right]_{2}$} \\
\hline & & {$[\mathrm{COS}]_{1}$} & & & {$[\mathrm{COS}]_{2}$} \\
\hline & & {$\left[\mathrm{NH}_{3}\right]_{1}$} & & & {$\left[\mathrm{NH}_{3}\right]_{2}$} \\
\hline & & {$\left[\mathrm{H}_{2} \mathrm{O}\right]_{1}$} & & & {$\left[\mathrm{H}_{2} \mathrm{O}\right]_{2}$} \\
\hline \multirow{3}{*}{\multicolumn{3}{|c|}{$\mathrm{CO}_{2}$ removal percentage }} & \multirow{2}{*}{$\mathrm{CO}_{2}$ flow } & Flow rate $(\mathrm{mole} / \mathrm{s})$ & $f_{5}$ \\
\hline & & & & Pressure & $\mathrm{P}_{5}$ \\
\hline & & & $\begin{array}{l}\text { Refrig. } \\
\text { power }\end{array}$ & Power recovery & $\begin{array}{l}\text { Comp. } \\
\text { power }\end{array}$ \\
\hline
\end{tabular}

Stream $\mathrm{S} 1$ is the syngas fed into the absorber at a given temperature, and $\alpha$ percent of $\mathrm{CO}_{2}$ is removed from the syngas. Stream $\mathrm{S} 4$ is the lean solvent at a design temperature. Due to heat transfer between the solvent and syngas and the absorption heat, the temperature of the rich solvent (stream $\mathrm{S} 3$ ) will be increased by $\Delta \mathrm{T}$. For the given $\mathrm{CO}_{2}$ removal efficiency $\alpha$, the flow rate of solvent, fuel gas and $\mathrm{CO}_{2}$ can be calculated as follows.

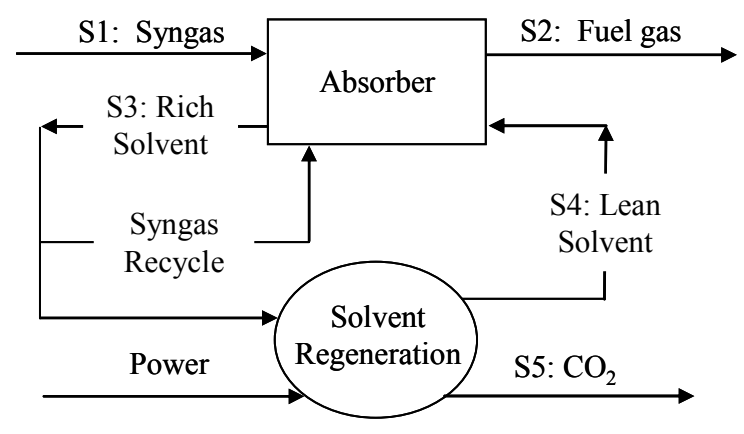

Figure 42 Simplified Selexol process

As mentioned in "Temperature Effect on Gas Solubility" above, the solubility of gases in Selexol is a function of temperature. For calculating the flow rate of solvent, the first step is to estimate the temperature change of solvent in the absorber.

Assuming the flow rate of solvent is $\omega \mathrm{lb}-\mathrm{mol} / \mathrm{hr}$, the temperature increase of solvent in the absorber is given by Equation (44):

$\Delta T=\Delta T_{1}+\Delta T_{2}$

According to the amount of heat transferred between the syngas and solvent, and the specific heat of the solvent, the temperature increase due to heat transfer is calculated by Equation (45): 


$$
\Delta T_{1}=\frac{Q_{1}}{\omega \cdot M W_{S e l} C_{p, s}}
$$

The temperature increase can be estimated according to the energy balance given by Equation (46):

$$
\begin{aligned}
Q_{1} & =\left(T_{S G, i}-T_{S G, o}\right) f_{S G, i}\left\{2.02\left[\mathrm{H}_{2}\right]_{1} C_{p, H_{2}}+16\left[\mathrm{CH}_{4}\right]_{1} C_{p, C H_{4}}\right. \\
& \left.+28[C O]_{1} C_{p, C O}+44\left[\mathrm{CO}_{2}\right]_{1}(1-\alpha) C_{p, C O_{2}}\right\} \\
& +44\left(T_{S G, i}-T_{S G, o}-\Delta T\right) f_{S G, i} \alpha\left[\mathrm{CO}_{2}\right]_{1} C_{p, C O_{2}}
\end{aligned}
$$

Specific heats $C_{p, i}$ of several gases are provided in Table 19

Table 19 Specific heat of gases in the syngas

\begin{tabular}{|l|l|l|l|l|l|l|l|l||}
\hline Gas & $\mathbf{C O}$ & $\mathbf{C O}_{2}$ & $\mathbf{H}_{\mathbf{2}}$ & $\mathbf{C H}_{4}$ & $\mathbf{A r}$ & $\mathbf{N}_{\mathbf{2}}$ & $\mathbf{H}_{\mathbf{2}} \mathbf{S}$ & $\mathbf{N H}_{\mathbf{3}}$ \\
\hline \hline $\begin{array}{l}\text { Specific heat } \\
\text { (Btu/lb F) }\end{array}$ & 0.248 & 0.199 & 3.425 & 0.593 & 0.125 & 0.249 & 0.245 & 0.52 \\
\hline
\end{tabular}

Table 20 Solution heat (Btu/lb-solute) of gases in the Selexol

\begin{tabular}{|l|l|l|l||}
\hline Gas & $\mathrm{CO}_{2}$ & $\mathrm{H}_{2} \mathbf{S}$ & $\mathrm{CH}_{3}$ \\
\hline \hline Heat of solution (Btu/lb-solute) & 160 & 190 & 75 \\
\hline
\end{tabular}

In Equation (44), $\Delta T_{2}$ is caused by the solution heat. Equation (47) calculates only the solution heat of $\mathrm{CO}_{2}$. The solution heat of other gases is negligible because the amount of other gases captured by Selexol is much less than that of $\mathrm{CO}_{2}$.

$$
\Delta T_{2}=\frac{44 f_{S G, i}\left[\mathrm{CO}_{2}\right]_{1} \alpha \psi_{\mathrm{CO}_{2}}}{\omega M W_{S e l} C_{p, S e l}}
$$

The solution heat $\psi_{\mathrm{CO}_{2}}$ of several gases is given in Table 20 [Korens, 2002].

In the flash tanks, the residual time is long enough to assume that equilibrium can be achieved in these tanks. In the last flash tank, the solvent temperature is about $\left(30+\Delta T_{1}\right)$, hence the volume and mass flow rate of the residual $\mathrm{CO}_{2}$ in the lean solvent (stream S4 in Figure 42) can be given by Equations (48) and (49) :

$$
\begin{aligned}
& V_{\mathrm{CO}_{2}, \text { res }}\left(\frac{S C F}{h r}\right)=S V_{s e l} \omega p_{\mathrm{CO}_{2}} \chi_{\mathrm{CO}_{2}} \\
& m_{\mathrm{CO}_{2}, \text { res }}\left(\frac{l b \cdot \mathrm{mol}}{h r}\right)=\frac{V_{\mathrm{CO}_{2}, r e s}}{S V_{\mathrm{CO}_{2}}}
\end{aligned}
$$

According to the $\mathrm{CO}_{2}$ capture percentage in the absorber, the amount of $\mathrm{CO}_{2}$ that needs be captured by the solvent is given by Equation $\underline{(50)}$ :

$$
V_{\mathrm{CO}_{2}, a b s}\left(\frac{\mathrm{SCF}}{\mathrm{hr}}\right)=\mathrm{SV}_{\mathrm{CO}_{2}} f_{S G, i}\left[\mathrm{CO}_{2}\right]_{1} \alpha
$$

In the absorber, the equilibrium cannot be achieved due to the limited residual time. The flow rate of solvent used in the absorber is larger than that of the solvent required to capture $\alpha$ percentage of $\mathrm{CO}_{2}$ at equilibrium. The ratio of the actual flow 
rate to the equilibrium flow rate of the solvent was regressed based on published data [Doctor, 1994, 1996, Sciamanna, 1988]. The ratio is given in Equation (51):

$$
\gamma=\frac{1.26}{(1-\alpha)^{0.07}}-0.0002 p_{1} \quad \quad \mathrm{R}^{2}=0.8
$$

Then the flow rate of Selexol for capturing $\alpha$ percentage of $\mathrm{CO}_{2}$ is given by Equation (52):

$$
\omega\left(\frac{l b \cdot m o l}{h r}\right)=\frac{\gamma\left(V_{\mathrm{CO}_{2}, r e s}+V_{\mathrm{CO}_{2}, a b s}\right)}{S V_{s e l} p_{1}\left[C \mathrm{CO}_{2}\right]_{1} \chi_{C O_{2}, 1}}
$$

Based on the above discussion, the calculation process for the flow rate of Selexol is concluded as in the following. First assuming the temperature of the Selexol solvent in the absorber is increased by $\left(\Delta T_{1}+\Delta T_{2}\right)$, then the solubility of $\mathrm{CO}_{2}$ at this increased temperature can be calculated. Second the solubility of $\mathrm{CO}_{2}$ at the solvent in the last flash tank is calculated at the temperature $\left(30+\Delta T_{1}\right)$. Given the amount of $\mathrm{CO}_{2}$ needed to be required, the flow rate of the solvent is calculated based on the solubility difference between the solvent in the absorber and in the last stage flash tank. Then the new values of $\Delta T_{1}$ and $\Delta T_{2}$ are computed using the calculated solvent flow rate of solvent. Such calculation process continues until the flow rate of the solvent is convergent. This calculation process is represented by Figure 43:

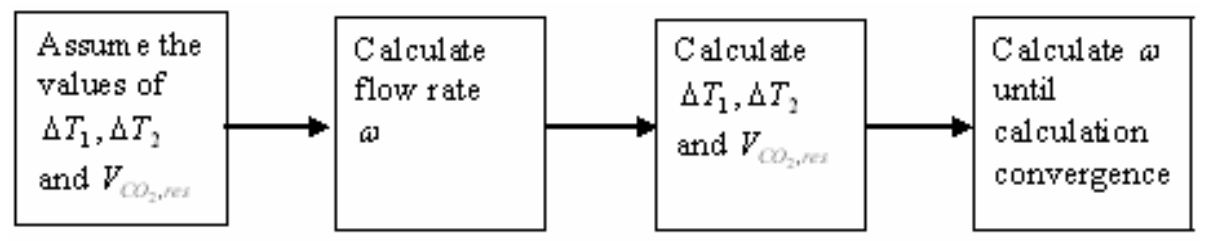

Figure 43 Calculation process for the flow rate of Selexol

\section{Composition and flow rate of fuel gas}

After $\mathrm{CO}_{2}$ capture, the syngas is converted into the fuel gas, the main component of which is hydrogen. The composition and flow rate of the fuel gas can be calculated as follows.

Knowing the Selexol flow rate and solubility of gases in the Selexol, the volume and mass amount of species $i$ that are captured by the solvent is given by Equations (53) and (54):

$$
\begin{aligned}
& V_{i}\left(\frac{S C F}{h r}\right)=S V_{s e l} \cdot \omega \cdot p_{i} \cdot \chi_{i} \\
& m_{i}\left(\frac{l b \cdot m o l}{h r}\right)=\frac{V_{i}}{v_{i}}
\end{aligned}
$$

In the sump tank, most of the $\mathrm{H}_{2}$, and $\mathrm{CH}_{4}$ captured in the Selexol are released and recycled back to the absorber. Because the solubility of $\mathrm{CO}_{2}$ is much higher, only a tiny amount of $\mathrm{CO}_{2}$ is released in the sump tank. The operating pressure of the sump tank is a design parameter. For this study, the operating pressure is determined to keep the loss of $\mathrm{H}_{2}$ to Selexol solvent no more than $1 \%$ of $\mathrm{H}_{2}$ in the syngas. The calculation process for the sump tank is as the follows: assuming the operating pressure is $p_{\text {sump }}$, the volume of species $i$ released from the sump tank is $V_{i}^{\prime}$, then the 
partial pressure $p_{i, \text { sump }}$ can be given by Equation (55). According to mass

conservation, the total volume of species $i$ captured in the absorber equals the volume released in the sump tank plus the volume retained in the solvent in the tank, expressed as Equation (56). Now recalling the Equation (53), the volume of species is retained in the solvent in the tank can calculated as Equation (57). Iteratively calculate Equations (55), (56), and (57) until the partial pressures are converged. If at the given operating pressure, the $\mathrm{H}_{2}$ volume retained in the solvent does not meet the design value, then the operating pressure is adjusted and the calculation is run again. The calculation procedure is given by Figure 44 .

$$
\begin{aligned}
& p_{i, \text { sump }}=\frac{V_{i}^{\prime}}{\sum_{i} V_{i}^{\prime}} p_{\text {sump }} \\
& V_{i}=V_{i, \text { sump }}+V_{i}^{\prime} \\
& V_{i, \text { sump }}\left(\frac{S C F}{h r}\right)=32.574 \omega \cdot p_{i, \text { sump }} \cdot \chi_{i}
\end{aligned}
$$

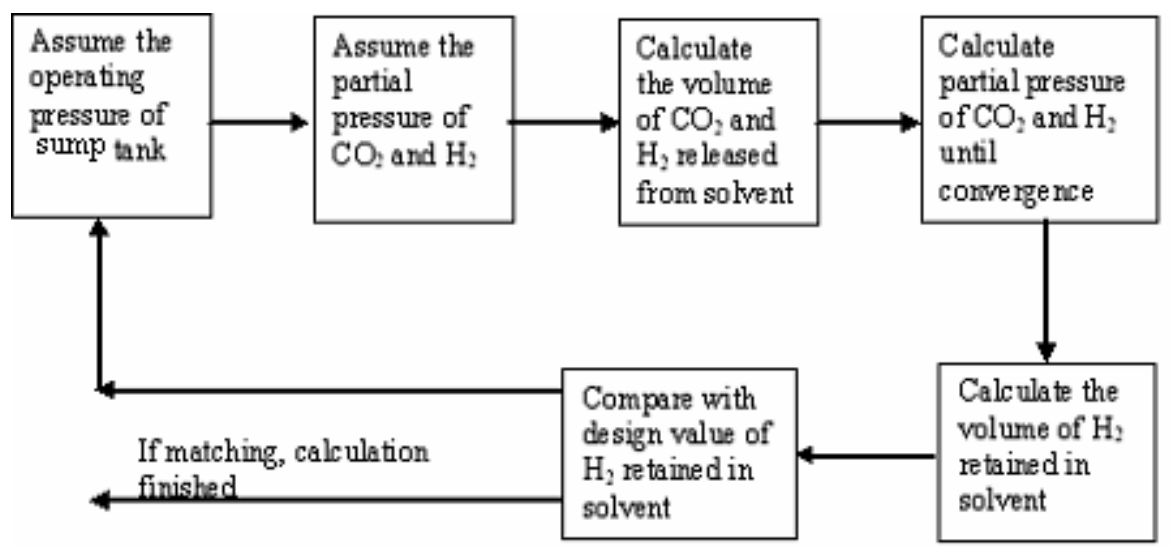

Figure 44 Calculation process for the operating pressure of the sump tank

\section{Composition and flow rate of $\mathrm{CO}_{2}$ rich flow}

At each stage of the flash tanks, the flash pressure is given. At this pressure, the residual gases in the lean solvent can be calculated based on their solubility. Based on mass conservation, the composition and flow rate of $\mathrm{CO}_{2}$ rich flow from the flash tanks can also be calculated, and the calculation procedure is similar to that shown in Figure 44.

\section{Power Requirements}

There is no heat duty in the Selexol process because the solvent is regenerated through pressure flashing, but the power input is required to compress the recycling gas from the sump tank, the lean solvent from the flash tank 3, and the $\mathrm{CO}_{2}$ rich product. At the same time, some electricity can be generated through the power recovery hydro turbine. The total power consumption is the difference between the power input and the recovered power from the turbine. 


\section{Power recovery}

In this performance model, the pressure of the high-pressure rich solvent from the absorber is reduced and the energy is recovered through one or two hydro turbines. According to the designs in other studies [Doctor, 1994, 1996, Sciamanna, 1988, Black, 2000], a thumb rule of design is concluded here. If the pressure of $\mathrm{CO}_{2}$ rich Selexol flow is larger than 240 psia, two power recovery turbines will be used. Otherwise, only one power recovery turbine will be used. Generally, this outlet pressure $\left(P_{o, 1}\right.$, psia) of the turbine can be determined based on the system pressure as shown in Equation (58):

$P_{o, 1}=0.0402 P_{i, 1}^{1.415}$

where

$$
\left(150 \leq p_{i, 1} \leq 1000\right)
$$

If the pressure of the $\mathrm{CO}_{2}$ rich Selexol flow is larger than 240 psia, then the outlet pressure of the second turbine is given by Equation (59):

$p_{o, 2}=35.619 \ln \left(p_{i, 1}\right)-169.88$

where

$$
\left(240 \leq p_{i, 1} \leq 1000\right)
$$

The power recovered from the liquid solvent is calculated from the following expression [Doctor, 1994],

$h p_{\text {tur }}=H_{S e l} \cdot \frac{f_{\mathrm{Sel}_{2}}}{1714} \cdot \eta_{\text {tur }}$

The temperature change of the solvent in the turbine can be calculated based on the change in enthalpy, which equals flow work, $\int v d p$. For the default efficiency of turbines, $78 \%$, the temperature can be given by,

$d T_{\text {tur }}=0.0047 \cdot d P_{\text {tur }}-0.0715$

\section{$\mathrm{CO}_{2}$ Compression}

There are three flashing pressure levels for $\mathrm{CO}_{2}$ release. The design of the flashing pressures in the three flashing tanks is an optimal problem, but a preliminary study showed that the effect of flashing pressures on the power consumption of the Selexol processes is not considerable. Hence, some default values are adopted here for the process design. If the system pressure is larger than $240 \mathrm{psia}$, the first flashing pressure equals the outlet pressure of the second turbine. If the system pressure is less than $240 \mathrm{psia}$, the first flashing pressure is set to be $25 \mathrm{psia}$. The second flashing pressure is set to be $14.7 \mathrm{psia}$, and the last flashing pressure is set to be 4 psia.

In each flashing tank, the gases released from solvent are calculated. $\mathrm{CO}_{2}$ released from flash tank 2 and tank 3 is compressed to the flashing pressure of tank 1 . The $\mathrm{CO}_{2}$ stream is finally compressed to a high pressure (>1000psia) for storage using a multi-stage, inter-stage cooling compressor. The power required by the $\mathrm{CO}_{2}$ compressors is estimated by [Doctor, 1994], 
$h p_{\text {comp } .}=\frac{0.00436}{\eta_{\text {comp. }}} V F_{\text {gas }} P_{\text {comp }, i}\left(\frac{k}{k-1}\right)\left[\left(\frac{P_{\text {comp }, o}}{P_{\text {comp., }, i}}\right)^{\left(\frac{k_{\text {gas }}-1}{k_{\text {gas }}}\right)}-1\right]$

\section{Solvent compression work}

The $\mathrm{CO}_{2}$-lean solvent is pumped back to the absorber operating pressure by a circulation pump. The power required by the circulation pump is estimated in a similar way as done in Equation (60):

$$
h p_{\text {pump }}=H_{s} \frac{f_{\text {Sel }}}{1714 \eta_{\text {pump }}}
$$

\section{Recycle gas compression work}

The gases from the sump tank are recycled to the absorber. A compressor is used to compress the gases to the operating pressure of the absorber. The power of the compressor is estimated using Equation (62).

\section{Solvent refrigeration}

Before the $\mathrm{CO}_{2}$-lean solvent fed into the absorber, it has to be cooled down to the absorber operating temperature $\left(30^{\circ} \mathrm{F}\right)$ by refrigeration. The refrigeration power in $\mathrm{kW}$ is estimated by [Doctor, 1994],

$$
W_{\text {ref. }}=\frac{\text { refrigeration load }\left(\frac{B t u}{h r}\right)}{1000\left(9+\frac{T_{\text {evap }}\left({ }^{\circ} F\right)}{10}\right)}
$$

\section{Makeup of the Selexol solvent}

The vapor pressure of the Selexol solvent is $1.35 \times 10^{-5}$ psia at $77^{\circ} \mathrm{F}$, which is very low. The real vapor pressure is even lower because the operating temperature is usually lower than $77^{\circ} \mathrm{F}$. Hence, the loss of solvent due to evaporation is negligible. On the other hand, due to leakage, especially in the start on and turn off processes, a certain amount of solvent is lost. Here the annual loss of solvent is assumed to be approximate $10 \%$ of the total solvent in the system [UOP, 2003].

\section{Capital Costs}

The outputs of this cost model include the process facility cost, total plant cost, total plant investment, total capital requirement, and O\&M cost.

\section{Process Facility Costs}

The major process facility costs of the Selexol system for $\mathrm{CO}_{2}$ capture are considered in the following sub-sections. Each is determined from actual costs and key performance parameters. 


\section{$\mathrm{CO}_{2}$ Absorption Column}

Table 21 Absorber cost data adjusted to the dollar values in 2000 [Doctor, 1996]

\begin{tabular}{||l|l|l|l||}
\hline PFC (2000\$) & P(atm) & $\begin{array}{l}\text { Flow rate of syngas } \\
\text { (lb-mol/h) }\end{array}$ & $\begin{array}{l}\text { Selexol flow rate } \\
\text { (lb-mol/hr) }\end{array}$ \\
\hline \hline $6.3 \mathrm{E}+05$ & 30.35 & 11771.88 & 11815.53 \\
\hline $9.2 \mathrm{E}+05$ & 10.21 & 12418.46 & 20802.84 \\
\hline $1.5 \mathrm{E}+06$ & 16.88 & 17614.58 & 23000 \\
\hline $1.3 \mathrm{E}+06$ & 68.05 & 17614.58 & 6900 \\
\hline
\end{tabular}

Using the data in Table 21, the process facility costs of the absorption column are regressed as a function of the operating pressure, the flow rates of the solvent and syngas. The process facility cost for the absorber in 1,000 US\$ for $2000 \$$ is:

$$
P F C_{a b s}=N_{T, a b s}\left[\begin{array}{l}
-1375.356+16.536 \cdot P_{a b s, i} \\
+0.127628\left(\frac{f_{S e l}+f_{\text {gas }}}{2}\right)
\end{array}\right] \quad \mathrm{R}^{2}=0.90
$$

\section{Power Recovery Turbine}

Table 22 Power recovery turbine cost data adjusted to the dollar value in 2000 [Doctor, 1996]

\begin{tabular}{||l|l|l||}
\hline \hline PFC (2000 k\$) & Outlet pressure & Power output(hp) \\
\hline \hline 277.23 & 13.60 & 649 \\
\hline 235.64 & 3.40 & 404 \\
\hline 246.66 & 5.10 & 293 \\
\hline 263.21 & 3.40 & 451 \\
\hline 246.66 & 1.70 & 293 \\
\hline 317.14 & 51.03 & 567 \\
\hline 317.14 & 6.80 & 567 \\
\hline \hline
\end{tabular}

Based on the data in Table 22, the process facility cost of the power recovery turbine is given in 1,000 US\$ for $2000 \$$ as follows:

$$
P F C_{\text {tur }}=219.086+0.080912 h p_{t u r}+0.020086 P_{t u r, o}^{2} \quad \mathrm{R}^{2}=0.91
$$

\section{Sump Tank}

Table 23 Sump tank cost data adjusted to the dollar value in 2000 [Doctor, 1996]

\begin{tabular}{||l|l||}
\hline PFC (2000 k\$) & Selexol flow rate $\mathbf{( k g / s )}$ \\
\hline \hline 179.04 & 416.85 \\
\hline 272.83 & 733.92 \\
\hline 205.11 & 811.44 \\
\hline 205.22 & 811.44 \\
\hline
\end{tabular}

The process facility cost of the sump tank is regressed as a function of the solvent flow rate as given in Table 23. The cost in 1,000 US\$ for 2000\$ is as follows: 


$$
\operatorname{PFC}_{\text {slump }}=2.0049 N_{T, \text { slump }}\left(\frac{f_{\text {Sel }}}{N_{\text {O,slump }}}\right)^{0.7446} \quad \mathrm{R}^{2}=0.87
$$

where

$$
f_{\text {Sel }} \sim 400-800 \mathrm{~kg} / \mathrm{s} \text { per train }
$$

\section{Recycle Compressor}

Table 24 Recycle compressor cost data adjusted to the dollar value in 2000 [Doctor, 1996]

\begin{tabular}{||l|l||}
\hline PFC (2000 1,000 US\$) & Compressor Capacity (hp) \\
\hline \hline 576.64 & 537 \\
\hline 361.19 & 259 \\
\hline 212.55 & 151 \\
\hline 212.55 & 151.3 \\
\hline
\end{tabular}

The process facility cost of the recycle compressor can be determined as a function of the recycle compressor capacity $h p_{R C}$ in 1,000 US $\$$ for $2000 \$$ is given by,

$$
P F C_{R C}=4.45519 h p_{R C}^{0.7784} \quad \mathrm{R}^{2}=0.98
$$

\section{Selexol Pump}

Table 25 Selexol pump cost data adjusted to the dollar value in 2000 [Doctor, 1996]

\begin{tabular}{||l|l||}
\hline PFC (2000 1,000 US\$) & Pump capacity (hp) \\
\hline \hline 301.52 & 2205 \\
\hline 207.29 & 1282 \\
\hline 326.63 & 2388 \\
\hline 326633.3 & 2388 \\
\hline
\end{tabular}

The process facility cost of the Selexol pump can be determined from the Selexol pump capacity $h p_{S P}$. The cost in 1,000 US\$ for $2000 \$$ is given by,

$$
P F C_{S P}=1.2286 h p_{S P}^{0.7164} \quad \mathrm{R}^{2}=0.92
$$

\section{$\mathrm{CO}_{2}$ Compressor}

Table $26 \mathrm{CO}_{2}$ compressor cost data adjusted to the dollar value in 2000 [Doctor, 1996]

\begin{tabular}{||l|l|}
\hline PFC (2000, 1,000 US\$) & Compressor capacity (hp) \\
\hline \hline 323.1754 & 600.41 \\
\hline 311.5061 & 255 \\
\hline 216.2418 & 155.52 \\
\hline 190.1031 & 120.54 \\
\hline 1026.139 & 1086 \\
\hline 576.6455 & 539.71 \\
\hline
\end{tabular}


The process facility cost of the $\mathrm{CO}_{2}$ compressor is determined as a function of the compressor capacity $h p_{\text {comp }}$. The cost in 1,000 US\$ for $2000 \$$ is given by,

$$
P F C_{\text {comp } 1}=7.0321 \text { hp } p_{\text {comp }}^{0.6769} \quad \mathrm{R}^{2}=0.83
$$

\section{$\mathrm{CO}_{2}$ Final Product Compressor}

Table $27 \mathrm{CO}_{2}$ final compressor cost data adjusted to the dollar value in 2000 [Doctor, 1996]

\begin{tabular}{||l|l|}
\hline PFC (2000 k\$) & Compressor Capacity (hp) \\
\hline \hline 2162.421 & 2582 \\
\hline 2851.544 & 2913 \\
\hline 2565.347 & 3369 \\
\hline 2382.109 & 3217 \\
\hline
\end{tabular}

The process facility cost of the multi-stage $\mathrm{CO}_{2}$ compressor is calculated similar to the $\mathrm{CO}_{2}$ compressor cost in Equation (70). Using the data in Table 27, the cost of the final product compressor in US\$ for 2000 is given by,

$$
P F C_{\text {comp } 2}=13.0969 h p_{\text {comp }}^{0.64} \quad \mathrm{R}^{2}=0.85
$$

\section{Refrigeration}

The process facility cost of the refrigeration unit is regressed as,

$$
P F C_{\text {refr }}=1.0019 N_{T, r e f r}\left[16.4796\left(\frac{f_{\text {Sel }}}{N_{O, \text { refr }}}\right)^{0.3618}\left(\Delta T_{\text {Sel }}\right)^{0.4064}\right] \quad \quad \mathrm{R}^{2}=0.97
$$

where

$$
\begin{aligned}
& 7,000<f_{\text {Sel }}<23,000 \mathrm{~kg} / \mathrm{s} \text { per train } \\
& 1<\Delta T_{\text {Sel }}<5{ }^{\circ} \mathrm{C}
\end{aligned}
$$

\section{Flash tank}

Table 28 Flash tank cost data adjusted to the dollar value in 2000 [Doctor, 1996]

\begin{tabular}{||l|l||}
\hline PFC (2000 \$) & Solvent flow rate $\mathbf{( k g / s )}$ \\
\hline \hline 129745.5 & 416.85 \\
\hline 197707.4 & 733.92 \\
\hline 205227.8 & 811.44 \\
\hline
\end{tabular}

The process facility cost of flash tanks is given by,

$$
P F C_{\tan k}=0.9832 \cdot N_{T, \tan k}\left(\frac{f_{S e l}}{N_{O, \tan k}}\right)^{0.8005} \quad \mathrm{R}^{2}=0.89
$$

where

$$
400<f_{S e l}<800 \mathrm{~kg} / \mathrm{s} \text { per train }
$$




\section{Other Costs}

Here the default values for the indirect capital cost calculations are provided. They are given by the relationships shown in Table 29 .

Table 29 Parameters for TCR of Selexol process

\begin{tabular}{||l|l||}
\hline Indirect Capital Cost Parameter & Definition or Unit Cost \\
\hline \hline Engineering and home office & $10 \%$ PFC \\
\hline General facilities & $15 \%$ PFC \\
\hline Project contingency & $15 \%$ PFC \\
\hline Process contingency & $10 \%$ PFC \\
\hline Total plant cost (TPC) = sum of the above values \\
\hline Interest during construction & Calculated \\
\hline Royalty fees & $0.5 \%$ PFC \\
\hline Preproduction fees & 1 month fee of fixed \& variable O\&M \\
\hline Inventory cost & $0.5 \%$ TPC \\
\hline Total capital requirement (TCR) $=$ sum of above values \\
\hline Fixed O\&M cost (FOM) & $2 \%$ TPC \\
\hline Total maintenance cost & $40 \%$ of total maintenance cost \\
\hline Maintenance cost allocated to labor & $30 \%$ of total labor cost \\
\hline Administration \& support labor cost & 2 jobs/shift \\
\hline Operation labor & $\$ 1.96 / l b$ \\
\hline Variable O\&M cost (VOM) & Selexol solvent \\
\hline
\end{tabular}

\section{References}

Black W.B., Pritchard V., Holiday A., Ong J.O. and Sharp C., 2000: Use of SELEXOL Process in Coke Gasification to Ammonia Project By Presented at the Laurance Reid Gas Conditioning Conference, The University of Oklahoma, Norman, Oklahoma

Doctor R.D., 1994: Gasification combined cycle: carbon dioxide recovery, transport, and disposal, ANL/ESD-24, Argonne National Laboratory, Energy Systems Division, Argonne, Illinois

Doctor R.D., 1996: KRW oxygen-blown gasification combined cycle carbon dioxide recovery, transport, and disposal, ANL/ESD-34, Argonne National Laboratory, Energy Systems Division, Argonne, Illinois

Epps R., 1994: Use of Selexol Solvent for Hydrocarbon Dewpoint Control and Dehydration of Natural Gas, presented at the Laurance Reid Gas Conditioning Conference, Norman, OK

Korens N., Simbeck D.R., Wilhelm D.J., 2002: Process Screening Analysis of Alternative Gas Treating and Sulfur Removal for Gasification, Revised Final Report, December 2002, Prepared by SFA Pacific, Inc. Mountain View, California

Kubeck D. J., E. Polla and F.P. Wilcher, 2000: Purfication and Recovery Options for Gasification, UOP LLC, Des Plaines, IL

Newman S. A., 1985: Acid and sour gas treating processes: latest data and methods for designing and operating today's gas treating facilities, Gulf Publishing Co. 
Sciamanna S. and Lynn S., 1988: Solubility of hydrogen sulfide, sulfur dioxide, carbon dioxide, propane, and n-butane in poly(glycol ethers), Ind. Eng., Chem. Res., 27

Shah V.A., 1988: Low-cost ammonia and carbon recovery, Hydrocarbon Process., 67(3)

UOP, 2002: Use of SELEXOL Process in Coke Gasification to Ammonia Project, UOP report

Personal communication with UOP, 2003 



\section{Power Block}

\section{Nomenclature}

\section{English Letter Symbols}

$\mathrm{P}_{\mathrm{a}}=$ Ambient pressure of inlet air

$r_{p}=$ Pressure ratio, ratio of compressor outlet pressure to compressor inlet pressure

$\mathrm{T}_{\mathrm{a}}=$ Ambient temperature of inlet air

$\mathrm{T}_{\mathrm{T}, \mathrm{in}},=$ Turbine inlet temperature

$y_{i}=$ Mole fraction of compound $i$

\section{Greek Letter Symbols}

$\Delta \mathrm{h}_{\mathrm{r}, \mathrm{i}}=$ Enthalpy of reaction for compound I $(\mathrm{j} / \mathrm{gmole})$

$\Delta \mathrm{p}_{\text {back }}=$ turbine back pressure $(\mathrm{psi})$

$\eta_{c}=$ Adiabatic compressor efficiency

$\eta_{T}=$ Adiabatic turbine efficiency

\section{Power Block Process Description}

\section{Boiler Feedwater System}

The boiler feedwater system consists of equipment for handling raw water and polished water in the steam cycle. This equipment includes a water dimineralization unit for raw water, a dimineralized water storage tank, a condensate surge tank for storage of both dimineralized raw water and steam turbine condensate water, a condensate polishing unit, and a blowdown flash drum. The major streams in this process section are the raw water inlet and the polished water outlet. Data on the cost of the boiler feedwater section and the flow rates of the raw water and polished water streams is available from five studies for 14 plant sizes. These studies include Texaco-based, Shell-based, and KRW-based IGCC systems (Fluor, 1983a; 1983b; $1984 ; 1985 ; 1986)$. Because all of these studies were developed by the same 
contractor using a consistent approach, they provide an excellent basis for developing a cost model. The boiler feedwater section is generic to the steam cycle.

\section{Gas Turbine}

The most commonly assumed gas turbine in IGCC performance and cost studies is the General Electric (GE) model MS7001F, also referred to as the "Frame 7F". This gas turbine is designed for a turbine inlet temperature of $2,300^{\circ} \mathrm{F}$ and has a power output of about 125 to $150 \mathrm{MW}$. By contrast, typical gas turbines have firing temperatures in the range of 2,020 to $2,150^{\circ} \mathrm{F}$. The thermal efficiency of gas turbines increases as the firing temperature increases. The higher firing temperature is the result of advances in turbine blade manufacturing. The Frame 7F turbine blades are manufactured using a process known as "directional solidification," which has been used on smaller aircraft engine turbine blades. Because of improvements in molding technology, the process can now be applied to the larger turbine blades of the Frame $7 F$. Further advances in manufacturing techniques may lead to the capability to cast turbine blades as single crystals with no grain boundaries, permitting an additional 50 to $150^{\circ} \mathrm{F}$ increase in firing temperature (Smock, 1989).

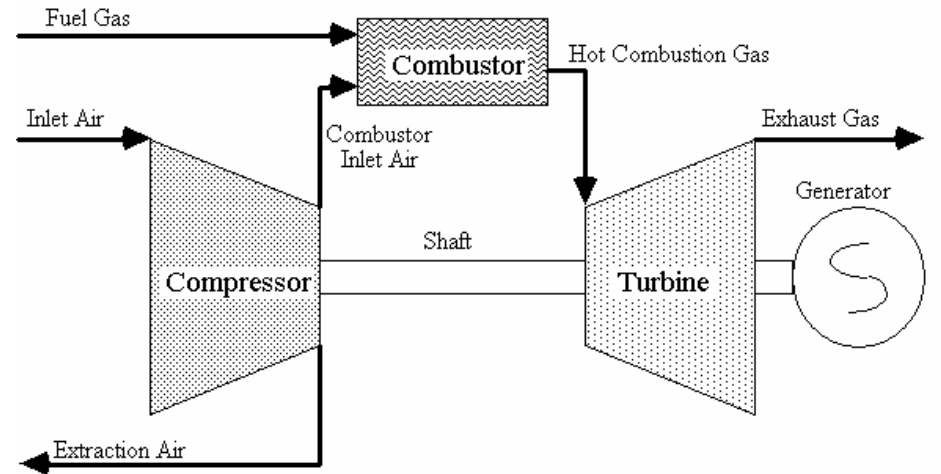

Figure 45 Simple Schematic of Gas Turbine Mass Balance with Compressor Air Extraction

The first Frame 7F has completed factory tests at General Electric and has been delivered to a Virginia Power site in Chesterfield, VA as part of a combined-cycle power plant. General Electric has rated this machine at $150 \mathrm{MW}$ with a heat rate of $9,880 \mathrm{Btu} / \mathrm{kWh}$. Figure 45 shows the schematic of the turbine with the associated compressor and combustor.

There are a number of design factors that affect the cost of a gas turbine in an IGCC process environment. For example, the firing of medium-BTU coal gas, as opposed to high-BTU natural gas, requires modification of the fuel nozzles and gas manifold in the gas turbine (BGE, 1989). Some additional concerns associated with firing coal gas are discussed by Cincotta (1984). The presence of contaminants in the syngas may affect gas turbine maintenance and long term performance. Liquid droplets may cause uneven combustion or may burn in the turbine first-stage nozzles, causing damage. Solids can deposit on fuel nozzles or cause erosion in the hot gas path of the gas turbine (e.g., combustor, turbine). Alkali materials that deposit on hot gas path parts cause corrosion. It is expected that, at fuel gas temperatures less than $1,000 \mathrm{oF}$, that alkali material is essentially condensed on any particulate matter in the raw syngas, and that the alkali removal efficiency is approximately the same as the particle removal efficiency. For sufficiently high particle removal efficiencies, erosion is not expected to be a problem. Corrosion is not expected to be any worse than for distillate oil firing. Deposition of particles is expected to be within the allowance of reasonable maintenance schedules. The design for an advanced high 
firing temperature gas turbine employs advanced air film cooling which could be affected by the ash content of combustion products.

Another design issue is the gas turbine fuel inlet temperature. A study by Fluor (Earley and Smelser, 1988) assumes that hot desulfurized syngas from an advanced hot gas cleanup process is fed directly to the gas turbine at $1,200^{\circ} \mathrm{F}$. The Fluor study indicates that General Electric expects that a fuel system capable of a $1,200^{\circ} \mathrm{F}$ fuel inlet temperature could be developed by 1994. The maximum fuel temperature test to date has been at $1,000^{\circ} \mathrm{F}$. An earlier study with hot gas cleanup included a hot gas cooler to reduce the gas temperature to $1,000^{\circ} \mathrm{F}$ (Corman, 1986). For the KRW (now KBR) system with cold gas cleanup, the coal gas temperature is within the limits of current technology. However, the gas turbine costs developed here should not be used in conjunction with IGCC systems featuring hot gas cleanup without some adjustments to account for the uncertainty in using a higher fuel inlet temperature.

Unfortunately, there is currently a lack of reported data from which to develop a detailed gas turbine cost model that is explicitly sensitive to the type of factors discussed above. In preliminary cost estimates, the typical approach to accounting for these uncertainties in performance, or for the possibility of increased capital cost due to design modifications, is through process contingency factors. The approach taken here is to use the available cost data for the GE Frame 7F to develop a cost estimate for a single gas turbine. In the use of this cost estimate for actual case studies in a later task, judgments about the uncertainty in cost, and about the likelihood of cost increases for applications with coal gases, have been encoded using process contingency factors.

\section{Heat Recovery Steam Generator}

The heat recovery steam generator (HRSG) is a set of heat exchangers in which heat is removed from the gas turbine exhaust gas to generate steam. Typically, steam is generated at two or three different pressures, and associated with the HRSG is one steam drum for each steam pressure level. High pressure superheated steam is generated for use in the steam turbine, and typically the exhaust from the steam turbine first stage is reheated. The input streams to the HRSG section include the gas turbine exhaust and boiler feedwater to the deaerator. The major output stream is the high pressure steam to the steam turbine. Several parts of the HRSG must be sized to accommodate the high pressure steam flow, including the superheater, reheater, high pressure steam drum, high pressure evaporator, and the economizers.

Most studies of IGCC systems aggregate the cost of the HRSG units with the cost of the gas turbine and the steam turbine. Only four studies were identified in which the cost of the HRSG units were reported as a separate line item. A study of Texaco and British Gas/Lurgi IGCC systems includes performance and cost estimates for several sizes of HRSGs used in combination with reheat steam turbines (Parsons, 1982). These HRSG units include two steam pressure levels, and are used in conjunction with a conventional gas turbine. The high pressure steam varies from $650 \mathrm{psia}$ to 1520 psia for these HRSGs. The exhaust gas flow rate and temperature indicate that the gas turbine is a GE Frame 7E or equivalent. A study by Bechtel and WE (1983c) for a KRW-based system included an HRSG design with three pressure levels using a large $130 \mathrm{MW}$ gas turbine with a high exhaust gas temperature. A study of Texacobased IGCC systems included performance and cost estimates for reheat steam turbines and HRSGs with two pressure levels (Fluor Technology, 1986). A recent study of Dow-based IGCC systems includes performance and cost estimates for twopressure level reheat HRSGs applied in conjunction with large advanced gas turbines (Fluor Daniel, 1989). 
A detailed approach to estimating the cost of HRSGs is reported by Foster-Pegg (1986). This approach requires detailed performance and design information for each heat exchanger in the HRSG. The necessary design values were not reported in the performance and cost studies, nor was sufficient detail about performance available to develop such a model. Furthermore, the level of detail in the Foster-Pegg model is not justifiable for the applications envisioned for this model for several reasons. The technical and cost growth risks of IGCC systems reside primarily in process areas such as gasification, gas cleanup, and advanced gas turbine designs. The HRSG is a conventional, commercially available component. Therefore, the priorities for cost model development should be with the more innovative systems. Secondly, in comparative studies of IGCC systems, the cost of HRSGs will be similar, and will not be a factor in distinguishing one system from another. Instead, differences in the gasification process area, gas cleanup, and byproduct recovery, as examples, are expected to be important in distinguishing alternative systems. Third, the purpose of this model is not to develop detailed, final estimates of site-specific costs for a particular project, but to develop preliminary cost estimates for the purpose of research planning. Therefore, there is not a need for a highly detailed cost model for this particular process area.

\section{Steam Turbine}

A typical steam turbine for an IGCC plant consists of high-pressure, intermediatepressure, and low-pressure turbine stages, a generator, and an exhaust steam condenser. The high pressure stage receives high pressure superheated steam from the HRSG. The outlet steam from the high pressure stage returns to the HRSG for reheat, after which it enters the intermediate pressure stage. The outlet from the intermediate pressure stage goes to the low pressure stage.

\section{Detailed Analysis of Gas Turbines}

\section{Commercial Offerings for $2,300{ }^{\circ} \mathrm{F}$ Gas Turbines}

In this research, the modeling of IGCC systems is intended to include performance representative of typical high-firing temperature gas turbine technology. However, the intent is not to attempt to model exactly the performance of any one proprietary gas turbine model.

Table 30 Representative 2,300 \% Firing Temperature Heavy-Duty Gas Turbine Commercial Offerings

\begin{tabular}{|l|l|l||}
\hline $\begin{array}{l}\text { Design Specification } \\
\text { (Fuel: Natural Gas) }\end{array}$ & $\begin{array}{l}\text { General Electric } \\
\text { MS7001F }\end{array}$ & $\begin{array}{l}\text { Westinghouse/Mitsubishi } \\
\mathbf{5 0 1 F}\end{array}$ \\
\hline \hline Net Power, $\mathrm{kW}$ & 150,000 & 145,000 \\
\hline Heat Rate, BTU/kWh & 9880 & 10,000 \\
\hline Compressor Inlet Air, pps & 918.7 & 912 \\
\hline Pressure Ratio & 13.5 & 14.2 \\
\hline Exhaust Temp., ${ }^{\circ} \mathrm{F}$ & 1,081 & 1,061 \\
\hline Compressor Stages & 18 & 16 \\
\hline Inlet Guide Vanes & Yes & Yes \\
\hline Variable Stator Vanes & No & No \\
\hline Compressor Cooling Air & & \\
\hline
\end{tabular}




\begin{tabular}{||l|l|l||}
\hline Extraction (stage no.) & 13,17, discharge & $13,10,6$, discharge \\
\hline Compressor Bleed (stage no.) & 13 & $6,10,13$ \\
\hline No. of Combustor Cans & 14 & 16 \\
\hline Standard Combustor Design & multiple fuel nozzles & pre-mix, two-stage \\
\hline (Natural Gas firing) & wet injection-- $\mathrm{NO}_{\mathrm{x}}$ & lean-burn low- $\mathrm{NO}_{\mathrm{x}}$ \\
\hline & ("quiet" combustor) & \\
\hline Turbine Stages & 3 & 4 \\
\hline Turbine Cooling: & & \\
\hline Row 1 rotor vanes & internal convection & film, impingement, pin fin \\
\hline Row 2 rotor vanes & internal convection & similar to Row 1 \\
\hline Row 3 rotor vanes & uncooled & inlet cavity convection \\
\hline Row 4 rotor vanes & N/A & uncooled \\
\hline \hline
\end{tabular}

NOTES: Brandt, 1988; Brandt (1989); Scalzo et al, (1989)

- The GE MS7001F apparently uses film cooling on the turbine stator vanes ("nozzles"), but not on the rotor vanes ("buckets").

- Both offerings use corrosion coatings on the hot gas path components.

Instead, the goal is to achieve reasonable accuracy in reproducing the key performance characteristics of this class of gas turbines.

Currently, there are two $2,300^{\circ} \mathrm{F}$ turbine inlet temperature heavy-duty gas turbine models which are expected to be offered commercially in the next year or two. These are the General Electric MS7001F and the Westinghouse/Mitsubishi 501F. Some characteristics and design assumptions for these gas turbines are given in Table 30. The MS7001F is designed to fire either natural gas or distillate oil at design point conditions of $59^{\circ} \mathrm{F}$ ambient temperature, $14.7 \mathrm{psia}$ ambient pressure, and 60 percent relative humidity. The use of coal gas represents a departure from the design fuel. Because coal gas has a substantially lower heating value than natural gas, the fuel mass flow rate is significantly larger than the design basis for the gas turbine. Typically, the mass flow at the turbine inlet nozzle is limited by choking. Therefore, an increase in the fuel mass flow rate must be compensated by a reduction in the compressor air flow rate, for a given pressure ratio and firing temperature. This results in off-design operating conditions for the gas turbine, which has implications for gas turbine performance, such as efficiency, exhaust temperature, and other parameters.

Many IGCC studies were developed prior to the testing and delivery of the prototype MS7001F. In these studies, a variety of assumptions regarding the projected performance of this unit were made regarding firing temperature, pressure ratio, efficiency, and other measures of performance. In most cases, these assumptions have proven to be different from the actual unit. This is an example of the difficulty involved in trying to predict the commercial scale performance of an advanced system for which no commercial experience is yet available. In many cases, the assumptions may have been unnecessarily conservative, while in other cases they may have been optimistic.

The studies appear to give only superficial consideration to the off-design nature of gas turbine operation on coal gas. Furthermore, the studies appear to give only superficial consideration to other factors associated with firing coal gas in a gas turbine. 
Although a MS7001F is now in commercial service, the performance of this model with coal gas has yet to be demonstrated.

\section{Operating Strategies for Coal Gas Firing}

The primary issues discussed in this section are the interactions between fuel flow, compressor performance, and compressor air extraction.

A gas turbine is designed to meet a set of goals for a specific set of operating conditions. When any of these conditions are changed, the turbine is said to be in an "off-design" mode. The response of the gas turbine to changes in operating conditions requires detailed knowledge which is specific to each machine. This type of information is closely held proprietary information. The design of a gas turbine, and prediction of its performance, involves a significant amount of empirical information. In many cases, off-design information must be obtained from testing under various conditions, which is expensive. At a minimum, some testing is required to verify the accuracy of theoretical models. Because of the expense of testing needed to support gas turbine design and to verify the operation the gas turbine once built, detailed information about gas turbine design, such as compressor operating maps, are not published (Eustis and Johnson, 1990). Furthermore, gas turbine manufacturers usually try to adopt existing successful designs where feasible into new models, or to modularize the system (in the case of combustor cans, for example) so that a change in one component requires only a simple substitution and no changes in other components (Cohen et al, 1987; Brandt, 1988; Scalzo et al, 1989).

Because of the expense of developing and testing gas turbines, it is unlikely that, in the near term, the gas turbine industry will develop a machine designed specifically for operation with coal gas. Instead, they will try to develop an understanding of how a machine designed for larger markets (e.g., natural gas firing) will behave when firing coal gas. The manufacturers may be required to offer some modifications, such as for fuel valves or combustors. However, the manufacturers are also likely to impose limitations on fuel composition or gas turbine operation to which a customer must adhere. The development of such limitations is presumably based on some type of technical risk analysis of the gas turbine, supported either by theoretical models, empirical testing, both or neither.

Uncertainties are likely to remain, however, regarding the long term maintainability and performance of the gas turbines when firing coal gas. In particular, problems such as loss of output or shorter maintenance cycles (e.g., more frequent reblading) may be encountered in machines fired with coal gas for long periods of time (a complete life cycle). In some cases, these uncertainties can be represented solely as uncertainties in cost. However, there may be trade-offs between changing operating conditions and maintenance costs. A major concern for reliable operation of an integrated plant is the stability of the compressor and the control system, particularly when air is extracted for use in the gasifier.

A key difference between natural gas firing and coal gas firing is the heating value of the fuel. Natural gas has a heating value of about 1,000 BTU/scf. Medium-BTU coal gas (MBG) has a heating value of 300 to $500 \mathrm{BTU} / \mathrm{scf}$, and low-BTU coal gas (LBG) has heating values around $100 \mathrm{BTU} / \mathrm{scf}$. As a result, the mass flow rate of fuel required to supply a given amount of chemical energy is significantly larger for LBG than for natural gas.

The factor that usually limits the mass flow in a gas turbine is the area of the turbine inlet nozzles (Eustis and Johnson, 1990). When the flow is choked (sonic) the mass flow is at its maximum, and the maximum mass flow for an ideal gas is given by: 
$m_{\max }=P A^{*} \sqrt{\frac{M W}{T}} \sqrt{\frac{\gamma}{R}\left(\frac{2}{\gamma+1}\right)^{\frac{\gamma+1}{\gamma-1}}}$

where,

$$
\begin{aligned}
& \mathrm{m}_{\max }=\text { maximum mass flow rate } \\
& \mathrm{P}=\text { total pressure } \\
& \mathrm{A}^{*}=\text { critical area where flow is choked } \\
& \mathrm{MW}=\text { molecular weight of gas } \\
& \mathrm{T}=\text { total temperature } \\
& \mathrm{R}=\text { universal gas constant } \\
& \gamma=\text { ratio of specific heats for the gas }
\end{aligned}
$$

The molecular weight of the exhaust gas varies within about two percent for all three cases compared to the natural gas design point. The term under the radical varies about 5 percent as the ratio of specific heats varies from 1.2 to 1.4 . At $2,000^{\circ} \mathrm{F}$, the ratio of specific heats of nitrogen, the largest component in the exhaust gas, is about 1.3. The mass flow into the gas turbine is proportional to the critical area (which is fixed for a given gas turbine model) for a given pressure ratio and firing temperature.

For natural gas-fired operation, the air flow into the GE MS7001F compressor is about $919 \mathrm{lb} / \mathrm{sec}$. The natural gas flow rate is about $20 \mathrm{lb} / \mathrm{sec}$, yielding an exhaust flow rate of about $939 \mathrm{lb} / \mathrm{sec}$. However, in the case of low-BTU coal gas, the fuel flow rate is likely to be on the order of $200 \mathrm{lb} / \mathrm{sec}$. This would imply a turbine flow rate of over $1,100 \mathrm{lb} / \mathrm{sec}$, or a compressor flow rate of about $720 \mathrm{lb} / \mathrm{sec}$, depending on the operating strategy employed and whether a substantially redesigned gas turbine is assumed.

Eustis and Johnson (1990) discuss several strategies for firing coal gas in a gas turbine. These options include:

- Increase the pressure ratio. This increases the maximum mass flow rate in the turbine nozzle. However, the compressor may not have enough surge margin to do this. Also, the increased mass flow would increase the thermal loads on the turbine blades and vanes, which may require a reduction in firing temperature.

- Reduce compressor mass flow using inlet guide vanes (IGV). This reduces the compressor mass flow to compensate for the increased fuel flow. The flow reduction is limited by the compressor design. Compressors with variable stators and intermediate air bleed points in addition to IGVs are better able to achieve flow reductions without inducing stalling in any of the compressor stages.

- Increase the inlet turbine nozzle critical area. This is a major redesign and would require a new gas turbine model. As a practical matter, it is unlikely that gas turbine manufacturers would develop such a machine.

- Reduce the turbine inlet temperature. This would reduce the gas turbine efficiency and power output, but allow increased turbine mass flow.

- Bleed air from the compressor. This is possible only where there is a use for high pressure air elsewhere in the plant. Otherwise, it is wasteful, and reduces plant efficiency. 
In this study, a combination of Strategies 2 and 5 is assumed. Both the GE MS7001F and the Westinghouse/Mitsubishi 501F have IGVs. They do not have variable stator vanes. For the low-BTU coal gas systems, a portion of the compressor discharge air is assumed to be extracted for use as gasifier blast air. However, as noted in Table $\underline{30}$, the ratio of extraction air to the fuel flow is about 0.5 to 0.6 . The extraction air does not fully compensate for the increased fuel mass flow. Thus, at full load, the IGVs would have to be partially closed.

IGVs are often used to respond to part load conditions without having to reduce firing temperature. At the point where the IGVs are "fully" closed, firing temperature must then be reduced to further reduce the load. In a coal gasification application, because the IGVs are already partially closed at full load, the gas turbine will be less efficient at part load operation, as the point at which firing temperature must be reduced will be at a higher load condition than for natural gas.

The partial closure of IGVs will slightly affect the gas turbine pressure ratio. However, because the gas turbine model used in these case studies is based on mass and energy balances only, and not the aerodynamic characteristics of a gas turbine, pressure ratio is not predicted. Any change in pressure ratio must be specified by the model user.

Closure of IGVs also affects the compressor surge margin. At surge conditions, the compressor is no longer able to generate a steady high pressure exit stream. Thus, any downstream pressurized gas, such as that in the combustor, will backflow into the compressor, possibly causing severe vibration and damage. Compressors are usually designed to operate at a point sufficiently removed from the "surge line" to reduce the possibility of encountering surge. However, the operation of the machine with IGVs closed may reduce the margin between the operating conditions and surge conditions (Eustis and Johnson, 1990).

The determination of the surge line and the compressor characteristics requires extensive testing under a variety of loads, corrected speeds, IGV settings, and mass flow rates. These data are summarized in compressor "maps." These maps are proprietary information, due to the expense of developing them and the importance of the information to the competitive position of the manufacturer. General Electric reports that the MS7001F has a better surge margin than the MS7001E, which has been commercially available for years. GE reports that no in-service surges of the MS7001E have been reported. Thus, GE expects a superior surge margin for the MS7001F (Brandt, 1989). This may alleviate any concerns about using the IGVs to reduce the compressor mass flow. However, without a compressor map, it is difficult to make any quantitative assertions.

The use of air extraction for the low-BTU coal gas cases helps to improve the surge margin of the compressor, by reducing the amount of IGV closure needed at full load conditions. However, air extraction poses significant control problems for the IGCC plant, because it imposes a coupling between the gas turbine and the gasifier. Changes in coal composition can affect the fuel/air ratio, but can also affect the gasifier blast air requirement. This requires a sophisticated control system to regulate the IGVs, extraction air flow rate, and fuel flow rate. Advanced control systems may be required (Corman, 1986).

\section{Fuel Valve}

The pressure drop across the fuel valve system has an important effect on system efficiency. The gasifier pressure must be high enough to compensate for all pressure losses between the gasifier outlet and the gas turbine combustor. The pressure in the combustor is determined based on the gas turbine pressure ratio. Pressure losses in the system include the fuel gas piping, fuel valve, particulate removal devices (e.g., 
cyclones), and sulfur removal devices (e.g., zinc ferrite absorbers). Increasing the gasification pressure above that required for fuel gas delivery can reduce the system efficiency (Simbeck et al., 1983).

Reduction in the fuel valve pressure drop was reported to be one goal of a proposed demonstration plant. The typical pressure drop in the fuel valve was reported at about $70 \mathrm{psi}$. The goal was to achieve about $10 \mathrm{psi}$. The demonstration project proposes to use a GE MS7001E with a fuel gas temperature of about $1,000{ }^{\circ} \mathrm{F}$. The material requirements for this system were claimed not to be a major problem (Hester and Pless, 1990).

A design study of an IGCC system with hot gas cleanup assumed a gas turbine fuel inlet temperature of $1,200^{\circ} \mathrm{F}$. The basis for this assumption was reported to be GE's expectation that by 1994 a fuel system for $1,200^{\circ} \mathrm{F}$ gas could be developed, although the highest fuel gas temperature tested to date has been $1,000{ }^{\circ} \mathrm{F}$ (Earley and Smelser, 1988).

The presence of particles in the fuel gas could lead to erosion or deposition in the fuel nozzles. Based on two-stage high-efficiency cyclones, a GE study concludes that the particle concentration and size distribution in the fuel gas would allow for "adequate" nozzle and control valve lives. However, any solids that deposit in the fuel nozzle can alter flow characteristics. This can result in reduced combustion efficiency. Solids deposits can also interfere with fuel valve operation. Naphthas, tars, and phenols can build up on valve internals (Cincotta, 1984).

Any liquids entering the combustor as large droplets may not burn completely within the combustor. They may carry over to, and burnout in, the first stage turbine nozzle. This can cause damage to the turbine (Cincotta, 1984).

The fuel control system poses a design challenge for an IGCC plant. The control system must account for changes in the heating value of the fuel gas during plant operation, as well as differences in the load-following capability of the gasifier and gas turbine. The fuel control system could potentially depressurize the gasifier by demanding more fuel than the gasifier can supply during ramp-up (Cincotta, 1984). The addition of gas turbine air extraction for gasifier blast air further complicates the control system (Corman, 1986).

In the modeling studies, the effect of pressure drop in the fuel gas valve can be explicitly included in the ASPEN performance simulation. The effect of exotic fuel valve materials or designs on gas turbine cost can be incorporated in the cost model through, for example, a direct capital cost multiplier factor.

\section{Combustion and Emissions}

Gas turbine combustors have been developed in an empirical-based manner. Mathematical analysis and scale model testing apparently have been inadequate predictors of full-scale combustor performance (Dawkins et al, 1986). As a result, heavy-duty gas turbines have been developed using multiple modular "can" combustors. Typically, many of these combustors are arranged around the circumference of the machine between the compressor and the turbine. As part of a development program only one combustor can needs to be used in testing (Cincotta, 1984). In a commercial-scale gas turbine, such as the ones summarized in Table 30 , perhaps 16 to 18 combustor cans are utilized. Each one can be changed out for maintenance and repair. The standard combustor can also be replaced by improved versions as they become available. The same combustor design can be used in different size machines by using an appropriate number of the combustor cans.

There are a number of pollutant species that may be contained in the hot gas exiting the combustor which have received attention in the literature. These are: 
- Thermal $\mathrm{NO}_{\mathrm{x}}$ resulting from thermal fixation of oxygen and nitrogen in air.

- Fuel $\mathrm{NO}_{\mathrm{x}}$ resulting from conversion of chemically bound nitrogen in the fuel (e.g, ammonia).

- $\quad \mathrm{SO}_{2}$ resulting from hydrogen sulfide, carbonyl sulfate, and sulfur contained in naphtha, tars, oils, and phenol.

- CO resulting from incomplete carbon conversion in the combustor.

- Uncombusted particles passing through the combustor.

- Alkali (sodium and potassium compounds) which may cause turbine blade corrosion.

The design of gas turbine combustors is undergoing changes in response to environmental constraints on $\mathrm{NO}_{\mathrm{x}}$ and $\mathrm{CO}$ emissions and an increasing array of potential gas turbine fuels. Currently, most efforts are focused on developing low$\mathrm{NO}_{\mathrm{x}}$ combustors for natural gas applications (Angello and Lowe, 1989). However, some theoretical studies, bench scale research, and a few commercial-scale demonstrations have involved medium- and low-BTU gases, such as those derived from coal gasification. The design of combustors for coal gas applications may be fundamentally different from those for natural gas applications, particularly with respect to $\mathrm{NO}_{\mathrm{x}}$ emissions.

\section{$\mathrm{NO}_{\mathrm{x}}$ Emissions}

$\mathrm{NO}_{\mathrm{x}}$ emissions result primarily from the thermal fixation of nitrogen and oxygen in the inlet combustion air and from conversion of chemically-bound nitrogen in the fuel. The former is referred to as "thermal" $\mathrm{NO}_{\mathrm{x}}$, while the latter is referred to as "fuel" $\mathrm{NO}_{\mathrm{x}}$. Thermal $\mathrm{NO}_{\mathrm{x}}$ formation is sensitive mainly to the flame temperature of the burning fuel. Poor mixing of fuel and air can lead to localized "hot spots" which generate high flame temperatures and, hence, high thermal $\mathrm{NO}_{\mathrm{x}}$ emissions. Uniform mixing of fuel and air leads to more uniform flame temperatures, which reduces thermal $\mathrm{NO}_{\mathrm{x}}$ formation. In addition, other measures which reduce flame temperatures, such as staged lean combustion or the addition of diluents such as water or steam, will reduce thermal $\mathrm{NO}_{\mathrm{x}}$ emissions (Davis et al, 1987; Touchton, 1984)

Fuel $\mathrm{NO}_{\mathrm{x}}$ arises from the conversion of ammonia, $\mathrm{HCN}$, or other nitrogen-containing chemical species in the fuel. The formation of fuel $\mathrm{NO}_{\mathrm{x}}$ is relatively insensitive to temperature compared to thermal $\mathrm{NO}_{\mathrm{x}}$ formation. Fuel $\mathrm{NO}_{\mathrm{x}}$ formation depends primarily on the concentration of fuel-bound nitrogen in the fuel gas and the method of fuel/air contacting (Folsom et al, 1980). To reduce fuel $\mathrm{NO}_{\mathrm{x}}$ formation, two-stage rich/lean combustion has been proposed and tested by several (e.g., Folsom et al, 1980; Sato et al, 1989; Unnasch et al, 1988). In the rich combustion stage, fuel bound nitrogen is converted mostly to diatomic nitrogen. In the lean stage, fuel burnout is completed under conditions which minimize the formation of thermal $\mathrm{NO}_{\mathrm{x}}$.

The most widely used gas turbine fuel is natural gas, which contains negligible fuelbound nitrogen. Most major gas turbine manufacturers are attempting to develop dry low- $\mathrm{NO}_{\mathrm{x}}$ combustors, to reduce the formation of "thermal" $\mathrm{NO}_{\mathrm{x}}$ by premixing the fuel and air and use of lean-burn or lean-lean two-staged combustion. The Westinghouse/Mitsubishi $501 \mathrm{~F}$ will be offered with a low $\mathrm{NO}_{\mathrm{x}}$ combustor featuring fuel and air premixing and a lean-burn combustor (Scalzo et al., 1989). The GE MS7001F is offered with a multiple fuel nozzle combustor can (Brandt, 1988). This is not a low- $\mathrm{NO}_{\mathrm{x}}$ design per se, but it does allow increased levels of water or steam 
injection to achieve low $\mathrm{NO}_{\mathrm{x}}$ emissions with fuels that do not contain fuel-bound nitrogen. The multiple nozzle design has been referred to as the "quiet" combustor because it has a lower vibration and noise level than GE's single fuel-nozzle combustor. The reduced vibrations permit higher levels of water injection.

\section{Medium-BTU Coal Gas}

IGCC systems that feature "cold" gas cleanup effectively remove any ammonia, the primary fuel-bound nitrogen species, from the raw coal gas. Thus, fuel $\mathrm{NO}_{\mathrm{x}}$ emissions are not expected to be a problem for this application. Thermal $\mathrm{NO}_{\mathrm{x}}$ emissions are of concern, however. MBG may have flame temperatures similar to that of distillate oil, and thus uncontrolled $\mathrm{NO}_{\mathrm{x}}$ emissions from firing MBG may be comparable or greater than uncontrolled emissions from firing distillate oil (Davis et al, 1987).

Most conceptual design studies assume that steam injection and/or fuel gas saturation can be used to reduce the combustor flame temperature and, hence, $\mathrm{NO}_{\mathrm{x}}$ emissions to meet current New Source Performance Standards (NSPS) for gas turbines (e.g., Gallaspy et al, 1990 and many of the other EPRI design studies). Wet injection is a standard technique for natural gas and oil fired gas turbines. The thermal diluent, steam or water, results in a reduction in peak combustion temperatures, thus reducing thermal $\mathrm{NO}_{\mathrm{x}}$ formation (e.g., Davis et al, 1987; Touchton, 1984; Touchton, 1985). Both steam injection and fuel gas saturation have been tested at the Cool Water demonstration plant, which uses MBG from a Texaco gasifier (Cool Water, 1988; Holt et al, 1989).

The NSPS is often quoted as $75 \mathrm{ppm}$ at 15 percent oxygen on a dry basis, but the standard actually includes a correction for plant efficiency. Thus, the actual allowable emissions under NSPS for a particular gas turbine model may be higher.

However, it is controversial whether the gas turbine NSPS is the applicable standard for IGCC power plants, or whether it is even a relevant standard. More likely, IGCC plants will be subject to local or EPA-mandated procedures such as Best Available Control Technology (BACT), which is determined on a plant-by-plant basis. The procedure for BACT analysis that is becoming increasingly common is known as the "top-down" approach. In this approach, a facility is asked to use the most stringent control system that has been demonstrated unless there are energy, environmental, or economic reasons to do otherwise. For natural gas-fired gas turbines, BACT may include combinations of low- $\mathrm{NO}_{\mathrm{x}}$ combustors, wet injection, and post-combustion $\mathrm{NO}_{\mathrm{x}}$ control using selective catalytic reduction (Smock, 1989; Moore-Staub et al, 1990). It is likely that an actual IGCC plant will be required to achieve very low $\mathrm{NO}_{\mathrm{x}}$ emissions on the order of $10 \mathrm{ppm}$, rather than the $75 \mathrm{ppm}$ (corrected) often assumed. Thus, SCR may be required. SCR has been applied to or required for a number of natural gas- and oil-fired gas turbines in California and a few other states (Radin and Boyles, 1987; Moore-Staub et al, 1990). SCR is expected to be capable of reducing IGCC system $\mathrm{NO}_{\mathrm{x}}$ emissions to $5 \mathrm{ppm}$ (Holt et al, 1989). At least one IGCC plant, a proposed demonstration plant in Florida, is to be permitted with SCR (Hester, 1990). This may set a BACT precedent for other IGCC plants.

For the purposes of the current study, fuel gas saturation and/or steam injection for combustion $\mathrm{NO}_{\mathrm{x}}$ control is assumed for medium-BTU coal gases with no fuel-bound nitrogen. The effect of SCR would primarily be to increase the capital and operating costs of the system, with a slight penalty on plant efficiency due to increased HRSG backpressure and the auxiliary power requirements of the SCR ammonia injection and control systems. SCR may be more advantageous for application with fuel gases containing significant concentrations fuel-bound nitrogen.

The applicability or efficacy of dry low- $\mathrm{NO}_{\mathrm{x}}$ combustors designed for natural gas when converted to coal gas firing may merit some testing and evaluation. Whether 
the combustors can be used "as is", other than modifications for the fuel nozzles, might be the subject of further research.

\section{Low-BTU Coal Gas}

Thermal $\mathrm{NO}_{\mathrm{x}}$ is not expected to be a major concern with LBG gases because of their low adiabatic flame temperatures resulting from the presence of thermal diluents in the fuel such as $\mathrm{N}_{2}$. The thermal $\mathrm{NO}_{\mathrm{x}}$ emissions from LBG are often dismissed in the literature as being insignificant, particularly if peak flame temperatures are limited to less than 2,800 ${ }^{\circ} \mathrm{F}$ (Davis et al, 1987; Folsom et al, 1980; Notestein, 1989; Sato et al, 1989; Unnasch et al, 1988). Uncontrolled thermal $\mathrm{NO}_{\mathrm{x}}$ emissions from LBG combustion may in fact be on the order of 10 to $50 \mathrm{ppm}$, as suggested by some small scale combustor tests (e.g., Unnasch et al, 1988).

A confounding factor for thermal $\mathrm{NO}_{\mathrm{x}}$ emissions from $\mathrm{LBG}$ is the expected high gas turbine fuel valve inlet temperatures associated with hot gas cleanup (HGCU) systems. Also, increasing pressure ratios for gas turbines may promote thermal $\mathrm{NO}_{\mathrm{x}}$ emissions (Folsom et al, 1980). Increasing the fuel gas temperature will tend to increase thermal $\mathrm{NO}_{\mathrm{x}}$ production because the flame temperatures will be marginally higher. However, this is not expected to significantly increase thermal $\mathrm{NO}_{\mathrm{x}}$ emissions for the fuel temperatures of current interest $\left(1,000\right.$ to $\left.1,200^{\circ} \mathrm{F}\right)$.

The primary concern regarding $\mathrm{NO}_{\mathrm{x}}$ emissions from $\mathrm{LBG}$ is fuel $\mathrm{NO}_{\mathrm{x}}$ resulting from ammonia, HCN, or other fuel bound nitrogen species. LBG is derived from airblown gasification systems. Air-blown gasification is commonly envisioned in conjunction with HGCU. HGCU systems typically are based on dry pollutant removal processes, such as cyclones or barrier filters for particulate control and chemical sorption for sulfur control. Unlike "cold" gas cleanup wet scrubbing processes, these dry processes do not remove ammonia, the primary fuel-bound nitrogen specie, in the fuel gas. In conventional gas turbine combustors, most of the ammonia would be converted to $\mathrm{NO}_{\mathrm{x}}$. For example, Cincotta (1984) states that the conventional GE MS7001E combustor would convert about 70 percent of ammonia in a Lurgi fuel gas to $\mathrm{NO}_{\mathrm{x}}$. Another study reports a similar finding (Sato et al, 1989). In a conventional combustor, the conversion rate of ammonia to $\mathrm{NO}_{\mathrm{x}}$ may vary from 50 to 90 percent depending on the concentration of ammonia in the fuel gas (Pillsbury, 1989).

The ammonia concentration in the fuel gas depends on the gasifier type and operating conditions. Notestein (1989) indicates typical ranges of ammonia concentration in coal gas as 200 to $600 \mathrm{ppmv}$ for fluidized bed gasifiers operating at 1,300 to $1,800^{\circ} \mathrm{F}, 2,000 \mathrm{ppm}$ for entrained flow gasifiers, and up to 5,000 ppm for fixed bed gasifiers operating below $1,200^{\circ} \mathrm{F}$. Holt et al (1989) suggest that about 50 to 60 percent of coal-bound nitrogen is converted to ammonia in fixed bed gasifiers, while only 10 to 15 percent is converted in entrained-flow gasifiers. Some typical concentrations from ASPEN simulation models are given in Table 30.

The most likely near-term solution for reducing fuel $\mathrm{NO}_{\mathrm{x}}$ emissions from $\mathrm{LBG}$ combustion appears to be staged rich/lean combustion (Cincotta, 1984; Folsom et al, 1980; Sato et al, 1989; Unnasch, 1988). In rich/lean combustion, the rich stage is used to convert ammonia to nitrogen, and the second stage is used for fuel burnout. The combination of a rich and lean stage also reduces the peak flame temperatures in the combustor, thereby reducing thermal $\mathrm{NO}_{\mathrm{x}}$ emissions.

Some of the findings of several combustor research efforts have been:

- Temperature. Fuel $\mathrm{NO}_{\mathrm{x}}$ formation is relatively insensitive to temperature (Holt et al, 1989). Variation in fuel heating value appears to have little effect on conversion of ammonia to $\mathrm{NO}_{\mathrm{x}}$ (Folsom et al, 1980). 
- Fuel-nitrogen concentration. The fraction of fuel-bound nitrogen converted to $\mathrm{NO}_{\mathrm{x}}$ decreases with increasing fuel-bound nitrogen concentration (Folsom et al, 1980; Sato et al, 1989; Unnasch et al, 1988). In the Unnasch et al (1988) tests, it was found that above 5,000 ppm ammonia concentration, there was very little marginal increase in $\mathrm{NO}_{\mathrm{x}}$ emissions.

- Stoichiometry. Fuel $\mathrm{NO}_{\mathrm{x}}$ formation is sensitive to the reaction stoichiometry. In an oxygen-deficient environment, a substantial portion of fuel-bound nitrogen can be converted to diatomic nitrogen. The optimal reactant stoichiometry (fuel/air ratio) in the rich stage to maximize conversion of fuel-bound nitrogen to $\mathrm{N}_{2}$ (minimize fuel $\mathrm{NO}_{\mathrm{x}}$ ) is influenced by reaction temperature (Folsom et al, 1980).

- Pre-Mixing. Uniform pre-mixing of fuel and air may be required to assure a uniform fuel/air ratio throughout the reaction mixture (Folsom et al, 1980).

- Hydrocarbons. The presence of hydrocarbons, such as methane, appears to promote the formation of fuel $\mathrm{NO}_{\mathrm{x}}$, due to reactions with intermediate reaction products which interfere with $\mathrm{N}_{2}$ formation. However, a hydrocarbon gas does appear to promote the conversion of $\mathrm{NO}$ to $\mathrm{N}_{2}$. This may have implications for the second stage (Folsom et $a l, 1980)$.

- Burnout. A rich stage for fuel-bound nitrogen "cracking" to $\mathrm{N}_{2}$ requires a second lean stage for fuel burnout (Folsom et al, 1980).

- Thermal $\mathrm{NO}_{\mathrm{x}}$. The lean mixture in the second stage can be adjusted to reduce or minimize thermal $\mathrm{NO}_{\mathrm{x}}$ formation (Folsom et al, 1980). However, the rich/lean combustor may not reduce thermal $\mathrm{NO}_{\mathrm{x}}$ as effectively as a lean/lean combustor would for fuels without nitrogen compounds (Holt et al, 1989). Unnasch et al (1988) found that MBG combustion yielded higher thermal $\mathrm{NO}_{\mathrm{x}}$ emissions than $\mathrm{LBG}$, and speculated that this was attributable to higher flame temperatures.

- Turbulence. Fuel $\mathrm{NO}_{\mathrm{x}}$ formation is expected to increase in turbulent flames. A laminar diffusion flame appears to allow for good conversion of ammonia to $\mathrm{N}_{2}$ (Folsom et al, 1980).

- Fuel heating value. If fuel heating value is too low, combustion may not start in the fuel-rich zone. If combustion begins in the fuel-lean zone, conversion of ammonia to $\mathrm{NO}_{\mathrm{x}}$ may be very high (Sato et al, 1989).

- $\quad$ Pressure. As combustor pressure increases, the conversion of ammonia to $\mathrm{NO}_{\mathrm{x}}$ appears to decrease slightly, based on testing from 1 to 14 atm using a half-scale conventional combustor model (Sato et al, 1989).

- Efficacy. Rich/lean combustor tests using small scale combustors at relatively low pressures have achieved up to 95 percent conversion of ammonia to $\mathrm{N}_{2}$ (Folsom et al, 1980; Unnasch, 1988; Notestein, 1989). Folsom et al attempted to develop ideal combustors of various designs on the bench-scale, but indicated that full-scale commercial designs may not be as successful in achieving $\mathrm{NO}_{\mathrm{x}}$ reductions. The tests by Sato et al (1989) did not appear to achieve such high conversion rates. These tests involved perhaps more realistic full- and half-scale gas turbine combustors. In the Sato tests, ammonia conversion to $\mathrm{N}_{2}$ was increased from a nominal value of 30 percent to a nominal value of 50 percent. This may be contrasted with the value of 30 percent typical of 
conventional combustors, discussed previously. These results imply that the efficacy of a commercial scale rich/lean combustor in reducing fuel $\mathrm{NO}_{\mathrm{x}}$ emissions may be in doubt.

- $\quad$ CO emissions. In the Sato et al (1989) tests, CO emissions were below $100 \mathrm{ppm}$.

Another concept that has received some attention is catalytic combustion. However, in the near term, rich/lean combustion appears to be receiving more attention and testing. Therefore, for this study, rich/lean combustion is assumed as the most likely alternative for fuel $\mathrm{NO}_{\mathrm{x}}$ control.

\section{Combustion Efficiency and CO Emissions}

$\mathrm{CO}$ emissions, which result from incomplete combustion of hydrocarbons or no combustion of $\mathrm{CO}$ in the fuel gas, are an indicator of poor combustion efficiency. Many of the measures which reduce $\mathrm{NO}_{\mathrm{x}}$ emissions, such as reducing flame temperature through wet injection or staged combustion, also tend to increase $\mathrm{CO}$ emissions by reducing the combustion efficiency. Most heavy-duty natural gas-fired and distillate oil-fired gas turbines have very low CO emissions (less than 5-10 ppm).

$\mathrm{CO}$ emissions increase at part load as the gas turbine combustor firing temperature is reduced during load-following (Entrekin and Edwards, 1987). Becker and Shulten (1985) report on part-load gas turbine combustion of low-BTU blast furnace gas in which it was difficult to achieve conversion of $\mathrm{CO}$ in the gas. However, coal gas has a higher hydrogen content than blast furnace gas, and may tend to combust more completely.

At the Cool Water demonstration plant, $\mathrm{CO}$ emissions were low with wet injection or fuel gas saturation. However, there are limits to fuel gas moisturization. As moisturization increases, the combustor flame becomes increasingly unstable, leading to pressure oscillations which can reduce the life of the combustor. At very high injection or moisturization rates, the combustion flame will ultimately blow out. Prior to the loss of flame, combustion efficiency will be low and $\mathrm{CO}$ emission will be high (Holt et al, 1989). The maximum fuel moisturization level is thus usually determined based on the point at which $\mathrm{CO}$ emissions begin to increase significantly.

A post-combustion flue gas $\mathrm{CO}$ catalyst can be used to convert $\mathrm{CO}$ to $\mathrm{CO} 2$. The $\mathrm{CO}$ catalyst is relatively low cost, compared to SCR catalyst for $\mathrm{NO}_{\mathrm{x}}$ control. However, the combination of reduced combustion efficiency and the exhaust gas pressure drop across the CO catalyst leads to reduced plant efficiency (Holt et al, 1989). The effects of flue gas from coal gas combustion on $\mathrm{CO}$ catalyst, such as catalyst masking or poisoning, may need to be assessed to determine the economics of $\mathrm{CO}$ catalysts in an IGCC process environment.

Incomplete combustion may occur due to local chilling of the flame, such as at points of secondary air entry (Cohen et al, 1987) or due to wet injection.

One advantage that coal gases have compared to natural gas or distillate oil with respect to combustion efficiency is the presence of hydrogen, which has a very high flame speed. This results in early ignition and promotes complete combustion (Holt et al, 1989).

\section{CO Emissions With MBG}

For a medium-BTU gas, $\mathrm{CO}$ emissions are not expected to be a major concern at baseload operation, particularly if there is hydrogen in the fuel gas. $\mathrm{CO}$ emissions could become a problem at part load if firing temperature is significantly reduced, or 
could become significant if high levels of water injection or fuel moisturization are used.

\section{CO Emissions with LBG}

CO emissions are more of a concern for LBG than MBG. Corman (1986) reports an estimate for baseload $\mathrm{CO}$ emissions from a 100-MW class gas turbine firing LBG with a heating value of less than $150 \mathrm{BTU} / \mathrm{scf}$ to be approximately 10,000 tons/year. Corman implies the emissions would be higher for part-load gas turbine operation. However, in a phone conversation (1990) Corman appeared to have no concern about CO emissions with LBG. Pillsbury (1989) indicated that heating value is not the proper determinant of combustion efficiency, particularly because hydrogen is highly flammable and will tend to promote complete combustion even in LBG. Pillsbury and Corman both stated that the expected $\mathrm{CO}$ emissions are on the order of 10 ppm or less when firing LBG at baseload conditions.

\section{Combustor Pressure Drop}

The combustor pressure drop is one of the significant losses in the gas turbine system. Pressure losses are due to skin friction and turbulence. The rise in temperature during combustion increases velocity and momentum of the gases in the combustor, which leads to temperature-related pressure losses. However, the pressure drop due to turbulence is usually much higher than the pressure loss associated with the temperature ratio in the combustor. The build-up of carbon or other deposits on the combustor liner may also affect skin friction and/or turbulencerelated pressure losses. Furthermore, aerodynamically excited vibrations in the combustor could lead to deposits breaking away, which could result in turbine damage (Cohen et al, 1987).

\section{Particles}

The particle loading in the fuel gas may be considered to consist of refractory materials or carbonaceous materials. Refractory particles may pass through the combustor without alternation. They can split into smaller particles, or possibly agglomerate into larger particles. Carbonaceous material may be fully or partially combusted, leaving perhaps ash residues (Cincotta, 1984). The particle discharge from the combustor may affect turbine maintenance.

\section{Combustor Life}

The combustor life has an effect on maintenance and repair work and, hence, the cost of maintaining the gas turbine. For industrial gas turbines, combustor chamber lives of 100,000 hours are desirable (Cohen et al, 1987). However, deposition, erosion, corrosion, and vibrations can shorten the life of combustor components such as the liners, requiring more frequent liner replacement or more expensive materials. The modular nature of the combustor cans makes this type of maintenance routine. However, the cost will increase with the frequency of maintenance and repair. The possible presence of particulates and alkalis in the coal gas may lead to more costly maintenance compared to clean fuel (e.g., natural gas) fired gas turbines.

\section{Turbine}

The heavy-duty high firing temperature gas turbines assumed for this study typically employ three or four turbine rotor stages. The first two or three stages are subject to high thermal loadings due to the high temperature exhaust gas. Improvements in 
turbine rotor blade cooling technology have made possible increases in gas turbine firing (turbine inlet) temperatures while maintaining essentially constant bulk metal temperatures in the rotors and stators of the first turbine stage. Possible future improvements in materials and manufacturing processes (such as making turbine blades from a single crystal with no grain boundaries) may allow higher blade bulk metal temperatures, due to the improved strength of the material, and further increases in firing temperature (Smock, 1989).

A number of potential problems with the effect of hot combustion gas on the turbine have been identified in various reports. These include:

- Corrosion of hot gas path components from alkali metals

- Erosion of material from airfoils (rotor and stator blades) due to ash particles of sufficient size and quantity. This would likely exacerbate corrosion as well, as the airfoils are often coated with a corrosion resistant layer.

- Deposition of ash on hot gas path components, changing the aerodynamic characteristics of the turbine and resulting in loss of efficiency. This would also affect film cooling and the heat transfer from the hot gas to the airfoils.

- Blockage of film cooling holes, reducing the efficiency of blade cooling. This could lead to localized thermal stresses arising from thermal gradients in the blade material, affecting the operating life and/or sustainable firing temperature of the turbine

All of these possible problems would affect the gas turbine maintenance cycle, thereby affecting maintenance costs. Some or all of these affects could also require changes in gas turbine operation, such as a reduction in firing temperature or strict specifications on fuel gas composition.

\section{Advanced Cooling Technology}

Aircraft derivative gas turbines, and particularly military engines, have employed a variety of advanced turbine cooling techniques. These machines fire clean jet fuel, and as such are not subject to the exhaust gas contaminants expected in coal gasfired units. Turbine blades and stator vanes subject to high temperature environments may have hollow internal cooling passages, through which compressed air is passed for convective cooling. These passages may have pin fins, to promote heat transfer from the metal to the cooling air. The cooling air is typically exhausted from the blade through holes in the blade tip or the trailing edge of the blade. The cooling air exhausted at the blade tip does provide some aerodynamic advantages by blocking against external bypass flow of exhaust gases between the blade tip and the rotor shroud. To further promote heat transfer in the internal cooling circuits, high velocity impingement of cooling air against the inside surface of a highly heated area may be used (referred to as impingement cooling). In addition, film cooling, in which some cooling air from inside the blade is vented near the leading edge of the blade, may also be employed. Film cooling results in a boundary layer of cooling air over the blade surface (Cohen et al, 1987; Dawkins et al, 1986).

The amount of cooling air required depends on the firing temperature, cooling air temperature, heat transfer features of the rotor and stator vanes, the material properties, and the design life of the system (Dawkins et al, 1986).

Based on testing of a prototype MS7001F engine with high $\left(2,300^{\circ} \mathrm{F}\right)$ firing temperature, GE reports that they expect their minimum hot gas component life design requirement to be met. The basis for this assertion is measurement of hot gas 
path metal temperatures to be 30 to $50^{\circ} \mathrm{F}$ below the design values. The test was conducted with natural gas (Brandt, 1989). The gas path metal temperatures in a coal

gas application may be affected by deposition or hole plugging, which is discussed in a later section.

The design of blades is complicated due to the changes in hot gas temperature across the blade surfaces, and the changes in temperature of cooling air inside the blade. Thus, the design must account for thermal gradients. Stresses in the blades may arise from thermal gradients (Cohen et al, 1987).

Any particles or liquid droplets which pass through the combustor and burn-out in the turbine nozzle or turbine first-stage may have deleterious effects on the thermal stresses in the hot gas path components.

\section{Turbine Blade Materials}

The selection of firing temperature for a gas turbine depends on both the turbine blade cooling technology employed and the blade materials. Three key criteria for selecting hot gas path materials, particularly for rotor blades, are: (1) creep-rupture properties; (2) hot corrosion resistance; and (3) hot oxidation resistance. The creep strength of a metal is a function of the bulk metal temperature. The time to obtain a standard 0.2 percent creep strain decreases as temperature increases. Also, the fatigue strength of a metal subject to cyclic stresses decreases as temperature increases. To provide blade strength, nickel-based superalloys may be used for rotor blades. To provide corrosion and oxidation resistance, coatings may be applied to the blade surfaces. Typical coatings include platinum-chromium-aluminide (Dawkins et al, 1986).

The GE MS7001F is reported to use a first-stage coating alloy containing cobalt, chromium, aluminum, and yttrium (Brandt, 1988). The blades for the GE turbine are reported to be manufactured using a technology called directional solidification that has been used for 20 years to make jet engine blades. In this casting method, the grain boundaries in the crystal structure of the metal are oriented to improve tensile strength, ductility, and fatigue strength. The use of this molding technology has permitted an increase in firing temperature of about $150^{\circ} \mathrm{F}$. Possible future improvements would be the casting of a single-crystal blade with no grain boundary, which would permit another 50 to $150^{\circ} \mathrm{F}$ improvement in firing temperature (Smock, 1989). Increases in firing temperature permit increased simple cycle efficiency. Such a design improvement is likely to be a long term development objective.

\section{Deposition}

Deposition of ash on surfaces in the hot gas path can restrict air flow, thus reducing turbine efficiency. Deposition of ash particles is expected to some extent in coalfueled gas turbines (Cincotta, 1984). Deposits can also lead to plugging of cooling air outlet holes, particularly those used for film cooling, on the turbine rotor blades (Becker and Schulten, 1985; Dawkins et al, 1986). This can lead to increased localized temperature gradients that can result in thermal stress cracking, and can be exacerbated by the stress riser effect of the cooling air holes themselves. Also, film cooling can be affected by deposits on the turbine blades and hot gas channels. Such deposits, of certain size and consistency, can significantly alter the flow and heat transfer characteristics of the blades (Becker and Schulten, 1985).

Hot gas path blockage is generally expected with any gas turbine application involving a fuel containing ash particles. GE predicted a blockage rate of about 0.4 percent of the first-stage turbine nozzle area per 100 hours of operation at a $2,300{ }^{\circ} \mathrm{F}$ 
firing temperature, based on a system with two-stages of high efficiency cyclones (Cincotta, 1984). This implies nozzle cleaning every 2,500 hours, if up to 10 percent blockage is allowed. The assumption appears to be that this cleaning can be accomplished using off-line water washing, for example.

GE conducted some tests with a turbine simulator to determine possible effects of ash deposition. No measurable deposits were found on the airfoils. However, the tests were only 57 hours in duration (Corman, 1986).

Evaluation of deposition appears to require a long term testing program, which in reality may not be realized until a demonstration plant is built and operating. The effect of deposition on the heat transfer characteristics of the turbine blades might be to require a reduction in firing temperature or to increase the frequency of blade replacements. Thus, either performance and/or cost may be affected by these types of problems.

\section{Erosion}

Erosion occurs due to contact of particles with sufficient mass or velocity to remove material from hot gas path surfaces, particularly rotor and stator vanes. Some possible sources of particles contributing to erosion include: particles not removed from the fuel gas in cyclones or barrier filters; break-away deposits from the fuel nozzle, fuel valves, combustor lining, transition piece, or turbine nozzles; and carryover of sorbent material from the zinc ferrite sorbent bed and, if included in the system, alkali removal sorbent bed. GE reported that they expect to achieve a particle size distribution and loading using two-stages of high efficiency cyclones to be within the erosion tolerance of the gas turbine materials (Cincotta, 1984).

However, some speculate that cyclones are insufficient to avoid the build up of particles and, hence, pressure drop in the zinc ferrite absorber bed. Therefore, barrier filtration upstream of the zinc ferrite unit may be required, in lieu of a single-stage cyclone. There is also speculation that a cyclone downstream of the zinc ferrite absorber may not be needed. Most design studies assume a cyclone between the absorber and the gas turbine combustor to capture any catastrophic loss of sorbent or unusual entrainment of sorbent, as well as to provide for additional removal of particles still present from the gasifier.

\section{Corrosion}

The most widely expressed concern regarding hot gas path corrosion is due to the presence of alkali in the exhaust gas. For systems with cold gas cleanup, alkali are not expected to pose a corrosion threat because it is believed that below 1,200 to $1,400{ }^{\circ} \mathrm{F}$, alkali condense onto particles in the gas stream (METC, 1987; Notestein, 1989), which are in turn removed very effectively by wet scrubbing. For hot gas cleanup systems using the zinc ferrite process, the fuel gas temperature in the particulate removal device is typically expected to be about $1,100^{\circ} \mathrm{F}$. The removal efficiency of alkali which condense on particles depends on the alkali concentration on the particles as a function of particle size, and the particle removal efficiency as a function of particle size. The expectation is that, because the smaller particles have a larger surface area per unit mass, there will be a larger concentration of condensed alkali on the smaller particles (Cincotta, 1984).

Several have reported that there is evidence that the alkali in coal gas may not pose as much of a threat as an equivalent concentration of alkali in petroleum fuels. The suggestion is that alkali in the coal gas are "gettered" by aluminosilicate ash materials (METC, 1987; Notestein, 1989). This, combined with the absence of 
"catalytic" elements, such as vanadium and molybdenum, are believed to reduce the ability of the coal gas alkali to cause corrosion.

In the event that particulate removal proves to be insufficient for alkali control, several alkali control technologies for hot gas cleanup systems have been explored (Notestein, 1989). Perhaps the most promising of these is an absorber utilizing emathlite, a naturally occurring clay (Bachovchin, 1987).

\section{Power Block Performance Model}

\section{Simple Cycle Gas Turbine: Mass and Energy Balance}

The simple cycle gas turbine (SCGT) mass and energy balance model is based upon the air-standard Brayton cycle, as described in Wark (1983). The case study examples are based upon data reported by General Electric for the Frame 7F gas turbine design (Brooks, 2000).

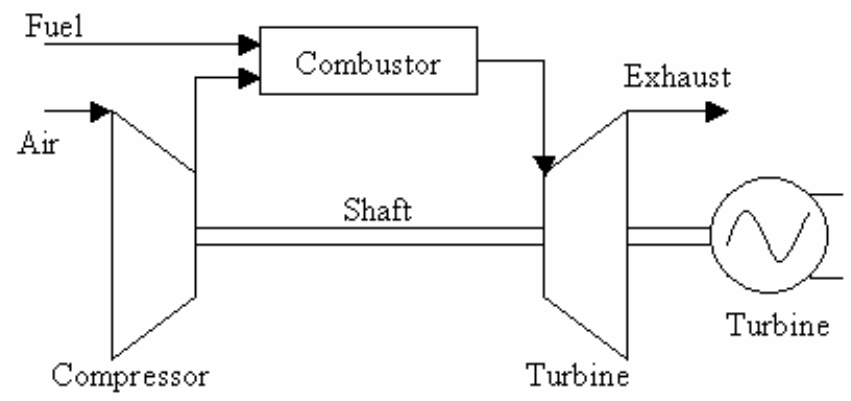

Figure 46 Simplified Schematic Diagram of a Simple Cycle Gas Turbine

A SCGT is comprised of three major components, including the compressor, combustor, and turbine, as shown in Figure 46. Air, at ambient pressure $\mathrm{P}_{\mathrm{a}}$ and ambient temperature, $T_{a}$, enters the compressor. The ratio of the compressor exit pressure to the inlet ambient air pressure is defined as the pressure ratio, $r_{p}$. Compression takes place approximately adiabatically. Therefore, the temperature of the compressed air is higher than the ambient temperature of the inlet air. The performance of an ideal adiabatic and isentropic compressor can be calculated using straight-forward thermodynamic principles. However, because real compressors are subject to inefficiencies, their performance will not be as good as the ideal case. Therefore, an adiabatic compressor efficiency, $\eta_{c}$, is defined to more accurately represent the real world performance of a compressor.

The compressed air enters a combustor, where it is mixed with high pressure gaseous fuel. The fuel and air are burned at essentially constant pressure. The conventional fuel for SCGT systems is natural gas, which is comprised mostly of methane. However, other fuels may be burned in a gas turbine, including syngas obtained from a gasification process. Syngas typically contains carbon monoxide (CO), hydrogen $\left(\mathrm{H}_{2}\right)$, methane $\left(\mathrm{CH}_{4}\right)$, carbon dioxide $\left(\mathrm{CO}_{2}\right)$, nitrogen $\left(\mathrm{N}_{2}\right)$, and water vapor $\left(\mathrm{H}_{2} \mathrm{O}\right)$ as the primary constituents. Syngases also may contain relatively small amounts of hydrogen sulfide $\left(\mathrm{H}_{2} \mathrm{~S}\right)$, carbonyl sulfide $(\mathrm{COS})$, and ammonia $\left(\mathrm{NH}_{3}\right)$. These latter three components are significant in terms of the formation of $\mathrm{SO}_{2}$ and $\mathrm{NO}_{\mathrm{x}}$ emissions, but are less important in terms of calculating the mass and energy balance of the system because they comprise only a small portion of the total fuel flow rate and the total fuel heating value. The combustor typically has a small pressure drop. 
Therefore, the exit pressure from the combustor is slightly less than that compared to the compressor outlet.

The high pressure hot product gases from the combustor enter the turbine, or expander, portion of the SCGT system. In the turbine, the gases are reduced in pressure, resulting in a corresponding reduction in temperature. The heat-removal process associated with expansion and cooling of the hot gases in the turbine results in an energy transfer from the gases to shaft work, leading to rotation of a shaft. In many heavy duty SCGT designs, the compressor, turbine, and a generator turn on the same shaft. The turbine must supply enough rotational shaft energy to power the compressor. The net difference between the work output of the turbine and the work input to the compressor is available for producing electricity in the generator. The ratio of compressor work to turbine work is referred to as the back work ratio.

The turbine inlet temperature is carefully controlled to prevent damage or fatigue of the first stage stator and rotor blades. The turbine inlet temperature and the pressure ratio are the two most important parameters that impact on system efficiency.

The expected operating practice for gas turbines in IGCC service is to adjust the air flow through the gas turbine compressor such that the flow at the turbine inlet nozzle is (approximately) choked. This usually involves the use of compressor inlet guide vanes to adjust the compressor air flow based on fuel flow and compressor air extraction (if any) to obtain design flow in the turbine.

As noted by Frey and Rubin (1991), the mass flow through a gas turbine is limited by the critical area of the turbine inlet nozzle. The critical area of the turbine inlet nozzle is a constant for a given make and model of gas turbine. Gas turbine operation on natural gas typically involves a relatively small fuel mass flow rate compared to the compressor mass flow rate. However, when operating on syngas, which may have a heating value substantially smaller than that of natural gas, a larger fuel mass flow rate is needed in order to supply approximately the same amount of energy to the gas turbine. The mass fuel-to-air ratio will be larger for a low BTU fuel than for a high BTU fuel. However, the total mass flow at the turbine inlet remains approximately the same. Therefore, the mass flow at the compressor inlet must be reduced to compensate for the higher fuel-to-air ratios needed for low BTU syngases.

The mass air flow at the turbine inlet nozzle is estimated, assuming choked flow conditions, based upon the following relationship (Frey and Rubin, 1991):

$$
m_{a c t}=m_{r e f}\left(\frac{P_{a c t}}{P_{r e f}}\right) \sqrt{\left(\frac{M W_{a c t}}{M W_{r e f}}\right)\left(\frac{T_{r e f}}{T_{a c t}}\right)}
$$

The reference values are determined based upon calibration to published data for gas turbine operation on natural gas. The actual values are determined based upon the desired simulated conditions. The pressure, temperature, and molecular weight in Equation (74) are evaluated at the turbine inlet nozzle.

The design specification adjusts the compressor air flow so that the ratio of the actual turbine inlet gas flow to the reference value, adjusted for temperature, pressure, and gas molecular weight, approaches unity to within a specified tolerance.

The effect of this new design specification is that the turbine inlet nozzle mass flow rate remains relatively constant even for varying values of fuel gas heating value and compressor air extraction. Thus, the gas turbine is more properly sized compared to the cost model.

The mass and energy balance for each of the following components are presented in the following sections: (1) compressor; (2) combustor; (3) turbine; and (4) generator. The calculation of overall SCGT performance is also discussed. 


\section{Compressor}

The outlet pressure of a compressor is specified by multiplying the pressure ratio and the inlet pressure:

$\mathrm{P}_{\mathrm{C} \text {,out }}=\mathrm{P}_{\mathrm{C}, \text { in }} \mathrm{r}_{\mathrm{p}}$

The outlet temperature is estimated via a multi-step procedure. The first step is to estimate the entropy of the inlet air based upon a regression relationship of thermodynamic data as given in Figure 47. Based upon the estimated entropy of the inlet air and the pressure ratio, the entropy of the compressor outlet air is estimated:

$\mathrm{s}_{\mathrm{C}, \text { out }}=\mathrm{s}_{\mathrm{C}, \text { in }}+\left(\mathrm{R} / \mathrm{MW}_{\text {air }}\right) \ln \left(\mathrm{r}_{\mathrm{p}}\right)$

For example, if the inlet temperature is $295 \mathrm{~K}$, then the entropy of the inlet air is estimated to be $1.682 \mathrm{~kJ} /(\mathrm{kg}-\mathrm{K})$. Suppose that the pressure ratio is 6 , and that the molecular weight of air is approximately 29 . The estimated outlet air entropy will be $2.196 \mathrm{~kJ} /(\mathrm{kg}-\mathrm{K})$. By comparison, the exact value reported in Wark (1993) for the same case is $2.199 \mathrm{~kJ} /(\mathrm{kg}-\mathrm{K})$. Thus, the regression-based approach here agrees well with the published case study.

Using the estimate of the entropy of the outlet air, a regression expression shown in Figure 48 is used to estimate the temperature of the outlet air. In this example, the temperature is estimated to be $488 \mathrm{~K}$, compared to a value of $490 \mathrm{~K}$ as reported by Wark (1983). With knowledge of the temperature of the outlet air, the enthalpy of the outlet air is estimated based upon the regression expression shown in Figure 49. The estimated enthalpy is $489.9 \mathrm{~kJ} / \mathrm{kg}$, versus a reported value of $492.7 \mathrm{~kJ} / \mathrm{kg}$. This procedure is based upon an isentropic compressor.

To take into account the irreversibilities in an actual compressor, the actual enthalpy of the outlet air is estimated based upon the following relationship:

$\mathrm{h}_{\mathrm{C}, \text { out }}=\mathrm{h}_{\mathrm{C}, \text { in }}+\left(\mathrm{h}_{\mathrm{C}, \text { out,isentropic }}-\mathrm{h}_{\mathrm{C}, \text { in }}\right) / \eta_{\mathrm{c}}$

If the adiabatic compressor efficiency is assumed to be 0.82 , then the estimated enthalpy at the compressor outlet is:

$\mathrm{h}_{\mathrm{C}, \text { out }}=294.8+(489.9-294.8) / 0.82=532.7 \mathrm{~kJ} / \mathrm{kg}$

The value reported by Wark (1983) is $536.1 \mathrm{~kJ} / \mathrm{kg}$. Based upon the estimated enthalpy for the actual compressor outlet air, the actual outlet temperature is estimated based upon the regression equation given in Figure 50. The estimated outlet temperature is $528 \mathrm{~K}$, versus a reported value of $532 \mathrm{~K}$. Thus, although there is some error in the estimation procedure, the result is within a few degrees of the reported value.

The work input requirement for the compressor is given by the mass flow of air multiplied by the difference in enthalpy between the outlet and inlet.

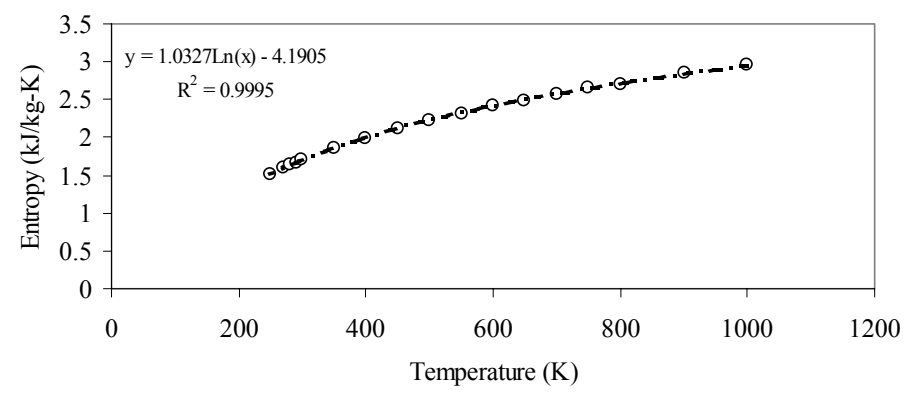

Figure 47 Regression Results for Entropy as a Function of Temperature for Air 


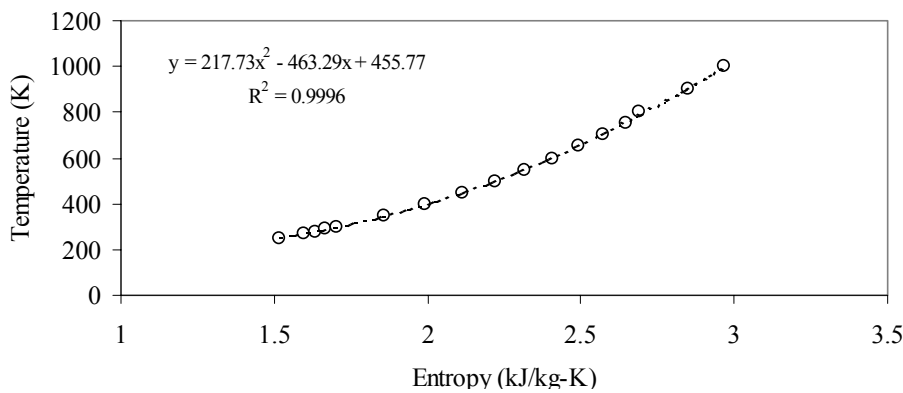

Figure 48 Regression Results for Temperature as a Function of Entropy for Air

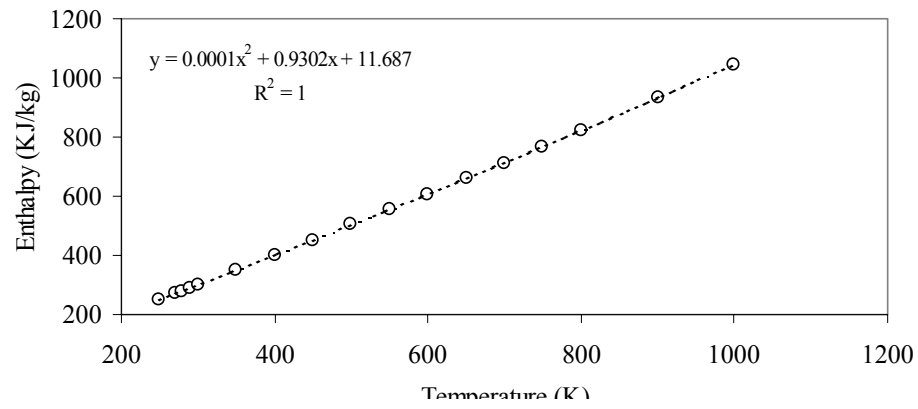

Figure 49 Regression Results for Enthalpy as a Function of Temperature for Air

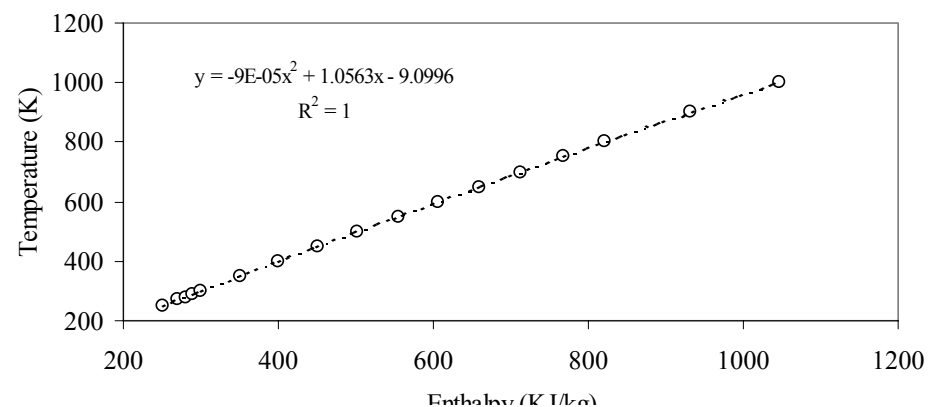

Figure 50 Regression Results for Temperature as a Function of Enthalpy for Air

\section{Combustor}

For the combustor, we assume that in general the fuel contains the following major components:

- $\quad$ carbon monoxide $(\mathrm{CO})$

- $\quad$ hydrogen $\left(\mathrm{H}_{2}\right)$

- methane $\left(\mathrm{CH}_{4}\right)$

- $\quad$ carbon dioxide $\left(\mathrm{CO}_{2}\right)$

- $\quad \operatorname{nitrogen}\left(\mathrm{N}_{2}\right)$

- water vapor $\left(\mathrm{H}_{2} \mathrm{O}\right)$

Although syngases also may contain relatively small amounts of hydrogen sulfide $\left(\mathrm{H}_{2} \mathrm{~S}\right)$, carbonyl sulfide (COS), and ammonia $\left(\mathrm{NH}_{3}\right)$, we will assume that these three components contribute negligibly to the mass and energy balance. These latter three components are significant in terms of the formation of $\mathrm{SO}_{2}$ and $\mathrm{NO}_{\mathrm{x}}$ emissions. 
The volume percent (or, equivalently, mole fraction) of each of the six major components will be known. Therefore, a heating value can be estimated for the fuel. Based upon date reported by Flagan and Seinfeld (1988), the enthalpy of reaction of $\mathrm{CO}$ is estimated as $283,400 \mathrm{~J} / \mathrm{gmole}$, the enthalpy of reaction of $\mathrm{H}_{2}$ is estimated as $242,200 \mathrm{~J} /$ gmole, and the enthalpy of reaction of $\mathrm{CH}_{4}$ is estimated as 803,500 $\mathrm{J} / \mathrm{gmole}$. These are estimated on a lower heating value basis, assuming that $\mathrm{H}_{2} \mathrm{O}$ produced is in the form of vapor. The other three major components are assumed to be non-reactive. The heating value of the syngas, on a J/gmole basis, is given by:

$\Delta \mathrm{h}_{\mathrm{r}, \mathrm{SG}}=\mathrm{y}_{\mathrm{CO}} \Delta \mathrm{h}_{\mathrm{r}, \mathrm{CO}}+\mathrm{y}_{\mathrm{H} 2} \Delta \mathrm{h}_{\mathrm{r}, \mathrm{H} 2}+\mathrm{y}_{\mathrm{CH} 4} \Delta \mathrm{h}_{\mathrm{r}, \mathrm{CH} 4}$

The syngas is represented by a mixture of the the six constituent gases. Air is a mixture primarily of oxygen and nitrogen. For every mole of oxygen in the air, there are approximately 3.76 moles of nitrogen. The major products of combustion are carbon dioxide, water vapor, nitrogen, and excess oxygen. Therefore, the mass balance for stoichiometric combustion is given by:

$\left[\mathrm{y}_{\mathrm{CO}} \mathrm{CO}+\mathrm{y}_{\mathrm{H} 2} \mathrm{H}_{2}+\mathrm{y}_{\mathrm{CH} 4} \mathrm{CH}_{4}+\mathrm{y}_{\mathrm{CO} 2} \mathrm{CO}_{2}+\mathrm{y}_{\mathrm{N} 2} \mathrm{~N}_{2}+\mathrm{y}_{\mathrm{H} 2 \mathrm{O}}\right.$

$\left.\mathrm{H}_{2} \mathrm{O}\right]+\mathrm{a} \mathrm{O}_{2}+3.76 \mathrm{a} \mathrm{N}_{2}$

$\rightarrow \mathrm{b} \mathrm{CO} 2+\mathrm{c} \mathrm{H}_{2} \mathrm{O}+\mathrm{d} \mathrm{N}_{2}$

The mass balance is given on the basis of one mole of syngas mixture. Thus, the units of each stoichiometric coefficient are moles of the respective compound per mole of syngas mixture. The mole fractions of each component in the syngas are known. Therefore, the unknowns are the stoichiometric coefficients a, b, c, d, and e. These can be solved based upon elemental balances:

$$
\begin{array}{ll}
\text { Carbon: } & \mathrm{y}_{\mathrm{CO}}+\mathrm{y}_{\mathrm{CH} 4}+\mathrm{y}_{\mathrm{CO} 2}=\mathrm{b} \\
\text { Hydrogen: } & 2 \mathrm{y}_{\mathrm{H} 2}+4 \mathrm{y}_{\mathrm{CH} 4}+2 \mathrm{y}_{\mathrm{H} 2 \mathrm{O}}=2 \mathrm{c} \\
\text { Oxygen: } & \mathrm{y}_{\mathrm{CO}}+2 \mathrm{y}_{\mathrm{CO} 2}+\mathrm{y}_{\mathrm{H} 2 \mathrm{O}}+2 \mathrm{a}=2 \mathrm{~b}+\mathrm{c} \\
\text { Nitrogen: } & 2 \mathrm{y}_{\mathrm{N} 2}+2(3.76) \mathrm{a}=2 \mathrm{~d}
\end{array}
$$

Based upon these four equations, the solutions for $\mathrm{a}, \mathrm{b}, \mathrm{c}$, and $\mathrm{d}$ are:

$$
\begin{aligned}
& \mathrm{a}=1 / 2 \mathrm{y}_{\mathrm{H} 2}+2 \mathrm{y}_{\mathrm{CH} 4}+1 / 2 \mathrm{y}_{\mathrm{CO}} \\
& \mathrm{b}=\mathrm{y}_{\mathrm{CO}}+\mathrm{y}_{\mathrm{CH} 4}+\mathrm{y}_{\mathrm{CO} 2} \\
& \mathrm{c}=\mathrm{y}_{\mathrm{H} 2}+2 \mathrm{y}_{\mathrm{CH} 4}+\mathrm{y}_{\mathrm{H} 2 \mathrm{O}} \\
& \mathrm{d}=\mathrm{y}_{\mathrm{N} 2}+3.76 \mathrm{a}
\end{aligned}
$$

However, gas turbine combustors operate with a significant amount of excess air. The mass balance for the case with excess air can be developed based upon the stoichiometric mass balance by introducing a new variable for the fraction of excess air, $e_{a}$. The fraction of excess air is given by:

$\mathrm{e}_{\mathrm{a}}=($ Total air - stoichiometric air) / (Stoichiometric air)

The mass balance for excess air is:

$$
\begin{aligned}
& {\left[\mathrm{y}_{\mathrm{CO}} \mathrm{CO}+\mathrm{y}_{\mathrm{H} 2} \mathrm{H}_{2}+\mathrm{y}_{\mathrm{CH} 4} \mathrm{CH}_{4}+\mathrm{y}_{\mathrm{CO} 2} \mathrm{CO}_{2}+\mathrm{y}_{\mathrm{N} 2} \mathrm{~N}_{2}+\mathrm{y}_{\mathrm{H} 2 \mathrm{O}}\right.} \\
& \left.\mathrm{H}_{2} \mathrm{O}\right]+\mathrm{a}\left(1+\mathrm{e}_{\mathrm{a}}\right) \mathrm{O}_{2}+3.76 \mathrm{a}\left(1+\mathrm{e}_{\mathrm{a}}\right) \mathrm{N}_{2} \\
& \rightarrow \mathrm{b} \mathrm{CO}_{2}+\mathrm{c} \mathrm{H}_{2} \mathrm{O}+\mathrm{d}^{\prime} \mathrm{N}_{2}+(\mathrm{a})\left(\mathrm{e}_{\mathrm{a}}\right) \mathrm{O}_{2}
\end{aligned}
$$

The solutions for $\mathrm{a}, \mathrm{b}$, and $\mathrm{c}$ are the same as in Equations (82), (83), and (84). The solution for $\mathrm{d}$ is replaced by the solution for d':

$\mathrm{d}^{\prime}=\mathrm{y}_{\mathrm{N} 2}+3.76 \mathrm{a}\left(1+\mathrm{e}_{\mathrm{a}}\right)$

For example, suppose that a fuel contains, on a mole or volume percentage basis, $24.8 \%$ hydrogen, $39.5 \%$ carbon dioxide, $1.5 \%$ methane, $9.3 \%$ carbon dioxide, 2.3 $\%$ nitrogen, and $22.7 \%$ water vapor. Stoichiometric combustion of this fuel would require 0.3515 moles of oxygen per mole of syngas mixture, and 1.32 moles of 
nitrogen in the inlet air. The exhaust gas would contain 0.50 moles of carbon dioxide, 0.50 moles of water vapor, and 1.34 moles of nitrogen, all based upon one mole of syngas combusted. If the fuel were burned with 100 percent excess air, then the exhaust gas would contain 0.50 moles of carbon dioxide, 0.50 moles of water vapor, and 2.67 moles of nitrogen, and 0.35 moles of oxygen, all based upon one mole of syngas combusted.

The actual amount of air that is needed to combust the fuel depends upon the desired turbine inlet temperature. Therefore, it is necessary to solve an energy balance in order to estimate the fuel to air ratio. The turbine inlet temperature, $\mathrm{T}_{\mathrm{T}, \mathrm{in}}$, is a known design parameter. The temperature of the air from the compressor is known based upon the compressor pressure ratio and adiabatic compressor efficiency, as explained in the previous section. The syngas temperature would also be known. The only unknown is the excess air ratio. Thus, the energy balance is:

b $\mathrm{H}_{\mathrm{CO} 2}\left(\mathrm{~T}_{\mathrm{T}, \mathrm{in}}\right)+\mathrm{c} \mathrm{H}_{\mathrm{H} 2 \mathrm{O}}\left(\mathrm{T}_{\mathrm{T}, \mathrm{in}}\right)+\mathrm{d}^{\prime} \mathrm{H}_{\mathrm{N} 2}\left(\mathrm{~T}_{\mathrm{T}, \text { in }}\right)+$

(a) $\left(\mathrm{e}_{\mathrm{a}}\right) \mathrm{H}_{\mathrm{O} 2}\left(\mathrm{~T}_{\mathrm{T}, \mathrm{in}}\right)-\left[\mathrm{y}_{\mathrm{CO}} \mathrm{H}_{\mathrm{CO}}\left(\mathrm{T}_{\mathrm{SG}}\right)+\mathrm{y}_{\mathrm{H} 2} \mathrm{H}_{\mathrm{H} 2}\left(\mathrm{~T}_{\mathrm{SG}}\right)+\mathrm{y}_{\mathrm{H} 2}\right.$

$\mathrm{H}_{\mathrm{H} 2}\left(\mathrm{~T}_{\mathrm{SG}}\right)+\mathrm{y}_{\mathrm{CO} 2} \mathrm{H}_{\mathrm{CO} 2}\left(\mathrm{~T}_{\mathrm{SG}}\right)+\mathrm{y}_{\mathrm{N} 2} \mathrm{H}_{\mathrm{N} 2}\left(\mathrm{~T}_{\mathrm{SG}}\right)+\mathrm{y}_{\mathrm{H} 2 \mathrm{O}}$

$\left.\mathrm{H}_{\mathrm{H} 2 \mathrm{O}}\left(\mathrm{T}_{\mathrm{SG}}\right)\right]-\mathrm{a}\left(1+\mathrm{e}_{\mathrm{a}}\right) \mathrm{H}_{\mathrm{O} 2}\left(\mathrm{~T}_{\mathrm{C}, \text { out }}\right)-3.76 \mathrm{a}\left(1+\mathrm{e}_{\mathrm{a}}\right) \mathrm{H}_{\mathrm{O} 2}\left(\mathrm{~T}_{\mathrm{C}, \text { out }}\right)=$

$\Delta \mathrm{h}_{\mathrm{r}, \mathrm{SG}}$

Because all of the terms in this equation are known except for the excess air fraction, the equation can be rearranged in terms of excess air fraction as follows:

$\mathrm{b} \mathrm{H}_{\mathrm{CO} 2}\left(\mathrm{~T}_{\mathrm{T}, \text { in }}\right)+\mathrm{c} \mathrm{H}_{\mathrm{H} 2 \mathrm{O}}\left(\mathrm{T}_{\mathrm{T}, \text { in }}\right)+\left\{\mathrm{y}_{\mathrm{N} 2}+3.76 \mathrm{a}\left(1+\mathrm{e}_{\mathrm{a}}\right)\right\} \mathrm{H}_{\mathrm{N} 2}$

$\left(\mathrm{T}_{\mathrm{T}, \mathrm{in}}\right)+(\mathrm{a})\left(\mathrm{e}_{\mathrm{a}}\right) \mathrm{H}_{\mathrm{O} 2}\left(\mathrm{~T}_{\mathrm{T}, \mathrm{in}}\right)-\left[\mathrm{y}_{\mathrm{CO}} \mathrm{H}_{\mathrm{CO}}\left(\mathrm{T}_{\mathrm{SG}}\right)+\mathrm{y}_{\mathrm{H} 2} \mathrm{H}_{\mathrm{H} 2}\left(\mathrm{~T}_{\mathrm{SG}}\right)+\right.$

$\mathrm{y}_{\mathrm{H} 2} \mathrm{H}_{\mathrm{H} 2}\left(\mathrm{~T}_{\mathrm{SG}}\right)+\mathrm{y}_{\mathrm{CO} 2} \mathrm{H}_{\mathrm{CO} 2}\left(\mathrm{~T}_{\mathrm{SG}}\right)+\mathrm{y}_{\mathrm{N} 2} \mathrm{H}_{\mathrm{N} 2}\left(\mathrm{~T}_{\mathrm{SG}}\right)+\mathrm{y}_{\mathrm{H} 2 \mathrm{O}}$

$\left.\mathrm{H}_{\mathrm{H} 2 \mathrm{O}}\left(\mathrm{T}_{\mathrm{SG}}\right)\right]-\mathrm{a}\left(1+\mathrm{e}_{\mathrm{a}}\right) \mathrm{H}_{\mathrm{O} 2}\left(\mathrm{~T}_{\mathrm{C}, \text { out }}\right)-3.76 \mathrm{a}\left(1+\mathrm{e}_{\mathrm{a}}\right) \mathrm{H}_{\mathrm{N} 2}\left(\mathrm{~T}_{\mathrm{C}, \text { out }}\right)=$

$\Delta \mathrm{h}_{\mathrm{r}, \mathrm{SG}}$

For convenience, we create the following groups of terms:

$\mathrm{H}_{\text {fuel }}=\mathrm{y}_{\mathrm{CO}} \mathrm{H}_{\mathrm{CO}}\left(\mathrm{T}_{\mathrm{SG}}\right)+\mathrm{y}_{\mathrm{H} 2} \mathrm{H}_{\mathrm{H} 2}\left(\mathrm{~T}_{\mathrm{SG}}\right)+\mathrm{y}_{\mathrm{CH} 4} \mathrm{H}_{\mathrm{CH} 4}\left(\mathrm{~T}_{\mathrm{SG}}\right)+$

$\mathrm{y}_{\mathrm{CO} 2} \mathrm{H}_{\mathrm{CO} 2}\left(\mathrm{~T}_{\mathrm{SG}}\right)+\mathrm{y}_{\mathrm{N} 2} \mathrm{H}_{\mathrm{N} 2}\left(\mathrm{~T}_{\mathrm{SG}}\right)+\mathrm{y}_{\mathrm{H} 20} \mathrm{H}_{\mathrm{H} 20}\left(\mathrm{~T}_{\mathrm{SG}}\right)$

$\mathrm{H}_{\text {air,stoich }}=\mathrm{aH}_{\mathrm{O} 2}\left(\mathrm{~T}_{\mathrm{C}, \text { out }}\right)+3.76 \mathrm{aH} \mathrm{H}_{\mathrm{N} 2}\left(\mathrm{~T}_{\mathrm{C}, \text { out }}\right)$

$\mathrm{H}_{\text {products,stoich }}=\mathrm{bH}_{\mathrm{CO} 2}\left(\mathrm{~T}_{\mathrm{T}, \text { in }}\right)+\mathrm{cH}_{\mathrm{H} 2 \mathrm{O}}\left(\mathrm{T}_{\mathrm{T}, \mathrm{in}}\right)+\left\{\mathrm{y}_{\mathrm{N} 2}+3.76 \mathrm{a}\right\}$

$\mathrm{H}_{\mathrm{N} 2}\left(\mathrm{~T}_{\mathrm{T}, \text { in }}\right)$

The solution for the excess air fraction is given by:

$e_{a}=\frac{H_{\text {fuel }}+H_{\text {air }, \text { stoich }}+\Delta h_{r, S G}-H_{\text {products,stoich }}}{a\left[3.76\left\{H_{N 2}\left(T_{T, \text { in }}\right)-H_{N 2}\left(T_{C, \text { out }}\right)\right\}+\left\{H_{O 2}\left(T_{C, \text { out }}\right)\right\}\right]}$

For example, suppose that the turbine inlet temperature is specified as 1,100 K. For the same syngas composition as previously assumed, and for the same compressor outlet temperature of $528 \mathrm{~K}$, the estimated excess air ratio is 4.218 . This excess air ratio was verified in two ways. First, the excess air ratio was substituted into the final mass balance, and an energy balance was calculated using Equation (87). The energy balance was properly closed. Second, the same assumptions were input into an independently developed spreadsheet that uses a different set of equations for estimating enthalpy. The results agreed to within a few degrees for the predicted turbine inlet temperature calculated by the independent software.

\section{Turbine}

The energy balance for the turbine is estimated in a manner similar to that for the compressor. However, a key difference is that the exhaust gas is not air, and therefore the thermodynamic data for air are not strictly applicable for use with the 
turbine. In addition, pressure losses in the combustor and the turbine back pressure must be accounted for when estimating the work capability of the turbine.

The pressure at the combustor outlet, which is assumed to be same pressure as for the turbine inlet, is given by:

$\mathrm{P}_{\mathrm{C}, \text { out }}=\mathrm{P}_{\mathrm{T}, \text { in }}=\mathrm{P}_{\mathrm{a}}\left(\mathrm{r}_{\mathrm{p}}\right)-\Delta \mathrm{p}_{\text {comb }}$

The pressure at the turbine outlet is given by:

$\mathrm{P}_{\mathrm{T}, \text { out }}=\mathrm{P}_{\mathrm{a}}+\Delta \mathrm{p}_{\text {back }}$

Therefore, the pressure ratio for the turbine is given by:

$\mathrm{r}_{\mathrm{p}, \text { turb }}=\mathrm{P}_{\mathrm{T}, \text { in }} / \mathrm{P}_{\mathrm{T}, \text { out }}=\left(\mathrm{P}_{\mathrm{a}}\left(\mathrm{r}_{\mathrm{p}}\right)-\Delta \mathrm{p}_{\text {comb }}\right) /\left(\mathrm{P}_{\mathrm{a}}+\Delta \mathrm{p}_{\text {back }}\right)$

Because nitrogen comprises approximately 70 percent or more (by volume) of the exhaust gases from the gas turbine, we use nitrogen as the basis for the calculations to determine the turbine exhaust temperature. Figure 51 and Figure 52 display the regression equations for entropy as a function of temperature, and for temperature as a function of entropy, respectively. For example, temperature is equal to $4.9161 \times 10^{-4}$ (entropy) $)^{6.9277}$ with an $\mathrm{R}^{2}=0.9999$. The entropy at the turbine inlet is estimated based upon the turbine inlet temperature. For example, if the turbine inlet temperature is $1,100 \mathrm{~K}$, then the estimated entropy from the Equation in Figure 51 will be $8.253 \mathrm{~kJ} / \mathrm{kg}-\mathrm{K}$. If the turbine pressure ratio is equal to 6 , then the entropy at the turbine outlet is estimated as:

$$
\begin{aligned}
& \mathrm{s}_{\mathrm{T}, \text { out }}=\mathrm{s}_{\mathrm{T}, \text { in }}+8.3144 / 28 \ln \left(1 / \mathrm{r}_{\mathrm{p}, \text { turb }}\right) \\
& \mathrm{s}_{\mathrm{T}, \text { out }}=8.253+8.3144 / 28 \ln (1 / 6)=7.721 \mathrm{~kJ} / \mathrm{kg}-\mathrm{K}
\end{aligned}
$$

At this value of entropy, the temperature is calculated, based upon the regression equation given in Figure 52, to be $694 \mathrm{~K}$. This temperature is exactly the same as that reported by Wark (1983) for a similar calculation based upon air.

If the turbine is not isentropic, then the turbine outlet temperature will be higher than that predicted based upon the above isentropic calculation. The isentropic turbine work output is given by the difference between the enthalpies of the inlet and outlet under isentropic conditions. The enthalpy of exhaust gas is estimated based on the regression equation shown in Figure 53.

$\mathrm{h}_{\mathrm{T}, \mathrm{I}, \text { out,isentropic }}=5.9731 \times 10^{-\mathrm{S}} \mathrm{T}^{2}+1.0373 \mathrm{~T}-10.1939$

The estimated enthalpy is $738.5 \mathrm{~kJ} / \mathrm{kg}$ when the outlet temperature is $694^{\circ} \mathrm{K}$. This procedure is based on an isentropic turbine. If the inlet termperature is $1,100^{\circ} \mathrm{K}$, then the enthalpy at the turbine inet is estimated to be:

$$
\begin{aligned}
& \mathrm{h}_{\mathrm{T}, \text { in }}=5.9731 \times 10^{-\mathrm{S}} 1100^{2}+1.0373 \times 1100-10.1939 \\
& =1,203.1 \mathrm{~kJ} / \mathrm{kg}
\end{aligned}
$$

To take into account the efficiency of an actual expander, the actual enthalpy of the outlet gas is estiated based on the following relationship:

$$
\mathrm{h}_{\mathrm{T}, \mathrm{i}, \text { out }}=\mathrm{h}_{\mathrm{T}, \mathrm{i}, \text { in }}+\left(\mathrm{h}_{\mathrm{T}, \mathrm{i} \text {,out,isentropic }}-\mathrm{h}_{\mathrm{T}, \mathrm{i}, \text { in }}\right) \eta_{\mathrm{Ti}}
$$

If the adiabatic turbine efficiency is assumed to be 0.95 , then the estimated enthalpy at the turbine outlet is:

$$
\mathrm{h}_{\mathrm{T}, \mathrm{i} \text {,out }}=1,203.1+(738.5-1,203.1) \times 0.95=761.7 \mathrm{~kJ} / \mathrm{kg}
$$

The actual temperature at the outlet is estimated based upon the regression expression shown in Figure 54. 


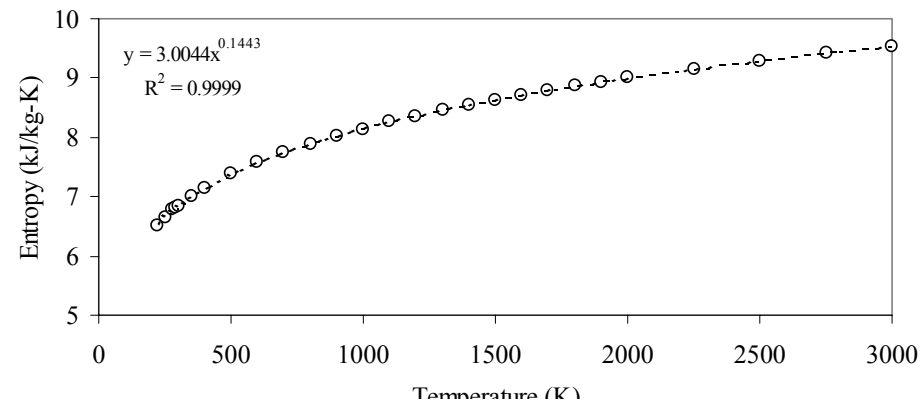

Figure 51 Regression Results for Entropy as a Function of Temperature for Nitrogen $\left(\mathrm{N}_{2}\right)$

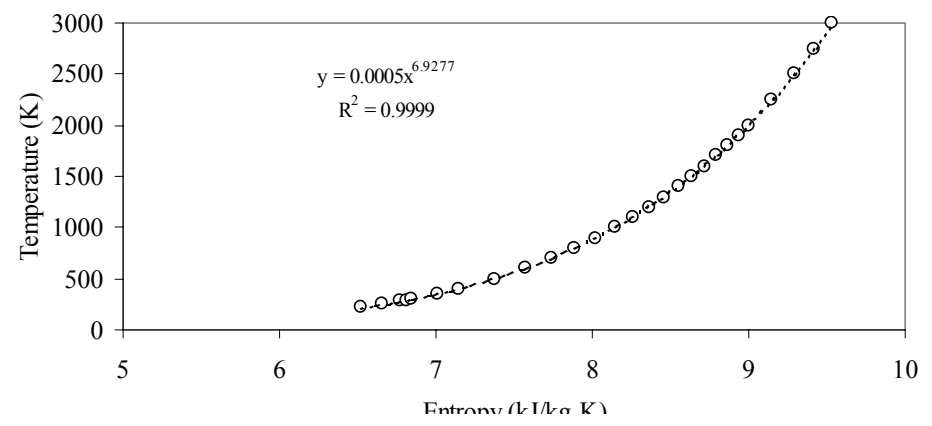

Figure 52 Regression Results for Temperature as a Function of Entropy for Nitrogen $\left(\mathrm{N}_{2}\right)$

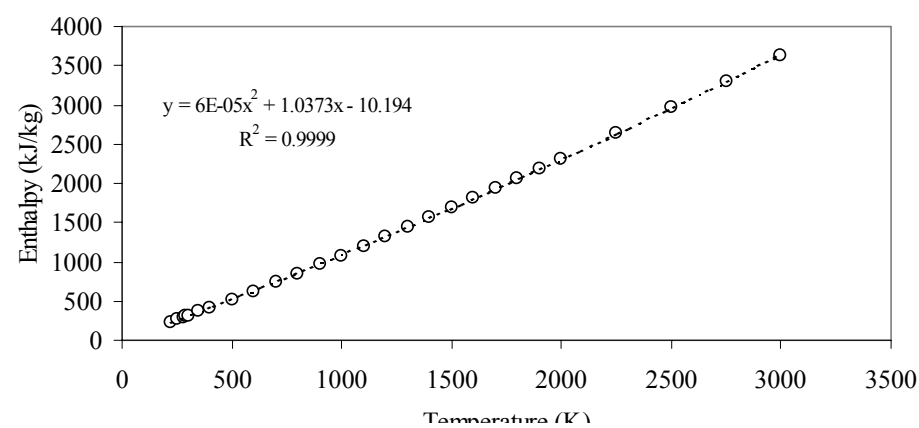

Figure 53 Regression Results for Enthalpy as a Function of Temperature for Nitrogen $\left(N_{2}\right)$

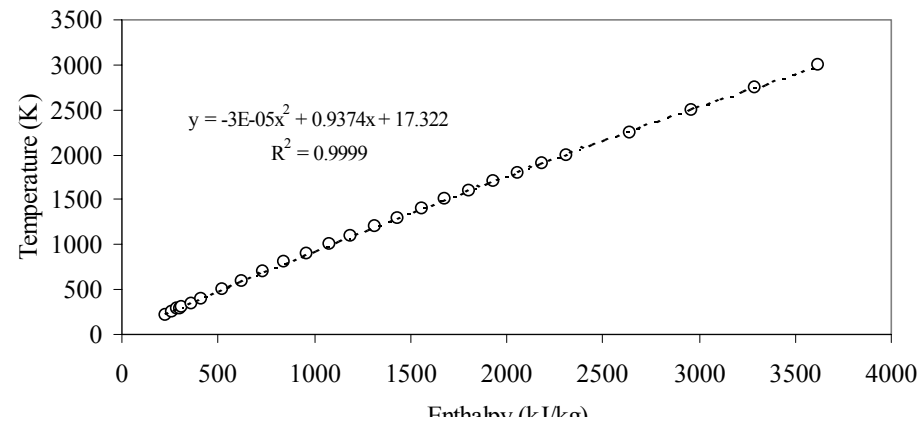

Figure 54 Regression Results for Temperature as a Function of Enthalpy for Nitrogen $\left(\mathrm{N}_{2}\right)$ 


\section{Calibration of the Gas Turbine Model}

In order to calibrate the gas turbine model, a simple cycle system was simulated for natural gas and one gas turbine and key input assumptions in the simulation were varied in order to match published specifications for the exhaust gas temperature, simple cycle efficiency, and net power output for a commercial gas turbine. The simple cycle efficiency, power output, and exhaust gas temperature vary with the isentropic efficiencies of compressors and expanders of the gas turbine, as illustrated in Figure 55, Figure 56, and Figure 57. The curves shown in these three figures were obtained from sensitivity analysis of the simple cycle gas turbine model. For natural gas firing, published data are available for a "Frame 7F" type of gas turbine. For example, the published values for a General Electric MS7001F gas turbine are a simple cycle efficiency of 36.35 percent on a lower heating value basis, a power output of 169.9 MW, an exhaust mass flow of 3,600,000 lb/hr, and an exhaust gas temperature of $1,116^{\circ} \mathrm{F}$ (Farmer, 1997). The required turbine isentropic efficiency is selected from Figure 55 based upon the desired exhaust temperature; in this case, an isentropic efficiency of 87.2 percent was selected. A compressor isentropic efficiency of 91.8 percent is selected based on Figure 56 in order to obtain the correct simple cycle efficiency. The reference mass flow at the turbine inlet is adjusted to $3,470,000 \mathrm{lb} / \mathrm{hr}$ obtain the desired power output. The estimated power output of $170.0 \mathrm{MW}$, obtained from the ASPEN gas turbine model with the selected values of isentropic efficiencies, is within 0.11 percent of the published data. A similar procedure was used to calibrate the gas turbine to data for a coal gasification application. The isentropic efficiencies obtained in the case of syngas are 0.81 and 0.919 for gas turbine compressors and gas turbine expanders respectively.

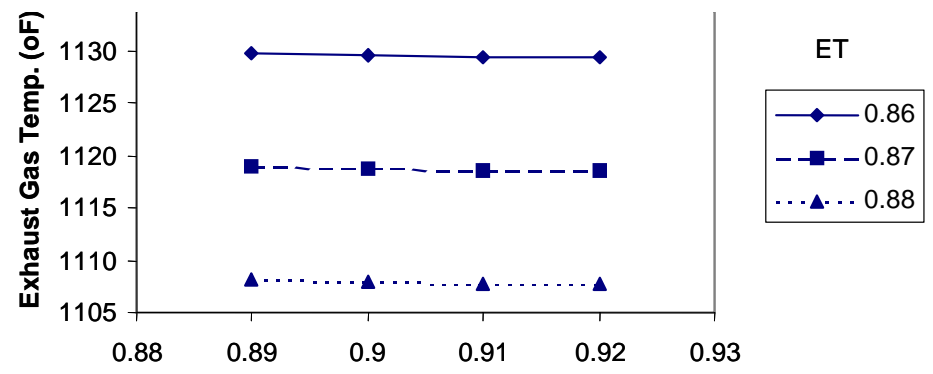

Figure 55 Exhaust Gas Temperature versus Gas Turbine Compressor isentropic Efficiency

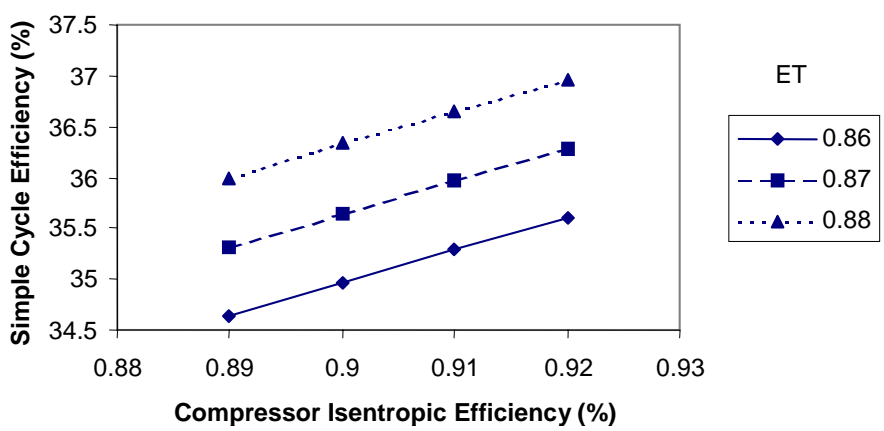

Figure 56 Simple Cycle Efficiency versus Gas Turbine Compressor isentropic Efficiency 


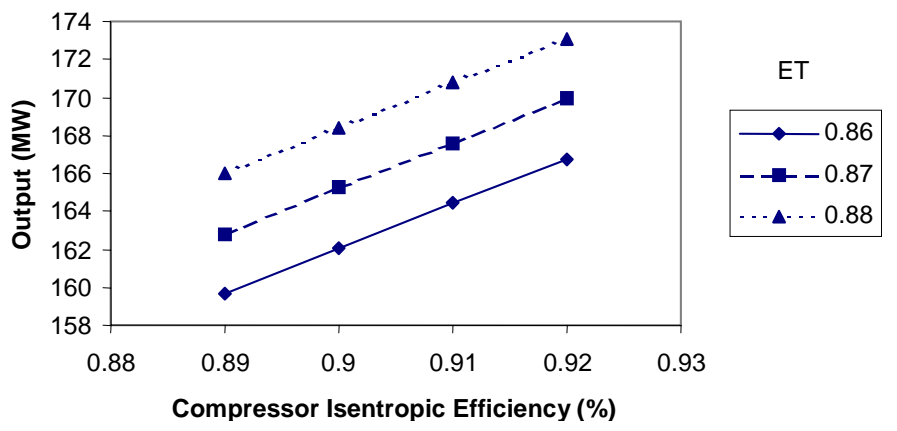

Figure 57 Output versus Gas Turbine Compressor Isentropic Efficiency. Note: $E T=$ Gas Turbine Expander Isentropic Efficiency

\section{Fuel Saturation/Combustor}

Thermal $\mathrm{NO}_{\mathrm{x}}$ constitutes a major portion of the total $\mathrm{NO}_{\mathrm{x}}$ emissions from a gas turbine combustor fired on syngas. To control the formation of thermal $\mathrm{NO}_{\mathrm{x}}$, water vapor must be introduced along with the cleaned gas into the combustors of gas turbines. The water vapor lowers the peak flame temperatures. The formation of NO from nitrogen and oxygen in the inlet air is highly temperature sensitive. Lowering the peak flame temperature in the combustor by introducing water vapor results in less formation of thermal NO and hence, lowers NO emissions.

Another advantage of fuel gas moisturization is to increase the net power output of the gas turbine. The introduction of moisture into the syngas lowers the syngas heating value and requires an increase in fuel mass flow in order to deliver the same amount of total heating value to the gas turbine engine. Because the mass flow of combustor gases is constrained by choked flow conditions at the turbine inlet nozzle, the inlet air flow has to be reduced to compensate for the increased fuel flow. This results in less power consumption of power by the gas turbine compressors, resulting in an increase in the net gas turbine output.

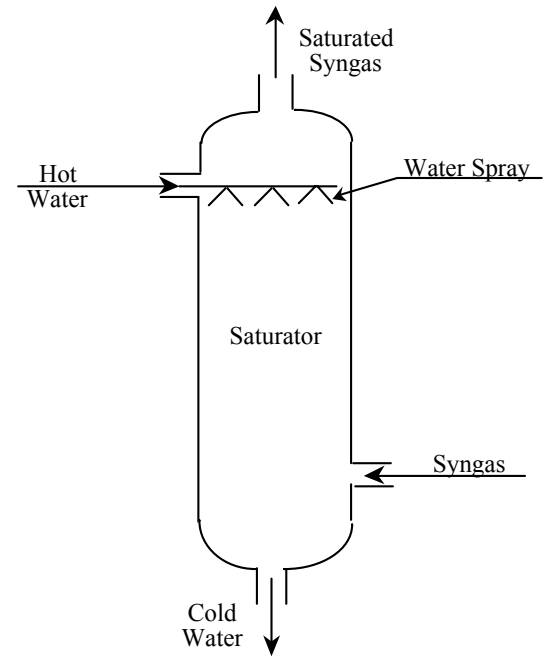

Figure 58 Fuel Gas Saturator

The saturation of fuel gas takes place in a saturator vessel, which is adiabatic. The clean gas from the acid gas removal system enters the saturator from the bottom while hot water, which is at a higher temperature than that of the syngas, is sprayed from the top of the vessel, as shown in Figure 58. The typical temperature of the hot 
water is $380^{\circ} \mathrm{F}$, while that of the syngas is $85^{\circ} \mathrm{F}$ before saturation. The saturated gas is heated to a temperature of approximately $350{ }^{\circ} \mathrm{F}$ and exits from the saturator from the top of the vessel while the hot water gets cooled and exits from the bottom of the vessel. The heat needed for heating the water is transferred from low temperature gas cooling units and the heat recovery steam generators to the fuel gas saturation unit as shown in Figure 59. A portion of the cold water leaving the fuel gas saturator is sent to heat exchangers in low temperature gas cooling section, where it get heated while cooling the hot syngas from the gas scrubbing section. The remaining portion of cold water is heated by heat exchange with boiler feedwater from the heat recovery steam generation system. Both the portions of heated water are combined to form the hot water spraying from the top of the saturator vessel. The clean, medium BTU gas from the fuel gas saturator is combusted in the gas turbine combustors.

Figure 59 shows the details of the fuel gas saturation unit. The syngas leaving the Selexol acid gas recovery unit, is saturated with moisture before the gas enters the gas turbine combustor. This is done with the intent of raising the net plant power output and to control $\mathrm{NO}_{\mathrm{x}}$ emissions from the gas turbine. The steam saturation increases the mass throughput and the heat capacity of the inlet pressurized fuel gas stream to the gas turbine resulting in an increase in the gas turbine power output. The amount of water required to saturate the clean syngas to 40 weight percent moisture is calculated.

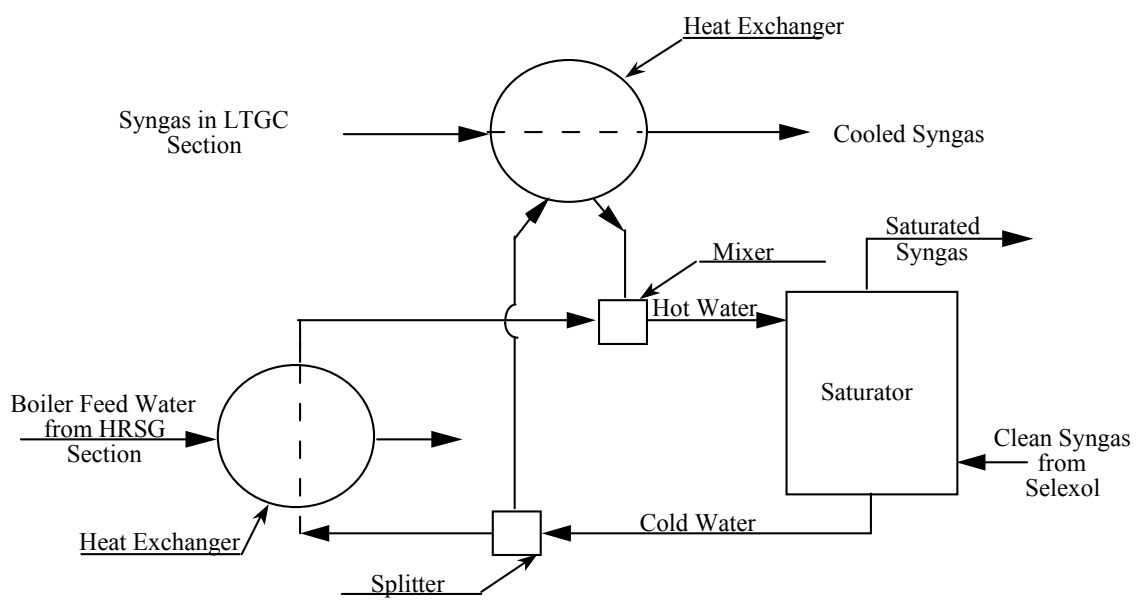

Figure 59 Simplified Schematic of Fuel Gas Saturation

\section{Gas Emissions}

\section{Environmental Emissions}

$\mathrm{SO}_{2}$ emissions from IGCC systems are controlled by removing sulfur species from the syngas prior to combustion in the gas turbine. $\mathrm{NO}_{\mathrm{x}}$ emissions tend to be low for this particular IGCC system for two reasons. The first is that there is very little fuelbound nitrogen in the fuel gas. The second reason is that thermal NO formation is low because of the low syngas heating value and correspondingly relatively low adiabatic flame temperature. A primary purpose of the gas cleanup system is to protect the gas turbine from contaminants in the fuel. Hence, no post-combustion control is assumed. However, it is possible to further control $\mathrm{NO}_{\mathrm{x}}$ emissions, for example, through use of Selective Catalytic Reduction (SCR) downstream of the gas turbine. The emission rates of these pollutants are lower than for conventional power plants and for many advanced coal-based power generation alternatives. $\mathrm{CO}_{2}$ emissions are lower than for conventional coal-fired power plants because of the 
higher thermal efficiency of the IGCC system (e.g., nearly 40 percent in this case versus typical values of 35 percent for conventional pulverized coal-fired power plants).

\section{$\mathrm{NO}_{x}$ Emissions}

The generation of $\mathrm{NO}$ and $\mathrm{NO}_{2}$ from the gas turbine has been modeled in Frey and Akunuri (2001). Both the fuel $\mathrm{NO}_{\mathrm{x}}$ as well as thermal $\mathrm{NO}_{\mathrm{x}}$ have been taken into consideration for the estimation of $\mathrm{NO}$ and $\mathrm{NO}_{2}$. The default assumptions made for these estimations are that fuel $\mathrm{NO}$ is 95 percent by volume of the fuel $\mathrm{NO}_{\mathrm{x}}$, and that the fraction of ammonia that is converted to fuel $\mathrm{NO}_{\mathrm{x}}$ is 0.90 . The conversion rate of nitrogen to $\mathrm{NO}_{\mathrm{X}}$ during the gas turbine combustion is assumed to be 0.00045 . Atmospheric emission rates are calculated on a lb/MMBTU basis as part of the model output.

\section{Particulate Matter Estimations}

PM emissions are controlled in the syngas cleanup system prior to the gas turbine and therefore, particulate matter emissions from the gas turbine are not modeled in the present model.

\section{$\mathrm{CO}$ and $\mathrm{CO}_{2}$ Emissions}

$\mathrm{CO}$ emissions from the power plant are assumed to come from the gas turbine section of the plant. The fraction of $\mathrm{CO}$ that is converted to $\mathrm{CO}_{2}$ in the gas turbine is assumed to be 0.99985 . Aside from the gas turbine, $\mathrm{CO}_{2}$ is also emitted by the Beavon-Stretford tail gas treatment unit. The emissions are expressed in terms of $\mathrm{lb} / \mathrm{kWh}$.

\section{$\mathrm{SO}_{2}$ Emissions}

$\mathrm{SO}_{2}$ emissions from the IGCC system are assumed to the result from combustion of syngas in the gas turbine. The $\mathrm{SO}_{2}$ emissions from the gas turbine are due to oxidation of $\mathrm{H}_{2} \mathrm{~S}$ and $\mathrm{COS}$ in the fuel gas. The amount of $\mathrm{H}_{2} \mathrm{~S}$ and $\mathrm{COS}$ in the fuel gas can be varied by changing the removal efficiency of the Selexol process. The emissions are calculated on a lb/MMBTU basis.

\section{Energy Use}

\section{HRSG Feedwater System}

Boiler Feed Water Treating

$\mathrm{W}_{\mathrm{e}, \mathrm{BF}}=20.8+2.13 \times 10^{-4} \mathrm{~m}_{\mathrm{pw}}$

$\mathrm{R}^{2}=0.975$

where,

$$
234,000 \leq \mathrm{m}_{\mathrm{pw}} \leq 3,880,000 \mathrm{lb} / \mathrm{hr}
$$

The standard error of the estimate is $38 \mathrm{~kW}$. The regression model is shown graphically in Figure 60. 


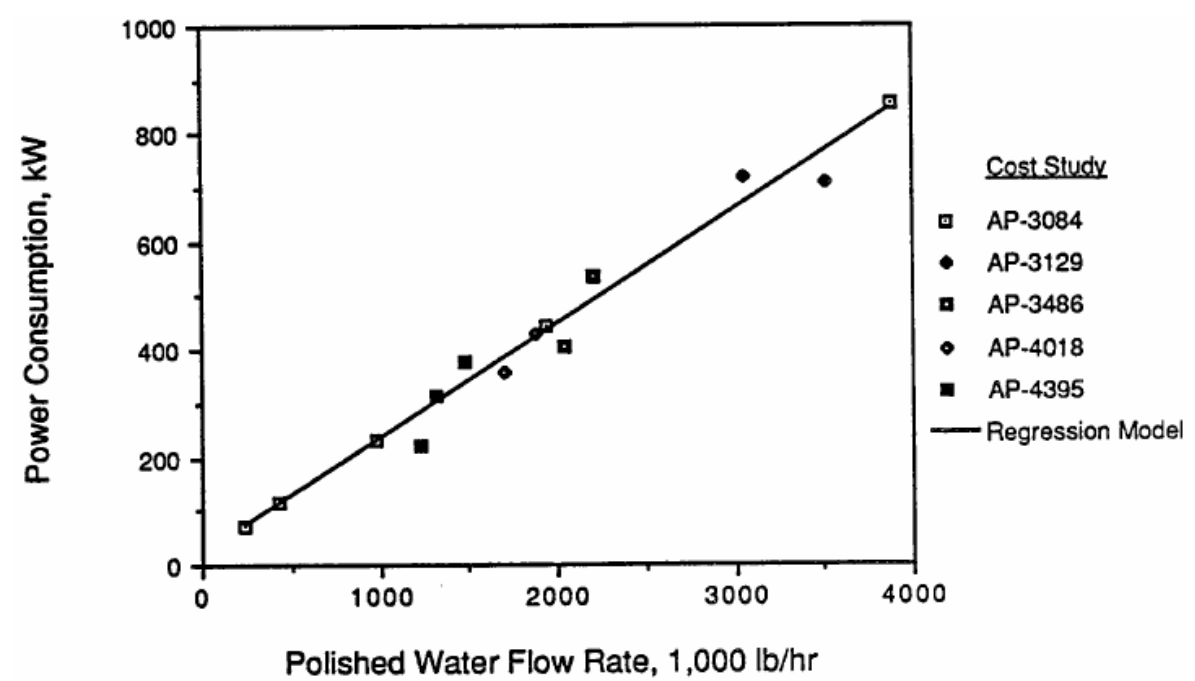

Figure 60 Power Requirement for Boiler Feed Water Treating

Process Condensate Treatment

$\mathrm{W}_{\mathrm{e}, \mathrm{PC}}=7.34 \times 10^{-4} \mathrm{~m}_{\mathrm{sbd}}$

$\mathrm{R}^{2}=1.00$

$\mathrm{n}=3$

where,

$$
196,000 \leq \mathrm{m}_{\mathrm{sbd}} \leq 237,000 \mathrm{lb} / \mathrm{hr}
$$

The standard error of the estimate is negligible. The regression model is shown graphically in Figure 61.

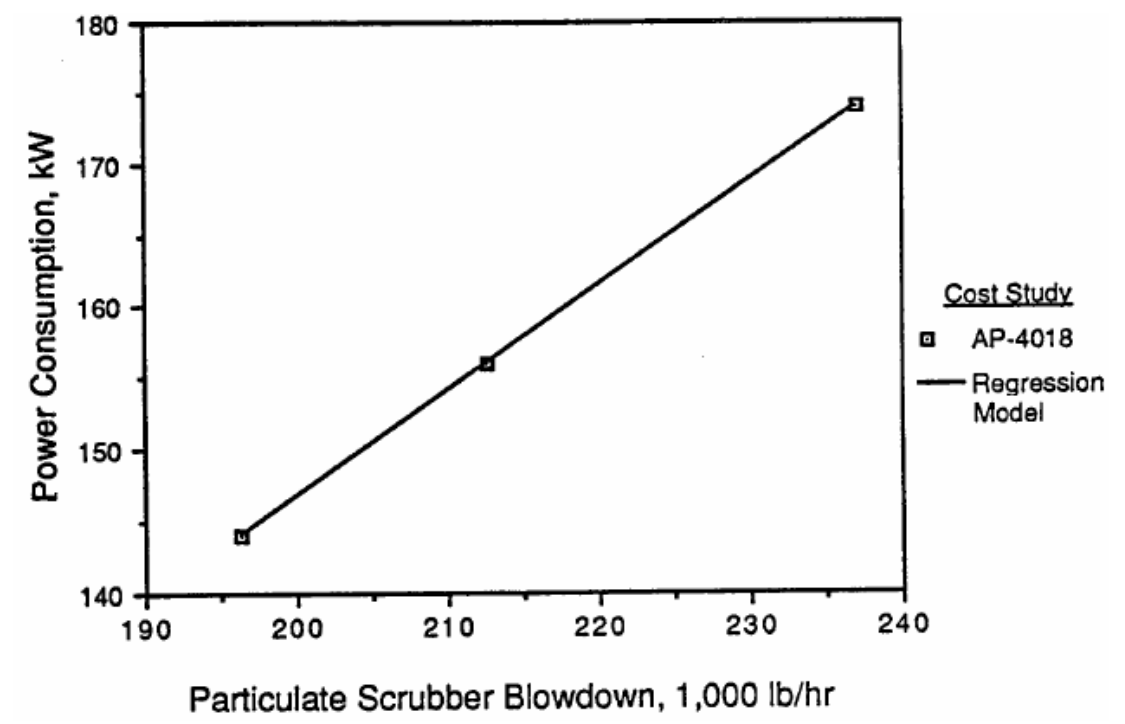

Figure 61 Power Requirement for Process Condensate Treatment 


\section{Power Block Cost Model}

\section{Power Block Capital Cost}

\section{Gas Turbine}

There are a number of design factors that affect the cost of a gas turbine in an IGCC process environment. For example, the firing of medium-BTU coal gas, as opposed to high-BTU natural gas, requires modification of the fuel nozzles and gas manifold in the gas turbine (BGE, 1989). Some additional concerns associated with firing coal gas are discussed by Cincotta (1984). The presence of contaminants in the syngas may affect gas turbine maintenance and long term performance. Liquid droplets may cause uneven combustion or may burn in the turbine first-stage nozzles, causing damage. Solids can deposit on fuel nozzles or cause erosion in the hot gas path of the gas turbine (e.g., combustor, turbine). Alkali materials that deposit on hot gas path parts cause corrosion. It is expected that, at fuel gas temperatures less than $1,000^{\circ} \mathrm{F}$, that alkali material is essentially condensed on any particulate matter in the raw syngas, and that the alkali removal efficiency is approximately the same as the particle removal efficiency. For sufficiently high particle removal efficiencies, erosion is not expected to be a problem. Corrosion is not expected to be any worse than for distillate oil firing. Deposition of particles is expected to be within the allowance of reasonable maintenance schedules. The design for an advanced high firing temperature gas turbine employs advanced air film cooling which could be affected by the ash content of combustion products.

Another design issue is the gas turbine fuel inlet temperature. A study by Fluor (Earley and Smelser, 1988) assumes that hot desulfurized syngas from an advanced hot gas cleanup process is fed directly to the gas turbine at $1,200^{\circ} \mathrm{F}$. The Fluor study indicates that General Electric expects that a fuel system capable of a $1,200^{\circ} \mathrm{F}$ fuel inlet temperature could be developed by 1994 . The maximum fuel temperature test to date has been at $1,000{ }^{\circ} \mathrm{F}$. An earlier study with hot gas cleanup included a hot gas cooler to reduce the gas temperature to $1,000^{\circ} \mathrm{F}$ (Corman, 1986). For the KRW system with cold gas cleanup, the coal gas temperature is within the limits of current technology. However, the gas turbine costs developed here should not be used in conjunction with IGCC systems featuring hot gas cleanup without some adjustments to account for the uncertainty in using a higher fuel inlet temperature.

Unfortunately, there is currently a lack of reported data from which to develop a detailed gas turbine cost model that is explicitly sensitive to the type of factors discussed above. In preliminary cost estimates, the typical approach to accounting for these uncertainties in performance, or for the possibility of increased capital cost due to design modifications, is through process contingency factors. The approach taken here is to use the available cost data for the GE Frame 7F to develop a cost estimate for a single gas turbine. This cost estimate has been encoded using process contingency factors.

Although cost estimates of the GE Frame 7F are available in a number of IGCC cost studies, recent cost estimates are significantly higher than older estimates. However, the more recent estimates are expected to be more reliable, because the Frame 7F was at or near commercialization at the time of the recent studies. In four recent sitespecific IGCC studies performed for EPRI (BGE, 1989; Fluor Daniel, 1988, 1989; FPL, 1989), the cost of the Frame 7F in the first phase of a phased IGCC construction schedule ranged from $\$ 30.8$ to 33.6 million, with an average of $\$ 32.0$ million (Jan 89). This cost excludes equipment associated with combined cycle systems, which are discussed in the following two sections. In two other studies 
(JCP\&L, 1989; NUSCo, 1988), the cost of the Frame 7F for application in natural gas-fired combined cycle plants was estimated at \$28.3 and \$26.8 million, respectively. The higher estimate of $\$ 32.0$ million per unit is consistent with the expectation that the cost of the gas turbine modified to fire medium-BTU coal gas will be higher than for the standard natural gas-fired unit. This high estimate will be used in the cost model:

$\mathrm{DC}_{\mathrm{GT}}=32,000 \mathrm{~N}_{\mathrm{T}, \mathrm{GT}}$

A competitor to the GE Frame 7F is under development by Mitsubishi Heavy Industries and Westinghouse Electric. The prototype model $501 \mathrm{~F}$ is expected to achieve a rating of $148.8 \mathrm{MW}$ and a turbine inlet temperature of $2,300^{\circ} \mathrm{F}$. This model was made available in 1992 (GTW, 1989). No cost data are currently available for this model; however, competition between the Frame 7F and the 501F could result in similar prices for both machines.

A Kraftwerk Union (KWU) gas turbine, model 84.2, was analyzed in an EPRI study (Fluor Daniel, 1988). This is a commercially available, moderate firing temperature machine that is rated at approximately $100 \mathrm{MW}$ with a cost of about $\$ 24.2$ million per unit. The combustor features a low-NOx design, and does not require water injection when operated on natural gas.

\section{Heat Recovery Steam Generator}

The cost of the HRSG is expected to depend on factors such as the high pressure steam flow rate to the steam turbine, the pressure of the steam, the gas turbine exhaust gas volume flow rate, the number of steam drums, and, to a lesser extent, the boiler feed water or saturated steam flowrates in each of the heat exchangers in the HRSG. A variety of regression models were investigated to represent these potential predictive parameters. However, because only 10 data points are included in the database, only a limited number of predictive parameters can be reasonably included in the model, based on statistical considerations. Furthermore, some parameters that are expected to be important in determining HRSG cost, such as the gas turbine exhaust flow rate, are not statistically important for this data set. When the gas turbine exhaust flow rate, high pressure inlet steam flow rate to the steam turbine, and the steam pressure are included in a regression model, the exponent for exhaust flow rate is small and is not statistically significant. The exhaust gas flow rate is not an influential predictive parameter because the cost studies are based primarily on either GE Frame 7E or 7F gas turbines; therefore, there was not a large range of variation for the exhaust gas flow rate. A simple regression model based only on the high pressure steam flow rate to the steam turbine yielded a high coefficient of determination. A multivariate regression based on the high pressure steam flow to the steam turbine and the pressure of the steam yielded satisfactory results:

$\left.D C_{H R}=11350 \times N_{T, H R}\left(\frac{P_{h p s, H R, o}}{1500}\right)^{1.526} \times\left(\frac{m_{h p s, H R, o}}{N_{O, H R}} / 600000\right)^{0.242}\right)^{2}=0.966 \quad(104$

where,

$$
\begin{aligned}
& 650 \leq P_{h p s, H R, o} \leq 1,545 \mathrm{psia} ; \text { and } \\
& 66,000 \leq \frac{\mathrm{m}_{\mathrm{hps}, \mathrm{HR}, \mathrm{o}}}{\mathrm{N}_{\mathrm{O}, \mathrm{HR}}} \leq 640,000 \mathrm{lb} / \mathrm{hr}
\end{aligned}
$$




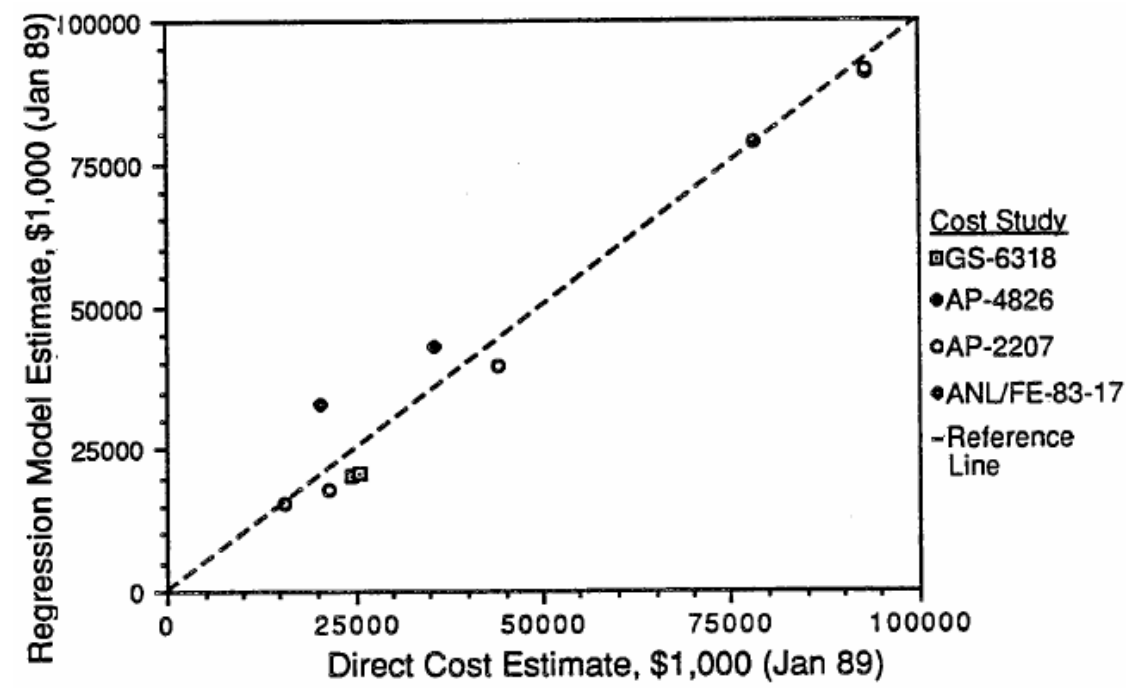

Figure 62 Predicted vs. Actual Cost for Heat Recovery Steam Generators.

\section{Steam Turbine}

A typical steam turbine for an IGCC plant consists of high-pressure, intermediatepressure, and low-pressure turbine stages, a generator, and an exhaust steam condenser. The high pressure stage receives high pressure superheated steam from the HRSG. The outlet steam from the high pressure stage returns to the HRSG for reheat, after which it enters the intermediate pressure stage. The outlet from the intermediate pressure stage goes to the low pressure stage.

The cost of a steam turbine is expected to depend on the mass flow rate of steam through the system, the pressures in each stage, and the generator output, among other factors. Nine cost estimates for the steam turbine were available from four studies. A single-variate regression based on the generator output was found to yield reasonable results:

$D C_{c}=158.7 \cdot W_{S T, E}$

$\mathrm{R}^{2}=0.958$

where,

$$
\mathrm{n}=9
$$

$$
200 \leq W_{S T, E} \leq 550 \mathrm{MW}
$$

Only one steam turbine is used in most IGCC designs. A graphical representation of the regression model is shown in Figure 63. 


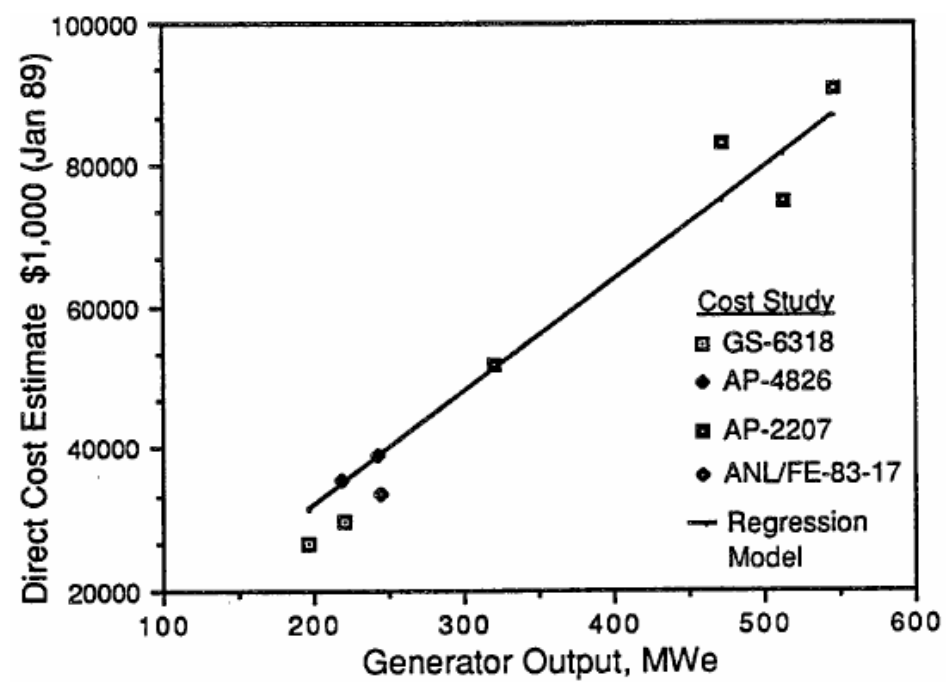

Figure 63 Direct Cost for the Steam Turbine-Generator Section

\section{HRSG Feedwater System}

The boiler feedwater system consists of equipment for handling raw water and polished water in the steam cycle. This equipment includes a water dimineralization unit for raw water, a dimineralized water storage tank, a condensate surge tank for storage of both dimineralized raw water and steam turbine condensate water, a condensate polishing unit, and a blowdown flash drum. The major streams in this process section are the raw water inlet and the polished water outlet. Data on the cost of the boiler feedwater section and the flow rates of the raw water and polished water streams is available from five studies for 14 plant sizes. These studies include Texaco-based, Shell-based, and KRW-based IGCC systems (Fluor, 1983a; 1983b; $1984 ; 1985 ; 1986)$. Because all of these studies were developed by the same contractor using a consistent approach, they provide an excellent basis for developing a cost model. The boiler feedwater section is generic to the steam cycle.

The cost of the boiler feedwater section is expected to depend on both the raw water flow rate through the dimineralization unit and the polished water flow rate through the polishing unit. The polished water flow rate includes primarily both the raw water and the steam turbine condensate. The steam cycle condensate is typically larger than the raw water flow rate. A two-variable regression model of the boiler feed water system cost as a function of the raw water and polished water flow rates was found to yield good results. The cost in 2000 dollars is:

$$
D C_{B F}=0.16 m_{r w}^{0.307} m_{p w}^{0.435}
$$

$$
\begin{aligned}
& \mathrm{R}^{2}=0.991 \\
& \mathrm{n}=14
\end{aligned}
$$

where,

$$
\begin{aligned}
& 24,000 \leq m_{r w} \leq 614,000 \mathrm{lb} / \mathrm{hr} \\
& 234,000 \leq m_{p w} \leq 3,880,000 \mathrm{lb} / \mathrm{hr}
\end{aligned}
$$

For this model, a nonlinear variable transformation was used. The error of the linearized model is approximated by a normal distribution. Therefore, the error of the nonlinear model shown above is represented by a lognormal distribution. The median of the errors is 1.0, with a mean of 1.002 and a standard deviation of 0.063 . The 90 percent probability range for the error is approximately 0.9 to 1.1 , implying a 90 percent confidence band of 90 to 110 percent of the nominal cost estimate. 
Typically only one train of equipment is used in this section, and all the equipment is commercially available. A comparison of the regression model cost estimates and the direct cost estimates from the detailed cost studies is shown in Figure 64. This model should not be extrapolated beyond the range of the predictive variables as indicated above. However, because the cost of the boiler feed water section is a very small portion of the total direct cost for a typical IGCC plant, the effect of any errors introduced by modest extrapolations may be acceptable for some purposes.

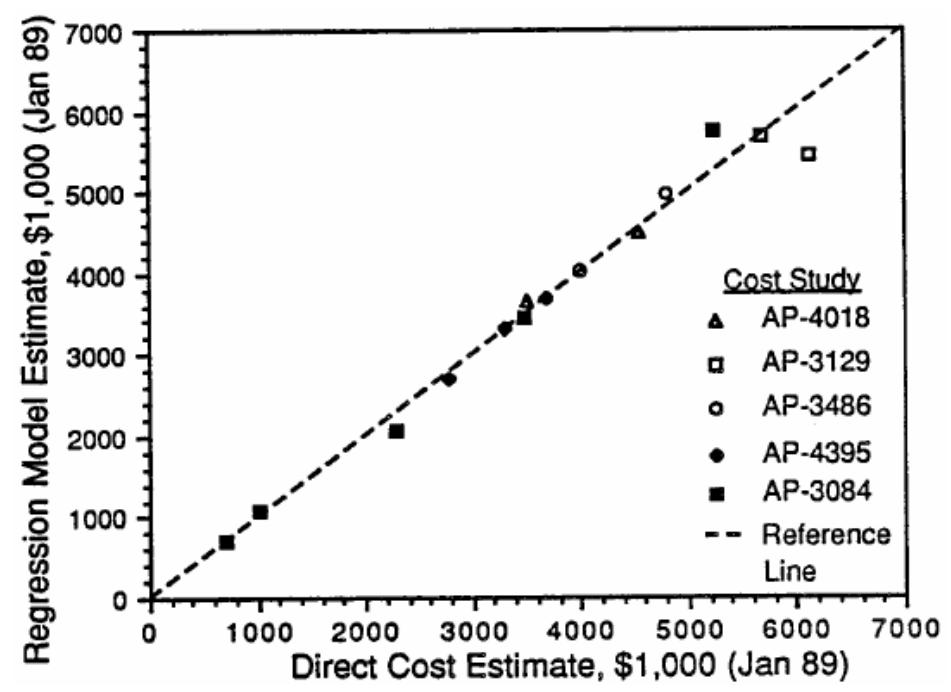

Figure 64 Predicted vs. Actual Direct Costs for the Boiler Feedwater Section

\section{Power Block References}

Bachovchin, D.M., M.A. Alvin, and L. M. Day (1987). "A Study of High Temperature Removal of Alkali in a Pressurized Gasification System." In Proceedings of the Seventh Annual Gasification and Gas Stream Cleanup Systems Contractors Review Meeting, Volume II. U.S. Department of Energy. Morgantown, WV. June, 1987. p. 495-504

Bechtel and WE (1983c). Design of Advanced Fossil Fuel Systems (DAFFS), A Study of Three Developing Technologies for Coal-Fired, Base-Load Electric Power Generation: Integrated Gasification Combined Cycle Power Plant With Westinghouse Gasification Process. Prepared by Bechtel Group, Inc., and Westinghouse Electric Corporation, Synthetic Fuels Division, for the U.S. Department of Energy Argonne National Laboratory. Argonne, Illinois. ANL/FE-8317. June. 1983

Becker, B., and W. Schulten (1985). "Advanced Gas Turbines for Efficient and Reliable Combined-Cycle Plants." In Proceedings: Conference on Coal Gasification Systems and Synthetic Fuels for Power Generation, Volume 2. Electric Power Research Institute. AP-4257-SR. December 1985. p. 25-1 to 25-21.

BGE (1989). Baltimore Gas and Electric Company's Study of a Shell-Based GCC Power Plant. Prepared by Baltimore Gas and Electric Company for Electric Power Research Institute, Palo Alto, CA. EPRI GS-6283. March 1989.

Brandt, D.E (1988). "The Design and Development of an Advanced Heavy-Duty Gas Turbine" Journal of Engineering for Gas Turbines and Power 110 (1988): 243-250.

Brandt, D.E (1989). "MS7001F Prototype Test Results." ASME Paper No. 89-GT102. 1989. 
Brooks, F.J. (2000), "GE Gas Turbine Performance Characteristics," GER-3567H, GE Power Systems, Schenectady, NY.

Cincotta, G.A. (1984). Gas Turbine Systems Research and Development Program. Prepared by the General Electric Company for the U.S. Department of Energy Morgantown Energy Technology Center. Morgantown, WV. DOE/MC/20315-1767Exec. Summ. September 1984.

Cohen, H., G.F.C. Rogers, and H.I.H. Saravanamuttoo (1987). Gas Turbine Theory, 3rd Ed. Longman Scientific and Technical. New York. 1987.

Cool Water (1988). Cool Water Coal Gasification Program: Fifth Annual Progress Report. Prepared by Cool Water Coal Gasification Program, Bechtel Power Corporation, and Radian Corporation for the Electric Power Research Institute, Palo Alto, CA. EPRI AP-4832. October. 1988

Corman, J.C. (1986). System Analysis of Simplified IGCC Plants, Topical Report. Prepared by General Electric Company for U.S. Department of Energy, Morgantown Energy Technology Center, Morgantown, West Virginia. DOE/ET/14928-2233. September 1986.

Dawkins, R.P., et al. (1986). Screening Evaluation of Advanced Power Cycles. Prepared for Electric Power Research Institute by Fluor Technology, Inc. AP-4826. November 1986.

Davis, L.B., M.B. Hilt, and R.B. Schiefer (1987). "NOx Emissions from Advanced Gas Turbines Fired on MBTU Gases." In Proceedings: Sixth Annual EPRI Contractors' Conference on Coal Gasification. Electric Power Research Institute. AP5343-SR. October 1987. p. 16-1 to 16-16.

Earley, P.I., and S.C. Smelser (1988a). Design and Economics of a Coal-to-PipelineGas Facility Using KRW Gasifiers with Reduced Carbon Conversion. Prepared by Fluor Technology, Inc. for Gas Research Institute. Chicago, Illinois. GRI-87/0169. January 1988. OR Earley, P.I. and S.C. Smelser (1988b). Design and Economics of a Plant to Convert Eastern Bituminous Coal to Pipeline Gas or Power Using KRW Gasifiers With In-Bed Desulfurization. Prepared by Fluor Technology, Inc. for Gas Research Institute. Chicago, Illinois. GRI-87/0166. September 1988.

Entrekin, H.D., and T.R. Edwards (1987). Effects of Load Following on Gas Turbine Emissions and Ambient Air Quality. Presented at the 80th Annual Meeting of the Air and Waste Management Association, New York, NY. June 21-26.

EPRI (1986). TAG(tm) - Technical Assessment Guide, Volume 1: Electricity Supply - 1986. EPRI P-4463-SR. Electric Power Research Institute, Inc. December 1986

Eustis, F. H. and M.S. Johnson (1990), "Gas Turbine Effects on IntegratedGasification-Combined-Cycle Power Plant Operations," GS/ER-6770, Prepared by Stanford, University for Electric Power Research Institute, Inc, Palo Alto, CA, March.

Farmer, R (1997); Gas Turbine World; Pequot Publishing Inc., Fairfield, CT; Vol 18., p 44.

Flagan, R.C. and Seinfeld, J.H. (1988). Fundamentals of air pollution engineering. Prentic Hall.

Fluor (1983a). Economic Assessment of the Impact of Plant Size on Coal Gasification Combined Cycle Plants. Prepared by Fluor Engineers, Inc. for Electric Power Research Institute. Palo Alto, CA. EPRI AP-3084. May.

Fluor(1983b). Shell-Based Gasification-Combined-Cycle Power Plant Evaluations. Prepared by Fluor Engineers, Inc. for Electric Power Research Institute, Palo Alto, CA. EPRI AP-3129. June 1983. 
Fluor (1984). Cost and Performance for Commercial Applications of Texaco-Based Gasification-Combined-Cycle Plants: Volume 1, Summary and Discussion of Results, and Volume 2, Design Details. Prepared by Fluor Engineers, Inc. for Electric Power Research Institute, Palo Alto, CA. EPRI AP-3486. April 1984.

Fluor (1985). Cost and Performance of Kellogg Rust Westinghouse-based Gasification-Combined-Cycle Plants. Prepared by Fluor Engineers, Inc. for Electric Power Research Institute, Palo Alto, CA. EPRI AP-4018. June 1985.

Fluor (1986). Planning Data Book for Gasification Combined Cycle Plants: Phased Capacity Additions. Prepared by Fluor Engineers, Inc. for Electric Power Research Institute. Palo Alto, CA. EPRI AP-4395. January 1986.

Fluor Daniel (1988). Evaluation of a Texaco Gasification Combined Cycle Plant with Kraftwerk Union Gas Turbines. Prepared by Fluor Daniel, Inc. for Electric Power Research Institute, Inc. Palo Alto, CA. EPRI GS-6160. December 1988.

Fluor Daniel (1989). Evaluation of a Dow-Based Gasification Combined Cycle Plant Using Low-Rank Coals. Prepared by Fluor Daniel, Inc. for Electric Power Research Institute, Inc. Palo Alto, CA. EPRI GS-6318. April 1989.

Fluor Technology (1986b). Screening Evaluation of Advanced Power Cycles. Prepared by Fluor Technology, Inc. for Electric Power Research Institute, Palo Alto, CA. EPRI AP-4826. November 1986.

Folsom, B.A., C.W. Courtney, and M.P. Heap (1980). "The Effect of LBG Composition and Combustor Characteristics on Fuel NOx Formation." Journal of Engineering for Power 102 (1980):459-467.

Foster-Pegg R. W., 1986, "Capital Cost of Gas-Turbine Heat Recovery Boilers“, Chemical Engineering, Vol. 93, n. 14, pp. 73-78.

FPL (1989). Florida Power and Light Company's Study of Shell-Based GCC Power Plants. Prepared by Florida Power and Light Company for Electric Power Research Institute, Inc. Palo Alto, CA. EPRI GS-6176. January 1989.

Frey, H.C. and N. Akunuri (2001), "Probabilistic Modeling and Evaluation of the Performance, Emissions, and Cost of Texaco Gasifier-Based Integrated Gasification Combined Cycle Systems Using ASPEN, Prepared by North Carolina State Univesity for Center for Energy and Environmental Studies, Carnegie Mellon University, Pittsburgh, PA.

Frey, H.C. and E.S. Rubin (1991), "Development and Application of a Probabilistic Evaluation Method for Advanced Process Technologies," DOE/MC 24248-3105 (DE91002095), Prepared by Carnegie Mellon University for U.S. Department of Energy, Morgantown, WV, April.

Farmer, R. (1989). "150 MW Class 501F Design to Begin Full Load Factory Testing This Summer," Gas Turbine World. May-June 1989. pp 12-17

Hester, J.C., and D.E. Pless (1990). Proposed Demonstration of An Air Blown Coal Gasification Combined Cycle Gas Turbine Concept. Presented at the Seventh Annual International Pittsburgh Coal Conference. September, 1990.

Holt, N.A., E.Clark, and A. Cohn (1989). "NOx Control in Coal Gasification Combined Cycle Systems." In 1989 Symposium on Stationary Combustion Nitrogen Oxide Control, Volume 1. Electric Power Research Institute. GS-6423. July 1989. p. 5A-17 to 5A-28.

METC (1987). Gas Stream Cleanup: Technology Status Report. Morgantown Energy Technology Center, U.S. Department of Energy. Morgantown, WV. DOE/METC$87 / 0255$. October. 
Moore-Staub, A.L., et al (1990). Gas Turbine Cogeneration Unit PSD BACT Determination: A 1990 Case Study. Presented at the 83rd Annual Meeting of the Air and Waste Management Association. Pittsburgh, PA. June

Notestein, J.E (1989). "Update on Department of Energy Hot Gas Cleanup Programs." In Eighth Annual EPRI Conference on Coal Gasification. Electric Power Research Institute. GS-6485. August 1989. p. 14-1 to p. 14-43

Parsons (1982). Evaluation of Coal Gasification-Combustion Turbine Power Plants Emphasizing Low Water Consumption. Prepared by Ralph M. Parsons Company for Electric Power Research Institute. Palo Alto, CA. EPRI AP-2207. January 1982.

Pillsbury, P (1989). Westinghouse. personal communication.

Sato, M., et al (1989). "Development of a Low-NOx LBG Combustor for Coal Gasification Combined Cycle Power Generation Systems." ASME Paper No. 89-GT104. 1989.

Scalzo, A.J. et al (1989). "A New 150 MW High-Efficiency Heavy-Duty Combustion Turbine." Journal of Engineering for Gas Turbines and Power 111 (1989): 211-217.

Simbeck, D.R., R.L. Dickenson, and E.D. Oliver (1983). Coal Gasification Systems: A Guide to Status, Applications, and Economics. Prepared by Synthetic Fuels Associates for the Electric Power Research Instutite, Palo Alto, CA. AP-3109. June.

Smock, R. "Gas Turbines Dominate New Capacity Ordering," Power Engineering Magazine. August 1989. pp 23-28.

Touchton, G.L (1984). "An Experimentally Verified NOx Prediction Algorithm Incorporating the Effects of Steam Injection." Journal of Engineering for Gas Turbines and Power 106 (1984): 833-840.

Touchton, G.L (1985). "Influence of Gas Turbine Combustor Design and Operating Parameters on Effectiveness of NOx Suppression by Injected Steam or Water" Journal of Engineering for Gas Turbines and Power 107 (1985): 706-713.

Unnasch, S., R. Chang, and H. Mason (1988). Study of Ammonia Removal in Coal Gasification Processes Using Integrated Systems Approach. Final Report. Prepared by Acurex Corporation for U.S. Department of Energy Morgantown Energy Technology Center. Morgantown, West Virginia. DOE/MC/23275-2589. March.

Wark, K. (1983). Thermodynamics, Fourth Edition. McGraw-Hill Book Company: New York. 



\section{$\mathrm{CO}_{2}$ Transport}

\section{Abstract}

The modeling of carbon dioxide $\left(\mathrm{CO}_{2}\right)$ transport via pipeline is important as pipeline is the primary mode by which $\mathrm{CO}_{2}$ captured from power plants can be moved from the plant site to the sequestration site. The cost of $\mathrm{CO}_{2}$ transport has been estimated by developing performance and cost models for $\mathrm{CO}_{2}$ transport by pipeline. The performance model estimates the required pipeline diameter as a function of engineering and design parameters, such as pipeline length and design $\mathrm{CO}_{2}$ mass flow. The economics model estimates the capital, and operating and maintenance cost of $\mathrm{CO}_{2}$ transport by pipeline as a function of parameters such as the project lifetime, discount rate, and operating and maintenance charges. The cost model has been developed by regressing data on actual U.S. pipeline construction projects (for natural gas) Using these models with a set of illustrative parameters, the cost of transporting 5 million tonnes per year of $\mathrm{CO}_{2}$, which is approximately the annual emissions of a $600 \mathrm{MW}$ (net) pulverized coal fired power plant capturing $90 \%$ of the $\mathrm{CO}_{2}$ produced, over $100 \mathrm{~km}$ in the Midwest is $\$ 1.2$ per tonne. The cost of $\mathrm{CO}_{2}$ transport decreases non-linearly with increasing amounts of $\mathrm{CO}_{2}$ transported, and increases non-linearly with the length of the pipeline. For longer pipeline lengths, the cost of $\mathrm{CO}_{2}$ transport can also be lowered by adding booster stations. A sensitivity analysis on several design and economic parameters has shown that the median cost to transport 5 million tonnes per year of $\mathrm{CO}_{2}$ over $100 \mathrm{~km}$ is between $\$ 1.1$ and $\$ 1.9$ per tonne depending on the geographic region of the U.S. The sensitivity analysis has shown the parameters that most affect the transport cost are, in decreasing order of importance: load factor, capital recovery factor, labor escalation factor, and inlet pressure. 
Nomenclature

$p=$ Absolute pressure $(\mathrm{Pa})$

$p_{r}=$ Reduced pressure

$p_{c}=$ Critical pressure $(\mathrm{K})$

$R=\mathrm{Gas}$ constant $\left(\mathrm{m}^{3} \mathrm{~Pa} / \mathrm{mol} / \mathrm{k}\right)$

$\rho=$ Fluid density $\left(\mathrm{kg} / \mathrm{m}^{3}\right)$

$v=$ Specific volume $\left(\mathrm{m}^{3} / \mathrm{kg}\right)$

$\dot{v}=$ Molar volume $\left(\mathrm{m}^{3} / \mathrm{mol}\right)$

$T=$ Absolute temperature $(\mathrm{K})$

$T_{r}=$ Reduced temperature

$T_{c}=$ Critical temperature $(\mathrm{K})$

$Z=$ Compressibility factor

$M=$ Molecular mass $(\mathrm{g} / \mathrm{mol})$

$\omega=$ Pitzer acentric factor

$k_{i j}=$ Peng-Robinson binary interaction parameter

$g=$ Acceleration due to gravity $\left(\mathrm{m} / \mathrm{s}^{2}\right)$

$g_{c}=$ Gravitational constant

$h_{i}=$ Height at location $i(\mathrm{~m})$

$u=$ Average fluid velocity $(\mathrm{m} / \mathrm{s})$

$\eta=$ Pump efficiency

$f_{F}=$ Fanning friction factor

$L=$ Pipe segment length (m)

$D=$ Pipe inner diameter $(\mathrm{m})$

$\dot{m}=$ Mass flow rate $(\mathrm{Kg} / \mathrm{s})$

$\varepsilon=$ Pipe roughness $(\mathrm{mm})$

$R e=$ Reynolds number

$\mu=$ Viscosity (Pa s)

$\dot{Q}=$ Volumetric flow rate $\left(\mathrm{m}^{3} / \mathrm{s}\right)$

$P=$ Pump power $(\mathrm{W})$

$D_{l}=$ Initial segment diameter $(\mathrm{m})$

$D_{n}=\mathrm{n}^{\text {th }}$ segment diameter $(\mathrm{m})$

$N_{S}=$ Number of segments

$N_{B}=$ Number of booster pumping stations

$C_{P}=$ Cost of power $(\$ / \mathrm{MWh})$ 


\section{Introduction}

Government regulators, policy-makers (public and private), and other interested parties require methods to estimate the cost of potential global climate change mitigation measures. One possible measure to reduce emissions of carbon dioxide $\left(\mathrm{CO}_{2}\right)$ to the atmosphere is carbon capture and storage (CCS). This report details the development of a model that calculates the pipeline transport cost of $\mathrm{CO}_{2}$ from the site of capture to the location of storage. This model will complement and link to the previously developed Integrated Environmental Control Model (IECM), which can be used to assess $\mathrm{CO}_{2}$ capture options for various types of power plants (Rao, et al. 2004).

Pipeline transport has been selected as the mode of $\mathrm{CO}_{2}$ transportation for this model because of it is the only reasonable method for terrestrial transport of the large quantities of $\mathrm{CO}_{2}$ involved (Skovholt, 2003; Svensson et al. 2004). Furthermore, there is considerable experience in the transport of $\mathrm{CO}_{2}$ by pipeline, as upwards of 50 million tonnes per year of $\mathrm{CO}_{2}$ is transported over nearly $3100 \mathrm{~km}$ of pipelines primarily for use in EOR operations (Gale et al. 2004; Smith et al. 2001; Bock et al. 2003; Doctor et al. 2005; Kinder Morgan, 2002).

In this report, the pipeline transport model is used to estimate the cost per tonne of transporting $\mathrm{CO}_{2}$ from a range of power plant sizes over variable distances and, to assess the effect of additional booster compression stations on the transport cost. Furthermore, in an attempt to quantify the sensitivity of the model to uncertainty and variability in the parameters, a probabilistic analysis has been performed, which shows the range of costs that could occur and the probability associated with these costs for specific scenarios.

\section{Pipeline Transport Process Description}

The performance model takes as input engineering design parameters, such as pipeline length and design $\mathrm{CO}_{2}$ mass flow and calculates the required pipe diameter. The transport performance model is based on previous work by the Massachusetts Institute of Technology (MIT) for the United States Department of Energy (DOE) and has been revised to include a comprehensive physical properties model for $\mathrm{CO}_{2}$ and other fluids of interest (e.g., $\mathrm{H}_{2} \mathrm{~S}$ ) and to account for the compressibility of $\mathrm{CO}_{2}$ during transport; booster pumping station options; segment elevation changes, and; probabilistic assessment capabilities (Bock et al. 2004). Figure 65 shows the inputs and outputs from the performance model, and how the performance model interacts with the pipeline cost model and the $\mathrm{CO}_{2}$ properties model. 


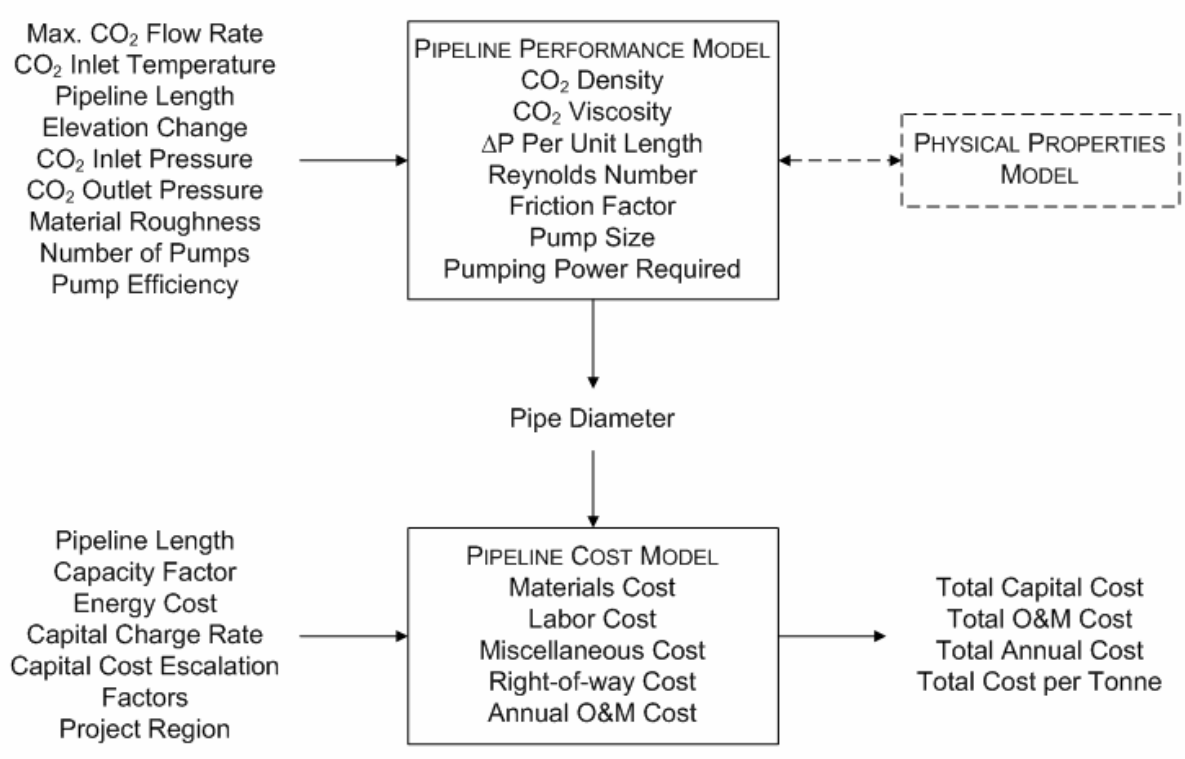

Figure 65. The boundaries, inputs, and output from the pipeline model

\section{Physical Properties of Carbon Dioxide}

At ambient temperatures and pressures, $\mathrm{CO}_{2}$ is a gas with a density higher than that of air. However, efficient transport of $\mathrm{CO}_{2}$ via pipeline requires that $\mathrm{CO}_{2}$ is compressed and cooled to the liquid state. Transportation at lower densities (i.e., gaseous $\mathrm{CO}_{2}$ ) is inefficient because of the large volumes that need to be moved. In pipeline transport, the density of $\mathrm{CO}_{2}$ varies between $800 \mathrm{~kg} / \mathrm{m}^{3}$ and $1000 \mathrm{~kg} / \mathrm{m}^{3}$. For comparison, the density of water under these conditions is approximately 1000 $\mathrm{kg} / \mathrm{m}^{3}$. Figure 66 shows the density of $\mathrm{CO}_{2}$ as a function of temperature for several isobars in the transport region.

The typically long length of a $\mathrm{CO}_{2}$ pipeline means that it can be treated approximately as an isothermal system, where the $\mathrm{CO}_{2}$ is at the temperature of the earth surrounding the pipeline.

In northern countries, the soil temperature varies from a few degrees below zero in the winter to $6-8^{\circ} \mathrm{C}$ in summer (Skovholt, 1993). In warmer countries, the soil temperature may reach up to $20^{\circ} \mathrm{C}$ (Skovholt, 1993). Under these temperature conditions, $\mathrm{CO}_{2}$ liquefies at pressures greater than $3 \mathrm{MPa}$ to $5 \mathrm{MPa}$. However, in a pipeline crossing hilly terrain, the pressure at the tops of the hills may drop below 3 $\mathrm{MPa}$ to $5 \mathrm{MPa}$, which would result in two-phase flow, i.e., slugs of both liquid and gas in the pipeline. Two-phase flow is highly undesirable as slugs of fluid can damage flow metering and pumping or compression equipment. Thus, as can be seen in Figure 67, if the pipeline is operated at pressures greater than the critical pressure of $\mathrm{CO}_{2}$, which is $7.38 \mathrm{MPa}$, two-phase flow is not possible at any temperature. Skovholt calls this the "dense phase condition." (Skovholt, 1993) 


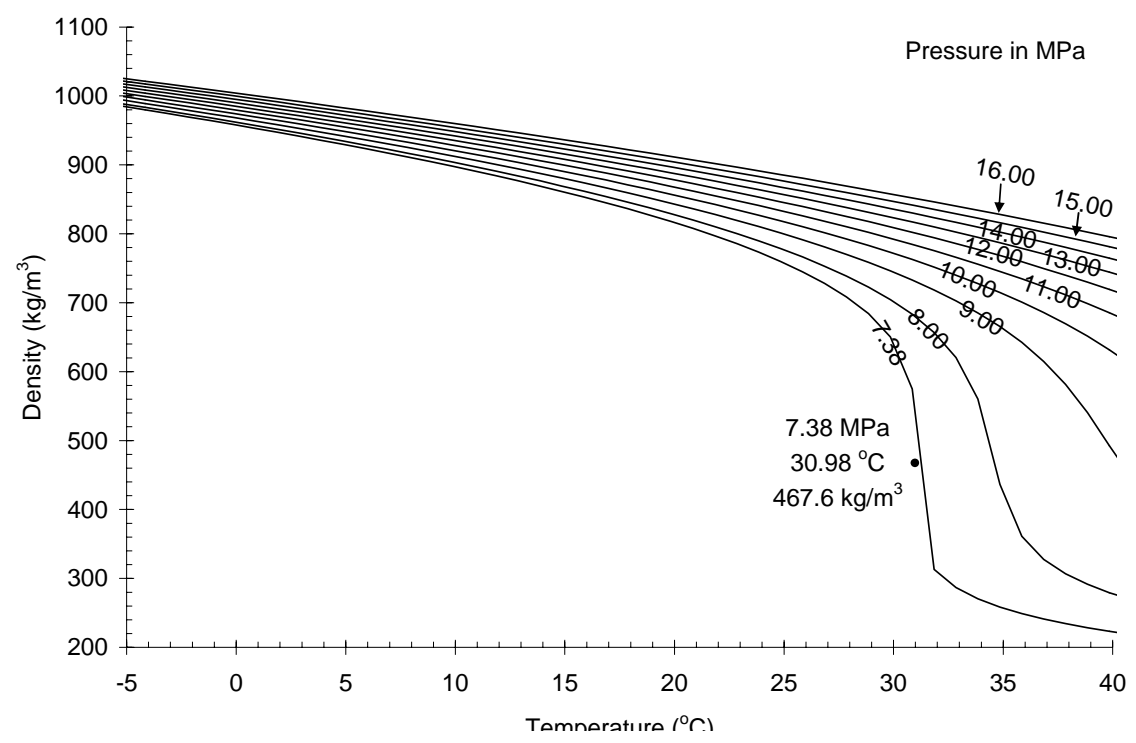

Figure 66. The density of carbon dioxide as a function of temperature for several isobars in the transport range.

To ensure that the flow in the pipeline remains liquid under all conditions it is recommended that the $\mathrm{CO}_{2}$ pipeline operating pressure not be allowed to drop below 8.6 MPa at $4^{\circ} \mathrm{C}$ (Mohitpour, 2003). Conversely, for pipe with ASME-ANSI 900\# flanges the maximum allowable operating pressure is $15.3 \mathrm{MPa}$ at $38^{\circ} \mathrm{C}$ (Mohitpour et al. 2003).

The design of $\mathrm{CO}_{2}$ pipelines is dependent on the physical and transport properties (e.g., density and viscosity) of $\mathrm{CO}_{2}$, thus it is necessary to use accurate representations of the phase behavior, density, and viscosity of $\mathrm{CO}_{2}$ in their design. Other models, such as the MIT model (Bock, 2003), have used correlations that approximate the density and viscosity of $\mathrm{CO}_{2}$. The shortcoming of these types of correlations is that they are only accurate over a small range of pressure and temperature and for pure $\mathrm{CO}_{2}$. Conversely, chemical \& petroleum industry process simulators (e.g., Aspen Plus or HYSYS) use generalized equations of state to represent the physical properties of multi-component liquid and gas mixtures accurately across a wide range of pressures and temperatures.

This model calculates physical properties of $\mathrm{CO}_{2}$ and $\mathrm{CO}_{2}$ containing mixtures using a cubic equation of state with Peng-Robinson parameters, and mixing rules employing a binary interaction parameter (Reid, 1987). Equation (107) shows the form of the cubic equation of state for a fluid mixture of $n$ pure components.

$p=\frac{R T}{\dot{v}-b_{m}}-\frac{a_{m}}{\dot{v}^{2}+2 b_{m} \dot{v}-b_{m}^{2}}$

In Equation (107), $p$ is the system pressure, $\mathrm{R}$ is the ideal gas constant, $T$ is the absolute temperature of the system, $\dot{v}$ is the molar volume of the system, and, am and $b m$ are constants defined below. 


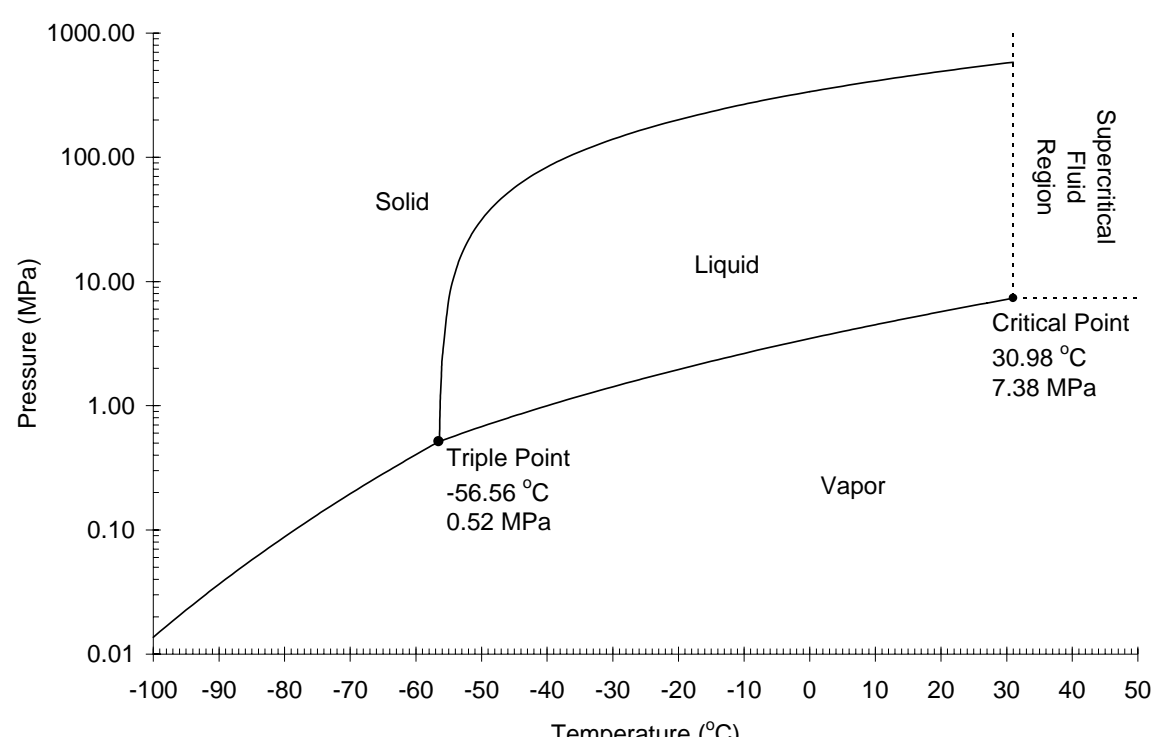

Figure 67. Phase diagram for CO2 showing the sublimation, melting, and boiling curves as well as the triple point and the critical point.

Equations (108) and (109) show the Peng-Robinson parameters for pure component $i$, and Equation (110) shows the mixing rules used to arrive at the mixture parameters for use in Equation (107).

$a_{i}=\frac{0.45724 R^{2} T_{c, i}^{2}}{p_{c, i}}\left[1+f\left(\omega_{i}\right)\left(1-T_{r, i}^{1 / 2}\right)\right]^{2}$

where,

$$
\begin{aligned}
& f\left(\omega_{i}\right)=0.37464+1.54226 \omega_{i}-0.26992 \omega_{i}^{2} \\
b_{i}= & \frac{0.07780 R T_{c, i}}{p_{c, i}} \\
a_{m}= & \sum_{i}^{n} \sum_{j}^{n} y_{i} y_{j}\left(a_{i} a_{j}\right)^{1 / 2}\left(1-k_{i j}\right) \\
b_{m}= & \sum_{i}^{n} y_{i} b_{i}
\end{aligned}
$$

In Equations (108) through (110), $i$ and $j$ denote different pure components, $T_{r}$ is the reduced temperature of the pure component, $\omega$ is the Pitzer acentric factor for the pure component, and $k_{i j}$ is the Peng-Robinson binary interaction parameter for the fluid pair. 


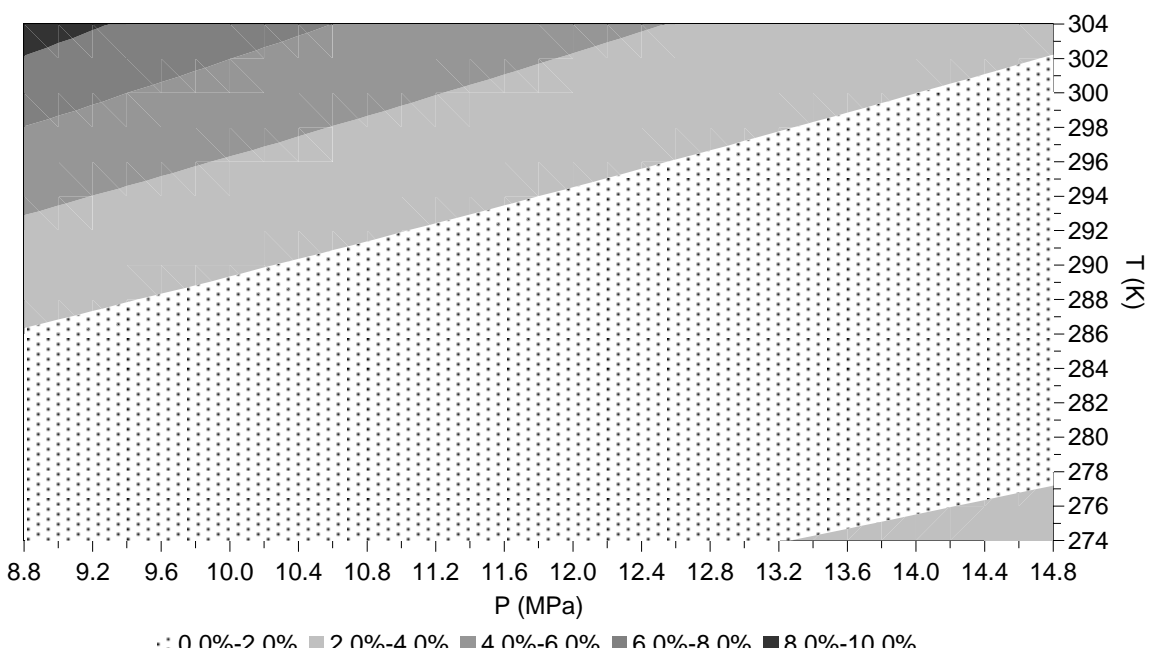

Figure 68. Relative error between the density of $\mathrm{CO}_{2}$ calculated by the Peng-Robinson equation of state and the density of $\mathrm{CO}_{2}$ as predicted by the Span and Wagner equation of state in the range of pressures and temperatures of interest for the transport model.

The model uses an analytical method to solve Equation (107) for the specific volume of the fluid, which can then be easily converted to density. For pure $\mathrm{CO}_{2}$, the relative error between the density predicted by the reference equation of state developed by Span and Wagner (Span et al. 1986) and the density of $\mathrm{CO}_{2}$ estimated by the Equation (107) is less than $9 \%$ in range of interest for the transport model, and averages approximately $2 \%$. Figure 68 shows the relative error over this range.

The viscosity of $\mathrm{CO}_{2}$ and $\mathrm{CO}_{2}$-containing mixtures is calculated via the Chung et al method (Chung, 1988), extended to high pressures by Reid, Prausnitz, and Poling (Reid et al. 1987). This method, like the Peng-Robinson equation of state, is fundamentally based on the thermodynamic properties of the fluid mixture. However, unlike the Peng-Robinson Equation of state it requires the solution of over a dozen equations. For the details of this method, see Reid, Prausnitz, and Poling Poling (Reid et al. 1987).

For pure $\mathrm{CO}_{2}$, the relative error between the viscosity predicted by the reference equation of state developed by Vesovic (Vesovic et al. 1990) and modified by Fenghour (Fenghour et al. 1998) and the viscosity of $\mathrm{CO}_{2}$ estimated by Equation (107) is less than $11 \%$ in range of interest for the transport model, and averages approximately $4 \%$. Figure 69 shows the relative error over this range. 


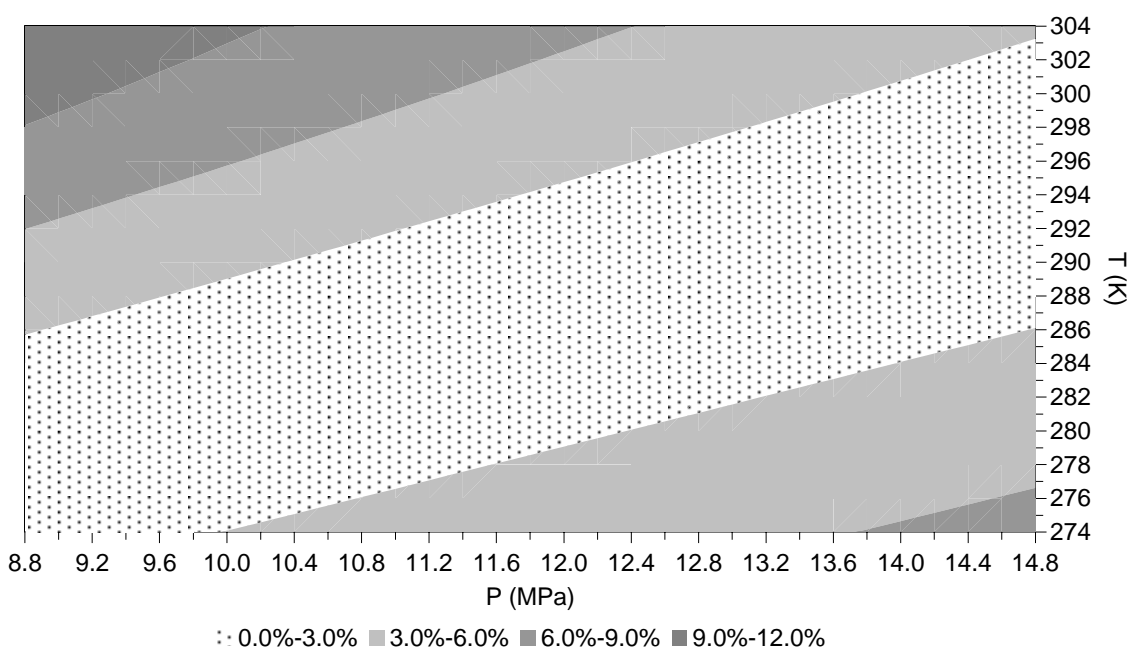

Figure 69. Relative error between the viscosity calculated by the Chung et al method and the viscosity predicted by the model of Vesovic et al (modified by Fenghour et al) for the range of temperatures and pressures of interest in the transport model.

\section{Pipe Segment Engineering and Design}

While liquid $\mathrm{CO}_{2}$ is relatively incompressible when compared with gaseous $\mathrm{CO}_{2}$, the small compressibility of the liquid over the relatively long distance of the pipeline can result in non-trivial error if the $\mathrm{CO}_{2}$ is assumed to be incompressible. For example, for a $100 \mathrm{~km}$ long pipeline with the same inlet and outlet pressures, the diameter predicted by a model that does not consider compressibility is 2 in less than the diameter predicted by a model which considers compressibility. ${ }^{3}$ Thus, liquid $\mathrm{CO}_{2}$ is considered a compressible fluid in the model. Additionally, as mentioned previously, the pipeline flow process and pumping processes are treated as isothermal.

The required pipe diameter is calculated from an energy balance on the flowing $\mathrm{CO}_{2}$. Equation (111) shows the differential form of this energy balance, which will be integrated in following steps by making several simplifying assumptions. Equation (111) accounts for changes in kinetic energy, pressure-volume work, changes in potential energy, and energy loss due to skin friction.

$$
\frac{c}{g_{c} v} d u+\frac{1}{v} d p+\frac{g}{g_{c} v^{2}} d h+\frac{2 f_{F} c^{2}}{g_{c} D} d L=0
$$

In Equation (111): $c$ is a constant equal to the product of density, $\rho$, and fluid velocity, $u ; g$ is acceleration due to gravity; $g_{c}$ is the conversion factor converting force units (in the SI system of units, this is equal to unity); $v$ is the specific volume of fluid; $p$ is pressure; $h$ is height; $f_{F}$ is the fanning friction factor (McCabe, 1993); $D$ is the pipeline diameter; and $L$ is the length of the pipe segment.

Each term in Equation (111) has to be integrated over the length of the pipe segment between the upstream and downstream conditions, represented as points 1 and 2, respectively. The first term in Equation (111) to integrate is the kinetic energy term, which is integrated with a simple substitution in Equation (112).

\footnotetext{
${ }^{3}$ All units in this report are in SI units with the exception of pipe diameter, which is commonly measured in inches (in).
} 


$$
\int_{1}^{2} \frac{c}{g_{c} v} d u=\frac{c^{2}}{g_{c}} \ln \left(\frac{u_{2}}{u_{1}}\right)
$$

Integration of the pressure-volume work term in Equation (111) is somewhat more complex, and requires substitution of the compressibility for specific volume, and definition of average pressure and temperature conditions. For any fluid, compressibility is defined as:

$$
Z=\frac{p v M}{R T}
$$

where, $R$ is the ideal gas constant, $T$ is the absolute temperature of the fluid, and $M$ is the molecular weight of the fluid. Thus the specific volume can be rewritten in terms of the compressibility as:

$$
v=\frac{Z R T}{p M}
$$

Substituting the definition of specific volume given above in Equation (114) into the pressure-volume work term of Equation (111) results in Equation (115):

$$
\int_{1}^{2} \frac{1}{v} d p=\int_{1}^{2} \frac{p M}{Z R T} d p=\frac{M\left(p_{2}^{2}-p_{1}^{2}\right)}{2 Z_{\text {ave }} R T_{\text {ave }}}
$$

The average temperature, $T_{\text {ave }}$, and pressure, $P_{\text {ave }}$, required in Equation (115) are defined in Equations (116) and (117), respectively. The derivation of the average pressure definition can be found ( Mohitpour et al. 2003):

$$
\begin{aligned}
T_{\text {ave }} & =\frac{T_{1}+T_{2}}{2} \\
P_{\text {ave }} & =\frac{2}{3}\left(p_{2}+p_{1}-\frac{p_{2} p_{1}}{p_{2}+p_{1}}\right)
\end{aligned}
$$

Integration of the potential energy term is relatively simple using the definitions of average temperature and pressure, and the result is given in Equation (118).

$\int_{1}^{2} \frac{g}{g_{c} v^{2}} d h=\frac{g p_{\text {ave }}^{2} M^{2}}{g_{c} Z_{\text {ave }}^{2} R^{2} T_{\text {ave }}^{2}}\left(h_{2}-h_{1}\right)$

The friction loss term is integrated in Equation (119).

$$
\frac{2 f_{F} c^{2}}{g_{c} D} \int_{1}^{2} d L=\frac{2 f_{F} c^{2}}{g_{c} D} L
$$

The result of integrating Equation (111), is then given below:

$$
\frac{c^{2}}{g_{c}} \ln \left(\frac{u_{2}}{u_{1}}\right)+\frac{M\left(p_{2}^{2}-p_{1}^{2}\right)}{2 Z_{\text {ave }} R T_{\text {ave }}}+\frac{g p_{\text {ave }}^{2} M^{2}}{g_{c} Z_{\text {ave }}^{2} R^{2} T_{\text {ave }}^{2}}\left(h_{2}-h_{1}\right)+\frac{2 f_{F} c^{2} L}{g_{c} D}
$$

where, for pipe with a circular cross section:

$$
c=\frac{4 \dot{m}}{\pi D^{2}}
$$

Solving Equation (120) for the internal diameter results in the following equation: 


$$
D=\left\{\frac{-64 Z_{\text {ave }}^{2} R^{2} T_{\text {ave }}^{2} f_{F} \dot{m}^{2} L}{\pi^{2}\left[g_{c} M Z_{\text {ave }} R T_{\text {ave }}\left(p_{2}^{2}-p_{1}^{2}\right)+2 g P_{\text {ave }}^{2} M^{2}\left(h_{2}-h_{1}\right)\right]}\right\}^{1 / 5}
$$

Where $\dot{m}$ is the design (i.e. maximum annual) mass flow rate of $\mathrm{CO}_{2}$. Thus, Equation (122) can be used to calculate the pipe diameter required for a given pressure drop. Complicating this, however, is the Fanning friction factor, which is a function of the pipe diameter. The Fanning friction factor can not be solved for analytically, thus an explicit approximation for Fanning friction factor is given by Equation (123) (Zigrang et al. 1982):

$$
\frac{1}{2 \sqrt{f_{F}}}=-2.0 \log \left\{\frac{\varepsilon / D}{3.7}-\frac{5.02}{\operatorname{Re}} \log \left[\frac{\varepsilon / D}{3.7}-\frac{5.02}{\operatorname{Re}} \log \left(\frac{\varepsilon / D}{3.7}+\frac{13}{\operatorname{Re}}\right)\right.\right.
$$

where $\varepsilon$ is the roughness of the pipe, which is approximately $0.0457 \mathrm{~mm}$ for commercial steel pipe (Boyce, 1997), and Re is the Reynolds number. The Reynolds number is given by Equation (124):

$$
\operatorname{Re}=\frac{4 \dot{m}}{\mu \pi D}
$$

Where $\mu$ is the viscosity of the fluid. As a result, Equations (122), (123), and (124) must be solved iteratively to determine the pipe diameter. In the iteration scheme, Equation (124) is first calculated using an initial guess for the pipe diameter, and then the calculated Reynolds number is substituted into Equation (123). The Fanning friction factor is then substituted into Equation (122), which leads to an updated diameter, which is compared with the value at the previous iteration. The values for the diameter converge to within $10^{-6} \mathrm{~m}$ in less than 10 iterations.

\section{Booster Pump Engineering and Design}

Booster pumping stations may be required for longer pipeline distances, or for pipelines in mountainous or hilly regions with large increases in elevation. Additionally, in some cases the use of booster pumping stations may allow a smaller pipe diameter to be used, reducing the cost of $\mathrm{CO}_{2}$ transport.

The pumping station size is developed from the energy balance on the flowing $\mathrm{CO}_{2}$, Equation (111), in a manner similar to the calculation of the pipe segment diameter. However, both the pumping station size and pipeline diameter are calculated on the basis of the maximum design mass flow rate of $\mathrm{CO}_{2}$, while the pumping station annual power consumption is calculated on the basis of the nominal (i.e., annual average) mass flow rate of $\mathrm{CO}_{2}$. The nominal mass flow rate of $\mathrm{CO}_{2}$ is the product of the pipeline load factor and the design mass flow rate of $\mathrm{CO}_{2}$. Pumping station size is required to determine the capital cost of the pump, while the pumping station annual power requirement is required to calculate operating cost.

For the calculation of the pumping station size, liquid phase $\mathrm{CO}_{2}$ is considered an incompressible fluid and pumping processes are treated as isothermal. In addition to the assumption of incompressibility, the assumptions in the derivation of the pumping station size and power requirement are: no elevation change, and no change in velocity between the inlet and the outlet of the pump. Equation (125) results from simplifying the energy balance using these assumptions: 
$P=\frac{\dot{Q} \Delta p}{\eta}$

Where $\mathrm{P}$ is the required pump power, $\dot{Q}$ is the volumetric flow rate, and $\eta$ is the pump efficiency, which accounts for all frictional losses.

\section{Illustrative Performance Model Results}

Figure 70 shows the internal diameter in inches of a pipeline carrying pure $\mathrm{CO}_{2}$ as a function of the $\mathrm{CO}_{2}$ mass flow rate, as calculated by Equations (122), (123), and (124). This figure shows discrete steps in pipeline diameter because pipe is generally only available in certain common diameters, referred to as Nominal Pipe Sizes (NPS). In addition, the pipe wall thickness must be accounted for to determine the inner diameter of the line pipe used in the calculations. The conversions between NPS and maximum inner diameter of line pipe are listed in Table 31.

For example, a pipeline spanning a distance of $100 \mathrm{~km}$, designed to carry 5 million tonnes per year of $\mathrm{CO}_{2}$ at a pressure drop of $28 \mathrm{kPa} / \mathrm{km}$, requires a internal diameter of 15 inches, based on Equations (122), (123), and (124). However, since this size is not a common line pipe size, the next largest NPS is selected by the model, which is 16 inches, resulting in an internal diameter of about 15.5 inches.

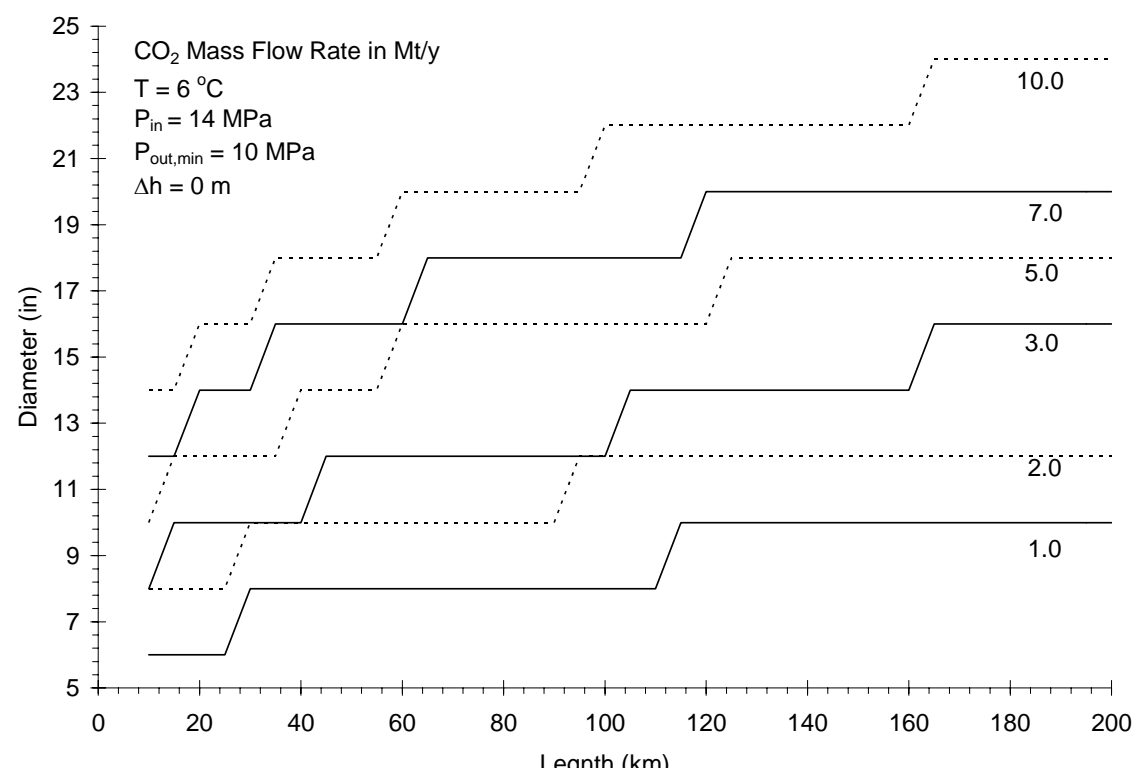

Figure 70. Pipeline diameter as a function of length for several flow rates in Mt $y$ for isothermal flow at $12^{\circ} \mathrm{C}$. 
Table 31. Conversions between NPS and maximum inner pipe diameter (Mohitpour, 2003)

\begin{tabular}{||l|l|l|l||}
\hline $\begin{array}{l}\text { Nominal Pipe } \\
\text { Size (NPS) }\end{array}$ & Pipe OD (inch) & $\begin{array}{l}\text { Minimum Wall } \\
\text { Thickness (inches) }\end{array}$ & $\begin{array}{l}\text { Maximum Pipe } \\
\text { ID (inch) }\end{array}$ \\
\hline \hline 4 & 4.5 & 0.126 & 4.248 \\
\hline 6 & 6.626 & 0.126 & 6.312 \\
\hline 8 & 8.626 & 0.157 & 8.312 \\
\hline 10 & 10.752 & 0.189 & 10.374 \\
\hline 12 & 12.752 & 0.189 & 12.374 \\
\hline 14 & 14 & 0.209 & 13.582 \\
\hline 16 & 16 & 0.220 & 15.560 \\
\hline 18 & 18 & 0.220 & 17.560 \\
\hline 20 & 20 & 0.220 & 19.560 \\
\hline 22 & 22 & 0.236 & 21.528 \\
\hline 24 & 24 & 0.252 & 23.496 \\
\hline 26 & 26 & 0.264 & 25.472 \\
\hline 30 & 30 & 0.287 & 29.426 \\
\hline 34 & 34 & 0.311 & 33.378 \\
\hline 36 & 36 & 0.323 & 35.354 \\
\hline 42 & 42 & 0.354 & 41.292 \\
\hline 48 & 48 & 0.402 & 47.196 \\
\hline & & & \\
\hline
\end{tabular}

\section{Pipeline Transport Cost Models}

The pipeline transport economic models take output from the performance model (i.e., pipeline diameter) combined with a user-specified pipeline length and the pipeline project region to estimate the capital cost and annual operating costs of the pipeline, as shown in Figure 65.

Cost data for actual $\mathrm{CO}_{2}$ pipelines are not readily available; nor are such projects as prevalent as oil or natural gas pipelines. For these reasons, the data set used to develop the pipeline capital cost models is based on natural gas pipelines; however, there are many similarities between transport of natural gas and $\mathrm{CO}_{2}$. Both $\mathrm{CO}_{2}$ and natural gas are transported at similar pressures, approximately $10 \mathrm{MPa}$ (or greater), and assuming that the $\mathrm{CO}_{2}$ is dry, both pipelines will require similar grades of steel. Thus, at the level of a preliminary analysis where predicted costs might differ from actual costs by approximately $30 \%$, using models based on natural gas pipelines is a reasonable approximation.

\section{Pipeline Data Set}

The $\mathrm{CO}_{2}$ pipeline model cost regression is based on natural gas pipeline project costs published in the Oil and Gas Journal between 1995 and 2005 (True, 1995; True, 1996; True, 1997; True, 1998; True, 1999; True, 2000; True, 2001; True, 2002; True, 2003; True, 2004; Smith et al. 2005). The project costs published are based on Federal Energy Regulatory Commission (FERC) filings from interstate gas 
transmission companies. ${ }^{4}$ The entire data set contains the "as-built" costs for 263 onshore pipeline projects in the contiguous 48 -states and excludes costs for pipelines with river or stream crossings and lateral projects (i.e., a pipeline of secondary significance to the mainline system, such as a tie-in between the mainline and a power plant). Data from each year's Oil and Gas Journal report have been inflated to 2004 dollars using the Marshall and Swift equipment cost index (published monthly in Chemical Engineering).

The pipeline data set contains information on the year and location of the project and the length and diameter of the pipeline. The locations are listed by state; however, to develop the regression, the states have been grouped into six regions. The project regions used here are the same as those used by the Energy Information Administration for natural gas pipeline regions (EIA, 2005), and are shown in Figure $\underline{71}$.

Pipeline Model Regions

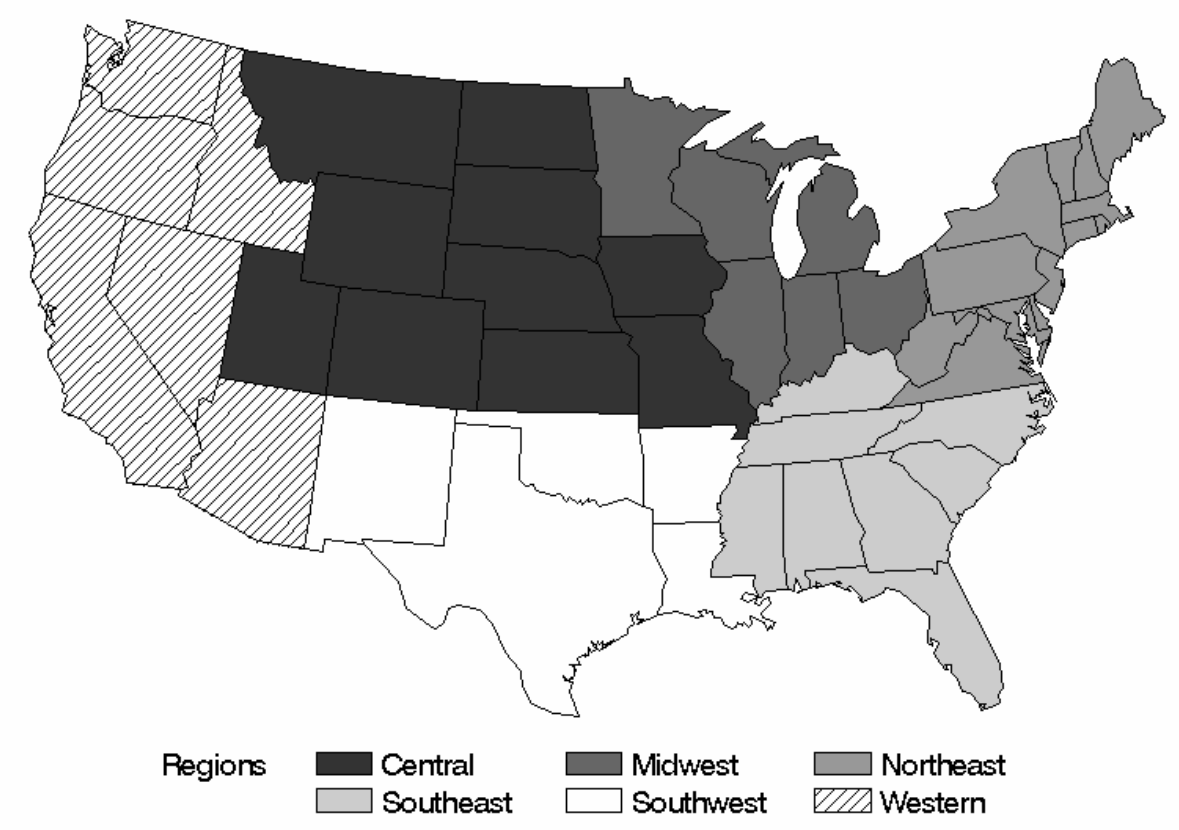

Figure 71. The breakdown of states in each EIA natural gas pipeline region.

The total cost for each project is broken down into four categories, which are: materials, labor, miscellaneous charges, and right-of-way (ROW). The materials category includes the cost of line pipe, pipe coatings, and cathodic ${ }^{5}$ protection. Labor covers the cost of labor during pipeline construction. Miscellaneous includes the costs of: surveying, engineering, supervision, contingencies, telecommunications equipment, freight, taxes, allowances for funds used during construction (AUFDC), administration and overheads, and regulatory filing fees. ROW covers the cost of obtaining right-of-way for the pipeline and allowance for damages to landowners' property during construction.

\footnotetext{
${ }^{4}$ When these companies want to modify their pipeline system, they must apply for a "certificate of public convenience and necessity" that specifies what the company estimates the construction will cost. Additionally, these companies must report back to FERC with the actual cost of construction after completion of the project.

${ }^{5}$ Cathodic protection prevents corrosion of the pipeline by connecting the pipeline with a sacrificial anode that is intended to corrode in place of the pipeline - these systems can be either galvanic or imposed current systems.
} 


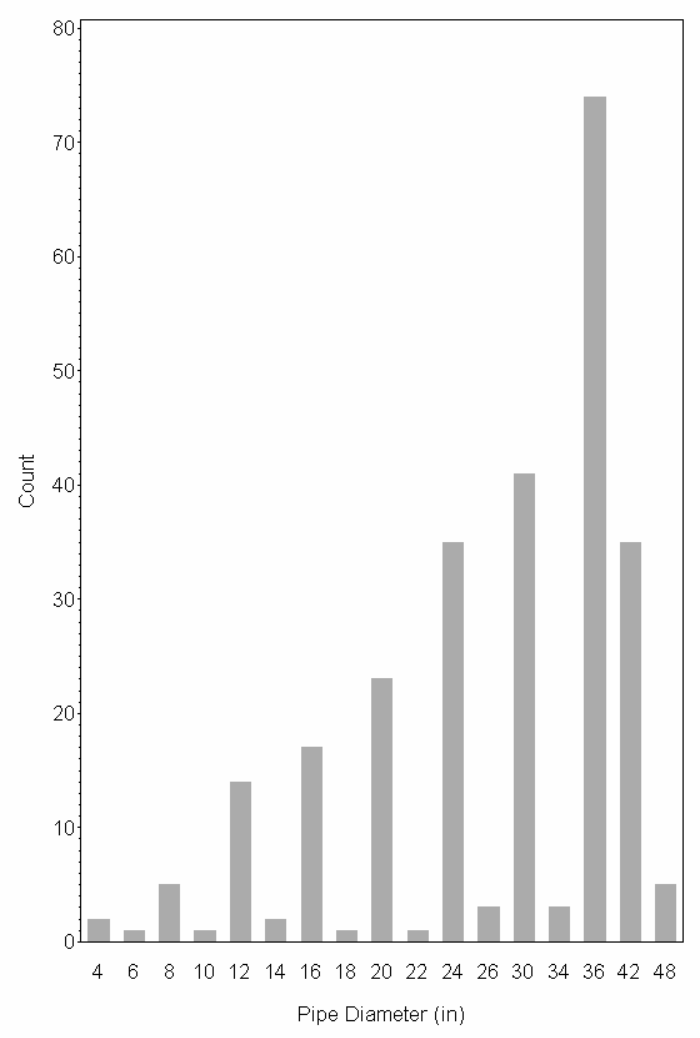

Figure 72: The frequency distribution of pipeline diameters.

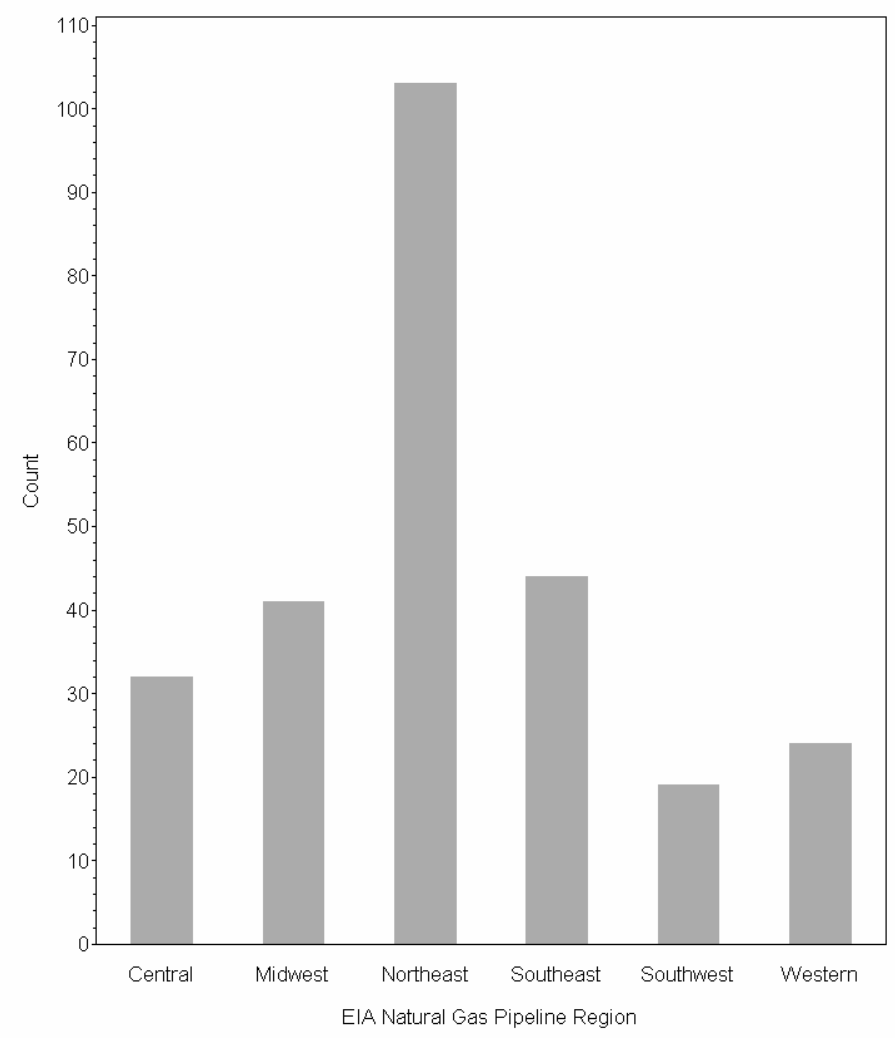

Figure 73: The frequency distribution of projects by region 


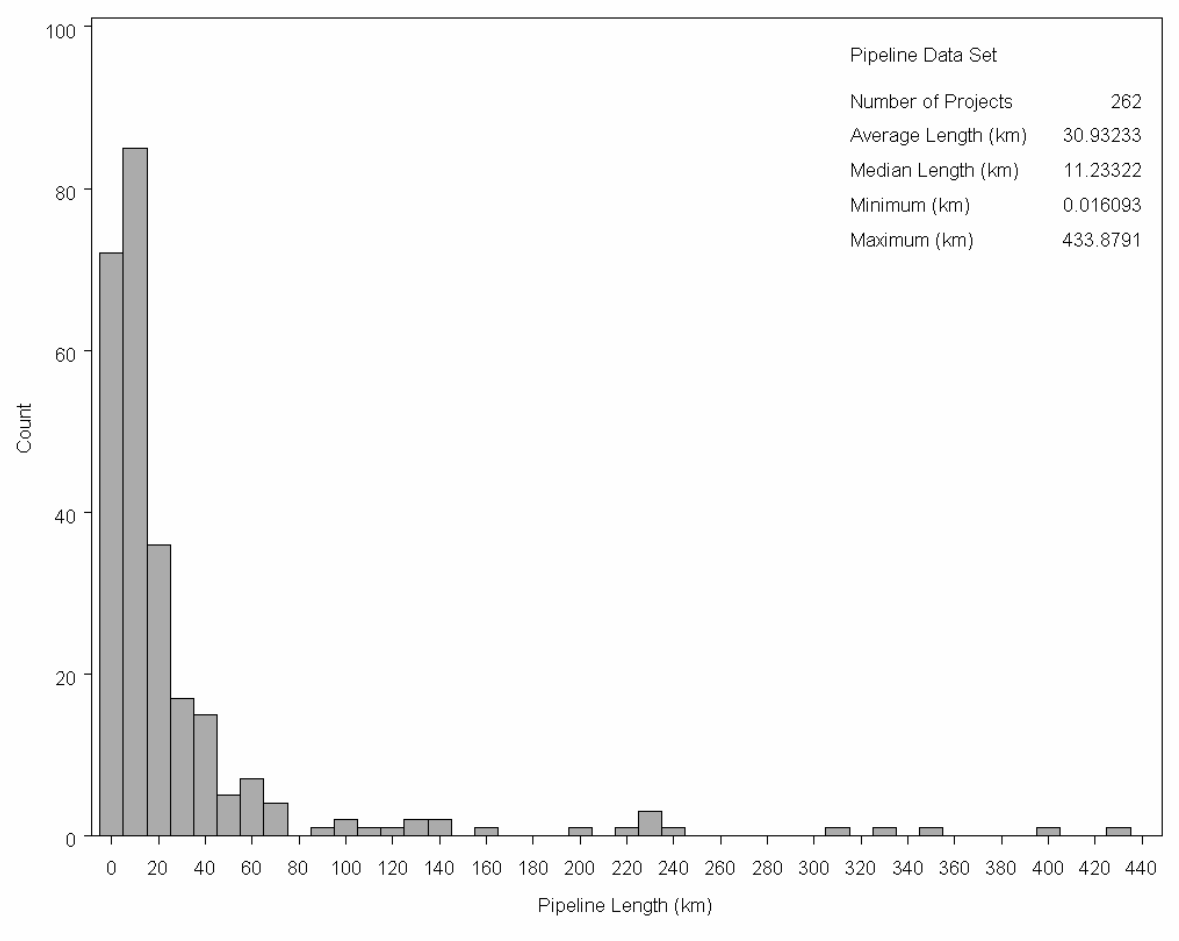

Histogram excludes a single $1400 \mathrm{~km}$ central region pipeline

Figure 74: The histogram of pipeline lengths, which excludes one $1400 \mathrm{~km}$ project for clarity

Figure 72 shows the distribution of pipeline projects by pipeline diameter, Figure 73 shows the distribution of projects by region, and Figure 74 shows the distribution of projects by length. Figure 72 clearly shows clearly that only certain pipe diameters are chosen for construction. This is because line pipe is manufactured only in discrete diameters, as noted earlier. Figure 73 shows that while most projects in the data set have been built in the Northeast region, the data set contains at least some projects in all regions. Finally, Figure 74 shows that the distribution of pipeline lengths in the data set is skewed towards shorter lengths, which is corroborated by the average pipeline length of $31 \mathrm{~km}$ being nearly $20 \mathrm{~km}$ longer than the median length.

\section{Capital Cost Models}

Separate cost models have been developed for materials, labor, miscellaneous charges, and ROW costs. The capital cost models take the general form shown in Equation (126):

$$
\begin{aligned}
& \log (\text { Cost })=\delta+\eta N E+\lambda S E+\omega C+\nu S W+\tau W \\
& +\beta \log (\text { Length })+\gamma \log (\text { Diameter })
\end{aligned}
$$

Where $N E, S E, C, S W$, and $W$ are binary variables that take a value of 1 or 0 depending on the region and adjust the estimated cost up or down from the Midwest value, which is the basis for the regression. Regional variables exist in the cost model only if they are statistically significant predictors of the cost, thus different models include different sets of regional variables. The regression intercept accounts for the fixed cost associated with a pipeline project of any length or diameter in the Midwest. 
In Equation (126), the dependent variable is the base-10 logarithm of the component capital cost and the independent variables are the base-10 logarithm of pipeline distance and pipeline diameter. Log-transformed variables have been used in the regression as opposed to the untransformed variables to reduce heteroskedasticity of the residuals. Heteroskedasticity of the residuals is caused by clustering of data and can result in poor estimates of the regression coefficients. For example, Figure 75 show clustering of pipeline projects at short distances and relatively low total capital costs, while Figure shows that the log-transformed variables are more evenly distributed.

If the intercept and regional variables in Equation (126) are collected into a single term, the cost model can be rewritten as shown below:

$$
\log (\text { Cost })=\log (\alpha)+\beta \log (\text { Length })+\gamma \log (\text { Diameter })
$$

where,

$$
\log (\alpha)=\delta+\eta N E+\lambda S E+\omega C+\nu S W+\tau W
$$

By reorganizing and taking the anti-logarithm of Equation (127), the cost model can be written in Cobb-Douglas form: ${ }^{6}$

$$
\text { Cost }=\alpha \text { Length }^{\beta} \text { Diameter }^{\gamma}
$$

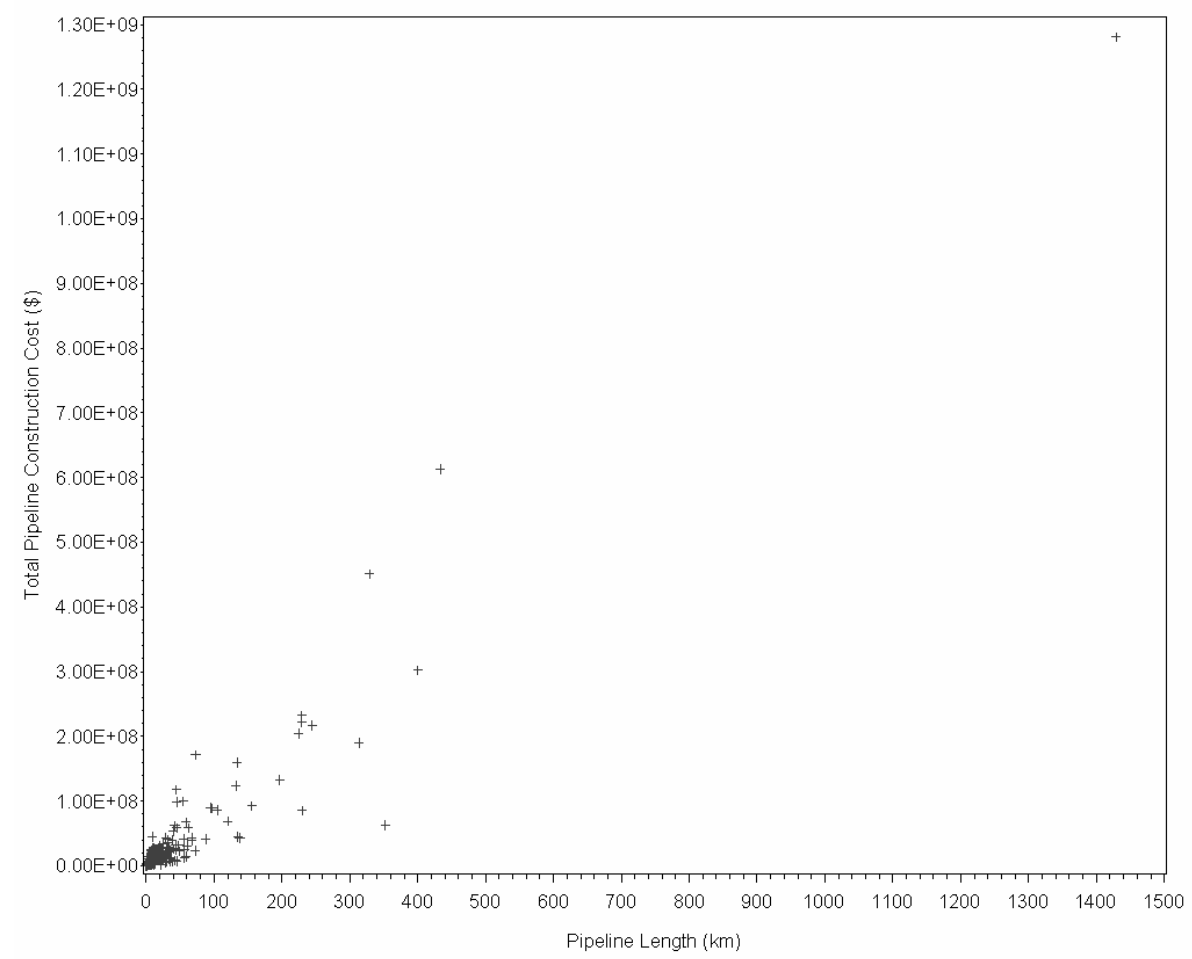

Figure 75. Total pipeline capital cost as a function of pipeline length, showing the clustering of variables at relatively low costs and short lengths

There are several interesting properties of Cobb-Douglas functions that are interesting in the context of the cost models. If the sum of $\beta$ and $\gamma$ is equal to one, the total cost exhibits constant returns to scale; if the sum is less than one, decreasing

\footnotetext{
${ }^{6}$ In economic theory, a Cobb-Douglas production function has the form $f(K, L)=A K^{a} L^{b}$, where $K$ and $L$, refer to capital and labor.
} 
returns to scale, and; if the sum is greater than one, increasing returns to scale. Moreover, the values of $\beta$ and $\gamma$ are the elasticity of cost with respect to length and diameter, respectively.

The use of separate cost models for each aspect of the capital cost allows real capital cost escalation factors to be applied to individual elements of the capital cost that can be used to scale the results to account for higher or lower than expected project specific costs (e.g. due to changes in the cost of steel). All of the capital cost models developed here report costs in 2004 dollars and the results of these models are subject the aforementioned escalation factors.

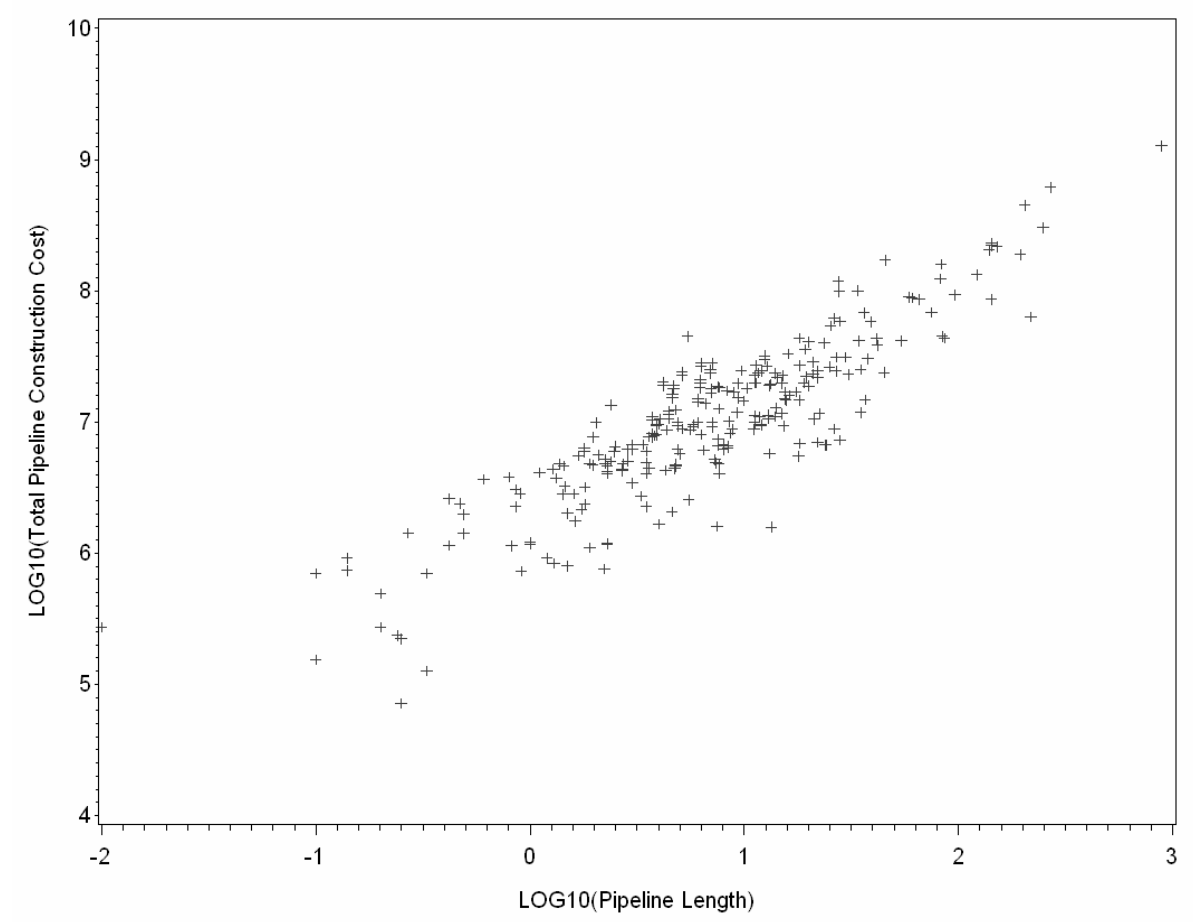

Figure 76. The logarithm of total pipeline construction cost and pipeline length showing a reduction in clustering of data points compared to the untransformed plot

\section{Pipeline Materials Cost Model}

The pipeline materials cost takes the form given in Equation (129):

$$
\log (\text { MaterialsCost })=\delta+\lambda S E+\beta \log (\text { Length })+\gamma \log (\text { Diameter })
$$

Where Diameter is in inches, Length is in miles, and SE is a binary variable. The SE regional variable has been included in the regression, however all others have been discarded as they are not significant at the $p=0.05$ level.

The regression model in Equation (129) is statistically significant, $F(3,244)=2318$, $p<0.001$, and has an adjusted $R^{2}$ value of $0.97 .^{7} 15$ projects were removed from the regression data set when performing the regression because they were found to be

\footnotetext{
${ }^{7}$ The F-value is an indicator of the significance of the regression - that is, that there is a significant relationship between the dependent and independent variables - while the $\mathrm{R}^{2}$ value is a measure of the goodness-of-fit of the regression, with higher values indicating that the model is a more accurate predictor of the dependent variable
} 
outliers based upon their deleted studentized residuals. ${ }^{8}$ Table 32 shows the parameter estimates for Equation (129), along with the associated 95\% confidence interval, $t$-values, and $p$-values.

Table 32. Parameter estimates for Equation (129), and their standard errors, t-values, and pvalues.

\begin{tabular}{||l|l|l|l|l|l||}
\hline Parameter & Value & $\begin{array}{l}\text { 95\% Cl } \\
\text { (Low) }\end{array}$ & $\begin{array}{l}\text { 95\% Cl } \\
\text { (High) }\end{array}$ & t-value & $\boldsymbol{p}$-value \\
\hline \hline$\delta$ & 3.29813 & 3.16753 & 3.42873 & 49.74 & $<0.001$ \\
\hline$\beta$ & 0.90131 & 0.87755 & 0.92507 & 74.72 & $<0.001$ \\
\hline$\gamma$ & 1.59000 & 1.50162 & 1.67838 & 35.44 & $<0.001$ \\
\hline$\delta$ & 0.07352 & 0.03214 & 0.11491 & 3.50 & $<0.001$ \\
\hline
\end{tabular}

Based on the regression results, several general observations can be made. The materials cost exhibits increasing returns to scale, which means that multiplying both the length and diameter by a constant $n$ multiplies the materials cost by a factor greater than $n$. In this case, a doubling of both length and diameter results in a nearly 6 -fold increase in materials cost. The elasticity of substitution for length is approximately 0.9 , thus a doubling in pipeline length results in slightly less than a cost doubling. Conversely, the elasticity of substitution for diameter is approximately 1.6 , thus a doubling in pipeline diameter results in a three-fold cost increase.

\section{Pipeline Labor Cost Model}

The pipeline labor cost model takes the form given in Equation (130):

$$
\log (\text { LaborCost })=\delta+\eta N E+\omega C+\nu S W+\beta \log (\text { Length })+\gamma \log (\text { Diameter })
$$

Where Diameter is in inches, Length is in miles, and $N E, S W$, and $C$ are binary variables that adjust the total cost of the pipeline if it is constructed in the Northeast, Southwest, or Central regions. The other two pipeline regions have not been included because they have been found not to be statistically significant predictors at the $p=0.05$ level.

Table 33. Parameter estimates for Equation (130), and their standard errors, $t$-values, and $p$ values.

\begin{tabular}{||l|l|l|l|l|l||}
\hline Parameter & Value & $\begin{array}{l}95 \% \mathrm{Cl} \\
\text { (Low) }\end{array}$ & $\begin{array}{l}\text { 95\% Cl } \\
\text { (High) }\end{array}$ & t-value & $\boldsymbol{p}$-value \\
\hline \hline$\delta$ & 4.65680 & 4.44281 & 4.87080 & 42.86 & $<0.001$ \\
\hline$\beta$ & 0.81986 & 0.77514 & 0.86458 & 36.10 & $<0.001$ \\
\hline$\gamma$ & 0.93951 & 0.78728 & 1.09174 & 12.15 & $<0.001$ \\
\hline$\eta$ & 0.07526 & 0.01175 & 0.13877 & 2.33 & 0.020 \\
\hline$\omega$ & -0.18719 & -0.28094 & -0.09345 & -3.93 & $<0.001$ \\
\hline$v$ & -0.21633 & -0.33169 & -0.10098 & -3.69 & $<0.001$ \\
\hline
\end{tabular}

The regression model in Equation $(130)$ is statistically significant, $F(5,253)=361$, $p<0.001$, and has an adjusted $R^{2}$ value of 0.87 . Two projects were removed from the

\footnotetext{
${ }^{8}$ Deleted studentized residuals are a measure of an observations influence on the parameters of the regression, where larger values can indicate undue influence on the regression parameters. A value of 3 has been used as a cutoff for acceptable deleted studentized residuals.
} 
regression data set when performing the regression because they were found to be outliers based upon its deleted studentized residual. Table 33 shows the parameter estimates for Equation (130), along with the associated $95 \%$ confidence intervals, $t$ values, and $p$-values.

The labor cost model shows increasing returns to scale - a doubling of length and diameter results in a 3-fold increase in labor costs. Both the elasticity of substitution for length and diameter are less than one, thus doubling the length or diameter results in a less than doubling in total cost.

\section{Pipeline Miscellaneous Cost Model}

The miscellaneous cost model takes the form given in Equation (131):

$$
\log (\text { Cost })=\delta+\eta N E+\lambda S E+\omega C+\tau W+\beta \log (\text { Length })+\gamma \log (\text { Diameter })
$$

Where Diameter is in inches, Length is in miles, and, as in the previous model the variables $N E, S E, C$, and $W$ are binary variables that adjust the total cost of the pipeline if it is constructed in the Northeast, Southeast, Central, or West regions. The Southwest pipeline region has not been explicitly included it is not a statistically significant predictor at the $p=0.05$ level.

The regression model in Equation (131) is statistically significant, $F(6,252)=185$, $p<0.001$, and has an adjusted $R 2$ value of 0.82 . Four projects were removed from the regression data set when performing the regression because they were found to be outliers based upon their deleted studentized residual. Table 34 shows the parameter estimates for Equation (131), along with their $95 \%$ confidence interval, $t$-values, and $p$-values.

The miscellaneous cost model shows increasing returns to scale- - a doubling of length and diameter results in an approximately 3 -fold increase in labor costs. Both the elasticity of substitution for length and diameter are less than one, thus doubling the length or diameter results in a less than doubling in total cost. 
Table 34. Parameter estimates for Equation (131), and their standard errors, $t$-values, and pvalues.

\begin{tabular}{||l|l|l|l|l|l||}
\hline Parameter & Value & $\begin{array}{l}95 \% \text { Cl } \\
\text { (Low) }\end{array}$ & $\begin{array}{l}95 \% \text { Cl } \\
\text { (High) }\end{array}$ & t-value & $p$-value \\
\hline \hline$\delta$ & 4.55194 & 4.29304 & 4.81084 & 34.63 & $<0.001$ \\
\hline$\beta$ & 0.78345 & 0.73114 & 0.83577 & 29.50 & $<0.001$ \\
\hline$\gamma$ & 0.79067 & 0.61242 & 0.96893 & 8.74 & $<0.001$ \\
\hline$\eta$ & 0.14543 & 0.05643 & 0.23443 & 3.22 & 0.002 \\
\hline$\omega$ & -0.36877 & -0.48889 & -0.24866 & -6.05 & $<0.001$ \\
\hline$\tau$ & -0.37723 & -0.50661 & -0.24785 & -5.74 & $<0.001$ \\
\hline$\lambda$ & 0.13236 & 0.02510 & 0.23963 & 2.43 & 0.0158 \\
\hline \hline
\end{tabular}

\section{Pipeline Right-of-Way Cost}

The ROW model takes the form given in Equation (132):

$$
\log (\text { Cost })=\delta+\omega C+\beta \log (\text { Length })+\gamma \log (\text { Diameter })
$$

Where Diameter is in inches, Length is in miles, and the variable $C$ is a binary variable that adjusts the total cost of the pipeline if it is constructed in the Central region. The other four pipeline regions have not been included because they have been found not to be statistically significant predictors at the $p=0.05$ level.

The regression model in Equation $(132)$ is statistically significant, $F(3,239)=168$, $p<0.001$, and has an adjusted $R^{2}$ value of 0.67 . This $R^{2}$ value is considerably less than for any of the other models. This is likely because of the greater variability in ROW costs, which depend on a number of factors not explicitly included in the model, such as property values along the pipeline route, etc.

Six projects were removed from the regression data set when performing the regression because they were found to be outliers based upon their deleted studentized residual. Table 35 shows the parameter estimates for Equation (132), along with their $95 \%$ confidence intervals, $t$-values, and $p$-values.

Table 35. Parameter estimates for Equation (132) and their standard errors, $t$-values, and $p$ values.

\begin{tabular}{|l|l|l|l|l|l||}
\hline Parameter & Value & $\begin{array}{l}95 \% \mathrm{Cl} \\
\text { (Low) }\end{array}$ & $\begin{array}{l}95 \% \mathrm{Cl} \\
\text { (High) }\end{array}$ & $\boldsymbol{t}$-value & $\boldsymbol{p}$-value \\
\hline \hline$\delta$ & 4.16650 & 3.68692 & 4.64607 & 17.11 & $<0.001$ \\
\hline$\beta$ & 1.04935 & 0.95493 & 1.14377 & 21.89 & $<0.001$ \\
\hline$\gamma$ & 0.40306 & 0.07409 & 0.73204 & 2.41 & 0.017 \\
\hline$\omega$ & -0.38195 & -0.56547 & -0.19842 & -4.10 & $<0.001$ \\
\hline
\end{tabular}

The ROW cost model shows increasing returns to scale - a doubling of length and diameter results in an approximately 3 -fold increase in labor costs. The elasticity of substitution for length is approximately one, thus doubling the length results in a doubling in total cost. This seems reasonable, as the cost per unit of land required for the pipeline ROW would not change due to the length of the pipeline. However, the elasticity of substitution for pipeline diameter is less than 1, which indicates that a doubling of pipeline diameter will result in less than a doubling of cost. 


\section{Pumping Station Capital Cost}

The total capital cost of a pumping station has been estimated by the IEA for a European study involving the pipeline transmission of $\mathrm{CO}_{2}$ (EIA, 2002). That cost is given by the regression in Equation (133):

PumpCost $=7.82 P+0.46$

where the result is in millions of US dollars (2002), and P is the installed booster station power in MW. This correlation yields a cost slope of $\$ 7,820$ per $\mathrm{kW}$ of installed capacity.

\section{Illustrative Model Results}

The behavior of the capital cost models is shown in Figure 77, where the category cost model results are stacked to indicate the total cost of a 16 inch diameter pipeline for distances from $10 \mathrm{mi}$ to $60 \mathrm{mi}$ located in the Midwest. For reference, a $16 \mathrm{inch}$ pipeline could transport approximately 5 million metric tonnes of $\mathrm{CO}_{2}$ per year over a $100 \mathrm{~km}$ distance, which would be approximately the maximum annual emissions of a $600 \mathrm{MW}$ (net) pulverized coal fired plant with $90 \% \mathrm{CO}_{2}$ capture.

Figure 77 shows that the labor cost accounts for over $50 \%$ of the total cost of a 16 " pipeline across all distances between $10 \mathrm{mi}$ and $60 \mathrm{mi}$. The next largest cost category is materials, followed by ROW, and miscellaneous. However, the size breakdown shown in Figure 77 is dependent on the pipeline diameter. For example, the material cost increases more rapidly with pipeline diameter than the miscellaneous cost, thus for a 36 in pipeline, the materials cost is much a much larger fraction of the total cost than the miscellaneous cost.

The regional dependence of the labor, miscellaneous, and ROW models means that the predicted cost of projects in some regions will be either higher or lower than the cost of equivalent projects in other regions. The difference in cost between the Midwest and the other five regions is summarized in Table 36 for a 16 inch diameter pipeline that is $100 \mathrm{~km}$ long. The results in this table show that, when compared to the Midwest, pipelines in the Northeast and Southeast are more expensive to construct, and pipelines in the Central and Southwest are less expensive to construct.

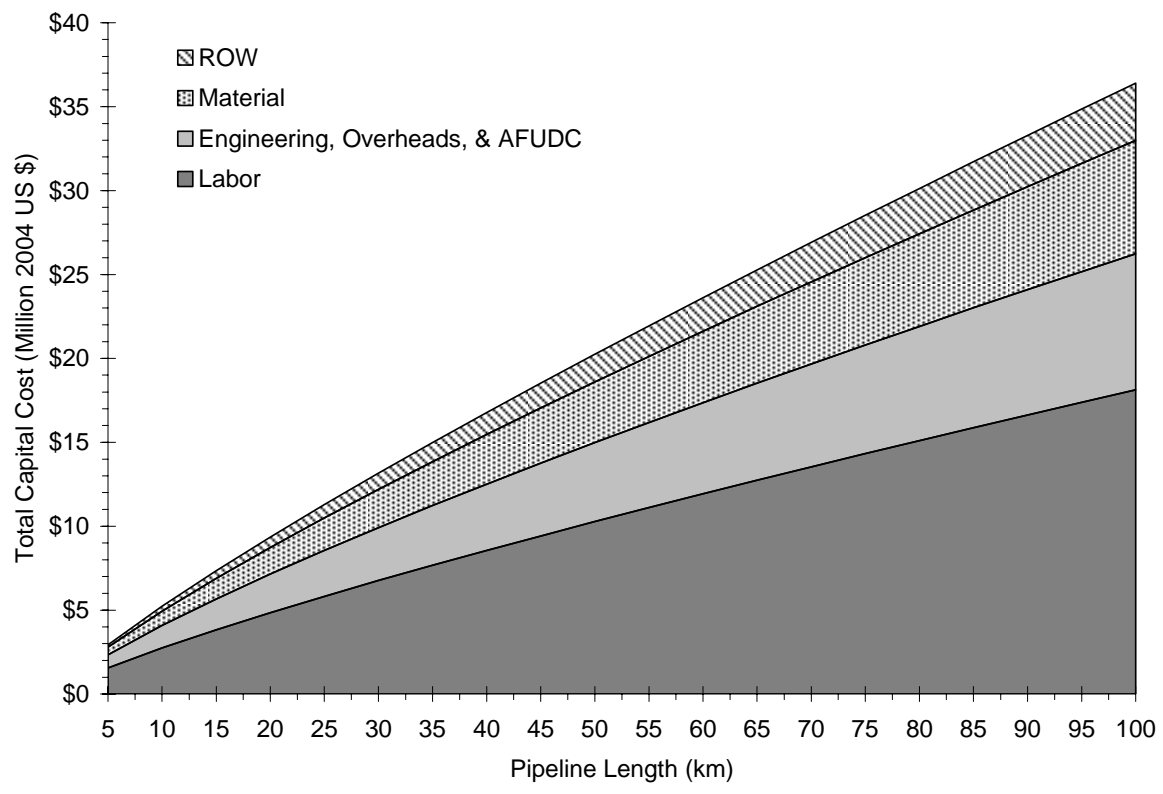

Figure 77. The capital cost of a 16 inch pipeline located in the Midwest over varying lengths 
Table 36. The cost of construction of a $100 \mathrm{~km}, 16$ inch pipeline in the Midwest, and the regional differences relative to the Midwest cost, where values in brackets are negative.

\begin{tabular}{||l|l|l|l|l|l|l||}
\hline \multirow{2}{*}{\begin{tabular}{l} 
Midwest \\
\cline { 3 - 7 }
\end{tabular}} & \multirow{2}{*}{\begin{tabular}{l} 
Difference from Midwest \\
\cline { 3 - 7 }
\end{tabular}} & $\mathbf{N E}$ & SE & SW & West & Central \\
\hline \hline Material & $\$ 6,745,996$ & $\$ 0$ & $\$ 1,244,359$ & $\$ 0$ & $\$ 0$ & $\$ 0$ \\
\hline Labor & $\$ 18,129,240$ & $\$ 3,430,305$ & $\$ 0$ & $(\$ 7,112,589)$ & $\$ 0$ & $(\$ 6,348,038)$ \\
\hline Miscellaneous & $\$ 8,109,657$ & $\$ 3,225,629$ & $\$ 2,889,578$ & $\$ 0$ & $(\$ 4,707,358)$ & $(\$ 4,640,432)$ \\
\hline ROW & $\$ 3,417,320$ & $\$ 0$ & $\$ 0$ & $\$ 0$ & $\$ 0$ & $(\$ 1,999,126)$ \\
\hline Total & $\$ 36,402,213$ & $\$ 6,655,934$ & $\$ 4,133,937$ & $\$(7,112,589)$ & $\$(4,707,358)$ & $\$(12,987,596)$ \\
\hline
\end{tabular}

\section{Operating \& Maintenance Cost Model}

While operating and maintenance (O\&M) costs are not large in comparison to the annualized capital cost of pipeline transport, they are nonetheless significant. For a $100 \mathrm{~km}$ long pipeline, transporting approximately 5 million tonnes per year of $\mathrm{CO}_{2}$ with no booster pumping stations, the O\&M cost would account for approximately $6 \%$ of the total cost per tonne of transportation. 


\section{Operating \& Maintenance Cost Components}

In the United States, pipeline maintenance activities are regulated under title 49 of the Code of Federal Regulations (CFR), section 195, subsections 400 through 452. These regulations specify requirements for training, inspections, and repairs. Routine activities that fall under the category of maintenance activities include (Mohitpour, 2005):

- ROW and facilities environmental protection

- $\quad$ ROW and site maintenance

- Pipeline depth of cover maintenance

- Aerial inspection/patrol and leak detection

- ROW erosion control and stabilization

- Cathodic protection monitoring and maintenance

- Pipeline integrity assessment

- Pipeline repair and modifications

- Pipeline encroachment assessment

- Equipment operational test and routine maintenance

- Aesthetics and landscaping

In addition to these activities, title 49 of the CFR, section 195, subpart 452 , requires the operator of a $\mathrm{CO}_{2}$ pipeline to develop and maintain an integrity management program that addresses risks along each segment of their pipeline system. This program is particularly addressed to address risks in high consequence areas (i.e., a populated place or navigable waterway).

\section{Pipeline O\&M Cost Model}

Bock et al. (2003) report that the O\&M cost of operating a $480 \mathrm{~km} \mathrm{CO}_{2}$ pipeline is between $\$ 40,000$ and $\$ 60,000$ per month. Thus, on an annual basis, this amounts to approximately $\$ 3,100$ per kilometer of pipeline in 2003 dollars.

Based on the EPRI Technical Assessment Guide (EPRI, 1993), the O\&M charges associated with the booster pumping stations are assumed to be $1.5 \%$ of their original capital cost, annually.

\section{Pipeline Routing Considerations}

In most situations, the straight line distance from a $\mathrm{CO}_{2}$ source to a $\mathrm{CO}_{2}$ sink will not result in the lowest cost pipeline, thus the actual pipeline length used in the model will be longer than the straight line distance. Moreover, ROW cost and, to some extent, materials cost are dependent on the pipeline routing and this is not explicitly accounted for by the cost models.

Pipeline routing depends heavily on the locations of existing ROW's. Use of existing right-of-ways, particularly those for power lines, which are frequently owned by a utility company, can significantly reduce the cost of the pipeline. On the other hand, if the pipeline operator must use an existing or new easement on landowners' properties, the pipeline operator must negotiate with the landowner for the right to create or use an already existing easement for a new purpose. If negotiations between the pipeline operator and the landowner break down, the pipeline operator may be 
able to acquire the ROW through eminent domain. However, regulations surrounding the use of eminent domain vary from state-to-state. For example, a recent Midwest Geological Sequestration Consortium report discusses the use of eminent domain in the State of Illinois for $\mathrm{CO}_{2}$ pipelines (Nyman et al. 2004).

In addition to consideration of existing ROW's, the pipeline route should consider features, such as: elevation changes; river, road, and rail crossings, and; population density. Locations with higher population density and locations at which the pipeline crosses roads and railway with result in the use more stringent pipeline design factors (Mohitpour et al. 2003). The use of more stringent design factors will increase grade of line pipe required for sections of the project and, thus, increase the total materials cost.

In the pipeline cost models, the additional costs of routing the pipeline through different areas and terrains are averaged into the regional dummy variables. Thus, pipelines in the Northeast have a more expensive ROW cost because they, on average, are built in areas with higher population densities. However, depending on the specifics of a pipeline project, use of escalation factors to account for some routing considerations may be necessary.

\section{Model Implementation}

The pipeline model algorithm has been developed using Visual Basic in Microsoft Excel; more recently, it has also been implemented in the IECM framework. The basic input and output screen is shown in Figure 78. From this input screen all of the pipeline parameters can be modified, and the model output viewed.

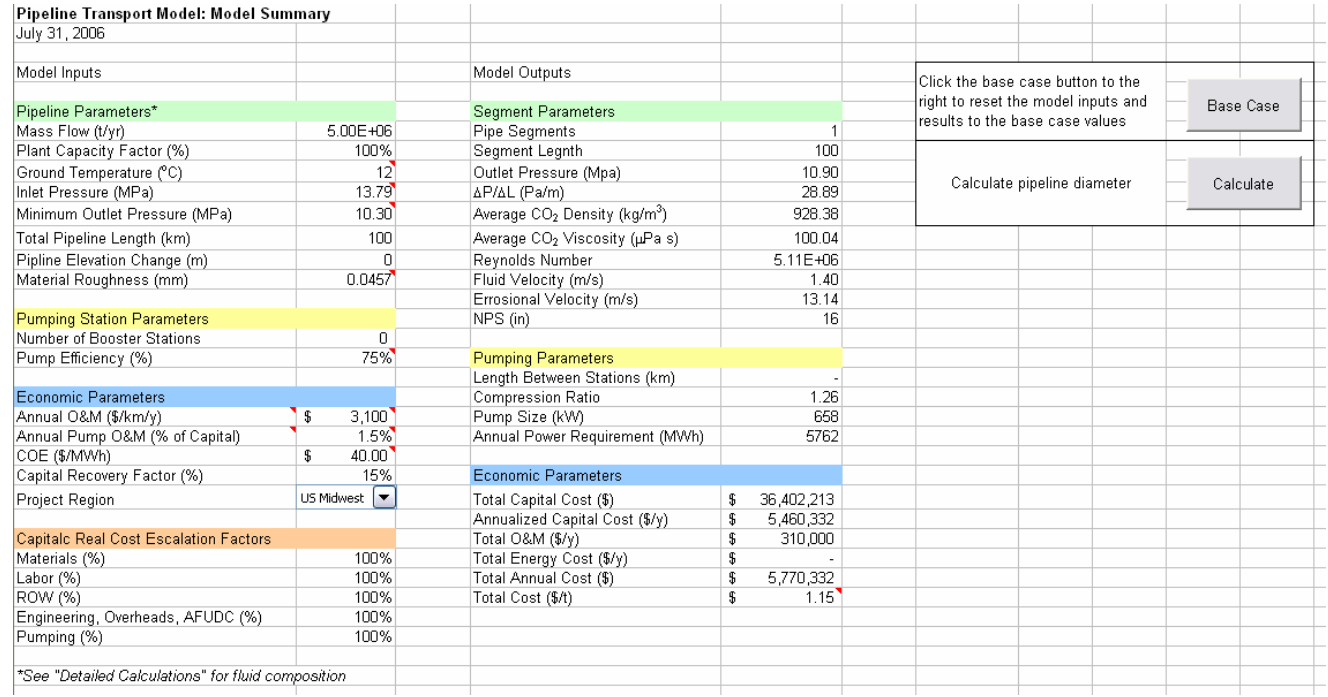

Figure 78. The $\mathrm{CO}_{2}$ pipeline transport model input screen in the Excel

\section{Combining Performance and Cost}

The cost model is dependent on the diameter of the pipeline as calculated by the performance model. Thus, the model must first calculate the pipeline diameter based on the users inputs.

In order to accommodate the booster stations, the pipeline is broken up into segments, each being equal in length. The segment length, $L$, and number, $N S$, of the pipe segments is determined by the number of booster stations specified by the user, 
$N B$, and the total pipeline length, $L$. The number of pipe segments is one greater than the number of booster stations and the segment length is the total length divided by the number of segments For example, for a $30 \mathrm{~km}$ pipeline if there are two booster pumping stations specified there are then three- $10 \mathrm{~km}$ long pipe segments. For all segments, the inlet pressure and minimum outlet pressure are given by the Inlet Pressure and Minimum Outlet Pressure fields in the model input.

The calculation of the desired pipeline diameter for a pipeline segment is a three step process. These steps are shown in Figure 79 along with other steps in the overall algorithm. The first step iteratively calculates the pipeline diameter based on the pressure difference between the inlet pressure and the minimum outlet pressure, using Equations (122), (123), and (124). This diameter is then compared with a list of commonly available diameters of line pipe, and then the next largest size is chosen (see Table 31). Finally, the new outlet pressure is iteratively calculated based on the available pipe diameter.

Following determination of the pipeline segment diameter, the booster pumping station size is calculated using Equation (125). Based on the pumping station size and the pipeline capacity factor, the annual power requirement for each booster pumping station is calculated.

Using the pipeline segment diameter, total length, and pipeline region, the capital cost is then calculated using the correlations presented earlier. If booster pumping stations are selected, then the cost of these stations is included in the total capital cost. The capital costs for materials, labor, miscellaneous, ROW and pumping costs are then multiplied by their respective capital cost escalation factors to account for any anticipated project specific deviations from the capital cost models. The total capital cost is then annualized using the capital charge rate, and divided by the annual expected amount of $\mathrm{CO}_{2}$ handled annually to determine the cost of transport. 


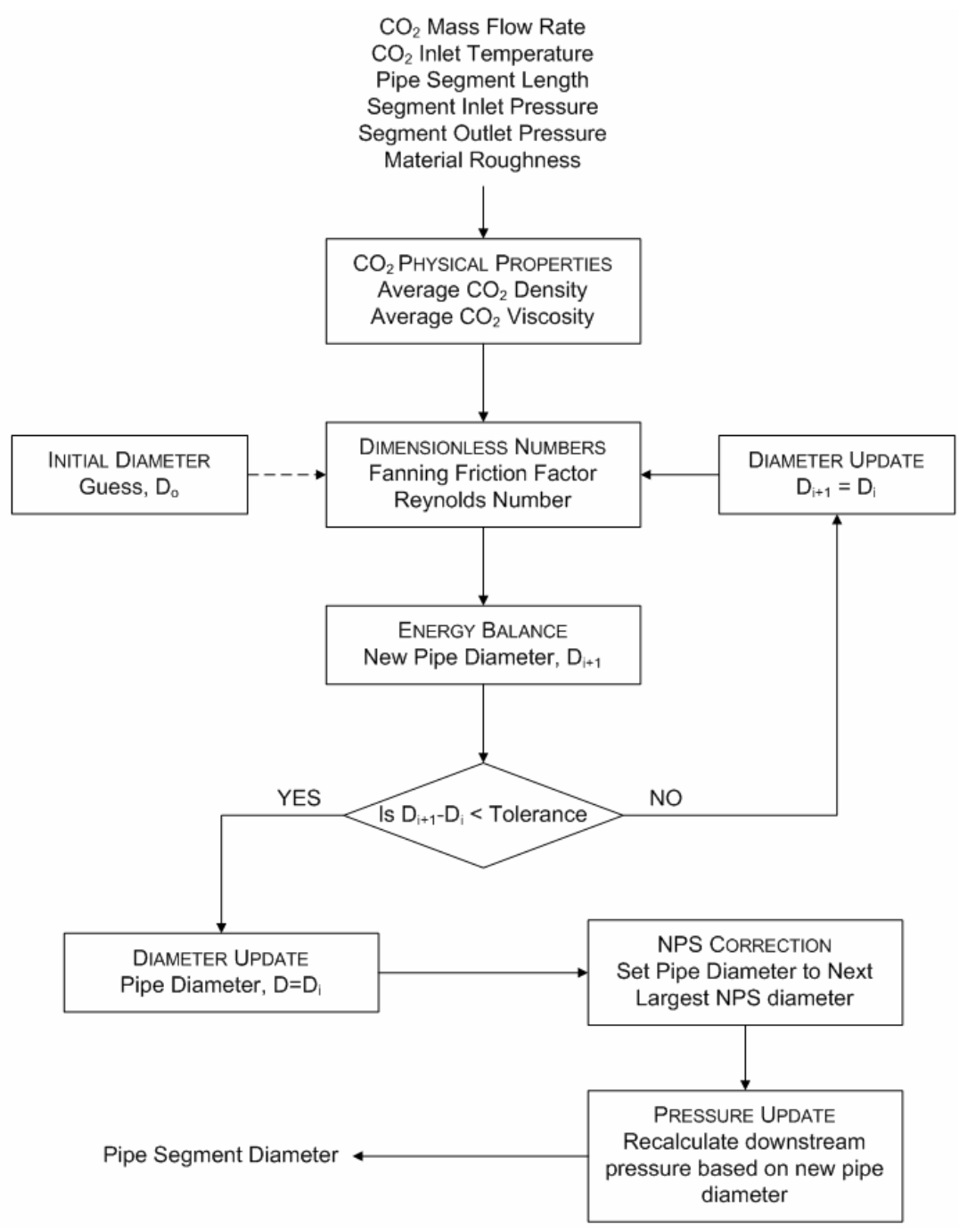

Figure 79. Flowchart showing the method used to calculate the pipe diameter.

\section{Sensitivity Analysis Tools}

Sensitivity of the model to uncertainty and variability in the input parameters is assessed via Monte Carlo simulation. In Monte Carlo simulation, a large number of cases are run; each case with parameter values independently and randomly selected from distributions that characterize the uncertainty or variability of the particular parameter. From the results of the simulation, a cumulative distribution function is generated that shows the probability of an outcome given the uncertainty and variability in the inputs. Furthermore, plots of the model response as a function of the input parameters can be generated which show the sensitivity of the model to variation in the input.

The model's Monte Carlo input screen is shown in Figure 80. From this screen the input parameters can either be deterministic, uniformly distributed between an upper and lower bound, or distributed according to a triangular distribution (between an upper and lower bound with a median). The number of iterations can also be specified depending on the needs of the user. 


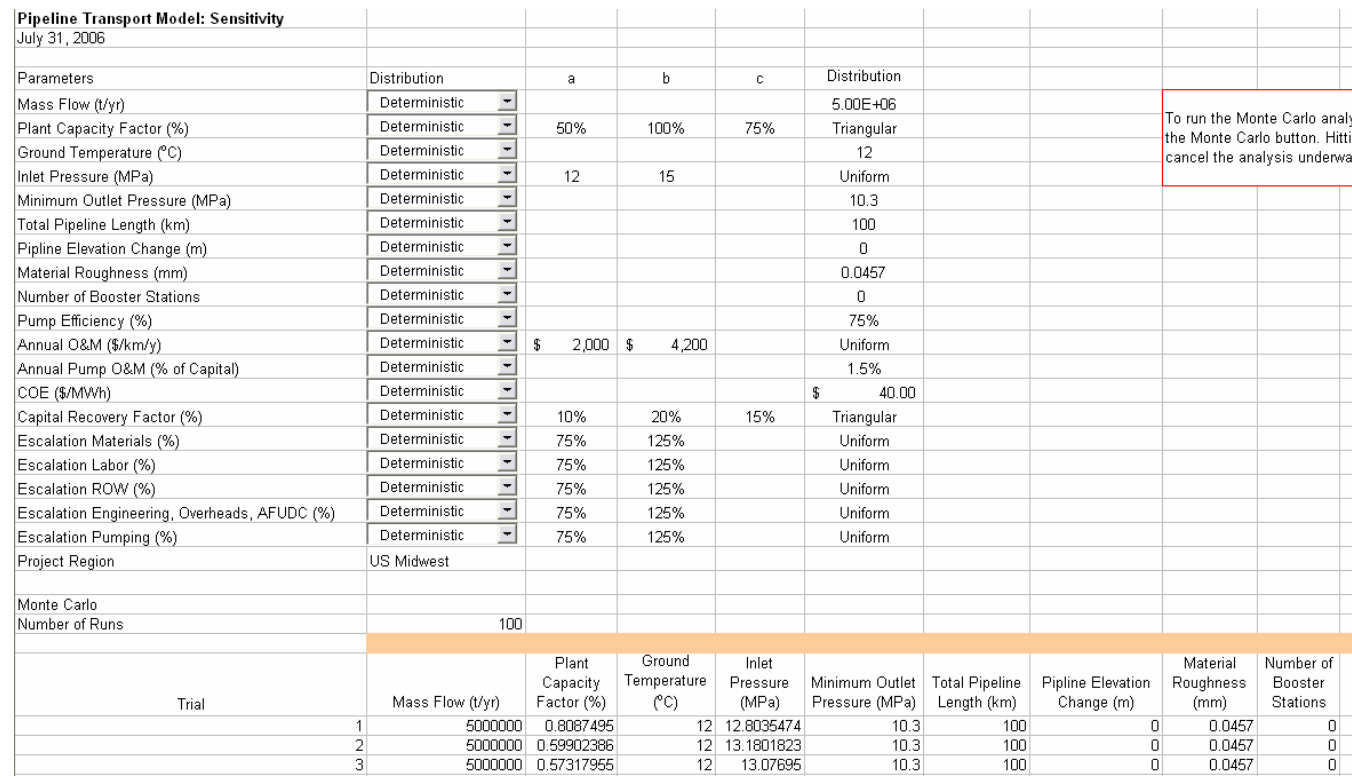

Figure 80. The input screen for the transport model sensitivity analysis.

\section{Illustrative Results}

Figure 81 shows typical results when the model is used to estimate the cost of transport for the US Midwest region. From Figure 81, we can see that the cost per tonne of $\mathrm{CO}_{2}$ transported increases with distance, and decreases for a fixed distance with increasing design capacity. However, the increase with distance is less than linear; that is, the cost per kilometer of a longer pipeline is less than the cost per kilometer for a shorter pipeline.

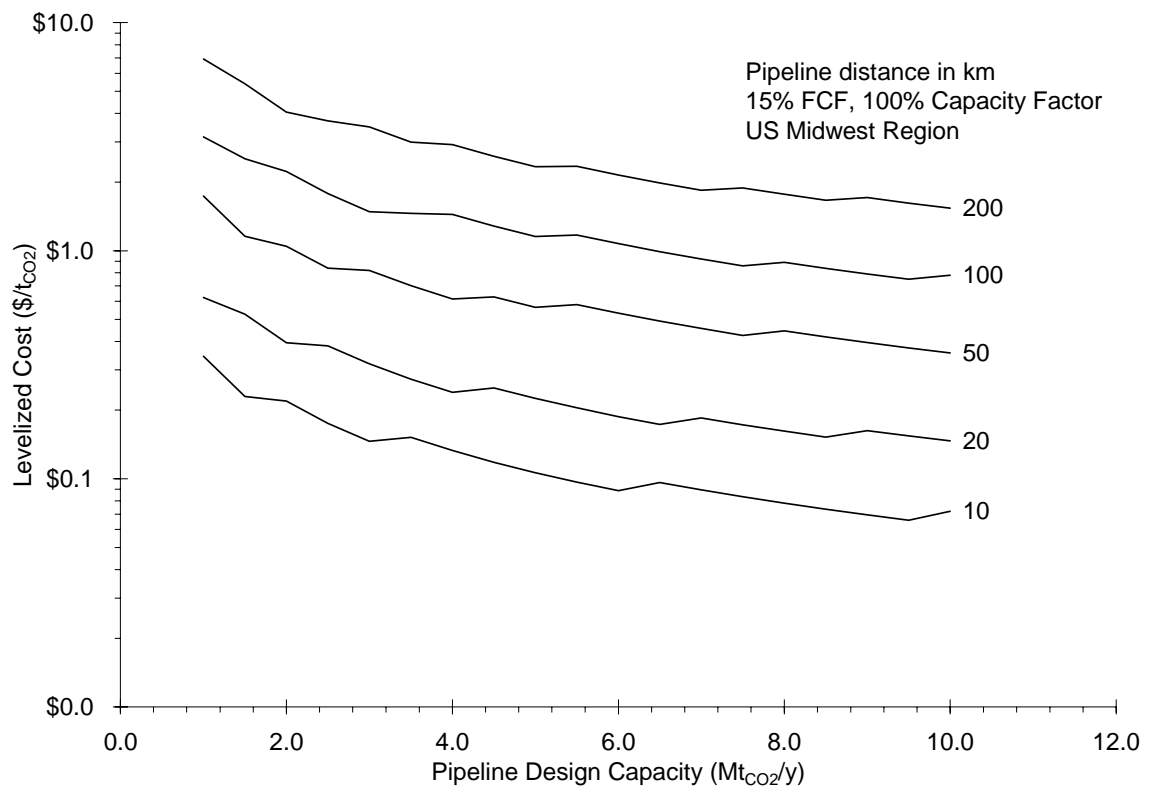

Figure 81. Cost per tonne of CO2 transported across the US Midwest via pipeline as estimated by the model for varying pipeline distances (in $\mathrm{km}$ ) and annual design capacities. 


\section{Comparison with Other Models}

Differences between the model developed here (referred to as the CMU model) and other models stem from differences in the performance model (i.e., the way the required pipeline diameter is calculated), as well as in the cost model. To better explain differences between available models, differences in the performance model, cost model, and overall results will be discussed separately.

\section{Performance Model Comparison}

The CMU performance model, described earlier, is compared in Figure 82 with a model developed by MIT described in a report for the DOE (Bock et al., 2003). The MIT model allows for continuous pipe sizes and does not account for the compressible nature of the flowing $\mathrm{CO}_{2}$.

Figure 85 shows that for the same conditions, the CMU model tends to predict a larger pipe diameter than the MIT model. There are likely several reasons for this difference, the primary one being that accounting for compressibility will result in a larger pipe diameter being required. Moreover, the MIT model calculates the properties of the flowing $\mathrm{CO}_{2}$ at the inlet of the pipeline, rather than averaged over the entire length of the pipeline as in the CMU model, resulting in a smaller calculated pipe diameter.

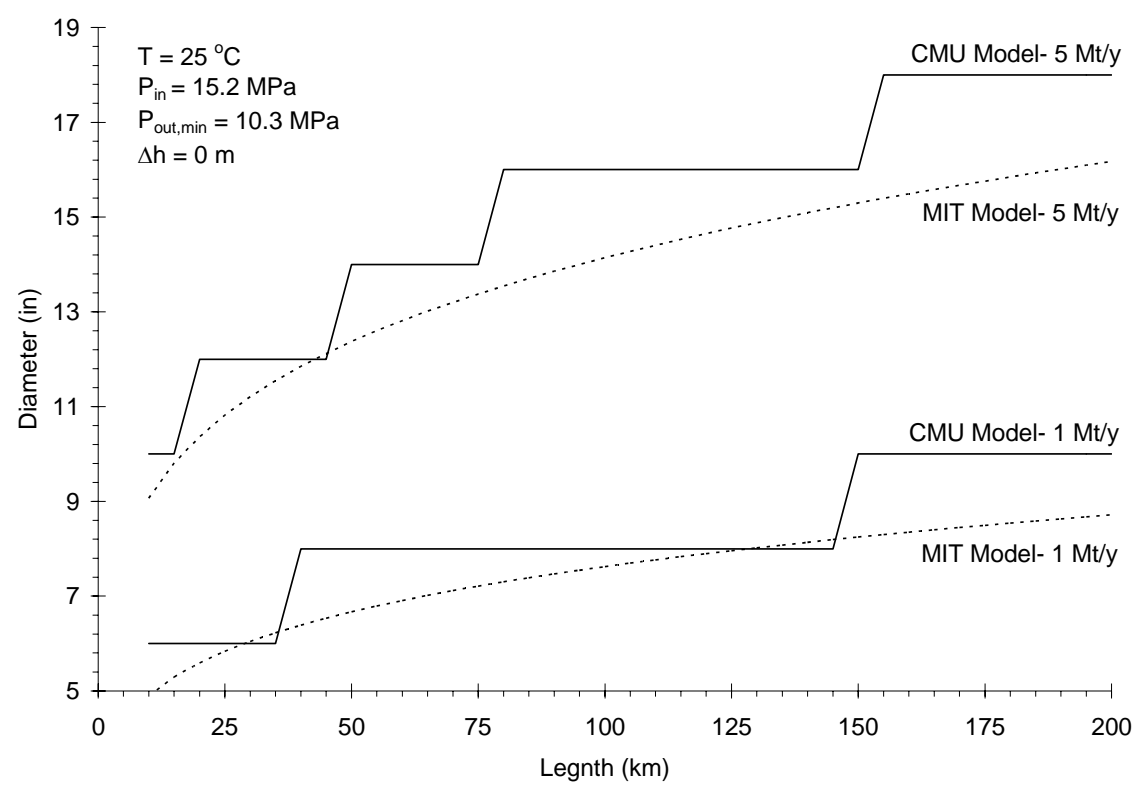

Figure 82. A comparison between the MIT model and the CMU model, showing that the CMU model generally predicts a larger pipe diameter for a range of flow rates (1-5 Mt/y)

A further comparison can be made with the rules of thumb proposed by Skholvolt (1993), which are based on relatively low pressure compared to the pressures that would likely be used in a $\mathrm{CO}_{2}$ constructed today. The parameters used by Skovholt are presented in Table 37.

Table 37. Parameters used by Skovholt to determine rules of thumb for pipe diameter

\begin{tabular}{|l|l|}
\hline Pipeline Parameter & Value \\
\hline \hline Segment Length $(\mathrm{km})$ & 250 \\
\hline
\end{tabular}




\begin{tabular}{||l|l||}
\hline Ground Temperature $\left({ }^{\circ} \mathrm{C}\right)$ & 6 \\
\hline Maximum Pressure $(\mathrm{MPa})$ & 11 \\
\hline Minimum Pressure $(\mathrm{MPa})$ & 9 \\
\hline
\end{tabular}

Using these parameters, the diameters calculated by Skovholt are compared with diameters calculated by the CMU model for the same conditions in Table 38. In this case, the diameters calculated by the CMU model are consistently larger for all mass flow rates. Moreover, the CMU model can not accommodate the case of 110 million tonnes per year in one pipeline. The reasons for the difference between the diameters presented by Skovholt and those calculated by the CMU model are not clear, as Skovholt does not describe the methods used to calculate the rules of thumb.

Table 38. The pipe diametrs proposed by Skholvolt compared with those calculated by the CMU model (all diameters in inches).

\begin{tabular}{|l|l|l||}
\hline $\begin{array}{l}\text { Design Mass Flow } \\
\left(\mathbf{M t}_{\text {Co2 } / \mathbf{y})}\right)\end{array}$ & Skholvolt & CMU Model \\
\hline \hline 3 & 16 & 18 \\
\hline 20 & 30 & 36 \\
\hline 35 & 40 & 48 \\
\hline 110 & 64 & N/A \\
\hline
\end{tabular}

\section{Cost Model Comparison}

The CMU cost model can be compared with the cost model from the previously mentioned MIT study (Bock et al., 2003), cost models developed in a study for the IEA (IEA, 2002), and models developed for the Midwest Geological Carbon Sequestration (MGSC) Partnership (Nyman et al., 2004). This comparison is shown in Figure 83 for the case of a 16-inch pipeline.

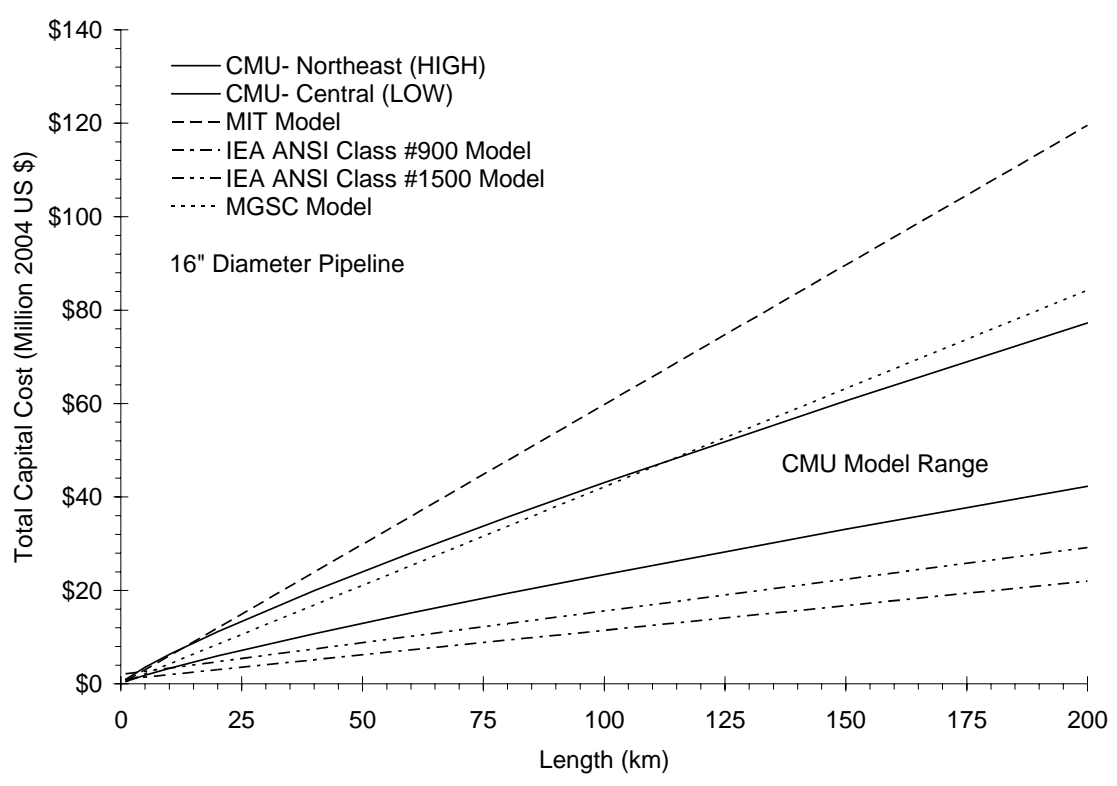

Figure 83. The range of capital costs possible from the CMU cost models, depending on region, compared with the capital costs possible from the MIT and IEA models for a 16 " NPS pipeline. 
Figure 83 shows the total capital cost of a 16 inch NPS pipeline for a range of distances as calculated by the MIT model, which uses a simple slope factor $(\$ / \mathrm{in} / \mathrm{km})$; the MGSC model, which uses discrete slope factors $(\$ / \mathrm{km})$ for diameters between 4 and 24 inches, and; the IEA models, which depends on the operating pressure of the pipeline as well as length and diameter. The IEA ANSI Class \#900 model is for pipelines with an operating pressure up to approximately $14 \mathrm{MPa}$, while the Class \#1500 model is for pressures up to about $23 \mathrm{MPa}$. The figure shows that the CMU model predicts costs that are less than those predicted by the MIT model, on the low side of the MGSC model, and higher than either of the IEA models. Moreover, Figure 83 shows that the MIT, IEA, and MGSC models are linear in length, but the CMU model is slightly non-linear. In the CMU model, the cost per unit length decreases slightly with increasing pipeline length.

The differences between the CMU, MIT, IEA, and MGSC models are likely due to the differing approaches taken in their development. Both the IEA and MGSC models are based on "bottom-up" cost estimates, developed from private design studies of pipeline projects. On the other hand, the MIT model is based on similar data to the CMU model, but with a smaller set of projects, no variation by region, and no accounting for the non-linear effects of length on cost.

\section{Overall Model Comparison}

Results from the MIT model and the CMU model can be compared over a range of lengths. Unfortunately, the overall results of the IEA and MGSC model can not be compared in the same way - the IEA model implementation is not amenable to sensitivity analysis, while the MGSC has not developed a design model. Figure 84 shows the results of the comparison between the MIT and CMU models for a fixed mass flow rate of $5 \mathrm{Mt} / \mathrm{y}$, and a charge factor of approximately $16 \%$.

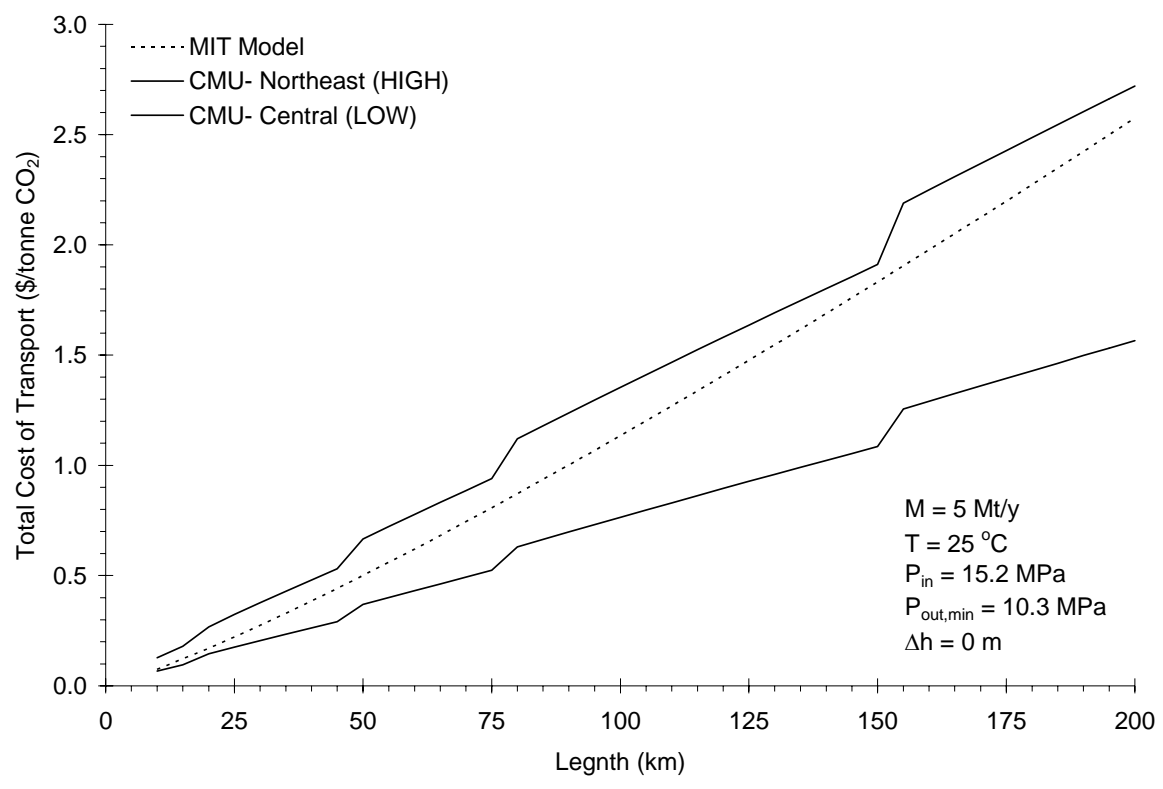

Figure 84. A comparison of results from the CMU pipeline transport model and the MIT pipeline transport model.

This figure shows that the lower costs and the larger pipe diameters predicted by the CMU transport model compared with the MIT cost model cancel out somewhat, depending on the region selected in the CMU model. Nonetheless, there are 
significant differences between the costs predicted by the models, particularly at long lengths for pipelines in the Central, West, and Southwest, where the cost predicted by the CMU model is at least $20 \%$ less than the cost predicted by the MIT model.

The CMU model is also compared in Figure 85 against the results presented in the IPCC Special Report on Carbon dioxide Capture and Storage in Figures 4.2 and 4.5 (Doctor et al. 2005).

The CMU model results shown in Figure 85(top) generally agrees with the results presented in the IPCC Special Report, repeated in Figure 85(bottom). However, costs for projects in the central region are lower than the lower "onshore" bound in Figure 85. This may be because the results represented in the IPCC Special Report figure are not region specific. Moreover, the pipeline inlet pressure, outlet pressure, and temperature could be adjusted to change the required pipe diameter, altering the costs presented in Figure 22(a). 

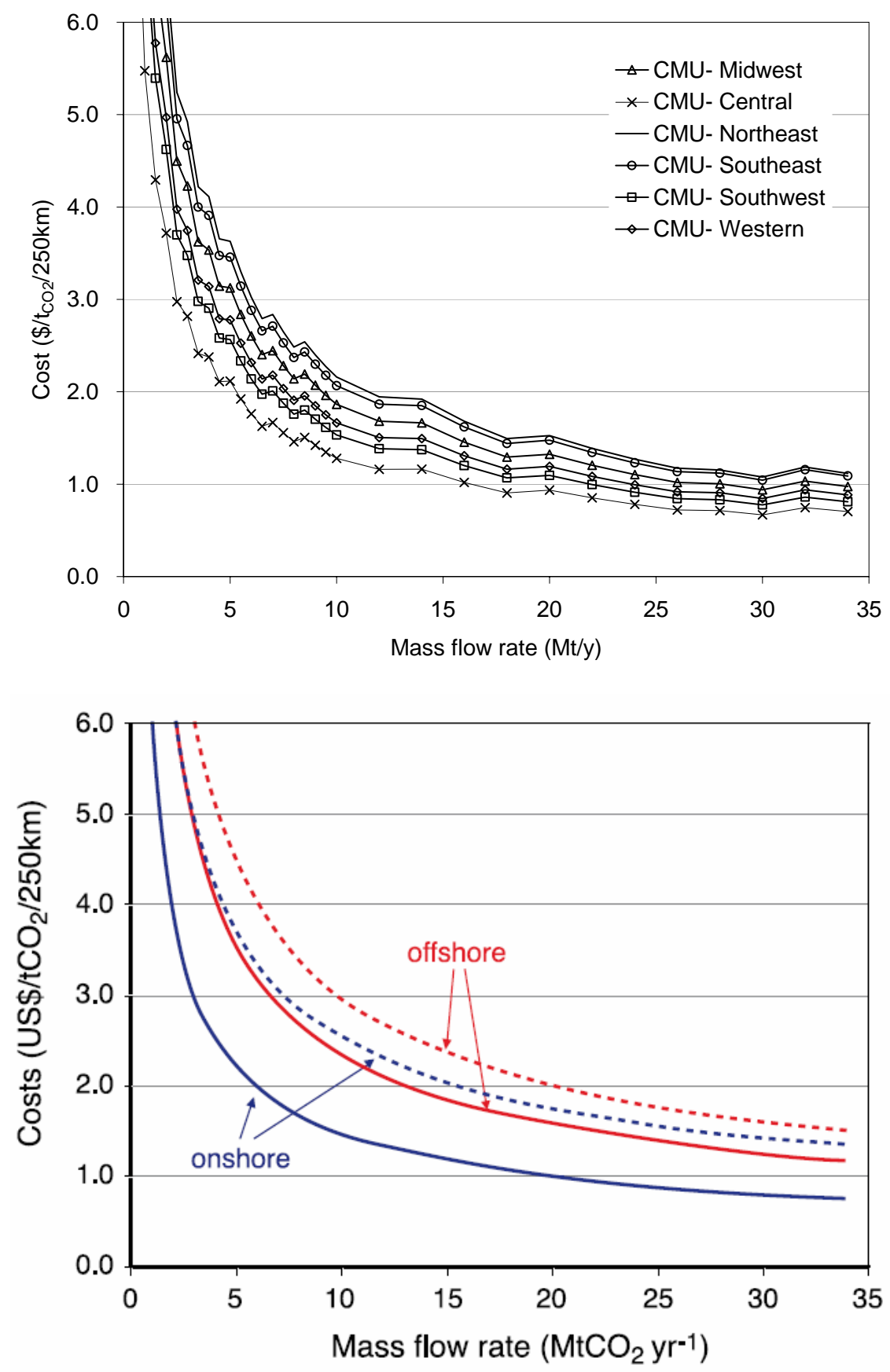

Figure 85. Comparison of results from the CMU model (top) and results presented in Figure 4.2 of the IPCC Special Report (bottom) 


\section{Illustrative Case Parameters}

The parameters for the illustrative case have been selected to be representative of a typical coal-fired power plant in continental North America. Table 39 lists these parameters and the source for the parameter estimates. Several of the parameters were taken from the Integrated Environmental Control Model (IECM) software (CMU, 2004), and in these cases, the default software parameters were used. Additionally, all of the capital cost escalation factors were unity. However, Table 39 excludes the $\mathrm{CO}_{2}$ mass flow rate and pipeline length, as these parameters are addressed separately.

Table 39. The illustrative case parameters for the model.

\begin{tabular}{|l|l|l||}
\hline Pipeline Parameters & Value & Source \\
\hline \hline Load Factor $(\%)$ & $100 \%$ & - \\
\hline Ground Temperature $\left({ }^{\circ} \mathrm{C}\right)$ & 12 & Skovholt $(1993)$ \\
\hline Inlet Pressure $(\mathrm{MPa})$ & 13.79 & IECM (CMU, 2004) \\
\hline Minimum Outlet Pressure (MPa) & 10.3 & TVA (Bock, 2003) \\
\hline Pipe Roughness (mm) & 0.0457 & Boyce (1997) \\
\hline Pumping Parameters & & \\
\hline Number of Booster Stations & 0 & - \\
\hline Pump Efficiency $(\%)$ & $75 \%$ & IECM (CMU, 2004) \\
\hline Economic Parameters & & \\
\hline Annual O\&M $(\$ / \mathrm{km} / \mathrm{y})$ & $\$ 3,100$ & TVA (Bock, 2003) \\
\hline Annual Pump O\&M (\% of Capital) & $1.5 \%$ & EPRI (1993) \\
\hline COE $(\$$ MWh) & $\$ 40.00$ & IECM (CMU, 2004) \\
\hline Capital Recovery Factor $(\%)$ & $15 \%$ & IECM (CMU, 2004) \\
\hline Project Region & Midwest & - \\
\hline \hline
\end{tabular}

Design $\mathrm{CO}_{2}$ mass flow rate is a function of the plant size and the plant technology. For illustration, a pipeline designed to handle 5 million tonnes per year of $\mathrm{CO}_{2}$ (at maximum flow rates) from a power plant, would be appropriate for an approximately $600 \mathrm{MW}$ pulverized coal (PC) or integrated gasification combined cycle (IGCC) plant. The distance between the plant and the storage site is highly site dependent, but will be assumed to be $100 \mathrm{~km}$ for illustrative purposes. Nonetheless, the amount of $\mathrm{CO}_{2}$ handled by the pipeline and the length of the pipeline will be varied parametrically.

\section{Illustrative Results}

For a $\mathrm{CO}_{2}$ pipeline project with the parameters defined in Table 39, running $100 \mathrm{~km}$ and transporting 5 million tonnes per year, the CMU project model predicts a cost of approximately $\$ 1.2$ per tonne $\mathrm{CO}_{2}$ for a 16 inch NPS pipeline. Figure 86 results from varying the pipeline length and $\mathrm{CO}_{2}$ mass flow rate, while continuing to assume that no booster stations are required. 


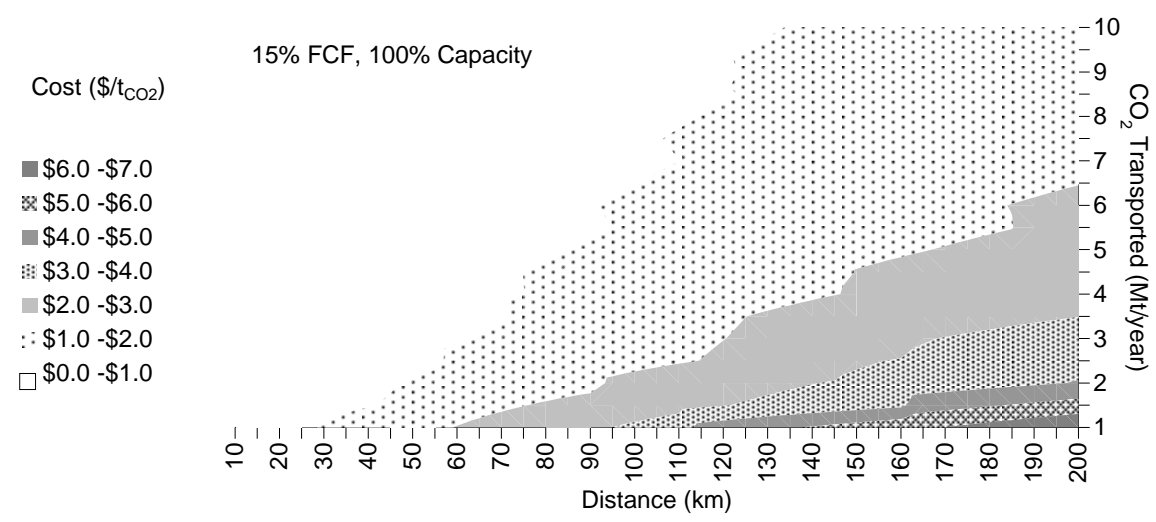

Figure 86. The transport cost surface for a coal fired plant with no booster stations.

From Figure 86 it is clear that economies of scale exist; for a fixed distance, the cost of transport per tonne decreases non-linearly as the net plant size increases. For example, for a $200 \mathrm{~km}$ pipeline, the cost of transporting 1 million tonnes per year via pipeline is nearly $\$ 7$ per tonne, whereas for 5 million tonnes per year the cost is approximately $\$ 2.3$ per tonne, and for 10 million tonnes per year the cost decreases to approximately $\$ 1.5$ per tonne.

\section{Cost Minimization Behavior}

Incorporating pumping stations into the design can result in cost savings and in many cases will be necessary due to the terrain over which the pipeline is laid. Cost savings can occur with the installation of pumping stations, particularly over longer distances, because the required pipeline diameter, and associated capital cost, decreases as booster stations are installed. Of course, the decreased capital cost must offset increased operating costs from pumping stations.

Figure 87 compares the cost of transport with and without the optimum number of cost minimizing booster stations for different annual $\mathrm{CO}_{2}$ flow rates and distances. This figure illustrates that the cost savings that are achieved by adding booster stations decrease with increasing amounts of $\mathrm{CO}_{2}$ handled, and increases with pipeline length. The optimum number of compressors in Figure 87 was arrived at through a "brute force" optimization method. In this method the number of compressors for a given flow rate and distance is increased in integer steps from zero to find the number of compressors that minimizes cost.

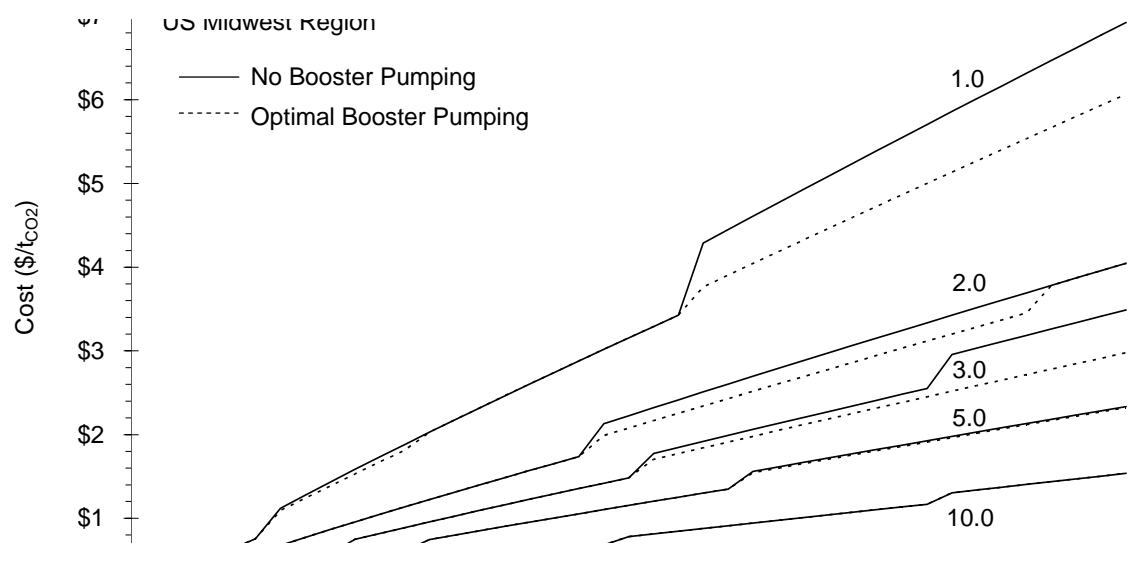


Figure 87. The transport cost as a function of length for amounts of CO2 transported for cases with no booster stations (solid line), and the cost minimizing optimum number of booster stations (dotted line).

\section{Model Sensitivity Analysis Results}

To assess the sensitivity of the model to changes in multiple simultaneous design parameters and financial parameters, parameters of interest have been drawn from uniform distributions over a series of Monte Carlo trials and the cost of pipeline transport calculated. The uniform distribution has been selected to model the range of input distributions because there is no prior information that would suggest choosing a more complex distribution (e.g., triangular, lognormal, etc.). The design parameters of interest are the ground temperature, and inlet pressure, while financial parameters include: load factor, capital recovery factor, and annual pipeline O\&M cost. The input parameters for the sensitivity analysis are shown in Table 40.

Increasing numbers of runs for the Monte Carlo sensitivity analysis will give results with better resolution; however, this also takes increased amounts of time. For this analysis, 1,000 runs have been completed, which takes about 10 minutes. From these runs a cumulative distribution (CDF) for transport cost has been generated, shown in Figure 88. 
Table 40. Parameters for the sensitivity analysis.

\begin{tabular}{|c|c|c|c|c|}
\hline Pipeline Parameters & $\begin{array}{l}\text { Illustrative } \\
\text { Value }\end{array}$ & Minimum & Maximum & $\mu$ \\
\hline Design Mass Flow (Mt/y) & 5 & - & - & - \\
\hline Pipeline Length (km) & 100 & - & - & - \\
\hline Load Factor (\%) & $100 \%$ & $50 \%$ & $100 \%$ & $75 \%$ \\
\hline Ground Temperature $\left({ }^{\circ} \mathrm{C}\right)$ & 12 & 0 & 20 & 10 \\
\hline Inlet Pressure (MPa) & 13.79 & 12 & 15 & 13.5 \\
\hline $\begin{array}{l}\text { Minimum Outlet Pressure } \\
\text { (Mpa) }\end{array}$ & 10.3 & - & - & - \\
\hline Pipe Roughness (mm) & 0.0457 & - & - & - \\
\hline \multicolumn{5}{|l|}{ Pumping Parameters } \\
\hline Number of Booster Stations & 0 & - & - & - \\
\hline Pump Efficiency (\%) & $75 \%$ & - & - & - \\
\hline \multicolumn{5}{|l|}{ Economic Parameters } \\
\hline Annual O\&M (\$/km/y) & $\$ 3,100$ & $\$ 2,000$ & $\$ 4,200$ & $\$ 3,100$ \\
\hline $\begin{array}{l}\text { Annual Pump O\&M (\% of } \\
\text { Capital) }\end{array}$ & $1.50 \%$ & - & - & - \\
\hline $\mathrm{COE}(\$ / \mathrm{MWh})$ & $\$ 40$ & - & - & - \\
\hline Capital Recovery Factor (\%) & $15 \%$ & $10 \%$ & $20 \%$ & $15 \%$ \\
\hline Escalation Materials & 1 & 0.75 & 1.25 & 1 \\
\hline Escalation Labor & 1 & 0.75 & 1.25 & 1 \\
\hline Escalation ROW & 1 & 0.75 & 1.25 & 1 \\
\hline $\begin{array}{l}\text { Escalation Engineering, } \\
\text { Overheads, \& AFUDC }\end{array}$ & 1 & 0.75 & 1.25 & 1 \\
\hline Escalation Pumping & 1 & 0.75 & 1.25 & 1 \\
\hline Project Region & Midwest & - & - & - \\
\hline
\end{tabular}

Figure 88 shows that depending on the selection of input parameters, for a Midwest pipeline project transporting 5 million tonnes of $\mathrm{CO}_{2}$ annually over $100 \mathrm{~km}$, the probability of the cost falling between approximately $\$ 1$ and $\$ 2.6$ per tonne of $\mathrm{CO}_{2}$ transported is $90 \%$. The minimum cost and maximum cost predicted by the model are $\$ 0.7$ and $\$ 3.4$ per tonne of $\mathrm{CO}_{2}$ transported; however, these values are highly sensitive to the number of Monte Carlo runs performed. A less sensitive measure is the median cost of transport, which is $\$ 1.6$ per tonne under these conditions.

Using the cost models for different regions changes the results of the sensitivity analysis, as shown in Figure 88. As expected, a project in the Central US region will have costs less than a project in the Midwest or Northeast for all combinations of input parameters. The median cost of a project in the Central US transporting 5 million tonnes of $\mathrm{CO}_{2}$ annually over $100 \mathrm{~km}$ is $\$ 1.1$ per tonne. In the Northeast, the project cost could approach that of the Midwest for some combinations of input parameters. The median cost of this project in the Northeast is $\$ 1.9$ per tonne. 


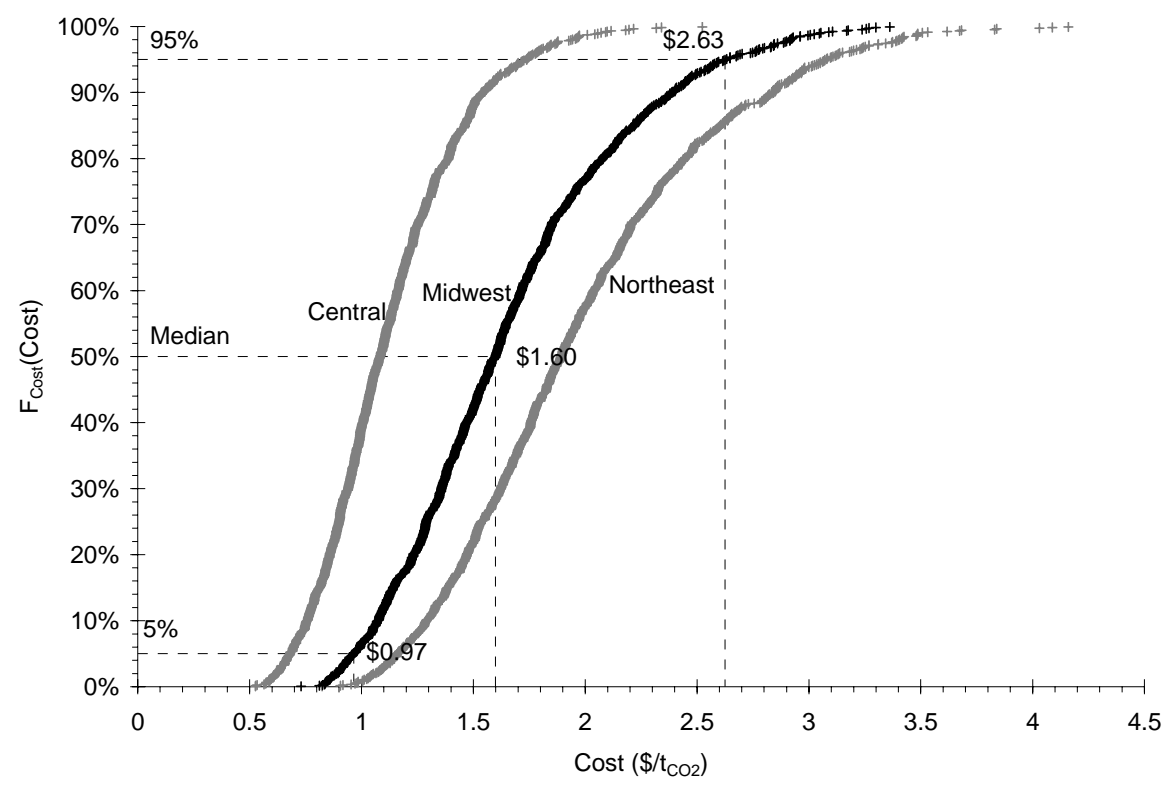

Figure 88. The CDF generated from the Monte Carlo sensitivity analysis on the transport model.

The relative importance of the variable input parameters in contributing to the variability of the transport is not clear from the CDF presented in Figure 88. In order to assess the relative contribution of variability to the cost calculated by the transport model, Spearman rank-order correlation coefficients were calculated. The rank-order correlation (ROC) coefficients are shown in Figure 89.

The dotted horizontal lines above and below the abscissa in Figure 89 indicate the $95 \%$ two-tailed confidence interval for the calculated rank-order correlation coefficients. Thus, variability in the annual pipeline O\&M cost $(R O C=2 \%)$ and ground temperature $(R O C=-1 \%)$ do not appear to affect the distribution of transport costs significantly. Variability in the ROW $(R O C=5 \%)$, engineering, overheads, and AFUDC $(R O C=8 \%)$, and materials escalation factors $(R O C=9 \%)$, has a limited effect on the distribution of the transportation cost. Consequently, the four parameters that drive the variability in the transportation cost are, in decreasing order of importance: load factor, capital recovery factor, labor escalation factor, and inlet pressure. 


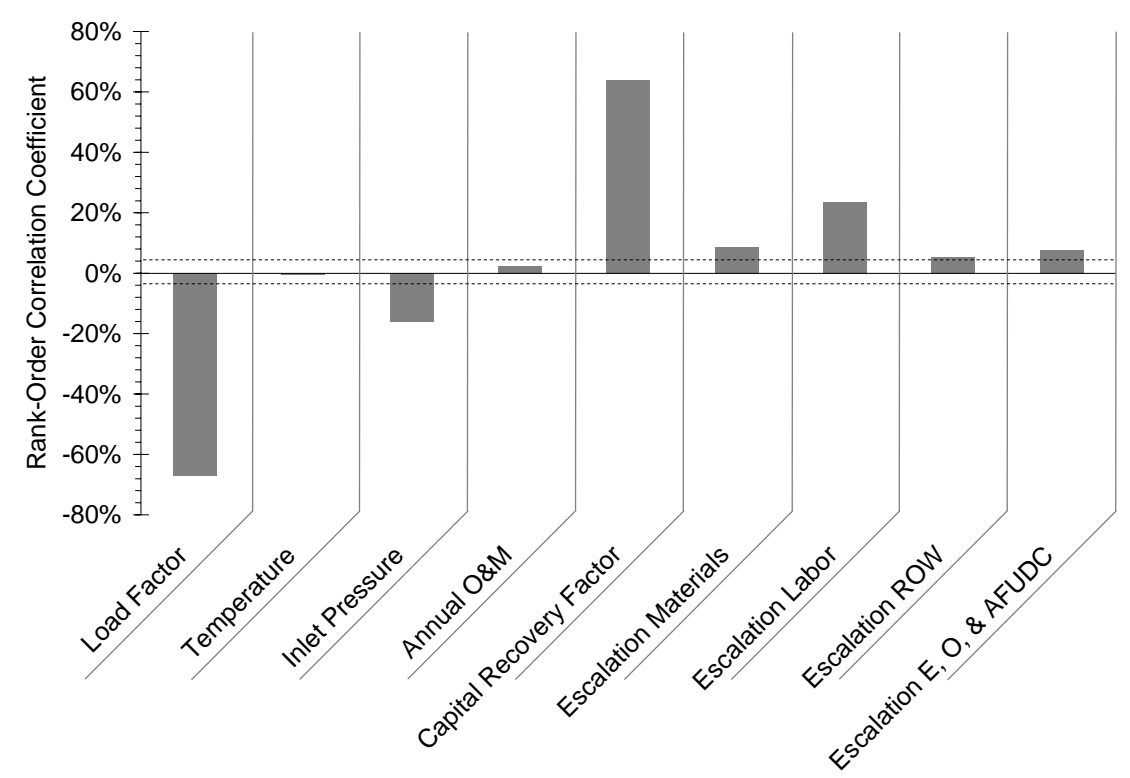

Figure 89. Rank-order correlation between the input parameters and the output parameters, showing the relative importance of variability in the input parameters to the cost of transport

\section{Conclusions}

The objective of this work is to develop an engineering-economic model for the transport of $\mathrm{CO}_{2}$. At pressures greater than $9 \mathrm{MPa}$ and typical ground temperatures, large amounts of $\mathrm{CO}_{2}$ can be transported via pipeline in the liquid state. This report described the development of a performance model that accounts for compressible flow of liquid $\mathrm{CO}_{2}$ based on a physical properties model for $\mathrm{CO}_{2}$ and $\mathrm{CO}_{2}$-containing mixtures. The report also describes the development of model that estimates material, labor, miscellaneous, and right-of-way costs, which is region specific and non linear in pipeline length.

Comparing the performance and cost models developed here against pipeline transport models developed by the IEA, MGSC, and MIT shows that all of the performance and cost models show similar trends. However, there are significant differences in the absolute cost estimated produced by the models. These differences are mainly due to two factors: the CMU cost model is non-linear in length, whereas the other models are linear, and; the CMU model accounts for regional differences, while the others do not. For example, for a pipeline transporting approximately 5 million tonnes per year of $\mathrm{CO}_{2}$ over $100 \mathrm{~km}$, the cost of transport in the Central region is nearly half that of the Northeast region, while the cost predicted in the Southwest region within $10 \%$ of that predicted by the MIT model.

The models developed here have been applied to an illustrative case of a pipeline constructed in the Midwest US, designed to transport 5 million tonnes of $\mathrm{CO}_{2}$ per year over a distance of $100 \mathrm{~km}$. For this base case, the model estimates a pipeline diameter of 16 inches and a cost of approximately $\$ 1.2$ per tonne of $\mathrm{CO}_{2}$ transported. For longer pipelines, however, it is possible to minimize the cost of transport by using booster pumping stations, because the required pipeline diameter decreases as pumping stations are added.

To assess the sensitivity of the model to changes in multiple simultaneous design and financial parameters, Monte Carlo methods have been used. The design parameters 
of interest are: ground temperature, and inlet pressure. Financial parameters of interest are: load factor, capital recovery factor, annual pipeline O\&M cost, and cost model escalation factors. The results shown that, depending on region, the median cost is between $\$ 1.1$ and $\$ 1.9$ per tonne of $\mathrm{CO}_{2}$ transported, and the most important parameters are, in decreasing order of importance: load factor, capital recovery factor, labor escalation factor, and inlet pressure.

The results presented in the report suggest that this model can be used to inform decision makers about the cost of $\mathrm{CO}_{2}$ transport, particularly in the electric power industry. Future work includes incorporating this model into the Integrated Environmental Control Model (IECM) and coupling it with storage models to assess the full cost of carbon capture and storage (CCS).

\section{References}

Rao, A.B., E.S. Rubin, M.B. Berkenpas, 2004. An Integrated Modeling Framework for Carbon Management Technologies. Final report to US Department of Energy (USDOE), Carnegie Mellon University, Pittsburgh, PA, 173 pp.

Skovholt, O., 1993: $\mathrm{CO}_{2}$ Transportation System. Energy Convers. Mgmt. 34, 10951103.

Svensson, R., M. Odenberger, F. Johnsson, L. Stromberg, 2004. Transportation systems for $\mathrm{CO}_{2}$ - application to carbon capture and storage. Energy. Convers. Manage. 45, 2243-2353.

Gale, J., J. Davison, 2004. Transmission of $\mathrm{CO}_{2}$ - safety and economic considerations. Energy. 29, 1319-1328.

Smith L, N. Gupta, B. Sass, T. Bubenik, 2001: Carbon Dioxide Sequestration in Saline Formations- Engineering and Economic Assessment. Final Report to US Department of Energy (USDOE), Battelle Memorial Institute, Columbus, OH, 92 pp.

Bock B, R. Rhudy, H. Herzog, et al, 2003: Economic Evaluation of $\mathrm{CO}_{2}$ Storage and Sink Enhancement Options. Final Report to US Department of Energy (USDOE), TVA Public Power Institute, Muscle Shoals, TN, 500 pp.

Doctor, R., A. Palmer, D. Coleman, et al, 2005: Transport of $\mathrm{CO}_{2}$. In IPCC Special Report on Carbon Dioxide Capture and Storage. B. Metz, O. Davidson, H. C. de Coninck, M. Loos, and L. A. Meyer (eds.), Cambridge University Press, Cambridge, pp. 181-192

Kinder Morgan, Inc, 2002: Kinder Morgan $\mathrm{CO}_{2}$ Company. http://www.kne.com/business/co2/transport.cfm\#co2_pipelines, 23 Dec 2004

Mohitpour, M., H. Golshan, A. Murray, 2003: Pipeline Design \& Construction. ASME Press, New York, NY, 648 pp.

Reid, R.C., J.M. Prausnitz, B.E. Poling, 1987: The Properties of Gases and Liquids. McGraw-Hill Book Company, New York, NY, 741 pp.

Span, R., W. Wagner, 1996: A New Equation of State for Carbon Dioxide Covering the Fluid Region from the Triple-Point Temperature to $1100 \mathrm{~K}$ at Pressures up to 800 MPa. J. Phys. Ref. Data, 25, 1509-1596.

Chung, T.H., M. Ajlan, L.L. Lee, K.E. Starling, 1988: Generalized Multiparameter Correlation for Nonpolar and Polar Fluid Transport Properties. Ind. Eng. Chem. Res., 27, 671-679.

Vesovic, V., W.A. Wakeham, G.A. Olchowy, J.V. Sengers, J.T.R. Watson, J. Millat, 1990: The Transport Properties of Carbon Dioxide. J. Phys. Ref. Data, 19, 763-808. 
Fenghour, A., W.A. Wakeham, V. Vescovic, 1998: The Viscosity of Carbon Dioxide. J Phys. Ref. Data, 27, 31-44.

McCabe, W.L., J.C. Smith, P. Harriott, 1993: Unit Operations of Chemical Engineering. $5^{\text {th }}$ ed. McGraw-Hill, New York, NY, 1130 pp.

Zigrang, D.J., N.D. Sylvester, 1982. Explicit Approximations to the Solution of Colebrook's Friction Factor Equation. AIChE Journal, 28, 514-515.

Boyce, M.P, 1997. Transport and Storage of Fluids. In Perry's Chemical Engineers Handbook. R.H. Perry, D.W. Green, (eds.), McGraw-Hill, New York, NY, Ch. 10, pp. 1-152.

True, W.R., 1995: U.S. Interstate Pipelines Ran More Efficiently in 1994. Oil \& Gas Journal, 93(48), 39-58.

True, W.R., 1996: U.S. Pipelines Continue Gains Into 1996. Oil \& Gas Journal, 94(48), 39-58.

True, W.R., 1997: Construction Plans Jump; Operations Skid in 1996. Oil \& Gas Journal, 95(31), 37-58.

True, W.R., 1998: Weather, Construction Inflation Could Squeeze North American Pipelines. Oil \& Gas Journal, 96(35), 33-55.

True, W.R., 1999: U.S. Pipelines Experience Another Tight Year, Reflect Merger Frenzy. Oil \& Gas Journal, 97(34), 45-69.

True, W.R., 2000: More Construction, Higher Costs. Oil \& Gas Journal, 98(36), 6886.

True, W.R., 2001: Profitable 2000, Higher Demand Push US Natural Gas Construction Plans. Oil \& Gas Journal, 99(36), 66-85.

True, W.R., 2002: Fed Data Solid 2001 For US Pipeline Companies. Oil \& Gas Journal, 100(38), 52-75.

True, W.R., 2003: US Pipeline Companies Solidly Profitable in 2002, Scale Back Construction Plans. Oil \& Gas Journal, 101(34), 60-90.

True, W.R., 2004: US Construction Plans Slide; Pipeline Companies Experience Flat 2003, Continue Mergers. Oil \& Gas Journal, 102(32), 52-67.

Smith, C.E., W.R. True, J. Stell, 2005: US Gas Carriers See 2004 Net Jump; Construction Plans Rebound. Oil \& Gas Journal, 103(34), 50-71

Energy Information Administration, 2005: Changes in U.S. Natural Gas Transportation Infrastructure in 2004:

http://www.eia.doe.gov/pub/oil_gas/natural_gas/feature_articles/2005/ngtrans/ngtran s/pdf.

International Energy Agency (IEA) Greenhouse Gas R\&D Programme, 2002: Pipeline Transmission of $\mathrm{CO}_{2}$ and Energy Transmission Study-Report. Report Number PH4/6, IEA, Cheltenham, UK, 61 pp.

Mohitpour, M., J. Szabo, T.V. Hardeveld, 2005: Pipeline Operation \& MaintenanceA Practical Approach. ASME Press, New York, NY, 600 pp.

Electric Power Research Institute (EPRI), 1993: Technical Assessment Guide Volume 1: Electricity Supply. EPRI, Palo Alto, CA.

Nyman, D.J., J.S. Dracos, R. Varagani, 2004: Carbon Dioxide Capture and Transportation Options in the Illinois Basin-Task 3: Assess Carbon Dioxide Transportation Options in the Illinois Basin. Report to the USDOE, Midwest Geological Sequestration Partnership (MGSC), 82 pp. 
Carnegie Mellon University, 2004: Center for Energy and Environmental Studies, http://www.iecm-online.com/cees_models.htm, 23 May 2004. 


\section{Appendix: Properties of $\mathrm{CO}_{2}$ and Fluids of Interest}

Table 41. Physical properties of $\mathrm{CO}_{2}$ and other fluids relevant to the transport model

\begin{tabular}{||l|l|l|l|l|l|l||}
\hline \hline Fluid & $\mathbf{M}(\mathbf{g} / \mathbf{m o l})$ & $\mathbf{T}_{\mathbf{c}} \mathbf{( K )}$ & $\mathbf{p}_{\mathbf{c}} \mathbf{( M p a )}$ & $\mathbf{V}_{\mathbf{c}} \mathbf{( \mathbf { c m } ^ { 3 } \mathbf { I m o l } )}$ & $\boldsymbol{\omega}$ & $\boldsymbol{\mu}$ (debyes) \\
\hline \hline $\mathrm{O}_{2}$ & 32 & 154.581 & 5.043 & 73.37 & 0.0222 & 0 \\
\hline $\mathrm{N}_{2}$ & 28.01 & 126.192 & 3.4428 & 89.4143 & 0.0372 & 0 \\
\hline $\mathrm{H}_{2} \mathrm{O}$ & 18.02 & 647.096 & 22.064 & 55.948037 & 0.3443 & 1.855 \\
\hline $\mathrm{CO}_{2}$ & 44.0098 & 304.128 & 7.3773 & 94.1 & 0.22394 & 0 \\
\hline $\mathrm{CH}_{4}$ & 16.04 & 190.564 & 4.5992 & 9.629 & 0.01142 & 0 \\
\hline $\mathrm{CO}$ & 28.01 & 132.8 & 3.4935 & 92.17 & 0.051 & 0.1 \\
\hline $\mathrm{SO}_{2}$ & 64.06 & 430.64 & 7.884 & 122.026 & 0.256 & 1.6 \\
\hline $\mathrm{H}_{2} \mathrm{~S}$ & 34.08 & 373.6 & 9.008 & 98.203 & 0.1012 & 0.9 \\
\hline $\mathrm{NH}_{3}$ & 17.03 & 405.5 & 11.333 & 72 & 0.25 & 1.47 \\
\hline \hline
\end{tabular}

Table 42. Binary interaction parameters for the Peng-Robinson equation used in the transport model

\begin{tabular}{||l|l|l|l|l|l|l|l|l|l||}
\hline \hline $\mathbf{k}_{\mathbf{i j}}$ & $\mathbf{O}_{\mathbf{2}}$ & $\mathbf{N}_{\mathbf{2}}$ & $\mathbf{H}_{\mathbf{2}} \mathbf{O}$ & $\mathbf{C O}_{\mathbf{2}}$ & $\mathbf{C H}_{\mathbf{4}}$ & $\mathbf{C O}$ & $\mathbf{S O}_{\mathbf{2}}$ & $\mathbf{H}_{\mathbf{2}} \mathbf{S}$ & $\mathbf{N H}_{\mathbf{4}}$ \\
\hline \hline $\mathrm{O}_{2}$ & 0 & -0.0119 & 0 & 0 & 0 & 0 & 0 & 0 & 0 \\
\hline $\mathrm{N}_{2}$ & -0.0119 & 0 & 0 & -0.017 & 0.0311 & 0.0307 & 0.08 & 0.1767 & 0.2193 \\
\hline $\mathrm{H}_{2} \mathrm{O}$ & 0 & 0 & 0 & 0.12 & 0 & 0 & 0 & 0.04 & -0.2589 \\
\hline $\mathrm{CO}_{2}$ & 0 & -0.0170 & 0.1200 & 0 & 0.0919 & 0 & 0 & 0.0974 & 0 \\
\hline $\mathrm{CH}_{4}$ & 0 & 0.0311 & 0 & 0.0919 & 0 & 0.03 & 0.1356 & 0 & 0 \\
\hline $\mathrm{CO}$ & 0 & 0.0307 & 0 & 0 & 0.0300 & 0 & 0 & 0.0544 & 0 \\
\hline $\mathrm{SO}_{2}$ & 0 & 0.0800 & 0 & 0 & 0.1356 & 0 & 0 & 0 & 0 \\
\hline $\mathrm{H}_{2} \mathrm{~S}$ & 0 & 0.1767 & 0.0400 & 0.0974 & 0 & 0.0544 & 0 & 0 & 0 \\
\hline $\mathrm{NH}_{3}$ & 0 & 0.2193 & -0.2589 & 0 & 0 & 0 & 0 & 0 & 0 \\
\hline
\end{tabular}




\section{Regression Analysis}

Regression analysis is used to help understand the interrelationships among a given set of variables. The use of regression analysis here is oriented toward developing useful and reasonable relationships between process area costs and key performance parameters. The emphasis is not on the use of extensive formal statistical tests but rather on the practical application of regression analysis for cost model development. Thus, some statistical tests, along with engineering judgments and the availability of data, are used to guide the selection of parameters, the representation of relationships in the regression models, and validation of the models. The "goodness" of the regression models are indicated with common summary statistics, graphical comparison of the model predictions with the actual data, and evaluation of the appropriateness of the model relationships with a priori engineering expectations.

This section will briefly discuss issues related to developing and interpreting the regression models. The issues related to developing the regression models include developing a data set for analysis, selecting parameters for inclusion in the model, and validating the model. Specific issues related to the development and use of the models in this study are then discussed.

\section{Overview of Multivariate Linear Least Squares}

The discussion in this section draws on Ang and Tang (1975), Chatterjee and Price (1977), DeGroot (1986), Dillon and Goldstein (1984), Edwards (1976), Montgomery and Peck (1982), and Weisberg (1985). An overview of key concepts is presented; details of multivariate regression can be obtained elsewhere in many texts such as the ones cited here.

$$
C=B\left(\frac{A_{\text {cap }}}{B_{\text {cap }}}\right)^{n}
$$

In general, regression analysis involves describing the mean and variance of a random variable, $\mathrm{Y}$, as a function of the value of another variable, $\mathrm{X}$, or a set of variables $X=\left(X_{1}, X_{2}, X_{3}, \ldots, X_{k}\right)$. The variables in the vector $X$ may take on specific values $\mathrm{x}=\mathrm{x}_{\mathrm{i}}\left(\mathrm{x}_{1}, \mathrm{i}, \mathrm{x}_{2}, \mathrm{i}, \mathrm{x}_{3}, \mathrm{i}, \ldots, \mathrm{x}_{\mathrm{k}}, \mathrm{i}\right)$. For each value $\mathrm{x}_{\mathrm{i}}$ in an actual data set, there is a corresponding value $\mathrm{y}_{\mathrm{i}}$. We use the notation $\mathrm{E}\left(\mathrm{Y} \mid \mathrm{X}=\mathrm{x}_{\mathrm{i}}\right)$ to indicate the mean, or expected value, of $Y$ associated with a specific vector of values $x i$ of the variables $X$. The notation $\operatorname{Var}(\mathrm{Y} \mid \mathrm{X})$ represents the conditional variance of $\mathrm{Y}$ on $\mathrm{X}$. If we expect that the value of $Y$ can be estimated from a weighted linear combination of the $k$ variables in $\mathrm{X}$, and if the conditional variance of $\mathrm{Y}$ is independent of the specific values $x i$ of $X$, then: 


$$
\begin{aligned}
& E(Y \mid X=x)=\alpha+\beta_{1} X_{1}+\beta_{2} X_{2}+\ldots+\beta_{k} X_{k} \\
& \operatorname{Var}(Y \mid X)=\sigma^{2}=\text { constant }
\end{aligned}
$$

The parameters in the linear equation are estimated, based on a limited number, $n$, of observed pairs of $\left(\mathrm{x}_{\mathrm{i}}, \mathrm{y}_{\mathrm{i}}\right)$, using multi-variable linear regression with constant variance. The linear regression model is written as:

$$
E\left(Y^{\prime} \mid X=x_{i}\right)=a+b_{1} X_{1}+b_{2} X_{2}+\ldots+b_{k} X_{k}
$$

or as:

$$
Y^{\prime}=a+b_{1} X_{1}+b_{2} X_{2}+\ldots+b_{k} X_{k}+\varepsilon
$$

The linear fit is usually obtained by selecting the values of $a$ and $b_{i}$ to minimize the sum of the square of the errors between $E\left(Y^{\prime} \mid X=x_{i}\right)$ from Equation $(A-4)$ and the values of $Y$ from actual data, $y_{i}$. Equation (A-5) differs from Equation (A-4) in that the model is used to predict the conditional random values of $Y^{\prime}$, rather than the conditional expected value of $\mathrm{Y}^{\prime}$. Equation (A-5) includes an error term, $\varepsilon$, which represents the variance in $Y$ that is unexplained by the model. Thus, for a specific data point $\mathrm{x}_{\mathrm{i}}$, there is a corresponding data value $\mathrm{y}_{\mathrm{i}}$, a conditional mean value $\mathrm{E}\left(\mathrm{Y}^{\prime} \mid \mathrm{X}=\mathrm{x}_{\mathrm{i}}\right)$, and a conditional random distribution for $\mathrm{Y}^{\prime}$. Using the method of least squares, as documented in any standard text, we obtain estimates for the coefficients of the regression model. It is important to recall that the coefficients of the model, a and $b_{i}$, known as the partial regression coefficients, and the values of $E\left(Y^{\prime} \mid X=x_{i}\right)$ or the parameters of the conditional distribution for $Y^{\prime}$ calculated using the model, are only estimates of the respective "true" population values of the parameters $\alpha$ and $\beta_{\mathrm{i}}$ and the "true" population of the values of $Y$ associated with each value $\mathrm{x}_{\mathrm{i}}$.

Common statistical measures of the adequacy of the regression model in describing the data set (X, Y) include the standard error of the estimate, the coefficient of determination, the t-test for significance of each partial regression coefficient, and the F-test for the significance of the regression model and coefficient of determination. Confidence intervals, in addition to significance tests, can also be used. Proper application of these statistics requires the existence of certain properties in the data set $(\mathrm{X}, \mathrm{Y})$ and in the regression model. Several of these key assumptions are:

- random sample of n paired values (X, Y) (e.g., values of $\mathrm{X}$ are not pre-selected

- $\quad$ or screened)

- $\mathrm{X}$ and $\mathrm{Y}$ are multivariate normal

- for each value of $\mathrm{x}$, there is an associated normal population of $\mathrm{Y}$

- for each value of $\mathrm{x}$, the variance of $\mathrm{Y}$ is constant

- no error in the measurement of $\mathrm{X}$

- residual errors are not auto correlated

- residual errors are normally distributed

- residual errors have constant variance

While these assumptions are often only approximately satisfied when developing regression models, the use of statistical evaluation methods based on these assumptions may provide some insight to guide the development of the model, even if a strict interpretation of the results is not correct. Therefore, blind application of significance tests to accept or reject parameters may not be appropriate. The most 
important consideration in selecting variables for use in a model, and for selecting the functional form of the model, is the analyst's knowledge of the substantive area under study and of each of the variables. The analyst will generally have expectations regarding the sign and magnitude of the coefficient for each variable, as well as which variables should be most significant in predicting the dependent variable.

The use of statistical tests is thus viewed here as an aid to, but not as a substitute for, the judgment of the analyst regarding the relationships among the variables. For example, it is common to test the significance of a model parameter by determining whether it is possible to reject a hypothesis that its coefficient is equal to zero. However, in many practical regression situations, it is known, based on theory or experience, that the coefficient must be greater than zero and, therefore, such a significance test is not particularly relevant. The potential inability to reject the hypothesis that a coefficient is zero in a regression model may be more an artifact of a small number of data points than due to a lack of relationship between $\mathrm{Y}$ and the predictive variable of concern.

Statistical tests are useful in identifying the independent variables which are relatively more important in predicting $\mathrm{Y}$ than others for the available data. For example, one can examine a correlation matrix of $\mathrm{X}$ and $\mathrm{Y}$ to determine which variables $\mathrm{X}_{\mathrm{i}}$ are most highly correlated with $\mathrm{Y}$. These variables are logical candidates for inclusion in the regression model. However, if a potential predictive variable $X_{\mathrm{i}}$ is also highly correlated with another variable $X_{\mathrm{i}}$, then the inclusion of both may not significantly improve the model and may lead to counter-intuitive results in terms of the sign or magnitude of the coefficient for one of the variables. In such cases, one of the variables would be excluded from the model. Statistical tests can be used to identify independent variables that have only a weak predictive power. These variables would also typically be excluded from the model. A few of the statistical measures used to evaluate regression models will be discussed here, with an indication of how they are used in this study.

The issues of statistical tests and model validation are closely linked. Statistical tests are used to determine the adequacy of the model in representing a known data set. To the extent that the model is used only to interpolate information from within the data set, checking the adequacy of the model is the same as model validation. A regression model can be used for prediction beyond the range of the original data set only if there is some basis in prior experience, industry practice, or physical theory for the relationships between variables. If the form of the regression model is not based on theoretical or expert judgment about the relationship between the dependent and independent variables, the model should not be used for extrapolation. The user is cautioned that the primary purpose of the models developed in this study is for interpolation within the range of data values used to develop the models.

Furthermore, the user is cautioned that the models are intended for application with very specific systems. Throughout the report, the limitations on the ranges of predictive variables and discussion of the design basis for process areas will be presented.

In using multiple regression models, it is easy to inadvertently extrapolate beyond the original domain for $\mathrm{X}$, because that domain is jointly defined by the pairing of the values of each independent variable used to generate the model. Therefore, range checks on each independent variable separately will not guarantee the avoidance of "hidden" extrapolation. However, because the regression models are developed with some engineering basis for the relationship between variables, hidden extrapolation may be acceptable and individual range checks on the independent variables will be used as a practical convenience. 


\section{Standard Error}

The standard error of the estimate is the standard deviation of the residual errors $\varepsilon$ for $\mathrm{Y}^{\prime}$. The standard error is a measure of the variability in $\mathrm{Y}$ that is not captured by the model. If the functional form of the regression model is "correct", this variability can be attributed to factors that are not quantified in the database and therefore cannot be investigated quantitatively. If the functional form of the regression model is not appropriate, then some portion of the standard error may be associated with an incorrect choice of the model, rather than unexplainable variability in the data set. Therefore, it is often useful to compare alternative functional forms of the model in terms of the standard error.

The standard error is estimated based on the residual sum of squares and the degrees of freedom of the residuals. The residual sum of squares is the sum of the squares of the difference between the values of $E\left(Y^{\prime} \mid X=x_{i}\right)$ estimated by the model in Equation $(\mathrm{A}-4)$ and the values $y_{i}$ from the data. The degrees of freedom of the regression model are the number of variables, $\mathrm{k}$. The degrees of freedom of the residuals are the number of data points less the number of partial regression coefficients, including the intercept term. Thus, the standard error is given by:

$$
s=\sqrt{\frac{\sum_{i=1}^{n}\left[E\left(Y^{\prime} \mid X=x_{i}\right)-y_{i}\right]^{2}}{n-k-1}}
$$

This is an unbiased estimate of the standard deviation of the error. The error is assumed to be normally distributed with a mean of zero. In practice, this assumption may be difficult to verify, particularly for a small number of observed data points. Typical methods for evaluating the normality of the error include plotting the residuals against the fitted values $\mathrm{E}\left(\mathrm{Y}^{\prime} \mid \mathrm{X}=\mathrm{x}_{\mathrm{i}}\right)$, or plotting the errors on normal probability paper. A normality test may also be based on a one-sample KolmogorovSmirnov test (e.g., see DeGroot, 1986). In this test, the estimated cumulative probability distribution (cdf) for the errors is compared to a cdf based on the standard normal distribution. The maximum difference between the values of the sample and normal cdf's, adjusted for sample size, is the basis for estimating the test statistic. If the test statistic is larger than a specified value, based on the acceptable significance level for the test, then the hypothesis that the errors are normally distributed is rejected.

The estimate of the standard error is dependent on the actual data as well as the number of data points. As the quantity (n-k-1) becomes small, the estimate of the standard error will tend to increase. The standard error can be used to place a confidence interval on the values of $Y^{\prime}$ using Equation (A-4) or to generate conditional random values of $\mathrm{Y}^{\prime}$ using Equation (A-5) and a probabilistic modeling capability. In the envisioned application of the regression models developed in this work, the standard error will be used as a basis for generating conditional random values of $Y^{\prime}$.

\section{Coefficient of Determination}

The most commonly used measure of the adequacy with which a regression model fits the data is the coefficient of determination, $\mathrm{R}^{2}$, which is defined as:

$$
R^{2}=1-\frac{\sum_{i=1}^{n}\left(y_{i}-E\left(Y^{\prime} \mid X=x_{i}\right)\right)^{2}}{\sum_{i=1}^{n}\left(y_{i}-E\left(Y^{\prime}\right)\right)^{2}}
$$


The numerator of the fractional term is the sum of the square of the residual errors between the actual data and the predicted conditional expected values of $Y^{\prime}$ from Equation (4). The denominator is the sum of the square of the differences between the actual data and the sample mean. The value of the coefficient of determination is interpreted as the proportion of the total variance in $\mathrm{Y}$ which is explained by the regression model, and it varies from 0 to 1 , with values near 1 typically considered to represent "good" fits. The coefficient of determination is the square of the multiple correlation coefficient, $\mathrm{R}$, between $\mathrm{Y}$ and the regression model. The multiple correlation coefficient is a measure of the degree of linear relationship between the dependent variable $\mathrm{Y}^{\prime}$ and the linear combination of predictive variables.

The coefficient of determination is not a sufficient measure of the goodness of the model. At a minimum, evaluation of a regression model should include consideration of how reasonably the functional form and values of the coefficients represent the expected relationships between variables, the significance level of the coefficients and the regression model as a whole, and a graphical comparison of the model results with the actual data. The coefficient of determination may be highly influenced by extreme data points. If those data points are removed, the correlation coefficient may be drastically altered. The addition of a new data point may lead to a large change in the value of the coefficient of determination. Also, if the range of the predictive variables is reduced or increased, the correlation coefficient may change considerably.

\section{Statistical Significance of the Model}

It may be appropriate to consider a significance test for the correlation coefficient. A significance test based on the t-statistic can be used for this purpose to test the hypothesis that the correlation is not significantly different from zero. The hypothesis that a parameter is equal to zero is known as the null hypothesis. The likelihood that a parameter is significantly different from the null hypothesis is determined using a test statistic, such as the t-test. The value of the test statistic computed from the data is then compared to the value of the statistic estimated for the significance level of the test. It is common to use significance levels of 0.05 or 0.01 as the basis for comparison. If the probability of a obtaining a value of the test statistic is less than the significance level (e.g., 5 percent or 1 percent), then the null hypothesis is rejected as being sufficiently improbable that it is regarded as false.

The null hypothesis for the correlation coefficient is a hypothesis that the correlation is zero. A correlation of zero implies that the regression model is not useful, and that the best predictor for the value of $Y$ is the mean of $Y$. Instead of doing a significance test, it is also possible to use a transformation of the correlation coefficient for use in developing a confidence interval for the correlation (Edwards, 1976). However, statistical tests on the correlation coefficient are related to statistical tests on the coefficient of determination. Furthermore, a test of the null hypothesis for the coefficient of determination is implicitly a test of the null hypothesis that the regression coefficients for the predictive parameters are all zero (Edwards, 1976; Dillon and Goldstein, 1984). This hypothesis is commonly tested using the F test statistic. Thus, an $\mathrm{F}$ test implicitly is a test of the null hypothesis for the coefficient of determination as well as for the partial regression coefficients for the predictive parameters.

The $\mathrm{F}$ test involves first computing the F-ratio of the regression model, which is related to the coefficient of determination as follows: 


$$
F=\frac{\left(\frac{R^{2}}{k}\right)}{\left(\frac{1-R^{2}}{n-k-1}\right)}
$$

As the coefficient of determination becomes large, the value of the F-ratio increases. The value of the F-ratio is then compared to the value of the F-distribution (published in many texts) for a selected significance level based on the degrees of freedom of the numerator $(\mathrm{k})$ and denominator $(\mathrm{n}-\mathrm{k}-1)$ of the F-ratio. Therefore, the F-test is influenced by both the number of data points and the number of predictive parameters included in the model. If the F-ratio is larger than the selected value of the F-distribution, then it is possible to reject the hypothesis that all the regression coefficients are equal to zero. However, rejection of this hypothesis does not imply that all of the regression coefficients are significantly different from zero; it only implies that at least one coefficient is significantly different from zero. Furthermore, even if the regression model is statistically significant, it may not necessarily be the best model of the data or even a theoretically valid model of the data. In this study, the F-ratio is compared to a significance level of 0.001 as the basis for rejecting the null hypothesis. In cases where the significance level is higher than 0.001 , the significance level of the F-ratio is reported.

To test the significance of individual regression coefficients, a commonly used technique is a t-test. For each regression coefficient, most computer regression packages will report the results of a t-test of the hypothesis that the individual regression coefficients are significantly different from zero. If a regression coefficient is not significantly different from zero, it can be deleted from the model with usually little effect on the residual error. In addition, the standard error for each coefficient is generally reported, which permits the evaluation of confidence intervals for the coefficients, using the t-distribution.

\section{Application of Regression Analysis to Model Development}

In general, the models developed here have high coefficients of determination and meet the F-test of significance at a significance level below 0.001 . These results are not unexpected, because the development of the models is based on prior engineering knowledge of the primary relationships between performance, design, and cost. In this section, issues specifically related to the development of the regression models in this report are discussed. These issues relate to the number of observations available in each model data set, the use of transformation of variables to develop nonlinear models using linear regression, the selection of predictive parameters, the collection of data, and the reporting of results.

\section{Number of Observations}

The number of data points used to develop the regression model has an important effect on variable selection and interpretation of model results. As the number of data points becomes small, the number of independent variables that can be used may become constrained. It is often possible to obtain a model with a high coefficient of determination by selecting a large number of independent parameters; however, such a model may contain counter-intuitive relationships, or relationships that violate principles of engineering. This often occurs when the range of a 
predictive variable is small, when other important predictive variables have not been included in the model, or when there is correlation or co-linearity between predictive variables. It is often appropriate to include only a small set of independent parameters that are expected to be fundamentally important and robust as more data are gathered, rather to include all possible variables for which data are currently available. To select the most important parameters, one may begin by including all possible predictive variables in the model. Those variables with regression coefficients that fail the t-test for significance are then deleted to yield a new model with fewer predictive variables. The deletion or inclusion of a variable may be tempered by judgment regarding relationships that must be included in the model, assuming that the coefficients of the particular variable are of the correct sign and magnitude.

For small numbers of data, the estimates for the standard error, and the significance levels for the F-ratio, will tend to increase, because the degrees of freedom are reduced. Therefore, confidence intervals on the regression coefficients and the estimate for $\mathrm{Y}$ will usually be larger than when more data are available. As more data become available, the regression models can be redeveloped. While the specific values of the regression coefficients would likely change, they would be expected to remain within the confidence intervals, unless the new data are from a different sample population than the original data. In this case, the original regression model is not an appropriate representation of the new data. It is important, therefore, to ascertain if the basis for the new data is the same as for the older data (e.g., same design for process area equipment, same battery limits for the process area). In some cases, it may not be appropriate to add the new data without also including other predictive variables to capture the differences in the basis for the new and old data.

\section{Transformation of Variables}

While linear regression analysis has been used for the regression models developed in this report, in many cases variable transformations have been used because the relationship between the dependent and predictive variables is non-linear. For example, the simplest cost model involves exponential scaling of a performance parameter to estimate cost, as presented in Equation (A-1). This functional form is standard in the chemical process industry, and cost capacity exponents for standard process plants are published in various sources (e.g., Peters and Timmerhaus, 1980; Ulrich, 1984; Humphreys and Wellman; 1987). The exponential scaling rule can be converted to linear form using the natural logarithm to transform the variables. A typical assumption for the functional form of the cost models is:

$$
Y=a X_{1}^{b_{i}} X_{2}^{b_{2}} \ldots X_{k}^{b_{k}}
$$

This model represents the expected exponential scaling relationship between key process flow rates or design parameters and cost. In most cases, the exponent is expected to be less than one, representing the "economy of scale" of building larger units compared to smaller units. Typically, the exponent of one of the parameters will be much larger than for the other parameters. This result is expected, for example, when the flow rate of one material stream is expected to have a major influence in cost, while other parameters, such as temperature, may have only a secondary effect. The model in Equation (A-9) can be transformed to linear form using the natural logarithm:

$$
\ln (Y)=\ln (a)+b_{2} \ln \left(X_{1}\right)+b_{2} \ln \left(X_{2}\right)+\ldots+b_{k} \ln \left(X_{k}\right)
$$

A linear regression is then developed based on the transformed variables. The transformation of variables affects the interpretation of distribution of the errors. If the errors for Equation (A-10) are normally distributed, which is the underlying 
assumption for the statistical tests discussed in the previous section, then the errors for Equation (A-9) will be lognormally distributed. The statistical tests are applied to the transformed model of Equation (A-10). These cases are noted in the text.

Recall that the probability density function (pdf) for the normal distribution is given by:

$$
f(x)=\frac{1}{\sigma \sqrt{2 \pi}} \exp \left(-\frac{[x-\mu]^{2}}{2 \sigma^{2}}\right) ;-\infty \leq x \leq \infty
$$

where $\mu$ is the mean and $\sigma$ is the standard deviation. If $y$ is lognormally distributed, then $\ln (\mathrm{y})$ is normally distributed. The pdf for the lognormal distribution is given by:

$$
f(y)=\frac{1}{\phi_{y} \sqrt{2 \pi}} \exp \left(-\frac{[\ln (y)-\xi]^{2}}{2 \phi^{2}}\right) ; 0 \leq y \leq \infty
$$

The parameters of the lognormal distribution are $\xi$ and $\phi$. These parameters correspond directly to the mean and standard deviation of the normal distribution for $\ln (y)$. The mean and variance of the lognormal distribution are given by:

$$
\begin{aligned}
\mu_{y} & =\exp \left(\xi+\frac{\phi^{2}}{2}\right) \\
\sigma_{y}^{2} & =\omega(\omega-1) \exp (2 \xi)
\end{aligned}
$$

where,

$$
\omega=\exp \left(\phi^{2}\right)
$$

Using these relationships, the parameters of the lognormal distribution of errors for the nonlinear regression models can be estimated from the parameters of the normal distribution for the errors of the linearized model. Therefore, the statistical model based on the functional form in Equation (A-9) is given by:

$$
Y^{\prime}=a X_{1}^{b_{i}} X_{2}^{b_{2}} \ldots X_{k}^{b_{k}} \varepsilon
$$

where the error term is multiplicative and lognormal, not additive and normal as with the linear model in Equation (A-5). The mean of $\ln (\varepsilon)$ is zero and the standard deviation is the standard error of the estimate for the linearized model. These parameters for $\ln (\varepsilon)$ are used to estimate the mean and standard deviation for the lognormal distribution of $\varepsilon$ using the relationships shown in Equations (A-12), (A$13)$, and (A-14). The median of the lognormal error term in Equation (A-15) will always be 1 . The mean of the error term will typically be a value close to, but larger than, 1 and the standard deviation will typically be less than 1 . The parameters that are reported for lognormal error terms in this report are the mean and standard deviation given by Equations (A-13) and (A-14).

\section{Two-Step Regressions}

In many cases, the relationship between cost and performance parameters is expected to be nonlinear, as described by Equation (A-15). However, the cost is also directly proportional to the number of trains of equipment for a given process area. To capture both the nonlinear relationships between performance and cost and the linear relationship between the number of trains and cost, a two-step approach to developing the regression models may be required. The primary reason for the twostep approach is because it is not possible to specify that the exponent of the number of trains must be equal to one when developing the nonlinear model. In the first 
step, a linearized regression of cost and performance parameters as just described is developed on the basis of a single train of equipment. In the second step, the predicted values from the nonlinear model for a single train are combined with information about the number of trains to predict the total cost of the process area. Thus, the final regression model from this process contains predictive variables for both performance and the number of total and operating trains.

The first step in the process involves estimating the coefficient and exponents of a model of the form of Equation (A-9) on the basis of a single train of equipment. The values of $Y$ estimated in this fashion are then multiplied by the corresponding total number of trains to form a new predictive variable. This predictive variable is then used in a simple linear regression model. The first regression yields a model of the form:

$$
Y^{1}=a\left(\frac{X_{1}}{N_{0}}\right)^{b_{1}}\left(\frac{X_{2}}{N_{0}}\right)^{b_{2}} \cdots\left(\frac{X_{k}}{N_{0}}\right)^{b_{k}}
$$

Note that this is a general functional form; in some cases, the predictive performance parameters (such as temperature or pressure) do not depend on the number of trains, and therefore would not be divided by the number of operating trains. The estimated values of cost from Equation (A-16) represent the cost per operating train. However, we are ultimately interested in the total cost for the process area. Therefore, we calculate a new predictive variable which is the estimated cost for all operating and spare trains:

$$
X^{(2)}=N_{T} Y^{1}
$$

We then use this new variable as the basis for a simple linear regression of the form:

$$
Y^{\prime}=a^{(2)}+b^{(2)} X^{(2)}+\varepsilon
$$

Typically, the value of $b(2)$ from this model is close to 1.0. The value of a(2) may occasionally be small enough (or statistically insignificant) to exclude from the model by estimating the regression without a constant. Note that the error term here is in the linear space. If the errors conform to a hypothesis of normality, then the error can be represented as normally distributed with a mean of zero. Based on Equations (A-16), (A-17), and (A-18), we can write the final regression model as:

$$
Y^{\prime}=a^{(2)}+b^{(2)}\left[N_{T} a\left(\frac{X_{1}}{N_{0}}\right)^{b_{1}}\left(\frac{X_{2}}{N_{0}}\right)^{b_{2}} \ldots\left(\frac{X_{k}}{N_{0}}\right)^{b_{k}}\right]+\varepsilon
$$

where the term within the square brackets is treated as a single variable in the simple linear regression. Thus, the first regression is essential a method for grouping a number of performance parameters into a single aggregate predictive term, while the second regression permits the addition of the linear relationship between cost and the number of trains of equipment. This approach permits the calculation of model statistics based on total, rather than per train, process area costs, which are the ultimate measures of interest.

\section{Selection of Predictive Variables}

Direct capital cost regression models for each IGCC plant section, and in some cases estimates of annual operating requirements, have been developed based on an analysis of approximately 30 detailed performance and cost studies of IGCC and coal-to-SNG (synthetic natural gas) systems. These models have been developed based on analysis of plant section direct costs and key plant section performance 
parameters. In each regression model, the parameters selected for inclusion in the model and the analytic relationships between model inputs and outputs were based on engineering judgments, statistical analysis, and data availability. These regression models relate the total direct cost (which includes delivered equipment cost, installation labor, and installation materials) to the statistically most significant performance parameters influencing cost. These parameters are typically mass flow rates, although in some cases parameters such as removal efficiency, pressure, or temperature were found to be statistically significant. In cases where parameters that are expected to be important were not found to be statistically significant, the variation in these parameters often is small for the available data samples (e.g., most gasifier designs are at a specific pressure and temperature), or the variation in these parameters is highly correlated with variations in the statistically most significant parameter (e.g., the syngas output from the gasification section is highly correlated with the coal feed rate). Similarly, some parameters that are expected to be important in influencing cost may yield counter-intuitive results in the regression models (e.g., cost inversely proportional to mass flow rate). This, too, occurs when two parameters are highly correlated.

\section{Collecting Data}

Performance and cost data were collected into separate data bases for each plant section, based on similarity of plant section definitions. Only direct equipment costs were collected. Direct costs include equipment, material, and labor costs associated with installing plant equipment. Because indirect costs are treated differently in different studies (e.g., EPRI vs. GRI), these were not included in the cost data bases. All direct costs were adjusted to a common year using the Chemical Engineering plant cost index (January $1989=351.5$ ). Because the studies varied in the amount of detail for each plant section, only a few performance parameters may be reported in common among studies for a given plant section. This limits the number of parameters that are candidates for regression analysis.

\section{Reporting Results}

For each plant section, the direct capital cost model is reported along with the error of the regression, the coefficient of determination, the number of data points used in developing the regression, and the range of values over which the regression was developed. The error term is typically expressed as a normal distribution with a mean of zero and a standard deviation estimated from the difference between the direct costs available in the literature and the direct costs estimated from the regression model. In cases where a non-linear variable transformation was used, the error is reported as a lognormal distribution. The error term provides a measure of the variance of the direct cost estimate. In principle, the variance would be zero if the model accounted for all the parameters that influence costs and if the model were of an appropriate functional form. However, because the models are simplified and include only one or a few parameters, not all of the variation in cost is captured. The variance represents differences in plant location, design, or performance parameters that are not included in the cost model.

\section{References}

Chatterjee, S., and B. Price (1977). Regression Analysis by Example. John Wiley and Sons, New York. 1977. 
DeGroot, M.H. (1986). Probability and Statistics, Second Edition. AddisonWesley, Reading, MA. 1986.

Dillon, W.R., and M. Goldstein (1984). Multivariate Analysis: Methods and Applications. John Wiley and Sons, New York. 1984.

Edwards, A.L. (1976). An Introduction to Linear Regression and Correlation. W.H. Freeman and Company, San Francisco, CA. 1976.

Montgomery, D.C., and E.A. Peck (1982). Introduction to Linear Regression Analysis. John Wiley and Sons, New York. 1982.

Peters, M.A., and K.D. Timmerhaus (1980). Plant Design and Economics for Chemical Engineers. Third Edition. McGraw-Hill, New York. 1980.

Ulrich, G.D. (1984). A Guide to Chemical Engineering Process Design and Economics. John Wiley and Sons, New York. 1984.

Weisberg, S. (1985). Applied Linear Regression. John Wiley and Sons, New York. 1985 . 



\section{DEVELOPMENT AND APPLICATION OF OPTIMAL DESIGN CAPABILITY FOR COAL GASIFICATION SYSTEMS}

User Documentation:

Integrated Environmental Control Model (IECM) with

Carbon Capture and Storage (CCS)

Final Report of

Work Performed Under Contract No.: DE-AC21-92MC29094

Reporting Period Start, October 2003

Reporting Period End, May 2007

Report Submitted, May 2007

to

U.S. Department of Energy

National Energy Technology Laboratory

626 Cochrans Mill Road, P.O. Box 10940

Pittsburgh, Pennsylvania 15236-0940

by

Edward S. Rubin (P.I.)

Michael B. Berkenpas

Constance J. Zaremsky

Carnegie Mellon University

Center for Energy and Environmental Studies

Department of Engineering and Public Policy

Pittsburgh, PA 15213-3890 



\section{Contents}

Disclaimer

$\begin{array}{ll}\text { Acknowledgements } & 2\end{array}$

Introduction 3

The Integrated Environmental Control Model .................................................................. 3

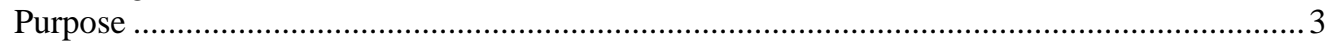

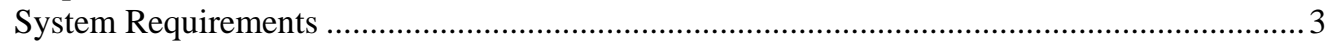

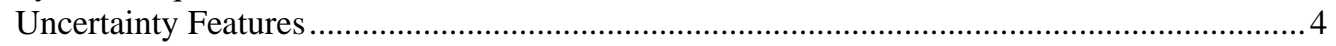

Software Used in Development ................................................................................ 4

Disclaimer of Warranties and Limitation of Liabilities .................................................. 5

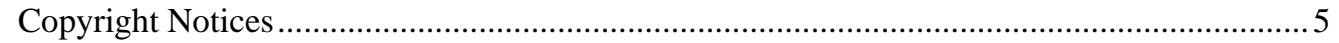

User Documentation and Help 9

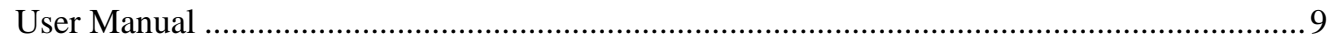

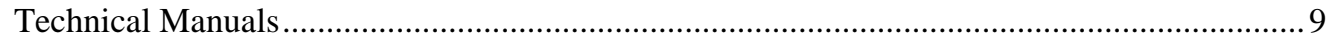

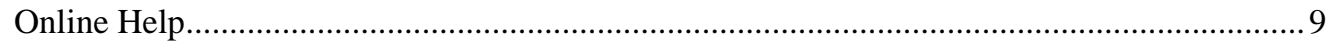

Accessing the IECM Help file:...................................................................... 9

$\begin{array}{ll}\text { Configure Plant } & 11\end{array}$

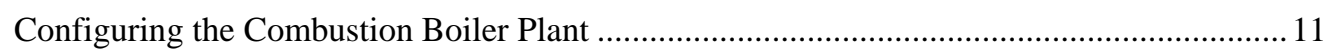

Combustion Controls............................................................................................ 11

Post-Combustion Controls............................................................................. 12

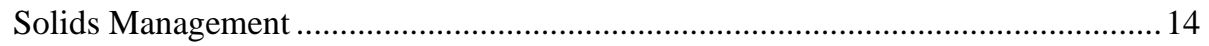

Configuring the Combustion Turbine Plant................................................................. 14

Post-Combustion Controls..................................................................................... 14

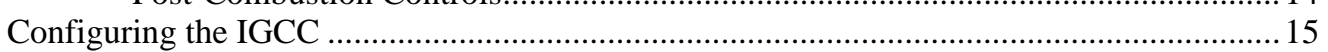

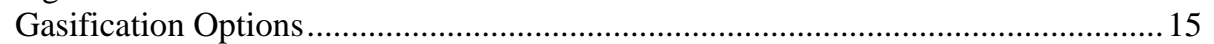

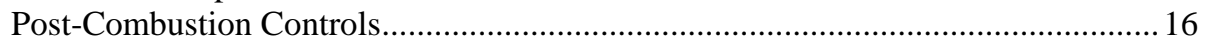

Solids Management .......................................................................................... 16

$\begin{array}{lr}\text { Combustion Overall Plant } & 19\end{array}$

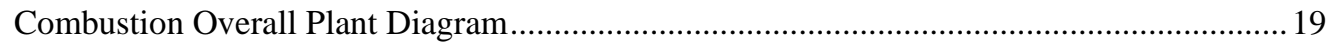

Combustion Overall Plant Performance Inputs ............................................................ 20

Combustion Overall Plant Constraints Inputs.................................................................... 21

Combustion Overall Plant Financing Inputs ................................................................. 22

Combustion Overall Plant O\&M Inputs ........................................................................... 24

Combustion Overall Plant Emis. Taxes Inputs ............................................................ 25

Combustion Overall Plant Performance Results................................................................. 26

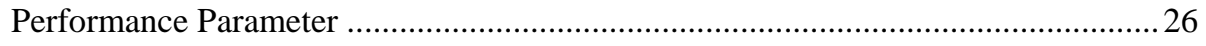

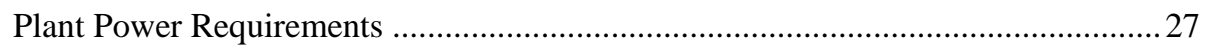




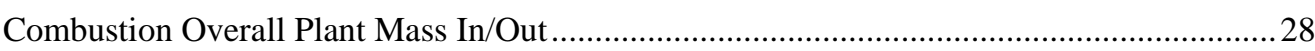

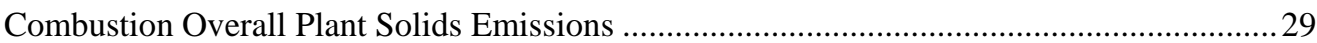

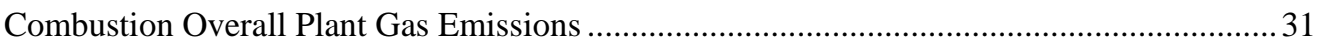

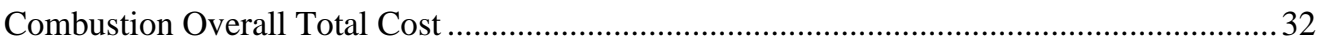

Combustion Overall Plant Cost Summary …………….............................................................. 33

Overall NGCC Plant $\quad 35$

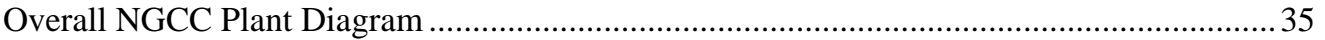

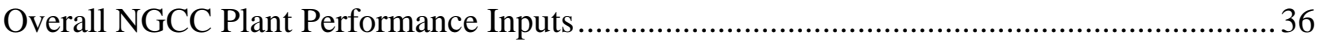

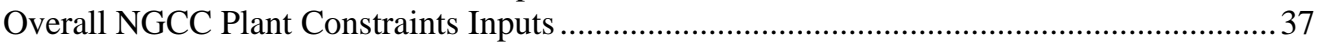

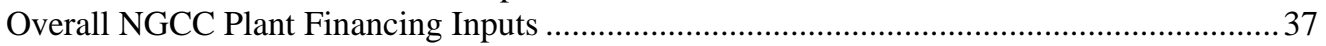

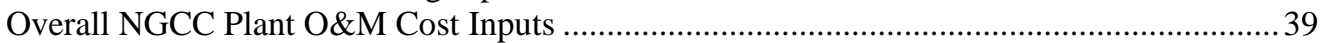

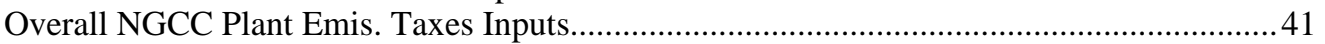

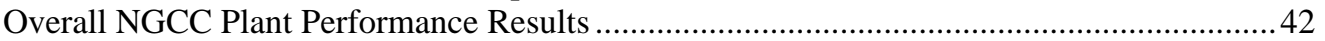

Performance Parameter …………....................................................................... 42

Plant Power Requirements ........................................................................................ 43

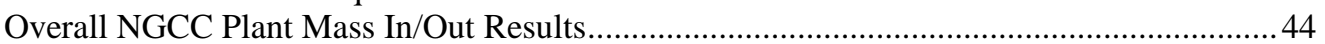

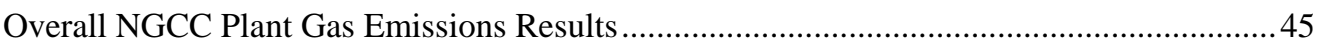

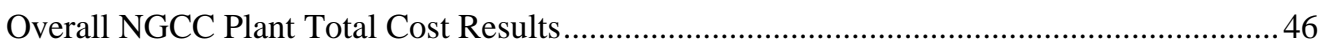

Overall NGCC Plant Cost Summary Results................................................................................ 48

Overall IGCC Plant $\quad 51$

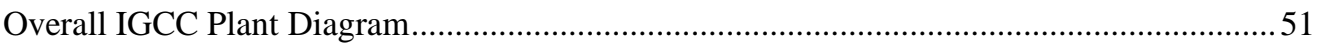

Overall IGCC Plant Performance Inputs ………….............................................................5 52

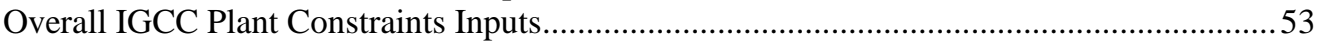

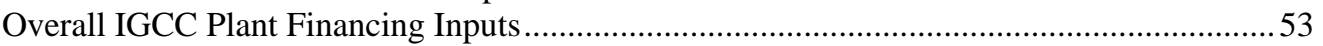

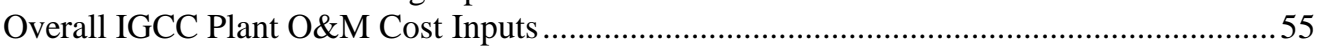

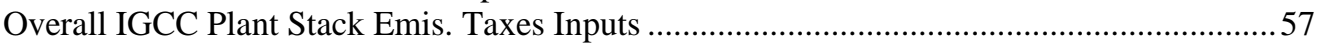

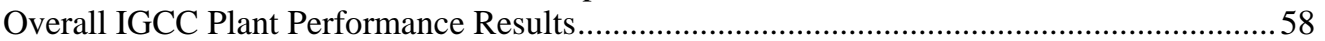

Performance Parameter …………………........................................................... 58

Plant Power Requirements ..................................................................................... 59

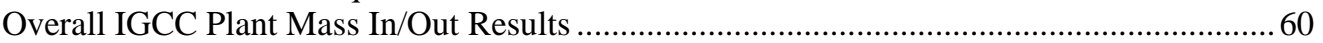

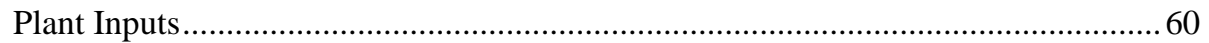

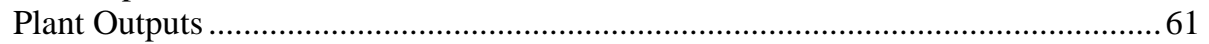

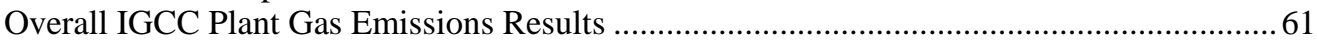

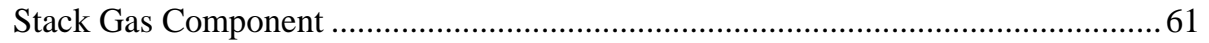

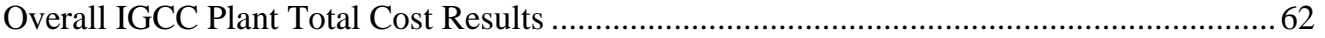

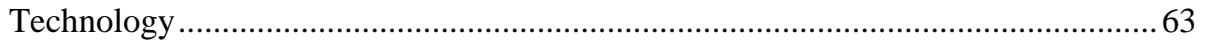

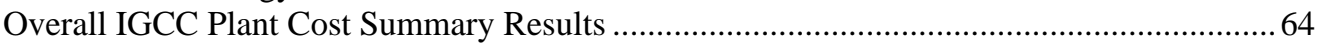

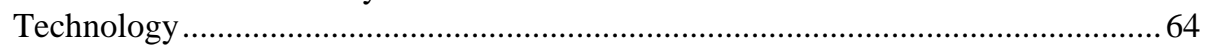

$\begin{array}{ll}\text { Fuel } & 67\end{array}$

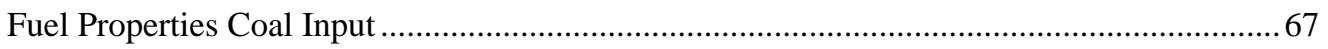

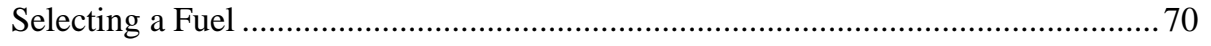

Modifying a Fuel ..................................................................................................... 70

Saving a Modified Fuel ........................................................................................... 71

Deleting a Fuel ........................................................................................................ 71

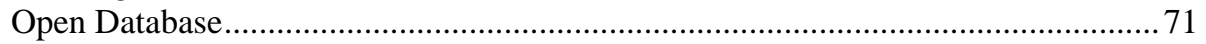

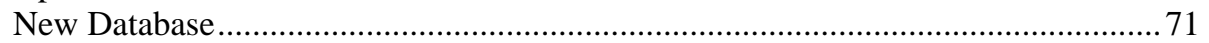

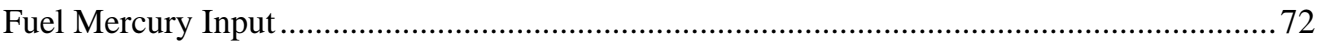

Concentration on a Dry Basis ......................................................................... 72

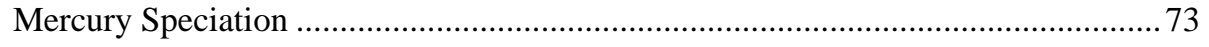

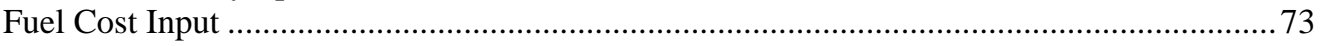

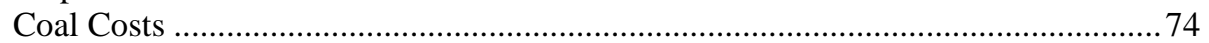




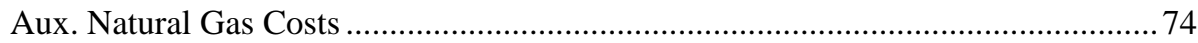

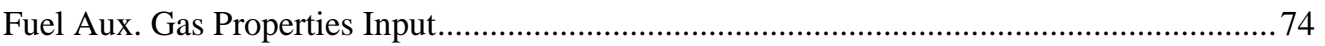

Natural Gas Composition ..................................................................................... 75

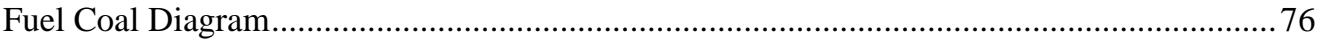

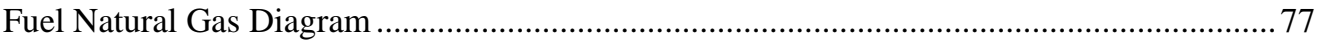

$\begin{array}{ll}\text { Air Separation } & \mathbf{7 9}\end{array}$

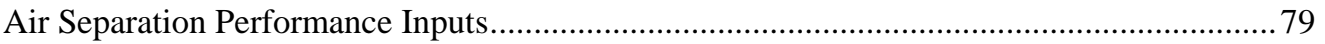

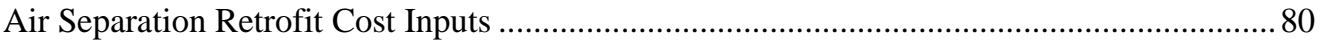

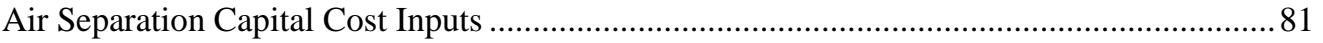

Air Separation O\&M Cost Inputs ....................................................................... 82

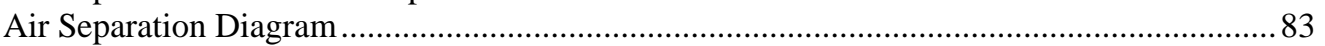

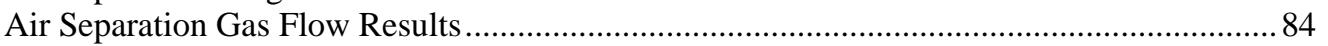

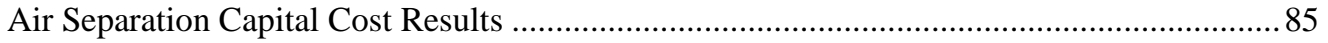

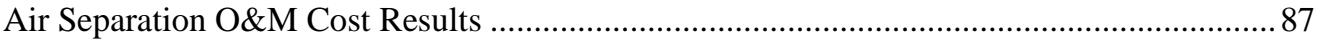

Air Separation Total Cost Results............................................................................... 88

$\begin{array}{ll}\text { Base Plant } & 89\end{array}$

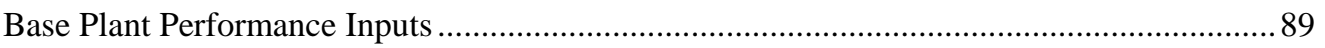

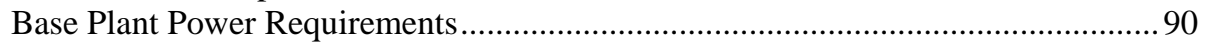

Base Plant Furnace Factors Inputs ............................................................................... 91

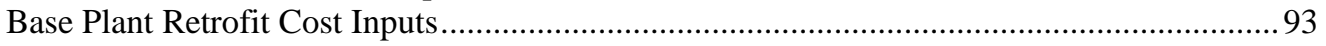

Base Plant Capital Cost Inputs...................................................................................... 94

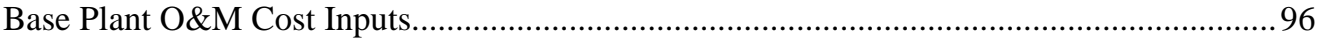

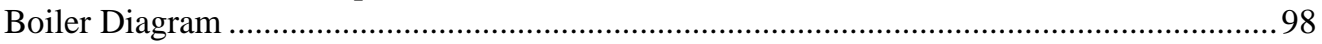

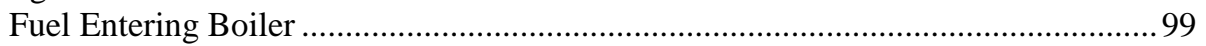

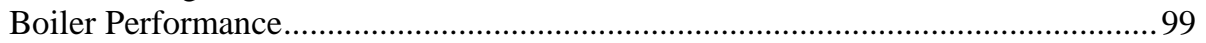

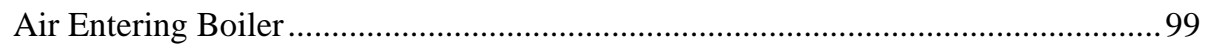

Flue Gas Exiting the Economizer ................................................................. 99

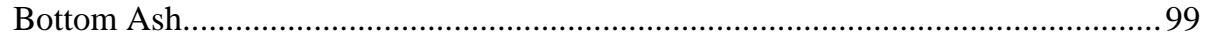

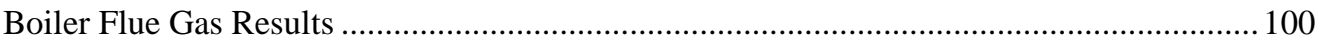

Boiler Capital Cost Results.............................................................................................. 101

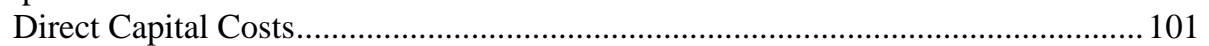

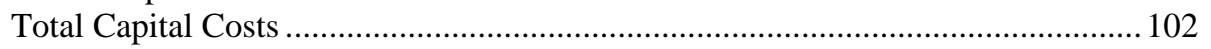

Boiler O\&M Cost Results........................................................................................ 103

Variable Cost Components ............................................................................ 103

Fixed Cost Components .............................................................................. 104

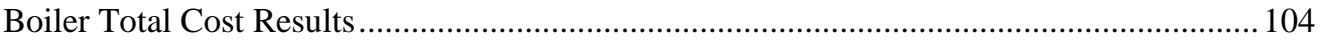

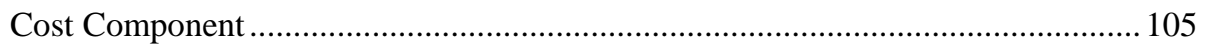

$\begin{array}{ll}\text { Auxiliary Boiler } & 107\end{array}$

Auxiliary Boiler Diagram ........................................................................................... 107

Auxiliary Boiler Natural Gas Results .............................................................................. 108

Natural Gas Components............................................................................ 109

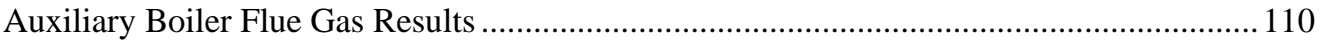

Major Flue Gas Components ...................................................................... 110

Auxiliary Boiler Costs Results ................................................................................ 111

$\begin{array}{ll}\text { Gasifier } & 113\end{array}$

Gasifier Performance Inputs ........................................................................................... 113

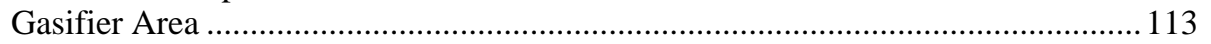

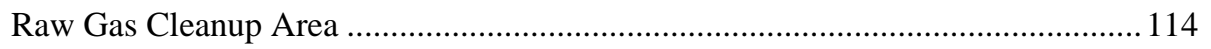

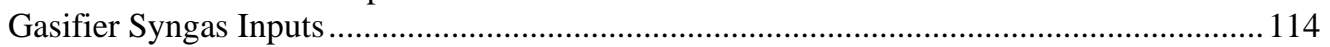




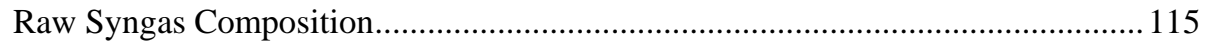

Gasifier Retrofit Cost Inputs ................................................................................... 115

Capital Cost Process Area ..................................................................................... 116

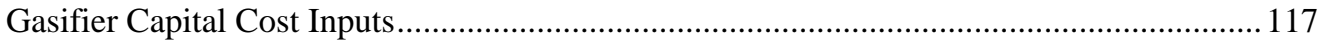

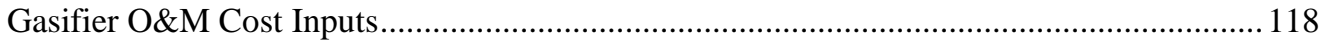

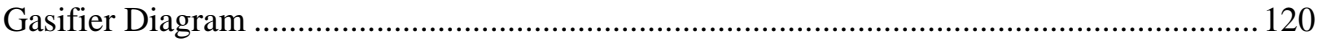

Gasifier Oxidant Results ........................................................................................ 121

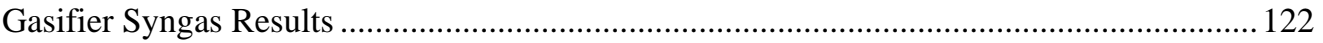

Gasifier Capital Cost Results ........................................................................................... 123

GE Gasifier Process Area Costs ........................................................................ 123

GE Gasifier Plant Costs.............................................................................. 124

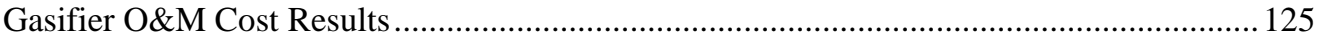

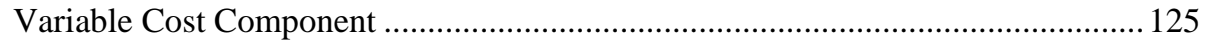

Fixed Cost Components .......................................................................... 126

Gasifier Total Cost Results ........................................................................................... 126

$\begin{array}{ll}\text { Air Preheater } & 129\end{array}$

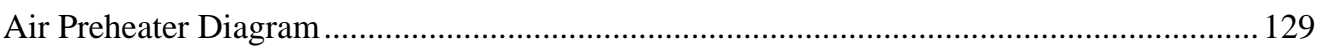

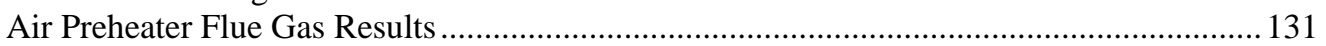

Major Flue Gas Components ................................................................................. 131

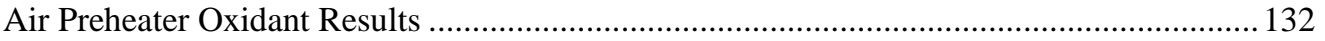

Oxidant Gas Components .......................................................................... 132

In-Furnace Controls 135

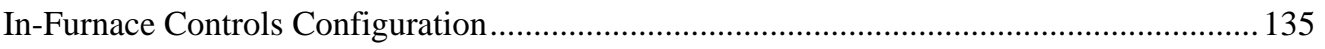

In-Furnace Controls Performance Input ....................................................................... 137

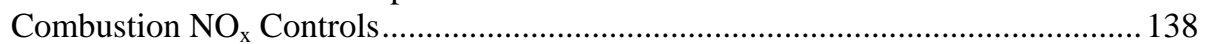

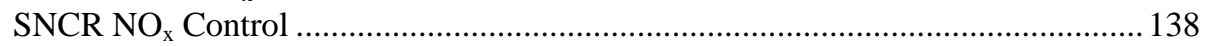

In-Furnace Controls Capital Cost ............................................................................. 139

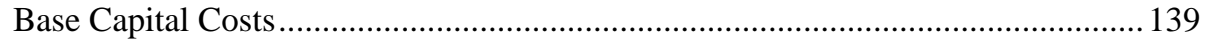

Retrofit Capital Cost Factors ...................................................................... 140

Total Capital Costs: ................................................................................ 140

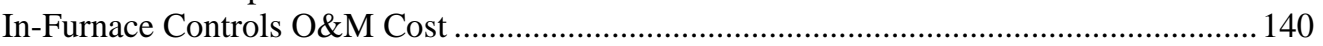

Variable O\&M Costs ...................................................................................... 141

Fixed O\&M Cost ................................................................................. 141

In-Furnace Controls Diagram ................................................................................ 142

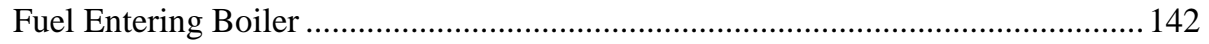

Air Entering Boiler ........................................................................................... 142

Flue Gas Exiting Convective Zone..................................................................... 143

Flue Gas Exiting the Economizer ....................................................................... 143

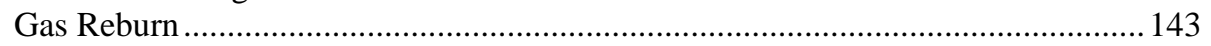

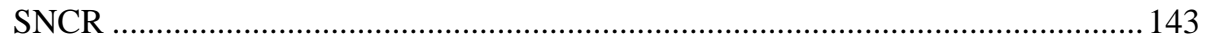

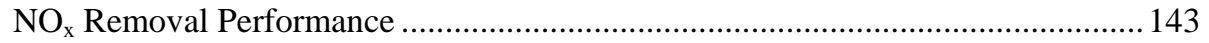

In-Furnace Controls Flue Gas Results .............................................................................. 144

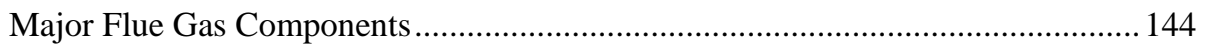

In-Furnace Controls Capital Cost Results........................................................................... 145

In-Furnace Controls O\&M Cost Results........................................................................... 146

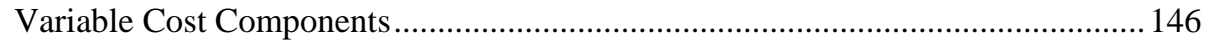

Fixed Cost Components ............................................................................ 147

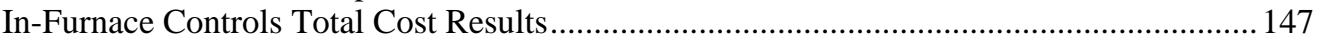

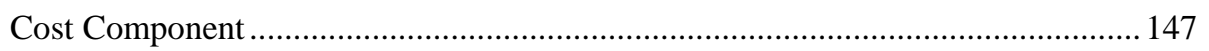

$\begin{array}{ll}\text { Hot-Side SCR } & 149\end{array}$

Hot-Side SCR Configuration ......................................................................................... 149 


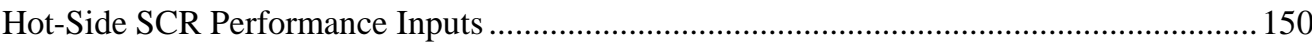

Hot-Side SCR Performance (Continued) ……………….......................................................... 153

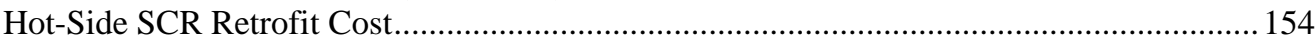

Capital Cost Process Area ……………………….............................................. 155

Hot-Side SCR Capital Cost Inputs........................................................................................... 156

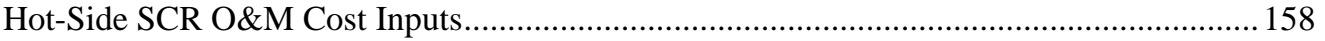

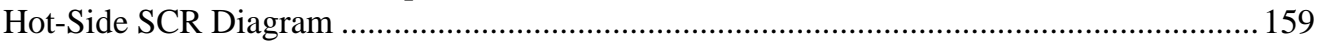

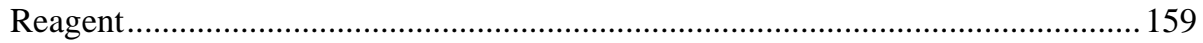

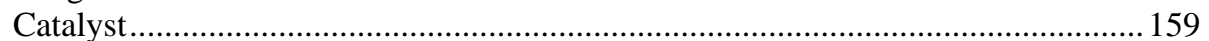

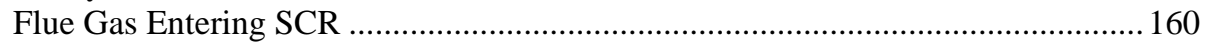

Flue Gas Exiting SCR ……………................................................................. 160

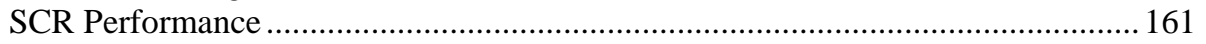

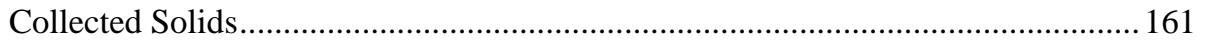

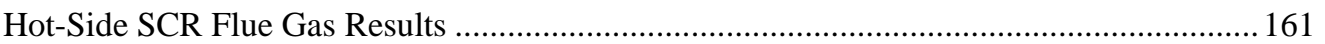

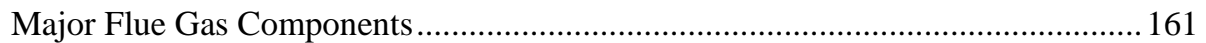

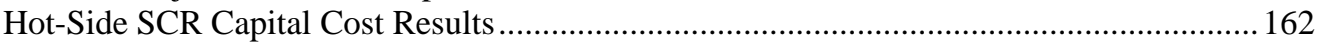

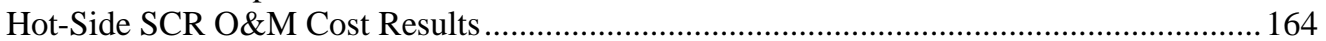

Variable Cost Components....................................................................................... 165

Fixed Cost Components ............................................................................................ 166

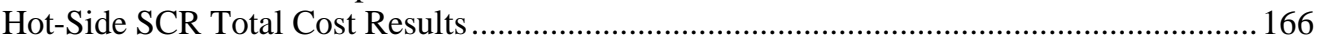

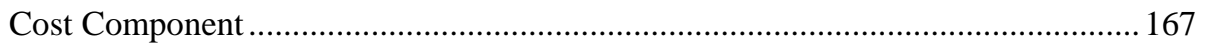

$\begin{array}{ll}\text { Mercury } & 169\end{array}$

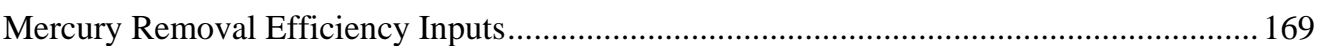

Removal Efficiency of Mercury ....................................................................... 170

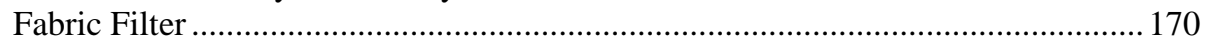

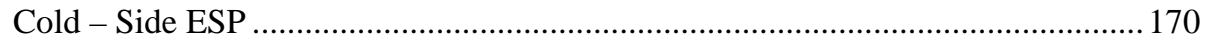

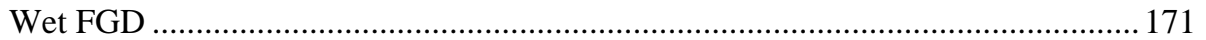

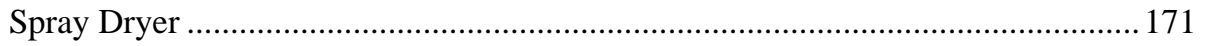

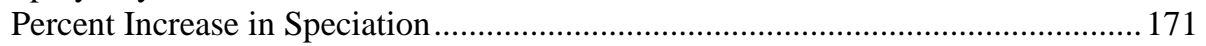

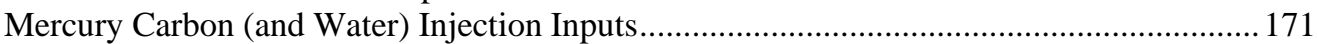

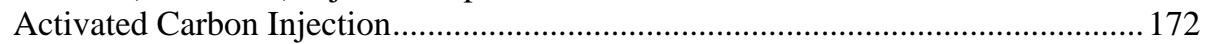

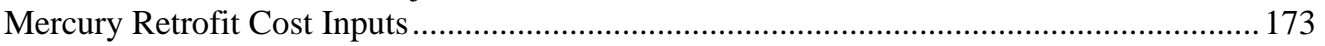

Capital Cost Process Area ………………………................................................. 174

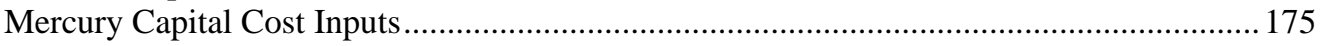

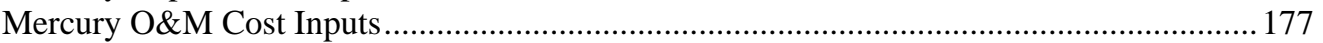

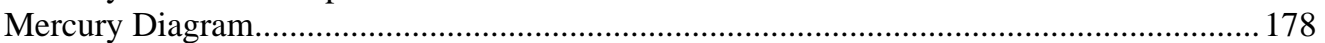

Flue Gas Prior to Injection ................................................................................... 178

Flue Gas After Injection .....................................................................................179

Flue Gas Conditioning.........................................................................................179

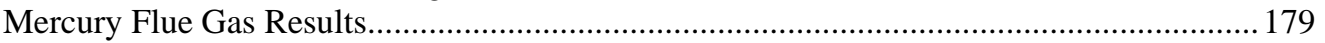

Major Flue Gas Components........................................................................... 180

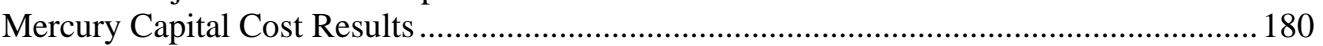

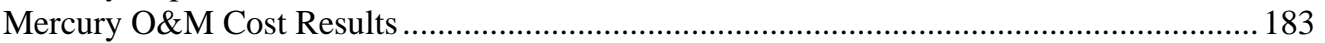

Variable Cost Components........................................................................................ 184

Fixed Cost Components ..................................................................................... 184

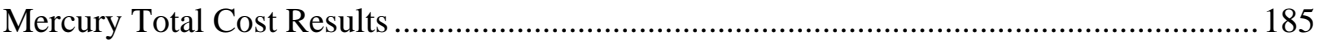

Cost Component .................................................................................................... 186

$\begin{array}{ll}\text { Cold-Side ESP } & 187\end{array}$

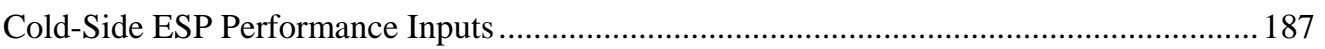

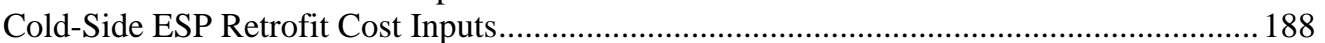

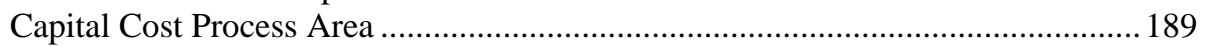

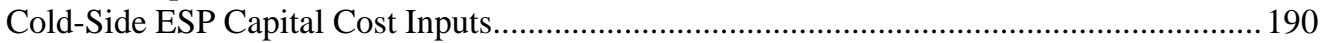




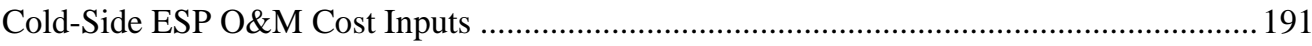

Cold-Side ESP Diagram ............................................................................................... 193

Flue Gas Entering ESP ..................................................................................... 193

Flue Gas Exiting ESP ......................................................................................... 193

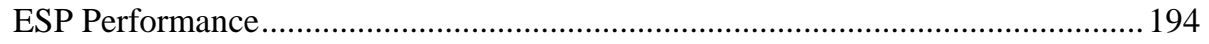

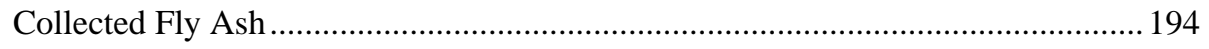

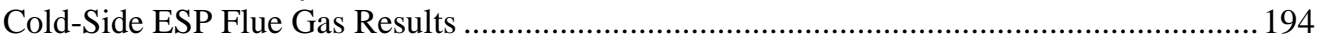

Major Flue Gas Components.............................................................................. 195

Cold-Side ESP Capital Cost Results ............................................................................... 195

Direct Capital Costs...................................................................................... 196

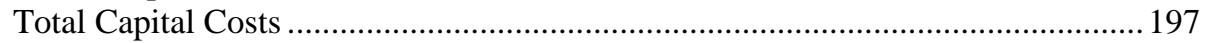

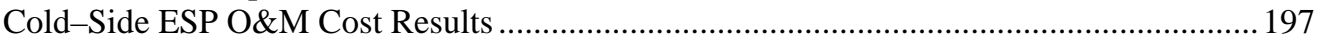

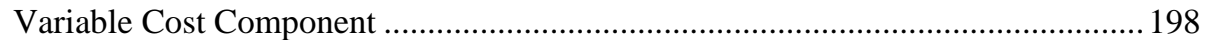

Fixed Cost Components ............................................................................ 198

Cold-Side ESP Total Cost Results .................................................................................... 199

Cost Component .............................................................................................. 199

Wet FGD 201

Wet FGD Configuration ........................................................................................ 201

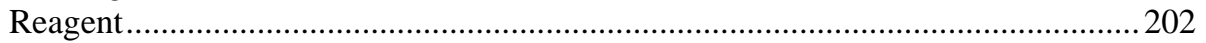

Flue Gas Bypass Control ........................................................................... 202

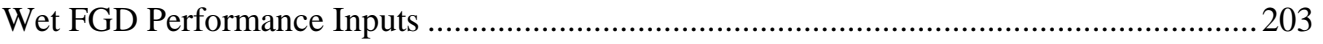

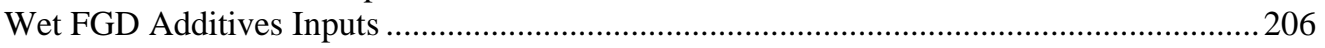

Wet FGD Retrofit Cost Inputs ............................................................................... 206

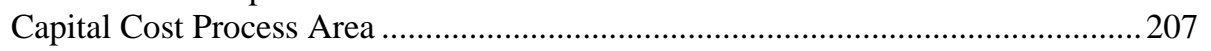

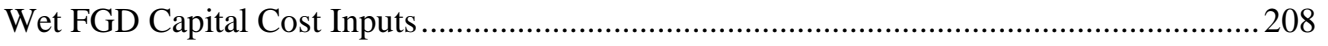

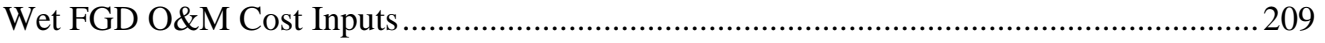

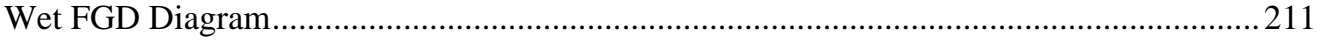

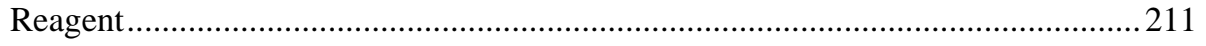

Flue Gas Entering FGD .......................................................................... 212

Flue Gas Exiting FGD ................................................................................ 212

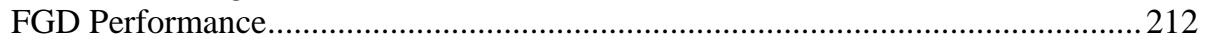

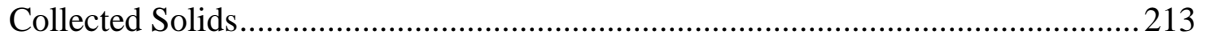

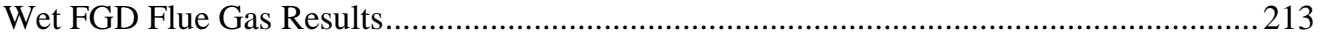

Major Flue Gas Component ...................................................................... 213

Wet FGD Bypass Results ....................................................................................... 214

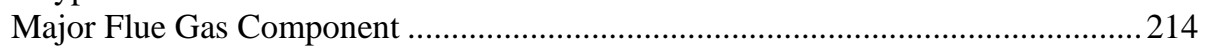

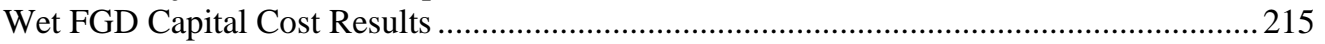

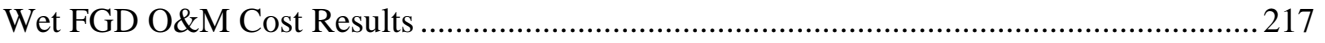

Variable Cost Components ......................................................................... 217

Fixed Cost Components ........................................................................... 218

Wet FGD Total Cost Results .............................................................................. 218

Cost Component .................................................................................... 219

$\begin{array}{ll}\text { Spray Dryer } & 221\end{array}$

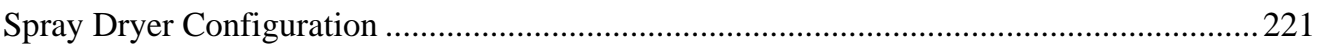

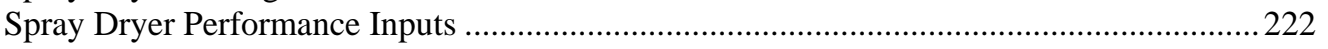

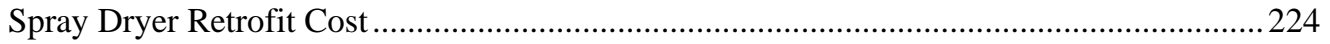

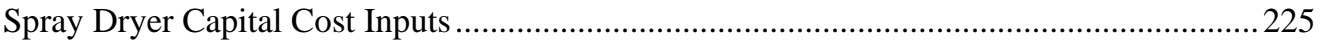

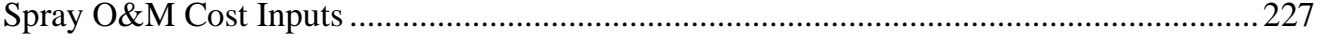

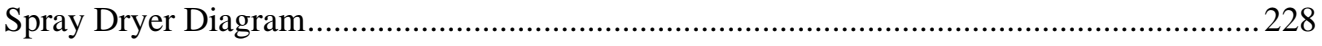

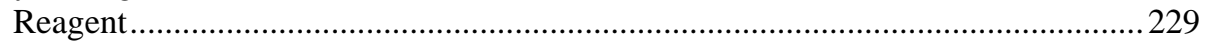

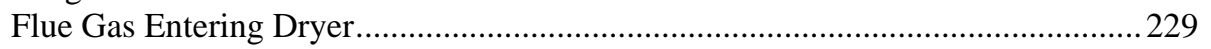

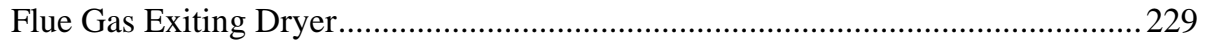


Spray Dryer Performance …………………....................................................... 230

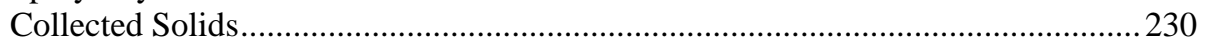

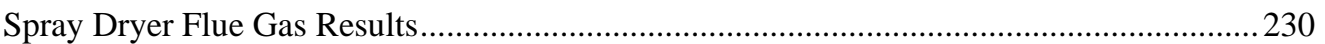

Major Flue Gas Components ...................................................................................2231

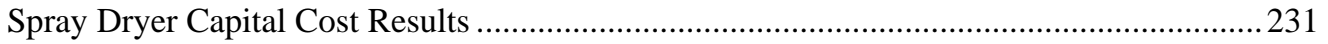

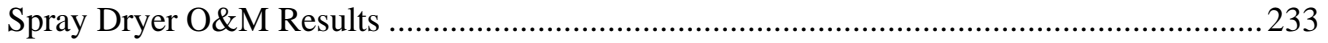

Variable Cost Components......................................................................................2234

Fixed Cost Components ……………………………............................................ 234

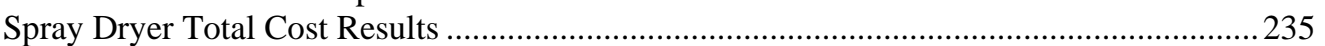

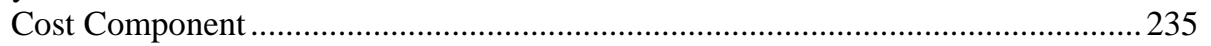

$\begin{array}{ll}\text { Amine System } & 237\end{array}$

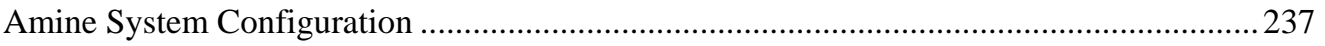

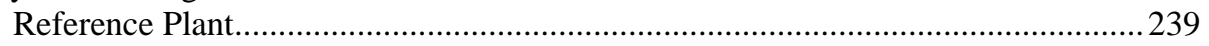

Auxiliary Boiler Configuration............................................................................................. 239

Amine System Performance Inputs ...................................................................................... 240

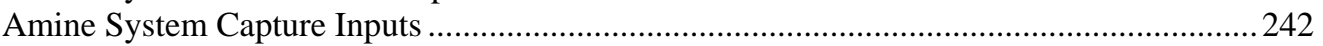

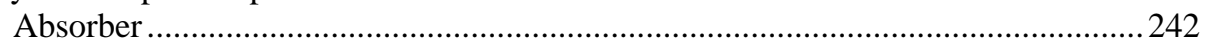

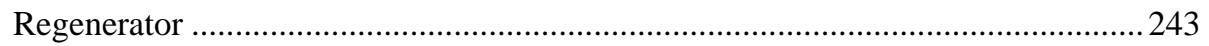

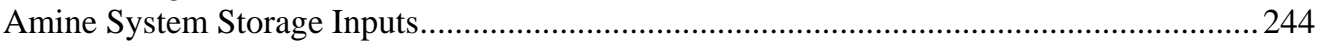

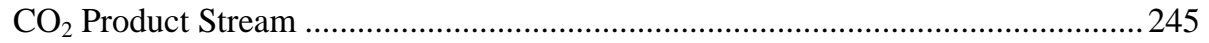

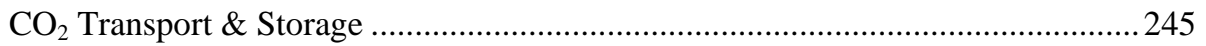

Amine System Retrofit Cost Inputs ....................................................................................... 245

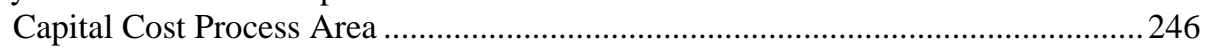

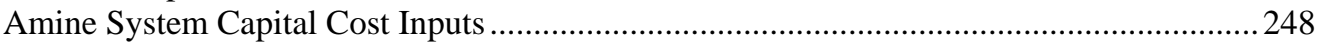

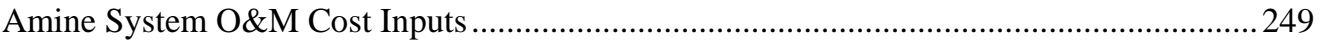

CO2 Transport and Storage Costs ………............................................................. 251

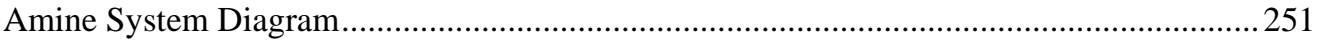

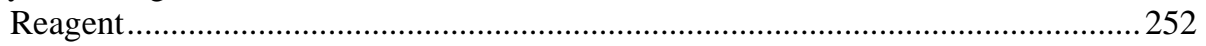

Flue Gas Entering Amine System …………………...........................................252

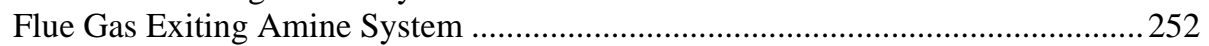

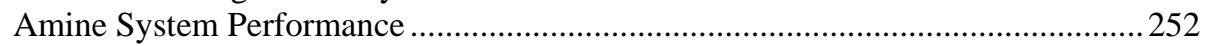

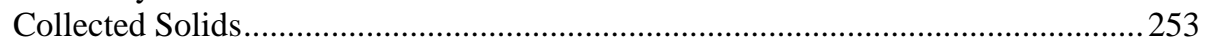

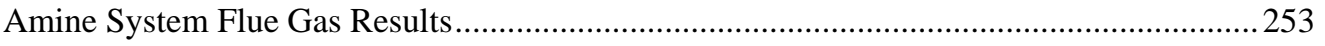

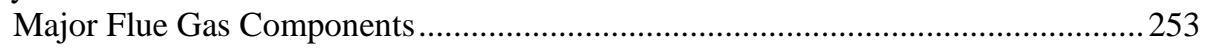

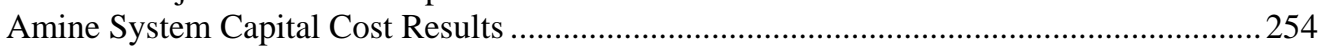

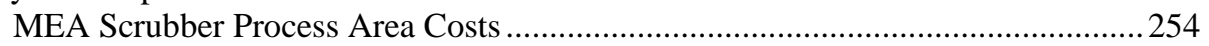

MEA Scrubber Plant Costs................................................................................... 256

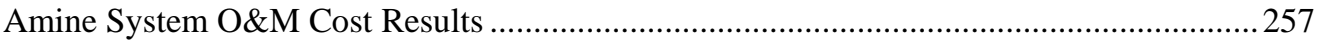

Variable Cost Components......................................................................................257

Fixed Cost Components ........................................................................................2258

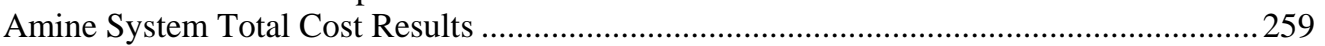

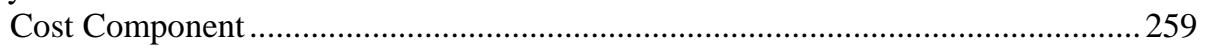

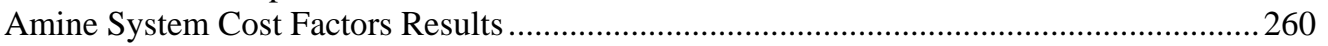

Important Performance and Cost Factors ................................................................... 260

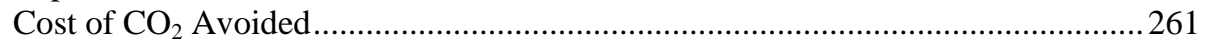

$\mathrm{O}_{2}-\mathrm{CO}_{2}$ Recycle 263

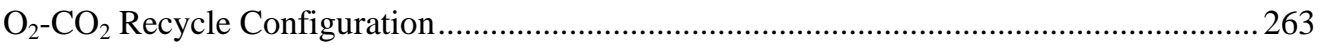

$\mathrm{O}_{2}-\mathrm{CO}_{2}$ Recycle Performance Inputs ..................................................................................264

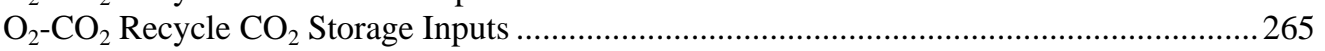

$\mathrm{O}_{2}-\mathrm{CO}_{2}$ Recycle Retrofit Cost Inputs..................................................................................267

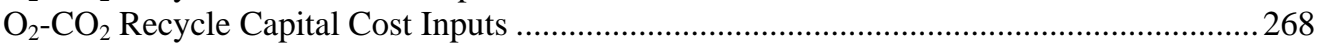

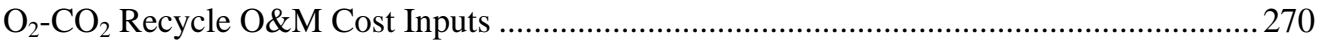




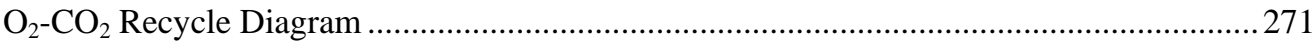

$\mathrm{O}_{2}-\mathrm{CO}_{2}$ Recycle DCC Gas Results ............................................................................. 272

$\mathrm{O}_{2}-\mathrm{CO}_{2}$ Recycle Purification Gas Results ......................................................................2 273

$\mathrm{O}_{2}-\mathrm{CO}_{2}$ Recycle Capital Cost Results..........................................................................2 274

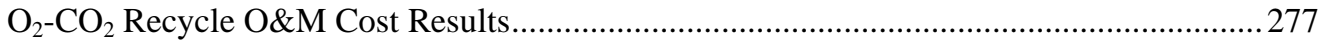

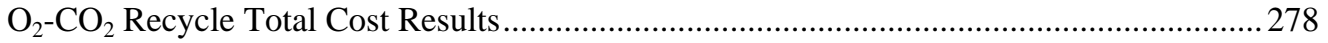

$\mathrm{O}_{2}-\mathrm{CO}_{2}$ Recycle Miscellaneous Results .....................................................................2 279

Selexol $\mathrm{CO}_{2}$ Capture $\quad 283$

Selexol $\mathrm{CO}_{2}$ Capture Reference Plant Inputs................................................................. 283

Reference Plant..................................................................................... 283

Selexol $\mathrm{CO}_{2}$ Capture Performance Inputs........................................................................ 284

Carbon Dioxide Removal Unit ............................................................................. 284

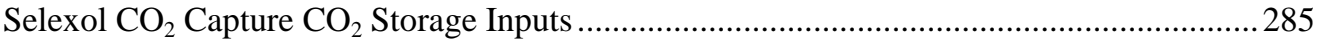

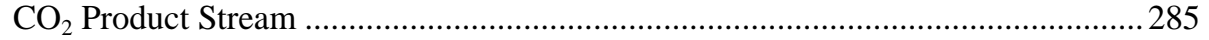

Transport \& Storage ................................................................................. 285

Selexol $\mathrm{CO}_{2}$ Capture Retrofit Cost Inputs ...................................................................... 286

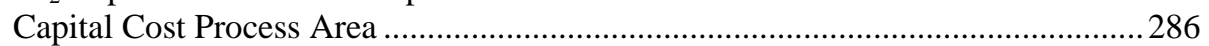

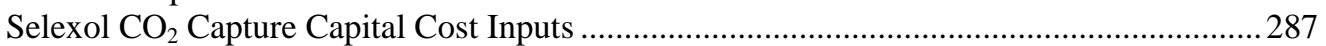

Selexol $\mathrm{CO}_{2}$ Capture O\&M Cost Inputs ..................................................................... 288

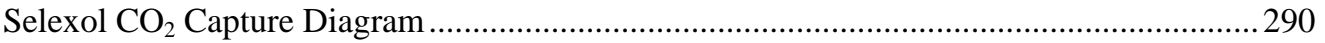

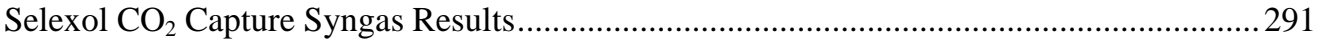

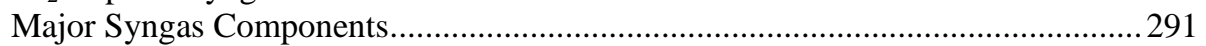

Selexol $\mathrm{CO}_{2}$ Capture Capital Cost Results ...................................................................... 292

Selexol $\mathrm{CO}_{2}$ Capture O\&M Cost Results ........................................................................ 294

Selexol $\mathrm{CO}_{2}$ Capture Total Cost Results..................................................................... 295

Cost Component ..................................................................................... 296

Selexol $\mathrm{CO}_{2}$ Capture Cost Factors Results .............................................................. 296

Water Gas Shift Reactor $\quad 299$

Water Gas Shift Reactor Performance Inputs .............................................................. 299

Water Gas Shift Reactor Unit ............................................................................. 299

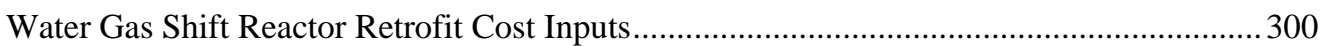

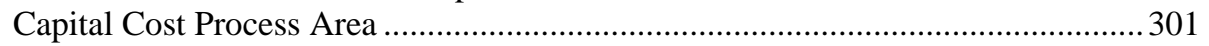

Water Gas Shift Reactor Capital Cost Inputs............................................................... 301

Water Gas Shift Reactor O\&M Cost Inputs............................................................... 303

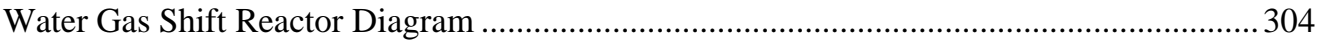

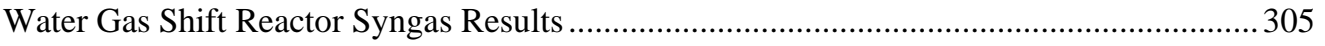

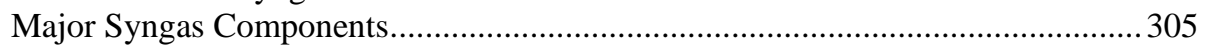

Water Gas Shift Reactor Capital Cost Results................................................................... 306

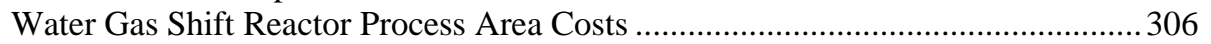

Water Gas Shift Reactor Plant Costs ................................................................ 307

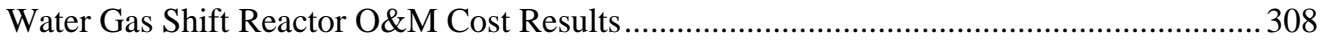

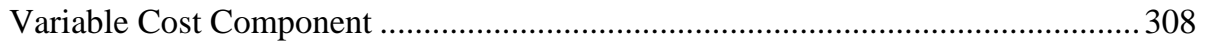

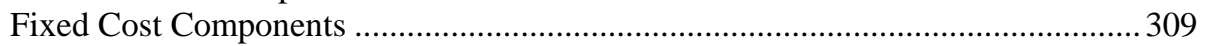

Water Gas Shift Reactor Total Cost Results .................................................................... 309

Cost Component ..................................................................................... 310

Sulfur Removal $\quad 311$

Sulfur Removal Performance Inputs......................................................................... 311

Hydrolyzer (or Shift Reactor) ...................................................................... 312

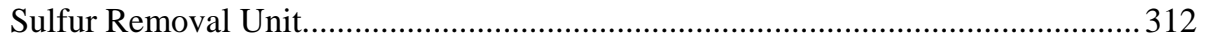

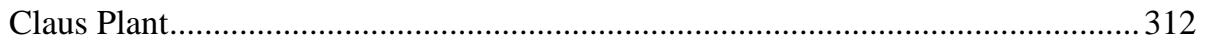

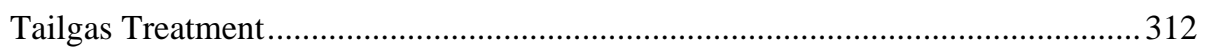




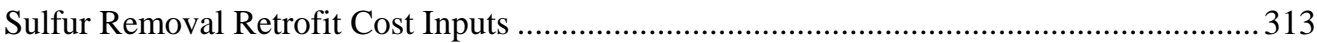

Capital Cost Process Area ……………….................................................................. 313

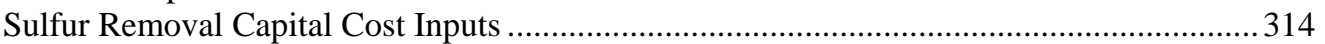

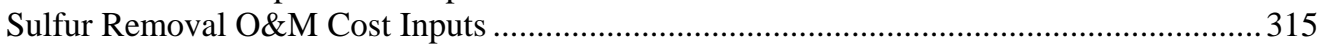

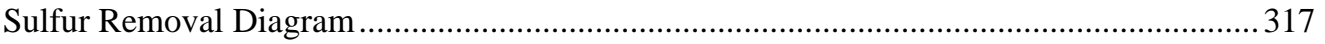

Sulfur Removal Capital Cost Results ................................................................................ 318

Sulfur Removal Process Area Costs ......................................................................... 318

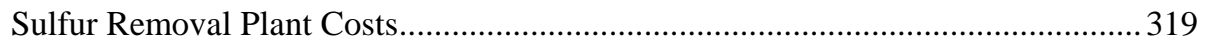

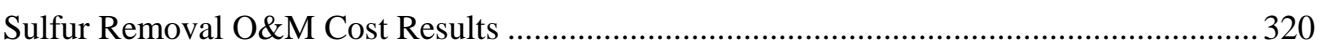

Variable Cost Component …………………………......................................... 320

Fixed Cost Components ............................................................................................. 321

Sulfur Removal Total Cost Results......................................................................................321

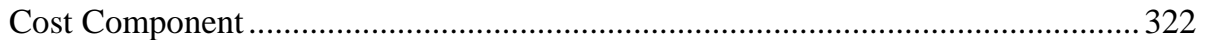

Sulfur Removal Hydrolyzer Syngas Results............................................................................ 322

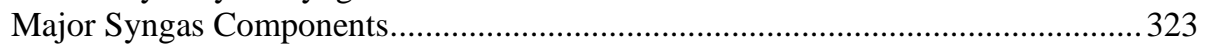

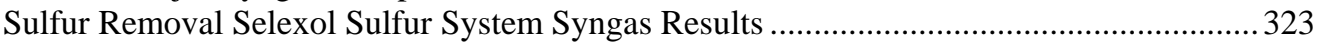

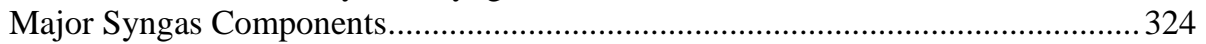

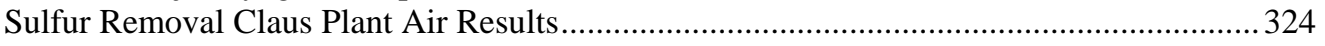

Major Syngas Components................................................................................... 325

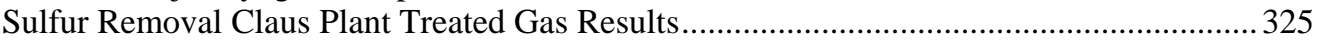

Major Syngas Components.................................................................................. 326

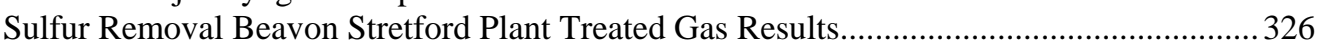

Major Syngas Components.......................................................................................... 327

Sulfur Removal Beavon Stretford Plant Flue Gas Results....................................................... 327

Major Flue Gas Components .................................................................................... 328

$\begin{array}{ll}\text { By Product Management } & 329\end{array}$

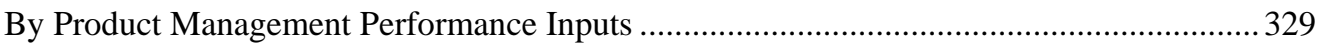

By Product Management Sequestration Input ......................................................................... 330

By Products Management Bottom Ash Pond Diagram............................................................ 330

By Products Management Flue Gas Treatment Diagram ......................................................331

By Products Management Fly Ash Disposal Diagram .............................................................. 333

By Products Management Geological Resevoir Diagram ....................................................... 334

$\mathrm{CO}_{2}$ Transport System $\quad 335$

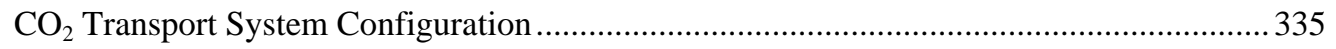

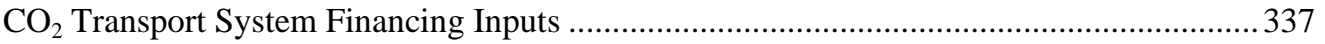

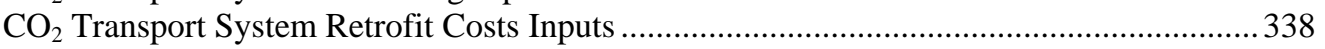

Capital Cost Process Area …………………............................................................... 338

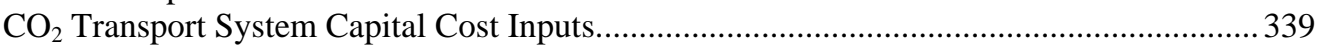

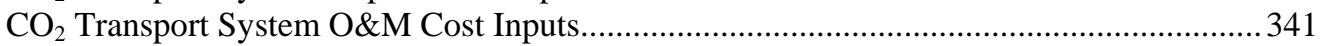

$\mathrm{CO}_{2}$ Transport System Diagram ………......................................................................... 342

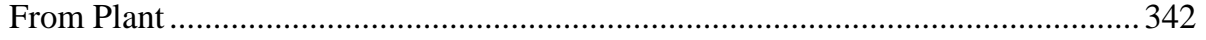

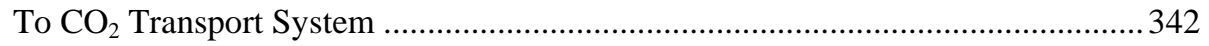

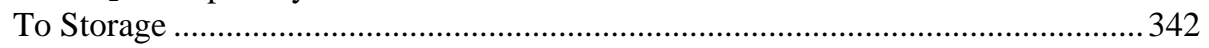

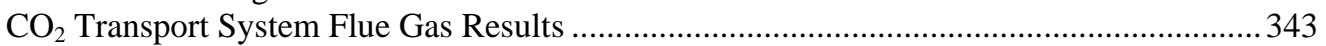

Major Flue Gas Components...................................................................................... 343

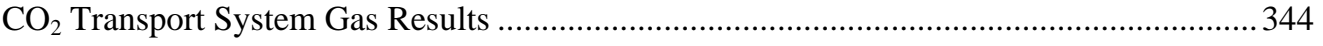

Major Gas Components ....................................................................................... 344

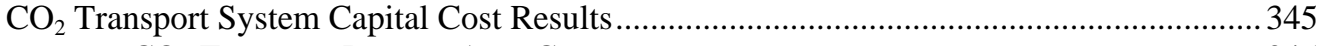

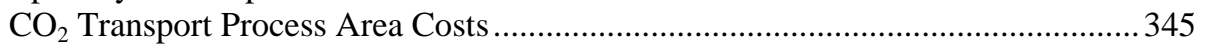

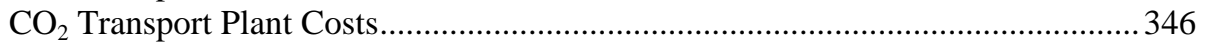

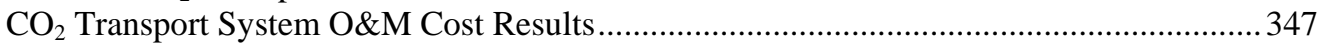

Variable Cost Components....................................................................................... 347 


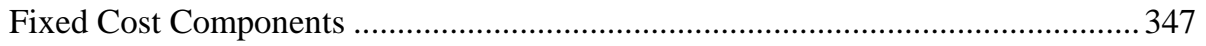

$\mathrm{CO}_{2}$ Transport System Total Cost Results ..................................................................... 348

$\begin{array}{ll}\text { Stack } & 349\end{array}$

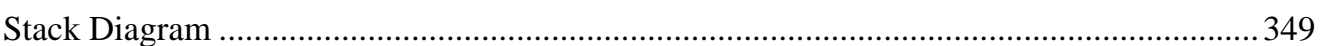

Flue Gas Out................................................................................................... 349

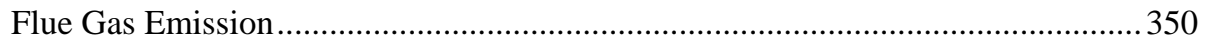

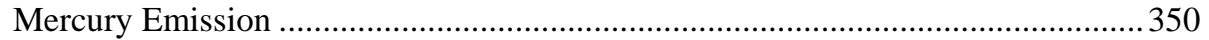

Mercury Exiting Stack............................................................................. 350

Stack Flue Gas Results ................................................................................................ 350

Major Flue Gas Components.............................................................................. 351

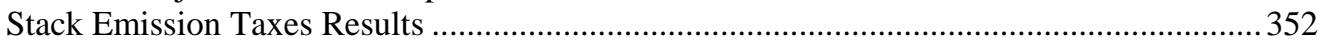

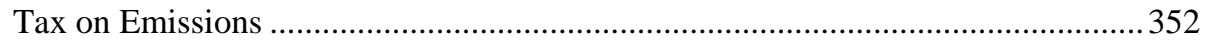

Power Block 353

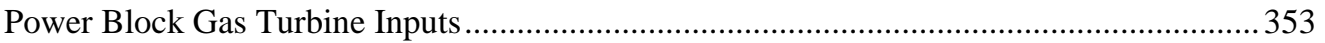

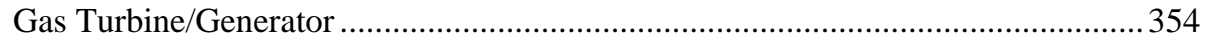

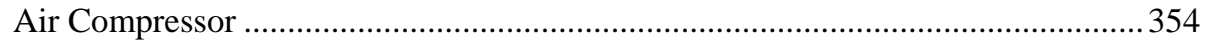

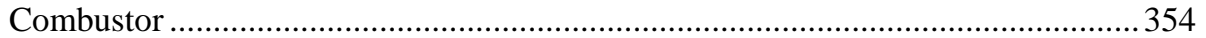

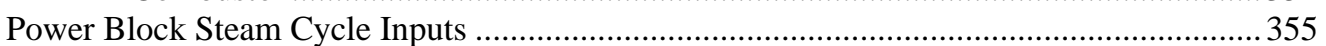

Heat Recovery Steam Generator ......................................................................... 355

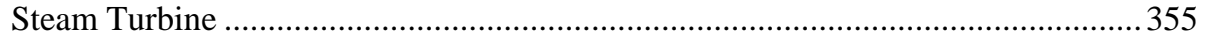

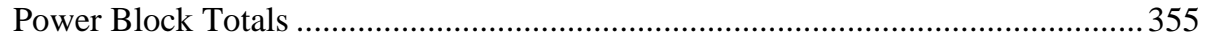

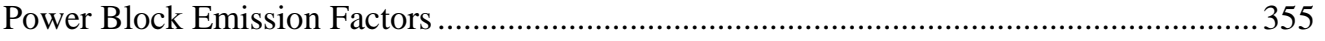

Emission Factors Input Parameters .............................................................. 356

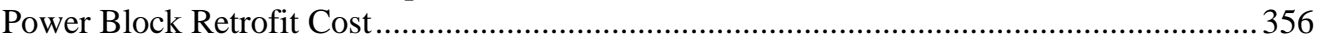

Power Block Retrofit Cost Input Parameters....................................................... 357

Power Block Capital Cost Inputs ................................................................................ 357

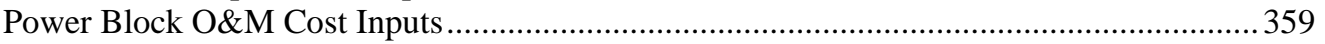

Power Block Gas Turbine Diagram .......................................................................... 360

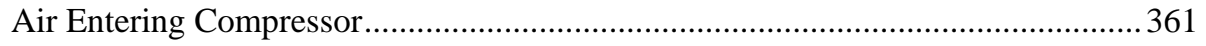

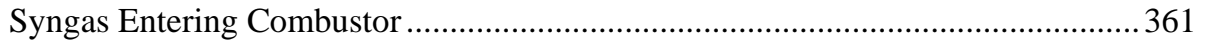

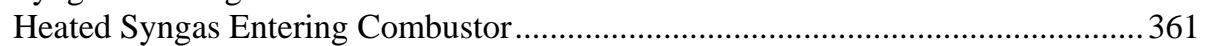

Flue Gas Exiting Gas Turbine ........................................................................ 361

Power Block Steam Diagram.................................................................................... 362

Flue Gas Exiting Steam Generator ................................................................. 362

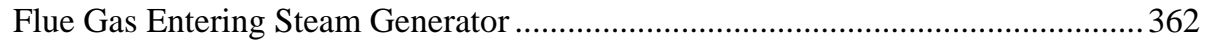

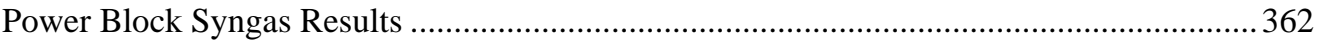

Major Syngas Components................................................................................ 363

Power Block Flue Gas Results........................................................................................ 363

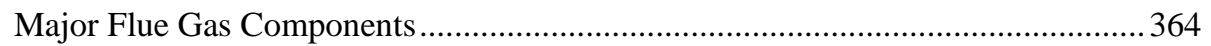

Power Block Capital Cost Results ............................................................................... 364

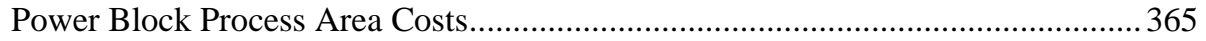

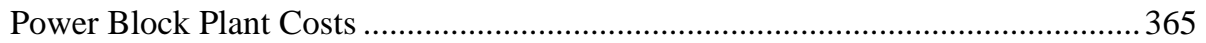

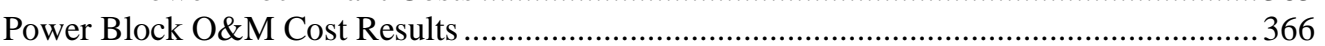

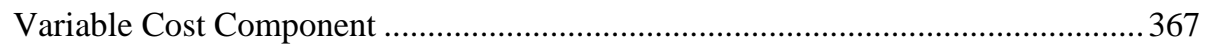

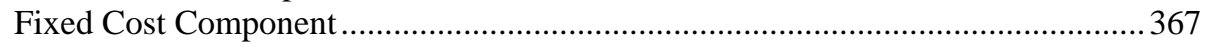

Power Block Total Cost Results ..................................................................................... 368

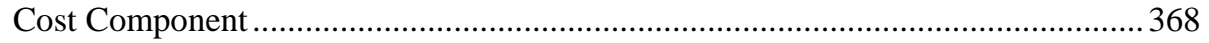

$\begin{array}{lr}\text { Units } & 371\end{array}$

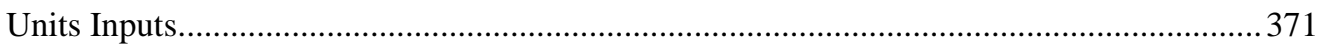

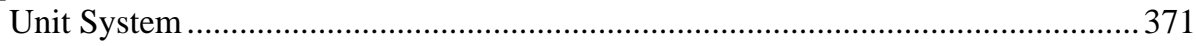

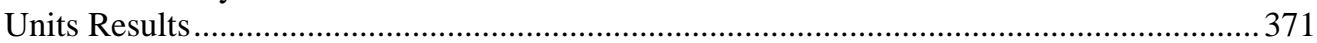




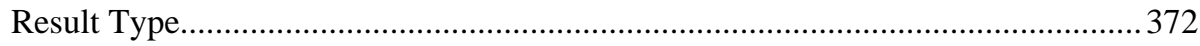

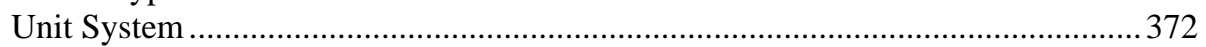

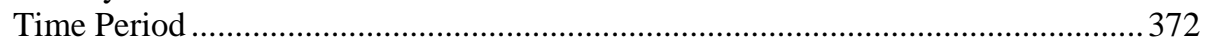

Performance Table ................................................................................................ 372

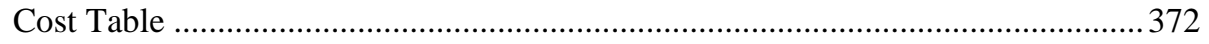

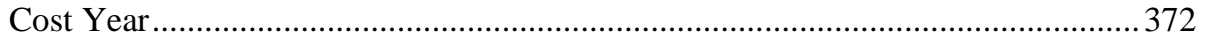

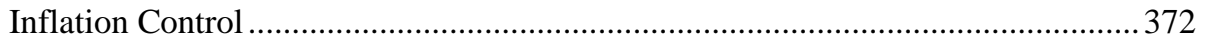

Working with Graphs $\quad 373$

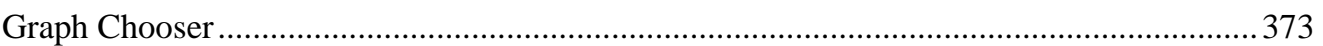

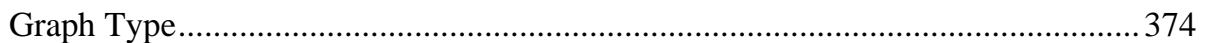

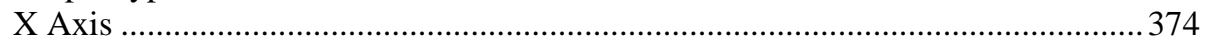

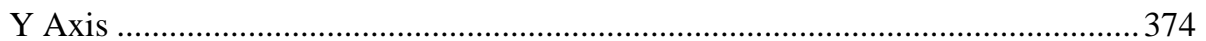

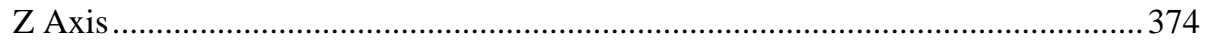

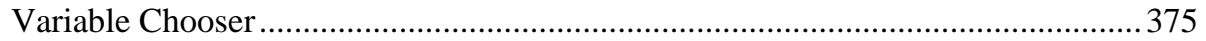

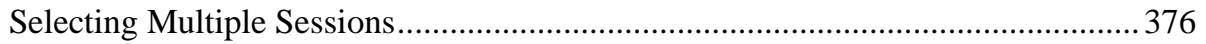

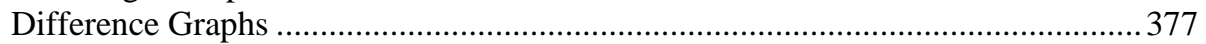

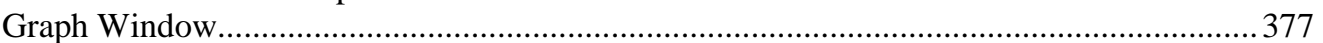

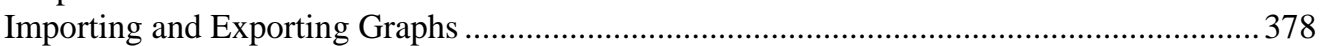

Graph Window Help....................................................................................... 379

Running a Probabilistic Analysis $\quad 381$

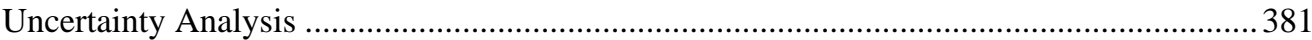

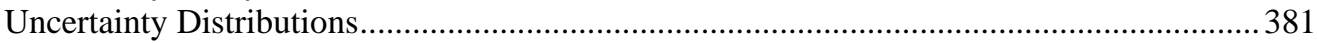

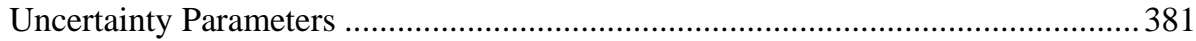

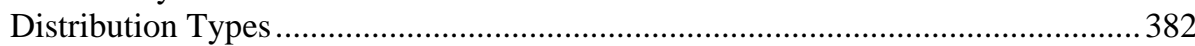

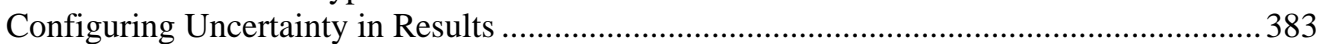

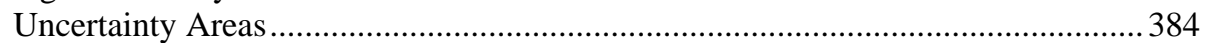

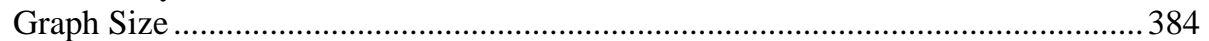

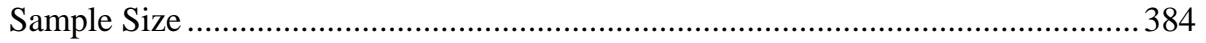

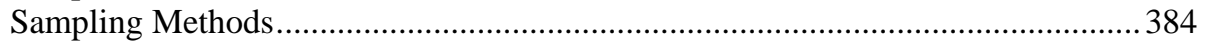

Appendix A - Introduction to Uncertainty Analysis 387

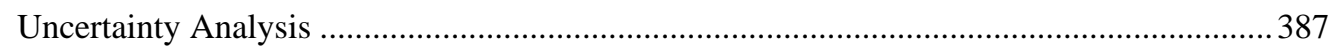

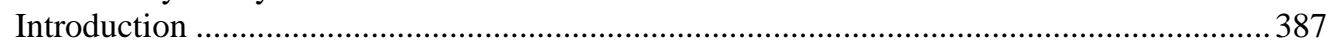

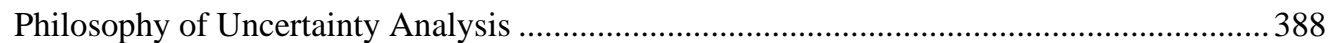

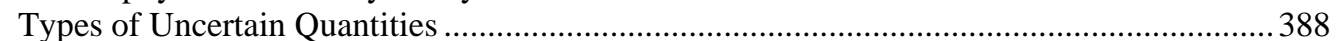

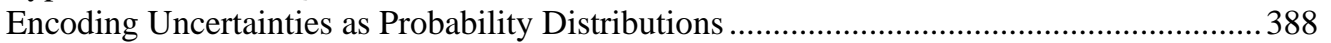

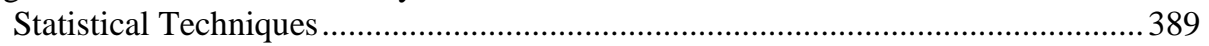

Judgments about Uncertainties................................................................................. 389

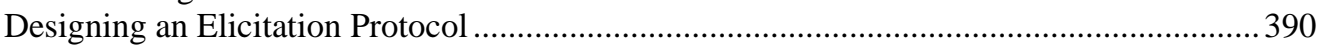

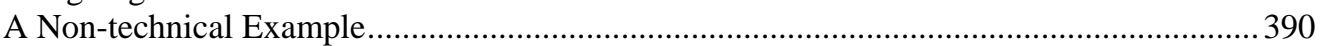

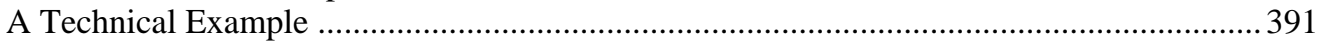

Appendix B - Technical Support 393

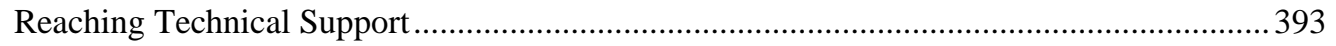

Carnegie Mellon University ............................................................................ 393

Glossary of Terms $\quad 395$

$\begin{array}{ll}\text { Index } & 397\end{array}$ 


\section{Disclaimer}

This report was prepared as an account of work sponsored by an agency of the United States Government. Neither the United States Government nor any agency thereof, nor any of their employees, makes any warranty, express or implied, or assumes any legal liability or responsibility for the accuracy, completeness, or usefulness of any information, apparatus, product, or process disclosed, or represents that its use would not infringe privately owned rights. Reference herein to any specific commercial product, process, or service by trade name, trademark, manufacturer, or otherwise does not necessarily constitute or imply its endorsement, recommendation, or favoring by the United States Government or any agency thereof. The views and opinions of authors expressed herein do not necessarily state or reflect those of the United States Government or any agency thereof. 


\section{Acknowledgements}

This report is an account of research sponsored by the U.S. Department of Energy's National Energy Technology Center (DOE/NETL) under Contract No. DE-AC2192MC29094. 


\section{Introduction}

\section{The Integrated Environmental Control Model}

This Integrated Environmental Control Model with Carbon Sequestration (IECM-cs) and Interface were developed for the U. S. Department of Energy's National Energy Technology Laboratory (NETL), formerly known as the Federal Energy Technology Center (FETC), under contracts No. DE-AC22-92PC91346 and DE-AC2192MC29094.

\section{Purpose}

The product of this work is a desktop computer model that allows different technology options to be evaluated systematically at the level of an individual plant or facility. The model takes into account not only avoided carbon emissions, but also the impacts on multi-pollutant emissions, plant-level resource requirements, costs (capital, operating, and maintenance), and net plant efficiency.

In addition, uncertainties and technological risks also can be explicitly characterized. The modeling framework is designed to support a variety of technology assessment and strategic planning activities by DOE and other organizations.

The model currently includes four types of fossil fuel power plants: a pulverized coal (PC) plant, a natural gas-fired combined cycle (NGCC) plant, a coal-based integrated gasification combined cycle (IGCC) plant, and an oxyfuel combustion plant. Each plant can be modeled with or without CO2 capture and storage. The IECM-cs can thus be employed to quantify the costs and emission reduction benefits of CCS for a particular system or to identify the most cost-effective option for a given application.

This model also can be used to quantify the benefits of technology R\&D and to identify advanced technology options having the highest potential payoffs.

A Graphical User Interface (GUI) facilitates the configuration of the technologies, entry of data, and retrieval of results.

\section{System Requirements}

The current model requires the following configuration:

- Intel-based computer running Windows 98 (or better) or Windows NT 4.0 (or better) operating system 
- Pentium Processor

- any SVGA (or better) display—at a resolution of 800x600 (or more) pixels $^{1}$

- at least 40 Megabytes of free hard disk space

- at least 128 Megabytes of total memory

\section{Uncertainty Features}

The ability to characterize uncertainties explicitly is a feature unique to this model. As many as one hundred input parameters can be assigned probability distributions. When input parameters are uncertain, an uncertainty distribution of results is returned. Such result distributions give the likelihood of a particular value, in contrast to conventional single-value estimates.

The model can run using single deterministic values or uncertainty distributions. The conventional deterministic form using single values for all input parameters and results may be used, or probabilistic analyses may be run-for instance, to analyze advanced technology costs (see Appendix A for more details).

\section{Software Used in Development}

The underlying engineering models are written in Intel ${ }^{\circledR}$ Visual Fortran. Fortran runtime libraries are included with the IECM Interface software. This language provides the flexibility to configure many various power plant designs while also providing the power to conduct probabilistic analyses.

All databases are in Microsoft ${ }^{\circledR}$ Access format and may be viewed in Access, as long as they are not changed. This format is a software industry standard and facilitates sharing and updating of information.

To simplify the use of the model, a Graphical User Interface (GUI) has been added. The interface eliminates the need to master the underlying commands normally required for model operation. The interface is written in Microsoft ${ }^{\circledR}$ Visual $\mathrm{C}^{++}$, a standard software development tool for the Windows environment. Visual C++ runtime libraries are included with the IECM Model software and do not need to be licensed separately.

Wise for Windows Installer was used to generate full installer programs. This product was chosen based on its flexibility and its support of Visual Basic runtime libraries and Microsoft Data Access Components (MDAC) ${ }^{2}$. The Visual Basic runtime libraries provide the support needed to run the database file compactor program provided with the IECM. MDAC provides the software support needed to link Microsoft ${ }^{\circledR}$ Access data files to the IECM interface program. Wise for Windows Installer provides the VB and MDAC installation as an option, rather than forcing the user to download it from Microsoft and install it prior to installing the IECM.

\footnotetext{
${ }^{1}$ Smaller screen resolution results in the interface screens being scaled smaller. The taskbar, part of the Windows operating system, reduces the useable resolution of the screen if it is always visible. This may force the IECM interface to be scaled down slightly. To avoid this situation, select the "Auto Hide" option of the Taskbar properties in Windows.

${ }^{2}$ The current version of MDAC is 2.8. This is installed with the full installer for the IECM. Any update installers provided for upgrading the IECM from a previous version to the current version do not upgrade MDAC unless the user updates MDAC separately.
} 


\section{Disclaimer of Warranties and Limitation of Liabilities}

This report was prepared by the organization(s) named below as an account of work sponsored or cosponsored by the U.S. Department of Energy National Energy Technology Laboratory (NETL). NEITHER NETL, ANY MEMBER OF NETL, ANY COSPONSOR, THE ORGANIZATION(S) NAMED BELOW, NOR ANY PERSON ACTING ON BEHALF OF THEM:

(A) MAKES ANY WARRANTY OR REPRESENTATION WHATSOEVER, EXPRESS OR IMPLIED, (I) WITH RESPECT TO THE USE OF ANY INFORMATION, APPARATUS, METHOD, PROCESS, OR SIMILAR ITEM DISCLOSED IN THIS REPORT, INCLUDING MERCHANTABILITY AND FITNESS FOR A PARTICULAR PURPOSE, OR (II) THAT SUCH USE DOES NOT INFRINGE ON OR INTERFERE WITH PRIVATELY OWNED RIGHTS, INCLUDING ANY PARTY'S INTELLECTUAL PROPERTY, OR (III) THAT THIS REPORT IS SUITABLE TO ANY PARTICULAR USER'S CIRCUMSTANCE; OR

(B) ASSUMES RESPONSIBILITY FOR ANY DAMAGES OR OTHER LIABILITY WHATSOEVER (INCLUDING ANY CONSEQUENTIAL DAMAGES, EVEN IF DOE OR ANY DOE REPRESENTATIVE HAS BEEN ADVISED OF THE POSSIBILITY OF SUCH DAMAGES) RESULTING FROM YOUR SELECTION OR USE OF THIS REPORT OR ANY INFORMATION, APPARATUS, METHOD, PROCESS, OR SIMILAR ITEM DISCLOSED IN THIS REPORT.

Organization(s) that prepared this report: Carnegie Mellon University

\section{Copyright Notices}

Intel ${ }^{\circledR}$ Fortran Compiler Integration for Microsoft Visual Studio .NET 2003 9.1, Copyright (C) 2002-2006, Intel Corporation. All Rights Reserved.

Spread 6.0, Copyright (C) 2002, FarPoint Technologies, Inc. All Rights Reserved.

Tab Pro 3.1, Copyright (C 1999, FarPoint Technologies, Inc. All Rights Reserved.

Graphics Server 6.15, @ 1988-2004 Graphics Server Technologies, L.P., All Rights Reserved.

Microsoft Visual Studio .NET 2003, Copyright (C 1987-2002, Microsoft Corporation. All Rights Reserved.

Microsoft Visual C++ .NET 7.1, Copyright @ 1987-2002, Microsoft Corporation. All Rights Reserved.

Microsoft .NET Framework 1.1, Copyright ( 1 1998-2002 Microsoft Corporation. All Rights Reserved.

Wise for Windows Installer 6.1, Copyright @ 2005, Wise Solutions, Inc. All Rights Reserved.

Microsoft Data Access Components 2.8, Copyright (C) 2003, Microsoft Corporation. All Rights Reserved.

Integrated Environmental Control Model (IECM) Interface 5.2.0, Copyright (C) 19972006, Carnegie Mellon University. All Rights Reserved.

Integrated Environmental Control Model (IECM) 5.2.0, Copyright (C 1997-2006, Carnegie Mellon University. All Rights Reserved. 
Median Latin Hypercube and Hammersley Sequence Sampling, Copyright (c) 1997, Urmila Diwekar, Carnegie Mellon University. All Rights Reserved.

Microsoft is a registered trademark; Windows, Windows 95, Windows 98, Windows NT, Windows ME, Windows 2000, Windows XP and Visual C++ are trademarks of Microsoft Corporation.

Graphics Server is a trademark of Graphics Server Technologies, L.P.

Spread is a trademark of FarPoint Technologies, Inc.

Tab Pro is a trademark of FarPoint Technologies, Inc.

Intel ${ }^{\circledR}$ and Pentium ${ }^{\circledR}$ are trademarks of Intel Corporation. 



\section{User Documentation and Help}

User Manual

The User Manual gives further information on both the interface and the underlying model. It provides detailed descriptions of plant configurations, parameter settings, and result screens. It also describes technical details behind the model's operation and includes an introduction to uncertainty analysis.

\section{Technical Manuals}

The Technical manuals are detailed engineering descriptions of the technologies and costing assumptions used in the IECM. These manuals are not provided by default with the IECM software; however, they can be downloaded with any web browser from http://www.iecm-online.com.

\section{Online Help}

Online help is provided via a Windows Help File containing the full text of the User Manual.

\section{Accessing the IECM Help file:}

If you are not running the IECM interface, click the Help icon inside the IECM folder on the Start menu. This opens the help file to the table of contents.

If you are running the IECM interface, do any one of the following:

- Press the F1 key. The IECM supports context-sensitive help and will open the help file to the topic associated with the item or screen you are viewing.

- Pull down the $\underline{H e l p}$ menu at the top of the IECM window. Select $\underline{H}$ elp Topics. This opens the help file to the table of contents.

- Click the Context-Sensitive Help icon on the toolbar on the left side of the IECM window. The IECM supports context-sensitive help and will open the help file to the topic associated with the item or screen you are viewing. 
- $\quad$ Click the Help Topics icon on the toolbar on the left side of the IECM window. This opens the help file to the table of contents. If this method does not work, try one of the other options above.

The IECM Help File Contents window will display.

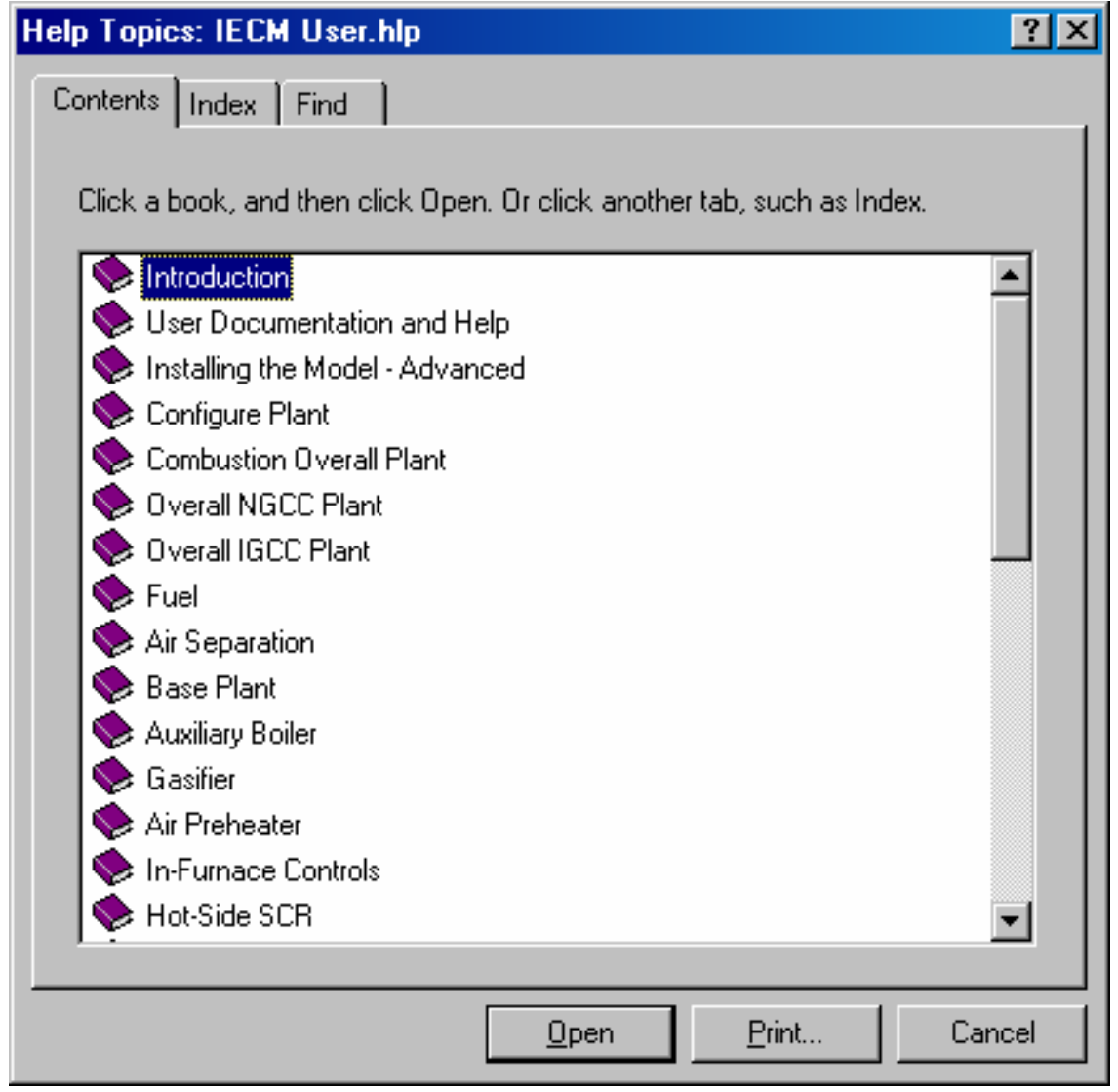

The IECM Help File Topics Window 


\section{Configure Plant}

\section{Configuring the Combustion Boiler Plant}

The following configuration options are available when the Combustion (Boiler) is selected as the plant type from the New Session pull down menu.

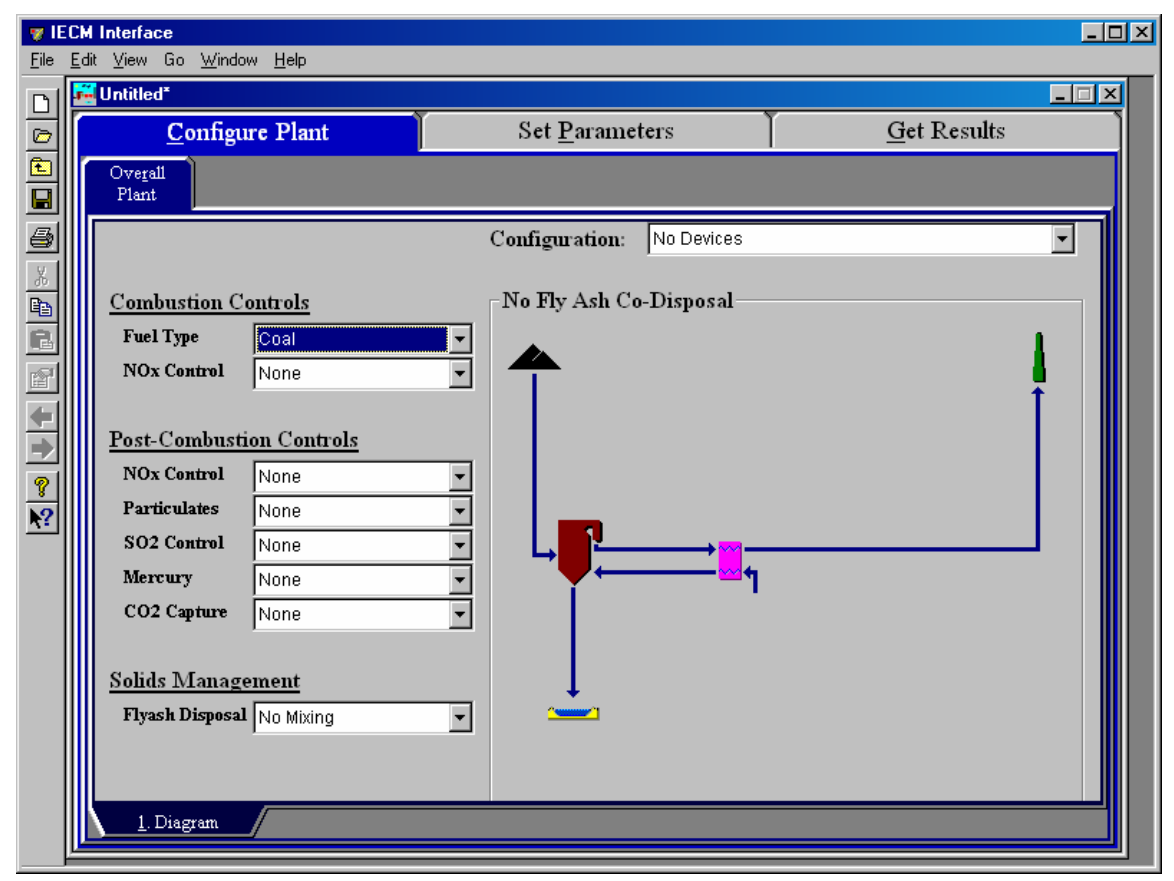

Configure Plant - Combustion (Boiler) input screen

The figure above shows the base configuration of the PC plant. Combustion, postcombustion, and solids management controls must be configured by the user. The following sections describe each popup menu on the configuration screen.

Pre-configuration settings can be selected using the Configuration menu at the top of the screen. No Devices is the default.

\section{Combustion Controls}

These configuration options determine the type of furnace and any technologies for reducing $\mathrm{NO}_{\mathrm{x}}$ emissions. 
Fuel Type: Coal is the primary fuel used by the PC plant. The choices also include the following which are grayed out and may be available in the future:

- Coal

- Oil

- Natural Gas

- Other

$\mathrm{NO}_{\mathrm{x}}$ Control: From this configuration screen, you may choose.

- None

- In-Furnace Controls: Controls include an assortment of options which combine low $\mathrm{NO}_{\mathrm{x}}$ burners (LNB) with overfire air (OFA), selective non-catalytic reduction (SNCR), and natural gas reburn. These options are selected from a pull-down menu in the Set Parameters menu

\section{Post-Combustion Controls}

These configuration options determine the presence and type of post-combustion emissions controls.

$\mathrm{NO}_{\mathrm{x}}$ Control: The default option is None. The choices available are

- None, for no post-combustion $\mathrm{NO}_{\mathrm{x}}$ control

- Hot Side SCR for a Hot-Side Selective Catalytic Reduction technology. Although an SCR technology can be positioned at various points along the flue gas train, the IECM considers only the hot-side, high dust configuration. Hot Side SCR may be together with In-Furnace Controls.

Particulates: The default option is None. The None setting is not available when the Mercury technology option is either Carbon Injection or Carbon + Water Injection. This assures the removal of the carbon being injected immediately downstream of the air preheater.

Multiple fabric filter types are provided. Fabric filter types are based on the bag cleaning techniques used. Various bag-cleaning techniques influence other process parameters. The choice of the bag cleaning method is usually based on the type of coal used - and therefore the filterability of the ash-and your experience with filtering the particular kind of ash. The particular option you select determines the air to cloth ratio, bag life, bag length, power requirements, pressure drop, capital costs and O\&M costs.

The choices available are:

- None: for no post-combustion particulate control

- Cold Side ESP: for a Cold-Side Electrostatic Precipitator

- Reverse Gas Fabric Filter: Uses an off-line bag cleaning technique in which an auxiliary fan forces a relatively gentle flow of filtered flue gas backwards through the bags causing them to partially collapse and dislodge the dust cake. Over $90 \%$ of baghouses in U. S. utilities use reverse-gas cleaning. 
- Reverse Gas Sonic Fabric Filter: Uses a variation of Reverse Gas cleaning in which low frequency pneumatic horns sound simultaneously with the flow of reverse gas to add energy to the dust cake removal process.

- Shake \& Deflate Fabric Filter: Uses a method for off-line cleaning in which the bags are mechanically shaken immediately after or while a small quantity of filtered gas is forced back to relax the bags. The amount of filtered gas used is smaller than that used in Reverse Gas cleaning.

- Pulse-Jet Fabric Filter: Uses a method for on-line cleaning in which pulses of compressed air are blown down inside and through the bags to remove dust cake while the bags are filtering flue gas. Wire support cages are used to prevent bag collapse during filtration and ash is collected outside of the bags.

$\mathrm{SO}_{2}$ Control: The default option is None. The following choices available are:

- None: for no post-combustion $\mathrm{SO}_{2}$ control

- Wet FGD: for a Wet Flue Gas Desulfurization technology. Multiple reagent options are available under the $\mathbf{S O}_{2}$ Control tab in the Set Parameters section of the interface.

- Lime Spray Dryer: for a dry scrubber using lime as a reagent. The interfact places this technology before the particulate control technology in the plant design and diagrams.

Mercury: The default option is None. Other options are only available if a particulate control is configured. The options provided are:

None: for no mercury control

- Carbon Injection: Although some mercury removal is accomplished naturally in a power plant. It is believed that some mercury is captured or trapped in ash and is removed with bottom ash and fly ash. Carbon injection is provided as a technology to achieve higher removals by injecting fine particles of activated carbon into the flue gas after the air preheater.

- Carbon + Water Injection: Because the removal increases with lower flue gas temperatures, water injection is added to the carbon injection as a second technology option.

$\mathrm{CO}_{2}$ Capture: The default option is None. The following choices available are:

None: for no $\mathrm{CO}_{2}$ capture.

- Amine System: this option puts an amine scrubber at the end of the flue gas train. Other locations may be available in the future.

- $\mathbf{C O}_{2}$ Adsorption: this option is grayed out and may be available in the future.

- $\mathrm{O}_{2}$ Transport Membrane: this option is grayed out and may be available in the future.

- Cryogenics: this option is grayed out and may be available in the future. 


\section{Solids Management}

Flyash Disposal: This configuration setting determines how flyash is disposed. Fly ash collected from a particulate removal system is typically combined with other solid waste streams if other waste streams exist. The waste disposal option has little effect on the rest of the IECM. The choices are

No Mixing: for no flyash mixing. This option disposes the flyash separately.

- Mixed w/FGD Wastes: to dispose flyash with FGD wastes. This option can only be selected if a wet FGD is configured under the $\mathrm{SO}_{2}$ Control option.

- Mixed w/ Bottom Ash: to dispose flyash with bottom ash (e.g. in the pond).

\section{Configuring the Combustion Turbine Plant}

The following configuration options are available when the Combustion (Turbine) is selected as the plant type from the New Session pull down menu.

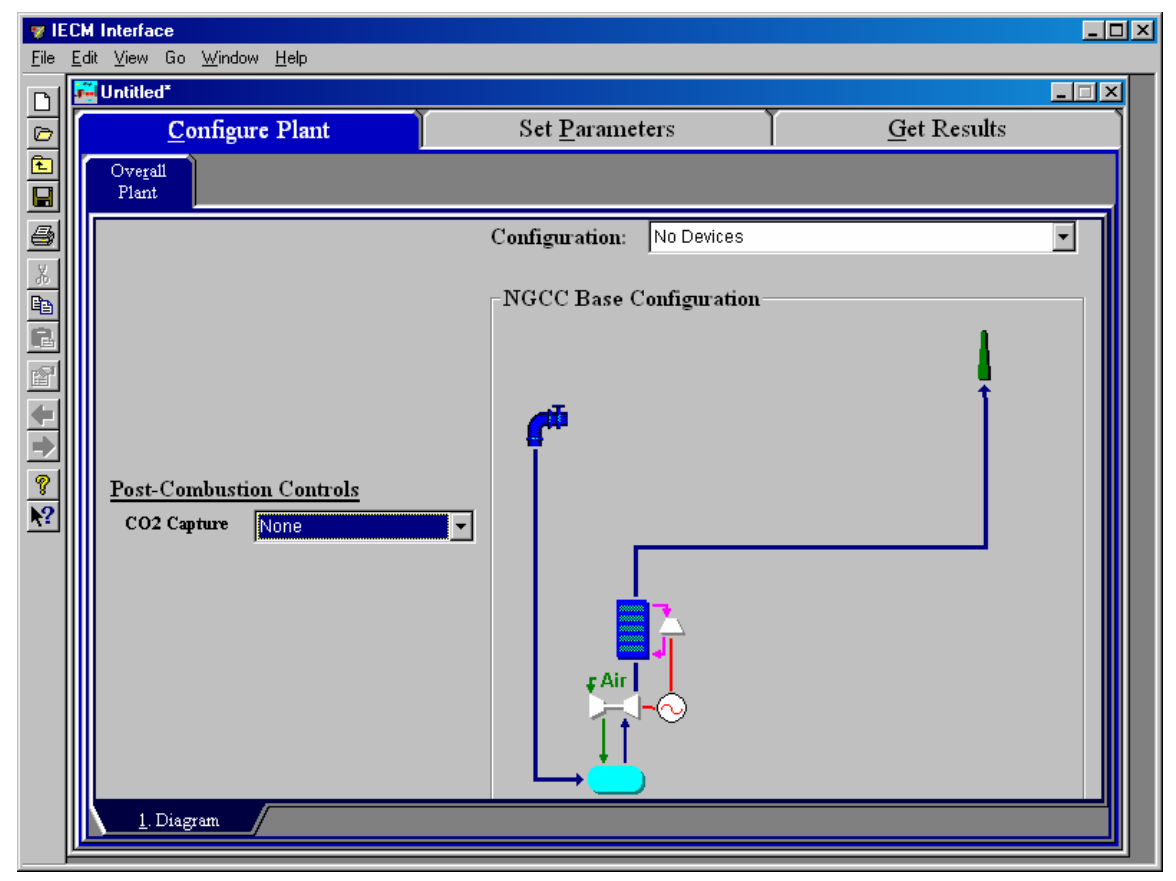

Configure Plant - Combustion (Turbine) input screen.

The figure above shows the base configuration of the Combustion (Turbine) or NGCC plant. Only post-combustion controls can be configured by the user. The following sections describe each popup menu on the configuration screen.

Pre-configuration settings can be selected using the Configuration menu at the top of the screen. No Devices is the default.

\section{Post-Combustion Controls}

$\mathrm{CO}_{2}$ Capture: The default is None. The following options are available: 


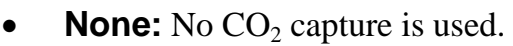

- Amine System: An MEA scrubber is the only method currently available in the IECM for capturing $\mathrm{CO}_{2}$.

- $\mathrm{CO}_{2}$ Adsorption: This method of $\mathrm{CO}_{2}$ capture is grayed out in the menu and is planned for a future release of the model.

- $\mathrm{O}_{\mathbf{2}}$ Transport Membrane: This method of $\mathrm{CO}_{2}$ capture is grayed out in the menu and is planned for a future release of the model.

- Cryogenics: This method of $\mathrm{CO}_{2}$ capture is grayed out in the menu and is planned for a future release of the model.

\section{Configuring the IGCC}

The following configuration options are available when the IGCC is selected as the plant type from the New Session pull down menu.

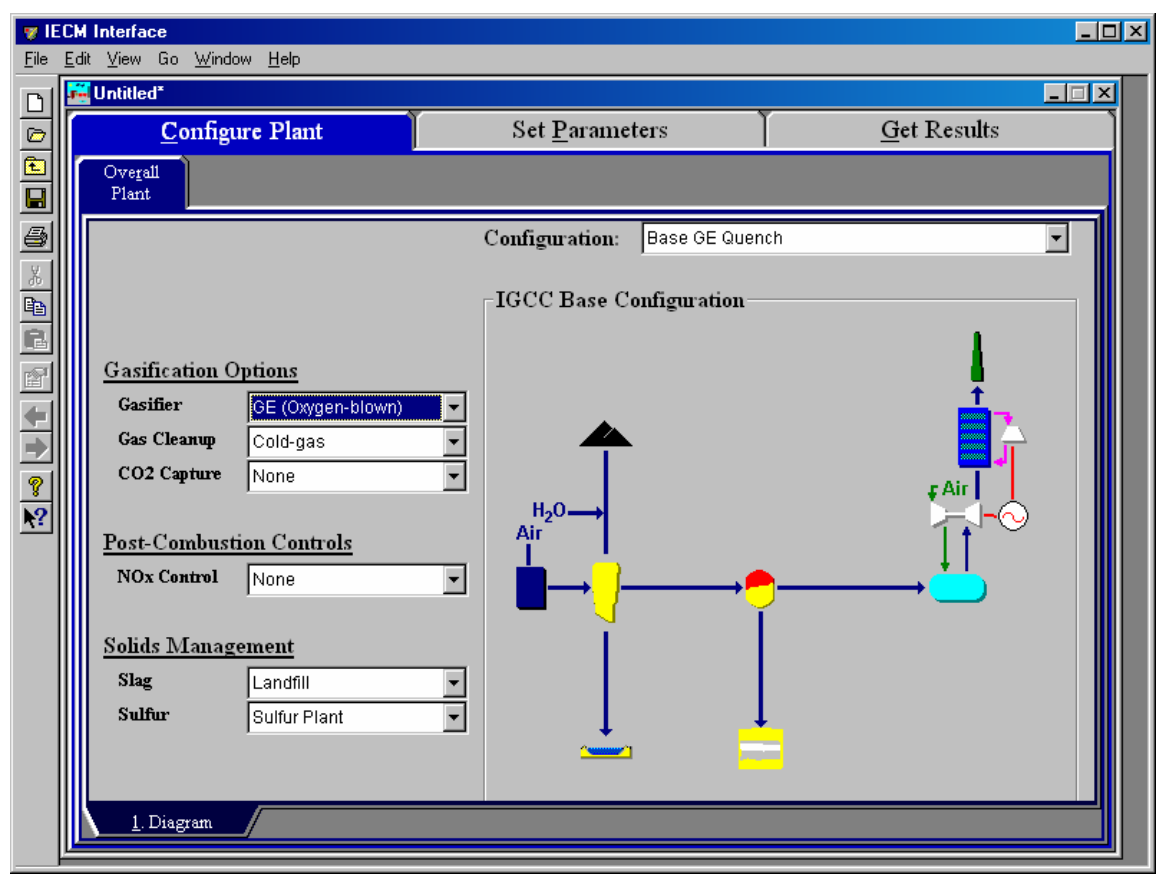

Configure Plant - IGCC input screen.

The figure above shows the base configuration of the IGCC plant. Gasification, postcombustion, and solids management controls can be configured by the user. The following sections describe each popup menu on the configuration screen.

Pre-configuration settings can be selected using the Configuration menu at the top of the screen. Base GE Quench is the default.

\section{Gasification Options}

Gasifier: There is a pull down menu so that the user may select the gasifier type. The choices are: 
- GE (Oxygen blown): This is the only gasifier currently available in the model.

- E-Gas (Oxygen blown): This option is grayed out in the pull down menu and will be available in a future release of the model.

- KRW (Air blown): This option is grayed out in the pull down menu and will be available in a future release of the model.

- Shell (Oxygen blown): This option is grayed out in the pull down menu and will be available in a future release of the model.

Gas Cleanup: This menu will be used in the future to allow a user to select a suite of gas cleanup technologies. Particular devices for removing solids and sulfur while altering the syngas temperature are loaded with this menu. Presently, Cold-gas Cleanup is used with the GE (Oxygen-blown) gasifier in the model. The future choices will be:

- None: This option is grayed out in the pull down menu and will be available in a future release of the model.

- Warm-gas: This option is grayed out in the pull down menu and will be available in a future release of the model.

- Cold-gas: This is implemented in the model.

$\mathbf{C O}_{2}$ Capture: The default is None. The user may select from the $\mathrm{CO}_{2}$ Capture pull down menu whether or not to capture $\mathrm{CO}_{2}$ and the method of capture.

- None: no $\mathrm{CO}_{2}$ capture is used.

- Sour Shift + Selexol: This option is the only one currently available in the model.

- Sweet Shift + Selexol: This option is grayed out in the pull down menu and will be available in a future release of the model.

- Shift + Comb. $\mathrm{CO}_{2} / \mathrm{H}_{2} \mathrm{~S}$ : This option is grayed out in the pull down menu and will be available in a future release of the model.

\section{Post-Combustion Controls}

$\mathrm{NO}_{\mathrm{x}}$ Control: At present the only option available for selection is None. The following are provided in the menu:

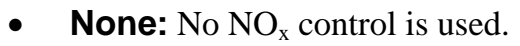

- SCR: This option is grayed out and will be available in a future release of the model.

\section{Solids Management}

Slag: Landfill is the default. The following choices are available:

- None: Slag collected is not sent to a landfill.

- Landfill: The slag collected is disposed in a landfill.

Sulfur: Sulfur captured can be processed by the following equipment options: 
- Sulfur Plant: Sulfur is processed into a solid form. This option is the only one currently available in the model.

- Sulfuric Acid Plant: Sulfur is processed into an acid form. This option is grayed out in the pull down menu and may be available in a future release of the model. 



\section{Combustion Overall Plant}

The input parameter screens described in the following sections are available when the Combustion (Boiler) is selected as the plant type from the New Session pull down menu. These screens apply to the power plant as a whole, not to specific technologies.

\section{Combustion Overall Plant Diagram}

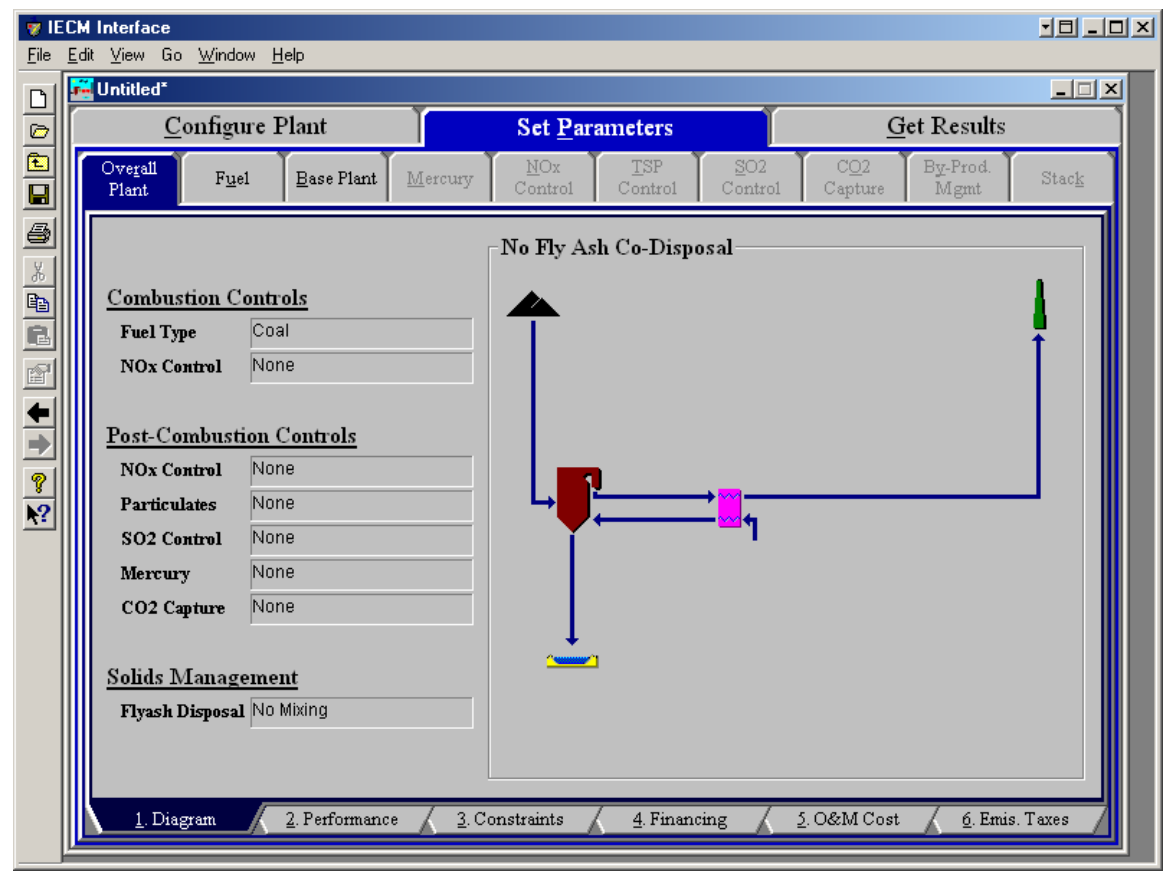

Combustion Overall Plant - Diagram result screen.

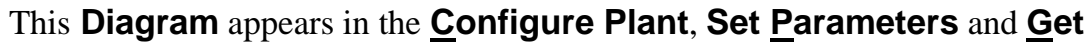
Results program areas. The screen displays the plant configuration settings on the left side of the page and a diagram of the configured plant on the right of the page. No input parameters or results are displayed on this screen. 


\section{Combustion Overall Plant Performance Inputs}

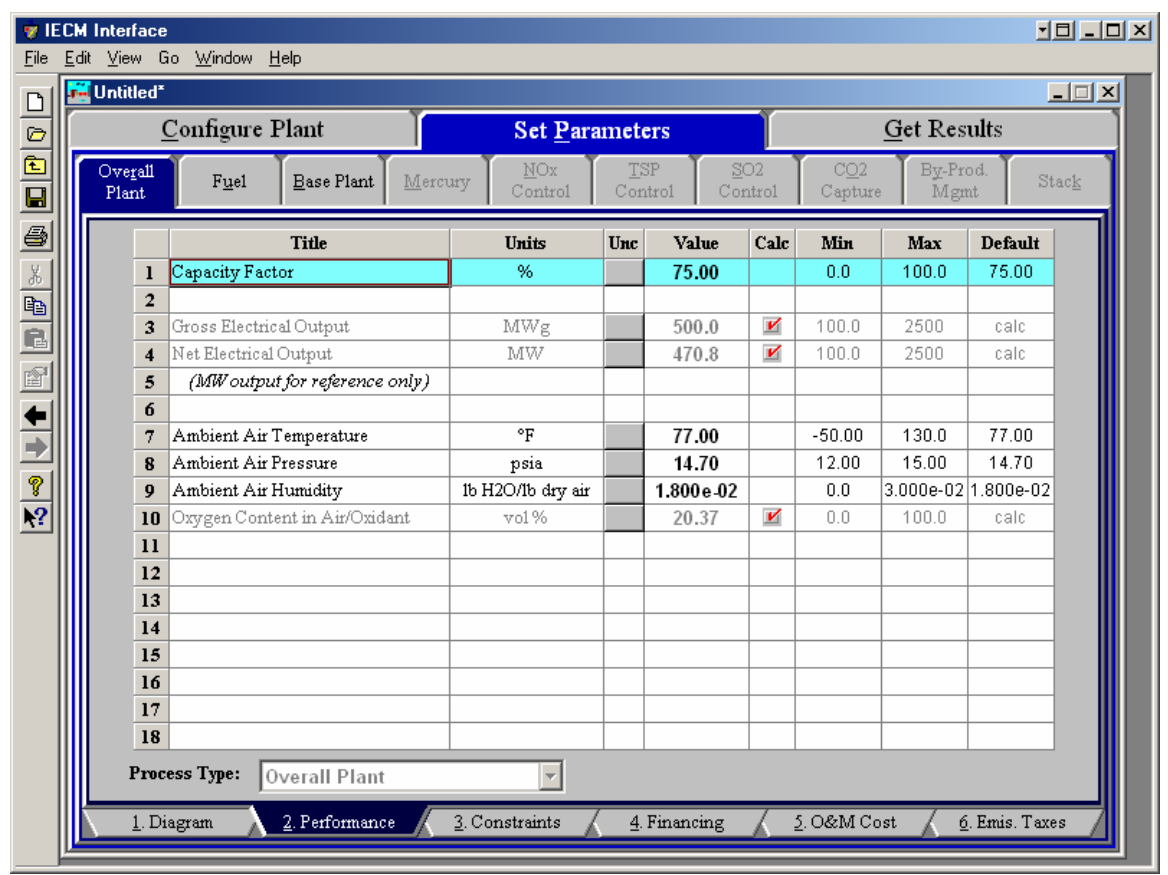

Combustion Overall Plant-Performance input screen.

The parameters available on this screen establish the plant availability, electrical requirements, and ambient conditions for the power plant. These parameters have a major impact on the performance and costs of each of the individual technologies.

Capacity Factor: This is an annual average value, representing the percent of equivalent full load operation during a year. The capacity factor is used to calculate annual average emissions and materials flows.

Gross Electrical Output: This is the gross output of the generator(s) in megawatts (MWg). The value does not include auxiliary power requirements. The model uses this information to calculate key mass flow rates. The value here is shown for reference only. The value can be changed for a combustion plant by navigating to the Base Plant Performance Inputs screen.

Net Electrical Output: This is the net plant capacity, which is the gross plant capacity minus the losses due to plant equipment and pollution equipment (energy penalties). The value cannot be changed and is shown for reference only.

Ambient Air Temperature: This is the inlet temperature of the ambient combustion air prior to entering the preheater. The model presumes an annual average temperature. Inlet air temperature affects the boiler energy balance and efficiency. It provides a reference point for the calculation of pressure throughout the system. Currently, the model cannot have temperatures below $77^{\circ} \mathrm{F}$.

Ambient Air Pressure: This is the absolute pressure of the air inlet stream to the boiler. The air pressure is used to convert flue gas molar flow rates to volume flow rates. 
Ambient Air Humidity: This is the water content of the inlet combustion air. This value is used in calculating the total water vapor content of the flue gas stream. The value is referred to as the specific humidity ratio, expressed as a ratio of the water mass to the dry air mass.

\section{Combustion Overall Plant Constraints Inputs}

The Constraints input parameters define the emission constraints as they apply to the gases emitted from the power plant.

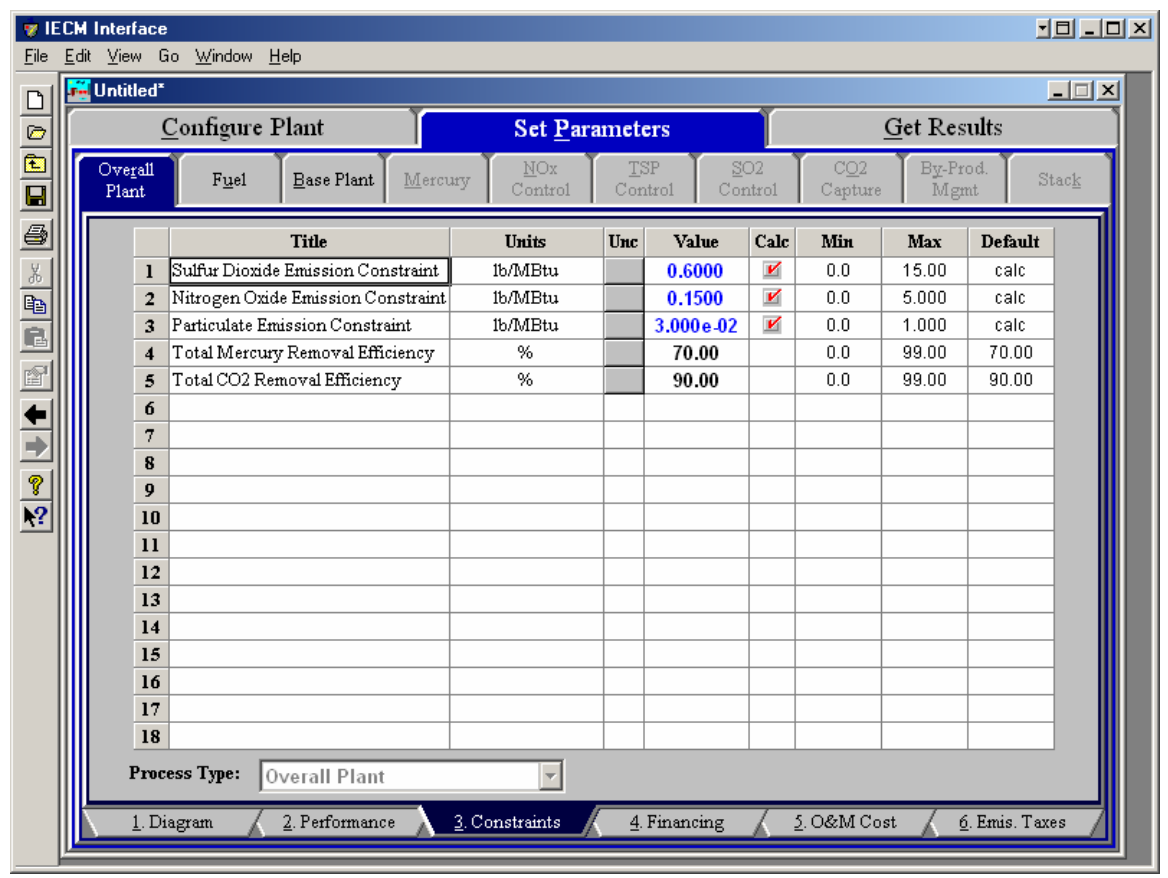

Overall Plant - Emission Constraints input screen.

This screen accepts input for the allowable emission limits for sulfur dioxide, nitrogen oxides and particulate matter. Mercury and carbon dioxide are constrained by their removal efficiencies across the entire plant.

The default values for the calculated inputs reflect current United States New Source Performance Standards (NSPS), which are applicable to all units constructed since 1978. $\mathrm{SO}_{2}$ emission limits are based on the NSPS limits that are a function of the sulfur content of the coal.

The emission constraints determine the removal efficiencies of control systems for $\mathrm{SO}_{2}, \mathrm{NO}_{\mathrm{x}}$, and particulate matter required to comply with the specified emission constraints. As discussed later, however, user-specified values for control technology performance may cause the plant to over-comply or under-comply with the emission constraints specified in this screen. Each parameter is described briefly below.

Sulfur Dioxide Emission Constraint: The emission constraint is defined by the 1979 revised NSPS. The calculated value is determined by the potential emission of the raw coal, minus the amount of sulfur retained in the ash streams. The emission limit is dependent on the fuel type and is used to determine the removal efficiency of $\mathrm{SO}_{\mathrm{x}}$ control systems. 
Nitrogen Oxide Emission Constraint: The combined emissions of $\mathrm{NO}_{2}$ and $\mathrm{NO}_{3}$ of present power plants are constrained by NSPS standards. The limit is a function of the coal rank and fuel type and is used to determine the removal efficiency of $\mathrm{NO}_{\mathrm{x}}$ control systems.

Particulate Emission Constraint: The emission constraint of the total suspended particulates is defined by the NSPS standards of 1978. The limit is a function of the fuel type and is used to determine the removal efficiency of particulate control systems.

Total Mercury Removal Constraint: The emission constraint of total after the economizer. Mercury removed in the furnace due to bottom ash removal is not considered in this constraint. The limit determines the removal efficiency of the particulate control systems.

Total $\mathrm{CO}_{2}$ Removal Constraint: The emission constraint applies to all the air emission sources in the power plant, primary or secondary. The default value is based on recent discussions and is not based on any currently enforced law.

\section{Combustion Overall Plant Financing Inputs}

Inputs for the financing costs of the base plant itself are entered on the Financing input screen.

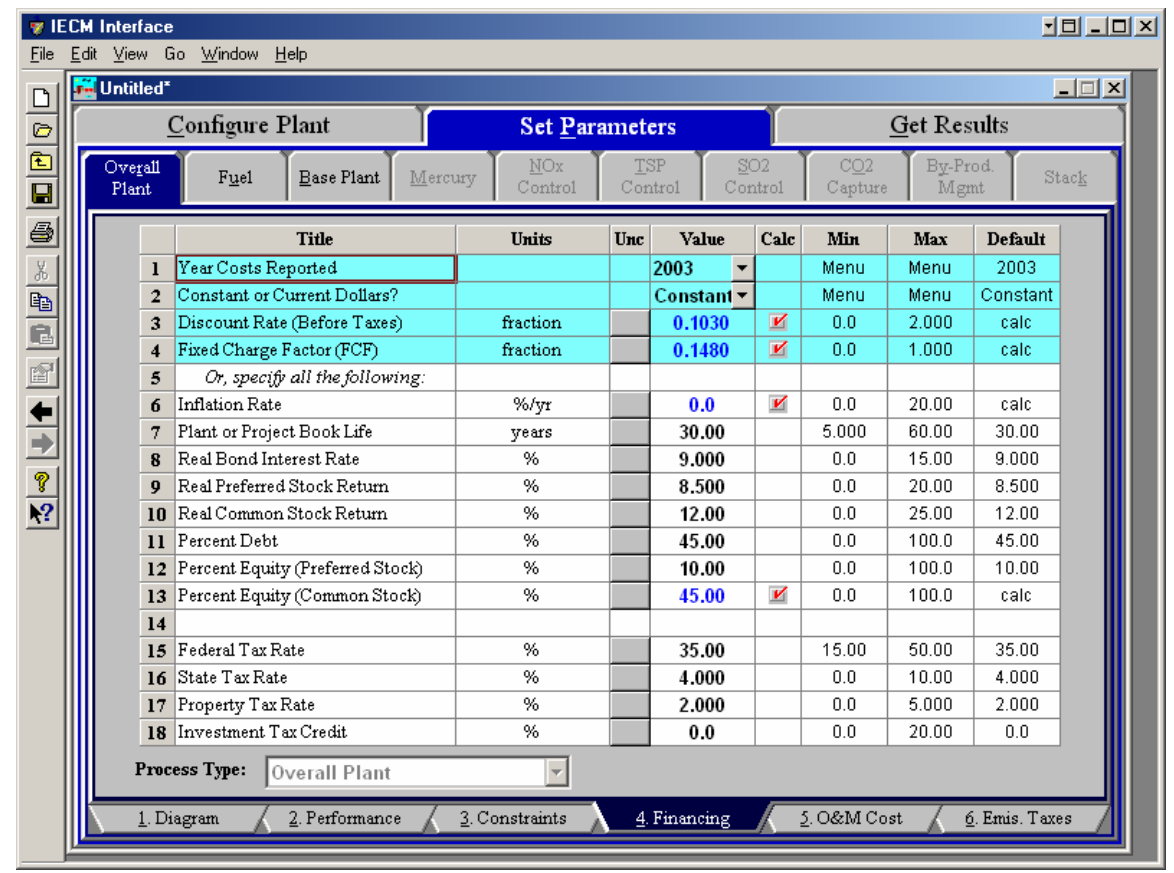

Overall Plant-Financing input screen.

This screen describes the factors required to determine the carrying charge for all capital investments. The carrying charge is defined as the revenue required for the capital investment. The total charge can also be expressed as a levelized cost factor or fixed charge factor. The fixed charge factor is a function of many items. The fixed charge factor can be specified directly or calculated from the other input quantities below it on the financial input screen.

Each parameter is described briefly below. 
Year Costs Reported: This is the year in which all costs are given or displayed, both in the input screens and the results. A cost index is used by the IECM to scale all costs to the cost year specified by this parameter. The cost year is reported on every input and result screen associated with costs throughout the interface.

Constant or Current Dollars: Constant dollar analysis does not include the affect of inflation, although real escalation is included. Current dollar analysis includes inflation and real escalation. This choice allows you to choose the mode of analysis for the entire IECM economics. The cost basis is reported on every input and result screen associated with costs throughout the interface.

Discount Rate (Before Taxes): This is also known as the cost of money. Discount rate (before taxes) is equal to the sum of return on debt plus return on equity, and is the time value of money used in before-tax present worth arithmetic (i.e., levelization).

Fixed Charge Factor (FCF): The fixed charge factor is one of the most important parameters in the IECM. It determines the revenue required to finance the power plant based on the capital expenditures. Put another way, it is a levelized factor which accounts for the revenue per dollar of total plant cost that must be collected from customers in order to pay the carrying charges on that capital investment.

One may specify a fixed charge factor, or fill in the following inputs and the model will calculate the FCF based on them:

Inflation Rate: This is the rise in price levels caused by an increase in the available currency and credit without a proportionate increase in available goods or services. It does not include real escalation.

Plant or Project Book Life: This is the years of service expected from a capital investment. It is also the period over which an investment is recovered through book depreciation.

Real Bond Interest Rate: This is a debt security associated with a loan or mortgage. It is the most secure form of security but the lowest in its return.

Real Preferred Stock Return: This equity security is the second most speculative type and pays the second highest rate of return. The holder of the stock is a part owner of the company.

Real Common Stock Return: This is the most speculative type of equity security sold by a utility and pays the highest relative return. The holder of the stock is a part owner of the company.

Percent Debt: This is the percent of the total capitalization that is associated with debt money. This includes loans and mortgage bonds.

Percent Equity (Preferred Stock): This is the percent of the total capitalization that is associated with the sale of preferred stock.

Percent Equity (Common Stock): This value is the remainder of the capitalization, calculated as $100 \%$ minus the percent debt, minus the percent equity in preferred stock.

Federal Tax Rate: This is the federal tax rate. It is used to calculate the amount of taxes paid and deferred.

State Tax Rate: This is the state tax rate. It is used to calculate the amount of taxes paid and deferred. 
Property Tax Rate: The property tax rate, or ad valorem, is used to calculate the carrying charge.

Investment Tax Credit: This is an immediate reduction in income taxes equal to a percentage of the installed cost of a new capital investment. It is zero by default. It is used to set the initial balance and the book depreciation.

\section{Combustion Overall Plant O\&M Inputs}

This screen combines the variable O\&M unit costs from all the model components and places them in one spot. These values will also appear in the technology input screens where they are actually used. Values changed on this screen will reflect exactly the same change everywhere else they appear. O\&M costs are typically expressed on an average annual basis and are provided in either constant or current dollars for a specified year, as shown on the bottom of the screen.

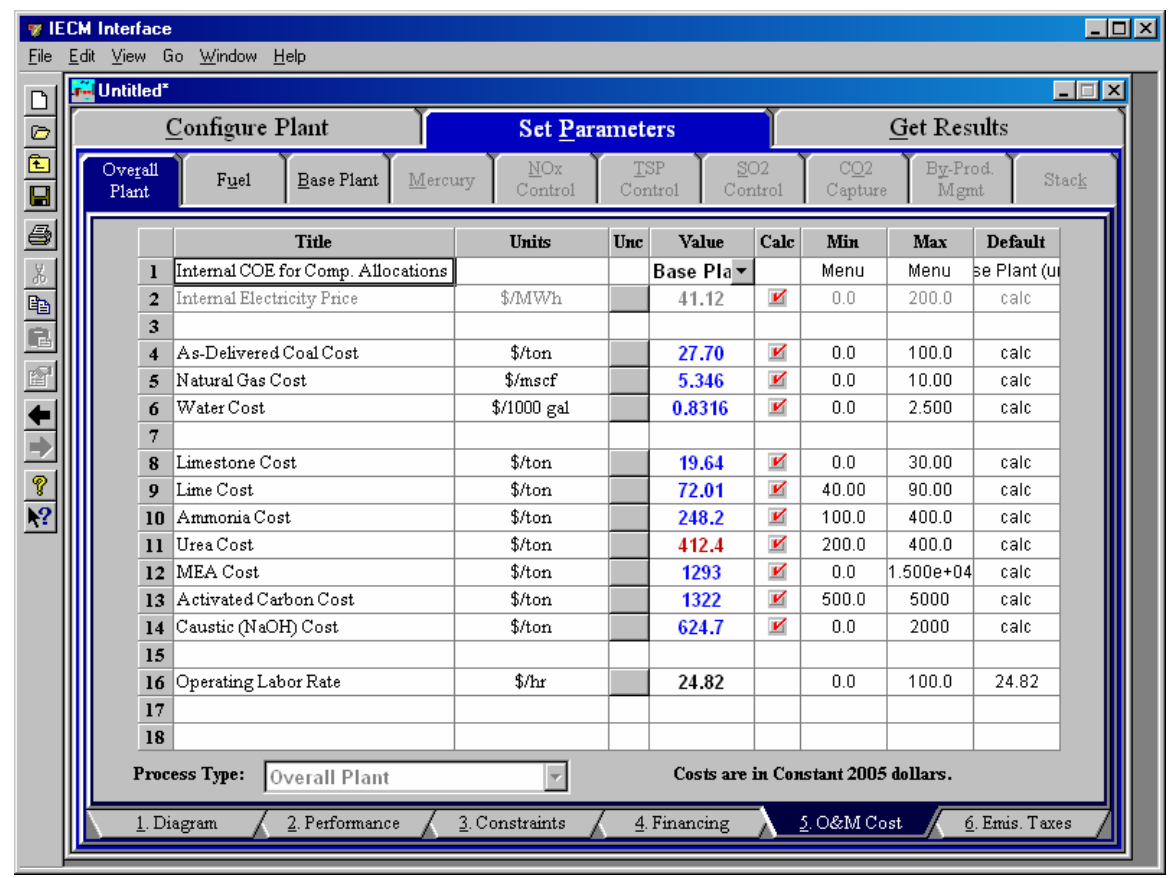

Overall Plant - O\&M Cost input screen.

Internal COE for Comp. Allocations: This is a pop-up selection menu that determines the method for determining electricity costs within the power plant. The selection of this pop-up menu determines the actual internal electricity price on the next line. The options are:

\section{- Base Plant (uncontrolled)}

- User Specified

\section{- Total Plant COE}

Internal Electricity Price: This is the price of electricity and is calculated as a function of the utility cost of the base plant. The base plant for the Combustion (Boiler) model is assumed to be a coal pile, combustion boiler, air preheater, and disposal sites. This value is 
calculated and provided for reference purposes only unless User Specified is selected in the pop-up in the previous line.

As-Delivered Coal Cost: This is the cost of the coal as-delivered.

Natural Gas Cost: This is the cost of natural gas in dollars per thousand standard cubic feet.

Water Cost: This is the cost of water in dollars per thousand gallons.

Limestone Cost: This is the cost of limestone in dollars per ton.

Lime Cost: This is the cost of lime in dollars per ton.

Ammonia Cost: This is the cost of ammonia in dollars per ton.

Urea Cost: This is the cost of natural gas in dollars per ton.

MEA Cost: This is the cost of MEA in dollars per ton.

Activated Carbon Cost: This is the cost of activated carbon in dollars per ton.

Caustic (NaOH) Cost: This is the cost of caustic (NaOH) gas in dollars per ton.

Operating Labor Rate: The hourly cost of labor is specified in the base plant O\&M cost screen. The same value is used throughout the other technologies.

\section{Combustion Overall Plant Emis. Taxes Inputs}

This screen allows users to specify emission taxes or credits as part of the overall plant cost economics. Taxes or credits are typically provided in either constant or current dollars for a specified year, as shown on the bottom of the screen.

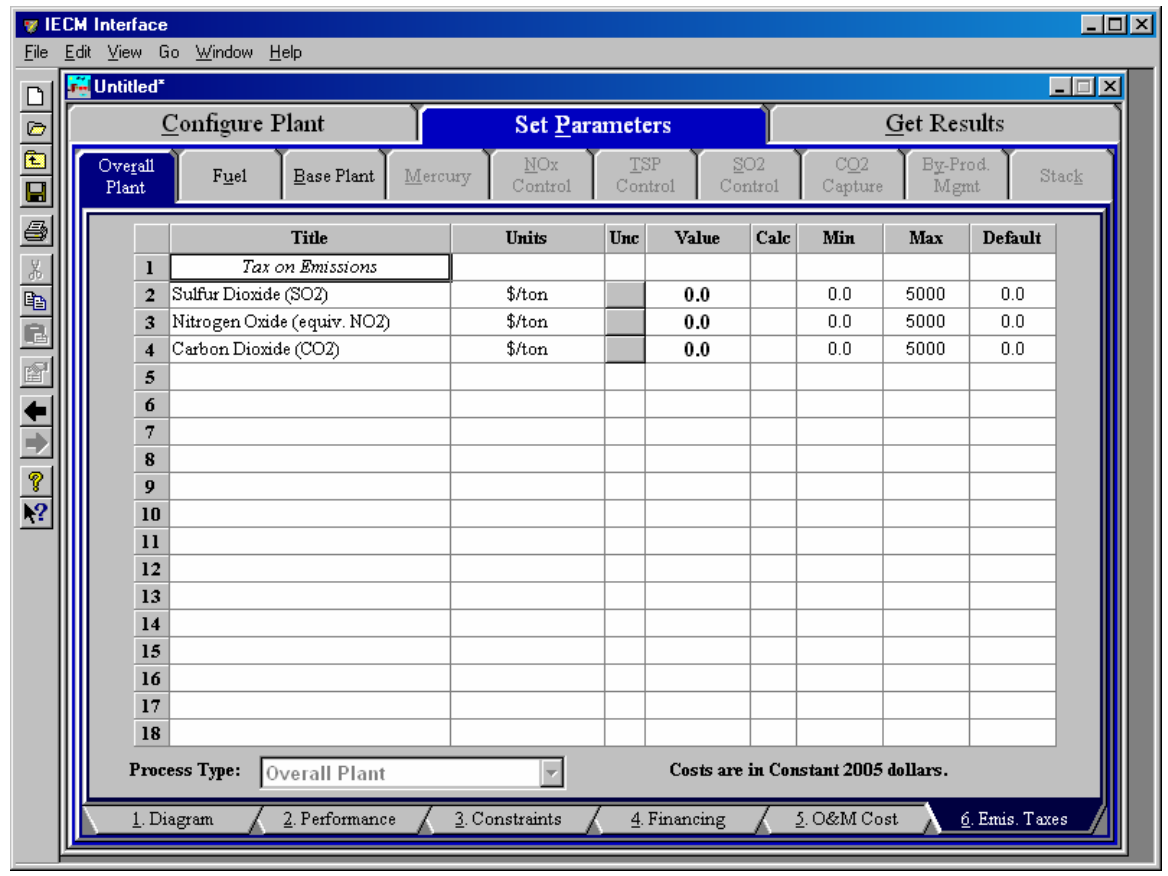

Emission Constraint Emission Taxes input screen. 
The Emis. Taxes input screen allows the user to enter the taxes on emissions in dollars per ton. The final costs determined from these inputs are available under the stack tab in the results section of the IECM. The costs are added to the overall plant cost, not a particular technology.

\section{Tax on Emissions}

Sulfur Dioxide $\left(\mathrm{SO}_{2}\right)$ : The user may enter a cost to the plant of emitting sulfur dioxide in dollars per ton.

Nitrogen Oxide (equiv. $\mathbf{N O}_{\mathbf{x}}$ ) : The user may enter a cost to the plant of emitting nitrogen oxide in dollars per ton.

Carbon Dioxide $\left(\mathrm{CO}_{2}\right)$ : The user may enter a cost to the plant of emitting carbon dioxide in dollars per ton.

\section{Combustion Overall Plant Performance Results}

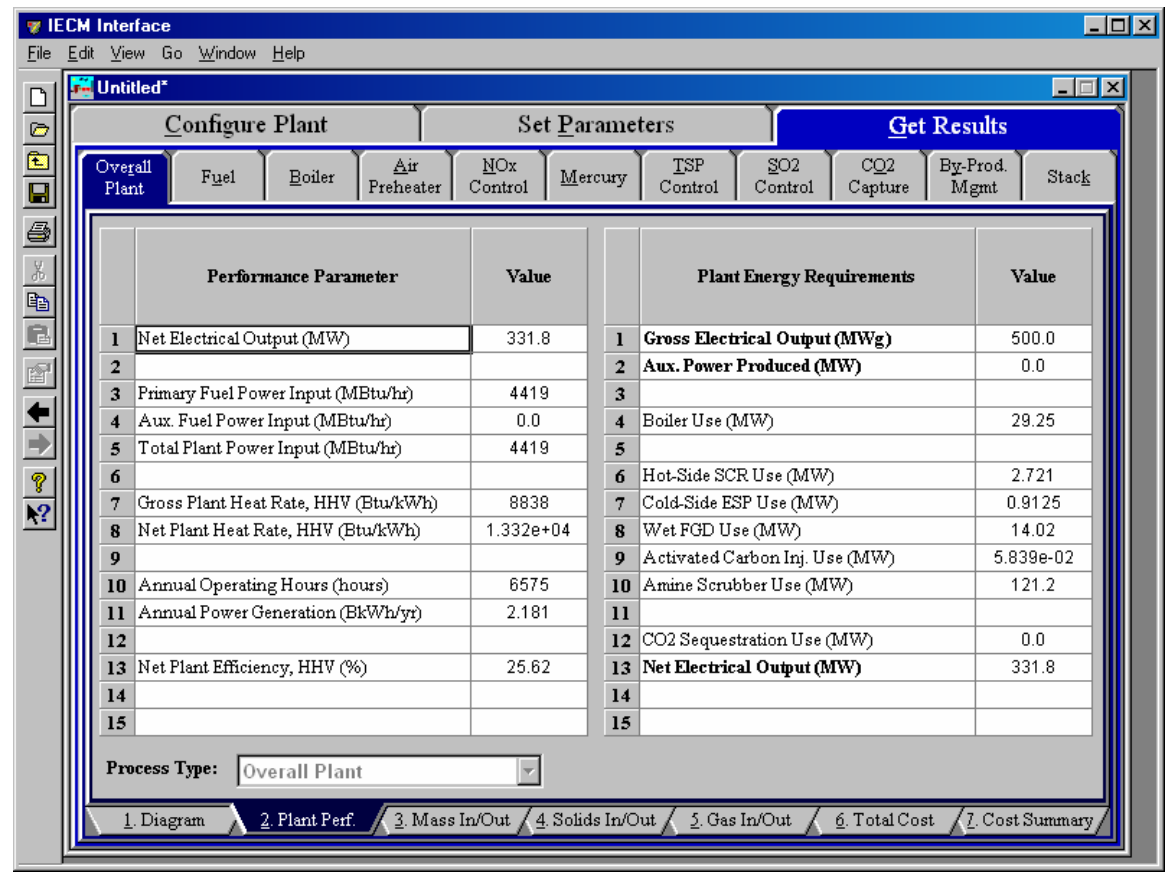

Combustion Overall Plant - Plant Perf. result screen.

The Plant Perf. result screen displays performance results for the plant as a whole. Heat rates and power in and out of the power plant are given. Each result is described briefly below.

\section{Performance Parameter}

Net Electrical Output: This is the net plant capacity, which is the gross plant capacity minus the losses due to plant equipment and pollution equipment (energy penalties).

Primary Fuel Power Input: This is the fuel energy input for the plant, given on an hourly basis (maximum capacity). This rate is also referred to as the fuel power input. 
Aux. Fuel Power Input: This is the fuel energy input for the auxiliary natural gas boiler if used with the Amine System. This is additional fuel energy used by the plant, given on an hourly basis. This rate is also referred to as the auxiliary fuel power input.

Total Plant Power Input: This is the total of all the fuel energy used by the plant, given on an hourly basis (maximum capacity). This rate is also referred to as the total plant power input.

Gross Plant Heat Rate: This is the heat rate of the gross cycle including the effects of the boiler efficiency. This is considered the gross heat rate.

Net Plant Heat Rate: This is the net heat rate, which includes the effect of plant equipment and pollution control equipment.

Annual Operating Hours: This is the number of hours per year that the plant is in operation. If a plant runs 24 hours per day, seven days per week, with no outages, the calculation is 24 hours * 365 days. or 8,760 hours/year.

Annual Power Generation: This is the net annual power production of the plant. The capacity factor and all energy credits or penalties are used in determining its value.

Net Plant Efficiency: The net plant efficiency is displayed here on a HHV basis.

\section{Plant Power Requirements}

A second group of results provide a breakdown of the internal power consumption for the individual technology areas. These are all given in units of megawatts. Individual plant sub-components will only be displayed when they are configured in the Configure Plant section of the model.

Gross Electrical Output: This is the gross output of the generator in megawatts (MWg). The value does not include auxiliary power requirements. The model uses this information to calculate key mass flow rates. The value is an input parameter.

Aux. Power Produced: If an auxiliary natural gas boiler is used to provide steam and power for the Amine System, this is the additional electricity that it produces.

Component Electrical Uses: Power used by various plant and pollution control equipment is reported in the middle portion of the second column. The number displayed varies as a function of the components configured in the power plant.

Net Electrical Output: This is the net plant capacity, which is the gross plant capacity plus any auxiliary electrical output minus the losses due to plant equipment and pollution equipment (energy penalties). This is the same value used in the first column. 


\section{Combustion Overall Plant Mass In/Out}

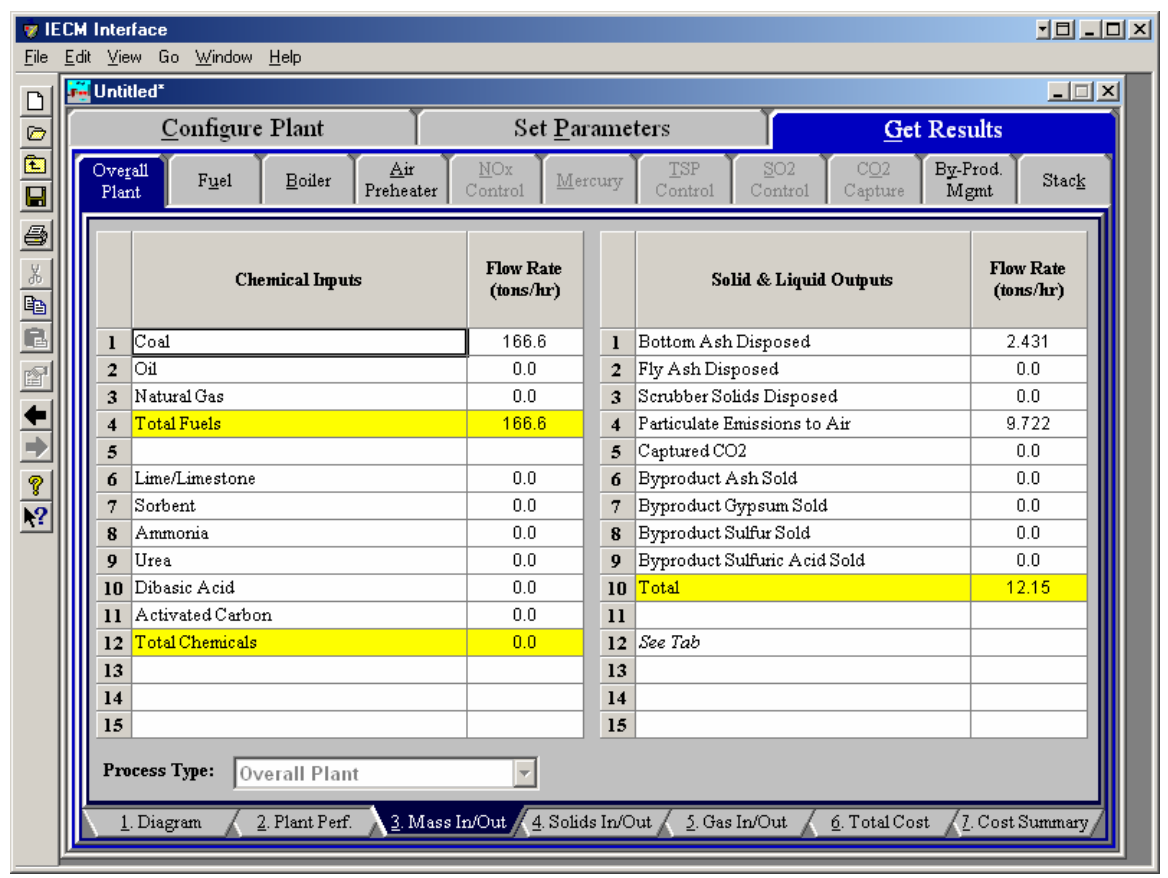

Combustion Overall Plant - Mass In/Out result screen.

The Mass In/Out result screen displays the flow rates of fuels and chemicals into the plant and solid and liquid flow rates out of the plant. Each result is described briefly below.

\section{Input Flow Rates}

Coal: Total mass of coal entering the boiler on a wet basis.

Oil: Total mass of oil used in the power plant

Natural Gas: Total mass of natural gas used in the power plant

Total Fuels: This is the total fuel mass entering the power plant. This result is highlighted in yellow.

Lime/Limestone: Total mass of this reagent used in the power plant on a wet basis.

Sorbent: This is the total mass of sorbent used in the power plant. The sorbent currently used is an amino acid used in the $\mathrm{CO}_{2}$ capture device.

Ammonia: Total mass of ammonia used in the power plant.

Urea: Total mass of urea used in the power plant. Urea is the reagent used to reduce $\mathrm{NO}_{\mathrm{x}}$ in the SNCR technology.

Dibasic Acid: Total mass of dibasic acid used in the power plant.

Activated Carbon: Total mass of activated carbon injected in the power plant.

Total Chemicals: This is the total reagent mass entering the power plant. This result is highlighted in yellow.

\section{Output Flow Rates}


Bottom Ash Disposed: Total mass of bottom ash collected in the power plant on a dry basis.

Fly Ash Disposed: Total mass of fly ash collected in the power plant on a dry basis.

Scrubber Solids Disposed: Total mass of scrubber solid wastes collected in the power plant on a dry basis.

Particulate Emissions to Air: Solids that remain in the flue gas and exit the plant are reported on a mass basis.

Captured $\mathrm{CO}_{2}$ : If a $\mathrm{CO}_{2}$ capture technology has been selected, the mass flow of $\mathrm{CO}_{2}$ captured is reported. It is transported off site. See the $\mathrm{CO}_{2}$ Transport System for more information.

Byproduct Ash Sold: Total mass of ash (bottom and fly ash) sold in commerce as a by-product on a dry basis.

Byproduct Gypsum Sold: Total mass of flue gas treatment solids sold in commerce as a by-product on a dry basis.

Byproduct Sulfur Sold: Total mass of elemental sulfur recovered from flue gas and sold in commerce as a by-product on a dry basis.

Byproduct Sulfuric Acid Sold: Total mass of sulfuric acid recovered from the flue gas and sold in commerce as a by-product.

Total: This is the total wet solid mass exiting the power plant. This result is highlighted in yellow.

\section{Combustion Overall Plant Solids Emissions}

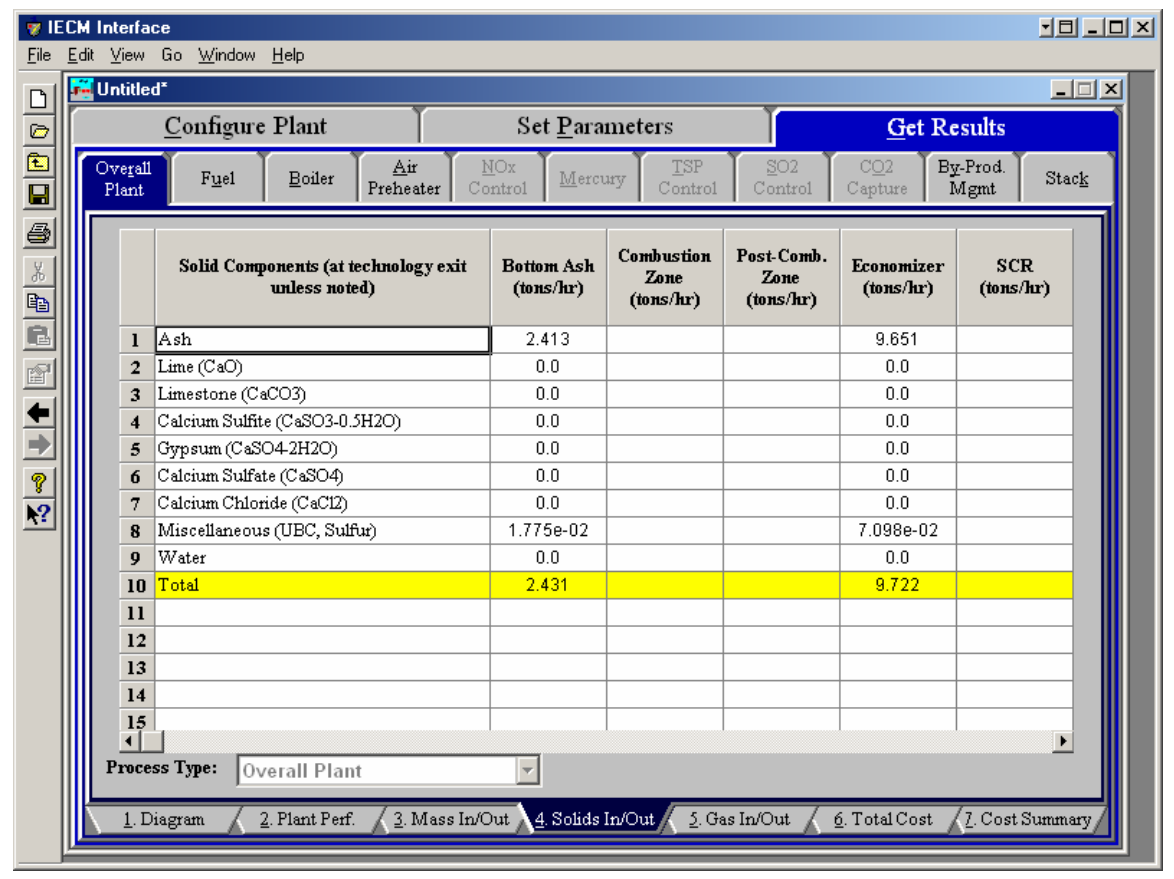

Combustion Overall Plant - Solids Emissions result screen.

The Solids In/Out result screen displays the values for the flow of the solid components in the gas and condensed streams throughout the various stages of the 
power plant. Each result is described briefly below. Note that each column represents the flow rate at the exit of the technology specified at the top of the column. Note that the solids are not reported in this detail inside the technology result screens.

\section{Solid Components}

Ash: Total mass of ash (primarily solid oxides).

Lime (CaO): Total mass flow of lime. This is typically added as a reagent and will react with the flue gas to form another compound.

Limestone $\left(\mathrm{CaCO}_{3}\right)$ : Total mass flow of limestone. This is typically added as a reagent and will react with the flue gas to form another compound.

Calcium Sulfite (CaSO ${ }_{3}^{-1} I_{2} \mathrm{H}_{2} \mathrm{O}$ ): Total mass flow of calcium sulfite, a byproduct of lime or limestone reacting with sulfur in the flue gas.

Gypsum ( $\left.\mathrm{CaSO}_{4}-2 \mathrm{H}_{2} \mathrm{O}\right)$ : Total mass flow of gypsum, a byproduct of lime or limestone reacting with sulfur in the flue gas.

Calcium Sulfate $\left(\mathrm{CaSO}_{4}\right)$ : Total mass flow of calcium sulfate, a byproduct of lime or limestone reacting with sulfur in the flue gas.

Calcium Chloride $\left(\mathrm{CaCl}_{2}\right)$ : Total mass flow of calcium sulfate, a byproduct of lime or limestone reacting with chlorine or chlorine compounds in the flue gas.

Miscellaneous (UCB, Sulfur): Total mass flow of other solids in the flue gas. This includes unburned carbon or unburned sulfur from the boiler.

Water: Total mass flow of condensed water associated with the solids stream. This is more clearly represented in what is considered liquid streams. See the Gas In/Out screen for a summary of the evaporated water flow rate through the power plant. 


\section{Combustion Overall Plant Gas Emissions}

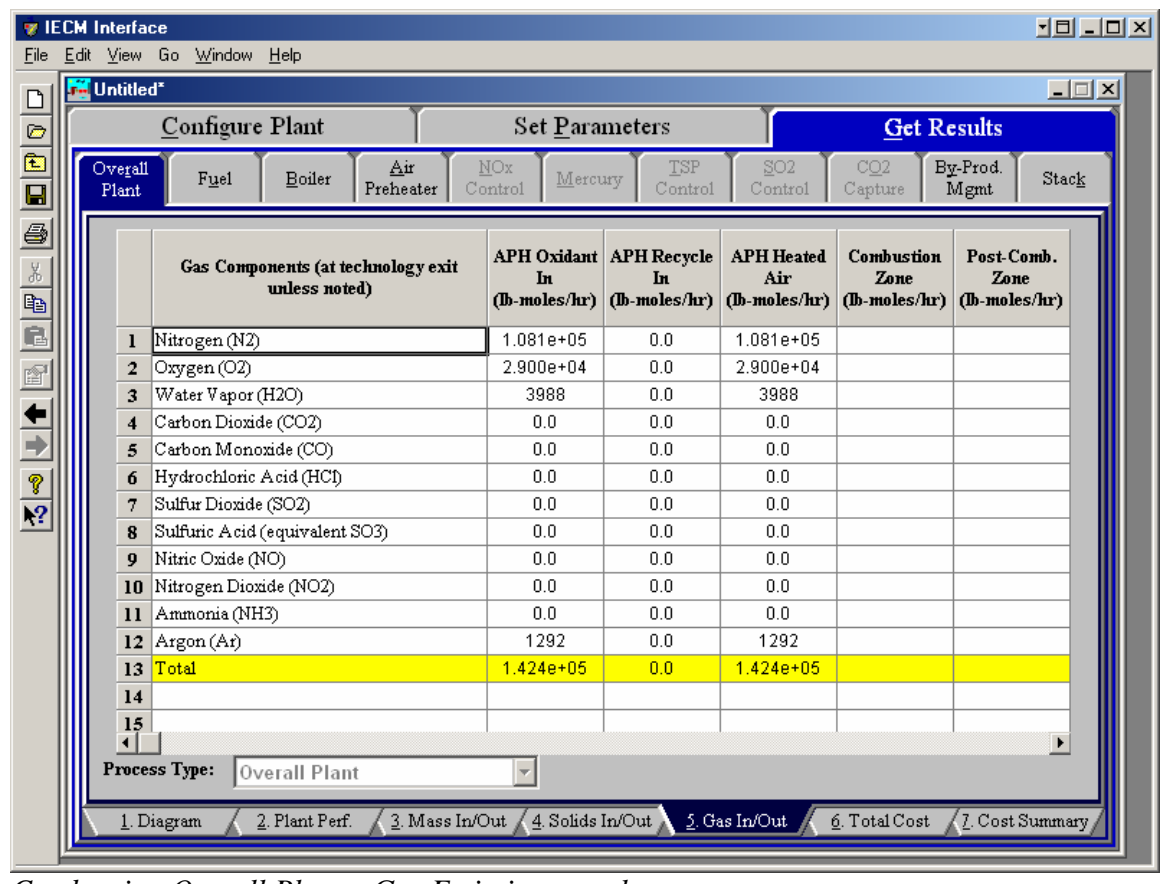

Combustion Overall Plant - Gas Emissions result screen.

The Gas In/Out result screen displays the values for the flow of the gas components in the flue gas throughout the various stages of the power plant. Each result is described briefly below. Note that each column represents the flow rate at the exit of the technology specified at the top of the column. These are also reported elsewhere in the particular technology result screens but duplicated here to provide a broad look at gas emissions.

\section{Stack Gas Components}

Nitrogen $\left(\mathbf{N}_{2}\right)$ : Total mass of emitted nitrogen.

Oxygen $\left(\mathbf{O}_{2}\right)$ : Total mass of emitted oxygen.

Water Vapor $\left(\mathrm{H}_{2} \mathbf{O}\right)$ : Total mass of water vapor.

Carbon Dioxide $\left(\mathrm{CO}_{2}\right)$ : Total mass of carbon dioxide.

Carbon Monoxide (CO): Total mass of carbon monoxide.

Hydrochloric Acid $(\mathrm{HCl})$ : Total mass of hydrochloric acid.

Sulfur Dioxide $\left(\mathrm{SO}_{2}\right)$ : Total mass of sulfur dioxide.

Sulfuric Acid (equivalent $\mathbf{S O}_{3}$ ): Total mass of sulfuric acid.

Nitric Oxide (NO): Total mass of nitric oxide.

Nitrogen Dioxide $\left(\mathrm{NO}_{\mathrm{x}}\right)$ : Total mass of nitrogen dioxide.

Ammonia $\left(\mathrm{NH}_{3}\right)$ : Total mass of ammonia.

Argon (Ar): Argon is present in small quantities in atmospheric air. The argon emitted from the power plant is shown on a mass basis.

Total Gases: Total flow rate of all gases. This result is highlighted in yellow. 


\section{Combustion Overall Total Cost}

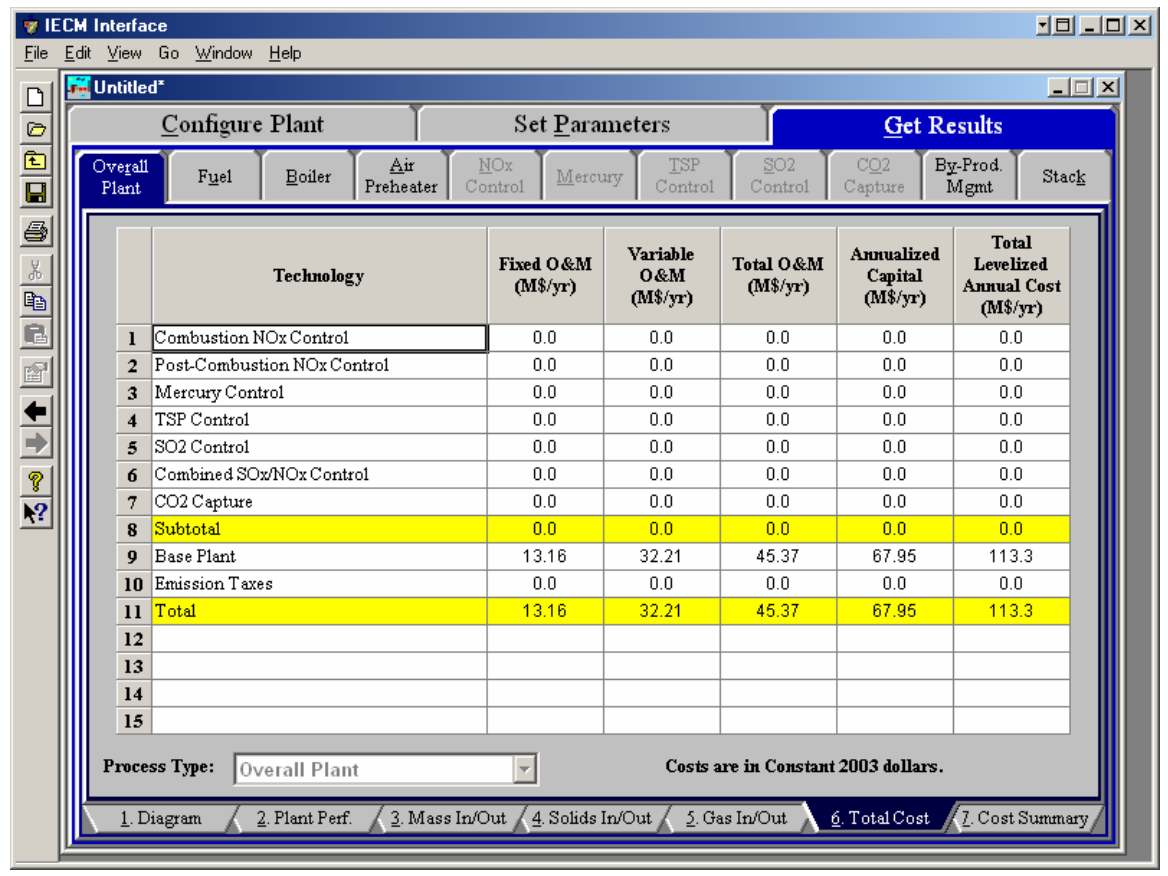

Combustion Overall Plant Total Cost result screen.

The Total Cost result screen displays a table which totals the annual fixed, variable, operations, maintenance, and capital costs associated with the power plant as a whole. The costs summarized on this screen are expressed on an average annual basis and are provided in either constant or current dollars for a specified year, as shown on the bottom of the screen. Each technology (row) is described briefly below.

Combustion $\mathrm{NO}_{\mathbf{x}}$ Control: The total cost of the In-Furnace $\mathrm{NO}_{\mathrm{x}}$ controls used.

Post-Combustion $\mathrm{NO}_{\mathrm{x}}$ Control: The total cost of all the PostCombustion $\mathrm{NO}_{\mathrm{x}}$ removal modules used.

Mercury Control: The total cost of all the mercury control modules used.

TSP Control: The total cost of all the conventional particulate removal modules used.

$\mathrm{SO}_{2}$ Control: The total cost of all the $\mathrm{SO}_{2}$ conventional removal modules used.

Combined $\mathrm{SO}_{\mathbf{x}} / \mathrm{NO}_{\mathrm{x}}$ : The total cost of all the combined $\mathrm{SO}_{\mathrm{x}} / \mathrm{NO}_{\mathrm{x}}$ advanced removal modules used.

Subtotal: This is the cost of the conventional and advanced abatement technology modules alone. This is the total abatement cost. The subtotal is highlighted in yellow.

Base Plant: The total cost of the base plant without consideration of any abatement technologies. This can be used to compare with other power plant types.

Emission Taxes: The total cost of taxes assessed to stack emissions is provided here. 
Total: This is the total cost of the entire power plant. This result is highlighted in yellow.

Each cost category (column) is described briefly below.

Fixed O\&M: The operating and maintenance fixed costs are given as an annual total. This number includes all maintenance materials and all labor costs for each technology.

Variable O\&M: The operating and maintenance variables costs are given as an annual total. This includes all reagent, chemical, steam, and power costs associated with a technology.

Total O\&M: This is the sum of the annual fixed and variable operating and maintenance costs for each technology.

Annualized Capital: This is the total capital cost expressed on an annualized basis, taking into consideration the levelized carrying charge factor, or fixed charge factor, over the entire book life.

Total Levelized Annual Cost: The total annual cost is the sum of the total annual O\&M cost and annualized capital cost items above. This result is highlighted in yellow

\section{Combustion Overall Plant Cost Summary}

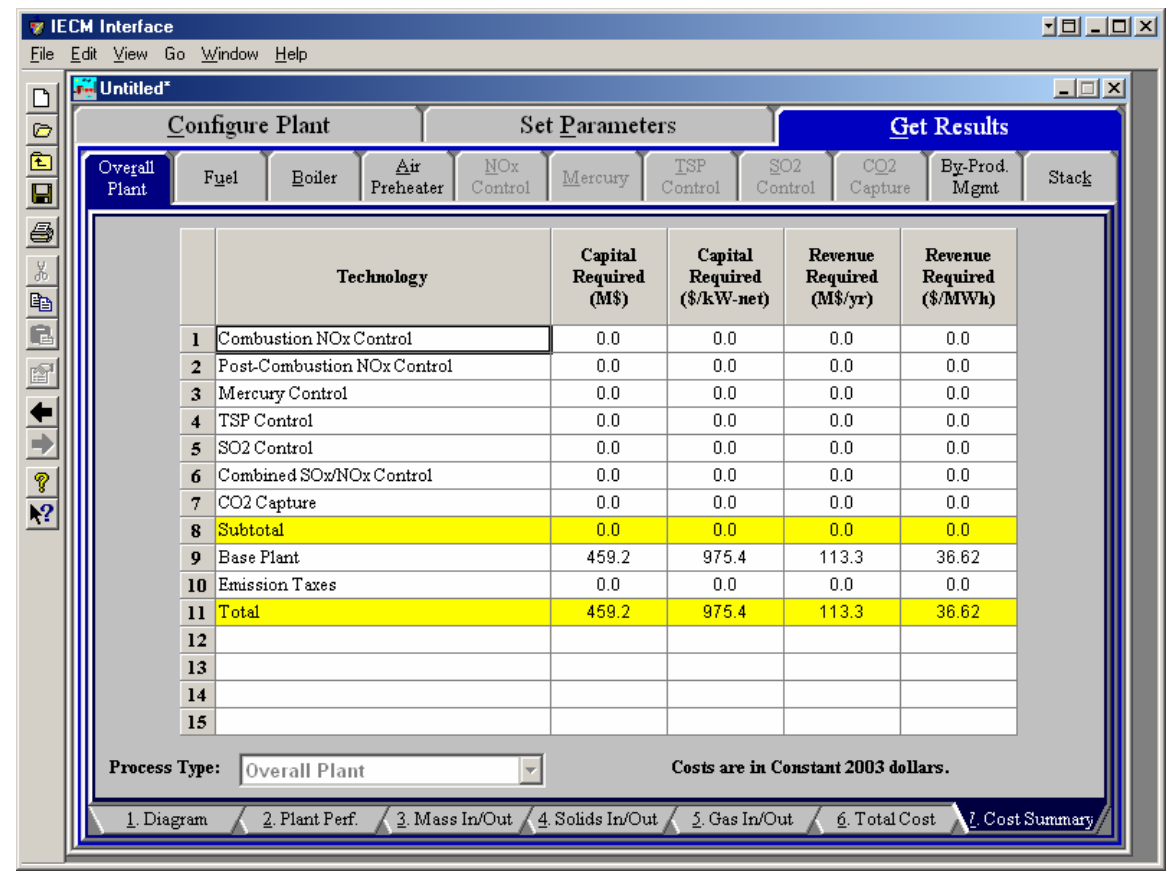

Combustion Overall Plant Cost Summary result screen.

The Cost Summary result screen displays costs associated with the power plant as a whole. The costs summarized on this screen are expressed in either constant or current dollars for a specified year, as shown on the bottom of the screen. Each technology (row) is described briefly below.

Combustion $\mathrm{NO}_{\mathrm{x}}$ Control: The total cost of the In-Furnace $\mathrm{NO}_{\mathrm{x}}$ controls used. 
Post-Combustion $\mathrm{NO}_{\mathrm{x}}$ Control: The total cost of all the PostCombustion $\mathrm{NO}_{\mathrm{x}}$ removal modules used.

Mercury Control: The total cost of all the mercury control modules used.

TSP Control: The total cost of all the conventional particulate removal modules used.

$\mathbf{S O}_{2}$ Control: The total cost of all the $\mathrm{SO}_{2}$ conventional removal modules used.

Combined SO $\mathrm{SO}_{\mathrm{x}} / \mathrm{NO}_{\mathrm{x}}$ : The total cost of all the combined $\mathrm{SO}_{\mathrm{x}} / \mathrm{NO}_{\mathrm{x}}$ advanced removal modules used.

Subtotal: This is the cost of the conventional and advanced abatement technology modules alone. This is the total abatement cost. The subtotal is highlighted in yellow.

Base Plant: The total cost of the base plant without consideration of any abatement technologies. This can be used to compare with other power plant types.

Total: This is the total cost of the entire power plant. This result is highlighted in yellow.

Each cost category (column) is described briefly below.

Capital Required: The total capital requirement (TCR). This is the money that is placed (capitalized) on the books of the utility on the service date. The total cost includes the total plant investment plus capitalized plant startup. Escalation and allowance for funds used during construction (AFUDC) are also included. The capital cost is given on both a total and an annualized basis.

Revenue Required: Amount of money that must be collected from customers to compensate a utility for all expenditures in capital, goods, and services. The revenue requirement is equal to the carrying charges plus expenses. The revenue required is given on both an annualized and a net power output basis. 


\section{Overall NGCC Plant}

The input parameter screens described in the following sections are available when the Combustion (Turbine) is selected as the plant type from the New Session pull down menu. These screens apply to the power plant as a whole, not to specific technologies.

\section{Overall NGCC Plant Diagram}

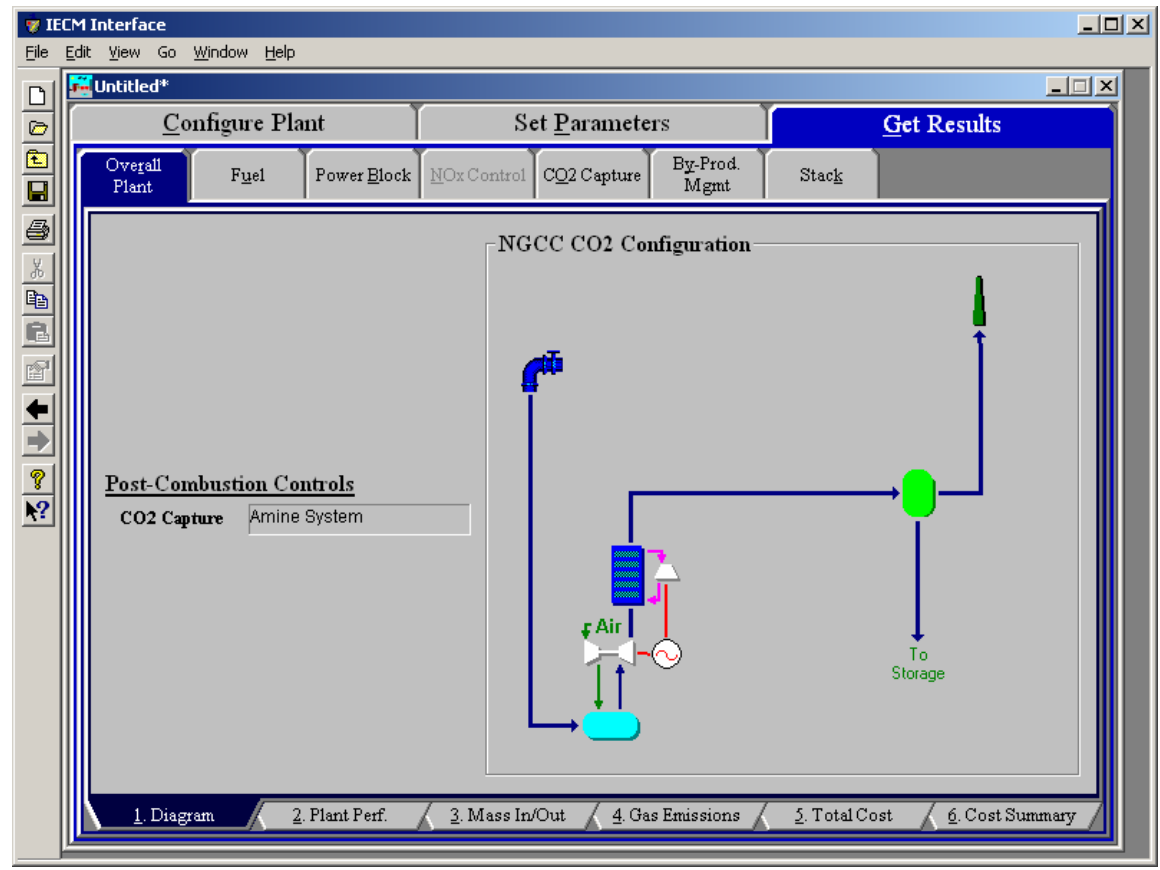

Overall NGCC Plant - Diagram input screen

The Overall NGCC Plant Diagram appears in the Configure Plant, Set Parameters and in the Get Results program area. The screen displays the plant configuration settings on the left side of the page and a diagram of the configured plant on the right of the page. No input parameters or results are displayed on this screen. 


\section{Overall NGCC Plant Performance Inputs}

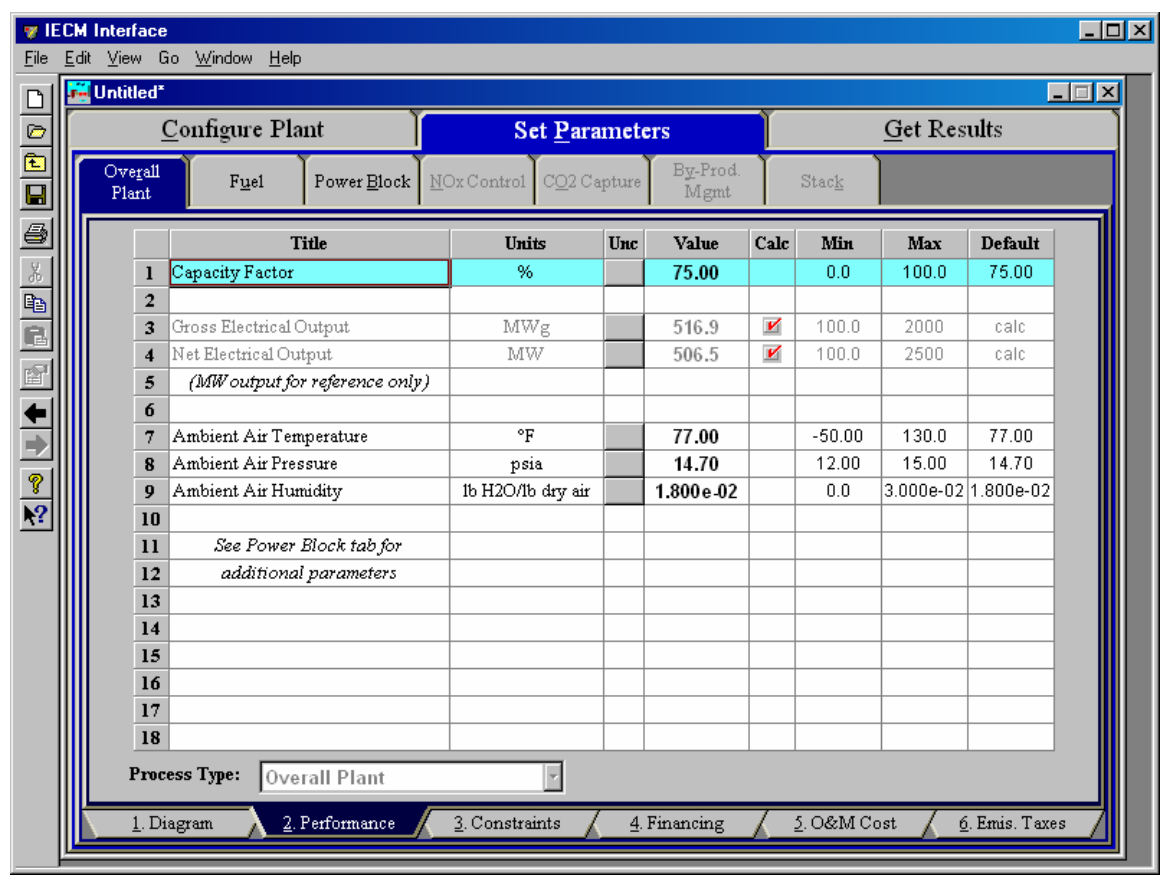

Overall NGCC Plant - Performance input screen.

The parameters available on this screen establish the plant availability, electrical requirements, and ambient conditions for the power plant. These parameters have a major impact on the performance and costs of each of the individual technologies.

Capacity Factor: This is an annual average value, representing the percent of equivalent full load operation during a year. The capacity factor is used to calculate annual average emissions and materials flows.

Gross Electrical Output: This is the gross output of the generator in megawatts (MWg). The value does not include auxiliary power requirements. The model uses this information to calculate key mass flow rates. The value here is shown for reference only. The value is controlled primarily by the number of gas turbines selected from the Power $\underline{\text { Block tab. }}$

Net Electrical Output: This is the net plant capacity, which is the gross plant capacity minus the losses due to plant equipment and pollution equipment (energy penalties). The value cannot be changed and is shown for reference only.

Ambient Air Temperature: This is the inlet temperature of the ambient combustion air prior to entering the preheater. The model presumes an annual average temperature. Inlet air temperature affects the boiler energy balance and efficiency. It provides a reference point for the calculation of pressure throughout the system. Currently, the model cannot have temperatures below 77F.

Ambient Air Pressure: This is the absolute pressure of the air inlet stream to the boiler. The air pressure is used to convert flue gas molar flow rates to volume flow rates. The default value is 14.7 psia. 
Ambient Air Humidity: This is the water content of the inlet combustion air. This value is used in calculating the total water vapor content of the flue gas stream. The value is referred to as the specific humidity ratio, expressed as a ratio of the water mass to the dry air mass. The default value is 0.018 .

\section{Overall NGCC Plant Constraints Inputs}

The Constraints input parameters define the emission constraints as they apply to the gases emitted from the power plant. Constraints for sulfur dioxide, nitrogen dioxides, particulates, and mercury are not needed due to the cleaner emissions from NGCC plants.

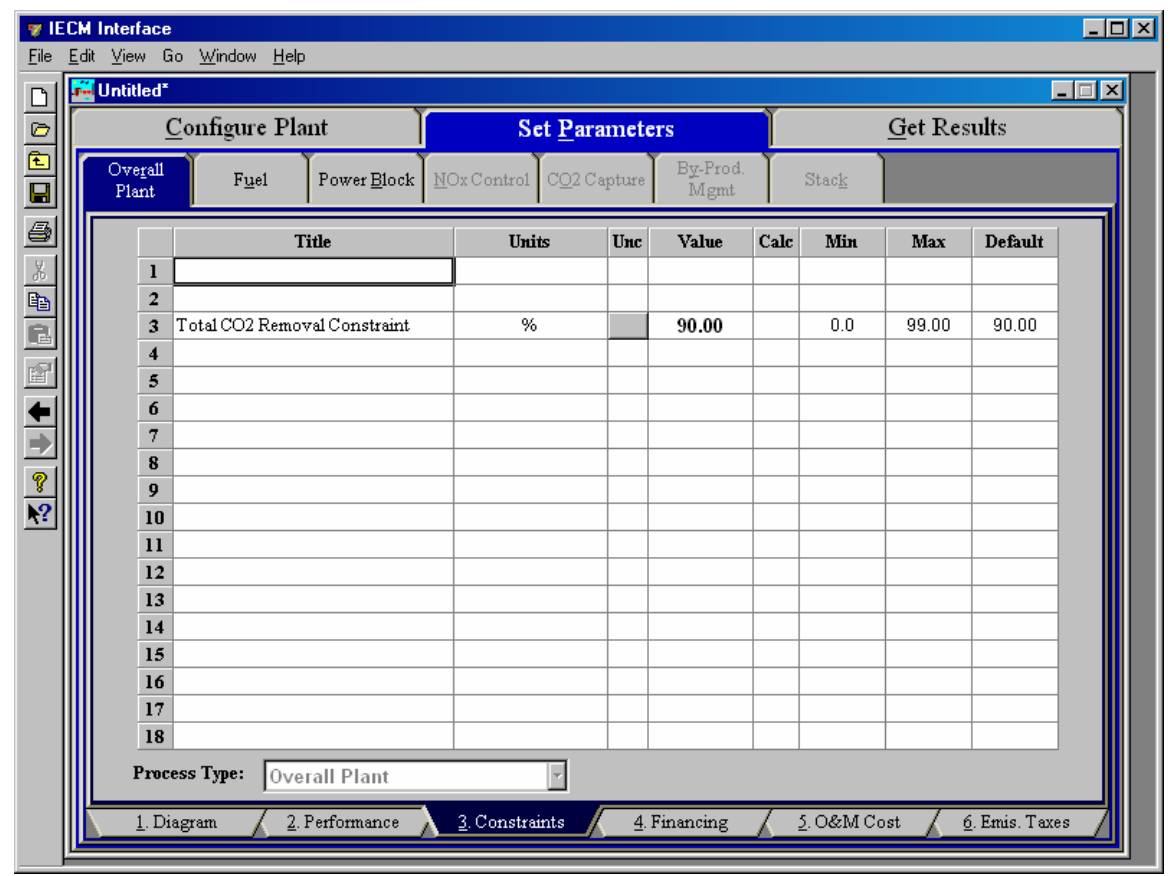

Overall NGCC Plant - Emission Constraints input screen.

The emission constraints determine the removal efficiencies of control systems that capture $\mathrm{CO}_{2}$. The level of capture is set to comply with the specified emission constraints. As discussed later, however, user-specified values for control technology performance may cause the plant to over-comply or under-comply with the emission constraints specified in this screen. Each parameter is described briefly below.

Total $\mathrm{CO}_{2}$ Removal Constraint: The emission constraint applies to all the air emission sources in the power plant, primary or secondary. The default value is based on recent discussions and is not based on any currently enforced law.

\section{Overall NGCC Plant Financing Inputs}

Inputs for the financing costs of the base plant itself are entered on the Financing input screen. 


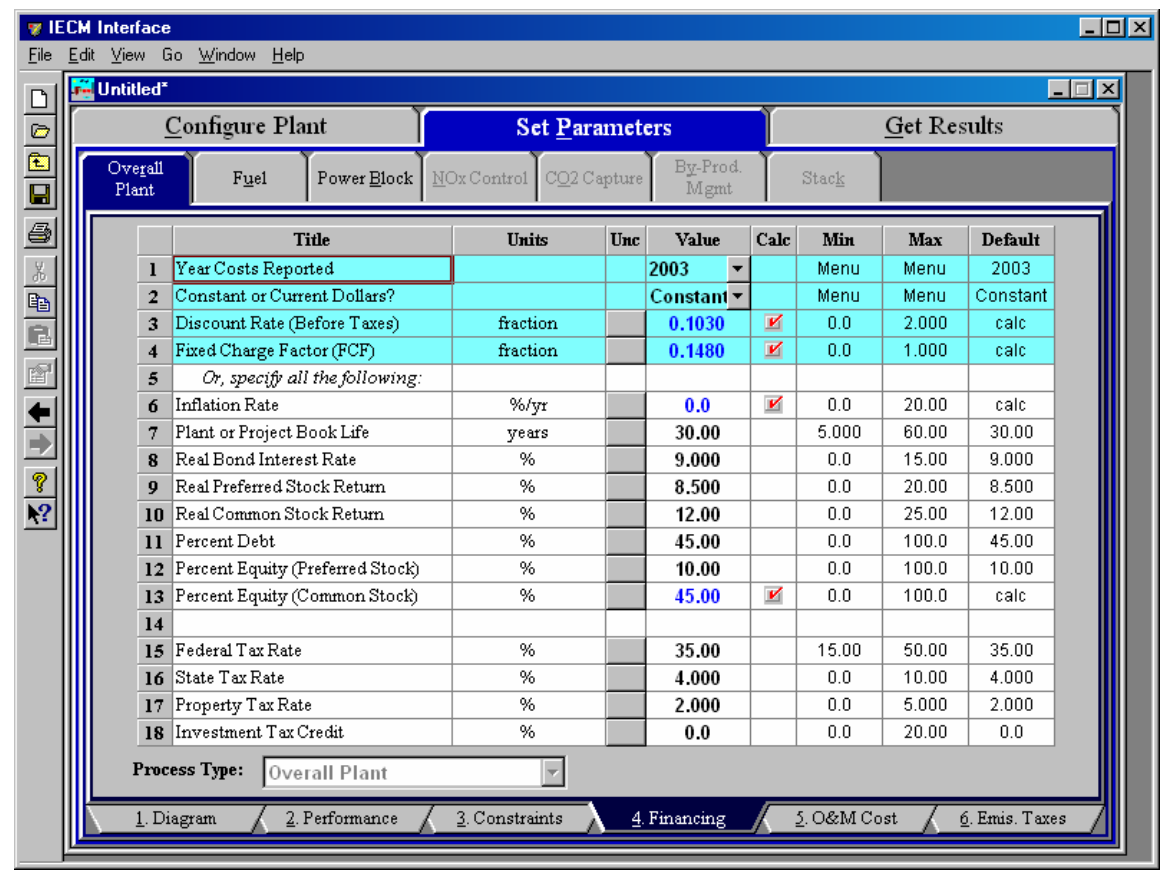

Overall NGCC Plant - Financing input screen.

This screen describes the factors required to determine the carrying charge for all capital investments. The carrying charge is defined as the revenue required for the capital investment. The total charge can also be expressed as a levelized cost factor or fixed charge factor. The fixed charge factor is a function of many items. The fixed charge factor can be specified directly or calculated from the other input quantities below it on the financial input screen.

Each parameter is described briefly below.

Year Costs Reported: This is the year in which all costs are given or displayed, both in the input screens and the results. A cost index is used by the IECM to scale all costs to the cost year specified by this parameter. The cost year is reported on every input and result screen associated with costs throughout the interface.

Constant or Current Dollars: Constant dollar analysis does not include the affect of inflation, although real escalation is included. Current dollar analysis includes inflation and real escalation. This choice allows you to choose the mode of analysis for the entire IECM economics. The cost basis is reported on every input and result screen associated with costs throughout the interface.

Discount Rate (Before Taxes): This is also known as the "cost of money". It is the return required by investors in order to attract investment capital. It is equal to the weighted sum of the return on debt and equity. It is the time value of money or the discount rate used in present worth arithmetic.

Fixed Charge Factor (FCF): The fixed charge factor is one of the most important parameters in the IECM. It determines the revenue required to finance the power plant based on the capital expenditures. Put another way, it is a levelized factor which accounts for the revenue per dollar of total plant cost that must be collected from customers in order to pay the carrying charges on that capital investment. 
One may specify a fixed charge factor, or fill in the following inputs and the model will calculate the FCF based on them:

Inflation Rate: This is the rise in price levels caused by an increase in the available currency and credit without a proportionate increase in available goods or services. It does not include real escalation.

Plant or Project Book Life: This is the years of service expected from a capital investment. It is also the period over which an investment is recovered through book depreciation.

Real Bond Interest Rate: This is a debt security associated with a loan or mortgage. It is the most secure form of security but the lowest in its return.

Real Preferred Stock Return: This equity security is the second most speculative type and pays the second highest rate of return. The holder of the stock is a part owner of the company.

Real Common Stock Return: This is the most speculative type of equity security sold by a utility and pays the highest relative return. The holder of the stock is a part owner of the company.

Percent Debt: This is the percent of the total capitalization that is associated with debt money. This includes loans and mortgage bonds.

Percent Equity (Preferred Stock): This is the percent of the total capitalization that is associated with the sale of preferred stock.

Percent Equity (Common Stock): This value is the remainder of the capitalization, calculated as $100 \%$ minus the percent debt, minus the percent equity in preferred stock.

Federal Tax Rate: This is the federal tax rate. It is used to calculate the amount of taxes paid and deferred.

State Tax Rate: This is the state tax rate. It is used to calculate the amount of taxes paid and deferred.

Property Tax Rate: The property tax rate, or ad valorem, is used to calculate the carrying charge.

Investment Tax Credit: This is an immediate reduction in income taxes equal to a percentage of the installed cost of a new capital investment. It is zero by default. It is used to set the initial balance and the book depreciation.

\section{Overall NGCC Plant O\&M Cost Inputs}

This screen combines the variable O\&M unit costs from all the model components and places them in one spot. These values will also appear in the technology input screens where they are actually used. Values changed on this screen will reflect exactly the same change everywhere else they appear. O\&M costs are typically expressed on an average annual basis and are provided in either constant or current dollars for a specified year, as shown on the bottom of the screen. 


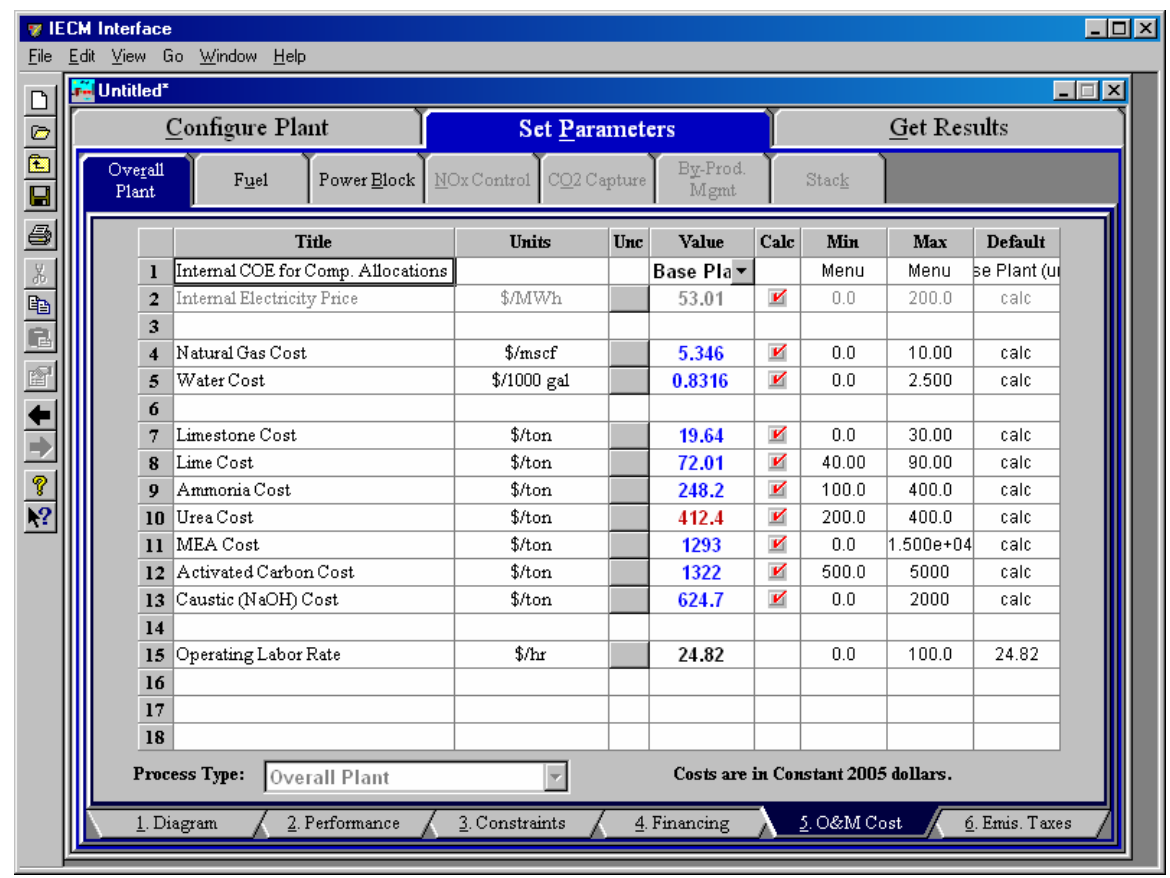

Overall NGCC Plant - O\&M Cost input screen.

Internal COE for Comp. Allocations: This is a pop-up selection menu that determines the method for determining electricity costs within the power plant. The selection of this pop-up menu determines the actual internal electricity price on the next line. The options are

- Base Plant (uncontrolled)

- User Specified

- Total Plant COE

Internal Electricity Price: This is the price of electricity and is calculated as a function of the utility cost of the base plant. The base plant for the Combustion (Turbine) model is assumed to be the natural gas supply, power block, and stack. This value is calculated and provided for reference purposes only unless User Specified is selected in the pop-up in the previous line.

As-Delivered Coal Cost: This is the cost of the coal as-delivered.

Natural Gas Cost: This is the cost of natural gas in dollars per thousand standard cubic feet.

Water Cost: This is the cost of water in dollars per thousand gallons.

Limestone Cost: This is the cost of limestone in dollars per ton.

Lime Cost: This is the cost of lime in dollars per ton.

Ammonia Cost: This is the cost of ammonia in dollars per ton.

Urea Cost: This is the cost of natural gas in dollars per ton.

MEA Cost: This is the cost of MEA in dollars per ton.

Activated Carbon Cost: This is the cost of activated carbon in dollars per ton. 
Caustic (NaOH) Cost: This is the cost of caustic (NaOH) gas in dollars per ton.

Operating Labor Rate: The hourly cost of labor is specified in the base plant O\&M cost screen. The same value is used throughout the other technologies.

\section{Overall NGCC Plant Emis. Taxes Inputs}

This screen allows users to specify emission taxes or credits as part of the overall plant cost economics. Taxes or credits are typically provided in either constant or current dollars for a specified year, as shown on the bottom of the screen.

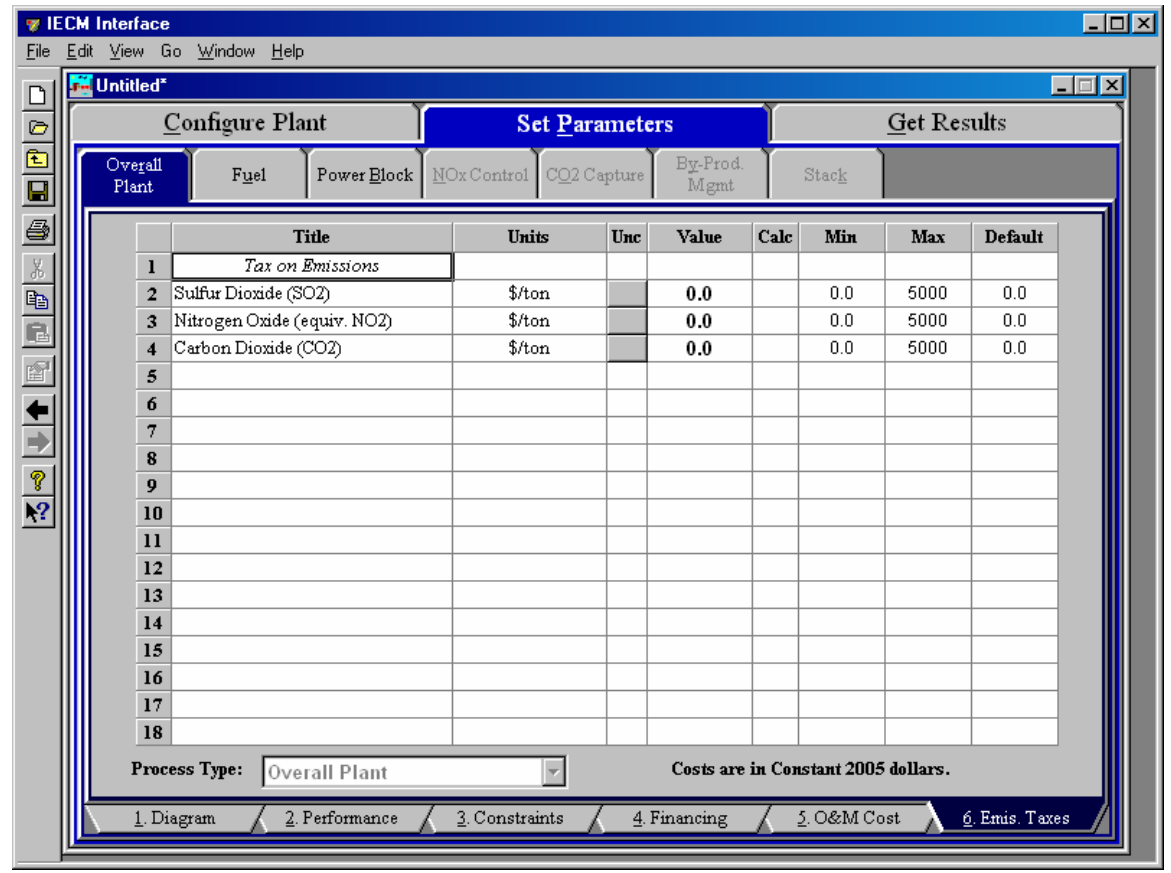

Emission Constraint Emission Taxes input screen.

The Emis. Taxes input screen allows the user to enter the taxes on emissions in dollars per ton. The final costs determined from these inputs are available under the stack tab in the results section of the IECM. The costs are added to the overall plant cost, not a particular technology.

\section{Tax on Emissions}

Sulfur Dioxide $\left(\mathrm{SO}_{2}\right)$ : The user may enter a cost to the plant of emitting sulfur dioxide in dollars per ton.

Nitrogen Oxide (equiv. $\mathbf{N O}_{2}$ ): The user may enter a cost to the plant of emitting nitrogen oxide in dollars per ton.

Carbon Dioxide $\left(\mathrm{CO}_{2}\right)$ : The user may enter a cost to the plant of emitting carbon dioxide in dollars per ton. 


\section{Overall NGCC Plant Performance Results}

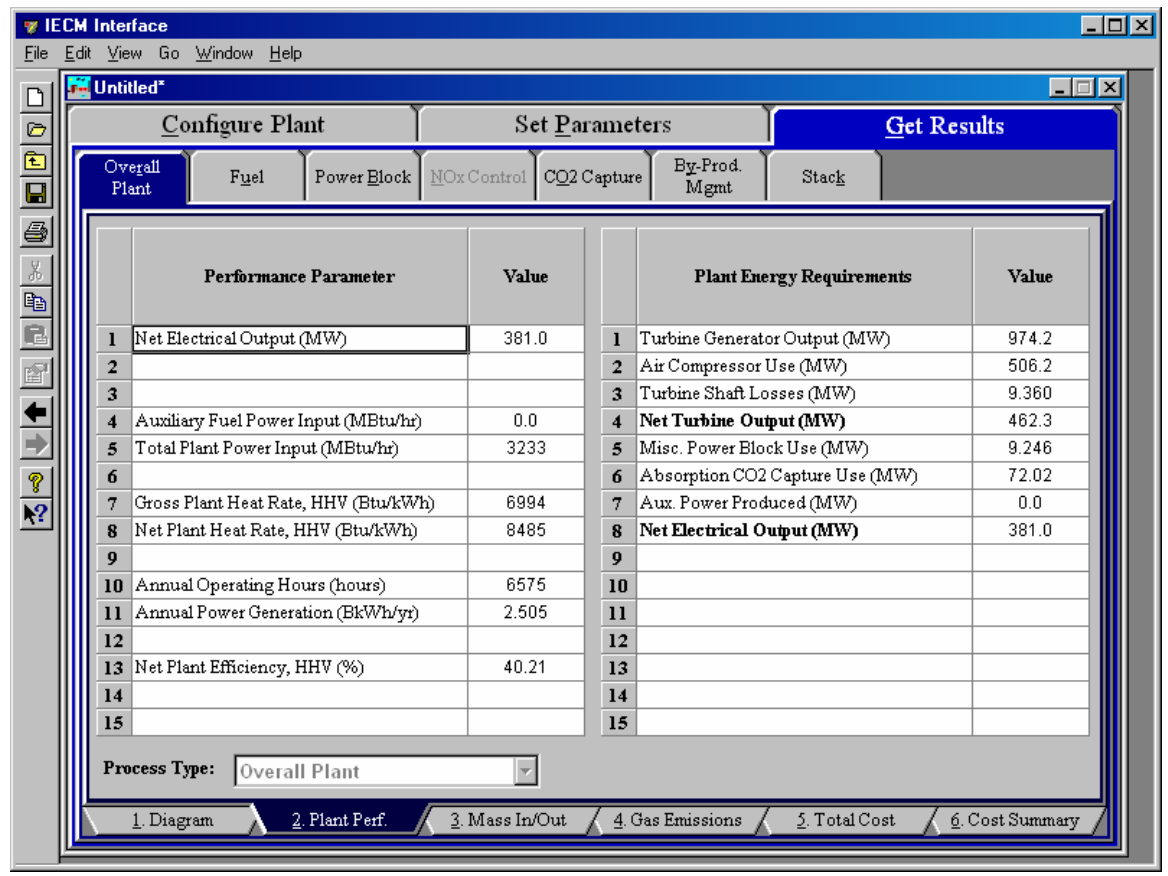

Overall NGCC Plant - Performance results screen.

The Plant Perf. result screen displays performance results for the plant as a whole. Heat rates and power in and out of the power plant are given. Each result is described briefly below.

\section{Performance Parameter}

Net Electrical Output: This is the net plant capacity, which is the gross plant capacity minus the losses due to plant equipment and pollution equipment (energy penalties).

Aux. Fuel Power Input: This is the fuel energy input for the auxiliary natural gas boiler if used with the Amine System. This is additional fuel energy used by the plant, given on an hourly basis. This rate is also referred to as the auxiliary fuel power input.

Total Plant Power Input: This is the total of all the fuel energy used by the plant, given on an hourly basis (maximum capacity). This rate is also referred to as the total plant power input.

Gross Plant Heat Rate, HHV: This is the gross heat rate of the entire plant.

Net Plant Heat Rate, HHV: This is the net heat rate of the entire plant (including aux power produced) which includes the effect of plant equipment and pollution control equipment.

Annual Operating Hours: This is the number of hours per year that the plant is in operation. If a plant runs 24 hours per day, seven days per week, with no outages, the calculation is 24 hours * 365 days. or 8,760 hours/year. 
Annual Power Generation: This is the net annual power production of the plant. The capacity factor and all energy credits or penalties are used in determining its value.

Net Plant Efficiency, HHV: This is the net efficiency of the entire plant.

\section{Plant Power Requirements}

A second group of results provide a breakdown of the internal power consumption for the individual technology areas. These are all given in units of megawatts. Individual plant sub-components will only be displayed when they are configured in the Configure Plant section of the model.

Turbine Generator Output: This is the power generated by the turbine.

Air Compressor Use: The power required to operate the air compressor.

Turbine Shaft Losses: This value accounts for any turbine electricity losses other than power used for the air compressor.

Net Turbine Output: This if the net power generated by the turbine. This is the gross output of the turbine minus the power required by the air compressor and any miscellaneous losses.

Misc. Power Block Use: This is the power required to operate pumps and motors associated with the power block area.

Absorption $\mathrm{CO}_{2}$ Capture Use: If a $\mathrm{CO}_{2}$ Capture system is in use, this is the power required to operate the system.

Aux. Power Produced: If an auxiliary natural gas boiler is used to provide steam and power, this is the additional power that it produces.

Net Electrical Output: This is the net plant capacity, which is the gross plant capacity minus the losses due to plant equipment and pollution equipment (energy penalties). 


\section{Overall NGCC Plant Mass In/Out Results}

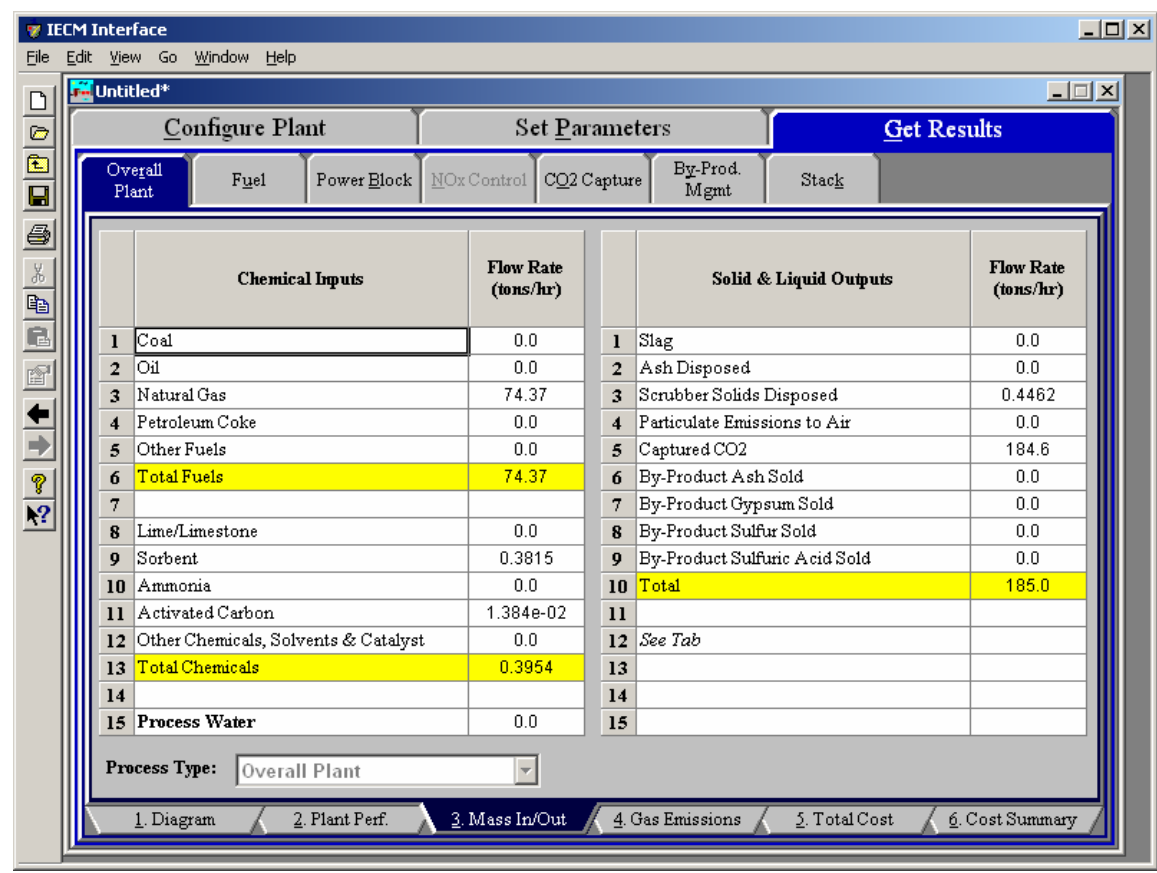

Overall NGCC Plant - Mass In/Out results screen.

\section{Chemical Inputs}

Coal: Flow rate of coal used in the power plant.

Oil: Flow rate of oil used in the power plant

Natural Gas: : Flow rate of natural gas used in the power plant

Petroleum Coke: Total mass of petroleum coke used in the power plant

Other Fuels: Flow rate of other fuels used in the power plant

Total Fuels: This is the flow rate of fuel entering the power plant. This result is highlighted in yellow.

Lime/Limestone: Total mass of this reagent used in the power plant on a wet basis.

Sorbent: Total mass of sorbent used in the power plant

Ammonia: Total mass of ammonia used in the power plant.

Activated Carbon: Flow rate of activated carbon injected in the power plant.

Other Chemicals, Solvents \& Catalyst: Flow rate of other chemicals, solvents and catalysts used in the power plant.

Total Chemicals: Flow rate of reagent entering the power plant. This result is highlighted in yellow.

Process Water: Flow rate of water used in the power plant.

\section{Solid \& Liquid Outputs}

Slag: Flow rate of slag from the power plant on a dry basis. 
Ash Disposed: Flow rate of ash from the power plant on a dry basis.

Scrubber Solids Disposed: Flow rate of scrubber treatment solid wastes from the power plant on a dry basis.

Particulate Emissions to Air: Solids that remain in the flue gas and exit the plant are reported on a mass basis.

Captured $\mathrm{CO}_{2}$ : Flow rate of the captured $\mathrm{CO}_{2}$.

Byproduct Ash Sold: Flow rate of ash (bottom and fly ash) sold in commerce as a by-product on a dry basis.

Byproduct Gypsum Sold: Flow rate of flue gas treatment solids sold in commerce as a by-product on a dry basis.

Byproduct Sulfur Sold: Flow rate of elemental sulfur recovered from flue gas and sold in commerce as a by-product on a dry basis.

Byproduct Sulfuric Acid Sold: Total mass of sulfuric acid recovered from the flue gas and sold in commerce as a by-product.

Total: This is the total wet solid mass exiting the power plant. This result is highlighted in yellow.

\section{Overall NGCC Plant Gas Emissions Results}

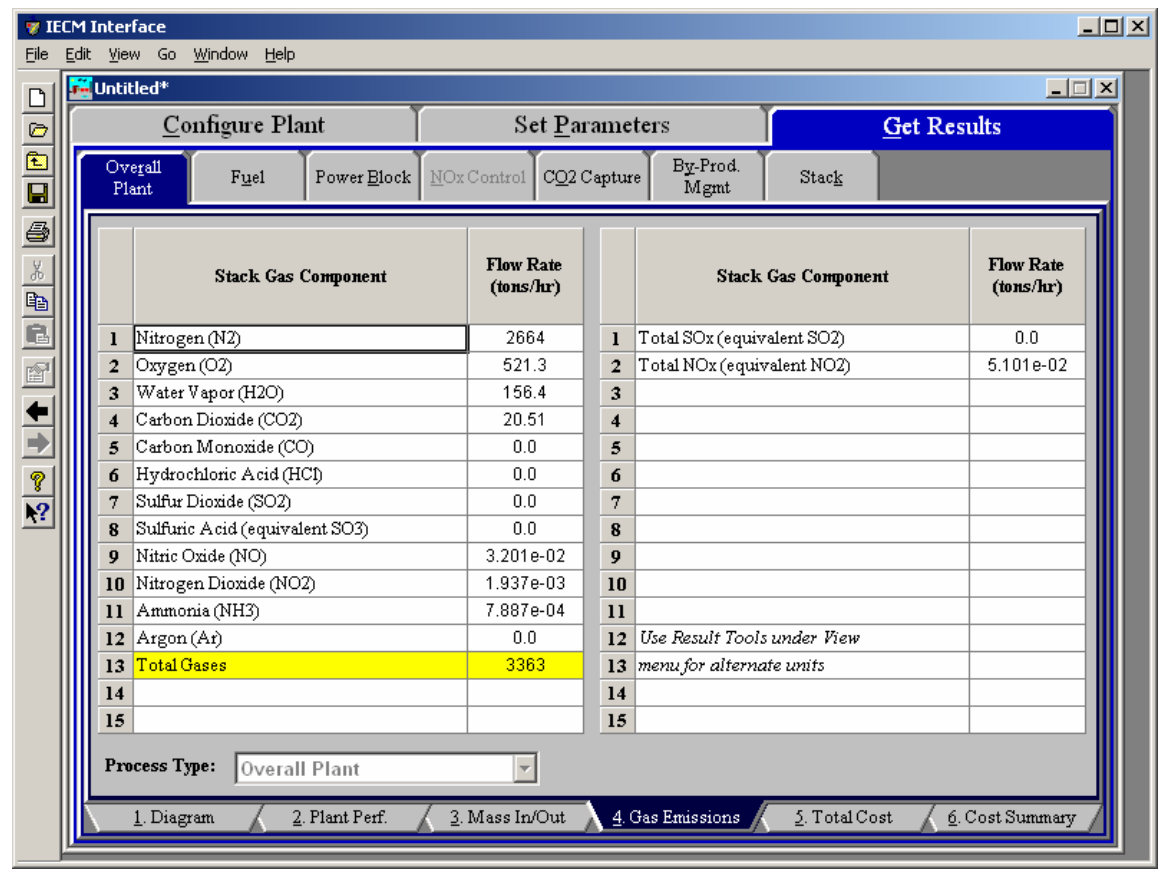

Overall NGCC Plant - Gas Emissions result screen.

\section{Stack Gas Component}

Each result is described briefly below:

Nitrogen $\left(\mathbf{N}_{2}\right)$ : Total mass of nitrogen.

Oxygen $\left(\mathrm{O}_{2}\right)$ : Total mass of oxygen.

Water Vapor $\left(\mathrm{H}_{2} \mathrm{O}\right)$ : Total mass of water vapor. 
Carbon Dioxide $\left(\mathrm{CO}_{2}\right)$ : Total mass of carbon dioxide.

Carbon Monoxide (CO): Total mass of carbon monoxide.

Hydrochloric Acid ( $\mathrm{HCl})$ : Total mass of hydrochloric acid.

Sulfur Dioxide $\left(\mathrm{SO}_{2}\right)$ : Total mass of sulfur dioxide.

Sulfuric Acid (equivalent $\mathbf{S O}_{3}$ ): Total mass of sulfuric acid.

Nitric Oxide (NO): Total mass of nitric oxide.

Nitrogen Dioxide $\left(\mathrm{NO}_{2}\right)$ : Total mass of nitrogen dioxide.

Ammonia $\left(\mathrm{NH}_{3}\right)$ : Total mass of ammonia.

Argon (Ar): Argon is present in small quantities in atmospheric air. The argon emitted from the power plant is shown on a mass basis.

Total Gases: Total of the individual components listed above. This item is highlighted in yellow.

Total $\mathrm{SO}_{\mathbf{x}}$ (equivalent $\mathrm{SO}_{2}$ ): Total mass of $\mathrm{SO}_{\mathrm{x}}$ as equivalent $\mathrm{SO}_{2}$.

Total $\mathrm{NO}_{\mathbf{x}}$ (equivalent $\mathbf{N O}_{2}$ ): Total mass of $\mathrm{NO}_{\mathbf{x}}$ as equivalent $\mathrm{NO}_{2}$.

\section{Overall NGCC Plant Total Cost Results}

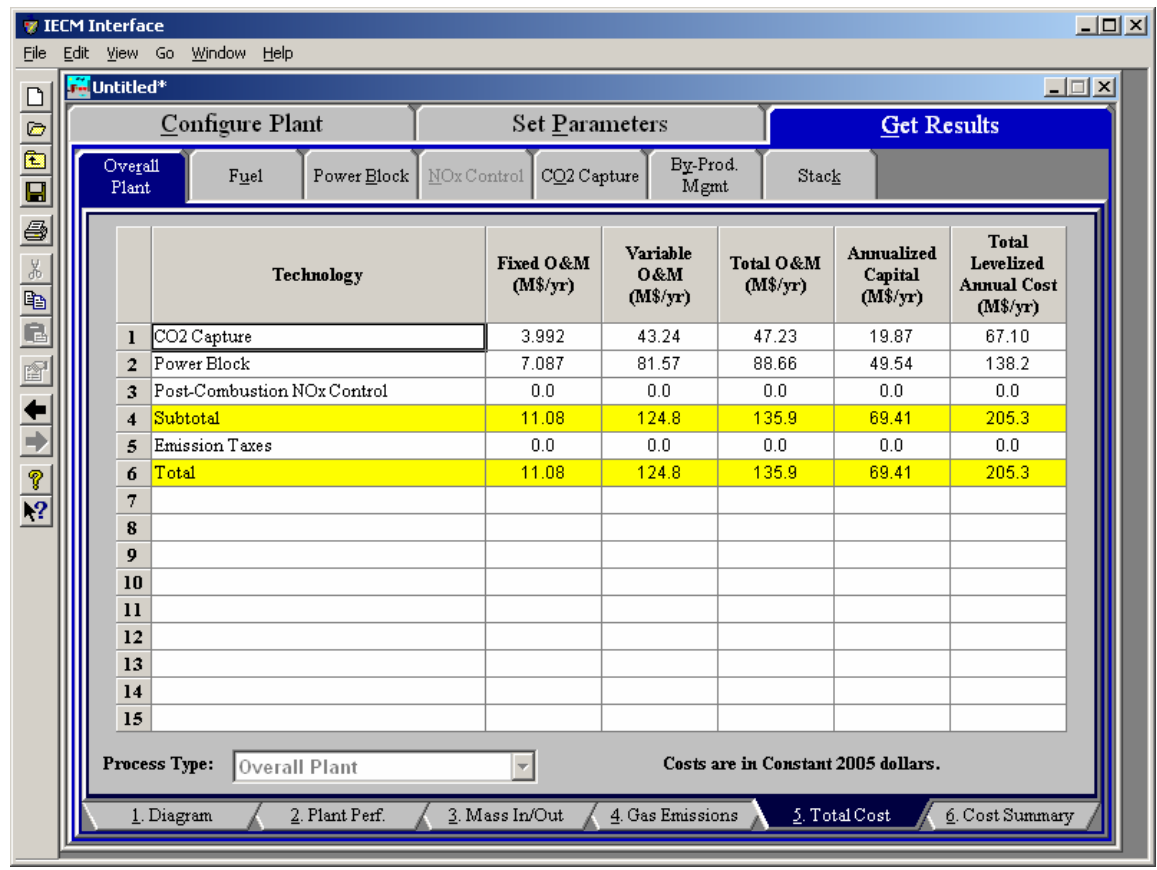

Overall NGCC Plant - Total Cost results screen.

The Total Cost result screen displays a table which totals the annual fixed, variable, operations, maintenance, and capital costs associated with the power plant as a whole. Each technology (row) is described briefly below.

\section{Technology}

$\mathrm{CO}_{2}$ Capture: The total cost of all the $\mathrm{CO}_{2}$ Capture modules used.

Power Block: The total cost of the power block without consideration of any abatement technologies. The Power Block contains the air 
compressor, gas turbine, steam turbine and heat recovery steam generator areas.

Post-Combustion $\mathrm{NO}_{\mathrm{x}}$ Control: The total cost of all the PostCombustion $\mathrm{NO}_{\mathrm{x}}$ removal modules used.

Subtotal: This is the cost of the conventional and advanced abatement technology modules alone. This is the total abatement cost. The subtotal is highlighted in yellow.

Emission Taxes: This is the sum of the user assessed taxes on the plant emissions of $\mathrm{SO}_{2}, \mathrm{NO}_{\mathrm{x}}$ and $\mathrm{CO}_{2}$.

Total: This is the total cost of the entire power plant. This result is highlighted in yellow.

Each cost category (column) is described briefly below.

Fixed O\&M: The operating and maintenance fixed costs are given as an annual total. This number includes all maintenance materials and all labor costs for each technology.

Variable O\&M: The operating and maintenance variables costs are given as an annual total. This includes all reagent, chemical, steam, and power costs associated with a technology.

Total O\&M: This is the sum of the annual fixed and variable operating and maintenance costs for each technology.

Annualized Capital: This is the total capital cost expressed on an annualized basis, taking into consideration the levelized carrying charge factor, or fixed charge factor, over the entire book life.

Total Levelized Annual Cost: The total annual cost is the sum of the total annual O\&M cost and annualized capital cost items above. This result is highlighted in yellow 


\section{Overall NGCC Plant Cost Summary Results}

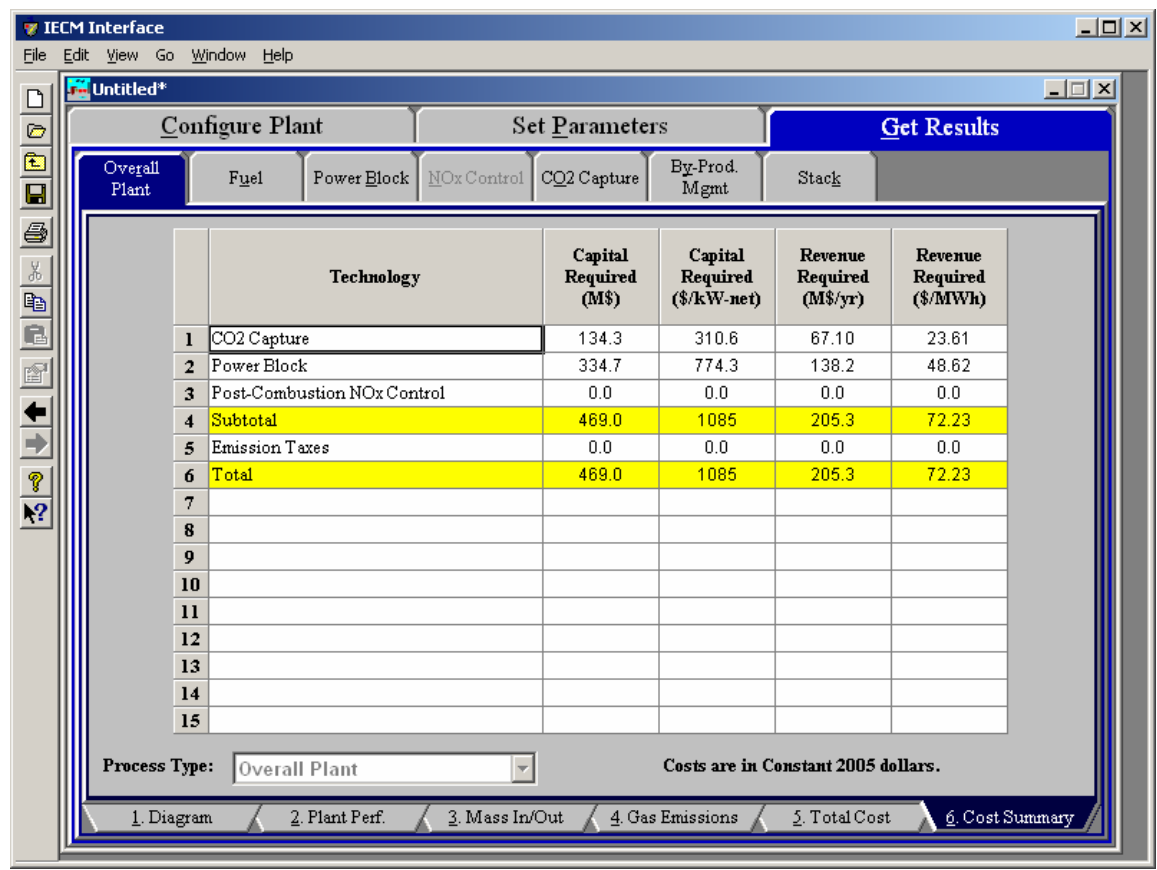

Overall NGCC Plant - Cost Summary results screen.

The Cost Summary result screen displays costs associated with the power plant as a whole. Each technology (row) is described briefly below.

\section{Technology}

$\mathrm{CO}_{2}$ Capture: This is the capital cost for the equipment that captures $\mathrm{CO}_{2}$ in the plant.

Power Block: This is the capital cost for the power block process area of the plant.

Post-Combustion $\mathrm{NO}_{\mathrm{x}}$ Control: This is the capital cost for the equipment that captures post-combustion $\mathrm{NO}_{\mathrm{x}}$ in the plant.

Subtotal: This is the cost of the conventional and advanced abatement technology modules alone. This is the total abatement cost. The subtotal is highlighted in yellow.

Emission Taxes: This is the sum of the user assessed taxes on the plant emissions of $\mathrm{SO}_{2}, \mathrm{NO}_{\mathrm{x}}$ and $\mathrm{CO}_{2}$.

Total: This is the sum of all of the above capital costs for all of the process areas in the plant.

Each cost category (column) is described briefly below.

Capital Cost: The total capital requirement (TCR). This is the money that is placed (capitalized) on the books of the utility on the service date. The total cost includes the total plant investment plus capitalized plant startup. Escalation and allowance for funds used during construction (AFUDC) are also included. The capital cost is given on both a total and an annualized basis. 
Revenue Required: Amount of money that must be collected from customers to compensate a utility for all expenditures in capital, goods, and services. The revenue requirement is equal to the carrying charges plus expenses. The revenue required is given on both an annualized and a net power output basis. 



\section{Overall IGCC Plant}

The input parameter screens described in the following sections are available when the IGCC is selected as the plant type from the New Session pull down menu. These screens apply to the power plant as a whole, not to specific technologies.

\section{Overall IGCC Plant Diagram}

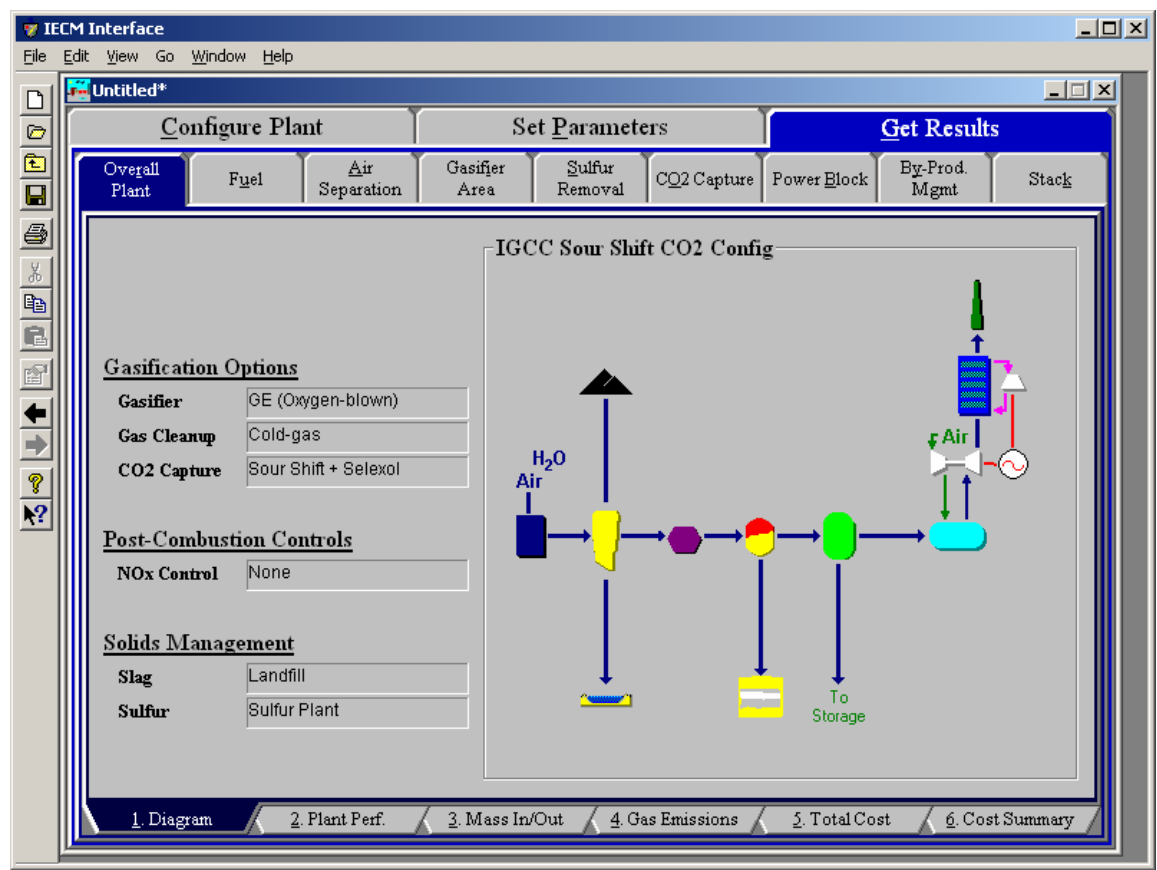

Overall IGCC Plant - Diagram screen.

The Overall IGCC Plant Diagram appears in the Configure Plant, Set Parameters and in the Get Results program area. The screen displays the plant configuration settings on the left side of the page and a diagram of the configured plant on the right of the page. No input parameters or results are displayed on this screen. 


\section{Overall IGCC Plant Performance Inputs}

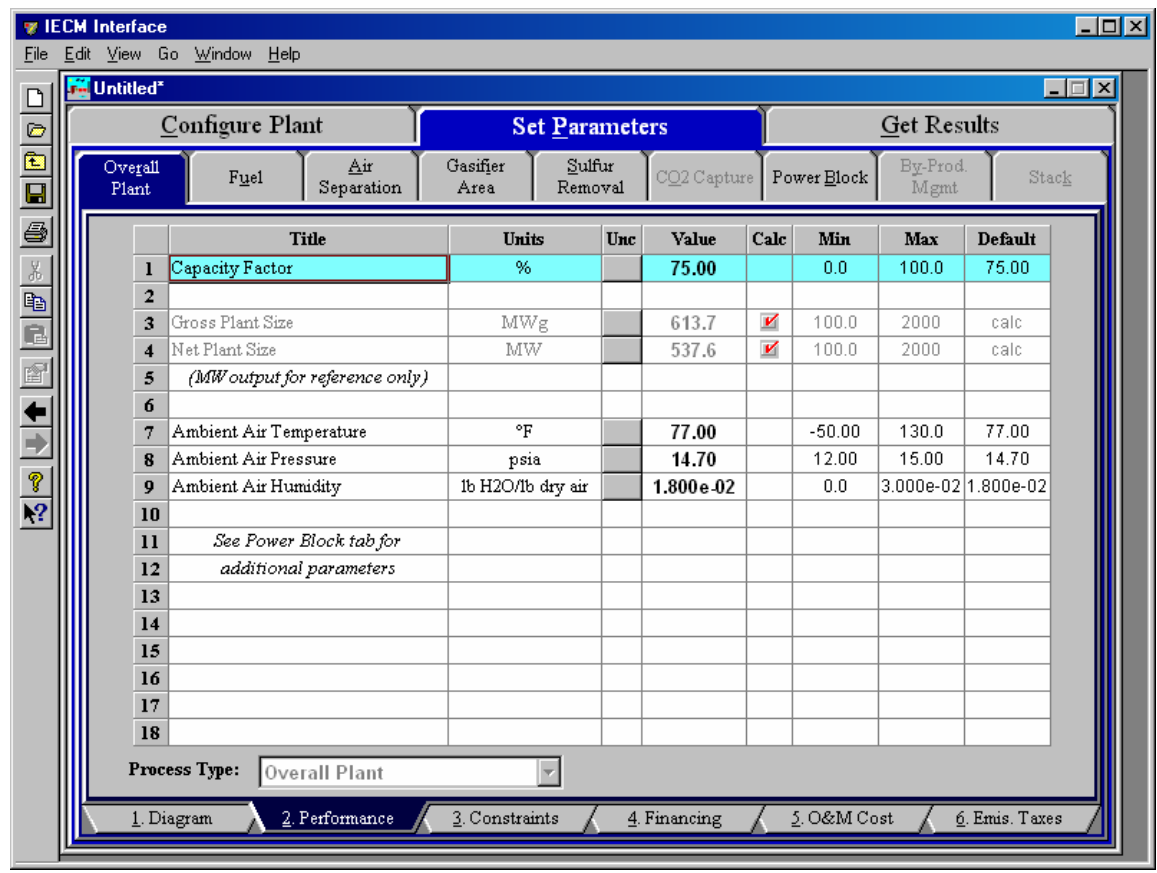

Overall IGCC Plant - Performance input screen.

The parameters available on this screen establish the plant availability, electrical requirements, and ambient conditions for the power plant. These parameters have a major impact on the performance and costs of each of the individual technologies.

Capacity Factor: This is an annual average value, representing the percent of equivalent full load operation during a year. The capacity factor is used to calculate annual average emissions and materials flows.

Gross Plant Size: This is the gross output of the generator in megawatts $\left(\mathrm{MW}_{\mathrm{g}}\right)$. The value does not include auxiliary power requirements. The model uses this information to calculate key mass flow rates. It is shown here for information only.

Net Plant Size: This is the net plant capacity, which is the gross plant capacity minus the losses due to plant equipment and pollution equipment (energy penalties). It is shown here for information only.

Ambient Air Temperature: This is the inlet temperature of the ambient combustion air prior to entering the preheater. The model presumes an annual average temperature. Inlet air temperature affects the boiler energy balance and efficiency. It provides a reference point for the calculation of pressure throughout the system. Currently, the model cannot have temperatures below $77^{\circ} \mathrm{F}$.

Ambient Air Pressure: This is the absolute pressure of the air inlet stream to the boiler. The air pressure is used to convert flue gas molar flow rates to volume flow rates.

Ambient Air Humidity: This is the water content of the inlet combustion air. This value is used in calculating the total water vapor content of the 
flue gas stream. The value is referred to as the specific humidity ratio, expressed as a ratio of the water mass to the dry air mass.

\section{Overall IGCC Plant Constraints Inputs}

The Constraints input parameters define the emission constraints as they apply to the gases emitted from the power plant. Constraints for sulfur dioxide, nitrogen dioxides, carbon dioxide, and mercury are not needed due to the cleaner emissions from IGCC plants.

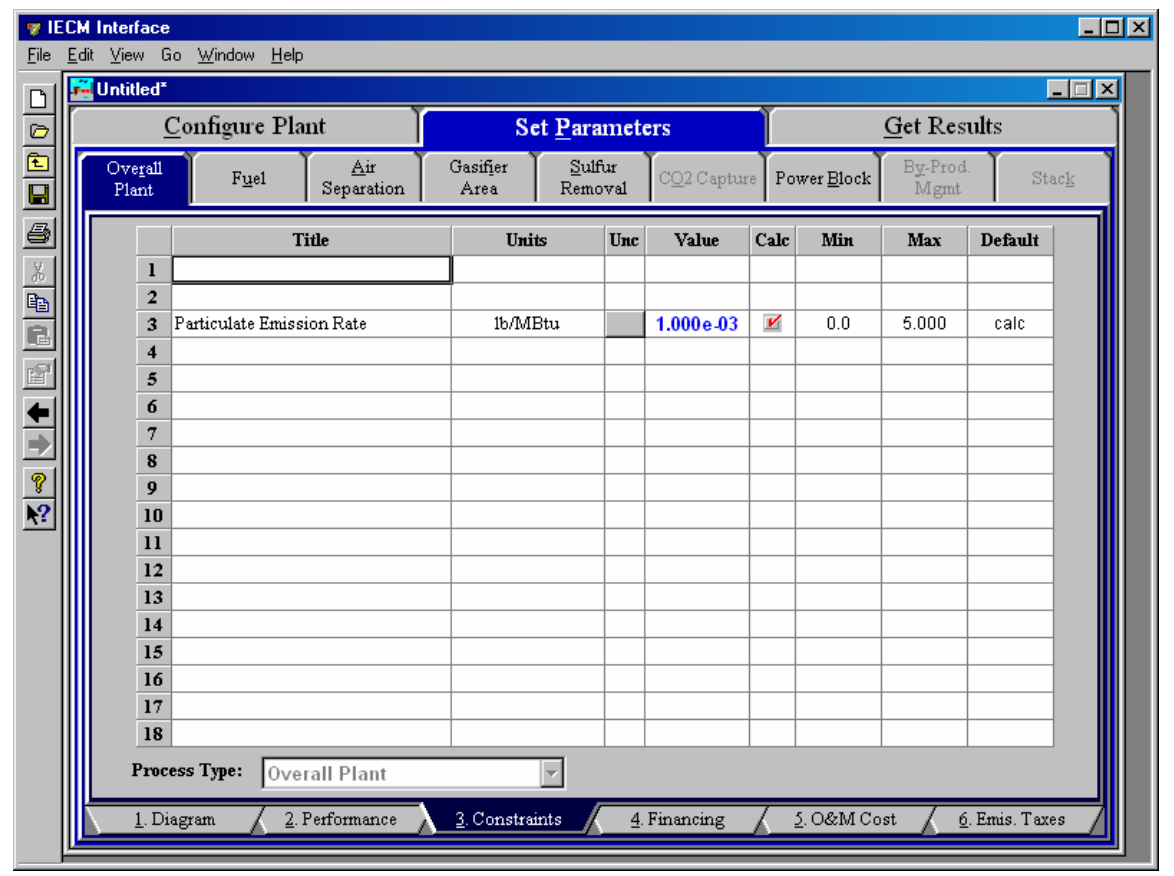

Overall IGCC Plant - Emission Constraints input screen.

The emission constraints determine the removal efficiencies of control systems that capture particulates. The level of capture is set to comply with the specified emission constraints. As discussed later, however, user-specified values for control technology performance may cause the plant to over-comply or under-comply with the emission constraints specified in this screen. Each parameter is described briefly below.

Particulate Emission Constraint: The emission constraint of the total suspended particulates is a function of the fuel type and is used to determine the removal efficiency of particulate control systems (if used).

\section{Overall IGCC Plant Financing Inputs}

Inputs for the financing costs of the base plant itself are entered on the Financing input screen. 


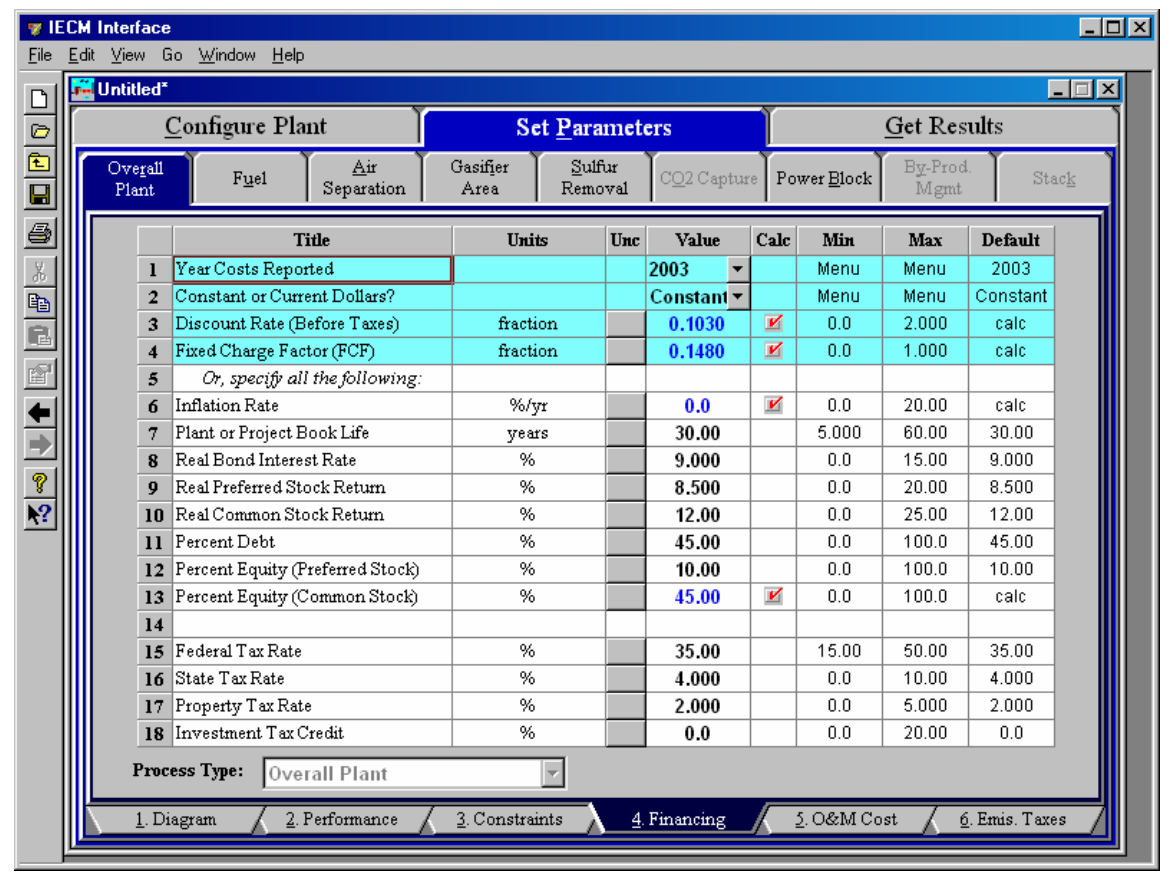

Overall IGCC Plant - Financing input screen.

This screen describes the factors required to determine the carrying charge for all capital investments. The carrying charge is defined as the revenue required for the capital investment. The total charge can also be expressed as a levelized cost factor or fixed charge factor. The fixed charge factor is a function of many items. The fixed charge factor can be specified directly or calculated from the other input quantities below it on the financial input screen.

Each parameter is described briefly below.

Year Costs Reported: This is the year in which all costs are given or displayed, both in the input screens and the results. A cost index is used by the IECM to scale all costs to the cost year specified by this parameter. The cost year is reported on every input and result screen associated with costs throughout the interface.

Constant or Current Dollars: Constant dollar analysis does not include the affect of inflation, although real escalation is included. Current dollar analysis includes inflation and real escalation. This choice allows you to choose the mode of analysis for the entire IECM economics. The cost basis is reported on every input and result screen associated with costs throughout the interface.

Discount Rate (Before Taxes): This is also known as the "cost of money". It is the return required by investors in order to attract investment capital. It is equal to the weighted sum of the return on debt and equity. It is the time values of money on the discount rate used in present worth arithmetic. One may specify a Fixed Charge Factor and Discount Rate, or fill in the following inputs and the model will calculate them.

Fixed Charge Factor (FCF): The fixed charge factor is one of the most important parameters in the IECM. It determines the revenue required to finance the power plant based on the capital expenditures. Put another way, it is a levelized factor which accounts for the revenue per 
dollar of total plant cost that must be collected from customers in order to pay the carrying charges on that capital investment.

One may specify a fixed charge factor, or fill in the following inputs and the model will calculate the FCF based on them:

Inflation Rate: This is the rise in price levels caused by an increase in the available currency and credit without a proportionate increase in available goods or services. It does not include real escalation.

Plant or Project Book Life: This is the years of service expected from a capital investment. It is also the period over which an investment is recovered through book depreciation.

Real Bond Interest Rate: This is a debt security associated with a loan or mortgage. It is the most secure form of security but the lowest in its return.

Real Preferred Stock Return: This equity security is the second most speculative type and pays the second highest rate of return. The holder of the stock is a part owner of the company.

Real Common Stock Return: This is the most speculative type of equity security sold by a utility and pays the highest relative return. The holder of the stock is a part owner of the company.

Percent Debt: This is the percent of the total capitalization that is associated with debt money. This includes loans and mortgage bonds.

Percent Equity (Preferred Stock): This is the percent of the total capitalization that is associated with the sale of preferred stock.

Percent Equity (Common Stock): This value is the remainder of the capitalization, calculated as $100 \%$ minus the percent debt, minus the percent equity in preferred stock.

Federal Tax Rate: This is the federal tax rate. It is used to calculate the amount of taxes paid and deferred.

State Tax Rate: This is the state tax rate. It is used to calculate the amount of taxes paid and deferred.

Property Tax Rate: The property tax rate, or ad valorem, is used to calculate the carrying charge.

Investment Tax Credit: This is an immediate reduction in income taxes equal to a percentage of the installed cost of a new capital investment. It is zero by default. It is used to set the initial balance and the book depreciation.

\section{Overall IGCC Plant O\&M Cost Inputs}

This screen combines the variable O\&M unit costs from all the model components and places them in one spot. These values will also appear in the technology input screens where they are actually used. Values changed on this screen will reflect exactly the same change everywhere else they appear. O\&M costs are typically expressed on an average annual basis and are provided in either constant or current dollars for a specified year, as shown on the bottom of the screen. 


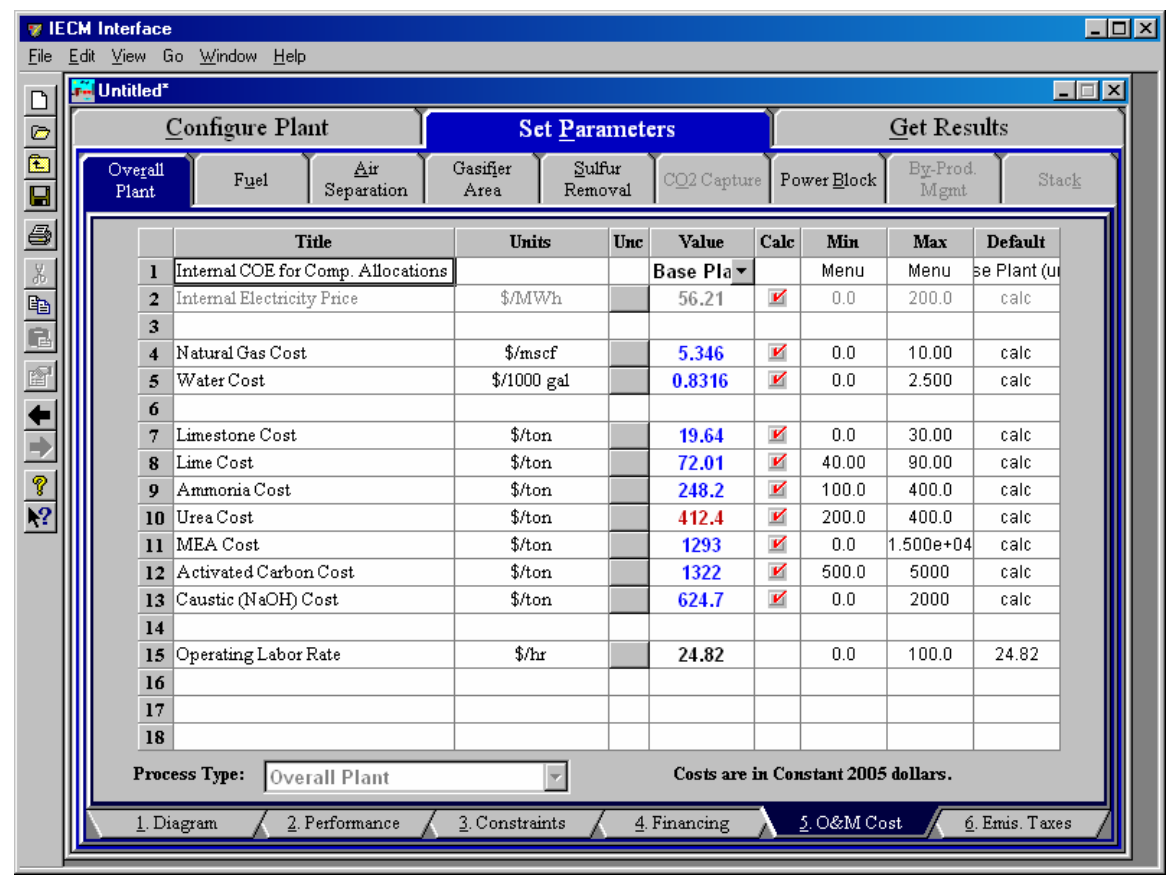

Overall IGCC Plant - O\& M Cost input screen.

Internal COE for Comp. Allocations: This is a pop-up selection menu that determines the method for determining electricity costs within the power plant. The selection of this pop-up menu determines the actual internal electricity price on the next line.The options are

\section{- Base Plant (uncontrolled)}

\section{- User Specified}

\section{- Total Plant COE}

Internal Electricity Price: This is the price of electricity and is calculated as a function of the utility cost of the base plant. The base plant for the IGCC model is assumed to be a coal pile, air separation unit, gasifier, power block, and disposal sites. This value is calculated and provided for reference purposes only unless User Specified is selected in the pop-up in the previous line.

As-Delivered Coal Cost: This is the cost of the coal as-delivered.

Natural Gas Cost: This is the cost of natural gas in dollars per thousand standard cubic feet.

Water Cost: This is the cost of water in dollars per thousand gallons.

Limestone Cost: This is the cost of limestone in dollars per ton.

Lime Cost: This is the cost of lime in dollars per ton.

Ammonia Cost: This is the cost of ammonia in dollars per ton.

Urea Cost: This is the cost of natural gas in dollars per ton.

MEA Cost: This is the cost of MEA in dollars per ton.

Activated Carbon Cost: This is the cost of activated carbon in dollars per ton. 
Caustic (NaOH) Cost: This is the cost of caustic (NaOH) gas in dollars per ton.

Operating Labor Rate: The hourly cost of labor is specified in the base plant O\&M cost screen. The same value is used throughout the other technologies.

\section{Overall IGCC Plant Stack Emis. Taxes Inputs}

This screen allows users to specify emission taxes or credits as part of the overall plant cost economics. Taxes or credits are typically provided in either constant or current dollars for a specified year, as shown on the bottom of the screen.

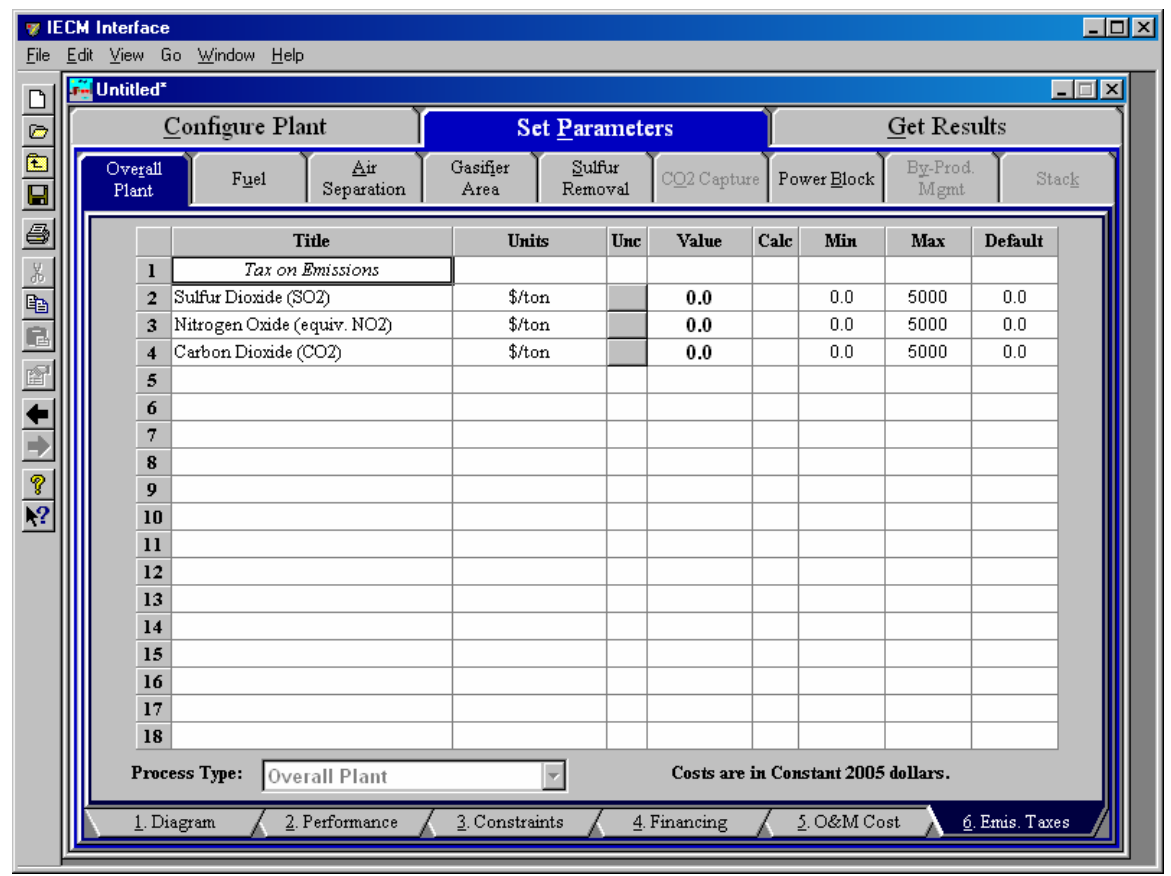

Overall IGCC Plant - Emis. Taxes input screen.

The Emis. Taxes input screen allows the user to enter the taxes on emissions in dollars per ton. The final costs determined from these inputs are available under the stack tab in the results section of the IECM. The costs are added to the overall plant cost, not a particular technology.

\section{Tax on Emissions}

Sulfur Dioxide $\left(\mathrm{SO}_{2}\right)$ : The user may enter a cost to the plant of emitting sulfur dioxide in dollars per ton.

Nitrogen Oxide (equiv. $\mathbf{N O}_{2}$ ): The user may enter a cost to the plant of emitting nitrogen oxide in dollars per ton.

Carbon Dioxide $\left(\mathrm{CO}_{2}\right)$ : The user may enter a cost to the plant of emitting carbon dioxide in dollars per ton. 


\section{Overall IGCC Plant Performance Results}

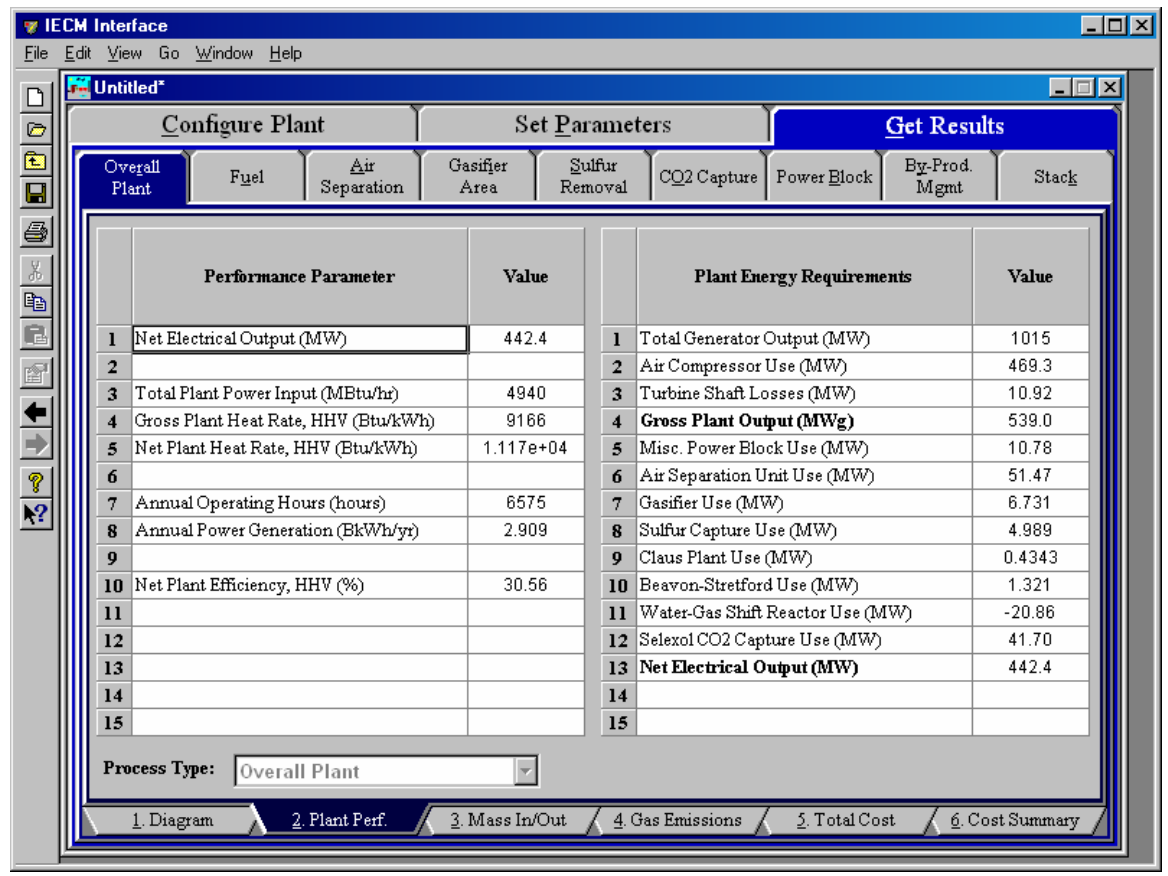

Overall IGCC Plant - Performance result screen.

The Plant Perf. result screen displays performance results for the plant as a whole. Heat rates and power in and out of the power plant are given. Each result is described briefly below.

\section{Performance Parameter}

Net Electrical Output: This is the net plant capacity, which is the gross plant capacity minus the losses due to plant equipment and pollution equipment (energy penalties).

Total Plant Power Input: This is the total of all the fuel energy used by the plant, given on an hourly basis (maximum capacity). This rate is also referred to as the total plant power input.

Gross Plant Heat Rate, HHV: This is the gross heat rate of the entire plant.

Net Plant Heat Rate, HHV: This is the net heat rate of the entire plant (including aux power produced) which includes the effect of plant equipment and pollution control equipment.

Annual Operating Hours: This is the number of hours per year that the plant is in operation. If a plant runs 24 hours per day, seven days per week, with no outages, the calculation is 24 hours * 365 days. or 8,760 hours/year.

Annual Power Generation: This is the net annual power production of the plant. The capacity factor and all power credits or penalties are used in determining its value.

Net Plant Efficiency, HHV: This is the net efficiency of the entire plant. 


\section{Plant Power Requirements}

A second group of results provide a breakdown of the internal power consumption for the individual technology areas. These are all given in units of megawatts. Individual plant sub-components will only be displayed when they are configured in

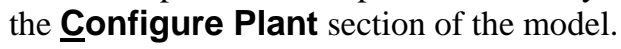

Total Generator Output: This is the gross power generated by the turbine.

Air Compressor Use: The power required to operate the air compressor.

Turbine Shaft Losses: This variable accounts for any turbine electricity losses that are not incorporated into the lossed due to air compressor use.

Gross Plant Output: This is the net power generated by the turbine. This is the gross output of the turbine minus the power required by the air compressor and any miscellaneous losses.

Misc. Power Block Use: This is the electrical power required to operate pumps and motors associated with the power block area.

Air Separation Unit Use: This is the power utilization of the compressors in the air separation system.

Gasifier Use: This is the power utilization of the gasification system.

Sulfur Capture Use: This is the power utilization of the sulfur capture system (this does not include the claus or beavon stretford systems).

Claus Plant Use: This is the power utilization of the claus plant equipment.

Beavon Stretford Use: This is the power utilization of the beavon stretford system.

Water-Gas Shift Reactor Use: This is the power-equivalent of the steam recovered from the water-gas shift reactor.

Selexol $\mathrm{CO}_{2}$ Capture Use (MW): This is the power utilization of the $\mathrm{CO}_{2}$ capture system.

Net Electrical Output: This is the net plant capacity, which is the gross plant capacity minus the losses due to plant equipment and pollution equipment (energy penalties).Also included are credits from steam generated and reused to produce electricity. 


\section{Overall IGCC Plant Mass In/Out Results}

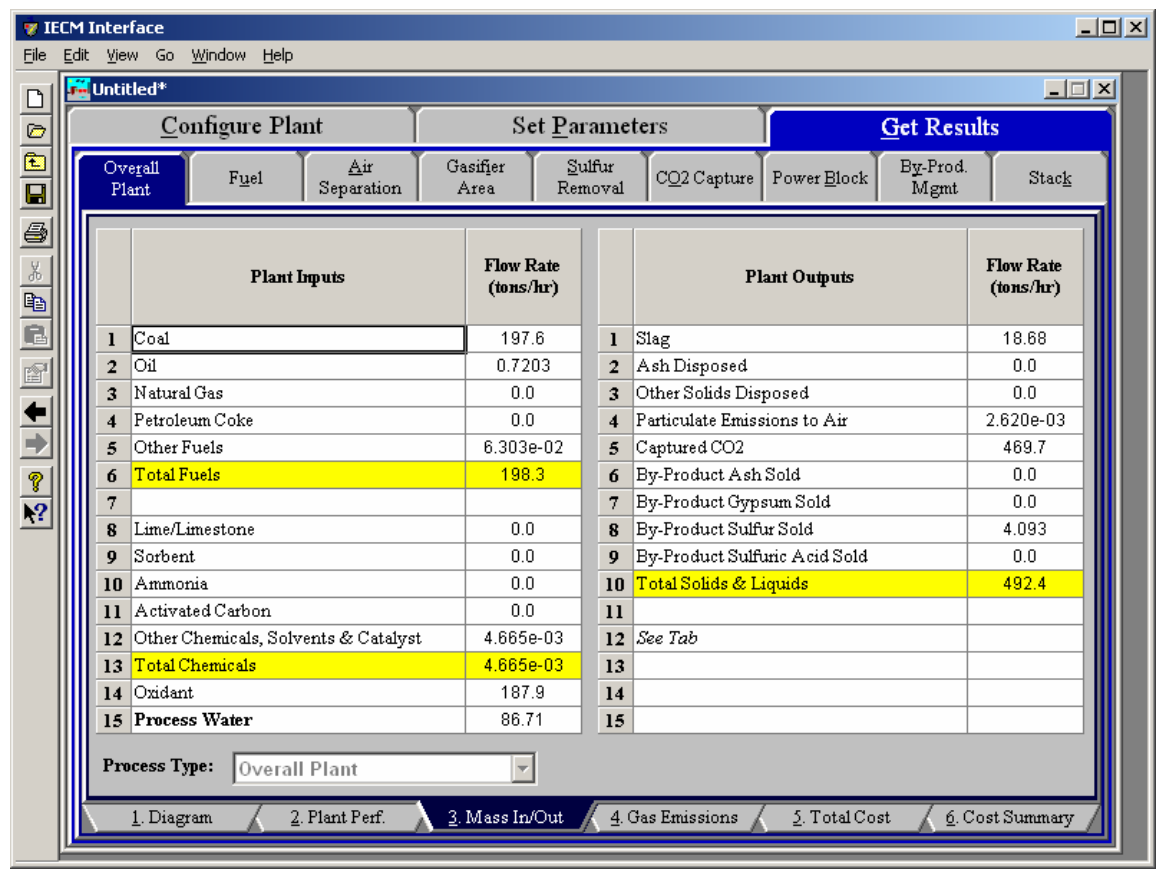

Overall IGCC Plant-Mass In/Out result screen.

\section{Plant Inputs}

Coal: Flow rate of coal used in the power plant.

Oil: Flow rate of oil used in the power plant.

Natural Gas: : Flow rate of natural gas used in the power plant

Petroleum Coke: Total mass of petroleum coke used in the power plant

Other Fuels: Flow rate of other fuels used in the power plant

Total Fuels: This is the flow rate of fuel entering the power plant. This result is highlighted in yellow.

Lime/Limestone: Total mass of this reagent used in the power plant on a wet basis.

Sorbent: Total mass of sorbent used in the power plant

Ammonia: Total mass of ammonia used in the power plant.

Activated Carbon: Flow rate of activated carbon injected in the power plant.

Other Chemicals, Solvents \& Catalyst: Flow rate of other chemicals, solvents and catalysts used in the power plant.

Total Chemicals: Flow rate of reagent entering the power plant. This result is highlighted in yellow.

Oxidant: Flow rate of oxidant entering the power plant. This includes oxygen, nitrogen and argon.

Process Water: Flow rate of water used in the power plant. 


\section{Plant Outputs}

Slag: Flow rate of slag from the power plant on a dry basis.

Ash Disposed: Flow rate of ash from the power plant on a dry basis.

Other Solids Disposed: Flow rate of scrubber and other treatment solid wastes from the power plant on a dry basis.

Particulate Emissions to Air: Flow rate of particulates emitted to the air from the plant.

Captured $\mathrm{CO}_{2}$ : Flow rate of the captured $\mathrm{CO}_{2}$.

Byproduct Ash Sold: : Flow rate of ash (bottom and fly ash) sold in commerce as a by-product on a dry basis.

Byproduct Gypsum Sold: : Flow rate of flue gas treatment solids sold in commerce as a by-product on a dry basis.

Byproduct Sulfur Sold: Flow rate of elemental sulfur recovered from flue gas and sold in commerce as a by-product on a dry basis.

Byproduct Sulfuric Acid Sold: Total mass of sulfuric acid recovered from the flue gas and sold in commerce as a by-product.

Total Solids \& Liquids: This is the total wet solid mass exiting the power plant. This result is highlighted in yellow.

\section{Overall IGCC Plant Gas Emissions Results}

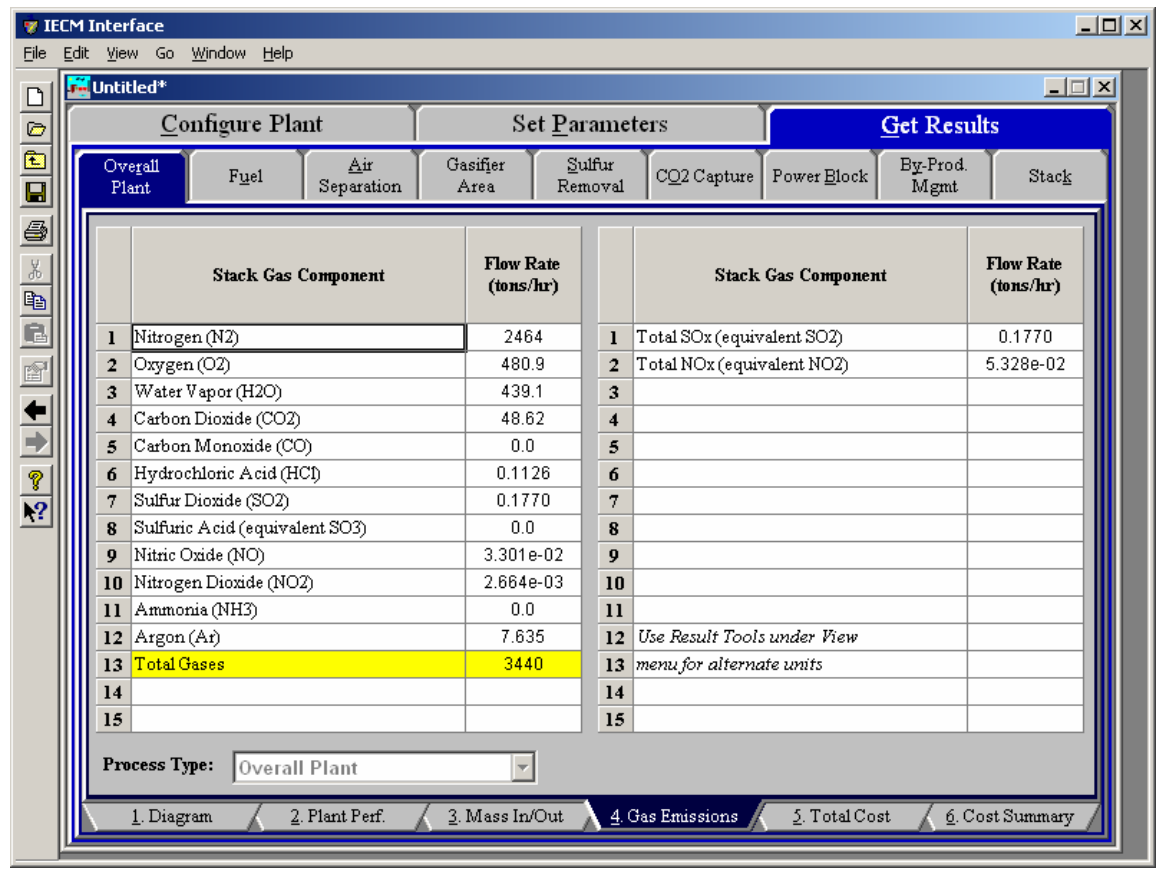

Overall IGCC Plant - Gas Emissions result screen.

\section{Stack Gas Component}

Each result is described briefly below: 
Nitrogen $\left(\mathrm{N}_{2}\right)$ : Total mass of nitrogen.

Oxygen $\left(\mathrm{O}_{2}\right)$ : Total mass of oxygen.

Water Vapor $\left(\mathrm{H}_{2} \mathrm{O}\right)$ : Total mass of water vapor.

Carbon Dioxide $\left(\mathrm{CO}_{2}\right)$ : Total mass of carbon dioxide.

Carbon Monoxide (CO): Total mass of carbon monoxide.

Hydrochloric Acid $(\mathbf{H C l})$ : Total mass of hydrochloric acid.

Sulfur Dioxide $\left(\mathrm{SO}_{2}\right)$ : Total mass of sulfur dioxide.

Sulfuric Acid (equivalent $\mathbf{S O}_{3}$ ): Total mass of sulfuric acid.

Nitric Oxide (NO): Total mass of nitric oxide.

Nitrogen Dioxide $\left(\mathrm{NO}_{2}\right)$ : Total mass of nitrogen dioxide.

Ammonia $\left(\mathrm{NH}_{3}\right)$ : Total mass of ammonia.

Argon (Ar): Total mass of argon.

Total Gases: Total of the individual components listed above. This item is highlighted in yellow.

Total SOx (equivalent $\mathrm{SO}_{2}$ ): Total mass of $\mathrm{SO}_{\mathrm{x}}$ as equivalent $\mathrm{SO}_{2}$.

Total NOx (equivalent $\mathrm{NO}_{2}$ ): Total mass of $\mathrm{NO}_{\mathrm{x}}$ as equivalent $\mathrm{NO}_{2}$.

\section{Overall IGCC Plant Total Cost Results}

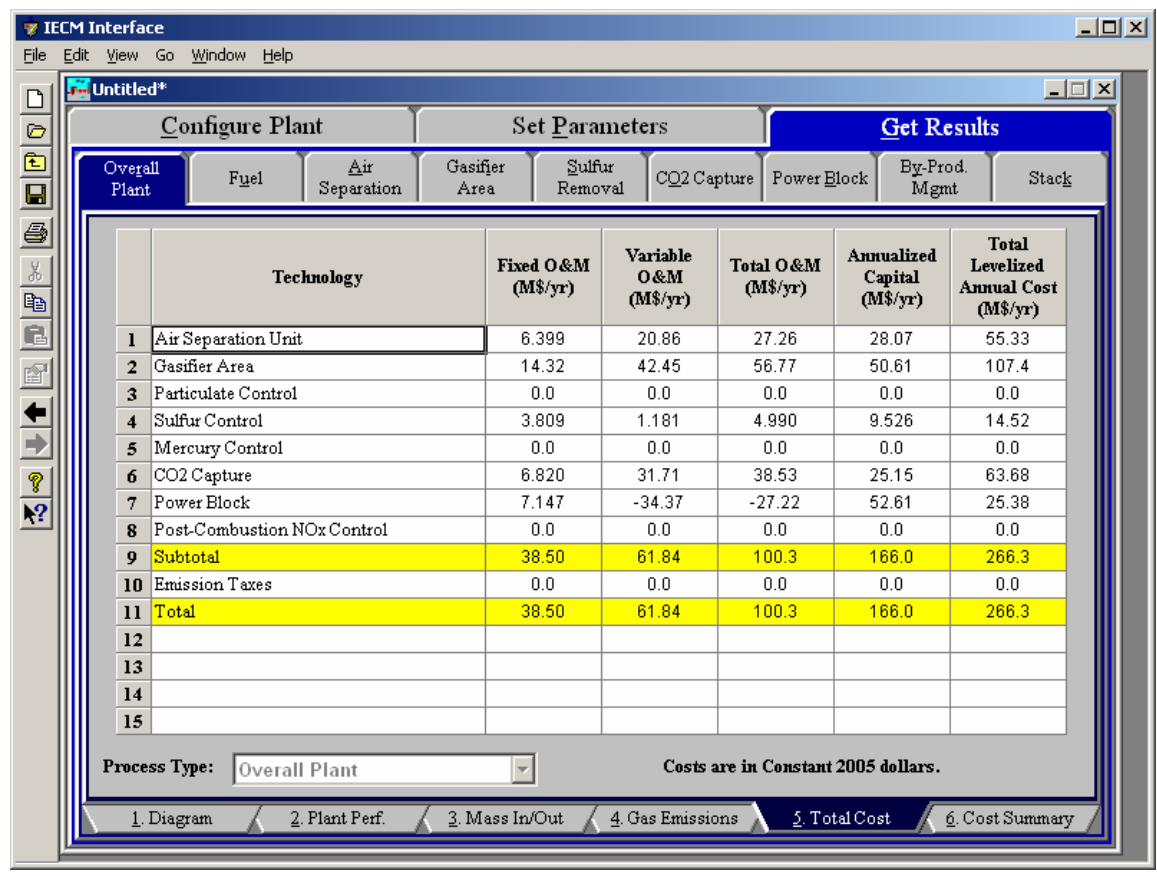

Overall IGCC Plant - Total Cost result screen.

The Total Cost result screen displays a table which totals the annual fixed, variable, operations, maintenance, and capital costs associated with the power plant as a whole. Each technology (row) is described briefly below. 


\section{Technology}

Air Separation Unit: This is the capital cost for the Air Separation process area of the plant.

Gasifier Area: This is the capital cost for the equipment in the gasifier process area of the plant.

Particulate Control: This is the capital cost for the equipment that performs particulate capture in the plant.

Sulfur Control: This is the capital cost for the equipment that performs sulfur capture in the plant.

Mercury Control: This is the capital cost for the mercury process area of the plant.

$\mathbf{C O}_{2}$ Capture: This is the capital cost for the equipment that performs $\mathrm{CO}_{2}$ capture in the plant.

Power Block: This is the capital cost for the power block process area of the plant.

Post-Combustion $\mathrm{NO}_{\mathbf{x}}$ Control: This is the capital cost for the equipment that captures post-combustion $\mathrm{NO}_{\mathrm{x}}$ in the plant.

Subtotal: This is the cost of the conventional and advanced abatement technology modules alone. This is the total abatement cost. The subtotal is highlighted in yellow.

Emission Taxes: This is the sum of the user assessed taxes on the plant emissions of $\mathrm{SO}_{2}, \mathrm{NO}_{\mathrm{x}}$ and $\mathrm{CO}_{2}$.

Total: This is the total cost of the entire power plant. This result is highlighted in yellow.

Each cost category (column) is described briefly below.

Fixed O\&M: The operating and maintenance fixed costs are given as an annual total. This number includes all maintenance materials and all labor costs for each technology.

Variable O\&M: The operating and maintenance variables costs are given as an annual total. This includes all reagent, chemical, steam, and power costs associated with a technology.

Total O\&M: This is the sum of the annual fixed and variable operating and maintenance costs for each technology.

Annualized Capital: This is the total capital cost expressed on an annualized basis, taking into consideration the levelized carrying charge factor, or fixed charge factor, over the entire book life.

Total Levelized Annual Cost: The total annual cost is the sum of the total annual O\&M cost and annualized capital cost items above. This result is highlighted in yellow 


\section{Overall IGCC Plant Cost Summary Results}

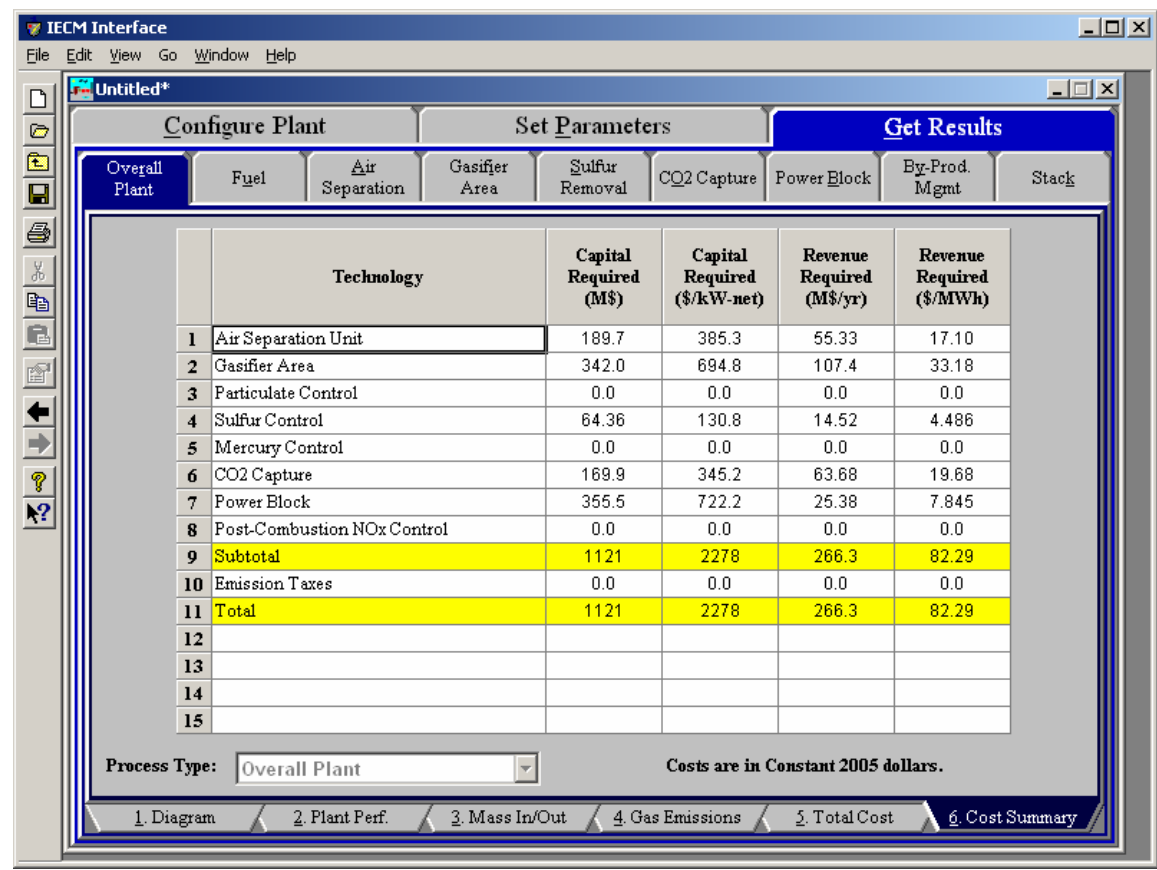

Overall IGCC Plant - Cost Summary result screen.

\section{Technology}

Air Separation Unit: This is the capital cost for the Air Separation process area of the plant.

Gasifier Area: This is the capital cost for the gasifier process area of the plant.

Particulate Control: This is the capital cost for the equipment that captures particulates in the plant.

Sulfur Control: This is the capital cost for the equipment that captures sulfur in the plant.

Mercury Control: This is the capital cost for the mercury process area of the plant.

$\mathbf{C O}_{2}$ Capture: This is the capital cost for the equipment that captures $\mathrm{CO}_{2}$ in the plant.

Power Block: This is the capital cost for the power block process area of the plant.

Post-Combustion $\mathrm{NO}_{\mathrm{x}}$ Control: This is the capital cost for the postcombustion equipment that captures $\mathrm{NO}_{\mathrm{x}}$ in the plant.

Total: This is the sum of the capital costs for all the process areas in the plant.

Each cost category (column) is described briefly below.

Capital Cost: The total capital requirement (TCR). This is the money that is placed (capitalized) on the books of the utility on the service date. 
The total cost includes the total plant investment plus capitalized plant startup. Escalation and allowance for funds used during construction (AFUDC) are also included. The capital cost is given on both a total and an annualized basis.

Revenue Required: Amount of money that must be collected from customers to compensate a utility for all expenditures in capital, goods, and services. The revenue requirement is equal to the carrying charges plus expenses. The revenue required is given on both an annualized and a net power output basis. 



\section{Fuel}

The screens associated with the Fuel Technology Navigation Tab display and define the composition and cost of the fuels used in the plant. The IECM supports the use of various fuels, ranging from coals of various rank, fuel oil of various weight, and natural gas of various places of origin. Default properties of fuels are provided, but user-specified properties can also be easily substituted.

The combustion model currently supports the use of pulverized coal in the furnace, with natural gas available as a reburn option to the in-furnace NOx controls and an optional natural gas auxiliary boiler. The coal properties can be modified. The natural gas properties will be made available in the future. At present, a common Pennsylvania natural gas is assumed (NGCC).

The natural gas combined cycle (NGCC) plant configurations all assume natural gas for fuel. The properties can be specified by the user.

The integrated gasification combined cycle (IGCC) plant configurations assume coal gasification to produce a synthetic fuel gas. The coal properties must be chosen from a predetermined set of coals.

\section{Fuel Properties Coal Input}

The selection of the particular coal model default, cleaned, saved externally, or userspecified and its ultimate and ash properties are selected and editable on the

Properties input screen. 


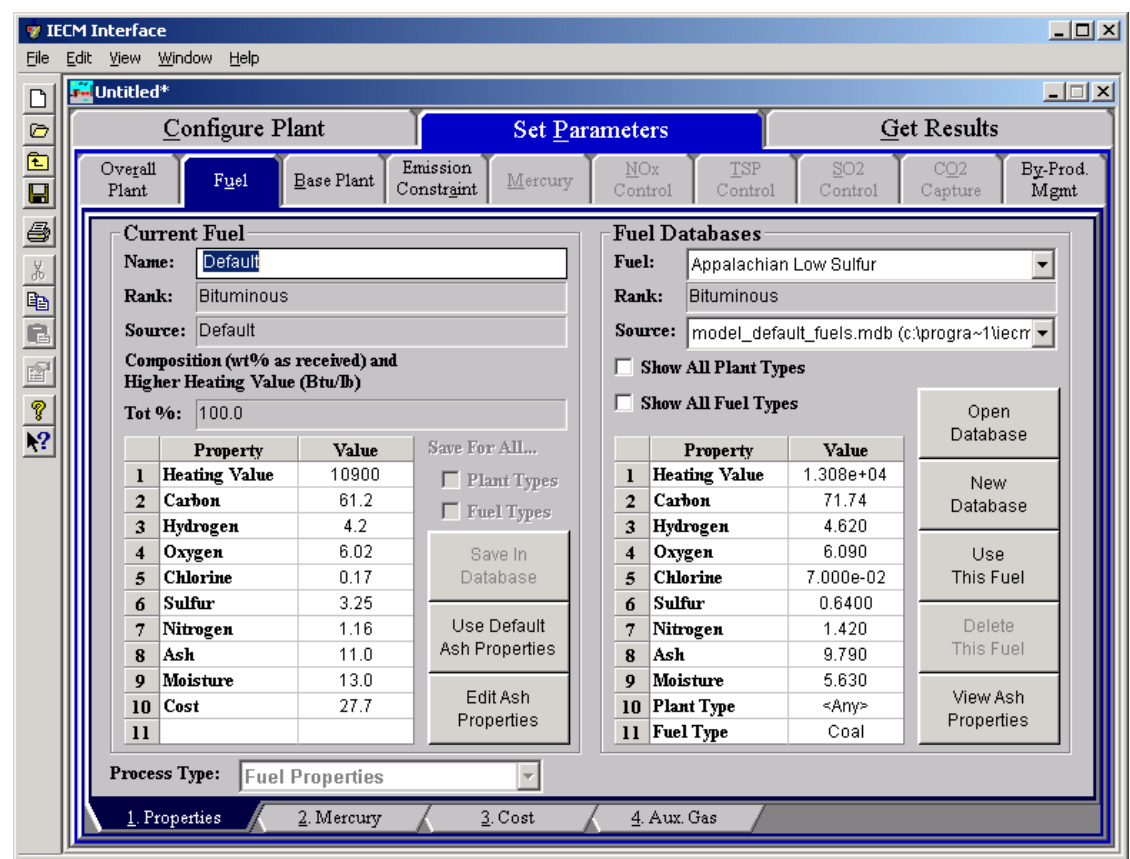

Fuel - Properties input screen.

There are two panes on the Fuel Properties input screen: one for the composition, higher heating value, and cost of the Current Fuel, the other for properties of the fuels in the Fuel Databases. The Current Fuel is the fuel for which the model will conduct its calculations. The IECM interface currently supports only one fuel selection per session. The Fuel Databases pane displays the properties for other selectable fuels. From this screen, you may choose a fuel from the model defaults, enter a user-defined fuel, or choose a previously saved user-defined fuel. Properties of existing fuels may be modified and new fuels may be created and saved to user specified databases. The user-specified databases can be transferred from one user to another. A full suite of buttons have been provided to make the selection and management of the fuel properties easier.

Both the Current Fuel pane and the Fuel Databases pane display the following information: for a fuel.

Name: This is the name of the fuel, it may be the trade name or a unique identifier supplied by the user.

Rank: The rank of a coal refers to the degree of coalification endured by the organic matter. It is estimated by measuring the moisture content, specific energy, reflectance of vitrinite or volatile matter (these are known as rank parameters

Source: The model provides the values for default fuel properties, these can be used "as is" or modified and used. Modified fuels maybe stored in a new database or an existing database. Source displays the database file from which the data was retrieved, or indicates that the data has been enetered by the user.

Fuel Properties: The property value spreadsheet is used to display the heating value and content of carbon, hydrogen, oxygen, chlorine, sulfur, nitrogen, ash, and moisture are specified on a weight percent basis for coal fuels. The data can be edited only in the Current Coal pane. The fuel composition is used in a combustion equation to calculate the flue gas composition in the furnace. The heating value is 
used to calculate the mass flow rate of fuel. Property data also determines the fuel rank (bituminous, subbituminous, or lignite). This, in turn, determines the default values of several boiler parameters. The editable fuel properties are:

- Heating Value: This is the higher heating value of the fuel in $\mathrm{Btu} / \mathrm{lb}$.

- Carbon: The weight percent of carbon in the fuel on a wet basis.

- Hydrogen: This is the weight percent of hydrogen in the fuel on a wet basis.

- Oxygen: This is the weight percent of oxygen in the fuel on a wet basis.

- Chlorine: This is the weight percent of chlorine in the fuel on a wet basis.

- Sulfur: This is the weight percent of sulfur in the fuel on a wet basis.

- Nitrogen: This is the weight percent of nitrogen in the fuel on a wet basis.

- Ash: This is the weight percent of ash in the fuel on a wet basis.

- Moisture: This is the weight percent of moisture in the fuel on a wet basis.

- Cost: This is the total as-delivered cost of the coal on a wet basis. A default value is provided for the default coals provided in the model. This value can be updated on this input screen or the fuel cost screen.

Ash Properties: The property value spreadsheet is also used to display the oxide content of the ash in coal on a percent of total ash basis. The data can be edited only in the Current Fuel pane. The ash content is used to determine the resistivity of the ash. This, in turn, determines the specific collection area (SCA) of the cold-side ESP. The editable ash properties are:

- $\mathrm{SiO}_{2}$ : The percent by weight of silicon dioxide in the ash.

- $\mathrm{Al}_{2} \mathbf{O}_{3}$ : The percent by weight of Aluminum Oxide in the ash.

- $\mathrm{Fe}_{2} \mathrm{O}_{3}$ : The percent by weight of ferric oxide in the ash.

- CaO: The percent by weight of calcium oxide in the ash.

- MgO: The percent by weight of magnesium oxide in the ash.

- $\mathrm{Na}_{2} \mathrm{O}$ : The percent by weight of sodium oxide in the ash.

- $\mathbf{K}_{\mathbf{2}} \mathrm{O}$ : The percent by weight of potassium oxide in the ash.

- $\mathrm{TiO}_{2}$ : The percent by weight of titanium dioxide in the ash.

- $\mathbf{M n O}_{2}$ : The percent by weight of manganese dioxide in the ash.

- $\mathbf{P}_{2} \mathbf{O}_{5}$ : The percent by weight of phosphorus pentoxide in the ash.

- $\mathbf{S O}_{3}$ : The percent by weight of sulfur trioxide in the ash.

The Current Fuel pane displays two check boxes that are grayed out when the "model_default_fuels.mdb" database file is currently open. If a personal fuel 
database is opened, these two check boxes become active. The check boxes serve to allow the fuel to be available to multiple plant types or fuel types. The current fuel must be saved to make the restrictions permanent. Once saved, all new sessions will use these filters to determine which fuels will be listed in the Fuel menu. These check boxes are:

Plant Types: This is a filtering agent that specifies whether or not this fuel is restricted to the current plant type. If the box is not checked, the fuel will only be available to new sessions with the same plant type as the current session. If the box is checked, the fuel will be available to all new sessions, regardless of their plant type.

Fuel Types: This is a filtering agent that specifies whether or not this fuel is restricted to a particular fuel type. If the box is not checked, the fuel will only be available to new sessions that use the same primary fuel type as the current session. If the box is checked, the fuel will be available to all new sessions, regardless of the primary fuel type they use. This filter will be more important when oil fuels are made available in the IECM.

The Fuel Databases pane displays two additional items that verify whether or not a particular fuel is restricted to particular plant types or for primary fuel types. Either a particular plant type and fuel type will be specified or the word " $<$ All $>$ " will be displayed.

\section{Selecting a Fuel}

The Current Fuel pane displays the fuel that is in use by the model. The Fuel Databases pane initially displays the first default fuel in the model's default database. To make the fuel that is displayed in the Fuel Database pane the fuel to be used by the model, press the Use this Fuel button. The fuel will then be displayed in the Current Fuel pane. To view the ash properties, press the View Ash Properties button in the Fuels Database, the ash properties are displayed and the button that was pressed, labeled View Ash Properties has changed to View Fuel Properties. This button toggles between View Ash Properties and View Fuel Properties. To find other fuels:

Select a Different Fuel in the Open Database: Select the pull down menu on the text box labeled Fuel:. The list of fuels in the database is displayed another fuel can be chosen.

Select a Different Open Database: Select the pull down menu on the text box labeled Source:. The list of other open databases is displayed.

Open Another Fuel Database: When pressed the button labeled Open Database will display the Windows Open screen. All files with .fdb extension will be displayed. . fdb is the default extension for the Fuel Databases files. Select a file and press the Open button.

\section{Modifying a Fuel}

The fuel values that are displayed in the Current Fuel pane may be modified. Put the cursor into the cell containing the value of the property to be edited and enter the new value. To edit the ash properties of the current fuel; press the Edit Ash

Properties button in the Current Fuel pane, the ash properties are displayed and the button that was pressed, labeled Edit Ash Properties has changed to Edit Fuel Properties. This button toggles between Edit Ash Properties and Edit Fuel Properties. . The ash properties may be edited in the same way as the fuel 
properties. Place the cursor in the value of the property to be modified and enter the new value. The model will run using the fuel that is displayed in the Current Fuel pane.

\section{Saving a Modified Fuel}

A fuel that has been modified may be saved to any user specified fuel database except the default database, model_default_fuels.mdb. Use the Save in Database button to save the modified fuel, displayed in the Current Fuel pane to the database that is displayed in the Source text box. If the default database, model_default_fuels.mdb is displayed in the text box titled Source, the Save in Database button will be grayed out, not active. Activate the Save in Database, by opening another database or creating a new database.

\section{Deleting a Fuel}

A fuel that is displayed in the Fuel Databases pane, may be deleted using the Delete this Fuel button, if it is not a model default fuel. Fuels in the model default database, model_default_fuels.mdb, cannot be deleted.

\section{Open Database}

Press the Open Database button on the Fuels Database pane and the Windows Open Screen will appear. A valid fuel database file as an .fdb extension. Click on the database file to open and press the Open button. The Fuels Database displays the first fuel in the selected database and the Source: text box displays the full path and file name of the database that has just been opened.

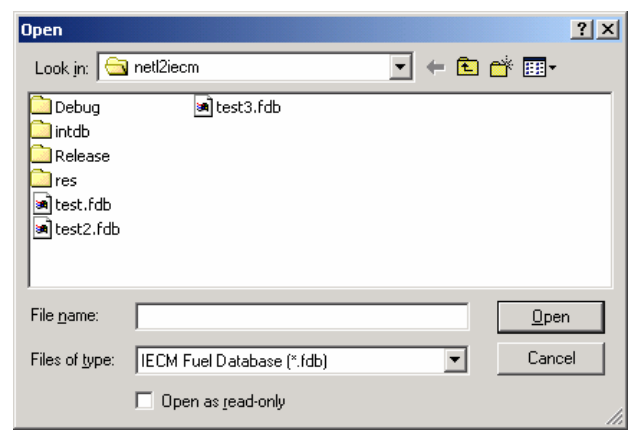

Fuels - Windows Open screen.

\section{New Database}

Press the New Database button on the Fuels Database pane and the Windows Save As Screen will appear. Type in the name of the new database file into the File name: text box. All fuel database files have an .fdb extension. Press the Save button. The Source: text box displays the full path and file name of the new database and all other fuel values in the Fuels Database pane will be blank 


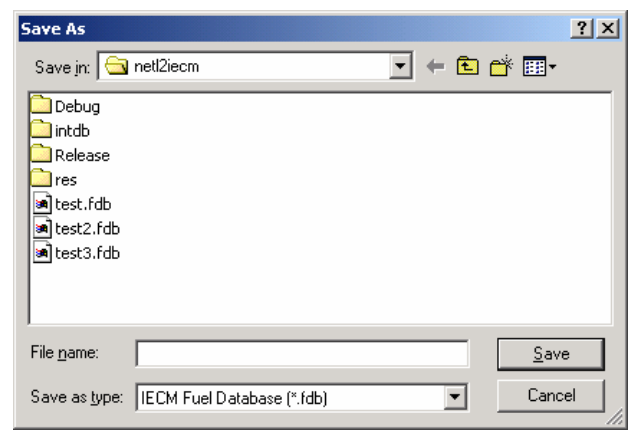

Fuels - Windows Save As screen.

\section{Fuel Mercury Input}

The concentration of mercury in the as-fired coal and speciation of mercury after combustion are entered on the Mercury input screen

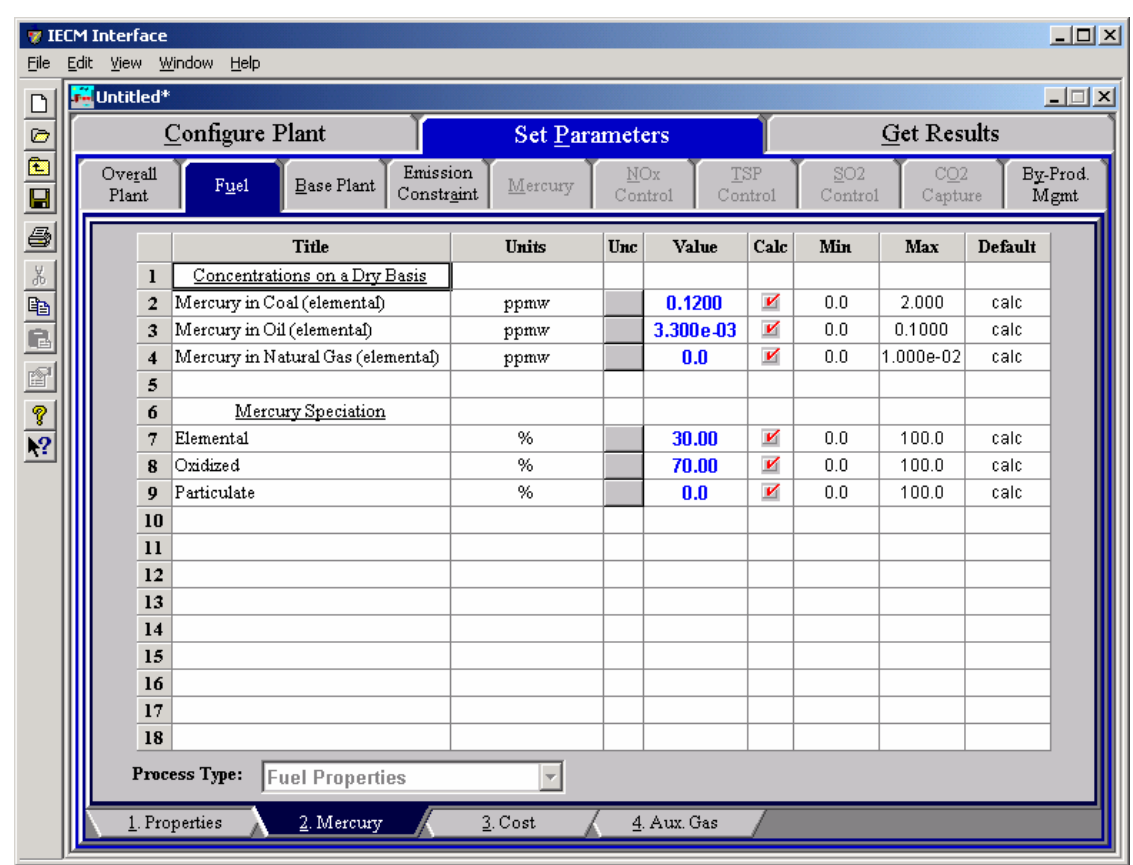

Fuel - Mercury input screen.

Each parameter is described briefly below:

\section{Concentration on a Dry Basis}

Trace elements found in fuels are typically measured and reported as a mass concentration given on a dry basis. The IECM uses this concentration in conjunction with the fuel flow rate and fuel moisture to determine the mass flow rate. Currently Mercury is the only trace species tracked in the IECM.

Mercury in Coal (elemental): This input parameter specifies the mass concentration of total mercury in the coal given on a dry basis. The mercury concentration should be given on an elemental basis, not on a 
mercury compound basis. The default value is a function of the coal rank.

Mercury in Oil (elemental): This input parameter specifies the mass concentration of total mercury in the oil. The mercury concentration should be given on an elemental basis, not on a mercury compound basis.

Mercury in Natural Gas (elemental): This input parameter specifies the mass concentration of total mercury in the natural gas. The mercury concentration should be given on an elemental basis, not on a mercury compound basis.

\section{Mercury Speciation}

Once the fuel is combusted, the mercury can be identified in primarily two chemical states: elemental $\left(\mathrm{Hg}^{0}\right)$ and oxidized $\left(\mathrm{Hg}^{+2}\right)$. Although mercury can alternatively be reported as particulate or gas phase, the IECM assumes Mercury is reported on an elemental and oxidized basis.

Elemental: This is the percent of total mercury that is in an elemental state $\left(\mathrm{Hg}^{0}\right)$ after combustion. Elemental mercury is typically unreactive and passes through a power plant. The default value is a function of the coal rank.

Oxidized: This is the percent of total mercury that is in an oxidized state $\left(\mathrm{Hg}^{+2}\right)$ after combustion. Oxidized mercury is very reactive and typically forms mercury compounds. The default value is a function of the coal rank.

Particulate: This parameter is not currently used in the IECM. It's value is set to force the sum of the speciation types to be $100 \%$.

\section{Fuel Cost Input}

The cost of the cleaned coal, transportation costs, and other miscellaneous for coal and the auxiliary natural gas costs are accessed on the Cost input screen. Note that coal parameters are not displayed for the Combustion (Turbine) plant type. 


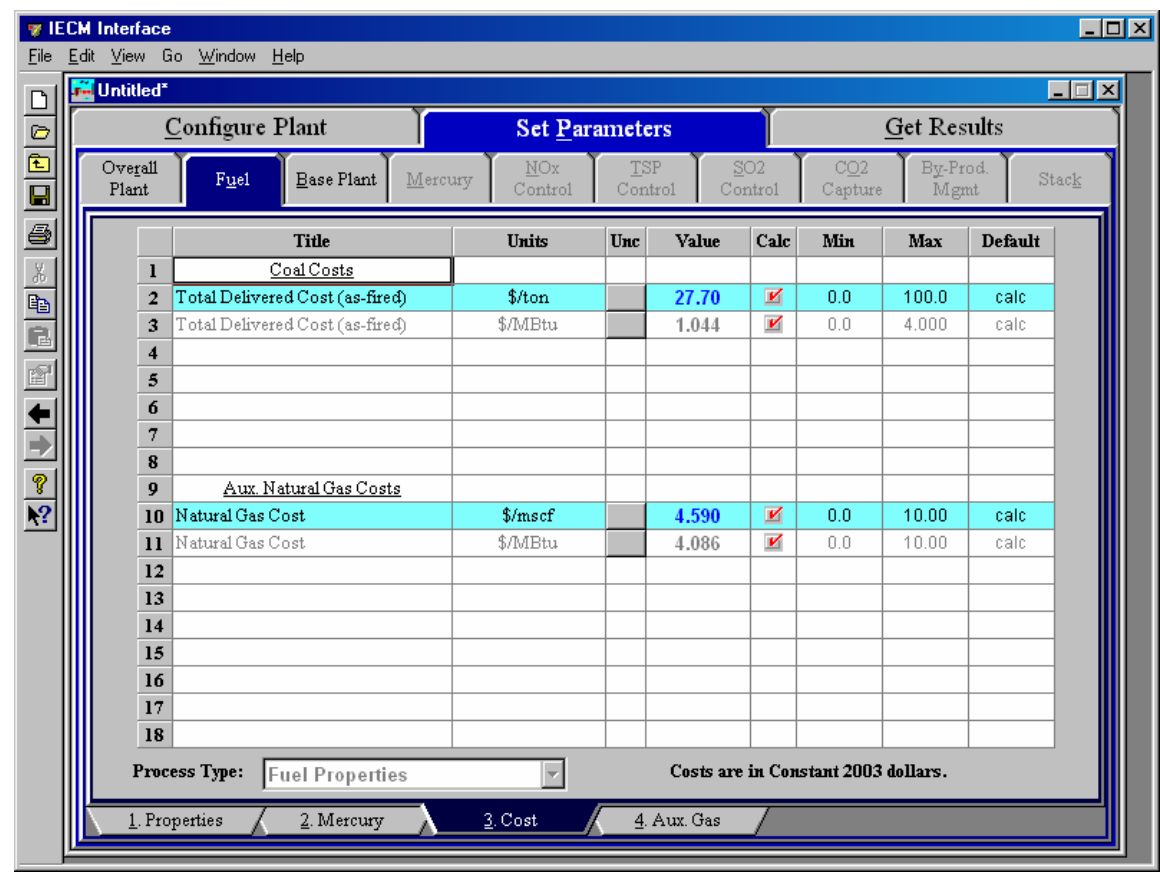

Fuel-Cost input screen.

Each parameter is described briefly below.

\section{Coal Costs}

Coal is the primary fuel for the combustion plant type. The costs associated with the coal have been simplified and contain only the total as-fired cost.

Total Delivered Cost (as-fired): This is the total cost of delivered coal on a wet ton basis in dollars per ton. It is assumed to contain any costs of cleaning and transportation. The total cost in units of $\$ /$ ton is the same value as shown on the fuel properties screen.

Total Delivered Cost (as-fired): This is also provided in units of $\$ / M B t u$. This value cannot be edited. It is based on the value given above in units of $\$ /$ ton.

\section{Aux. Natural Gas Costs}

Natural gas is an auxiliary fuel used as an option for the combustion NOx control and the amine $\mathrm{CO}_{2}$ capture configurations.

Natural Gas Cost: This is also provided in units of $\$ / M B t u$. This value cannot be edited. It is based on the value given in units of $\$ / \mathrm{mscf}$.

Natural Gas Cost: This is also provided in units of $\$ / M B t u$. This value cannot be edited.

\section{Fuel Aux. Gas Properties Input}

The natural gas composition and density can be entered on the natural gas properties screen. The screen below is shown when accessed from the Combustion (Turbine) plant type. It is also available for combustion plant configurations that 
include $\mathbf{C O}_{\mathbf{2}}$ Capture with an Auxiliary Natural Gas Boiler or In-Furnace $\mathbf{N O}_{\mathbf{x}}$ Control with Gas Reburn and is accessed by selecting 4. Aux. Gas from the Fuel Screen of the Set Parameters Tab

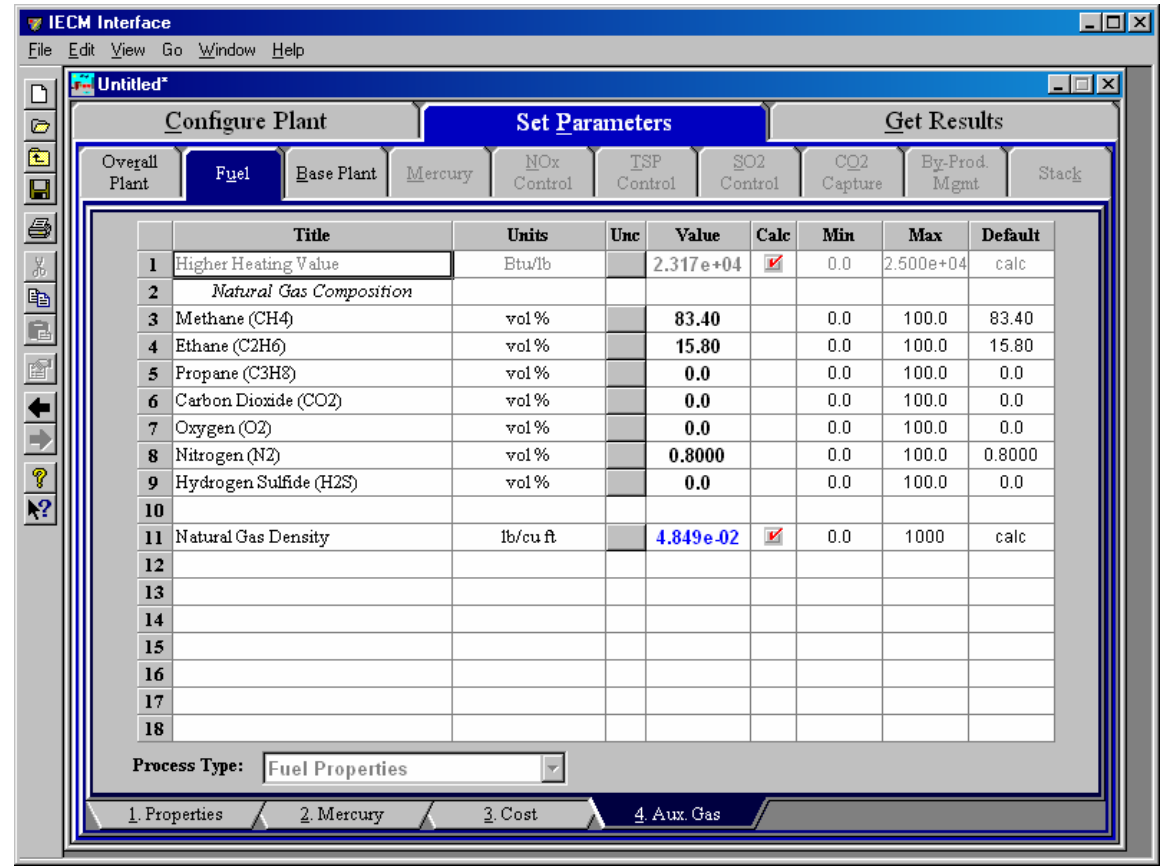

Fuel - Auxiliary Natural Gas input screen.

The Natural Gas input screen displays and allows the user to update the fuel properties of Natural Gas.

Higher Heating Value: Higher heating value (HHV) is the thermal energy produced in Btu/lb of fuel from completely burning the fuel to produce carbon dioxide and liquid water. The latent heat of condensation is included in the value. This value is calculated from the natural gas composition below and cannot be changed by the user.

\section{Natural Gas Composition}

Methane (CH4): The volume, by percent, of methane in the natural gas.

Ethane (C2H6): The volume, by percent, of ethane in the natural gas.

Propane (C3H8): The volume, by percent, of propane in the natural gas.

Carbon Dioxide (CO2):The volume, by percent, of carbon dioxide in the natural gas.

Oxygen (02):The volume, by percent, of oxygen in the natural gas.

Nitrogen (N2): The volume, by percent, of nitrogen in the natural gas.

Hydrogen Sulfide (H2S): The volume, by percent, of hydrogen sulfide in the natural gas.

Natural Gas Density: The natural gas density is a weighted average of the individual densities of the natural gas constituents. This value is used in many unit conversion operations. 


\section{Fuel Coal Diagram}

The Fuel Technology Navigation Tab in the Get Results program area contains the Diagram result screen. It displays the properties set up in the Fuel Properties

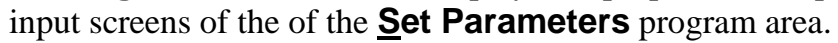

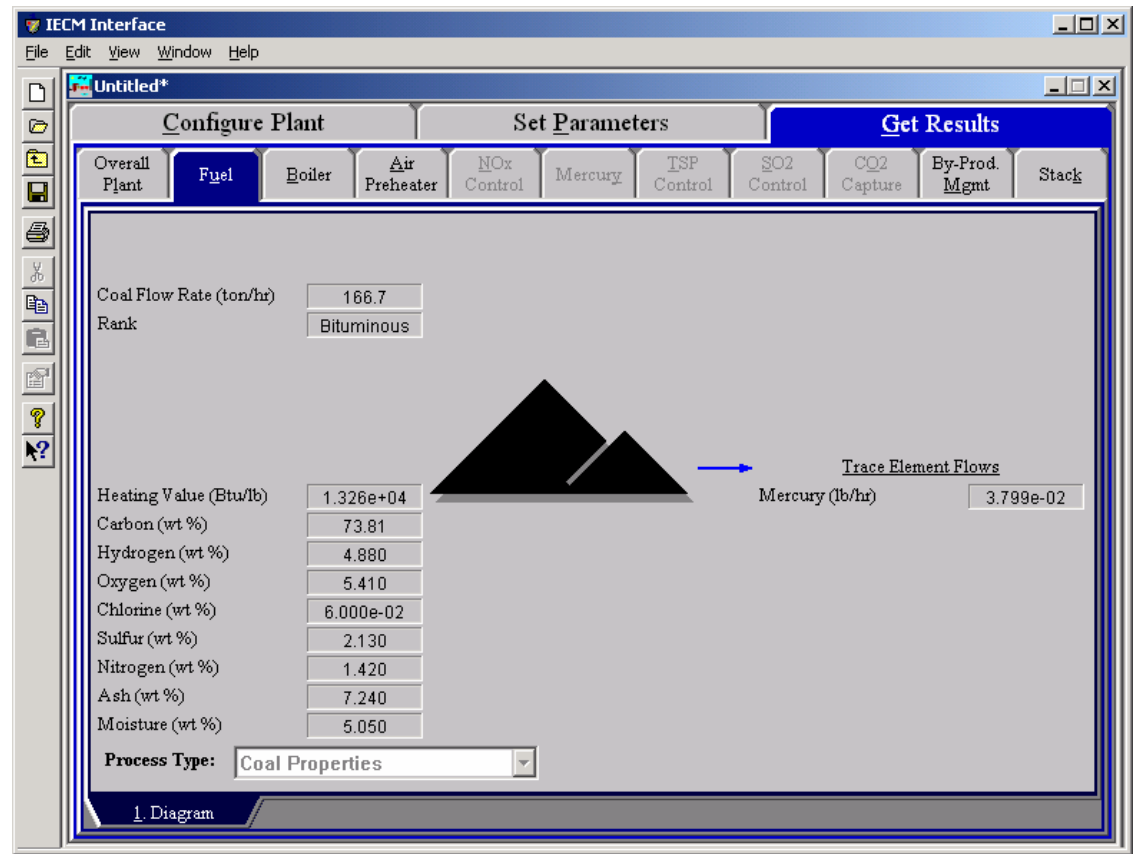

Fuel - Diagram result screen for coal.

The Coal Diagram result screen displays fuel composition and flow rate information, which is described briefly below.

Coal Flow Rate: Coal flow rate into the boiler on a wet basis. Waste products removed prior to the burners are not considered here.

Rank: The rank of the coal based on the higher heating value. This is primarily determined by the higher heating value and to a lesser degree by the sulfur and ash content.

Heating Value: Higher heating value (HHV) is the thermal energy produced in Btu/lb of fuel (wet) from completely burning the fuel to produce carbon dioxide and liquid water. The latent heat of condensation is included in the value.

Carbon: The carbon content of the coal by weight on an elemental and wet basis.

Hydrogen: The hydrogen content of the coal by weight on an elemental (H) and wet basis.

Oxygen: The oxygen content of the coal by weight on an elemental (O) and wet basis.

Chlorine: The chlorine content of the coal by weight on an elemental (Cl) and wet basis.

Sulfur: The sulfur content of the coal by weight on an elemental (S) and wet basis. 
Nitrogen: The nitrogen content of the coal by weight on an elemental $(\mathrm{N})$ and wet basis.

Ash: The ash content of the coal by weight on a wet basis.

Moisture: The inherent moisture content of the coal by weight.

\section{Trace Element Flows}

Trace elements are now supported in the IECM. The mass flow rate is reported in units of pounds per unit of time. All values reflect the elemental mass flow rate.

Mercury: This is the elemental mercury flow rate in coal. At present, mercury is not tracked in the IGCC plant type and is displayed as a zero value.

\section{Fuel Natural Gas Diagram}

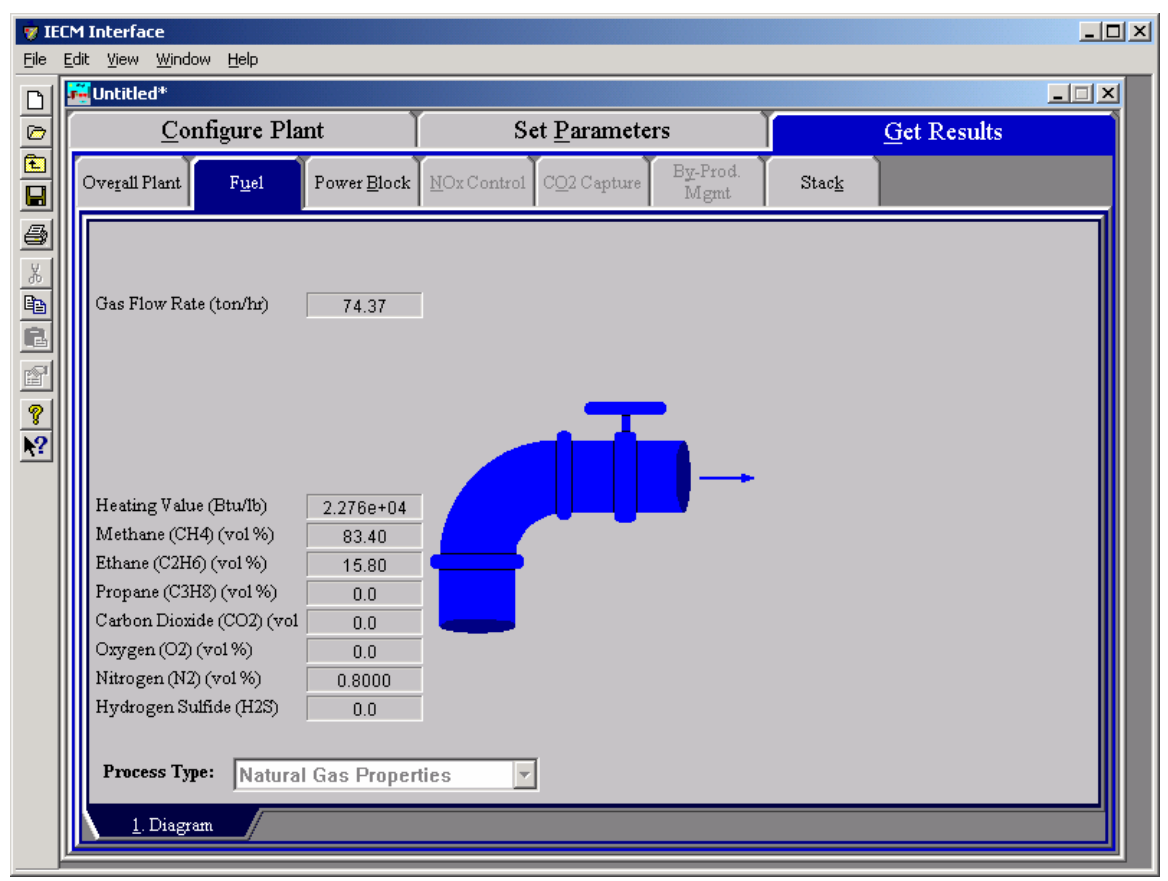

Fuel - Diagram result screen for natural gas.

The Natural Gas Diagram result screen displays fuel composition and flow rate information, which is described briefly below.

Gas Flow Rate: The natural gas flow rate to the turbine.

Heating Value: Higher heating value (HHV) is the thermal energy produced in Btu/lb of fuel.

Methane $\left(\mathrm{CH}_{4}\right)$ : The volume, by percent, of methane in the natural gas.

Ethane $\left(\mathrm{C}_{2} \mathrm{H}_{6}\right)$ : The volume, by percent, of ethane in the natural gas.

Propane $\left(\mathrm{C}_{3} \mathrm{H}_{8}\right)$ : The volume, by percent, of propane in the natural gas.

Carbon Dioxide $\left(\mathrm{CO}_{2}\right)$ : The volume, by percent, of carbon dioxide in the natural gas.

Oxygen $\left(\mathrm{O}_{2}\right)$ : The volume, by percent, of oxygen in the natural gas. 
Nitrogen $\left(\mathbf{N}_{2}\right)$ : The volume, by percent, of nitrogen in the natural gas.

Hydrogen Sulfide $\left(\mathrm{H}_{2} \mathbf{S}\right)$ : The volume, by percent, of hydrogen sulfide in the natural gas. 


\section{Air Separation}

This chapter illustrates the configuration, inputs and results of the air separation technology. It is presently used only for the IGCC plant configurations.

\section{Air Separation Performance Inputs}

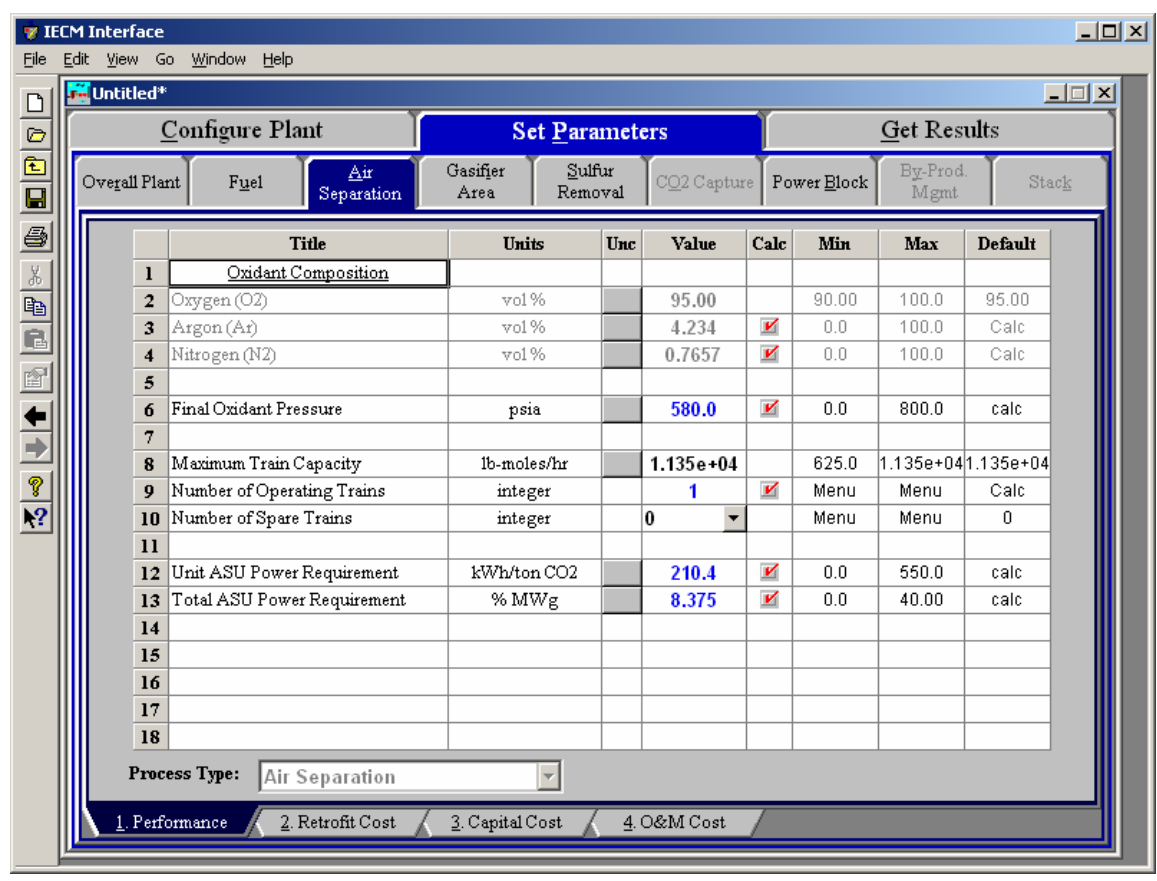

Air Separation - Performance input screen.

\section{Oxidant Composition}

Oxygen $\left(\mathrm{O}_{2}\right)$ : This is the percent of oxygen that is in the oxidant that is produced by the air separation unit. The value is fixed for the IGCC plant type.

Argon (Ar): This is the percent of argon that is in the oxidant that is produced by the air separation unit.

Nitrogen $\left(\mathbf{N}_{2}\right)$ : This is the percent of nitrogen that is in the oxidant that is produced by the air separation unit. 
Final Oxidant Pressure: The final oxidant stream from the ASU can be provided at a high pressure. The default value is determined by the plant type being used.

Maximum Train Capacity: The maximum production rate of oxidant is specified here. It is used to determine the number of operating trains required.

Number of Operating Trains: This is the total number of operating trains. It is used primarily to calculate capital costs. The value must be an integer

Number of Spare Trains: This is the total number of spare trains. It is used primarily to calculate capital costs. The value must be an integer.

Unit ASU Power Requirement: The main air compressor (MAC) pressurizes atmospheric air to approximately $550 \mathrm{kPA}$ (65 psig), but is expressed as a function of the oxygen product required.

Total ASU Power Requirement: This is the electricity used by the air separation unit for internal use. A majority of the power is used for the main air compressor and a secondary amount used for the product stream compressor (if required). It is expressed as a percent of the gross plant capacity.

\section{Air Separation Retrofit Cost Inputs}

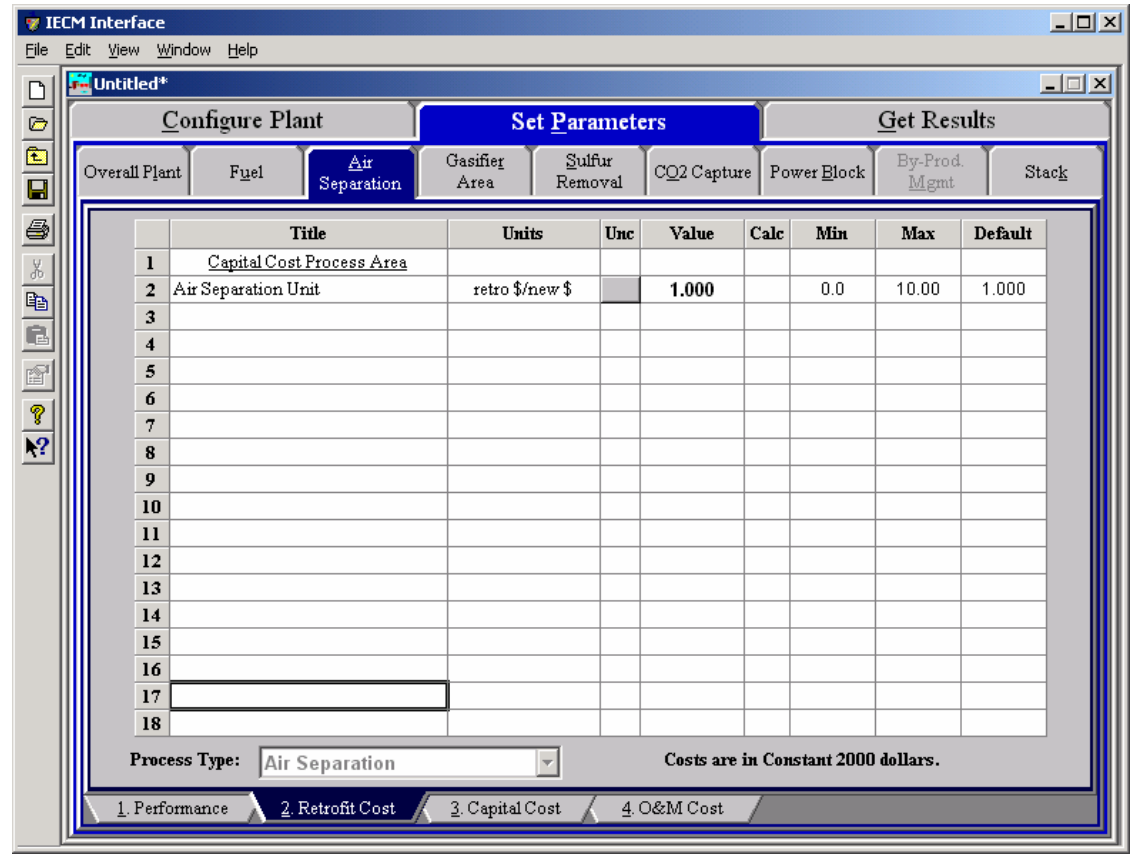

Air Separation - Retrofit Cost input screen.

\section{Capital Cost Process Area}

Air Separation Unit: The retrofit factor is a ratio of the costs of retrofitting an existing facility with an air separation unit versus a new facility, using the same equipment. 


\section{Air Separation Capital Cost Inputs}

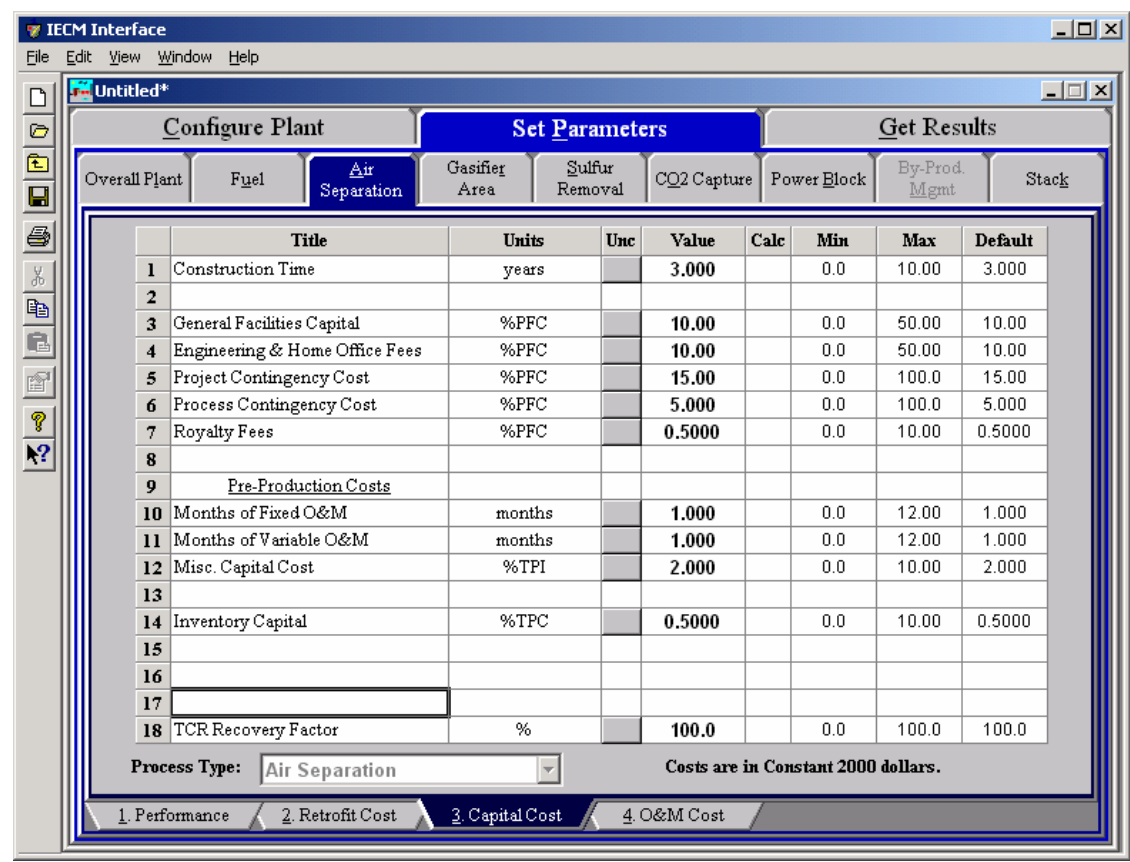

Air Separation - Capital Cost input screen.

Inputs for capital costs are entered on the Capital Cost input screen.

Construction Time: This is the idealized construction period in years. It is used to determine the allowance for funds used during construction (AFUDC).

General Facilities Capital (GFC): The general facilities include construction costs of roads, office buildings, shops, laboratories, etc. Sales taxes and freight costs are included implicitly. The cost typically ranges from $5-20 \%$.

Engineering \& Home Office Fees: The engineering \& home office fees are a percent of total direct capital cost. This is an overhead fee paid to the architect/engineering company. These fees typically range from 7$15 \%$.

Project Contingency Cost: This is factor covering the cost of additional equipment or other costs resulting from a more detailed design. Higher contingency factors will be applied to simplified or preliminary designs and lower factors to detailed or finalized designs.

Process Contingency Cost: This quantifies the design uncertainty and cost of a commercial-scale system. This is generally applied on an areaby-area basis. Higher contingency factors are applied to new regeneration systems tested at a pilot plant and lower factors to full-size or commercial systems.

Royalty Fees: Royalty charges may apply to some portions of generating units incorporating new proprietary technologies.

Pre-Production Costs: These costs consider the operator training, equipment checkout, major changes in unit equipment, extra maintenance, and inefficient use of fuel or other materials during startup. These are typically applied to the O\&M costs over a specified 
period of time (months). The two time periods for fixed and variable O\&M costs are described below with the addition of a miscellaneous capital cost factor.

- Months of Fixed O\&M: Time period of fixed operating costs used for preproduction to cover training, testing, major changes in equipment, and inefficiencies in start-up. This includes operating, maintenance, administrative and support labor. It also considers maintenance materials.

- Months of Variable O\&M: Time period of variable operating costs used for preproduction to cover chemicals, water, consumables, and solid disposal charges in start-up, assuming $100 \%$ load. This excludes any fuels.

- Misc. Capital Cost: This is a percent of total plant investment (sum of TPC and AFUDC) to cover expected changes to equipment to bring the system up to full capacity.

Inventory Capital: Percent of the total direct capital for raw material supply based on $100 \%$ capacity during a 60 day period. These materials are considered storage. The inventory capital includes fuels, consumables, by-products, and spare parts. This is typically $0.5 \%$.

TCR Recovery Factor: The actual total capital required (TCR) as a percent of the TCR in a new power plant. This value is $100 \%$ for a new installation and may be set as low as $0 \%$ for a fabric filter that has been paid off.

\section{Air Separation O\&M Cost Inputs}

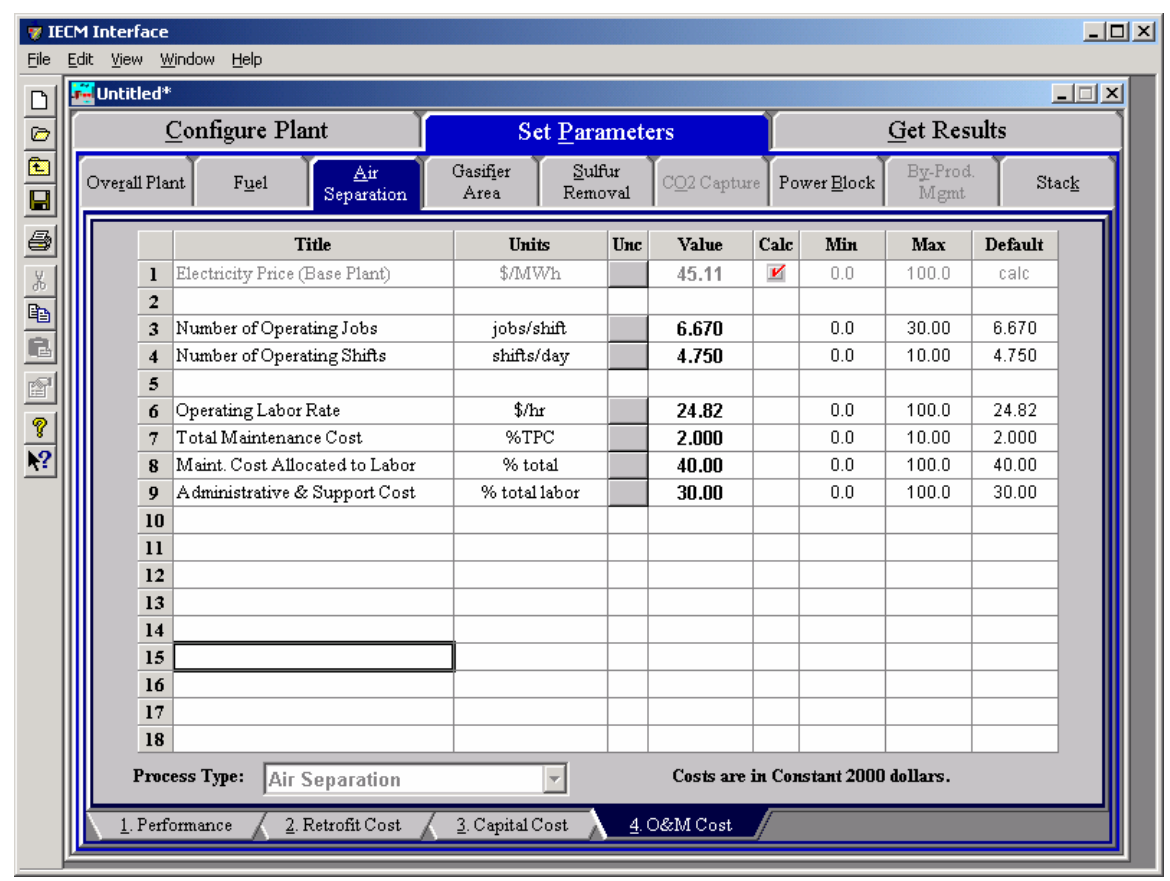

Air Separation - O\&M Cost input screen.

Inputs for O\&M costs are entered on the Air Separation O\&M Cost input screen. O\&M costs are typically expressed on an average annual basis and are provided in 
either constant or current dollars for a specified year, as shown on the bottom of the screen.

Electricity Price (Base Plant): This is the price of electricity and is calculated as a function of the utility cost of the base plant, where the base plant for the IGCC Model is an air separation unit, gasifier and the power block

Number of Operating Jobs: This is the total number of operating jobs that are required to operate the plant per eight-hour shift.

Number of Operating Shifts: This is the total number of equivalent operating shifts in the plant per day. The number takes into consideration paid time off and weekend work ( 3 shifts/day * 7 days/5 day week * 52 weeks/(52 weeks -6 weeks PTO $)=4.75$ equiv. Shifts/day)

Operating Labor Rate: The hourly cost of labor is specified in the base plant O\&M cost screen. The same value is used throughout the other technologies.

Total Maintenance Cost: This is the annual maintenance cost as a percentage of the total plant cost. Maintenance cost estimates can be developed separately for each process area.

Maint. Cost Allocated to Labor: Maintenance cost allocated to labor as a percentage of the total maintenance cost.

Administrative \& Support Cost: This is the percent of the total operating and maintenance labor associated with administrative and support labor.

\section{Air Separation Diagram}

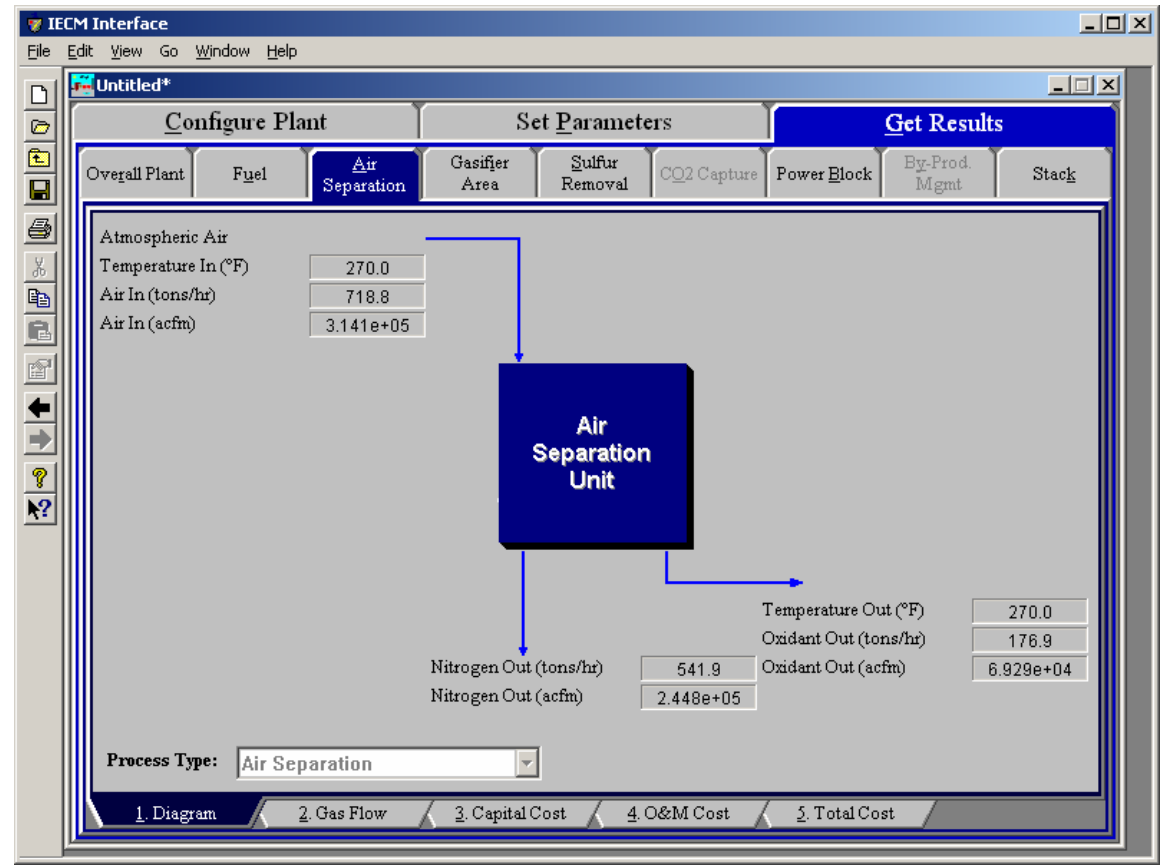

Air Separation - Diagram result screen. 
The Air Separation Diagram result screen displays an icon for the Air Separation Unit and values for major flows in and out of it. Each result is described briefly below in flow:

Atmospheric Air Temperature In: Temperature of the atmospheric air entering the air separation unit.

Atmospheric Air In: Mass flow rate of air entering the air separation unit, based on the atmospheric air temperature and atmospheric pressure.

Atmospheric Air In: Volumetric flow rate of air entering the air separation unit, based on the atmospheric air temperature and atmospheric pressure.

Nitrogen Out: Mass flow rate of the nitrogen exiting the Air Separation Unit.

Nitrogen Out: Volumetric flow rate of the nitrogen exiting the Air Separation Unit.

Temperature Out: Temperature of the oxidant exiting the Air Separation Unit.

Oxidant Out: Mass flow rate of the oxidant exiting the Air Separation Unit.

Oxidant Out: Volumetric flow rate of the oxidant exiting the Air Separation Unit.

\section{Air Separation Gas Flow Results}

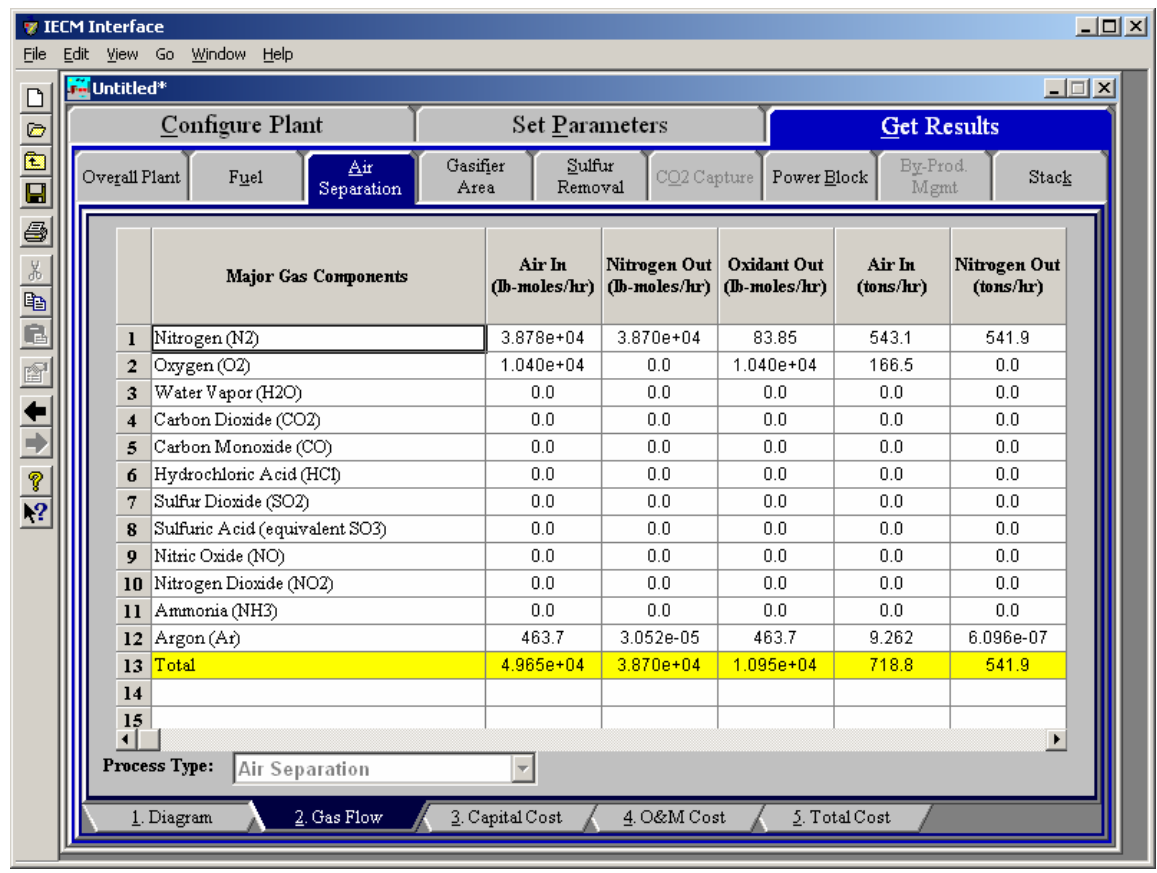

Air Separation - Gas Flow result screen.

Each result is described briefly below.

Nitrogen $\left(\mathbf{N}_{2}\right)$ : Total mass of nitrogen. 
Oxygen $\left(\mathrm{O}_{2}\right)$ : Total mass of oxygen.

Water Vapor $\left(\mathrm{H}_{2} \mathrm{O}\right)$ : Total mass of water vapor.

Carbon Dioxide $\left(\mathrm{CO}_{2}\right)$ : Total mass of carbon dioxide.

Carbon Monoxide (CO): Total mass of carbon monoxide.

Hydrochloric Acid ( $\mathbf{H C l})$ : Total mass of hydrochloric acid.

Sulfur Dioxide $\left(\mathrm{SO}_{2}\right)$ : Total mass of sulfur dioxide.

Sulfuric Acid (equivalent $\mathrm{SO}_{3}$ ): Total mass of sulfuric acid.

Nitric Oxide (NO): Total mass of nitric oxide.

Nitrogen Dioxide $\left(\mathrm{NO}_{2}\right)$ : Total mass of nitrogen dioxide.

Ammonia $\left(\mathrm{NH}_{3}\right)$ : Total mass of ammonia.

Argon (Ar): Total mass of argon.

Total: Total of the individual components listed above. This item is highlighted in yellow.

\section{Air Separation Capital Cost Results}

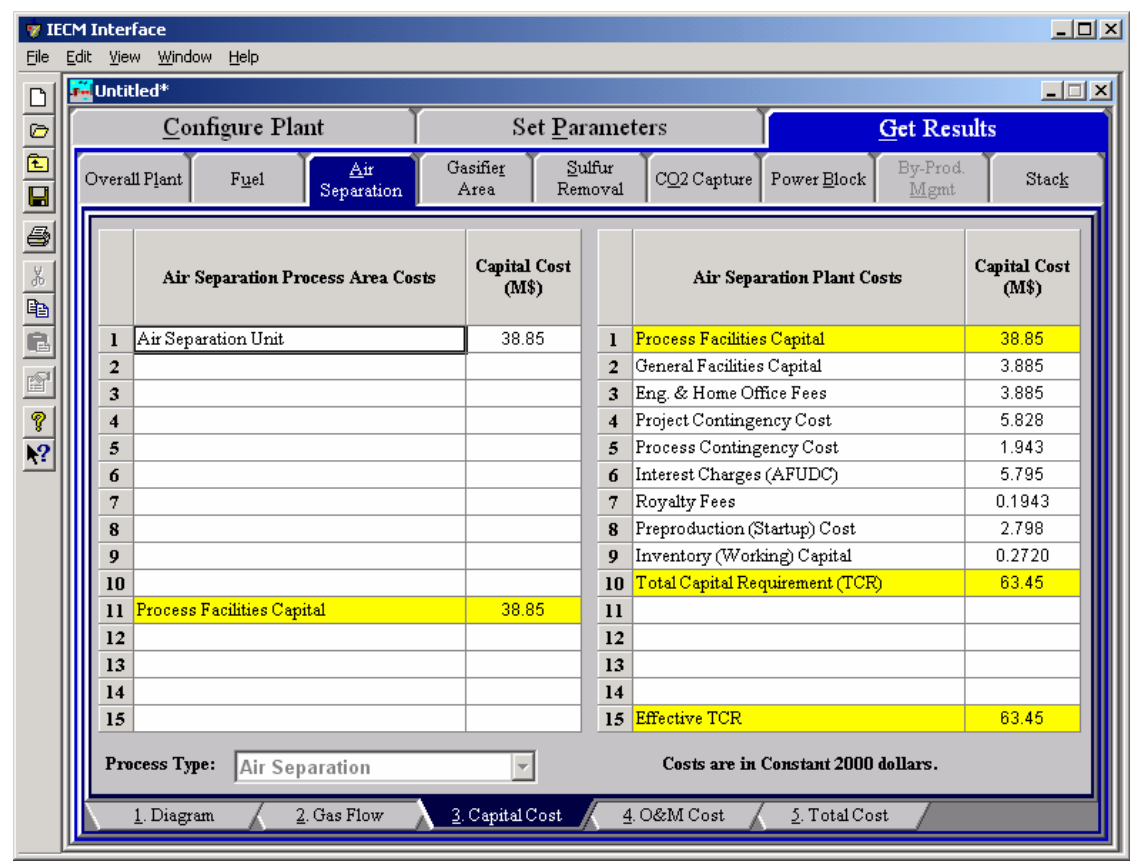

Air Separation Capital Cost results screen.

The Air Separation Capital Cost result screen displays tables for the capital costs. Capital costs are typically expressed in either constant or current dollars for a specified year, as shown on the bottom of the screen. Each result is described briefly below:

\section{Air Separation Process Area Costs}

Air Separation Unit: The cost of oxygen plants depends mostly on the oxygen feed rate to the gasifier, because size and cost of compressors and air separation systems are proportional to this flow rate. The 
number of trains is determined based on the total mass flow rate of oxygen. The minimum number of operating trains is two

Process Facilities Capital: The process facilities capital is the total constructed cost of all on-site processing and generating units listed above, including all direct and indirect construction costs. All sales taxes and freight costs are included where applicable implicitly. This result is highlighted in yellow.

\section{Air Separation Plant Costs}

Process Facilities Capital: (see definition above)

General Facilities Capital: The general facilities include construction costs of roads, office buildings, shops, laboratories, etc. Sales taxes and freight costs are included implicitly.

Eng. \& Home Office Fees: The engineering \& home office fees are a percent of total direct capital cost. This is an overhead fee paid to the architect/engineering company.

Project Contingency Cost: Capital cost contingency factor covering the cost of additional equipment or other costs that would result from a more detailed design of a definitive project at the actual site.

Process Contingency Cost: Capital cost contingency factor applied to a new technology in an effort to quantify the uncertainty in the technical performance and cost of the commercial-scale equipment.

Interest Charges (AFUDC): Allowance for funds used during construction, also referred to as interest during construction, is the time value of the money used during construction and is based on an interest rate equal to the before-tax weighted cost of capital. This interest is compounded on an annual basis (end of year) during the construction period for all funds spent during the year or previous years.

Royalty Fees: Royalty charges may apply to some portions of generating units incorporating new proprietary technologies.

Preproduction (Startup) Cost: These costs consider the operator training, equipment checkout, major changes in unit equipment, extra maintenance, and inefficient use of fuel or other materials during startup.

Inventory (Working) Capital: The raw material supply based on $100 \%$ capacity during a 60 day period. These materials are considered storage. The inventory capital includes fuels, consumables, byproducts, and spare parts.

Total Capital Requirement (TCR): Money that is placed (capitalized) on the books of the utility on the service date. TCR includes all the items above. This result is highlighted in yellow.

Effective TCR: The TCR of the spray dryer that is used in determining the total power plant cost. The effective TCR is determined by the "TCR Recovery Factor”. 


\section{Air Separation O\&M Cost Results}

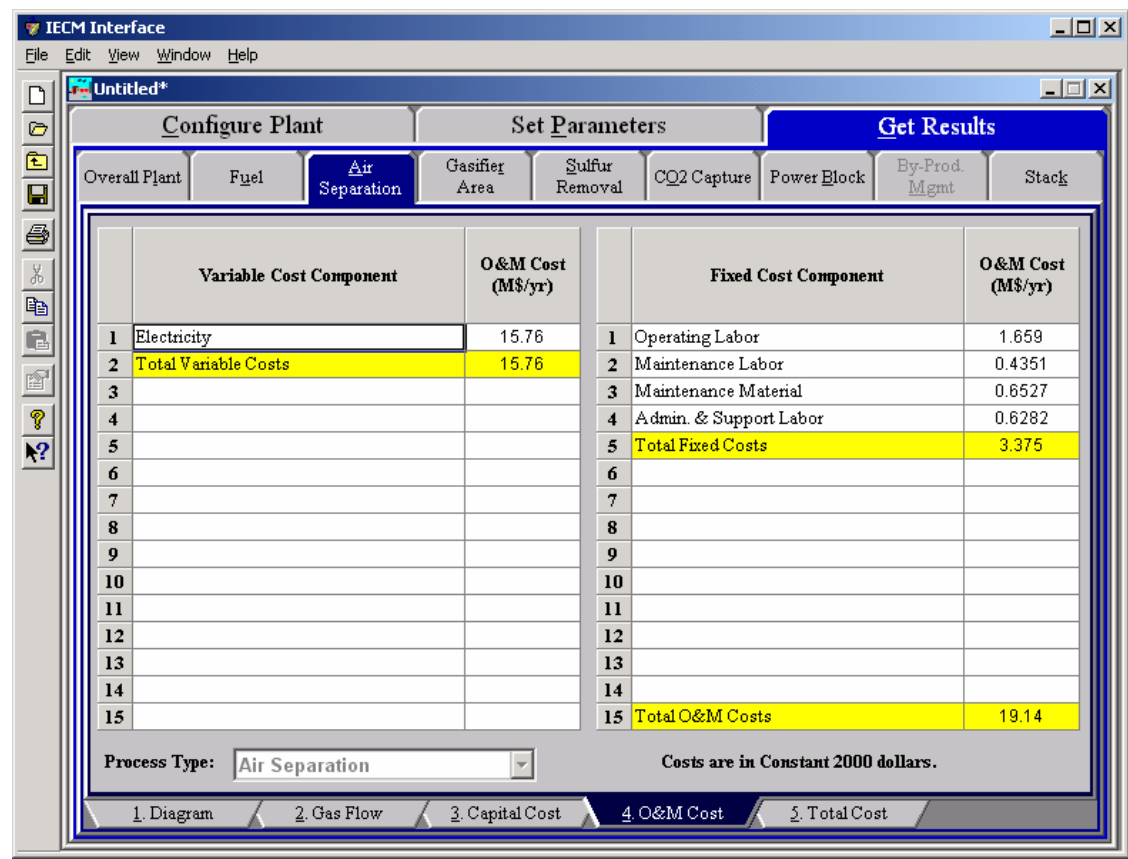

Air Separation - O\&M Cost results screen.

O\&M costs are typically expressed on an average annual basis and are provided in either constant or current dollars for a specified year, as shown on the bottom of the screen.

\section{Variable Cost Component}

Electricity: The cost of electricity consumed by the Air Separation System.

Total Variable Costs: This is the sum of all the variable O\&M costs listed above. This result is highlighted in yellow.

\section{Fixed Cost Components}

Fixed operating costs are essentially independent of actual capacity factor, number of hours of operation, or amount of kilowatts produced. All the costs are subject to inflation.

Operating Labor: Operating labor cost is based on the operating labor rate, the number of personnel required to operate the plant per eighthour shift, and the average number of shifts per day over 40 hours per week and 52 weeks.

Maintenance Labor: The maintenance labor is determined as a fraction of the total maintenance cost.

Maintenance Material: The cost of maintenance material is the remainder of the total maintenance cost, considering the fraction associated with maintenance labor.

Admin. \& Support Labor: The administrative and support labor is the only overhead charge. It is taken as a fraction of the total operating and maintenance labor costs. 
Total Fixed Costs: This is the sum of all the fixed O\&M costs listed above. This result is highlighted in yellow.

Total O\&M Costs: This is the sum of the total variable and total fixed O\&M costs. It is used to determine the base plant total revenue requirement. This result is highlighted in yellow.

\section{Air Separation Total Cost Results}

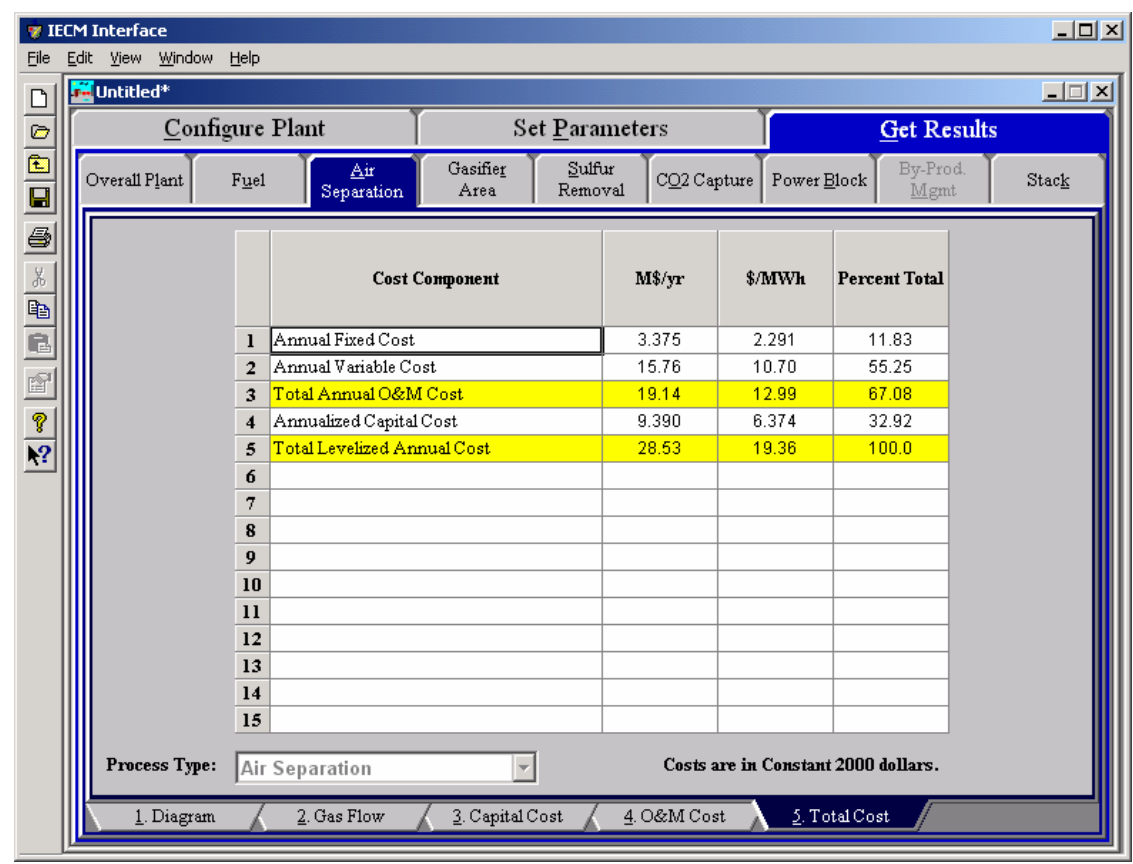

Air Separation - Total Cost results screen.

The Total Cost result screen displays a table which totals the annual fixed, variable, operations and maintenance, and capital costs associated with the Air Separation Unit. Each result is described briefly below.

\section{Cost Component}

Annual Fixed Cost: The operating and maintenance fixed costs are given as an annual total. This number includes all maintenance materials and all labor costs.

Annual Variable Cost: The operating and maintenance variables costs are given as an annual total. This includes all reagent, chemical, steam, and power costs.

Total Annual O\&M Cost: This is the sum of the annual fixed and variable operating and maintenance costs above. This result is highlighted in yellow.

Annualized Capital Cost: This is the total capital cost expressed on an annualized basis, taking into consideration the levelized carrying charge factor, or fixed charge factor, over the entire book life.

Total Levelized Annual Cost: The total annual cost is the sum of the total annual O\&M cost and annualized capital cost items above. This result is highlighted in yellow. 


\section{Base Plant}

The Base Plant Technology Navigation Tab screens display and define the performance and costs directly associated with the combustion power plant, particularly the boiler. Pre-combustion and post-combustion control technologies are not considered part of the Base Plant.

The screens described in this chapter all apply to the Combustion (Boiler) plant type.

\section{Base Plant Performance Inputs}

Inputs for the major flow rates and concentrations of the gas and solids streams are entered on the Performance input screen

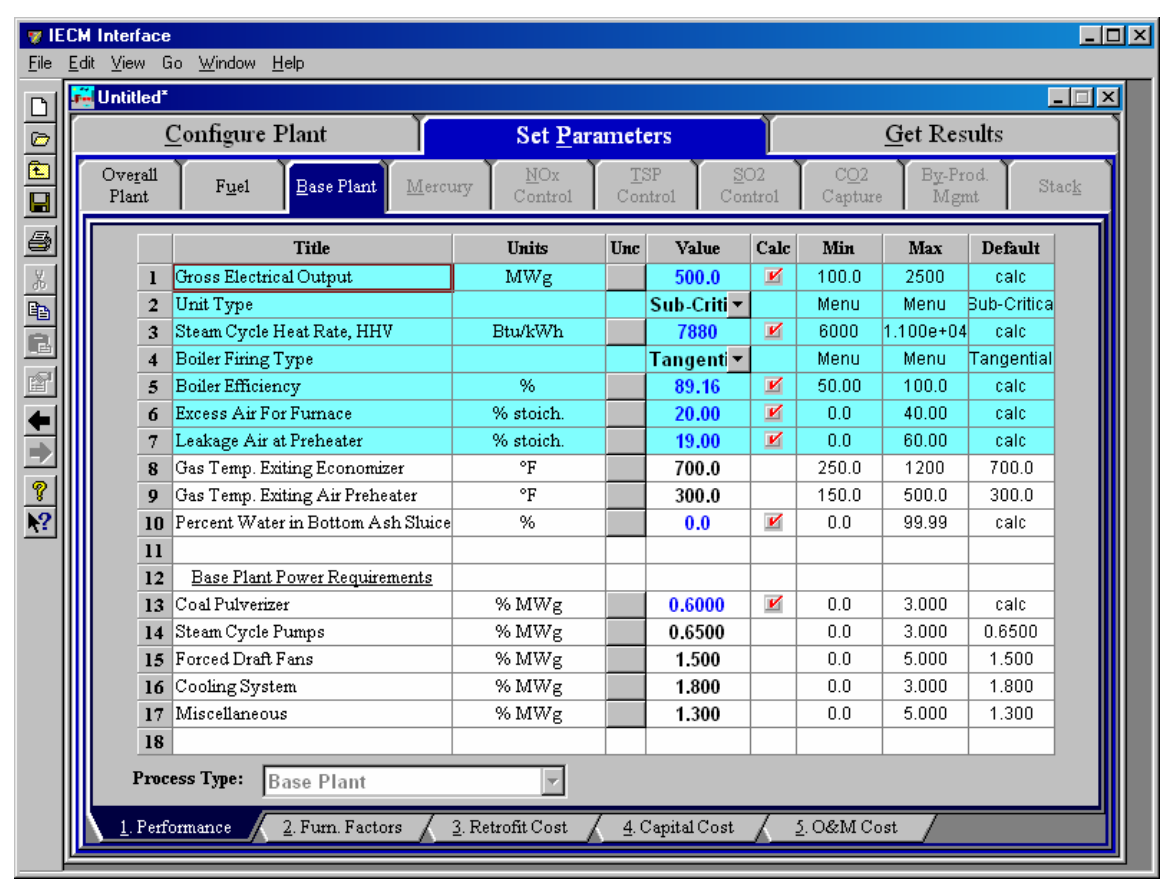

Base Plant-Performance input screen.

The first six inputs are highlighted in blue. Each parameter is described briefly below. 
Gross Electrical Output: This is the gross output of the generator in megawatts $\left(\mathrm{MW}_{\mathrm{g}}\right)$. The value does not include auxiliary power requirements. The model uses this information to calculate key mass flow rates.

Unit Type: This is the type of steam turbine system being used. The possible selections are: Sub-Critical, Super-Critical, and UltraSupercritical. This selection determines the steam cycle heat rate default value.

Steam Cycle Heat Rate: This is the gross amount of energy in steam needed to produce a kilowatt-hour $(\mathrm{kWh})$ of electricity at the generator. This variable does not consider auxiliary power requirements. This heat rate, plus the boiler efficiency, is used to figure out the overall plant performance (i.e., the gross cycle heat rate).

Boiler Firing Type: Combination boilers are most often represented by three types: wall, tangential, and cyclone. The 'wall' category is the most general and represents variations such as opposed, top, cell, and others. The solution of boiler type affects the boiler efficiency and furnace emission factors.

Boiler Efficiency: This is the percentage of fuel input energy transferred to steam in the boiler. The model default is to calculate the boiler efficiency using standard algorithms described in the literature. The efficiency is a function of energy losses due to inefficient heat transfer across the preheater, latent heat of evaporation, incomplete combustion, radiation losses, and unaccounted losses.

Excess Air for Furnace: This is the excess theoretical air used for combustion. It is added to the stoichiometric air requirement calculated by the model. The value is calculated and based on the fuel type and boiler type.

Leakage Air at Preheater: This is the additional excess air introduced because of leakage into the system at or beyond the air preheater. It is based on the stoichiometric air required for combustion. The leakage air increases the total gas volume downstream of the air preheater.

Gas Temperature Exiting Economizer: This is the temperature of the flue gas exiting the economizer. The temperature is used in the calculation of the flue gas volume and air preheater performance.

Gas Temperature Exiting Air Preheater: This is the temperature of the flue gas exiting the air preheater. The temperature is used in the calculation of the flue gas volume and air preheater performance.

Percent Water in Bottom Ash Sluice: Bottom ash collected can be removed from the combustion bolier and disposed by sluicing the bottom ash with water. This is the percent water in the sluice.

\section{Base Plant Power Requirements}

These parameters specify the electrical power requirements of pulverizers, steam pumps, forced draft fans, cooling system equipment (fans and pumps), and other miscellaneous equipment excluding gas cleanup systems. These power requirements or penalties are expressed as a percent of a gross plant capacity and are used to calculate the net plant performance. 
Coal Pulverizer: This is the power needed to run the coal pulverizers prior to the coal being blown into the boiler. It is also referred to as an energy penalty to the base plant. The value is calculated and based on the fuel type. It is expressed as a percentage of the gross plant capacity.

Steam Cycle Pumps: This is the power needed to operate the pumps in the steam cycle. It is also referred to as an energy penalty to the base plant. It is expressed as a percentage of the gross plant capacity.

Forced Draft Fans: This is the power required for the forced draft fans and primary air fan expressed as a percentage of the gross plant capacity. It is also referred to as an energy penalty for the base plant.

Cooling System: This is the power needed to run the pumps and other equipment for the water cooling system. It is expressed as a percentage of the gross plant capacity. It is also referred to as a base plant energy penalty.

Miscellaneous: This is the power used by any other miscellaneous equipment in the base plant, not including equipment used for pollution control equipment. It is expressed as a percentage of the gross plant capacity. It is also referred to as a base plant energy penalty.

\section{Base Plant Furnace Factors Inputs}

Inputs for the furnace factors that effect the major flow rates and concentrations of the gas and solids streams are entered on the Furnace Factors input screen.

This screen accepts inputs for the flue gas and ash products emitted from the boiler into the flue gas and ash streams. Factors in emissions include: incomplete combustion and thermodynamic equilibrium between gas species associated with the combustion products.

This screen's inputs are needed to calculate boiler efficiency and air pollutant emissions. The emission of carbon, ash, sulfur and nitrogen are specified by the United States Government's Environmental Protection Agency's (EPA) compilation of emission factors. Also included from the compilation are the incomplete transfer percentages of solid and gaseous forms of these substances.

This screen is available for all plant configurations. 


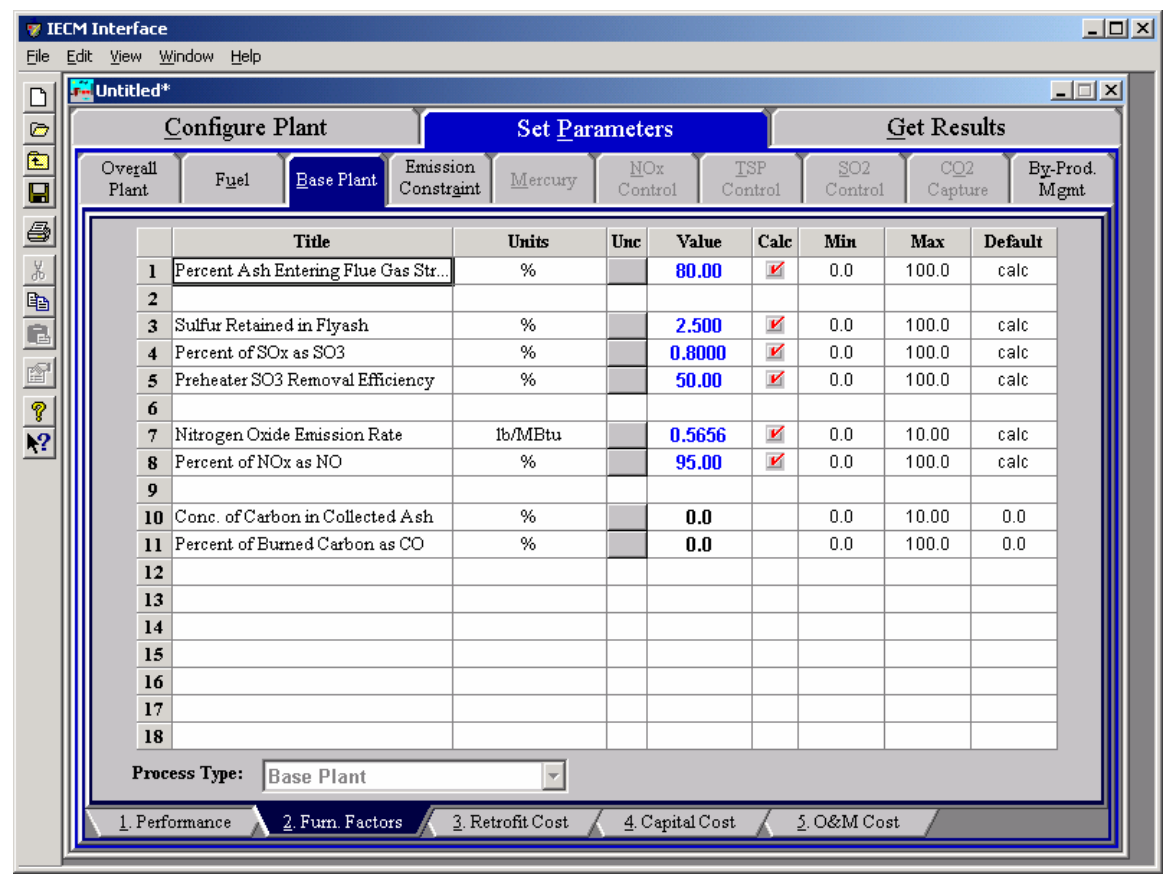

Base Plant - Furn. Factors input screen.

Each parameter is described briefly below:

Percent Ash Entering Flue Gas Stream: The default values for this parameter are a function of the fuel and boiler types and are based on the AP-42 EPA emission factors. Ash not entering the flue gas stream is assumed to be removed as bottom ash. This is also referred to as the overhead ash fraction.

Sulfur Retained in Flyash: This parameter gives the percent of total sulfur input to the boiler that is retained in the flyash stream of a coalfired power plant. The default values are a function of the selected boiler type and the coal rank as specified by the AP-42 EPA compilation of emission factors.

Percent of $\mathrm{SO}_{\mathrm{x}}$ as $\mathrm{SO}_{3}$ : This parameter quantifies the sulfur species in the flue gas stream. Sulfur not converted to $\mathrm{SO}_{2}$ is assumed to be converted to $\mathrm{SO}_{3}$. The default value is based on emission factors derived by Southern Company ${ }^{3}$ and are a function of the selected coal.

Preheater $\mathrm{SO}_{3}$ Removal Efficiency: Sulfuric acid $\left(\mathrm{H}_{2} \mathrm{SO}_{4}\right)$ is created downstream of the boiler by the reaction of $\mathrm{SO}_{3}$ with $\mathrm{H}_{2} \mathrm{O}$. A percent of the sulfuric acid is condensed on particulates in the preheater and removed from the flue gas. This parameter specifies the amount of $\mathrm{SO}_{3}$ removed from the flue gas in the preheater as a function of the coal rank. The default value is taken from the removal efficiency reported in the literature (references are below). This efficiency then determines the mass of $\mathrm{SO}_{3}$ removed from the flue gas in the collector. For more information see also:

- www.netl.doe.gov/publications/proceedings/98/98fg/hardman.pdf

- $\quad$ www.netl.doe.gov/publications/proceedings/98/98fg/rubin.pdf

${ }^{3}$ Hardman, R., R. Stacy, et al. (1998). Estimating Total Sulfuric Acid Emissions from Coal-FIred Power Plants, Southern Company Services. 
Nitrogen Oxide Emission Rate: This parameter establishes the level of $\mathrm{NO}_{\mathrm{x}}$ emissions from the boiler. The default values reflect the AP-42 EPA emission factors. It is a function of boiler firing method and the coal rank. The model calculates this value and expresses it in pounds of equivalent $\mathrm{NO}_{2}$ per ton of coal.

Percent of $\mathrm{NO}_{\mathbf{x}}$ as NO: This parameter establishes the level of nitric oxide (NO) in the flue gas stream. The remainder of the total $\mathrm{NO}_{\mathrm{x}}$ emissions is assumed to be nitrogen dioxide $\left(\mathrm{NO}_{2}\right)$. The default parameters reflect the AP-42 EPA emission factors and are dependent on the fuel type.

Conc. of Carbon in Collected Ash: This parameter accounts for retention of carbon in the fly ash and bottom ash. The amount of carbon in the collected ash streams is typically known. It is used to calculate the total unburned carbon in coal, boiler efficiency and flue gas composition.

Percent of Burned Carbon as CO: This parameter accounts for any incomplete combustion in the furnace, and is used to calculate boiler efficiency and flue gas composition. The remainder is assumed to be $\mathrm{CO}_{2}$ or unburned carbon.

\section{Base Plant Retrofit Cost Inputs}

Inputs for the capital costs of modifications to process areas of the base plant itself are entered on the Retrofit Cost input screen

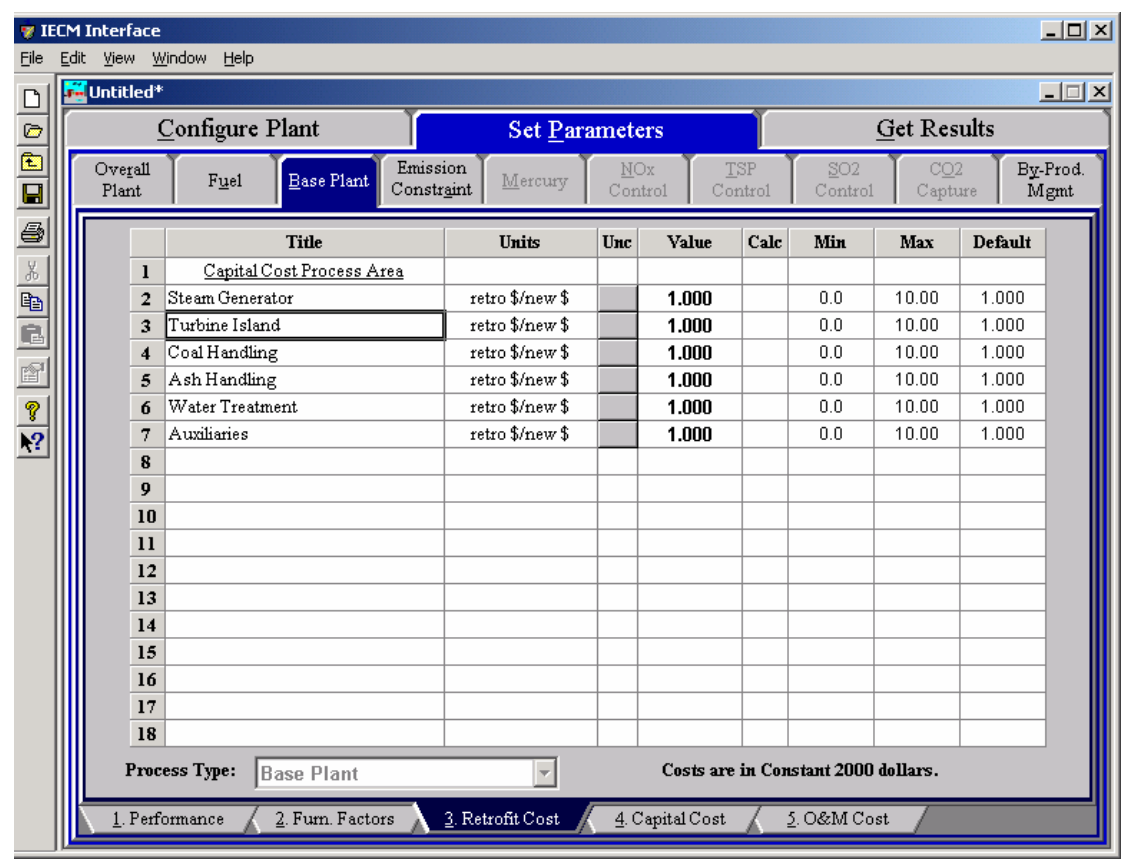

Base Plant-Retrofit Cost input screen.

The retrofit cost factor of each process is a multiplicative cost adjustment, which considers the cost of retrofitted capital equipment relative to similar equipment installed in a new plant. These factors affect the capital costs directly and the operating and maintenance costs indirectly. 
Direct capital costs for each process area are calculated in the IECM. These calculations are reduced form equations derived from more sophisticated models and reports. The sum of the direct capital costs associated with each process area is defined as the process facilities capital (PFC). The retrofit cost factor provided for each of the process areas can be used as a tool for adjusting the anticipated costs and uncertainties across the process area separate from the other areas.

Uncertainty can be applied to the retrofit cost factor for each process area in each technology. Thus, uncertainty can be applied as a general factor across an entire process area, rather than as a specific uncertainty for the particular cost on the capital or O\&M input screens. Any uncertainty applied to a process area through the retrofit cost factor compounds any uncertainties specified later in the capital and O\&M cost input parameter screens.

Each Capital Cost Process Area is described briefly below.

Steam Generator: This area accounts for the steam cycle equipment and pumps.

Turbine Island: This area accounts for the turbine island and associated pumps.

Coal Handling: This area accounts for the mechanical collection and transport equipment of coal in the plant.

Ash Handling: This area accounts for the mechanical collection and transport of ash in the plant.

Water Treatment: This area accounts for the pumps, tanks, and transport equipment used for water treatment.

Auxiliaries: Any miscellaneous auxiliary equipment is treated in this process area.

\section{Base Plant Capital Cost Inputs}

Inputs for the capital costs of the Combustion (Boiler) base plant itself are entered on the Capital Cost input screen. 


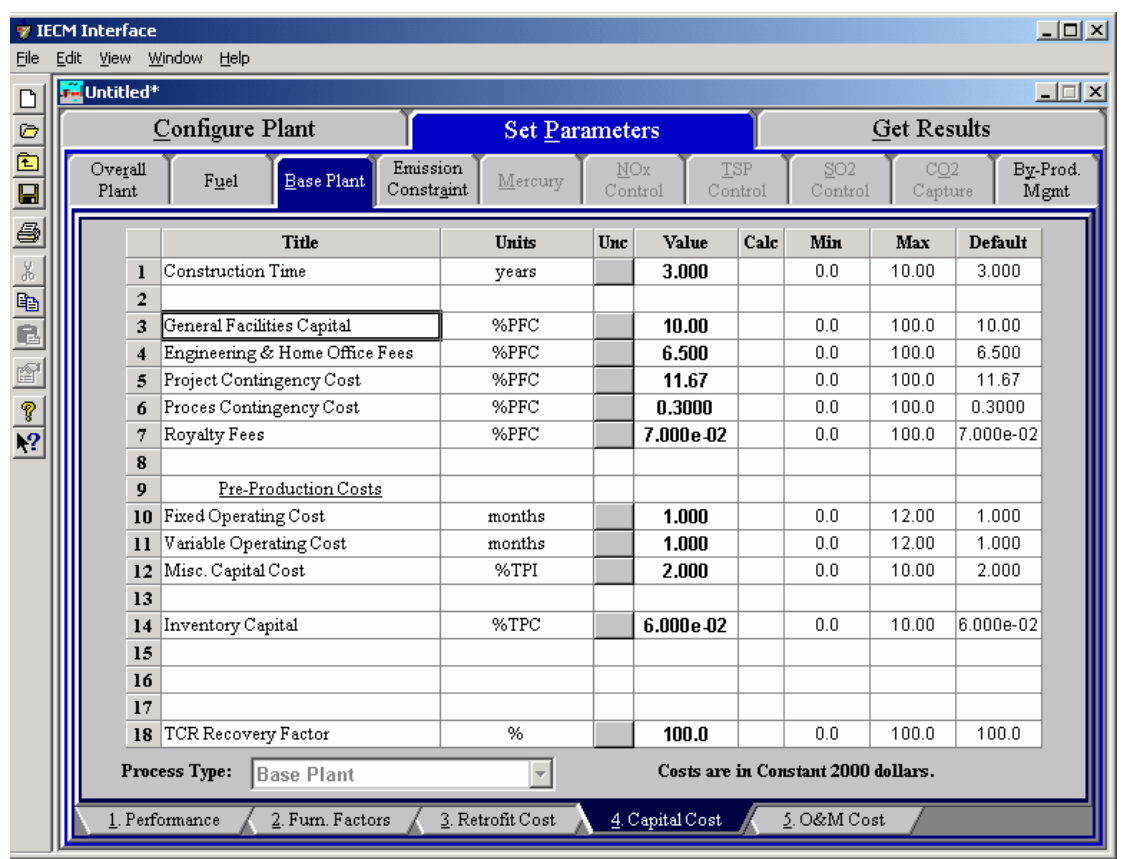

Base Plant-Capital Cost input screen

The necessary capital cost input parameters associated with the base plant are on this input screen. The capital cost parameters and terminology used in the IECM are based on the methodologies developed by the Electric Power Research Institute (EPRI). They have prepared a Technical Assessment Guide (TAG) in order to provide a consistent basis for reporting cost and revenues associated with the electric power industry. This system of reporting is used by a wide audience, including energy engineers, researchers, planners, and managers. The IECM has been developed around this TAG system so that costs associated with various technologies can be compared directly on a consistent basis and communicated in the language used by the audience listed above.

Construction Time: This is the idealized construction period in years. It is used to determine the allowance for funds used during construction (AFUDC).

General Facilities Capital (GFC): The general facilities include construction costs of roads, office buildings, shops, laboratories, etc. Sales taxes and freight costs are included implicitly. The cost typically ranges from $5-20 \%$.

Engineering \& Home Office Fees: The engineering \& home office fees are a percent of total direct capital cost. This is an overhead fee paid to the architect/engineering company. These fees typically range from 7$15 \%$.

Project Contingency Cost: This is factor covering the cost of additional equipment or other costs resulting from a more detailed design. Higher contingency factors will be applied to simplified or preliminary designs and lower factors to detailed or finalized designs.

Process Contingency Cost: This quantifies the design uncertainty and cost of a commercial-scale system. This is generally applied on an areaby-area basis. Higher contingency factors are applied to new regeneration systems tested at a pilot plant and lower factors to full-size or commercial systems. 
Royalty Fees: Royalty charges may apply to some portions of generating units incorporating new proprietary technologies.

\section{Pre-Production Costs}

These costs consider the operator training, equipment checkout, major changes in unit equipment, extra maintenance, and inefficient use of fuel or other materials during start-up. These are typically applied to O\&M costs over a specified period of time (months).

Fixed Operating Cost: Time period of fixed operating costs (operating and maintenance labor, administrative and support labor, and maintenance materials) used for plant startup.

Variable Operating Cost: Time period of variable operating costs at full capacity (chemicals, water, and other consumables, and waste disposal changes) used for plant startup. Full capacity estimates of the variable operating costs will assume operations at $100 \%$ load.

Misc. Capital Cost: This is a percent of total plant investment (sum of TPC and AFUDC) to cover expected changes to equipment to bring the system up to full capacity.

Inventory Capital: Percent of the total direct capital for raw material supply based on $100 \%$ capacity during a 60 day period. These materials are considered storage. The inventory capital includes fuels, consumables, by-products, and spare parts. This is typically $0.5 \%$.

TCR Recovery Factor: The actual total capital required (TCR) to finance the base plant as a percent of the TCR of a new power plant. This value is $100 \%$ for a new plant and may be set as low as $0 \%$ for a base plant that has been paid off.

\section{Base Plant O\&M Cost Inputs}

Inputs for the operation and maintenance costs of the Combustion (Boiler) base plant itself are entered on the $\mathbf{O} \& \mathbf{M}$ Cost input screen. 


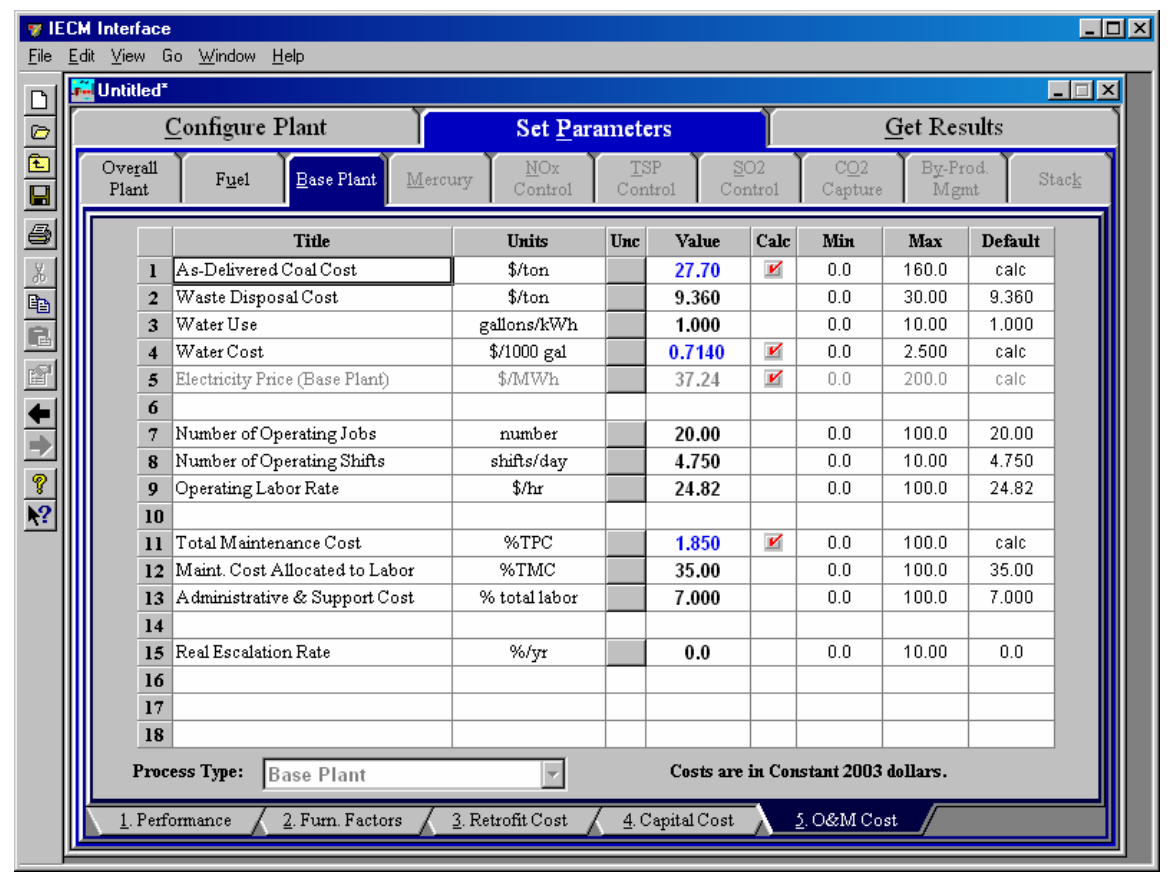

Base Plant-O\&M Cost input screen

The EPRI TAG method of categorization has been used for operating and maintenance costs screens. It provides a consistent basis of reporting for a wider audience of users.

O\&M costs are expressed on an average annual basis and are provided in either constant or current dollars for a specified year, as shown on the bottom of the screen. The costs are broken down into two categories: variable and fixed. Variable costs include the costs of reagents, chemicals, water, and other materials consumed during plant operation. Fixed costs are associated with labor and overhead charges. All operating costs are subject to inflation.

The base plant considers a more detailed breakdown for the costs associated with the fuel. Together they characterize the fuel costs. Each parameter is described briefly below.

As-Delivered Coal Cost: This is the cost of the delivered coal in dollars per wet ton. The value is calculated by the IECM from the particular regional coal selected. It does not include any cleaning costs.

Waste Disposal Cost: This is the bottom ash disposal cost for the base plant.

Water Use: This is the water used by the base plant.

Water Cost: This is the water cost as used for the base plant.

Electricity Price (Base Plant): This is the price of electricity and is calculated as a function of the utility cost of the base plant, where the base plant is defined as combustion boiler and an air preheater.

Number of Operating Jobs: This is the total number of operating jobs that are required to operate the plant per eight-hour shift.

Number of Operating Shifts: This is the total number of equivalent operating shifts in the plant per day. The number takes into consideration paid time off and weekend work ( 3 shifts/day * 7 days/5 
day week * 52 weeks $/(52$ weeks -6 weeks PTO $)=4.75$ equiv.

Shifts/day)

Operating Labor Rate: The hourly cost of labor is specified in the base plant O\&M cost screen. The same value is used throughout the other technologies.

Total Maintenance Cost: This is the annual maintenance cost as a percentage of the total plant cost. Maintenance cost estimates can be developed separately for each process area.

Maint. Cost Allocated to Labor: Maintenance cost allocated to labor as a percentage of the total maintenance cost.

Administrative \& Support Cost: This is the percent of the total operating and maintenance labor associated with administrative and support labor.

Real Escalation Rate: This is the annual rate of increase of an expenditure due to factors such as resource depletion, increased demand, and improvements in design, manufacturing or construction techniques (negative rate). The real escalation rate does not include inflation.

\section{Boiler Diagram}

The Diagram result screen displays an icon for the Combustion Boiler and values for major flows in and out of it.

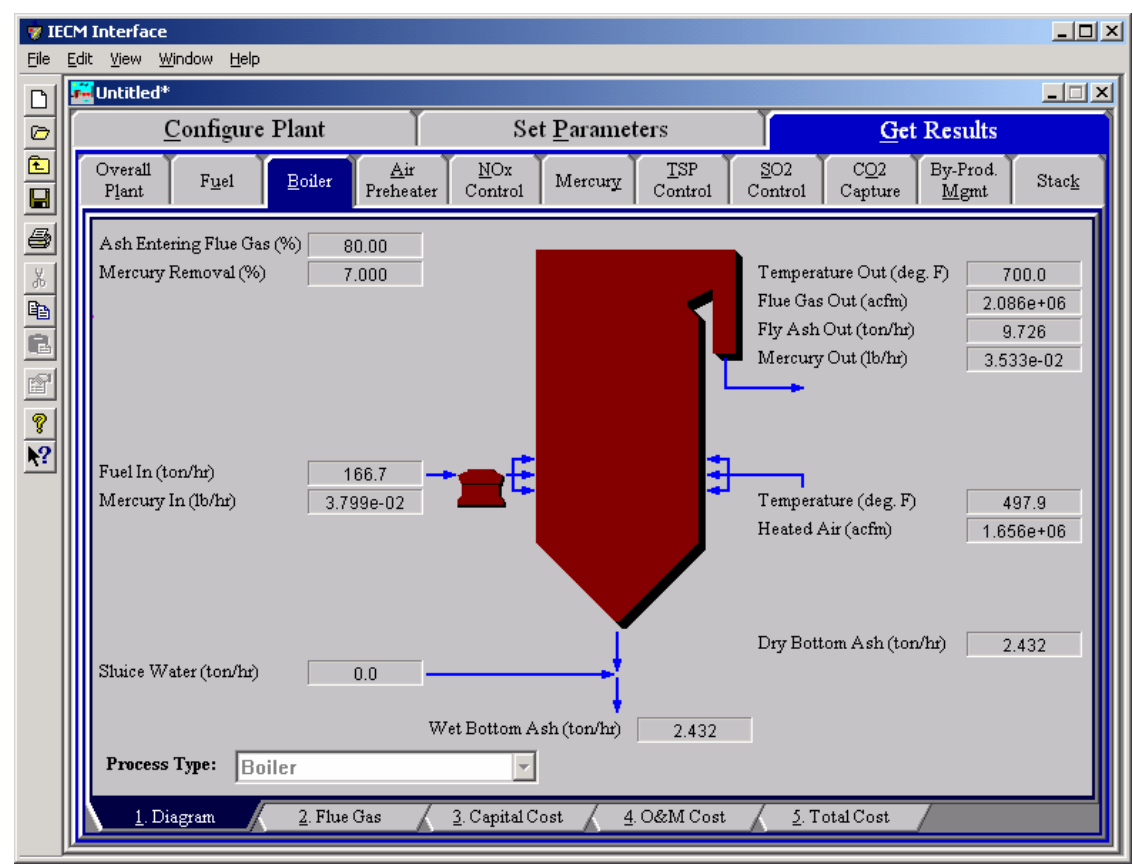

Boiler-Diagram result screen.

Each result is described briefly below in flow order (not from top to bottom and left to right as they display on the screen). 


\section{Fuel Entering Boiler}

Wet Fuel In: Fuel flow rate into the boiler on a wet basis. Waste products removed prior to the burners are not considered here.

Mercury In: This is the mass flow rate of total mercury entering the boiler. The mass reflects the molecular weight of elemental mercury.

\section{Boiler Performance}

Ash Entering Flue Gas: Percent of the ash in coal exiting the boiler in the flue gas.

Mercury Removal: Percent of the total mercury in coal removed from the boiler in the bottom ash.

\section{Air Entering Boiler}

Temperature: Heated air temperature measured at the burners. This is generally determined by the combustion air temperature exiting the air preheater.

Heated Air: Volumetric flow rate of the air at the burners, based on the air temperature at the burners and atmospheric pressure.

\section{Flue Gas Exiting the Economizer}

Temperature Out: Temperature of the flue gas at the exit of the economizer.

Flue Gas Out: Volumetric flow rate of the flue gas at the exit of the economizer, based on the temperature at the exit of the economizer and atmospheric pressure.

Fly Ash Out: Total solids mass flow rate in the flue gas at the exit of the economizer. This includes ash, unburned carbon and unburned sulfur.

Mercury Out: Total mass of mercury exiting the economizer. The value is a sum of all the forms of mercury (elemental, oxidized, and particulate).

\section{Bottom Ash}

Sluice Water: Water added to the dry bottom ash. This water is added for transportation purposes.

Dry Bottom Ash: Total solids mass flow rate of the bottom ash. This includes ash, unburned carbon and unburned sulfur. The value is given on a dry basis.

Wet Bottom Ash: Total solids mass flow rate of the bottom ash for waste management. This includes dry bottom ash and sluice water. The value is given on a wet basis. 


\section{Boiler Flue Gas Results}

The Flue Gas result screen displays a table of quantities of flue gas components entering the combustion boiler in heated air and exiting the boiler in the flue gas. For each component, quantities are given in both moles and mass per hour.

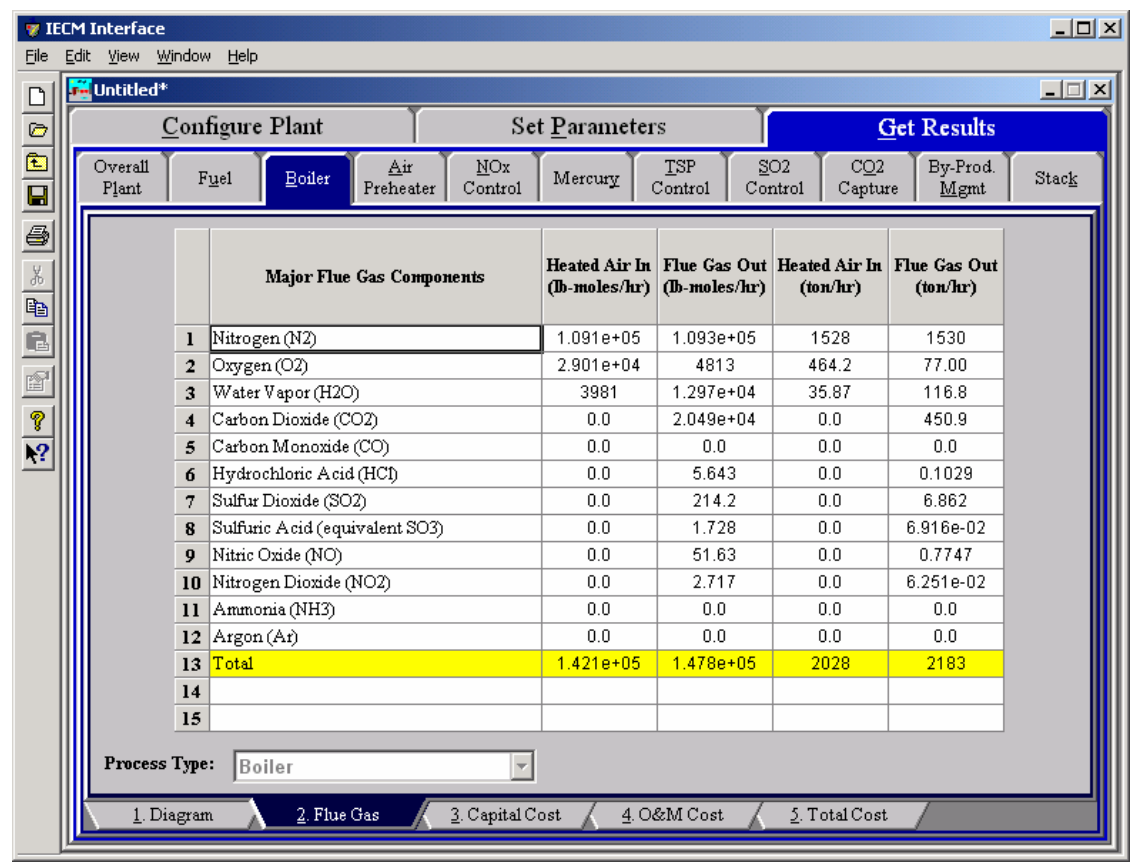

Boiler-Flue Gas result screen.

Each result is described briefly below.

Nitrogen $\left(\mathbf{N}_{2}\right)$ : Total mass of nitrogen.

Oxygen $\left(\mathrm{O}_{2}\right)$ : Total mass of oxygen.

Water Vapor $\left(\mathrm{H}_{2} \mathrm{O}\right)$ : Total mass of water vapor.

Carbon Dioxide $\left(\mathrm{CO}_{2}\right)$ : Total mass of carbon dioxide.

Carbon Monoxide (CO): Total mass of carbon monoxide.

Hydrochloric Acid $(\mathbf{H C l})$ : Total mass of hydrochloric acid.

Sulfur Dioxide $\left(\mathrm{SO}_{2}\right)$ : Total mass of sulfur dioxide.

Sulfuric Acid (equivalent $\mathbf{S O}_{3}$ ): Total mass of sulfuric acid.

Nitric Oxide (NO): Total mass of nitric oxide.

Nitrogen Dioxide $\left(\mathrm{NO}_{2}\right)$ : Total mass of nitrogen dioxide.

Ammonia $\left(\mathrm{NH}_{3}\right)$ : Total mass of ammonia.

Argon (Ar): Total mass of argon.

Total: Total of the individual components listed above. This item is highlighted in yellow. 


\section{Boiler Capital Cost Results}

The Capital Cost result screen displays tables for the direct and indirect capital costs related to the Combustion Boiler.

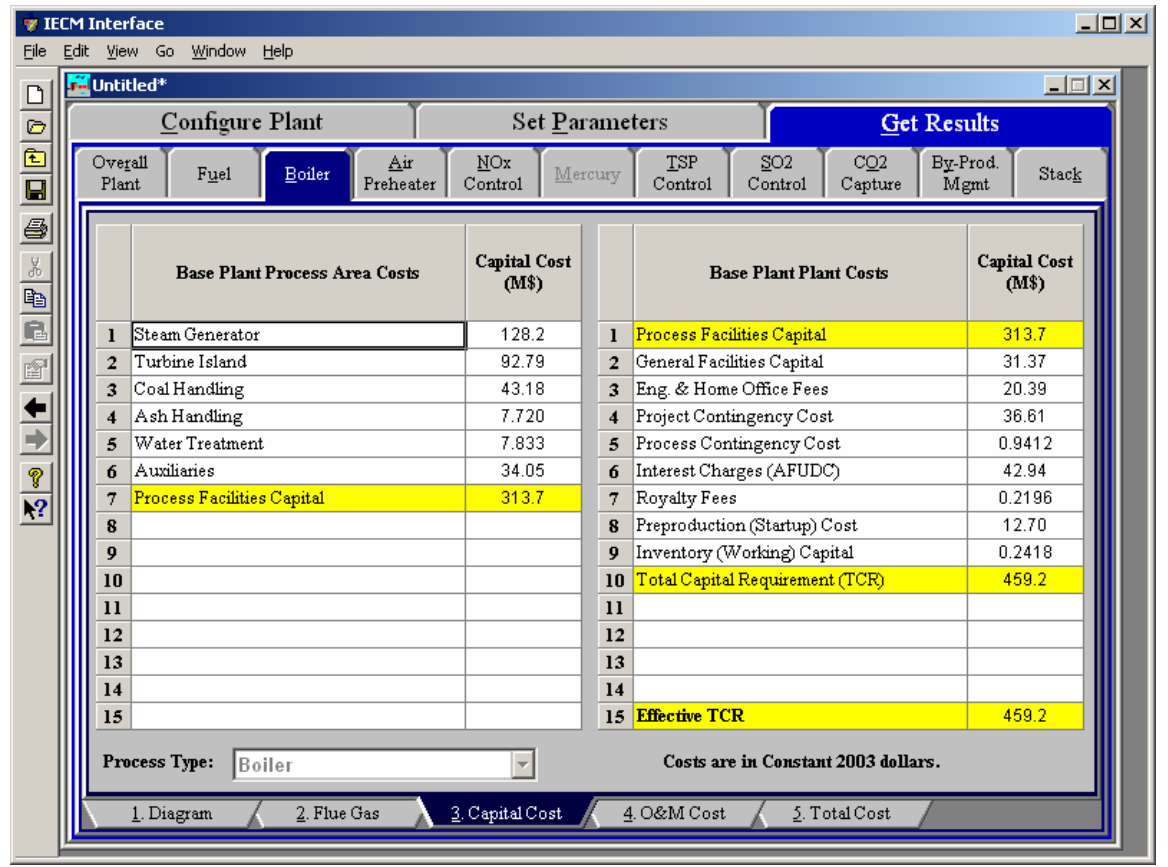

Boiler-Capital Cost result screen.

Capital costs are typically expressed in either constant or current dollars for a specified year, as shown on the bottom of the screen. Each result is described briefly below.

\section{Direct Capital Costs}

The direct capital costs described here apply to the "base power plant" without any of the environmental control options that are separately modeled in the IECM. While the purpose of the IECM is to model the cost and performance of emission control systems, costs for the base plant are also needed to properly account for precombustion control options that increase the cost of fuel, and affect the characteristics or performance of the base plant. Base plant costs are also needed to calculate the internal cost of electricity which determines pollution control energy costs.

Each process area direct capital cost is a reduced-form model based on regression analysis of data collected from several reports and analyses. They are described in general below. The primary factors in the model that effect the capital cost of the base plant are the plant size, the coal rank, and the geographic location of the plant.

Steam Generator: This area accounts for the steam cycle equipment and pumps.

Turbine Island: This area accounts for the turbine island and associated pumps.

Coal Handling: This area accounts for the mechanical collection and transport equipment of coal in the plant. 
Ash Handling: This area accounts for the mechanical collection and transport of ash in the plant.

Water Treatment: This area accounts for the pumps, tanks, and transport equipment used for water treatment.

Auxiliaries: Any miscellaneous auxiliary equipment is treated in this process area.

Process Facilities Capital: The process facilities capital is the total constructed cost of all on-site processing and generating units listed above, including all direct and indirect construction costs. All sales taxes and freight costs are included where applicable implicitly. This result is highlighted in yellow.

\section{Total Capital Costs}

Process Facilities Capital: See definition above. This result is highlighted in yellow.

General Facilities Capital: The general facilities include construction costs of roads, office buildings, shops, laboratories, etc. Sales taxes and freight costs are included implicitly.

Eng. \& Home Office Fees: The engineering \& home office fees are a percent of total direct capital cost. This is an overhead fee paid to the architect/engineering company.

Project Contingency Cost: Capital cost contingency factor covering the cost of additional equipment or other costs that would result from a more detailed design of a definitive project at the actual site.

Process Contingency Cost: Capital cost contingency factor applied to a new technology in an effort to quantify the uncertainty in the technical performance and cost of the commercial-scale equipment.

Interest Charges (AFUDC): Allowance for funds used during construction, also referred to as interest during construction, is the time value of the money used during construction and is based on an interest rate equal to the before-tax weighted cost of capital. This interest is compounded on an annual basis (end of year) during the construction period for all funds spent during the year or previous years.

Royalty Fees: Royalty charges may apply to some portions of generating units incorporating new proprietary technologies.

Preproduction (Startup) Cost: These costs consider the operator training, equipment checkout, major changes in unit equipment, extra maintenance, and inefficient use of fuel or other materials during startup.

Inventory (Working) Capital: The raw material supply based on $100 \%$ capacity during a 60 day period. These materials are considered storage. The inventory capital includes fuels, consumables, byproducts, and spare parts.

Total Capital Requirement (TCR): Money that is placed (capitalized) on the books of the utility on the service date. TCR includes all the items above. This result is highlighted in yellow. 
Effective TCR: The TCR of the base plant that is used in determining the total power plant cost. The effective TCR is determined by the "TCR Recovery Factor" for the base plant.

\section{Boiler O\&M Cost Results}

The O\&M Cost result screen displays tables for the variable and fixed operation and maintenance costs involved with the combustion base plant. The variable O\&M costs are calculated from the variable costs for fuel, water consumption and bottom ash disposal (from the furnace). The fixed O\&M costs are based on maintenance and labor costs.

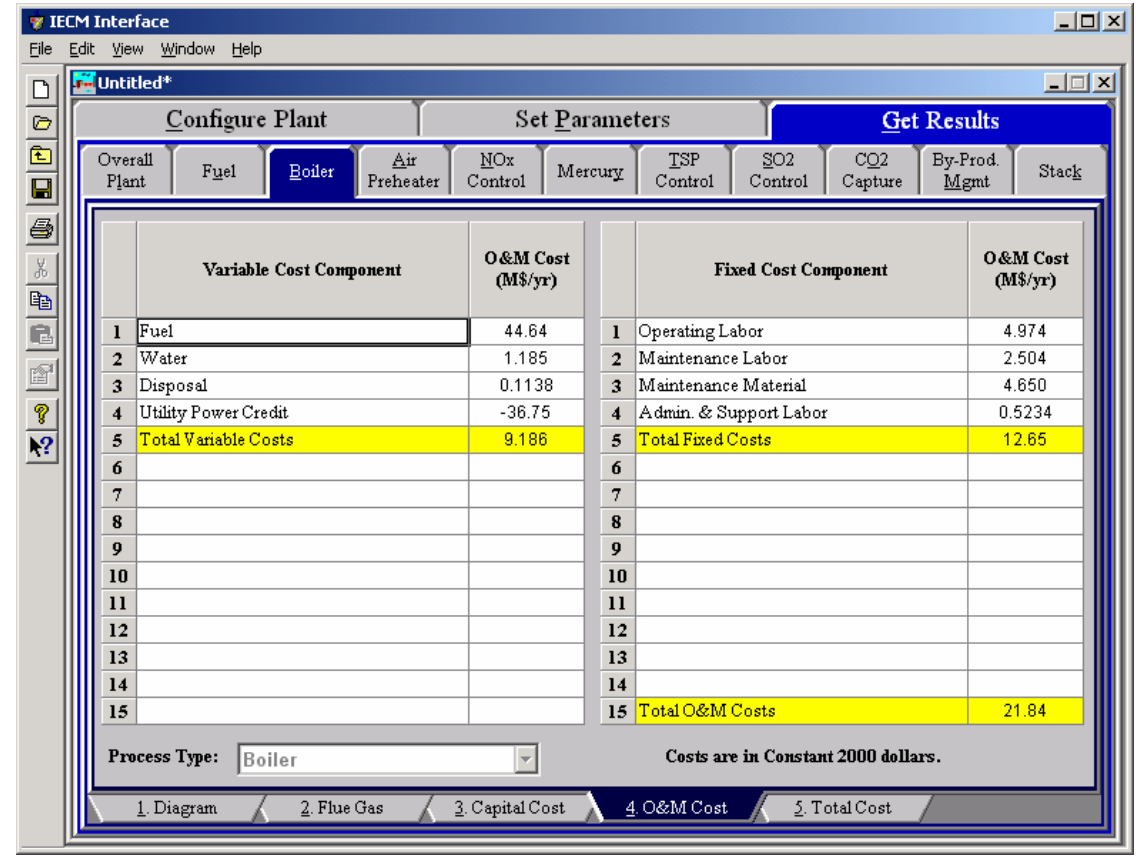

The Boiler-O\&M Cost result screen.

O\&M costs are typically expressed on an average annual basis and are provided in either constant or current dollars for a specified year, as shown on the bottom of the screen. Each result is described briefly below.

\section{Variable Cost Components}

Variable operating costs and consumables are directly proportional to the amount of kilowatts produced and are referred to as incremental costs. All the costs are subject to inflation.

Fuel: The total cost of as-fired fuel. Minemouth cost, coal cleaning costs and transportation costs are all included.

Water: The total cost of water consumed by the base plant for direct or reheat use.

Disposal: The total cost of bottom ash disposal. The value is given on a wet ash basis. This does not consider by-product ash sold in commerce.

Utility Power Credit: Power consumed by abatement technologies result in lower net power produced and lost revenue. The IECM charges each 
technology for the internal use of electricity and treats the charge as a credit for the base plant. When comparing individual components of the plant, these utility charges are taken into consideration. For total plant costs they balance out and have no net effect on the plant O\&M costs.

Total Variable Costs: This is the sum of all the variable O\&M costs listed above. This result is highlighted in yellow.

\section{Fixed Cost Components}

Fixed operating costs are essentially independent of actual capacity factor, number of hours of operation, or amount of kilowatts produced. All the costs are subject to inflation.

Operating Labor: Operating labor cost is based on the operating labor rate, the number of personnel required to operate the plant per eighthour shift, and the average number of shifts per day over 40 hours per week and 52 weeks.

Maintenance Labor: The maintenance labor is determined as a fraction of the total maintenance cost.

Maintenance Material: The cost of maintenance material is the remainder of the total maintenance cost, considering the fraction associated with maintenance labor.

Admin. \& Support Labor: The administrative and support labor is the only overhead charge. It is taken as a fraction of the total operating and maintenance labor costs.

Total Fixed Costs: This is the sum of all the fixed O\&M costs listed above. This result is highlighted in yellow.

Total O\&M Costs: This is the sum of the total variable and total fixed O\&M costs. It is used to determine the base plant total revenue requirement. This result is highlighted in yellow.

\section{Boiler Total Cost Results}

The Total Cost result screen displays a table which totals the annual fixed, variable, operations and maintenance, and capital costs associated with the boiler. 


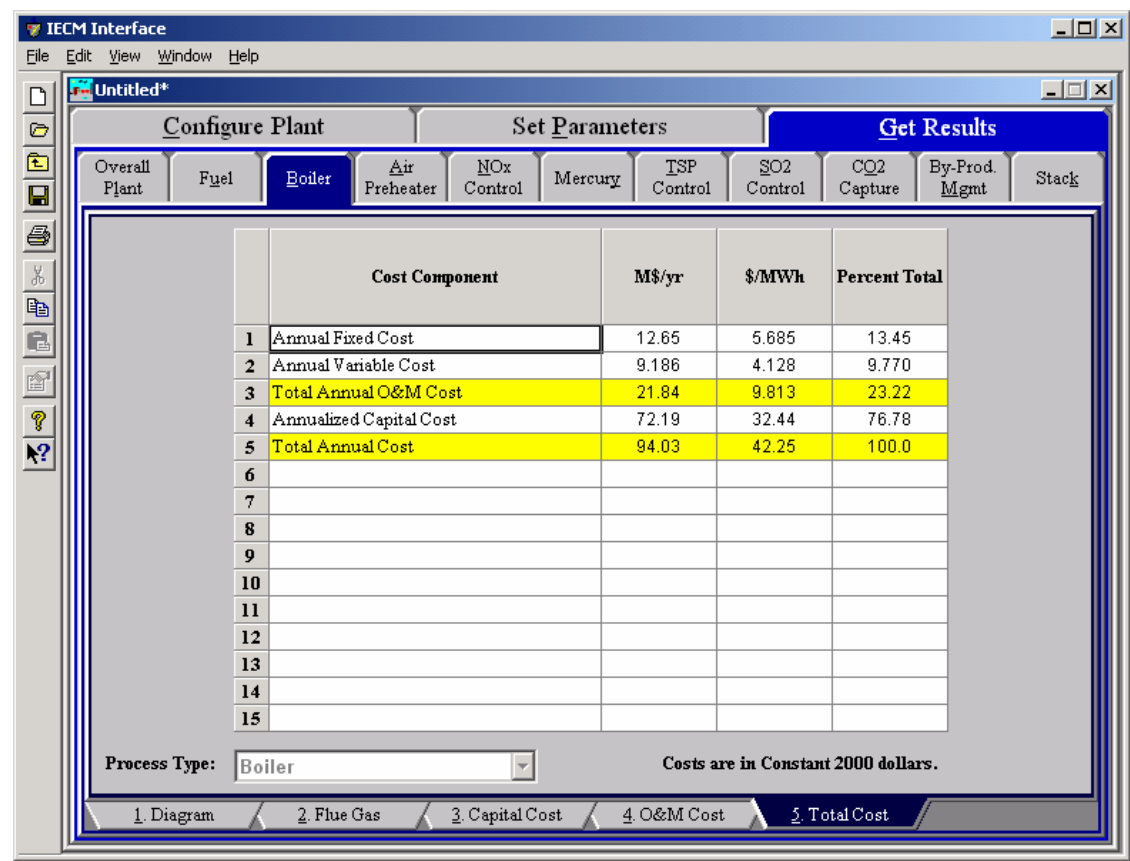

Boiler-Total Cost result screen.

\section{Cost Component}

Total costs are typically expressed in either constant or current dollars for a specified year, as shown on the bottom of the screen. Each result is described briefly below.

Annual Fixed Cost: The operating and maintenance fixed costs are given as an annual total. This number includes all maintenance materials and all labor costs.

Annual Variable Cost: The operating and maintenance variables costs are given as an annual total. This includes all reagent, chemical, steam, and power costs.

Total Annual O\&M Cost: This is the sum of the annual fixed and variable operating and maintenance costs above. This result is highlighted in yellow.

Annualized Capital Cost: This is the total capital cost expressed on an annualized basis, taking into consideration the levelized carrying charge factor, or fixed charge factor, over the entire book life.

Total Annual Cost: The total annual cost is the sum of the total annual O\&M cost and annualized capital cost items above. This result is highlighted in yellow. 



\section{Auxiliary Boiler}

An Auxiliary Boiler System is available as an option from within the amine scrubber system. It is specified from the Set Parameters program area of the Cô2 Capture configuration input screen using the Process Type pull-down menu at the bottom of the screen.

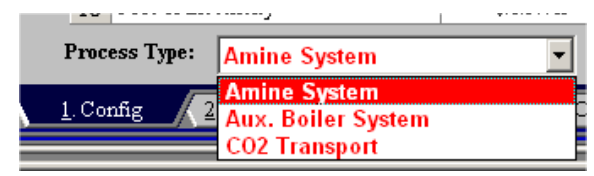

Auxiliary Boiler - Process Type

Input parameters are included as part of the amine system and not specified separately. Several performance result screens are provide separately for the auxiliary boiler system, but cost results are incorporated into the amine system. The following sections describe the results that are displayed explicitly for the auxiliary boiler system.

\section{Auxiliary Boiler Diagram}

The Diagram result screen displays an icon for the Auxiliary Boiler and values for major flows in and out of it. The auxiliary boiler is available in the Combustion (Boiler) and Combustion (Turbine) plant types when an amine scrubber is configured. It is a sub-system inside the amine scrubber when the auxiliary boiler option is added. 


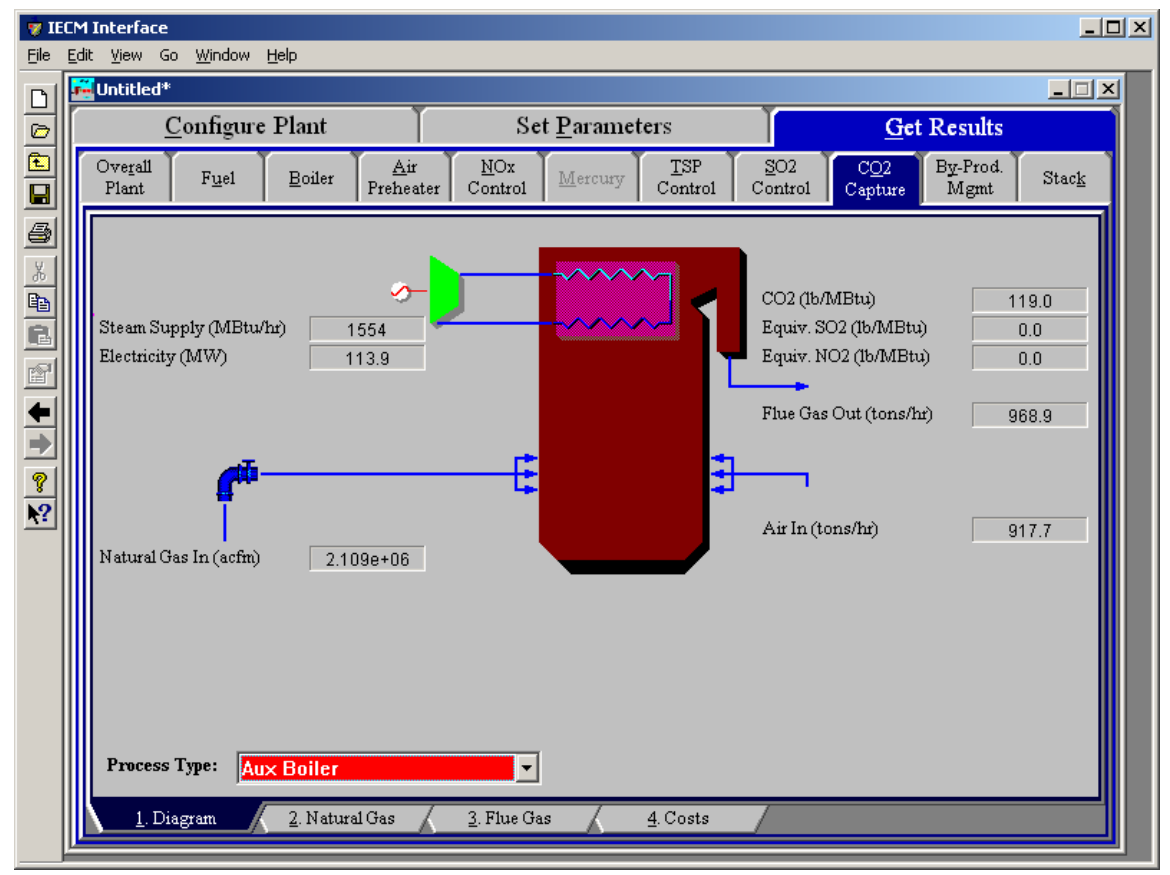

Auxiliary Boiler - Diagram.

Each result is described briefly below.

Air and Fuel

Air In: The mass flow rate of fresh air is provided. This is the stoichiometric amount of air and excess air as specified on the $\mathrm{CO}_{2}$ Capture input screen.

Natural Gas In: This is the flow rate of natural gas necessary to provide the heat necessary to provide regeneration heat to the MEA regenerator.

\section{Steam and Power Generation}

Steam Supply: This is the total steam energy required by the $\mathrm{CO}_{2}$ regenerator. The steam is supplied to the MEA regenerator.

Electricity: Low pressure steam generated by the auxiliary boiler may be used to generate electricity in a steam turbine. This electricity supplements that produced by the base plant.

\section{Flue Gas Exiting Aux. Boiler System}

$\mathbf{C O}_{2}$ : This is the flow rate of emission dioxide from the auxiliary boiler. It is emitted from a secondary stack.

Equivalent $\mathbf{S O}_{2}$ : This is the emission rate of sulfur dioxide from the auxiliary boiler. It is emitted from a secondary stack.

Equivalent $\mathrm{NO}_{2}$ : This is the emission rate of nitrogen dioxide from the auxiliary boiler. It is emitted from a secondary stack.

\section{Auxiliary Boiler Natural Gas Results}

This screen is only available for the Combustion (Boiler) and Combustion (Turbine) plant types. It is a sub-system inside the amine scrubber when the auxiliary boiler option is added. 


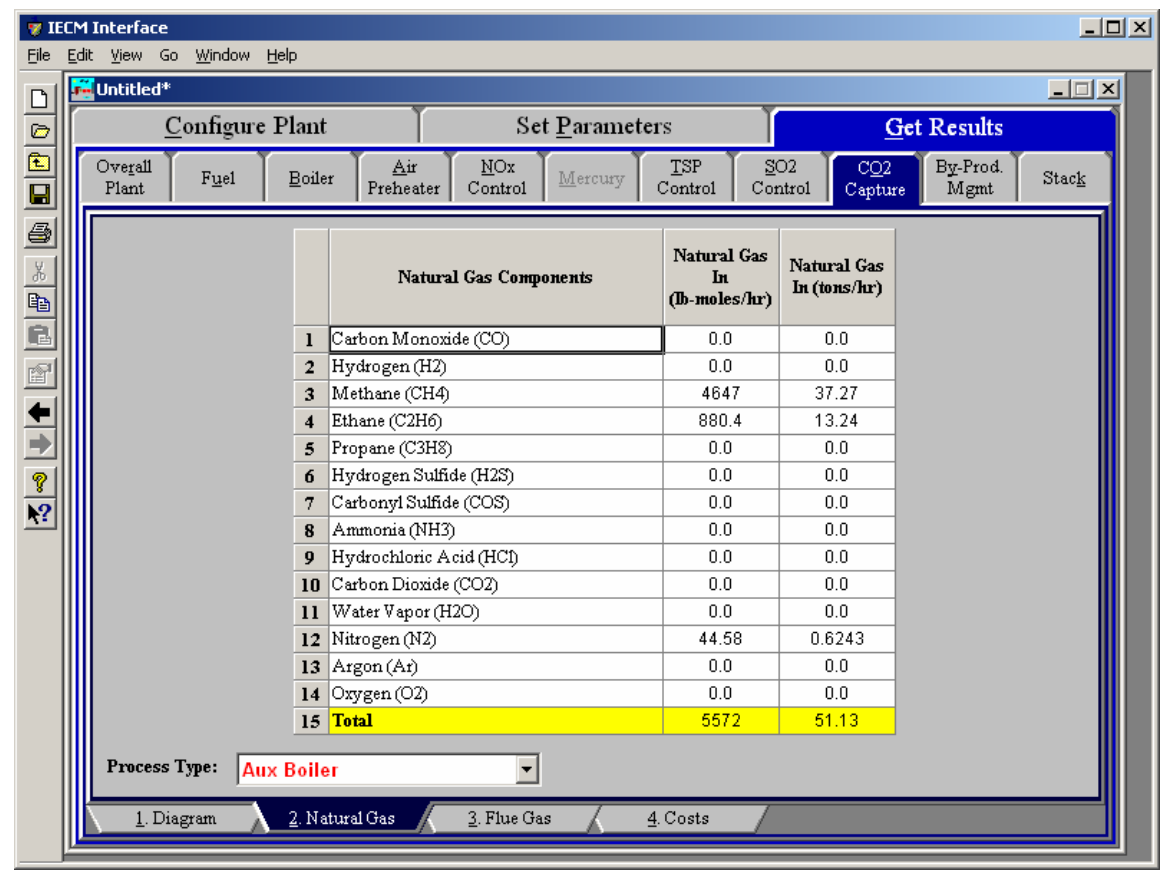

Auxiliary Boiler System - Natural Gas.

\section{Natural Gas Components}

The breakdown of components in the natural gas entering the auxiliary boiler are described briefly below:

Carbon Monoxide (CO): Total mass of carbon monoxide.

Hydrogen $\left(\mathbf{H}_{2}\right)$ : Total mass of hydrogen.

Methane $\left(\mathrm{CH}_{4}\right)$ : Total mass of methane.

Ethane $\left(\mathrm{C}_{2} \mathrm{H}_{6}\right)$ : Total mass of ethane.

Propane $\left(\mathrm{C}_{3} \mathrm{H}_{8}\right)$ : Total mass of propane.

Hydrogen Sulfide $\left(\mathrm{H}_{\mathbf{2}} \mathrm{S}\right)$ : Total mass of hydrogen sulfide.

Carbonyl Sulfide (COS): Total mass of carbonyl sulfide.

Ammonia $\left(\mathrm{NH}_{3}\right)$ : Total mass of ammonia.

Hydrochloric Acid (HCl): Total mass of hydrochloric acid.

Water Vapor $\left(\mathbf{H}_{\mathbf{2}} \mathbf{O}\right)$ : Total mass of water vapor.

Carbon Dioxide $\left(\mathbf{C O}_{2}\right)$ : Total mass of carbon dioxide.

Nitrogen $\left(\mathbf{N}_{\mathbf{2}}\right)$ : Total mass of nitrogen.

Argon (Ar): Total mass of argon.

Oxygen $\left(\mathrm{O}_{2}\right)$ : Total mass of oxygen.

Total: Total of the individual components listed above. This item is highlighted in yellow. 


\section{Auxiliary Boiler Flue Gas Results}

This screen is only available for the Combustion (Boiler) and Combustion (Turbine) plant types.

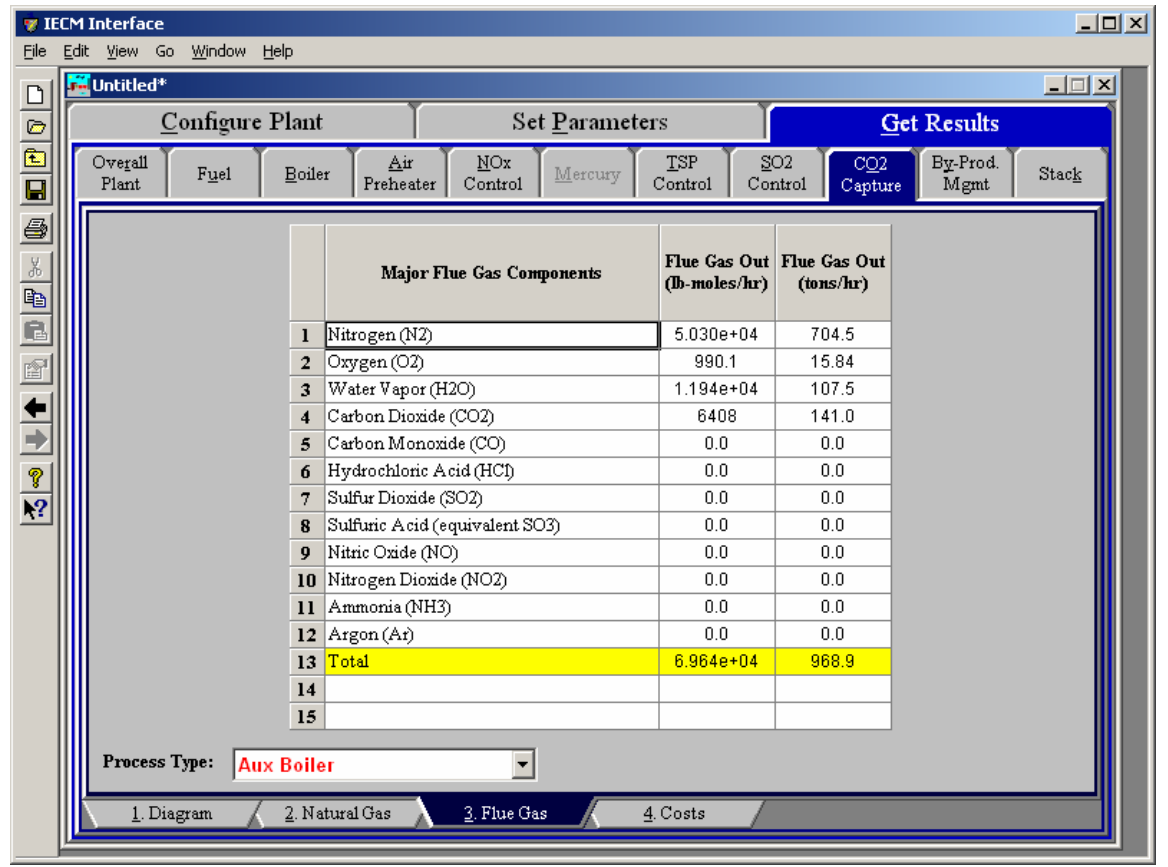

Auxiliary Boiler System - Flue Gas result screen

\section{Major Flue Gas Components}

Natural gas fired in the auxiliary boiler produces a flue gas. This flue gas is emitted to the atmosphere via a secondary stack. Each component is described briefly below:

Nitrogen $\left(\mathrm{N}_{2}\right)$ : Total mass of nitrogen.

Oxygen $\left(\mathrm{O}_{2}\right)$ : Total mass of oxygen.

Water Vapor $\left(\mathrm{H}_{2} \mathrm{O}\right)$ : Total mass of water vapor.

Carbon Dioxide $\left(\mathrm{CO}_{2}\right)$ : Total mass of carbon dioxide.

Carbon Monoxide (CO): Total mass of carbon monoxide.

Hydrochloric Acid (HCl): Total mass of hydrochloric acid.

Sulfur Dioxide $\left(\mathrm{SO}_{2}\right)$ : Total mass of sulfur dioxide.

Sulfuric Acid (equivalent $\mathbf{S O}_{3}$ ): Total mass of sulfuric acid.

Nitric Oxide (NO): Total mass of nitric oxide.

Nitrogen Dioxide $\left(\mathrm{NO}_{2}\right)$ : Total mass of nitrogen dioxide.

Ammonia $\left(\mathrm{NH}_{3}\right)$ : Total mass of ammonia.

Argon (Ar): Total mass of argon.

Total: Total of the individual components listed above. This item is highlighted in yellow. 


\section{Auxiliary Boiler Costs Results}

This screen is only available for the Combustion (Boiler) and Combustion (Turbine) plant types.

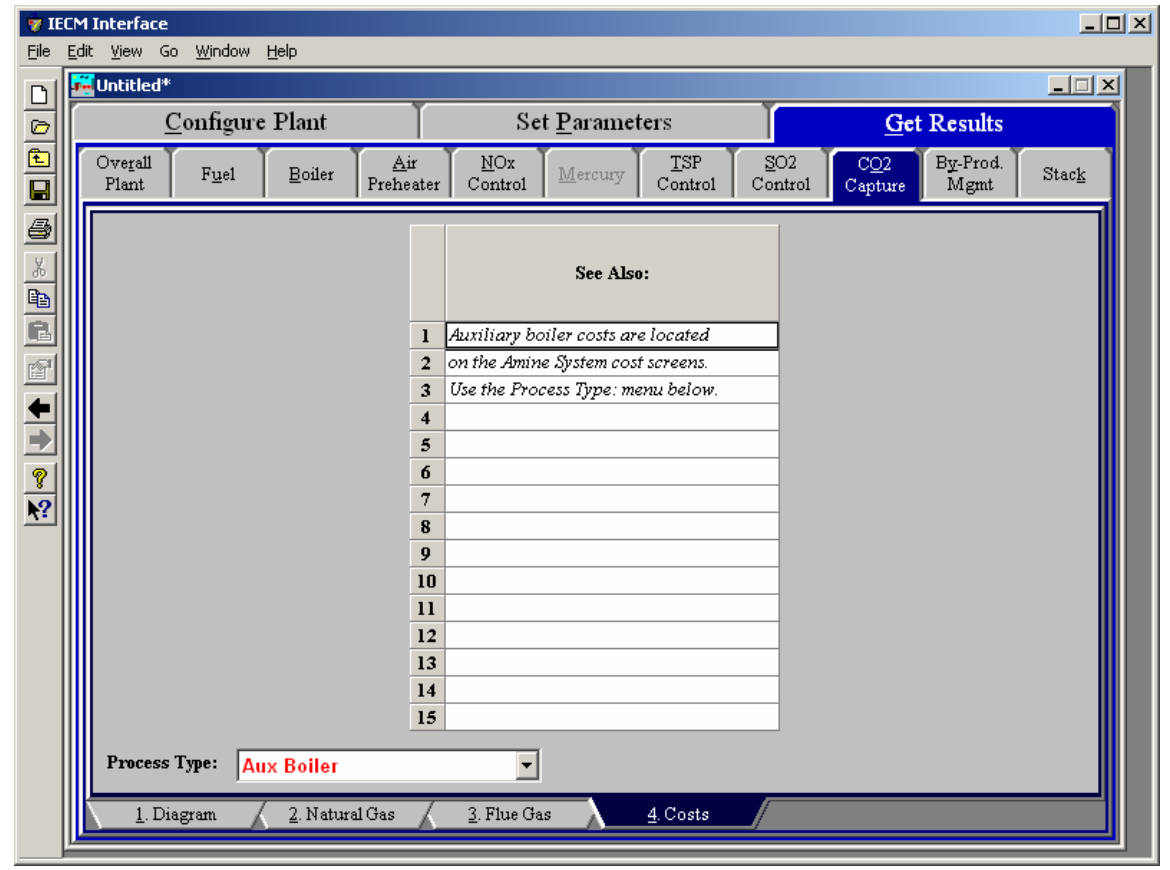

Amine System - Total Cost result screen.

The Costs result screen displays a note, pointing the user to the amine system cost screens. Because the auxiliary boiler is a sub-system of the amine system, the costs associated with the Auxiliary Boiler are displayed by the Amine System cost screens. View these by selecting the Amine System from the Process Type menu on the bottom of the screen. 



\section{Gasifier}

This gasifier chapter describes the coal gasification equipment used in the IGCC plant types.

\section{Gasifier Performance Inputs}

This screen is only available for the IGCC plant type.

\begin{tabular}{|c|c|c|c|c|c|c|c|c|c|c|c|c|}
\hline 71 & CM Interface & & & & & & & & & & & $-1 \square$ \\
\hline File & Edit View Go & to Window & & & & & & & & & & \\
\hline$\Gamma$ & $F^{*}$ Untitled $^{x}$ & & & & & & & & & & & $-\square x$ \\
\hline$\theta$ & & Configure & & & Par & met & & & & Get Rest & ults & \\
\hline \begin{tabular}{|l|l|}
$t$ \\
$\square$
\end{tabular} & Overall Plan & Fuel & $\underset{\text { Separation }}{\stackrel{\text { Air }}{a}}$ & $\begin{array}{c}\text { Gasifier } \\
\text { Area }\end{array}$ & $\begin{array}{r}\text { Su } \\
\text { Rem }\end{array}$ & & $\mathrm{CO} 2$ Capture & & ower Block & $\begin{array}{c}\text { By-Prod. } \\
\text { Mgmt }\end{array}$ & & ack \\
\hline 星 & & & itle & & & Unc & Value & Calc & Min & $\operatorname{Max}$ & Default & \\
\hline$y$ & 1 & & ex Area & & & & & & & & & \\
\hline 跑 & 2 & Gasifier Tem & & & & & $2450 \quad-$ & & Menu & Menu & 2450 & \\
\hline$\Rightarrow$ & 3 & Gasifier Pres: & & & & & 615.0 & & 600.0 & 650.0 & 615.0 & \\
\hline 些 & 4 & Total Water & team Input & $\mathrm{mol} \mathrm{H}$ & $\mathrm{nol} \mathrm{C}$ & & 0.4419 & $\underline{\underline{Z}}$ & 0.0 & 1.000 & calc & \\
\hline 圆 & 5 & Oxygen Inpu & mASU & $\mathrm{molc}$ & & & 0.4550 & $\underline{\underline{Z}}$ & 0.0 & 1.000 & calc & \\
\hline 4 & 67 & Total Carbon & & & & & -1 & & Menu & Menu & 3 & \\
\hline 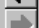 & 7 & Sulfur Loss $\mathrm{t}$ & & & & & 0.0 & $\underline{\underline{\nabla}}$ & 0.0 & 100.0 & calc & \\
\hline 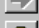 & 8 & Coal Ash in & Syngas & & & & 0.0 & $\underline{\underline{Z}}$ & 0.0 & 100.0 & calc & \\
\hline 8 & 91 & Percent Wat & Slag Sluice & & & & 0.0 & $\underline{\underline{Z}}$ & 0.0 & 99.00 & calc & \\
\hline A? & 10 & & & & & & & & & & & \\
\hline & 111 & Number of $\mathrm{O}$ & ting Trains & & & & 2 & $\underline{\underline{Z}}$ & Menu & Menu & Calc & \\
\hline & 121 & Number of $\mathrm{S}$ & Trains & & & & - & & Menu & Menu & 1 & \\
\hline & 13 & & & & & & & & & & & \\
\hline & 14 & $\underline{\operatorname{Raw} \mathrm{G}}$ & leanup Area & & & & & & & & & \\
\hline & 15 & Particulate $\mathrm{R}$ & val Efficiency & & & & 100.0 & $\underline{\nabla}$ & 0.0 & 100.0 & calc & \\
\hline & 16 & & & & & & & & & & & \\
\hline & 17 & Power Requir & & & & & 1.095 & $\underline{\nabla}$ & 0.0 & 6.000 & calc & \\
\hline & 18 & & & & & & & & & & & \\
\hline & Proce & ss Type: & & & $r$ & & & & & & & \\
\hline & 1. Perfor & rmance & yngas Out & 3. Retro & & & $\overline{\text { Capital Cost }}$ & & S. O\&M & & & \\
\hline
\end{tabular}

Gasifier-Performance input screen.

\section{Gasifier Area}

Gasifier Temperature: This is the temperature of the syngas exiting GE Entrained-Flow Reactor.

Gasifier Pressure: This is the pressure of the syngas exiting GE Entrained-Flow Reactor. 
Total Water-or-Steam Input: This is the ratio of water to carbon in the coal slurry.

Oxygen Input from ASU: The GE gasifier requires a constant value for the oxygen $\left(\mathrm{O}_{2}\right)$ in the oxidant to carbon (C) in coal ratio.

Total Carbon Loss: This the percent of carbon in the fuel that is lost.

Sulfur Loss to Solids: This is the percent of the sulfur in coal that is lost in the slag.

Coal Ash in Raw Syngas: This is the percent of ash in the coal that is in the syngas.

Percent Water in Slag Sluice: This is the percent of the slag sluice that is water.

Number of Operating Trains: This is the total number of operating trains. It is used primarily to calculate capital costs. The value must be an integer

Number of Spare Trains: This is the total number of spare trains. It is used primarily to calculate capital costs. The value must be an integer.

\section{Raw Gas Cleanup Area}

Fly Ash Removal Efficiency: This is the percentage of the ash which is removed by the raw gas cleanup process.

Power Requirement: This is the equivalent electrical output of thermal (steam) energy used for reheat, plus the actual electrical output power required.

\section{Gasifier Syngas Inputs}

The syngas generated by the gasifier is calculated as a function of the coal, water, and oxidant input flow rates, the carbon loss, and the gasifier temperature. The composition may be changed by the user. The location of this syngas composition is after the gasification but prior to the low temperature cooling and water quench.

Hence, the steam content of the syngas is typically in the $10-15 \%$ by volume range. This screen is only available for the IGCC plant type. 


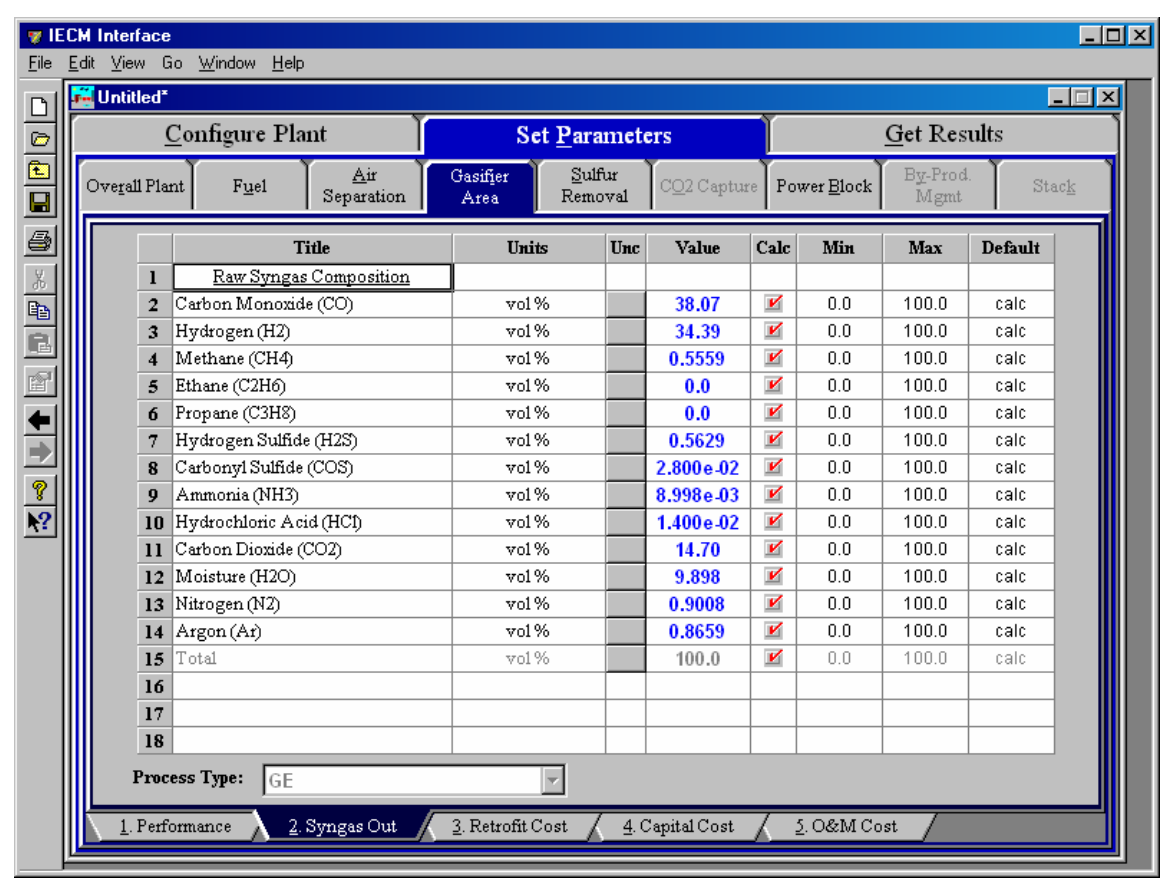

Gasifier - Gas Flow result screen..

\section{Raw Syngas Composition}

Carbon Monoxide (CO): Total mass of carbon monoxide.

Hydrogen $\left(\mathbf{H}_{2}\right)$ :Total mass of hydrogen.

Methane $\left(\mathrm{CH}_{4}\right)$ :Total mass of methane.

Ethane $\left(\mathrm{C}_{2} \mathrm{H}_{6}\right)$ :Total mass of methane.

Propane $\left(\mathrm{C}_{3} \mathrm{H}_{8}\right)$ :Total mass of methane.

Hydrogen Sulfide $\left(\mathrm{H}_{2} \mathrm{~S}\right)$ :Total mass of hydrogen sulfide.

Carbonyl Sulfide (COS):Total mass of carbonyl sulfide.

Ammonia $\left(\mathrm{NH}_{3}\right)$ : Total mass of ammonia.

Hydrochloric Acid $(\mathrm{HCl})$ : Total mass of hydrochloric acid.

Carbon Dioxide $\left(\mathrm{CO}_{2}\right)$ : Total mass of carbon dioxide.

Moisture $\left(\mathrm{H}_{2} \mathrm{O}\right)$ : Total mass of water vapor.

Nitrogen $\left(\mathbf{N}_{2}\right)$ : Total mass of nitrogen.

Argon (Ar): Total mass of argon.

Total: Total of the individual components listed above. This item is highlighted in yellow.

\section{Gasifier Retrofit Cost Inputs}

This screen is only available for the IGCC plant type. 


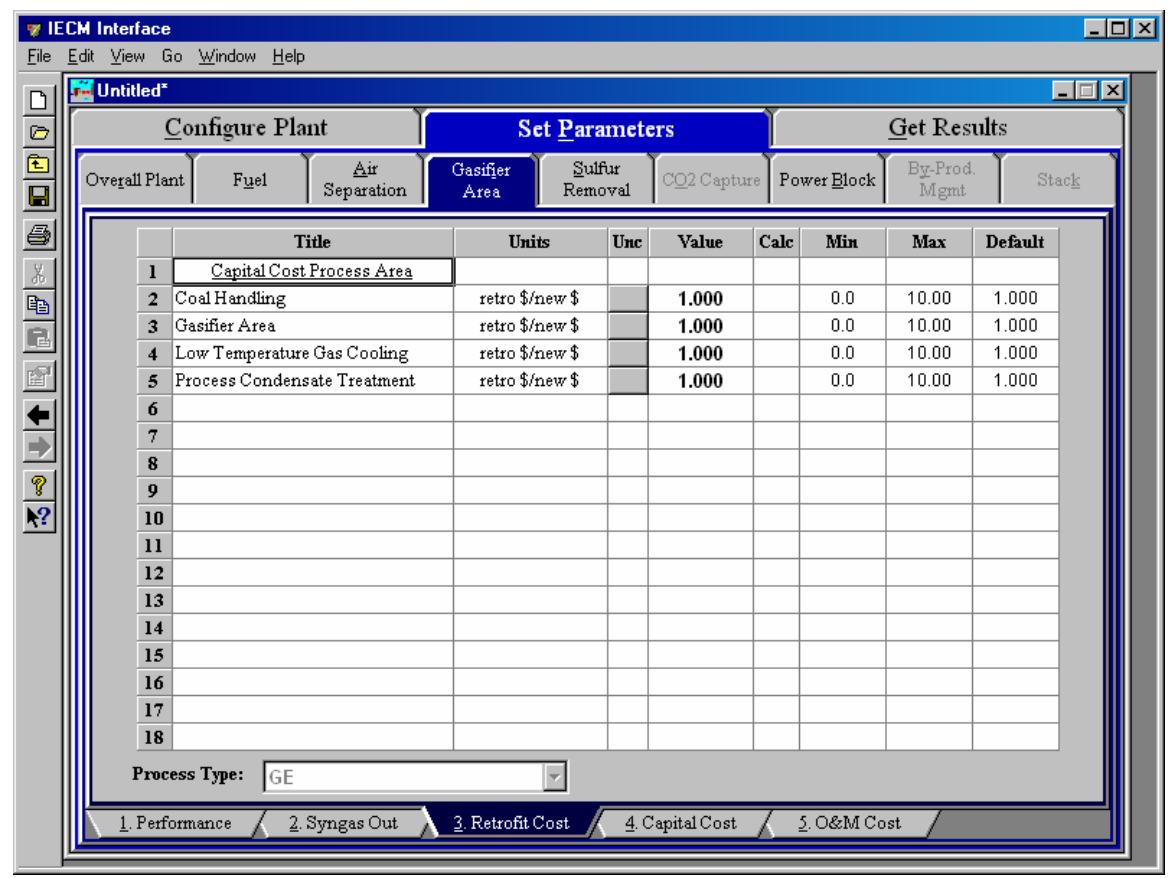

Gasifier - Retrofit Cost input screen.

\section{Capital Cost Process Area}

Coal Handling: Coal handling involves unloading coal from a train, storing the coal, moving the coal to the grinding mills, and feeding the gasifier with positive displacement pumps. A typical coal handling section contains one operating train and no spare train. A train consists of a bottom dump railroad car unloading hopper, vibrating feeders, conveyors, belt scale, magnetic separator, sampling system, deal coal storage, stacker, reclaimer, as well as some type of dust suppression system. Slurry preparation trains typically have one to five operating trains with one spare train. The typical train consists of vibrating feeders, conveyors, belt scale, rod mills, storage tanks, and positive displacement pimps to feed the gasifiers. All of the equipment for both the coal handling and the slurry feed are commercially available. A regression model was developed for the direct cost of coal handling and slurry preparation using the data collected for possible independent variables affecting direct capital cost. Coal feed rate to the gasifier on as-received basis is the most common and easily available independent variable. The direct cost model for the coal handling is based upon the overall flow to the plant rather than on a per train basis.

Gasifier Area: The GE gasification section of an IGCC plant contains gasifier, gas cooling, slag handling, and ash handling sections. For IGCC plants of $400 \mathrm{MW}$ to $1100 \mathrm{MW}$, typically 2 to 4 operating gasification trains are used along with one spare train. The mass flow of coal to the gasifier is assumed to be between 3000 and 3500 tons/day per train (as_received).

Low Temperature Gas Cooling: The low temperature gas cooling section includes a series of three shell and tube exchangers. The number of operating trains are estimated based on the total syngas mass flow rate and the range of syngas flow rates per train used. 
Process Condensate Treatment: This model is based upon one data point from AP-5950. Because the treated process condensate is used as make-up to the gas scrubbing unit, and because blowdown from the gas scrubbing unit is the larger of the flow streams entering the process condensate treatment section, it is expected that process condensate treatment cost will depend primarily on the scrubber blowdown flow rate.

\section{Gasifier Capital Cost Inputs}

This screen is only available for the IGCC plant type.

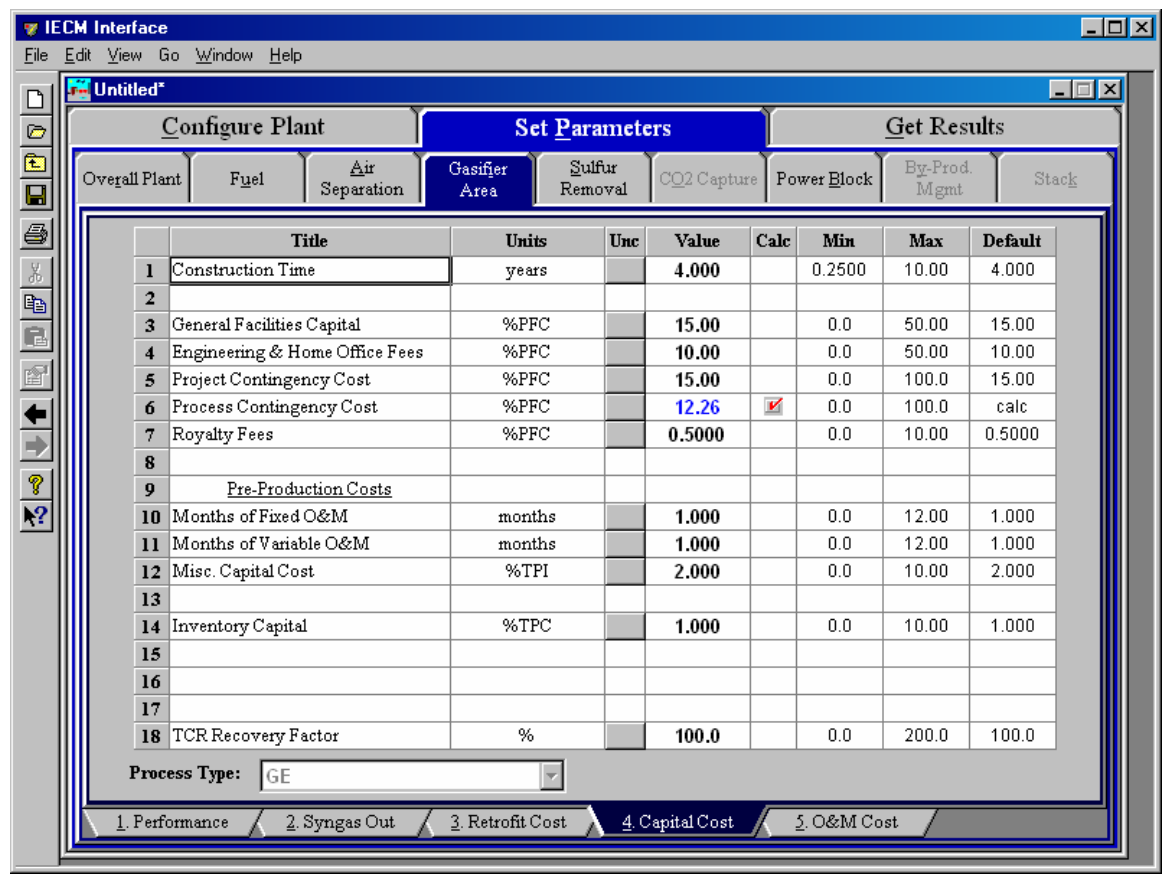

Gasifier - Capital Cost input screen.

Inputs for capital costs are entered on the Capital Cost input screen.

Construction Time: This is the idealized construction period in years. It is used to determine the allowance for funds used during construction (AFUDC).

General Facilities Capital (GFC): The general facilities include construction costs of roads, office buildings, shops, laboratories, etc. Sales taxes and freight costs are included implicitly. The cost typically ranges from $5-20 \%$.

Engineering \& Home Office Fees: The engineering \& home office fees are a percent of total direct capital cost. This is an overhead fee paid to the architect/engineering company. These fees typically range from 7$15 \%$.

Project Contingency Cost: This is factor covering the cost of additional equipment or other costs resulting from a more detailed design. Higher contingency factors will be applied to simplified or preliminary designs and lower factors to detailed or finalized designs.

Process Contingency Cost: This quantifies the design uncertainty and cost of a commercial-scale system. This is generally applied on an area- 
by-area basis. Higher contingency factors are applied to new regeneration systems tested at a pilot plant and lower factors to full-size or commercial systems.

Royalty Fees: Royalty charges may apply to some portions of generating units incorporating new proprietary technologies.

Pre-Production Costs: These costs consider the operator training, equipment checkout, major changes in unit equipment, extra maintenance, and inefficient use of fuel or other materials during startup. These are typically applied to the O\&M costs over a specified period of time (months). The two time periods for fixed and variable O\&M costs are described below with the addition of a miscellaneous capital cost factor.

- Months of Fixed O\&M: Time period of fixed operating costs used for preproduction to cover training, testing, major changes in equipment, and inefficiencies in start-up. This includes operating, maintenance, administrative and support labor. It also considers maintenance materials.

- Months of Variable O\&M: Time period of variable operating costs used for preproduction to cover chemicals, water, consumables, and solid disposal charges in start-up, assuming $100 \%$ load. This excludes any fuels.

- Misc. Capital Cost: This is a percent of total plant investment (sum of TPC and AFUDC) to cover expected changes to equipment to bring the system up to full capacity.

Inventory Capital: Percent of the total direct capital for raw material supply based on $100 \%$ capacity during a 60 day period. These materials are considered storage. The inventory capital includes fuels, consumables, by-products, and spare parts. This is typically $0.5 \%$.

TCR Recovery Factor: The actual total capital required (TCR) as a percent of the TCR in a new power plant. This value is $100 \%$ for a new installation and may be set as low as $0 \%$ for a fabric filter that has been paid off.

\section{Gasifier O\&M Cost Inputs}

This screen is only available for the IGCC plant type. 


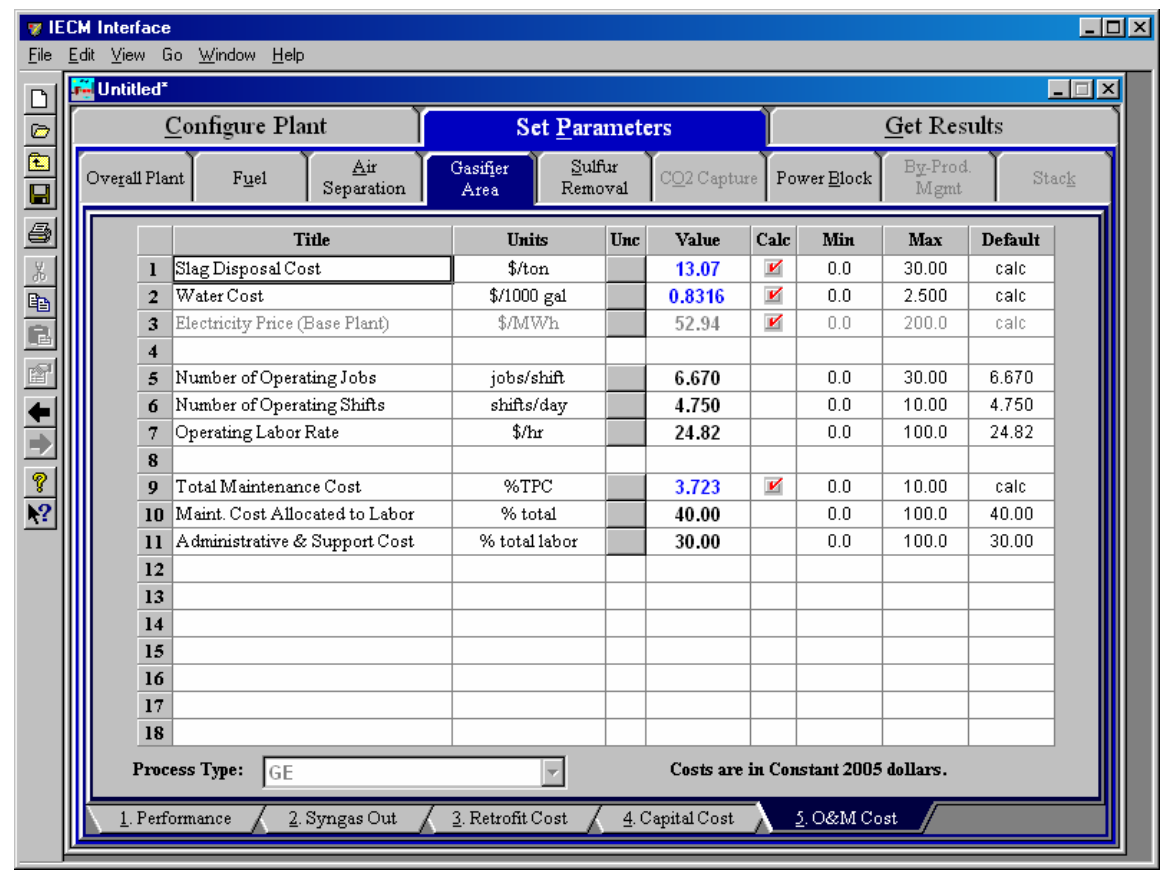

Gasifier - O\&M Cost input screen.

Inputs for O\&M costs are entered on the Gasifier O\&M Cost input screen. O\&M costs are typically expressed on an average annual basis and are provided in either constant or current dollars for a specified year, as shown on the bottom of the screen.

Slag Disposal Cost: This is the solid disposal cost per ton.

Water Cost: This is the cost of the water per 1000 gallons.

Electricity Price (Base Plant): This is the price of electricity and is calculated as a function of the utility cost of the base plant, where the base plant is defined as an air separation unit, gasifier and the power block.

Number of Operating Jobs: This is the total number of operating jobs that are required to operate the plant per eight-hour shift.

Number of Operating Shifts: This is the total number of equivalent operating shifts in the plant per day. The number takes into consideration paid time off and weekend work ( 3 shifts/day * 7 days/5 day week * 52 weeks/(52 weeks -6 weeks PTO $)=4.75$ equiv. Shifts/day)

Operating Labor Rate: The hourly cost of labor is specified in the base plant O\&M cost screen. The same value is used throughout the other technologies.

Total Maintenance Cost: This is the annual maintenance cost as a percentage of the total plant cost. Maintenance cost estimates can be developed separately for each process area.

Maint. Cost Allocated to Labor: Maintenance cost allocated to labor as a percentage of the total maintenance cost.

Administrative \& Support Cost: This is the percent of the total operating and maintenance labor associated with administrative and support labor. 


\section{Gasifier Diagram}

This screen is only available for the IGCC plant type.

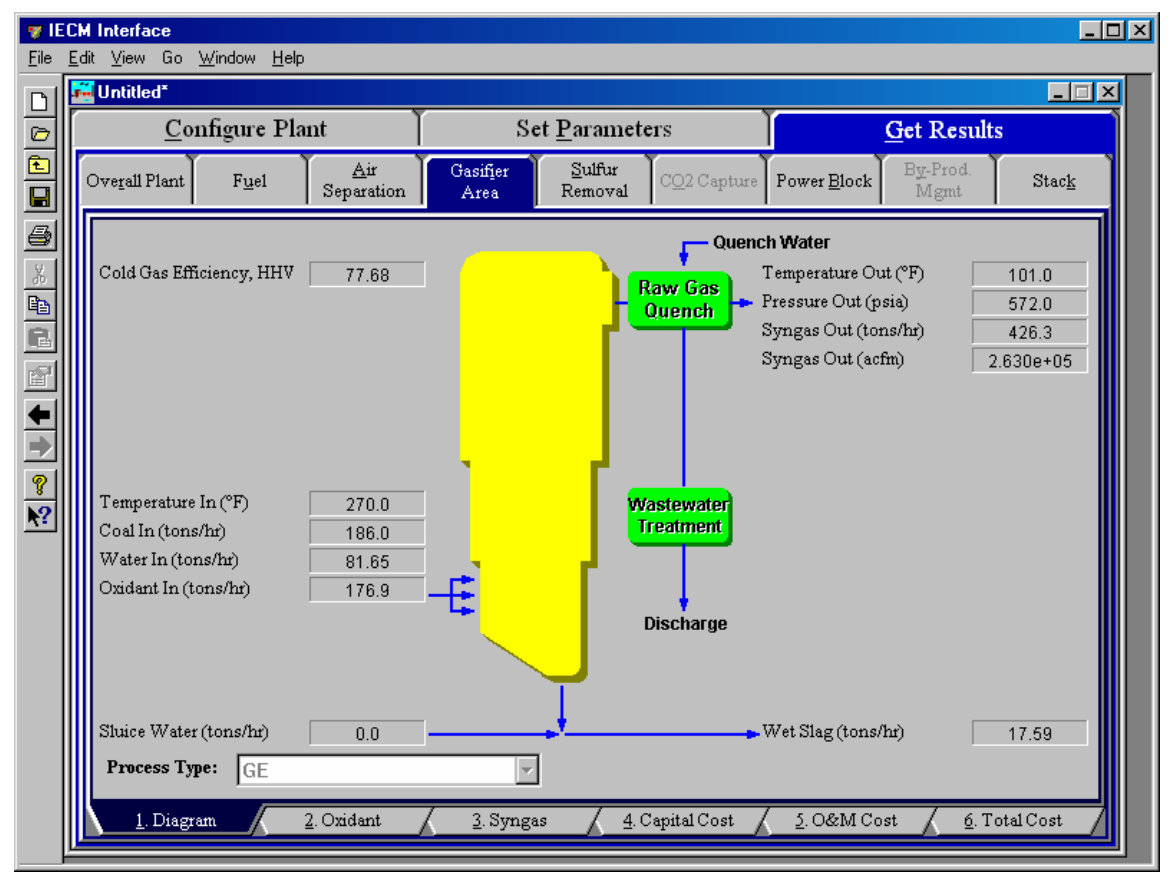

Gasifier-Diagram result screen.

The Gasifier Diagram result screen displays an icon for the Gasifier Unit and values for major flows in and out of it. Each result is described briefly below in flow:

Cold Gas Efficiency: This is the ratio of the heat contents calculated at room temperature of the syngas fuel output and the coal fuel input. The higher heating value is used here.

Temperature In: This is the temperature of the oxidant stream into the gasifier.

Coal In: This is the mass flow of coal into the gasifier on a wet-basis.

Water In: This is additional mass flow of water added to the coal. (Wet coal already contains some water).

Oxidant In: This is the mass flow of oxidant into the gasifier.

Sluice Water: Slag collected can be removed from the gasifier and disposed by sluicing the slag with water.

Temperature Out: This is the syngas temperature exiting the raw gas quench.

Pressure Out: .This is the approximate pressure of the syngas exiting the raw gas quench.

Syngas Out:.This is the mass flow rate of syngas exiting the gasification but prior to the raw gas quench process.

Syngas Out:.This is the volumetric flow rate of syngas exiting the gasification but prior to the raw gas quench process. 
Wet Slag:.Slag collected is removed from the gasifier. Sluice water may or may not be used to facilitate its transportation. This is the total slag flow rate leaving the gasifier on a wet basis.

\section{Gasifier Oxidant Results}

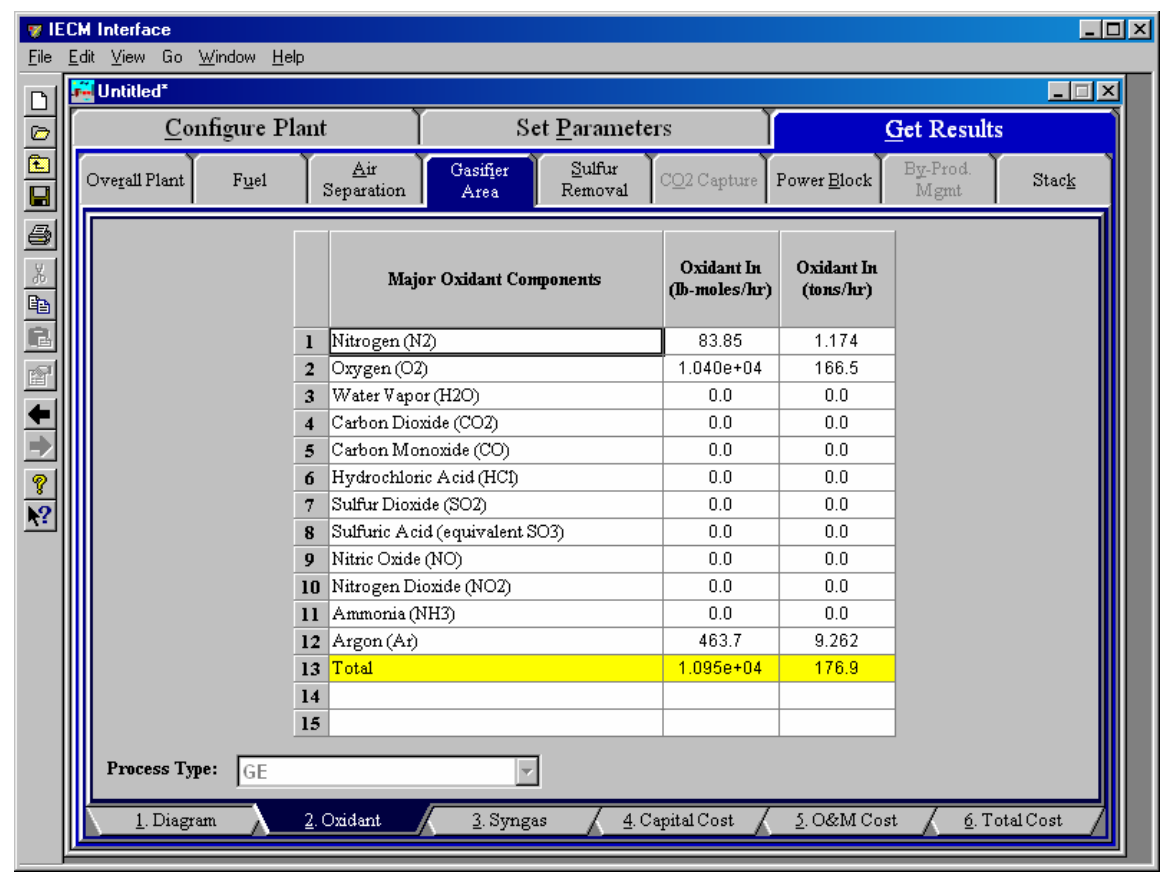

Gasifier - Gas Flow result screen..

Each result is described briefly below.

Nitrogen $\left(\mathrm{N}_{2}\right)$ : Total mass of nitrogen.

Oxygen $\left(\mathrm{O}_{2}\right)$ : Total mass of oxygen.

Water Vapor $\left(\mathrm{H}_{2} \mathrm{O}\right)$ : Total mass of water vapor.

Carbon Dioxide $\left(\mathrm{CO}_{2}\right)$ : Total mass of carbon dioxide.

Carbon Monoxide (CO): Total mass of carbon monoxide.

Hydrochloric Acid ( $\mathbf{H C l})$ : Total mass of hydrochloric acid.

Sulfur Dioxide $\left(\mathrm{SO}_{2}\right)$ : Total mass of sulfur dioxide.

Sulfuric Acid (equivalent $\mathrm{SO}_{3}$ ): Total mass of sulfuric acid.

Nitric Oxide (NO): Total mass of nitric oxide.

Nitrogen Dioxide $\left(\mathrm{NO}_{2}\right)$ : Total mass of nitrogen dioxide.

Ammonia $\left(\mathrm{NH}_{3}\right)$ : Total mass of ammonia.

Argon (Ar): Total mass of argon.

Total: Total of the individual components listed above. This item is highlighted in yellow. 


\section{Gasifier Syngas Results}

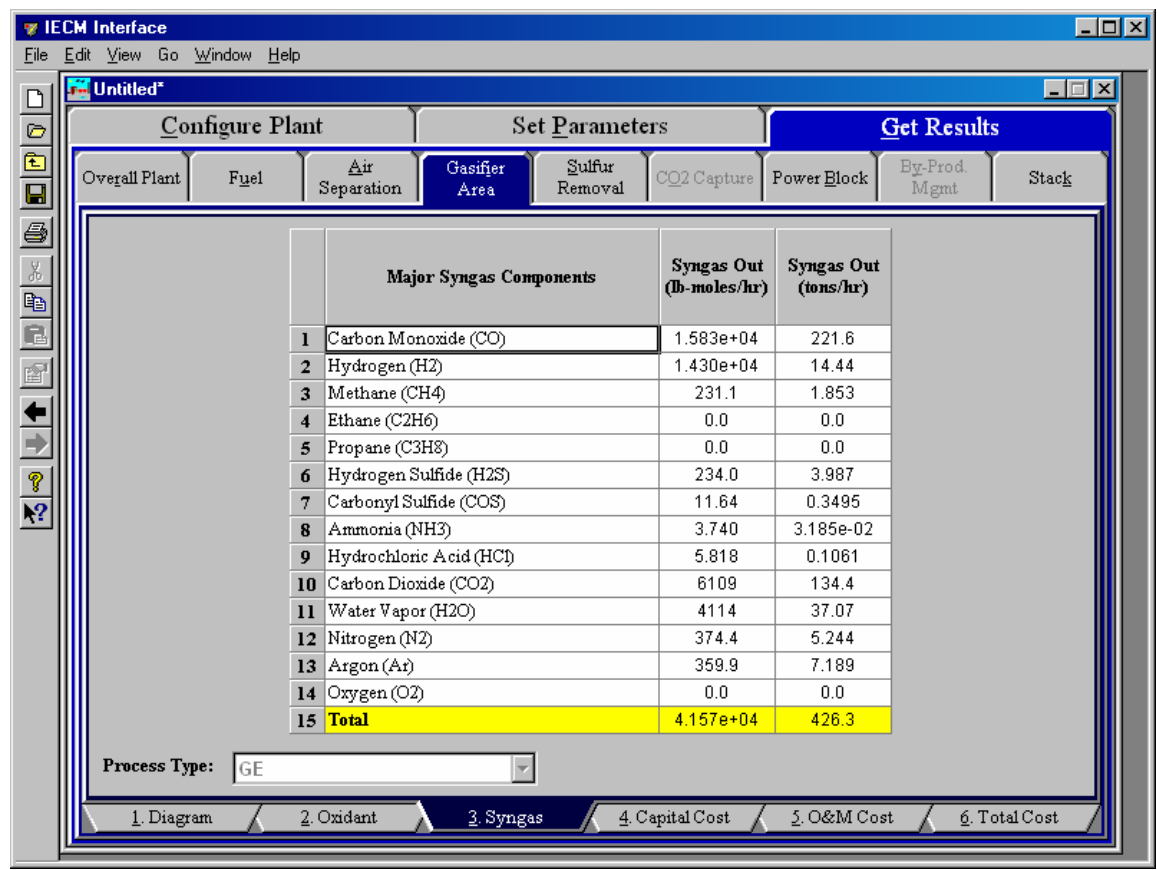

Gasifier - Gas Flow result screen..

\section{Major Syngas Components}

Carbon Monoxide (CO): Total mass of carbon monoxide.

Hydrogen $\left(\mathbf{H}_{\mathbf{2}}\right)$ :Total mass of hydrogen.

Methane $\left(\mathrm{CH}_{4}\right)$ :Total mass of methane.

Ethane $\left(\mathrm{C}_{2} \mathrm{H}_{6}\right)$ :Total mass of ethane.

Propane $\left(\mathrm{C}_{3} \mathrm{H}_{8}\right)$ :Total mass of propane.

Hydrogen Sulfide $\left(\mathrm{H}_{2} \mathrm{~S}\right)$ :Total mass of hydrogen sulfide.

Carbonyl Sulfide (COS):Total mass of carbonyl sulfide.

Ammonia $\left(\mathrm{NH}_{3}\right)$ : Total mass of ammonia.

Hydrochloric Acid $(\mathrm{HCl})$ : Total mass of hydrochloric acid.

Carbon Dioxide $\left(\mathrm{CO}_{2}\right)$ : Total mass of carbon dioxide.

Water Vapor $\left(\mathrm{H}_{2} \mathrm{O}\right)$ : Total mass of water vapor.

Nitrogen $\left(\mathbf{N}_{2}\right)$ : Total mass of nitrogen.

Argon (Ar): Total mass of argon.

Oxygen $\left(\mathrm{O}_{2}\right)$ : Total mass of oxygen.

Total: Total of the individual components listed above. This item is highlighted in yellow. 


\section{Gasifier Capital Cost Results}

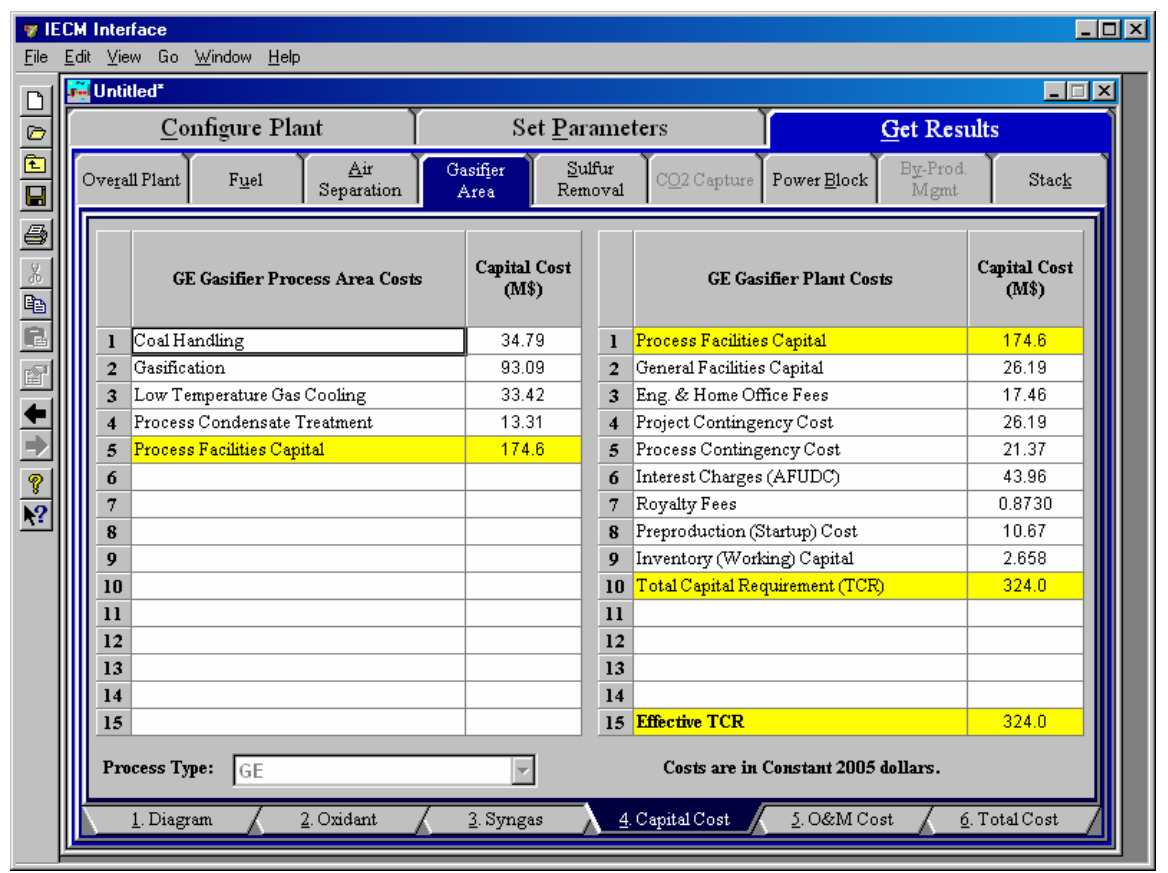

Gasifier Capital Cost results screen.

The GE Gasifier Capital Cost result screen displays tables for the capital costs. Capital costs are typically expressed in either constant or current dollars for a specified year, as shown on the bottom of the screen. Each result is described briefly below:

\section{GE Gasifier Process Area Costs}

Coal Handling: This is the cost associated with the coal handling process area. Coal handling involves unloading coal from a train, storing the coal, moving the coal to the grinding mills, and feeding the gasifier with positive displacement pumps. A typical coal handling section contains one operating train and no spare train. A train consists of a bottom dump railroad car unloading hopper, vibrating feeders, conveyors, belt scale, magnetic separator, sampling system, deal coal storage, stacker, reclaimer, as well as some type of dust suppression system. Slurry preparation trains typically have one to five operating trains with one spare train. The typical train consists of vibrating feeders, conveyors, belt scale, rod mills, storage tanks, and positive displacement pimps to feed the gasifiers. All of the equipment for both the coal handling and the slurry feed are commercially available. The direct cost model for the coal handling is based upon the overall flow to the plant rather than on a per train basis.

Gasifier Area: The GE gasification section of an IGCC plant contains gasifier, gas cooling, slag handling, and ash handling sections. For IGCC plants of $400 \mathrm{MW}$ to $1100 \mathrm{MW}$, typically 4 to 8 operating gasification trains are used along with one spare train.

Low Temperature Gas Cooling: This is the cost associated with the Low Temperature Gas Cooling process area. The low temperature gas 
cooling section includes a series of three shell and tube exchangers. The number of operating trains are estimated based on the total syngas mass flow rate and the range of syngas flow rates per train used.

Process Condensate Treatment: The treated process condensate is used as make-up to the gas scrubbing unit, and because blowdown from the gas scrubbing unit is the larger of the flow streams entering the process condensate treatment section, it is expected that process condensate treatment cost will depend primarily on the scrubber blowdown flow rate.

Process Facilities Capital: The process facilities capital is the total constructed cost of all on-site processing and generating units listed above, including all direct and indirect construction costs. All sales taxes and freight costs are included where applicable implicitly. This result is highlighted in yellow.

\section{GE Gasifier Plant Costs}

Process Facilities Capital: (see definition above)

General Facilities Capital: The general facilities include construction costs of roads, office buildings, shops, laboratories, etc. Sales taxes and freight costs are included implicitly.

Eng. \& Home Office Fees: The engineering \& home office fees are a percent of total direct capital cost. This is an overhead fee paid to the architect/engineering company.

Project Contingency Cost: Capital cost contingency factor covering the cost of additional equipment or other costs that would result from a more detailed design of a definitive project at the actual site.

Process Contingency Cost: Capital cost contingency factor applied to a new technology in an effort to quantify the uncertainty in the technical performance and cost of the commercial-scale equipment.

Interest Charges (AFUDC): Allowance for funds used during construction, also referred to as interest during construction, is the time value of the money used during construction and is based on an interest rate equal to the before-tax weighted cost of capital. This interest is compounded on an annual basis (end of year) during the construction period for all funds spent during the year or previous years.

Royalty Fees: Royalty charges may apply to some portions of generating units incorporating new proprietary technologies.

Preproduction (Startup) Cost: These costs consider the operator training, equipment checkout, major changes in unit equipment, extra maintenance, and inefficient use of fuel or other materials during startup.

Inventory (Working) Capital: The raw material supply based on $100 \%$ capacity during a 60 day period. These materials are considered storage. The inventory capital includes fuels, consumables, byproducts, and spare parts.

Total Capital Requirement (TCR): Money that is placed (capitalized) on the books of the utility on the service date. TCR includes all the items above. This result is highlighted in yellow. 
Effective TCR: The TCR of the spray dryer that is used in determining the total power plant cost. The effective TCR is determined by the "TCR Recovery Factor".

\section{Gasifier O\&M Cost Results}

This screen is only available for the IGCC plant type.

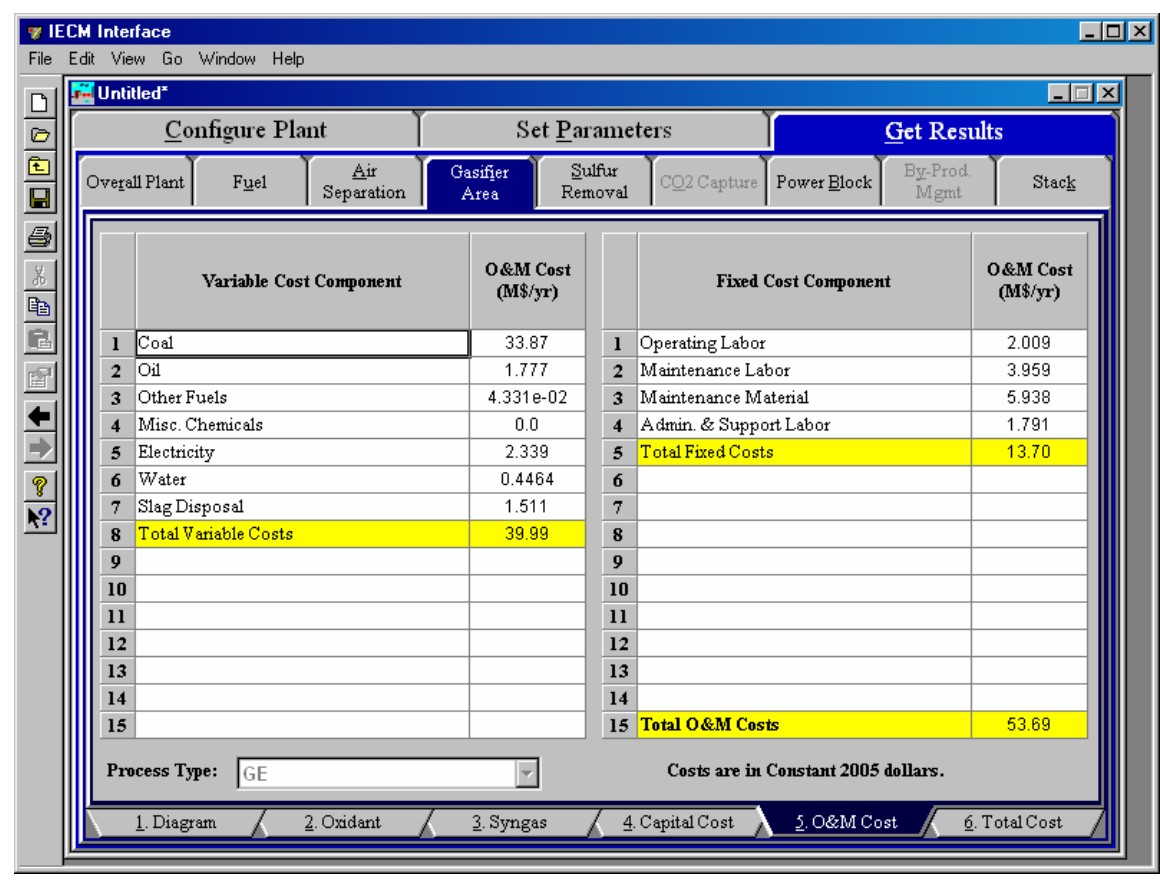

Gasifier - O\&M Cost results screen.

O\&M costs are typically expressed on an average annual basis and are provided in either constant or current dollars for a specified year, as shown on the bottom of the screen.

\section{Variable Cost Component}

Coal: This is the annual cost of the coal used by the gasifier.

Oil: This is the annual cost of the oil consumed by the gasifier.

Other Fuels: This is the annual cost of any other fuels used by the gasifier.

Misc. Chemicals: This is the annual cost of the miscellaneous chemicals used by the gasifier.

Electricity: The cost of electricity consumed by the processes in the gasifier area..

Water: This is the annual cost of the water used by the gasifier.

Slag Disposal: This is the solid disposal cost per year for the GE entrained-flow reactor.

Total Variable Costs: This is the sum of all the variable O\&M costs listed above. This result is highlighted in yellow. 


\section{Fixed Cost Components}

Fixed operating costs are essentially independent of actual capacity factor, number of hours of operation, or amount of kilowatts produced. All the costs are subject to inflation.

Operating Labor: Operating labor cost is based on the operating labor rate, the number of personnel required to operate the plant per eighthour shift, and the average number of shifts per day over 40 hours per week and 52 weeks.

Maintenance Labor: The maintenance labor is determined as a fraction of the total maintenance cost.

Maintenance Material: The cost of maintenance material is the remainder of the total maintenance cost, considering the fraction associated with maintenance labor.

Admin. \& Support Labor: The administrative and support labor is the only overhead charge. It is taken as a fraction of the total operating and maintenance labor costs.

Total Fixed Costs: This is the sum of all the fixed O\&M costs listed above. This result is highlighted in yellow.

Total O\&M Costs: This is the sum of the total variable and total fixed $\mathrm{O} \& \mathrm{M}$ costs. It is used to determine the base plant total revenue requirement. This result is highlighted in yellow.

\section{Gasifier Total Cost Results}

This screen is only available for the IGCC plant type.

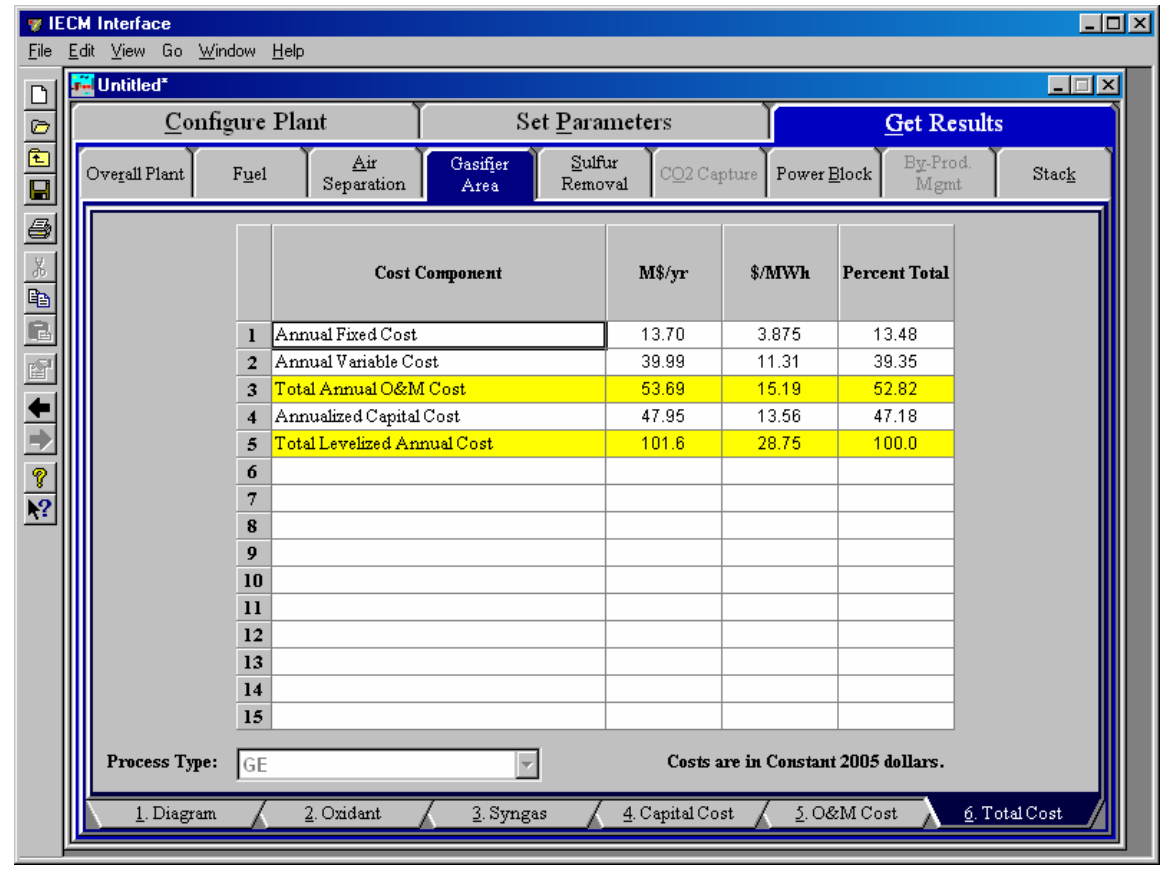

Gasifier - Total Cost results screen. 
The Total Cost result screen displays a table which totals the annual fixed, variable, operations and maintenance, and capital costs associated with the Gasifier Unit.

Total costs are typically expressed in either constant or current dollars for a specified year, as shown on the bottom of the screen. Each result is described briefly below.

\section{Cost Component}

Annual Fixed Cost: The operating and maintenance fixed costs are given as an annual total. This number includes all maintenance materials and all labor costs.

Annual Variable Cost: The operating and maintenance variables costs are given as an annual total. This includes all reagent, chemical, steam, and power costs.

Total Annual O\&M Cost: This is the sum of the annual fixed and variable operating and maintenance costs above. This result is highlighted in yellow.

Annualized Capital Cost: This is the total capital cost expressed on an annualized basis, taking into consideration the levelized carrying charge factor, or fixed charge factor, over the entire book life.

Total Levelized Annual Cost: The total annual cost is the sum of the total annual O\&M cost and annualized capital cost items above. This result is highlighted in yellow. 



\section{Air Preheater}

The Air Preheater Technology Navigation Tab in the Get Results program area contains result screens that display the flow rates and temperatures of substances through the air preheater. This is only available in the Combustion (Boiler) plant type.

\section{Air Preheater Diagram}

This screen is only available for the Combustion (Boiler) plant type.

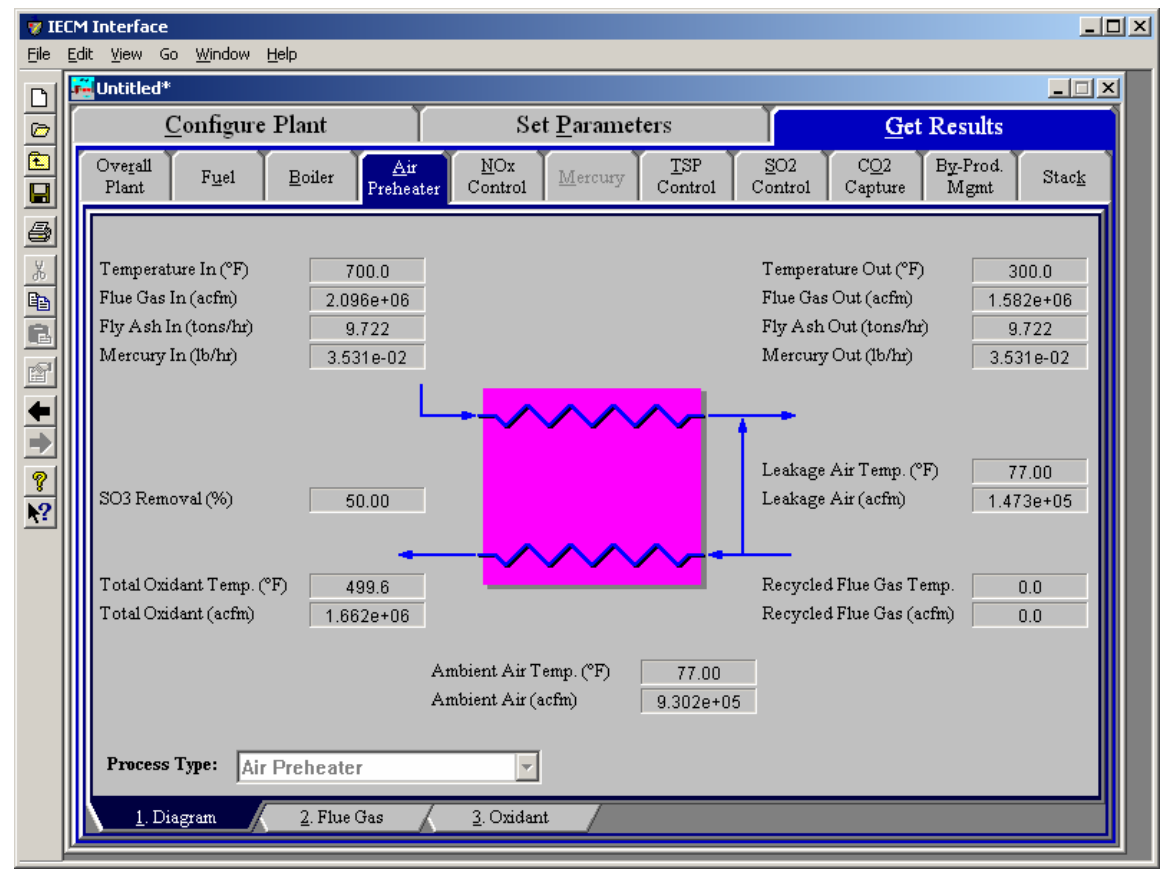

Air Preheater - Diagram.

The Diagram result screen displays an icon for the Air Preheater and values for major flows in and out of it. Each result is described briefly below in flow order (not from top to bottom and left to right as they display on the screen).

\section{Recycled Flue Gas Entering Preheater}


Flue gas can be recycled back into the boiler when an $\mathbf{O}_{2}-\mathbf{C O}_{2}$ Recycle

configuration is specified in Configure Plant. This is more commonly known as an "oxyfuel" configuration. Flue gas is not recycled in any other configuration.

Recycled Flue Gas Temp: Temperature of the recycled flue gas entering the induced-draft fan.

Recycled Flue Gas: Volumetric flow rate of the recycled flue gas entering the induced-draft fan.

\section{Atmospheric Air Entering Preheater}

Ambient Air Temp: Temperature of the atmospheric air entering the induced-draft fan.

Ambient Air: Volumetric flow rate of air entering the induced-draft fan, based on the atmospheric air temperature and atmospheric pressure.

\section{Heated Air Exiting Preheater}

Heated Oxidant Temp: Heated combustion air or recycled flue gas temperature exiting the air preheater. This is a complicated function of the heat content and temperatures of the flue gas.

Heated Oxidant: Volumetric flow rate of the combustion air or recycled flue gas exiting the air preheater, based on the combustion air temperature and atmospheric pressure.

\section{Leakage Air}

Leakage Air Temp: Temperature of the atmospheric air leaking across the air preheater into the flue gas. This is determined by the leakage parameter on the base plant performance input screen.

Leakage Air: Volumetric flow rate of the atmospheric air leaking across the air preheater into the flue gas. This is based on the leakage temperature and atmospheric pressure.

\section{Flue Gas Entering Preheater}

Temperature In: Temperature of the flue gas entering the air preheater. This is determined by the flue gas outlet temperature of the module upstream of the air preheater (e.g., the boiler economizer).

Flue Gas In: Volumetric flow rate of the flue gas entering the air preheater, based on the flue gas inlet temperature and atmospheric pressure.

Fly Ash In: Total solids mass flow rate in the flue gas entering the air preheater. This is determined by the solids exiting the module upstream of the air preheater (e.g., the boiler economizer)

Mercury In: Total mass of mercury entering the air preheater in the flue gas. The value is a sum of all the forms of mercury (elemental, oxidized, and particulate).

\section{Air Preheater Performance}

SO3 Removal: Percent of the $\mathrm{SO}_{3}$ removed from the flue gas.

\section{Cooled Flue Gas Exiting Preheater}

Temperature Out: Temperature of the flue gas exiting the air preheater. This is determined by the parameter on the base plant performance input screen. 
Flue Gas Out: Volumetric flow rate of the flue gas exiting the air preheater, based on the flue gas exit temperature and atmospheric pressure.

Fly Ash Out: Total solids mass flow rate in the flue gas exiting the air preheater. This is a function of the percent ash entering the flue gas (furnace emissions input parameter) and the ash content of the fuel.

Mercury Out: Total mass of mercury exiting the air preheater in the flue gas. The value is a sum of all the forms of mercury (elemental, oxidized, and particulate).

\section{Air Preheater Flue Gas Results}

This screen is only available for the Combustion (Boiler) plant type.

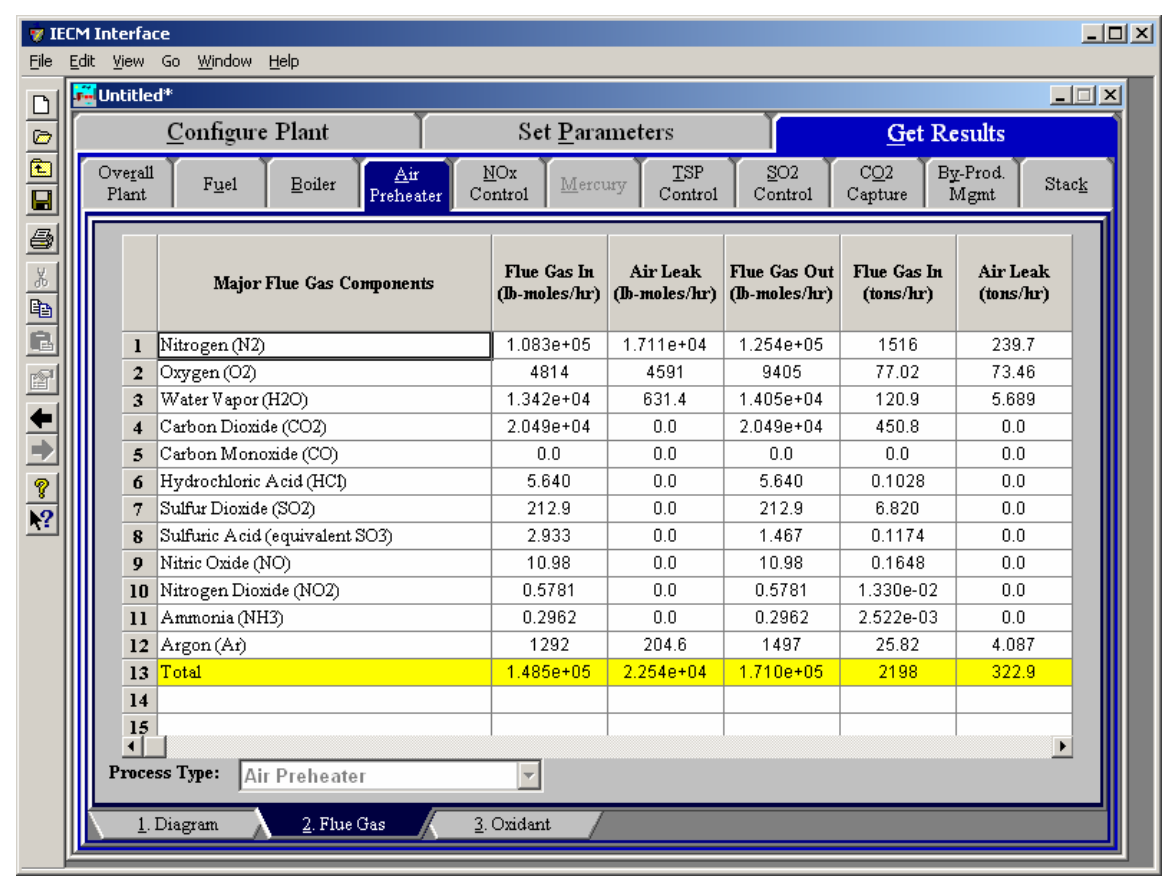

Air Preheater - Flue Gas result screen.

\section{Major Flue Gas Components}

The Flue Gas result screen displays a table of quantities of flue gas components entering and exiting the air preheater. For each component entering and exiting in flue gas, values are given in both moles and mass per hour. For each component entering in atmospheric air, values are given in moles per hour. Each result is described briefly below.

Nitrogen (N2): Total mass of nitrogen.

Oxygen (02): Total mass of oxygen.

Water Vapor (H2O): Total mass of water vapor.

Carbon Dioxide (CO2): Total mass of carbon dioxide.

Carbon Monoxide (CO): Total mass of carbon monoxide. 
Hydrochloric Acid ( $\mathrm{HCl})$ : Total mass of hydrochloric acid.

Sulfur Dioxide (SO2): Total mass of sulfur dioxide.

Sulfuric Acid (equivalent SO3): Total mass of sulfuric acid.

Nitric Oxide (NO): Total mass of nitric oxide.

Nitrogen Dioxide (NO2): Total mass of nitrogen dioxide.

Ammonia (NH3): Total mass of ammonia.

Argon (Ar): Total mass of argon.

Total: Total of the individual components listed above. This item is highlighted in yellow.

\section{Air Preheater Oxidant Results}

This screen is only available for the Combustion (Boiler) plant type.

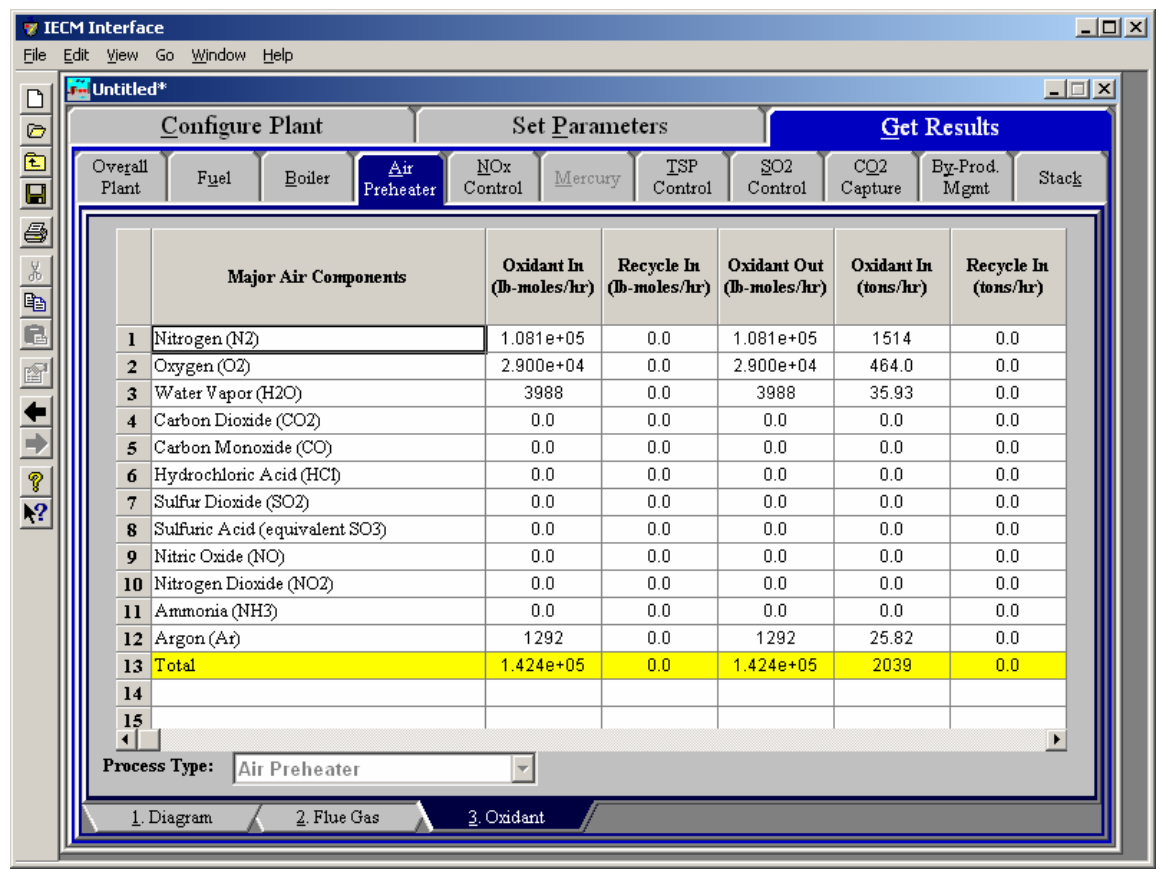

Air Preheater - Flue Gas result screen.

\section{Oxidant Gas Components}

The Oxidant result screen displays a table of quantities of air or recycled flue gas components entering and exiting the air preheater. For each component entering and exiting in flue gas, values are given in both moles and mass per hour. For each component entering in atmospheric air, values are given in moles per hour. Each result is described briefly below.

Nitrogen $\left(\mathbf{N}_{2}\right)$ : Total mass of nitrogen.

Oxygen $\left(\mathrm{O}_{2}\right)$ : Total mass of oxygen.

Water Vapor $\left(\mathrm{H}_{2} \mathrm{O}\right)$ : Total mass of water vapor.

Carbon Dioxide $\left(\mathrm{CO}_{2}\right)$ : Total mass of carbon dioxide. 
Carbon Monoxide (CO): Total mass of carbon monoxide.

Hydrochloric Acid $(\mathrm{HCl})$ : Total mass of hydrochloric acid.

Sulfur Dioxide $\left(\mathrm{SO}_{2}\right)$ : Total mass of sulfur dioxide.

Sulfuric Acid (equivalent $\mathbf{S O}_{3}$ ): Total mass of sulfuric acid.

Nitric Oxide (NO): Total mass of nitric oxide.

Nitrogen Dioxide $\left(\mathrm{NO}_{2}\right)$ : Total mass of nitrogen dioxide.

Ammonia $\left(\mathrm{NH}_{3}\right)$ : Total mass of ammonia.

Argon (Ar): Total mass of argon.

Total: Total of the individual components listed above. This item is highlighted in yellow. 



\section{In-Furnace Controls}

The NOx Control Technology Navigation Tab contains screens that address combustion or post-combustion air pollution technologies for Nitrogen Oxides.

These screens are available if the In-Furnace Controls for the Combustion (Boiler) plant type configurations have been selected for $\mathrm{NO}_{\mathrm{x}}$ control under Combustion Controls. If you have selected both In-Furnace Controls and a Hot-Side SCR for $\mathrm{NO}_{\mathrm{x}}$ control, you may switch between the two sets of screens that configure these technologies by using the Process Type pull-down menu at the bottom of the screen

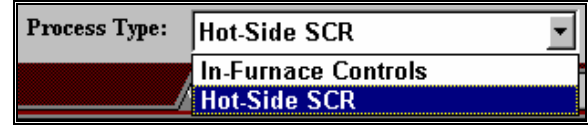

The Process Type pull-down menu

\section{In-Furnace Controls Configuration}

This screen is only available for the Combustion (Boiler) plant type. Inputs for configuring the $\mathrm{NO}_{\mathrm{x}}$ Control technology are entered on the Config input screen. Each parameter is described briefly below. 


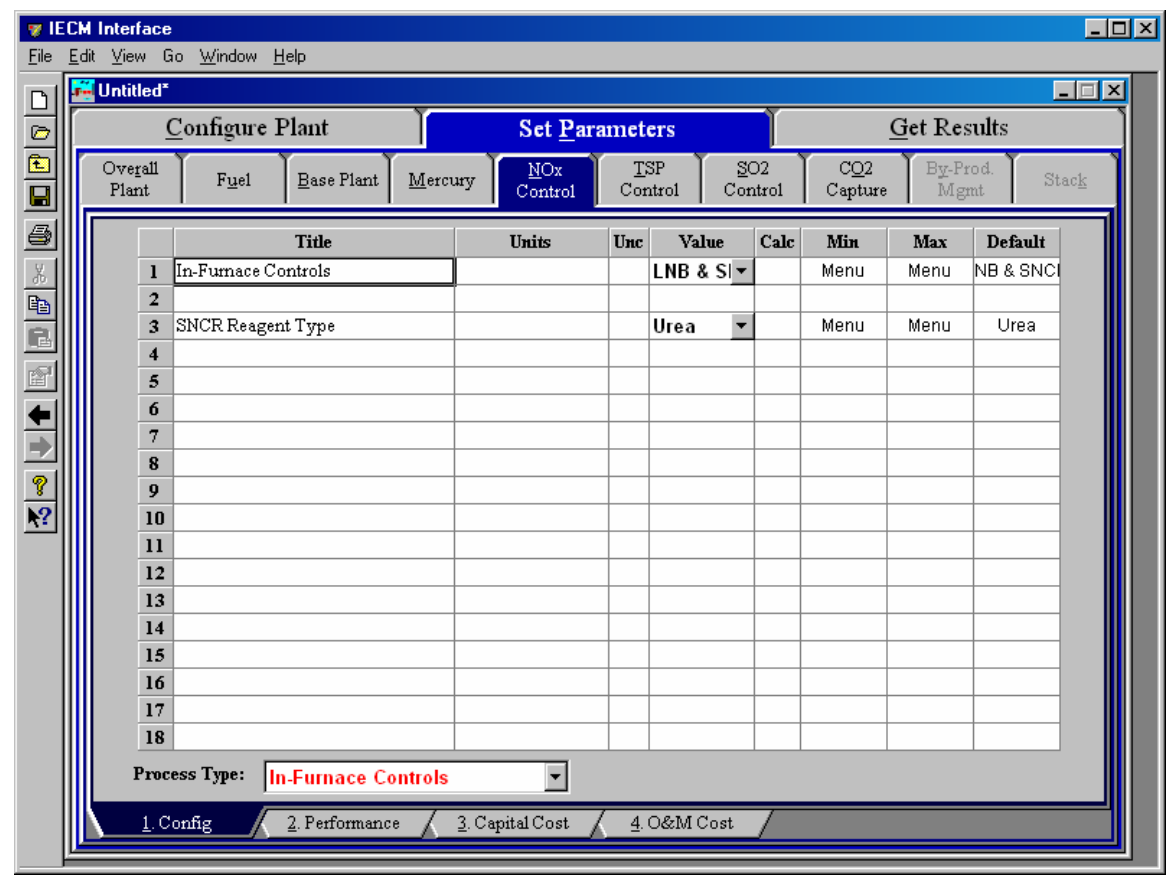

In - Furnace Controls - Config input screen.

\section{In - Furnace Controls}

This pull-down menu chooses what type of in-furnace $\mathrm{NO}_{\mathrm{x}}$ controls are used. These technologies reduce $\mathrm{NO}_{\mathrm{x}}$ between the primary fuel injection into the furnace and the economizer. These can be used in the combinations given in addition to the SCR.

The low $\mathrm{NO}_{\mathrm{x}}$ burner options are not displayed when a cyclone boiler is configured. The full list of choices is:

LNB - Low $\mathrm{NO}_{\mathrm{x}}$ burners are a combustion $\mathrm{NO}_{\mathrm{x}}$ control. These burners replace the upper coal nozzle of the standard two-nozzle cell burner with a secondary air port. The lower burner coal nozzle is enlarged to the same fuel input capacity as the two standard coal nozzles. The LNB operates on the principle of staged combustion to reduce $\mathrm{NO}_{\mathrm{x}}$ emissions. Approximately 70\% of the total air (primary, secondary, and excess air) is supplied through or around the coal-feed nozzle. The remainder of the air is directed to the upper port of each cell to complete the combustion process. The fuel-bound nitrogen compounds are converted to nitrogen gas, and the reduced flame temperature minimizes the formation of thermal $\mathrm{NO}_{\mathrm{x}}$. The net effect of this technology is greater than $50 \%$ reduction in $\mathrm{NO}_{\mathrm{x}}$ formation with no boiler pressure part changes and no impact on boiler operation or performance. Low $\mathrm{NO}_{\mathrm{x}}$ burners are not available for cyclone boilers.

LNB \& OFA - Low $\mathrm{NO}_{x}$ burners (see above) with overfire air is another combustion $\mathrm{NO}_{\mathrm{x}}$ reduction method. Overfire air is an enhancement to LNB to reduce $\mathrm{NO}_{\mathrm{x}}$ formation by further separating the air injection locations. An addition of approximately $10 \% \mathrm{NO}_{\mathrm{x}}$ is reduced by the addition of OFA. A portion of the secondary air used by LNB is diverted to injection ports located above the primary combustion zone, reducing available oxygen in the primary combustion zone. Overfire air in the IECM refers to separated OFA for both wall and tangential-fired boilers. This option is not supported for cyclone boilers. 
Gas Reburn - Gas reburn is a post-combustion $\mathrm{NO}_{\mathrm{x}}$ reduction method. Gas reburn substitutes up to one-fourth of the heat input of coal with natural gas, reducing the $\mathrm{NO}_{\mathrm{x}}$ up to $60 \%$ as a function of the amount of reburn. The natural gas is injected above the primary combustion zone to create a reducing zone. Reburn has been shown to be effective for wall and tangential-fired boilers and more recently for cyclone boilers.

SNCR - Selective non-catalytic reduction is a post-combustion $\mathrm{NO}_{\mathrm{x}}$ reduction method. This process removes $\mathrm{NO}_{\mathrm{x}}$ from flue gas by injecting one of two nitrogen-based reagents, ammonia or urea, in the presence of oxygen to form nitrogen and water vapor. Optimum removal is achieved in a temperature window of 1600-2000 F. Although the technology is very simple, the narrow temperature window provides the primary challenge. Ammonia slip and ash contamination are additional concerns that must be considered with SNCR.

LNB \& SNCR - Low $\mathrm{NO}_{\mathrm{x}}$ burners can be used in conjunction with SNCR to achieve very high $\mathrm{NO}_{\mathrm{x}}$ removals. Both technologies are described in detail above.

If a Tangential or Wall Furnace Type have been selected in $\underline{\text { Configure Plant, then }}$ all five options will display. If you have selected a Cyclone Furnace type, then only Gas Reburn and SNCR will display.

The default for Tangential and Wall furnaces is LNB \& SNCR. The default for a Cyclone furnace is Gas Reburn.

\section{SNCR Reagent Type}

Only displayed when SNCR or LNB \& SNCR have been selected in the In-Furnace Controls pull-down menu. Nitrogen-based reagent injection is used in an SNCR to reduce $\mathrm{NO}_{\mathrm{x}}$ in the presence of oxygen to form nitrogen and water vapor. The reagent choices are:

Urea - Urea $\left(\mathrm{CO}\left(\mathrm{NH}_{2}\right)_{2}\right)$ is typically diluted to a $15-20 \%$ concentration with water. Urea has the advantage of safety and ease of storage and handling. Urea is the default reagent used in the IECM.

Ammonia - Ammonia can be supplied in two forms: anhydrous $\left(\mathrm{NH}_{3}\right)$ and aqueous $\left(\mathrm{NH}_{4} \mathrm{OH}\right)$. The IECM considers only anhydrous ammonia. Ammonia may be an advantage when using an SNCR in conjunction with an SCR system.

\section{In-Furnace Controls Performance Input}

This screen is only available for the Combustion (Boiler) plant type. 


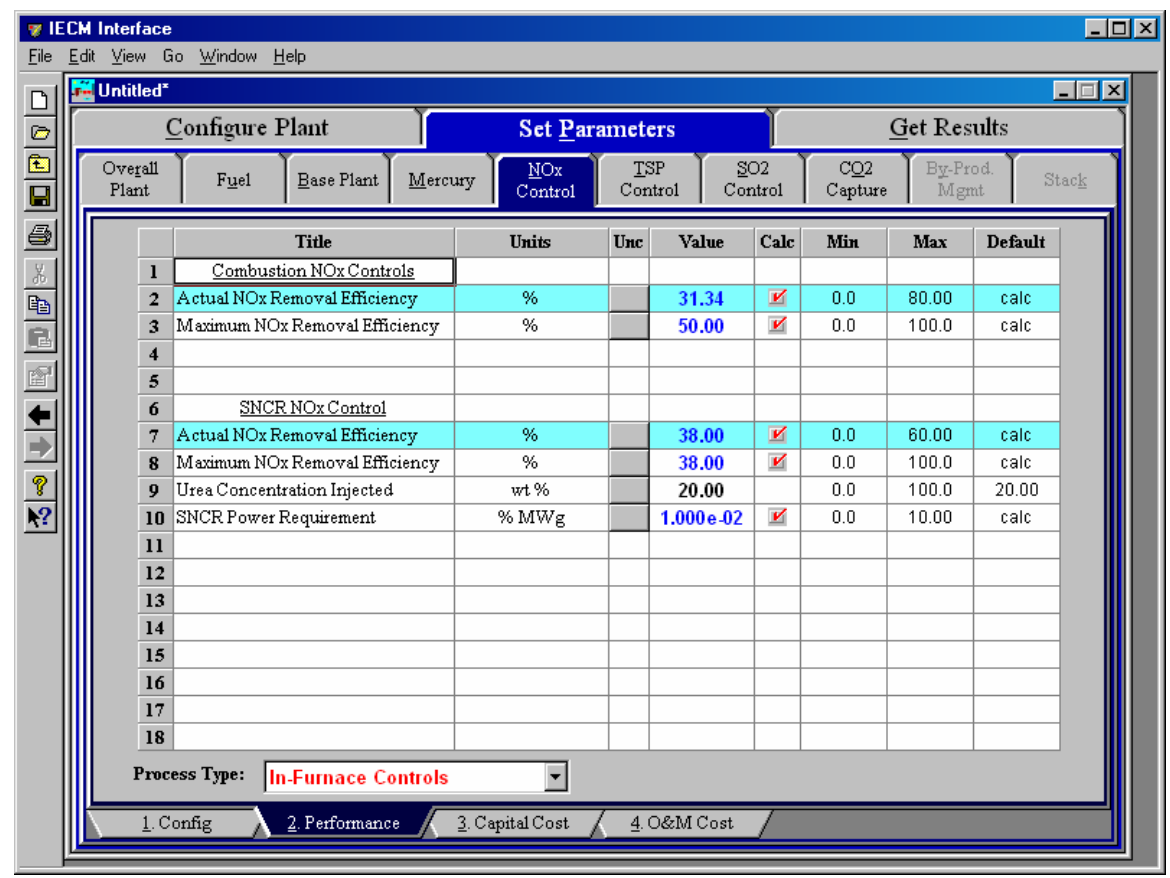

In - Furnace Controls - Performance input screen.

Inputs for the performance of the In-Furnace Controls $\mathrm{NO}_{\mathrm{x}}$ control technology are entered on the on the Performance input screen. Combustion NOx Controls These inputs will display if any combustion technology is used in the option selected in the In-Furnace Controls pull-down menu. This includes the LNB, LNB + OFA, Gas Reburn, and the LNB + SNCR options.

\section{Combustion $\mathrm{NO}_{x}$ Controls}

Actual NOx Removal Efficiency: This is the $\mathrm{NO}_{\mathrm{x}}$ removal efficiency of the LNB, LNB + OFA, and Gas Reburn options, and the LNB removal portion of the LNB + SNCR option. The percent reduction of $\mathrm{NO}_{\mathrm{x}}$ is calculated by comparing the actual $\mathrm{NO}_{\mathrm{x}}$ emission to the uncontrolled $\mathrm{NO}_{\mathrm{x}}$ emission. The removal is a function of the InFurnace Control type selected in the pull-down menu, the boiler type, and the maximum removal efficiency (below). Note: that the removal is not a function of the $\mathrm{NO}_{\mathrm{x}}$ emission constraint. This input is highlighted in blue.

Maximum NOx Removal Efficiency: The maximum removal efficiency of $\mathrm{NO}_{\mathrm{x}}$ sets the upper bound for the actual $\mathrm{NO}_{\mathrm{x}}$ removal efficiency (above). The maximum removal is a function of the InFurnace control type and the boiler type.

Natural Gas Heat Input: This input will only display if Gas Reburn is selected in the In-Furnace Controls pull-down menu. The flow rate of natural gas injected is determined by this input on a Btu heat input basis.

\section{SNCR NO Control $_{x}$}

These inputs will only display if SNCR or LNB \& SNCR is selected in the InFurnace Controls pull-down menu. 
Actual NOx Removal Efficiency: The actual $\mathrm{NO}_{\mathrm{x}}$ removal efficiency is a function of the maximum $\mathrm{NO}_{\mathrm{x}}$ removal efficiency (below) and the $\mathrm{NO}_{\mathrm{x}}$ emission constraint. This input is highlighted in blue.

Maximum NOx Removal Efficiency: The maximum removal efficiency is calculated as a function of the gross electrical output. Because of difficulty mixing the reagent in the flue gas for larger boilers, the maximum efficiency decreases with increasing plant size.

Urea Concentration Injected: Urea is typically injected as a liquid diluted by water. This parameter defines the amount of water used to dilute the urea prior to injection.

SNCR Power Requirement: As mentioned above, the power requirement for the SNCR is a function of gross electrical output of the power plant. The value is determined by the need for tank heaters when urea reagent is used.

\section{In-Furnace Controls Capital Cost}

This screen is only available for the Combustion (Boiler) plant type. Unlike most capital cost input screens, these technologies costs are provided as total capital costs on an energy input basis.

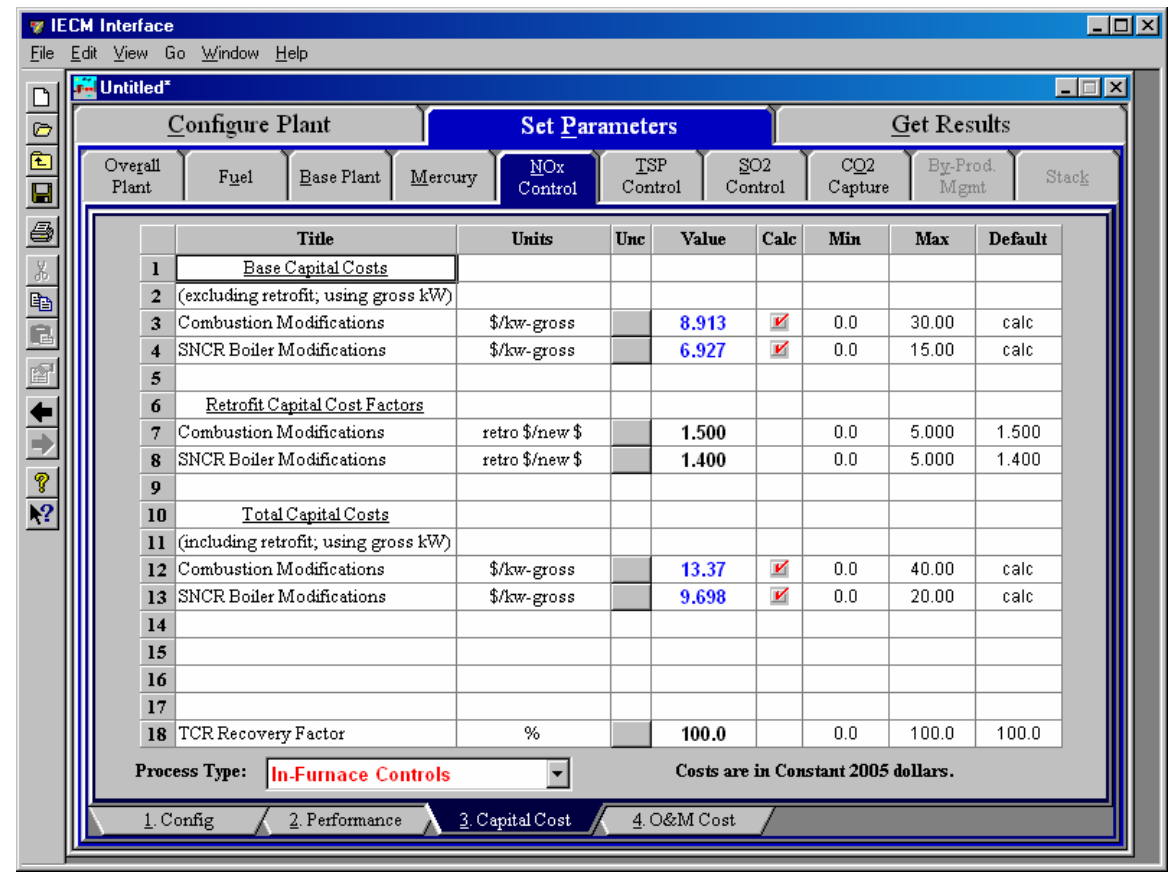

In-Furnace Controls - Capital Cost input screen.

The Combustion Modifications inputs will not display if SNCR is selected in the In-Furnace Controls pull-down menu. The SNCR Boiler Modifications inputs will only display if SNCR or LNB \& SNCR is selected

\section{Base Capital Costs}

The base capital costs (excluding retrofit, using gross KW) specify the total base capital costs, not considering any retrofit factors. No detailed information about 
direct or indirect costs is given. The costs are given as a total in units of dollars per gross kilowatt.

Combustion Modifications: This is the base capital cost of the LNB, LNB + OFA, and Gas Reburn options, and the LNB removal portion of the LNB + SNCR option. This parameter is not shown when one of these options is not selected.

SNCR Boiler Modifications: This specifies the total base capital cost for the SNCR boiler $\mathrm{NO}_{\mathrm{x}}$ removal equipment alone. This parameter is not shown when one of the SNCR options is not selected.

\section{Retrofit Capital Cost Factors}

Retrofit cost factors allow you to differentiate between the base cost of purchasing the capital equipment and the actual cost incurred. These factors vary from unit to unit.

Combustion Modifications: This is the retrofit cost factor for the LNB, LNB + OFA, and Gas Reburn options, and the LNB removal portion of the LNB + SNCR option. This parameter is not shown when one of these options is not selected

SNCR Boiler Modifications: This is the retrofit cost factor for the SNCR option alone. This parameter is not shown when one of the SNCR options is not selected

\section{Total Capital Costs:}

Combustion Modifications: This is the total capital cost of the LNB, LNB + OFA, and Gas Reburn options, and the LNB removal portion of the LNB + SNCR option. This combines the base capital cost with the retrofit cost factor. This parameter is not shown when one of these options is not selected.

SNCR Boiler Modifications: This specifies the total capital cost for the SNCR boiler $\mathrm{NO}_{\mathrm{x}}$ removal equipment alone. This parameter is not shown when one of the SNCR options is not selected

TCR Recovery Factor: The actual total capital required (TCR) as a percent of the TCR in a new power plant. This value is $100 \%$ for a new installation and may be set as low as $0 \%$ for in-furnace controls that has been paid off.

\section{In-Furnace Controls O\&M Cost}

This screen is only available for the Combustion (Boiler) plant type. 


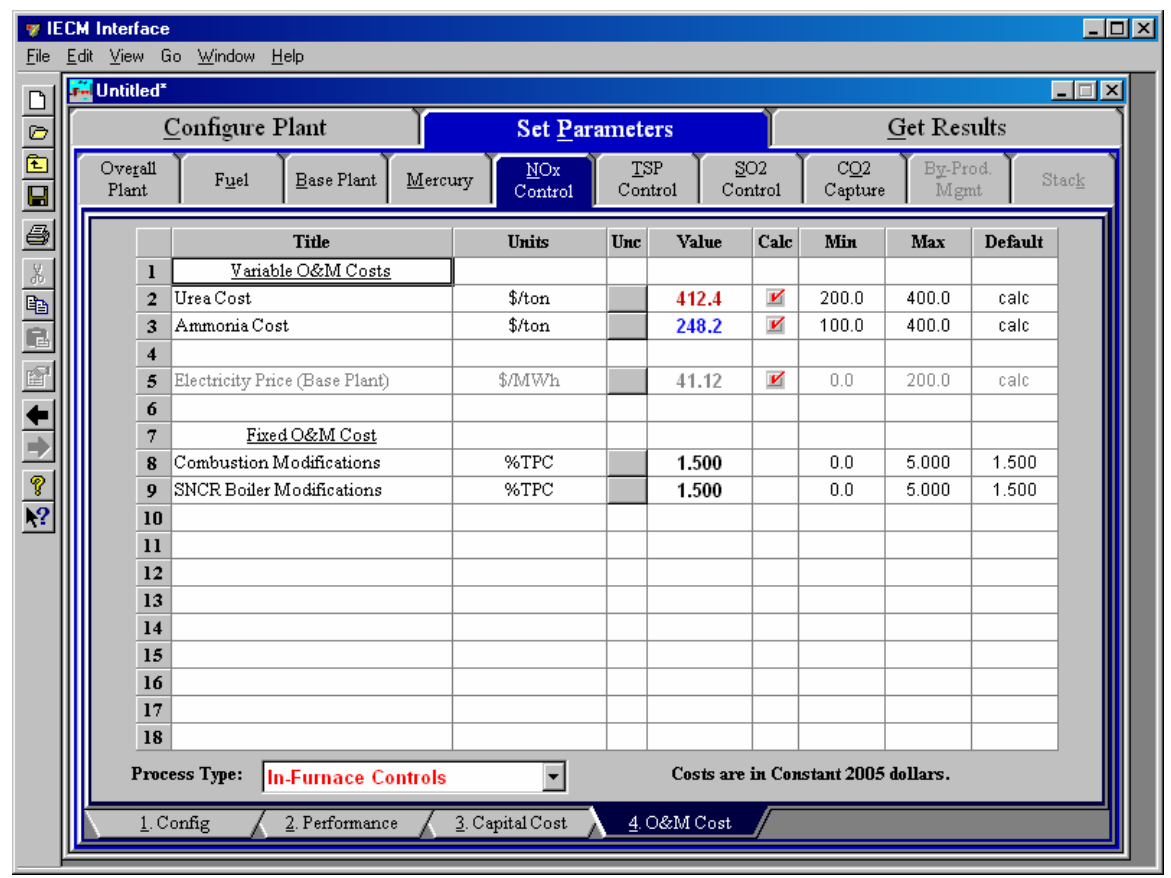

In-Furnace Controls - O\&M Cost input screen.

O\&M costs are typically expressed on an average annual basis and are provided in either constant or current dollars for a specified year, as shown on the bottom of the screen. Each parameter is described briefly below.

\section{Variable O\&M Costs}

Urea Cost: This is the cost of urea used for any of the SNCR options. This input will only display if SNCR or LNB \& SNCR is selected in the InFurnace Controls pull-down menu

Ammonia Cost: This is the cost of ammonia used for any of the SNCR options. This input will only display if SNCR or LNB \& SNCR is selected in the In-Furnace Controls pull-down menu

Natural Gas Cost: This is the cost of natural gas used for the Gas Reburn option. This input will only display if Gas Reburn is selected

Electricity Price (Base Plant): This is the price of electricity and is calculated as a function of the utility cost of the base plant, where the base plant is defined as combustion boiler and an air preheater.

\section{Fixed O\&M Cost}

Fixed O\&M costs are given as a total cost, rather than itemized costs broken down by individual maintenance and labor costs. The results are given as a percent of the total capital cost.

Combustion Modifications: This is the total fixed operating and maintenance cost for boiler $\mathrm{NO}_{\mathrm{x}}$ modifications made in the combustion zone (LNB, OFA, natural gas reburn). This parameter is not shown if one of these options is not selected. 
SNCR Boiler ModificationsVariable O\&M Costs: This is the total fixed O\&M cost for the SNCR equipment alone. This input is not shown if one of the SNCR options is not selected.

\section{In-Furnace Controls Diagram}

This screen is only available for the Combustion (Boiler) plant type.

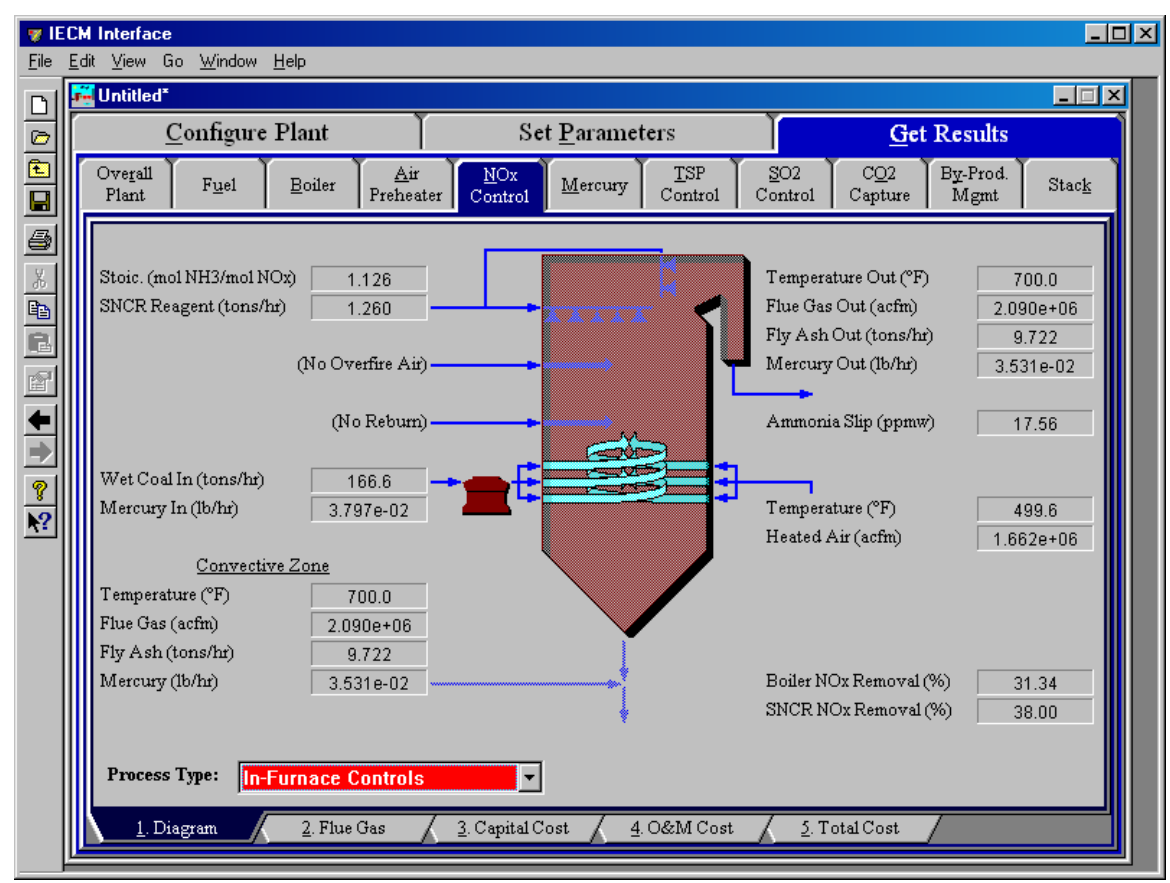

In-Furnace Controls - Diagram

The Diagram result screen displays an icon for the In-Furnace Controls $\mathrm{NO}_{\mathrm{x}}$ technology selected and values for major flows in and out of it.

\section{Fuel Entering Boiler}

Wet Coal In: Fuel flow rate into the boiler on a wet basis. Waste products removed prior to the burners are not considered here.

Mercury In: This is the mass flow rate of total mercury entering the boiler. The mass reflects the molecular weight of elemental mercury.

\section{Air Entering Boiler}

Temperature: Heated air temperature measured at the burners. This is generally determined by the combustion air temperature exiting the air preheater.

Heated Air: Volumetric flow rate of the air at the burners, based on the air temperature at the burners and atmospheric pressure. 


\section{Flue Gas Exiting Convective Zone}

This the area of the furnace between the combustion zone and the SNCR (if present). Changes in the flue gas after combustion due to in-furnace combustion $\mathrm{NO}_{\mathrm{x}}$ controls are reflected here.

Temperature: Temperature of the flue gas exiting the convective zone.

Flue Gas: Volumetric flow rate of the flue gas exiting the convective zone, based on the temperature exiting the convective zone and atmospheric pressure.

Fly Ash: Total solids mass flow rate in the flue gas exiting the convective zone. This includes ash, unburned carbon and unburned sulfur.

Mercury: Total mass of mercury in the flue gas exiting the convective zone. The value is a sum of all the forms of mercury (elemental, oxidized, and particulate).

\section{Flue Gas Exiting the Economizer}

Temperature Out: Temperature of the flue gas at the exit of the economizer.

Flue Gas Out: Volumetric flow rate of the flue gas at the exit of the economizer, based on the temperature at the exit of the economizer and atmospheric pressure.

Fly Ash Out: Total solids mass flow rate in the flue gas at the exit of the economizer. This includes ash, unburned carbon and unburned sulfur.

Mercury Out: Total mass of mercury in the flue gas exiting the economizer. The value is a sum of all the forms of mercury (elemental, oxidized, and particulate).

\section{Gas Reburn}

Reburn Gas: This is the flow rate of natural gas into the boiler. This result will only display if Gas Reburn is selected in the In-Furnace Controls pull-down menu

\section{SNCR}

The SNCR is located in the upper portion of the boiler. Several parameters are reported as a summary. These results will only display if SNCR or LNB \& SNCR is selected in the In-Furnace Controls pull-down menu in the Set Inputs part of the interface.

Stoic.: This is the actual reagent stoichiometry used in the SNCR. Note that urea has double the moles of nitrogen relative to that of ammonia.

SNCR Reagent: This is the mass flow rate of reagent (urea or ammonia) injected by the SNCR into the boiler. Note that water used to dilute the urea is included in this flow rate.

\section{NO $\mathrm{O}_{\mathrm{x}}$ Removal Performance}

Boiler NOx Removal: This is the composite removal efficiency of the boiler $\mathrm{NO}_{\mathrm{x}}$ technologies associated with low $\mathrm{NO}_{\mathrm{x}}$ burners, overfire air, 
and reburn. It does not include the removal efficiency of an SNCR

system.

SNCR NOx Removal: This is the removal efficiency of the SNCR system alone. It does not take into consideration any other $\mathrm{NO}_{\mathrm{x}}$ reduction prior to the SNCR.

\section{In-Furnace Controls Flue Gas Results}

This screen is only available for the Combustion (Boiler) plant type.

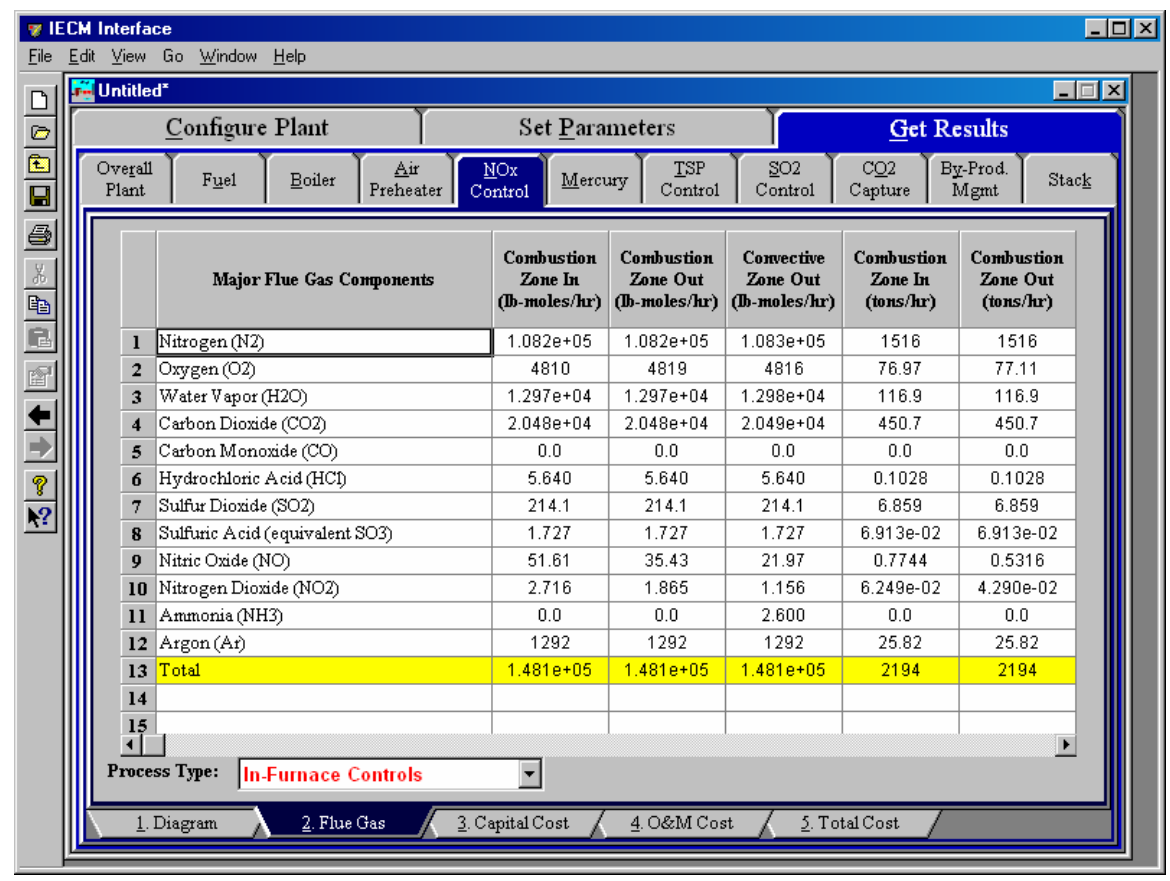

In-Furnace Controls - Flue Gas result screen.

The Flue Gas result screen for In-Furnace Controls displays a table of quantities of gas components entering and exiting the combustion zone. For each component, quantities are given in both moles and mass per hour. It also displays quantities of gas components exiting the convective zone in moles per hour. Each result is described briefly below.

\section{Major Flue Gas Components}

Nitrogen $\left(\mathrm{N}_{2}\right)$ : Total mass of nitrogen.

Oxygen $\left(\mathrm{O}_{2}\right)$ : Total mass of oxygen.

Water Vapor $\left(\mathrm{H}_{2} \mathrm{O}\right)$ : Total mass of water vapor.

Carbon Dioxide $\left(\mathrm{CO}_{2}\right)$ : Total mass of carbon dioxide.

Carbon Monoxide (CO): Total mass of carbon monoxide.

Hydrochloric Acid $(\mathrm{HCl})$ : Total mass of hydrochloric acid.

Sulfur Dioxide $\left(\mathrm{SO}_{2}\right)$ : Total mass of sulfur dioxide.

Sulfuric Acid (equivalent $\mathrm{SO}_{3}$ ): Total mass of sulfuric acid. 
Nitric Oxide (NO): Total mass of nitric oxide.

Nitrogen Dioxide $\left(\mathrm{NO}_{2}\right)$ : Total mass of nitrogen dioxide.

Ammonia $\left(\mathrm{NH}_{3}\right)$ : Total mass of ammonia.

Argon (Ar): Total mass of argon

Total: Total of the individual components listed above. This item is highlighted in yellow.

\section{In-Furnace Controls Capital Cost Results}

This screen is only available for the Combustion (Boiler) plant type.

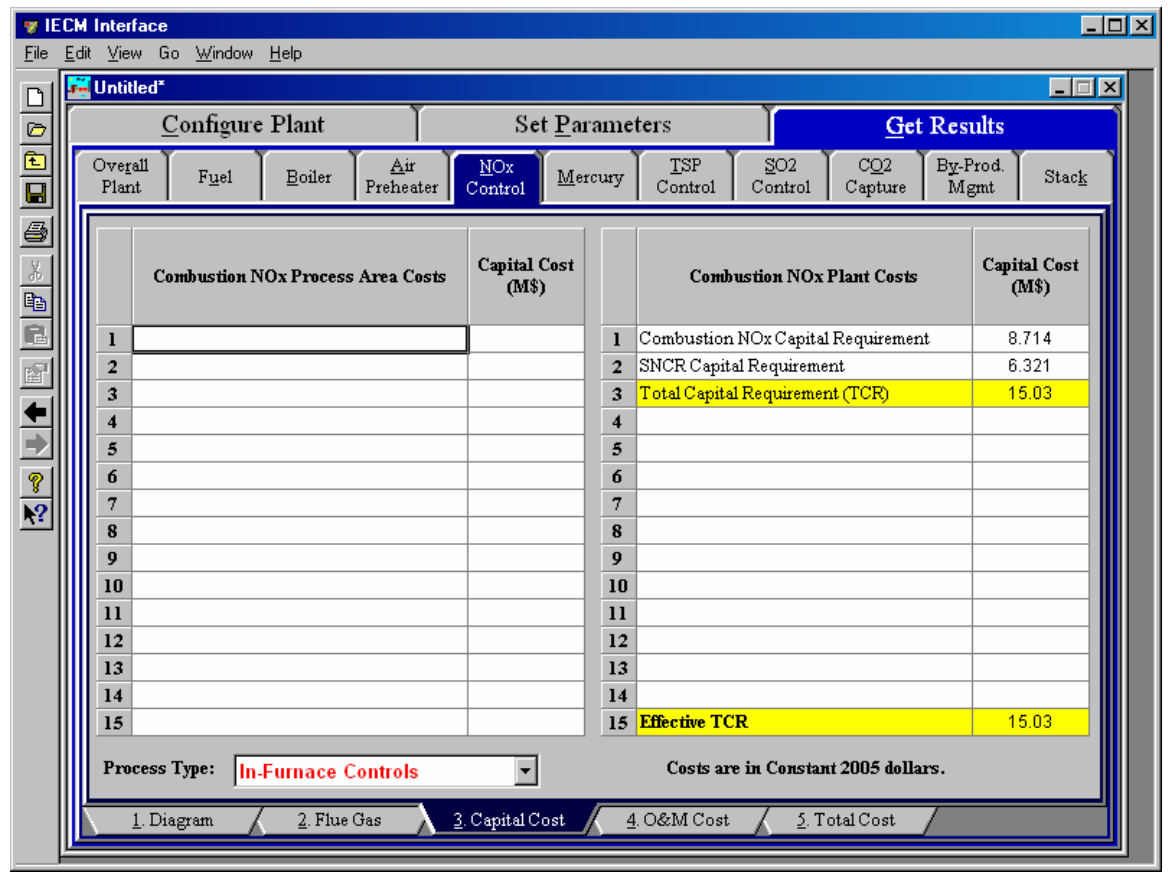

In-Furnace Controls - Capital Cost result screen.

The Capital Cost result screen displays tables for the direct and indirect capital costs related to the In-Furnace Controls $\mathrm{NO}_{\mathrm{x}}$ control technology. Capital costs are typically expressed in either constant or current dollars for a specified year, as shown on the bottom of the screen.

\section{Total Capital Costs}

Combustion NOx Capital Requirement: The total capital costs, including retrofit costs, for the LNB, OFA, and gas reburn technologies are included here. A zero is displayed when none of these technologies are installed.

SNCR Capital Requirement: The total capital costs, including retrofit costs, for the SNCR technology is included here. A zero is displayed when an SNCR is not installed.

Total Capital Requirement: Sum of the above.

Effective TCR: The TCR of the retrofit $\mathrm{NO}_{\mathrm{x}}$ controls that is used in determining the total power plant cost. The effective TCR is determined by the "TCR Recovery Factor" for the hot-side SCR. 


\section{In-Furnace Controls O\&M Cost Results}

This screen is only available for the Combustion (Boiler) plant type.

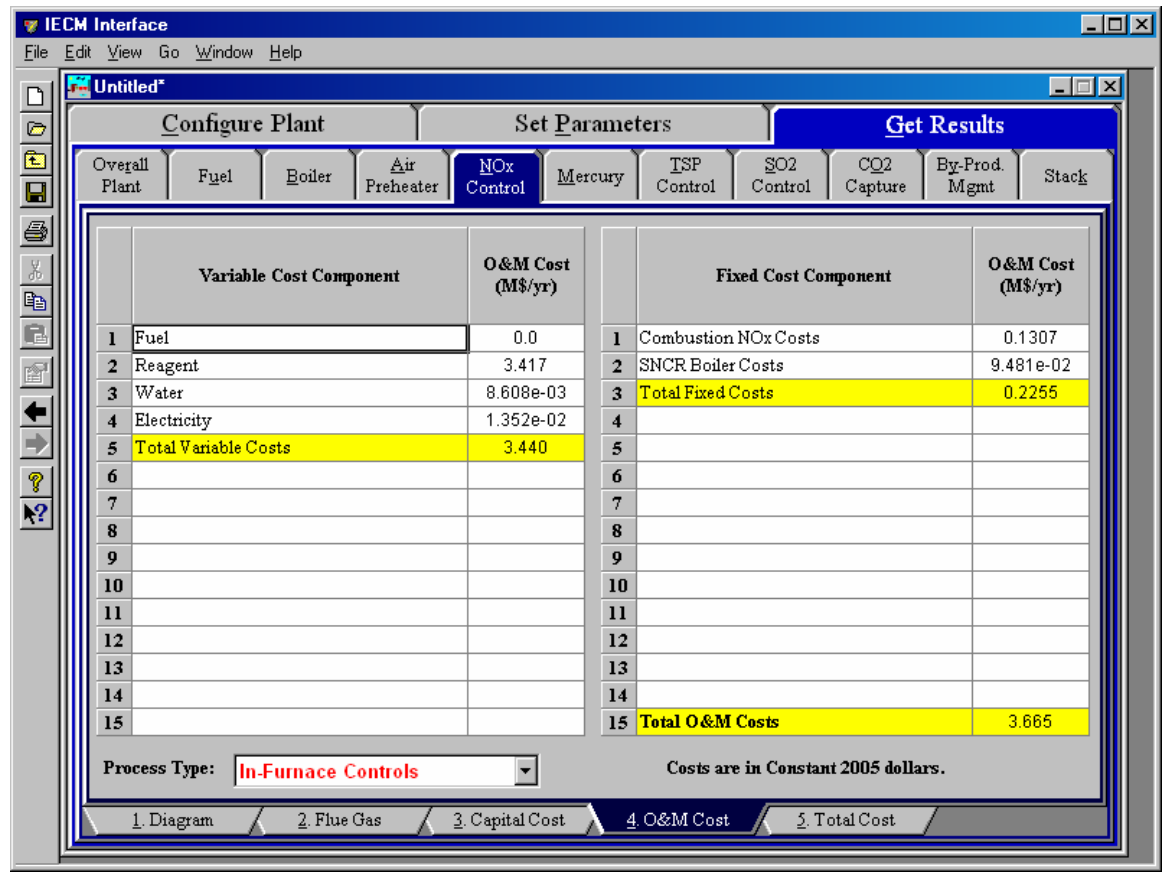

In-Furnace Controls- O\&M Cost result screen.

The O\&M Cost result screen displays tables for the variable and fixed operation and maintenance costs involved with the In-Furnace Controls $\mathrm{NO}_{\mathrm{x}}$ control technology. O\&M costs are typically expressed on an average annual basis and are provided in either constant or current dollars for a specified year, as shown on the bottom of the screen. Each result is described briefly below

\section{Variable Cost Components}

Variable operating costs and consumables are directly proportional to the amount of kilowatts produced and are referred to as incremental costs. All the costs are subject to inflation.

Fuel: The total fuel costs associated with gas reburn are included here.

Reagent: The total reagent costs (urea and ammonia) used for the SNCR system are included here.

Water: This is the cost of the water used to dilute the urea for the SNCR.

Power: This is the power used for the pumps to move reagents and water in the SNCR.

Total Variable Costs: This is the sum of the entire variable O\&M costs listed above. This result is highlighted in yellow. 


\section{Fixed Cost Components}

Fixed operating costs are essentially independent of actual capacity factor, number of hours of operation, or amount of kilowatts produced. All the costs are subject to inflation.

Combustion NOx Costs: This is the fixed O\&M costs associated with the LNB, OFA, and gas reburn systems.

SNCR Boiler Costs: This is the fixed O\&M costs associated with the SNCR system.

Total Fixed Costs: This is the sum of all the fixed O\&M costs listed above. This result is highlighted in yellow.

Total O\&M Costs: This is the sum of the total variable and total fixed O\&M costs. It is used to determine the base plant total revenue requirement. This result is highlighted in yellow.

\section{In-Furnace Controls Total Cost Results}

This screen is only available for the Combustion (Boiler) plant type.

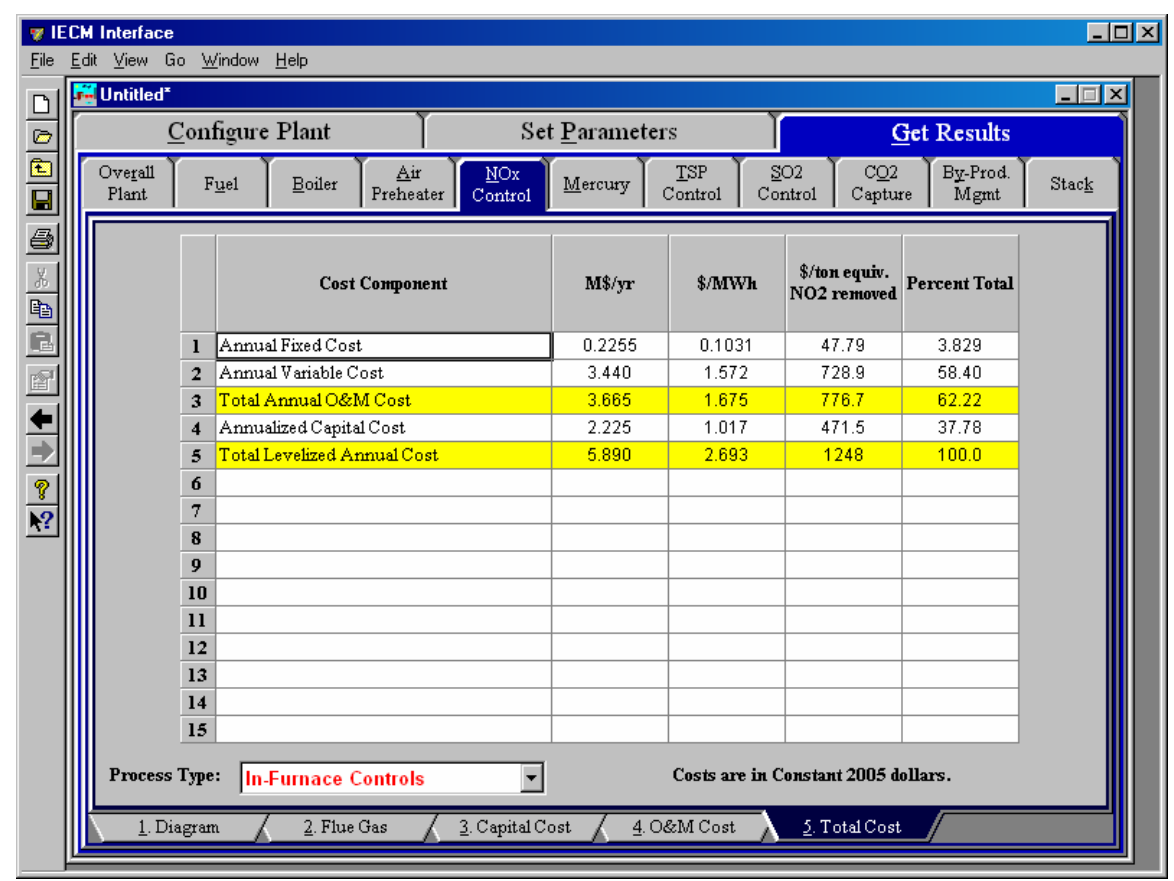

In-Furnace Controls - Total Cost result screen

\section{Cost Component}

The Total Cost result screen displays a table which totals the annual fixed, variable, operations and maintenance, and capital costs associated with the In-Furnace Controls $\mathrm{NO}_{\mathrm{x}}$ Control technology. These costs are typically expressed in either constant or current dollars for a specified year, as shown on the bottom of the screen. Each result is described briefly below. Note that all costs expressed in $\$$ /ton of $\mathrm{NO}_{2}$ removed assume tons of equivalent $\mathrm{NO}_{2}$. 
Annual Fixed Cost: The operating and maintenance fixed costs are given as an annual total. This number includes all maintenance materials and all labor costs.

Annual Variable Cost: The operating and maintenance variables costs are given as an annual total. This includes all reagent, chemical, steam, and power costs.

Total Annual O\&M Cost: This is the sum of the annual fixed and variable operating and maintenance costs above. This result is highlighted in yellow.

Annualized Capital Cost: This is the total capital cost expressed on an annualized basis, taking into consideration the levelized carrying charge factor, or fixed charge factor, over the entire book life.

Total Levelized Annual Cost: The total annual cost is the sum of the total annual O\&M cost and annualized capital cost items above. This result is highlighted in yellow. 


\section{Hot-Side SCR}

The NOx Control Technology Navigation Tab contains screens that address combustion or post-combustion air pollution technologies for Nitrogen Oxides in the Combustion (Boiler) plant type configurations.

If you have selected a Hot-Side SCR, there will be six input screens and therefore six Input Navigation Tabs. If you have selected In-Furnace Controls, there will be four input screens and therefore four Input Navigation Tabs.

These input screens are only available if a Hot-Side SCR has been selected under Post-Combustion Controls in the Configure Plant program area.

If you have selected both In-Furnace Controls and a Hot-Side SCR for $\mathrm{NO}_{\mathrm{x}}$ control, you may switch between the two sets of screens that configure these technologies by using the Process Type pull-down menu at the bottom of the screen.

\begin{tabular}{|l|l||}
\hline Process Type: & Hot-Side SCR \\
& In-Furnace Controls \\
\hline \hline & Hot-Side SCR \\
\hline
\end{tabular}

The Process Type pull-down menu

\section{Hot-Side SCR Configuration}

This screen is only available for the Combustion (Boiler) plant type. 


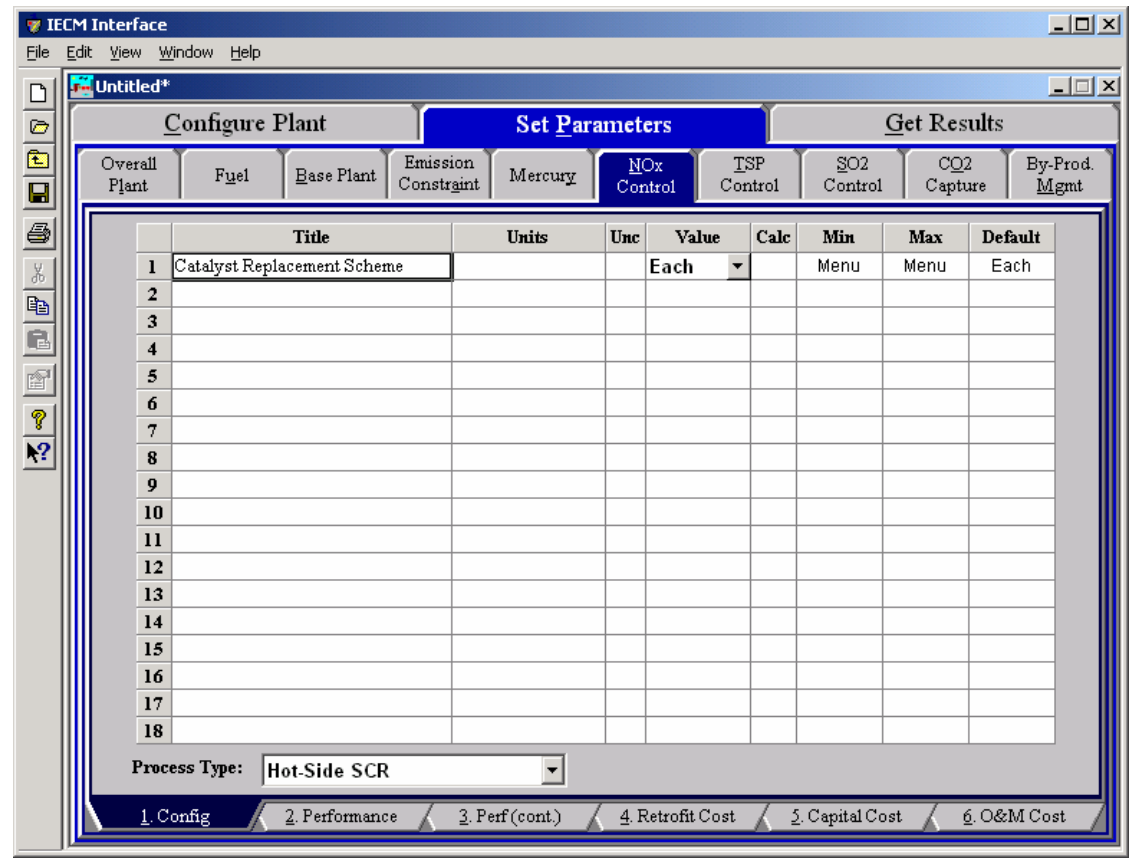

Hot-Side SCR - Config. input screen.

Inputs for configuring the Hot-Side SCR $\mathrm{NO}_{\mathrm{x}}$ Control technology are entered on the Config input screen. Each parameter is described briefly below.

Catalyst Replacement Scheme: Catalyst is installed in the SCR as a series of layers. These activity or effectiveness of these layers decreases with time due to fouling and poisoning. The layers are replaced with clean layers on a regular basis in one of two ways: all at once or one layer at time (staggered). The selection of the replacement scheme involves trade-offs between capital and annual costs via the initial catalyst requirement and the replacement interval. More specifically:

- $\quad$ Each - Individual Layers. Replacing individual layers sequentially, rather than simultaneously, increases the effective catalyst life for a given volume of catalyst, decreasing the replacement interval. This reduces the O\&M cost relative to simultaneous replacement.The default setting is Each.

- All - All Layers: Simultaneous replacement may lead to a smaller initial catalyst volume to achieve the same design activity as a sequential replacement scheme. This reduces the capital cost but increases the O\&M cost.

\section{Hot-Side SCR Performance Inputs}

This screen is only available for the Combustion (Boiler) plant type. 


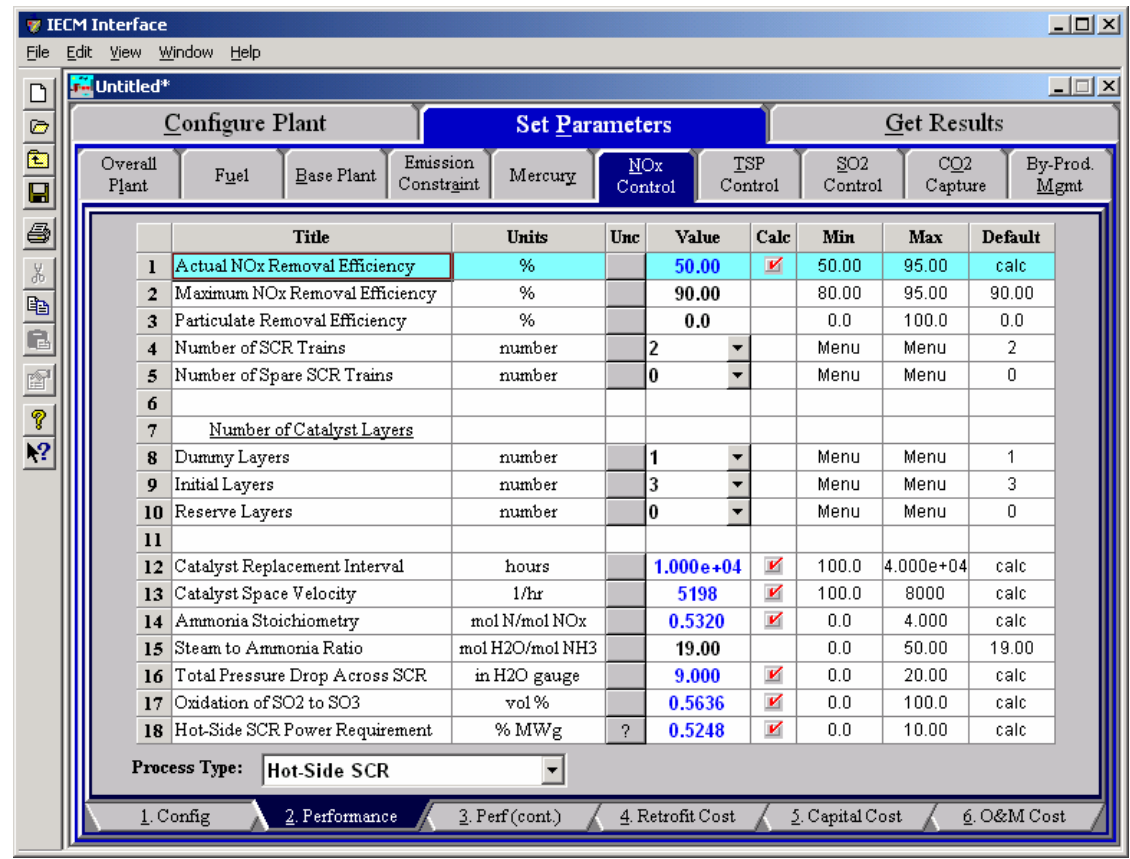

Hot-Side SCR - Performance input screen.

Inputs for the performance of the Hot-Side SCR $\mathrm{NO}_{\mathrm{x}}$ control technology are entered on the on the Performance input screen. Each parameter is described briefly below.

Actual NOx Removal Efficiency: The actual removal efficiency is dependent on the minimum and maximum removal efficiencies of the SCR and the emission constraint for $\mathrm{NO}_{\mathrm{x}}$. The model assumes a minimum removal of $50 \%$. The actual removal is set to match the constraint, if feasible. It is possible that the SCR may under or over comply with the emission constraint. This input is highlighted in blue.

Maximum NOx Removal Efficiency: This parameter specifies the maximum efficiency possible for the absorber on an annual average basis. The value is used as a limit in calculating the actual $\mathrm{NO}_{\mathrm{x}}$ removal efficiency for compliance.

Particulate Removal Efficiency: The ash in the high dust gas entering the SCR collects on the catalyst layers and causes fouling. Ash removal is not a design goal; rather, it is a reality which is taken into consideration by this parameter.

Number of SCR Trains: This is the total number of SCR equipment trains. It is used primarily to calculate the capital costs. The value must be an integer.

Number of Spare SCR Trains: This is the total number of spare SCR equipment trains. It is used primarily to calculate capital costs. The value must be an integer.

Number of Catalyst Layers: The total number of catalyst layers is a sum of the dummy, initial and spares used. All catalyst layer types are of equal dimensions, geometry, and catalyst formulation. You specify each value; the value must be an integer. The catalyst layer types and quantities are combined with pressure drop information to determine the auxiliary power requirements and the capital cost of the SCR 
technology. A layer may be interpreted as either a full layer (e.g., typically 1 meter deep), or a half layer (e.g., typically 0.5 meters deep) to represent alternative SCR catalyst replacement schemes. There is a limit of 8 total initial and reserve layers.

- Dummy Layers: This is the number of dummy catalyst layers. The value must be an integer. A dummy layer corrects the flow distribution. It is used to calculate the total pressure drop across the SCR and the auxiliary power requirements.

- Initial Layers: This is the number of initial active catalyst layers. The value must be an integer. Three layers are installed initially. It is used to calculate the total pressure drop across the SCR and the auxiliary power requirements.

- Reserve Layers: This is the number of reserve or extra catalyst layers. These are available for later catalyst additions. The value must be an integer. It is used to calculate the total pressure drop across the SCR and the auxiliary power requirements.

Catalyst Replacement Interval: This parameter calculates the operating hour interval between catalyst replacements. The interval is determined by the decision to replace all at once or each of them separately after each interval. Currently, the model is not set up to replace two half layers simultaneously.

Catalyst Space Velocity: The calculated space velocity is determined by several factors, including many of the reference parameters in the next Section. The space velocity is used to determine the catalyst volume required.

Ammonia Stoichiometry: This is the molar stoichiometry ratio of ammonia to $\mathrm{NO}_{\mathrm{x}}$ entering the SCR device. The calculated quantity is based on an assumed $\mathrm{NO}_{\mathrm{x}}$ removal reaction stoichiometry of 1:1 for both $\mathrm{NO}$ and $\mathrm{NO}_{2}$, and a specified ammonia slip. It affects the amount of ammonia used and the amount of $\mathrm{NO}_{\mathrm{x}}$ converted to moisture.

Steam to Ammonia Ratio: The molar ratio of steam to ammonia is used to determine the amount of steam injected to vaporize the ammonia. The value assumes the steam is saturated at 450 degrees Fahrenheit and the ammonia is diluted to 5 volume percent of the injected gas.

Total Pressure Drop Across SCR: The total is determined from the individual pressure drops due to air preheater deposits, the active catalyst layers, the dummy catalyst layers, the ammonia injection system and the duct work. It is used to calculate the total pressure drop across the SCR and the auxiliary power requirements.

Oxidation of $\mathrm{SO}_{2}$ to $\mathrm{SO}_{3}$ : The oxidation rate is calculated for a high sulfur catalyst and affects the flue gas composition. It uses the space velocity and the inlet temperature. The $\mathrm{SO}_{3}$ produced acts as an ashconditioning agent if an ESP is used downstream.

Hot-Side SCR Power Requirement: The default calculation of auxiliary power is based on the additional pressure drop, electricity to operate pumps and compressors, and equivalent energy for steam consumed. It is expressed as a percent of the gross plant capacity. 


\section{Hot-Side SCR Performance (Continued)}

This screen is only available for the Combustion (Boiler) plant type.

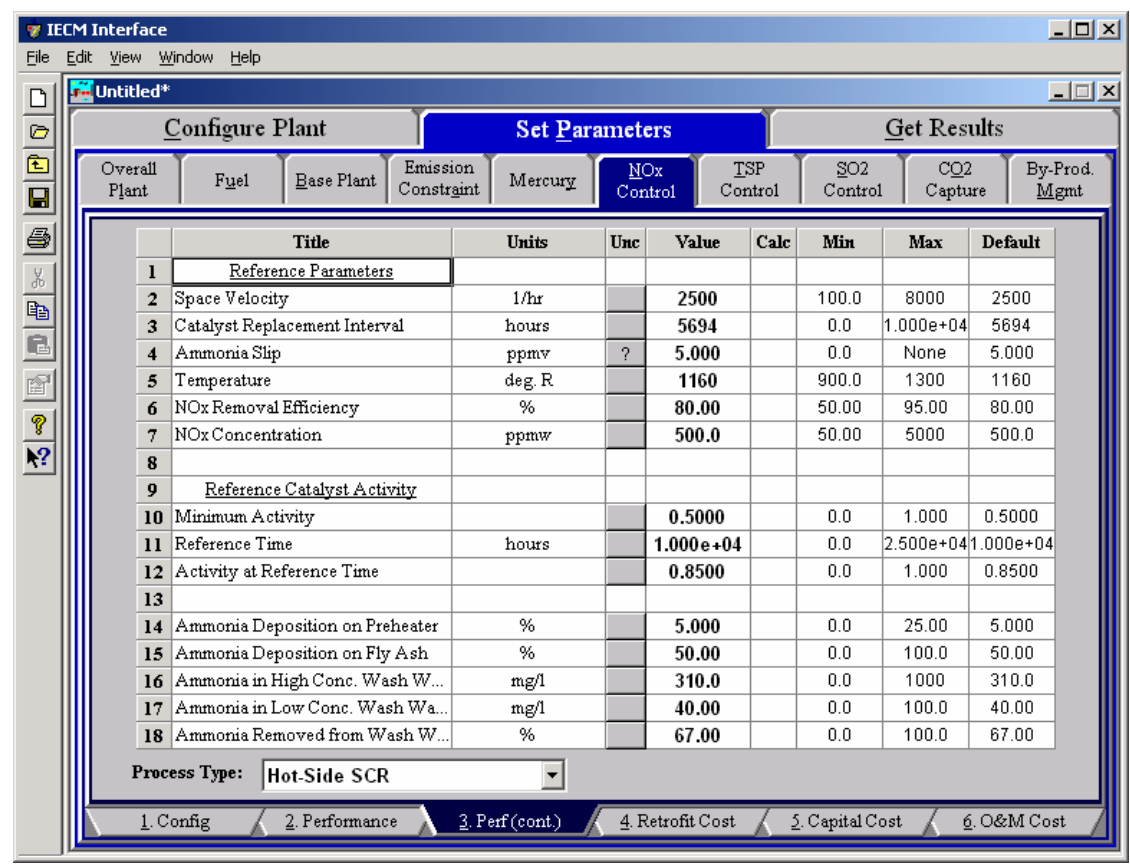

Hot-Side SCR - Perf.(cont.) input screen

The Hot-Side SCR system has additional inputs for performance entered on the Perf (Cont.) input screen. Many of the calculated quantities on the Performance screen are determined by the reference parameters described below.

\section{Reference Parameters}

The first set of reference parameters is primarily used to determine the actual space velocity. The values are used with actual operating conditions through a series of correction factors in the IECM. If you set the actual space velocity displayed on the Performance screen, this set of input parameters is not used by the IECM and does not have to be set.

Space Velocity: This is the reference space velocity for a high dust system. It is used to calculate the actual space velocity.

Catalyst Replacement Interval: This is the reference operating life in hours associated with the reference space velocity for the high dust catalyst. It is used to calculate the actual space velocity.

Ammonia Slip: Ammonia slip accounts for the ammonia passing through the reactor unchanged and further downstream. The value is based on an 80 percent or lower $\mathrm{NO}_{\mathrm{x}}$ removal efficiency. It is used in calculating the ammonia stoichiometry and actual space velocity.

Temperature: This is the operating temperature associated with the reference space velocity. It is used to determine the actual space velocity.

$\mathbf{N O}_{\mathrm{x}}$ Removal Efficiency: This is the $\mathrm{NO}_{\mathrm{x}}$ removal efficiency associated with the reference design specifications for the SCR system. It is used to determine the actual space velocity. 
$\mathrm{NO}_{\mathrm{x}}$ Concentration: This is the inlet $\mathrm{NO}_{\mathrm{x}}$ concentration associated with the reference design specifications for the SCR system. It is used to determine the actual space velocity

\section{Reference Catalyst Activity}

Catalyst activity decreases with operating time due to plugging and catalyst poisoning. The loss is a complex function of the catalyst formulation and geometry, the operating conditions associated with the flue gas, including temperature and composition, and the loading and composition of the fly ash. This complex function is represented by an exponential decay formula in the IECM. The following parameters are used to determine the reference catalyst activity, assuming the initial activity has a value of unity:

Minimum Activity: The minimum activity is a lower limit for catalyst activity decay. The actual activity approaches this value over a long period of time.

Reference Time: This is the time that corresponds to a particular activity known for the catalyst. It is used to determine a decay rate constant.

Activity at Reference Time: A second activity reference point is needed to determine the activity decay rate. The activity should correspond to the reference time specified. It is used to determine a decay rate constant.

Ammonia Deposition on Preheater: This is the percent of the ammonia slip that is deposited as ammonium salts in the air preheater. It is treated like a partition coefficient.

\section{Ammonia Parameters}

Ammonia Deposition on Fly Ash: This is the percent of the ammonia slip that is absorbed onto the fly ash. It is treated like a partition coefficient. This is important for high dust systems.

Ammonia in High Conc. Wash Water: The ammonia that deposits in the air preheater is periodically removed by washing. It is initially highly concentrated and requires denitrification pretreatment prior to regular treatment. This is the average concentration in that stream.

Ammonia in Low Conc. Wash Water: The ammonia that deposits in the air preheater is periodically removed by washing. The concentration is initially high, but gradually decreases. This is the average concentration of the low concentration stream.

Ammonia Removed from Wash Water: The ammonia that deposits in the air preheater is periodically removed by washing. This is the average amount of ammonia removed from the high and low concentrated streams.

\section{Hot-Side SCR Retrofit Cost}

This screen is only available for the Combustion (Boiler) plant type. 


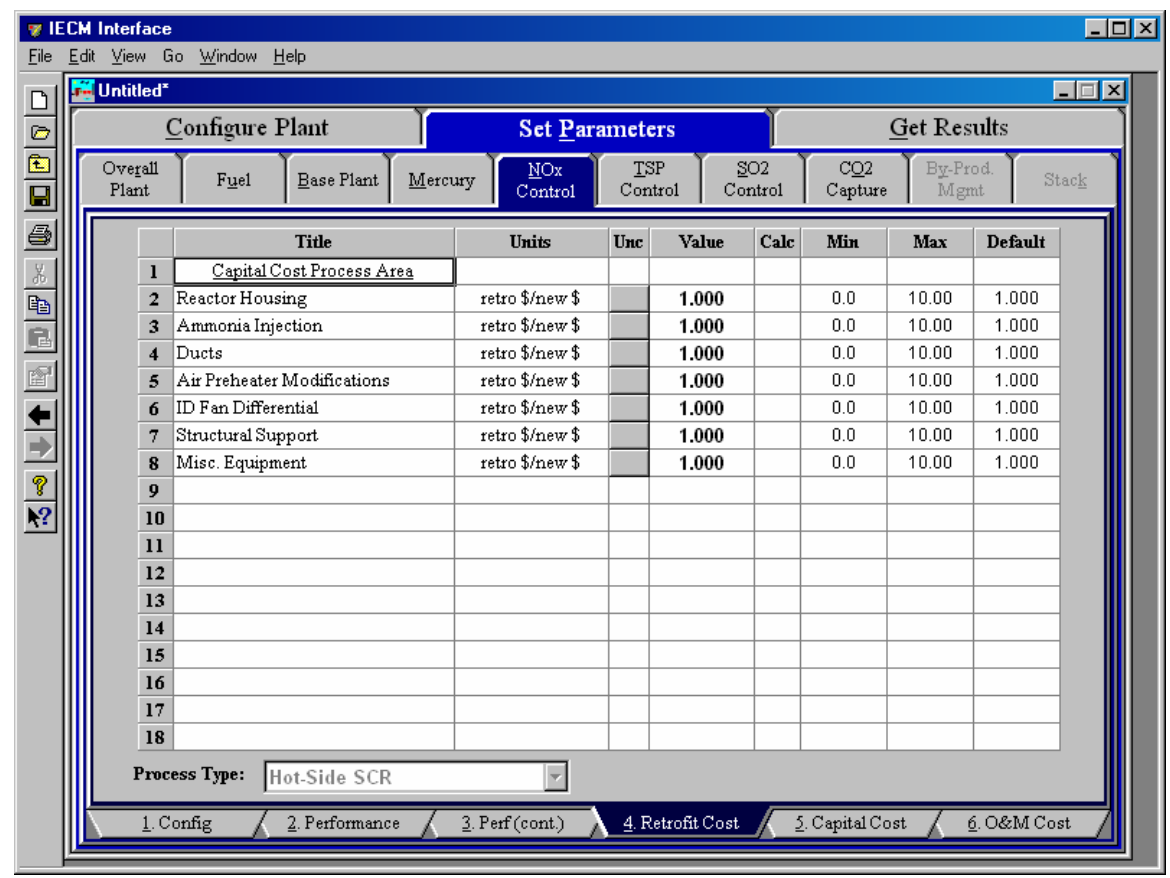

Hot-Side SCR - Retrofit Cost input screen.

The Hot-Side SCR system has inputs for the capital costs of modifications to process areas necessary to implement the technology entered on the Retrofit Cost input screen.

The retrofit cost factor of each process is a multiplicative cost adjustment, which considers the cost of retrofitted capital equipment relative to similar equipment installed in a new plant. These factors affect the capital costs directly and the operating and maintenance costs indirectly.

Direct capital costs for each process area are calculated in the IECM. These calculations are reduced form equations derived from more sophisticated models and reports. The sum of the direct capital costs associated with each process area is defined as the process facilities capital (PFC). The retrofit cost factor provided for each of the process areas can be used as a tool for adjusting the anticipated costs and uncertainties across the process area separate from the other areas.

Uncertainty can be applied to the retrofit cost factor for each process area in each technology. Thus, uncertainty can be applied as a general factor across an entire process area, rather than as a specific uncertainty for the particular cost on the capital or O\&M input screens. Any uncertainty applied to a process area through the retrofit cost factor compounds any uncertainties specified later in the capital and O\&M cost input parameter screens. Each parameter is described briefly below.

\section{Capital Cost Process Area}

Reactor Housing: The reactor housing costs include carbon steel reactor vessel with six inches of mineral wool insulation, vessel internals and supports, steam sootblowers, reactor crane and hoist, installation, labor, foundations, structures, piping, and electrical equipment.

Ammonia Injection: The ammonia unloading, storage, and supply system includes a storage vessel with a seven day capacity, an ammonia 
vaporizer, mixer, injection grid, ductwork, dampers, and a truck unloading station.

Ducts: The ductwork includes economizer bypass and outlet ducts, SCR inlet and outlet ducts, SCR and economizer control dampers, air preheater inlet plenum, various expansion joints in the ductwork, and air preheater cross-over ducting.

Air Preheater Modifications: Thicker and smoother material is used for the heat transfer surfaces in the preheater. A larger motor is provided for the heat exchanger. High pressure steam soot blowers and water wash spray nozzles are also added.

ID Fan Differential: The ID fans must be sized to deal with the increased flue gas pressure drop resulting from the additional ductwork and the SCR reactor.

Structural Support: The costs of this area are related primarily to the structural support required for the SCR reactor housing, ductwork, and air preheater.

Misc. Equipment: This area includes the capital costs incurred for ash handling addition, water treatment addition, and flow modeling for a hot-side SCR system.

\section{Hot-Side SCR Capital Cost Inputs}

This screen is only available for the Combustion (Boiler) plant type.

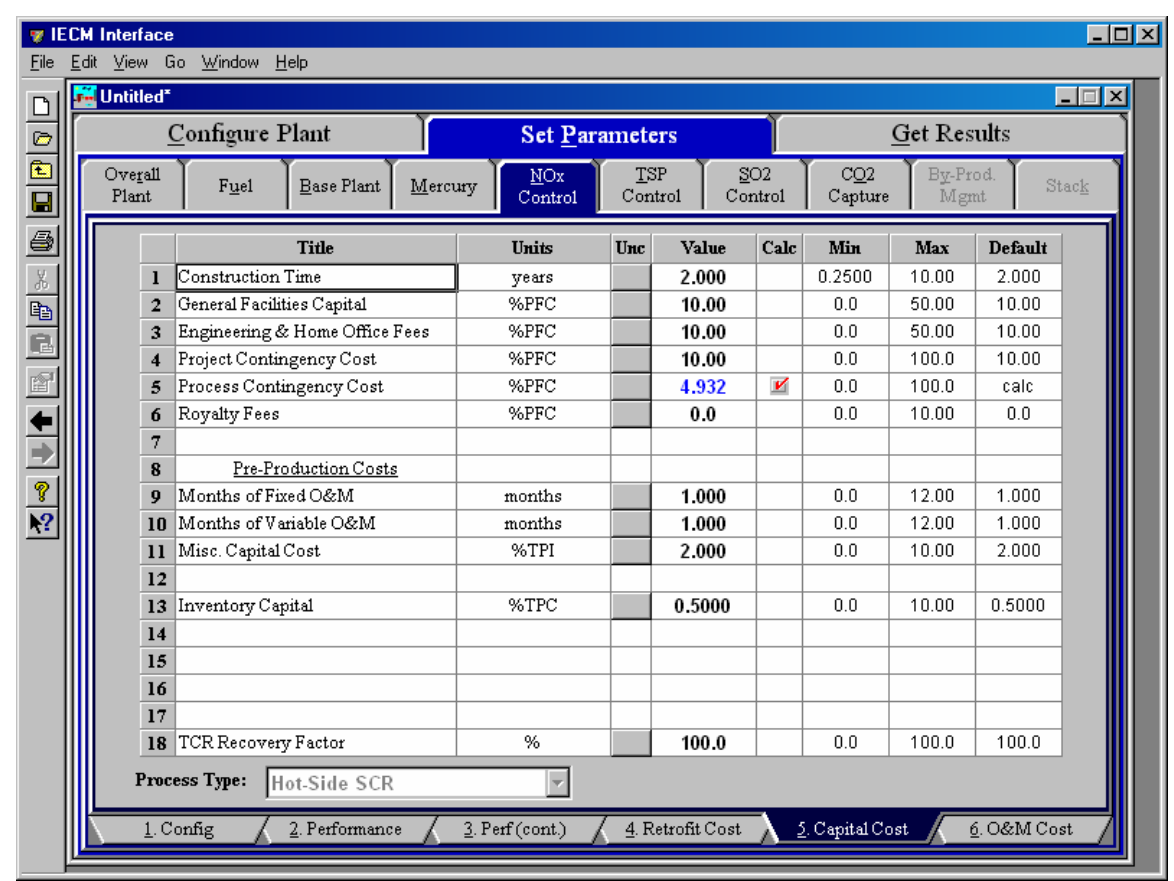

Hot-Side SCR - Capital Cost input screen.

Inputs for the capital costs of the Hot-Side SCR $\mathrm{NO}_{\mathrm{x}}$ control technology are entered on the Capital Cost screen for the Hot-Side SCR, and the Capital Cost input screen for In-Furnace Controls. Each parameter is described briefly below. 
Construction Time: This is the idealized construction period in years. It is used to determine the allowance for funds used during construction (AFUDC).

General Facilities Capital (GFC): The general facilities include construction costs of roads, office buildings, shops, laboratories, etc. Sales taxes and freight costs are included implicitly. The cost typically ranges from $5-20 \%$.

Engineering \& Home Office Fees: The engineering \& home office fees are a percent of total direct capital cost. This is an overhead fee paid to the architect/engineering company. These fees typically range from 7$15 \%$.

Project Contingency Cost: This is factor covering the cost of additional equipment or other costs resulting from a more detailed design. Higher contingency factors will be applied to simplified or preliminary designs and lower factors to detailed or finalized designs.

Process Contingency Cost: This quantifies the design uncertainty and cost of a commercial-scale system. This is generally applied on an areaby-area basis. Higher contingency factors are applied to new regeneration systems tested at a pilot plant and lower factors to full-size or commercial systems.

Royalty Fees: Royalty charges may apply to some portions of generating units incorporating new proprietary technologies.

Pre-Production Costs: These costs consider the operator training, equipment checkout, major changes in unit equipment, extra maintenance, and inefficient use of fuel or other materials during startup. These are typically applied to the O\&M costs over a specified period of time (months). The two time periods for fixed and variable O\&M costs are described below with the addition of a miscellaneous capital cost factor.

- Months of Fixed O\&M: Time period of fixed operating costs used for preproduction to cover training, testing, major changes in equipment, and inefficiencies in start-up. This includes operating, maintenance, administrative and support labor. It also considers maintenance materials.

- Months of Variable O\&M: Time period of variable operating costs used for preproduction to cover chemicals, water, consumables, and solid disposal charges in start-up, assuming $100 \%$ load. This excludes any fuels.

- Misc. Capital Costs: This is a percent of total plant investment (sum of TPC and AFUDC) to cover expected changes to equipment to bring the system up to full capacity.

Inventory Capital: Percent of the total direct capital for raw material supply based on $100 \%$ capacity during a 60 day period. These materials are considered storage. The inventory capital includes fuels, consumables, by-products, and spare parts. This is typically $0.5 \%$.

TCR Recovery Factor: The actual total capital required (TCR) as a percent of the TCR in a new power plant. This value is $100 \%$ for a new installation and may be set as low as $0 \%$ for a hot-side SCR that has been paid off. 


\section{Hot-Side SCR O\&M Cost Inputs}

This screen is only available for the Combustion (Boiler) plant type.

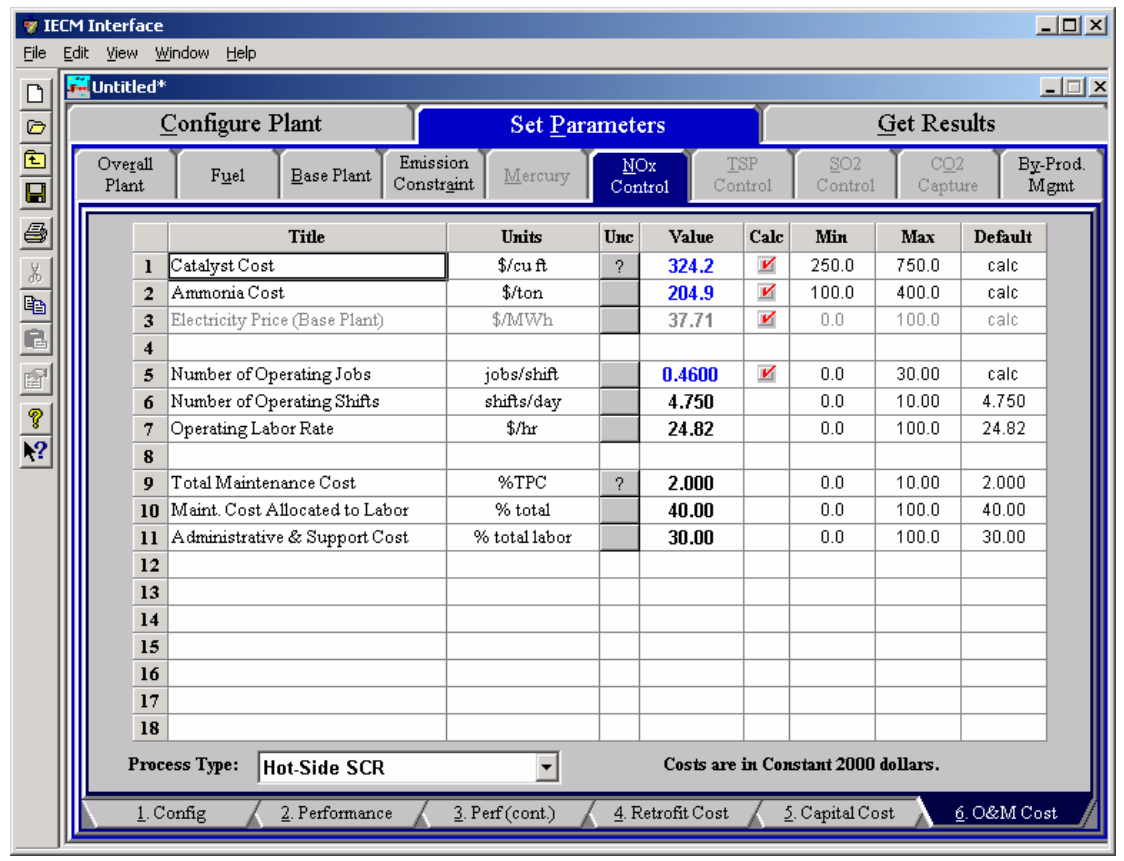

Hot-Side SCR - O\&M Cost input screen.

Inputs for the operation and maintenance costs of the Hot-Side SCR $\mathrm{NO}_{\mathrm{x}}$ control technology are entered on the $\mathbf{O} \& \mathbf{M}$ Cost input screen. O\&M costs are typically expressed on an average annual basis and are provided in either constant or current dollars for a specified year, as shown on the bottom of the screen. Each parameter is described briefly below.

Catalyst Cost: This is the cost of the catalyst used for the SCR technology.

Ammonia Cost: This is the cost of the ammonia used for the SCR technology.

Electricity Price (Base Plant): This is the price of electricity and is calculated as a function of the utility cost of the base plant, where the base plant is a combustion boiler and an air preheater.

Number of Operating Jobs: This is the total number of operating jobs that are required to operate the plant per eight-hour shift.

Number of Operating Shifts: This is the total number of equivalent operating shifts in the plant per day. The number takes into consideration paid time off and weekend work ( 3 shifts/day * 7 days/5 day week * 52 weeks/(52 weeks -6 weeks PTO $)=4.75$ equiv. Shifts/day).

Operating Labor Rate: The hourly cost of labor is specified in the base plant O\&M cost screen. The same value is used throughout the other technologies.

Total Maintenance Cost: This is the annual maintenance cost as a percentage of the total plant cost. Maintenance cost estimates can be developed separately for each process area. 
Maint. Cost Allocated to Labor: Maintenance cost allocated to labor as a percentage of the total maintenance cost.

Administrative \& Support Cost: This is the percent of the total operating and maintenance labor associated with administrative and support labor.

\section{Hot-Side SCR Diagram}

This screen is only available for the Combustion (Boiler) plant type.

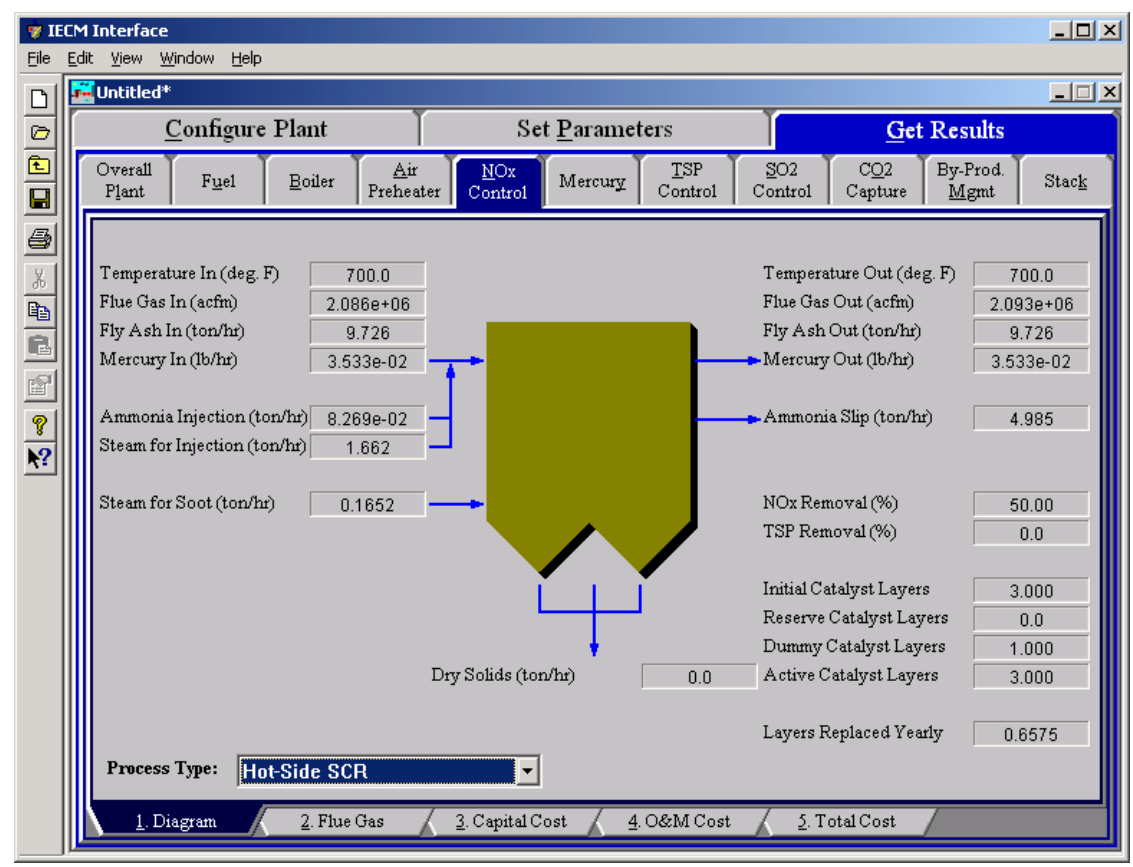

Hot-Side SCR - Diagram result screen.

The Diagram result screen displays an icon for the Hot-Side SCR $\mathrm{NO}_{\mathrm{x}}$ technology selected and values for major flows in and out of it.

\section{Reagent}

Ammonia Injection: The total mass flow rate of ammonia injected into the SCR. This is a function of the $\mathrm{NO}_{\mathrm{x}}$ concentration in the flue gas and the ammonia stoichiometric performance input value.

Steam for Injection: The total mass flow rate of steam into the SCR. This is the amount of steam added to the SCR to vaporize and transport ammonia into the inlet gas stream. This is determined by the steam to ammonia ratio input value and the ammonia injection.

\section{Catalyst}

Steam for Soot: This is the amount of steam blown into the hot-side SCR to remove soot buildup on the catalyst layers. The soot blowing steam is assumed to be directly proportional to catalyst volume. 
Initial Catalyst Layers: This is the number of initial active catalyst layers. Three layers are installed initially. It is used to calculate the total pressure drop across the SCR and the auxiliary power requirements. This is set by the input parameter.

Reserve Catalyst Layers: This is the number of reserve or extra catalyst layers. These are available for later catalyst additions. It is used to calculate the total pressure drop across the SCR and the auxiliary power requirements. This is set by the input parameter.

Dummy Catalyst Layers: This is the number of dummy catalyst layers. A dummy layer corrects the flow distribution. It is used to calculate the total pressure drop across the SCR and the auxiliary power requirements. This is set by the input parameter.

Active Catalyst Layers: This is the number of initial active catalyst layers. Three layers are installed initially. It is used to calculate the total pressure drop across the SCR and the auxiliary power requirements. It is equal to the number of initial and reserve catalyst layers.

Layers Replaced Yearly: Average catalyst layer replacement rate per year. This assumes that all catalyst layers are of equal depth.

\section{Flue Gas Entering SCR}

Temperature In: Temperature of the flue gas entering the SCR. This is determined by the flue gas outlet temperature of the module upstream of the SCR (e.g., the boiler economizer)

Flue Gas In: Volumetric flow rate of flue gas entering the SCR, based on the flue gas temperature entering the SCR and atmospheric pressure.

Fly Ash In: Total solids mass flow rate in the flue gas entering the SCR. This is determined by the solids exiting from the module upstream of the SCR (e.g., the boiler economizer).

Mercury In: Total mass of mercury entering the hot-side SCR in the flue gas. The value is a sum of all the forms of mercury (elemental, oxidized, and particulate).

\section{Flue Gas Exiting SCR}

Temperature Out: Temperature of the flue gas exiting the SCR. The model currently does not alter this temperature through the SCR.

Flue Gas Out: Volumetric flow rate of the flue gas exiting the SCR, based on the flue gas temperature exiting the SCR and atmospheric pressure.

Fly Ash Out: Total solids mass flow rate in the flue gas exiting the SCR. This is a function of the ash removal parameter on the SCR performance input screen.

Ammonia Slip: Total mass flow rate of ammonia that is unreacted and exits the SCR in the flue gas stream. This is a function if the ammonia injection flow rate, $\mathrm{NO}_{\mathrm{x}}$ concentration in the flue gas, and $\mathrm{NO}_{\mathrm{x}}$ removal efficiency.

Mercury Out: Total mass of mercury exiting the hot-side SCR in the flue gas. The value is a sum of all the forms of mercury (elemental, oxidized, and particulate). 


\section{SCR Performance}

NOx Removal: Actual removal efficiency of $\mathrm{NO}_{\mathrm{x}}$ in the SCR. This is a function of the minimum (50\%) and maximum removal efficiencies (SCR performance input parameter) and the emission constraint for $\mathrm{NO}_{\mathrm{x}}$ (emission constraints input parameter). It is possible that the SCR may over or under-comply with the emission constraint.

TSP Removal: Actual particulate removal efficiency in the SCR. This is set by the SCR input parameter.

\section{Collected Solids}

Dry Solids: Total solids mass flow rate of solids removed from the SCR. This is a function of the solids content in the flue gas and the particulate removal efficiency of the SCR.

\section{Hot-Side SCR Flue Gas Results}

This screen is only available for the Combustion (Boiler) plant type.

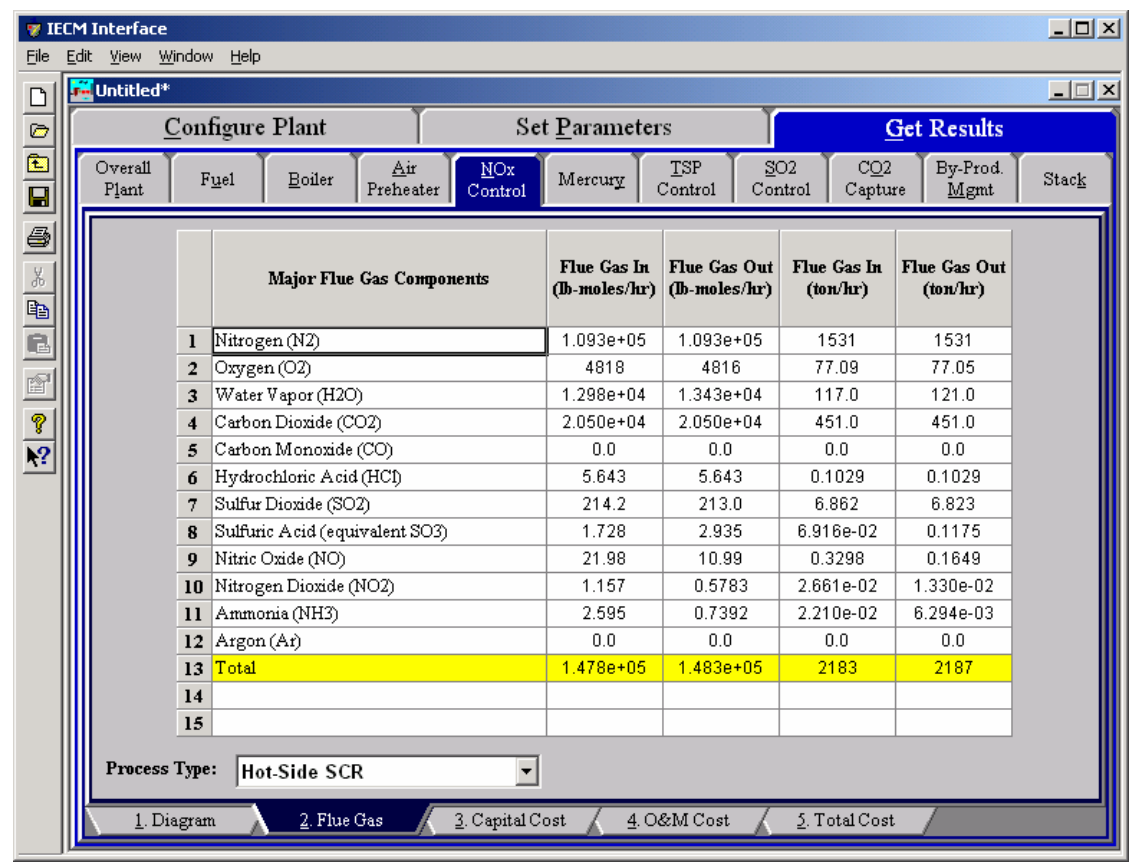

Hot-Side SCR - Flue Gas result screen.

\section{Major Flue Gas Components}

The Flue Gas result screen for the Hot-Side SCR displays a table of quantities of flue gas components entering and exiting the SCR. For each component, quantities are given in both moles and mass per hour. Each result is described briefly below.

Nitrogen $\left(\mathbf{N}_{2}\right)$ : Total mass of nitrogen.

Oxygen $\left(\mathrm{O}_{2}\right)$ : Total mass of oxygen.

Water Vapor $\left(\mathrm{H}_{2} \mathrm{O}\right)$ : Total mass of water vapor. 
Carbon Dioxide $\left(\mathrm{CO}_{2}\right)$ : Total mass of carbon dioxide.

Carbon Monoxide (CO): Total mass of carbon monoxide.

Hydrochloric Acid ( $\mathrm{HCl})$ : Total mass of hydrochloric acid.

Sulfur Dioxide $\left(\mathrm{SO}_{2}\right)$ : Total mass of sulfur dioxide.

Sulfuric Acid (equivalent $\mathbf{S O}_{3}$ ): Total mass of sulfuric acid.

Nitric Oxide (NO): Total mass of nitric oxide.

Nitrogen Dioxide $\left(\mathrm{NO}_{2}\right)$ : Total mass of nitrogen dioxide.

Ammonia $\left(\mathrm{NH}_{3}\right)$ : Total mass of ammonia.

Argon (Ar): Total mass of argon

Total: Total of the individual components listed above. This item is

highlighted in yellow.

\section{Hot-Side SCR Capital Cost Results}

This screen is only available for the Combustion (Boiler) plant type.

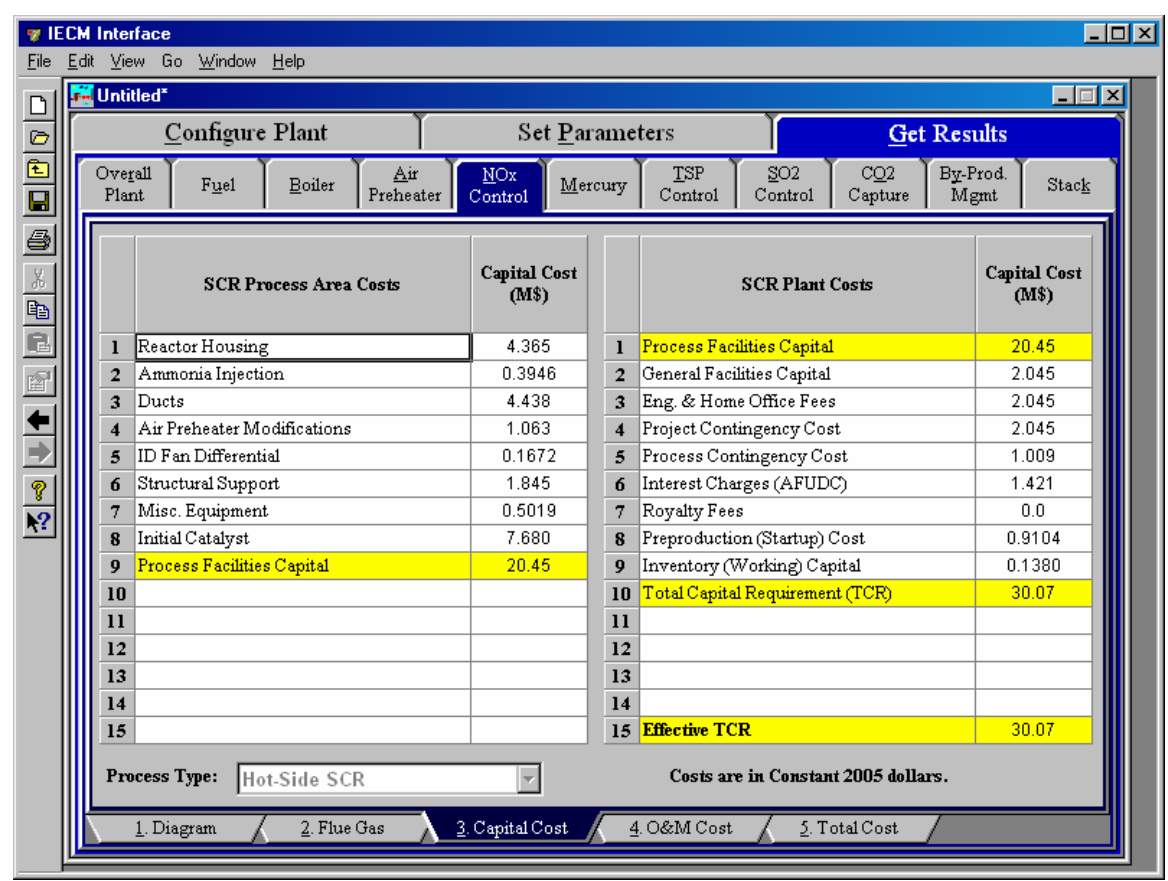

Hot-Side SCR - Capital Cost result screen.

The Capital Cost result screen displays tables for the direct and indirect capital costs related to the Hot-Side SCR $\mathrm{NO}_{\mathrm{x}}$ control technology. Capital costs are typically expressed in either constant or current dollars for a specified year, as shown on the bottom of the screen. Each result is described briefly below:

\section{Direct Capital Costs}

Each process area direct capital cost is a reduced-form model based on regression analysis of data collected from several reports and analyses of hot-side SCR units. They are described in general with specific model parameters that effect them described in particular. 
Reactor Housing: The reactor housing costs include carbon steel reactor vessel with six inches of mineral wool insulation, vessel internals and supports, steam soot blowers, reactor crane and hoist, installation labor, foundations, structures, piping, and electrical equipment. The costs are a function of the number of vessels, including spares, and the volume of catalyst required. Catalyst costs are excluded.

Ammonia Injection: The ammonia unloading, storage, and supply system includes a storage vessel with a seven day capacity, an ammonia vaporizer, mixer, injection grid, ductwork, dampers, and a truck unloading station. The costs are a function of the ammonia injected.

Ducts: The ductwork includes economizer bypass and outlet ducts, SCR inlet and outlet ducts, SCR and economizer control dampers, air preheater inlet plenum, various expansion joints in the ductwork, and air preheater cross-over ducting. The costs are a function of the flue gas flow rate through the SCR.

Air Preheater Modifications: Thicker and smoother material is used for the heat transfer surfaces in the preheater. A larger motor is provided for the heat exchanger. High pressure steam soot blowers and water wash spray nozzles are also added. The costs are a function of the number of operating vessels, and the heat transfer efficiency of the air preheater (UA product).

ID Fan Differential: The ID fans must be sized to deal with the increased flue gas pressure drop resulting from the additional ductwork and the SCR reactor. The costs are a function of the flue gas flow rate and pressure drop across the SCR.

Structural Support: The costs of this area are related primarily to the structural support required for the SCR reactor housing, ductwork, and air preheater. The costs are a function of the reactor housing costs, duct costs and air preheater modification costs above.

Misc. Equipment: This area includes the capital costs incurred for ash handling addition, water treatment addition, and flow modeling for a hot-side SCR system. The costs are a function of the gross plant capacity.

Initial Catalyst: The cost of the initial catalyst charge is included in the total direct cost, because it is such a large and integral part of the SCR system. The costs are a function of the initial catalyst charge.

Process Facilities Capital: The process facilities capital is the total constructed cost of all on-site processing and generating units listed above, including all direct and indirect construction costs. All sales taxes and freight costs are included where applicable implicitly. This result is highlighted in yellow.

\section{Total Capital Costs}

Process Facilities Capital: (see definition above)

General Facilities Capital: The general facilities include construction costs of roads, office buildings, shops, laboratories, etc. Sales taxes and freight costs are included implicitly.

Eng. \& Home Office Fees: The engineering \& home office fees are a percent of total direct capital cost. This is an overhead fee paid to the architect/engineering company. 
Project Contingency Cost: Capital cost contingency factor covering the cost of additional equipment or other costs that would result from a more detailed design of a definitive project at the actual site.

Process Contingency Cost: Capital cost contingency factor applied to a new technology in an effort to quantify the uncertainty in the technical performance and cost of the commercial-scale equipment.

Interest Charges (AFUDC): Allowance for funds used during construction, also referred to as interest during construction, is the time value of the money used during construction and is based on an interest rate equal to the before-tax weighted cost of capital. This interest is compounded on an annual basis (end of year) during the construction period for all funds spent during the year or previous years.

Royalty Fees: Royalty charges may apply to some portions of generating units incorporating new proprietary technologies.

Preproduction (Startup) Cost: These costs consider the operator training, equipment checkout, major changes in unit equipment, extra maintenance, and inefficient use of fuel or other materials during startup.

Inventory (Working) Capital: The raw material supply based on $100 \%$ capacity during a 60 day period. These materials are considered storage. The inventory capital includes fuels, consumables, byproducts, and spare parts.

Total Capital Requirement (TCR): Money that is placed (capitalized) on the books of the utility on the service date. TCR includes all the items above. This result is highlighted in yellow.

Effective TCR: The TCR of the hot-side SCR that is used in determining the total power plant cost. The effective TCR is determined by the “TCR Recovery Factor” for the hot-side SCR.

\section{Hot-Side SCR O\&M Cost Results}

This screen is only available for the Combustion (Boiler) plant type. 


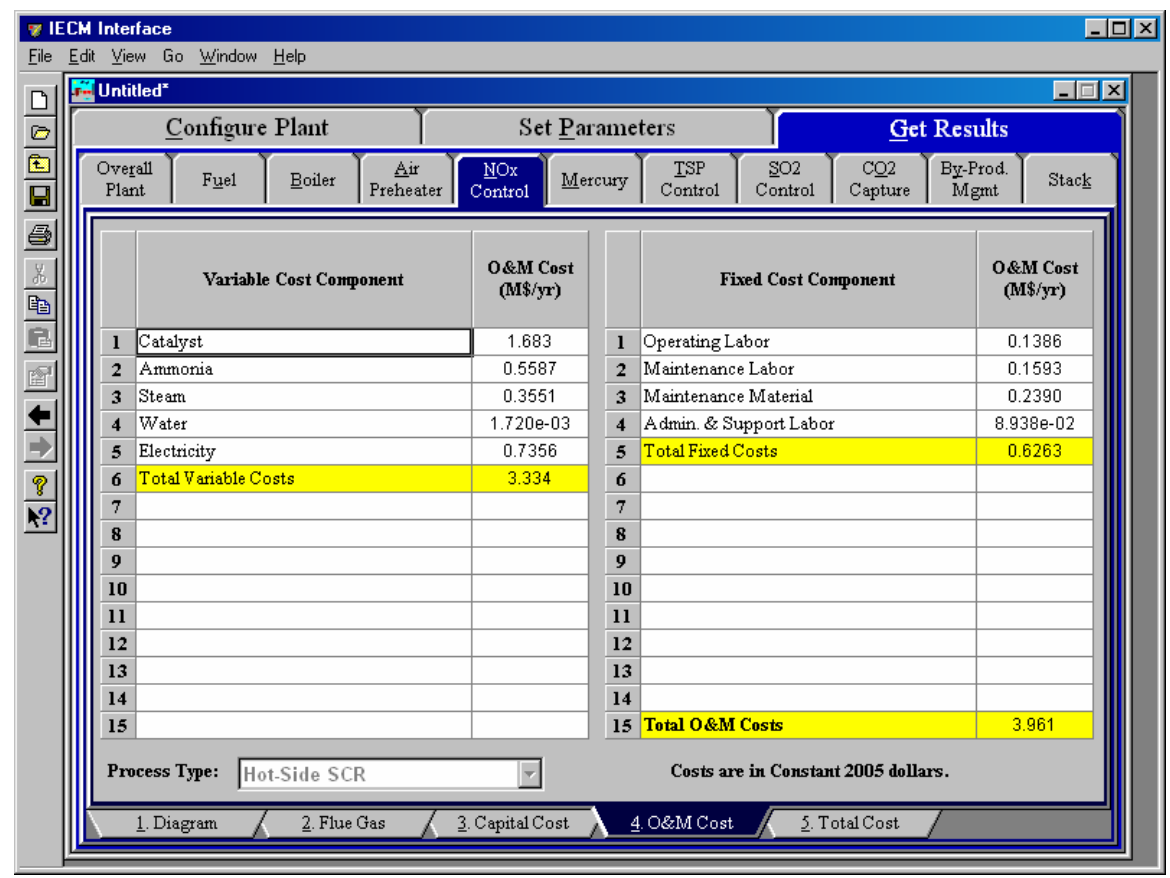

Hot-Side SCR - O\&M Cost result screen.

The O\&M Cost result screen displays tables for the variable and fixed operation and maintenance costs involved with the Hot Side SCR NO control technology. O\&M costs are typically expressed on an average annual basis and are provided in either constant or current dollars for a specified year, as shown on the bottom of the screen. Each result is described briefly below:

\section{Variable Cost Components}

Variable operating costs and consumables are directly proportional to the amount of kilowatts produced and are referred to as incremental costs. All the costs are subject to inflation.

Catalyst: Replacement catalyst cost per year for the hot-side SCR. This is a function of the number of catalyst layers, the number of layers replaced each year, and the catalyst space velocity (all three are performance input parameters).

Ammonia: Ammonia reagent cost per year for the hot-side SCR. This is a function of the concentration of $\mathrm{NO}_{\mathrm{x}}$ in the flue gas and the ammonia mass flow rate.

Steam: Annual cost of steam used for ammonia vaporization and ammonia injection. This is a function of the steam to ammonia ratio (performance input parameter) and the ammonia mass flow rate.

Water: Cost of water used to wash ammonia that deposits in the air preheater. This is a function of the efficiency and concentration of ammonia removed by wash water performance input parameters and the amount of ammonia salts deposited on the air preheater.

Electricity: Cost of electricity consumption of the hot-side SCR. This is a function of the gross plant capacity and the SCR energy penalty performance input parameter. 
Total Variable Costs: This is the sum of all the variable O\&M costs listed above. This result is highlighted in yellow.

\section{Fixed Cost Components}

Fixed operating costs are essentially independent of actual capacity factor, number of hours of operation, or amount of kilowatts produced. All the costs are subject to inflation.

Operating Labor: Operating labor cost is based on the operating labor rate, the number of personnel required to operate the plant per eighthour shift, and the average number of shifts per day over 40 hours per week and 52 weeks.

Maintenance Labor: The maintenance labor is determined as a fraction of the total maintenance cost.

Maintenance Material: The cost of maintenance material is the remainder of the total maintenance cost, considering the fraction associated with maintenance labor.

Admin. \& Support Labor: The administrative and support labor is the only overhead charge. It is taken as a fraction of the total operating and maintenance labor costs.

Total Fixed Costs: This is the sum of all the fixed O\&M costs listed above. This result is highlighted in yellow.

Total O\&M Costs: This is the sum of the total variable and total fixed O\&M costs. It is used to determine the base plant total revenue requirement. This result is highlighted in yellow.

\section{Hot-Side SCR Total Cost Results}

This screen is only available for the Combustion (Boiler) plant type.

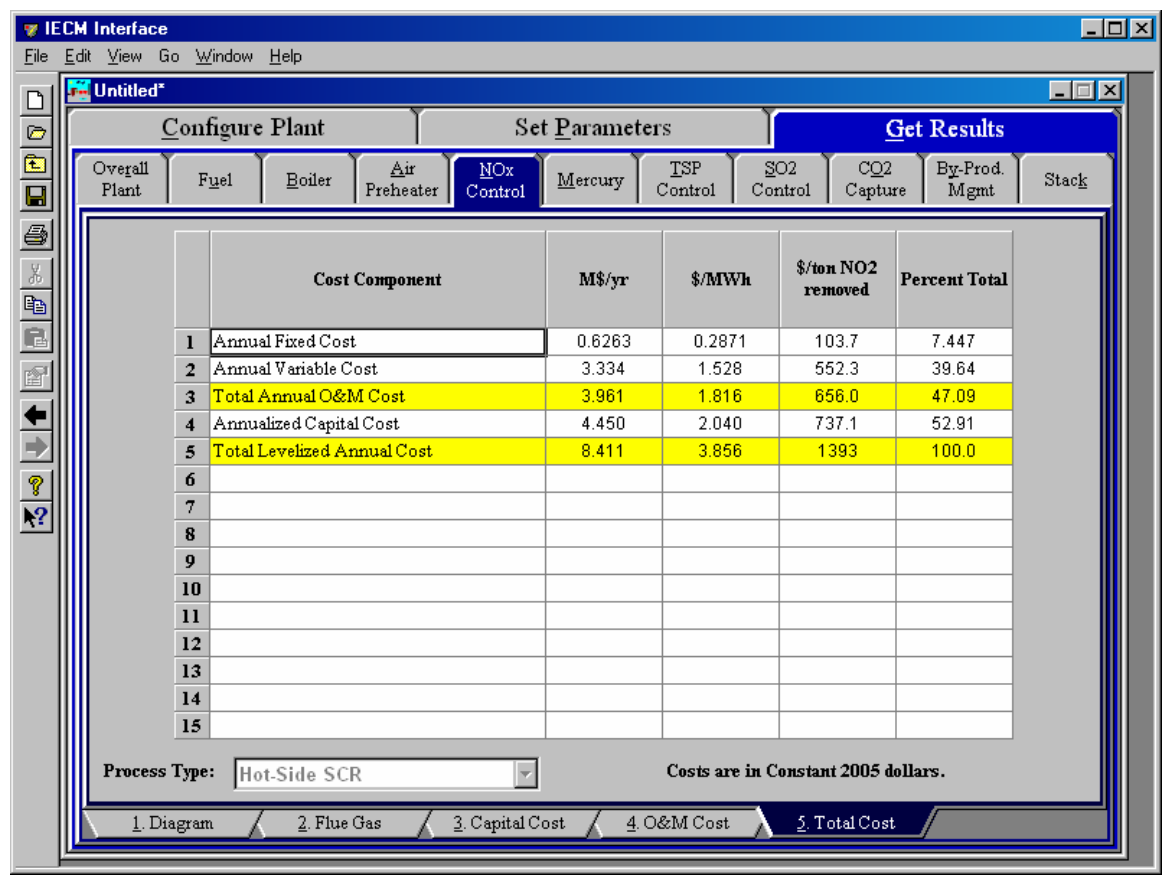


The Total Cost result screen displays a table which totals the annual fixed, variable, operations and maintenance, and capital costs associated with the Hot-Side SCR $\mathrm{NO}_{\mathrm{x}}$ Control technology. Note that all costs expressed in $\$ /$ ton of $\mathrm{NO}_{2}$ removed assume tons of equivalent $\mathrm{NO}_{2}$. Total costs are typically expressed in either constant or current dollars for a specified year, as shown on the bottom of the screen. Each result is described briefly below.

\section{Cost Component}

Annual Fixed Cost: The operating and maintenance fixed costs are given as an annual total. This number includes all maintenance materials and all labor costs.

Annual Variable Cost: The operating and maintenance variables costs are given as an annual total. This includes all reagent, chemical, steam, and power costs.

Total Annual O\&M Cost: This is the sum of the annual fixed and variable operating and maintenance costs above. This result is highlighted in yellow.

Annualized Capital Cost: This is the total capital cost expressed on an annualized basis, taking into consideration the levelized carrying charge factor, or fixed charge factor, over the entire book life.

Total Levelized Annual Cost: The total annual cost is the sum of the total annual O\&M cost and annualized capital cost items above. This result is highlighted in yellow. 



\section{Mercury}

Mercury Control is a Technology Navigation Tab in the Set Parameters and in the Get Results program area. These screens define and display results for the performance and costs directly associated with the removal of mercury from each technology in the power plant Pre-combustion and post-combustion control technologies are all considered. Special consideration is given to flue gas conditioning used to enhance mercury removal. Water and activated carbon injection are currently considered as conditioning agents.

\section{Mercury Removal Efficiency Inputs}

This screen is only available for the Combustion (Boiler) plant type. Inputs for the removal of the speciated mercury from the flue gas stream are entered on the Removal Eff. input screen.

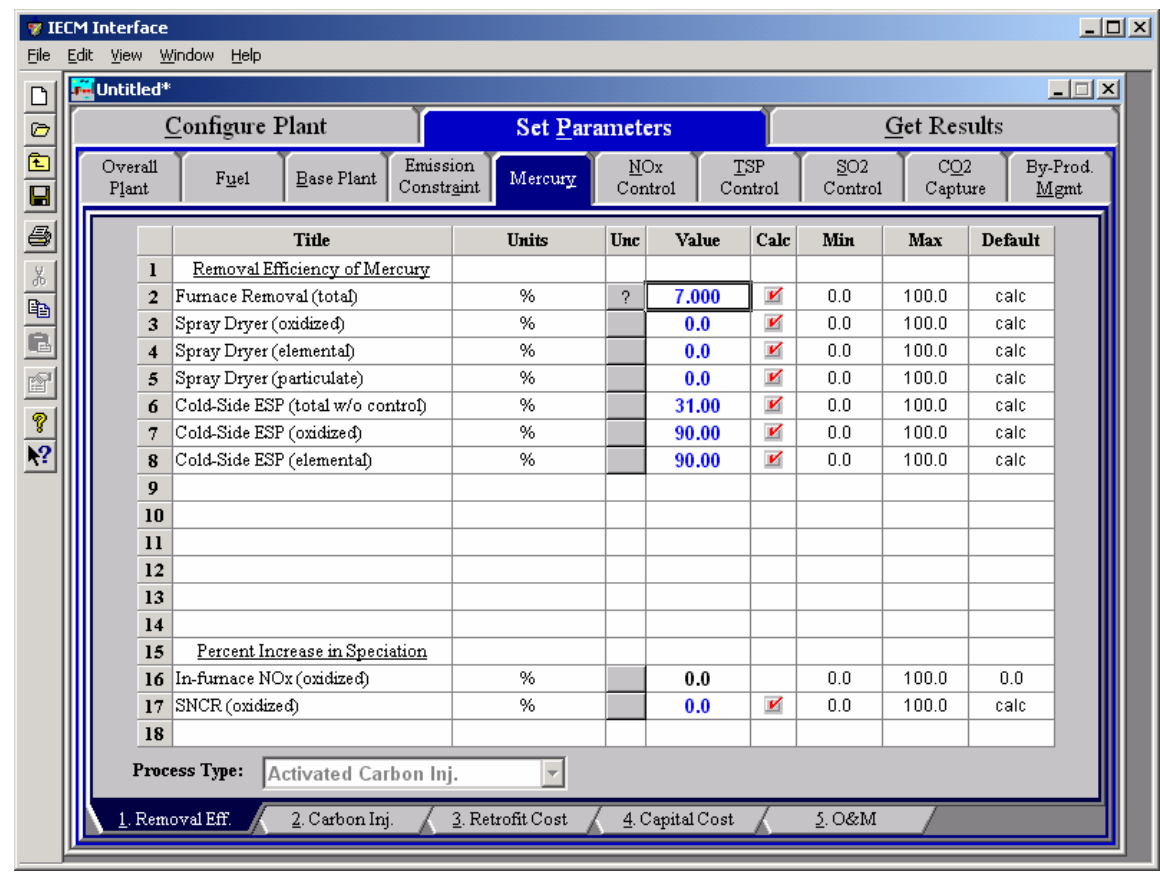

Mercury - Removal Efficiency input screen.

Each parameter is described briefly below. 


\section{Removal Efficiency of Mercury}

The removal of mercury for each control technology configured is given as a percent of the total entering the control technology. The user is given the opportunity to specify the removal separately for each speciation type. Control technologies not currently configured are hidden.

Furnace Removal (total): Mercury present in ash is removed from the furnace through the removal of bottom ash. The speciation is not known, so the removal is specified as a total removal. The mercury removed in bottom ash is not credited toward the required removal to meet the mercury emission constraint.

\section{Fabric Filter}

Fabric Filter (total w/o control): Mercury present in ash is removed from the fabric filter through the removal of captured fly ash. The speciation is not known, so the removal is specified as a total removal. The value shown is determined without regard to particular mercury control methods. It has a substantial effect on the amount of activated carbon needed to meet the required removal of mercury.

Fabric Filter (oxidized): The fabric filter typically removes some mercury without adding a specific mercury control technology. This mercury is present in the ash and is removed with the collected ash. When a mercury control technology is added, the removal is enhanced. The default value is set to meet the overall removal efficiency constraint, with consideration given to the mercury removed by flue gas desulfurization and elemental mercury oxidized in a $\mathrm{NO}_{\mathrm{x}}$ control technology. The lower limit is set by the removal efficiency of ash alone as specified by "Fabric Filter (total w/o control)" specified above.

Fabric Filter (elemental): Elemental mercury is assumed to be removed with the same efficiency as the removal of oxidized mercury specified above.

\section{Cold - Side ESP}

Cold-Side ESP (total w/o control): Mercury present in ash is removed from the cold-side ESP through the removal of captured fly ash. The speciation is not known, so the removal is specified as a total removal. The value shown is determined without regard to particular mercury control methods. It has a substantial effect on the amount of activated carbon needed to meet the required removal of mercury.

Cold-Side ESP (oxidized): The cold-side ESP typically removes some mercury without adding a specific mercury control technology. This mercury is present in the ash and is removed with the collected ash. When a mercury control technology is added, the removal is enhanced. The default value is set to meet the overall removal efficiency constraint, with consideration given to the mercury removed by flue gas desulfurization and elemental mercury oxidized in a $\mathrm{NO}_{\mathrm{x}}$ control technology. The lower limit is set by the removal efficiency of ash alone as specified by "Cold-Side ESP (total w/o control)" specified above. 
Cold-Side ESP (elemental): Elemental mercury is assumed to be removed with the same efficiency as the removal of oxidized mercury specified above.

\section{Wet FGD}

Wet FGD (oxidized): The wet lime/limestone FGD typically removes all the oxidized mercury due to its' high solubility in water.

Wet FGD (elemental): Elemental mercury is assumed to pass through the wet lime/limestone FGD. It is assumed that elemental mercury is present in the flue gas and is unreactive.

\section{Spray Dryer}

Spray Dryer (oxidized): Oxidized mercury is assumed to pass through the lime spray dryer. Although soluble in water, moisture injected into the spray dryer evaporates, resulting in the mercury remaining in the flue gas. The default value is zero.

Spray Dryer (elemental): Elemental mercury is assumed to pass through the lime spray dryer. It is assumed that elemental mercury is present in the flue gas and is unreactive.

\section{Percent Increase in Speciation}

Although $\mathrm{NO}_{\mathrm{x}}$ control technologies do not remove mercury from the flue gas, they can change the mercury from one form to another. This is particularly true when catalysts are present. In this case, elemental mercury is converted to oxidized mercury. The parameters in this section define the percent increase in oxidized mercury across the control technology.

In-furnace NOx (oxidized): Low $\mathrm{NO}_{\mathrm{x}}$ burners with or without overfire air and gas reburn can effect the amount of oxidized mercury. At present, there is insufficient information available to specify a default value. The default is set to zero.

SNCR (oxidized): An SNCR does not affect the relative amounts of oxidized and elemental mercury. The default is set to zero.

Hot-Side SCR (oxidized): Hot-side SCR as a control technology chances elemental mercury to oxidized mercury. It is believed that the catalyst is responsible for this shift in speciation. The default value is a function of the coal rank.

\section{Mercury Carbon (and Water) Injection Inputs}

This screen is only available for the Combustion (Boiler) plant type. Inputs for activated carbon and water injected into the flue gas are entered on the Carbon Inj. input screen. Water can be optionally added to reduce the flue gas temperature and enhance the effect of the carbon on removing mercury. Note that the actual removal of the carbon and mercury are accomplished in particulate and flue gas desulfurization control technologies downstream 


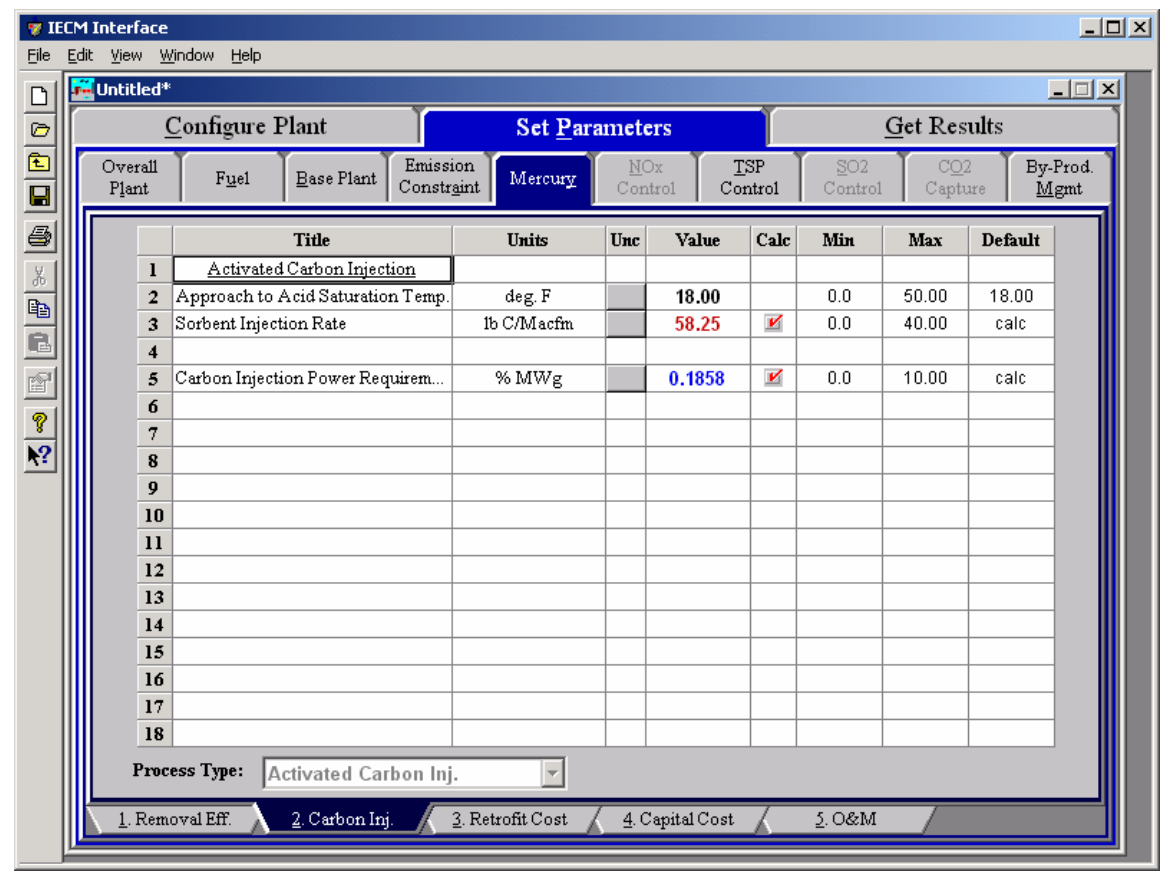

Mercury - Removal Efficiency input screen.

Each parameter is described briefly below.

\section{Activated Carbon Injection}

Injection of water to reduce the flue gas temperature and activated carbon to enhance mercury removal are the only control technologies presently incorporated into the IECM.

Approach to Acid Saturation Temperature: When water is selected to be injected with the activated carbon this parameter appears on the Removal Efficiency input screen. It is important to keep the flue gas temperature above the sulfuric acid dew point temperature. This avoids condensation of acid on equipment. This parameter determines the amount of water injected into the flue gas. If the approach is above the actual temperature, the temperature is dropped to be the approach above the dew point. The dew point is a function of the $\mathrm{SO}_{3}$ and $\mathrm{H}_{2} \mathrm{O}$ content in the flue gas and the pressure of the flue gas.

Sorbent Injection Rate: The flue gas temperature, the mercury removal efficiency in the particulate device, the coal rank, and the mercury removal efficiency without control, determines the injection rate of activated carbon into the flue gas. Mercury removal due to the ash removed in a cold-side ESP or fabric filter in the absence of enhanced mercury control methods is specified in the input screen. The default value is most sensitive to the flue gas temperature and the mercury removal efficiency without control.

Carbon Injection Power Requirement: The power required for the water and carbon injection system is a function of carbon injection rate, the water injection rate, and the flue gas flow rate. This assumes the addition of a fan in the flue gas to balance the pressure drop. The default value is calculated as the ratio of the actual energy consumption by the gross electrical output of the power plant. 


\section{Mercury Retrofit Cost Inputs}

This screen is only available for the Combustion (Boiler) plant type. Inputs for the capital costs of modifications to process areas of the activated carbon and water injection system are entered on the Retrofit Cost input screen.

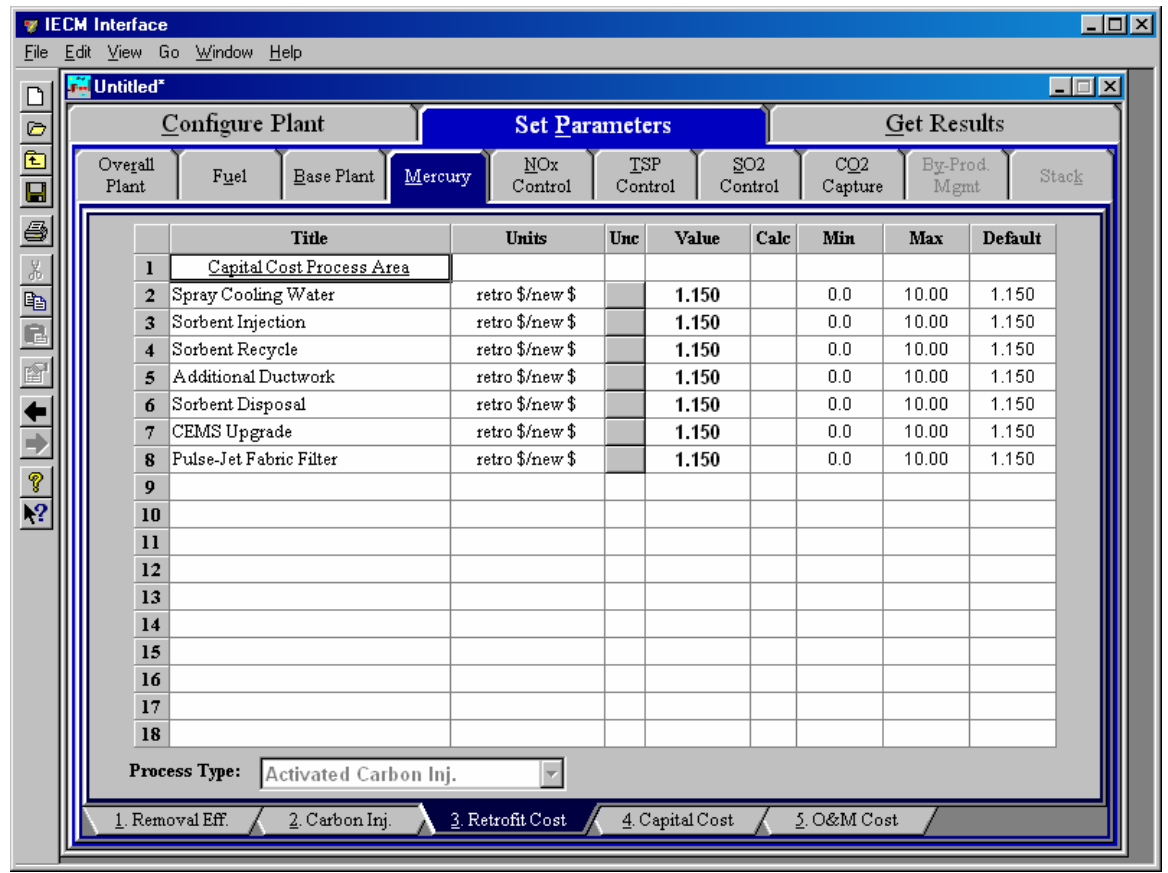

Mercury - Retrofit Cost input screen.

The retrofit cost factor of each process is a multiplicative cost adjustment, which considers the cost of retrofitted capital equipment relative to similar equipment installed in a new plant. These factors affect the capital costs directly and the operating and maintenance costs indirectly.

Direct capital costs for each process area are calculated in the IECM. These calculations are reduced form equations derived from more sophisticated models and reports. The sum of the direct capital costs associated with each process area is defined as the process facilities capital (PFC). The retrofit cost factor provided for each of the process areas can be used as a tool for adjusting the anticipated costs and uncertainties across the process area separate from the other areas.

Uncertainty can be applied to the retrofit cost factor for each process area in each technology. Thus, uncertainty can be applied as a general factor across an entire process area, rather than as a specific uncertainty for the particular cost on the capital or O\&M input screens. Any uncertainty applied to a process area through the retrofit cost factor compounds any uncertainties specified later in the capital and O\&M cost input parameter screens.

Each parameter is described briefly below. Although the user cannot set the capital cost directly, the descriptions below include the key parameters used to determine the capital cost itself. The input parameters on this screen adjust this capital cost as calculated in the IECM. 


\section{Capital Cost Process Area}

Spray Cooling Water: This capital cost area represents the materials and equipment necessary to inject water into the flue gas duct for the purpose of cooling the flue gas to a prerequisite temperature. Equipment includes water storage tanks, pumps, transport piping, injection grid with nozzles, and a control system. The direct capital cost is a function of the water flow rate.

Sorbent Injection: This capital cost area represents the materials and equipment necessary to deliver the activated carbon into the flue gas. Equipment includes silo pneumatic loading system, storage silos, hoppers, blowers, transport piping, and a control system. The direct capital cost is a function of the sorbent flow rate.

Sorbent Recycle: This capital cost area represents the materials and equipment necessary to recycle ash and activated carbon from the particulate collector back into the duct injection point. The purpose is to create a equilibrium state where the carbon is reintroduced to improve performance. Equipment includes hoppers, blowers, transport piping, and a control system. The direct capital cost is a function of the recycle rate of ash and spent sorbent.

NOTE: Sorbent recycling is a feature to be added in a future version of the IECM.

Additional Ductwork: This capital cost area represents materials and equipment for ductwork necessary beyond the other process areas. Extra ductwork may be required for difficult retrofit installations.

NOTE: Future versions of the IECM will include parameters to determine a capital cost for this area. The current version assumes no additional ductwork.

Sorbent Disposal: This capital cost area represents materials and equipment required to house and dispose the collected sorbent. Equipment includes hoppers, blowers, transport piping, and a control system. This is in excess of existing hoppers, tanks, and piping used for existing particulate collectors. The direct capital cost is determined by the incremental increase in collected solids in the particulate collector.

CEMS Upgrade: This capital cost area represents materials and equipment required to install a continuous emissions monitoring system (CEMS) upgrade. The direct capital cost is determined by the net electrical output of the power plant.

Pulse-Jet Fabric Filter: This capital costs area represents an upgrade to an existing cold-side ESP, where one section at the back end of the unit is replaced with a pulse-jet fabric filter. This can be considered a pseudo-COHPAC. Equipment includes pulse-jet FF, filter bags, ductwork, dampers, and MCCs, instrumentation and PLC controls for baghouse operation. Equipment excludes ash removal system, power distribution and power supply, and distributed control system. The direct capital cost is a function of the flue gas flow rate and the air to cloth ratio of the fabric filter.

NOTE: The IECM currently does not support multiple particulate devices in the same configuration nor a modified cold-side ESP. 


\section{Mercury Capital Cost Inputs}

This screen is only available for the Combustion (Boiler) plant type. Inputs for the capital costs of the activated carbon and water injection system are entered on the Capital Cost input screen.

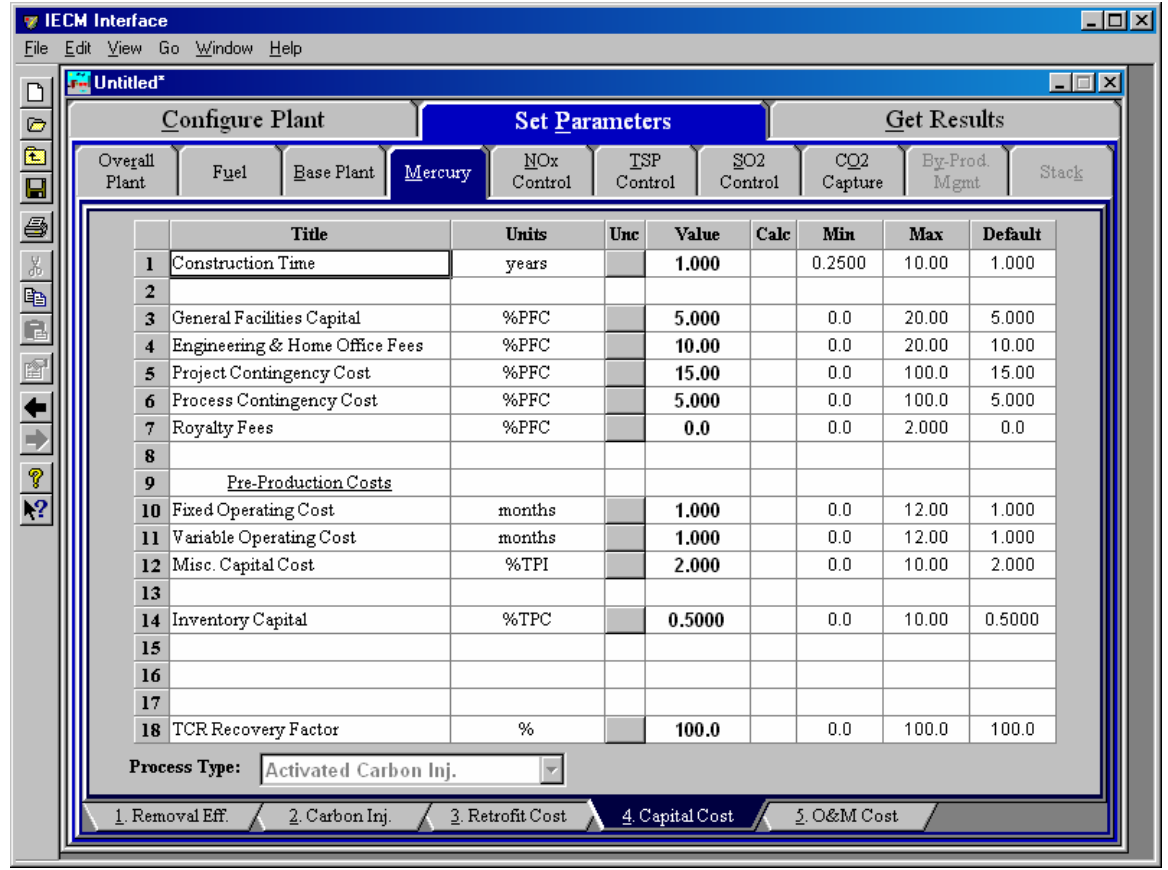

Mercury - Capital Cost input screen.

The necessary capital cost input parameters associated with the base plant are on this input screen. The capital cost parameters and terminology used in the IECM are based on the methodologies developed by the Electric Power Research Institute (EPRI). They have prepared a Technical Assessment Guide (TAG) in order to provide a consistent basis for reporting cost and revenues associated with the electric power industry. This system of reporting is used by a wide audience, including energy engineers, researchers, planners, and managers. The IECM has been developed around this TAG system so that costs associated with various technologies can be compared directly on a consistent basis and communicated in the language used by the audience listed above.

Total Plant Cost (TPC) is the sum of the process facilities capital, general facilities capital, engineering and home office fees, and the contingencies (project and process). This is considered the cost on an instantaneous basis (overnight), and expressed in December dollars of a reference year.

Direct Capital Costs: Direct capital costs for each process area are calculated in the IECM. These calculations are reduced form equations derived from more sophisticated models and reports. The sum of the direct capital costs associated with each process area is defined as the process facilities capital (PFC). This is the basis for all other capital cost parameters.

The process facilities capital for the technology is the total constructed cost of all onsite processing and generating units, including all direct and indirect construction costs. All sales taxes and freight costs are included where applicable implicitly. These direct capital costs are generally calculated by the IECM and not presented 
directly on input screens. However, when important input variables are required for these calculations, they are listed at the top of the input screen.

Indirect Capital Costs: Costs that are indirectly applied to the technology are based on the process facilities cost. Each of the cost factors below is expressed as a percentage of the process facilities cost, and is entered on this screen. Each parameter is described briefly below.

Construction Time: This is the idealized construction period in years. It is used to determine the allowance for funds used during construction (AFUDC).

General Facilities Capital (GFC): The general facilities include construction costs of roads, office buildings, shops, laboratories, etc. Sales taxes and freight costs are included implicitly. The cost typically ranges from $5-20 \%$.

Engineering \& Home Office Fees: The engineering \& home office fees are a percent of total direct capital cost. This is an overhead fee paid to the architect/engineering company. These fees typically range from 7$15 \%$.

Project Contingency Cost: This is factor covering the cost of additional equipment or other costs resulting from a more detailed design. Higher contingency factors will be applied to simplified or preliminary designs and lower factors to detailed or finalized designs.

Process Contingency Cost: This quantifies the design uncertainty and cost of a commercial-scale system. This is generally applied on an areaby-area basis. Higher contingency factors are applied to new regeneration systems tested at a pilot plant and lower factors to full-size or commercial systems.

Royalty Fees: Royalty charges may apply to some portions of generating units incorporating new proprietary technologies.

Pre-Production Costs: These costs consider the operator training, equipment checkout, major changes in unit equipment, extra maintenance, and inefficient use of fuel or other materials during startup. These are typically applied to O\&M costs over a specified period of time (months).

- Fixed Operating Cost: Time period of fixed operating costs (operating and maintenance labor, administrative and support labor, and maintenance materials) used for plant startup.

- Variable Operating Cost: Time period of variable operating costs at full capacity (chemicals, water, and other consumables, and waste disposal changes) used for plant startup. Full capacity estimates of the variable operating costs will assume operations at $100 \%$ load.

- Misc. Capital Cost: This is a percent of total plant investment (sum of TPC and AFUDC) to cover expected changes to equipment to bring the system up to full capacity.

Inventory Capital: Percent of the total direct capital for raw material supply based on $100 \%$ capacity during a 60 day period. These materials are considered storage. The inventory capital includes fuels, consumables, by-products, and spare parts. This is typically $0.5 \%$. 
TCR Recovery Factor: The actual total capital required (TCR) as a percent of the TCR in a new power plant. This value is $100 \%$ for a new installation and may be set as low as $0 \%$ for an activated carbon and water injection system that has been paid off.

\section{Mercury O\&M Cost Inputs}

This screen is only available for the Combustion (Boiler) plant type.

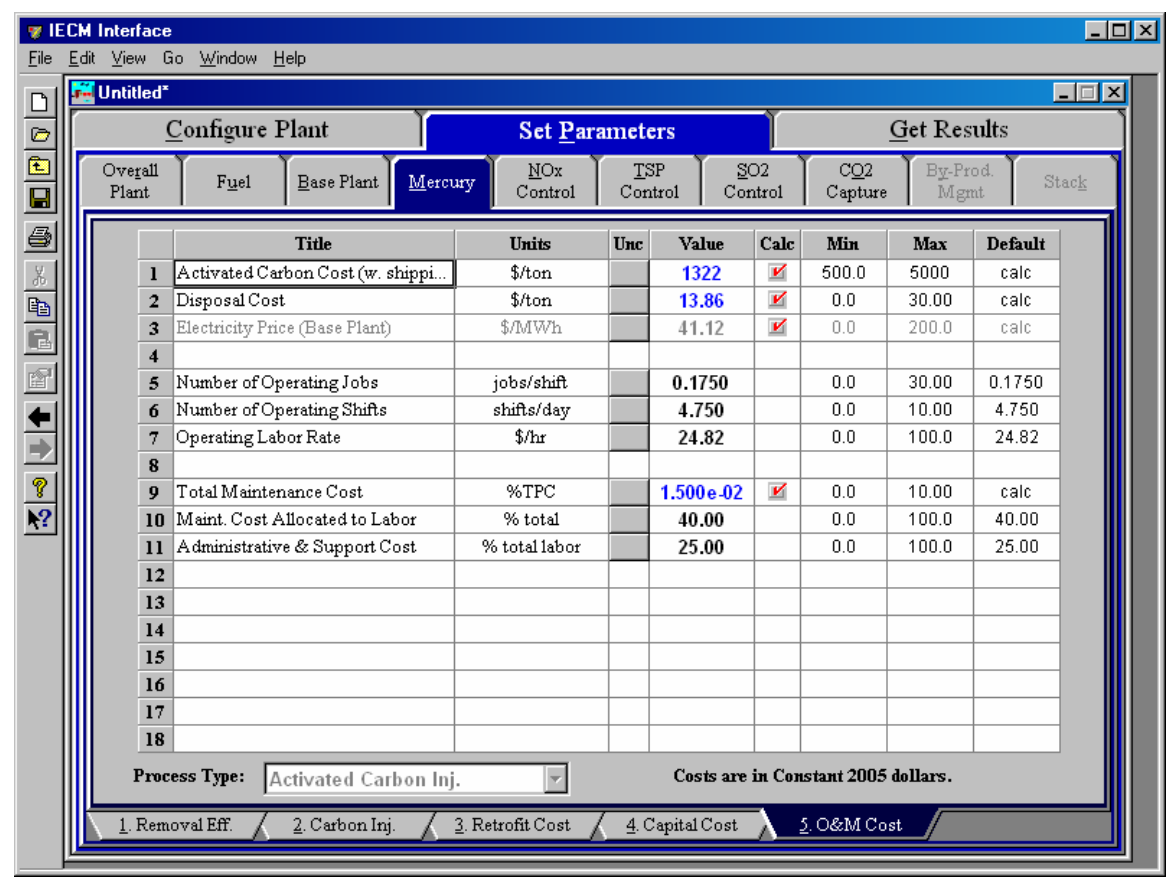

Mercury-O\&M input screen.

Inputs for the operation and maintenance costs of the mercury control technology are entered on the $\mathbf{O} \& \mathbf{M}$ cost input screen. O\&M costs are typically expressed on an average annual basis and are provided in either constant or current dollars for a specified year, as shown on the bottom of the screen.

Activated Carbon Cost (w. shipping): This is the cost for the activated carbon, including the cost of shipping.

Disposal Cost: This is the disposal cost for the particulate control system. It is assumed that the ash is not hazardous, therefore can be disposed with the collected fly ash.

Electricity Price (Base Plant): This is the price of electricity and is calculated as a function of the utility cost of the base plant, where the base plant is a combustion boiler and an air preheater.

Number of Operating Jobs: This is the total number of operating jobs that are required to operate the plant per eight-hour shift.

Number of Operating Shifts: This is the total number of equivalent operating shifts in the plant per day. The number takes into consideration paid time off and weekend work ( 3 shifts/day * 7 days/5 day week * 52 weeks/(52 weeks -6 weeks PTO $)=4.75$ equiv. Shifts/day). 
Operating Labor Rate: The hourly cost of labor is specified in the base plant O\&M cost screen. The same value is used throughout the other technologies.

Total Maintenance Cost: This is the annual maintenance cost as a percentage of the total plant cost. Maintenance cost estimates can be developed separately for each process area.

Maint. Cost Allocated to Labor: Maintenance cost allocated to labor as a percentage of the total maintenance cost.

Administrative \& Support Cost: This is the percent of the total operating and maintenance labor associated with administrative and support labor.

\section{Mercury Diagram}

This screen is only available for the Combustion (Boiler) plant type. The Diagram result screen displays an icon for the water and carbon injection systems, both part of the overall mercury control option and values for major flows in and out of it

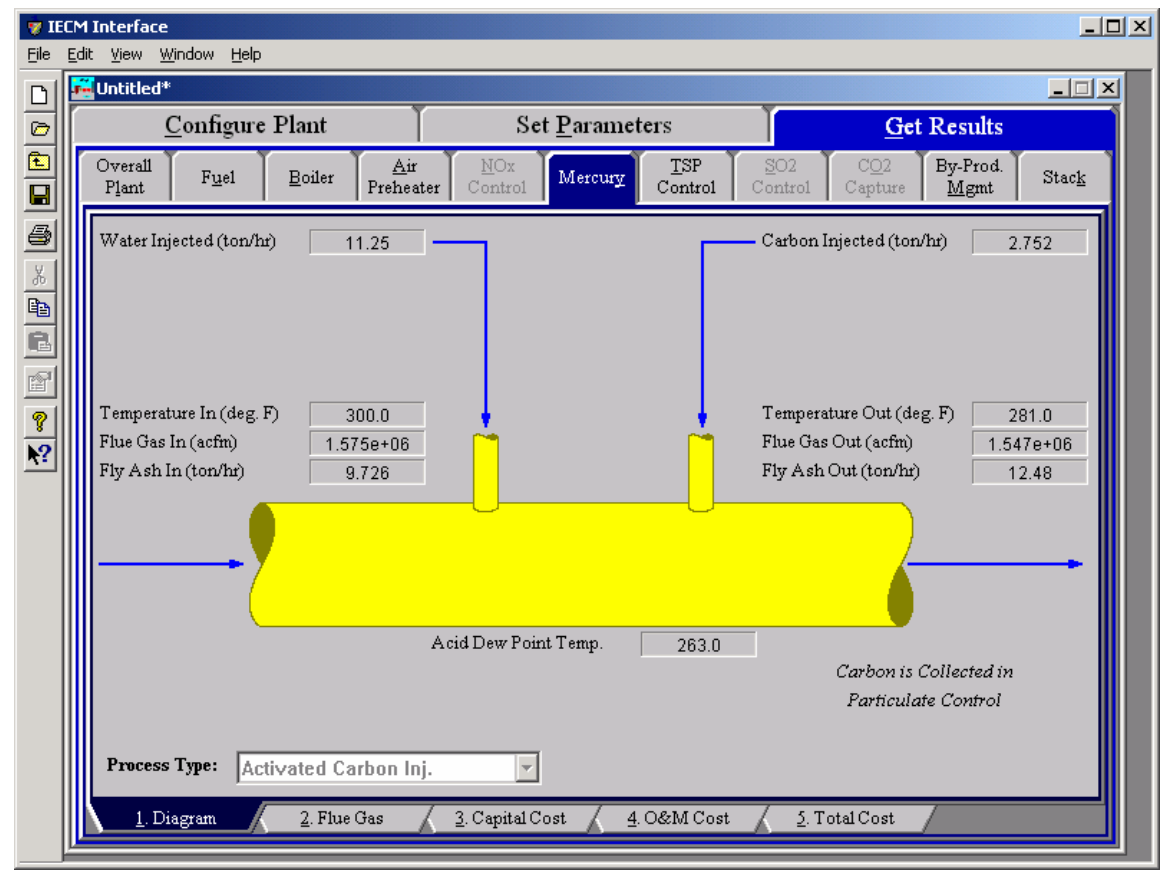

Mercury_Diagram result screen

Each result is described briefly below in flow order (not from top to bottom and left to right as they display on the screen).

\section{Flue Gas Prior to Injection}

Temperature In: Temperature of the flue gas prior to flue gas conditioning.

Flue Gas In: Volumetric flow rate of the flue gas prior to flue gas conditioning, based on the temperature prior to flue gas conditioning and atmospheric pressure. 
Fly Ash In: Total solids mass flow rate in the flue gas prior to flue gas conditioning. This includes ash, unburned carbon and unburned sulfur.

\section{Flue Gas After Injection}

Temperature Out: Temperature of the flue gas after flue gas conditioning. This should be above the acid dew point temperature at the bottom of the screen.

Flue Gas Out: Volumetric flow rate of the flue gas after flue gas conditioning, based on the temperature after flue gas conditioning and atmospheric pressure.

Fly Ash Out: Total solids mass flow rate in the flue gas after flue gas conditioning. This includes ash, unburned carbon, activated carbon, and unburned sulfur.

Acid Dew Point: This is the temperature that $\mathrm{H}_{2} \mathrm{SO}_{4}$ vapor condenses into the liquid phase. .

\section{Flue Gas Conditioning}

Water Injected: Water added to the flue gas to reduce the temperature No water is injected if water injection is not specified in the configuration or the inlet temperature is within the approach to saturation relative to the acid dew point.

Carbon Injected: Total activated carbon mass flow rate injected into the flue gas.

NOTE: Carbon injected into the flue gas is collected downstream in the particulate control device (e.g., the cold-side ESP).

\section{Mercury Flue Gas Results}

This screen is only available for the Combustion (Boiler) plant type. The Flue Gas result screen displays a table of quantities of flue gas components entering and exiting the flue gas conditioning area. For each component, quantities are given in both moles and mass per hour. 


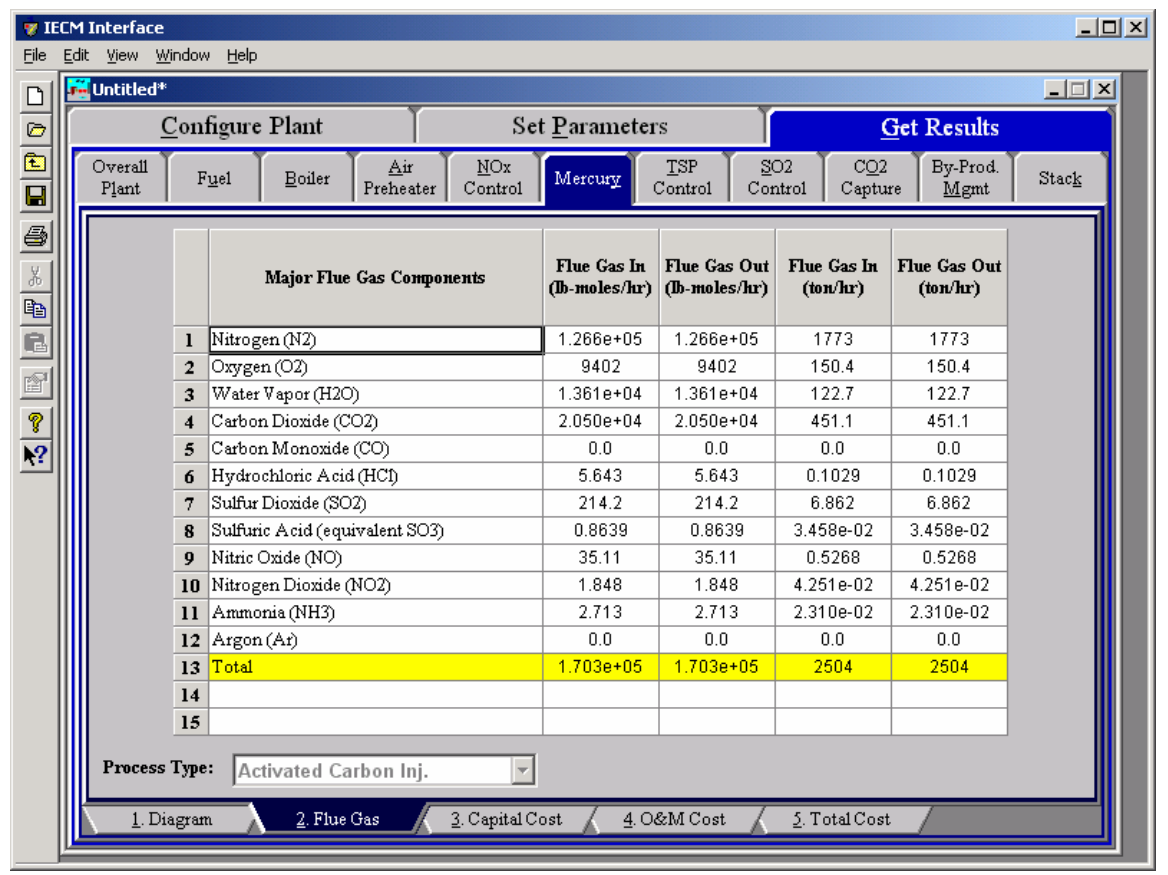

Mercury - Flue Gas result screen.

\section{Major Flue Gas Components}

Each result is described briefly below.

Nitrogen $\left(\mathbf{N}_{\mathbf{2}}\right)$ : Total mass of nitrogen.

Oxygen $\left(\mathrm{O}_{2}\right)$ : Total mass of oxygen.

Water Vapor $\left(\mathbf{H}_{2} \mathbf{O}\right)$ : Total mass of water vapor.

Carbon Dioxide $\left(\mathrm{CO}_{2}\right)$ : Total mass of carbon dioxide.

Carbon Monoxide (CO): Total mass of carbon monoxide.

Hydrochloric Acid (HCl): Total mass of hydrochloric acid.

Sulfur Dioxide $\left(\mathrm{SO}_{2}\right)$ : Total mass of sulfur dioxide.

Sulfuric Acid (equivalent $\mathbf{S O}_{3}$ ): Total mass of sulfuric acid.

Nitric Oxide (NO): Total mass of nitric oxide.

Nitrogen Dioxide $\left(\mathrm{NO}_{2}\right)$ : Total mass of nitrogen dioxide.

Ammonia $\left(\mathrm{NH}_{3}\right)$ : Total mass of ammonia.

Argon (Ar): Total mass of argon.

Total: Total of the individual components listed above. This item is highlighted in yellow.

\section{Mercury Capital Cost Results}

This screen is only available for the Combustion (Boiler) plant type. The Capital

Cost result screen displays tables for the direct and indirect capital costs related to 
the water and carbon injection systems, both part of the overall mercury control option.

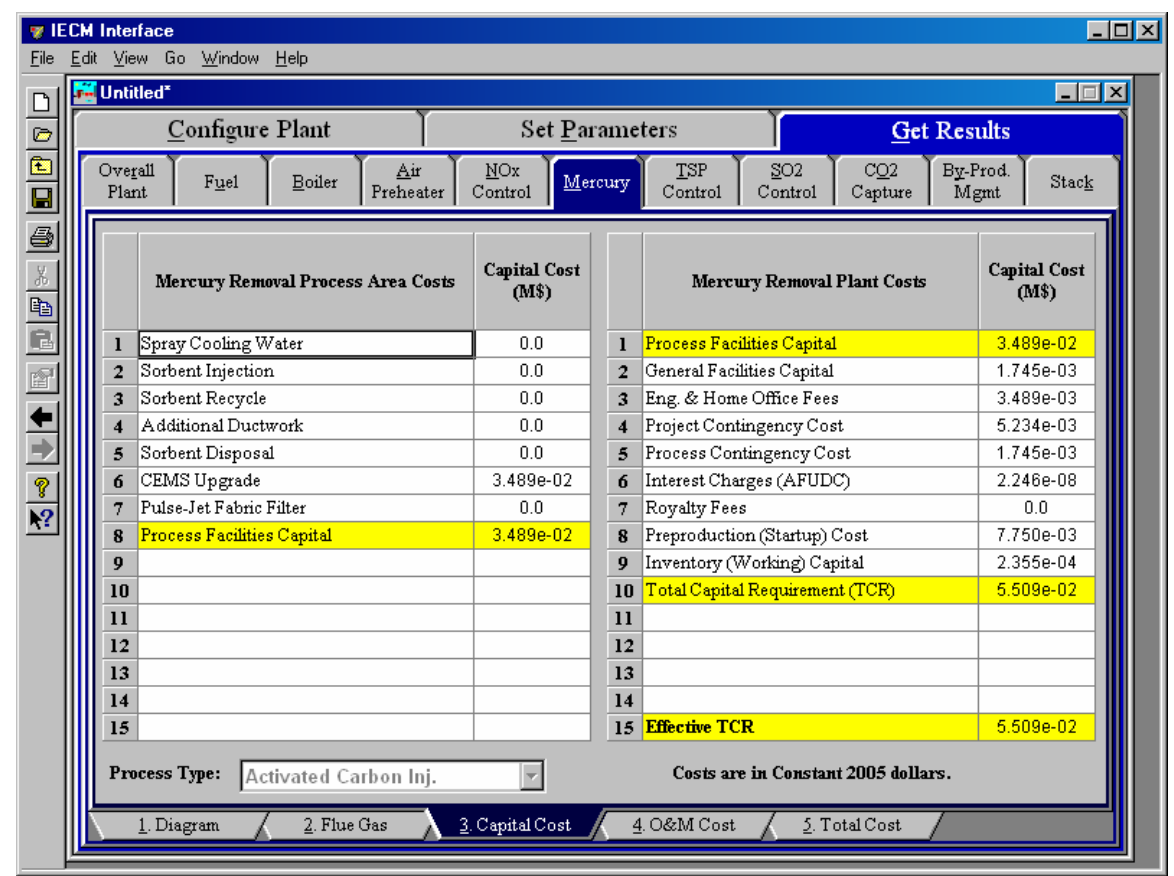

Mercury - Capital Cost result screen.

Capital costs are typically expressed in either constant or current dollars for a specified year, as shown on the bottom of the screen. Each result is described briefly below.

\section{Direct Capital Costs}

The direct capital costs described here apply to the various mercury control equipment added to the power plant. These controls may physically be part of other control technologies, but have their particular capital costs considered here.

Each process area direct capital cost is a reduced-form model based on regression analysis of data collected from several reports and analyses. They are described in general below. The primary factors in the model that effect the capital cost of the base plant are the plant size, the amount of water injected, the amount of activated carbon injected, and the sulfur and moisture content of the coal.

Spray Cooling Water: This capital cost area represents the materials and equipment necessary to inject water into the flue gas duct for the purpose of cooling the flue gas to a prerequisite temperature.

Equipment includes water storage tanks, pumps, transport piping, injection grid with nozzles, and a control system. The direct capital cost is a function of the water flow rate.

Sorbent Injection: This capital cost area represents the materials and equipment necessary to deliver the activated carbon into the flue gas. Equipment includes silo pneumatic loading system, storage silos, hoppers, blowers, transport piping, and a control system. The direct capital cost is a function of the sorbent flow rate.

Sorbent Recycle: This capital cost area represents the materials and equipment necessary to recycle ash and activated carbon from the particulate collector back into the duct injection point. The purpose is 
to create a equilibrium state where the carbon is reintroduced to improve performance. Equipment includes hoppers, blowers, transport piping, and a control system. The direct capital cost is a function of the recycle rate of ash and spent sorbent.

NOTE: Sorbent recycling is a feature to be added in a future version of the IECM.

Additional Ductwork: This capital cost area represents materials and equipment for ductwork necessary beyond the other process areas. Extra ductwork may be required for difficult retrofit installations.

NOTE: Future versions of the IECM will include parameters to determine a capital cost for this area. The current version assumes no additional ductwork.

Sorbent Disposal: This capital cost area represents materials and equipment required to house and dispose the collected sorbent. Equipment includes hoppers, blowers, transport piping, and a control system. This is in excess of existing hoppers, tanks, and piping used for existing particulate collectors. The direct capital cost is determined by the incremental increase in collected solids in the particulate collector.

CEMS Upgrade: This capital cost area represents materials and equipment required to install a continuous emissions monitoring system (CEMS) upgrade. The direct capital cost is determined by the net electrical output of the power plant.

Pulse-Jet Fabric Filter: This capital costs area represents an upgrade to an existing cold-side ESP, where one section at the back end of the unit is replaced with a pulse-jet fabric filter. This can be considered a pseudo-COHPAC. Equipment includes pulse-jet FF, filter bags, ductwork, dampers, and MCCs, instrumentation and PLC controls for baghouse operation. Equipment excludes ash removal system, power distribution and power supply, and distributed control system. The direct capital cost is a function of the flue gas flow rate and the air to cloth ratio of the fabric filter.

NOTE: The IECM currently does not support multiple particulate devices in the same configuration nor a modified cold-side ESP.

Process Facilities Capital: The process facilities capital is the total constructed cost of all on-site processing and generating units listed above, including all direct and indirect construction costs. All sales taxes and freight costs are included where applicable implicitly. This result is highlighted in yellow.

\section{Total Capital Costs}

Process Facilities Capital: See definition above. This result is highlighted in yellow.

General Facilities Capital: The general facilities include construction costs of roads, office buildings, shops, laboratories, etc. Sales taxes and freight costs are included implicitly.

Eng. \& Home Office Fees: The engineering \& home office fees are a percent of total direct capital cost. This is an overhead fee paid to the architect/engineering company. 
Project Contingency Cost: Capital cost contingency factor covering the cost of additional equipment or other costs that would result from a more detailed design of a definitive project at the actual site.

Process Contingency Cost: Capital cost contingency factor applied to a new technology in an effort to quantify the uncertainty in the technical performance and cost of the commercial-scale equipment.

Interest Charges (AFUDC): Allowance for funds used during construction, also referred to as interest during construction, is the time value of the money used during construction and is based on an interest rate equal to the before-tax weighted cost of capital. This interest is compounded on an annual basis (end of year) during the construction period for all funds spent during the year or previous years.

Royalty Fees: Royalty charges may apply to some portions of generating units incorporating new proprietary technologies.

Preproduction (Startup) Cost: These costs consider the operator training, equipment checkout, major changes in unit equipment, extra maintenance, and inefficient use of fuel or other materials during startup.

Inventory (Working) Capital: The raw material supply based on $100 \%$ capacity during a 60 day period. These materials are considered storage. The inventory capital includes fuels, consumables, byproducts, and spare parts.

Total Capital Requirement (TCR): Money that is placed (capitalized) on the books of the utility on the service date. TCR includes all the items above. This result is highlighted in yellow.

Effective TCR: The TCR of the water and carbon injection controls that is used in determining the total power plant cost. The effective TCR is determined by the "TCR Recovery Factor" for the water and carbon injection system.

\section{Mercury O\&M Cost Results}

This screen is only available for the Combustion (Boiler) plant type. The O\&M Cost result screen displays tables for the variable and fixed operation and maintenance costs related to the water and carbon injection systems, both part of the overall mercury control option. The variable O\&M costs are calculated from the variable costs for carbon, water consumption and fly ash disposal (from the particulate control device). The fixed O\&M costs are based on maintenance and labor costs 


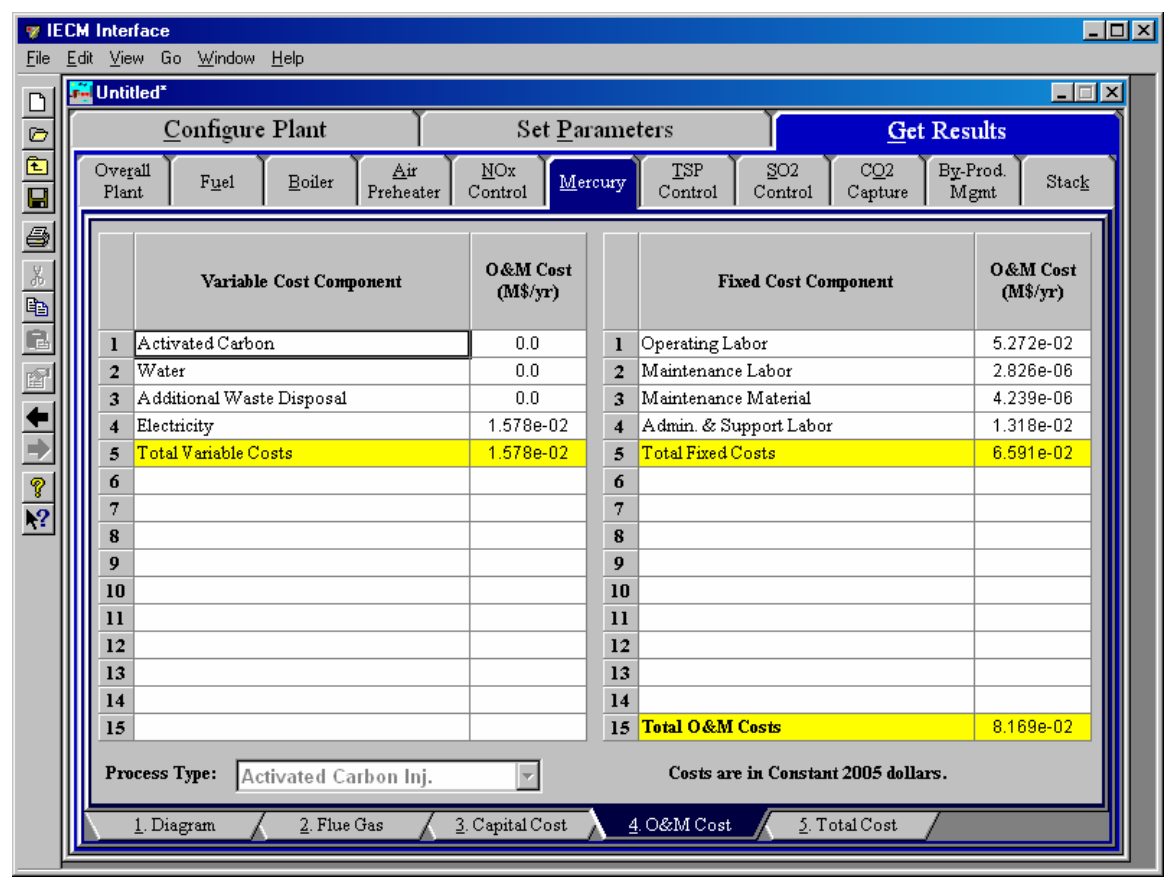

Mercury-O\&M Cost result screen.

O\&M costs are typically expressed on an average annual basis and are provided in either constant or current dollars for a specified year, as shown on the bottom of the screen. Each result is described briefly below.

\section{Variable Cost Components}

Variable operating costs and consumables are directly proportional to the amount of kilowatts produced and are referred to as incremental costs. All the costs are subject to inflation.

Activated Carbon: This is the activated carbon cost for flue gas conditioning.

Water: This is the water cost for flue gas conditioning.

Additional Waste Disposal: This is the solid disposal cost per year for the flue gas conditioning. Only the removal of carbon from the particulate device is considered here.

Electricity: This is the power utilization cost per year for the flue gas conditioning.

Total Variable Costs: This is the sum of all the variable O\&M costs listed above. This result is highlighted in yellow.

\section{Fixed Cost Components}

Fixed operating costs are essentially independent of actual capacity factor, number of hours of operation, or amount of kilowatts produced. All the costs are subject to inflation.

Operating Labor: Operating labor cost is based on the operating labor rate, the number of personnel required to operate the plant per eight- 
hour shift, and the average number of shifts per day over 40 hours per week and 52 weeks.

Maintenance Labor: The maintenance labor is determined as a fraction of the total maintenance cost.

Maintenance Material: The cost of maintenance material is the remainder of the total maintenance cost, considering the fraction associated with maintenance labor.

Admin. \& Support Labor: The administrative and support labor is the only overhead charge. It is taken as a fraction of the total operating and maintenance labor costs.

Total Fixed Costs: This is the sum of all the fixed O\&M costs listed above. This result is highlighted in yellow.

Total O\&M Costs: This is the sum of the total variable and total fixed O\&M costs. It is used to determine the base plant total revenue requirement. This result is highlighted in yellow.

\section{Mercury Total Cost Results}

This screen is only available for the Combustion (Boiler) plant type. The Total Cost result screen displays a table which totals the annual fixed, variable, operations and maintenance, and capital costs related to the water and carbon injection systems, both part of the overall mercury control option.

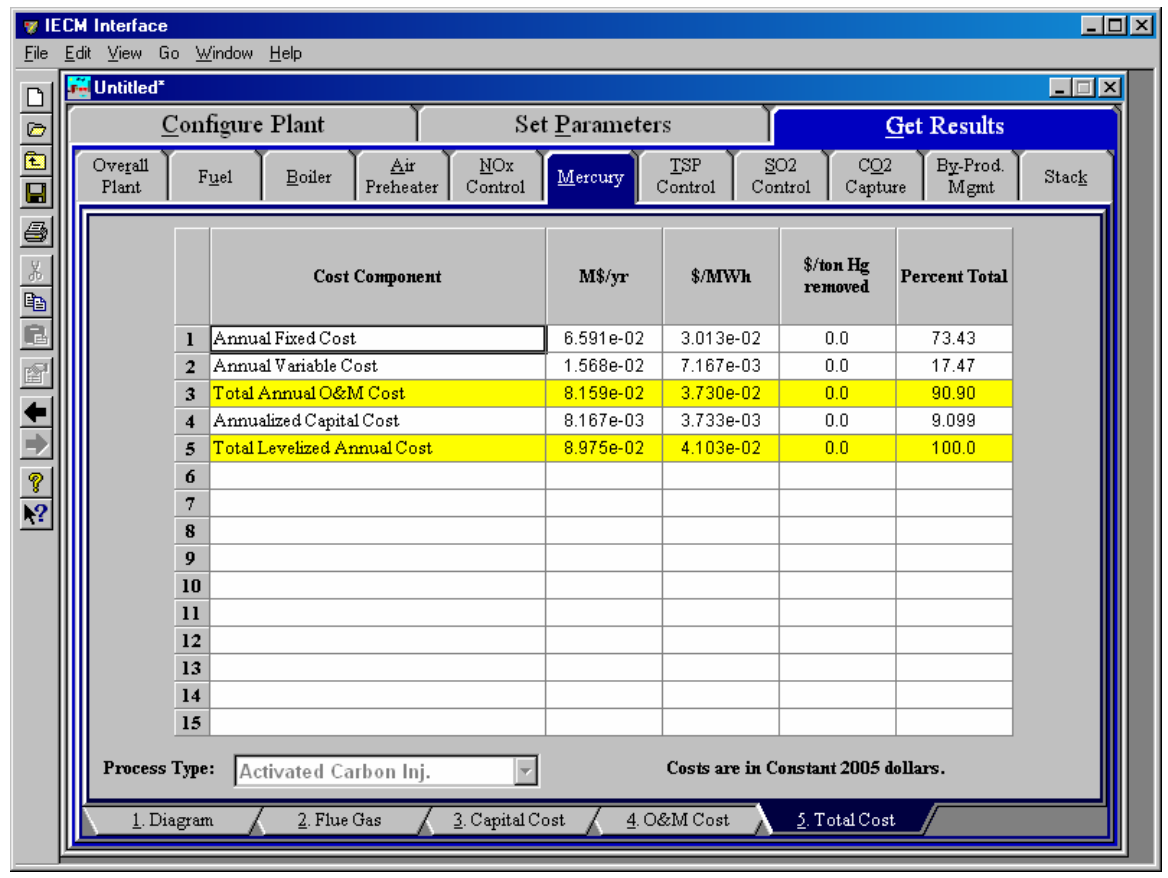

Mercury - Total Cost result screen.

Total costs are typically expressed in either constant or current dollars for a specified year, as shown on the bottom of the screen. Each result is described briefly below. 


\section{Cost Component}

Annual Fixed Cost: The operating and maintenance fixed costs are given as an annual total. This number includes all maintenance materials and all labor costs.

Annual Variable Cost: The operating and maintenance variables costs are given as an annual total. This includes all reagent, chemical, steam, and power costs.

Total Annual O\&M Cost: This is the sum of the annual fixed and variable operating and maintenance costs above. This result is highlighted in yellow.

Annualized Capital Cost: This is the total capital cost expressed on an annualized basis, taking into consideration the levelized carrying charge factor, or fixed charge factor, over the entire book life.

Total Levelized Annual Cost: The total annual cost is the sum of the total annual O\&M cost and annualized capital cost items above. This result is highlighted in yellow. 


\section{Cold-Side ESP}

The TSP Control. Technology Navigation screens define and display flows and costs related to the particulate control technology. These screens are available only if the Cold-Side ESP TSP control technology is selected in the Combustion (Boiler) plant type configurations.

\section{Cold-Side ESP Performance Inputs}

This screen is only available for the Combustion (Boiler) plant type. Inputs for the performance of the Cold-Side ESP TSP control technology are entered on the Performance input screen. Many of the parameters are calculated by the IECM. Each parameter is described briefly below.

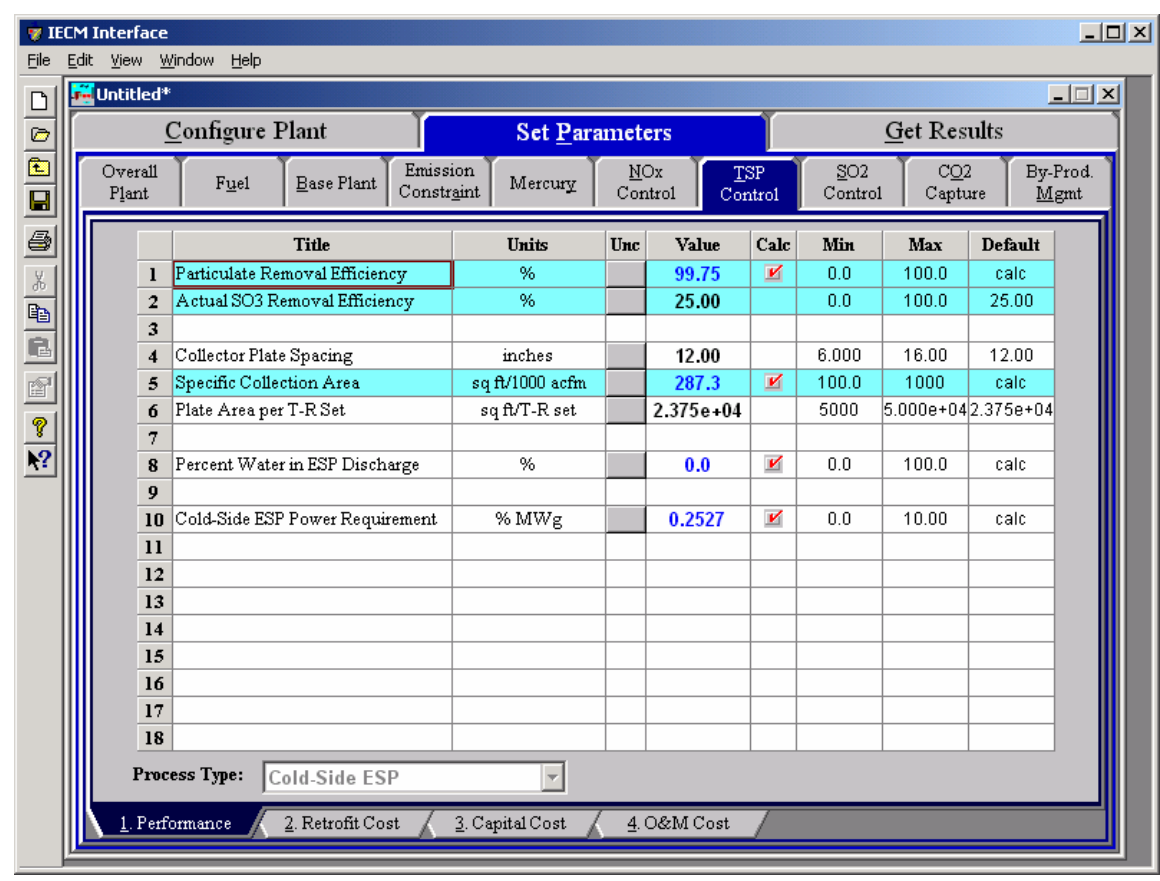

Cold-Side ESP - Performance input screen.

ESPs consist of a series of parallel plates with rows of electrodes in between them and carry a high voltage of opposite polarity. As the particle laden flue gas enters the unit, the particles are charged by the electrodes and is attracted to the plates. At controlled intervals the plates are rapped which shakes the dust to a hopper below. 
However, some of the dust is re-entrained and carried to the next zone or out of the stack. Most ESPs use rigid collecting plates with shielded air pockets (baffles) through which ash falls into the hoppers after rapping.

The major design parameters which can significantly impact the total system capital cost are gas flow volume (which depends on the generating unit size), SCA, the collecting plate area per transformer-rectifier (T-R) set and the spacing between collector plates.

Particulate Removal Efficiency: The calculated value determines the removal efficiency needed to comply with the specified particulate emission limit set earlier. This efficiency then determines the mass of particulate matter removed in the collector.

Actual $\mathrm{SO}_{3}$ Removal Efficiency: The default value is taken from the removal efficiency reported in the literature (references are below). This efficiency then determines the mass of $\mathrm{SO}_{3}$ removed from the flue gas in the collector. For more information see also:

- $\quad$ www.netl.doe.gov/publications/proceedings/98/98fg/hardman.pdf

- $\quad$ www.netl.doe.gov/publications/proceedings/98/98fg/rubin.pdf

Collector Plate Spacing: The collector plate spacing is typically 12 inches. The spacing is used to determine the specific collection area.

Specific Collection Area: The specific collection area (SCA) is the ratio of the total plate area and flue gas volume. It sizes the ESP. The value is calculated from the removal efficiency, plate spacing, and the drift velocity. It is used to determine the capital cost and the total collection area required.

Plate Area per T-R Set: This is the total surface area of one T-R set of plates. It is used to determine the total number of T-R sets needed and the capital costs.

Percent Water in ESP Discharge: This is the water content of the collected fly ash. Fly ash disposed with bottom ash is assumed to be sluiced with water and dry otherwise. The occluded water in wet fly ash is difficult to remove, resulting in a rather high water content when the fly ash is mixed with bottom ash.

Cold-Side ESP Power Requirement: The default calculation is based on the T-R set power consumption with estimates for auxiliary power requirements and electro-mechanical efficiencies of fan motors. The T$\mathrm{R}$ set power consumption is a function of removal efficiency.

\section{Cold-Side ESP Retrofit Cost Inputs}

This screen is only available for the Combustion (Boiler) plant type. Inputs for the capital costs of modifications to process areas to implement the Particulate control technology are entered on the Retrofit Cost input screen.

The retrofit cost factor of each process is a multiplicative cost adjustment, which considers the cost of retrofitted capital equipment relative to similar equipment installed in a new plant. These factors affect the capital costs directly and the operating and maintenance costs indirectly.

Direct capital costs for each process area are calculated in the IECM. These calculations are reduced form equations derived from more sophisticated models and 
reports. The sum of the direct capital costs associated with each process area is defined as the process facilities capital (PFC). The retrofit cost factor provided for each of the process areas can be used as a tool for adjusting the anticipated costs and uncertainties across the process area separate from the other areas.

Uncertainty can be applied to the retrofit cost factor for each process area in each technology. Thus, uncertainty can be applied as a general factor across an entire process area, rather than as a specific uncertainty for the particular cost on the capital or O\&M input screens. Any uncertainty applied to a process area through the retrofit cost factor compounds any uncertainties specified later in the capital and O\&M cost input parameter screens.

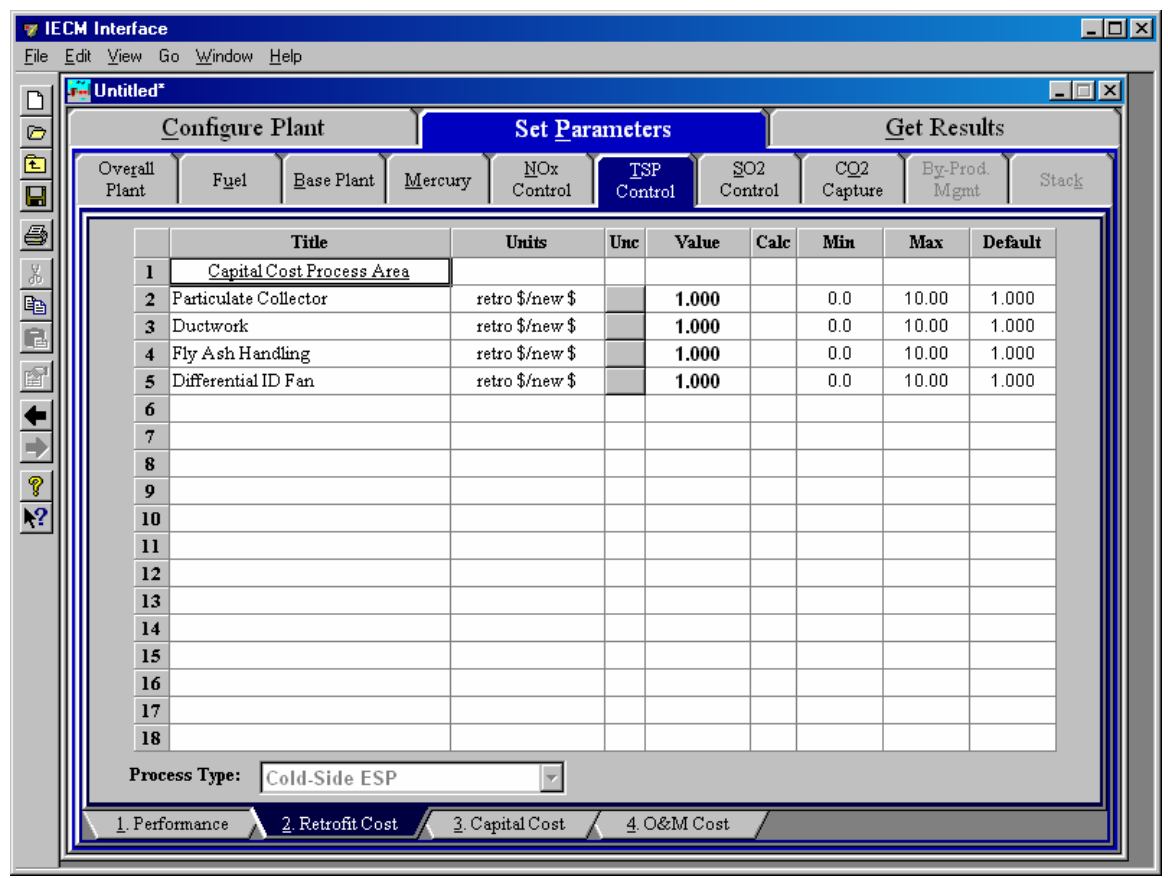

Cold-Side ESP - Retrofit Cost input screen.

Each parameter is described briefly below.

\section{Capital Cost Process Area}

Particulate Collector: This area covers the material and labor, flange to flange, for the equipment and labor cost for installation of the entire collection system.

Ductwork: This area includes the material and labor for the ductwork needed to distribute flue gas to the inlet flange, and from the outlet flange to a common duct leading to the suction side of the ID fan.

Fly Ash Handling: The complete fly ash handling cost includes the conveyor system and ash storage silos.

Differential ID Fan: The complete cost of the ID fan and motor due to the pressure loss that results from particulate collectors. 


\section{Cold-Side ESP Capital Cost Inputs}

This screen is only available for the Combustion (Boiler) plant type. Inputs for the capital costs of particulate control technology are entered on the Capital Cost input screen.

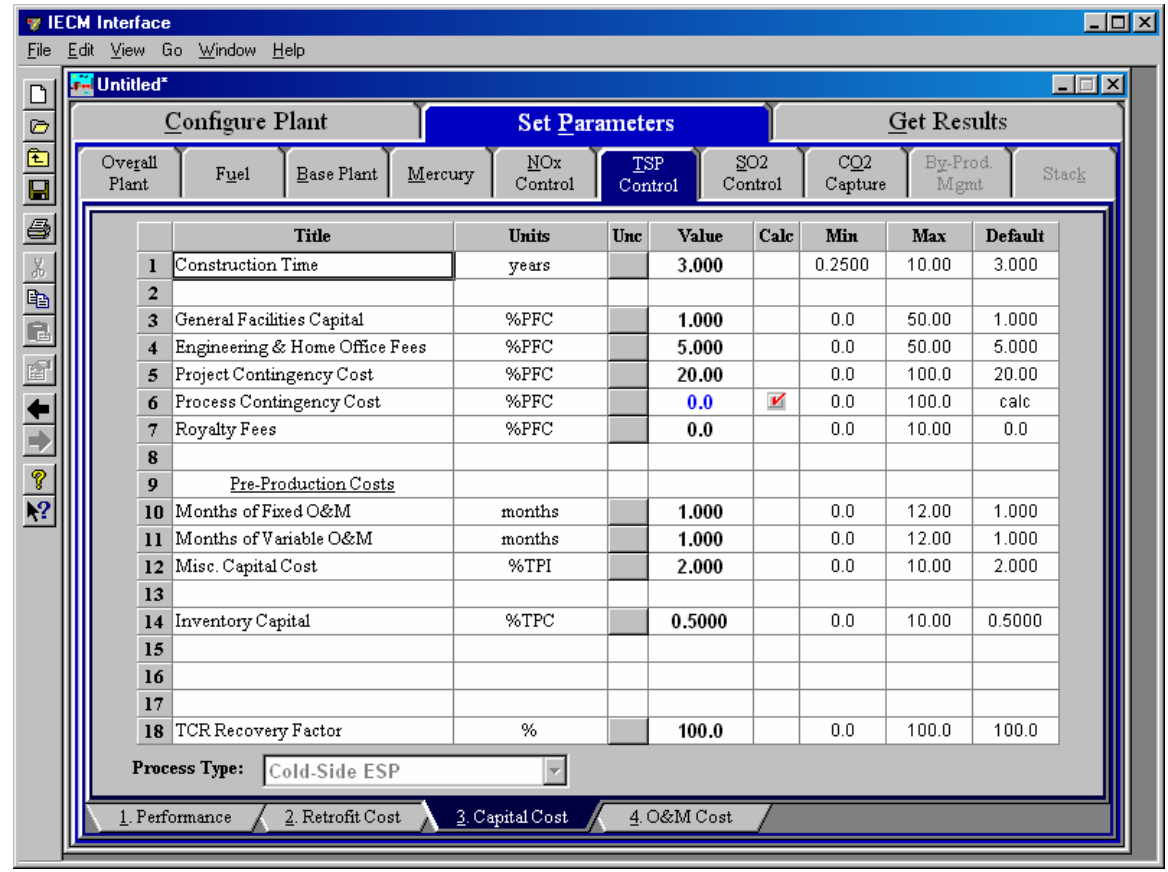

Cold-Side ESP - Capital Cost input screen.

The necessary capital cost input parameters associated with the electrostatic precipitator control technology are shown on this input screen.

Indirect Capital Costs: Costs that are indirectly applied to the technology are based on the process facilities cost. Each of the cost factors below is expressed as a percentage of the process facilities cost, and is entered on this screen. Each parameter is described briefly below.

Construction Time: This is the idealized construction period in years. It is used to determine the allowance for funds used during construction (AFUDC).

General Facilities Capital (GFC): The general facilities include construction costs of roads, office buildings, shops, laboratories, etc. Sales taxes and freight costs are included implicitly. The cost typically ranges from $5-20 \%$.

Engineering \& Home Office Fees: The engineering \& home office fees are a percent of total direct capital cost. This is an overhead fee paid to the architect/engineering company. These fees typically range from 7$15 \%$.

Project Contingency Cost: This is factor covering the cost of additional equipment or other costs resulting from a more detailed design. Higher contingency factors will be applied to simplified or preliminary designs and lower factors to detailed or finalized designs.

Process Contingency Cost: This quantifies the design uncertainty and cost of a commercial-scale system. This is generally applied on an area- 
by-area basis. Higher contingency factors are applied to new regeneration systems tested at a pilot plant and lower factors to full-size or commercial systems.

Royalty Fees: Royalty charges may apply to some portions of generating units incorporating new proprietary technologies.

Pre-Production Costs : These costs consider the operator training, equipment checkout, major changes in unit equipment, extra maintenance, and inefficient use of fuel or other materials during startup. These are typically applied to the O\&M costs over a specified period of time (months)The two time periods for fixed and variable O\&M costs are described below with the addition of a miscellaneous capital cost factor.

- Months of Fixed O\&M: Time period of fixed operating costs used for preproduction to cover training, testing, major changes in equipment, and inefficiencies in start-up. This includes operating, maintenance, administrative and support labor. It also considers maintenance materials.

- Months of Variable O\&M: Time period of variable operating costs used for preproduction to cover chemicals, water, consumables, and solid disposal charges in start-up, assuming $100 \%$ load. This excludes any fuels.

- Misc. Capital Cost: This is a percent of total plant investment (sum of TPC and AFUDC) to cover expected changes to equipment to bring the system up to full capacity.

Inventory Capital: Percent of the total direct capital for raw material supply based on $100 \%$ capacity during a 60 day period. These materials are considered storage. The inventory capital includes fuels, consumables, by-products, and spare parts. This is typically $0.5 \%$.

TCR Recovery Factor: The actual total capital required (TCR) as a percent of the TCR in a new power plant. This value is $100 \%$ for a new installation and may be set as low as $0 \%$ for a cold-side ESP that has been paid off.

\section{Cold-Side ESP O\&M Cost Inputs}

This screen is only available for the Combustion (Boiler) plant type. 


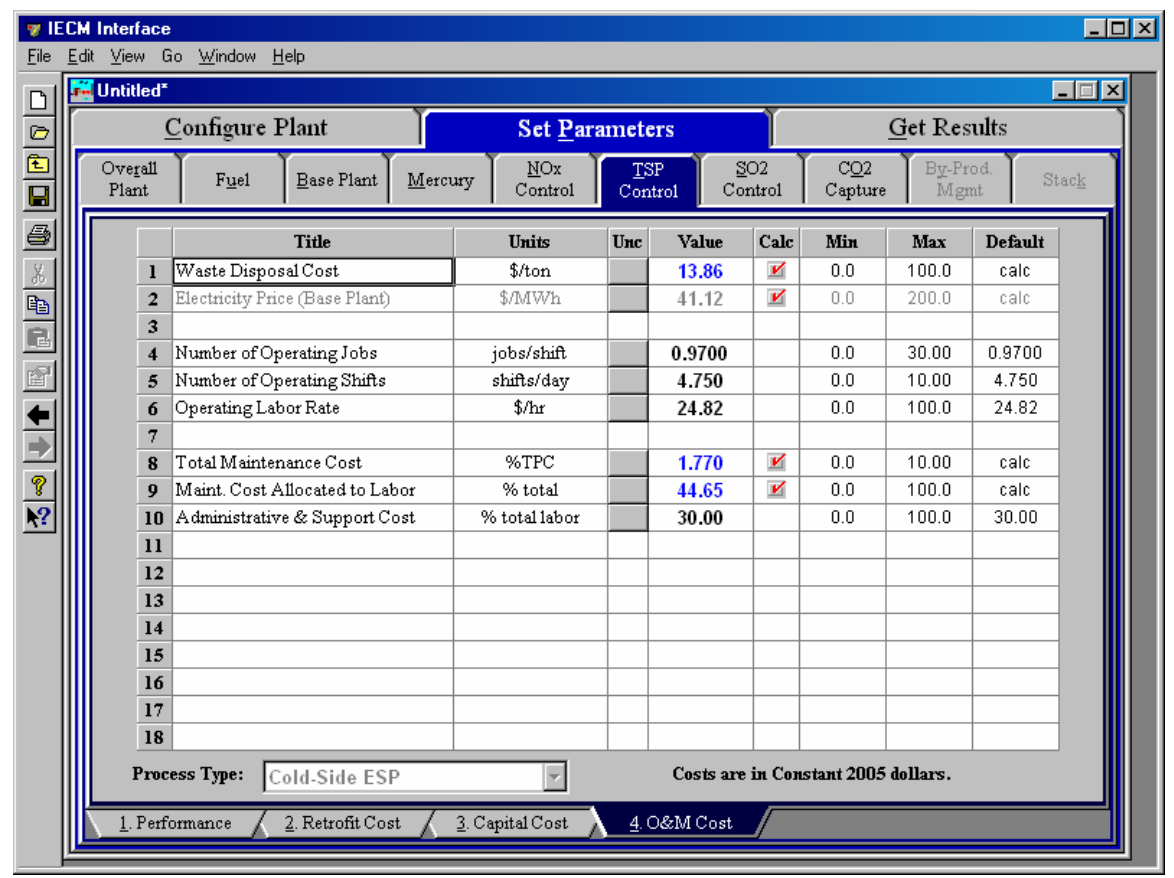

Cold-Side ESP - O\&M Cost screen input.

O\&M costs are typically expressed on an average annual basis and are provided in either constant or current dollars for a specified year, as shown on the bottom of the screen. Inputs for the operation and maintenance costs of the particulate control technology are entered on this screen.

Waste Disposal Cost: This is the disposal cost for the particulate control system.

Electricity Price (Base Plant): This is the price of electricity and is calculated as a function of the utility cost of the base plant, where the base plant is defined as combustion boiler and an air preheater.

Number of Operating Jobs: This is the total number of operating jobs that are required to operate the plant per eight-hour shift.

Number of Operating Shifts: This is the total number of equivalent operating shifts in the plant per day. The number takes into consideration paid time off and weekend work ( 3 shifts/day * 7 days/5 day week $* 52$ weeks $/(52$ weeks -6 weeks PTO $)=4.75$ equiv. Shifts/day)

Operating Labor Rate: The hourly cost of labor is specified in the base plant O\&M cost screen. The same value is used throughout the other technologies.

Total Maintenance Cost: This is the annual maintenance cost as a percentage of the total plant cost. Maintenance cost estimates can be developed separately for each process area.

Maint. Cost Allocated to Labor: Maintenance cost allocated to labor as a percentage of the total maintenance cost.

Administrative \& Support Cost: This is the percent of the total operating and maintenance labor associated with administrative and support labor. 


\section{Cold-Side ESP Diagram}

This screen is only available for the Combustion (Boiler) plant type. The Diagram result screen displays an icon for the particulate control technology selected and values for major flows in and out of it.

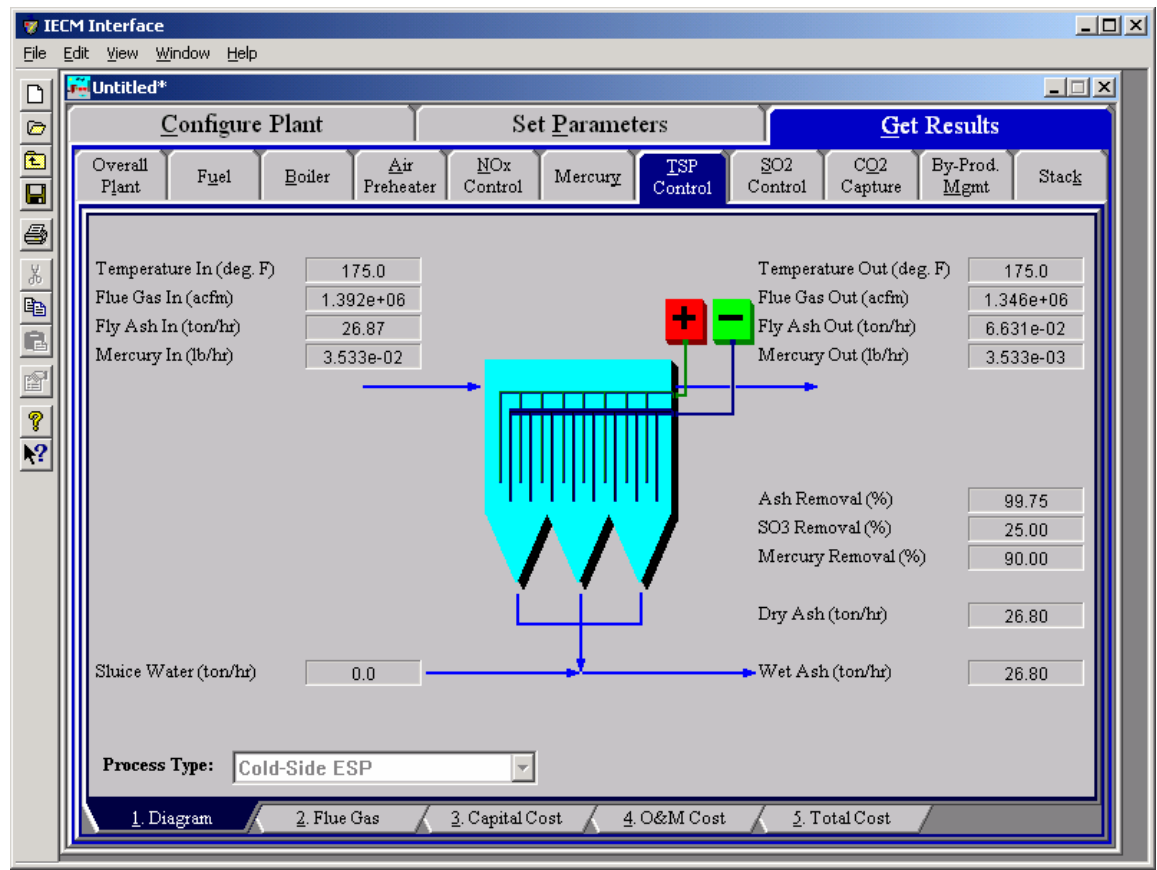

Cold-Side ESP - Diagram

Each result is described briefly below:

\section{Flue Gas Entering ESP}

Temperature In: Temperature of the flue gas entering the particulate control technology. This is determined by the flue gas outlet temperature of the module upstream of the air preheater (e.g., the air preheater).

Flue Gas In: Volumetric flow rate of the flue gas entering the particulate control technology, based on the flue gas inlet temperature and atmospheric pressure.

Fly Ash In: Total solids mass flow rate in the flue gas entering the air preheater. This is determined by the solids exiting the module upstream of the particulate control technology (e.g., the air preheater).

Mercury In: Total mass of mercury entering the particulate control technology. The value is a sum of all the forms of mercury (elemental, oxidized, and particulate).

\section{Flue Gas Exiting ESP}

Temperature Out: Temperature of the flue gas exiting the particulate control technology. The model currently does not alter this temperature through the particulate control technology. 
Flue Gas Out: Volumetric flow rate of the flue gas exiting the particulate control technology, based on the flue gas exit temperature and atmospheric pressure.

Fly Ash Out: Total solids mass flow rate in the flue gas exiting the particulate control technology. This is a function of the ash content of the inlet flue gas and the ash removal efficiency performance input parameter.

Mercury Out: Total mass of mercury exiting the particulate control technology. The value is a sum of all the forms of mercury (elemental, oxidized, and particulate).

\section{ESP Performance}

Ash Removal: Ash removal efficiency of the particulate control technology. This is a function of the ash emission constraint and the inlet ash mass flow rate.

$\mathrm{SO}_{3}$ Removal: Percent of $\mathrm{SO}_{3}$ in the flue gas removed from the particulate control technology. The $\mathrm{SO}_{3}$ is assumed to combine with $\mathrm{H}_{2} \mathrm{O}$ and leave with the ash solids as a sulfate (in the form of $\mathrm{H}_{2} \mathrm{SO}_{4}$ ).

Mercury Removal: Percent of the total mercury removed from the particulate control technology. The value reflects a weighted average based on the particular species of mercury present (elemental, oxidized, and particulate).

\section{Collected Fly Ash}

Dry Ash: Total mass flow rate of the solids removed from the ESP. This is a function of the solids content in the flue gas and the particulate removal efficiency of the ESP. The value is given on a dry basis.

Sluice Water: Water added to the dry fly ash. This water is added for transportation purposes.

Wet Ash: Total mass flow rate of the solids removed for waste management. This includes dry fly ash and sluice water. The value is given on a wet basis.

\section{Cold-Side ESP Flue Gas Results}

This screen is only available for the Combustion (Boiler) plant type. The Flue Gas result screen displays a table of quantities of flue gas components entering and exiting the Particulate Control Technology. For each component, quantities are given in both moles and mass per hour. 


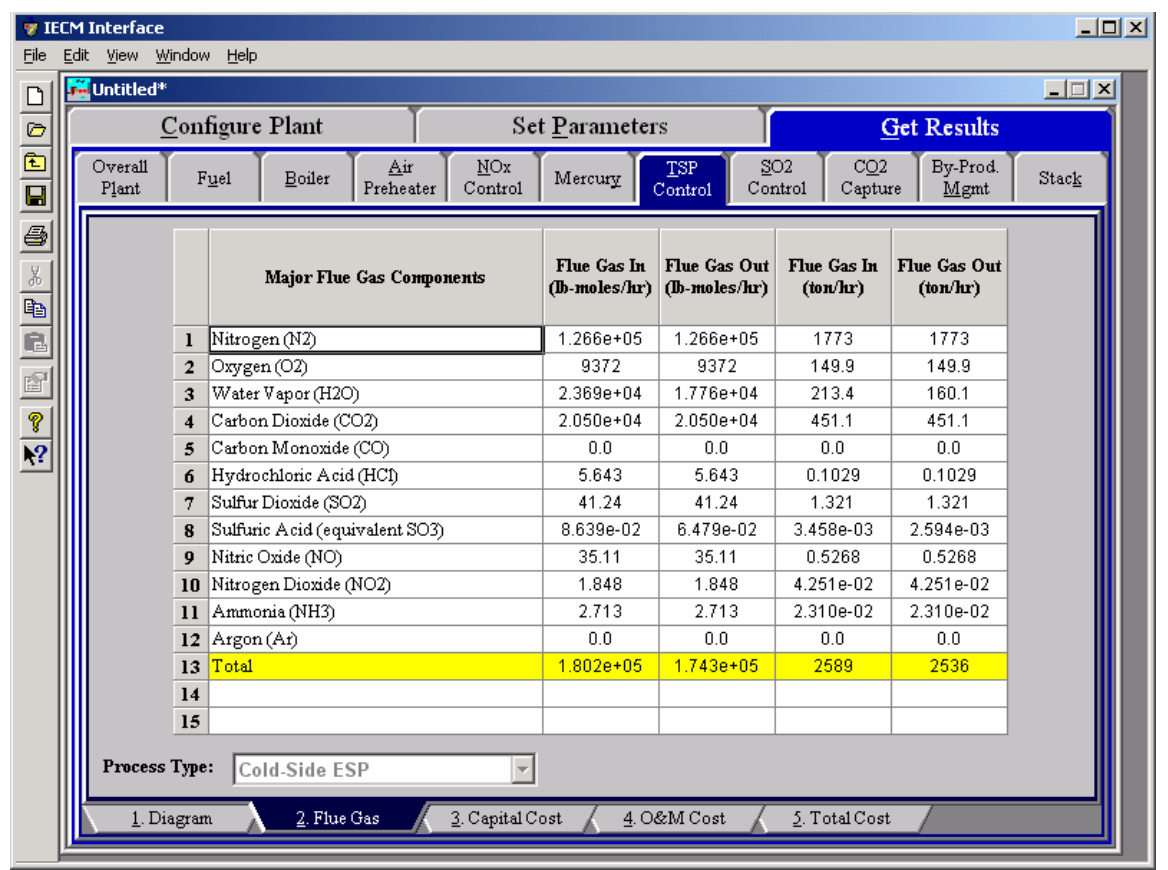

Cold-Side ESP - Flue Gas results screen.

Each result is described briefly below:

\section{Major Flue Gas Components}

Nitrogen (N2): Total mass of nitrogen.

Oxygen (02): Total mass of oxygen.

Water Vapor (H2O): Total mass of water vapor.

Carbon Dioxide (CO2): Total mass of carbon dioxide.

Carbon Monoxide (CO): Total mass of carbon monoxide.

Hydrochloric Acid $(\mathrm{HCl})$ : Total mass of hydrochloric acid.

Sulfur Dioxide (SO2): Total mass of sulfur dioxide.

Sulfuric Acid (equivalent SO3): Total mass of sulfuric acid.

Nitric Oxide (NO): Total mass of nitric oxide.

Nitrogen Dioxide (NO2): Total mass of nitrogen dioxide.

Ammonia (NH3): Total mass of Ammonia.

Argon (Ar): Total mass of Argon.

Total: Total of the individual components listed above. This item is highlighted in yellow.

\section{Cold-Side ESP Capital Cost Results}

This screen is only available for the Combustion (Boiler) plant type. The Capital Cost result screen displays tables for the direct and indirect capital costs related to the particulate control technology. 


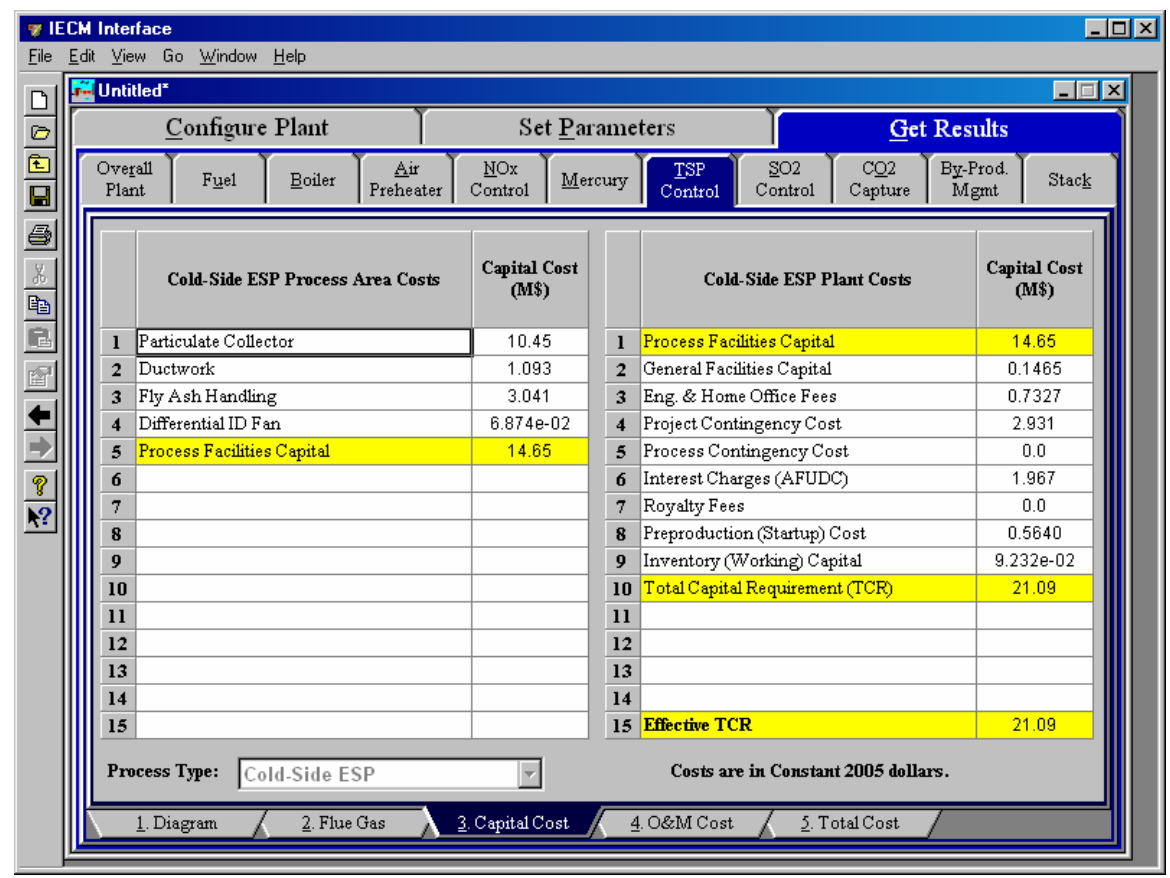

Cold-Side ESP - Capital Costs results screen.

\section{Direct Capital Costs}

Each process area direct capital cost is a reduced-form model based on regression analysis of data collected from several reports and analyses of particulate control technology units. They are described in general below. The primary factors in the model that effect the capital costs of the cold-side ESP are the specific and total collection areas of the T-R plate sets, and the flue gas flow rate through the ESP. The primary model factors that effect the capital costs of the fabric filter are the fabric filter type, the air to cloth ratio, the number of bags and compartments, and the flue gas flow rate through the fabric filter.

Capital costs are typically expressed in either constant or current dollars for a specified year, as shown on the bottom of the screen. The parameters are described below.

Particulate Collector: This area covers the material and labor, flange to flange, for the equipment and labor cost for installation of the entire collection system.

Ductwork: This area includes the material and labor for the ductwork needed to distribute flue gas to the inlet flange, and from the outlet flange to a common duct leading to the suction side of the ID fan.

Fly Ash Handling: The complete fly ash handling cost includes the conveyor system and ash storage silos.

Differential ID Fan: The complete cost of the ID fan and motor due to the pressure loss that results from particulate collectors.

Process Facilities Capital: The process facilities capital is the total constructed cost of all on-site processing and generating units listed above, including all direct and indirect construction costs. All sales taxes and freight costs are included where applicable implicitly. This result is highlighted in yellow. 


\section{Total Capital Costs}

Process Facilities Capital: (see definition above)

General Facilities Capital: The general facilities include construction costs of roads, office buildings, shops, laboratories, etc. Sales taxes and freight costs are included implicitly.

Eng. \& Home Office Fees: The engineering \& home office fees are a percent of total direct capital cost. This is an overhead fee paid to the architect/engineering company.

Project Contingency Cost: Capital cost contingency factor covering the cost of additional equipment or other costs that would result from a more detailed design of a definitive project at the actual site.

Process Contingency Cost: Capital cost contingency factor applied to a new technology in an effort to quantify the uncertainty in the technical performance and cost of the commercial-scale equipment.

Interest Charges (AFUDC): Allowance for funds used during construction, also referred to as interest during construction, is the time value of the money used during construction and is based on an interest rate equal to the before-tax weighted cost of capital. This interest is compounded on an annual basis (end of year) during the construction period for all funds spent during the year or previous years.

Royalty Fees: Royalty charges may apply to some portions of generating units incorporating new proprietary technologies.

Preproduction (Startup) Cost: These costs consider the operator training, equipment checkout, major changes in unit equipment, extra maintenance, and inefficient use of fuel or other materials during startup.

Inventory (Working) Capital: The raw material supply based on $100 \%$ capacity during a 60 day period. These materials are considered storage. The inventory capital includes fuels, consumables, byproducts, and spare parts.

Total Capital Requirement (TCR): Money that is placed (capitalized) on the books of the utility on the service date. TCR includes all the items above. This result is highlighted in yellow.

Effective TCR: The TCR of the cold-side ESP that is used in determining the total power plant cost. The effective TCR is determined by the TCR Recovery Factor for the cold-side ESP.

\section{Cold-Side ESP O\&M Cost Results}

This screen is only available for the Combustion (Boiler) plant type. The O\&M

Cost result screen displays tables for the variable and fixed operation and maintenance costs involved with the Cold-Side ESP TSP particulate control technology. 


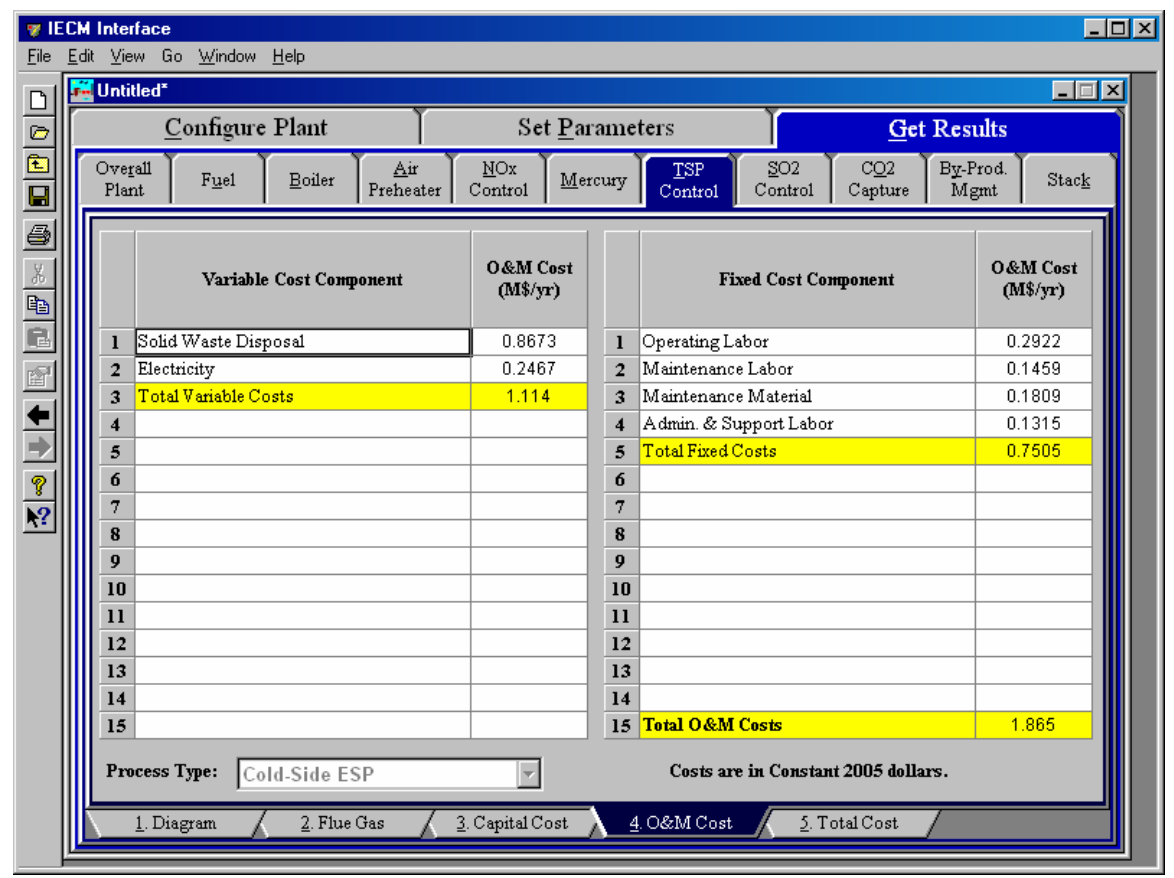

Cold-Side ESP - O\&M Cost result screen.

O\&M costs are typically expressed on an average annual basis and are provided in either constant or current dollars for a specified year, as shown on the bottom of the screen. Each result is described briefly below

\section{Variable Cost Component}

Variable operating costs and consumables are directly proportional to the amount of kilowatts produced and are referred to as incremental costs. All the costs are subject to inflation.

Solid Waste Disposal: Total cost to dispose the collected fly ash. This does not consider by-product ash sold in commerce.

Power: Cost of power consumption of the particulate control technology. This is a function of the flue gas flow rate, ash removal efficiency and the type of coal (ash properties).

Total Variable Costs: This is the sum of all the variable O\&M costs listed above. This result is highlighted in yellow.

\section{Fixed Cost Components}

Fixed operating costs are essentially independent of actual capacity factor, number of hours of operation, or amount of kilowatts produced. All the costs are subject to inflation.

Operating Labor: Operating labor cost is based on the operating labor rate, the number of personnel required to operate the plant per eighthour shift, and the average number of shifts per day over 40 hours per week and 52 weeks.

Maintenance Labor: The maintenance labor is determined as a fraction of the total maintenance cost. 
Maintenance Material: The cost of maintenance material is the remainder of the total maintenance cost, considering the fraction associated with maintenance labor.

Admin. \& Support Labor: The administrative and support labor is the only overhead charge. It is taken as a fraction of the total operating and maintenance labor costs.

Total Fixed Costs: This is the sum of all the fixed O\&M costs listed above. This result is highlighted in yellow.

Total O\&M Costs: This is the sum of the total variable and total fixed O\&M costs. It is used to determine the base plant total revenue requirement. This result is highlighted in yellow.

\section{Cold-Side ESP Total Cost Results}

This screen is only available for the Combustion (Boiler) plant type. The Total Cost result screen displays a table which totals the annual fixed, variable, operations and maintenance, and capital costs associated with the Cold-Side ESP TSP Control technology.

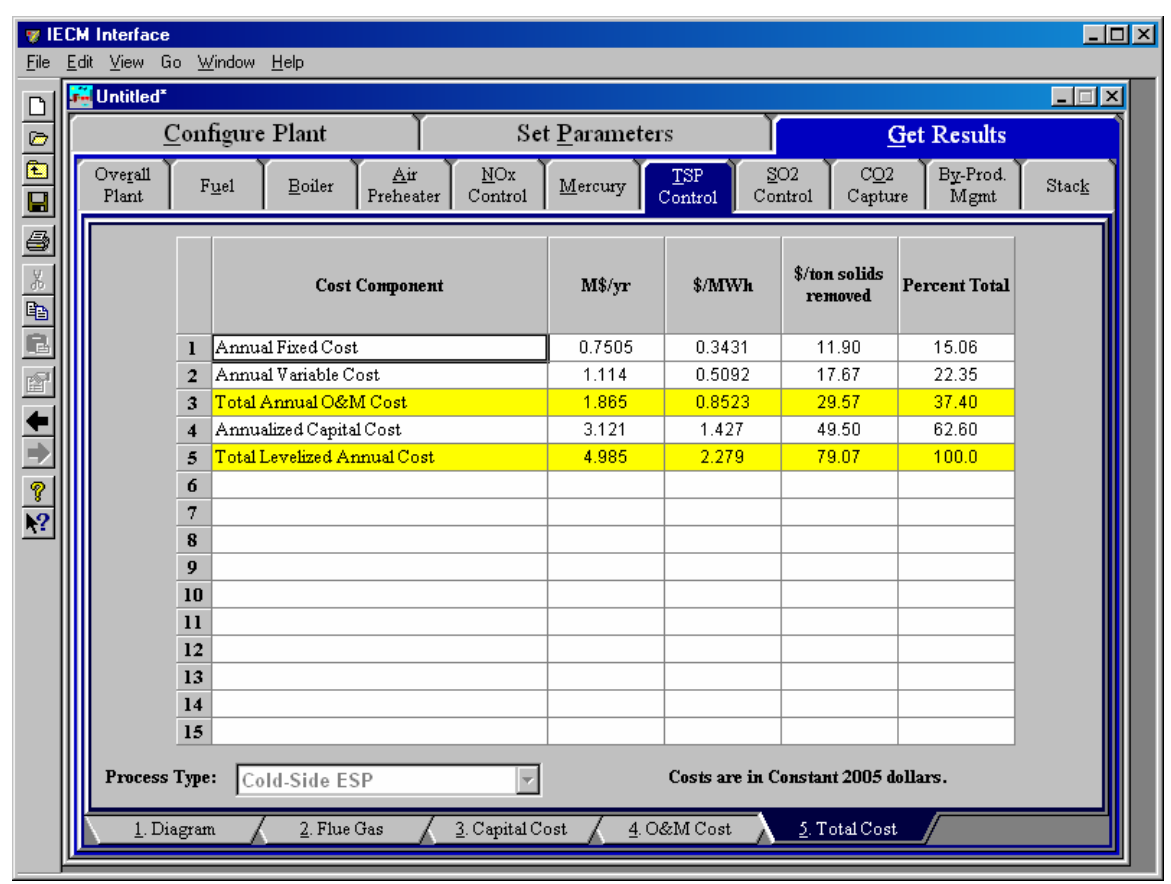

Cold-Side ESP - Total Cost result screen.

Total costs are typically expressed in either constant or current dollars for a specified year, as shown on the bottom of the screen. Each result is described briefly below.

\section{Cost Component}

Annual Fixed Cost: The operating and maintenance fixed costs are given as an annual total. This number includes all maintenance materials and all labor costs. 
Annual Variable Cost: The operating and maintenance variables costs are given as an annual total. This includes all reagent, chemical, steam, and power costs.

Total Annual O\&M Cost: This is the sum of the annual fixed and variable operating and maintenance costs above. This result is highlighted in yellow.

Annualized Capital Cost: This is the total capital cost expressed on an annualized basis, taking into consideration the levelized carrying charge factor, or fixed charge factor, over the entire book life.

Total Levelized Annual Cost: The total annual cost is the sum of the total annual O\&M cost and annualized capital cost items above. This result is highlighted in yellow. 


\section{Wet FGD}

The Sô2 Control Technology Navigation contains screens that address postcombustion air pollution technologies for Sulfur Dioxide. The model includes options for a Wet FGD. The screens are available if this $\mathrm{SO}_{2}$ control technology has been selected in Configure Plant for the Combustion (Boiler) plant type.

\section{Wet FGD Configuration}

This screen is only available for the Combustion (Boiler) plant type. Inputs for configuration of the Wet FGD SO${ }_{2}$ control technology are entered on the Config input screen.

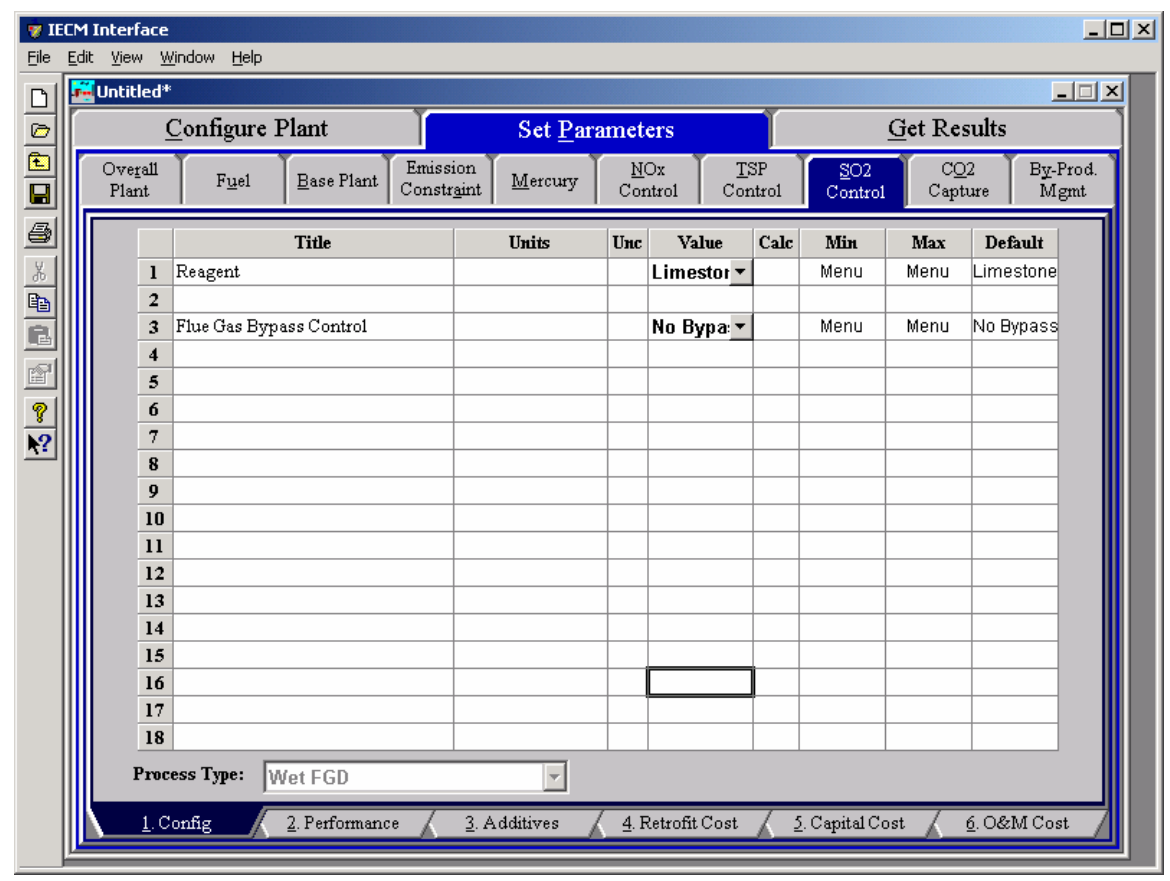

Wet FGD - Config. Input screen (no bypass). .

Each parameter is described briefly below. 


\section{Reagent}

For Wet FGD systems, the choice of reagent affects nearly all of the performance and economic parameters of the FGD. Three choices are available:

Limestone: Limestone with Forced Oxidation-A limestone slurry is used in an open spray tower with in-situ oxidation to remove $\mathrm{SO}_{2}$ and form a gypsum sludge. The main advantages as compared to conventional systems are easier dewatering, more economical disposal of scrubber products, and decreased scaling on tower walls.

Limestone with Additives: Limestone with Dibasic Acid AdditiveDibasic acid (DBA) is added to the Limestone to act as a buffer/catalyst in the open spray tower. The main advantages are increased $\mathrm{SO}_{2}$ removal and decreased liquid to gas ratio.

Lime: Magnesium Enhanced Lime System-A magnesium sulfite and lime slurry (maglime) is used to remove $\mathrm{SO}_{2}$ and form a precipitate high in calcium sulfite. The high alkalinity of the maglime slurry allows very high $\mathrm{SO}_{2}$ removal. However, the reagent cost is also higher and solid waste is not easily disposed.

\section{Flue Gas Bypass Control}

This popup selection menu controls whether or not a portion of the inlet flue gas may bypass the scrubber and recombine with the treated flue gas. Bypass allows the scrubber to operate at full efficiency while allowing some of the flue gas to go untreated. Two choices are available:

No Bypass: This option forces the entire flue gas to pass through the scrubber. This is the default option.

Bypass: This option allows for the possibility of a portion of the flue gas to bypass the scrubber. The amount of bypass is controlled by several additional input parameters described below.

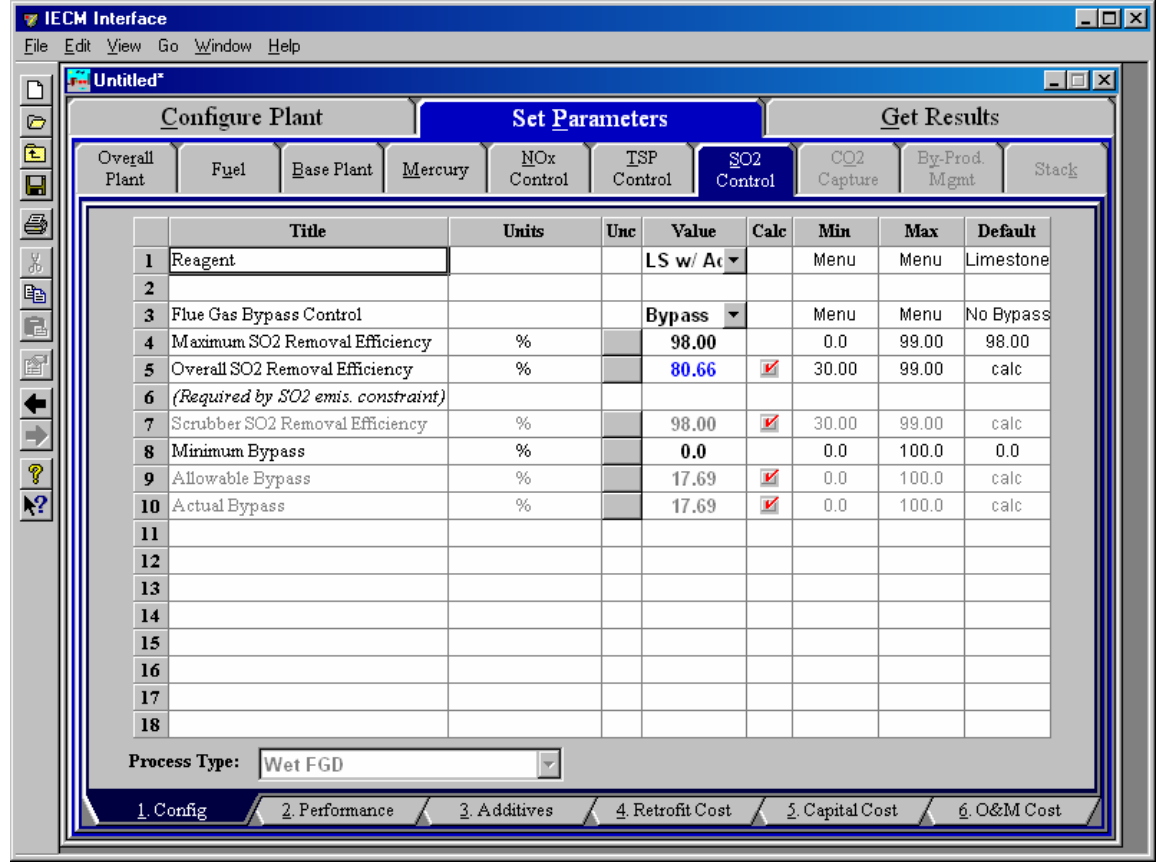

Wet FGD - Config. input screen (with bypass). 
The following five choices are available for flue gas bypass:

Maximum $\mathrm{SO}_{2}$ Removal Efficiency: This parameters specifies the maximum efficiency possible for the absorber on an annual average basis. The value is used as a limit in calculating the actual $\mathrm{SO}_{2}$ removal efficiency for compliance.

Overall $\mathrm{SO}_{2}$ Removal Efficiency: This value is the $\mathrm{SO}_{2}$ removal efficiency required for the entire power plant to meet the $\mathrm{SO}_{2}$ emission constraint set earlier. It is used to determine the actual flue gas bypass above.

Scrubber $\mathrm{SO}_{2}$ Removal Efficiency: This is the actual removal efficiency of the scrubber alone. It is a function of the $\mathrm{SO}_{2}$ emission constraint and the actual flue gas bypass. This value is also shown on the next input screen.

Minimum Bypass: This specifies the trigger point for allowing flue gas to bypass the scrubber. No bypass is allowed until the allowable amount reaches the minimum level set by this parameter.

Allowable Bypass: This is the amount of flue gas that is allowed to bypass the scrubber, based on the actual and maximum performance of the $\mathrm{SO}_{2}$ removal. It is provided for reference only. The model determines the bypass that produces the maximum $\mathrm{SO}_{2}$ removal and compares this potential bypass with the minimum bypass value specified above. Bypass is only allowed when the potential bypass value exceeds the minimum bypass value.

Actual Bypass: This displays the actual bypass being used in the model. It is based on all of the above and is provided for reference purposes only.

\section{Wet FGD Performance Inputs}

This screen is only available for the Combustion (Boiler) plant type. Inputs for performance of the Wet FGD SO${ }_{2}$ control technology are entered on the Performance input screen. Each parameter is described briefly below. 


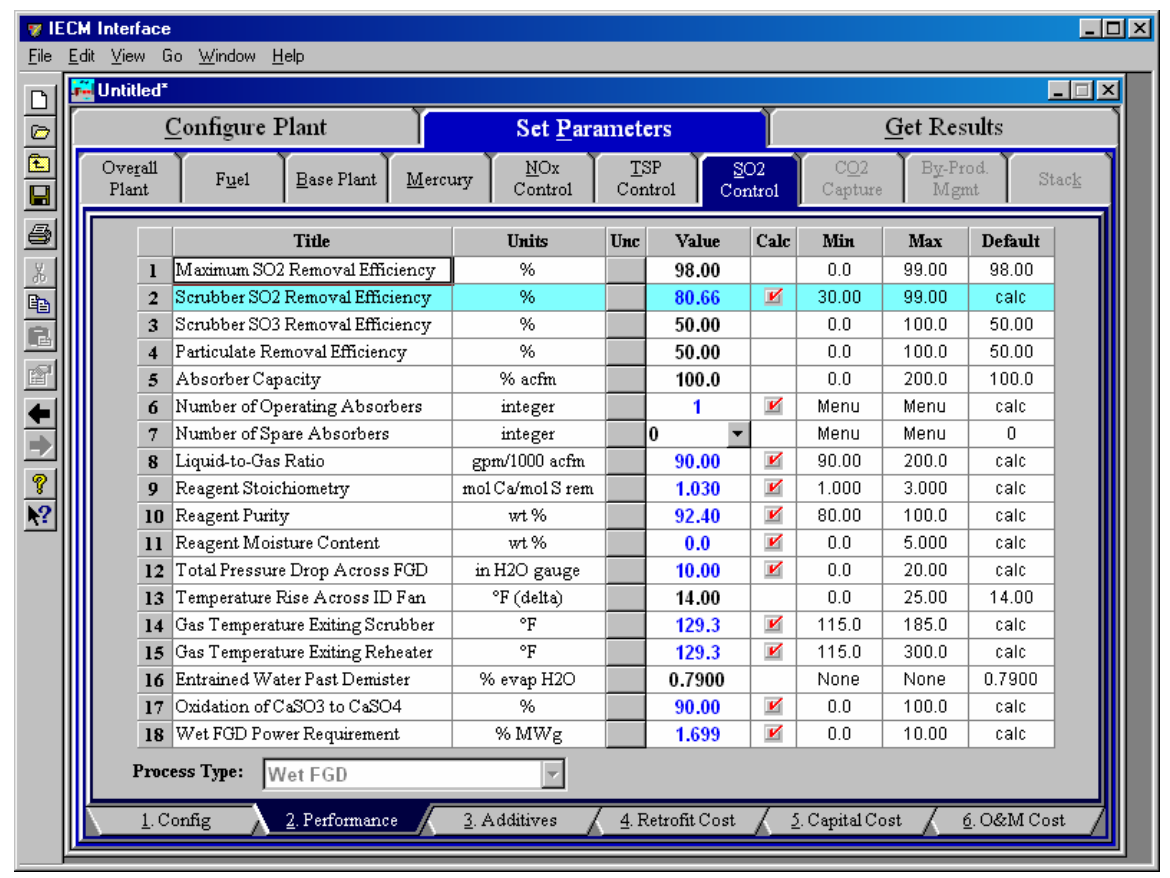

Wet FGD - Performance input screen.

Maximum $\mathrm{SO}_{2}$ Removal Efficiency: This parameters specifies the maximum efficiency possible for the absorber on an annual average basis. The value is used as a limit in calculating the actual $\mathrm{SO}_{2}$ removal efficiency for compliance.

Scrubber $\mathrm{SO}_{2}$ Removal Efficiency: This is the annual average $\mathrm{SO}_{2}$ removal efficiency achieved in the absorber. The calculated value assumes compliance with the $\mathrm{SO}_{2}$ emission limit specified earlier, if possible. The efficiency is used to determine the liquid to gas ratio and emissions. This input is highlighted in blue.

Scrubber $\mathrm{SO}_{3}$ Removal Efficiency: The default value is taken from the removal efficiency reported in the literature (references are below). This efficiency then determines the mass of $\mathrm{SO}_{3}$ removed from the flue gas in the collector. For more information see also:

- $\quad$ www.netl.doe.gov/publications/proceedings/98/98fg/hardman.pdf

- $\quad$ www.netl.doe.gov/publications/proceedings/98/98fg/rubin.pdf

Particulate Removal Efficiency: This is the percent removal of particulate matter entering the FGD system from the upstream particulate collector. Particulate collectors are designed to comply with the specified particulate emission limit. This is additional particulate removal.

Absorber Capacity: This is the percent of the flue gas treated by each operating absorber. This value is used to determine the number of operating absorbers and the capital costs.

Number of Operating Absorbers: This is the number of operating scrubber towers. The number is determined by the absorber capacity and is used to calculate the capital costs. The value must be an integer. 
Number of Spare Absorbers: This is the total number of spare absorber vessels. It is used primarily to calculate capital costs. The value must be an integer.

Liquid to Gas Ratio: The design of spray towers for high efficiency is achieved by using high liquid-to-gas $(\mathrm{L} / \mathrm{G})$ ratios. The calculated value is a function of the reagent type, the removal efficiency, and stoichiometry. It determines the power requirement and capital cost.

Reagent Stoichiometry: This is the moles of calcium per mole of sulfur removed from the absorber. The stoichiometry is calculated as a function of the reagent type. It is used to determine the liquid to gas ratio, reagent usage, reagent waste, and capital cost.

Reagent Purity: This is the percent of the reagent that is lime $(\mathrm{CaO})$ or limestone $\left(\mathrm{CaCO}_{3}\right)$. The calculated value is a function of the reagent type. This parameter determines the waste solids produced and the reagent needed to remove the necessary $\mathrm{SO}_{2}$.

Reagent Moisture Content: This is the moisture content of the reagent. The remaining reagent impurities are assumed to be inert substances such as silicon dioxide (sand). This parameter is used to determine the waste solids produced.

Total Pressure Drop across FGD: This is the total pressure drop across the FGD vessel prior to the reheater. This is used in the calculations of the power requirements (or energy penalty) and thermodynamic properties of the flue gas.

Temperature Rise Across ID Fan: An induced draft (ID) fan is assumed to be located upstream of the FGD system. The fan raises the temperature of the flue gas due to dissipation of electro-mechanical .

Gas Temperature Exiting Scrubber: A thermodynamic equation is used to calculate this equilibrium flue gas temperature exiting the scrubber. The gas is assumed to be saturated with water at the exiting temperature and pressure. The value determines the water evaporated in the scrubber.

Gas Temperature Exiting Reheater: This is the desired temperature of flue gas after the reheater. It is assumed to be equal to the stack gas exit temperature. If scrubber bypass is employed, reheat requirements are reduced or eliminated. It determines the reheat energy required.

Entrained Water Past Demister: This is a liquid water entrained in the flue gas leaving the demister expressed as a percentage of the total water evaporated in the absorber.

Oxidation of $\mathrm{CaSO}_{3}$ to $\mathrm{CaSO}_{4}$ : This parameter determines the mixture of chemical species (calcium sulfite and calcium sulfate) in the solid waste stream. The default values depend on the selection of forced or natural oxidation.

Wet FGD Power Requirement: This is the equivalent electrical output of thermal (steam) energy used for reheat, plus the actual electrical output power required for pumps and booster fans. 


\section{Wet FGD Additives Inputs}

This screen is only available for the Combustion (Boiler) plant type. If a limestone reagent with additives is selected from the Config input screen, the screen below will be displayed.

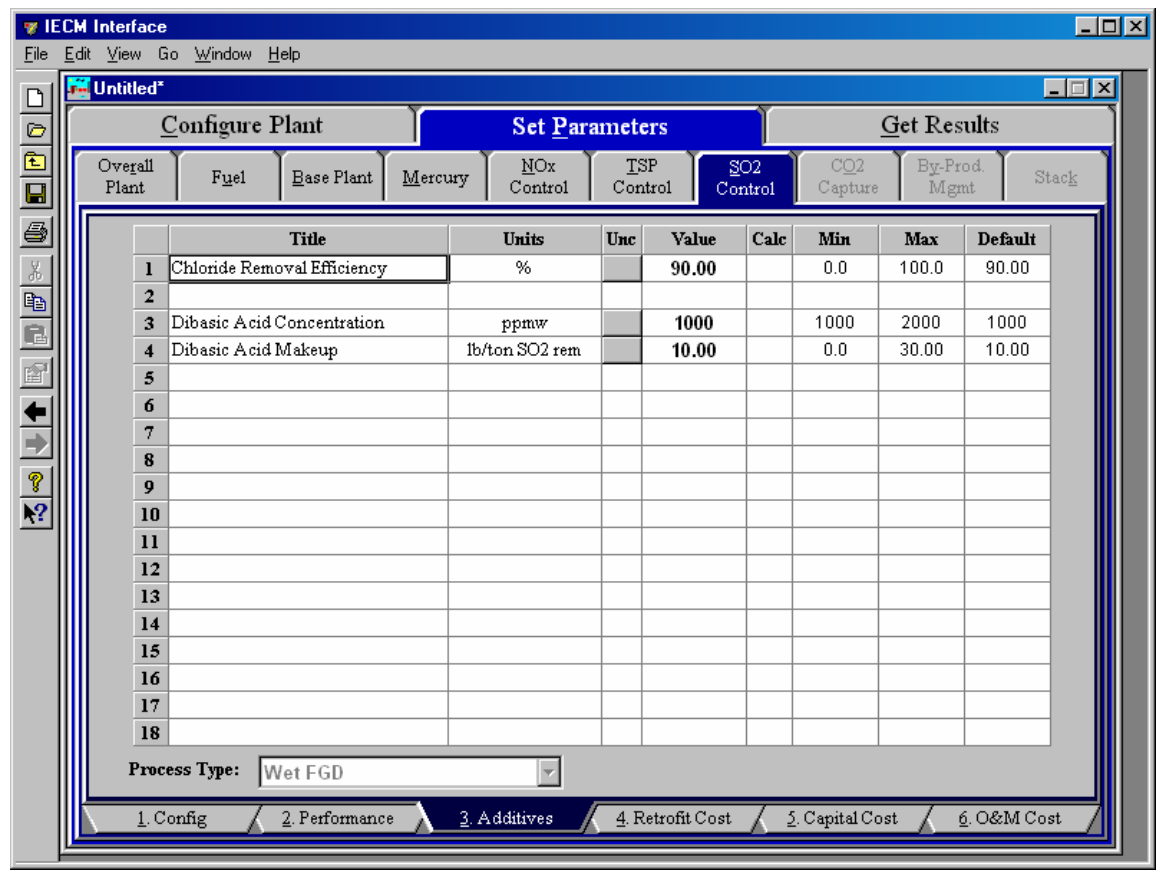

Wet FGD - Additives input screen (for limestone and lime reagents)

The parameters are described briefly below.

Chloride Removal Efficiency: Chlorides in the flue gas inlet stream are removed by the lime/limestone slurry. This parameter determines the amount of chlorides removed.

Dibasic Acid Concentration: Dibasic acid (DBA) is added to limestone to reduce the liquid to gas ratio, enhancing the removal of $\mathrm{SO}_{2}$. This is the concentration of DBA in the limestone slurry.

Dibasic Acid Makeup: DBA is not completely recovered in the reagent feedback loop. This parameter is used to determine the makeup flow rate of DBA.

\section{Wet FGD Retrofit Cost Inputs}

This screen is only available for the Combustion (Boiler) plant type. Inputs for capital costs of modifications to process areas to implement the $\mathrm{SO}_{2}$ control technology are entered on the Retrofit Cost input screen for the Wet FGD system.

The retrofit cost factor of each process is a multiplicative cost adjustment which considers the cost of retrofitted capital equipment relative to similar equipment installed in a new plant. These factors affect the capital costs directly and the operating and maintenance costs indirectly.

Direct capital costs for each process area are calculated in the IECM. These calculations are reduced form equations derived from more sophisticated models and 
reports. The sum of the direct capital costs associated with each process area is defined as the process facilities capital (PFC). The retrofit cost factor provided for each of the process areas can be used as a tool for adjusting the anticipated costs and uncertainties across the process area separate from the other areas.

Uncertainty can be applied to the retrofit cost factor for each process area in each technology. Thus, uncertainty can be applied as a general factor across an entire process area, rather than as a specific uncertainty for the particular cost on the capital or O\&M input screens. Any uncertainty applied to a process area through the retrofit cost factor compounds any uncertainties specified later in the capital and O\&M cost input parameter screens.

Each parameter is described briefly below.

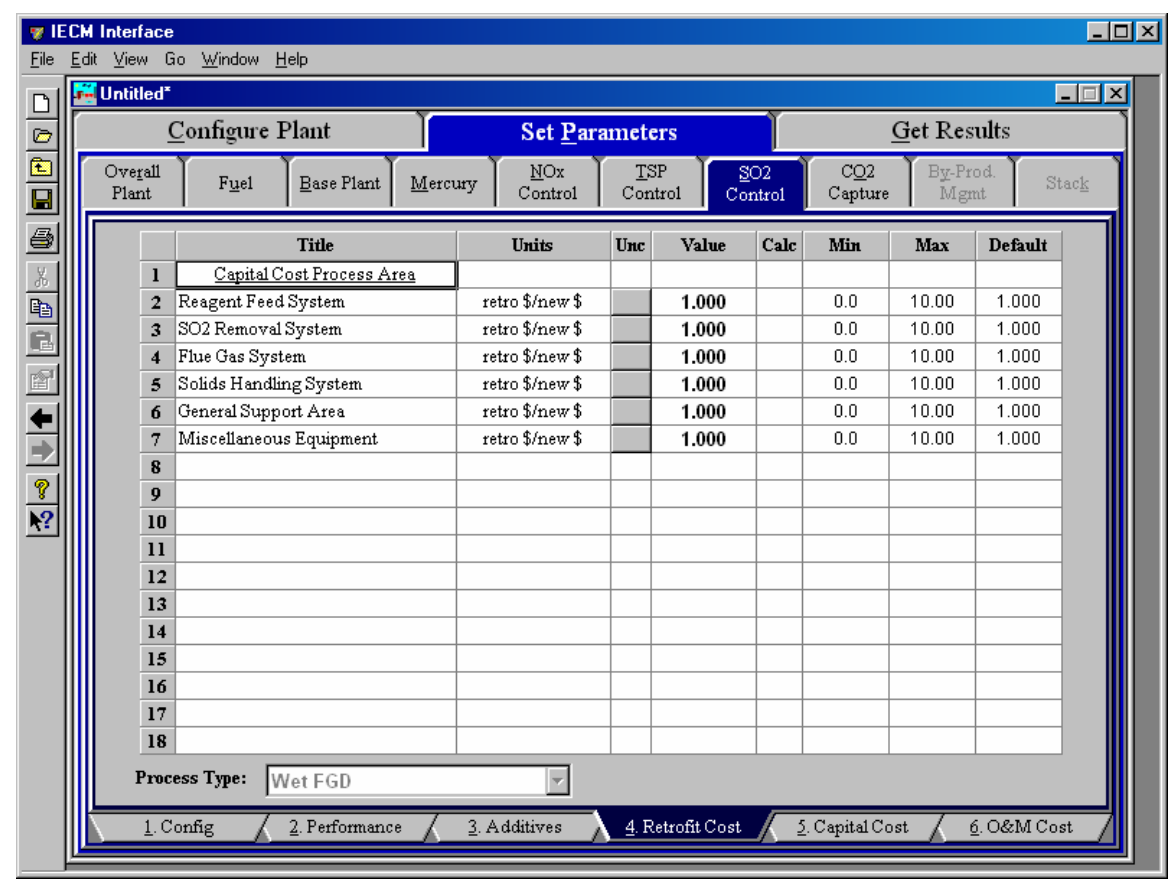

Wet FGD - Retrofit Cost input screen.

\section{Capital Cost Process Area}

Reagent Feed System: This area includes all equipment for storage, handling and preparation of raw materials, reagents, and additives used.

SO2 Removal System: This area deals with the cost of equipment for $\mathrm{SO}_{2}$ scrubbing, such as absorption tower, recirculation pumps, and other equipment.

Flue Gas System: This area treats the cost of the duct work and fans required for flue gas distribution to $\mathrm{SO}_{2}$ system, plus gas reheat equipment.

Solids Handling System: This area includes the cost of the equipment for fixation, treatment, and transportation of all sludge/dry solids materials produced by scrubbing.

General Support Area: The cost associated with the equipment required to support FGD system operation such as makeup water and instrument air are treated here. 
Miscellaneous Equipment: Any miscellaneous equipment is treated in this process area.

\section{Wet FGD Capital Cost Inputs}

This screen is only available for the Combustion (Boiler) plant type.

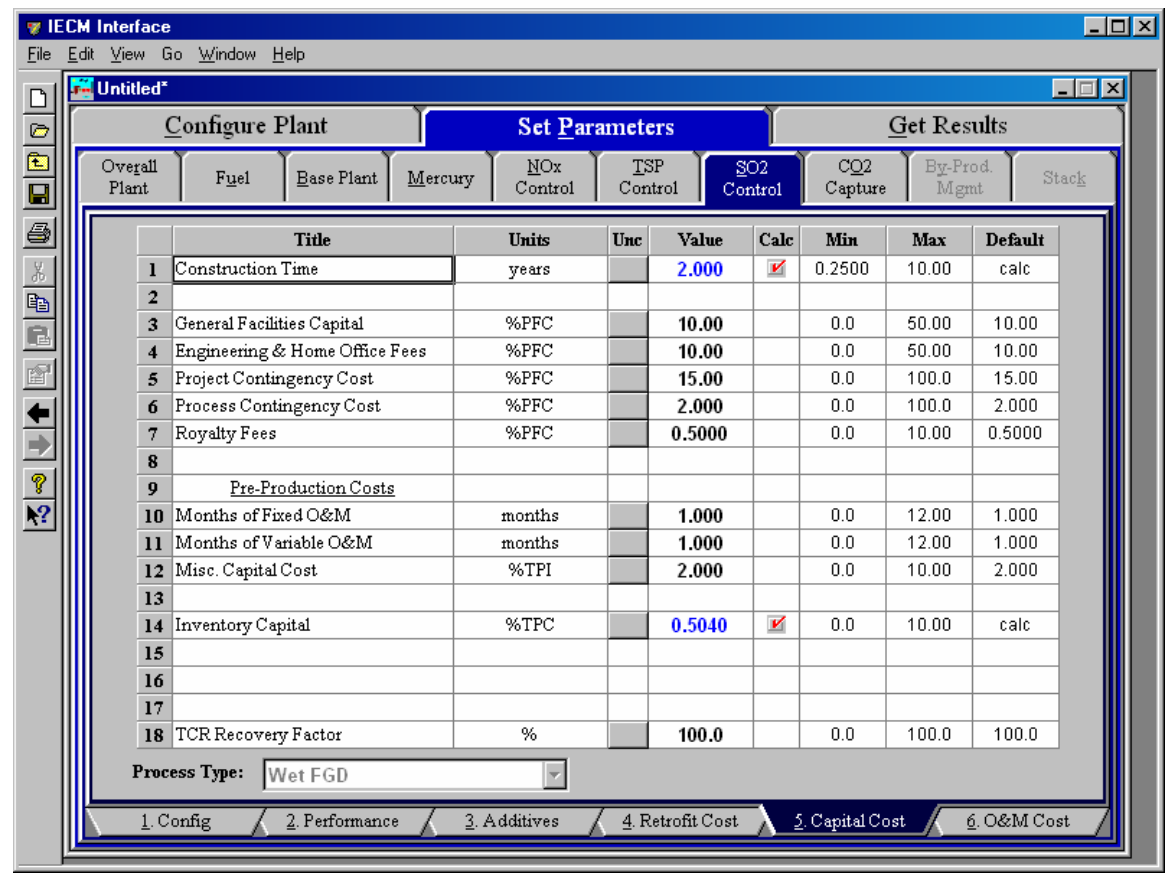

Wet FGD - Capital Cost input screen.

Each parameter is described briefly below

Construction Time: This is the idealized construction period in years. It is used to determine the allowance for funds used during construction (AFUDC).

Bypass Duct Cost Adder: The bypass capital costs are not specified with the other process areas. This parameter allows any direct capital costs incurred by the addition of bypass ducts to be added to the Flue Gas System process area (see retrofit cost screen for a list of the direct cost process areas).

General Facilities Capital (GFC): The general facilities include construction costs of roads, office buildings, shops, laboratories, etc. Sales taxes and freight costs are included implicitly. The cost typically ranges from $5-20 \%$.

Engineering \& Home Office Fees: The engineering \& home office fees are a percent of total direct capital cost. This is an overhead fee paid to the architect/engineering company. These fees typically range from 7$15 \%$.

Project Contingency Cost: This is factor covering the cost of additional equipment or other costs resulting from a more detailed design. Higher contingency factors will be applied to simplified or preliminary designs and lower factors to detailed or finalized designs. 
Process Contingency Cost: This quantifies the design uncertainty and cost of a commercial-scale system. This is generally applied on an areaby-area basis. Higher contingency factors are applied to new regeneration systems tested at a pilot plant and lower factors to full-size or commercial systems.

Royalty Fees: Royalty charges may apply to some portions of generating units incorporating new proprietary technologies.

Pre-Production Costs: These costs consider the operator training, equipment checkout, major changes in unit equipment, extra maintenance, and inefficient use of fuel or other materials during startup. These are typically applied to the O\&M costs over a specified period of time (months). The two time periods for fixed and variable O\&M costs are described below with the addition of a miscellaneous capital cost factor.

- Months of Fixed O\&M: Time period of fixed operating costs used for preproduction to cover training, testing, major changes in equipment, and inefficiencies in start-up. This includes operating, maintenance, administrative and support labor. It also considers maintenance materials.

- Months of Variable O\&M: Time period of variable operating costs used for preproduction to cover chemicals, water, consumables, and solid disposal charges in start-up, assuming $100 \%$ load. This excludes any fuels.

- Misc. Capital Cost: This is a percent of total plant investment (sum of TPC and AFUDC) to cover expected changes to equipment to bring the system up to full capacity.

Inventory Capital: Percent of the total direct capital for raw material supply based on $100 \%$ capacity during a 60 day period. These materials are considered storage. The inventory capital includes fuels, consumables, by-products, and spare parts. This is typically $0.5 \%$.

TCR Recovery Factor: The actual total capital required (TCR) as a percent of the TCR in a new power plant. This value is $100 \%$ for a new installation and may be set as low as $0 \%$ for a wet FGD that has been paid off.

\section{Wet FGD O\&M Cost Inputs}

This screen is only available for the Combustion (Boiler) plant type. 


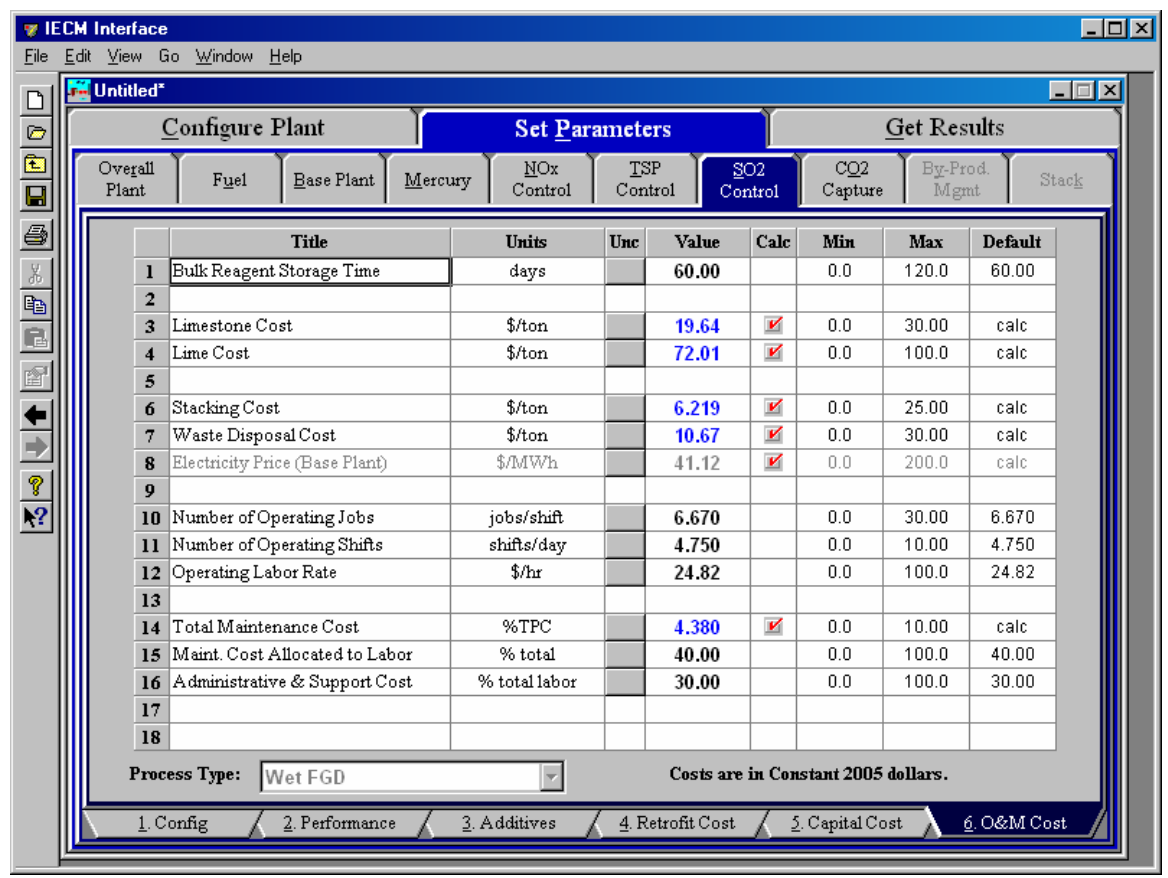

Wet FGD - O\&M Cost input screen

O\&M costs are typically expressed on an average annual basis and are provided in either constant or current dollars for a specified year, as shown on the bottom of the screen. Each parameter is described briefly below:

Bulk Reagent Storage Time: This is the number of days of bulk storage of reagent. This factor is used to determine the inventory capital cost.

Limestone Cost: This is the cost of Limestone for the Wet FGD system.

Lime Cost: This is the cost of Lime for the Wet FGD or Lime Spray Dryer system.

Dibasic Acid Cost: This is the cost of the Dibasic Acid for the Wet FGD or Lime Spray Dryer system.

Stacking Cost: This is the stacking cost as used for the Wet FGD system.

Waste Disposal Cost: This is the sludge disposal cost for the FGD system.

Electricity Price (Base Plant): This is the price of electricity and is calculated as a function of the utility cost of the base plant, where the base plant is a combustion boiler and an air preheater.

Number of Operating Jobs: This is the total number of operating jobs that are required to operate the plant per eight-hour shift.

Number of Operating Shifts: This is the total number of equivalent operating shifts in the plant per day. The number takes into consideration paid time off and weekend work ( 3 shifts/day * 7 days/5 day week * 52 weeks/(52 weeks -6 weeks PTO $)=4.75$ equiv. Shifts/day).

Operating Labor Rate: The hourly cost of labor is specified in the base plant O\&M cost screen. The same value is used throughout the other technologies. 
Total Maintenance Cost: This is the annual maintenance cost as a percentage of the total plant cost. Maintenance cost estimates can be developed separately for each process area.

Maint. Cost Allocated to Labor: Maintenance cost allocated to labor as a percentage of the total maintenance cost.

Administrative \& Support Cost: This is the percent of the total operating and maintenance labor associated with administrative and support labor.

\section{Wet FGD Diagram}

This screen is only available for the Combustion (Boiler) plant type. The Diagram result screen displays an icon for theWet $\mathrm{FGD} \mathrm{SO}_{2}$ control technology selected and values for major flows in and out of it.

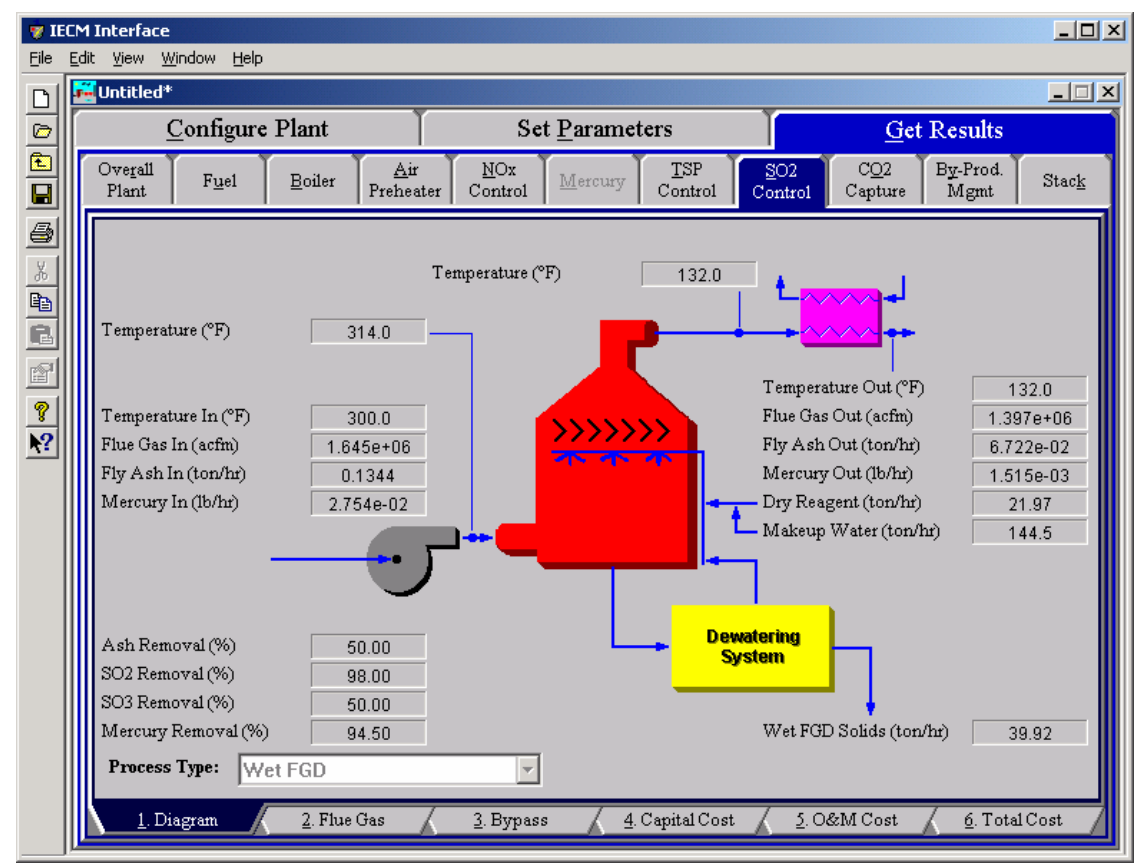

Wet FGD - Diagram.

Each result is described briefly below.

\section{Reagent}

Dry Reagent: The total mass flow rate of lime, limestone or limestone with dibasic acid injected into the scrubber. This is a function of the $\mathrm{SO}_{2}$ removal efficiency, the reagent purity and the reagent stoichiometric (all performance input parameters).

Makeup Water: Water needed to replace the evaporated water in the reagent sluice circulation stream. 


\section{Flue Gas Entering FGD}

Temperature In: Temperature of the flue gas entering the scrubber. This is determined by the flue gas outlet temperature of the module upstream of the scrubber (e.g., a particulate removal technology).

Flue Gas In: Volumetric flow rate of flue gas entering the scrubber, based on the flue gas temperature entering the scrubber and atmospheric pressure.

Fly Ash In: Total solids mass flow rate in the flue gas entering the scrubber. This is determined by the solids exiting from the module upstream of the scrubber (e.g., a particulate removal technology).

Mercury In: Total mass of mercury entering the scrubber. The value is a sum of all the forms of mercury (elemental, oxidized, and particulate).

Temperature: Temperature of the flue gas entering the scrubber after the forced draft fan. This is determined by the flue gas inlet temperature of the FGD and the temperature rise across ID fan input parameter.

\section{Flue Gas Exiting FGD}

Temperature: Temperature of the flue gas immediately on exiting the scrubber, prior to any flue gas bypass remixing and prior to reheating.

Temperature Out: Temperature of the flue gas exiting the scrubber. This is a function of flue gas bypass, saturation temperature, reheater and .the flue gas component concentrations.

Flue Gas Out: Volumetric flow rate of the flue gas exiting the scrubber after the reheater, based on the flue gas temperature exiting the scrubber and atmospheric pressure.

Fly Ash Out: Total solids mass flow rate in the flue gas exiting the scrubber after the reheater. This is a function of the ash removal and flue gas bypass input parameters.

Mercury Out: Total mass of mercury exiting the scrubber after the reheater. The value is a sum of all the forms of mercury (elemental, oxidized, and particulate).

\section{FGD Performance}

Ash Removal: Actual particulate removal efficiency in the scrubber. This is set by the scrubber ash removal input parameter.

SO2 Removal: Actual removal efficiency of $\mathrm{SO}_{2}$ in the scrubber. This is a function of the maximum removal efficiency (scrubber performance input parameter) and the emission constraint for $\mathrm{SO}_{2}$ (emission constraints input parameter). It is possible that the scrubber may over or under-comply with the emission constraint.

SO3 Removal: Percent of $\mathrm{SO}_{3}$ in the flue gas removed from the scrubber. The $\mathrm{SO}_{3}$ is assumed to combine with $\mathrm{H}_{2} \mathrm{O}$ and leave with the ash solids or sluice water as a sulfate (in the form of $\mathrm{H}_{2} \mathrm{SO}_{4}$ ).

Mercury Removal: Percent of the total mercury removed from the scrubber. The value reflects a weighted average based on the particular species of mercury present (elemental, oxidized, and particulate). 


\section{Collected Solids}

Wet FGD Solids: Total solids mass flow rate of solids removed from the scrubber. This is a function of the solids content in the flue gas and the particulate removal efficiency of the scrubber. The solids are shown on a wet basis.

\section{Wet FGD Flue Gas Results}

This screen is only available for the Combustion (Boiler) plant type. The Flue Gas result screen displays a table of quantities of flue gas components entering and exiting the Wet FGD SO${ }_{2}$ Control Technology. For each component, quantities are given in both moles and mass per hour.

\begin{tabular}{|c|c|c|c|c|c|c|c|c|c|c|c|c|c|}
\hline \multicolumn{13}{|c|}{$\nabla$ IECM Interface } & \multirow[t]{2}{*}{$-|\square| x$} \\
\hline \multicolumn{13}{|c|}{ File Edit View Window Help } & \\
\hline \multirow{3}{*}{ 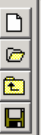 } & \multicolumn{12}{|c|}{ Fintitled* } & $-10 \underline{x}$ \\
\hline & \multicolumn{5}{|c|}{ Configure Plant } & \multicolumn{3}{|c|}{ Set $\underline{P}$ arameters } & & \multicolumn{4}{|c|}{ Get Results } \\
\hline & $\begin{array}{c}\text { Overall } \\
\text { Plant }\end{array}$ & & uel & Boiler & $\begin{array}{c}\text { Air } \\
\text { Preheater }\end{array}$ & $\begin{array}{c}\stackrel{\mathrm{N} O x}{\text { Control }} \\
\text { Cont }\end{array}$ & Mercury & $\underset{\text { Control }}{\text { TSP }}$ & Cor & & $\begin{array}{c}\mathrm{CO} 2 \\
\text { Capture }\end{array}$ & $\begin{array}{c}\text { By-Prod. } \\
\text { Mgmt }\end{array}$ & Stack \\
\hline 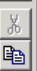 & & & \multicolumn{4}{|c|}{ Major Flue Gas Conponents } & $\begin{array}{c}\text { Total Flue } \\
\text { Gas In } \\
\text { (lh-moles/hr) }\end{array}$ & \multicolumn{2}{|c|}{$\begin{array}{c}\text { Total Flue } \\
\text { Gas Out } \\
\text { (lb-moles/hr) }\end{array}$} & & $\begin{array}{l}\text { I Flue } \\
\text { s In } \\
n / h r)\end{array}$ & $\begin{array}{c}\text { Total Flue } \\
\text { Gas Out } \\
\text { (ton/hr) }\end{array}$ & \\
\hline 斯 & & \multicolumn{5}{|c|}{ Nitrogen (N2) } & $1.302 \mathrm{e}+05$ & \multicolumn{2}{|c|}{$1.302 \mathrm{e}+05$} & & 823 & 1823 & \\
\hline 图 & & \multicolumn{5}{|c|}{ Oxygen $(\mathrm{O} 2)$} & 9685 & \multicolumn{2}{|c|}{9509} & & 55.0 & 152.1 & \\
\hline 91 & & 3 & \multicolumn{4}{|c|}{ Water Vapor $(\mathrm{H} 2 \mathrm{O})$} & $1.671 \mathrm{e}+04$ & \multicolumn{2}{|c|}{$3.287 \mathrm{e}+04$} & & 50.5 & 296.1 & \\
\hline 8 & & \multicolumn{5}{|c|}{ Carbon Dioxide (CO2) } & $2.096 \mathrm{e}+04$ & \multicolumn{2}{|c|}{$2.135 \mathrm{e}+04$} & & 61.1 & 469.8 & \\
\hline A? & & \multicolumn{5}{|c|}{ Carbon Monoxide (CO) } & 0.0 & 0.0 & & & 0.0 & 0.0 & \\
\hline & & \multicolumn{5}{|c|}{ Hydrochloric Acid ( $\mathrm{HCl})$} & 19.71 & 1.97 & & & 3594 & $3.594 \mathrm{e}-02$ & \\
\hline & & \multirow{2}{*}{$\begin{array}{ll}7 & S \\
8 & S\end{array}$} & \multicolumn{4}{|c|}{ Sulfur Dioxide (SO2) } & 400.8 & 8.016 & & & 2.84 & 0.2568 & \\
\hline & & & \multicolumn{4}{|c|}{ Sulfuric Acid (equivalent SO3) } & 2.066 & 1.03 & & 8.27 & $2 \mathrm{e}-02$ & $4.136 \mathrm{e}-02$ & \\
\hline & & 9 & Nitric & Dxide (NO) & & & 11.29 & $11.2 \mathrm{~s}$ & & & 694 & 0.1694 & \\
\hline & & 101 & Nitro & en Dioxide & NO2) & & 0.5942 & 0.594 & & 1.36 & $7 e-02$ & $1.367 \mathrm{e}-02$ & \\
\hline & & 11 & Amm & $\operatorname{nia}(\mathrm{NH} 3)$ & & & 0.3088 & 0.308 & & 2.62 & $9 e-03$ & $2.629 \mathrm{e}-03$ & \\
\hline & & 12 & Argo: & (At) & & & 0.0 & 0.0 & & & 0.0 & 0.0 & \\
\hline & & 13 & Total & & & & $1.780 e+05$ & $1.940 \mathrm{e}$ & +05 & & 604 & 2742 & \\
\hline & & 14 & & & & & & & & & & & \\
\hline & & 15 & & & & & & & & & & & \\
\hline & Process & Type: & $W$ & FGD & & 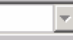 & & & & & & & \\
\hline & 1. D & gram & & 2. Flu & & 3. Bypas & 4. $\mathrm{Ca}$ & apital Cost & & 5.0 & \&M Cost & 6. T & Cost \\
\hline
\end{tabular}

Wet FGD - Flue Gas result screen.

Each result is described briefly below

\section{Major Flue Gas Component}

Nitrogen $\left(\mathbf{N}_{\mathbf{2}}\right)$ : Total mass of nitrogen.

Oxygen $\left(\mathrm{O}_{2}\right)$ : Total mass of oxygen.

Water Vapor $\left(\mathrm{H}_{\mathbf{2}} \mathrm{O}\right)$ : Total mass of water vapor.

Carbon Dioxide $\left(\mathrm{CO}_{2}\right)$ : Total mass of carbon dioxide.

Carbon Monoxide (CO): Total mass of carbon monoxide.

Hydrochloric Acid (HCl): Total mass of hydrochloric acid.

Sulfur Dioxide $\left(\mathrm{SO}_{2}\right)$ : Total mass of sulfur dioxide.

Sulfuric Acid (equivalent $\mathbf{S O}_{3}$ ): Total mass of sulfuric acid.

Nitric Oxide (NO): Total mass of nitric oxide. 
Nitrogen Dioxide $\left(\mathrm{NO}_{2}\right)$ : Total mass of nitrogen dioxide.

Ammonia $\left(\mathrm{NH}_{3}\right)$ : Total mass of ammonia.

Argon (Ar): Total mass of argon.

Total: Total of the individual components listed above. This item is highlighted in yellow.

\section{Wet FGD Bypass Results}

This screen is only available for the Combustion (Boiler) plant type. The Flue Gas Bypass result screen displays a table of quantities of flue gas components entering and bypassing the Wet FGD $\mathrm{SO}_{2}$ Control Technology. For each component, quantities are given in both moles and mass per hour.

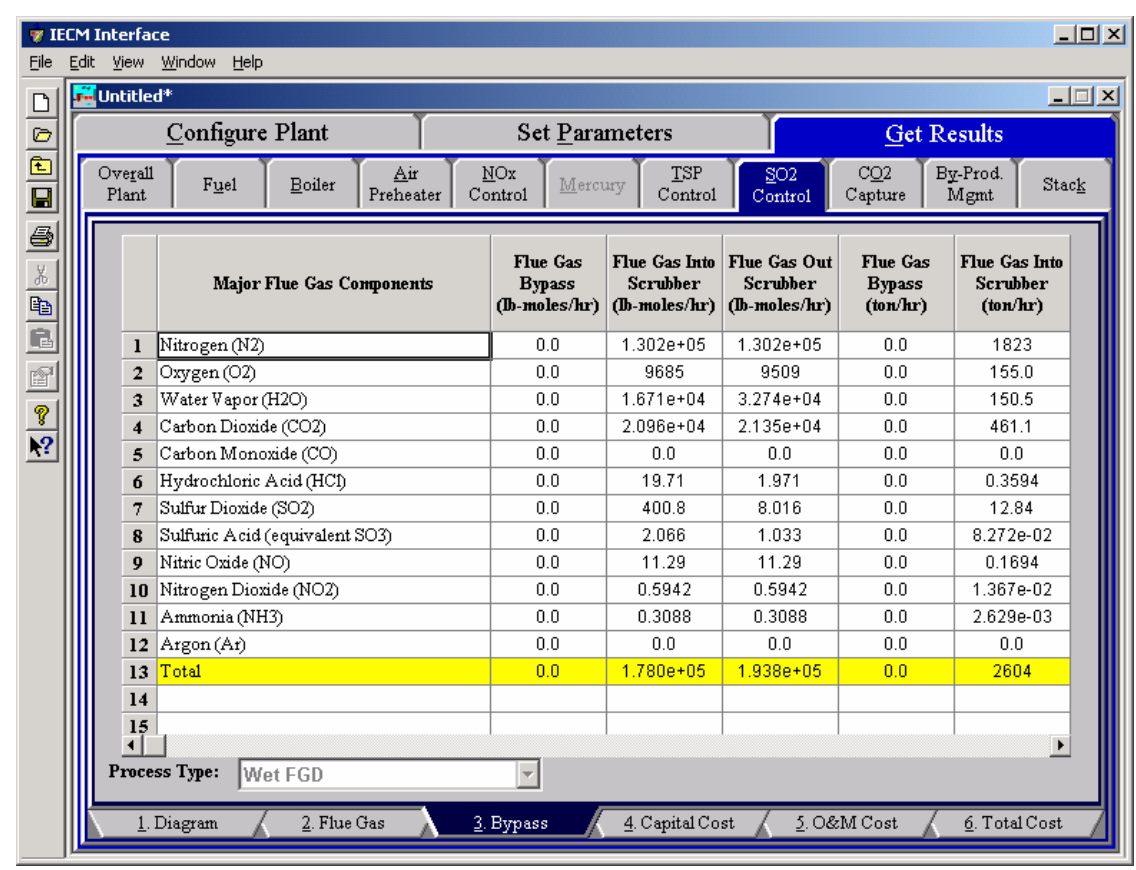

Wet FGD - Bypass result screen.

Each result is described briefly below

\section{Major Flue Gas Component}

Nitrogen $\left(\mathrm{N}_{2}\right)$ : Total mass of nitrogen.

Oxygen $\left(\mathrm{O}_{2}\right)$ : Total mass of oxygen.

Water Vapor $\left(\mathrm{H}_{2} \mathrm{O}\right)$ : Total mass of water vapor.

Carbon Dioxide $\left(\mathrm{CO}_{2}\right)$ : Total mass of carbon dioxide.

Carbon Monoxide (CO): Total mass of carbon monoxide.

Hydrochloric Acid $(\mathrm{HCl})$ : Total mass of hydrochloric acid.

Sulfur Dioxide $\left(\mathrm{SO}_{2}\right)$ : Total mass of sulfur dioxide.

Sulfuric Acid (equivalent $\mathrm{SO}_{3}$ ): Total mass of sulfuric acid.

Nitric Oxide (NO): Total mass of nitric oxide. 
Nitrogen Dioxide $\left(\mathrm{NO}_{2}\right)$ : Total mass of nitrogen dioxide.

Ammonia $\left(\mathrm{NH}_{3}\right)$ : Total mass of ammonia.

Argon (Ar): Total mass of argon.

Total: Total of the individual components listed above. This item is highlighted in yellow.

\section{Wet FGD Capital Cost Results}

This screen is only available for the Combustion (Boiler) plant type. The Capital Cost result screen displays tables for the direct and indirect capital costs related to the $\mathrm{SO}_{2}$ control technology.

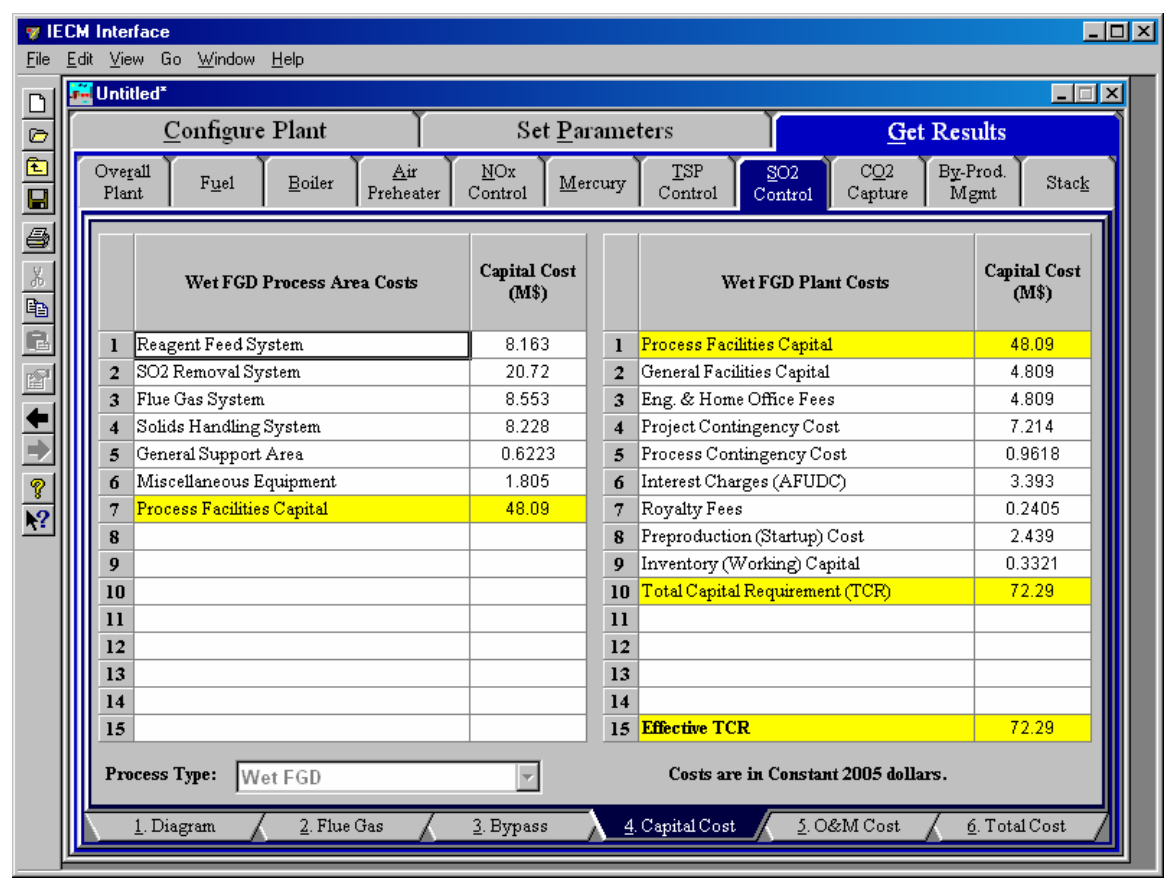

Wet FGD - Capital Cost result screen.

Capital costs are typically expressed in either constant or current dollars for a specified year, as shown on the bottom of the screen. Each result is described briefly below

\section{Direct Capital Costs}

Each process area direct capital cost is a reduced-form model based on regression analysis of data collected from several reports and analyses of particulate control technology units. They are described in general below. The primary factors in the model that effect the capital costs of the scrubbers are the flue gas flow rate through the scrubber, the composition of the flue gas, the reagent stoichiometry, and the reagent flow rate.

Reagent Feed System: This area includes all equipment for storage, handling and preparation of raw materials, reagents, and additives used.

$\mathrm{SO}_{2}$ Removal System: This area deals with the cost of equipment for $\mathrm{SO}_{2}$ scrubbing, such as absorption tower, recirculation pumps, and other equipment. 
Flue Gas System: This area treats the cost of the duct work and fans required for flue gas distribution to $\mathrm{SO}_{2}$ system, plus gas reheat equipment.

Solids Handling System: This area includes the cost of the equipment for fixation, treatment, and transportation of all sludge/dry solids materials produced by scrubbing.

General Support Area: The cost associated with the equipment required to support FGD system operation such as makeup water and instrument air are treated here.

Miscellaneous Equipment: Any miscellaneous equipment is treated in this process area.

Process Facilities Capital: The process facilities capital is the total constructed cost of all on-site processing and generating units listed above, including all direct and indirect construction costs. All sales taxes and freight costs are included where applicable implicitly. This result is highlighted in yellow.

\section{Total Capital Costs}

Process Facilities Capital: (see definition above)

General Facilities Capital: The general facilities include construction costs of roads, office buildings, shops, laboratories, etc. Sales taxes and freight costs are included implicitly.

Eng. \& Home Office Fees: The engineering \& home office fees are a percent of total direct capital cost. This is an overhead fee paid to the architect/engineering company.

Project Contingency Cost: Capital cost contingency factor covering the cost of additional equipment or other costs that would result from a more detailed design of a definitive project at the actual site.

Process Contingency Cost: Capital cost contingency factor applied to a new technology in an effort to quantify the uncertainty in the technical performance and cost of the commercial-scale equipment.

Interest Charges (AFUDC): Allowance for funds used during construction, also referred to as interest during construction, is the time value of the money used during construction and is based on an interest rate equal to the before-tax weighted cost of capital. This interest is compounded on an annual basis (end of year) during the construction period for all funds spent during the year or previous years.

Royalty Fees: Royalty charges may apply to some portions of generating units incorporating new proprietary technologies.

Preproduction (Startup) Cost: These costs consider the operator training, equipment checkout, major changes in unit equipment, extra maintenance, and inefficient use of fuel or other materials during startup.

Inventory (Working) Capital: The raw material supply based on $100 \%$ capacity during a 60 day period. These materials are considered storage. The inventory capital includes fuels, consumables, byproducts, and spare parts. 
Total Capital Requirement (TCR): Money that is placed (capitalized) on the books of the utility on the service date. TCR includes all the items above. This result is highlighted in yellow.

Effective TCR: The TCR of the wet FGD that is used in determining the total power plant cost. The effective TCR is determined by the "TCR Recovery Factor" for the wet FGD.

\section{Wet FGD O\&M Cost Results}

This screen is only available for the Combustion (Boiler) plant type. The O\&M Cost result screen displays tables for the variable and fixed operation and maintenance costs involved with the $\mathrm{SO}_{2}$ control technology.

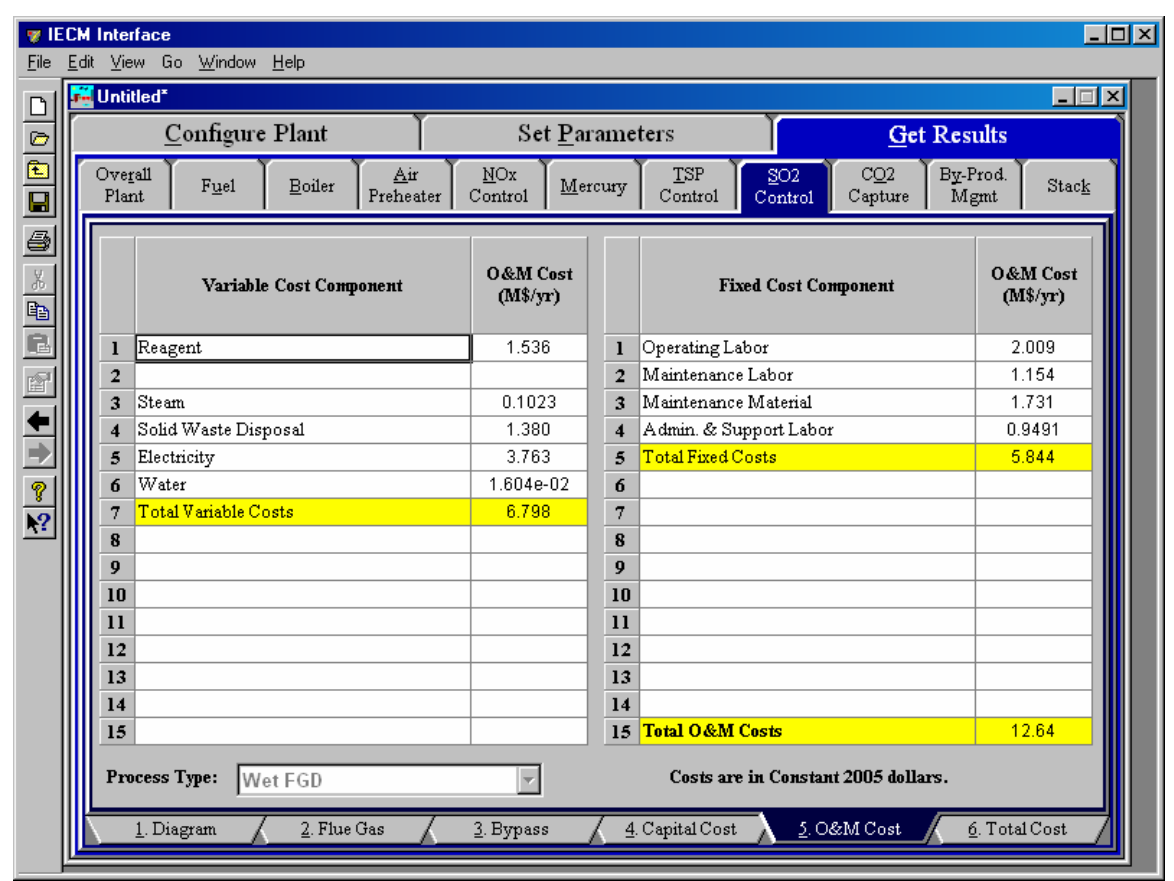

Wet FGD - O\&M Cost result screen.

O\&M costs are typically expressed on an average annual basis and are provided in either constant or current dollars for a specified year, as shown on the bottom of the screen. Each result is described briefly below

\section{Variable Cost Components}

Variable operating costs and consumables are directly proportional to the amount of kilowatts produced and are referred to as incremental costs. All the costs are subject to inflation.

Reagent: The total mass flow rate of lime or limestone injected into the scrubber on a wet basis. This is a function of the $\mathrm{SO}_{2}$ concentration in the flue gas and the reagent stoichiometric performance input value.

Steam: Annual cost of steam used for direct or reheat use in the scrubber. This is a function of the steam heat rate, reheat energy requirement and gross plant capacity. 
Solid Waste Disposal: Total cost to dispose the collected flue gas waste solids. This does not consider by-product gypsum sold in commerce.

Electricity: Cost of power consumption of the scrubber. This is a function of the gross plant capacity and the scrubber energy penalty performance input parameter.

Water: Cost of water for reagent sluice in the scrubber. This is a function of the liquid to gas ratio performance input parameter for the wet FGD. The cost is a function of the flue gas flow rate and the slurry recycle ratio performance input parameter for the spray dryer.

Total Variable Costs: This is the sum of all the variable O\&M costs listed above. This result is highlighted in yellow.

\section{Fixed Cost Components}

Fixed operating costs are essentially independent of actual capacity factor, number of hours of operation, or amount of kilowatts produced. All the costs are subject to inflation.

Operating Labor: Operating labor cost is based on the operating labor rate, the number of personnel required to operate the plant per eighthour shift, and the average number of shifts per day over 40 hours per week and 52 weeks.

Maintenance Labor: The maintenance labor is determined as a fraction of the total maintenance cost.

Maintenance Material: The cost of maintenance material is the remainder of the total maintenance cost, considering the fraction associated with maintenance labor.

Admin. \& Support Labor: The administrative and support labor is the only overhead charge. It is taken as a fraction of the total operating and maintenance labor costs.

Total Fixed Costs: This is the sum of all the fixed O\&M costs listed above. This result is highlighted in yellow.

Total O\&M Costs: This is the sum of the total variable and total fixed O\&M costs. It is used to determine the base plant total revenue requirement. This result is highlighted in yellow.

\section{Wet FGD Total Cost Results}

This screen is only available for the Combustion (Boiler) plant type. The Total Cost result screen displays a table which totals the annual fixed, variable, operations and maintenance, and capital costs associated with the $\mathrm{SO}_{2}$ control technology. The result categories are the same for both the Wet FGD and the Lime Spray Dryer. 


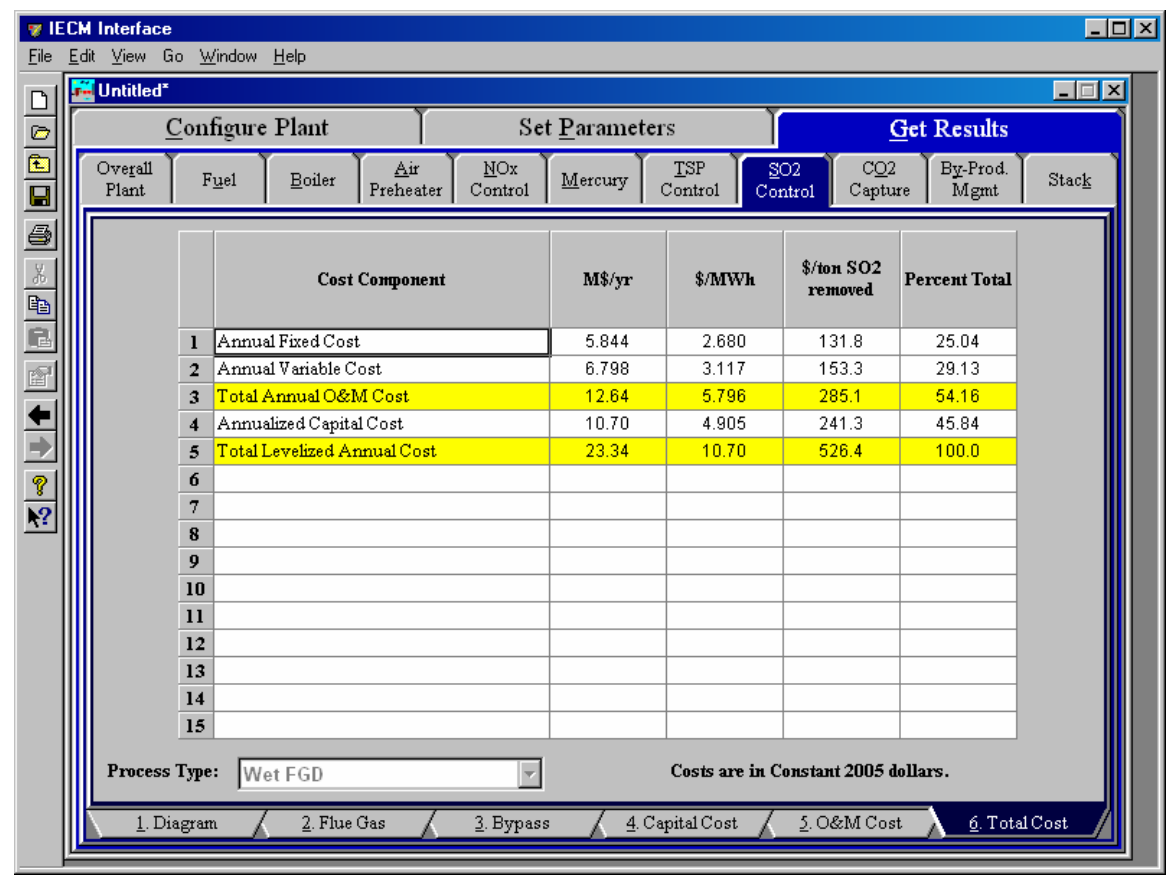

Wet FGD - Total Cost result screen.

\section{Cost Component}

Total costs are typically expressed in either constant or current dollars for a specified year, as shown on the bottom of the screen. Each result is described briefly below.

Annual Fixed Cost: The operating and maintenance fixed costs are given as an annual total. This number includes all maintenance materials and all labor costs.

Annual Variable Cost: The operating and maintenance variables costs are given as an annual total. This includes all reagent, chemical, steam, and power costs.

Total Annual O\&M Cost: This is the sum of the annual fixed and variable operating and maintenance costs above. This result is highlighted in yellow.

Annualized Capital Cost: This is the total capital cost expressed on an annualized basis, taking into consideration the levelized carrying charge factor, or fixed charge factor, over the entire book life.

Total Levelized Annual Cost: The total annual cost is the sum of the total annual O\&M cost and annualized capital cost items above. This result is highlighted in yellow. 



\section{Spray Dryer}

The So2 2 Control Technology Navigation Tab contains screens that address postcombustion air pollution technologies for Sulfur Dioxide. The model includes options for a Lime Spray Dryer. A spray dryer is sometimes used instead of a wet scrubber because it provides simpler waste disposal and can be installed with lower capital costs. These screens are available if the Lime Spray Dryer $\mathrm{SO}_{2}$ control

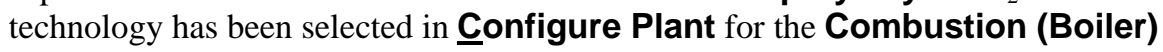
plant type.

\section{Spray Dryer Configuration}

This screen is only available for the Combustion (Boiler) plant type. Inputs for configuration of the Lime Spray Dryer $\mathrm{SO}_{2}$ control technology are entered on the Config input screen

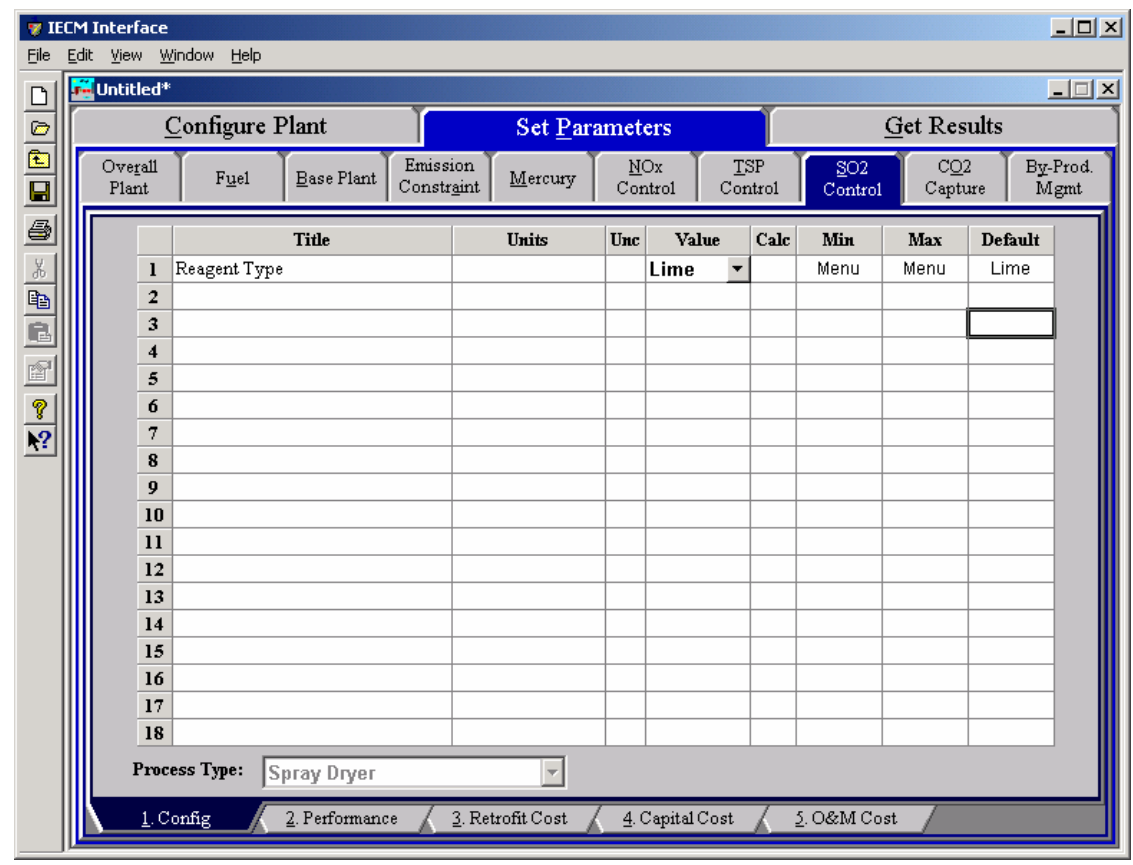

Spray Dryer - Config. input screen.

Each parameter is described briefly below.

Reagent: For the Lime Spray Dryer the only option is Lime. 
- Lime: Magnesium Enhanced Lime System-A magnesium sulfite and lime slurry (maglime) is used to remove SO2 and form a precipitate high in calcium sulfite. The high alkalinity of the maglime slurry allows very high SO2 removal. However, the reagent cost is also higher and solid waste is not easily disposed.

\section{Spray Dryer Performance Inputs}

This screen is only available for the Combustion (Boiler) plant type. Inputs for performance of the Lime Spray Dryer $\mathrm{SO}_{2}$ control technology are entered on the Performance input screen.

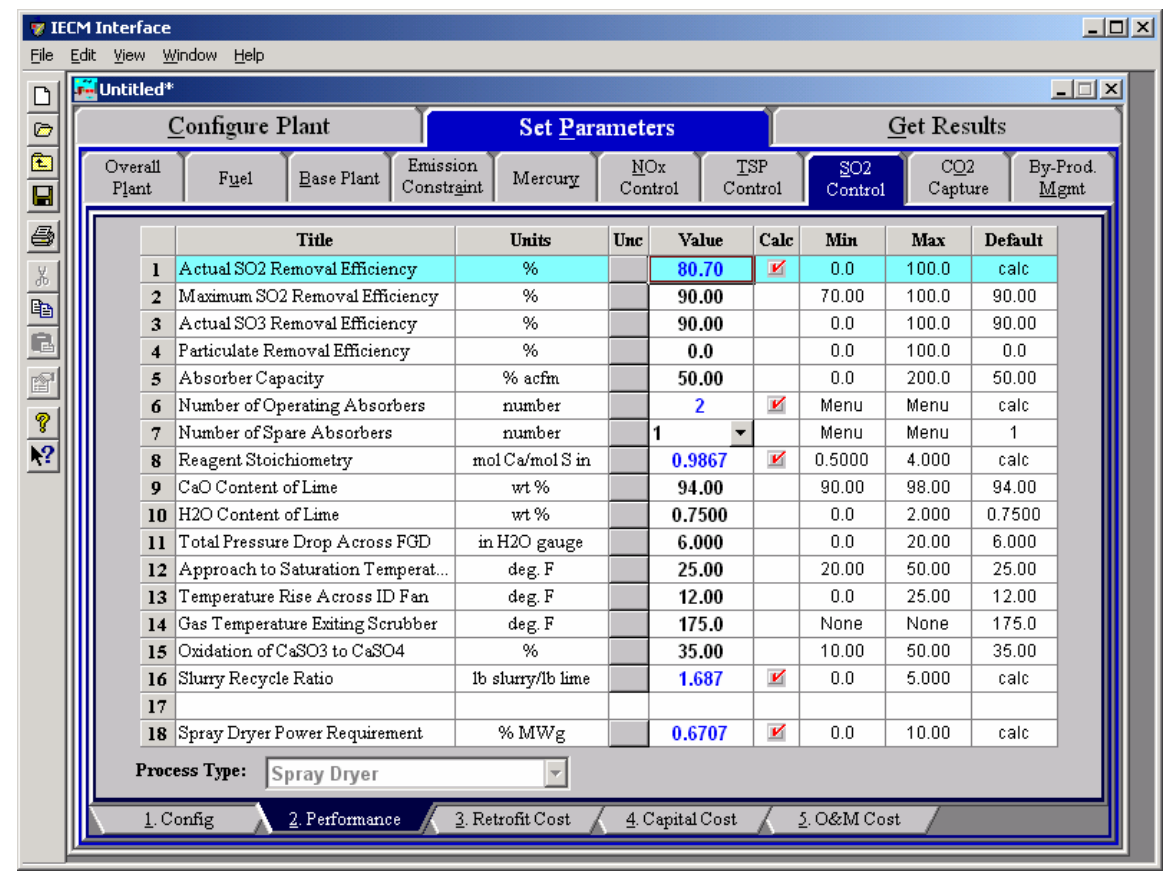

Spray Dryer - Performance input screen.

In a Lime Spray Dryer, an atomized spray of a mixture of lime slurry and recycled solids is brought into contact with the hot flue gas. The water in the slurry evaporates leaving dry reaction products and flyash, which drops out of the scrubber. A particulate control device such as a baghouse is also used to remove the rest of the dry products from the flue gas before releasing it. The $\mathrm{SO}_{2}$ removal efficiency is the total of $\mathrm{SO}_{2}$ removed in the scrubber and the baghouse.

Many lime spray dryer input parameters are similar to those defined above for wet lime/limestone systems. Each parameter is described briefly below.

Actual $\mathrm{SO}_{2}$ Removal Efficiency: This is the annual average $\mathrm{SO}_{2}$ removal efficiency achieved in the absorber. The calculated default value assumes compliance with the $\mathrm{SO}_{2}$ emission limit specified earlier, if possible. The default value reflects other model parameter values, including the sulfur retained in bottom ash. This input is highlighted in blue.

Maximum $\mathrm{SO}_{2}$ Removal Efficiency: This parameters specifies the maximum efficiency possible for the absorber on an annual average basis. The value is used as a limit in calculating the actual $\mathrm{SO}_{2}$ removal efficiency for compliance. 
Actual $\mathrm{SO}_{3}$ Removal Efficiency: The default value is taken from the removal efficiency reported in the literature (references are below). This efficiency then determines the mass of $\mathrm{SO}_{3}$ removed from the flue gas in the collector. For more information see also:

- $\quad$ www.netl.doe.gov/publications/proceedings/98/98fg/hardman.pdf

- $\quad$ www.netl.doe.gov/publications/proceedings/98/98fg/rubin.pdf

Particulate Removal Efficiency: Ash and particulate matter are assumed to be removed by a separate particulate removal device, such as a fabric filter. However, this parameters is provided for conditions where particulates are removed directly from the scrubber.

Absorber Capacity: This is the percent of the flue gas treated by each operating absorber. This value is used to determine the number of operating absorbers and the capital costs.

Number of Operating Absorbers: This is the number of operating scrubber towers. The number is determined by the absorber capacity and is used to calculate the capital costs. The value must be an integer.

Number of Spare Absorbers: This is the total number of spare absorber vessels. It is used primarily to calculate capital costs. The value must be an integer.

Reagent Stoichiometry: This is the moles of calcium per mole of sulfur into the absorber. The stoichiometry is calculated as a function of the required $\mathrm{SO}_{2}$ removal efficiency, inlet flue gas temperature, inlet sulfur concentration, and approach to saturation temperature.

$\mathrm{CaO}$ Content of Lime: This is the percent of reagent that is pure lime $(\mathrm{CaO})$. This parameter determines the waste solids produced and the reagent mass requirements, given the stoichiometry needed for $\mathrm{SO}_{2}$ removal.

H2O Content of Lime: This is the moisture content of the lime (CaO). The remaining reagent impurities are assumed to be inert substances such as silicon dioxide (sand). This parameter is used to determine the waste solids produced.

Total Pressure Drop Across FGD: This is the total pressure drop across the spray dryer vessel prior to the reheater. This is used in the calculations of the power requirements (or energy penalty) and thermodynamic properties of the flue gas.

Approach to Saturation Temperature: This defines the gas temperature exiting the absorber. The approach is the increment over the water saturation temperature at the exit pressure. As the approach to saturation temperature increases, the evaporation time decreases thereby decreasing removal efficiency.

Temperature Rise Across ID Fan: An induced draft (ID) fan is assumed to be located upstream of the FGD system. The fan raises the temperature of the flue gas due to dissipation of electro-mechanical energy.

Gas Temperature Exiting Scrubber: A thermodynamic equation is used to calculate this equilibrium flue gas temperature exiting the scrubber. The gas is assumed to be saturated with water at the exiting temperature and pressure. The value determines the water evaporated in the scrubber. 
Oxidation of CaSO3 to CaSO4: This parameter determines the mixture of the two chemical species in the solid waste stream.

Slurry Recycle Ratio: An atomized spray of a mixture of lime slurry and recycled solids is brought into contact with the hot flue gas. This parameter specifies the amount of solid waste recycled and lime slurry used. It is calculated from the sulfur content of the coal.

Spray Dryer Power Requirement: This is the equivalent electrical output of thermal (steam) energy used for reheat, plus the actual electrical output power required for pumps and booster fans.

\section{Spray Dryer Retrofit Cost}

This screen is only available for the Combustion (Boiler) plant type. Inputs for capital costs of modifications to process areas to implement the $\mathrm{SO}_{2}$ control technology are entered on the Retrofit Cost input screen.

The retrofit cost factor of each process is a multiplicative cost adjustment which considers the cost of retrofitted capital equipment relative to similar equipment installed in a new plant. These factors affect the capital costs directly and the operating and maintenance costs indirectly.

Direct capital costs for each process area are calculated in the IECM. These calculations are reduced form equations derived from more sophisticated models and reports. The sum of the direct capital costs associated with each process area is defined as the process facilities capital (PFC). The retrofit cost factor provided for each of the process areas can be used as a tool for adjusting the anticipated costs and uncertainties across the process area separate from the other areas.

Uncertainty can be applied to the retrofit cost factor for each process area in each technology. Thus, uncertainty can be applied as a general factor across an entire process area, rather than as a specific uncertainty for the particular cost on the capital or O\&M input screens. Any uncertainty applied to a process area through the retrofit cost factor compounds any uncertainties specified later in the capital and O\&M cost input parameter screens. 


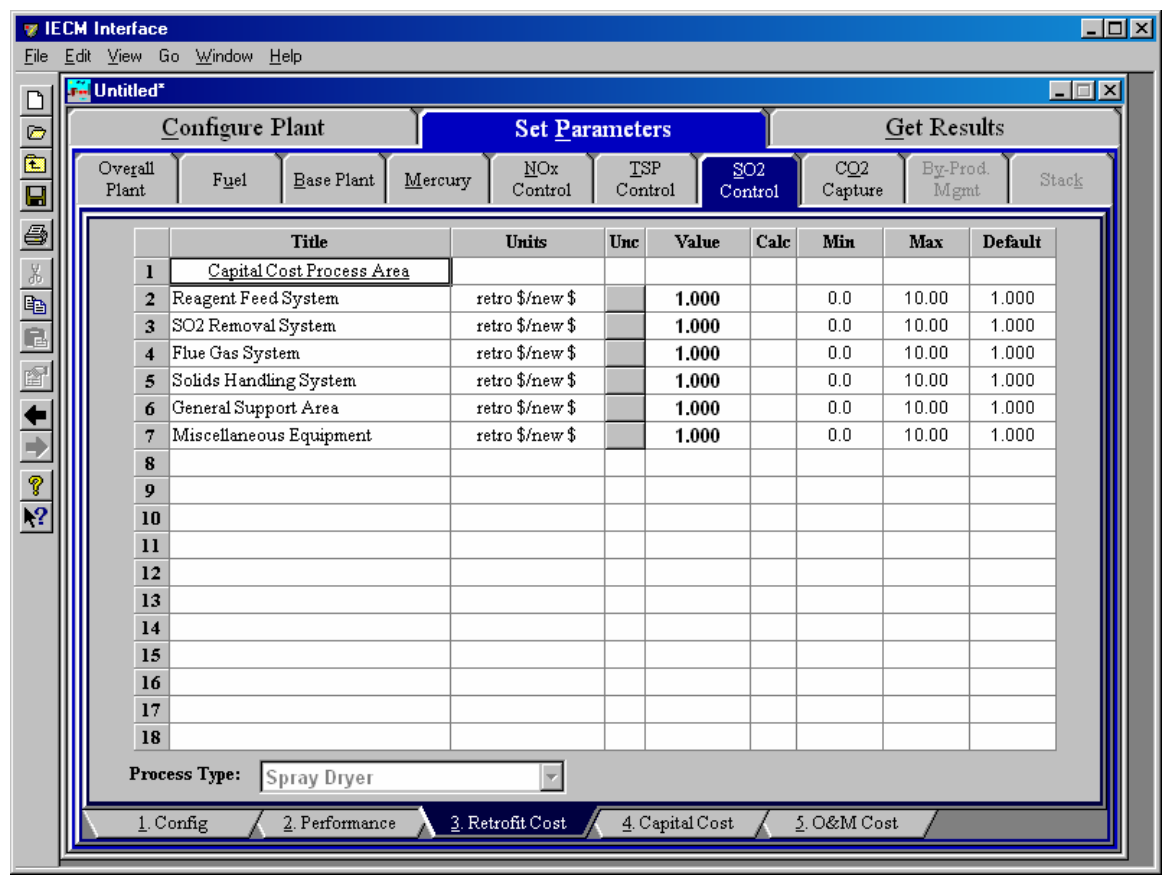

Spray Dryer - Retrofit Cost input screen.

Each parameter is described briefly below.

Reagent Feed System: This area includes all equipment for storage, handling and preparation of raw materials, reagents, and additives used.

$\mathrm{SO}_{2}$ Removal System: This area deals with the cost of equipment for $\mathrm{SO}_{2}$ scrubbing, such as absorption tower, recirculation pumps, and other equipment.

Flue Gas System: This area treats the cost of the duct work and fans required for flue gas distribution to $\mathrm{SO}_{2}$ system, plus gas reheat equipment.

Solids Handling System: This area includes the cost of the equipment for fixation, treatment, and transportation of all sludge/dry solids materials produced by scrubbing.

General Support Area: The cost associated with the equipment required to support FGD system operation such as makeup water and instrument air are treated here.

Miscellaneous Equipment: Any miscellaneous equipment is treated in this process area.

\section{Spray Dryer Capital Cost Inputs}

This screen is only available for the Combustion (Boiler) plant type. 


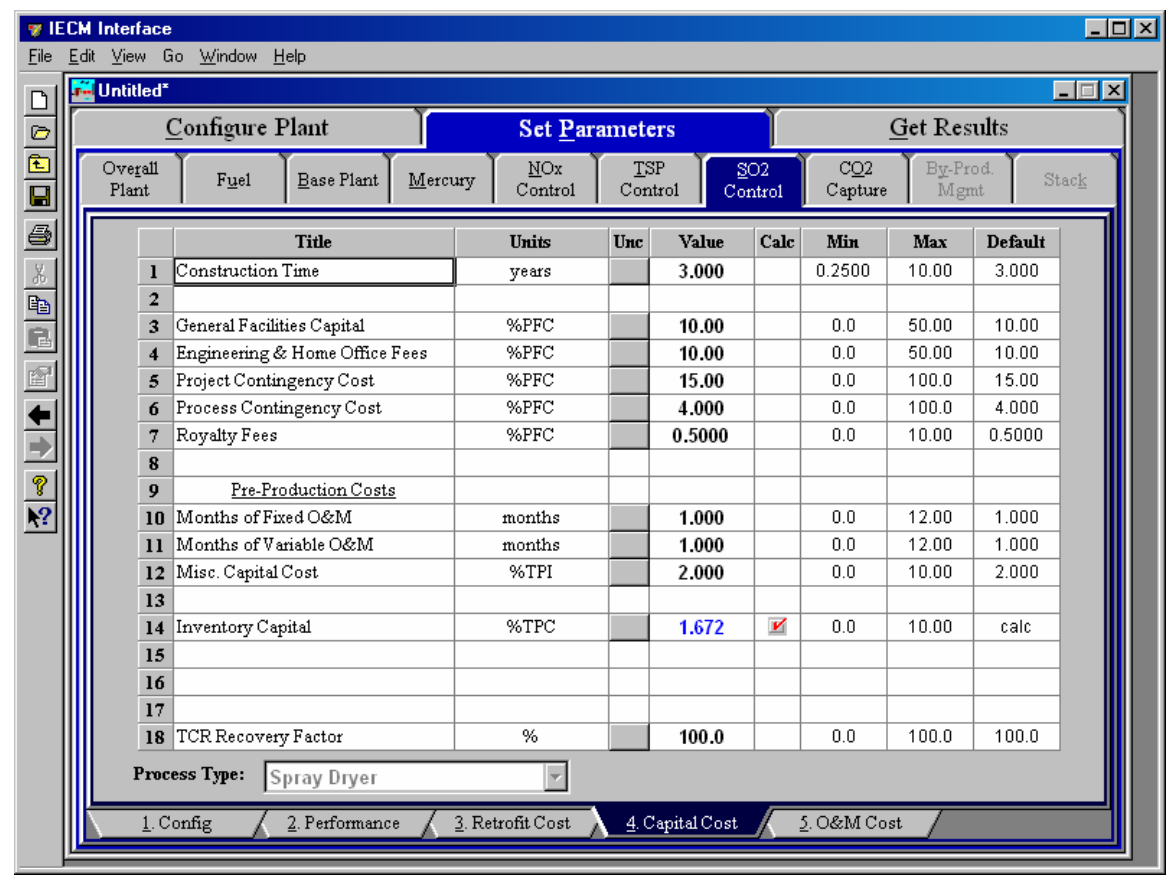

Spray Dryer - Capital Cost input screen.

Inputs for capital costs are entered on the Capital Cost input screen.

Construction Time: This is the idealized construction period in years. It is used to determine the allowance for funds used during construction (AFUDC).

General Facilities Capital (GFC): The general facilities include construction costs of roads, office buildings, shops, laboratories, etc. Sales taxes and freight costs are included implicitly. The cost typically ranges from $5-20 \%$.

Engineering \& Home Office Fees: The engineering \& home office fees are a percent of total direct capital cost. This is an overhead fee paid to the architect/engineering company. These fees typically range from 7$15 \%$.

Project Contingency Cost: This is factor covering the cost of additional equipment or other costs resulting from a more detailed design. Higher contingency factors will be applied to simplified or preliminary designs and lower factors to detailed or finalized designs.

Process Contingency Cost: This quantifies the design uncertainty and cost of a commercial-scale system. This is generally applied on an areaby-area basis. Higher contingency factors are applied to new regeneration systems tested at a pilot plant and lower factors to full-size or commercial systems.

Royalty Fees: Royalty charges may apply to some portions of generating units incorporating new proprietary technologies.

Pre-Production Costs: These costs consider the operator training, equipment checkout, major changes in unit equipment, extra maintenance, and inefficient use of fuel or other materials during startup. These are typically applied to the O\&M costs over a specified period of time (months). The two time periods for fixed and variable 
O\&M costs are described below with the addition of a miscellaneous capital cost factor.

- Months of Fixed O\&M: Time period of fixed operating costs used for preproduction to cover training, testing, major changes in equipment, and inefficiencies in start-up. This includes operating, maintenance, administrative and support labor. It also considers maintenance materials.

- Months of Variable O\&M: Time period of variable operating costs used for preproduction to cover chemicals, water, consumables, and solid disposal charges in start-up, assuming $100 \%$ load. This excludes any fuels.

- Misc. Capital Cost: This is a percent of total plant investment (sum of TPC and AFUDC) to cover expected changes to equipment to bring the system up to full capacity.

- Inventory Capital: Percent of the total direct capital for raw material supply based on $100 \%$ capacity during a 60 day period. These materials are considered storage. The inventory capital includes fuels, consumables, by-products, and spare parts. This is typically $0.5 \%$.

TCR Recovery Factor: The actual total capital required (TCR) as a percent of the TCR in a new power plant. This value is $100 \%$ for a new installation and may be set as low as $0 \%$ for a fabric filter that has been paid off.

\section{Spray O\&M Cost Inputs}

This screen is only available for the Combustion (Boiler) plant type.

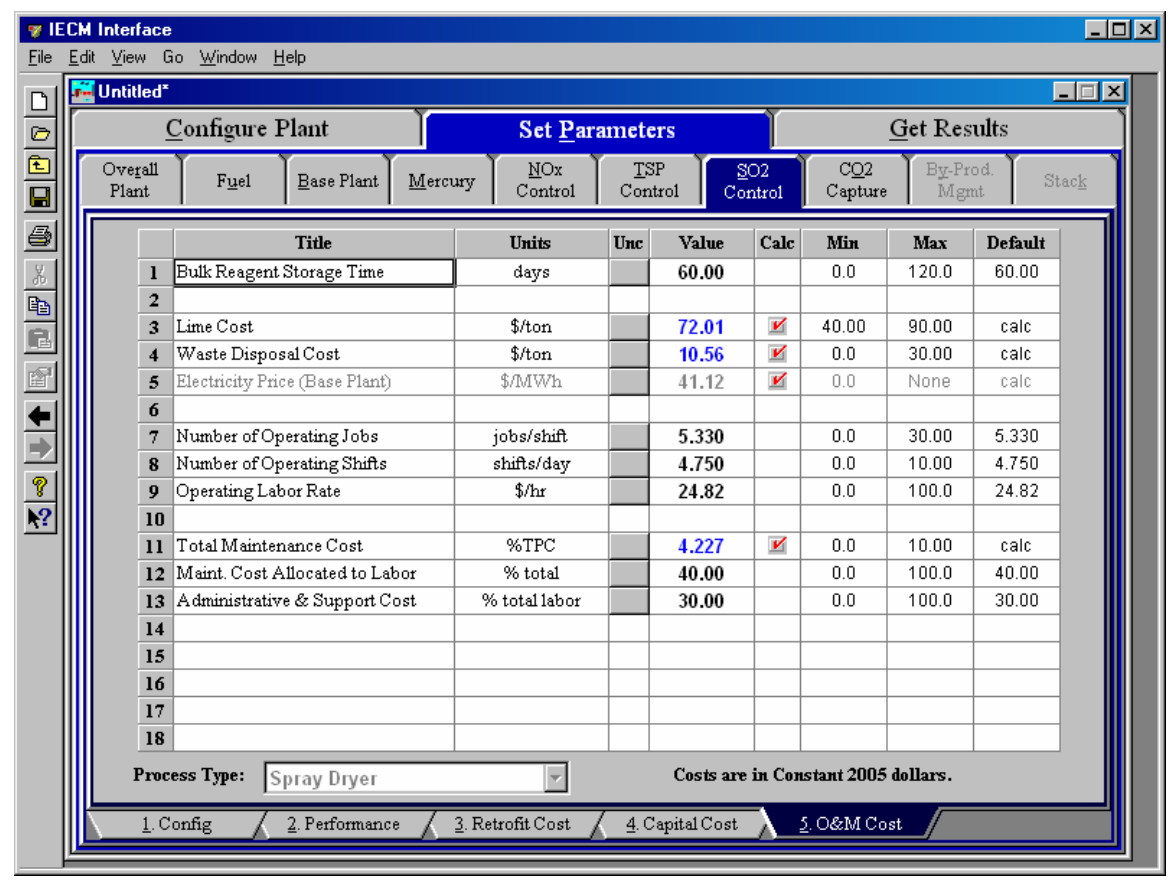

Spray Dryer - O\&M Cost input screen. 
Inputs for operation and maintenance are entered on the O\&M Cost input tab. O\&M costs are typically expressed on an average annual basis and are provided in either constant or current dollars for a specified year, as shown on the bottom of the screen. Each parameter is described briefly below

Bulk Reagent Storage Time: This is the number of days of bulk storage of reagent. This factor is used to determine the inventory capital cost.

Lime Cost: This is the cost of Lime for the Wet FGD or Lime Spray Dryer system.

Waste Disposal Cost: This is the sludge disposal cost for the FGD system.

Electricity Price (Base Plant): This is the price of electricity and is calculated as a function of the utility cost of the base plant, where the base plant is for the Combustion (Boiler) Model is a combustion boiler and an air preheater.

Total Maintenance Cost: This is the annual maintenance cost as a percentage of the total plant cost. Maintenance cost estimates can be developed separately for each process area.

Maint. Cost Allocated to Labor: Maintenance cost allocated to labor as a percentage of the total maintenance cost.

Administrative \& Support Cost: This is the percent of the total operating and maintenance labor associated with administrative and support labor.

\section{Spray Dryer Diagram}

This screen is only available for the Combustion (Boiler) plant type.

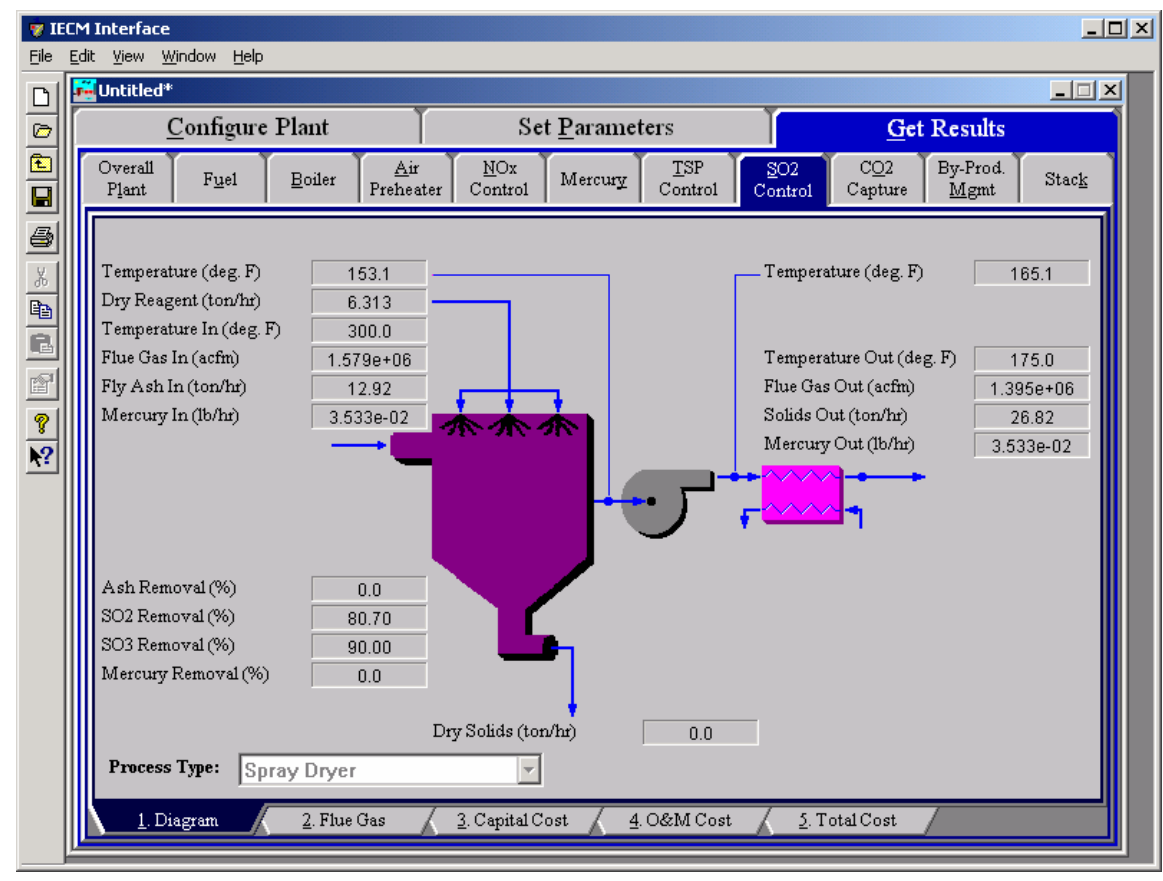

Spray Dryer - Diagram 
The Diagram result screen displays an icon for the Lime Spray Dryer $\mathrm{SO}_{2}$ control technology selected and values for major flows in and out of it. Each result is described briefly below:

\section{Reagent}

Dry Reagent: The total mass flow rate of lime, limestone or limestone with dibasic acid injected into the scrubber. This is a function of the $\mathrm{SO}_{2}$ removal efficiency, the reagent purity and the reagent stoichiometric (all performance input parameters). The reagent is assumed to be dry.

\section{Flue Gas Entering Dryer}

Temperature In: Temperature of the flue gas entering the scrubber. This is determined by the flue gas outlet temperature of the module upstream of the scrubber (e.g., a particulate removal technology).

Flue Gas In: Volumetric flow rate of flue gas entering the scrubber, based on the flue gas temperature entering the scrubber and atmospheric pressure.

Fly Ash In: Total solids mass flow rate in the flue gas entering the scrubber. This is determined by the solids exiting from the module upstream of the scrubber (e.g., a particulate removal technology).

Mercury In: Total mass of mercury entering the scrubber. The value is a sum of all the forms of mercury (elemental, oxidized, and particulate).

\section{Flue Gas Exiting Dryer}

Temperature: Temperature of the flue gas immediately after exiting the scrubber. This is a function of saturation temperature, and the flue gas component concentrations. This temperature is used to determine the flue gas bypass required.

Temperature: Temperature of the flue gas immediately after exiting the induced draft fan. This is a function of flue gas temperature exiting the scrubber, the flue gas bypass and the temperature rise across ID fan input parameter.

Temperature Out: Temperature of the flue gas immediately after exiting the reheater. This is determined by the gas temperature exiting reheater input parameter.

Flue Gas Out: Volumetric flow rate of the flue gas exiting the reheater, based on the flue gas temperature exiting the scrubber and atmospheric pressure.

Solids Out: Total solids mass flow rate in the flue gas exiting the reheater. This is a function of the ash removal parameter on the scrubber performance input screen.

Mercury Out: Total mass of mercury exiting the scrubber after the reheater. The value is a sum of all the forms of mercury (elemental, oxidized, and particulate). 


\section{Spray Dryer Performance}

Ash Removal: Actual particulate removal efficiency in the scrubber. This is set by the scrubber performance input parameter.

$\mathbf{S O}_{2}$ Removal: Actual removal efficiency of $\mathrm{SO}_{2}$ in the scrubber. This is a function of the maximum removal efficiency (scrubber performance input parameter) and the emission constraint for $\mathrm{SO}_{2}$ (emission constraints input parameter). It is possible that the scrubber may over or under-comply with the emission constraint.

$\mathrm{SO}_{3}$ Removal: Percent of $\mathrm{SO}_{3}$ in the flue gas removed from the scrubber. The $\mathrm{SO}_{3}$ is assumed to combine with $\mathrm{H}_{2} \mathrm{O}$ and leave with the ash solids or sluice water as a sulfate (in the form of $\mathrm{H}_{2} \mathrm{SO}_{4}$ ).

Mercury Removal: Percent of the total mercury removed from the scrubber. The value reflects a weighted average based on the particular species of mercury present (elemental, oxidized, and particulate).

\section{Collected Solids}

Dry Solids: Total solids mass flow rate of solids removed from the scrubber. This is a function of the solids content in the flue gas and the particulate removal efficiency of the scrubber. The solids are assumed to be dry.

\section{Spray Dryer Flue Gas Results}

This screen is only available for the Combustion (Boiler) plant type.

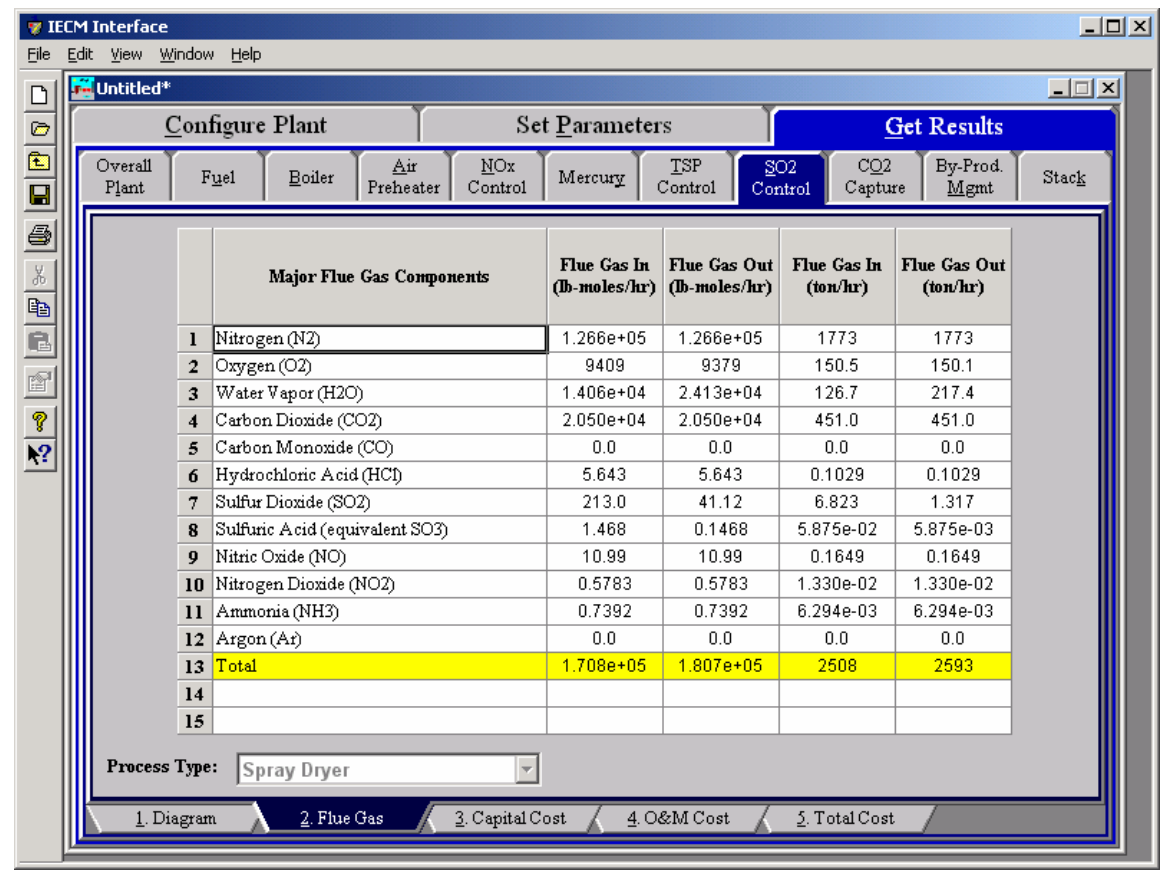

Spray Dryer - Flue Gas result screen. 


\section{Major Flue Gas Components}

Each result is described briefly below:

Nitrogen $\left(\mathbf{N}_{\mathbf{2}}\right)$ : Total mass of nitrogen.

Oxygen $\left(\mathrm{O}_{2}\right)$ : Total mass of oxygen.

Water Vapor $\left(\mathbf{H}_{2} \mathbf{O}\right)$ : Total mass of water vapor.

Carbon Dioxide $\left(\mathrm{CO}_{2}\right)$ : Total mass of carbon dioxide.

Carbon Monoxide (CO): Total mass of carbon monoxide.

Hydrochloric Acid (HCl): Total mass of hydrochloric acid.

Sulfur Dioxide $\left(\mathrm{SO}_{2}\right)$ : Total mass of sulfur dioxide.

Sulfuric Acid (equivalent $\mathrm{SO}_{3}$ ): Total mass of sulfuric acid.

Nitric Oxide (NO): Total mass of nitric oxide.

Nitrogen Dioxide $\left(\mathbf{N O}_{2}\right)$ : Total mass of nitrogen dioxide.

Ammonia (NH3): Total mass of ammonia.

Argon (Ar): Total mass of argon.

Total: Total of the individual components listed above. This item is highlighted in yellow.

\section{Spray Dryer Capital Cost Results}

This screen is only available for the Combustion (Boiler) plant type.

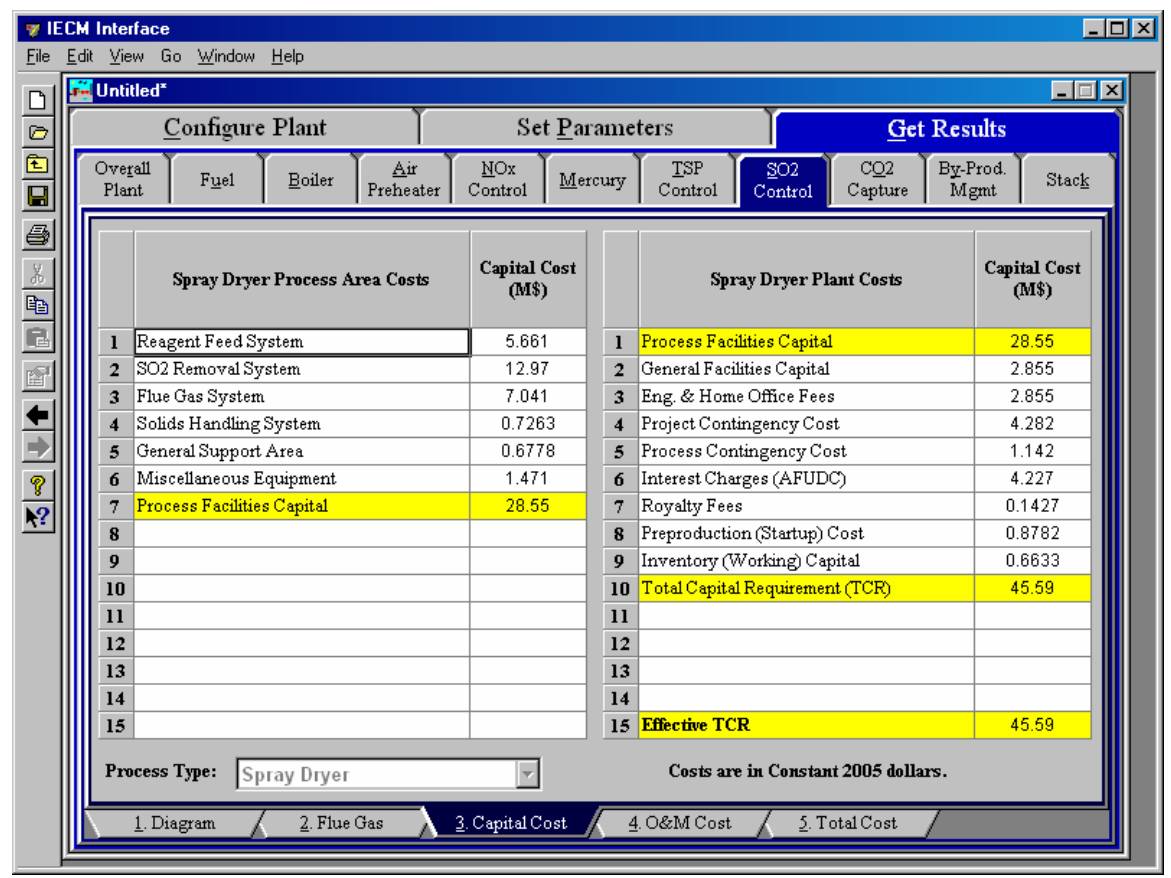

Spray Dryer - Capital Cost result screen.

The Capital Cost result screen displays tables for the direct and indirect capital costs. Capital costs are typically expressed in either constant or current dollars for a 
specified year, as shown on the bottom of the screen. Each result is described briefly below:

Each process area direct capital cost is a reduced-form model based on regression analysis of data collected from several reports and analyses of particulate control technology units. They are described in general below. The primary factors in the model that effect the capital costs of the scrubbers are the flue gas flow rate through the scrubber, the composition of the flue gas, the reagent stoichiometry, and the reagent flow rate.

Reagent Feed System: This area includes all equipment for storage, handling and preparation of raw materials, reagents, and additives used.

$\mathrm{SO}_{2}$ Removal System: This area deals with the cost of equipment for $\mathrm{SO}_{2}$ scrubbing, such as absorption tower, recirculation pumps, and other equipment.

Flue Gas System: This area treats the cost of the duct work and fans required for flue gas distribution to $\mathrm{SO}_{2}$ system, plus gas reheat equipment.

Solids Handling System: This area includes the cost of the equipment for fixation, treatment, and transportation of all sludge/dry solids materials produced by scrubbing.

General Support Area: The cost associated with the equipment required to support spray dryer system operation such as makeup water and instrument air are treated here.

Miscellaneous Equipment: Any miscellaneous equipment is treated in this process area.

Process Facilities Capital: The process facilities capital is the total constructed cost of all on-site processing and generating units listed above, including all direct and indirect construction costs. All sales taxes and freight costs are included where applicable implicitly. This result is highlighted in yellow.

General Facilities Capital: The general facilities include construction costs of roads, office buildings, shops, laboratories, etc. Sales taxes and freight costs are included implicitly.

Eng. \& Home Office Fees: The engineering \& home office fees are a percent of total direct capital cost. This is an overhead fee paid to the architect/engineering company.

Project Contingency Cost: Capital cost contingency factor covering the cost of additional equipment or other costs that would result from a more detailed design of a definitive project at the actual site.

Process Contingency Cost: Capital cost contingency factor applied to a new technology in an effort to quantify the uncertainty in the technical performance and cost of the commercial-scale equipment.

Interest Charges (AFUDC): Allowance for funds used during construction, also referred to as interest during construction, is the time value of the money used during construction and is based on an interest rate equal to the before-tax weighted cost of capital. This interest is compounded on an annual basis (end of year) during the construction period for all funds spent during the year or previous years.

Royalty Fees: Royalty charges may apply to some portions of generating units incorporating new proprietary technologies. 
Preproduction (Startup) Cost: These costs consider the operator training, equipment checkout, major changes in unit equipment, extra maintenance, and inefficient use of fuel or other materials during startup.

Inventory (Working) Capital: The raw material supply based on 100\% capacity during a 60 day period. These materials are considered storage. The inventory capital includes fuels, consumables, byproducts, and spare parts.

Total Capital Requirement (TCR): Money that is placed (capitalized) on the books of the utility on the service date. TCR includes all the items above. This result is highlighted in yellow.

Effective TCR: The TCR of the spray dryer that is used in determining the total power plant cost. The effective TCR is determined by the "TCR Recovery Factor".

\section{Spray Dryer O\&M Results}

This screen is only available for the Combustion (Boiler) plant type.

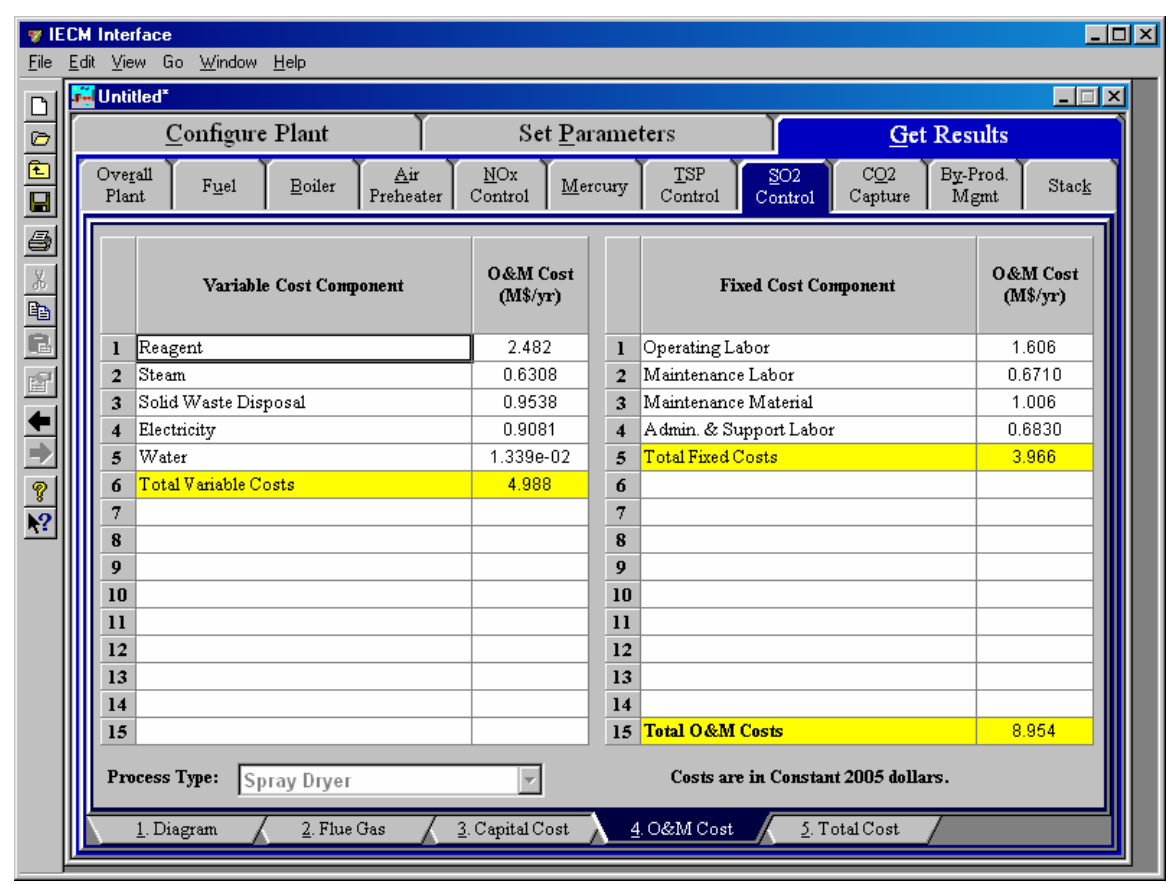

Spray Dryer - O\&M Cost result screen.

The O\&M Cost result screen displays tables for the variable and fixed operation and maintenance costs involved with the $\mathrm{SO}_{2}$ control technology. O\&M costs are typically expressed on an average annual basis and are provided in either constant or current dollars for a specified year, as shown on the bottom of the screen. Each result is described briefly below: 


\section{Variable Cost Components}

Variable operating costs and consumables are directly proportional to the amount of kilowatts produced and are referred to as incremental costs. All the costs are subject to inflation.

Reagent: Annual cost of lime or limestone injected into the scrubber on a wet basis. This is a function of the $\mathrm{SO}_{2}$ concentration in the flue gas and the reagent stoichiometric performance input value.

Steam: Annual cost of steam used for direct or reheat use in the scrubber. This is a function of the steam heat rate, reheat energy requirement, and gross plant capacity.

Solid Waste Disposal: Total cost to dispose the collected flue gas waste solids. This does not consider by-product gypsum sold in commerce.

Power: Cost of power consumption of the scrubber. This is a function of the gross plant capacity and the scrubber energy penalty performance input parameter.

Water: Cost of water for reagent sluice in the scrubber. This is a function of the liquid to gas ratio performance input parameter for the wet FGD. The cost is a function of the flue gas flow rate and the slurry recycle ratio performance input parameter for the spray dryer.

Total Variable Costs: This is the sum of all the variable O\&M costs listed above. This result is highlighted in yellow.

\section{Fixed Cost Components}

Fixed operating costs are essentially independent of actual capacity factor, number of hours of operation, or amount of kilowatts produced. All the costs are subject to inflation.

Operating Labor: Operating labor cost is based on the operating labor rate, the number of personnel required to operate the plant per eighthour shift, and the average number of shifts per day over 40 hours per week and 52 weeks.

Maintenance Labor: The maintenance labor is determined as a fraction of the total maintenance cost.

Maintenance Material: The cost of maintenance material is the remainder of the total maintenance cost, considering the fraction associated with maintenance labor.

Admin. \& Support Labor: The administrative and support labor is the only overhead charge. It is taken as a fraction of the total operating and maintenance labor costs.

Total Fixed Costs: This is the sum of all the fixed O\&M costs listed above. This result is highlighted in yellow.

Total O\&M Costs: This is the sum of the total variable and total fixed O\&M costs. It is used to determine the base plant total revenue requirement. This result is highlighted in yellow. 


\section{Spray Dryer Total Cost Results}

This screen is only available for the Combustion (Boiler) plant type.

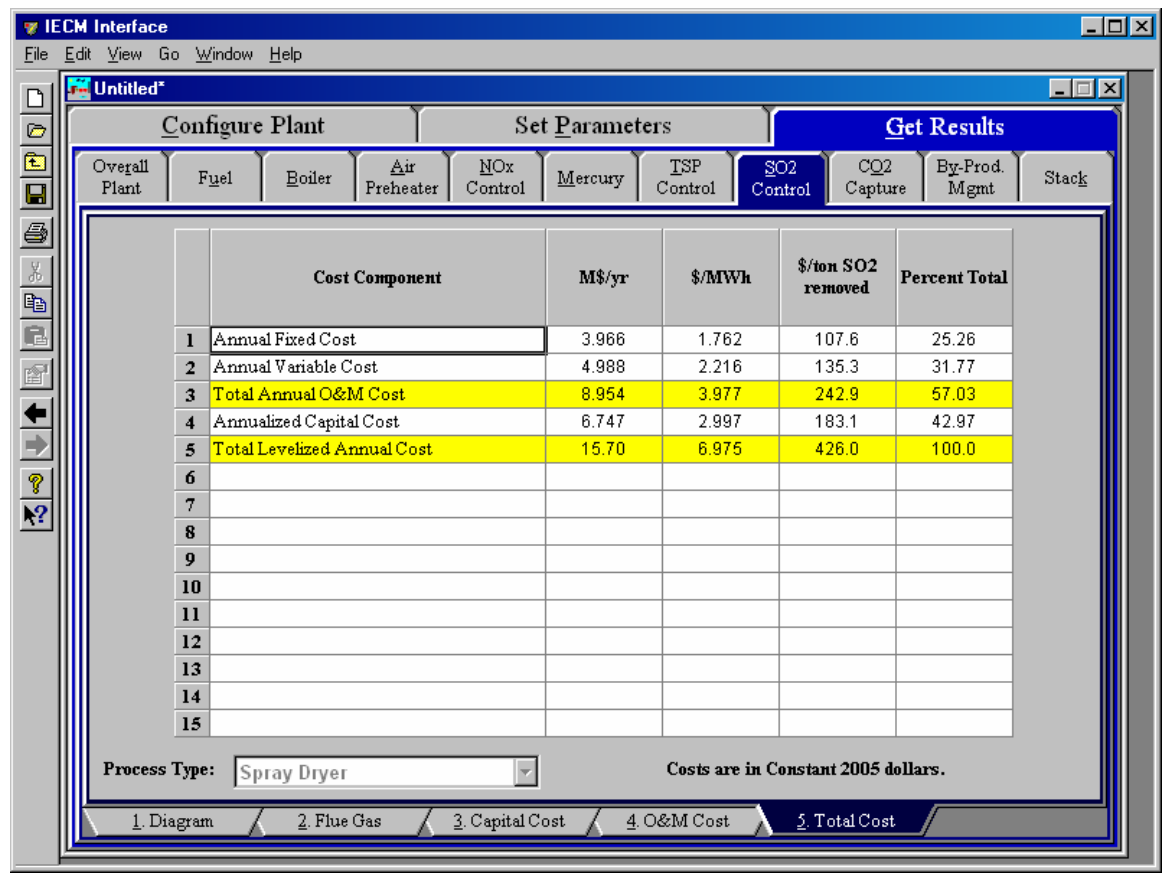

Spray Dryer - Total Cost result screen.

\section{Cost Component}

The Total Cost result screen displays a table which totals the annual fixed, variable, operations, maintenance, and capital costs. Total costs are typically expressed in either constant or current dollars for a specified year, as shown on the bottom of the screen. Each result is described briefly below.

Annual Fixed Cost: The operating and maintenance fixed costs are given as an annual total. This number includes all maintenance materials and all labor costs.

Annual Variable Cost: The operating and maintenance variables costs are given as an annual total. This includes all reagent, chemical, steam, and power costs.

Total Annual O\&M Cost: This is the sum of the annual fixed and variable operating and maintenance costs above. This result is highlighted in yellow.

Annualized Capital Cost: This is the total capital cost expressed on an annualized basis, taking into consideration the levelized carrying charge factor, or fixed charge factor, over the entire book life.

Total Levelized Annual Cost: The total annual cost is the sum of the total annual O\&M cost and annualized capital cost items above. This result is highlighted in yellow. 



\section{Amine System}

The amine $\mathrm{CO}_{2}$ scrubber is a post-combustion capture technology. It is only used in the Combustion (Boiler) and Combustion (Turbine) plant type configurations.

\section{Amine System Configuration}

This screen is only available for the Combustion (Boiler) and Combustion (Turbine) plant types. The screens under the $\mathbf{C} \underline{\mathbf{O}}_{2}$ Capture Technology Navigation Tab display and design flows and data related to the Amine System.

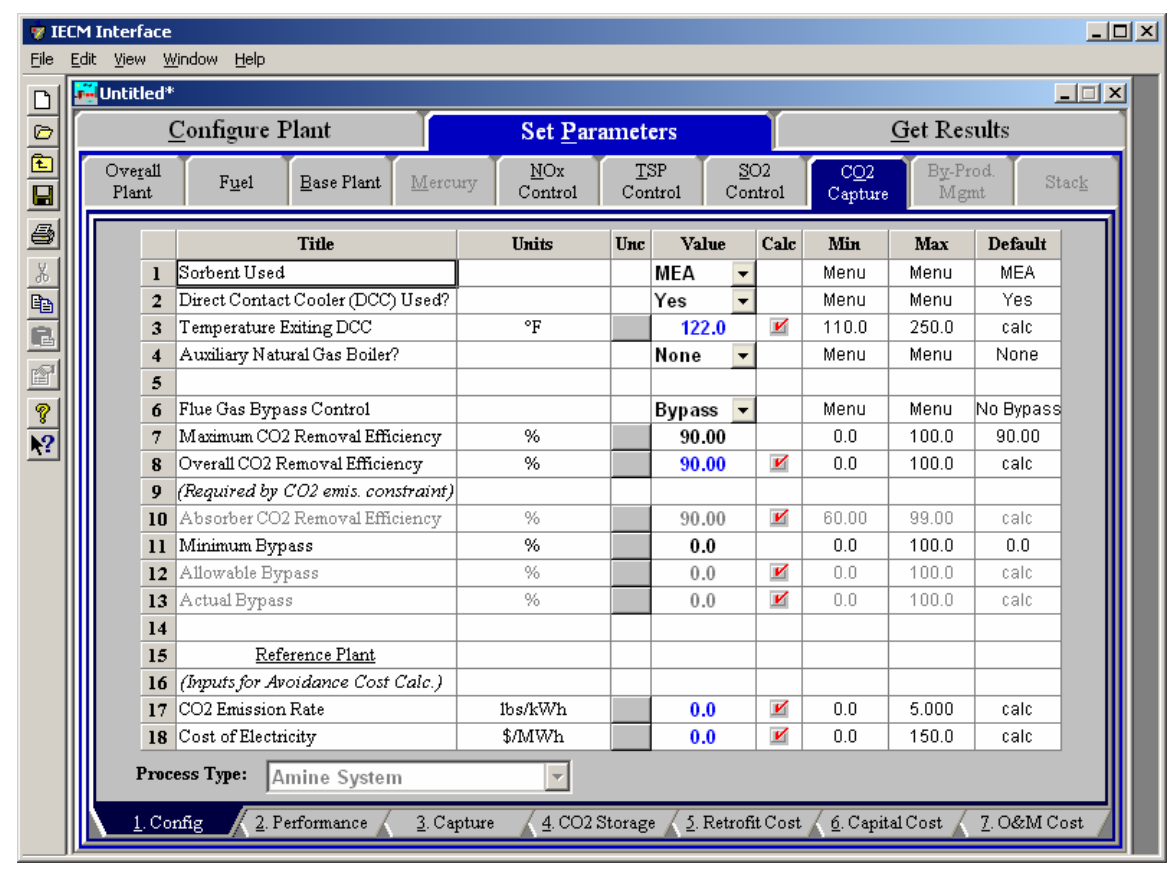

Amine System - Config. input screen (flue gas bypass added).

The parameters below describe the amine system alone. Additional parameters may be added to the screen if an auxiliary boiler or flue gas bypass is specified in the menus provided. The common input parameters are:

Sorbent Used: MEA is the sorbent used in the system and the nominal values of various parameters are based on a process simulation model that uses MEA. At present, no other sorbents are included. 
Direct Contact Cooler (DCC) Used: A DCC is configured by default to cool the flue gas before it enters the amine system. The lower flue gas temperature enhances the absorption reaction (absorption of $\mathrm{CO}_{2}$ in MEA sorbent is an exothermic process) and decreases the flue gas volume. The typically acceptable range of flue gas temperature is about $120-140{ }^{\circ} \mathrm{F}$. A DCC is often not needed if a wet FGD is installed upstream.

Temperature Exiting DCC: This is the temperature exiting the DCC. The desirable temperature of the flue gas entering the $\mathrm{CO}_{2}$ capture system is about $113-122{ }^{\circ} \mathrm{F}$. If the inlet temperature to the DCC is at or below this temperature, the DCC is not used. This variable is only displayed if a DCC is specified.

Auxiliary Natural Gas Boiler?: An auxiliary natural gas-fired boiler can be added to the amine system. The options available are None, Steam Only, and Steam + Power. It may be added to generate separate power for the amine system (mainly compressors) and low pressure steam for sorbent regeneration. When used, the original steam cycle of the power plant remains undisturbed and the net power generation capacity of the power plant is not adversely affected. The auxiliary boiler comes at an additional cost of capital requirement for the boiler (and turbine) and the cost of supplemental fuel. Also, the auxiliary boiler adds to the $\mathrm{CO}_{2}$ and $\mathrm{NO}_{\mathrm{x}}$ emissions. When an auxiliary boiler is added, an additional process type will be added to the selection menu at the bottom of the screen.

Flue Gas Bypass Control: This popup selection menu controls whether or not a portion of the inlet flue gas may bypass the scrubber and recombine with the treated flue gas. Bypass allows the scrubber to operate at full efficiency while allowing some of the flue gas to go untreated. Two choices are available: No Bypass and Bypass. The no bypass option is the default and forces the entire flue gas to pass through the scrubber. The bypass option allows for the possibility of a portion of the flue gas to bypass the scrubber. The amount of bypass is controlled by several additional input parameters described below.

Maximum $\mathrm{SO}_{2}$ Removal Efficiency: This parameters specifies the maximum efficiency possible for the absorber on an annual average basis. The value is used as a limit in calculating the actual $\mathrm{SO}_{2}$ removal efficiency for compliance. This is only visible if bypass is specified.

Overall $\mathrm{SO}_{2}$ Removal Efficiency: This value is the $\mathrm{SO}_{2}$ removal efficiency required for the entire power plant to meet the $\mathrm{SO}_{2}$ emission constraint set earlier. It is used to determine the actual flue gas bypass above. This is only visible if bypass is specified.

Scrubber $\mathrm{SO}_{2}$ Removal Efficiency: This is the actual removal efficiency of the scrubber alone. It is a function of the $\mathrm{SO}_{2}$ emission constraint and the actual flue gas bypass. This value is also shown on the next input screen. This is only visible if bypass is specified.

Minimum Bypass: This specifies the trigger point for allowing flue gas to bypass the scrubber. No bypass is allowed until the allowable amount reaches the minimum level set by this parameter. This is only visible if bypass is specified.

Allowable Bypass: This is the amount of flue gas that is allowed to bypass the scrubber, based on the actual and maximum performance of the $\mathrm{SO}_{2}$ removal. It is provided for reference only. The model 
determines the bypass that produces the maximum $\mathrm{SO}_{2}$ removal and compares this potential bypass with the minimum bypass value specified above. Bypass is only allowed when the potential bypass value exceeds the minimum bypass value. This is only visible if bypass is specified.

Actual Bypass: This displays the actual bypass being used in the model. It is based on all of the above and is provided for reference purposes only. This is only visible if bypass is specified.

\section{Reference Plant}

The following reference plant inputs are used to determine the avoided cost of $\mathrm{CO}_{2}$ avoidance. The default value is zero for both parameters, requiring the user to supply the actual reference plant values. Reference values can be obtained by simulating the same plant configuration minus the $\mathrm{CO}_{2}$ capture. Analysts commonly express the cost of an environmental control system in terms of either the cost per ton of pollutant removed or the cost per ton "avoided." For an energy-intensive system like amine scrubbers there is a big difference between the cost per ton $\mathrm{CO}_{2}$ removed and the cost per ton $\mathrm{CO}_{2}$ avoided based on net plant capacity. Since the purpose of adding a capture unit is to reduce the $\mathrm{CO}_{2}$ emissions per net $\mathrm{kWh}$ delivered, the cost of $\mathrm{CO}_{2}$ avoidance (relative to a reference plant with no $\mathrm{CO}_{2}$ control) is the economic indicator most widely used. The reference plant parameters required are:

$\mathbf{C O}_{2}$ Emission Rate: This is the emission rate for the reference power plant (without $\mathrm{CO}_{2}$ capture)

Cost of Electricity: This is the cost of electricity for the reference power plant (without $\mathrm{CO}_{2}$ capture)

\section{Auxiliary Boiler Configuration}

This screen is only available for the Combustion (Boiler) and Combustion (Turbine) plant types.

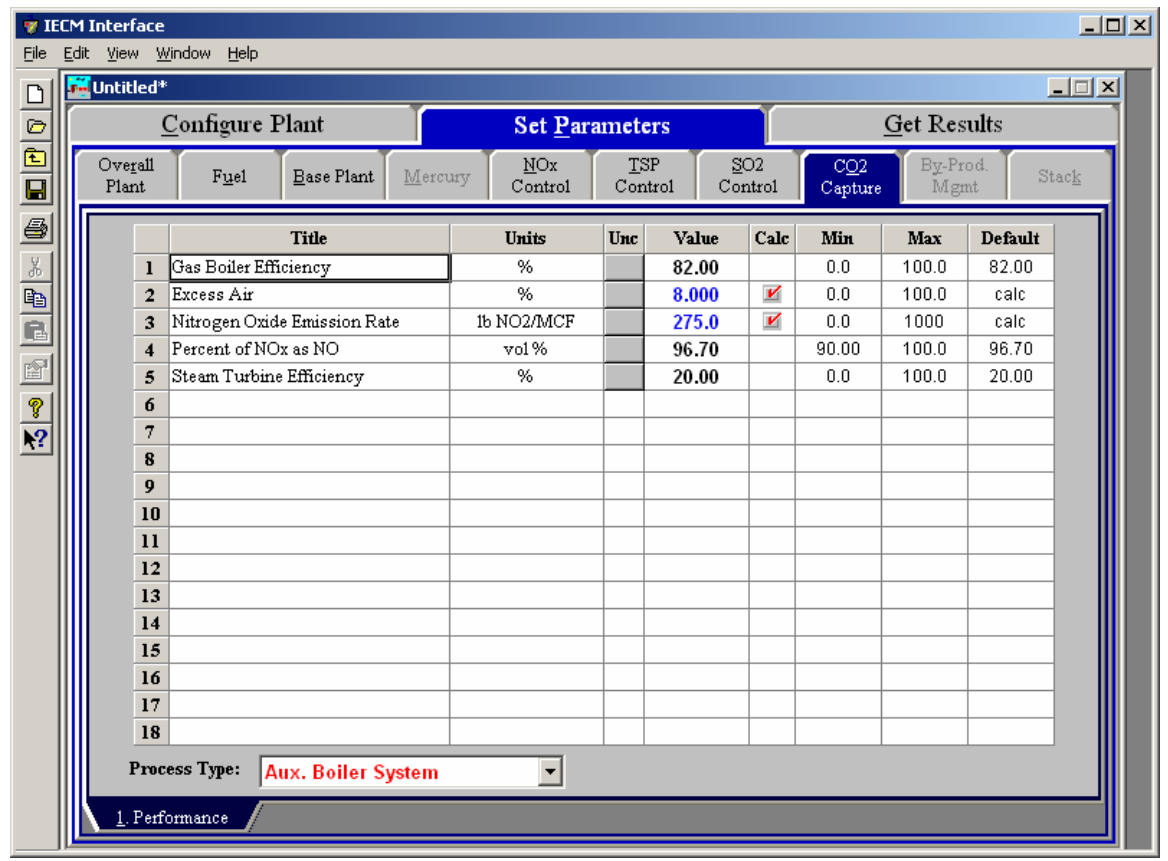


An auxiliary boiler may be added to the amine system to produced additional power and steam. It is accessed by using the "Process Type:" menu at the bottom of the input screen. Use this menu to return to the amine system input screens. If an auxiliary boiler is specified, the following parameters are available:

Gas Boiler Efficiency: This is the percentage of fuel input energy transferred to steam in the boiler. The model default is based on standard algorithms described in the literature. It takes into consideration the energy losses due to inefficient heat transfer across the preheater, latent heat of evaporation, incomplete combustion, radiation losses, and unaccounted losses.

Excess Air: This is the excess theoretical air used for combustion in the auxiliary boiler.

Nitrogen Oxide Emission Rate: This parameter establishes the level of NOx emissions from the boiler. The default value reflects the AP-42 EPA emission factor, which is a function of boiler firing method and the coal rank. The value is given in pounds of equivalent NO2 per ton of coal.

Percent of $\mathrm{NO}_{\mathrm{x}}$ as NO: This parameter establishes the level of nitric oxide (NO) in the flue gas stream. The remainder of the total NOx emissions is assumed to be nitrogen dioxide (NO2). The default parameter reflects the AP-42 EPA emission factor, which is dependent on the fuel type.

Steam Turbine Efficiency: The steam turbine efficiency may be considered the power generation efficiency when converting heat of the low pressure (LP) steam into usable electricity. The efficiency is much lower due to the low quality of the steam being converted. This is only visible when steam and power are specified.

\section{Amine System Performance Inputs}

This screen is only available for the Combustion (Boiler) and Combustion (Turbine) plant types. 


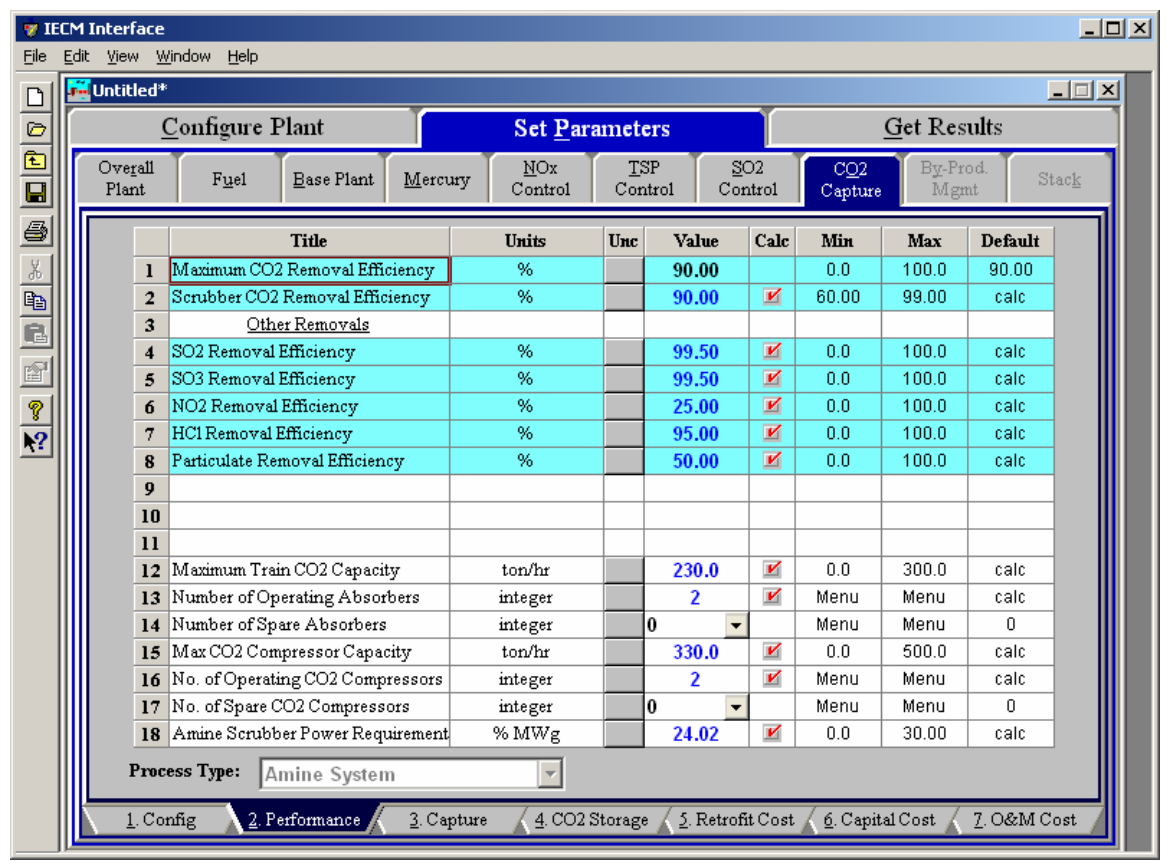

Amine System - Performance input screen.

The amine-based absorption system for $\mathrm{CO}_{2}$ removal is a wet scrubbing operation. This process removes other acid gases and particulate matter in addition to $\mathrm{CO}_{2}$ from the flue gas. These are listed below along with additional performance parameters:

$\mathbf{C O}_{\mathbf{2}}$ Removal Efficiency: Most studies report the $\mathrm{CO}_{2}$ capture efficiency of the amine-based systems to be $90 \%$, with few others reporting as high as $96 \%$ capture efficiency. Here, it has been assumed to be $90 \%$.

$\mathrm{SO}_{\mathbf{2}}$ Removal Efficiency: $\mathrm{SO}_{2}$ is removed at a very high rate. The default efficiency is $99.5 \%$.

$\mathrm{SO}_{3}$ Removal Efficiency: $\mathrm{SO}_{3}$ is removed at a very high rate. The default efficiency is $99.5 \%$.

$\mathrm{NO}_{2}$ Removal Efficiency: A small amount of $\mathrm{NO}_{2}$ is removed. The default efficiency is $25 \%$.

HCl Removal Efficiency: $\mathrm{HCl}$ is removed at a high rate. The default efficiency is $95 \%$.

Particulate Removal Efficiency: Particulates are removed in any wet scrubbing system at a rate of approximately $50 \%$.

Maximum Train $\mathbf{C O}_{2}$ Capacity: The default maximum train size is used with the actual $\mathrm{CO}_{2}$ capture rate to determine the number of trains required.

Number of Operating Absorbers: This is the total number of operating absorber vessels. It is determined by the train capacity specified above and is used primarily to calculate capital costs. The value must be an integer.

Number of Spare Absorbers: This is the total number of spare absorber vessels. It is used primarily to calculate capital costs. The value must be an integer. 
Max. $\mathrm{CO}_{2}$ Compressor Capacity: This is the maximum amount of $\mathrm{CO}_{2}$ product that can be compressed per hour at the specified pressure (see the storage input screen).

No. of Operating $\mathrm{CO}_{2}$ Compressors: This is the total number of operating $\mathrm{CO}_{2}$ compressors. It is used primarily to calculate capital costs. The value must be an integer.

No. of Spare $\mathrm{CO}_{2}$ Compressors: This is the total number of spare $\mathrm{CO}_{2}$ compressors. It is used primarily to calculate capital costs. The value must be an integer.

Amine Scrubber Power Requirement: This is the equivalent electrical output of thermal (steam) energy used for reheat, plus the actual electrical power required for pumps and booster fans.

\section{Amine System Capture Inputs}

This screen is only available for the Combustion (Boiler) and Combustion (Turbine) plant types.

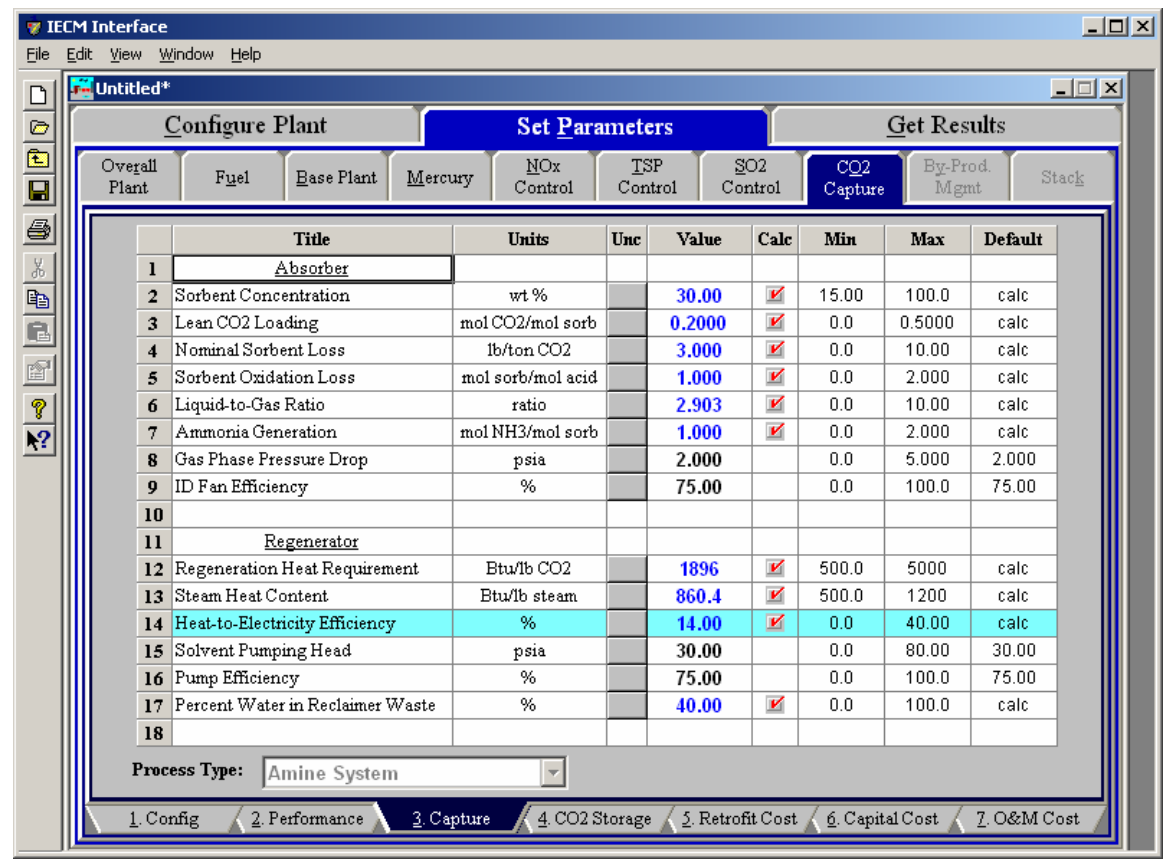

Amine System - Capture input screen.

\section{Absorber}

The absorber is the vessel where the flue gas makes contact with the MEA-based sorbent, and some of the $\mathrm{CO}_{2}$ from the flue gas is dissolved in the sorbent. The column may be plate-type or a packed one. Most of the $\mathrm{CO}_{2}$ absorbers are packed columns using some kind of polymer-based packing to provide large interfacial area.

Sorbent Concentration: The solvent used for $\mathrm{CO}_{2}$ absorption is a mixture of monoethanolamine (MEA) with water. MEA is a highly corrosive liquid, especially in the presence of oxygen and carbon dioxide, and hence needs to be diluted. Today the commercially available MEA-based technology supplied by Fluor Daniel uses 30\% 
w/w MEA solvent with the help of some corrosion inhibitors. Other suppliers, who do not use this inhibitor, prefer to use lower MEA concentrations in the range of $15 \%-20 \%$ by weight.

Lean $\mathrm{CO}_{2}$ Loading: Ideally, the solvent will be completely regenerated on application of heat in the regenerator section. Actually, even on applying heat, not all the MEA molecules are freed from $\mathrm{CO}_{2}$. So, the regenerated (or lean) solvent contains some "left-over" $\mathrm{CO}_{2}$. The level of lean solvent $\mathrm{CO}_{2}$ loading mainly depends upon the initial $\mathrm{CO}_{2}$ loading in the solvent and the amount of regeneration heat supplied, or alternatively, the regeneration heat requirement depends on the allowable level of lean sorbent loading..

Nominal Sorbent Loss: MEA is a reactive solvent. In spite of dilution with water and use of inhibitors, a small quantity of MEA is lost through various unwanted reactions, mainly the polymerization reaction (to form long-chained compounds) and the oxidation reaction forming organic acids and liberating ammonia. It is assumed that $50 \%$ of this MEA loss is due to polymerization and the remaining $50 \%$ of the MEA loss is due to oxidation to acids.

Sorbent Oxidation Loss: The sorbent oxidation loss variable is a ratio of the number moles of sorbent that are lost for every mole of acid formed due to oxidation of the sorbent.

Liquid to Gas Ratio: The liquid to gas ration is the ratio of total molar flow rate of the liquid (MEA sorbent plus water) to the total molar flow rate of flue gas being treated in the absorber.

Ammonia Generation: The oxidation of MEA to organic acids (oxalic, formic, etc.) also leads to formation of $\mathrm{NH}_{3}$. Each mole of MEA lost in oxidation, liberates a mole of ammonia $\left(\mathrm{NH}_{3}\right)$.

Gas Phase Pressure Drop: This is the pressure drop that the flue gas has to overcome as it passes through a very tall absorber column, countercurrent to the sorbent flow.

ID Fan Efficiency: The cooled flue gas is pressurized using a flue gas blower before it enters the absorber. This is the efficiency of the fan/blower to convert electrical power input into mechanical work output.

\section{Regenerator}

The regenerator is the column where the weak intermediate compound (carbamate) formed between the MEA-based sorbent and dissolved $\mathrm{CO} 2$ is broken down with the application of heat and $\mathrm{CO}_{2}$ gets separated from the sorbent to leave reusable sorbent behind. In case of unhindered amines like MEA, the carbamate formed is stable and it takes large amount of energy to dissociate. It also consists of a flash separator where $\mathrm{CO}_{2}$ is separated from most of the moisture and evaporated sorbent, to give a fairly rich $\mathrm{CO}_{2}$ stream.

Regeneration Heat Requirement: This is the total amount of heat energy required in the reboiler for sorbent regeneration.

Steam Heat Content: The regeneration heat is provided in the form of LP steam extracted from the steam turbine (in case of coal-fired power plants and combined-cycle gas plants), through the reboiler (a heat exchanger). In case of simple cycle natural gas fired power plants, a 
heat recovery unit maybe required. This is the enthalpy or heat content of the steam used for solvent regeneration.

Heat to Energy Efficiency: This is the efficiency of converting low pressure steam to electricity. The value reflects the loss of electricity to the base plant when the LP steam is used for regenerator heat.

Solvent Pumping Head: The solvent has to flow through the absorber column (generally through packed media) countercurrent to the flue gas flowing upwards. So, some pressure loss is encountered in the absorber column and sufficient solvent head has to be provided to overcome these pressure losses. Solvent circulation pumps are used to provide the pressure head.

Pump Efficiency: This is the efficiency of the solvent circulation pumps to convert electrical power input into mechanical power output.

Percent Water in Reclaimer Waste: This is the amount of water typically present in the reclaimer waste.

\section{Amine System Storage Inputs}

This screen is only available for the Combustion (Boiler) and Combustion (Turbine) plant types.

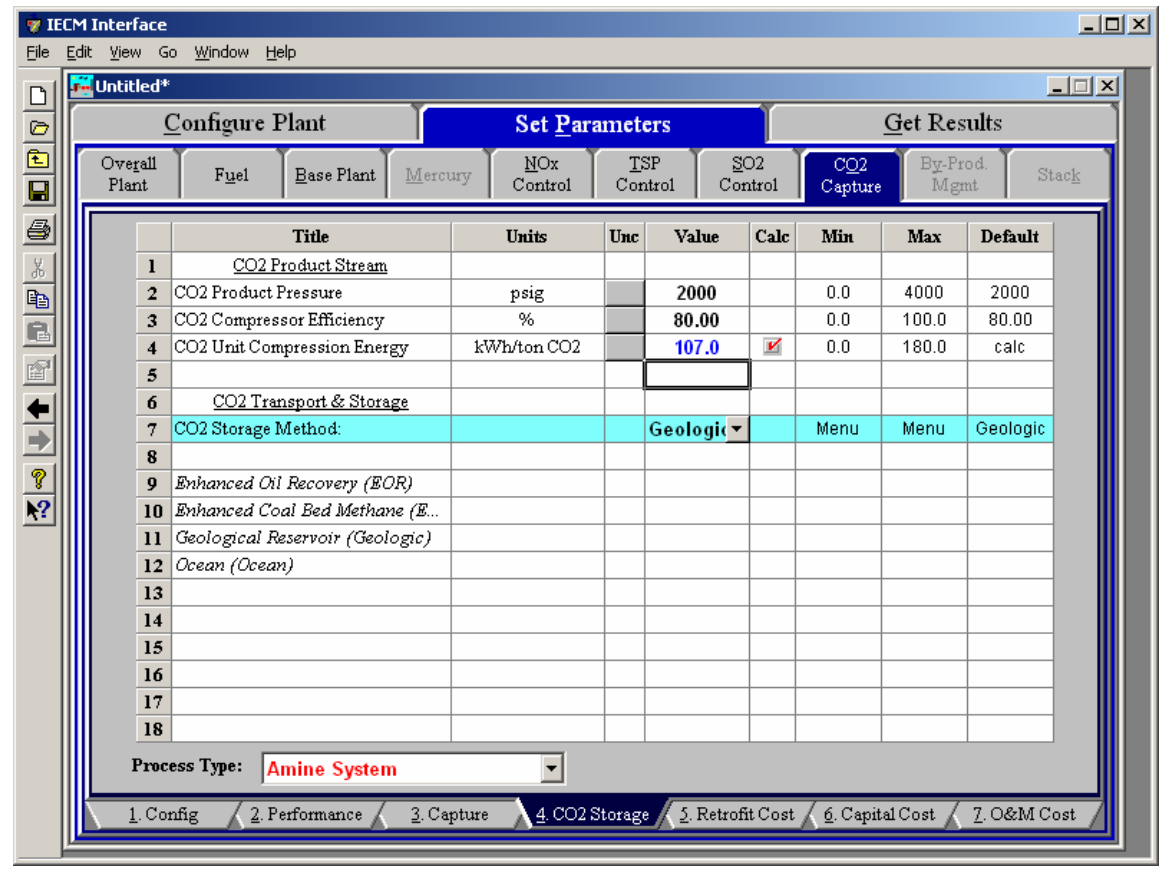

Amine System - Storage input screen

This screen characterizes the compression and storage location for the product $\mathrm{CO}_{2}$. A separate pipeline model is provided to specify inputs for that sub-system. The pipeline model is accessed from the Process Type menu at the bottom of the screen. 


\section{$\mathrm{CO}_{2}$ Product Stream}

The concentrated $\mathrm{CO}_{2}$ product stream obtained from sorbent regeneration is compressed and dried using a multi-stage compressor with inter-stage cooling.

Product Pressure: The $\mathrm{CO}_{2}$ product may have to be carried over long distances. Hence it is necessary to compress (and liquefy) it to very high pressures, so that it maybe delivered to the required destination in liquid form and (as far as possible) without recompression facilities en route. The critical pressure for $\mathrm{CO}_{2}$ is about 1070 psig. The typically reported value of final pressure to which the product $\mathrm{CO}_{2}$ stream has to be pressurized using compressors, before it is transported is about 2000 psig.

$\mathbf{C O}_{2}$ Compressor Efficiency: This is the effective efficiency of the compressors used to compress $\mathrm{CO}_{2}$ to the desirable pressure.

$\mathrm{CO}_{2}$ Unit Compression Energy: This is the electrical energy required to compress a unit mass of $\mathrm{CO}_{2}$ product stream to the designated pressure. Compression of $\mathrm{CO}_{2}$ to high pressures requires substantial energy, and is a principle contributor to the overall energy penalty of a $\mathrm{CO}_{2}$ capture unit in a power plant.

\section{$\mathrm{CO}_{2}$ Transport \& Storage}

Storage Method: The default option for $\mathrm{CO}_{2}$ disposal is underground geological storage.

- $\quad$ EOR - Enhanced Oil Recovery

- $\quad$ ECBM - Enhanced Coalbed Methane Recovery

- Geologic-Geological Reservoir

- Ocean

\section{Amine System Retrofit Cost Inputs}

This screen is only available for the Combustion (Boiler) and Combustion (Turbine) plant types. 


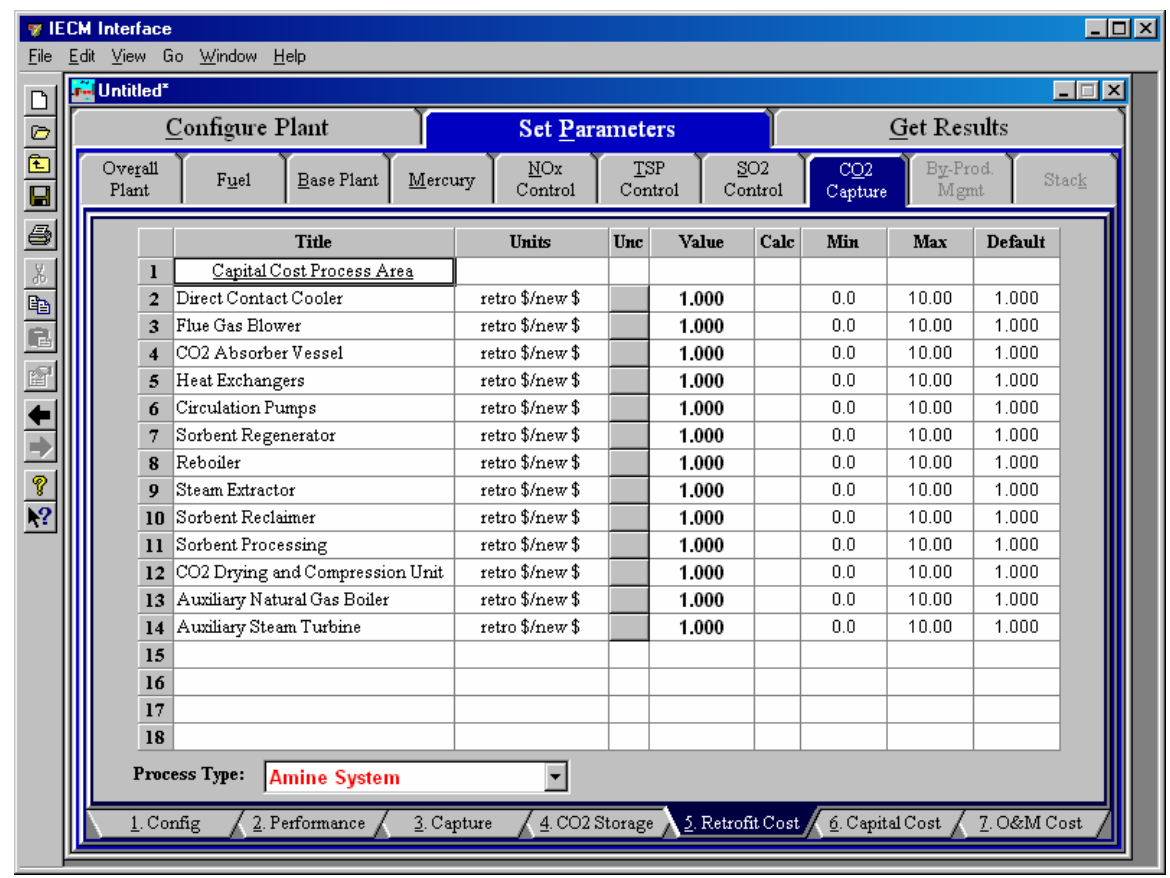

Amine System - Retrofit Cost input screen

\section{Capital Cost Process Area}

The retrofit cost factor of each process is a multiplicative cost adjustment, which considers the cost of retrofitted capital equipment relative to similar equipment installed in a new plant. These factors affect the capital costs directly and the operating and maintenance costs indirectly.

Direct capital costs for each process area are calculated in the IECM. These calculations are reduced form equations derived from more sophisticated models and reports. The sum of the direct capital costs associated with each process area is defined as the process facilities capital (PFC). The retrofit cost factor provided for each of the process areas can be used as a tool for adjusting the anticipated costs and uncertainties across the process area separate from the other areas.

Uncertainty can be applied to the retrofit cost factor for each process area in each technology. Thus, uncertainty can be applied as a general factor across an entire process area, rather than as a specific uncertainty for the particular cost on the capital or O\&M input screens. Any uncertainty applied to a process area through the retrofit cost factor compounds any uncertainties specified later in the capital and O\&M cost input parameter screens.

The following are the Capital Cost Process Areas for the Amine System:

Direct Contact Cooler: A direct contact cooler is typically used in plant configurations that do not include a wet FGD. A direct contact cooler is a large vessel where the incoming hot flue gas is placed in contact with cooling water. The cost is a function of the gas flow rate and temperature of the flue gas.

Flue Gas Blower: The flue gas enters the bottom of the absorber column and flows upward, countercurrent to the sorbent flow. Blowers are required to overcome the substantial pressure drop as it passes through 
a very tall absorber column. The cost is a function of the volumetric flow rate of the flue gas.

$\mathrm{CO}_{2}$ Absorber Vessel: The capital cost of the absorber will go down with higher MEA concentration and higher $\mathrm{CO}_{2}$ loading level of the solvent, and lower $\mathrm{CO}_{2}$ content in the lean solvent. Therefore, a power law relationship based on flue gas flow rate is used. This is based on cost and flow rate data from Fluor Daniel, Inc. The cost assumes one absorber vessel per train. The cost is a function of the volumetric flow rate of the flue gas and the flue gas temperature.

Heat Exchangers: The $\mathrm{CO}_{2}$-loaded sorbent must be heated in order to strip off $\mathrm{CO}_{2}$ and regenerate the sorbent. In addition, the regenerated sorbent must be cooled down before it can be recirculated back to the absorber column. Heat exchangers are used to accomplish these two tasks. This area is a function of the sorbent flow rate.

Circulation Pumps: Circulation pumps are required to take the sorbent, introduced at atmospheric pressure, and lift it to the top of the absorber column. This area is a function of the sorbent flow rate.

Sorbent Regenerator: The regenerator (or stripper) is a column where the weak intermediate compound (carbamate) is broken down by the application of heat. The result is the release of $\mathrm{CO}_{2}$ (in concentrated form) and return of the recovered sorbent back to the absorber. This process is accomplished by the application of heat using a heat exchanger and low-pressure steam. MEA requires substantial heat to dissociate the carbamate. Therefore a flash separator is also required, where the $\mathrm{CO}_{2}$ is separated from the moisture and evaporated sorbent to produce a concentrated $\mathrm{CO}_{2}$ stream. This area is a function of the sorbent flow rate.

Reboiler: The regenerator is connected to a reboiler, which is a heat exchanger that utilizes low pressure steam to heat the loaded sorbent. The reboiler is part of the sorbent regeneration cycle. The cost is a function of the sorbent and steam flow rates.

Steam Extractor: Steam extractors are installed to take low pressure steam from the steam turbines in the power plant. The cost is a function of the steam flow rate.

Sorbent Reclaimer: A portion of the sorbent stream is distilled in the reclaimer in order to avoid accumulation of heat stable salts in the sorbent stream. Caustic is added to recover some of the MEA in this vessel. The reclaimer cost is a function of the sorbent makeup flow rate.

Sorbent Processing: The sorbent processing area primarily consists of a sorbent cooler, MEA storage tank, and a mixer. The regenerated sorbent is further cooled with the sorbent cooler and MEA added to makeup for sorbent losses. This area is a function of the sorbent makeup flow rate.

$\mathrm{CO}_{2}$ Drying and Compression Unit: The product $\mathrm{CO}_{2}$ must be separated from the water vapor (dried) and compressed to liquid form in order to transport it over long distances. The multi-stage compression unit with inter-stage cooling and drying yields a final $\mathrm{CO}_{2}$ product at the nominal pressure of $2000 \mathrm{psig}$. This area is a function of the $\mathrm{CO}_{2}$ flow rate. 
Auxiliary Natural Gas Boiler: An auxiliary natural gas boiler is typically combined with a steam turbine to generate some additional power and/or low pressure steam. The cost is a function of the steam flow rate generated by the boiler. The boiler cost is lower if electricity is not being produced.

Auxiliary Steam Turbine: The steam turbine is used in conjunction with the natural gas boiler to generate some additional power and/or low pressure steam. The cost is a function of the secondary power generated by the turbine.

\section{Amine System Capital Cost Inputs}

This screen is only available for the Combustion (Boiler) and Combustion (Turbine) plant types.

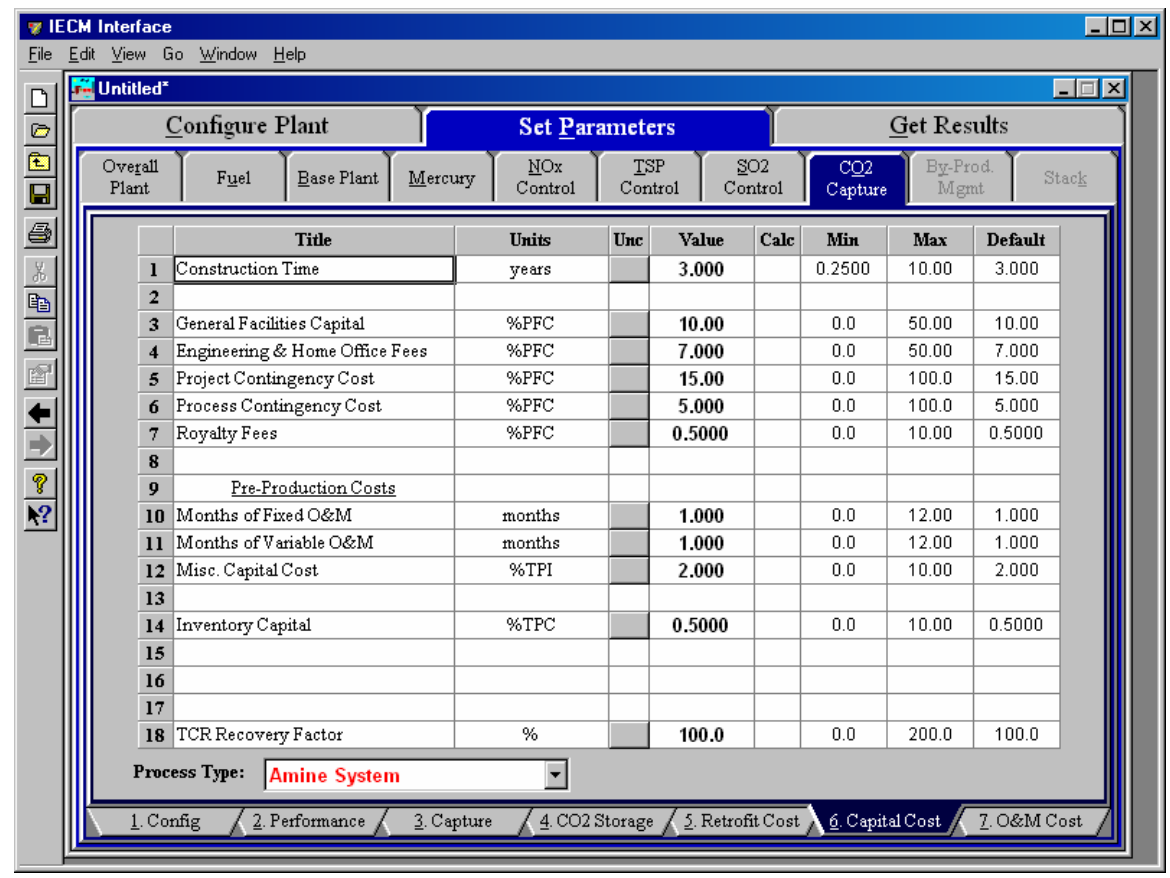

Amine System - Capital Cost input screen.

Inputs for capital costs are entered on the Capital Cost input screen.

Construction Time: This is the idealized construction period in years. It is used to determine the allowance for funds used during construction (AFUDC).

General Facilities Capital (GFC): The general facilities include construction costs of roads, office buildings, shops, laboratories, etc. Sales taxes and freight costs are included implicitly. The cost typically ranges from $5-20 \%$.

Engineering \& Home Office Fees: The engineering \& home office fees are a percent of total direct capital cost. This is an overhead fee paid to the architect/engineering company. These fees typically range from 7$15 \%$.

Project Contingency Cost: This is factor covering the cost of additional equipment or other costs resulting from a more detailed design. Higher 
contingency factors will be applied to simplified or preliminary designs and lower factors to detailed or finalized designs.

Process Contingency Cost: This quantifies the design uncertainty and cost of a commercial-scale system. This is generally applied on an areaby-area basis. Higher contingency factors are applied to new regeneration systems tested at a pilot plant and lower factors to full-size or commercial systems.

Royalty Fees: Royalty charges may apply to some portions of generating units incorporating new proprietary technologies.

Pre-Production Costs: These costs consider the operator training, equipment checkout, major changes in unit equipment, extra maintenance, and inefficient use of fuel or other materials during startup. These are typically applied to the O\&M costs over a specified period of time (months). The two time periods for fixed and variable O\&M costs are described below with the addition of a miscellaneous capital cost factor.

- Months of Fixed O\&M: Time period of fixed operating costs used for preproduction to cover training, testing, major changes in equipment, and inefficiencies in start-up. This includes operating, maintenance, administrative and support labor. It also considers maintenance materials.

- Months of Variable O\&M: Time period of variable operating costs used for preproduction to cover chemicals, water, consumables, and solid disposal charges in start-up, assuming $100 \%$ load. This excludes any fuels.

- Misc. Capital Cost: This is a percent of total plant investment (sum of TPC and AFUDC) to cover expected changes to equipment to bring the system up to full capacity.

Inventory Capital: Percent of the total direct capital for raw material supply based on $100 \%$ capacity during a 60 day period. These materials are considered storage. The inventory capital includes fuels, consumables, by-products, and spare parts. This is typically $0.5 \%$.

TCR Recovery Factor: The actual total capital required (TCR) as a percent of the TCR in a new power plant. This value is $100 \%$ for a new installation and may be set as low as $0 \%$ for a fabric filter that has been paid off.

\section{Amine System O\&M Cost Inputs}

This screen is only available for the Combustion (Boiler) and Combustion (Turbine) plant types. 


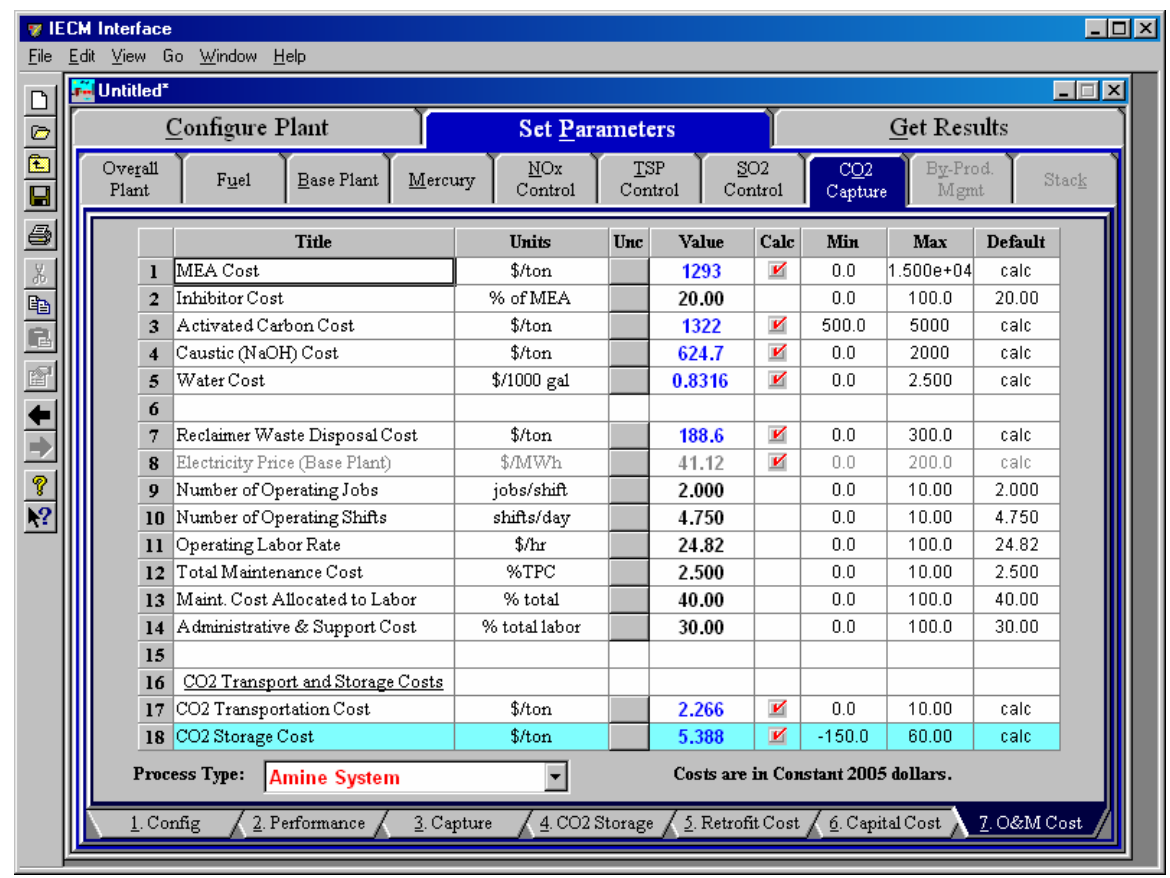

Amine System - O\&M Cost input screen.

Inputs for operation and maintenance are entered on the O\&M Cost input. O\&M costs are typically expressed on an average annual basis and are provided in either constant or current dollars for a specified year, as shown on the bottom of the screen. Each parameter is described briefly below

MEA Cost: This is the unit cost of the makeup MEA.

Inhibitor Cost: Addition of inhibitor makes it possible to use higher concentrations of MEA solvent in the system with minimal corrosion problems. Inhibitors are special compounds that come at a cost premium. The cost of inhibitor is estimated as a percent of the cost of MEA. The model default is $20 \%$.

Activated Carbon Cost: This is the cost of the activated carbon in \$ per ton.

Caustic (NaOH) Cost: This is the cost of the caustic (NaOH) in \$ per ton.

Water Cost: Water is mainly required for cooling and also as process makeup. Cost of water may vary depending upon the location of the power plant.

Natural Gas Cost: This is the cost of the natural gas. This is only visible if an auxiliary boiler is specified.

Reclaimer Waste Disposal Cost: The unit cost of waste disposal for the reclaimer waste.

Electricity Price (Base Plant): This is the price of electricity and is calculated as a function of the utility cost of the base plant.

Number of Operating Jobs: This is the total number of operating jobs that are required to operate the plant per eight-hour shift.

Number of Operating Shifts: This is the total number of equivalent operating shifts in the plant per day. The number takes into 
consideration paid time off and weekend work ( 3 shifts/day * 7 days/5 day week * 52 weeks/(52 weeks -6 weeks PTO $)=4.75$ equiv. Shifts/day)

Operating Labor Rate: This is the hourly labor rate for operators working with the amine system. This is not used for maintenance, administrative, or support labor.

Total Maintenance Cost: This is the annual maintenance cost as a percentage of the total plant cost. Maintenance cost estimates can be developed separately for each process area.

Maint. Cost Allocated to Labor: Maintenance cost allocated to labor as a percentage of the total maintenance cost.

Administrative \& Support Cost: This is the percent of the total operating and maintenance labor associated with administrative and support labor.

\section{CO2 Transport and Storage Costs}

$\mathrm{CO}_{2}$ Transportation Cost: Transportation of $\mathrm{CO}_{2}$ product is assumed to take place via pipelines. This is the unit cost of $\mathrm{CO}_{2}$ transport in $\$ /$ ton -mile. The cost is calculated from the pipeline sub-process model.

$\mathbf{C O}_{2}$ Storage Cost: This is the unit cost of $\mathrm{CO}_{2}$ disposal. Depending upon the method of $\mathrm{CO}_{2}$ disposal or storage, either there may be some revenue generated (Enhanced Oil Recovery, Coal Bed Methane) which may be treated as a "negative cost", or additional cost (all other disposal methods).

\section{Amine System Diagram}

This screen is only available for the Combustion (Boiler) and Combustion (Turbine) plant types.

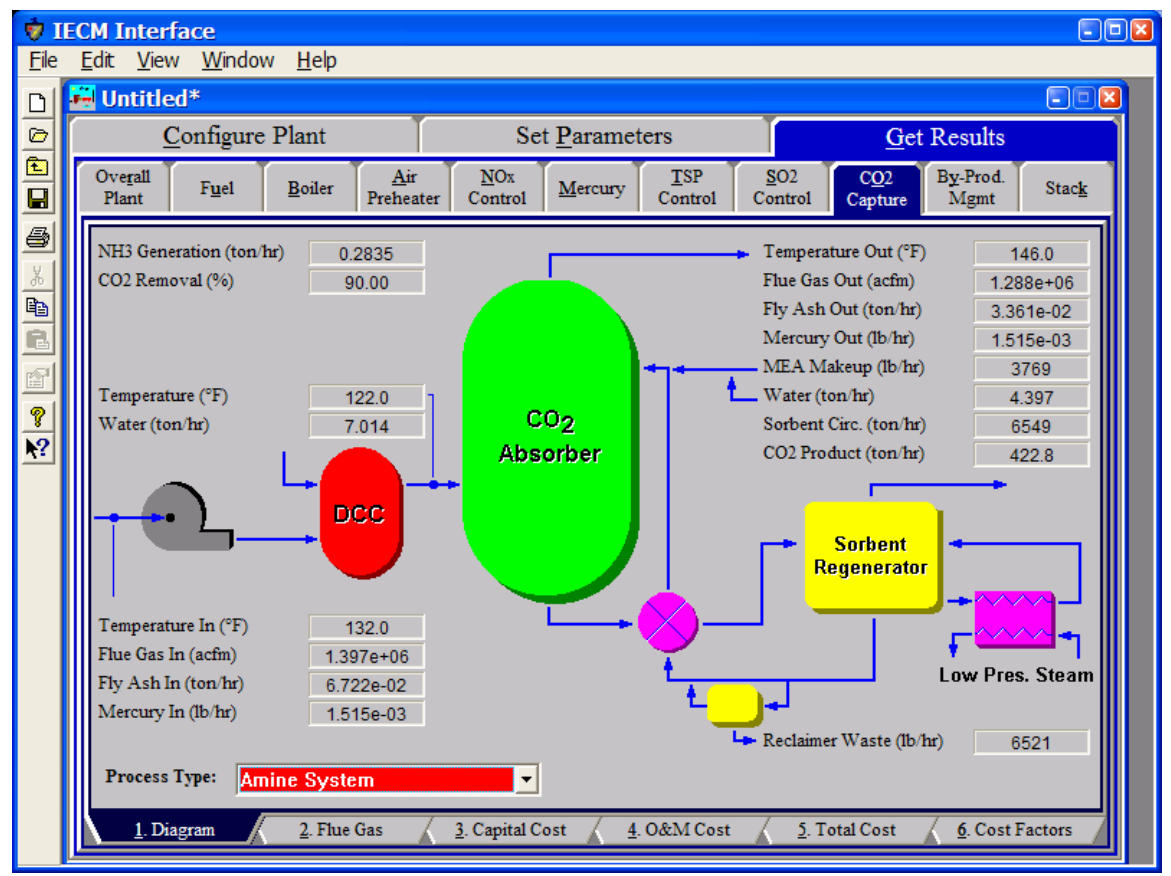




\section{Reagent}

MEA Makeup: The mass flow rate of fresh MEA needed to replace the amount used in the process.

Water: This is the flow rate of water that is used to mix with the MEA Makeup.

\section{Flue Gas Entering Amine System}

Temperature In: Temperature of the flue gas entering the amine system area, prior to any processing. This is determined by the flue gas outlet temperature of the process area upstream.

Flue Gas In: Volumetric flow rate of flue gas entering the amine system.

Fly Ash In: Total solids mass flow rate in the flue gas entering the Amine System. This is determined by the solids exiting from the module upstream.

Mercury In: Total mass of mercury entering the amine system. The value is a sum of all the forms of mercury (elemental, oxidized, and particulate).

Temperature: Temperature of the flue gas entering the amine scrubber system.

Water: This is the flow rate of water into the Direct Contact Cooler.

\section{Flue Gas Exiting Amine System}

Temperature Out: Temperature of the flue gas exiting the amine scrubber system.

Flue Gas Out: Volumetric flow rate of the flue gas exiting the amine scrubber.

Fly Ash Out: Total solids mass flow rate in the flue gas exiting the amine scrubber.

Mercury Out: Total mass of mercury exiting the amine scrubber. The value is a sum of all the forms of mercury (elemental, oxidized, and particulate).

\section{Amine System Performance}

$\mathbf{N H}_{3}$ Generation: The flow rate of ammonia by product produced in the amine scrubbing process.

$\mathrm{CO}_{2}$ Removal: Actual removal efficiency of $\mathrm{CO}_{2}$ in the amine scrubber.

Sorbent Circ.: The flow rate of the sorbent through the amine scrubber system.

$\mathbf{C O}_{2}$ Product: Actual amount of $\mathrm{CO}_{2}$ produced as a result of the amine scrubbing. 
$\mathrm{CO}_{2}$ Pressure: Compressed $\mathrm{CO}_{2}$ product pressure. The product stream is compressed and sent through the pipeline system to the configured sequestration system.

\section{Collected Solids}

Reclaimer Waste: Total solids mass flow rate of solids removed from the amine scrubber.

\section{Amine System Flue Gas Results}

This screen is only available for the Combustion (Boiler) and Combustion (Turbine) plant types.

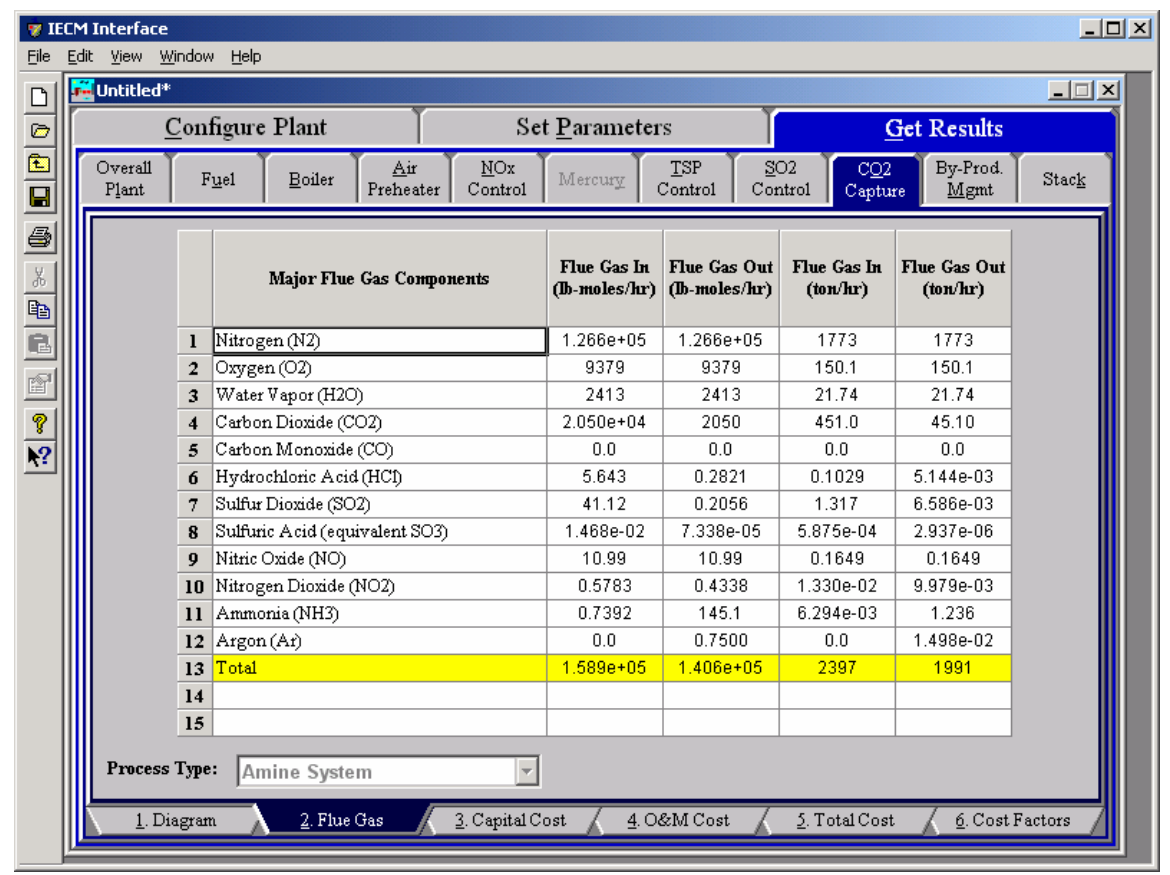

Amine System - Flue Gas result screen

\section{Major Flue Gas Components}

Each result is described briefly below:

Nitrogen (N2): Total mass of nitrogen.

Oxygen (02): Total mass of oxygen.

Water Vapor (H2O): Total mass of water vapor.

Carbon Dioxide (CO2): Total mass of carbon dioxide.

Carbon Monoxide (CO): Total mass of carbon monoxide.

Hydrochloric Acid $(\mathrm{HCl})$ : Total mass of hydrochloric acid.

Sulfur Dioxide (SO2): Total mass of sulfur dioxide.

Sulfuric Acid (equivalent SO3): Total mass of sulfuric acid. 
Nitric Oxide (NO): Total mass of nitric oxide.

Nitrogen Dioxide (NO2): Total mass of nitrogen dioxide.

Ammonia (NH3): Total mass of ammonia.

Argon (Ar): Total mass of argon.

Total: Total of the individual components listed above. This item is highlighted in yellow.

\section{Amine System Capital Cost Results}

This screen is only available for the Combustion (Boiler) and Combustion (Turbine) plant types.

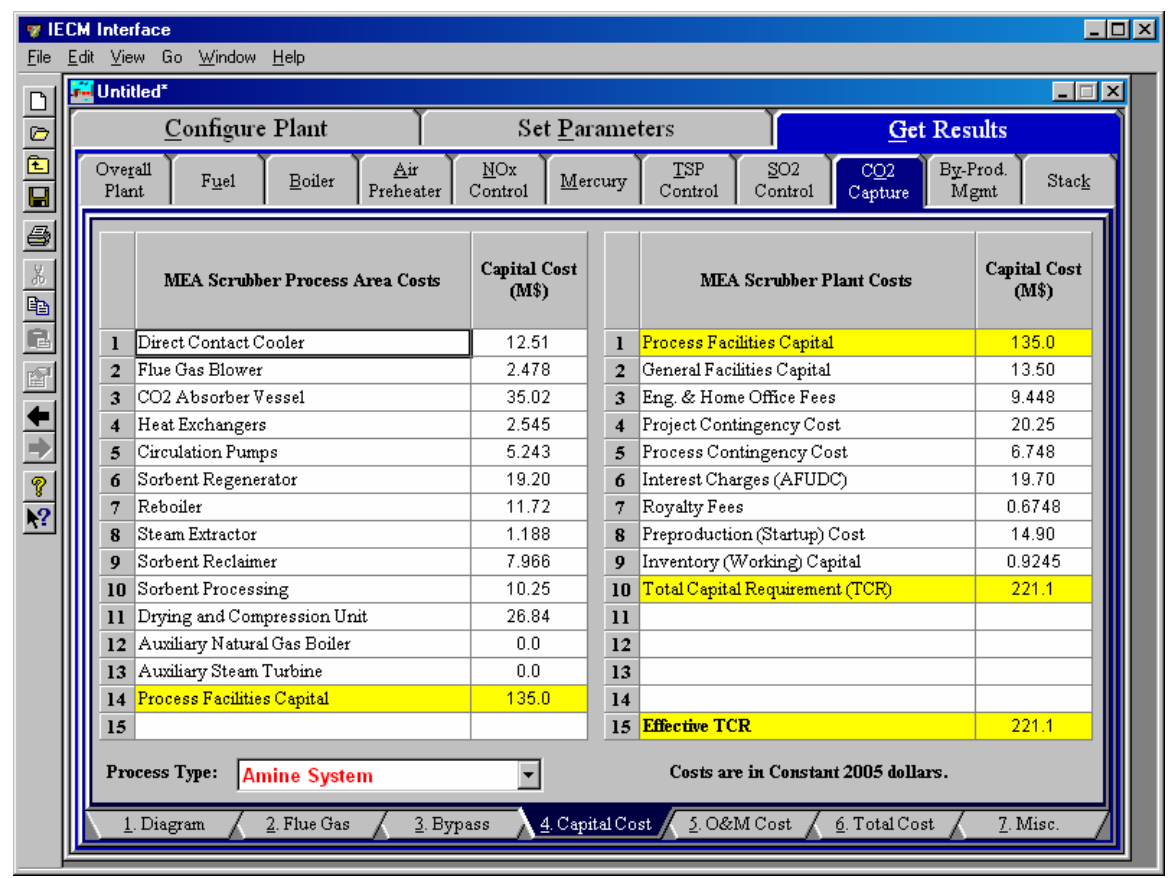

Amine System - Capital Cost result screen.

The Capital Cost result screen displays tables for the capital costs. Capital costs are typically expressed in either constant or current dollars for a specified year, as shown on the bottom of the screen. Each result is described briefly below:

\section{MEA Scrubber Process Area Costs}

Direct Contact Cooler: This area includes the equipment required to cool the flue gas in order to improve absorption of $\mathrm{CO}_{2}$ into the amine sorbent. In case of coal-fired power plant applications that have a wet FGD (flue gas desulfurization) unit upstream of the amine system, the wet scrubber helps in substantial cooling of the flue gases, and additional cooler may not be required.

Flue Gas Blower: The flue gas has to overcome a substantial pressure drop as it passes through a very tall absorber column, countercurrent to the sorbent flow. Hence the cooled flue gas has to be pressurized using a blower before it enters the absorber. 
CO2 Absorber Vessel: This is the vessel where the flue gas is made to contact with the MEA-based sorbent, and some of the $\mathrm{CO}_{2}$ from the flue gas gets dissolved in the sorbent. The column may be plate-type or a packed one. Most of the $\mathrm{CO}_{2}$ absorbers are packed columns using some kind of polymer-based packing to provide large interfacial area.

Heat Exchangers: The $\mathrm{CO}_{2}$-loaded sorbent needs to be heated in order to strip off $\mathrm{CO}_{2}$ and regenerate the sorbent. On the other hand, the regenerated (lean) sorbent coming out of the regenerator has to be cooled down before it could be circulated back to the absorber column. Hence these two sorbent streams are passed through a cross heat exchanger, where the rich $\left(\mathrm{CO}_{2}\right.$-loaded $)$ sorbent gets heated and the lean (regenerated) sorbent gets cooled.

Circulation Pumps: The cost associated with the equipment required to support FGD system operation such as makeup water and instrument air are treated here.

Sorbent Regenerator: This is the column where the weak intermediate compound (carbamate) formed between the MEA-based sorbent and dissolved $\mathrm{CO}_{2}$ is broken down with the application of heat and $\mathrm{CO}_{2}$ gets separated from the sorbent to leave reusable sorbent behind. In case of unhindered amines like MEA, the carbamate formed is stable and it takes large amount of energy to dissociate. It also consists of a flash separator where $\mathrm{CO}_{2}$ is separated from most of the moisture and evaporated sorbent, to give a fairly rich $\mathrm{CO}_{2}$ stream.

Reboiler: The regenerator is connected with a reboiler which is basically a heat exchanger where low-pressure steam extracted from the power plant is used to heat the loaded sorbent

Steam Extractor: In case of coal-fired power plants that generate electricity in a steam turbine, a part of the LP/IP steam has to be diverted to the reboiler for sorbent regeneration. Steam extractors are installed to take out steam from the steam turbines.

Sorbent Reclaimer: Presence of acid gas impurities $\left(\mathrm{SO}_{2}, \mathrm{SO}_{3}, \mathrm{NO}_{2}\right.$ and $\mathrm{HCl}$ ) in the flue gas leads to formation of heat stable salts in the sorbent stream, which can not be dissociated even on application of heat. In order to avoid accumulation of these salts in the sorbent stream and to recover some of this lost MEA sorbent, a part of the sorbent stream is periodically distilled in this vessel. Addition of caustic helps in freeing of some of the MEA. The recovered MEA is taken back to the sorbent stream while the bottom sludge (reclaimer waste) is sent for proper disposal.

Sorbent Processing: The regenerated sorbent has to be further cooled down even after passing through the rich/lean cross heat exchanger using a cooler, so that the sorbent temperature is brought back to acceptable level (about $40 \mathrm{deg} \mathrm{C}$ ). Also, in order to make up for the sorbent losses, a small quantity of fresh MEA sorbent has to be added to the sorbent stream. So, the sorbent processing area primarily consists of sorbent cooler, MEA storage tank, and a mixer. It also consists of an activated carbon bed filter that adsorbs impurities (degradation products of MEA) from the sorbent stream.

Drying and Compression Unit: The $\mathrm{CO}_{2}$ product may have to be carried to very long distances via pipelines. Hence it is desirable that it does not contain any moisture in order to avoid corrosion in the pipelines. Also, it has to be compressed to very high pressures so that 
it gets liquefied and can overcome the pressure losses during the pipeline transport. The multi-stage compression unit with inter-stage cooling and drying yields a final $\mathrm{CO}_{2}$ product at the specified pressure (about 2000 psig) that contains moisture and other impurities (e.g. $\mathrm{N}_{2}$ ) at acceptable levels.

Auxiliary Natural Gas Boiler: The cost of the natural gas boiler is estimated on the basis of the steam flow rate generated from the auxiliary boiler.

Auxiliary Steam Turbine: The regeneration heat is provided in the form of low pressure (LP) steam extracted from the steam turbine (in case of coal-fired power plants and combined-cycle gas plants), through the reboiler (a heat exchanger). In case of simple cycle natural gas fired power plants, a heat recovery unit maybe required.

Process Facilities Capital: The process facilities capital is the total constructed cost of all on-site processing and generating units listed above, including all direct and indirect construction costs. All sales taxes and freight costs are included where applicable implicitly. This result is highlighted in yellow.

\section{MEA Scrubber Plant Costs}

Process Facilities Capital: (see definition above)

General Facilities Capital: The general facilities include construction costs of roads, office buildings, shops, laboratories, etc. Sales taxes and freight costs are included implicitly.

Eng. \& Home Office Fees: The engineering \& home office fees are a percent of total direct capital cost. This is an overhead fee paid to the architect/engineering company.

Project Contingency Cost: Capital cost contingency factor covering the cost of additional equipment or other costs that would result from a more detailed design of a definitive project at the actual site.

Process Contingency Cost: Capital cost contingency factor applied to a new technology in an effort to quantify the uncertainty in the technical performance and cost of the commercial-scale equipment.

Interest Charges (AFUDC): Allowance for funds used during construction, also referred to as interest during construction, is the time value of the money used during construction and is based on an interest rate equal to the before-tax weighted cost of capital. This interest is compounded on an annual basis (end of year) during the construction period for all funds spent during the year or previous years.

Royalty Fees: Royalty charges may apply to some portions of generating units incorporating new proprietary technologies.

Preproduction (Startup) Cost: These costs consider the operator training, equipment checkout, major changes in unit equipment, extra maintenance, and inefficient use of fuel or other materials during startup.

Inventory (Working) Capital: The raw material supply based on $100 \%$ capacity during a 60 day period. These materials are considered storage. The inventory capital includes fuels, consumables, byproducts, and spare parts. 
Total Capital Requirement (TCR): Money that is placed (capitalized) on the books of the utility on the service date. TCR includes all the items above. This result is highlighted in yellow.

Effective TCR: The TCR of the spray dryer that is used in determining the total power plant cost. The effective TCR is determined by the "TCR Recovery Factor”.

\section{Amine System O\&M Cost Results}

This screen is only available for the Combustion (Boiler) and Combustion (Turbine) plant types.

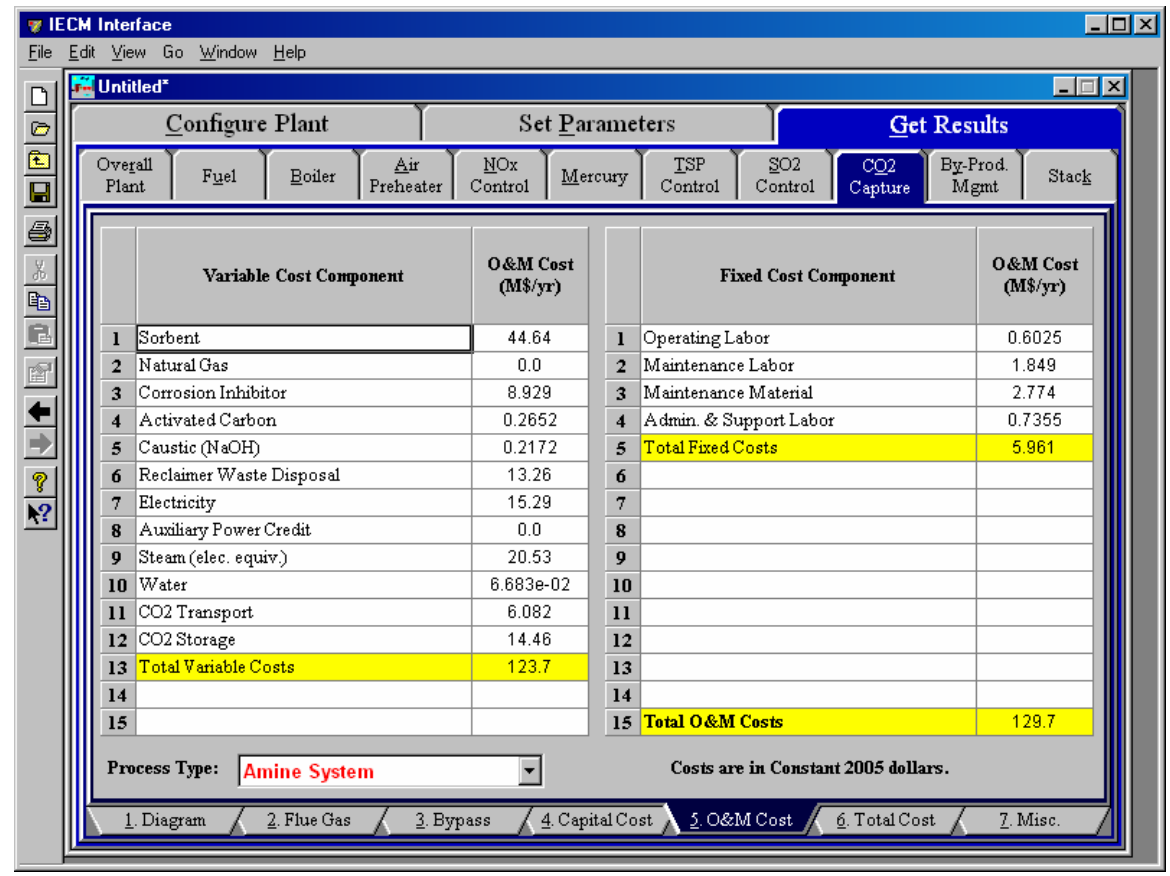

Amine System - O\&M Cost result screen.

The O\&M Cost result screen displays tables for the variable and fixed operation and maintenance costs involved with the $\mathbf{C}_{2}$ Capture technology. O\&M costs are typically expressed on an average annual basis and are provided in either constant or current dollars for a specified year, as shown on the bottom of the screen. Each result is described briefly below:

\section{Variable Cost Components}

Variable operating costs and consumables are directly proportional to the amount of kilowatts produced and are referred to as incremental costs. All the costs are subject to inflation.

Sorbent: MEA is the default sorbent used in the system and this is the annual cost of the MEA. This is a function of the concentration of $\mathrm{CO} 2$ in the flue gas and the flue gas flow rate.

Natural Gas: If the user has added an auxiliary natural gas boiler, the cost of the natural gas used to fuel the boiler is added here. 
Corrosion Inhibitor: The inhibitor helps in two ways - reduced sorbent degradation and reduced equipment corrosion. This is the annual cost of the corrosion inhibitor.

Activated Carbon: This is the cost of activated carbon used to adsorb impurities from the sorbent (degradation products of MEA).

Caustic (NaOH): This is the annual cost of caustic. The presence of acid gas impurities $\left(\mathrm{SO}_{2}, \mathrm{SO}_{3}, \mathrm{NO}_{2}\right.$ and $\left.\mathrm{HCl}\right)$ in the flue gas leads to formation of heat stable salts in the sorbent stream, which can not be dissociated even on application of heat. In order to avoid accumulation of these salts in the sorbent stream and to recover some of this lost MEA sorbent, a part of the sorbent stream is periodically distilled in this vessel. Addition of caustic helps in freeing of some of the MEA. The recovered MEA is taken back to the sorbent stream while the bottom sludge (reclaimer waste) is sent for proper disposal.

Reclaimer Waste Disposal: This is the reclaimer waste disposal cost per year.

Electricity: The cost of electricity consumed by the Amine System.

Auxiliary Power Credit: An auxiliary natural gas boiler can be added by the user to provide steam and power for the Amine System. If it is added by the user then the additional power it provides is subtracted from the overall operating and maintenance cost.

Steam (elec. equiv.): Cost of steam used in the regeneration of the sorbent. This is a cost that is incurred only when steam is taken from the base plant.

Water: This is the annual cost for water to the amine scrubber system; it is mainly required for cooling and also as process makeup.

$\mathbf{C O}_{\mathbf{2}}$ Transport: The $\mathrm{CO}_{2}$ captured at the power plant site has to be carried to the appropriate storage/ disposal site. Transport of $\mathrm{CO}_{2}$ to a storage site is assumed to be via pipeline. This is the annual cost of maintaining those pipelines.

$\mathrm{CO}_{2}$ Storage: Once the $\mathrm{CO}_{2}$ is captured, it needs to be securely stored (sequestered). This cost is based upon the storage option chosen on the Amine System - Storage input screen.

Total Variable Costs: This is the sum of the variable O\&M costs listed above. This result is highlighted in yellow.

\section{Fixed Cost Components}

Fixed operating costs are essentially independent of actual capacity factor, number of hours of operation, or amount of kilowatts produced. All the costs are subject to inflation.

Operating Labor: Operating labor cost is based on the operating labor rate, the number of personnel required to operate the plant per eighthour shift, and the average number of shifts per day over 40 hours per week and 52 weeks.

Maintenance Labor: The maintenance labor is determined as a fraction of the total maintenance cost. 
Maintenance Material: The cost of maintenance material is the remainder of the total maintenance cost, considering the fraction associated with maintenance labor.

Admin. \& Support Labor: The administrative and support labor is the only overhead charge. It is taken as a fraction of the total operating and maintenance labor costs.

Total Fixed Costs: This is the sum of all the fixed O\&M costs listed above. This result is highlighted in yellow.

Total O\&M Costs: This is the sum of the total variable and total fixed O\&M costs. It is used to determine the base plant total revenue requirement. This result is highlighted in yellow.

\section{Amine System Total Cost Results}

This screen is only available for the Combustion (Boiler) and Combustion (Turbine) plant types.

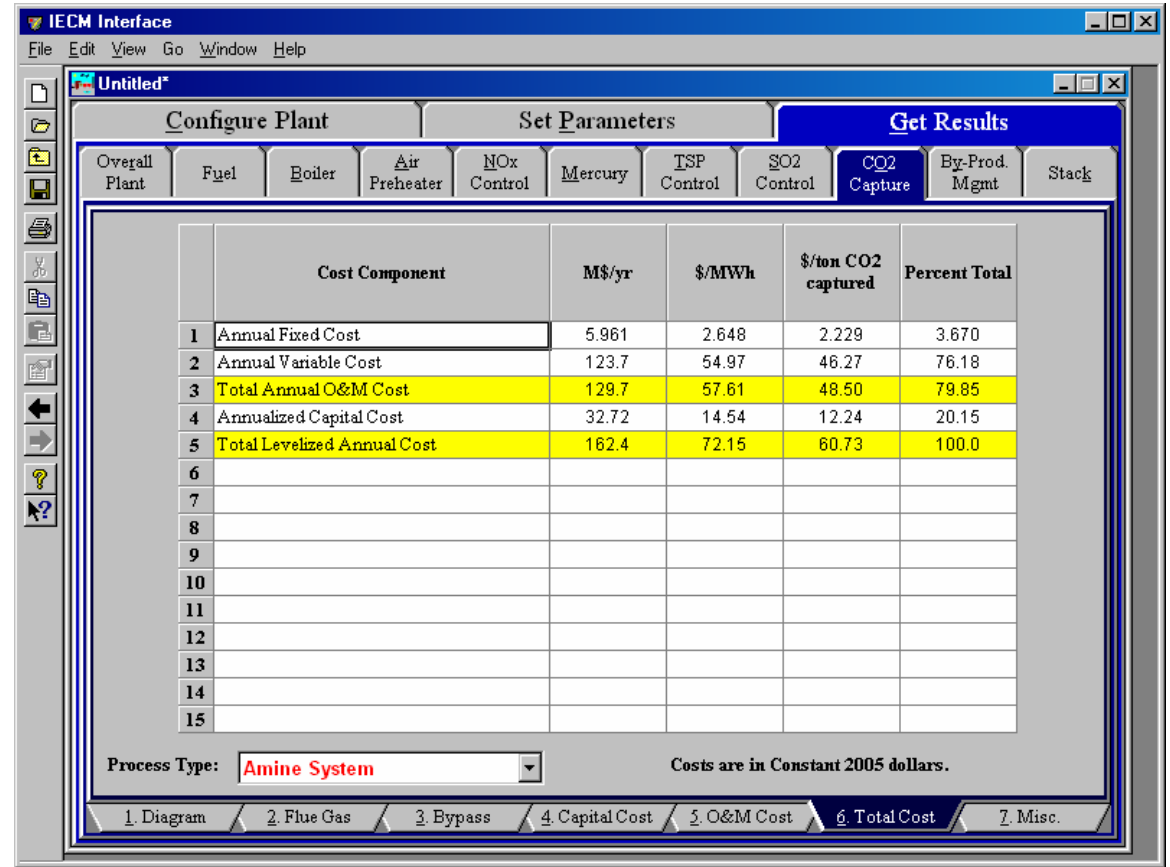

Amine System - Total Cost result screen.

The Total Cost result screen displays a table which totals the annual fixed, variable, operations and maintenance, and capital costs associated with the Amine System $\mathbf{C O}_{2}$ Control technology. Total costs are typically expressed in either constant or current dollars for a specified year, as shown on the bottom of the screen. Each result is described briefly below.

\section{Cost Component}

Annual Fixed Cost: The operating and maintenance fixed costs are given as an annual total. This number includes all maintenance materials and all labor costs. 
Annual Variable Cost: The operating and maintenance variables costs are given as an annual total. This includes all reagent, chemical, steam, and power costs.

Total Annual O\&M Cost: This is the sum of the annual fixed and variable operating and maintenance costs above. This result is highlighted in yellow.

Annualized Capital Cost: This is the total capital cost expressed on an annualized basis, taking into consideration the levelized carrying charge factor, or fixed charge factor, over the entire book life.

Total Levelized Annual Cost: The total annual cost is the sum of the total annual O\&M cost and annualized capital cost items above. This result is highlighted in yellow.

\section{Amine System Cost Factors Results}

This screen is only available for the Combustion (Boiler) and Combustion (Turbine) plant types.

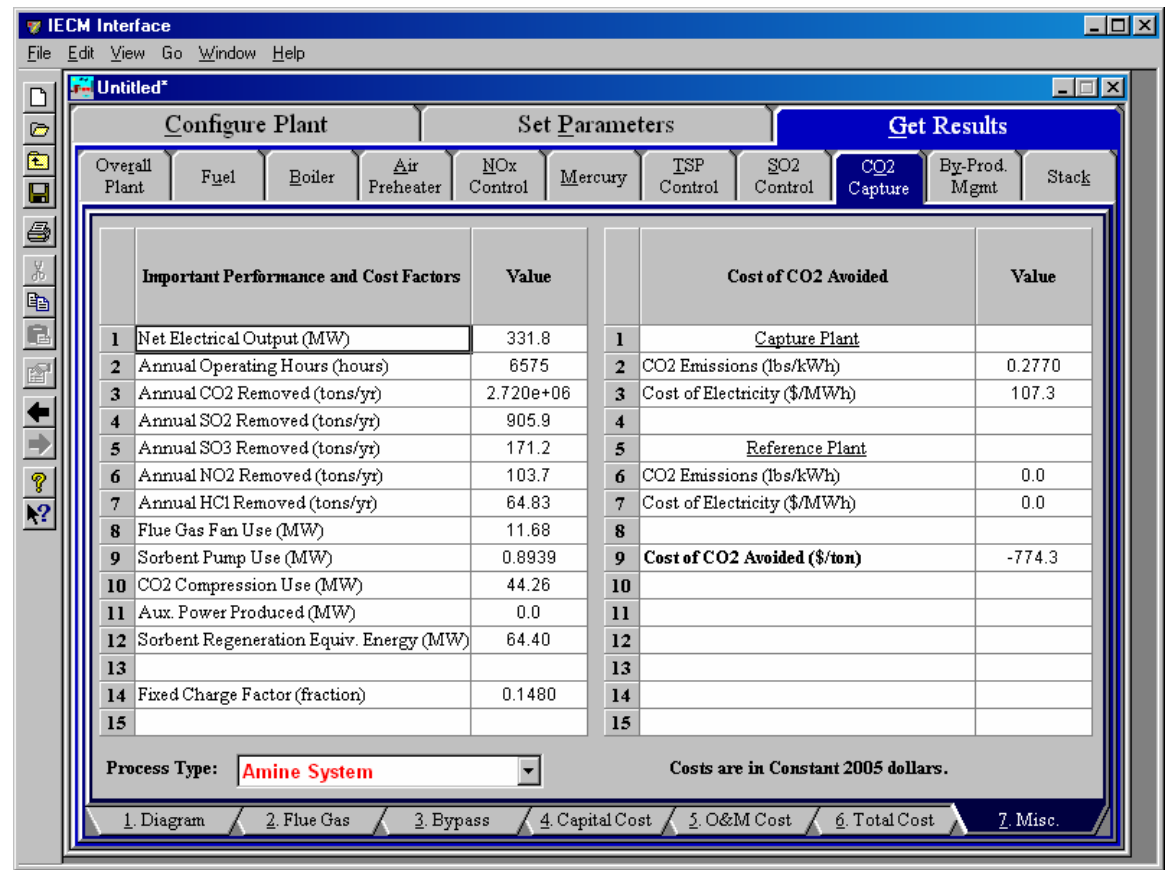

Amine System - Cost Factors result screen.

\section{Important Performance and Cost Factors}

This screen displays information that is key to the model calculations. The data is available else where in the model.

Net Plant Size (MW): This is the net plant capacity, which is the gross plant capacity minus the losses due to plant equipment and pollution equipment (energy penalties).

Annual Operating Hours (hours): This is the number of hours per year that the plant is in operation. If a plant runs 24 hours per day, seven 
days per week, with no outages, the calculation is 24 hours * 365 days. or 8,760 hours/year.

Annual $\mathrm{CO}_{\mathbf{2}}$ Removed (ton/yr): This is thel amount of $\mathrm{CO}_{2}$ removed from the flue gas by the $\mathrm{CO}_{2}$ capture system per year.

Annual $\mathrm{SO}_{2}$ Removed (ton/yr): This is the amount of $\mathrm{SO}_{2}$ removed from the flue gas by the $\mathrm{CO}_{2}$ capture system per year.

Annual $\mathrm{SO}_{3}$ Removed (ton/yr): This is the amount of $\mathrm{SO}_{3}$ removed from the flue gas by the $\mathrm{CO}_{2}$ capture system per year.

Annual $\mathrm{NO}_{\mathbf{2}}$ Removed (ton/yr): This is the amount of $\mathrm{NO}_{2}$ removed from the flue gas by the $\mathrm{CO}_{2}$ capture system per year.

Annual $\mathrm{HCl}$ Removed (ton/yr): This is the amount of $\mathrm{HCl}$ removed from the flue gas by the $\mathrm{CO}_{2}$ capture system per year.

Flue Gas Fan Use (MW): The flue gas has to be compressed in a flue gas blower so that it can overcome the pressure drop in the absorber tower. This is the electrical power required by the blower.

Sorbent Pump Use (MW): The solvent has to flow through the absorber column (generally through packed media) countercurrent to the flue gas flowing upwards. This is the power required by the solvent circulation pumps to supply pressure to overcome the pressure losses encountered by the solvent in the absorber column.

$\mathrm{CO}_{2}$ Compression Use (MW): This is the electrical power required to compress the $\mathrm{CO}_{2}$ product stream to the designated pressure.

Compression of $\mathrm{CO}_{2}$ to high pressures takes lot of power, and is a principle contributor to the overall energy penalty of a $\mathrm{CO}_{2}$ capture unit in a power plant.

Aux. Power Produced (MW): If an auxiliary natural gas boiler is used to provide steam and power for the Amine System, this is the additional electricity that it produces.

Sorbent Regeneration Equiv. Power (MW): This is the electrical equivalent power for the regeneration steam required (taken from the steam cycle). The equivalent electricity penalty is about $10-15 \%$ of the actual regeneration heat requirement.

Fixed Charge Factor (fraction): The fixed charge factor is one of the most important parameters in the IECM. It determines the revenue required to finance the power plant based on the capital expenditures. Put another way, it is a levelized factor which accounts for the revenue per dollar of total plant cost that must be collected from customers in order to pay the carrying charges on that capital investment.

\section{Cost of $\mathrm{CO}_{2}$ Avoided}

Many analysts like to express the cost of an environmental control system in terms of the cost per ton of pollutant removed or avoided. For energy-intensive $\mathrm{CO}_{2}$ controls there is a big difference between the cost per ton $\mathrm{CO}_{2}$ removed and the cost per ton "avoided" based on net plant capacity. Since the purpose of adding a $\mathrm{CO}_{2}$ unit is to reduce the $\mathrm{CO}_{2}$ emissions per net $\mathrm{kWh}$ delivered, the cost of $\mathrm{CO}_{2}$ avoidance is the economic indicator that is widely used in this field. 


\section{Capture Plant}

- $\quad$ CO2 Emissions (lb/kWh): This is the amount of $\mathrm{CO} 2$ vented to the air for every kilowatt hour of electricity produced in the power plant that is using CO2 Capture Technology.

- Cost of Electricity (\$/MWh):The IECM framework calculates the cost of electricity (COE) for the overall Capture Plant by dividing the total annualized plant cost $(\$ / y r)$ by the net electricity generated $(\mathrm{kWh} / \mathrm{yr})$

\section{Reference Plant}

- $\quad$ CO2 Emissions (lb/kWh): This is the amount of CO2 vented to the air for every kilowatt hour of electricity produced in the power plant with NO CO2 Capture.

- Cost of Electricity (\$/MWh):The IECM framework calculates the cost of electricity (COE) for the overall Reference Plant by dividing the total annualized plant cost $(\$ / \mathrm{yr})$ by the net electricity generated $(\mathrm{kWh} / \mathrm{yr})$

- Cost of $\mathrm{CO}_{2}$ Avoided (\$/ton): This is the economic indicator widely used in the field, calculated as the difference between the cost of electricity in the capture plant and the reference plant divided by the difference between the $\mathrm{CO} 2$ emissions in the reference plant and the capture plant.

Cost of CO2 Avoided =

(Cost of Electricity cap. - Cost of Electricity ref.)

/ (CO2 emissions ref. - CO2 emissions cap.) 


\section{$\mathrm{O}_{2}-\mathrm{CO}_{2}$ Recycle}

The $\mathbf{O}_{\mathbf{2}}-\mathbf{C O}_{\mathbf{2}} \mathbf{R e c y c l e}$ is a post-combustion technology used for $\mathrm{CO}_{2}$ capture. It is more frequently referred to as "oxyfuel" combustion. Two systems are associated with this technology, Air Separation and Flue Gas Recycle. The following sections describe the performance and result screens for each of these systems. The $\mathrm{O}_{2}-\mathbf{C O}_{2}$ Recycle option is available in the IECM in the Combustion (Boiler) plant type configuration.

Please refer to the air separation chapter for help with the oxidant feed input parameters and results.

\section{$\mathrm{O}_{2}-\mathrm{CO}_{2}$ Recycle Configuration}

This screen is available for Combustion (Boiler) plant types.

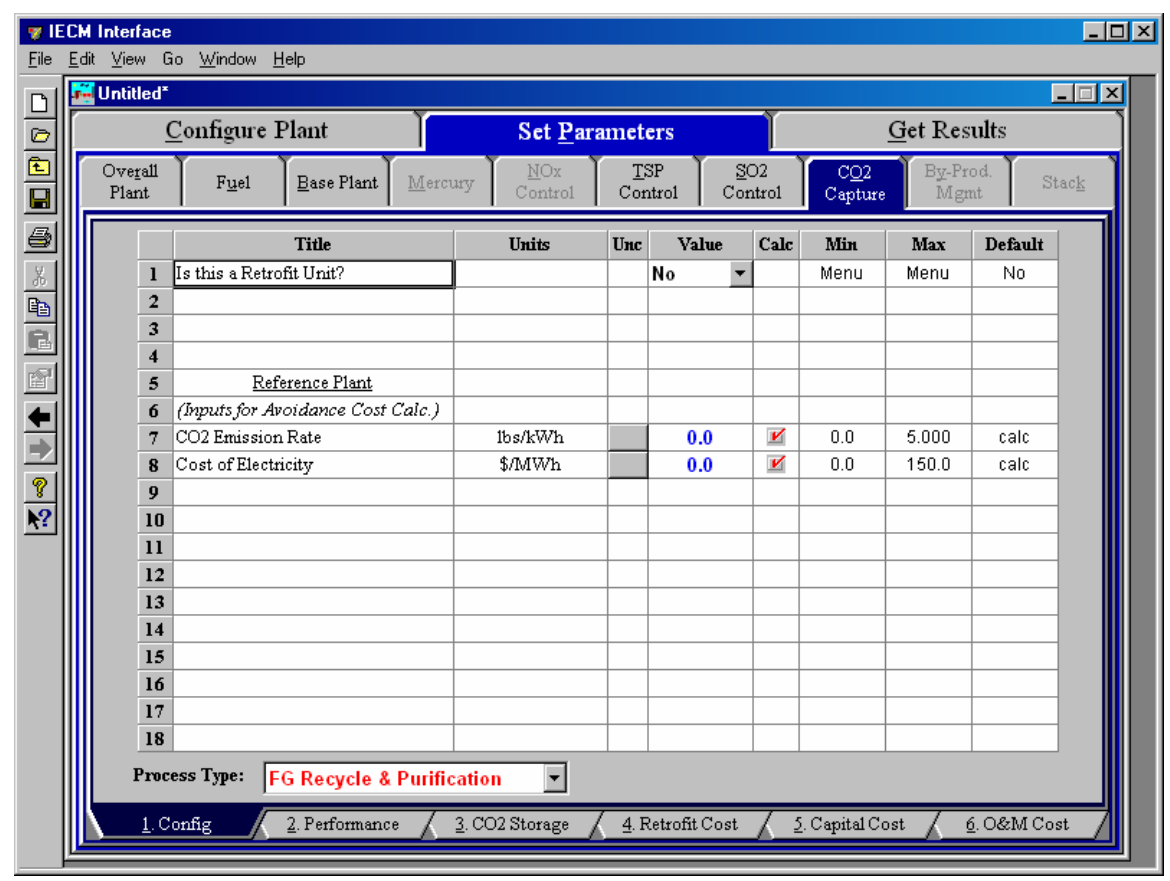

$\mathrm{O}_{2}-\mathrm{CO}_{2}$ Recycle Flue Gas - Configuration input screen.

Is this a Retrofit Unit? The user may decide whether the unit is added to a new or existing plant. 


\section{Reference Plant}

The following reference plant inputs are used to determine the avoided cost of $\mathrm{CO}_{2}$ avoidance. The default value is zero for both parameters, requiring the user to supply the actual reference plant values. Reference values can be obtained by simulating the same plant configuration minus the $\mathrm{CO}_{2}$ capture. Analysts commonly express the cost of an environmental control system in terms of either the cost per ton of pollutant removed or the cost per ton "avoided." For an energy-intensive system like amine scrubbers there is a big difference between the cost per ton $\mathrm{CO}_{2}$ removed and the cost per ton $\mathrm{CO}_{2}$ avoided based on net plant capacity. Since the purpose of adding a capture unit is to reduce the $\mathrm{CO}_{2}$ emissions per net $\mathrm{kWh}$ delivered, the cost of $\mathrm{CO}_{2}$ avoidance (relative to a reference plant with no $\mathrm{CO}_{2}$ control) is the economic indicator most widely used. The reference plant used to compare to the actual plant must be defined as follows:

$\mathbf{C O}_{2}$ Emission Rate: This is the emission rate for the reference power plant (without $\mathrm{CO}_{2}$ capture)

Cost of Electricity: This is the cost of electricity for the reference power plant (without $\mathrm{CO}_{2}$ capture)

\section{$\mathrm{O}_{2}-\mathrm{CO}_{2}$ Recycle Performance Inputs}

This screen is available for Combustion (Boiler) plant types.

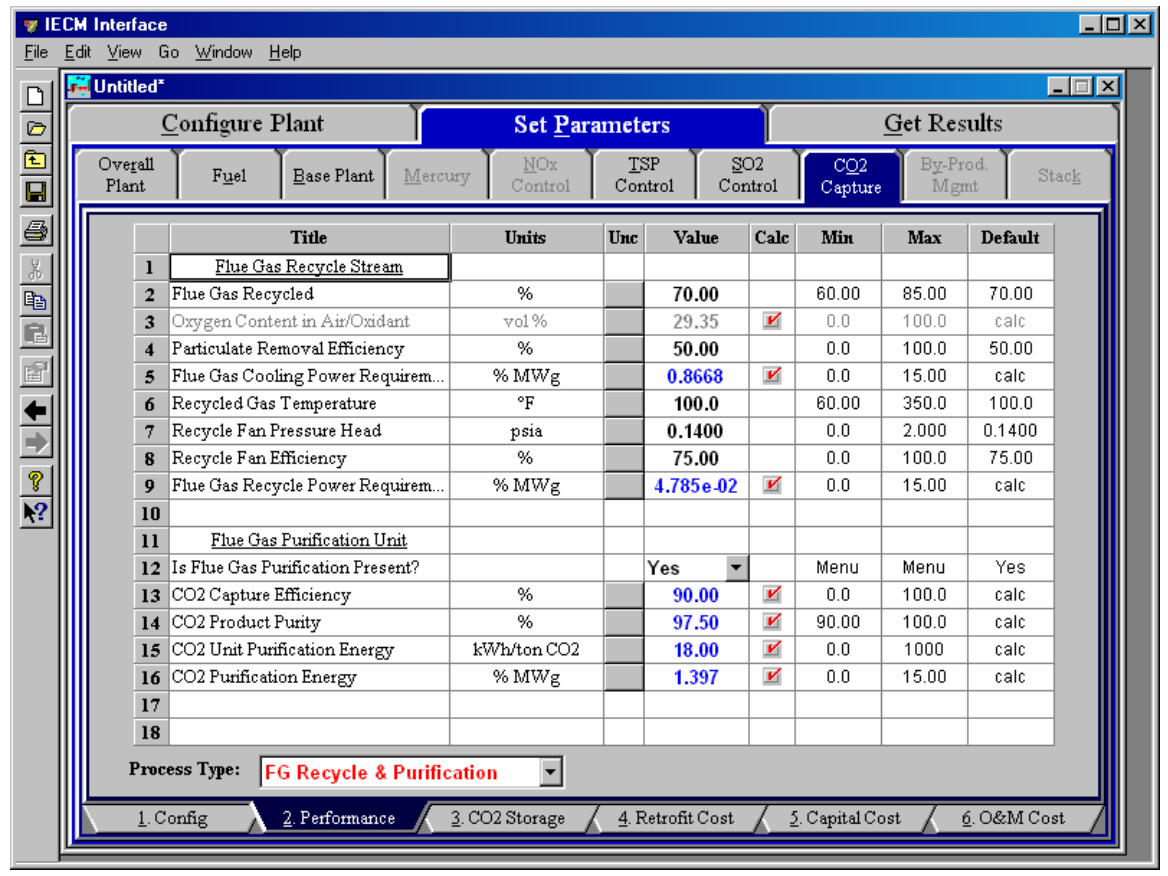

$\mathrm{O}_{2}-\mathrm{CO}_{2}$ Recycle Flue Gas - Performance input screen.

\section{Flue Gas Recycle Stream}

Flue Gas Recycled: This is the percentage of the total flue gas that is to be recycled

Oxygen Content in Air/Oxidant: This is the volume percent that is oxygen. 
Particulate Removal Efficiency: This is the percentage of particulates that are removed by the Flue Gas Recycle system.

Flue Gas Cooling Power Requirement: This is the percentage of the total gross power of the plant required to cool the flue gas being recycled.

Recycled Gas Temperature: This is the temperature of the recycled flue gas.

Recycle Fan Pressure Head: A fan is used to provide a small pressure head for the recycled flue gas stream going back to the boiler. This FGR fan pressure head along with the recycled flue gas flow rate, determine the power used by the fan.

Recycle Fan Efficiency: This is the efficiency of the fan converting electrical power input into mechanical work output.

Flue Gas Recycle Power Requirement: This is the percentage of the total gross power of the plant required to recycle the flue gas.

\section{Flue Gas Purification Unit}

Is Flue Gas Purification Present?: The user may add a flue gas purification system.

$\mathrm{CO}_{2}$ Capture Efficiency: This is the percentage of the $\mathrm{CO}_{2}$ which the system is able to capture.

$\mathbf{C O}_{2}$ Product Purity: This is the percentage of the product that is carbon dioxide.

$\mathrm{CO}_{2}$ Unit Purification Energy: This is the energy required for one unit to purify the $\mathrm{CO}_{2}$ product per ton purified.

$\mathrm{CO}_{2}$ Purification Energy: This is the total energy required to purify the $\mathrm{CO}_{2}$ product.

\section{$\mathrm{O}_{2}-\mathrm{CO}_{2}$ Recycle $\mathrm{CO}_{2}$ Storage Inputs}

This screen is available for Combustion (Boiler) plant types. 


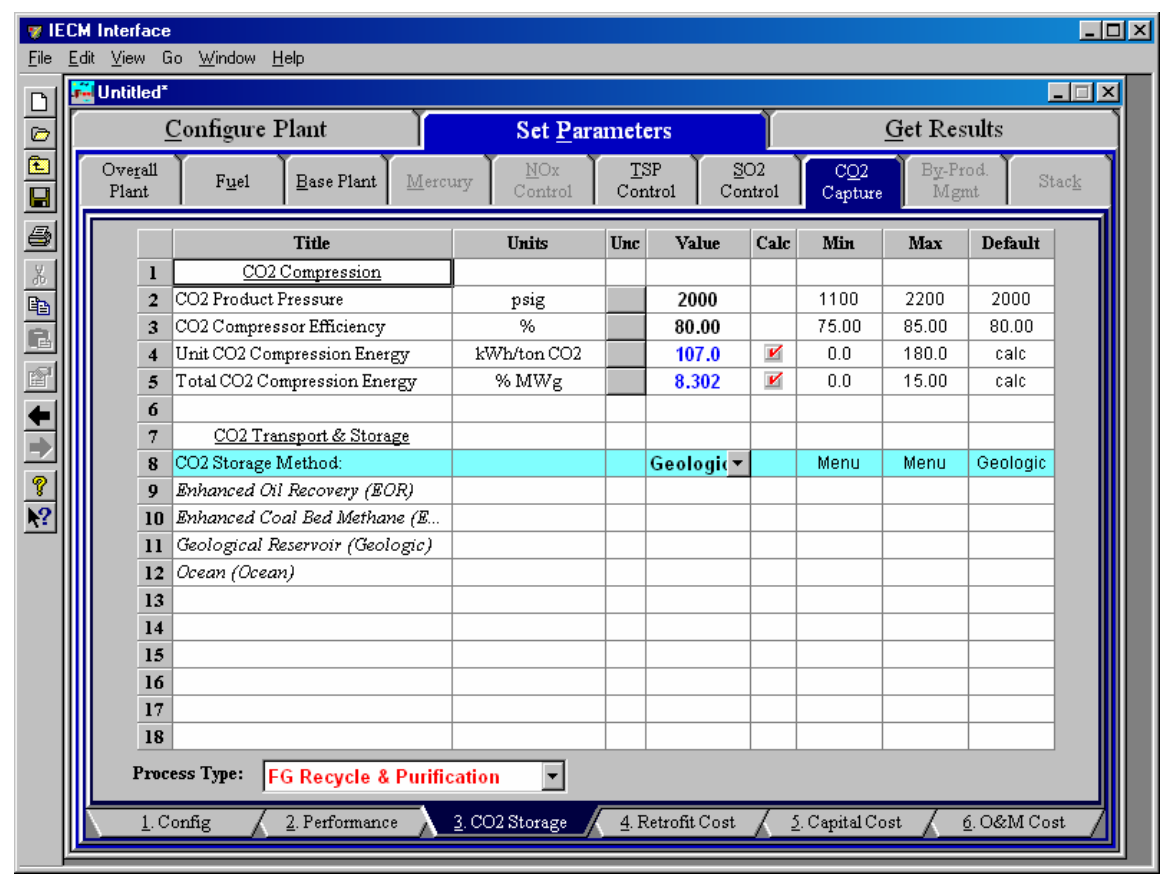

$\mathrm{O}_{2}-\mathrm{CO}_{2}$ Recycle Flue Gas - $\mathrm{CO}_{2}$ storage input screen.

\section{CO2 Compression}

The concentrated $\mathrm{CO}_{2}$ product stream obtained from sorbent regeneration is compressed and dried using a multi-stage compressor with inter-stage cooling.

$\mathrm{CO}_{2}$ Product Pressure: The $\mathrm{CO}_{2}$ product may have to be carried over long distances. Hence it is necessary to compress (and liquefy) it to very high pressures, so that it maybe delivered to the required destination in liquid form and (as far as possible) without recompression facilities en route. The critical pressure for $\mathrm{CO}_{2}$ is about 1070 psig. The typically reported value of final pressure to which the product $\mathrm{CO}_{2}$ stream has to be pressurized using compressors, before it is transported is about 2000 psig.

$\mathrm{CO}_{2}$ Compressor Efficiency: This is the effective efficiency of the compressors used to compress $\mathrm{CO}_{2}$ to the desirable pressure.

Unit $\mathrm{CO}_{2}$ Compression Energy: This is the electrical energy required to compress a unit mass of $\mathrm{CO}_{2}$ product stream to the designated pressure. Compression of $\mathrm{CO}_{2}$ to high pressures requires substantial energy, and is a principle contributor to the overall energy penalty of a $\mathrm{CO}_{2}$ capture unit in a power plant.

Total $\mathrm{CO}_{2}$ Compression Energy: This is the electrical energy required to compress the $\mathrm{CO}_{2}$ product stream to the designated pressure, given as a percent of the total gross power generated by the power plant. Compression of $\mathrm{CO}_{2}$ to high pressures requires substantial energy, and is a principle contributor to the overall energy penalty of a $\mathrm{CO}_{2}$ capture unit in a power plant.

\section{CO2 Transport \& Storage}

$\mathrm{CO}_{2}$ Storage Method: The following are the optional methods for $\mathrm{CO}_{2}$ disposal. The default option for $\mathrm{CO}_{2}$ disposal is underground geological storage. 
- Enhanced Oil Recovery (EOR)

- Enhanced Coal Bed Methane (ECBM)

- Geological Reservoir (Geologic)

- Ocean (Ocean)

\section{$\mathrm{O}_{2}-\mathrm{CO}_{2}$ Recycle Retrofit Cost Inputs}

This screen is available for Combustion (Boiler) plant types.

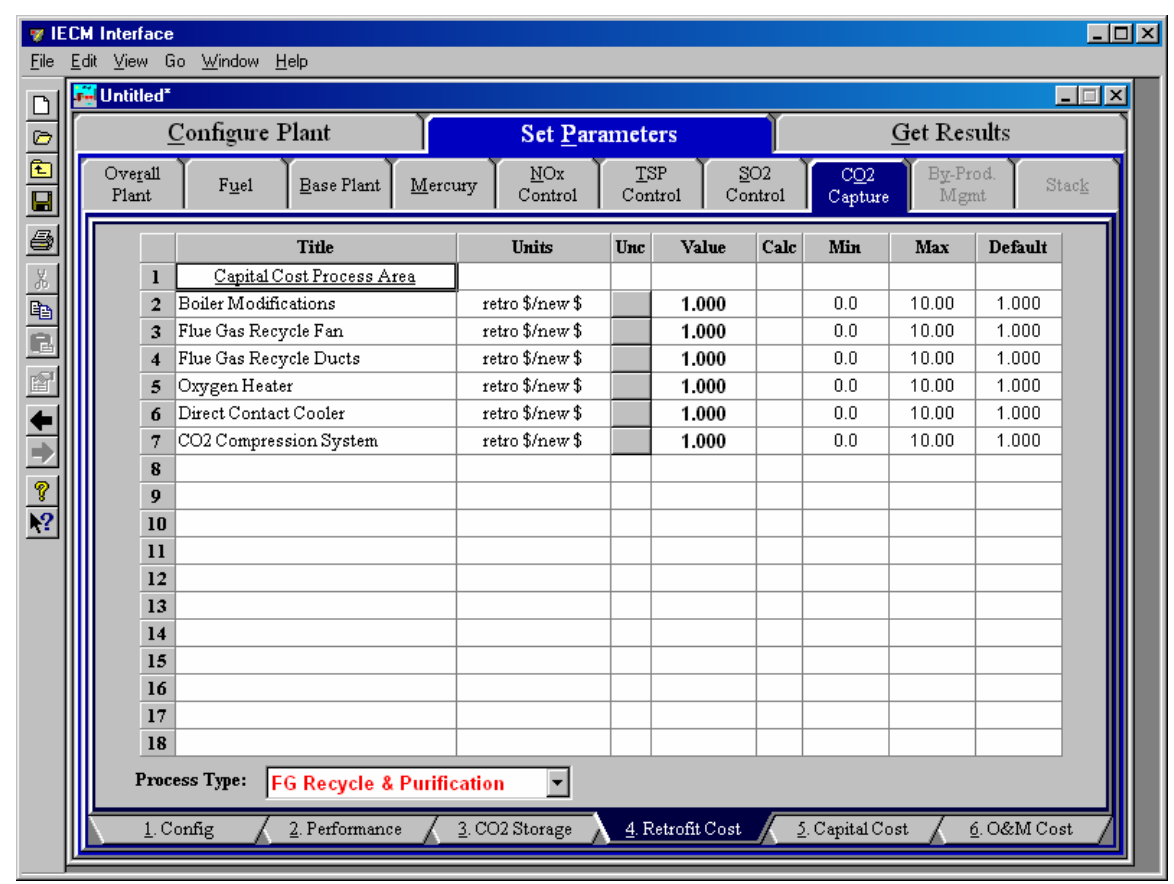

$\mathrm{O}_{2}-\mathrm{CO}_{2}$ Recycle Flue Gas - Retrofit cost input screen.

\section{Capital Cost Process Area}

The retrofit cost factor of each process is a multiplicative cost adjustment, which considers the cost of retrofitted capital equipment relative to similar equipment installed in a new plant. These factors affect the capital costs directly and the operating and maintenance costs indirectly.

Direct capital costs for each process area are calculated in the IECM. These calculations are reduced form equations derived from more sophisticated models and reports. The sum of the direct capital costs associated with each process area is defined as the process facilities capital (PFC). The retrofit cost factor provided for each of the process areas can be used as a tool for adjusting the anticipated costs and uncertainties across the process area separate from the other areas.

Uncertainty can be applied to the retrofit cost factor for each process area in each technology. Thus, uncertainty can be applied as a general factor across an entire process area, rather than as a specific uncertainty for the particular cost on the capital or O\&M input screens. Any uncertainty applied to a process area through the retrofit cost factor compounds any uncertainties specified later in the capital and O\&M cost input parameter screens. 
The following are the Capital Cost Process Areas for the Flue Gas Recycle portion of the plant:

Boiler Modifications: In case of a pre-existing PC plant being retrofitted for $\mathrm{CO}_{2}$ capture, the boiler must be modified to suit the new oxyfuel combustion system. The cost for these modifications is estimated as a percentage of the cost of the boiler

Flue Gas Recycle Fan: The cost of the fan required for recycling part of the flue gas is scaled on the basis of the flow rate of the flue gas being recycled

Flue Gas Recycle Ducts: Additional ducting is necessary to recycle part of the flue gas in the oxyfuel combustion system. The cost of this ducting is assumed to be a function of the flow rate of recycled flue gas.

Oxygen Heater: In addition to the air preheater that exists in a conventional PC plant, the oxyfuel combustion system includes an additional heat exchanger called the "oxygen heater" for better heat integration. The cost of this heat exchanger is scaled on the basis of the gross plant size

Direct Contact Cooler: The cost of the flue gas cooler is scaled on the basis of the flow rate of the flue gas.

$\mathrm{CO}_{2}$ Compression System: The multi-stage compression unit with inter-stage cooling and drying yields the final $\mathrm{CO}_{2}$ product at the specified pressure (about 2000 psig) that contains only acceptable levels of moisture and other impurities (e.g. $\mathrm{N}_{2}$ ) The size (and cost) of this unit will be a function of the $\mathrm{CO}_{2}$ product compression power.

\section{$\mathrm{O}_{2}-\mathrm{CO}_{2}$ Recycle Capital Cost Inputs}

This screen is available for Combustion (Boiler) plant types.

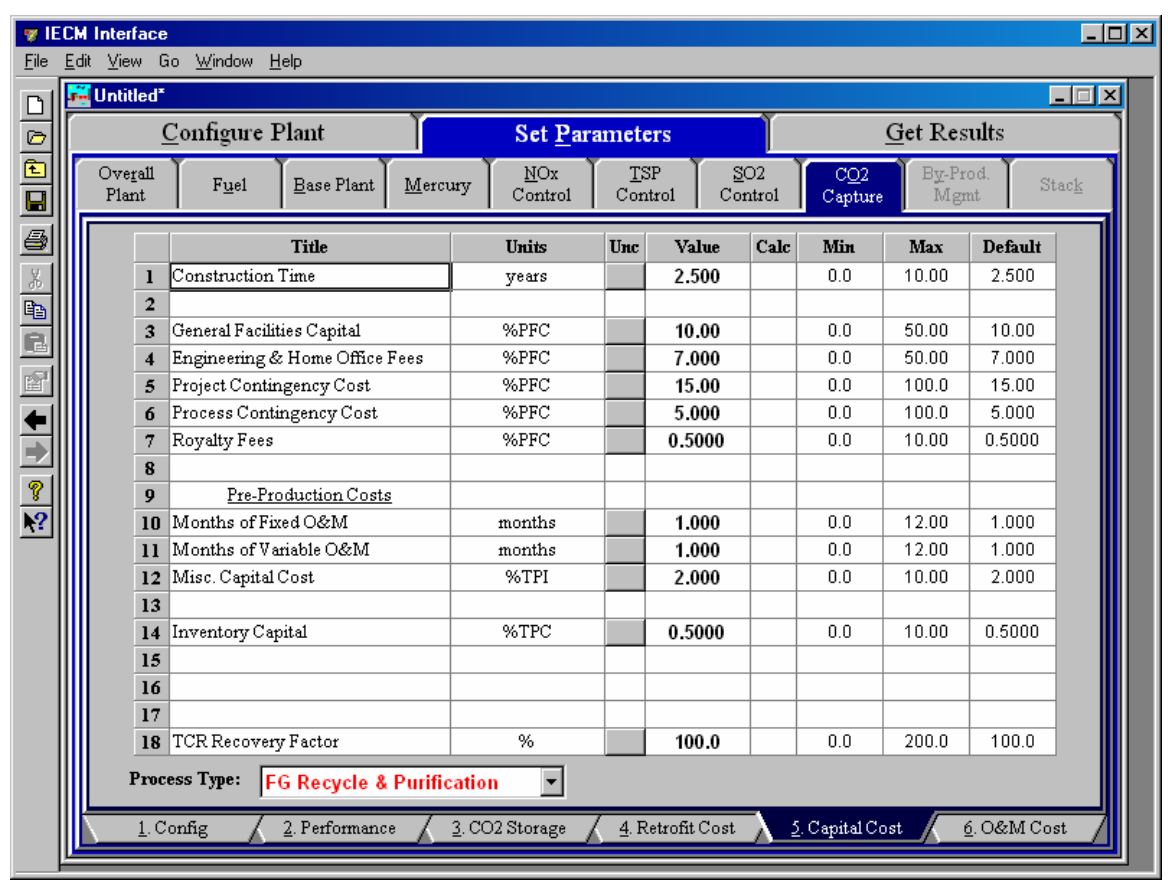


$\mathrm{O}_{2}-\mathrm{CO}_{2}$ Recycle Flue Gas - Capital cost input screen.

Inputs for capital costs are entered on the Capital Cost input screen.

Construction Time: This is the idealized construction period in years. It is used to determine the allowance for funds used during construction (AFUDC).

General Facilities Capital (GFC): The general facilities include construction costs of roads, office buildings, shops, laboratories, etc. Sales taxes and freight costs are included implicitly. The cost typically ranges from $5-20 \%$.

Engineering \& Home Office Fees: The engineering \& home office fees are a percent of total direct capital cost. This is an overhead fee paid to the architect/engineering company. These fees typically range from 7$15 \%$.

Project Contingency Cost: This is factor covering the cost of additional equipment or other costs resulting from a more detailed design. Higher contingency factors will be applied to simplified or preliminary designs and lower factors to detailed or finalized designs.

Process Contingency Cost: This quantifies the design uncertainty and cost of a commercial-scale system. This is generally applied on an areaby-area basis. Higher contingency factors are applied to new regeneration systems tested at a pilot plant and lower factors to full-size or commercial systems.

Royalty Fees: Royalty charges may apply to some portions of generating units incorporating new proprietary technologies.

Pre-Production Costs: These costs consider the operator training, equipment checkout, major changes in unit equipment, extra maintenance, and inefficient use of fuel or other materials during startup. These are typically applied to the O\&M costs over a specified period of time (months). The two time periods for fixed and variable O\&M costs are described below with the addition of a miscellaneous capital cost factor.

Months of Fixed O\&M: Time period of fixed operating costs used for preproduction to cover training, testing, major changes in equipment, and inefficiencies in start-up. This includes operating, maintenance, administrative and support labor. It also considers maintenance materials.

Months of Variable O\&M: Time period of variable operating costs used for preproduction to cover chemicals, water, consumables, and solid disposal charges in start-up, assuming 100\% load. This excludes any fuels.

Misc. Capital Cost: This is a percent of total plant investment (sum of TPC and AFUDC) to cover expected changes to equipment to bring the system up to full capacity.

Inventory Capital: Percent of the total direct capital for raw material supply based on $100 \%$ capacity during a 60 day period. These materials are considered storage. The inventory capital includes fuels, consumables, by-products, and spare parts. This is typically $0.5 \%$.

TCR Recovery Factor: The actual total capital required (TCR) as a percent of the TCR in a new power plant. This value is $100 \%$ for a new 
installation and may be set as low as $0 \%$ for a fabric filter that has been paid off.

\section{$\mathrm{O}_{2}-\mathrm{CO}_{2}$ Recycle O\&M Cost Inputs}

This screen is available for Combustion (Boiler) plant types.

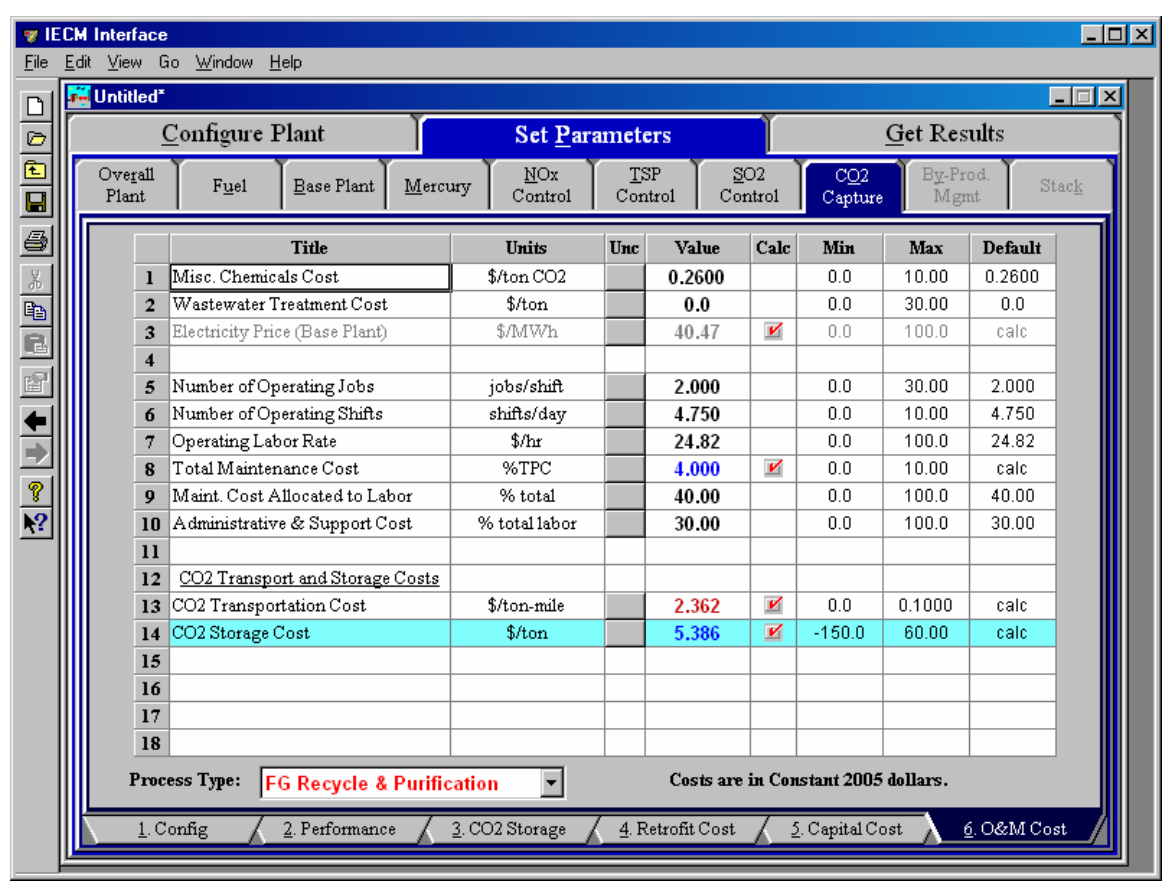

$\mathrm{O}_{2}-\mathrm{CO}_{2}$ Recycle Flue Gas - O\&M cost input screen

Inputs for operation and maintenance are entered on the O\&M Cost input. O\&M costs are typically expressed on an average annual basis and are provided in either constant or current dollars for a specified year, as shown on the bottom of the screen. Each parameter is described briefly below

Misc. Chemicals Cost: This is the annual cost of chemicals that are used in the Flue Gas Recycle area of the plant. The cost is reported in dollars per ton of $\mathrm{CO} 2$ captured.

Wastewater Treatment Cost: This is the annual cost of treating the wastewater that is used in the Flue Gas Recycle area of the plant. The cost is reported in dollars per ton.

Electricity Price (Base Plant): This is the price of electricity and is calculated as a function of the utility cost of the base plant, where the base plant is a combustion boiler and an air preheater.

Number of Operating Jobs: This is the total number of operating jobs that are required to operate the plant per eight-hour shift.

Number of Operating Shifts: This is the total number of equivalent operating shifts in the plant per day. The number takes into consideration paid time off and weekend work ( 3 shifts/day * 7 days $/ 5$ day week * 52 weeks $/(52$ weeks -6 weeks PTO $)=4.75$ equiv. Shifts/day) 
Operating Labor Rate: The number of dollars paid per hour to an operator for one hour of work.

Total Maintenance Cost: This is the annual maintenance cost as a percentage of the total plant cost. Maintenance cost estimates can be developed separately for each process area.

Maint. Cost Allocated to Labor: Maintenance cost allocated to labor as a percentage of the total maintenance cost.

Administrative \& Support Cost: This is the percent of the total operating and maintenance labor associated with administrative and support labor.

\section{$\mathrm{CO}_{2}$ Transport and Storage Costs}

- $\mathrm{CO}_{2}$ Transportation Cost: Transportation of $\mathrm{CO}_{2}$ product is assumed to take place via pipelines. This is the unit cost of $\mathrm{CO}_{2}$ transport in \$/ton -mile.

- $\mathrm{CO}_{2}$ Storage Cost: This is the unit cost of $\mathrm{CO}_{2}$ disposal. Depending upon the method of $\mathrm{CO}_{2}$ disposal or storage, either there may be some revenue generated (Enhanced Oil Recovery, Coal Bed Methane) which may be treated as a "negative cost", or additional cost (all other disposal methods).

\section{$\mathrm{O}_{2}-\mathrm{CO}_{2}$ Recycle Diagram}

This screen is available for Combustion (Boiler) plant types.

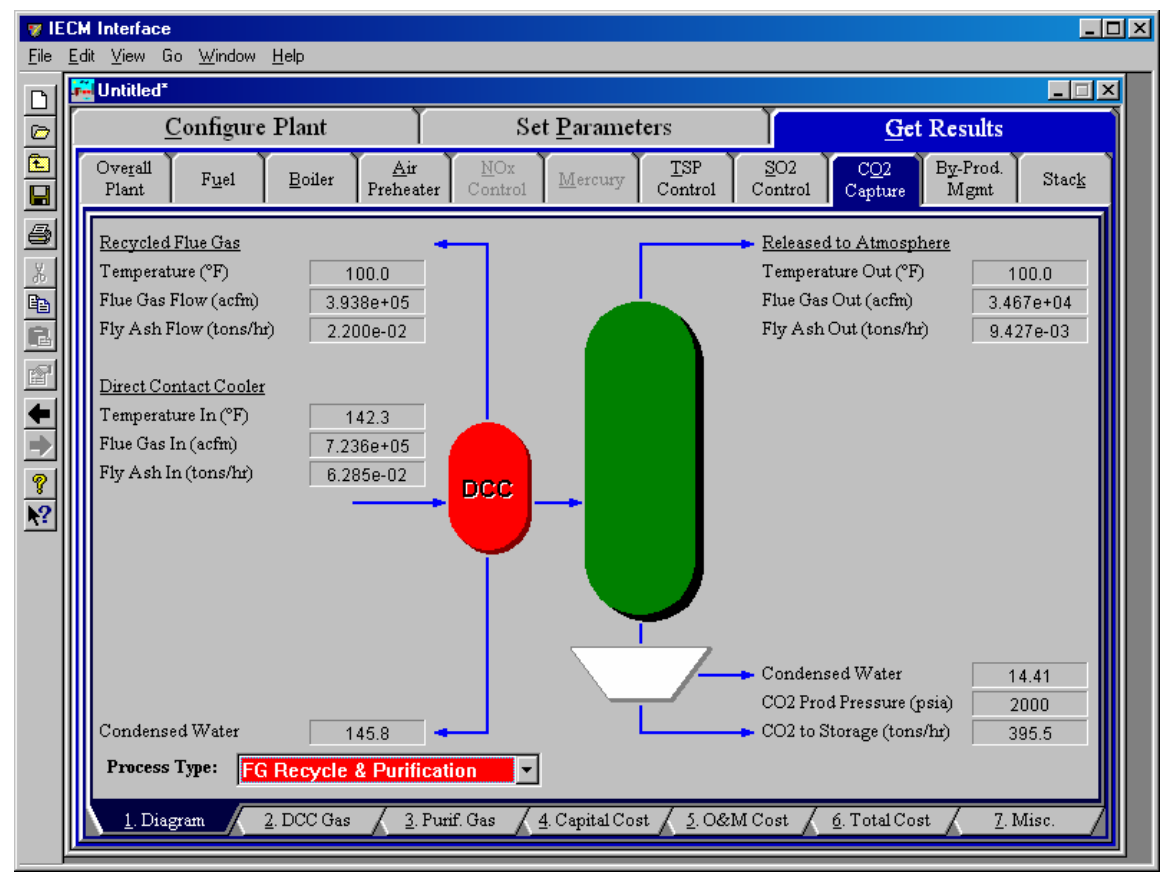

$\mathrm{O}_{2}-\mathrm{CO}_{2}$ Recycle Flue Gas - Diagram.

\section{Recycled Flue Gas}

Temperature: The temperature of the Recycled Flue Gas from the direct contact cooler. 
Flue Gas Flow: The mass flow rate of the Recycled Flue Gas from the direct contact cooler.

Fly Ash Flow: The mass flow rate of fly ash in the Recycled Flue Gas from the direct contact cooler.

\section{Direct Contact Cooler}

Temperature In: The temperature of the flue gas, to be recycled, entering the direct contact cooler.

Flue Gas In: The mass flow rate of the flue gas, to be recycled, entering the direct contact cooler.

Fly Ash In: The mass flow rate of fly ash in to the direct contact cooler.

Condensed Water: The mass flow rate of condensed water leaving the direct contact cooler.

\section{Released to Atmosphere}

Temperature Out: The temperature of the flue gas being released to the atmosphere.

Flue Gas Out: The mass flow rate of the flue gas being released to the atmosphere.

Fly Ash Out: The mass flow rate of the fly ash being released to the atmosphere.

Other

Condensed Water: The mass flow rate of condensed water.

$\mathrm{CO}_{2}$ Product Pressure: This is the target pressure of product $\mathrm{CO}_{2}$ being sent to storage.

$\mathrm{CO}_{2}$ to Storage: The mass flow rate of $\mathrm{CO}_{2}$ being sent to storage.

\section{$\mathrm{O}_{2}-\mathrm{CO}_{2}$ Recycle DCC Gas Results}

This screen is available for Combustion (Boiler) plant types. 


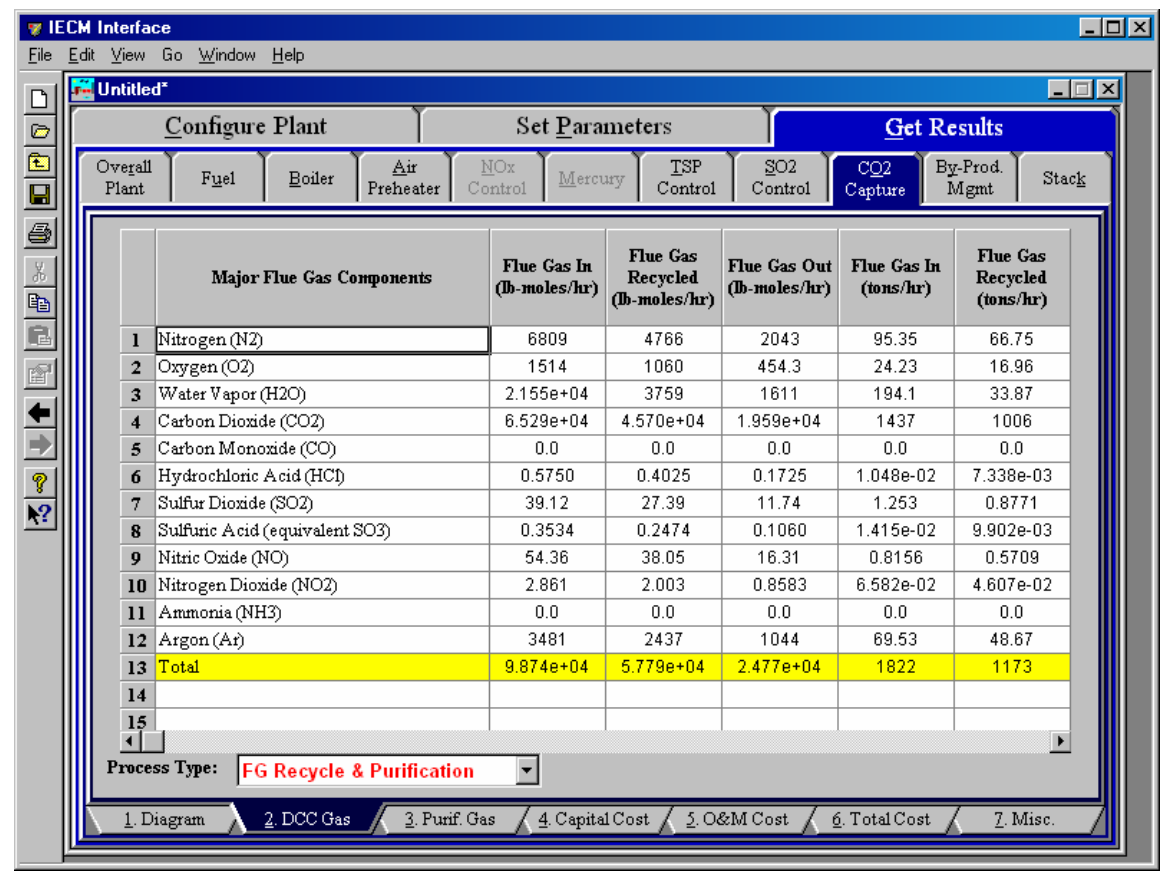

$\mathrm{O}_{2}-\mathrm{CO}_{2}$ Recycle Flue Gas - DCC Gas result screen.

\section{Major Flue Gas Components}

Each result is described briefly below:

Nitrogen $\left(\mathbf{N}_{2}\right)$ : Total mass of nitrogen.

Oxygen $\left(\mathrm{O}_{2}\right)$ : Total mass of oxygen.

Water Vapor $\left(\mathrm{H}_{2} \mathrm{O}\right)$ : Total mass of water vapor.

Carbon Dioxide $\left(\mathrm{CO}_{2}\right)$ : Total mass of carbon dioxide.

Carbon Monoxide (CO): Total mass of carbon monoxide.

Hydrochloric Acid (HCl): Total mass of hydrochloric acid.

Sulfur Dioxide $\left(\mathrm{SO}_{2}\right)$ : Total mass of sulfur dioxide.

Sulfuric Acid (equivalent $\mathbf{S O}_{3}$ ): Total mass of sulfuric acid.

Nitric Oxide (NO): Total mass of nitric oxide.

Nitrogen Dioxide $\left(\mathrm{NO}_{2}\right)$ : Total mass of nitrogen dioxide.

Ammonia $\left(\mathrm{NH}_{3}\right)$ : Total mass of ammonia.

Argon (Ar): Total mass of argon.

Total: Total of the individual components listed above. This item is highlighted in yellow.

\section{$\mathrm{O}_{2}-\mathrm{CO}_{2}$ Recycle Purification Gas Results}

This screen is available for Combustion (Boiler) plant types. 


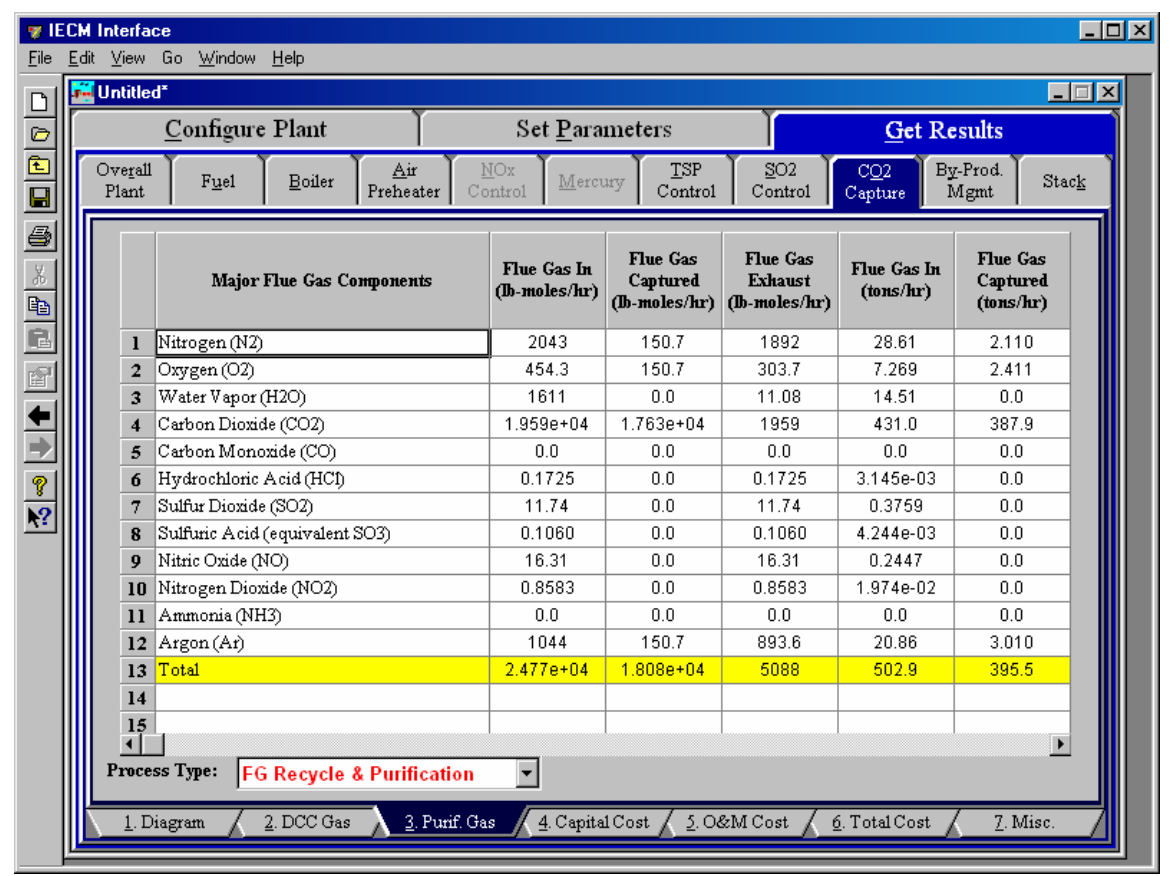

$\mathrm{O}_{2}-\mathrm{CO}_{2}$ Recycle Flue Gas - Purif. gas result screen.

\section{Major Flue Gas Components}

Each result is described briefly below:

Nitrogen $\left(\mathbf{N}_{2}\right)$ : Total mass of nitrogen.

Oxygen $\left(\mathrm{O}_{2}\right)$ : Total mass of oxygen.

Water Vapor $\left(\mathrm{H}_{\mathbf{2}} \mathrm{O}\right)$ : Total mass of water vapor.

Carbon Dioxide $\left(\mathrm{CO}_{2}\right)$ : Total mass of carbon dioxide.

Carbon Monoxide (CO): Total mass of carbon monoxide.

Hydrochloric Acid (HCl): Total mass of hydrochloric acid.

Sulfur Dioxide $\left(\mathrm{SO}_{2}\right)$ : Total mass of sulfur dioxide.

Sulfuric Acid (equivalent $\mathbf{S O}_{3}$ ): Total mass of sulfuric acid.

Nitric Oxide (NO): Total mass of nitric oxide.

Nitrogen Dioxide $\left(\mathrm{NO}_{2}\right)$ : Total mass of nitrogen dioxide.

Ammonia $\left(\mathrm{NH}_{3}\right)$ : Total mass of ammonia.

Argon (Ar): Total mass of argon.

Total: Total of the individual components listed above. This item is

highlighted in yellow.

\section{$\mathrm{O}_{2}-\mathrm{CO}_{2}$ Recycle Capital Cost Results}

This screen is available for Combustion (Boiler) plant types. 


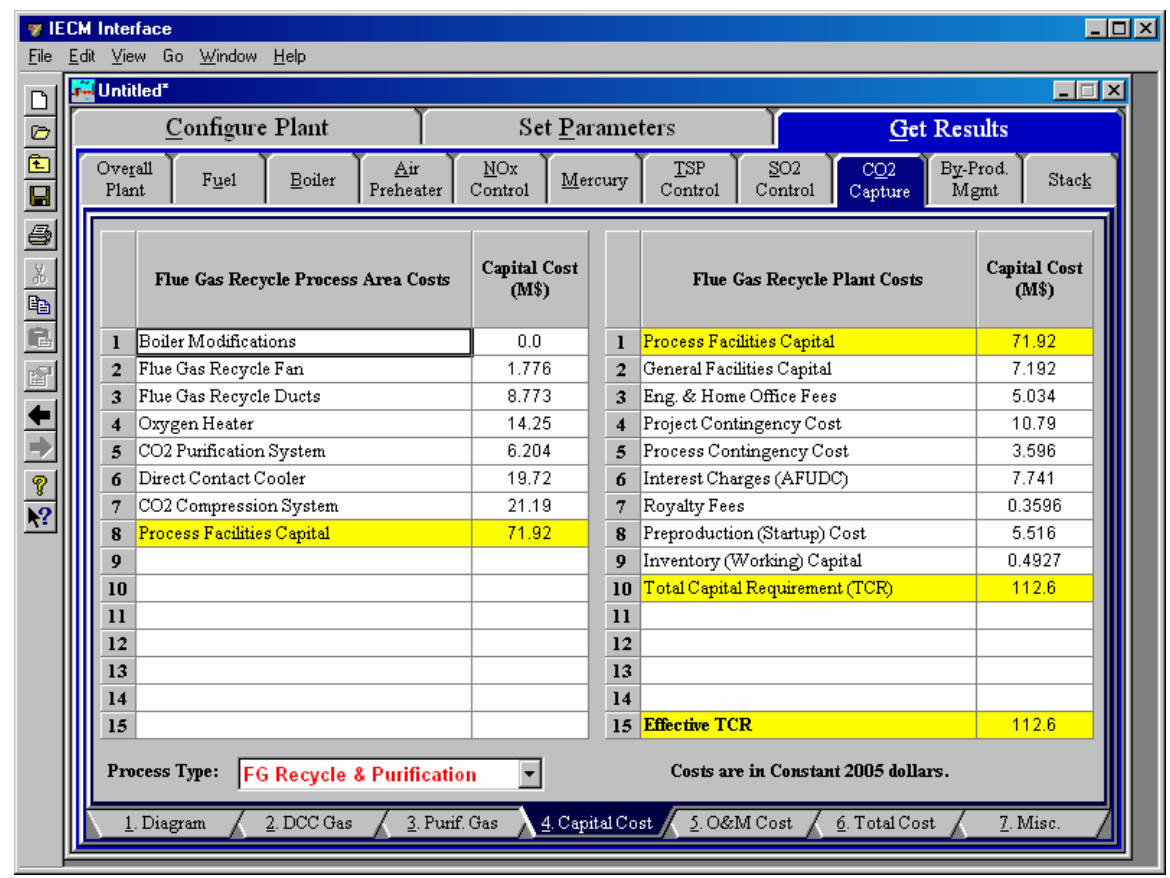

$\mathrm{O}_{2}-\mathrm{CO}_{2}$ Recycle Flue Gas - Capital cost result screen.

The Capital Cost result screen displays tables for the capital costs. Capital costs are typically expressed in either constant or current dollars for a specified year, as shown on the bottom of the screen. Each result is described briefly below:

\section{Flue Gas Recycle Process Area Costs}

Boiler Modifications: In case of a pre-existing PC plant being retrofitted for $\mathrm{CO}_{2}$ capture, the boiler must be modified to suit the new oxyfuel combustion system. The cost for these modifications is estimated as a percentage of the cost of the boiler

Flue Gas Recycle Fan: The cost of the fan required for recycling part of the flue gas is scaled on the basis of the flow rate of the flue gas being recycled

Flue Gas Recycle Ducts: Additional ducting is necessary to recycle part of the flue gas in the oxyfuel combustion system. The cost of this ducting is assumed to be a function of the flow rate of recycled flue gas.

Oxygen Heater: In addition to the air preheater that exists in a conventional PC plant, the oxyfuel combustion system includes an additional heat exchanger called the "oxygen heater" for better heat integration. The cost of this heat exchanger is scaled on the basis of the gross plant size

$\mathrm{CO}_{2}$ Purification System: The cost of the $\mathrm{CO}_{2}$ purification system depends on the desired purity level of the $\mathrm{CO}_{2}$ product, and the total $\mathrm{CO}_{2}$ product flow rate.

Direct Contact Cooler: The cost of the flue gas cooler is scaled on the basis of the flow rate of the flue gas.

$\mathrm{CO}_{2}$ Compression System: The multi-stage compression unit with inter-stage cooling and drying yields the final $\mathrm{CO}_{2}$ product at the specified pressure (about 2000 psig) that contains only acceptable 
levels of moisture and other impurities (e.g. $\mathrm{N}_{2}$ ) The size (and cost) of this unit will be a function of the $\mathrm{CO}_{2}$ product compression power.

Process Facilities Capital: The process facilities capital is the total constructed cost of all on-site processing and generating units listed above, including all direct and indirect construction costs. All sales taxes and freight costs are included where applicable implicitly. This result is highlighted in yellow.

\section{Flue Gas Recycle Plant Costs}

Process Facilities Capital: The process facilities capital is the total constructed cost of all on-site processing and generating units listed above, including all direct and indirect construction costs. All sales taxes and freight costs are included where applicable implicitly. This result is highlighted in yellow.

General Facilities Capital: The general facilities include construction costs of roads, office buildings, shops, laboratories, etc. Sales taxes and freight costs are included implicitly.

Eng. \& Home Office Fees: The engineering \& home office fees are a percent of total direct capital cost. This is an overhead fee paid to the architect/engineering company.

Project Contingency Cost: Capital cost contingency factor covering the cost of additional equipment or other costs that would result from a more detailed design of a definitive project at the actual site.

Process Contingency Cost: Capital cost contingency factor applied to a new technology in an effort to quantify the uncertainty in the technical performance and cost of the commercial-scale equipment.

Interest Charges (AFUDC): Allowance for funds used during construction, also referred to as interest during construction, is the time value of the money used during construction and is based on an interest rate equal to the before-tax weighted cost of capital. This interest is compounded on an annual basis (end of year) during the construction period for all funds spent during the year or previous years.

Royalty Fees: Royalty charges may apply to some portions of generating units incorporating new proprietary technologies.

Preproduction (Startup) Cost: These costs consider the operator training, equipment checkout, major changes in unit equipment, extra maintenance, and inefficient use of fuel or other materials during startup.

Inventory (Working) Capital: The raw material supply based on $100 \%$ capacity during a 60 day period. These materials are considered storage. The inventory capital includes fuels, consumables, byproducts, and spare parts.

Total Capital Requirement (TCR): Money that is placed (capitalized) on the books of the utility on the service date. TCR includes all the items above. This result is highlighted in yellow.

Effective TCR: The TCR of the spray dryer that is used in determining the total power plant cost. The effective TCR is determined by the "TCR Recovery Factor". 


\section{$\mathrm{O}_{2}-\mathrm{CO}_{2}$ Recycle O\&M Cost Results}

This screen is available for Combustion (Boiler) plant types.

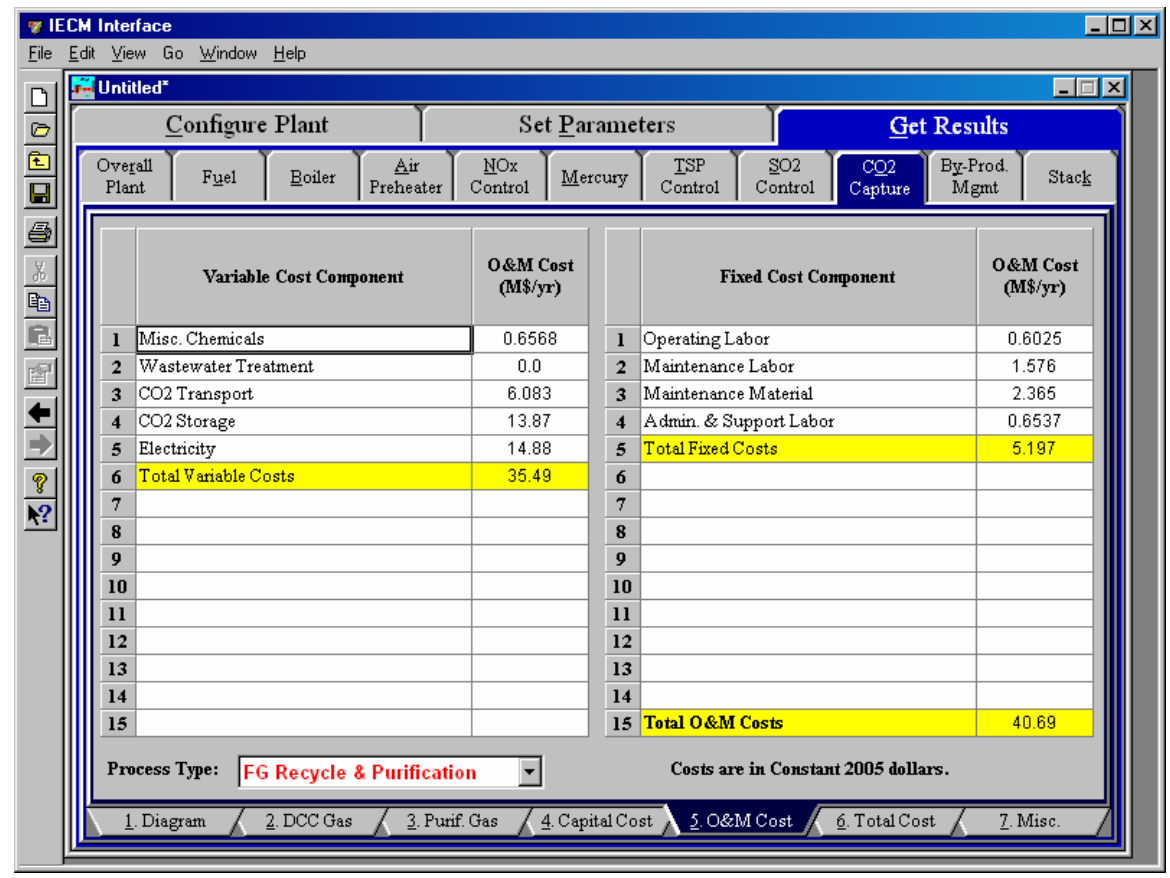

$\mathrm{O}_{2}-\mathrm{CO}_{2}$ Recycle Flue Gas - O\&M cost result screen.

The O\&M Cost result screen displays tables for the variable and fixed operation and maintenance costs involved with the CO2 Capture technology. O\&M costs are typically expressed on an average annual basis and are provided in either constant or current dollars for a specified year, as shown on the bottom of the screen. Each result is described briefly below:

\section{Variable Cost Components}

Variable operating costs and consumables are directly proportional to the amount of kilowatts produced and are referred to as incremental costs. All the costs are subject to inflation.

Misc. Chemicals: A small quantity of chemicals is used in this process, including chemicals, desiccant and lubricants. The aggregate cost of these chemicals is estimated based on the flow rate of $\mathrm{CO}_{2}$ captured

Wastewater Treatment: The user may enter a cost for treating the moisture condensed from the flue gas.

$\mathbf{C O}_{2}$ Transport: The $\mathrm{CO}_{2}$ captured at the power plant site has to be carried to the appropriate storage/ disposal site. Transport of $\mathrm{CO}_{2}$ to a storage site is assumed to be via pipeline This is the annual cost of maintaining those pipelines.

$\mathrm{CO}_{2}$ Storage: Once the $\mathrm{CO}_{2}$ is captured, it needs to be securely stored (sequestered). This cost is based upon the storage option chosen on the $\mathrm{O}_{2}-\mathrm{CO}_{2}$ Recycle Flue Gas - $\mathrm{CO}_{2}$ storage input screen.

Electricity: The cost of electricity consumed by the Flue Gas Recycle System. 
Total Variable Costs: This is the sum of all the variable O\&M costs listed above. This result is highlighted in yellow.

\section{Fixed Cost Components}

Fixed operating costs are essentially independent of actual capacity factor, number of hours of operation, or amount of kilowatts produced. All the costs are subject to inflation.

Operating Labor: Operating labor cost is based on the operating labor rate, the number of personnel required to operate the plant per eighthour shift, and the average number of shifts per day over 40 hours per week and 52 weeks.

Maintenance Labor: The maintenance labor is determined as a fraction of the total maintenance cost.

Maintenance Material: The cost of maintenance material is the remainder of the total maintenance cost, considering the fraction associated with maintenance labor.

Admin. \& Support Labor: The administrative and support labor is the only overhead charge. It is taken as a fraction of the total operating and maintenance labor costs.

Total Fixed Costs: This is the sum of all the fixed O\&M costs listed above. This result is highlighted in yellow.

Total O\&M Costs: This is the sum of the total variable and total fixed O\&M costs. It is used to determine the base plant total revenue requirement. This result is highlighted in yellow.

\section{$\mathrm{O}_{2}-\mathrm{CO}_{2}$ Recycle Total Cost Results}

This screen is available for Combustion (Boiler) plant types.

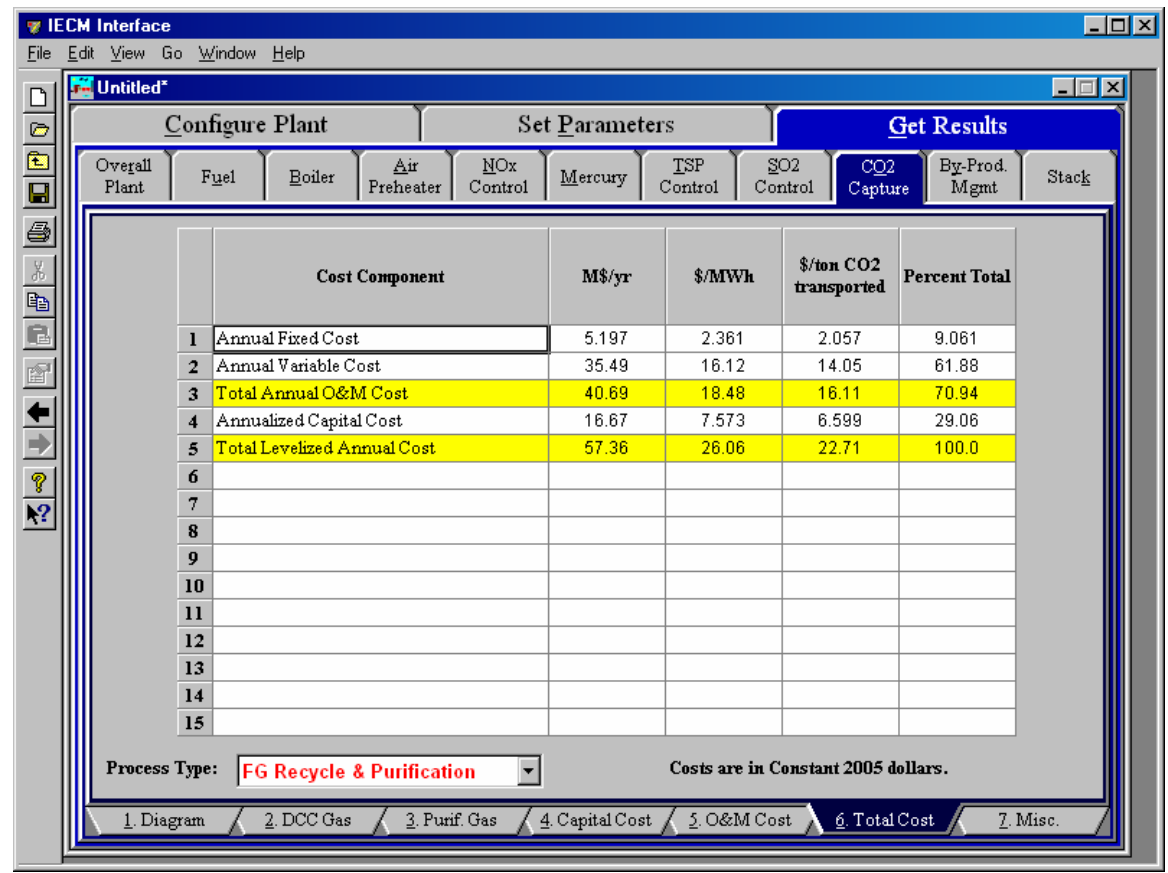

$\mathrm{O}_{2}-\mathrm{CO}_{2}$ Recycle Flue Gas - Total cost result screen. 
The Total Cost result screen displays a table which totals the annual fixed, variable, operations and maintenance, and capital costs associated with the Flue Gas Recycle portion of the $\mathbf{C O} 2$ Control technology. Total costs are typically expressed in either constant or current dollars for a specified year, as shown on the bottom of the screen. Each result is described briefly below.

\section{Cost Component}

Annual Fixed Cost: The operating and maintenance fixed costs are given as an annual total. This number includes all maintenance materials and all labor costs.

Annual Variable Cost: The operating and maintenance variables costs are given as an annual total. This includes all reagent, chemical, steam, and power costs.

Total Annual O\&M Cost: This is the sum of the annual fixed and variable operating and maintenance costs above. This result is highlighted in yellow.

Annualized Capital Cost: This is the total capital cost expressed on an annualized basis, taking into consideration the levelized carrying charge factor, or fixed charge factor, over the entire book life.

Total Levelized Annual Cost: The total annual cost is the sum of the total annual O\&M cost and annualized capital cost items above. This result is highlighted in yellow.

\section{$\mathrm{O}_{2}-\mathrm{CO}_{2}$ Recycle Miscellaneous Results}

This screen is available for Combustion (Boiler) plant types.

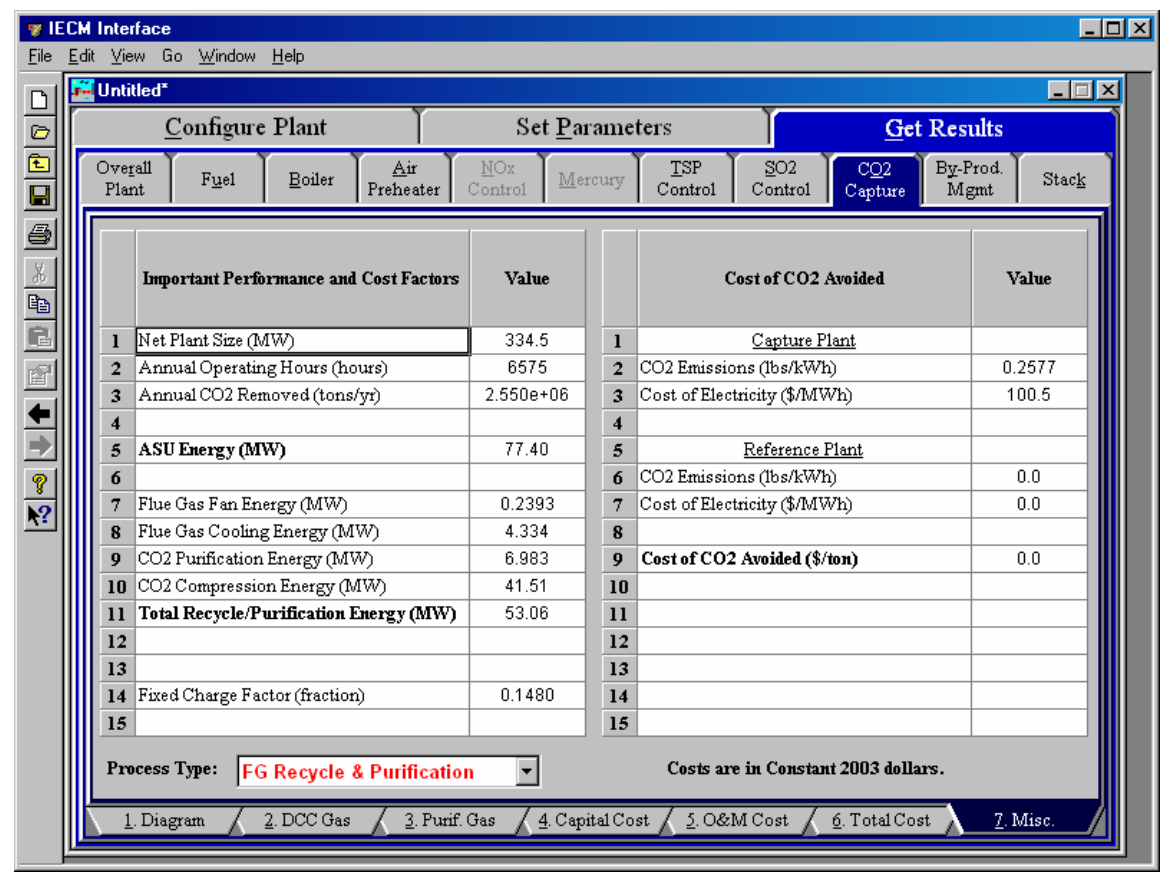

$\mathrm{O}_{2}-\mathrm{CO}_{2}$ Recycle Flue Gas - Miscellaneous factor result screen.

The Misc. result screen displays a table which totals the annual fixed, variable, operations and maintenance, and capital costs associated with the Flue Gas 
Recycle portion of the $\mathrm{CO}_{2}$ Control technology. Each result is described briefly below.

\section{Important Performance and Cost Factors}

This screen displays information that is key to the model calculations. The data is available else where in the model.

Net Plant Size (MW): This is the net plant capacity, which is the gross plant capacity minus the losses due to plant equipment and pollution equipment (energy penalties).

Annual Operating Hours (hours): This is the number of hours per year that the plant is in operation. If a plant runs 24 hours per day, seven days per week, with no outages, the calculation is 24 hours * 365 days. or 8,760 hours/year.

Annual $\mathrm{CO}_{2}$ Removed (ton/yr): This is the amount of $\mathrm{CO}_{2}$ removed from the flue gas by the $\mathrm{CO}_{2}$ capture system per year.

\section{ASU Power (MW)}

Flue Gas Fan Power (MW): The flue gas has to be compressed in a flue gas blower so that it can overcome the pressure drop in the absorber tower. This is the electrical power required by the blower.

\section{$\mathrm{CO}_{2}$ Purification Power (MW)}

$\mathrm{CO}_{2}$ Compression Power (MW): This is the electrical power required to compress the $\mathrm{CO}_{2}$ product stream to the designated pressure. Compression of $\mathrm{CO}_{2}$ to high pressures requires considerable power, and is a principle contributor to the overall energy penalty of a $\mathrm{CO}_{2}$ capture unit in a power plant.

Fixed Charge Factor (fraction): The fixed charge factor is one of the most important parameters in the IECM. It determines the revenue required to finance the power plant based on the capital expenditures. Put another way, it is a levelized factor which accounts for the revenue per dollar of total plant cost that must be collected from customers in order to pay the carrying charges on that capital investment.

\section{Cost of $\mathrm{CO}_{2}$ Avoided}

Many analysts like to express the cost of an environmental control system in terms of the cost per ton of pollutant removed or avoided. For energy-intensive $\mathrm{CO}_{2}$ controls there is a big difference between the cost per ton $\mathrm{CO}_{2}$ removed and the cost per ton "avoided" based on net plant capacity. Since the purpose of adding a $\mathrm{CO}_{2}$ unit is to reduce the $\mathrm{CO}_{2}$ emissions per net $\mathrm{kWh}$ delivered, the cost of $\mathrm{CO}_{2}$ avoidance is the economic indicator that is widely used in this field.

\section{Capture Plant}

$\mathrm{CO}_{2}$ Emissions (Ib/kWh): This is the amount of $\mathrm{CO}_{2}$ vented to the air for every kilowatt hour of electricity produced in the power plant that is using $\mathrm{CO}_{2}$ Capture Technology.

Cost of Electricity (\$/MWh):The IECM framework calculates the cost of electricity (COE) for the overall Capture Plant by dividing the total annualized plant cost (\$/yr) by the net electricity generated $(\mathrm{kWh} / \mathrm{yr})$

Reference Plant 
$\mathbf{C O}_{2}$ Emissions (lb/kWh): This is the amount of $\mathrm{CO}_{2}$ vented to the air for every kilowatt hour of electricity produced in the power plant with $\mathrm{No} \mathrm{CO}_{2}$ Capture.

Cost of Electricity (\$/MWh): The IECM framework calculates the cost of electricity (COE) for the overall Reference Plant by dividing the total annualized plant cost $(\$ / y r)$ by the net electricity generated $(\mathrm{kWh} / \mathrm{yr})$

Cost of $\mathrm{CO}_{2}$ Avoided (\$/ton): This is the economic indicator widely used in the field, calculated as the difference between the cost of electricity in the capture plant and the reference plant divided by the difference between the $\mathrm{CO}_{2}$ emissions in the reference plant and the capture plant.

Cost of $\mathrm{CO}_{2}$ Avoided $=($ Cost of Electricity cap. - Cost of Electricity ref. $)$

/ $\left(\mathrm{CO}_{2}\right.$ emissions ref. $-\mathrm{CO}_{2}$ emissions cap. $)$ 



\section{Selexol $\mathrm{CO}_{2}$ Capture}

IGCC systems use less energy-intensive physical absorption processes to capture $\mathrm{CO}_{2}$ than post-combustion chemical absorption processes required by the Combustion (Boiler) or Combustion (Turbine) plant types. Physical absorption using Selexol solvent is currently the most effective technique for removing $\mathrm{CO}_{2}$ from IGCC fuel gases. The $\mathrm{CO}_{2}$ capture using Selexol is described in the following section.

\section{Selexol $\mathrm{CO}_{2}$ Capture Reference Plant Inputs}

This screen is only available for the IGCC plant type.

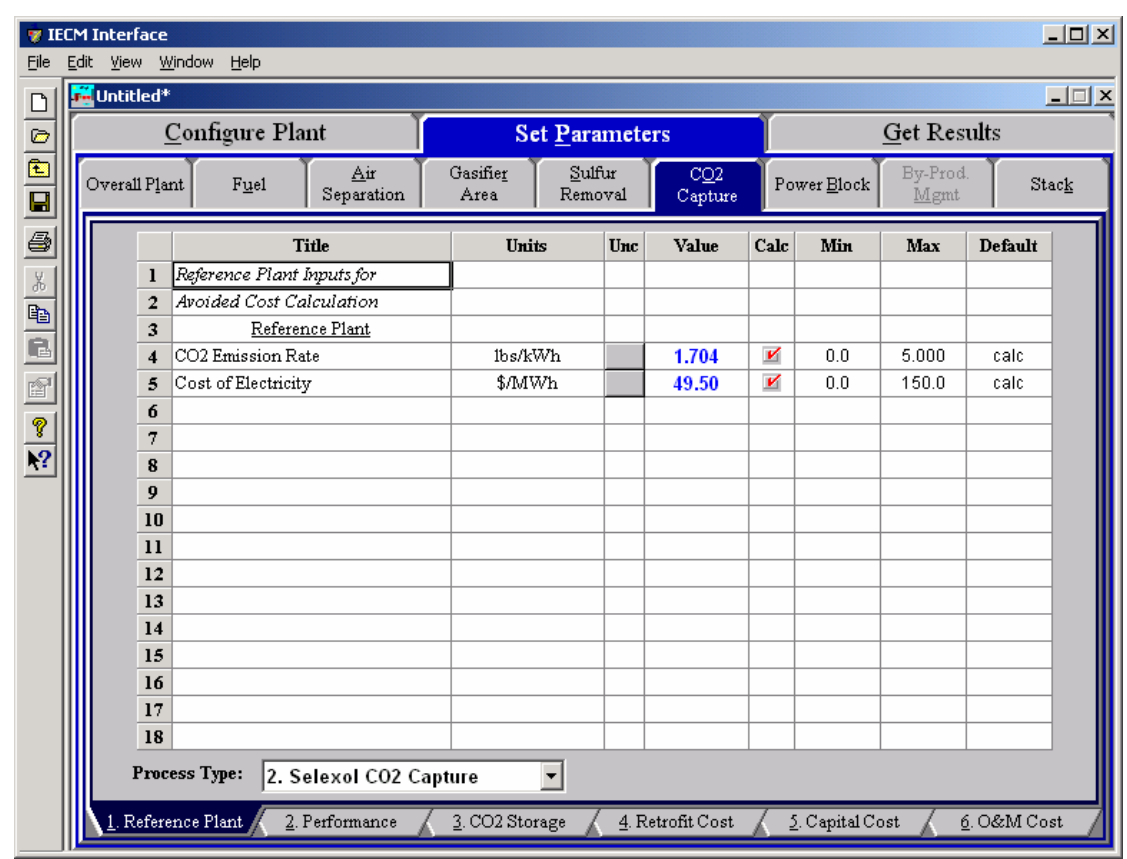

Selexol $\mathrm{CO}_{2}$ Capture - Reference Plant input screen.

\section{Reference Plant}

$\mathbf{C O}_{2}$ Emission Rate: This is the emission rate for the reference power plant (without $\mathrm{CO}_{2}$ capture). 
Cost of Electricity: This is the cost of electricity for the reference power plant (without $\mathrm{CO}_{2}$ capture).

\section{Selexol $\mathrm{CO}_{2}$ Capture Performance Inputs}

This screen is only available for the IGCC plant type.

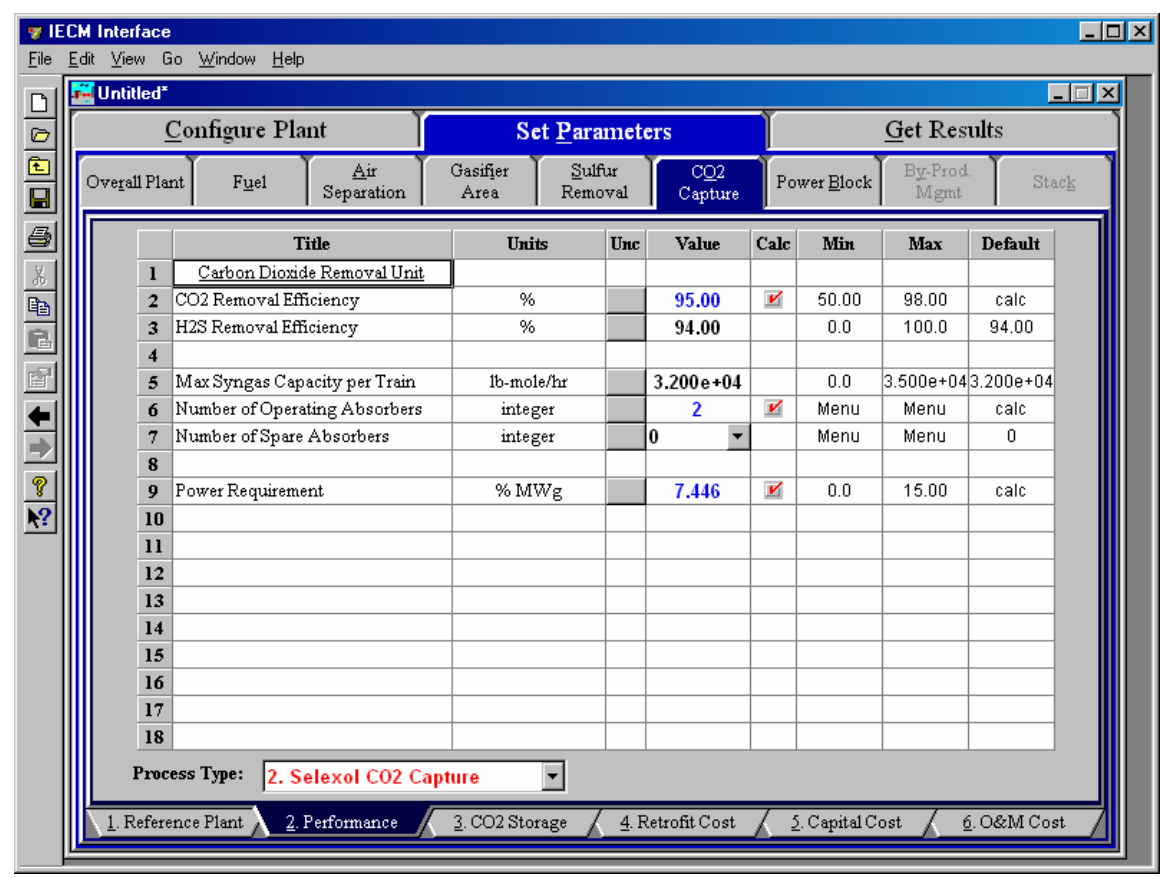

Selexol $\mathrm{CO}_{2}$ Capture - Performance input screen.

\section{Carbon Dioxide Removal Unit}

$\mathrm{CO}_{2}$ Removal Efficiency: $\mathrm{CO}_{2}$ removal is specified by the user and is used to determine the solvent makeup flow, capital cost, and operating and maintenance costs.

$\mathbf{H}_{2}$ S Removal Efficiency: $\mathrm{H}_{2} \mathrm{~S}$ is naturally removed with $\mathrm{CO}_{2}$. This parameter specifies the amount it is captured.

Max Syngas Capacity per Train: Each train contains one absorber vessel that has a maximum flow rate. This parameter determines the maximum flow rate through the vessel.

Number of Operating Absorbers: This is the total number of operating absorber vessels. The calculated value is determined by comparing the total flow rate of syngas through the Selexol process and the maximum syngas capacity per train. The value must be an integer.

Number of Spare Absorbers: This is the total number of spare absorber vessels. It is used primarily to calculate capital costs. The value must be an integer.

Power Requirement: This is the electricity used by the Selexol CO2 Capture System for internal use. It is expressed as a percent of the gross plant capacity. 


\section{Selexol $\mathrm{CO}_{2}$ Capture $\mathrm{CO}_{2}$ Storage Inputs}

This screen is only available for the IGCC plant type.

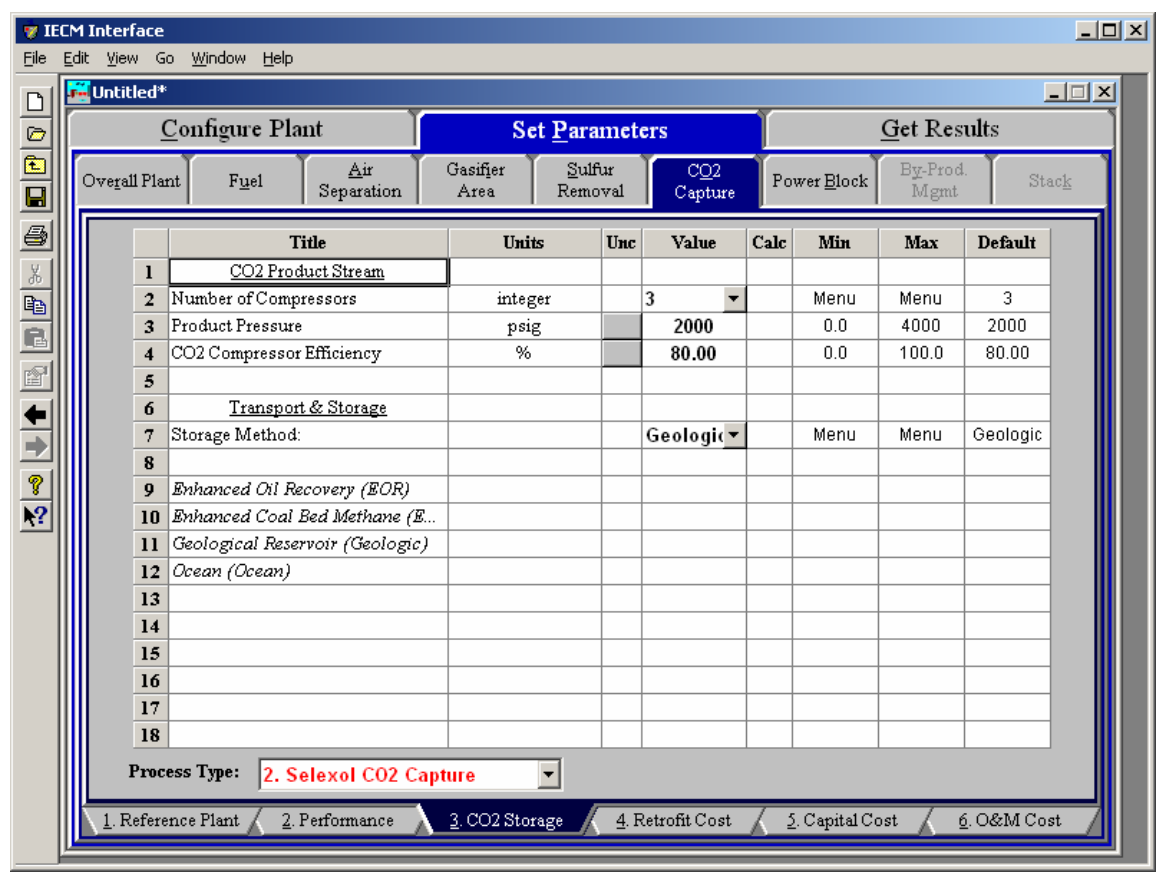

Selexol $\mathrm{CO}_{2}$ Capture $-\mathrm{CO}_{2}$ Storage input screen.

\section{$\mathrm{CO}_{2}$ Product Stream}

The concentrated $\mathrm{CO}_{2}$ product stream obtained from $\mathrm{CO}_{2}$ capture technology is compressed and dried using a multi-stage compressor with inter-stage cooling.

Number of Compressors: The number of compressors is a userspecified number. The value is used to determine the capital cost for sequestration.

Product Pressure: The $\mathrm{CO}_{2}$ product may have to be carried over long distances. Hence, it is necessary to compress (and liquefy) it to very high pressures, so that it may be delivered to the required destination in liquid form and (as far as possible) without recompression facilities en route. The critical pressure for $\mathrm{CO}_{2}$ is about 1070 psig.

$\mathrm{CO}_{2}$ Compressor Efficiency: This is the effective efficiency of the compressors used to compress $\mathrm{CO}_{2}$ to the desired pressure.

\section{Transport \& Storage}

Storage Method: The default option for $\mathrm{CO}_{2}$ disposal is underground geological storage.

- $\quad$ EOR - Enhanced Oil Recovery

- $\quad$ ECBM - Enhanced Coal Bed Methane

- Geologic-Geological Reservoir

- Ocean 


\section{Selexol $\mathrm{CO}_{2}$ Capture Retrofit Cost Inputs}

This screen is only available for the IGCC plant type.

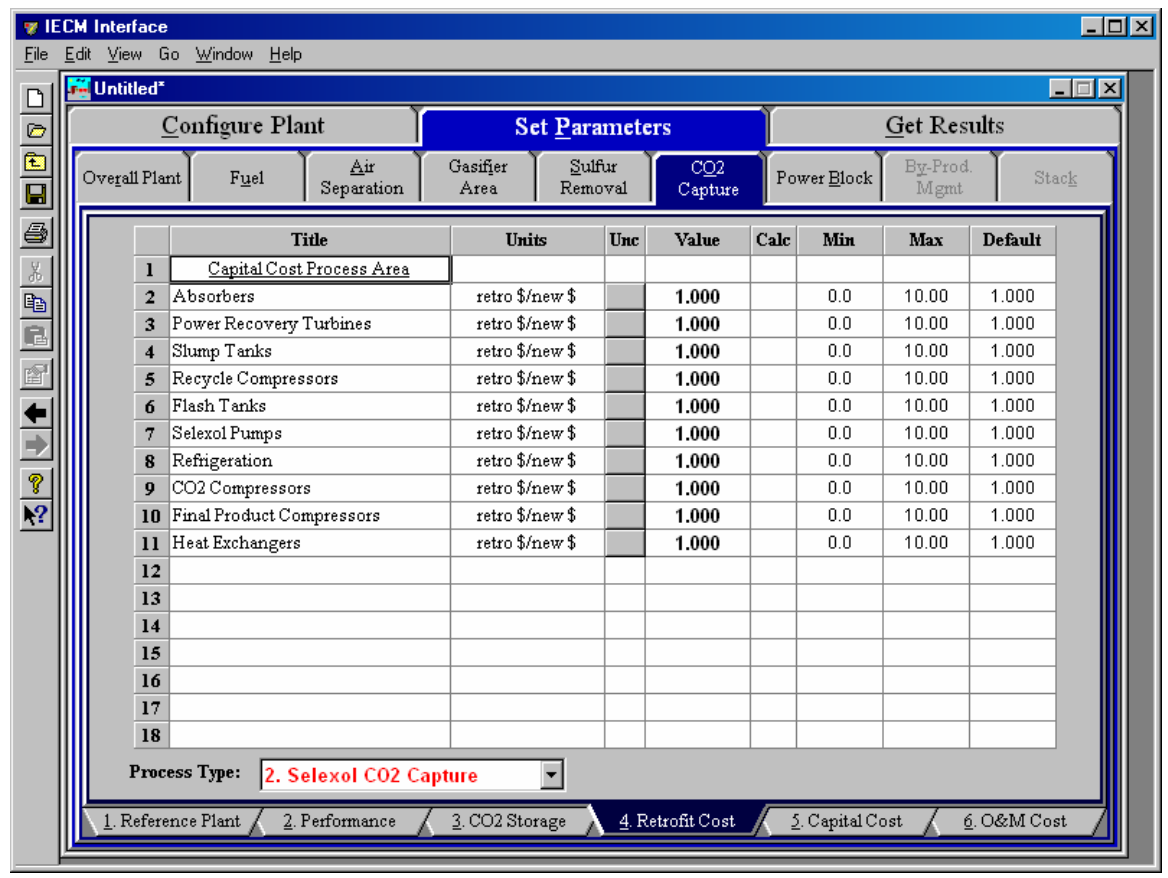

Selexol $\mathrm{CO}_{2}$ Capture - Retrofit Cost input screen.

\section{Capital Cost Process Area}

The retrofit ratios can be specified for the following process areas:

Absorbers: The Selexol absorbers use physical absorption to capture $\mathrm{CO}_{2}$. Because the solubility of $\mathrm{CO}_{2}$ in the solvent is proportional to its partial pressure in the gas phase, the performance of the absorbers increases with increasing $\mathrm{CO}_{2}$ partial pressures.

Power Recovery Turbines: The $\mathrm{CO}_{2}$ rich solvent from the absorber is fed into a set of hydraulic power recovery turbines to recover some of the pressure energy before it is fed into the slump tanks.

Slump Tanks: A slight pressure drop in the slump tanks releases a majority of $\mathrm{H}_{2}$ and $\mathrm{CH}_{4}$ and a small amount of $\mathrm{CO}_{2}$. This process area enriches the $\mathrm{CO}_{2}$ concentration.

Recycle Compressors: Gases from the slump tank are recycled back into the absorber. A compressor is used to compress the gases to the operating pressure of the absorber.

Flash Tanks: $\mathrm{CO}_{2}$ is released in multiple stages by reducing the pressure in successive flash tanks. Three flash tanks are typically used in a single train. The staging process reduces the power of $\mathrm{CO}_{2}$ compression later.

Selexol Pumps: The $\mathrm{CO}_{2}$-lean solvent is pumped back to the absorber operating pressure by a Selexol circulation pump. 
Refrigeration: $\mathrm{CO}_{2}$-lean solvent must be cooled to the absorber operating temperature before being returned to the absorber vessel. A

refrigeration unit is used to reduce the temperature of the solvent.

$\mathrm{CO}_{2}$ Compressors: $\mathrm{CO}_{2}$ released from the first two flash tanks is compressed to the flashing pressure of the first flash tank. The two $\mathrm{CO}_{2}$ streams are then combined and sent to the final product compressors.

Final Product Compressors: The product $\mathrm{CO}_{2}$ must be separated from the water vapor (dried) and compressed to liquid form in order to transport it over long distances. The multi-stage compression unit with inter-stage cooling and drying yields a final $\mathrm{CO}_{2}$ product at the nominal pressure of $2000 \mathrm{psig}$. This area is a function of the $\mathrm{CO}_{2}$ flow rate.

Heat Exchangers: This process area considers miscellaneous heat exchangers used in the overall process.

\section{Selexol $\mathrm{CO}_{2}$ Capture Capital Cost Inputs}

This screen is only available for the IGCC plant type.

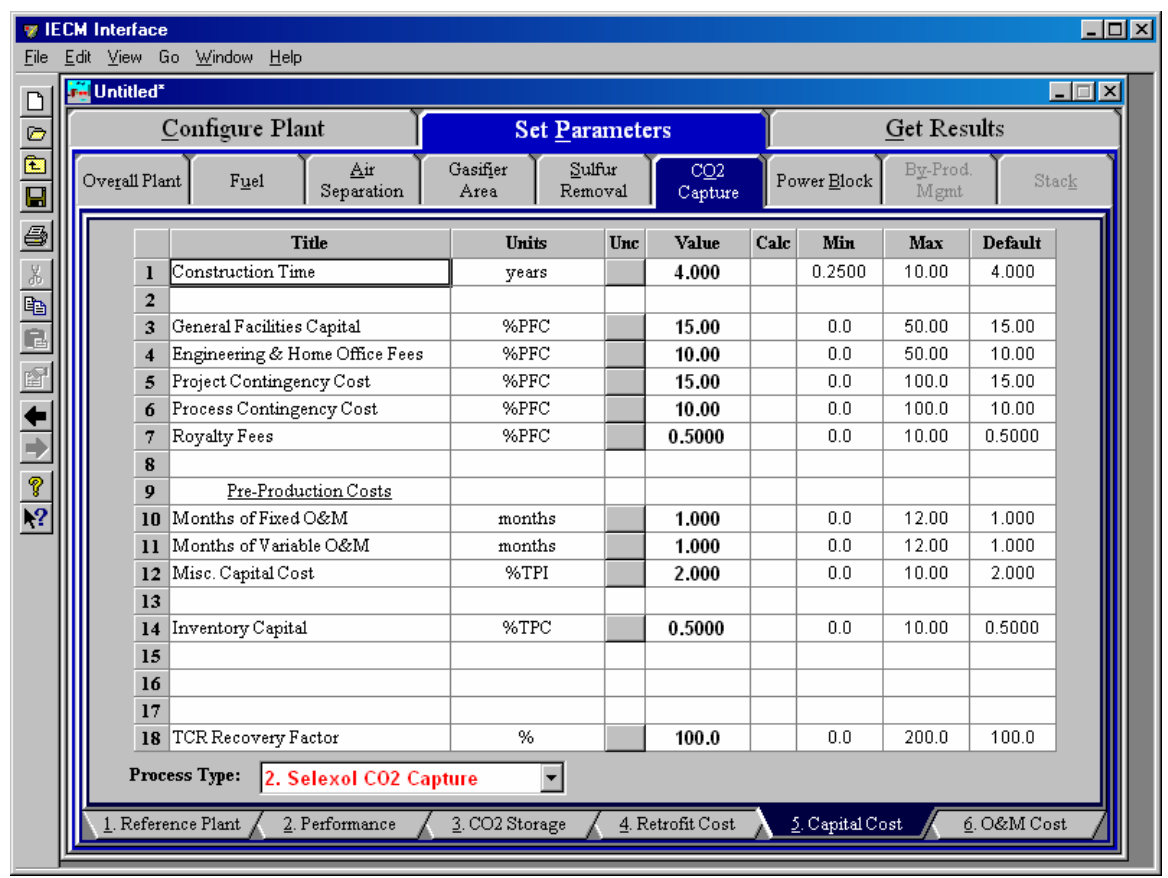

Selexol $\mathrm{CO}_{2}$ Capture - Capital Cost input screen.

Inputs for capital costs are entered on the Capital Cost input screen.

Construction Time: This is the idealized construction period in years. It is used to determine the allowance for funds used during construction (AFUDC).

General Facilities Capital (GFC): The general facilities include construction costs of roads, office buildings, shops, laboratories, etc. Sales taxes and freight costs are included implicitly. The cost typically ranges from $5-20 \%$.

Engineering \& Home Office Fees: The engineering \& home office fees are a percent of total direct capital cost. This is an overhead fee paid to 
the architect/engineering company. These fees typically range from 7$15 \%$.

Project Contingency Cost: This is factor covering the cost of additional equipment or other costs resulting from a more detailed design. Higher contingency factors will be applied to simplified or preliminary designs and lower factors to detailed or finalized designs.

Process Contingency Cost: This quantifies the design uncertainty and cost of a commercial-scale system. This is generally applied on an areaby-area basis. Higher contingency factors are applied to new regeneration systems tested at a pilot plant and lower factors to full-size or commercial systems.

Royalty Fees: Royalty charges may apply to some portions of generating units incorporating new proprietary technologies.

Pre-Production Costs: These costs consider the operator training, equipment checkout, major changes in unit equipment, extra maintenance, and inefficient use of fuel or other materials during startup. These are typically applied to the O\&M costs over a specified period of time (months). The two time periods for fixed and variable O\&M costs are described below with the addition of a miscellaneous capital cost factor.

- Months of Fixed O\&M: Time period of fixed operating costs used for preproduction to cover training, testing, major changes in equipment, and inefficiencies in start-up. This includes operating, maintenance, administrative and support labor. It also considers maintenance materials.

- Months of Variable O\&M: Time period of variable operating costs used for preproduction to cover chemicals, water, consumables, and solid disposal charges in start-up, assuming $100 \%$ load. This excludes any fuels.

- Misc. Capital Cost: This is a percent of total plant investment (sum of TPC and AFUDC) to cover expected changes to equipment to bring the system up to full capacity.

Inventory Capital: Percent of the total direct capital for raw material supply based on $100 \%$ capacity during a 60 day period. These materials are considered storage. The inventory capital includes fuels, consumables, by-products, and spare parts. This is typically $0.5 \%$.

TCR Recovery Factor: The actual total capital required (TCR) as a percent of the TCR in a new power plant. This value is $100 \%$ for a new installation and may be set as low as $0 \%$ for a fabric filter that has been paid off.

\section{Selexol $\mathrm{CO}_{2}$ Capture O\&M Cost Inputs}

This screen is only available for the IGCC plant type. 


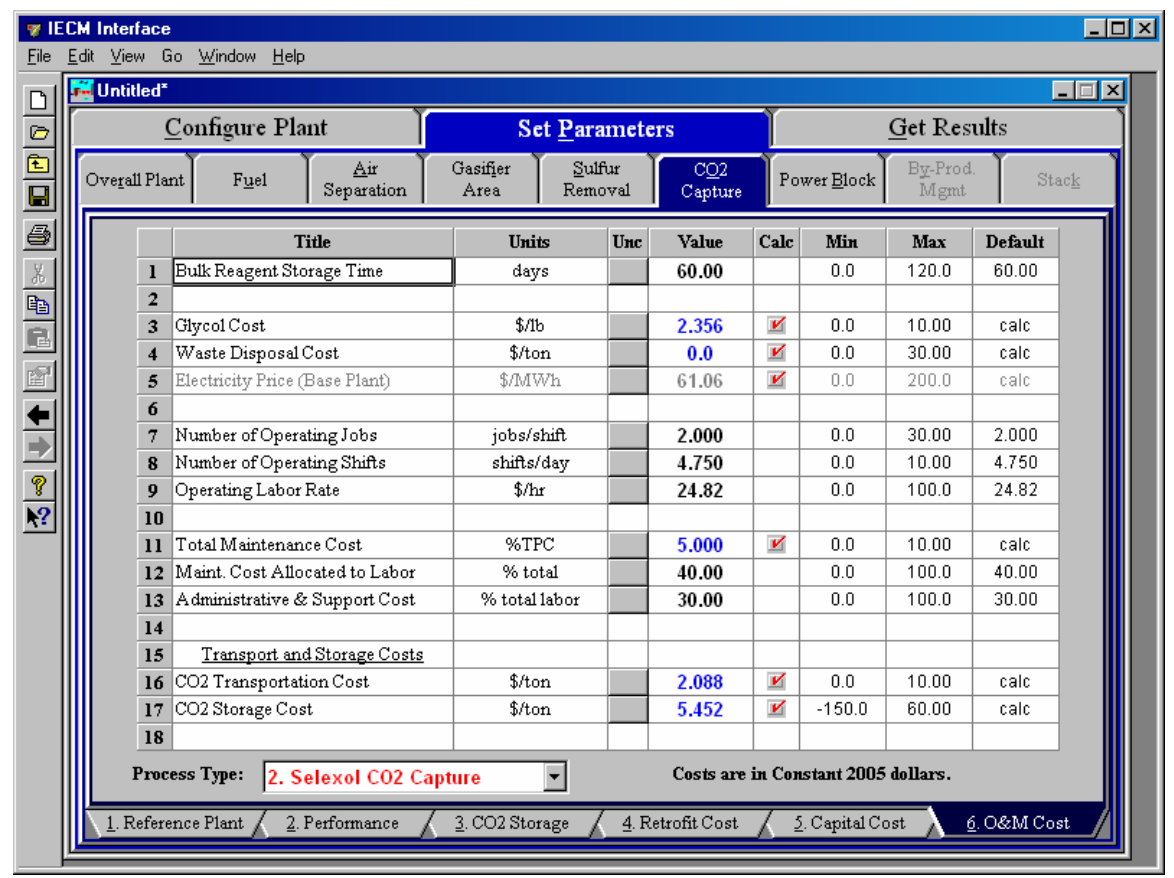

Selexol $\mathrm{CO}_{2}$ Capture - O\&M Cost input screen.

O\&M costs are typically expressed on an average annual basis and are provided in either constant or current dollars for a specified year, as shown on the bottom of the screen. The following inputs for operating and maintenance costs are available:

Bulk Reagent Storage Time: This is the reagent stored at the plant.

Glycol Cost: This is the cost in \$/ton for glycol that is used by the Selexol $\mathrm{CO}_{2}$ capture system.

Waste Disposal Cost: This is the cost of disposing the water that is used in the Selexol $\mathrm{CO}_{2}$ capture process.

Electricity Price (Base Plant): This is the price of electricity and is calculated as a function of the utility cost of the base plant, where the base plant is an air separation unit, gasifier and the power block

Number of Operating Jobs: This is the total number of operating jobs that are required to operate the plant per eight-hour shift.

Number of Operating Shifts: This is the total number of equivalent operating shifts in the plant per day. The number takes into consideration paid time off and weekend work ( 3 shifts/day * 7 days/5 day week $* 52$ weeks $/(52$ weeks -6 weeks PTO $)=4.75$ equiv. Shifts/day)

Operating Labor Rate: The hourly cost of labor is specified in the base plant O\&M cost screen. The same value is used throughout the other technologies.

Total Maintenance Cost: This is the annual maintenance cost as a percentage of the total plant cost. Maintenance cost estimates can be developed separately for each process area.

Maint. Cost Allocated to Labor: Maintenance cost allocated to labor as a percentage of the total maintenance cost. 
Administrative \& Support Cost: This is the percent of the total operating and maintenance labor associated with administrative and support labor.

\section{Transport and Storage Costs}

- $\mathrm{CO}_{2}$ Transportation Cost: This is the cost of moving the $\mathrm{CO}_{2}$ (i.e. pipeline, truck) to the place where it will be sequestered.

- $\mathrm{CO}_{2}$ Disposal Cost: This is the cost of sequestering the $\mathrm{CO}_{2}$.

\section{Selexol $\mathrm{CO}_{2}$ Capture Diagram}

This screen is only available for the IGCC plant type.

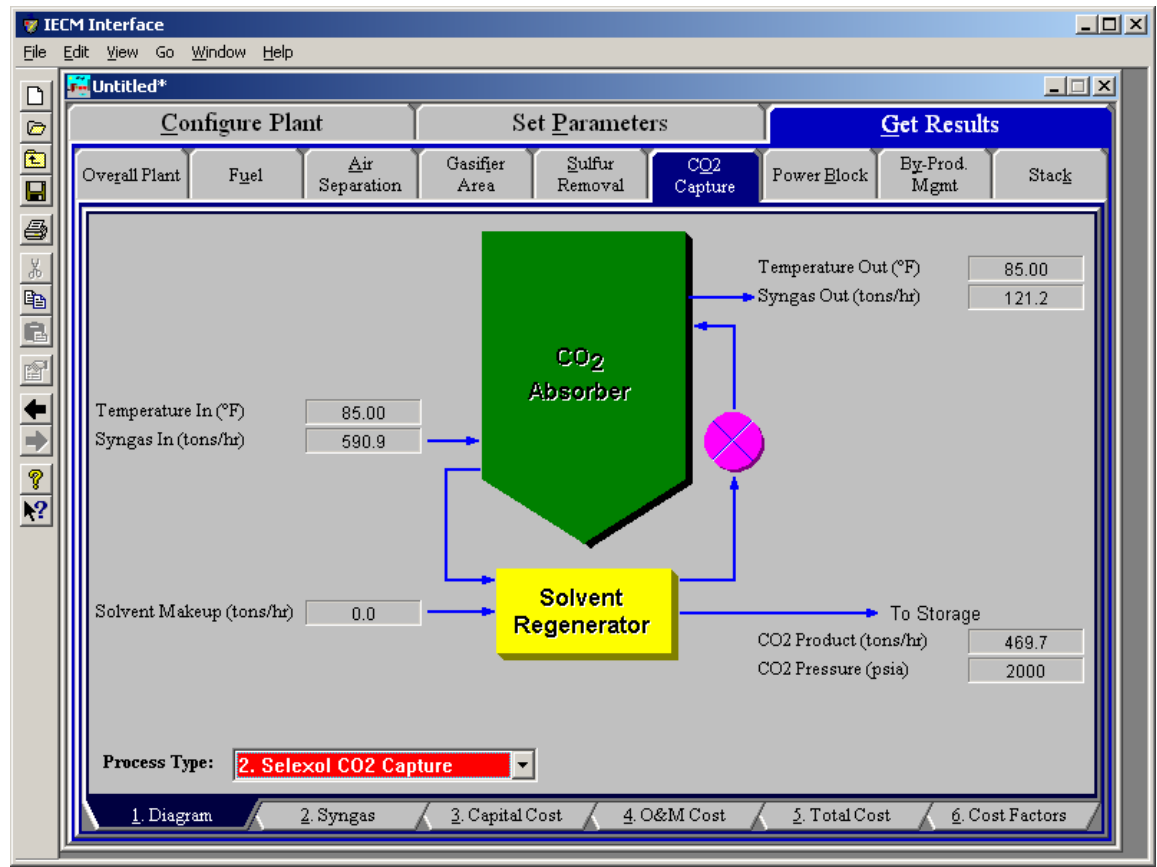

Selexol $\mathrm{CO}_{2}$ Capture - Diagram result screen.

The Selexol $\mathbf{C O}_{2}$ Capture Diagram result screen displays an icon for the Selexol $\mathrm{CO}_{2}$ capture unit and values for major flows in and out of it. Each result is described briefly below:

Temperature In: Temperature of the syngas entering the $\mathrm{CO}_{2}$ absorber unit.

Syngas In: Flow rate of the syngas entering the $\mathrm{CO}_{2}$ absorber unit.

Solvent Makeup: Flow rate of the Selexol solvent added to the regenerator.

Temperature Out: Temperature of the syngas exiting the $\mathrm{CO}_{2}$ absorber unit.

Syngas Out: Flow rate of the syngas exiting the $\mathrm{CO}_{2}$ absorber unit.

$\mathrm{CO}_{2}$ Product: Flow rate of the $\mathrm{CO}_{2}$ product exiting the regenerator.

$\mathrm{CO}_{2}$ Syngas Pressure: $\mathrm{CO}_{2}$ product pressure entering the pipeline. 


\section{Selexol $\mathrm{CO}_{2}$ Capture Syngas Results}

This screen is only available for the IGCC plant type.

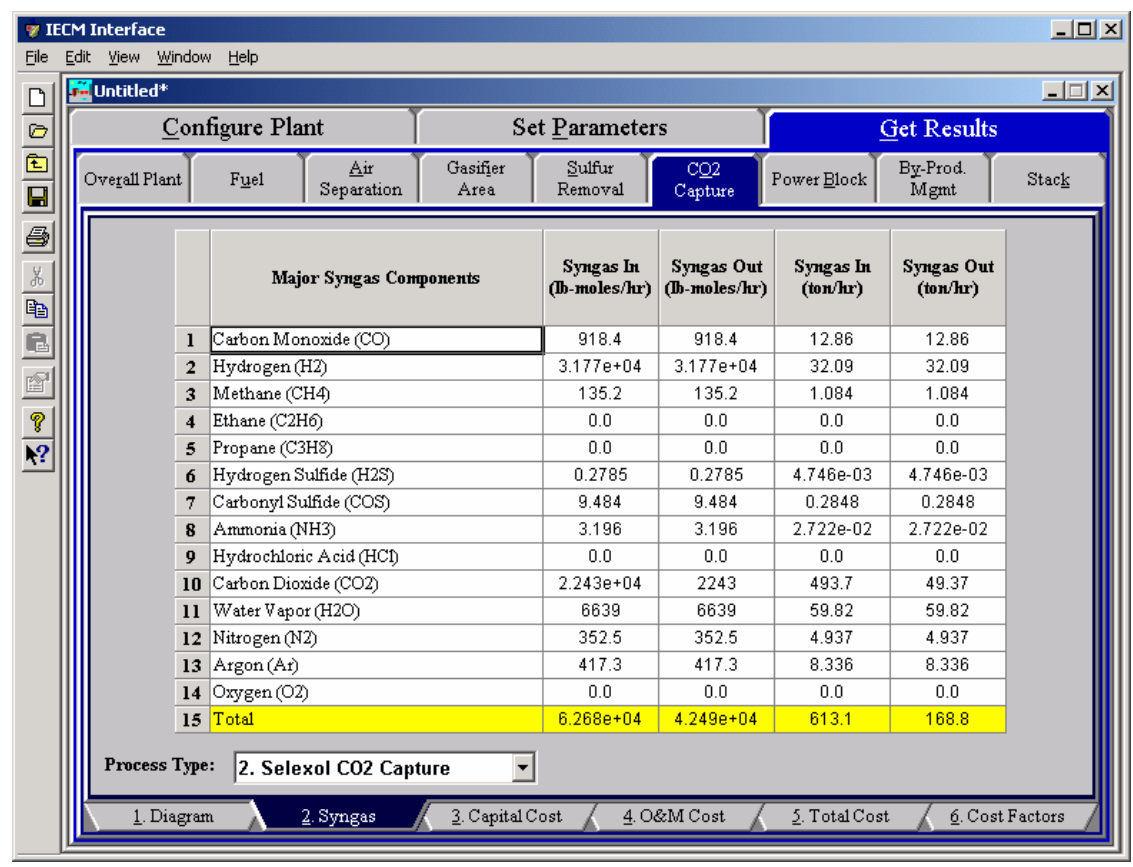

Selexol $\mathrm{CO}_{2}$ Capture - Gas Flow result screen..

\section{Major Syngas Components}

Carbon Monoxide (CO): Total mass of carbon monoxide.

Hydrogen $\left(\mathbf{H}_{\mathbf{2}}\right)$ :Total mass of hydrogen.

Methane $\left(\mathrm{CH}_{4}\right)$ : Total mass of methane.

Ethane $\left(\mathrm{C}_{2} \mathrm{H}_{6}\right)$ : Total mass of ethane.

Propane $\left(\mathrm{C}_{3} \mathrm{H}_{8}\right)$ : Total mass of propane.

Hydrogen Sulfide $\left(\mathrm{H}_{2} \mathrm{~S}\right)$ :Total mass of hydrogen sulfide.

Carbonyl Sulfide (COS):Total mass of carbonyl sulfide.

Ammonia $\left(\mathrm{NH}_{3}\right)$ : Total mass of ammonia.

Hydrochloric Acid $(\mathrm{HCl})$ : Total mass of hydrochloric acid.

Carbon Dioxide $\left(\mathrm{CO}_{2}\right)$ : Total mass of carbon dioxide.

Water Vapor $\left(\mathrm{H}_{2} \mathrm{O}\right)$ : Total mass of water vapor.

Nitrogen $\left(\mathbf{N}_{2}\right)$ : Total mass of nitrogen.

Argon (Ar): Total mass of argon.

Oxygen $\left(\mathrm{O}_{2}\right)$ : Total mass of oxygen.

Total: Total of the individual components listed above. This item is highlighted in yellow. 


\section{Selexol $\mathrm{CO}_{2}$ Capture Capital Cost Results}

This screen is only available for the IGCC plant type.

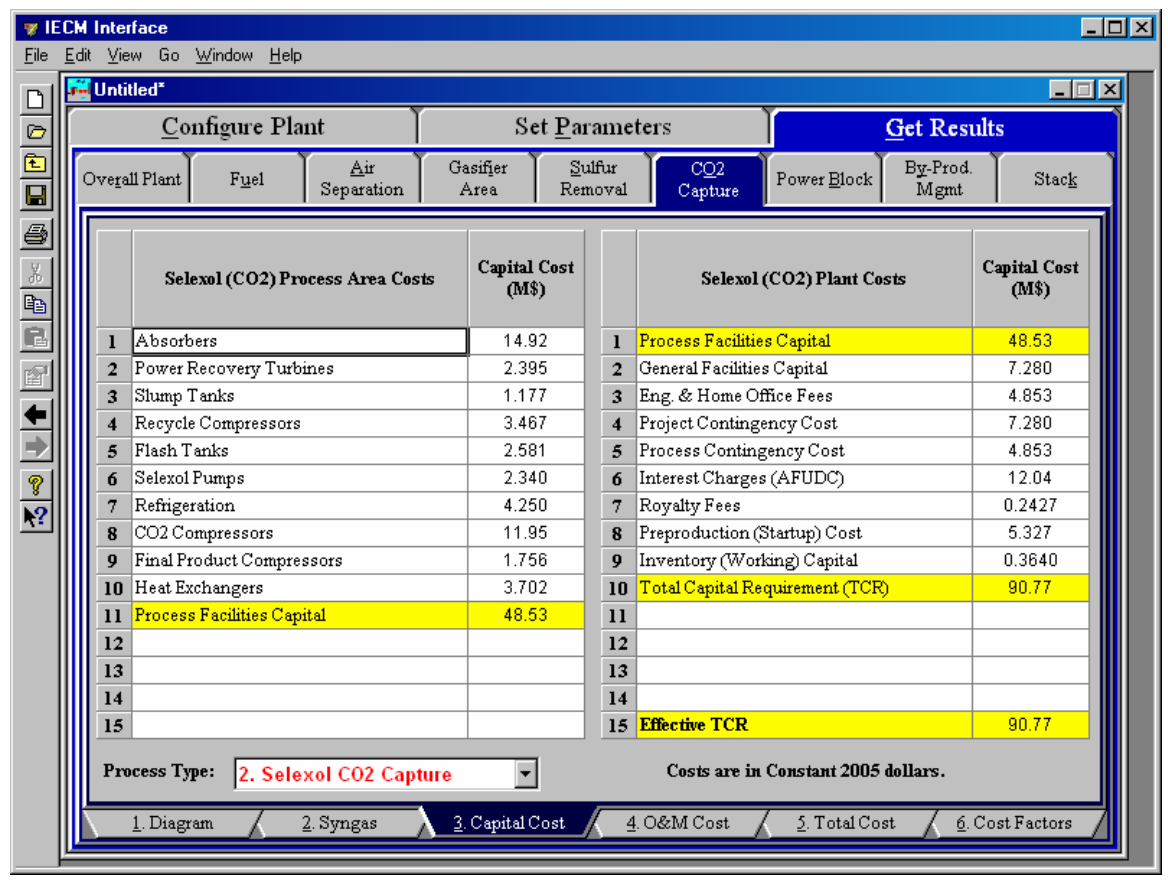

Selexol $\mathrm{CO}_{2}$ Capture Capital Cost results screen.

The Selexol $\mathbf{C O}_{2}$ Capture Capital Cost result screen displays tables for the capital costs. Capital costs are typically expressed in either constant or current dollars for a specified year, as shown on the bottom of the screen. Each result is described briefly below:

\section{Selexol $\left(\mathrm{CO}_{2}\right)$ Capture Process Area Costs}

Absorbers: This is the series of columns where the syngas is made to contact with the Selexol solvent. Some of the $\mathrm{CO}_{2}$ is absorbed by the $\mathrm{CO}_{2}$ lean solvent at high pressure in the counter flow absorber. This process area PFC is a function of the solvent flow rate, the capture $\mathrm{CO}_{2}$ flow rate, and the inlet temperature.

Power Recovery Turbines: The pressure energy in the $\mathrm{CO}_{2}$ rich solvent is recovered with one or two hydro turbines. This process area PFC is a function of the turbine horsepower and the turbine outlet pressure.

Slump Tanks: $\mathrm{H}_{2}$, $\mathrm{CO}$, and $\mathrm{CH}_{4}$ entrained or absorbed in the solvent is released in the slump tank and recycled back to the absorber. Because extra Selexol is used in the absorber, only a small amount of $\mathrm{CO}_{2}$ is released in the slump tank. This process area PFC is a function of the solvent flow rate.

Recycle Compressors: The lean solvent is compressed and cooled in preparation for recycling back into the absorbers. This process area PFC is a function of the compressor horse power.

Flash Tanks: Most of the $\mathrm{CO}_{2}$ absorbed by the solvent is recovered through flashing. The captured $\mathrm{CO}_{2}$ is then ready for transport and sequestration. To reduce the compression power, three flashing tanks with different pressures are used. There is no heat demand for solvent 
regeneration because solvent recovery is possible through flashing. This process area PFC is a function of the solvent flow rate.

Selexol Pumps: The lean solvent fed back into the absorber via pumps. This process area PFC is a function of the pump horse power.

Refrigeration: The solvent must be cooled down to the absorber operating temperature $\left(30^{\circ} \mathrm{F}\right)$ by refrigeration. This process PFC is a function of the solvent flow rate and the temperature difference.

$\mathrm{CO}_{2}$ Compressors: The $\mathrm{CO}_{2}$ from the flash tanks is compressed to high pressure (>1000psia) for storage using a multi-stage, inter-stage cooling compressor. This process area PFC is a function of the compressor horse power.

Final Product Compressors: Compressed $\mathrm{CO}_{2}$ from the $\mathrm{CO}_{2}$ compressors must be further compressed to the final product pressure. This process area PFC is a function of the compressor horse power.

Heat Exchangers: Gas-gas heat exchangers are used to extract heat from the syngas. This process PFC is a function of the heat load of the exchangers and the temperature difference across them.

Process Facilities Capital: The process facilities capital is the total constructed cost of all on-site processing and generating units listed above, including all direct and indirect construction costs. All sales taxes and freight costs are included where applicable implicitly. This result is highlighted in yellow.

\section{Selexol $\left(\mathrm{CO}_{2}\right)$ Capture Plant Costs}

Process Facilities Capital: (see definition above)

General Facilities Capital: The general facilities include construction costs of roads, office buildings, shops, laboratories, etc. Sales taxes and freight costs are included implicitly.

Eng. \& Home Office Fees: The engineering \& home office fees are a percent of total direct capital cost. This is an overhead fee paid to the architect/engineering company.

Project Contingency Cost: Capital cost contingency factor covering the cost of additional equipment or other costs that would result from a more detailed design of a definitive project at the actual site.

Process Contingency Cost: Capital cost contingency factor applied to a new technology in an effort to quantify the uncertainty in the technical performance and cost of the commercial-scale equipment.

Interest Charges (AFUDC): Allowance for funds used during construction, also referred to as interest during construction, is the time value of the money used during construction and is based on an interest rate equal to the before-tax weighted cost of capital. This interest is compounded on an annual basis (end of year) during the construction period for all funds spent during the year or previous years.

Royalty Fees: Royalty charges may apply to some portions of generating units incorporating new proprietary technologies.

Preproduction (Startup) Cost: These costs consider the operator training, equipment checkout, major changes in unit equipment, extra maintenance, and inefficient use of fuel or other materials during startup. 
Inventory (Working) Capital: The raw material supply based on $100 \%$ capacity during a 60 day period. These materials are considered storage. The inventory capital includes fuels, consumables, byproducts, and spare parts.

Total Capital Requirement (TCR): Money that is placed (capitalized) on the books of the utility on the service date. TCR includes all the items above. This result is highlighted in yellow.

Effective TCR: The TCR of the spray dryer that is used in determining the total power plant cost. The effective TCR is determined by the "TCR Recovery Factor”.

\section{Selexol $\mathrm{CO}_{2}$ Capture O\&M Cost Results}

This screen is only available for the IGCC plant type.

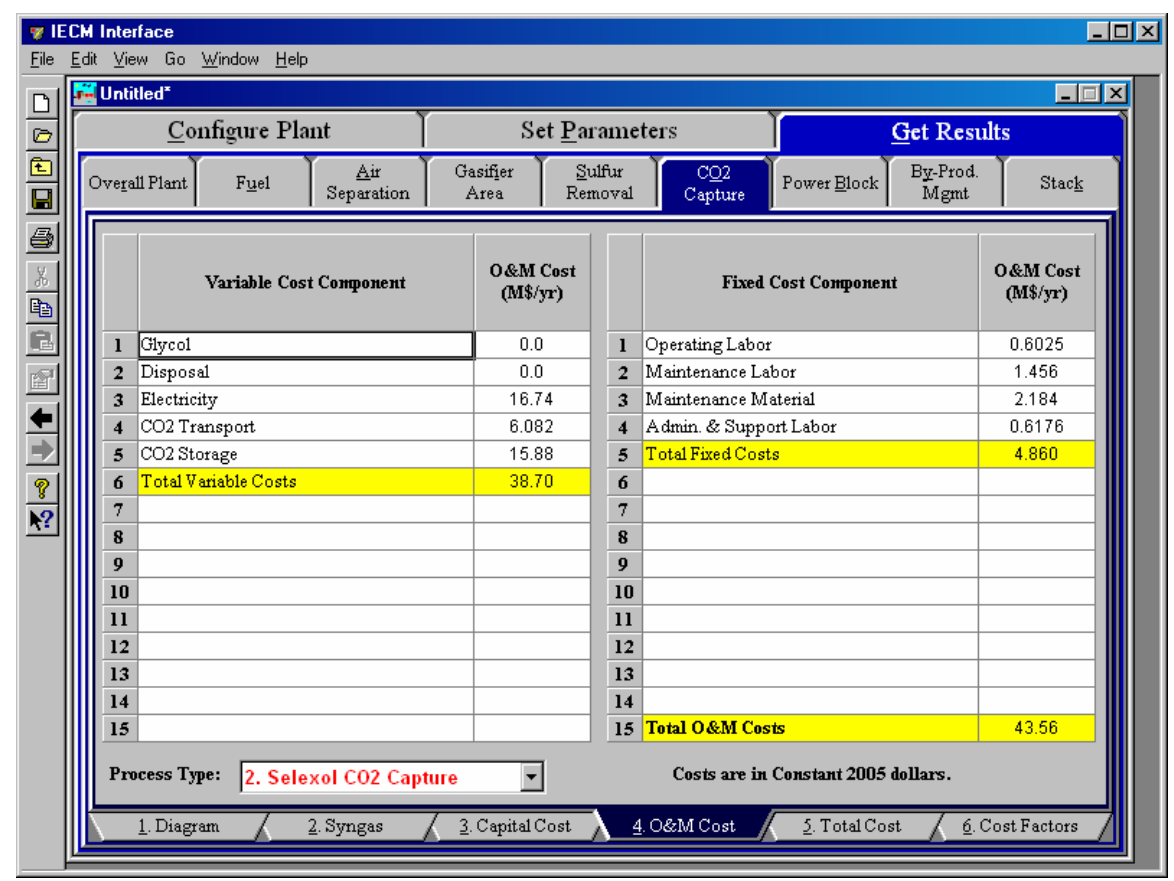

Selexol $\mathrm{CO}_{2}$ Capture - O\&M Cost results screen.

O\&M costs are typically expressed on an average annual basis and are provided in either constant or current dollars for a specified year, as shown on the bottom of the screen.

\section{Variable Cost Component}

Glycol: Selexol is a commercially available physical solvent that is a mixture of dimethyl ether and polyethylene glycol. This is the annual cost of the makeup solvent.

Disposal: This is the annual cost of waste disposal for this process. It does not include the $\mathrm{CO}_{2}$ product stream disposal cost.

Electricity: The cost of electricity consumed by the $\mathrm{CO}_{2}$ Selexol system.

$\mathbf{C O}_{2}$ Transport: The $\mathrm{CO}_{2}$ captured at the power plant site has to be carried to the appropriate storage/disposal site. Transport of $\mathrm{CO}_{2}$ to a storage 
site is assumed to be via pipeline. This is the annual cost of maintaining those pipelines.

$\mathrm{CO}_{2}$ Storage/Disposal: Once the $\mathrm{CO}_{2}$ is captured, it needs to be securely stored (sequestered). This annual cost is based upon the storage option chosen.

Total Variable Costs: This is the sum of the variable O\&M costs listed above. This result is highlighted in yellow.

\section{Fixed Cost Components}

Fixed operating costs are essentially independent of actual capacity factor, number of hours of operation, or amount of kilowatts produced. All the costs are subject to inflation.

Operating Labor: Operating labor cost is based on the operating labor rate, the number of personnel required to operate the plant per eighthour shift, and the average number of shifts per day over 40 hours per week and 52 weeks.

Maintenance Labor: The maintenance labor is determined as a fraction of the total maintenance cost.

Maintenance Material: The cost of maintenance material is the remainder of the total maintenance cost, considering the fraction associated with maintenance labor.

Admin. \& Support Labor: The administrative and support labor is the only overhead charge. It is taken as a fraction of the total operating and maintenance labor costs.

Total Fixed Costs: This is the sum of all the fixed O\&M costs listed above. This result is highlighted in yellow.

Total O\&M Costs: This is the sum of the total variable and total fixed O\&M costs. It is used to determine the base plant total revenue requirement. This result is highlighted in yellow.

\section{Selexol $\mathrm{CO}_{2}$ Capture Total Cost Results}

This screen is only available for the IGCC plant type. 


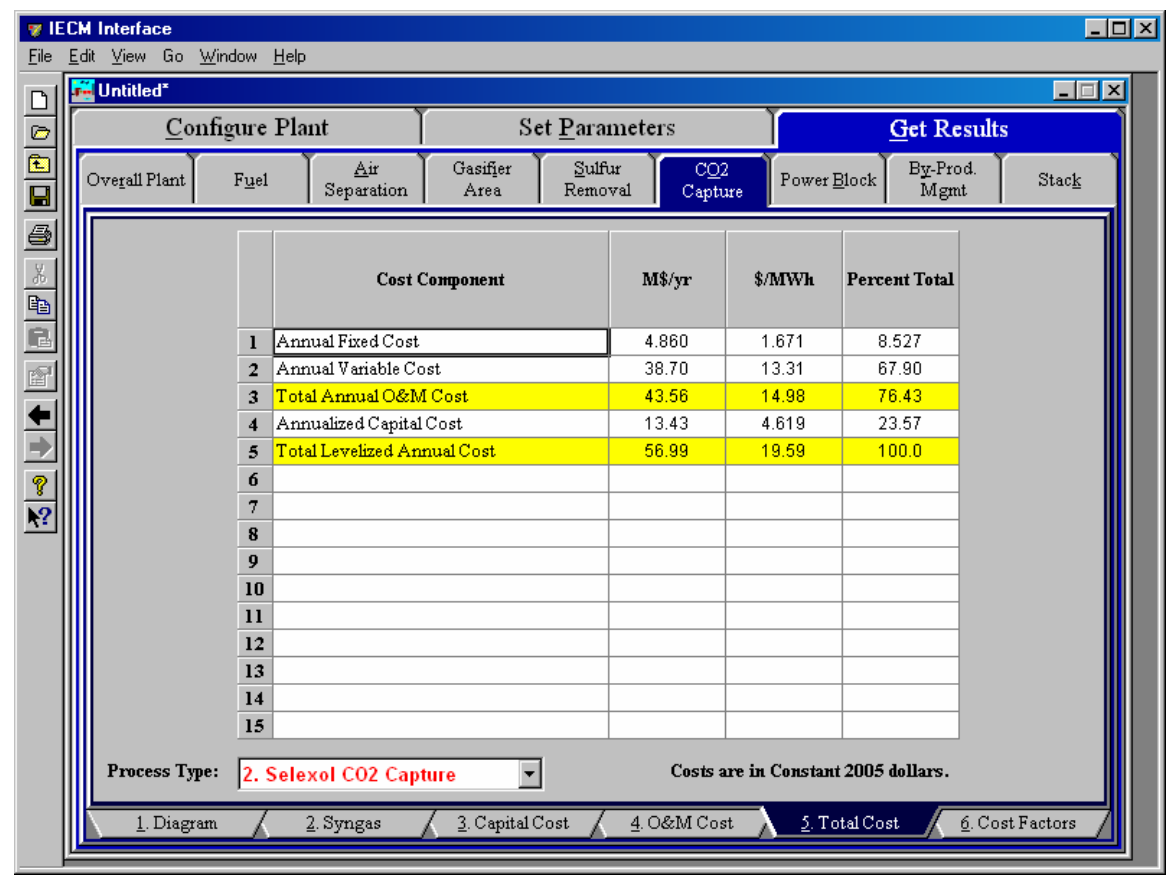

Selexol $\mathrm{CO}_{2}$ Capture - Total Cost results screen.

The Total Cost result screen displays a table which totals the annual fixed, variable, operations and maintenance, and capital costs associated with the Selexol $\mathbf{C O}_{2}$ Capture Unit. Total costs are typically expressed in either constant or current dollars for a specified year, as shown on the bottom of the screen. Each result is described briefly below.

\section{Cost Component}

Annual Fixed Cost: The operating and maintenance fixed costs are given as an annual total. This number includes all maintenance materials and all labor costs.

Annual Variable Cost: The operating and maintenance variables costs are given as an annual total. This includes all reagent, chemical, steam, and power costs.

Total Annual O\&M Cost: This is the sum of the annual fixed and variable operating and maintenance costs above. This result is highlighted in yellow.

Annualized Capital Cost: This is the total capital cost expressed on an annualized basis, taking into consideration the levelized carrying charge factor, or fixed charge factor, over the entire book life.

Total Levelized Annual Cost: The total annual cost is the sum of the total annual O\&M cost and annualized capital cost items above. This result is highlighted in yellow.

\section{Selexol $\mathrm{CO}_{2}$ Capture Cost Factors Results}

This screen is only available for the IGCC plant type. 


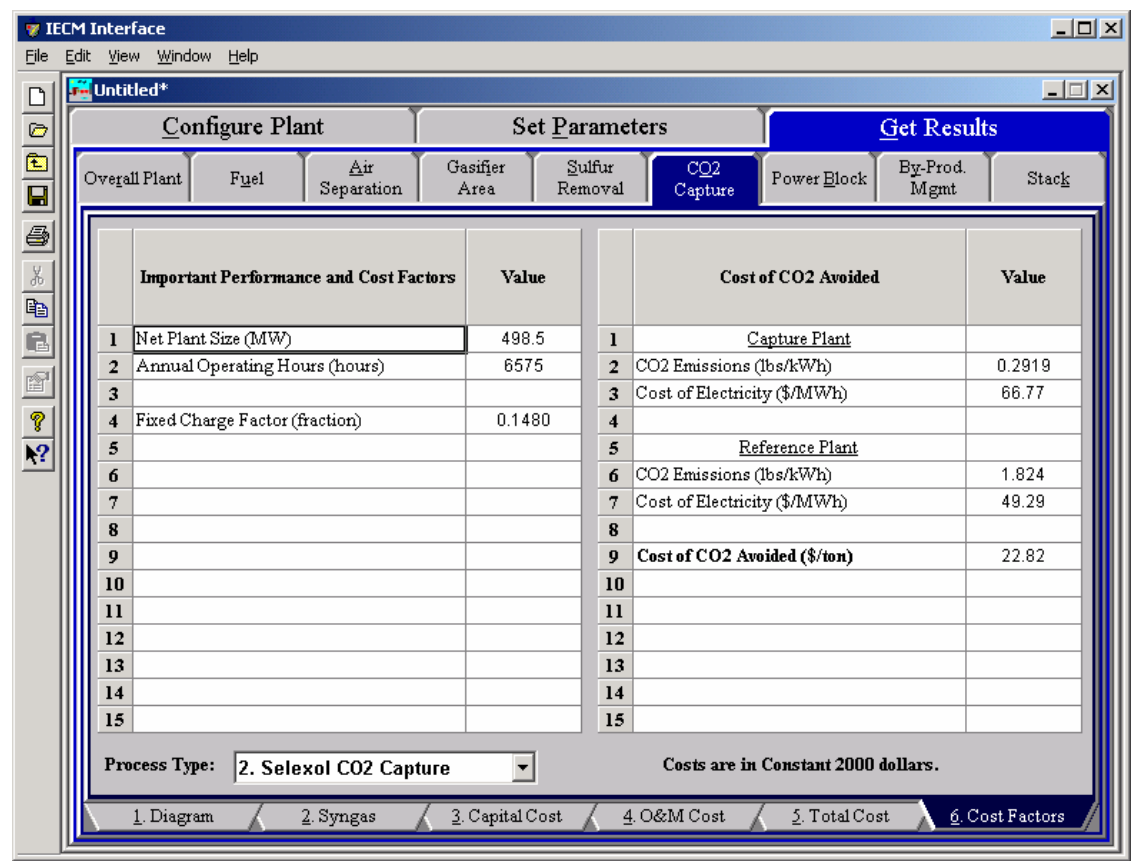

Selexol $\mathrm{CO}_{2}$ Capture - Cost Factors results screen.

\section{Important Performance and Cost Factors}

This screen displays information that is a key to the model calculations. The data is available else where in the model.

Net Plant Size (MW): This is the net plant capacity, which is the gross plant capacity minus the losses due to plant equipment and pollution equipment (energy penalties).

Annual Operating Hours (hours): This is the number of hours per year that the plant is in operation. If a plant runs 24 hours per day, seven days per week, with no outages, the calculation is 24 hours * 365 days or 8,760 hours/year.

Fixed Charge Factor (fraction): The fixed charge factor is one of the most important parameters in the IECM. It determines the revenue required to finance the power plant based on the capital expenditures. Put another way, it is a levelized factor which accounts for the revenue per dollar of total plant cost that must be collected from customers in order to pay the carrying charges on that capital investment.

\section{Cost of $\mathrm{CO}_{2}$ Avoided}

\section{Capture Plant}

- $\quad \mathbf{C O}_{2}$ Emissions (Ibs/kWh): This is the amount of $\mathrm{CO}_{2}$ vented to the air for every kilowatt hour of electricity produced in the power plant that is using a $\mathrm{CO}_{2}$ Capture technology.

- Cost of Electricity (\$/MWh): The IECM framework calculates the cost of electricity (COE) for the overall capture plant by dividing the total annualized plant cost $(\$ / y r)$ by the net electricity generated (kWh/hr).

\section{Reference Plant}


- CO2 Emissions (lbs/kWh): This is the amount of $\mathrm{CO}_{2}$ vented to the air for every kilowatt hour of electricity produced in the power plant with no $\mathrm{CO}_{2}$ capture.

- Cost of Electricity (\$/MWh): The IECM framework calculates the cost of electricity (COE) for the overall reference plant by dividing the total annualized plant cost ( $\$ / \mathrm{yr})$ by the net electricity generated $(\mathrm{kWh} / \mathrm{hr})$.

Cost of $\mathrm{CO}_{2}$ Avoided (\$/ton): This is the economic indicator widely used in the field, calculated as the difference between the cost of electricity in the capture plant and the reference plant divided by the difference between the $\mathrm{CO}_{2}$ emissions in the reference plant and the capture plant.

Cost of CO2 Avoided $=($ Cost of Electricity cap - Cost of Electricity ref) / (CO2 emissions ref-CO2 emissions cap) 


\section{Water Gas Shift Reactor}

\section{Water Gas Shift Reactor Performance Inputs}

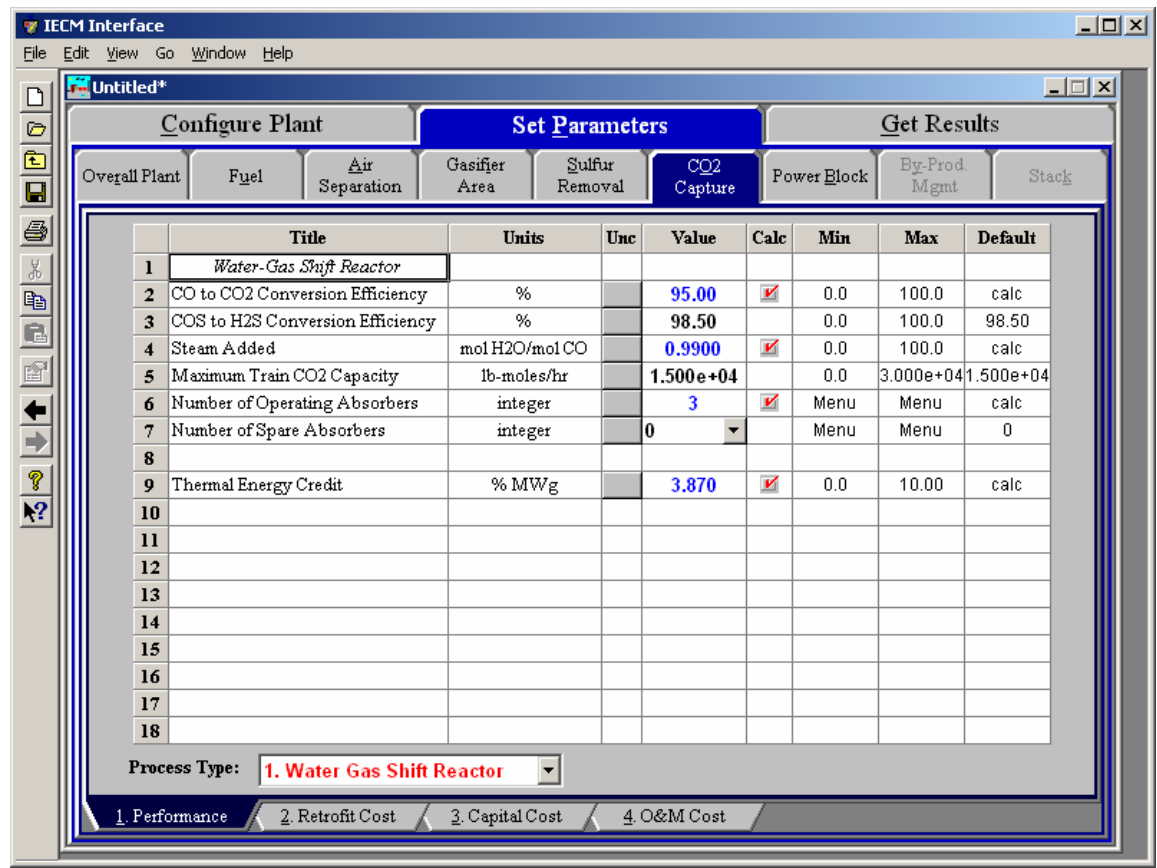

Water Gas Shift Reactor - Performance input screen.

\section{Water Gas Shift Reactor Unit}

CO to $\mathbf{C O}_{2}$ Conversion Efficiency: Most of the $\mathrm{CO}$ in the raw syngas is converted into $\mathrm{CO}_{2}$ through the Water Gas Shift reaction. $\mathrm{CO}_{2}$ is removed from the shifted syngas through a physical absorption unit. This variable is the percentage of $\mathrm{CO}$ that is converted to $\mathrm{CO}_{2}$ in the reaction.

COS to $\mathrm{H}_{2}$ S Conversion Efficiency: COS is difficult to remove in the Selexol unit, so a polishing unit is added to convert COS to $\mathrm{H}_{2} \mathrm{~S}$. This is the conversion efficiency of the polishing unit. 
Steam Added: This parameter determines the amount of water added to the shift reactor in converting $\mathrm{CO}$ to $\mathrm{CO}_{2}$. The moles of steam added is proportional to the moles of $\mathrm{CO}$ converted.

Maximum Train $\mathrm{CO}_{2}$ Capacity: The maximum production rate of $\mathrm{CO}_{2}$ is specified here. It is used to determine the number of operating trains required.

Number of Operating Trains: This is the total number of operating trains. It is used primarily to calculate capital costs. The value must be an integer

Number of Spare Trains: This is the total number of spare trains. It is used primarily to calculate capital costs. The value must be an integer.

Thermal Energy Credit: The Water Gas Shift reaction is an exothermic process, producing heat that can be extracted and converted to steam for use in generating electricity. This is the thermal energy credit for steam produced and used in the steam cycle.

\section{Water Gas Shift Reactor Retrofit Cost Inputs}

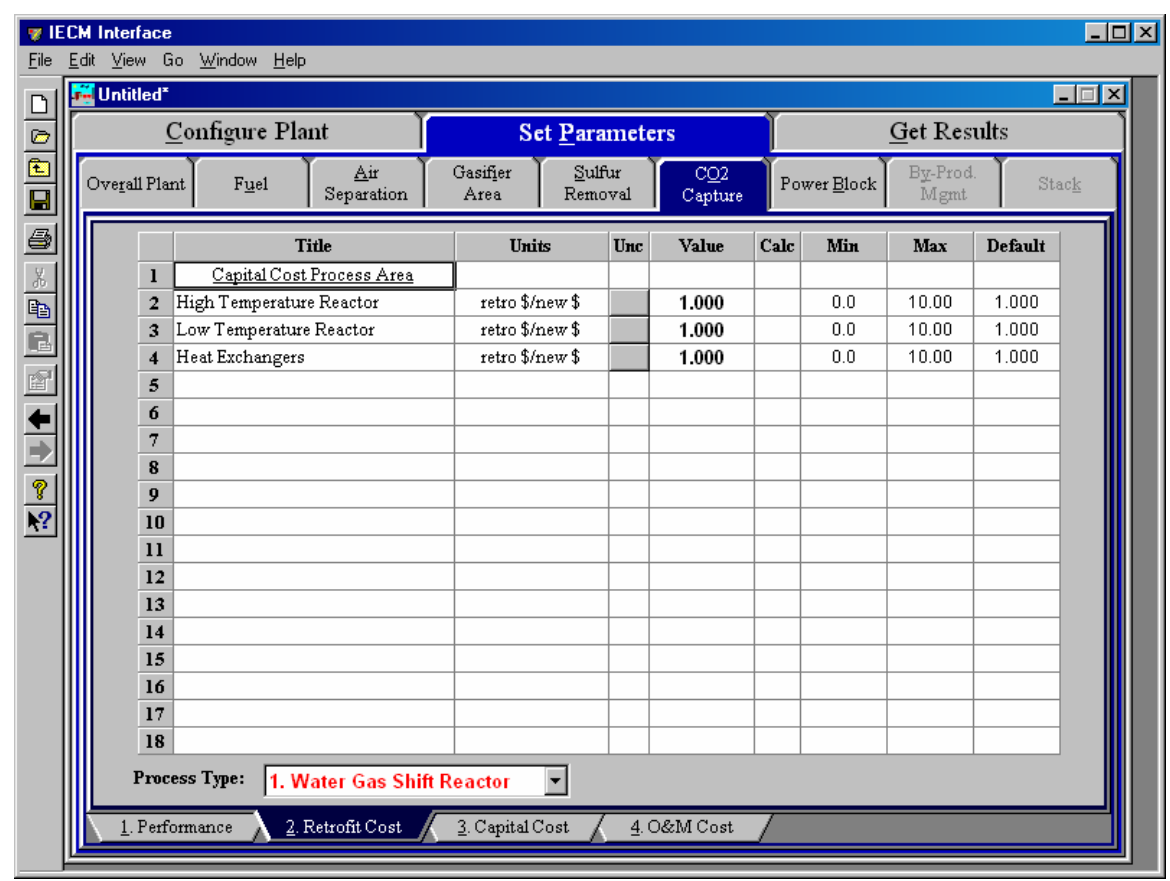

Water Gas Shift Reactor - Retrofit Cost input screen.

The retrofit cost factor of each process is is a multiplicative cost adjustment, which considers the cost of retrofitted capital equipment relative to similar equipment installed in a new plant. These factors affect the capital cost directly and the operating and maintenance costs indirectly.

Direct capital costs for each process area are calculated in the IECM. These calculations are reduced form equations derived from more sophisticated models and reports. The sum of the direct capital costs associated with each process area is defined as the process facilities capital (PFC). The retrofit cost factor provided for each of the process areas can be used as a tool for adjusting the anticipated costs and uncertainties across the process area separate from the other areas. 
Each Capital Cost Process Area is described briefly below.

\section{Capital Cost Process Area}

High Temperature Reactor: This area accounts for the high temperature reactor vessel used for water gas shift. The iron-based catalyst is designed to be effective at high temperatures $\left(650-1100^{\circ} \mathrm{F}\right)$. The high temperature reactor has a high reaction rate and converts a large amount of $\mathrm{CO}$ into $\mathrm{CO}_{2}$.

Low Temperature Reactor: This area accounts for the low temperature reactor vessel used for water gas shift. The copper-based catalyst is designed to be effective at lower temperatures $\left(450-650^{\circ} \mathrm{F}\right)$. The low temperature reactor has a lower reaction rate, but converts a very high percentage of the remaining $\mathrm{CO}$ into $\mathrm{CO}_{2}$.

Heat Exchangers: The water gas shift process involves substantial cooling because of the exothermic reaction. Heat is recovered and temperature control is maintained through heat exchangers added after each reactor. This process area accounts for the heat exchangers used. Steam generated in the heat exchangers is sent to the steam cycle.

\section{Water Gas Shift Reactor Capital Cost Inputs}

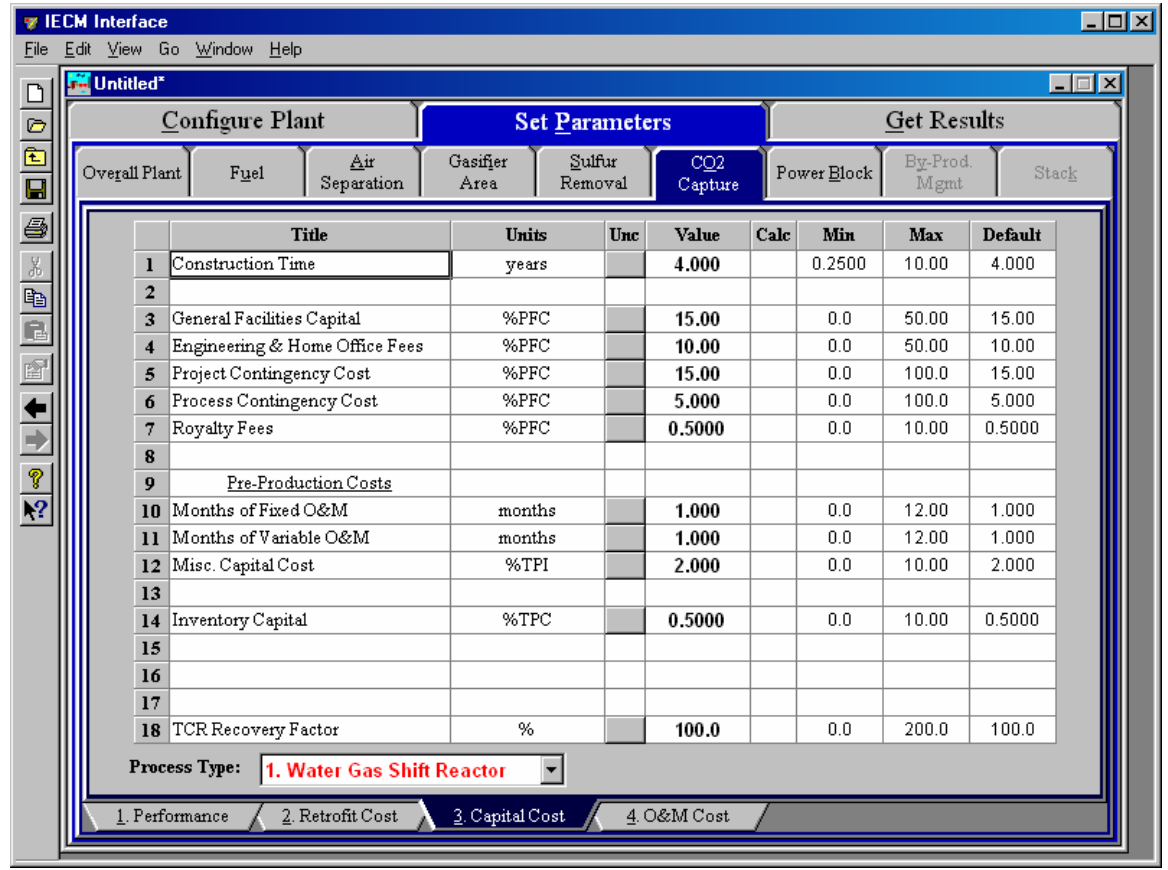

Water Gas Shift Reactor - Capital Cost input screen.

Inputs for capital costs are entered on the Capital Cost input screen.

Construction Time: This is the idealized construction period in years. It is used to determine the allowance for funds used during construction (AFUDC).

General Facilities Capital (GFC): The general facilities include construction costs of roads, office buildings, shops, laboratories, etc. 
Sales taxes and freight costs are included implicitly. The cost typically ranges from $5-20 \%$.

Engineering \& Home Office Fees: The engineering \& home office fees are a percent of total direct capital cost. This is an overhead fee paid to the architect/engineering company. These fees typically range from 7$15 \%$.

Project Contingency Cost: This is factor covering the cost of additional equipment or other costs resulting from a more detailed design. Higher contingency factors will be applied to simplified or preliminary designs and lower factors to detailed or finalized designs.

Process Contingency Cost: This quantifies the design uncertainty and cost of a commercial-scale system. This is generally applied on an areaby-area basis. Higher contingency factors are applied to new regeneration systems tested at a pilot plant and lower factors to full-size or commercial systems.

Royalty Fees: Royalty charges may apply to some portions of generating units incorporating new proprietary technologies.

Pre-Production Costs: These costs consider the operator training, equipment checkout, major changes in unit equipment, extra maintenance, and inefficient use of fuel or other materials during startup. These are typically applied to the O\&M costs over a specified period of time (months). The two time periods for fixed and variable O\&M costs are described below with the addition of a miscellaneous capital cost factor.

- Months of Fixed O\&M: Time period of fixed operating costs used for preproduction to cover training, testing, major changes in equipment, and inefficiencies in start-up. This includes operating, maintenance, administrative and support labor. It also considers maintenance materials.

- Months of Variable O\&M: Time period of variable operating costs used for preproduction to cover chemicals, water, consumables, and solid disposal charges in start-up, assuming $100 \%$ load. This excludes any fuels.

- Misc. Capital Cost: This is a percent of total plant investment (sum of TPC and AFUDC) to cover expected changes to equipment to bring the system up to full capacity.

Inventory Capital: Percent of the total direct capital for raw material supply based on $100 \%$ capacity during a 60 day period. These materials are considered storage. The inventory capital includes fuels, consumables, by-products, and spare parts. This is typically $0.5 \%$.

TCR Recovery Factor: The actual total capital required (TCR) as a percent of the TCR in a new power plant. This value is $100 \%$ for a new installation and may be set as low as $0 \%$ for a fabric filter that has been paid off. 


\section{Water Gas Shift Reactor O\&M Cost Inputs}

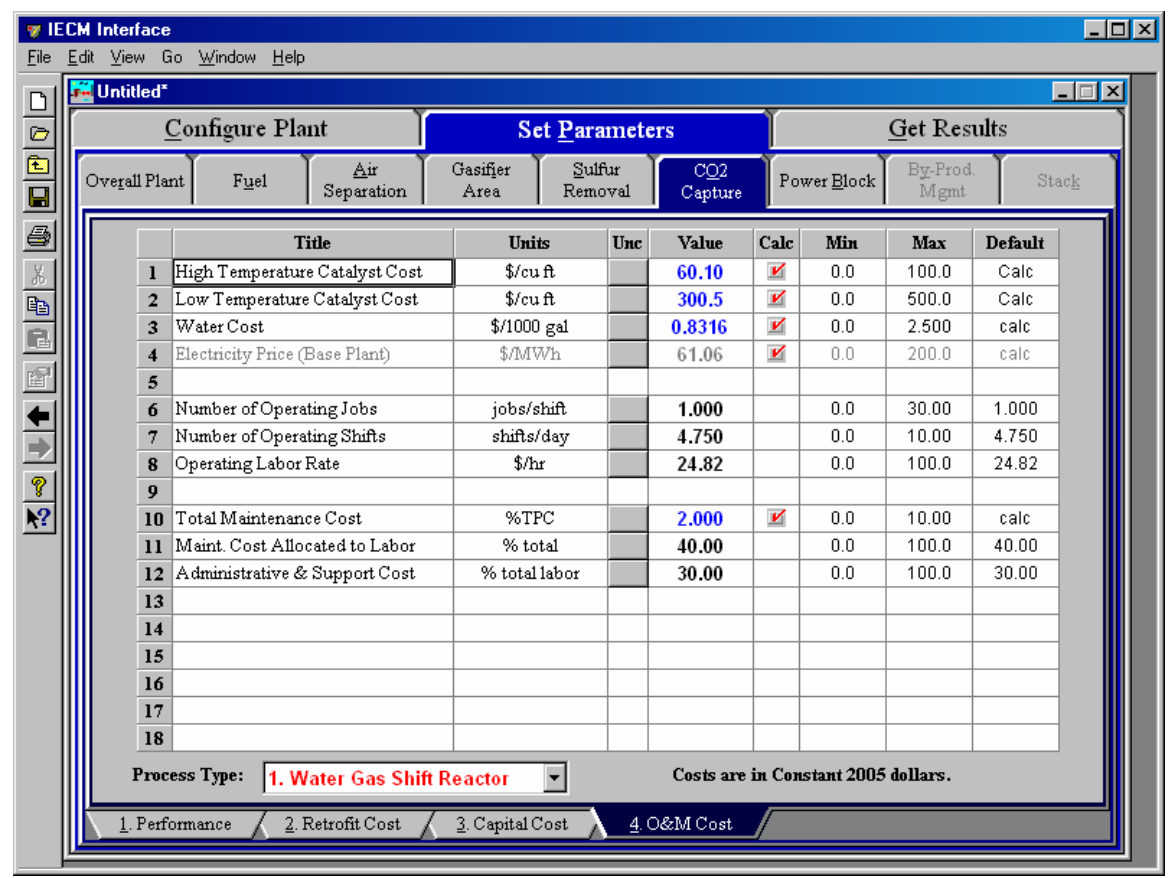

Water Gas Shift Reactor - O \& M Cost input screen.

Inputs for O\&M costs are entered on the Water Gas Shift Reactor O\&M Cost input screen. O\&M costs are typically expressed on an average annual basis and are provided in either constant or current dollars for a specified year, as shown on the bottom of the screen.

High Temperature Catalyst Cost: This is the unit cost of the ironbased high temperature catalyst.

Low Temperature Catalyst Cost: This is the unit cost of the copperbased low temperature catalyst.

Water Cost: This is unit cost of water used to drive the water gas shift reaction.

Electricity Price (Base Plant): This is the price of electricity and is calculated as a function of the utility cost of the base plant, where the base plant is defined as the air separation unit, gasifier, and the power block.

Number of Operating Jobs: This is the total number of operating jobs that are required to operate the plant per eight-hour shift.

Number of Operating Shifts: This is the total number of equivalent operating shifts in the plant per day. The number takes into consideration paid time off and weekend work ( 3 shifts/day * 7 days/5 day week * 52 weeks $/(52$ weeks -6 weeks PTO $)=4.75$ equiv. Shifts/day)

Operating Labor Rate: This is the hourly cost of labor for maintenance, administrative, and support personnel. The same rate is applied to all jobs across all technologies in the power plant. 
Total Maintenance Cost: This is the annual maintenance cost as a percentage of the total plant cost. Maintenance cost estimates can be developed separately for each process area.

Maint. Cost Allocated to Labor: Maintenance cost allocated to labor as a percentage of the total maintenance cost.

Administrative \& Support Cost: This is the percent of the total operating and maintenance labor associated with administrative and support labor.

\section{Water Gas Shift Reactor Diagram}

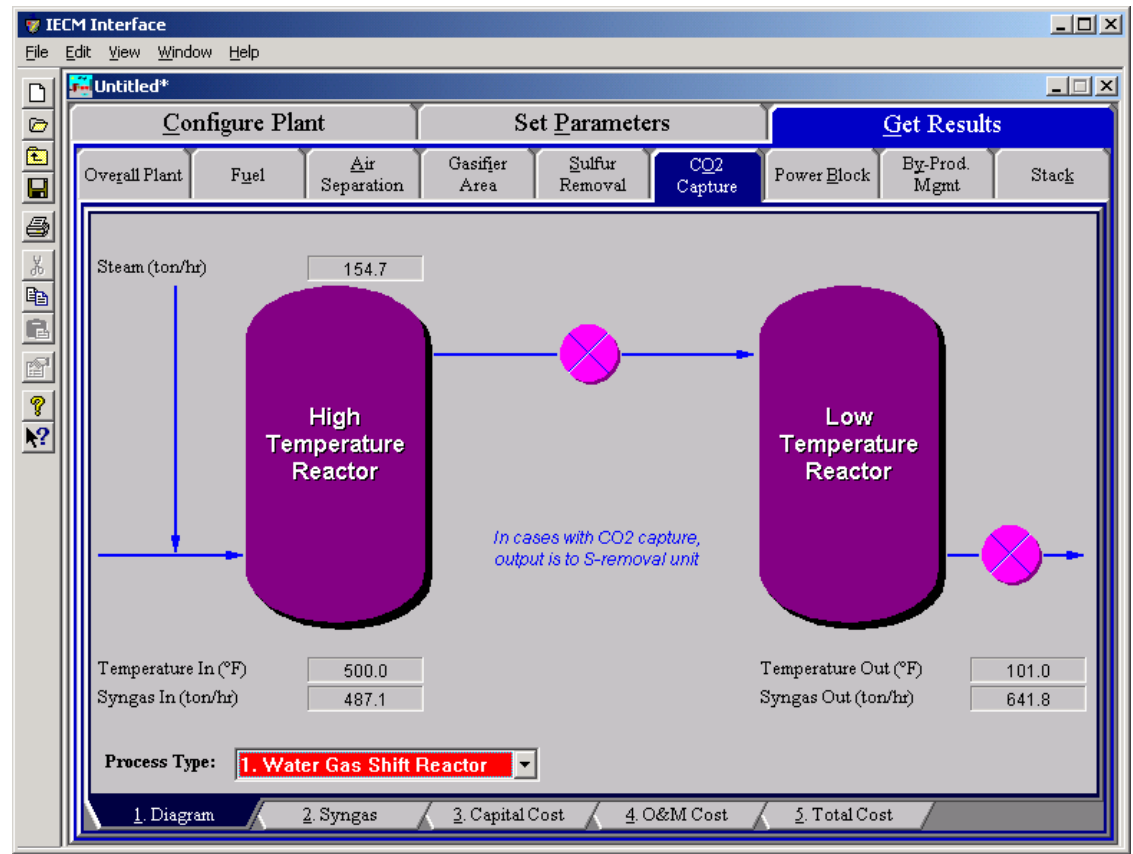

Water Gas Shift Reactor - Diagram result screen.

The Water Gas Shift Reactor Diagram result screen displays an icon for the Water Gas Shift Reactor Unit and values for major flows in and out of it. Each result is described briefly below in flow:

Steam In: This is the flow rate of steam added. The steam reacts with CO to produce $\mathrm{H}_{2}$ and $\mathrm{CO}_{2}$ in the presence of the catalyst in the two reactors.

Temperature In: Temperature of the syngas entering the high temperature reactor.

Syngas In: Flow rate of the syngas entering the high temperature reactor.

Temperature Out: Temperature of the syngas exiting the final heat exhanger.

Syngas Out: Flow rate of the syngas exiting the final heat exchanger. 


\section{Water Gas Shift Reactor Syngas Results}

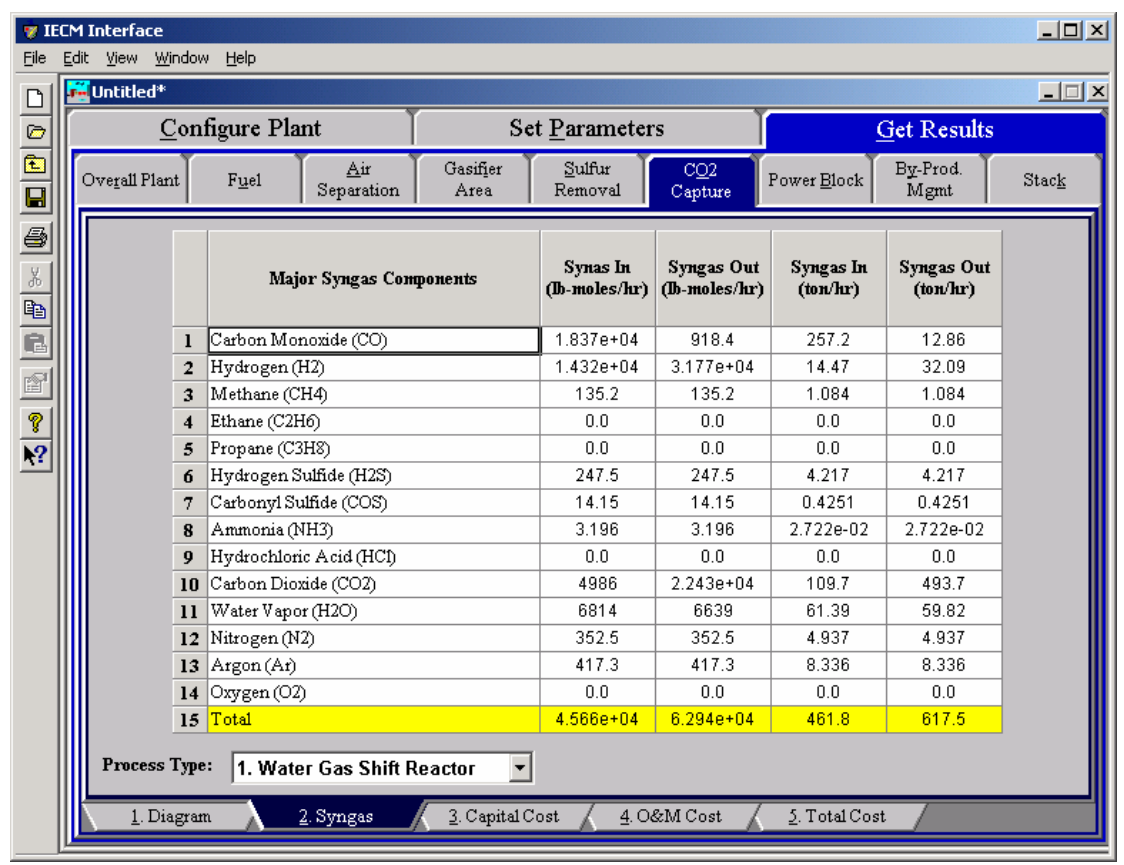

Water Gas Shift Reactor - Syngas result screen.

\section{Major Syngas Components}

Carbon Monoxide (CO): Total mass of carbon monoxide.

Hydrogen $\left(\mathbf{H}_{2}\right)$ :Total mass of hydrogen.

Methane $\left(\mathrm{CH}_{4}\right)$ :Total mass of methane.

Ethane $\left(\mathrm{C}_{2} \mathrm{H}_{6}\right)$ :Total mass of ethane.

Propane $\left(\mathrm{C}_{3} \mathrm{H}_{8}\right)$ :Total mass of propane.

Hydrogen Sulfide $\left(\mathrm{H}_{2} \mathrm{~S}\right)$ :Total mass of hydrogen sulfide.

Carbonyl Sulfide (COS):Total mass of carbonyl sulfide.

Ammonia $\left(\mathrm{NH}_{3}\right)$ : Total mass of ammonia.

Hydrochloric Acid $(\mathrm{HCl})$ : Total mass of hydrochloric acid.

Carbon Dioxide $\left(\mathrm{CO}_{2}\right)$ : Total mass of carbon dioxide.

Water Vapor $\left(\mathrm{H}_{2} \mathrm{O}\right)$ : Total mass of water vapor.

Nitrogen $\left(\mathbf{N}_{2}\right)$ : Total mass of nitrogen.

Argon (Ar): Total mass of argon.

Oxygen $\left(\mathrm{O}_{2}\right)$ : Total mass of oxygen.

Total: Total of the individual components listed above. This item is highlighted in yellow. 


\section{Water Gas Shift Reactor Capital Cost Results}

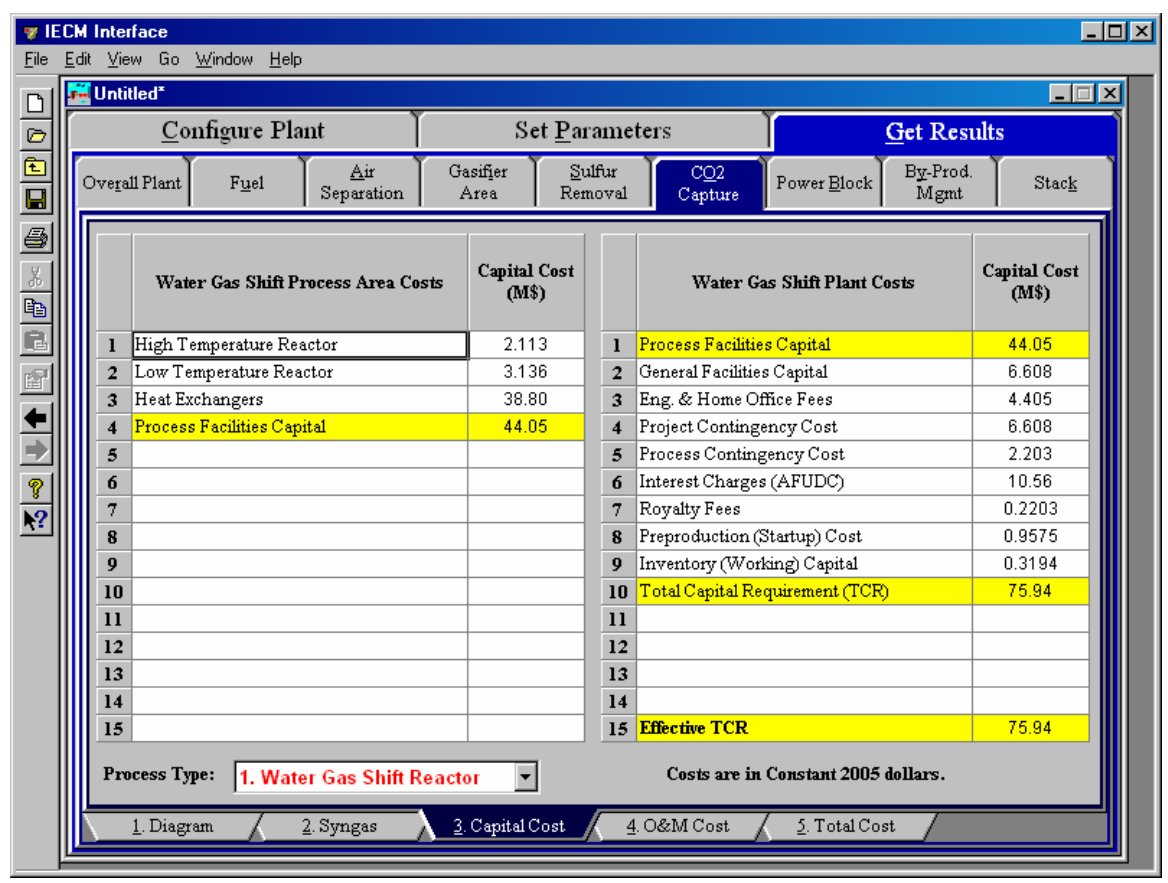

Water Gas Shift Reactor - Capital Cost result screen.

The Water Gas Shift Reactor Capital Cost result screen displays tables for the capital costs. Capital costs are typically expressed in either constant or current dollars for a specified year, as shown on the bottom of the screen. Each result is described briefly below:

\section{Water Gas Shift Reactor Process Area Costs}

High Temperature Reactor: This area accounts for the high temperature reactor vessel used for water gas shift. The iron-based catalyst is designed to be effective at high temperatures $\left(650-1100^{\circ} \mathrm{F}\right)$. The high temperature reactor has a high reaction rate and converts a large amount of $\mathrm{CO}$ into $\mathrm{CO}_{2}$.

Low Temperature Reactor: This area accounts for the low temperature reactor vessel used for water gas shift. The copper-based catalyst is designed to be effective at lower temperatures $\left(450-650^{\circ} \mathrm{F}\right)$. The low temperature reactor has a lower reaction rate, but converts a very high percentage of the remaining $\mathrm{CO}$ into $\mathrm{CO}_{2}$.

Heat Exchangers: The water gas shift process involves substantial cooling because of the exothermic reaction. Heat is recovered and temperature control is maintained through heat exchangers added after each reactor. This process area accounts for the heat exchangers used. Steam generated in the heat exchangers is sent to the steam cycle.

Process Facilities Capital: The process facilities capital is the total constructed cost of all on-site processing and generating units listed above, including all direct and indirect construction costs. All sales taxes and freight costs are included where applicable implicitly. This result is highlighted in yellow. 


\section{Water Gas Shift Reactor Plant Costs}

Process Facilities Capital: (see definition above)

General Facilities Capital: The general facilities include construction costs of roads, office buildings, shops, laboratories, etc. Sales taxes and freight costs are included implicitly.

Eng. \& Home Office Fees: The engineering \& home office fees are a percent of total direct capital cost. This is an overhead fee paid to the architect/engineering company.

Project Contingency Cost: Capital cost contingency factor covering the cost of additional equipment or other costs that would result from a more detailed design of a definitive project at the actual site.

Process Contingency Cost: Capital cost contingency factor applied to a new technology in an effort to quantify the uncertainty in the technical performance and cost of the commercial-scale equipment.

Interest Charges (AFUDC): Allowance for funds used during construction, also referred to as interest during construction, is the time value of the money used during construction and is based on an interest rate equal to the before-tax weighted cost of capital. This interest is compounded on an annual basis (end of year) during the construction period for all funds spent during the year or previous years.

Royalty Fees: Royalty charges may apply to some portions of generating units incorporating new proprietary technologies.

Preproduction (Startup) Cost: These costs consider the operator training, equipment checkout, major changes in unit equipment, extra maintenance, and inefficient use of fuel or other materials during startup.

Inventory (Working) Capital: The raw material supply based on $100 \%$ capacity during a 60 day period. These materials are considered storage. The inventory capital includes fuels, consumables, byproducts, and spare parts.

Total Capital Requirement (TCR): Money that is placed (capitalized) on the books of the utility on the service date. TCR includes all the items above. This result is highlighted in yellow.

Effective TCR: The percent of the water gas shift reactor TCR that is used in determining the total power plant cost. The effective TCR is determined by the "TCR Recovery Factor". 


\section{Water Gas Shift Reactor O\&M Cost Results}

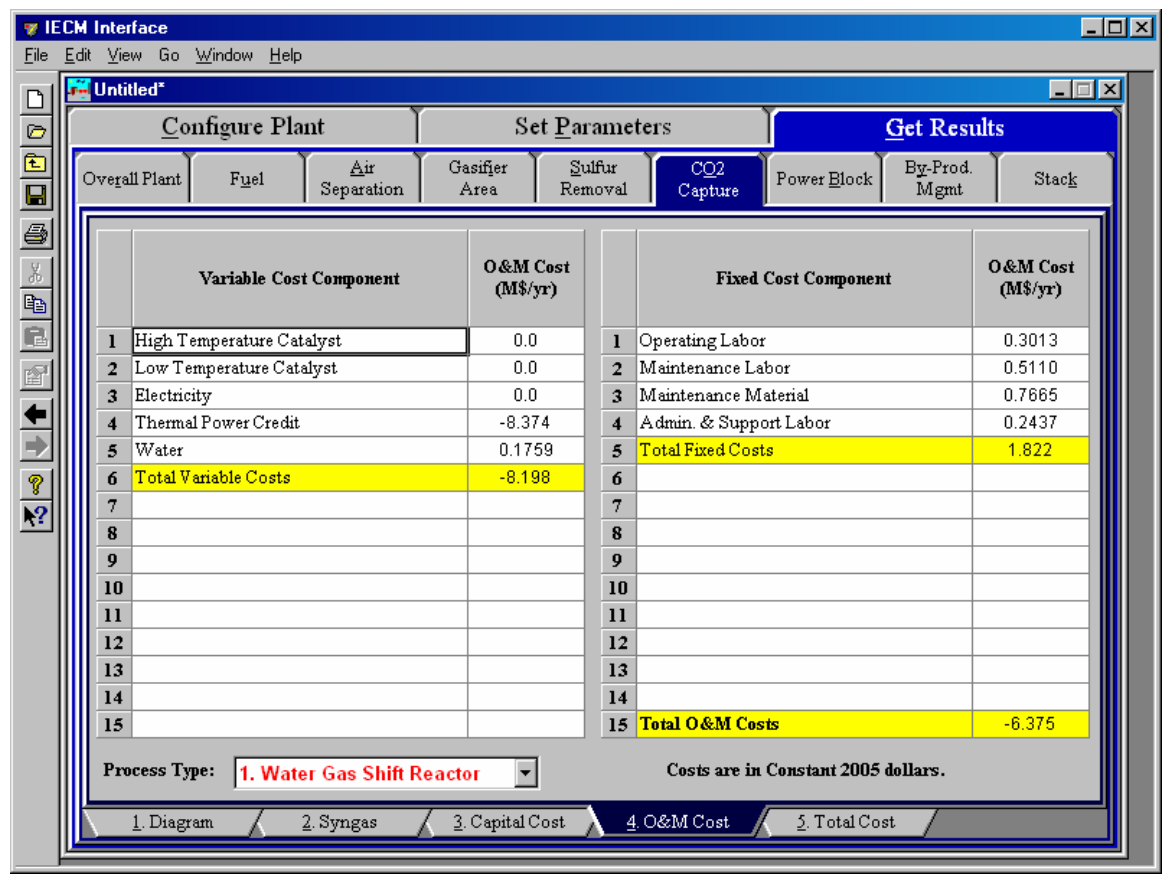

Water Gas Shift Reactor - O \& M Cost result screen.

O\&M costs are typically expressed on an average annual basis and are provided in either constant or current dollars for a specified year, as shown on the bottom of the screen.

\section{Variable Cost Component}

High Temperature Catalyst Cost: This is the replacement cost of the iron-based high temperature catalyst. The initial cost is not included in this parameter.

Low Temperature Catalyst Cost: This is the replacement cost of the copper-based low temperature catalyst.The initial cost is not included in this parameter.

Electricity: The cost of electricity consumed by the water gas shift process areas.

Thermal Power Credit: The credit for thermal power generated from steam provided by the heat exchangers in the water shift reactor vessels.

Water Cost: This is total cost of water used to drive the water gas shift reaction.

Total Variable Costs: This is the sum of all of the variable O\&M costs listed above. This result is highlighted in yellow. 


\section{Fixed Cost Components}

Fixed operating costs are essentially independent of actual capacity factor, number of hours of operation, or amount of kilowatts produced. All the costs are subject to inflation.

Operating Labor: Operating labor cost is based on the operating labor rate, the number of personnel required to operate the plant per eighthour shift, and the average number of shifts per day over 40 hours per week and 52 weeks.

Maintenance Labor: The maintenance labor is determined as a fraction of the total maintenance cost.

Maintenance Material: The cost of maintenance material is the remainder of the total maintenance cost, considering the fraction associated with maintenance labor.

Admin. \& Support Labor: The administrative and support labor is the only overhead charge. It is taken as a fraction of the total operating and maintenance labor costs.

Total Fixed Costs: This is the sum of all the fixed O\&M costs listed above. This result is highlighted in yellow.

Total O\&M Costs: This is the sum of the total variable and total fixed $\mathrm{O} \& \mathrm{M}$ costs. It is used to determine the base plant total revenue requirement. This result is highlighted in yellow.

\section{Water Gas Shift Reactor Total Cost Results}

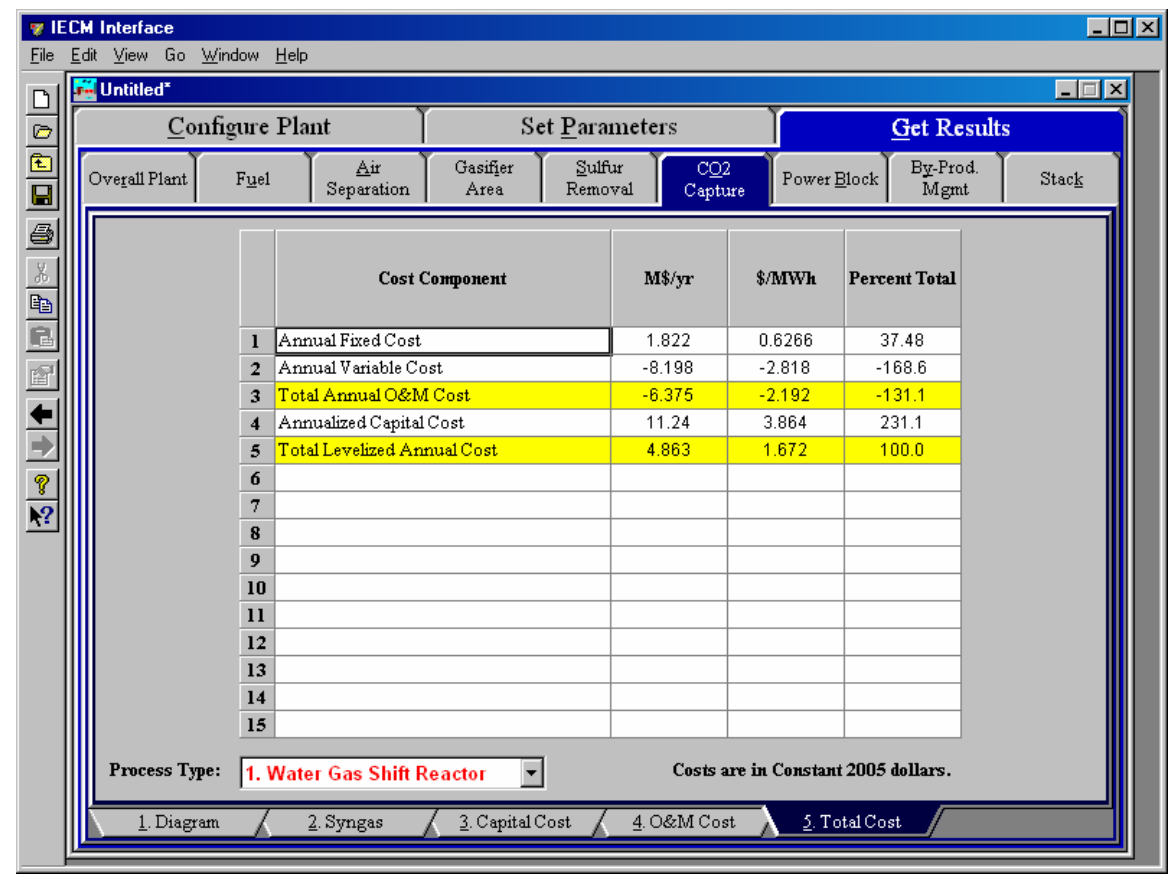

Water Gas Shift Reactor - Total Cost result screen.

The Total Cost result screen displays a table which totals the annual fixed, variable, operations and maintenance, and capital costs associated with the Water Gas Shift Reactor Unit. Total costs are typically expressed in either constant or current 
dollars for a specified year, as shown on the bottom of the screen. Each result is described briefly below.

\section{Cost Component}

Annual Fixed Cost: The operating and maintenance fixed costs are given as an annual total. This number includes all maintenance materials and all labor costs.

Annual Variable Cost: The operating and maintenance variables costs are given as an annual total. This includes all reagent, chemical, steam, and power costs.

Total Annual O\&M Cost: This is the sum of the annual fixed and variable operating and maintenance costs above. This result is highlighted in yellow.

Annualized Capital Cost: This is the total capital cost expressed on an annualized basis, taking into consideration the levelized carrying charge factor, or fixed charge factor, over the entire book life.

Total Levelized Annual Cost: The total annual cost is the sum of the total annual O\&M cost and annualized capital cost items above. This result is highlighted in yellow. 


\section{Sulfur Removal}

$\mathrm{SO}_{2}$ emissions from IGCC systems are controlled by removing sulfur species from the syngas prior to combustion in the gas turbine. The syngas is assumed to be scrubbed of particulates prior to entering the sulfur removal system and is further cooled to $101^{\circ} \mathrm{F}$ prior to entering a Selexol acid gas separation unit. $\mathrm{H}_{2} \mathrm{~S}$ and COS are removed from the syngas in the Selexol unit and sent to a Claus plant and a Beavon-Stretford tail gas treatment unit for sulfur recovery. The sulfur recovered can be sold as a by-product and credited to the sulfur removal technology area.

\section{Sulfur Removal Performance Inputs}

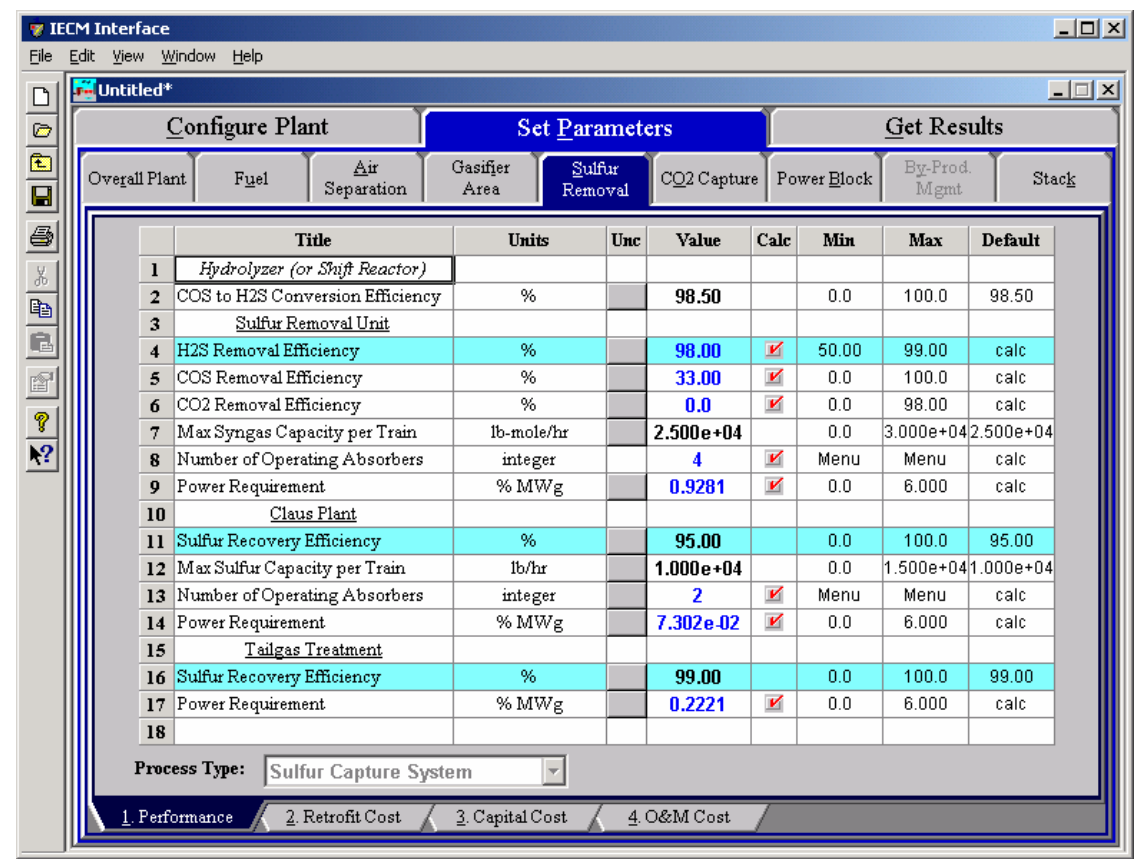

Sulfur Removal - Performance input screen.

The acid gas removal system employs the Selexol process for selective removal of hydrogen sulfide $\left(\mathrm{H}_{2} \mathrm{~S}\right)$ and carbonyl sulfide (COS). Usually COS is present in much smaller quantities than $\mathrm{H}_{2} \mathrm{~S}$. In this unit, most of the $\mathrm{H}_{2} \mathrm{~S}$ is removed by absorption in the Selexol solvent, with a typical removal efficiency of 95 to 98 percent. Typically only about one third of COS in the syngas will be absorbed. A hydrolyzer is used to convert the captured COS to $\mathrm{H}_{2} \mathrm{~S}$ in preparation for the stripping of $\mathrm{H}_{2} \mathrm{~S}$ from the 
Selexol solvent, along with sour gas from the process water treatment unit. This concentrated gas stream is then sent to the Claus sulfur plant for recovery of elemental sulfur.

\section{Hydrolyzer (or Shift Reactor)}

COS to $\mathrm{H}_{2}$ S Conversion Efficiency: This is the efficiency with which carbonyl sulfide is converted to hydrogen sulfide.

\section{Sulfur Removal Unit}

$\mathbf{H}_{2} \mathbf{S}$ Removal Efficiency: This is the removal efficiency of $\mathrm{H}_{2} \mathrm{~S}$ from the inlet syngas stream. The $\mathrm{H}_{2} \mathrm{~S}$ is removed by an absorption process that is very effective at capture of $\mathrm{H}_{2} \mathrm{~S}$.

cos Removal Efficiency: This is the removal efficiency of COS. The absorption process is not very effective at capturing COS, so the removal efficiency default is very low.

$\mathbf{C O}_{2}$ Removal Efficiency: This is removal efficiency of $\mathrm{CO}_{2}$ for the sulfur recovery system. This system is optimized to capture sulfurbearing components of a syngas, but maintains an affinity for $\mathrm{CO}_{2}$. The $\mathrm{CO} 2$ removed is eventually vented to the atmosphere from the BeavonStretford technology.

Max Syngas Capacity per Train: This is the maximum flow rate of one Selexol-based sulfur recovery vessel. It is used to determine the number of absorber vessels required to treat the syngas.

Number of Operating Absorbers: This is the number of absorbers required to treat the entire syngas stream. It is used primarily to determine the cost of the sulfur control area.

Power Requirement: This is the equivalent electrical output of thermal (steam) energy used for reheat, plus the actual electrical output power required. It is calculated as a function of the syngas flow rate.

\section{Claus Plant}

Sulfur Recovery Efficiency: This is the recovery efficiency of the Claus Plant in converting $\mathrm{H}_{2} \mathrm{~S}$ to elemental sulfur.

Max Sulfur Capacity per Train: This is the maximum capacity of elemental sulfur from one Claus train.

Number of Operating Absorbers: The number of trains is estimated from the recovered sulfur mass flow rate and the allowable range of recovered sulfur mass flow rate per train

Power Requirement: This is the equivalent electrical output of thermal (steam) energy used for reheat, plus the actual electrical output power required. It is calculated as a function of the sulfur flow from the Claus plant.

\section{Tailgas Treatment}

(Note: The number of trains for this area is the same as the number of trains for the Claus plant process area.) 
Sulfur Recovery Efficiency: This is the recovery efficiency of the Beavon-Stretford plant in generating elemental sulfur. The remainder is oxidized to $\mathrm{SO}_{2}$ and sent to a stack.

Power Requirement: This is the equivalent electrical output of thermal (steam) energy used for reheat, plus the actual electrical output power required for all three technologies above. It is calculated as a function of the sulfur flow rate from the Beavon-Stretford plant.

\section{Sulfur Removal Retrofit Cost Inputs}

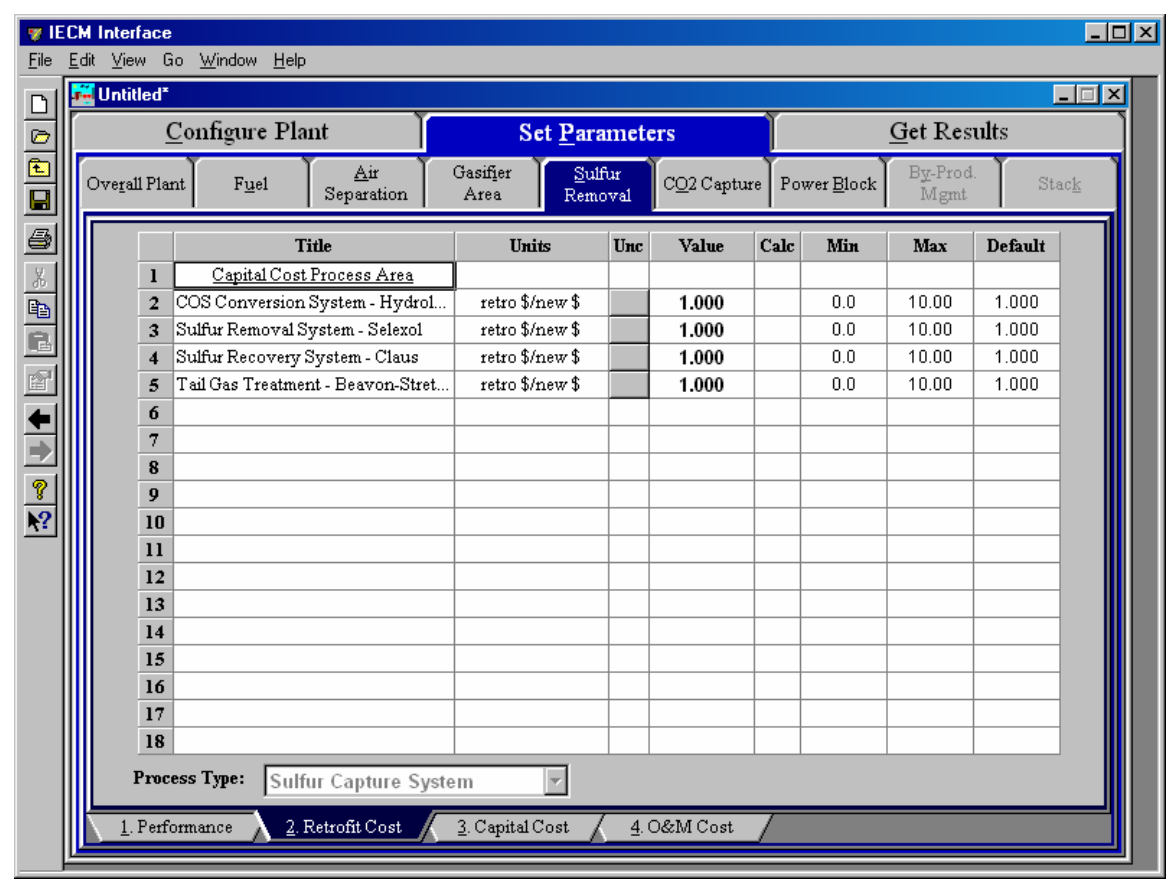

Sulfur Removal - Retrofit Cost input screen.

\section{Capital Cost Process Area}

CoS Conversion System - Hydrolyzer: The Hydrolyzer helps to separate the carbon from the sulfur by converting carbonyl sulfide to hydrogen sulfide.

Sulfur Removal System - Selexol: $\mathrm{H}_{2} \mathrm{~S}$ in the syngas is removed through counter-current contact with Selexol solvent. The cost of the Selexol section includes the acid gas absorber, syngas knock-out drum, syngas heat exchanger, flash drum, lean solvent cooler, mechanical refrigeration unit, lean/rich solvent heat exchanger, solvent regenerator, regenerator air-cooled overhead condenser, acid gas knock-out drum, regenerator reboiler, and pumps and expanders associated with the Selexol process.

Sulfur Recovery System - Claus: The Claus plant contains a twostage sulfur furnace, sulfur condensers, and catalysts.

Tail Gas Treatment - Beavon-Stretford: The process facilities capital is the total constructed cost of all on-site processing and generating units listed above, including all direct and indirect construction costs. 
All sales taxes and freight costs are included where applicable implicitly. This result is highlighted in yellow.

\section{Sulfur Removal Capital Cost Inputs}

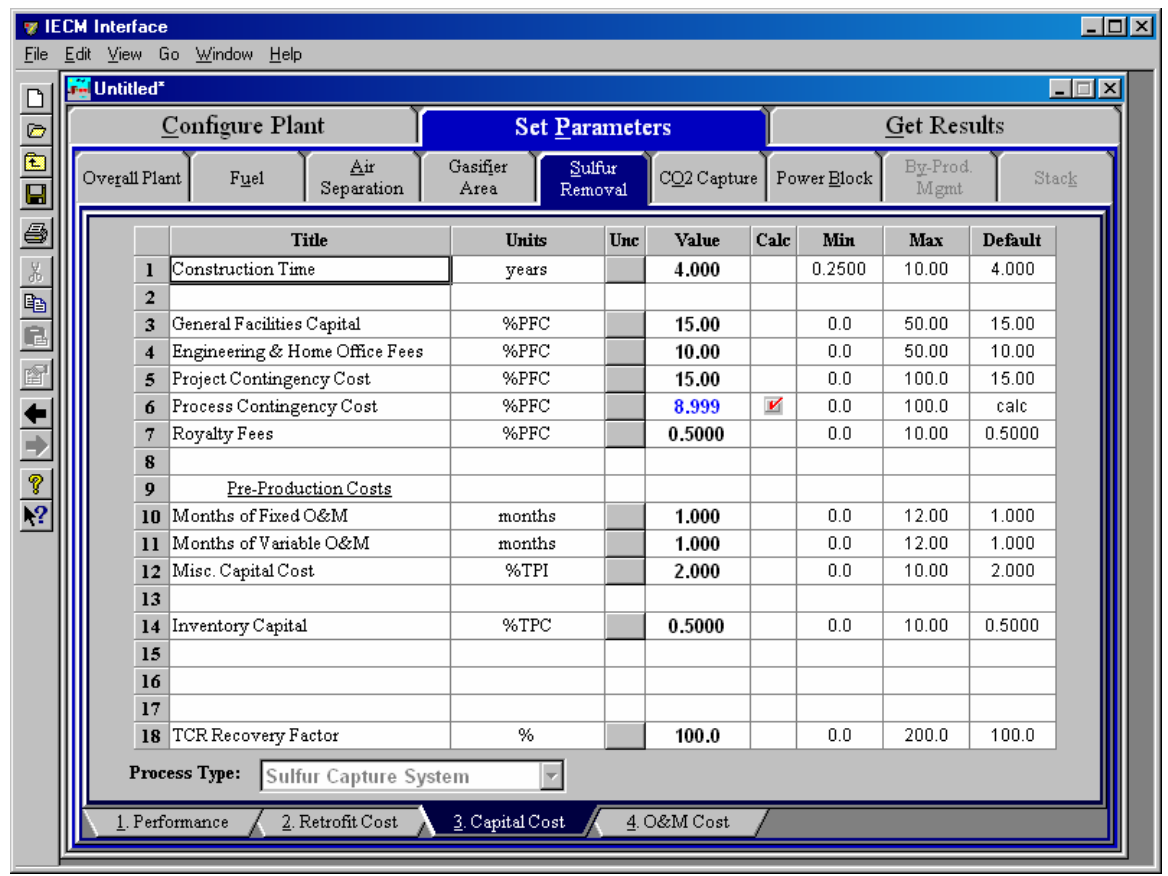

Sulfur Removal - Capital Cost input screen.

Inputs for capital costs are entered on the Capital Cost input screen.

Construction Time: This is the idealized construction period in years. It is used to determine the allowance for funds used during construction (AFUDC).

General Facilities Capital (GFC): The general facilities include construction costs of roads, office buildings, shops, laboratories, etc. Sales taxes and freight costs are included implicitly. The cost typically ranges from $5-20 \%$.

Engineering \& Home Office Fees: The engineering \& home office fees are a percent of total direct capital cost. This is an overhead fee paid to the architect/engineering company. These fees typically range from 7$15 \%$.

Project Contingency Cost: This is factor covering the cost of additional equipment or other costs resulting from a more detailed design. Higher contingency factors will be applied to simplified or preliminary designs and lower factors to detailed or finalized designs.

Process Contingency Cost: This quantifies the design uncertainty and cost of a commercial-scale system. This is generally applied on an areaby-area basis. Higher contingency factors are applied to new regeneration systems tested at a pilot plant and lower factors to full-size or commercial systems.

Royalty Fees: Royalty charges may apply to some portions of generating units incorporating new proprietary technologies. 
Pre-Production Costs: These costs consider the operator training, equipment checkout, major changes in unit equipment, extra maintenance, and inefficient use of fuel or other materials during startup. These are typically applied to the O\&M costs over a specified period of time (months). The two time periods for fixed and variable O\&M costs are described below with the addition of a miscellaneous capital cost factor.

- Months of Fixed O\&M: Time period of fixed operating costs used for preproduction to cover training, testing, major changes in equipment, and inefficiencies in start-up. This includes operating, maintenance, administrative and support labor. It also considers maintenance materials.

- Months of Variable O\&M: Time period of variable operating costs used for preproduction to cover chemicals, water, consumables, and solid disposal charges in start-up, assuming $100 \%$ load. This excludes any fuels.

- Misc. Capital Cost: This is a percent of total plant investment (sum of TPC and AFUDC) to cover expected changes to equipment to bring the system up to full capacity.

Inventory Capital: Percent of the total direct capital for raw material supply based on $100 \%$ capacity during a 60 day period. These materials are considered storage. The inventory capital includes fuels, consumables, by-products, and spare parts. This is typically $0.5 \%$.

TCR Recovery Factor: The actual total capital required (TCR) as a percent of the TCR in a new power plant. This value is $100 \%$ for a new installation and may be set as low as $0 \%$ for a fabric filter that has been paid off.

\section{Sulfur Removal O\&M Cost Inputs}

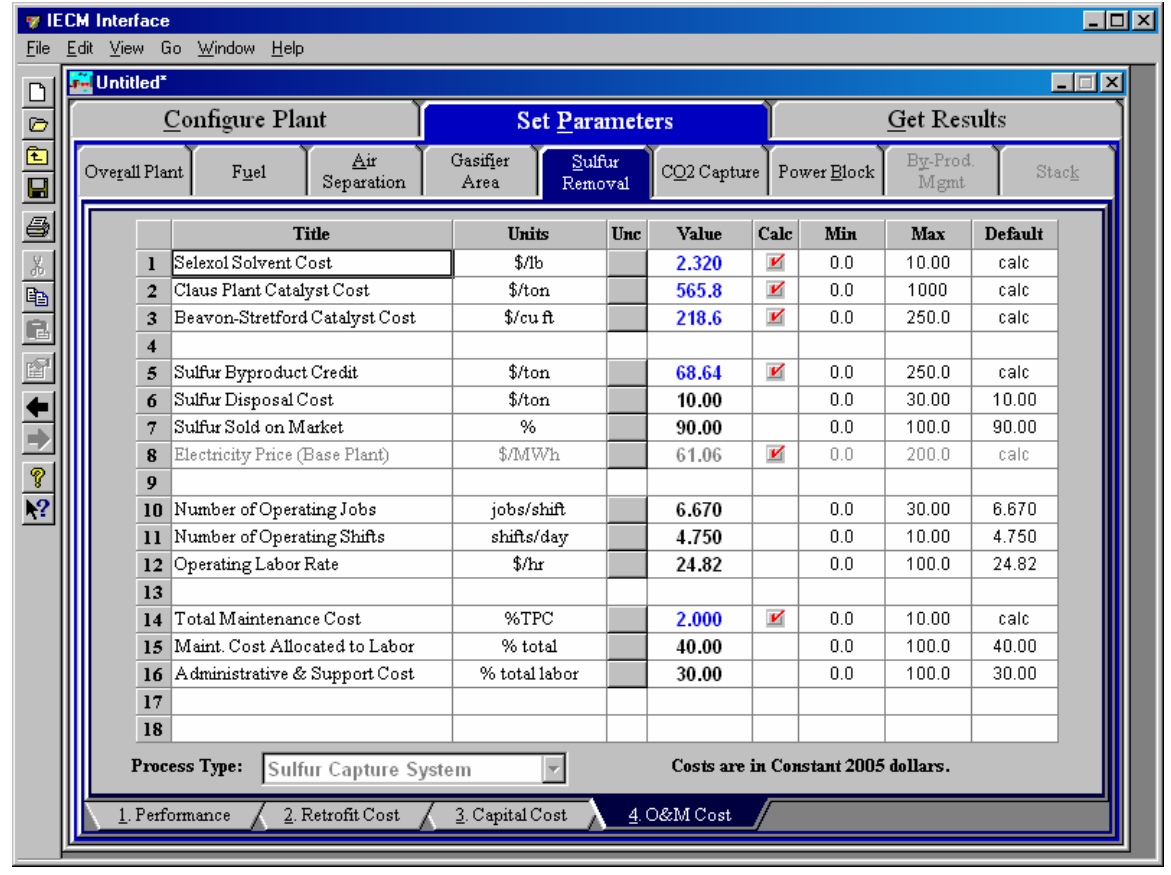


Inputs for O\&M costs are entered on the Sulfur Removal O\&M Cost input screen. O\&M costs are typically expressed on an average annual basis and are provided in either constant or current dollars for a specified year, as shown on the bottom of the screen.

Selexol Solvent Cost: This is the unit cost of Selexol.

Claus Plant Catalyst Cost: This is the unit cost of catalyst used in the Claus plant.

Beavon-Stretford Catalyst Cost: This is the unit cost of catalyst used in the Beavon-Stretford plant.

Sulfur Byproduct Credit: This is the unit price of sulfur sold on the market.

Sulfur Disposal Cost: This is the unit cost of any disposal wastes generated by the sulfur recovery processes.

Sulfur Sold on Market: This is the fraction of the collected sulfur that is sold on the market. Any remaining sulfur is assumed to be utilized at no cost (i.e., neither disposed nor sold).

Electricity Price (Base Plant) : This is the price of electricity and is calculated as a function of the utility cost of the base plant, where the base plant is defined as the air separation unit, the gasifier, and the power block.

Number of Operating Jobs: This is the total number of operating jobs that are required to operate the plant per eight-hour shift.

Number of Operating Shifts: This is the total number of equivalent operating shifts in the plant per day. The number takes into consideration paid time off and weekend work ( 3 shifts/day * 7 days/5 day week * 52 weeks $/(52$ weeks -6 weeks PTO $)=4.75$ equiv. Shifts/day)

Operating Labor Rate: The hourly cost of labor is specified in the base plant O\&M cost screen. The same value is used throughout the other technologies.

Total Maintenance Cost: This is the annual maintenance cost as a percentage of the total plant cost. Maintenance cost estimates can be developed separately for each process area.

Maint. Cost Allocated to Labor: Maintenance cost allocated to labor as a percentage of the total maintenance cost.

Administrative \& Support Cost: This is the percent of the total operating and maintenance labor associated with administrative and support labor. 


\section{Sulfur Removal Diagram}

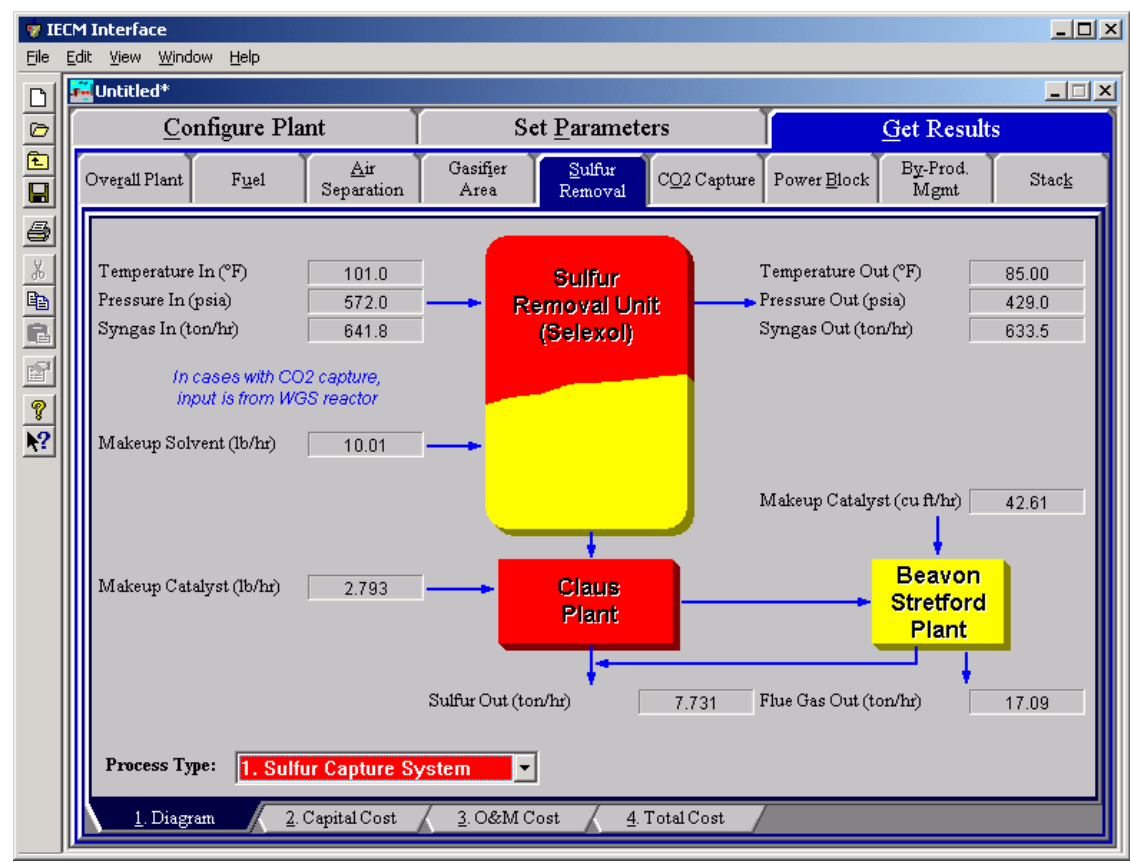

Sulfur Removal - Diagram result screen.

The Sulfur Removal Diagram result screen displays an icon for the Sulfur Removal Unit (Selexol), the Claus Plant, the Beavon Stretford Plant and values for major flows in and out of it. The user may switch between the three process types' results by choosing from the pull down menu labeled Process Type, located above the bottom tabs on the left side of the Sulfur Removal Diagram. Each result shown on the Sulfur Removal Diagram is described briefly below in flow::

Temperature In: Temperature of the syngas entering the Selexol-based sulfur removal unit.

Pressure In: Pressure of the syngas entering the Selexol-based sulfur removal unit.

Syngas In: Flow rate of the syngas entering the Selexol-based sulfur removal unit.

Makeup Solvent In: This is the Selexol solvent makeup rate into the sulfur removal unit expressed on a continuous basis.

Makeup Catalyst In: This is the catalyst makeup rate for the Claus plant expressed on a continuous basis.

Temperature Out: Temperature of the syngas exiting the Selexol-based sulfur removal unit.

Pressure Out: Pressure of the syngas exiting the Selexol-based sulfur removal unit.

Syngas Out: Flow rate of the syngas exiting the Selexol-based sulfur removal unit.

Makeup Catalyst In: This is the catalyst makeup rate for the BeavonStretford plant expressed on a continuous basis. 
Sulfur Out: Flow rate of the elemental sulfur collected in both the Claus and Beavon-Stretford plants.

Flue Gas Out: The exhaust gas from the Beavon-Stretford plant is completely burned and sent to a stack. This is the flow rate of combusted exhaust gases.

\section{Sulfur Removal Capital Cost Results}

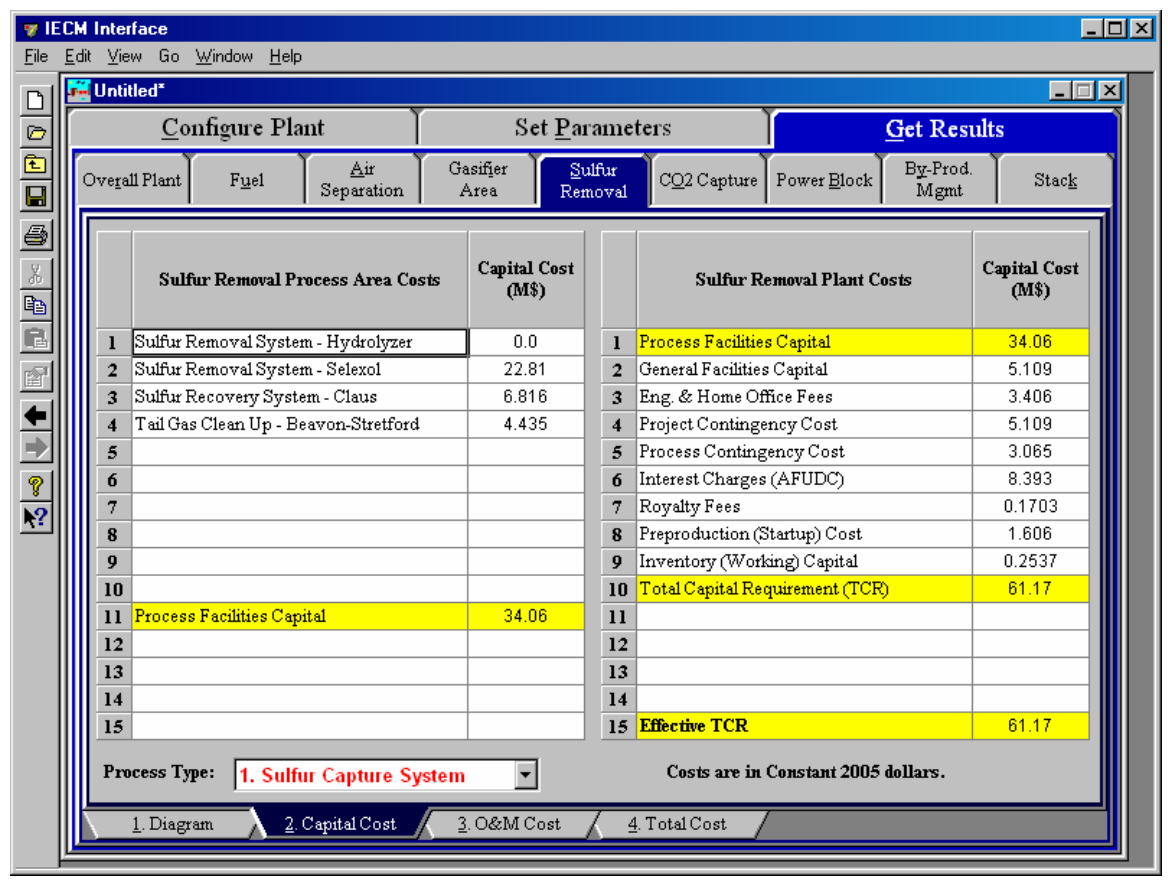

Sulfur Removal Capital Cost results screen.

The Sulfur Removal Capital Cost result screen displays tables for the capital costs. Capital costs are typically expressed in either constant or current dollars for a specified year, as shown on the bottom of the screen. Each result is described briefly below:

\section{Sulfur Removal Process Area Costs}

Sulfur Removal System - Hydrolyzer This is the capital cost for the hydrolyzer system, which converts carbonyl sulfide to hydrogen sulfide.

Sulfur Removal System - Selexol $\mathrm{H}_{2} \mathrm{~S}$ in the syngas is removed through counter-current contact with Selexol solvent. The cost of the Selexol section includes the acid gas absorber, syngas knock-out drum, syngas heat exchanger, flash drum, lean solvent cooler, mechanical refrigeration unit, lean/rich solvent heat exchanger, solvent regenerator, regenerator air-cooled overhead condenser, acid gas knock-out drum, regenerator reboiler, and pumps and expanders associated with the Selexol process.

Sulfur Recovery System - Claus The Claus plant contains a two-stage sulfur furnace, sulfur condensers, and catalysts. 
Tail Gas Clean Up - Beavon-Stretford The capital cost of a BeavonStretford unit varies with the volume flow rate of the input gas streams and with the mass flow rate of the sulfur produced. The regression model is based only on the sulfur produced by the Beavon-Stretford process.

Process Facilities Capital: The process facilities capital is the total constructed cost of all on-site processing and generating units listed above, including all direct and indirect construction costs. All sales taxes and freight costs are included where applicable implicitly. This result is highlighted in yellow.

\section{Sulfur Removal Plant Costs}

Process Facilities Capital: (see definition above)

General Facilities Capital: The general facilities include construction costs of roads, office buildings, shops, laboratories, etc. Sales taxes and freight costs are included implicitly.

Eng. \& Home Office Fees: The engineering \& home office fees are a percent of total direct capital cost. This is an overhead fee paid to the architect/engineering company.

Project Contingency Cost: Capital cost contingency factor covering the cost of additional equipment or other costs that would result from a more detailed design of a definitive project at the actual site.

Process Contingency Cost: Capital cost contingency factor applied to a new technology in an effort to quantify the uncertainty in the technical performance and cost of the commercial-scale equipment.

Interest Charges (AFUDC): Allowance for funds used during construction, also referred to as interest during construction, is the time value of the money used during construction and is based on an interest rate equal to the before-tax weighted cost of capital. This interest is compounded on an annual basis (end of year) during the construction period for all funds spent during the year or previous years.

Royalty Fees: Royalty charges may apply to some portions of generating units incorporating new proprietary technologies.

Preproduction (Startup) Cost: These costs consider the operator training, equipment checkout, major changes in unit equipment, extra maintenance, and inefficient use of fuel or other materials during startup.

Inventory (Working) Capital: The raw material supply based on $100 \%$ capacity during a 60 day period. These materials are considered storage. The inventory capital includes fuels, consumables, byproducts, and spare parts.

Total Capital Requirement (TCR): Money that is placed (capitalized) on the books of the utility on the service date. TCR includes all the items above. This result is highlighted in yellow.

Effective TCR: The TCR of the spray dryer that is used in determining the total power plant cost. The effective TCR is determined by the "TCR Recovery Factor". 


\section{Sulfur Removal O\&M Cost Results}

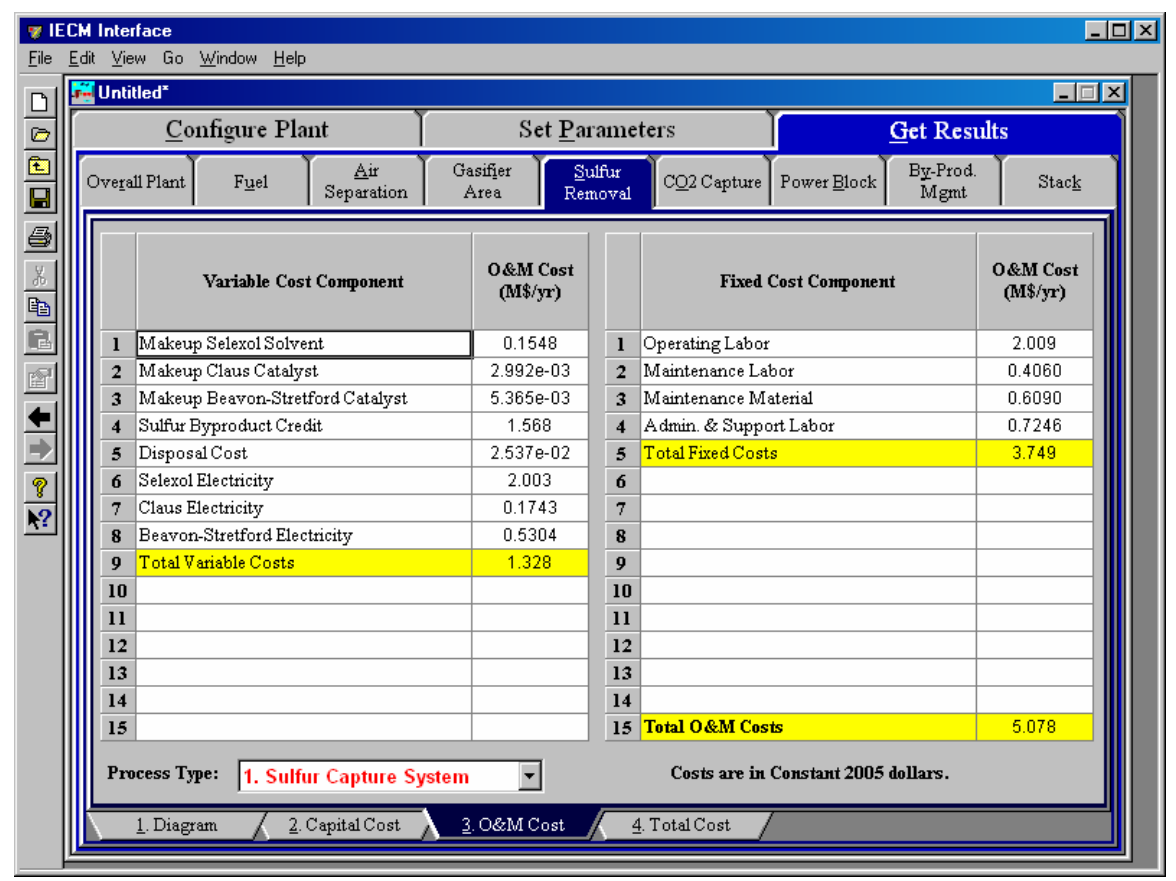

Sulfur Removal - O\&M Cost results screen.

O\&M costs are typically expressed on an average annual basis and are provided in either constant or current dollars for a specified year, as shown on the bottom of the screen.

\section{Variable Cost Component}

Makeup Selexol Solvent This is the annual cost of makeup Selexol.

Makeup Claus Catalyst This is the annual cost of makeup catalyst used in the Claus plant.

Makeup Beavon-Stretford Catalyst This is the annual cost of makeup catalyst used in the Beavon-Stretford plant.

Sulfur Byproduct Credit This is the annual profit for sulfur sold on the market.

Disposal Cost This is the annual cost of all wastes generated by the sulfur recovery processes and disposed.

Selexol Electricity This is the annual cost of electricity used by the Selexol-based sulfur capture process area. It is based on the electricity price of the base plant and the power consumed in the process areas.

Claus Electricity This is the annual cost of electricity used by the Claus plant process area. It is based on the electricity price of the base plant and the power consumed in the process areas.

Beavon-Stretford Electricity: This is the annual cost of electricity used by the Beavon-Stretford process area. It is based on the electricity price of the base plant and the power consumed in the process areas. 
Total Variable Costs: This is the sum of all the variable O\&M costs listed above. This result is highlighted in yellow.

\section{Fixed Cost Components}

Fixed operating costs are essentially independent of actual capacity factor, number of hours of operation, or amount of kilowatts produced. All the costs are subject to inflation.

Operating Labor: Operating labor cost is based on the operating labor rate, the number of personnel required to operate the plant per eighthour shift, and the average number of shifts per day over 40 hours per week and 52 weeks.

Maintenance Labor: The maintenance labor is determined as a fraction of the total maintenance cost.

Maintenance Material: The cost of maintenance material is the remainder of the total maintenance cost, considering the fraction associated with maintenance labor.

Admin. \& Support Labor: The administrative and support labor is the only overhead charge. It is taken as a fraction of the total operating and maintenance labor costs.

Total Fixed Costs: This is the sum of all the fixed O\&M costs listed above. This result is highlighted in yellow.

Total O\&M Costs: This is the sum of the total variable and total fixed O\&M costs. It is used to determine the base plant total revenue requirement. This result is highlighted in yellow.

\section{Sulfur Removal Total Cost Results}

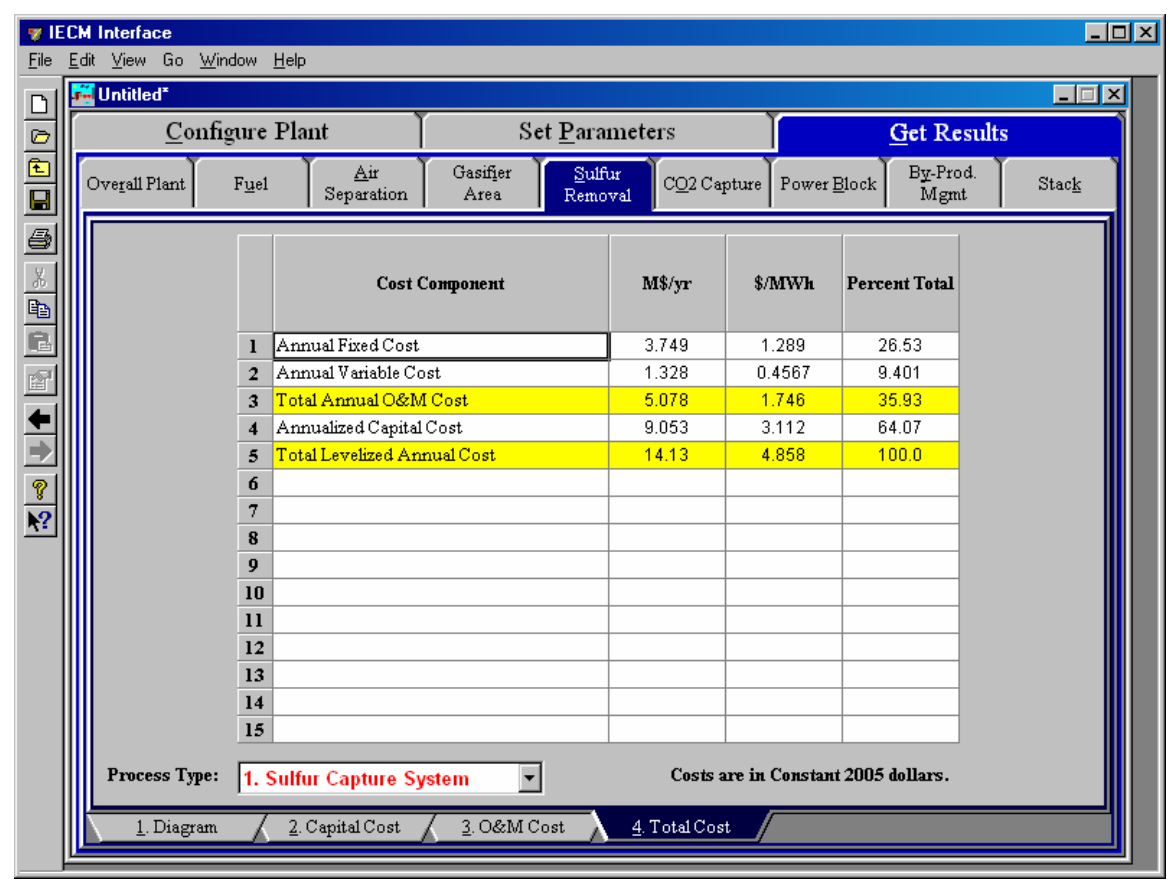

Sulfur Removal - Total Cost results screen. 
The Total Cost result screen displays a table which totals the annual fixed, variable, operations and maintenance, and capital costs associated with the Sulfur Removal Unit. Total costs are typically expressed in either constant or current dollars for a specified year, as shown on the bottom of the screen. Each result is described briefly below.

\section{Cost Component}

Annual Fixed Cost: The operating and maintenance fixed costs are given as an annual total. This number includes all maintenance materials and all labor costs.

Annual Variable Cost: The operating and maintenance variables costs are given as an annual total. This includes all reagent, chemical, steam, and power costs.

Total Annual O\&M Cost: This is the sum of the annual fixed and variable operating and maintenance costs above. This result is highlighted in yellow.

Annualized Capital Cost: This is the total capital cost expressed on an annualized basis, taking into consideration the levelized carrying charge factor, or fixed charge factor, over the entire book life.

Total Levelized Annual Cost: The total annual cost is the sum of the total annual O\&M cost and annualized capital cost items above. This result is highlighted in yellow.

\section{Sulfur Removal Hydrolyzer Syngas Results}

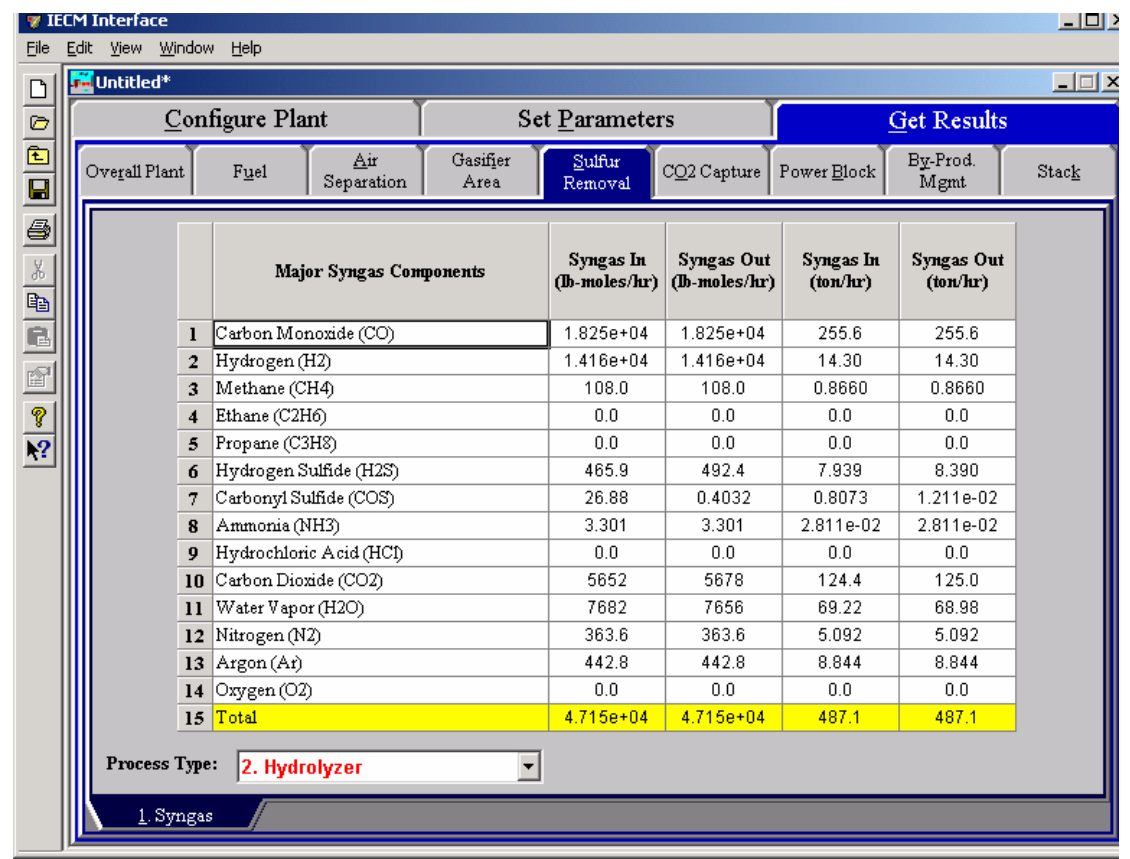

Sulfur Removal Hydrolyzer Syngas results screen. 


\section{Major Syngas Components}

Carbon Monoxide (CO): Total mass of carbon monoxide.

Hydrogen $\left(\mathbf{H}_{2}\right)$ :Total mass of hydrogen.

Methane $\left(\mathrm{CH}_{4}\right)$ :Total mass of methane.

Ethane $\left(\mathrm{C}_{2} \mathrm{H}_{6}\right)$ : Total mass of ethane.

Propane $\left(\mathrm{C}_{3} \mathrm{H}_{8}\right)$ : Total mass of propane.

Hydrogen Sulfide $\left(\mathrm{H}_{2} \mathrm{~S}\right)$ :Total mass of hydrogen sulfide.

Carbonyl Sulfide (COS):Total mass of carbonyl sulfide.

Ammonia $\left(\mathrm{NH}_{3}\right)$ : Total mass of ammonia.

Hydrochloric Acid $(\mathrm{HCl})$ : Total mass of hydrochloric acid.

Carbon Dioxide $\left(\mathrm{CO}_{2}\right)$ : Total mass of carbon dioxide.

Water Vapor $\left(\mathrm{H}_{2} \mathrm{O}\right)$ : Total mass of water vapor.

Nitrogen $\left(\mathbf{N}_{2}\right)$ : Total mass of nitrogen.

Argon (Ar): Total mass of argon.

Oxygen $\left(\mathrm{O}_{2}\right)$ : Total mass of oxygen.

Total: Total of the individual components listed above. This item is highlighted in yellow.

\section{Sulfur Removal Selexol Sulfur System Syngas Results}

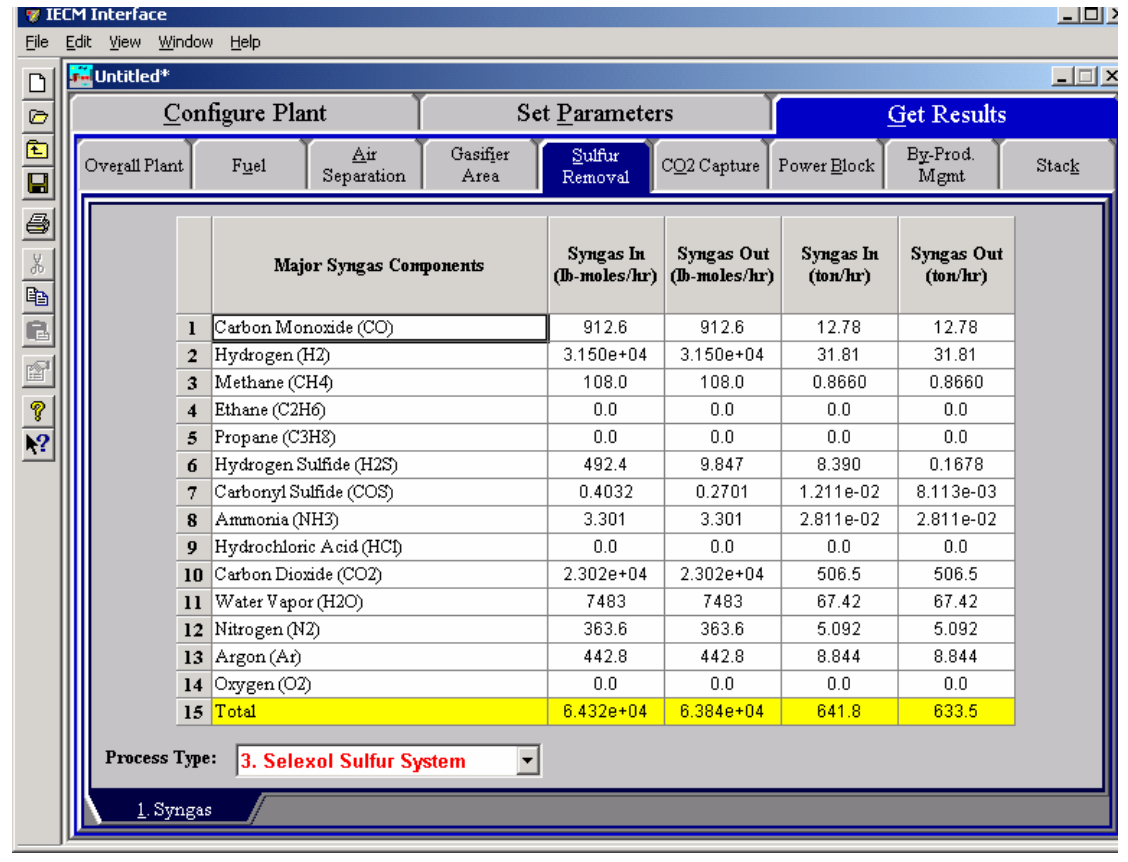

Selexol Sulfur System Syngas results screen. 


\section{Major Syngas Components}

Carbon Monoxide (CO): Total mass of carbon monoxide.

Hydrogen $\left(\mathbf{H}_{\mathbf{2}}\right)$ :Total mass of hydrogen.

Methane $\left(\mathrm{CH}_{4}\right)$ :Total mass of methane.

Ethane $\left(\mathrm{C}_{2} \mathrm{H}_{6}\right)$ : Total mass of ethane.

Propane $\left(\mathrm{C}_{3} \mathrm{H}_{8}\right)$ : Total mass of propane.

Hydrogen Sulfide $\left(\mathrm{H}_{2} \mathrm{~S}\right)$ :Total mass of hydrogen sulfide.

Carbonyl Sulfide (COS):Total mass of carbonyl sulfide.

Ammonia $\left(\mathrm{NH}_{3}\right)$ : Total mass of ammonia.

Hydrochloric Acid $(\mathrm{HCl})$ : Total mass of hydrochloric acid.

Carbon Dioxide $\left(\mathrm{CO}_{2}\right)$ : Total mass of carbon dioxide.

Water Vapor $\left(\mathrm{H}_{2} \mathrm{O}\right)$ : Total mass of water vapor.

Nitrogen $\left(\mathbf{N}_{2}\right)$ : Total mass of nitrogen.

Argon (Ar): Total mass of argon.

Oxygen $\left(\mathrm{O}_{2}\right)$ : Total mass of oxygen.

Total: Total of the individual components listed above. This item is highlighted in yellow.

\section{Sulfur Removal Claus Plant Air Results}

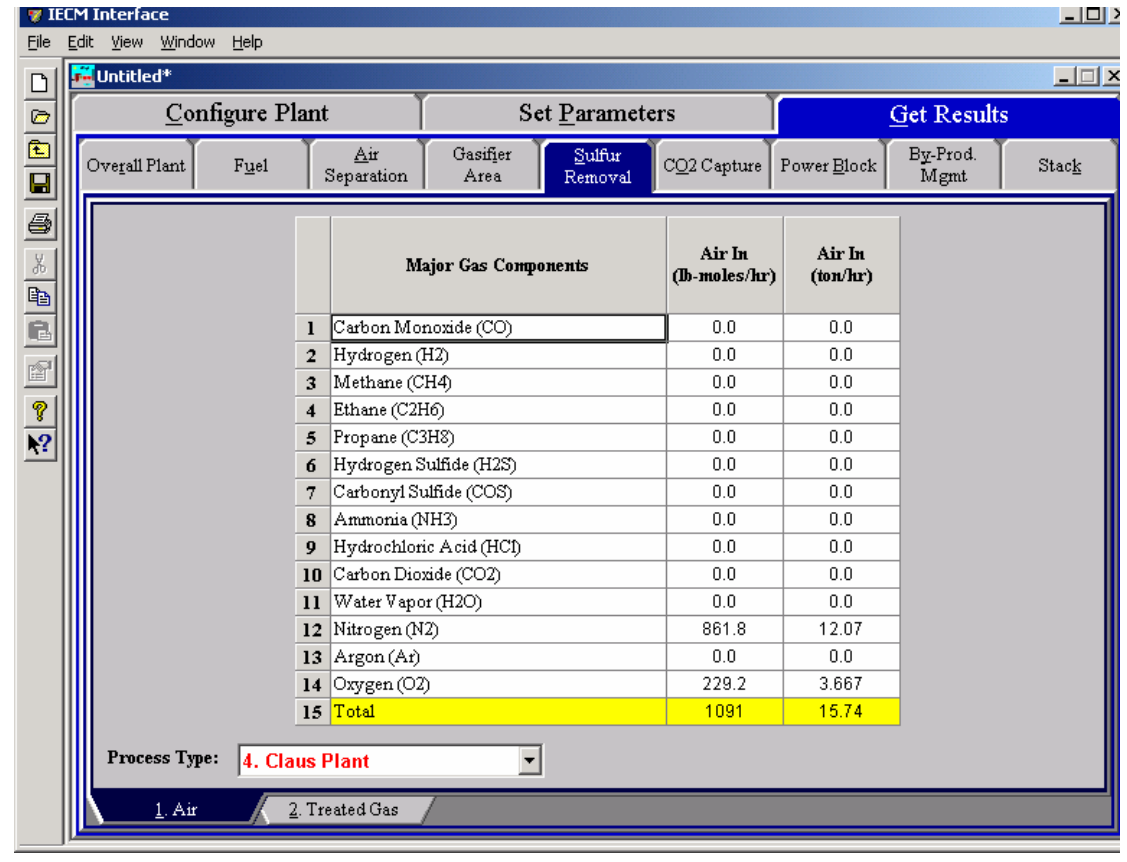

Sulfur Removal Claus Plant Air results screen. 


\section{Major Syngas Components}

Carbon Monoxide (CO): Total mass of carbon monoxide.

Hydrogen $\left(\mathbf{H}_{\mathbf{2}}\right)$ :Total mass of hydrogen.

Methane $\left(\mathrm{CH}_{4}\right)$ :Total mass of methane.

Ethane $\left(\mathrm{C}_{2} \mathrm{H}_{6}\right)$ : Total mass of ethane.

Propane $\left(\mathrm{C}_{3} \mathrm{H}_{8}\right)$ : Total mass of propane.

Hydrogen Sulfide $\left(\mathrm{H}_{2} \mathrm{~S}\right)$ :Total mass of hydrogen sulfide.

Carbonyl Sulfide (COS):Total mass of carbonyl sulfide.

Ammonia $\left(\mathrm{NH}_{3}\right)$ : Total mass of ammonia.

Hydrochloric Acid $(\mathrm{HCl})$ : Total mass of hydrochloric acid.

Carbon Dioxide $\left(\mathrm{CO}_{2}\right)$ : Total mass of carbon dioxide.

Water Vapor $\left(\mathrm{H}_{2} \mathrm{O}\right)$ : Total mass of water vapor.

Nitrogen $\left(\mathbf{N}_{2}\right)$ : Total mass of nitrogen.

Argon (Ar): Total mass of argon.

Oxygen $\left(\mathrm{O}_{2}\right)$ : Total mass of oxygen.

Total: Total of the individual components listed above. This item is highlighted in yellow.

\section{Sulfur Removal Claus Plant Treated Gas Results}

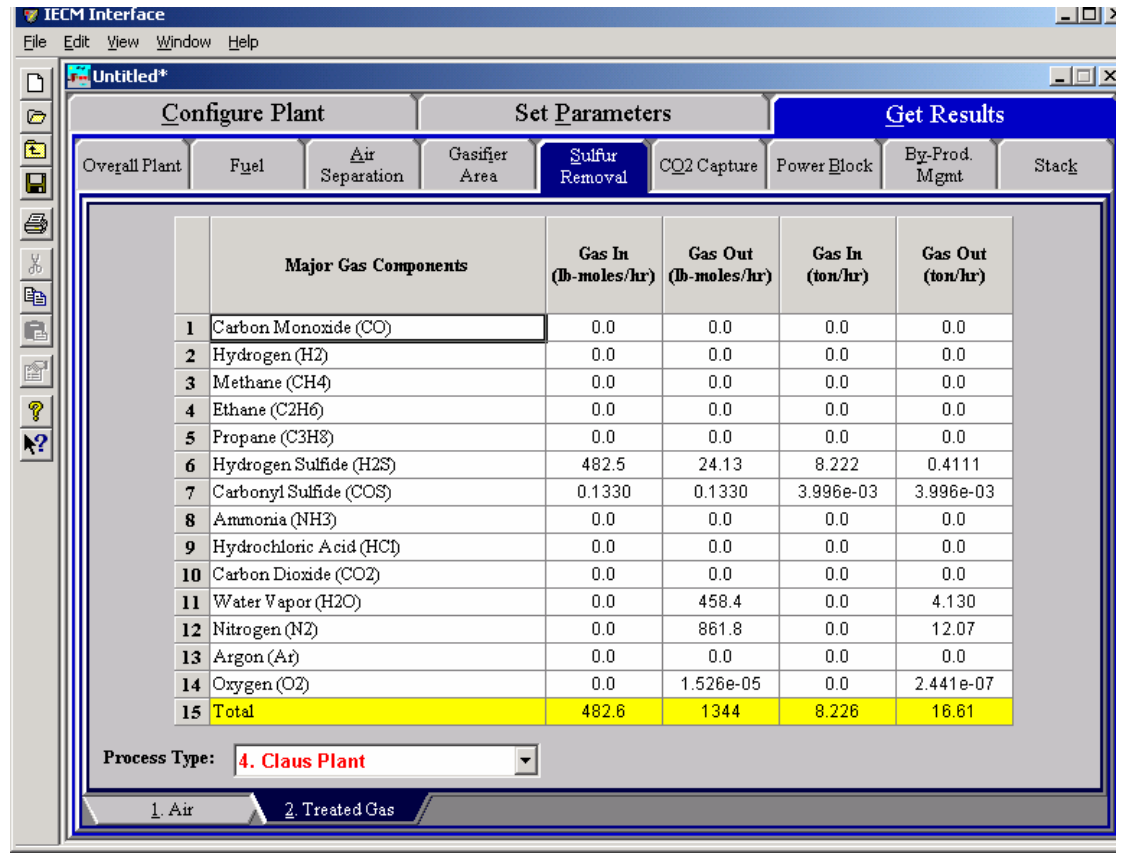

Sulfur Removal Claus Plant Treated Gas results screen. 


\section{Major Syngas Components}

Carbon Monoxide (CO): Total mass of carbon monoxide.

Hydrogen $\left(\mathbf{H}_{\mathbf{2}}\right)$ :Total mass of hydrogen.

Methane $\left(\mathrm{CH}_{4}\right)$ :Total mass of methane.

Ethane $\left(\mathrm{C}_{2} \mathrm{H}_{6}\right)$ : Total mass of ethane.

Propane $\left(\mathrm{C}_{3} \mathrm{H}_{8}\right)$ : Total mass of propane.

Hydrogen Sulfide $\left(\mathrm{H}_{2} \mathrm{~S}\right)$ :Total mass of hydrogen sulfide.

Carbonyl Sulfide (COS):Total mass of carbonyl sulfide.

Ammonia $\left(\mathrm{NH}_{3}\right)$ : Total mass of ammonia.

Hydrochloric Acid $(\mathrm{HCl})$ : Total mass of hydrochloric acid.

Carbon Dioxide $\left(\mathrm{CO}_{2}\right)$ : Total mass of carbon dioxide.

Water Vapor $\left(\mathrm{H}_{2} \mathrm{O}\right)$ : Total mass of water vapor.

Nitrogen $\left(\mathbf{N}_{2}\right)$ : Total mass of nitrogen.

Argon (Ar): Total mass of argon.

Oxygen $\left(\mathrm{O}_{2}\right)$ : Total mass of oxygen.

Total: Total of the individual components listed above. This item is highlighted in yellow.

\section{Sulfur Removal Beavon Stretford Plant Treated Gas Results}

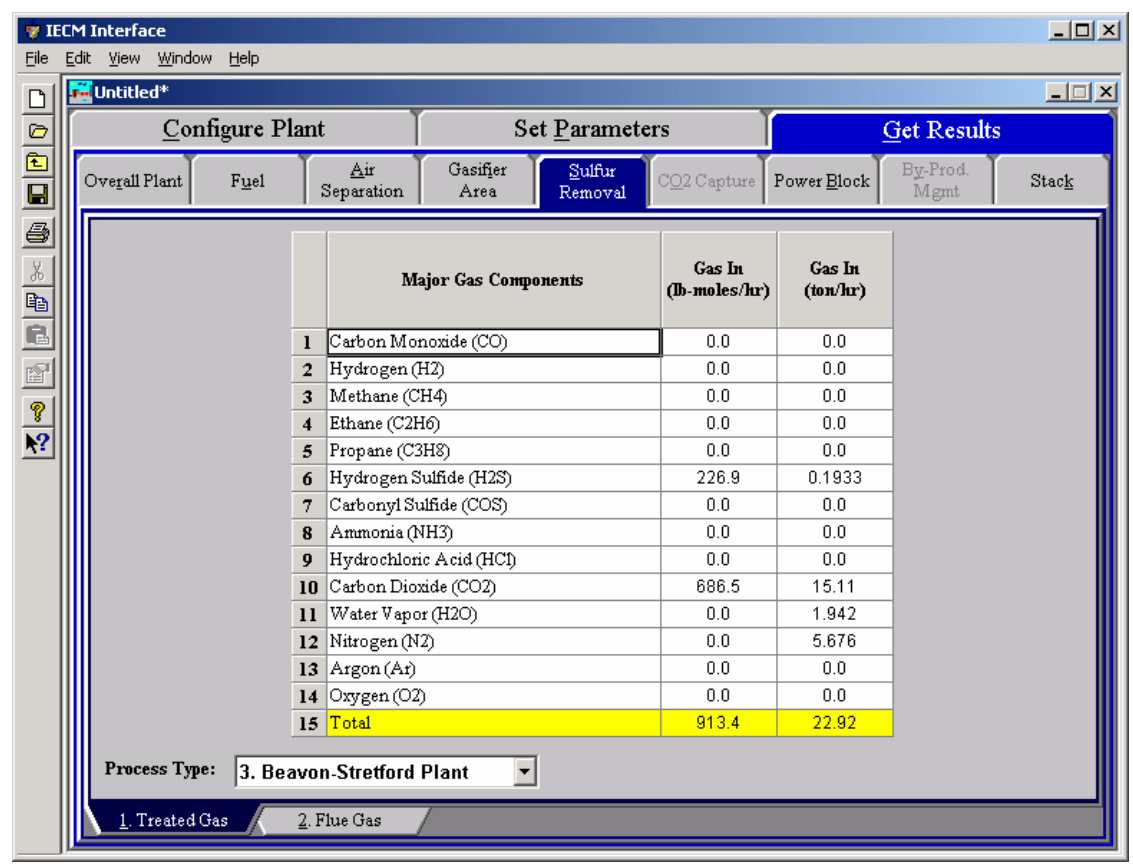

Sulfur Removal Beavon Stretford Plant Treated Gas results screen. 


\section{Major Syngas Components}

Carbon Monoxide (CO): Total mass of carbon monoxide.

Hydrogen $\left(\mathbf{H}_{\mathbf{2}}\right)$ :Total mass of hydrogen.

Methane $\left(\mathrm{CH}_{4}\right)$ :Total mass of methane.

Ethane $\left(\mathrm{C}_{2} \mathrm{H}_{6}\right)$ : Total mass of ethane.

Propane $\left(\mathrm{C}_{3} \mathrm{H}_{8}\right)$ : Total mass of propane.

Hydrogen Sulfide $\left(\mathrm{H}_{2} \mathrm{~S}\right)$ :Total mass of hydrogen sulfide.

Carbonyl Sulfide (COS):Total mass of carbonyl sulfide.

Ammonia $\left(\mathrm{NH}_{3}\right)$ : Total mass of ammonia.

Hydrochloric Acid $(\mathrm{HCl})$ : Total mass of hydrochloric acid.

Carbon Dioxide $\left(\mathrm{CO}_{2}\right)$ : Total mass of carbon dioxide.

Water Vapor $\left(\mathrm{H}_{2} \mathrm{O}\right)$ : Total mass of water vapor.

Nitrogen $\left(\mathbf{N}_{2}\right)$ : Total mass of nitrogen.

Argon (Ar): Total mass of argon.

Oxygen $\left(\mathrm{O}_{2}\right)$ : Total mass of oxygen.

Total: Total of the individual components listed above. This item is highlighted in yellow.

\section{Sulfur Removal Beavon Stretford Plant Flue Gas Results}

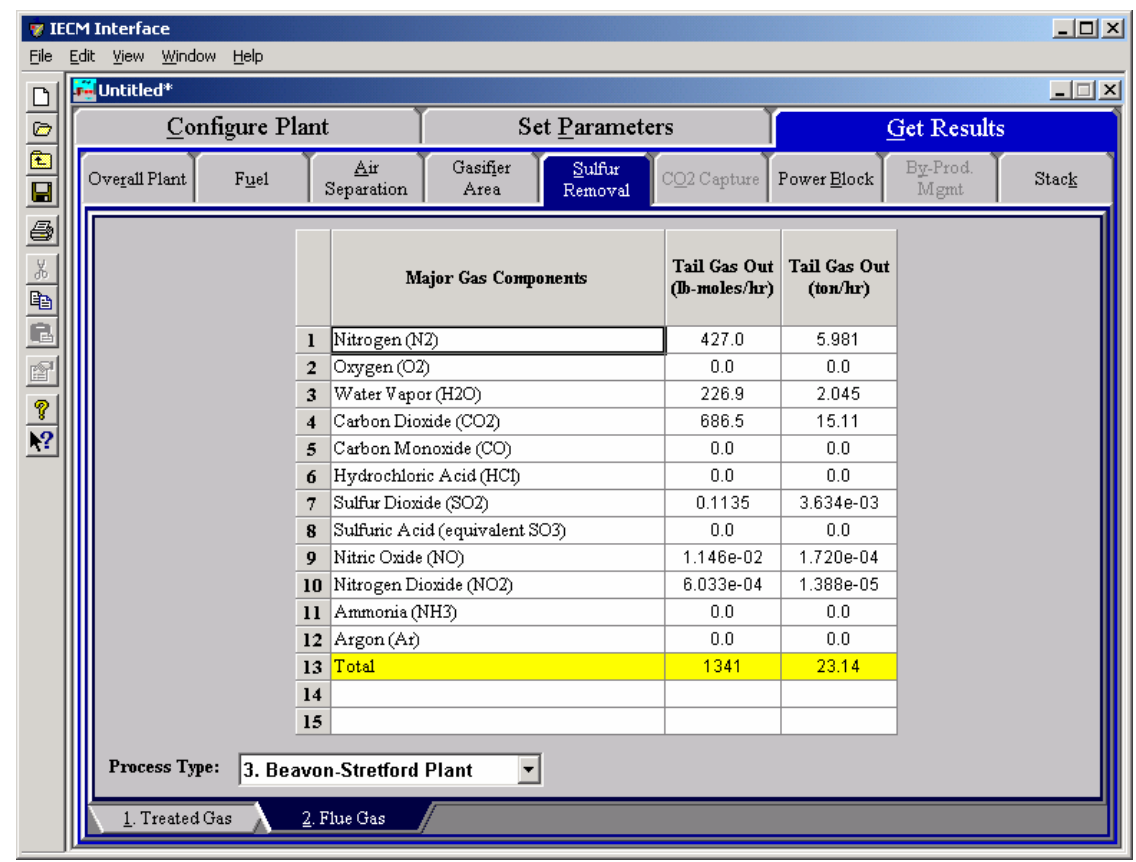

Sulfur Removal Beavon Stretford Plant Flue Gas Results 


\section{Major Flue Gas Components}

Nitrogen $\left(\mathrm{N}_{2}\right)$ : Total mass of nitrogen.

Oxygen $\left(\mathrm{O}_{2}\right)$ : Total mass of oxygen.

Water Vapor $\left(\mathrm{H}_{2} \mathrm{O}\right)$ : Total mass of water vapor.

Carbon Dioxide $\left(\mathrm{CO}_{2}\right)$ : Total mass of carbon dioxide.

Carbon Monoxide (CO): Total mass of carbon monoxide.

Hydrochloric Acid (HCl): Total mass of hydrochloric acid.

Sulfur Dioxide $\left(\mathrm{SO}_{2}\right)$ : Total mass of sulfur dioxide.

Sulfuric Acid (equivalent $\mathrm{SO}_{3}$ ): Total mass of sulfuric acid (on an $\mathrm{SO}_{3}$ equivalency basis).

Nitric Oxide (NO): Total mass of nitric oxide.

Nitrogen Dioxide $\left(\mathrm{NO}_{2}\right)$ : Total mass of nitrogen dioxide.

Ammonia $\left(\mathrm{NH}_{3}\right)$ : Total mass of ammonia.

Argon (Ar): Total mass of argon.

Total: Total of the individual components listed above. This item is highlighted in yellow. 


\section{By Product Management}

The ByProduct Mg $\underline{\mathbf{g m t}}$ Technology Navigation Tab screens display and design the management of by products and waste disposal.

\section{By Product Management Performance Inputs}

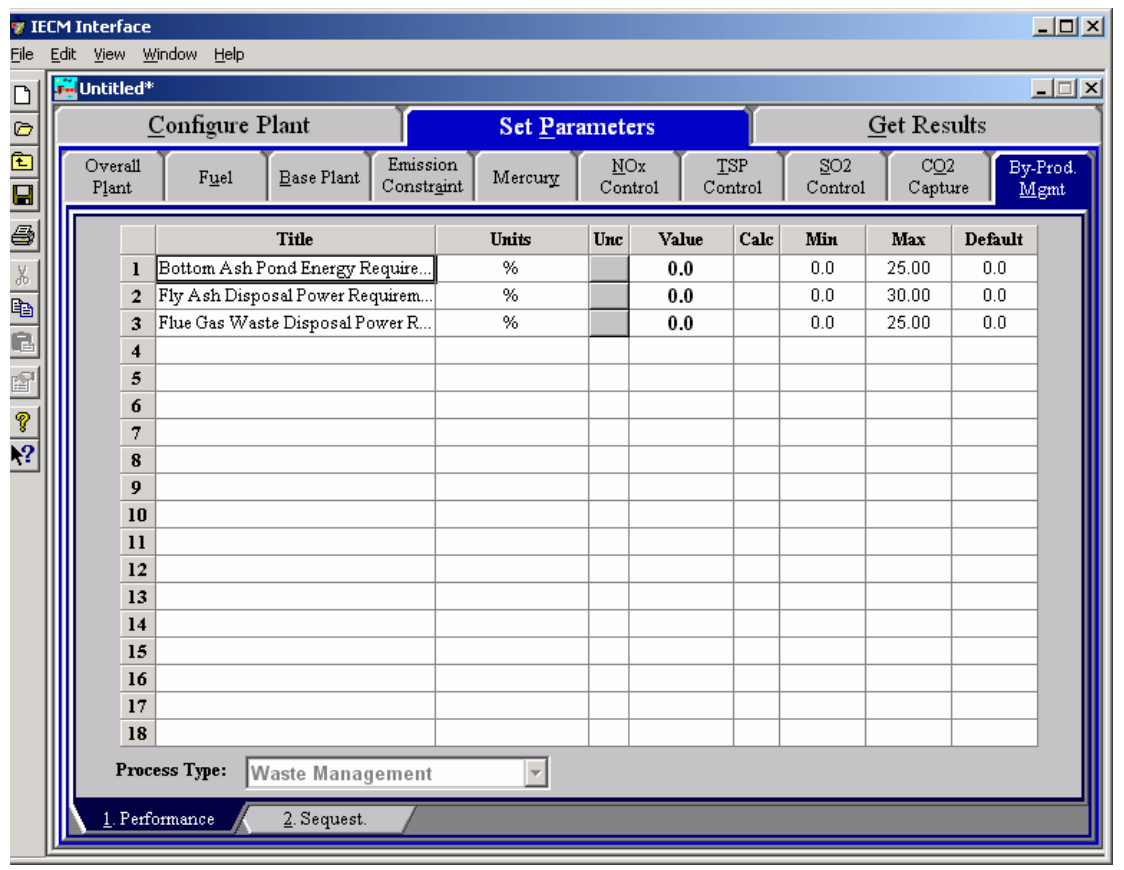

By Product Management - Performance input screen.

General inputs regarding solid waste management are entered on the Performance input screen. This screen is displayed for all plant configurations. One or more of the following By Product Management options will be shown on the input screen depending upon the options selected in the Configure Plant program area. Each of the possible parameters are described briefly below.

Bottom Ash Pond Energy Requirements: The energy requirement is zero by default. Any requirements are considered by the abatement technologies that dispose solids into the bottom ash pond. 
Fly Ash Disposal Power Requirements: The energy requirement is zero by default. Any requirements are considered by the abatement technologies that dispose of fly ash.

Flue Gas Waste Disposal Power Requirements: The energy requirement is zero by default. Any requirements are considered by the abatement technologies that dispose of flue gas waste.

\section{By Product Management Sequestration Input}

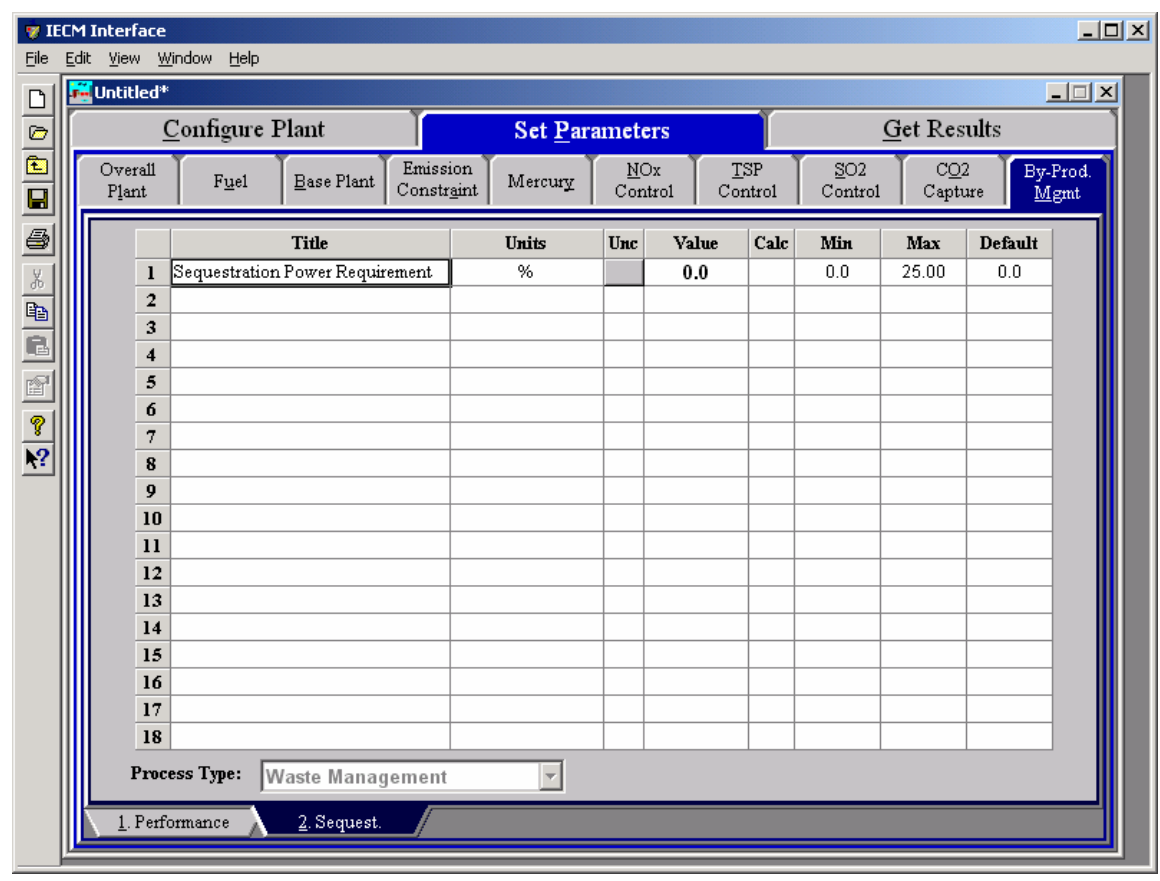

By Product Management - Sequestration input screen.

If the user has selected $\mathbf{C O}_{2}$ Capture in the Configure Plant program area this input screen will also be available. Its parameter is described briefly below.

Sequestration Power Requirement: The energy requirement is zero by default.

\section{By Products Management Bottom Ash Pond Diagram}

The By Product Management Technology Navigation Tab screens displays the flow rates of solid and liquid substances collected which require management (disposal or recovery). There are three By Product Management areas, Bottom Ash Pond, Flue Gas Treatment and Fly Ash Disposal. If $\mathbf{C O}_{2}$ Capture has been configured for the plant by the user then a Geological Reservoir is also available. These are accessed by the Process Type drop-down menu. Each 


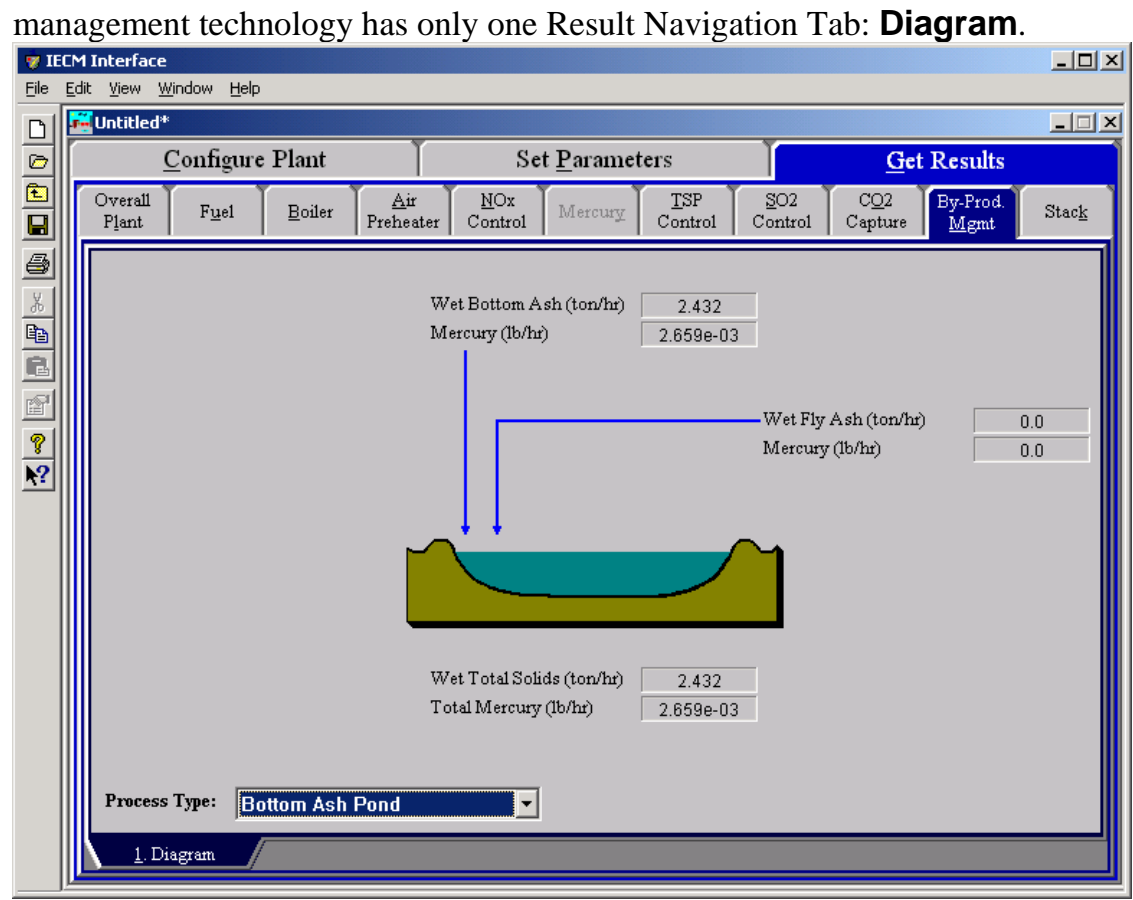

By Products Management Bottom Ash Pond_Diagram result screen

The Bottom Ash Pond Diagram result screen displays an icon for the Pond and values for major flows into it. Each result is described briefly below:

\section{Bottom Ash Pond Inputs}

Solids mixed with sluice water that are collected in the bottom of the boiler and by the particulate removal technologies are transported to the Pond for treatment. The IECM currently provides no additional treatment or consideration of these substances, and therefore simply reports the quantities entering the technology.

Wet Bottom Ash: Mass flow rate of bottom ash solids on a wet basis.

Mercury (contained in Bottom Ash): Mass flow rate of mercury present in the bottom ash solids on a wet basis.

Wet Fly Ash: Mass flow rate of total fly ash solids on a wet basis. This value is zero when the fly ash is disposed in a landfill.

Mercury (contained in Fly Ash): Mass flow rate of mercury present in the fly ash solids on a wet basis.

\section{Bottom Ash Pond - Totals}

Wet Total Solids: The sum of the fly ash and bottom ash solids on a wet basis.

Total Mercury: Mass flow rate of mercury present in the combined bottom ash and fly ash solids on a wet basis.

\section{By Products Management Flue Gas Treatment Diagram}

The By Product Management Technology Navigation Tab screens displays the flow rates of solid and liquid substances collected which require management (disposal or recovery). There are three By Product Management areas, Bottom 
Ash Pond, Flue Gas Treatment and Fly Ash Disposal. If $\mathrm{CO}_{2}$ capture has been configured for the plant by the user then a Geological Reservoir is also available. These are accessed by the Process Type drop-down menu. Each management technology has only one Result Navigation Tab: Diagram.

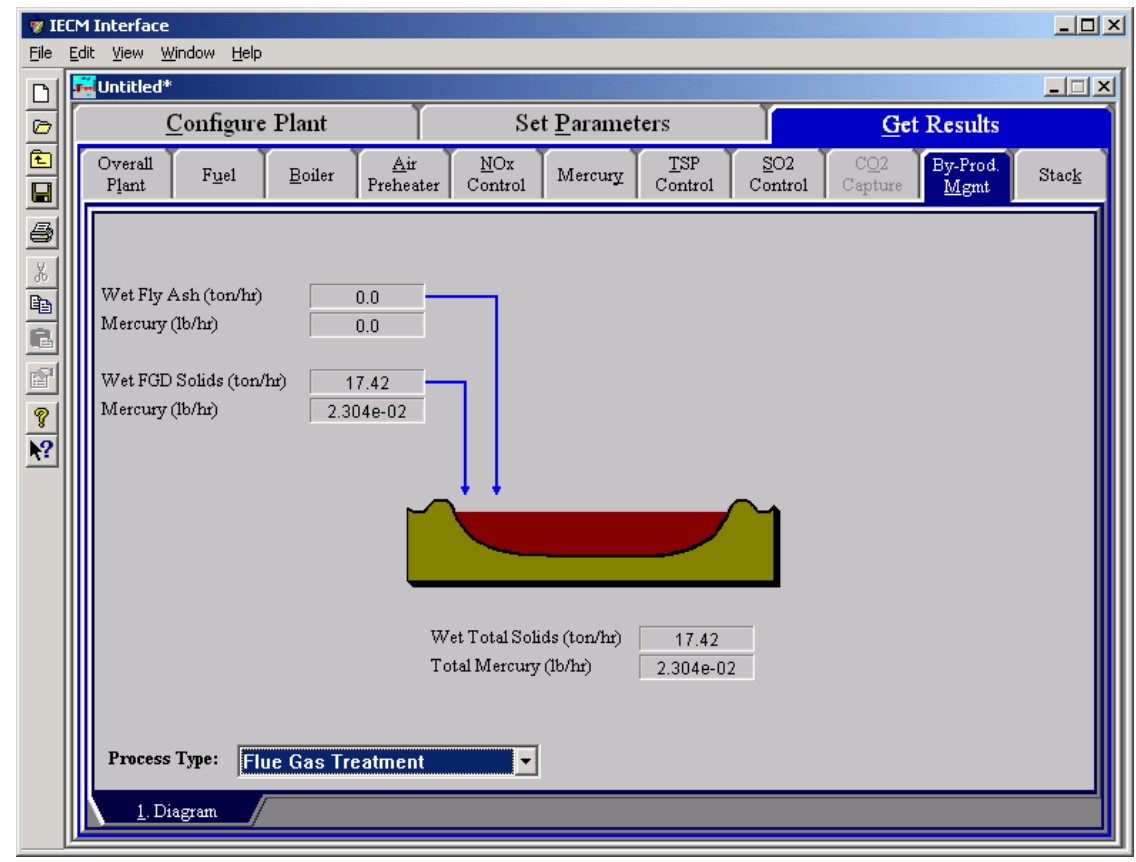

By Products Management Bottom Ash Pond-Diagram result screen

The Flue Gas Treatment Diagram result screen displays an icon for the Landfill and values for major flows into it. Each result is described briefly below:

\section{Flue Gas Treatment Inputs}

Solids mixed with sluice water that are collected in the bottom of the boiler and by the particulate removal technologies are transported to the Pond for treatment. The IECM currently provides no additional treatment or consideration of these substances, and therefore simply reports the quantities entering the technology.

Wet FGD Solids: Mass flow rate of wet FGD solids.

Mercury (contained in Wet FGD Solids): Mass flow rate of mercury present in the Wet FGD solids.

Wet Fly Ash: Mass flow rate of total fly ash solids on a wet basis. This value is zero when the fly ash is disposed in a landfill.

Mercury(contained in Fly Ash): Mass flow rate of mercury present in the fly ash solids on a wet basis.

\section{Flue Gas Treatment - Totals}

Wet Total Solids: The sum of the wet FGD solids and the fly ash on a wet basis.

Total Mercury: Mass flow rate of mercury present in the combined wet FGD solids and fly ash solids on a wet basis. 
By Products Management Fly Ash Disposal Diagram

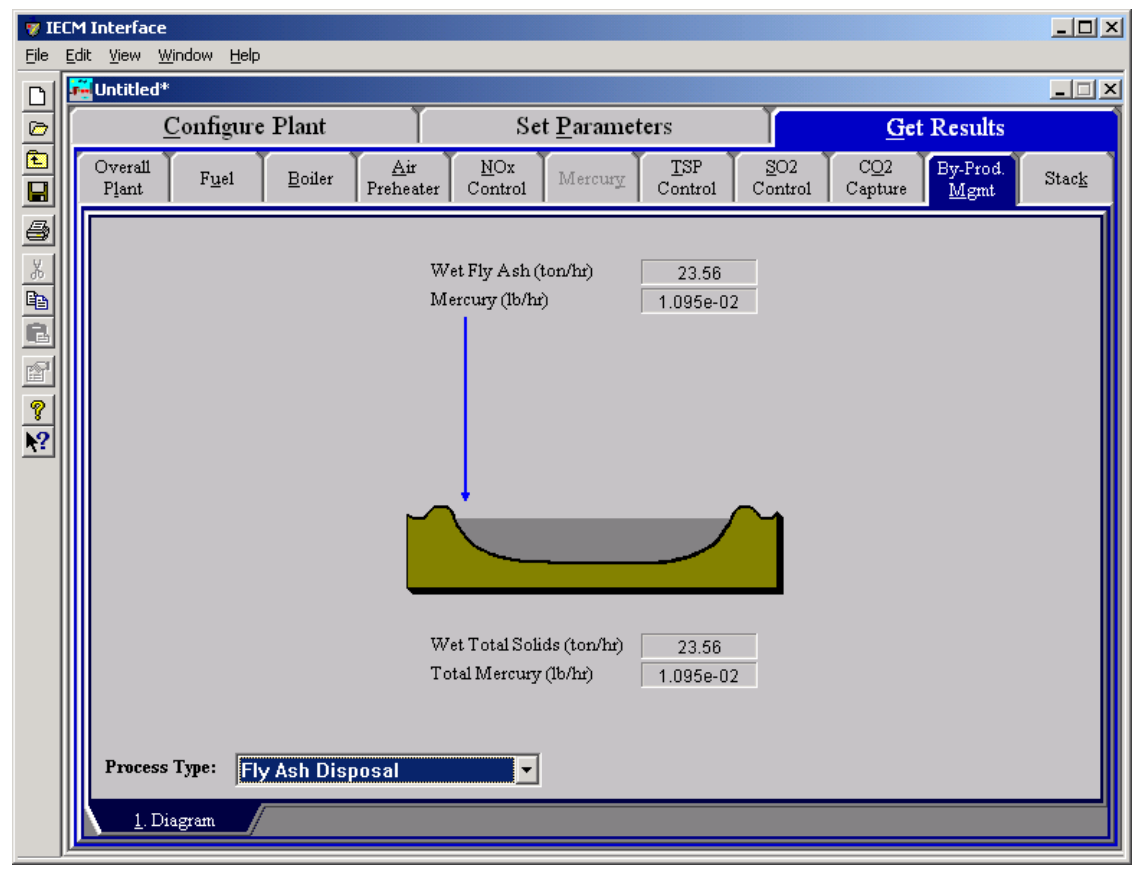

By Products Management Fly Ash Disposal-Diagram result screen

The By Products Management Fly Ash Disposal Diagram result screen displays an icon for the Landfill and values for major flows into it. This screen is only an option if $\mathbf{C O}_{2}$ Capture has been configured for the plant by the user. Each result is described briefly below:

\section{Fly Ash Disposal Inputs}

Solids mixed with sluice water are collected in the particulate removal technologies and may be transported to the Landfill for treatment. The IECM currently provides no additional treatment or consideration of these substances, and therefore simply reports the quantities entering the technology.

Wet Fly Ash: Mass flow rate of total fly ash solids on a wet basis.

Mercury: Mass flow rate of mercury present in the fly ash solids on a wet basis.

\section{Fly Ash Disposal Totals}

Wet Total Solids: The sum of the fly ash and FGD solids on a wet basis.

Total Mercury: Mass flow rate of mercury present in the combined fly ash and FGD solids on a wet basis. 


\section{By Products Management Geological Resevoir Diagram}

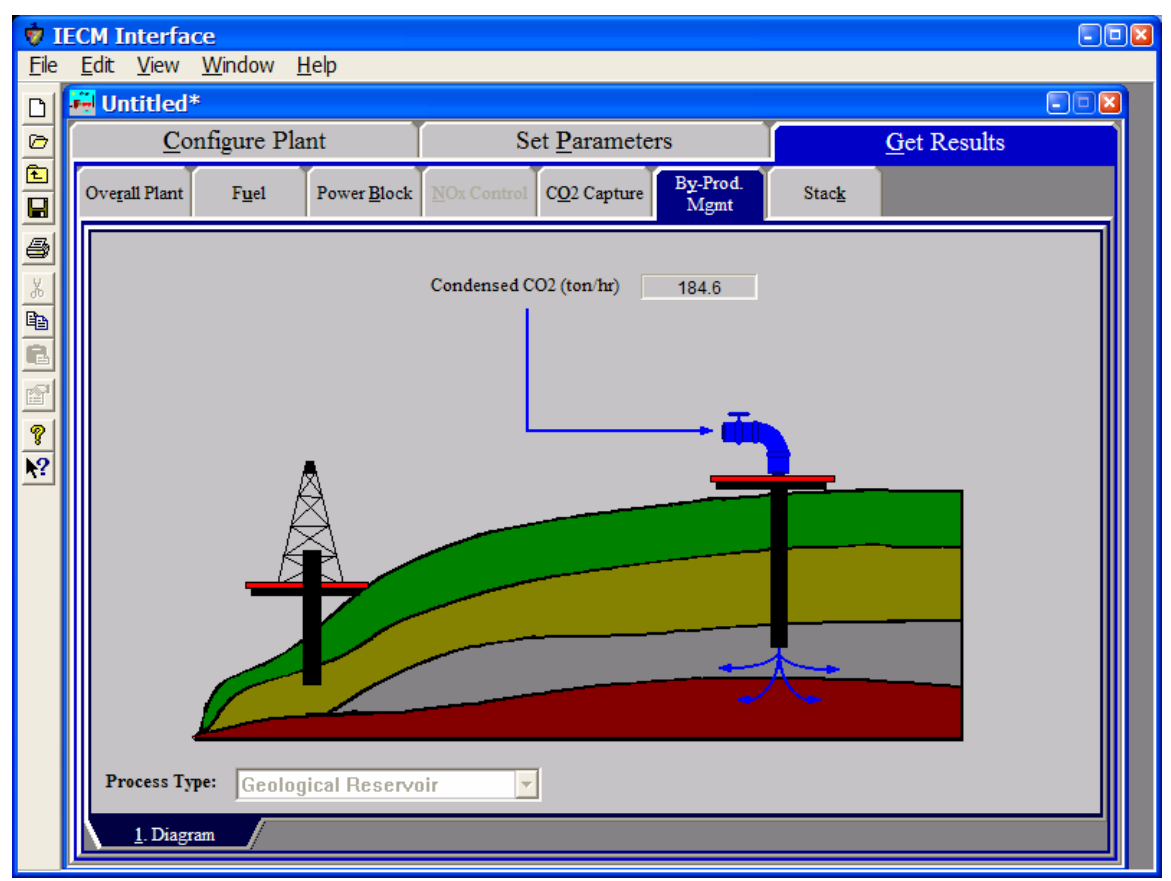

By Product Management - Geological Reservoir diagram.

The By Products Management Geological Reservoir Diagram result screen displays an icon for the Geological Reservoir and values for the concentrated $\mathrm{CO}_{2}$ that flows into it. The result is described briefly below:

Condensed $\mathrm{CO}_{2}$ : Mass flow rate of $\mathrm{CO}_{2}$. 


\section{$\mathrm{CO}_{2}$ Transport System}

The $\mathrm{CO}_{2}$ Transport System models the transport via pipeline of carbon dioxide $\left(\mathrm{CO}_{2}\right)$ captured at a power plant from plant site to sequestration site. It may be used in all of the plant type configurations.

\section{$\mathrm{CO}_{2}$ Transport System Configuration}

This screen is available for all plant types. The screens under the $\mathbf{C O}_{\mathbf{2}}$ Capture Technology Navigation Tab display and design flows and data related to the $\mathbf{C O}_{2}$ Transport System.

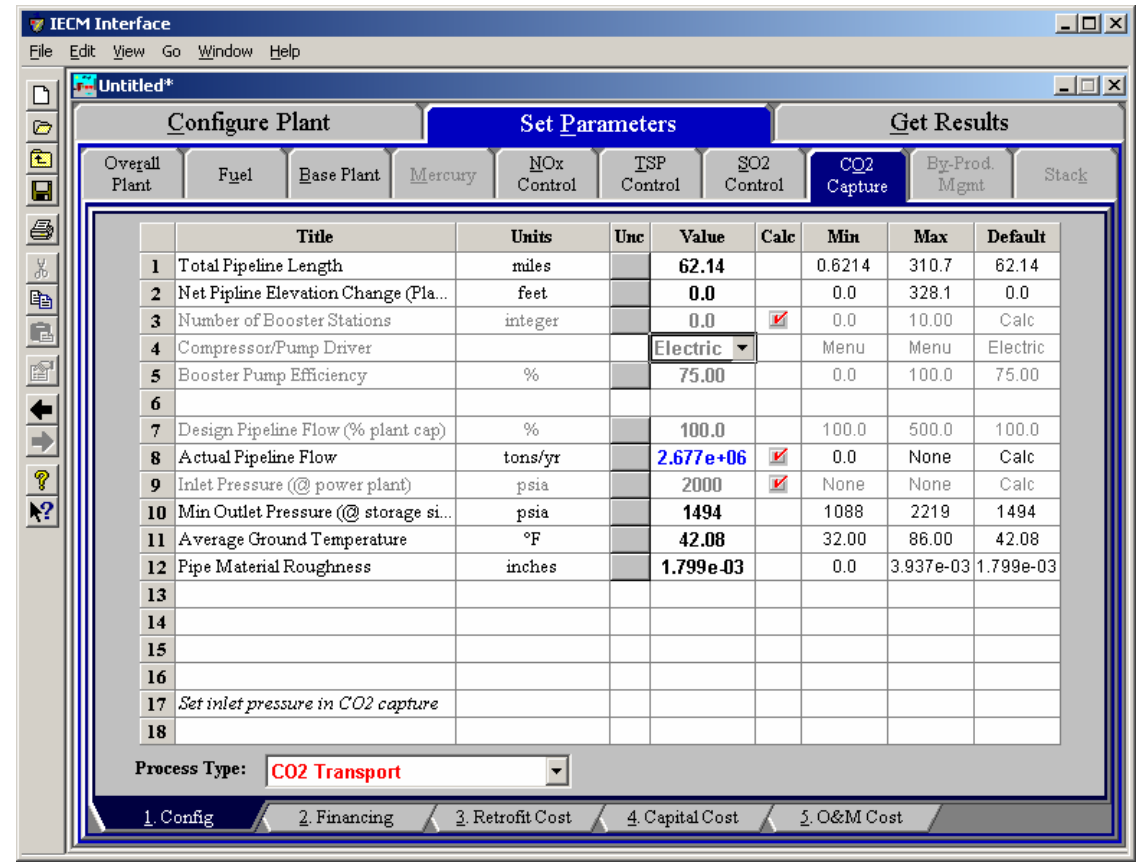

$\mathrm{CO}_{2}$ Transport System - Config. input screen.

Each configuration parameter is described briefly below.

Total Pipeline Length: This is the total length of the pipe between the plant site and the sequestration site. 
Net Pipeline Elevation Change (Plant->Injection): The pipeline may traverse hilly terrain; this is the overall elevation change from plant site to injection site.

Number of Booster Stations: The cost of $\mathrm{CO}_{2}$ transport may be lowered by adding booster stations for longer pipeline lengths. This is the number of those stations that are to be modeled.

Compressor/Pump Driver: This is the type of motor that drives the compressor or pump; electric, diesel or natural gas.

Booster Pump Efficiency: This is the efficiency of the pump, and accounts for all frictional losses.

Design Pipeline Flow (\% plant cap): This is the flow of liquid $\mathrm{CO}_{2}$ that the pipeline has been designed to handle as a percent of the total that the plant is capable of producing.

Actual Pipeline Flow: This is the amount of liquid $\mathrm{CO}_{2}$ that flows through the pipeline in tons per year.

Inlet Pressure (@ power plant): The inlet pressure is shown here for reference only and may be modified in the parameters for the $\mathrm{CO}_{2}$ capture device (e.g., amine scrubber, selexol scrubber)

Min. Outlet Pressure (@ storage site): This the minimum outlet pressure of the $\mathrm{CO}_{2}$ at the storage site

Average Ground Temperature: This is the average temperature of the ground where the pipeline will traverse.

Pipe Material Roughness: The roughness measure is the average size of the bumps on the pipe wall, for commercial pipes this is usually a very small number. Note that perfectly smooth pipes would have a roughness of zero. 


\section{$\mathrm{CO}_{2}$ Transport System Financing Inputs}

This screen is available for all plant types.

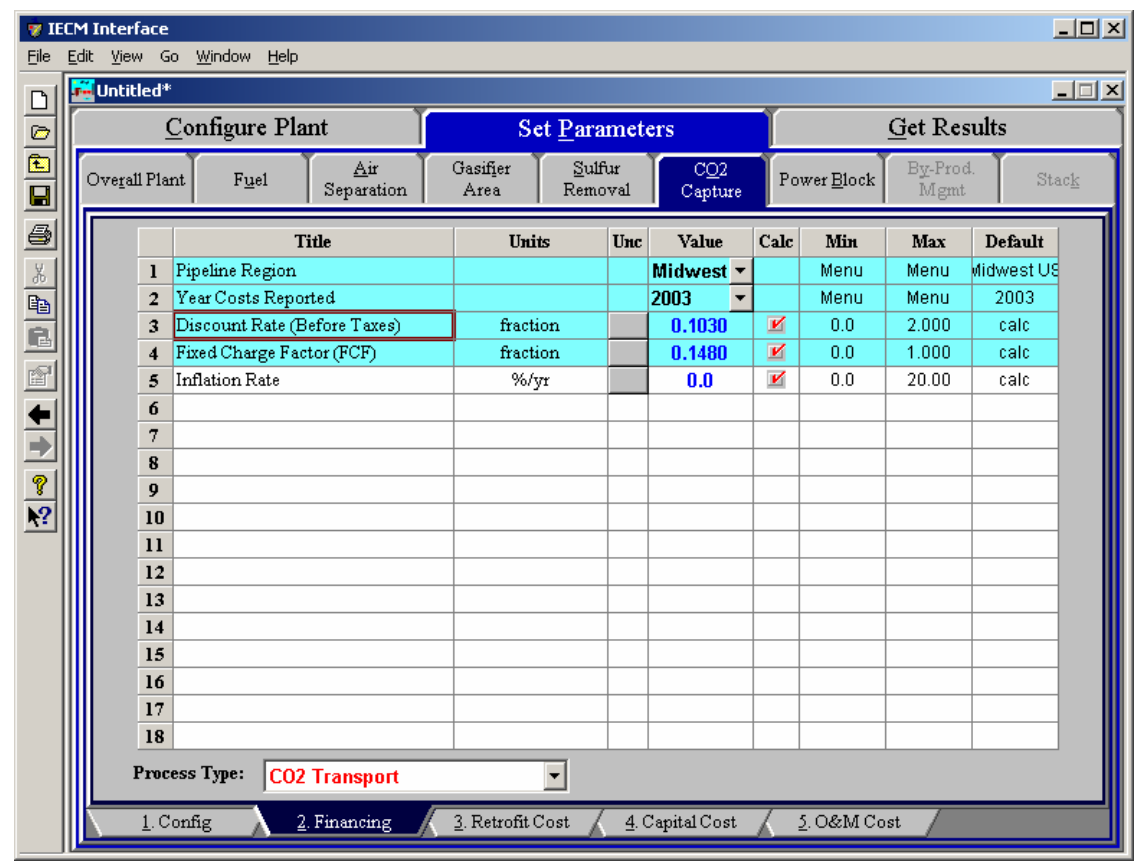

$\mathrm{CO}_{2}$ Transport System -Financing input screen.

Pipeline Region: This is the region of the U.S. where the project will be built; central, mid-west, northeast, southeast or western. These regions are based on the EIA natural gas pipeline regions.

Year Costs Reported: This is the year in which all costs are given or displayed, both in the input screens and the results. A cost index is used by the IECM to scale all costs to the cost year specified by this parameter.

Discount Rate (Before Taxes): This is also known as the cost of money. Discount rate (before taxes) is equal to the sum or return on debt plus return on equity, and is the time value of money used in before-tax present worth arithmetic (i.e., levelization).

Fixed Charge Factor (FCF): This parameter, also known as the capital recovery factor, is used to find the uniform annual amount needed to repay a loan or investment with interest. It is one of the most important parameters in the IECM. It determines the revenue required to finance the power plant based on the capital expenditures. Put another way, it is a levelized factor which accounts for the revenue per dollar of total plant cost that must be collected from customers in order to pay the carrying charges on that capital investment.

Inflation Rate: This is the rise in price levels caused by an increase in the available currency and credit without a proportionate increase in available goods or services. It does not include real escalation. 


\section{$\mathrm{CO}_{2}$ Transport System Retrofit Costs Inputs}

This screen is available for all plant types.

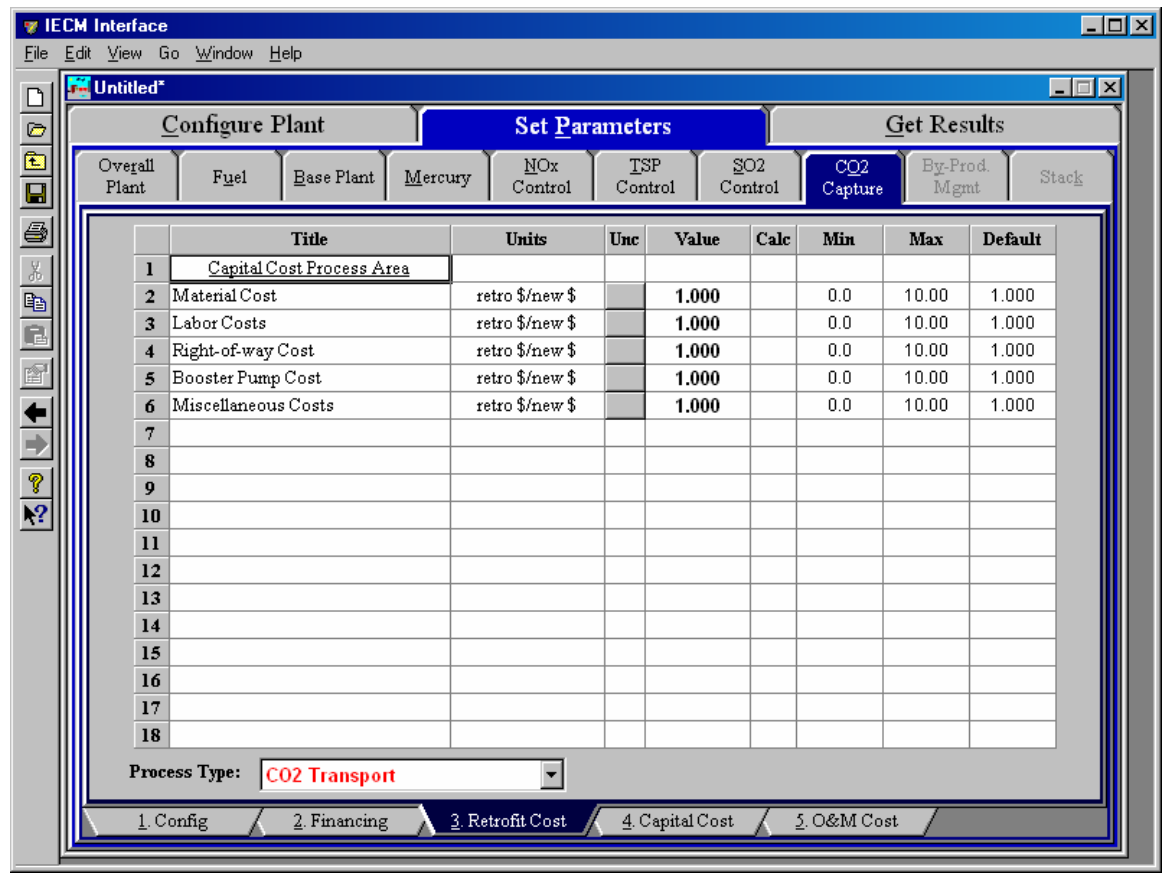

$\mathrm{CO}_{2}$ Transport System - Retrofit Cost input screen.

\section{Capital Cost Process Area}

The retrofit cost factor of each process is a multiplicative cost adjustment, which considers the cost of retrofitted capital equipment relative to similar equipment installed in a new plant. These factors affect the capital costs directly and the operating and maintenance costs indirectly.

Direct capital costs for each process area are calculated in the IECM. These calculations are reduced form equations derived from more sophisticated models and reports. The sum of the direct capital costs associated with each process area is defined as the process facilities capital (PFC). The retrofit cost factor provided for each of the process areas can be used as a tool for adjusting the anticipated costs and uncertainties across the process area separate from the other areas.

Uncertainty can be applied to the retrofit cost factor for each process area in each technology. Thus, uncertainty can be applied as a general factor across an entire process area, rather than as a specific uncertainty for the particular cost on the capital or O\&M input screens. Any uncertainty applied to a process area through the retrofit cost factor compounds any uncertainties specified later in the capital and O\&M cost input parameter screens.

The following are the Capital Cost Process Areas for the $\mathrm{CO}_{2}$ Transport System:

Material Cost: This includes the cost of line pipe, pipe coatings, and cathodic protection.

Labor Costs: This covers the cost of labor during pipeline construction. 
Right-of-way Cost: This is the cost of obtaining right-of-way for the pipeline. This cost not only includes compensating landowners for signing easement agreements but landowners may be also be paid for loss of certain uses of the land during and after construction, loss of any other resources, and any damage to property.

Booster Pump Cost: This is the total capital cost of a booster pump.

Miscellaneous Cost: This includes the costs of: surveying, engineering, supervision, contingencies, telecommunications equipment, freight, taxes, allowances for funds used during construction (AUFDC), administration and overheads, and regulatory filing fees.

\section{$\mathrm{CO}_{2}$ Transport System Capital Cost Inputs}

This screen is available for all of the plant types; the Combustion (Boiler), the Combustion (Turbine) and IGCC.

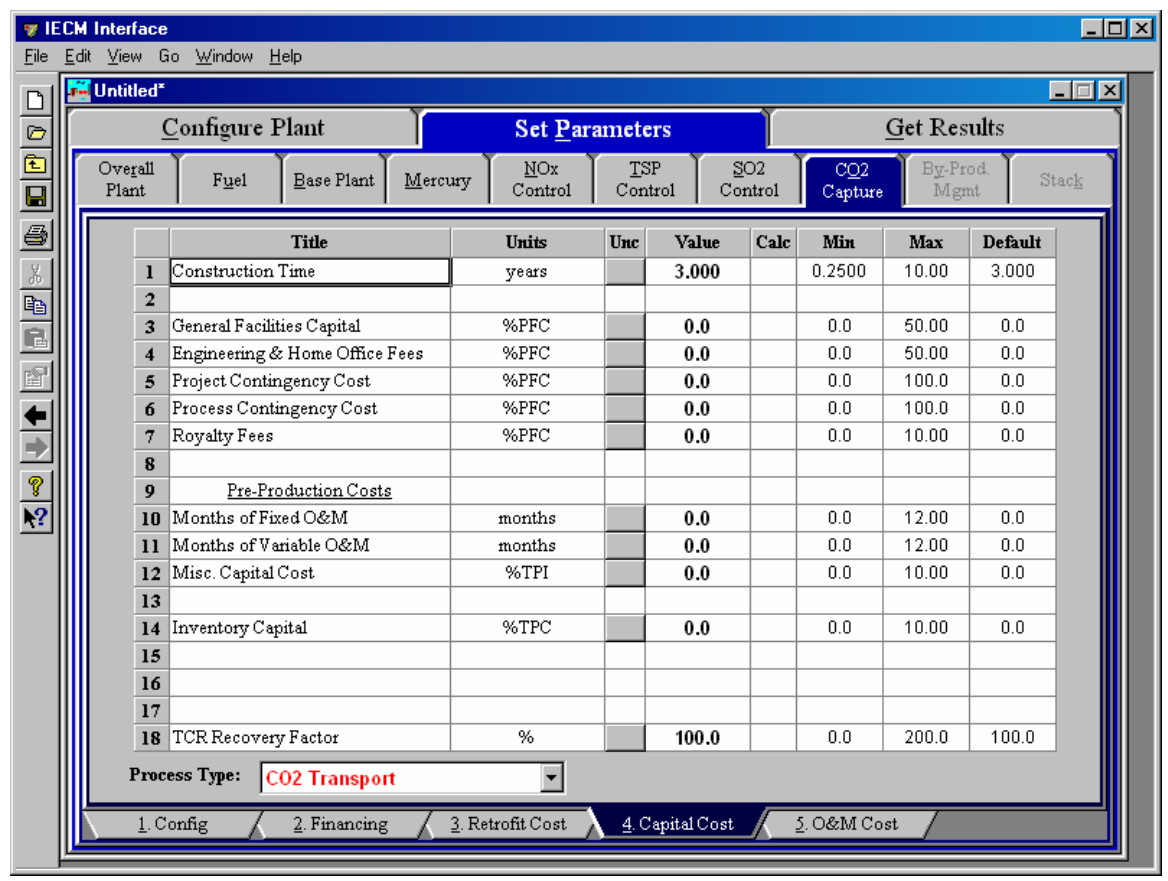

$\mathrm{CO}_{2}$ Transport System -Capital Cost input screen

Inputs for capital costs are entered on the Capital Cost input screen.

Construction Time: This is the idealized construction period in years. It is used to determine the allowance for funds used during construction (AFUDC).

General Facilities Capital (GFC): The general facilities include construction costs of roads, office buildings, shops, laboratories, etc. Sales taxes and freight costs are included implicitly. The cost typically ranges from $5-20 \%$.

Engineering \& Home Office Fees: The engineering \& home office fees are a percent of total direct capital cost. This is an overhead fee paid to the architect/engineering company. These fees typically range from 7$15 \%$. 
Project Contingency Cost: This is factor covering the cost of additional equipment or other costs resulting from a more detailed design. Higher contingency factors will be applied to simplified or preliminary designs and lower factors to detailed or finalized designs.

Process Contingency Cost: This quantifies the design uncertainty and cost of a commercial-scale system. This is generally applied on an areaby-area basis. Higher contingency factors are applied to new regeneration systems tested at a pilot plant and lower factors to full-size or commercial systems.

Royalty Fees: Royalty charges may apply to some portions of generating units incorporating new proprietary technologies.

Pre-Production Costs: These costs consider the operator training, equipment checkout, major changes in unit equipment, extra maintenance, and inefficient use of fuel or other materials during startup. These are typically applied to the O\&M costs over a specified period of time (months). The two time periods for fixed and variable O\&M costs are described below with the addition of a miscellaneous capital cost factor.

- Months of Fixed O\&M: Time period of fixed operating costs used for preproduction to cover training, testing, major changes in equipment, and inefficiencies in start-up. This includes operating, maintenance, administrative and support labor. It also considers maintenance materials.

- Months of Variable O\&M: Time period of variable operating costs used for preproduction to cover chemicals, water, consumables, and solid disposal charges in start-up, assuming $100 \%$ load. This excludes any fuels.

- Misc. Capital Cost: This is a percent of total plant investment (sum of TPC and AFUDC) to cover expected changes to equipment to bring the system up to full capacity.

Inventory Capital: Percent of the total direct capital for raw material supply based on $100 \%$ capacity during a 60 day period. These materials are considered storage. The inventory capital includes fuels, consumables, by-products, and spare parts. This is typically $0.5 \%$.

TCR Recovery Factor: The actual total capital required (TCR) as a percent of the TCR in a new power plant. This value is $100 \%$ for a new installation and may be set as low as $0 \%$ for a fabric filter that has been paid off. 


\section{$\mathrm{CO}_{2}$ Transport System O\&M Cost Inputs}

This screen is available for all plant types.

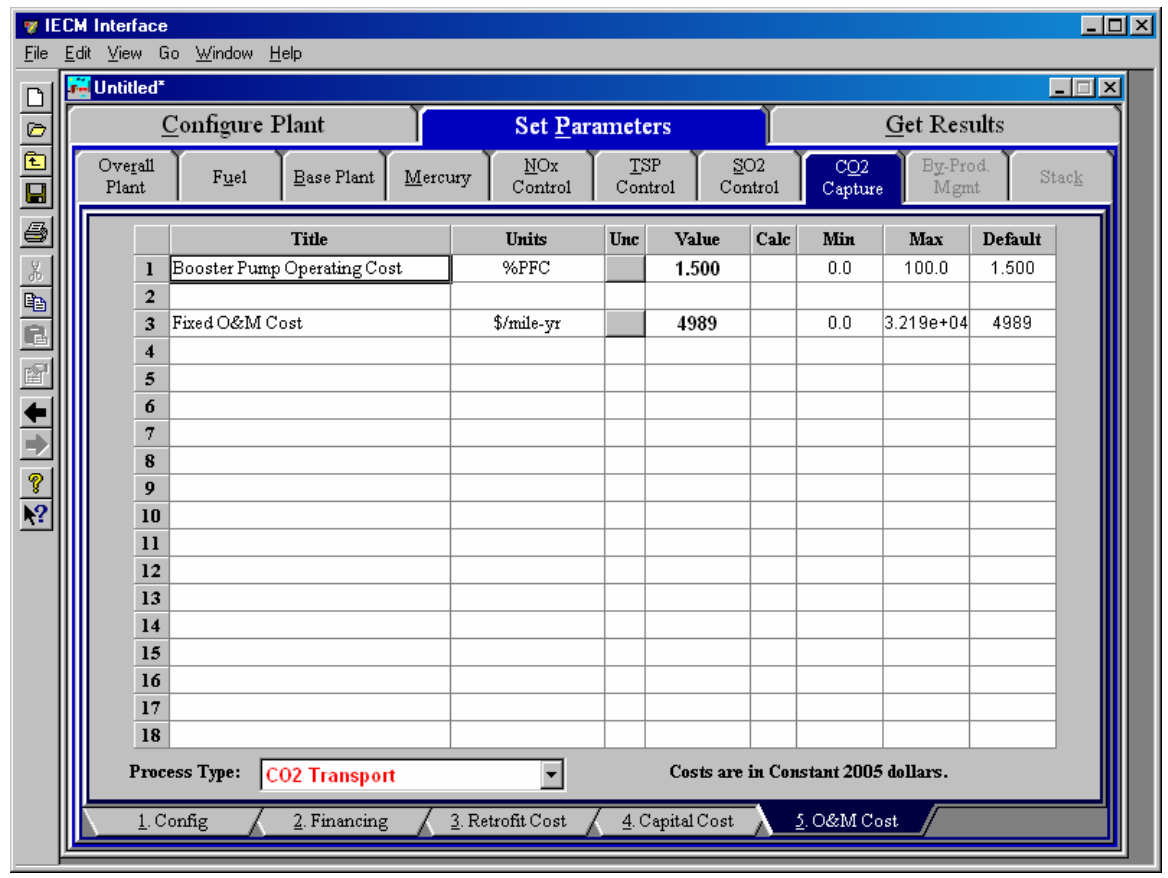

$\mathrm{CO}_{2}$ Transport System - O\&M Cost input screen.

Inputs for operation and maintenance are entered on the O\&M Cost input. O\&M costs are typically expressed on an average annual basis and are provided in either constant or current dollars for a specified year, as shown on the bottom of the screen. Each parameter is described briefly below:

Booster Pump Operating Cost: This is the cost of operating a booster pump as a percent of the process facilities capital

Fixed O\&M Cost: These are the operating and maintenance fixed costs including all maintenance materials and all labor costs and is given in dollars per mile of pipeline per year. 


\section{$\mathrm{CO}_{2}$ Transport System Diagram}

This screen is available for all plant types.

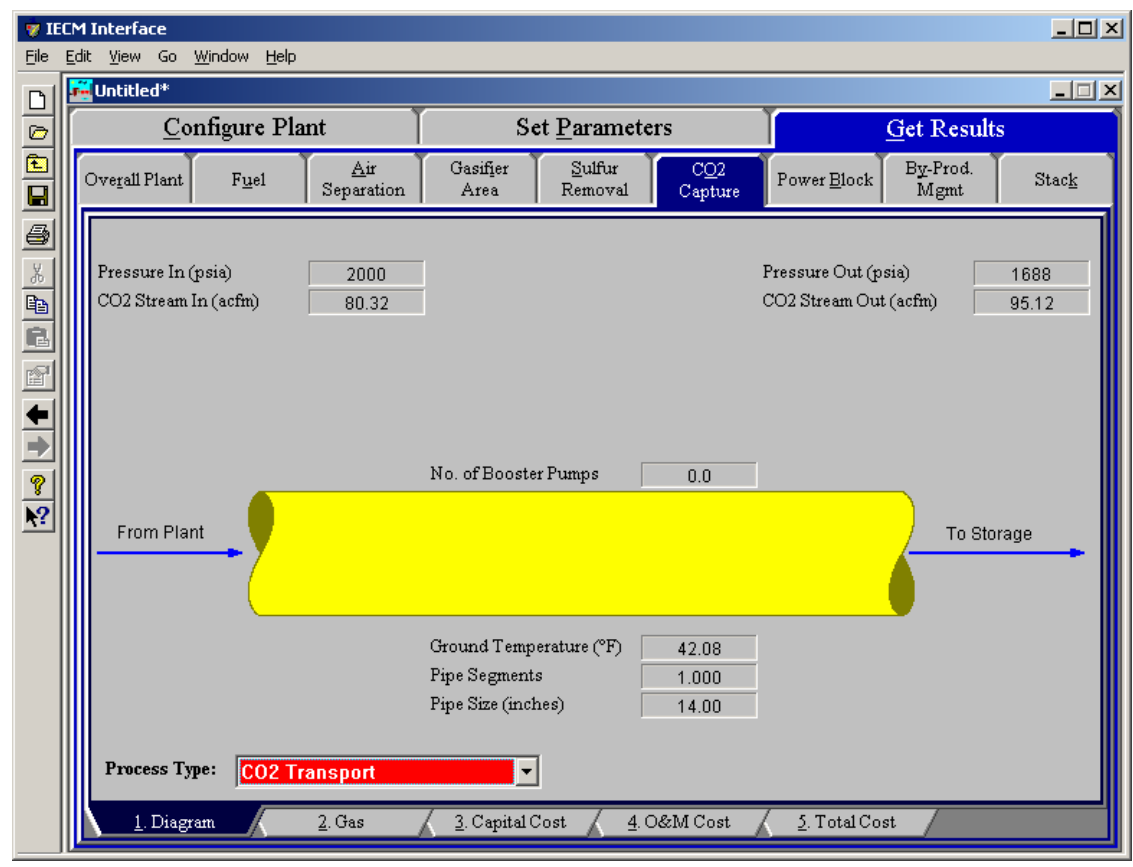

$\mathrm{CO}_{2}$ Transport System - Diagram.

\section{From Plant}

Pressure In: This is the pressure of the $\mathrm{CO}_{2}$ from the plant into the pipeline in absolute pounds per square inch.

$\mathbf{C O}_{2}$ Stream In: This is the flow of the $\mathrm{CO}_{2}$ from the plant into the pipeline in actual cubic feet per minute.

\section{To $\mathrm{CO}_{2}$ Transport System}

No. of Booster Pumps: This is the number of booster pumps used (if any).

Ground Temperature: Average ground temperature that the pipeline traverses.

Pipe Segments: Total number of pipe segments from plant to injection site.

Pipe Size: Outer diameter of the pipe in inches.

\section{To Storage}

Pressure Out: This is the pressure of the $\mathrm{CO}_{2}$ when it enters the storage site in absolute pounds per square inch.

$\mathrm{CO}_{2}$ Stream Out: This is the flow of the $\mathrm{CO}_{2}$ from the pipeline into the storage site in actual cubic feet per minute. 


\section{$\mathrm{CO}_{2}$ Transport System Flue Gas Results}

This screen is only available for the Combustion (Boiler) and Combustion (Turbine) plant types.

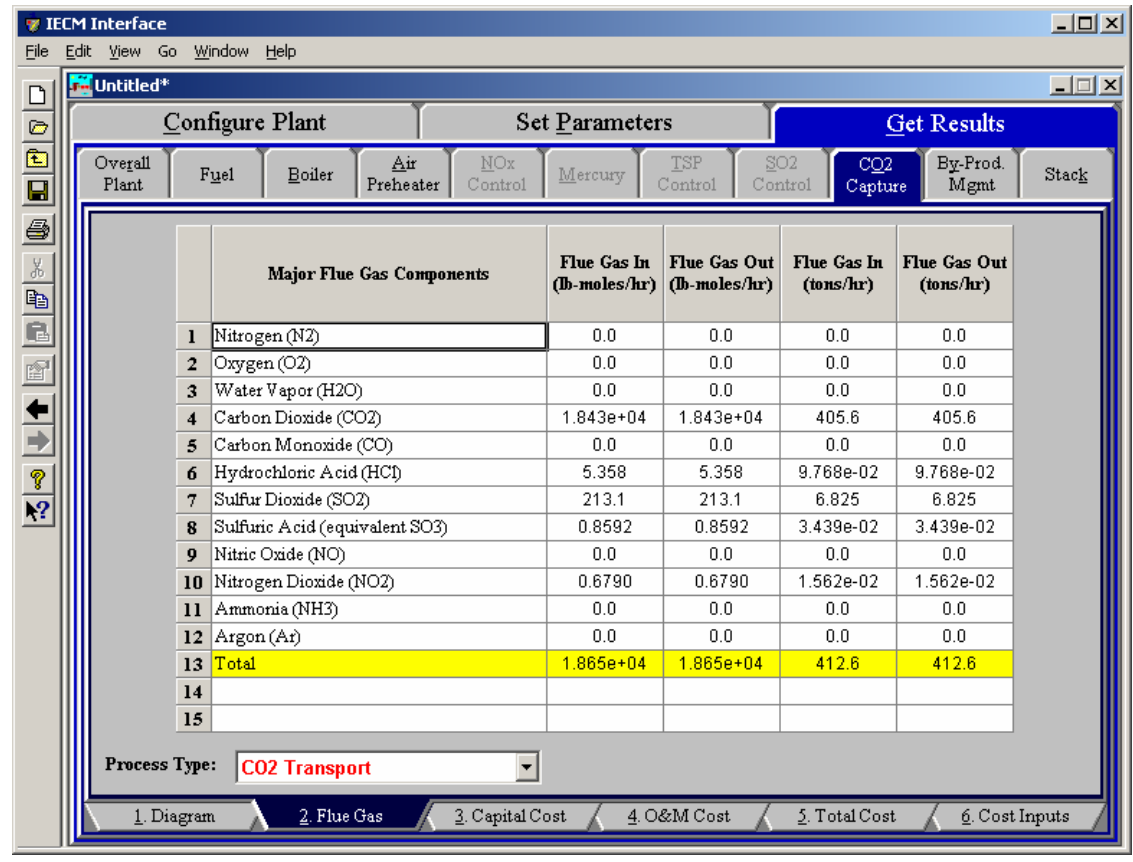

$\mathrm{CO}_{2}$ Transport System - Flue Gas result screen

\section{Major Flue Gas Components}

Each result is described briefly below:

Nitrogen $\left(\mathbf{N}_{2}\right)$ : Total mass of nitrogen.

Oxygen $\left(\mathrm{O}_{2}\right)$ : Total mass of oxygen.

Water Vapor $\left(\mathrm{H}_{2} \mathrm{O}\right)$ : Total mass of water vapor.

Carbon Dioxide $\left(\mathrm{CO}_{2}\right)$ : Total mass of carbon dioxide.

Carbon Monoxide (CO): Total mass of carbon monoxide.

Hydrochloric Acid $(\mathbf{H C l})$ : Total mass of hydrochloric acid.

Sulfur Dioxide $\left(\mathrm{SO}_{2}\right)$ : Total mass of sulfur dioxide.

Sulfuric Acid (equivalent $\mathbf{S O}_{3}$ ): Total mass of sulfuric acid.

Nitric Oxide (NO): Total mass of nitric oxide.

Nitrogen Dioxide $\left(\mathrm{NO}_{2}\right)$ : Total mass of nitrogen dioxide.

Ammonia $\left(\mathrm{NH}_{3}\right)$ : Total mass of ammonia.

Argon (Ar): Total mass of argon.

Total: Total of the individual components listed above. This item is highlighted in yellow. 


\section{$\mathrm{CO}_{2}$ Transport System Gas Results}

This screen is only available for the IGCC plant type.

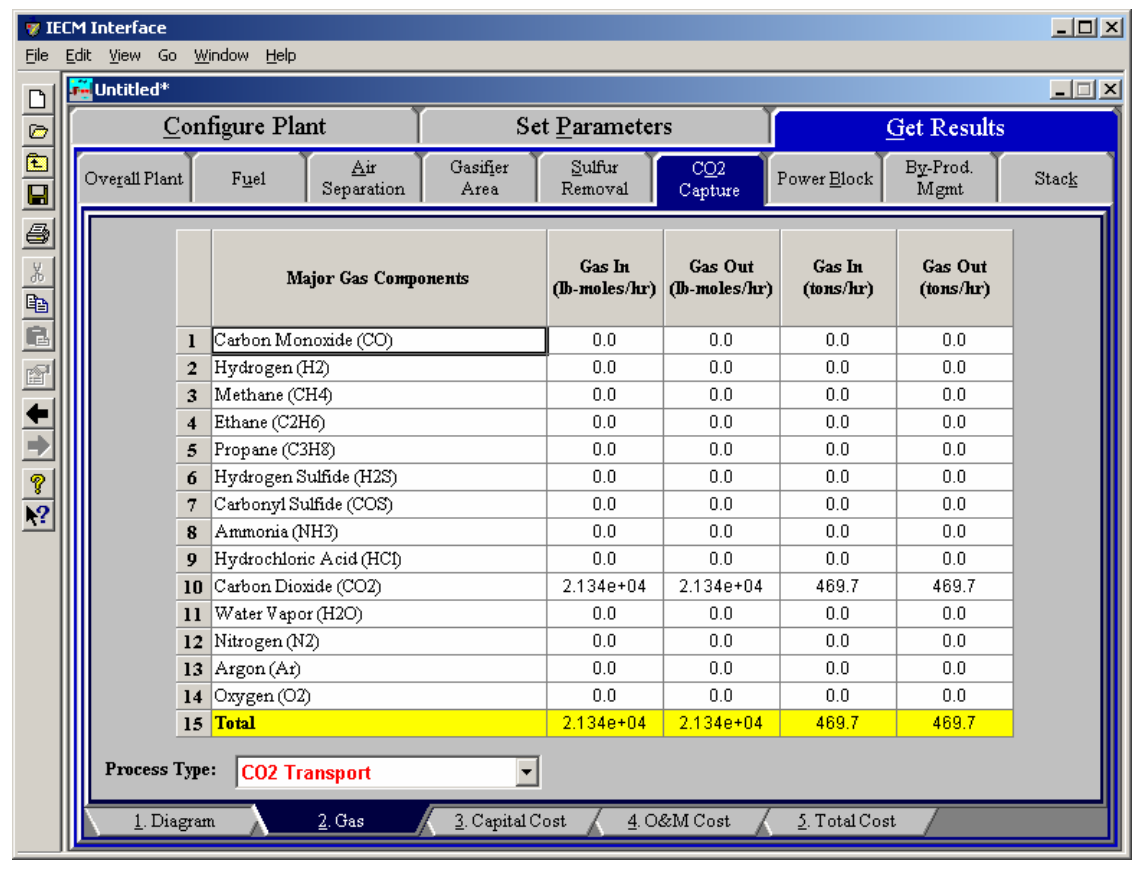

$\mathrm{CO}_{2}$ Transport System - Gas result screen

\section{Major Gas Components}

Each result is described briefly below:

Carbon Monoxide (CO): Total mass of carbon monoxide.

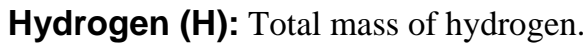

Methane $\left(\mathrm{CH}_{4}\right)$ : Total mass of methane.

Ethane $\left(\mathrm{C}_{2} \mathrm{H}_{6}\right)$ : Total mass of ethane.

Propane $\left(\mathrm{C}_{3} \mathrm{H}_{8}\right)$ : Total mass of propane.

Hydrogen Sulfide $\left(\mathrm{H}_{2} \mathbf{S}\right)$ : Total mass of hydrogen sulfide.

Carbonyl Sulfide (COS): Total mass of carbon dioxide.

Ammonia $\left(\mathrm{NH}_{3}\right)$ : Total mass of ammonia.

Hydrochloric Acid ( $\mathrm{HCl})$ : Total mass of hydrochloric acid.

Carbon Dioxide $\left(\mathrm{CO}_{2}\right)$ : Total mass of carbon dioxide.

Water Vapor $\left(\mathrm{H}_{2} \mathrm{O}\right)$ : Total mass of water vapor.

Nitrogen $\left(\mathrm{N}_{2}\right)$ : Total mass of nitrogen.

Argon (Ar): Total mass of argon.

Oxygen $\left(\mathrm{O}_{2}\right)$ : Total mass of oxygen.

Total: Total of the individual components listed above. This item is highlighted in yellow. 


\section{$\mathrm{CO}_{2}$ Transport System Capital Cost Results}

This screen is available for all plant types.

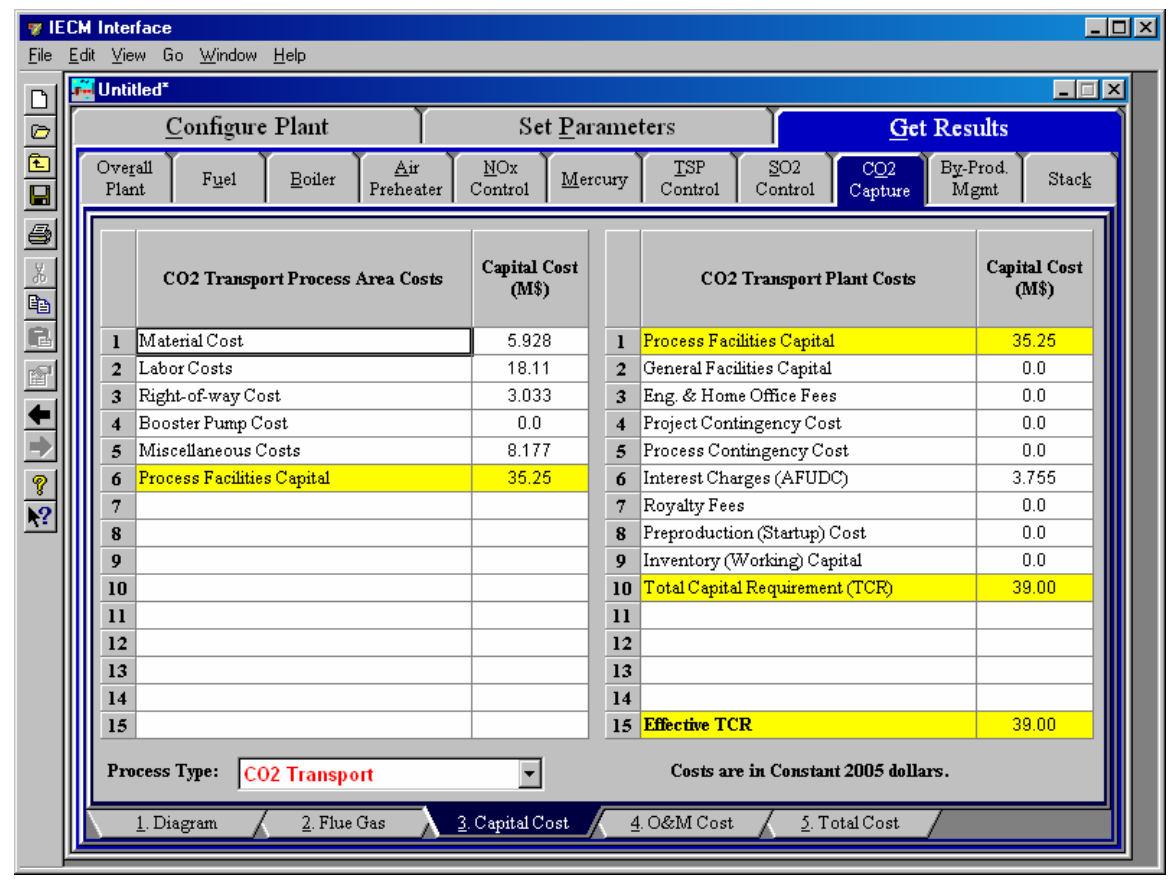

$\mathrm{CO}_{2}$ Transport System - Capital Cost result screen.

The Capital Cost result screen displays tables for the capital costs. Capital costs are typically expressed in either constant or current dollars for a specified year, as shown on the bottom of the screen. Each result is described briefly below:

\section{$\mathrm{CO}_{2}$ Transport Process Area Costs}

Material Cost: This includes the cost of line pipe, pipe coatings, and cathodic protection.

Labor Costs: This covers the cost of labor during pipeline construction.

Right-of-way Cost: This is the cost of obtaining right-of-way for the pipeline. This cost not only includes compensating landowners for signing easement agreements but landowners may be also be paid for loss of certain uses of the land during and after construction, loss of any other resources, and any damage to property.

Booster Pump Cost: This is the total capital cost of a booster pump.

Miscellaneous Cost: This includes the costs of: surveying, engineering, supervision, contingencies, telecommunications equipment, freight, taxes, allowances for funds used during construction (AUFDC), administration and overheads, and regulatory filing fees.

Process Facilities Capital: The process facilities capital is the total constructed cost of all on-site processing and generating units listed above, including all direct and indirect construction costs. All sales taxes and freight costs are included where applicable implicitly. This result is highlighted in yellow. 


\section{$\mathrm{CO}_{2}$ Transport Plant Costs}

Process Facilities Capital: (see definition above).

General Facilities Capital: The general facilities include construction costs of roads, office buildings, shops, laboratories, etc. Sales taxes and freight costs are included implicitly.

Eng. \& Home Office Fees: The engineering \& home office fees are a percent of total direct capital cost. This is an overhead fee paid to the architect/engineering company.

Project Contingency Cost: Capital cost contingency factor covering the cost of additional equipment or other costs that would result from a more detailed design of a definitive project at the actual site.

Process Contingency Cost: Capital cost contingency factor applied to a new technology in an effort to quantify the uncertainty in the technical performance and cost of the commercial-scale equipment.

Interest Charges (AFUDC): Allowance for funds used during construction, also referred to as interest during construction, is the time value of the money used during construction and is based on an interest rate equal to the before-tax weighted cost of capital. This interest is compounded on an annual basis (end of year) during the construction period for all funds spent during the year or previous years.

Royalty Fees: Royalty charges may apply to some portions of generating units incorporating new proprietary technologies.

Preproduction (Startup) Cost: These costs consider the operator training, equipment checkout, major changes in unit equipment, extra maintenance, and inefficient use of fuel or other materials during startup.

Inventory (Working) Capital: The raw material supply based on $100 \%$ capacity during a 60 day period. These materials are considered storage. The inventory capital includes fuels, consumables, byproducts, and spare parts.

Total Capital Requirement (TCR): Money that is placed (capitalized) on the books of the utility on the service date. TCR includes all the items above. This result is highlighted in yellow.

Effective TCR: The TCR of the pipeline transport system that is used in determining the total power plant cost. The effective TCR is determined by the "TCR Recovery Factor". 


\section{$\mathrm{CO}_{2}$ Transport System O\&M Cost Results}

This screen is available for all plant types.

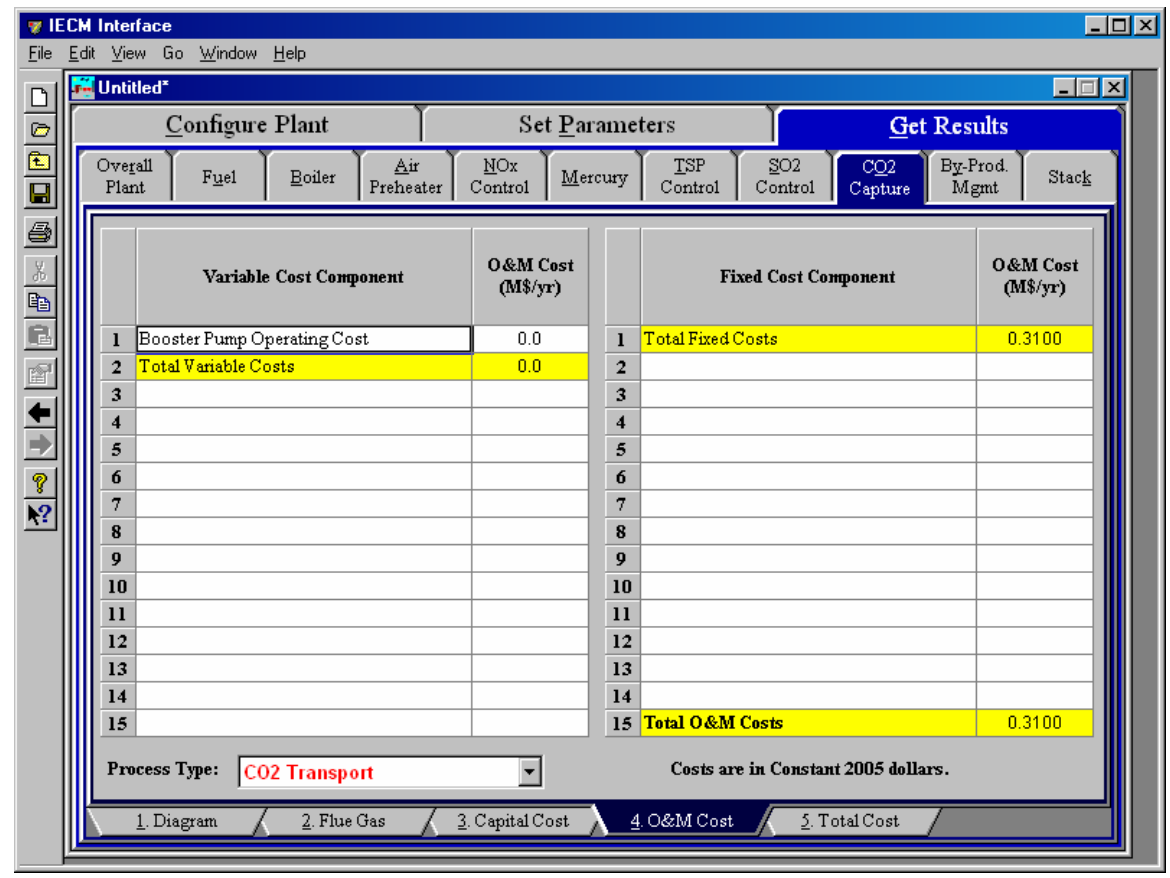

$\mathrm{CO}_{2}$ Transport System - O\&M Cost result screen.

The O\&M Cost result screen displays tables for the variable and fixed operation and maintenance costs involved with the $\mathbf{C O}_{2}$ Capture technology. O\&M costs are typically expressed on an average annual basis and are provided in either constant or current dollars for a specified year, as shown on the bottom of the screen. Each result is described briefly below:

\section{Variable Cost Components}

Variable operating costs and consumables are directly proportional to the amount of kilowatts produced and are referred to as incremental costs. All the costs are subject to inflation.

Booster Pump Operating Cost: This is the total capital cost of a booster pump.

Total Variable Costs: This is the sum of all the variable O\&M costs listed above. This result is highlighted in yellow.

\section{Fixed Cost Components}

Fixed operating costs are essentially independent of actual capacity factor, number of hours of operation, or amount of kilowatts produced. All the costs are subject to inflation.

Total Fixed Costs: This is the sum of all the fixed O\&M costs listed above. This result is highlighted in yellow. 
Total O\&M Costs: This is the sum of the total variable and total fixed O\&M costs. It is used to determine the base plant total revenue requirement. This result is highlighted in yellow.

\section{$\mathrm{CO}_{2}$ Transport System Total Cost Results}

This screen is available for all plant types.

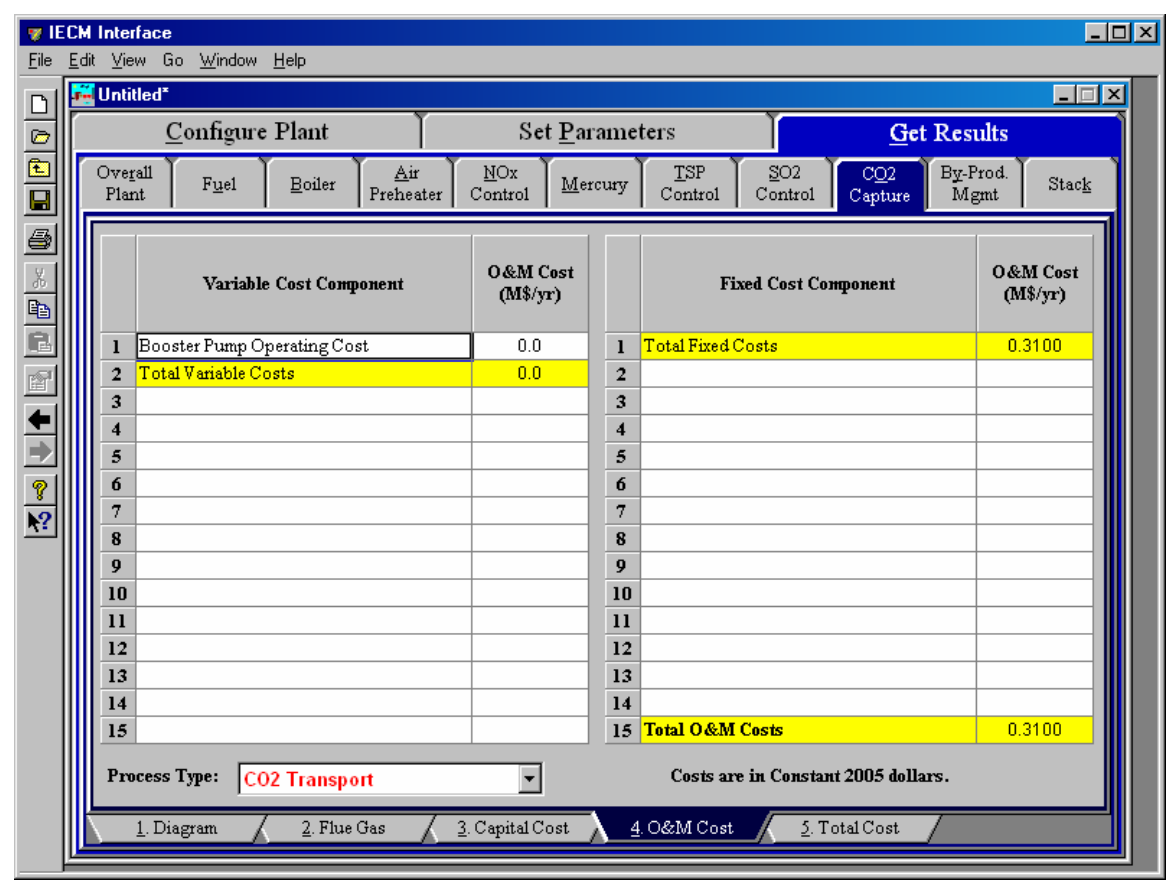

$\mathrm{CO}_{2}$ Transport System - Total Cost result screen.

The Total Cost result screen displays a table which totals the annual fixed, variable, operations and maintenance, and capital costs associated with the $\mathrm{CO}_{2}$ Transport System $\mathrm{CO}_{2}$ Control technology. Total costs are typically expressed in either constant or current dollars for a specified year, as shown on the bottom of the screen. Each result is described briefly below.

Annual Fixed Cost: The operating and maintenance fixed costs are given as an annual total. This number includes all maintenance materials and all labor costs.

Annual Variable Cost: The operating and maintenance variables costs are given as an annual total. This includes all reagent, chemical, steam, and power costs.

Total Annual O\&M Cost: This is the sum of the annual fixed and variable operating and maintenance costs above. This result is highlighted in yellow.

Annualized Capital Cost: This is the total capital cost expressed on an annualized basis, taking into consideration the levelized carrying charge factor, or fixed charge factor, over the entire book life.

Total Levelized Annual Cost: The total annual cost is the sum of the total annual O\&M cost and annualized capital cost items above. This result is highlighted in yellow. 


\section{Stack}

\section{Stack Diagram}

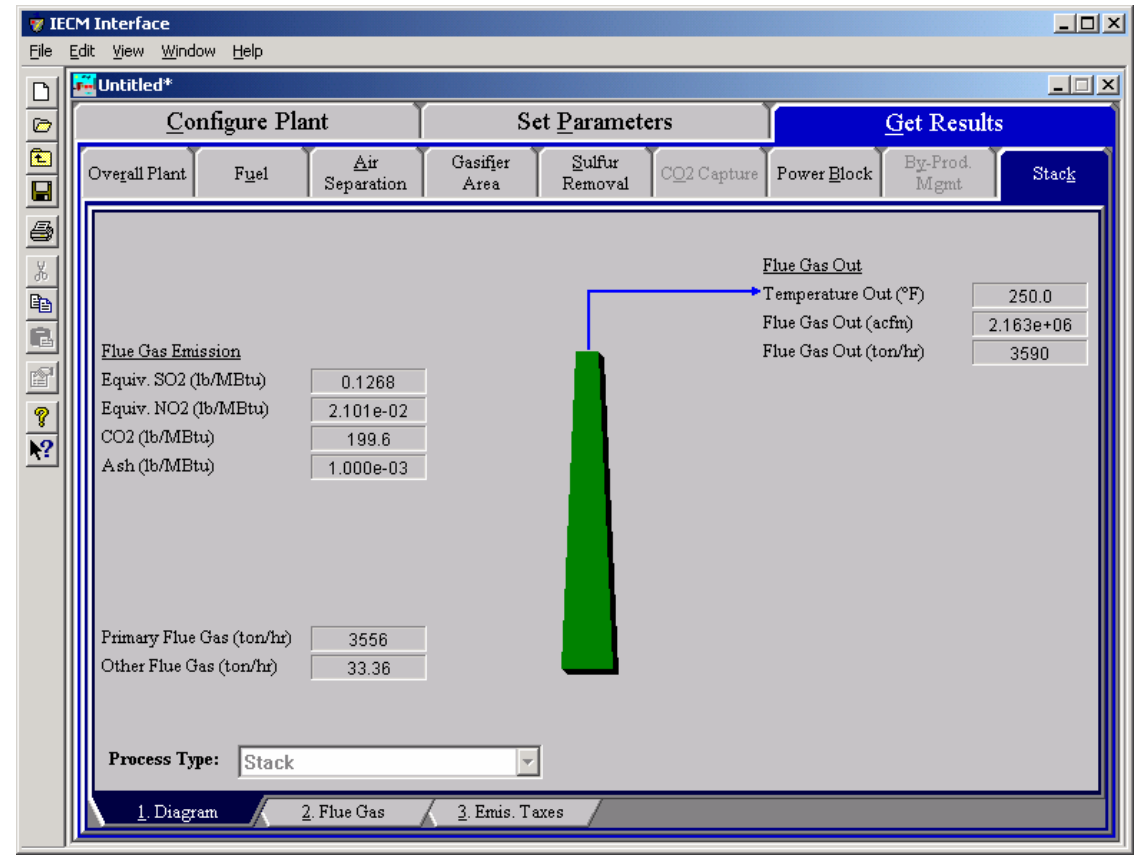

Stack-Diagram.

The Diagram result screen displays an icon for the stack and values for major flows out of it. Each result is described briefly below.

\section{Flue Gas Out}

Temperature Out: Temperature of the flue gas exiting the stack.

Flue Gas Out: Volumetric flow rate of flue gas exiting the stack, based on the flue gas temperature exiting the stack and atmospheric pressure.

Fly Ash Out: Mass flow rate of solids in the flue gas exiting the stack. 


\section{Flue Gas Emission}

$\mathbf{C O}_{2}$ : This is the number of pounds of $\mathbf{C O}_{2}$ vented to the air for every MBtu.

Equivalent $\mathrm{SO}_{2}$ : This is the number of pounds of Equivalent $\mathbf{S O}_{2}$ vented to the air for every MBtu.

Equivalent $\mathbf{N O}_{2}$ :This is the number of pounds of Equivalent $\mathbf{N O}_{2}$ vented to the air for every MBtu.

Particulate: This is the number of pounds of Particulate vented to the air for every MBtu.

\section{Mercury Emission}

Elemental: This is the number of pounds of Elemental Mercury vented to the air for every MBtu.

Oxidized: This is the number of pounds of Oxidized Mercury vented to the air for every MBtu.

Total: This is the number of pounds of Total Mercury vented to the air for every MBtu.

\section{Mercury Exiting Stack}

Elemental Mercury: Mass flow rate of elemental mercury $\left(\mathrm{Hg}^{0}\right)$ in the flue gas exiting the stack.

Oxidized Mercury: Mass flow rate of oxidized mercury $\left(\mathrm{Hg}^{+2}\right)$ in the flue gas exiting the stack.

Total Mercury: Mass flow rate of total mercury in the flue gas exiting the stack (elemental, oxidized, and particulate).

\section{Stack Flue Gas Results}

The FlueGas result screen displays a table of quantities of flue gas components exiting the stack. For each component, quantities are given in both moles and mass per hour. 


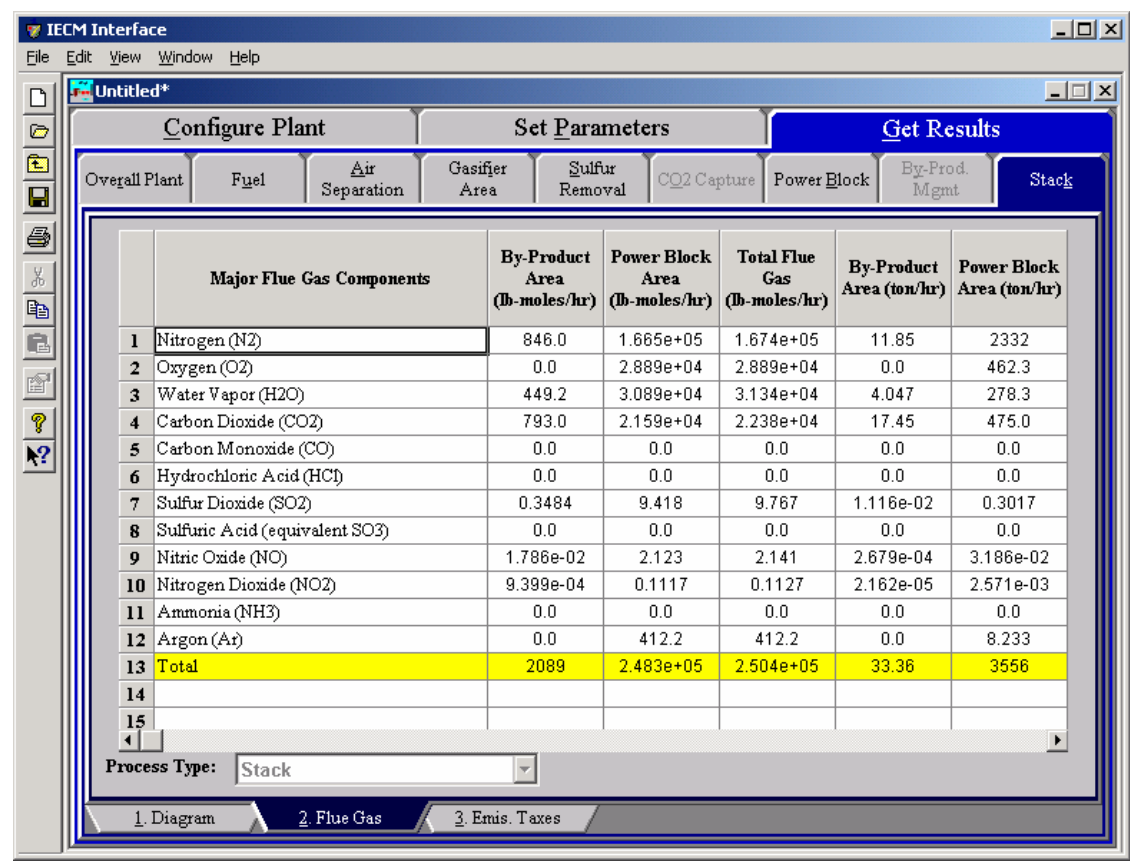

Stack Flue Gas result screen.

\section{Major Flue Gas Components}

Each result is described briefly below

Nitrogen $\left(\mathbf{N}_{\mathbf{2}}\right)$ : Total mass of nitrogen.

Oxygen $\left(\mathrm{O}_{2}\right)$ : Total mass of oxygen.

Water Vapor $\left(\mathrm{H}_{\mathbf{2}} \mathrm{O}\right)$ : Total mass of water vapor.

Carbon Dioxide $\left(\mathrm{CO}_{2}\right)$ : Total mass of carbon dioxide.

Carbon Monoxide (CO): Total mass of carbon monoxide.

Hydrochloric Acid (HCl): Total mass of hydrochloric acid.

Sulfur Dioxide $\left(\mathbf{S O}_{2}\right)$ : Total mass of sulfur dioxide.

Sulfuric Acid (equivalent $\mathbf{S O}_{3}$ ): Total mass of sulfuric acid.

Nitric Oxide (NO): Total mass of nitric oxide.

Nitrogen Dioxide $\left(\mathbf{N O}_{\mathbf{2}}\right)$ : Total mass of nitrogen dioxide.

Ammonia $\left(\mathrm{NH}_{3}\right)$ : Total mass of ammonia.

Argon(Ar): Total mass ofargon.

Total: Total of the individual components listed above. This item is highlighted in yellow. 


\section{Stack Emission Taxes Results}

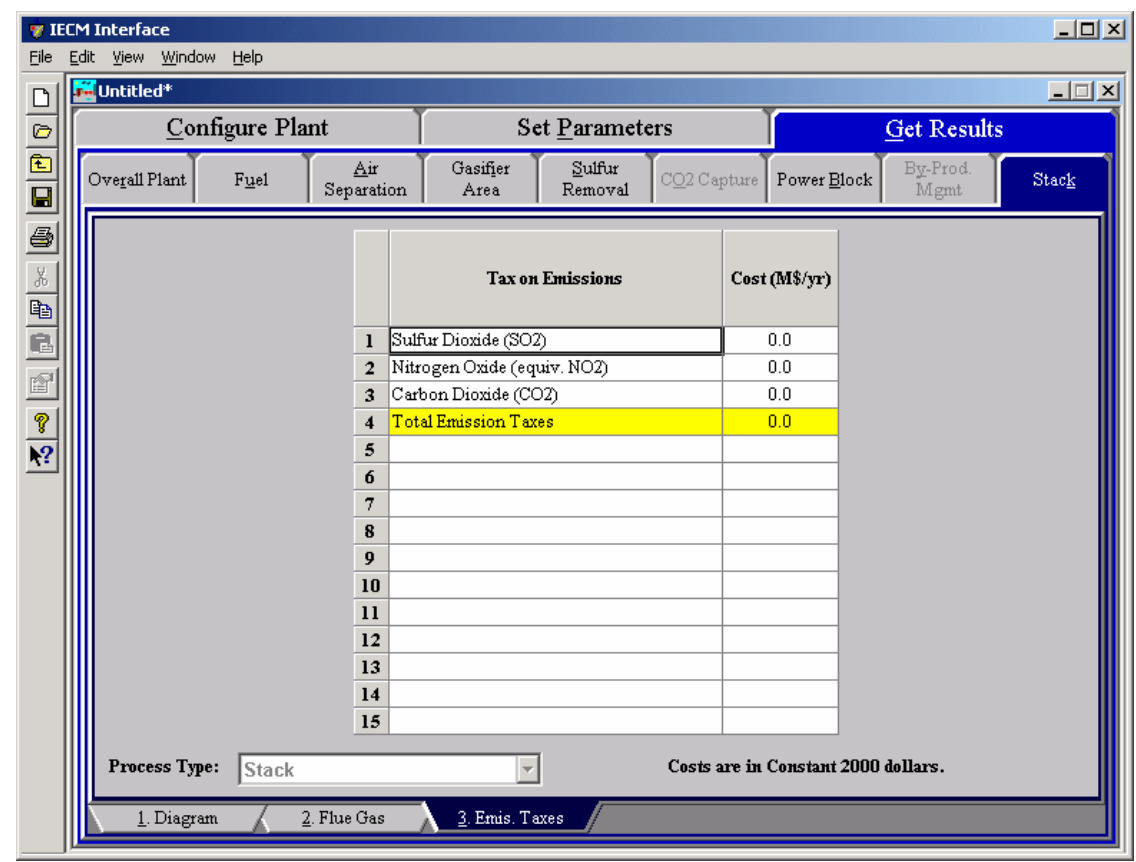

Stack - Emis. Taxes result screen

The Stack Emis. Taxes results screen shows the cost of to the plant for emissions. The Taxes on Emissions are entered by the user in dollars per ton.

\section{Tax on Emissions}

Sulfur Dioxide $\left(\mathrm{SO}_{2}\right)$ : The cost (as a result of user entered data) to the plant of emitting sulfur dioxide in dollars per ton.

Nitrogen Oxide (equiv. $\mathrm{NO}_{2}$ ): The cost (as a result of user entered data) to the plant of emitting nitrogen oxide in dollars per ton.

Carbon Dioxide $\left(\mathrm{CO}_{2}\right)$ : The cost (as a result of user entered data) to the plant of emitting carbon dioxide in dollars per ton.

Total Emission Taxes: This is the sum of the emission taxes displayed above. It is highlighted in yellow. 


\section{Power Block}

The power block technology area includes all the equipment necessary to convert the potential and kinetic energy of natural gas or syngas fuels into steam and electricity.

The process equipment is divided into several areas: the gas turbine/generator, the air compressor, the combustor, the steam turbine, and the heat recovery steam generator. These are all available in the Combustion (Turbine) and IGCC plant types.

\section{Power Block Gas Turbine Inputs}

This screen is only available for the Combustion (Turbine) and IGCC plant types.

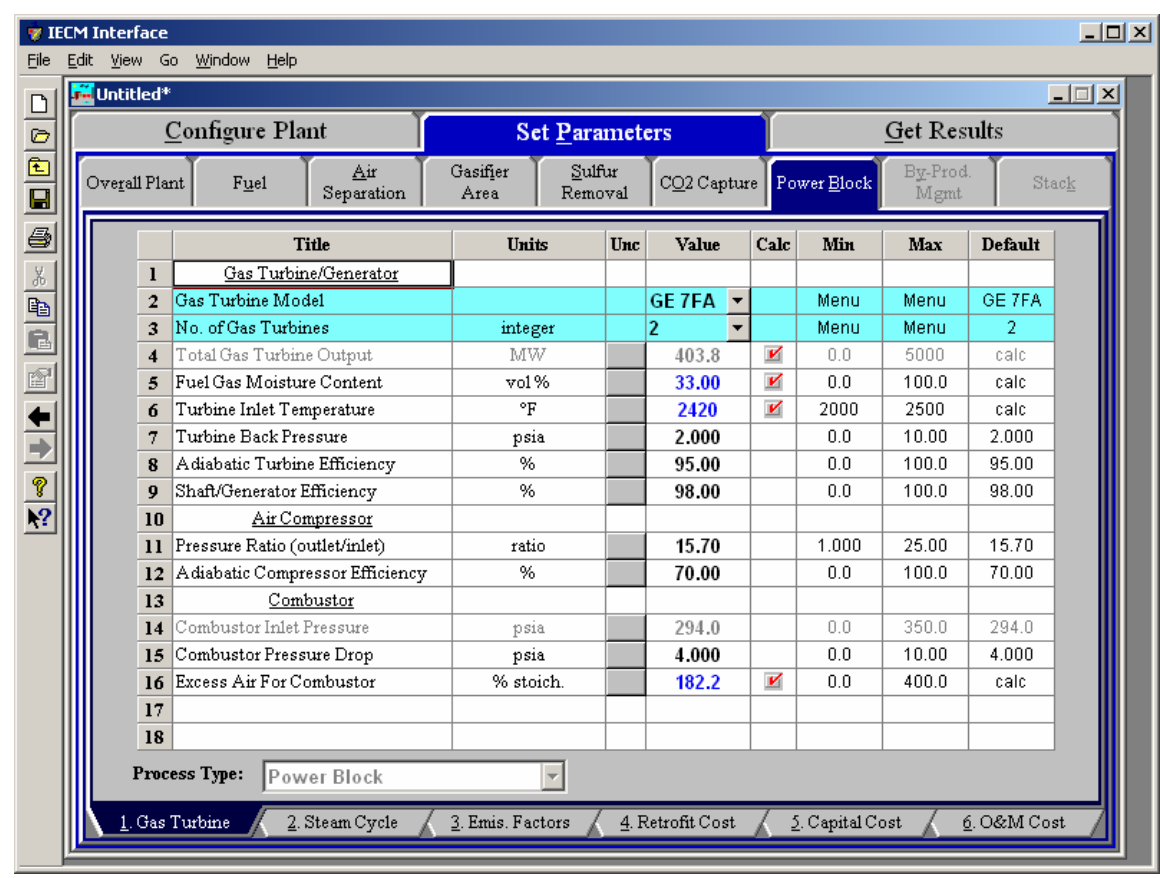

Power Block - Gas Turbine input screen. 


\section{Gas Turbine/Generator}

Gas Turbine Model: This is a selection of the type of turbine model used (manufacturer types currently include only the "7FA"). The type determines the inlet temperature, pressure ratio, and size parameters. This parameter list will be expanded in future versions.

No. of Gas Turbines: This is the number of gas turbines. Since each turbine is able to produce a fixed output, the number of turbines will determine the plant size (e.g., gross plant size).

Total Gas Turbine Output: This parameter is provided for reference purposes only. It provides the gross power generated from the gas turbines alone.

Fuel Gas Moisture Content: Steam is typically added to the fuel gas prior to being combusted. This increases the volume of the fuel gas and results in a higher power output in the gas turbine.

Turbine Inlet Temperature: The turbine inlet temperature is carefully controlled to prevent damage or fatigue of the first stage stator and rotor blades. This temperature is one of the two most important parameters that impacts system efficiency.

Turbine Back Pressure: The turbine exit pressure must be higher than atmospheric pressure to provide a positive pressure on the flue gas exiting the turbine.

Adiabatic Turbine Efficiency: The adiabatic turbine efficiency adjusts for inefficiencies in real turbines. The ratio is an estimate of real to ideal performance.

Shaft/Generator Efficiency: The combined shaft/generator efficiency adjusts for inefficiencies in generator and shaft between the compressor and the generator. The ratio is an estimate of real to ideal performance.

\section{Air Compressor}

Pressure Ratio (outlet/inlet): This is the ratio of the compressor exit pressure to the inlet ambient air pressure. Compression takes place approximately adiabatically.

Adiabatic Compressor Efficiency: The adiabatic compressor efficiency adjusts for inefficiencies in real compressors. The ratio is an estimate of real to ideal performance.

\section{Combustor}

Combustor Inlet Pressure: The combustor inlet pressure is currently fixed at a single value. It is provided for reference purposes only.

Combustor Pressure Drop: Although the combustor operates at essentially constant pressure, a small pressure drop is typically observed in the combustor exit from the compressor exit.

Excess Air For Combustor: This is the excess theoretical air used for combustion. It is added to the stoichiometric air requirement calculated by the model. This value is based on the required mass flow rate of syngas through the combustor, the heat content of the syngas, and the flame temperature of the combustor. 


\section{Power Block Steam Cycle Inputs}

This screen is only available for the Combustion (Turbine) and IGCC plant types.

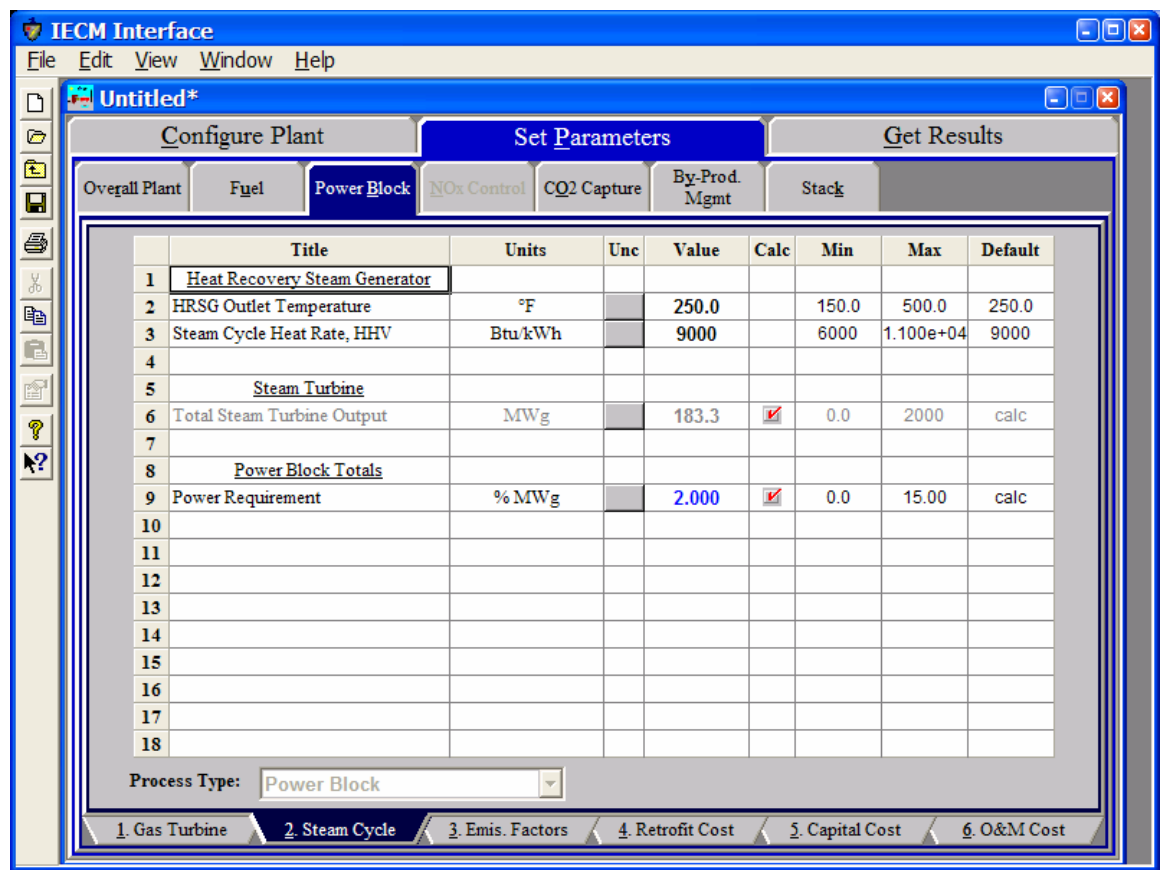

Power Block - Steam Cycle input screen

\section{Heat Recovery Steam Generator}

HRSG Outlet Temperature: This is the desired output temperature from the heat recovery steam generator (HRSG).

Steam Cycle Heat Rate, HHV: This is the steam cycle heat rate for the heat recovery steam generator.

\section{Steam Turbine}

Total Steam Turbine Output: This is the net electricity produced by the steam turbine associated with the HRSG (steam cycle). This value cannot be edited. It is provided for reference only.

\section{Power Block Totals}

Power Requirement: This is the electricity for internal use. It is expressed as a percent of the gross plant capacity.

\section{Power Block Emission Factors}

This screen is only available for the Combustion (Turbine) and IGCC plant types. 


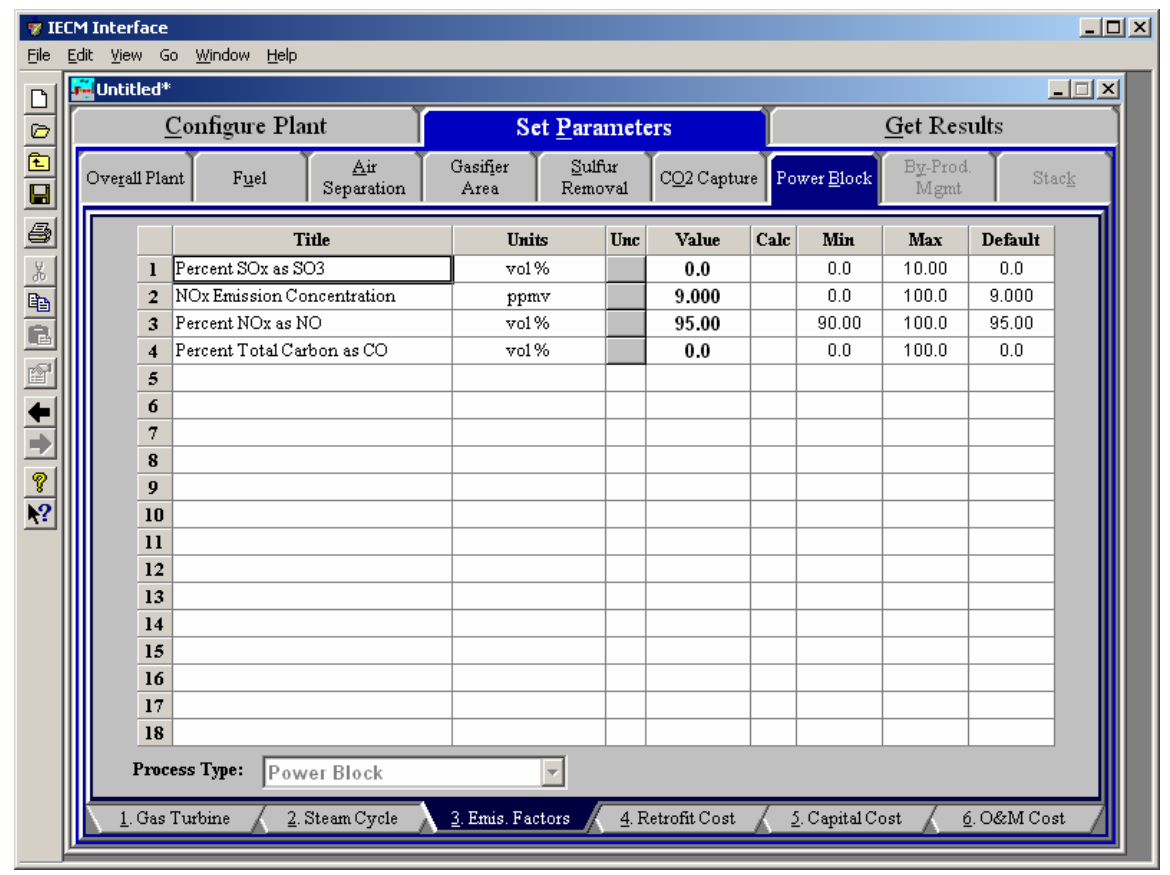

Power Block - Emission Factors input screen.

\section{Emission Factors Input Parameters}

Percent $\mathrm{SO}_{\mathrm{x}}$ as $\mathrm{SO}_{3}$ : This is the volume percent of $\mathrm{SO}_{\mathrm{x}}$ that is $\mathrm{SO}_{3}$. The remainder is $\mathrm{SO}_{2}$.

$\mathrm{NO}_{\mathrm{x}}$ Emission Concentration: This is the concentration of $\mathrm{NO}_{\mathrm{x}}$ emitted from the gas turbine after combustion.

Percent $\mathrm{NO}_{\mathrm{x}}$ as NO: This is the volume percent of $\mathrm{NO}_{\mathrm{x}}$ that is $\mathrm{NO}$. The remainder is $\mathrm{NO}_{2}$.

Percent Total Carbon as CO: This is the volume percent of the total carbon in the syngas entering the combustor that is emitted from the gas turbine as CO.

\section{Power Block Retrofit Cost}

This screen is only available for the Combustion (Turbine) and IGCC plant types. 


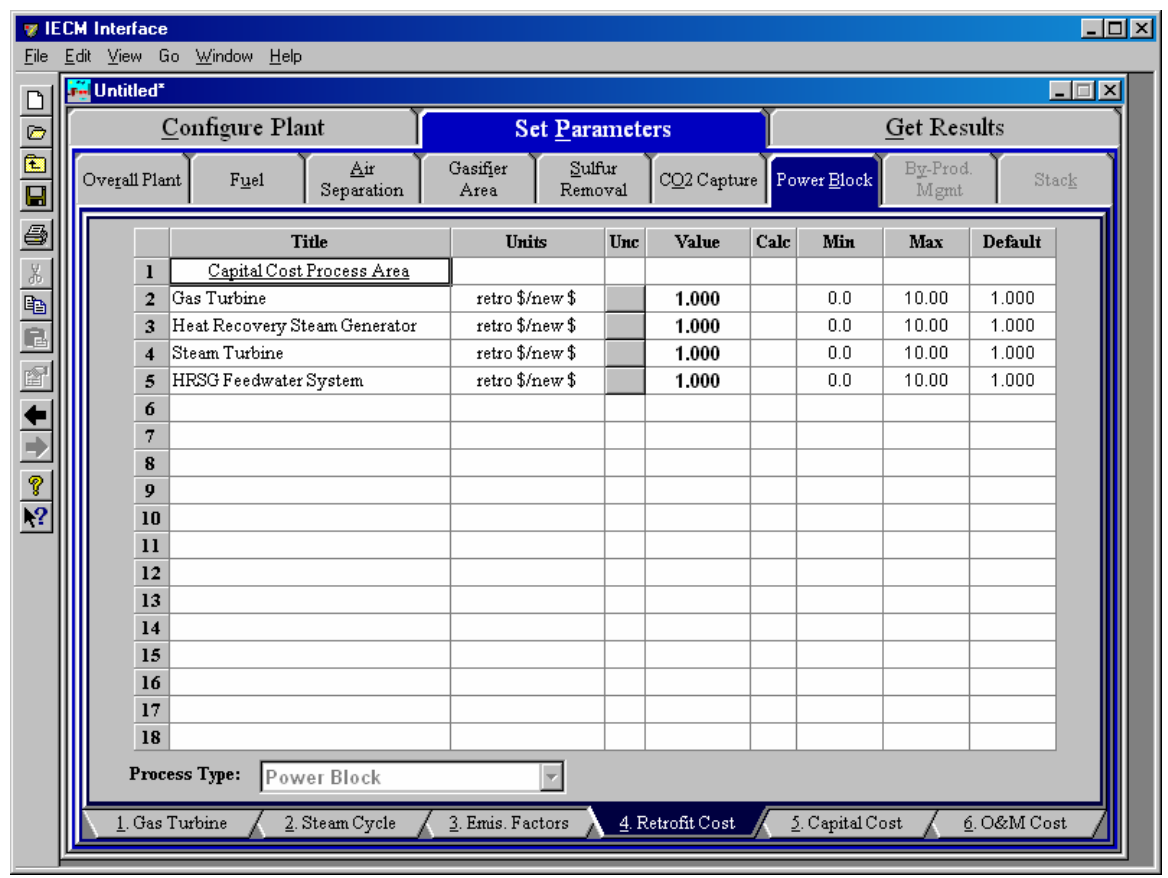

Power Block - Retrofit Cost input screen.

\section{Power Block Retrofit Cost Input Parameters}

Gas Turbine: The Gas Turbine retrofit factor is a ratio of the costs of retrofiting an existing facility versus a new facility, using the same equipment.

Heat Recovery Steam Generator: The Heat Recovery Steam Generator retrofit factor is a ratio of the costs of retrofiting an existing facility versus a new facility, using the same equipment.

Steam Turbine: The Steam Turbine retrofit factor is a ratio of the costs of retrofiting an existing facility versus a new facility, using the same equipment.

HRSG Feedwater System: The Boiler Feedwater retrofit factor is a ratio of the costs of retrofiting an existing facility versus a new facility, using the same equipment.

\section{Power Block Capital Cost Inputs}

This screen is only available for the Combustion (Turbine) and IGCC plant types. 


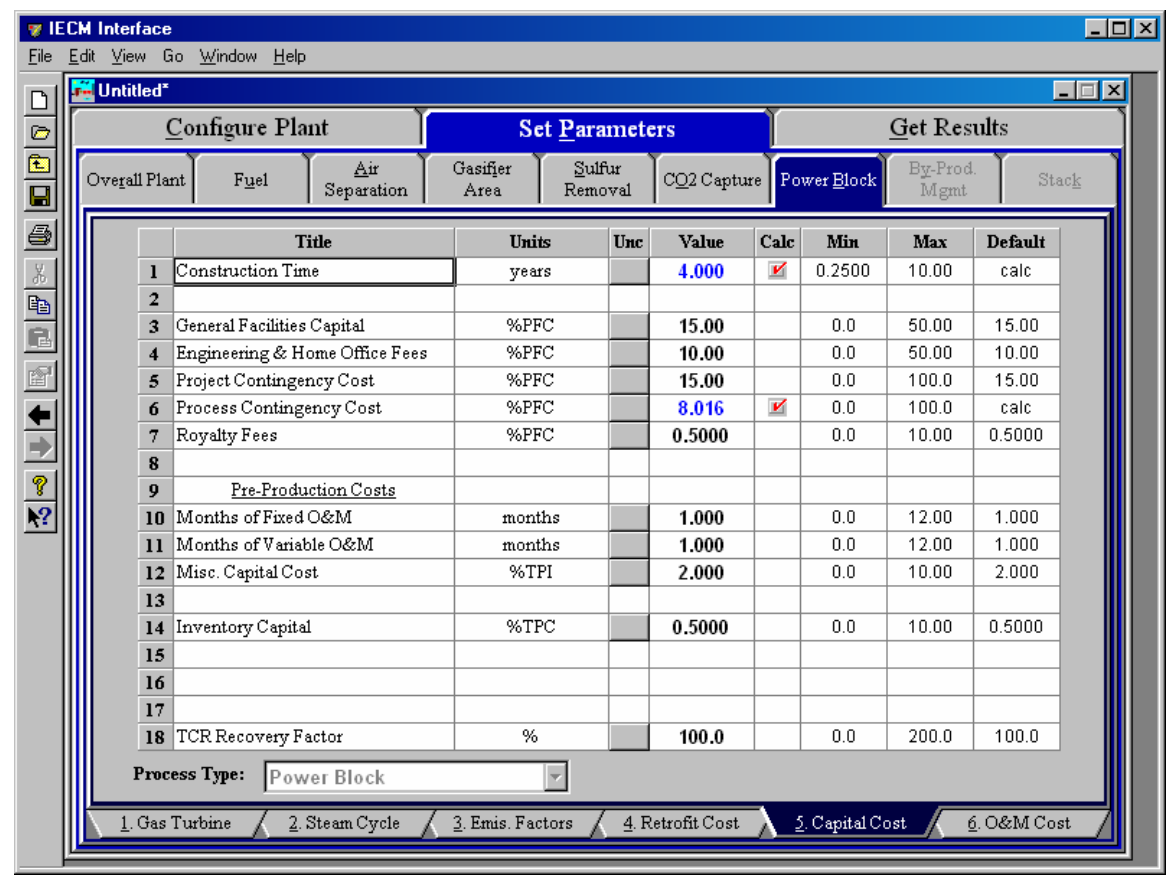

Power Block - Capital Cost input screen.

Inputs for capital costs are entered on the Capital Cost input screen.

Construction Time: This is the idealized construction period in years. It is used to determine the allowance for funds used during construction (AFUDC).

General Facilities Capital (GFC): The general facilities include construction costs of roads, office buildings, shops, laboratories, etc. Sales taxes and freight costs are included implicitly. The cost typically ranges from $5-20 \%$.

Engineering \& Home Office Fees: The engineering \& home office fees are a percent of total direct capital cost. This is an overhead fee paid to the architect/engineering company. These fees typically range from 7$15 \%$.

Project Contingency Cost: This is factor covering the cost of additional equipment or other costs resulting from a more detailed design. Higher contingency factors will be applied to simplified or preliminary designs and lower factors to detailed or finalized designs.

Process Contingency Cost: This quantifies the design uncertainty and cost of a commercial-scale system. This is generally applied on an areaby-area basis. Higher contingency factors are applied to new regeneration systems tested at a pilot plant and lower factors to full-size or commercial systems.

Royalty Fees: Royalty charges may apply to some portions of generating units incorporating new proprietary technologies.

Pre-Production Costs: These costs consider the operator training, equipment checkout, major changes in unit equipment, extra maintenance, and inefficient use of fuel or other materials during startup. These are typically applied to the O\&M costs over a specified period of time (months). The two time periods for fixed and variable 
O\&M costs are described below with the addition of a miscellaneous capital cost factor.

- Months of Fixed O\&M: Time period of fixed operating costs used for preproduction to cover training, testing, major changes in equipment, and inefficiencies in start-up. This includes operating, maintenance, administrative and support labor. It also considers maintenance materials.

- Months of Variable O\&M: Time period of variable operating costs used for preproduction to cover chemicals, water, consumables, and solid disposal charges in start-up, assuming $100 \%$ load. This excludes any fuels.

- Misc. Capital Cost: This is a percent of total plant investment (sum of TPC and AFUDC) to cover expected changes to equipment to bring the system up to full capacity.

Inventory Capital: Percent of the total direct capital for raw material supply based on $100 \%$ capacity during a 60 day period. These materials are considered storage. The inventory capital includes fuels,

consumables, by-products, and spare parts. This is typically $0.5 \%$.

TCR Recovery Factor: The actual total capital required (TCR) as a percent of the TCR in a new power plant. This value is $100 \%$ for a new installation and may be set as low as $0 \%$ for a fabric filter that has been paid off.

\section{Power Block O\&M Cost Inputs}

This screen is only available for the Combustion (Turbine) and IGCC plant types.

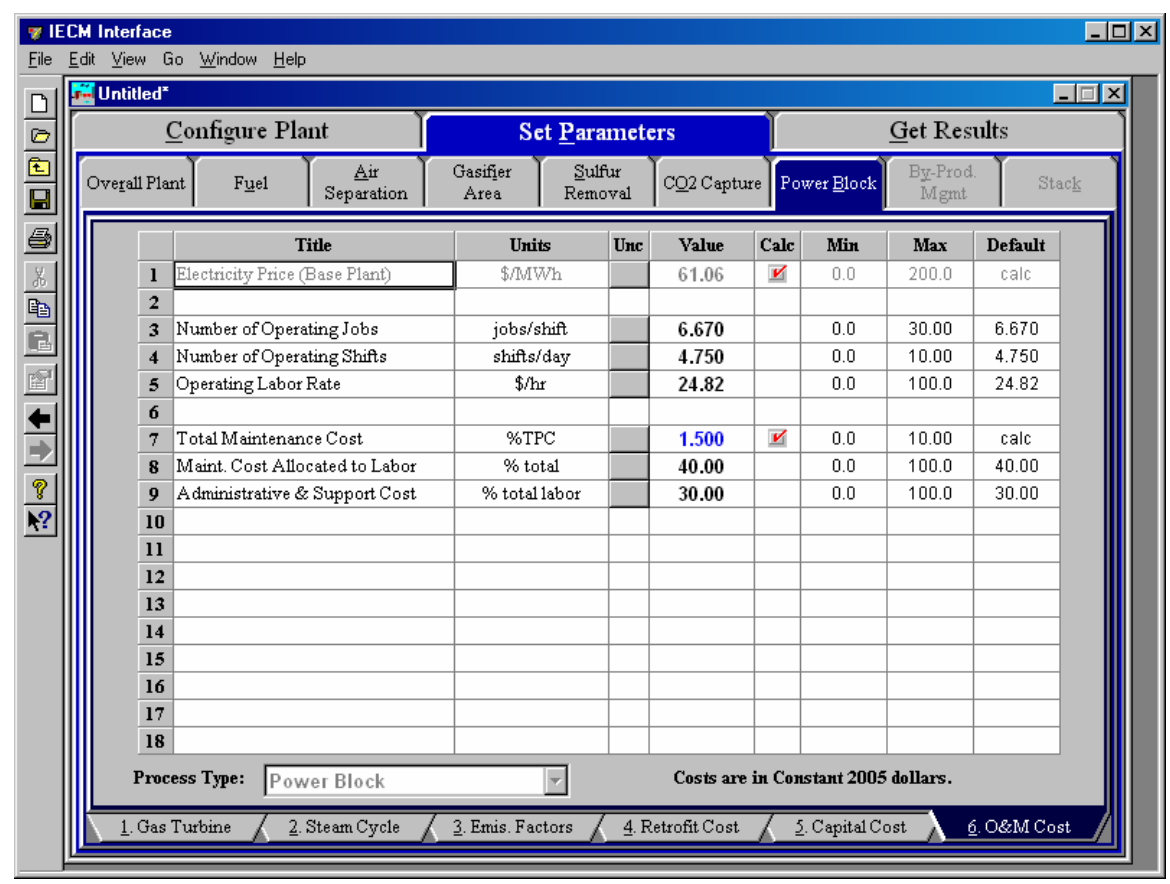

Power Block - O\&M Cost input screen. 
Inputs for operating and maintenance costs are entered on the O\&M Cost input screen. O\&M costs are typically expressed on an average annual basis and are provided in either constant or current dollars for a specified year, as shown on the bottom of the screen.

Electricity Price (Base Plant): This is the price of electricity and is calculated as a function of the utility cost of the base plant, where the base plant is the power block. This is provided for reference purposes only.

Number of Operating Jobs: This is the total number of operating jobs that are required to operate the plant per eight-hour shift.

Number of Operating Shifts: This is the total number of equivalent operating shifts in the plant per day. The number takes into consideration paid time off and weekend work ( 3 shifts/day * 7 days/5 day week $* 52$ weeks $/(52$ weeks -6 weeks PTO $)=4.75$ equiv. Shifts/day)

Operating Labor Rate: The hourly cost of labor is specified in the base plant O\&M cost screen. The same value is used throughout the other technologies.

Total Maintenance Cost: This is the annual maintenance cost as a percentage of the total plant cost. Maintenance cost estimates can be developed separately for each process area.

Maint. Cost Allocated to Labor: Maintenance cost allocated to labor as a percentage of the total maintenance cost.

Administrative \& Support Cost: This is the percent of the total operating and maintenance labor associated with administrative and support labor.

\section{Power Block Gas Turbine Diagram}

This screen is only available for the Combustion (Turbine) and IGCC plant types. 


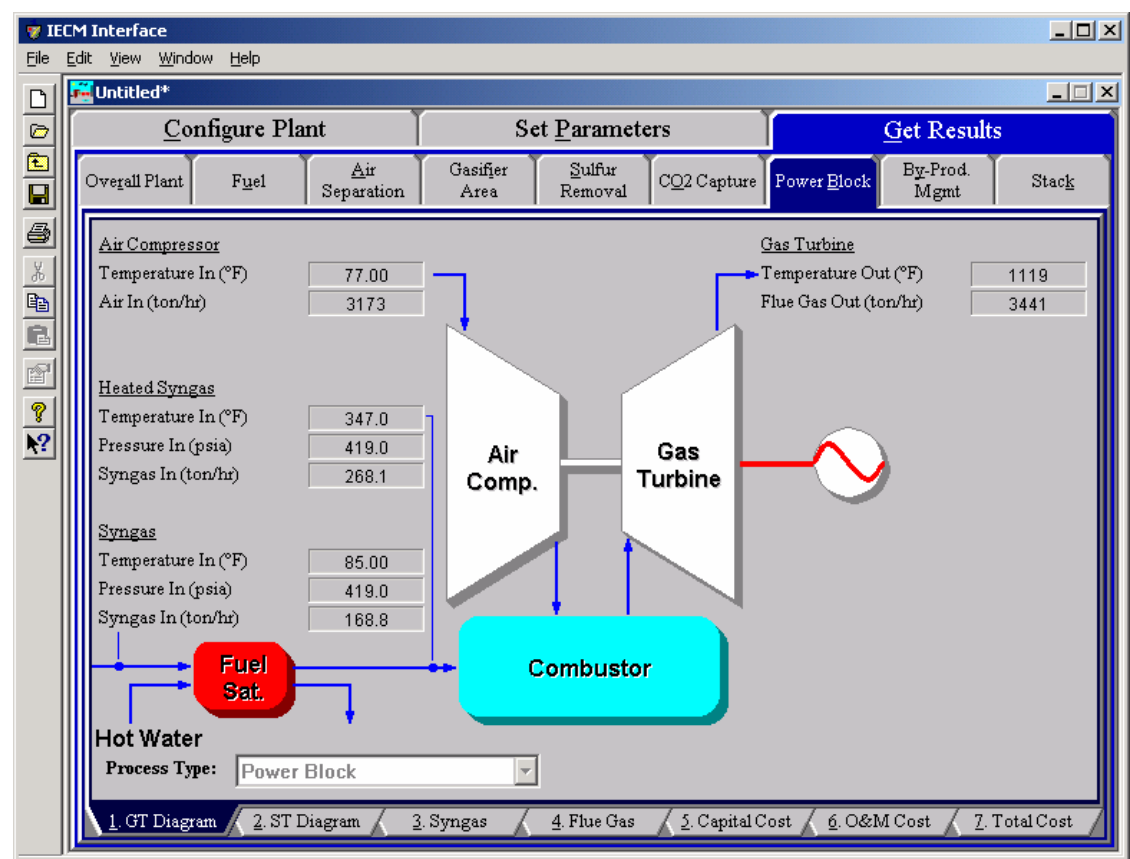

Power Block - Gas Turbine Diagram result screen.

\section{Air Entering Compressor}

Temperature In: Temperature of the atmospheric air entering the air compressor.

Air In: Volumetric flow rate of the air entering the air compressor.

\section{Syngas Entering Combustor}

Temperature In: Temperature of the syngas entering the fuel heater and saturator.

Pressure In: This is the pressure of the synas as it enters the fuel heater and saturator.

Syngas In: This is the mass flow rate of the syngas to the fuel heater and saturator.

\section{Heated Syngas Entering Combustor}

Temperature In: Temperature of the heated and saturated syngas entering the combustor.

Pressure In: This is the pressure of the heated and saturated syngas as it enters the combustor.

Syngas In: This is the mass flow rate of the heated and saturated syngas to the combustor.

\section{Flue Gas Exiting Gas Turbine}

Temperature Out: Temperature of the flue gas exiting the gas turbine. 
Flue Gas Out: Volumetric flow rate of the flue gas exiting the gas turbine.

\section{Power Block Steam Diagram}

This screen is only available for the Combustion (Turbine) and IGCC plant types.

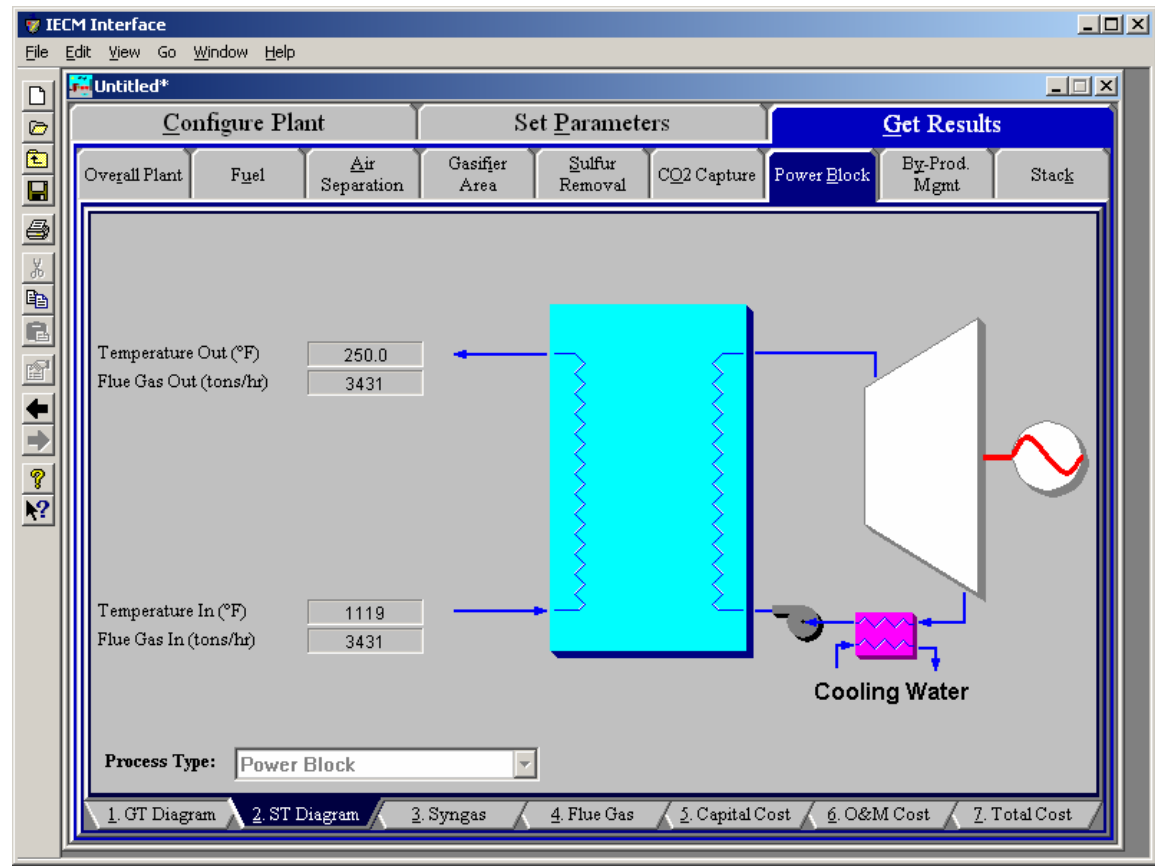

Power Block - HRSG/ Steam Diagram results screen.

\section{Flue Gas Exiting Steam Generator}

Temperature Out: Temperature of the flue gas exiting the HRSG system.

Flue Gas Out: Volumetric flow rate of the flue gas exiting the HRSG.

\section{Flue Gas Entering Steam Generator}

Temperature In: Temperature of the flue gas entering the HRSG.

Flue Gas In: Volumetric flow rate of flue gas entering the HRSG.

\section{Power Block Syngas Results}

This screen is only available for the Combustion (Turbine) and IGCC plant types. 


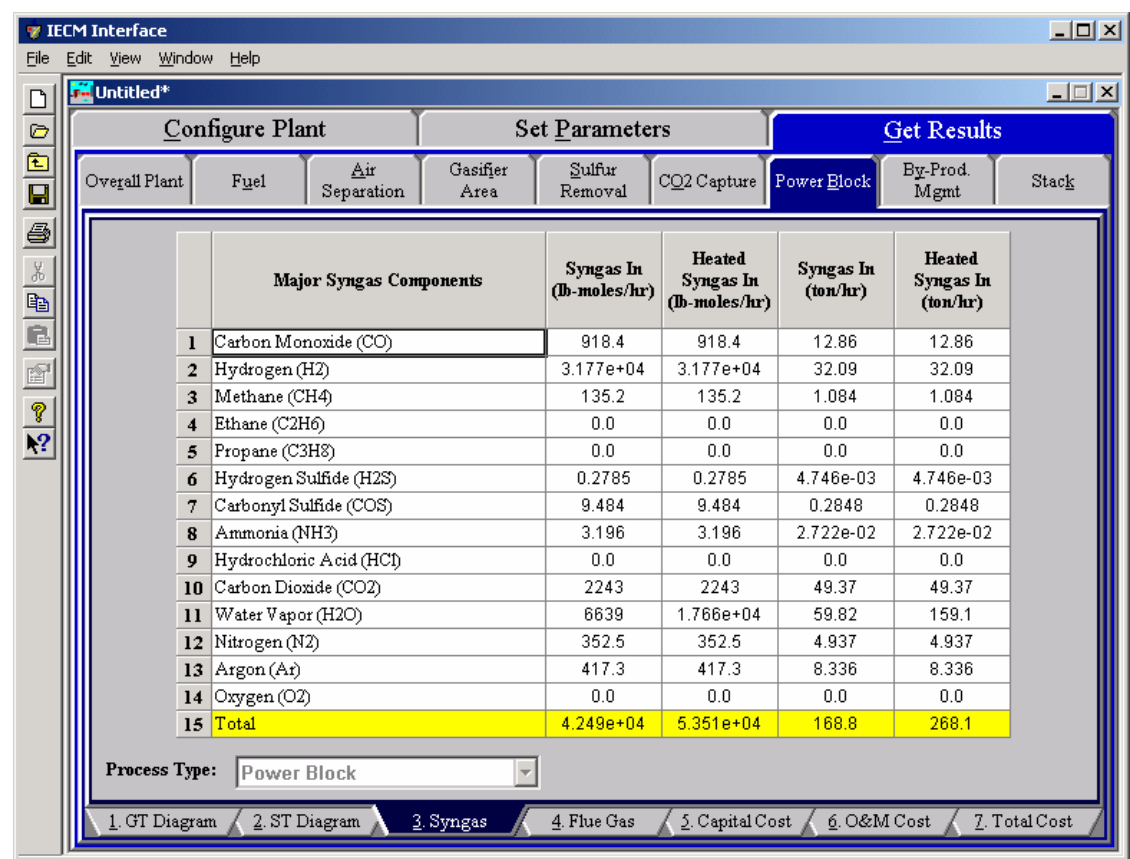

Power Block - Syngas result screen.

\section{Major Syngas Components}

Carbon Monoxide (CO): Flow rate of carbon monoxide in the syngas.

Hydrogen $\left(\mathbf{H}_{2}\right)$ : Flow rate of hydrogen in the syngas.

Methane $\left(\mathrm{CH}_{4}\right)$ : Flow rate of methane in the syngas.

Ethane $\left(\mathrm{C}_{2} \mathrm{H}_{6}\right)$ : Flow rate of ethane in the syngas.

Propane $\left(\mathrm{C}_{3} \mathrm{H}_{8}\right)$ : Flow rate of propane in the syngas.

Hydrogen Sulfide $\left(\mathrm{H}_{2} \mathrm{~S}\right)$ : Flow rate of hydrogen sulfide in the syngas.

Carbonyl Sulfide (COS): Flow rate of carbon sulfide in the syngas.

Ammonia $\left(\mathrm{NH}_{3}\right)$ : Flow rate of ammonia in the syngas.

Hydrochloric Acid $\mathbf{( H C l ) : ~ F l o w ~ r a t e ~ o f ~ h y d r o c h l o r i c ~ a c i d ~ i n ~ t h e ~ s y n g a s . ~}$

Carbon Dioxide $\left(\mathrm{CO}_{2}\right)$ : Flow rate of carbon dioxide in the syngas.

Water Vapor $\left(\mathrm{H}_{2} \mathrm{O}\right)$ : Flow rate of water vapor in the syngas.

Nitrogen $\left(\mathbf{N}_{2}\right)$ : Flow rate of nitrogen in the syngas.

Argon (Ar): Flow rate of argon in the syngas.

Oxygen $\left(\mathrm{O}_{2}\right)$ : Flow rate of oxygen in the syngas.

Total: Total flow rate of the syngas.

\section{Power Block Flue Gas Results}

This screen is only available for the Combustion (Turbine) and IGCC plant types. 


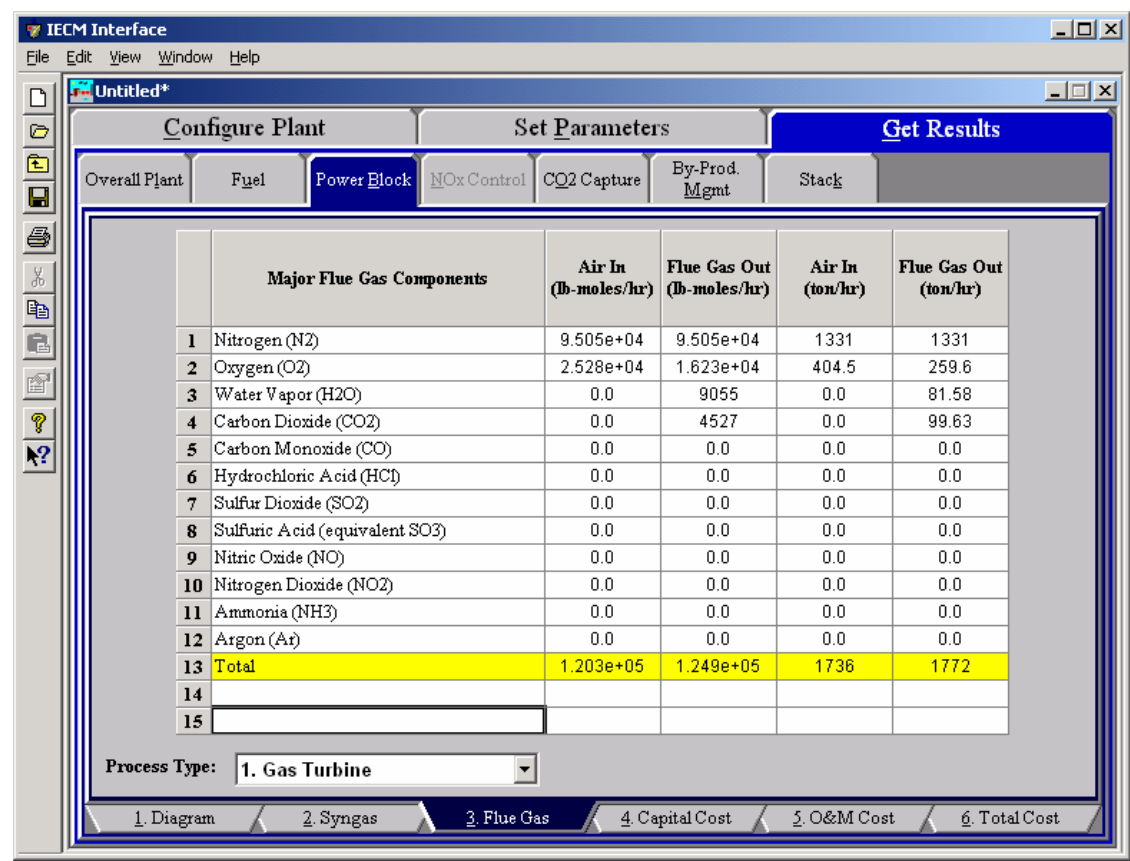

Power Block - Flue Gas results screen.

\section{Major Flue Gas Components}

Each result is described briefly below:

Nitrogen $\left(\mathbf{N}_{\mathbf{2}}\right)$ : Total mass of nitrogen.

Oxygen $\left(\mathrm{O}_{2}\right)$ : Total mass of oxygen.

Water Vapor $\left(\mathrm{H}_{\mathbf{2}} \mathrm{O}\right)$ : Total mass of water vapor.

Carbon Dioxide $\left(\mathrm{CO}_{2}\right)$ : Total mass of carbon dioxide.

Carbon Monoxide (CO): Total mass of carbon monoxide.

Hydrochloric Acid (HCl): Total mass of hydrochloric acid.

Sulfur Dioxide $\left(\mathbf{S O}_{2}\right)$ : Total mass of sulfur dioxide.

Sulfuric Acid (equivalent $\mathbf{S O}_{3}$ ): Total mass of sulfuric acid.

Nitric Oxide (NO): Total mass of nitric oxide.

Nitrogen Dioxide $\left(\mathbf{N O}_{2}\right)$ : Total mass of nitrogen dioxide.

Ammonia $\left(\mathrm{NH}_{3}\right)$ : Total mass of ammonia.

Argon (Ar): Total mass of argon.

Total: Total of the individual components listed above. This item is highlighted in yellow.

\section{Power Block Capital Cost Results}

This screen is only available for the Combustion (Turbine) and IGCC plant types. 


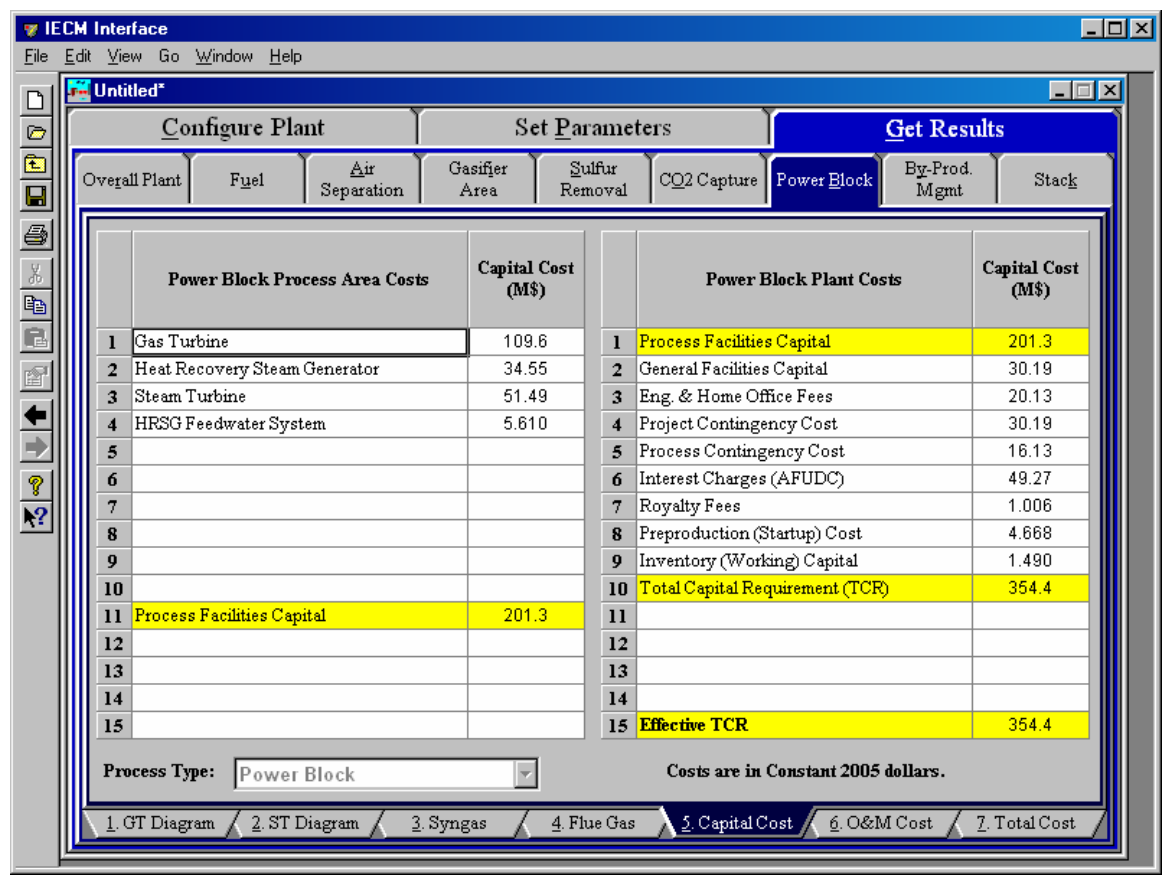

Power Block - Capital Cost results screen.

This result screen displays tables containing the Power Block Capital Costs. Capital costs are typically expressed in either constant or current dollars for a specified year, as shown on the bottom of the screen. Each result is described briefly below:

\section{Power Block Process Area Costs}

Gas Turbine: The capital cost of the gas turbines, the air compressor, and the combustor.

Heat Recovery Steam Generator:The heat recovery steam generator is a set of heat exchangers in which heat is removed from the gas turbine exhaust gas to generate steam for the steam turbine.

Steam Turbine: The cost of a steam turbine is depends on the mass flow rate of steam through the turbine, the pressures in each stage, and the generator output.

HRSG Feedwater System: The boiler feedwater system consists of equipment for handling raw water and polished water in the steam cycle, including a water mineralization unit for raw water, a dimineralized water storage tank, a condensate water, a condensate polishing unit, and a blowdown flash drum.

Process Facilities Capital: The process facilities capital is the total constructed cost of all on-site processing and generating units listed above, including all direct and indirect construction costs. All sales taxes and freight costs are included where applicable implicitly. This result is highlighted in yellow.

\section{Power Block Plant Costs}

Process Facilities Capital: (see definition above) 
General Facilities Capital: The general facilities include construction costs of roads, office buildings, shops, laboratories, etc. Sales taxes and freight costs are included implicitly.

Eng. \& Home Office Fees: The engineering \& home office fees are a percent of total direct capital cost. This is an overhead fee paid to the architect/engineering company.

Project Contingency Cost: Capital cost contingency factor covering the cost of additional equipment or other costs that would result from a more detailed design of a definitive project at the actual site.

Process Contingency Cost: Capital cost contingency factor applied to a new technology in an effort to quantify the uncertainty in the technical performance and cost of the commercial-scale equipment.

Interest Charges (AFUDC): Allowance for funds used during construction, also referred to as interest during construction, is the time value of the money used during construction and is based on an interest rate equal to the before-tax weighted cost of capital. This interest is compounded on an annual basis (end of year) during the construction period for all funds spent during the year or previous years.

Royalty Fees: Royalty charges may apply to some portions of generating units incorporating new proprietary technologies.

Preproduction (Startup) Cost: These costs consider the operator training, equipment checkout, major changes in unit equipment, extra maintenance, and inefficient use of fuel or other materials during startup.

Inventory (Working) Capital: The raw material supply based on 100\% capacity during a 60 day period. These materials are considered storage. The inventory capital includes fuels, consumables, byproducts, and spare parts.

Total Capital Requirement (TCR): Money that is placed (capitalized) on the books of the utility on the service date. TCR includes all the items above. This result is highlighted in yellow.

Effective TCR: The TCR of the power block that is used in determining the total power plant cost. The effective TCR is determined by the "TCR Recovery Factor".

\section{Power Block O\&M Cost Results}

This screen is only available for the Combustion (Turbine) and IGCC plant types. 


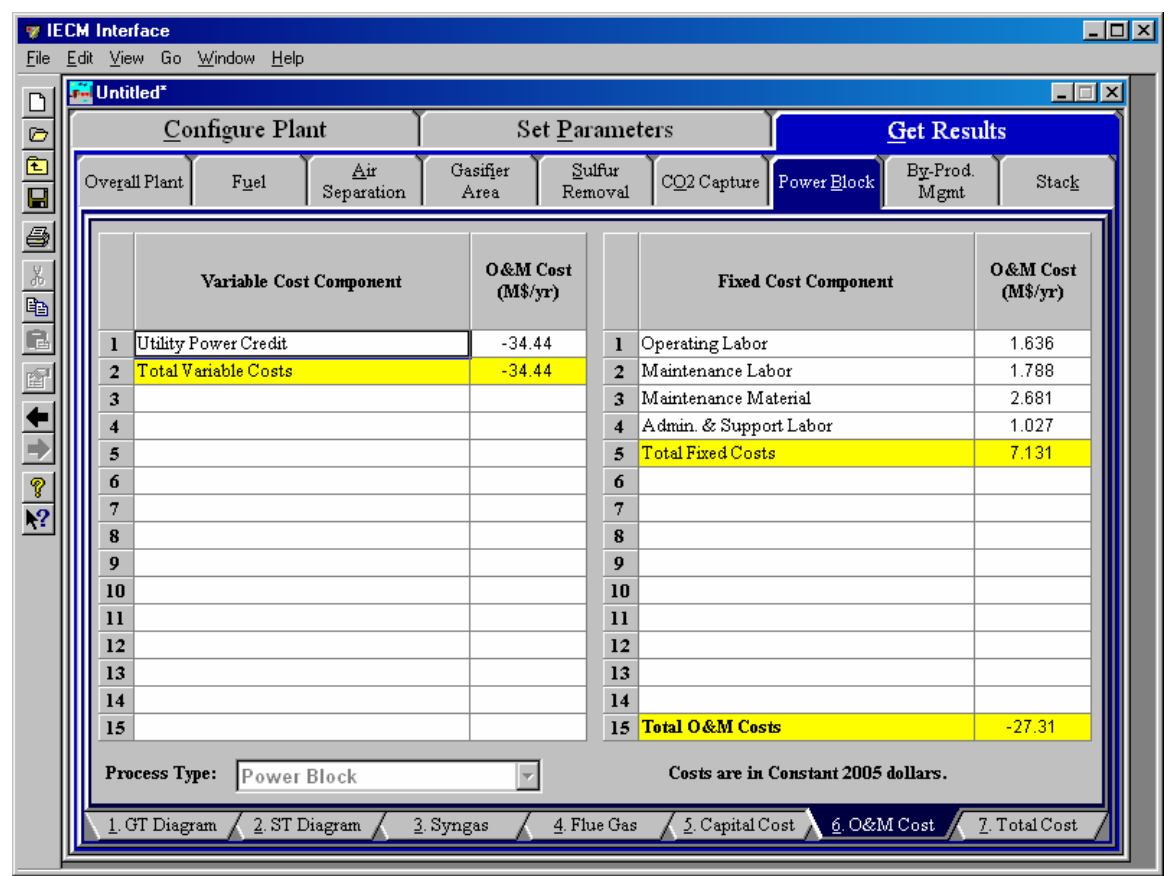

Power Block - O\&M Cost results screen.

O\&M costs are typically expressed on an average annual basis and are provided in either constant or current dollars for a specified year, as shown on the bottom of the screen.

\section{Variable Cost Component}

Utility Power Credit: Power consumed by abatement technologies result in lower net power produced and lost revenue. The IECM charges each technology for the internal use of electricity and treats the charge as a credit for the base plant. When comparing individual components of the plant, these utility charges are taken into consideration. For total plant costs they balance out and have no net effect on the plant O\&M costs.

Total Variable Costs: This is the sum of all the variable O\&M costs listed above. This result is highlighted in yellow.

\section{Fixed Cost Component}

Fixed operating costs are essentially independent of actual capacity factor, number of hours of operation, or amount of kilowatts produced. All the costs are subject to inflation.

Operating Labor: Operating labor cost is based on the operating labor rate, the number of personnel required to operate the plant per eighthour shift, and the average number of shifts per day over 40 hours per week and 52 weeks.

Maintenance Labor: The maintenance labor is determined as a fraction of the total maintenance cost.

Maintenance Material: The cost of maintenance material is the remainder of the total maintenance cost, considering the fraction associated with maintenance labor. 
Admin. \& Support Labor: The administrative and support labor is the only overhead charge. It is taken as a fraction of the total operating and maintenance labor costs.

Total Fixed Costs: This is the sum of all the fixed O\&M costs listed above. This result is highlighted in yellow.

Total O\&M Costs: This is the sum of the total variable and total fixed O\&M costs. It is used to determine the base plant total revenue requirement. This result is highlighted in yellow.

\section{Power Block Total Cost Results}

This screen is only available for the Combustion (Turbine) and IGCC plant types.

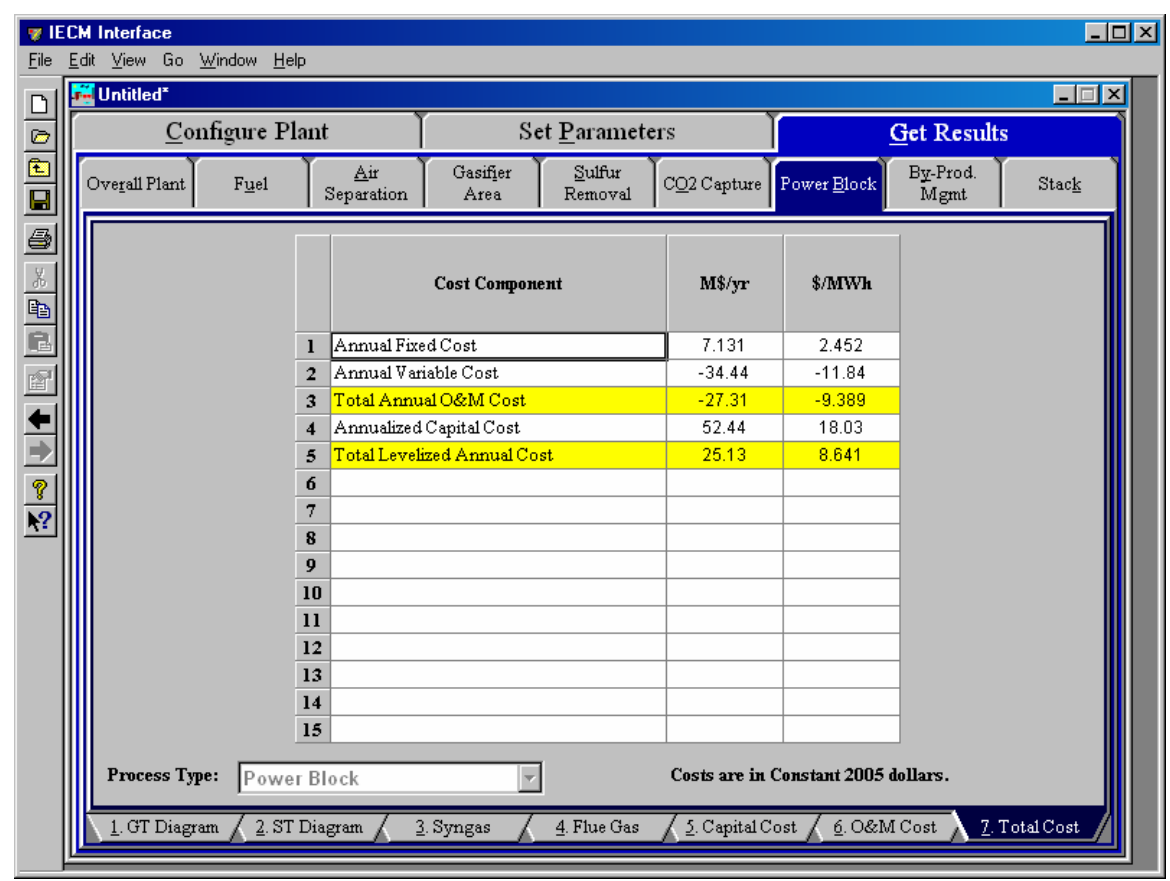

Power Block - Total Cost results screen.

The Total Cost result screen displays a table which totals the annual fixed, variable, operations, maintenance, and capital costs. Total costs are typically expressed in either constant or current dollars for a specified year, as shown on the bottom of the screen. Each result is described briefly below.

\section{Cost Component}

Annual Fixed Cost: The operating and maintenance fixed costs are given as an annual total. This number includes all maintenance materials and all labor costs.

Annual Variable Cost: The operating and maintenance variables costs are given as an annual total. This includes all reagent, chemical, steam, and power costs.

Total Annual O\&M Cost: This is the sum of the annual fixed and variable operating and maintenance costs above. This result is highlighted in yellow. 
Annualized Capital Cost: This is the total capital cost expressed on an annualized basis, taking into consideration the levelized carrying charge factor, or fixed charge factor, over the entire book life.

Total Levelized Annual Cost: The total annual cost is the sum of the total annual O\&M cost and annualized capital cost items above. This result is highlighted in yellow. 



\section{Units}

\section{Units Inputs}

Inputs may be entered using different units. Changing the units in which inputs are entered using the Input Tools floating palette is described in Getting Started. This section will describe the various unit settings in detail

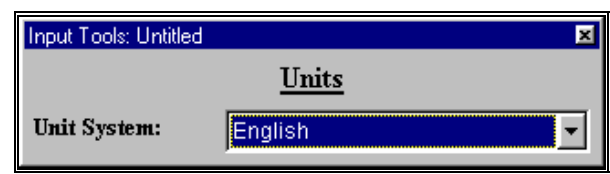

The Input Tools Floating Palette

\section{Unit System}

The Unit System option determines the unit system in which input values are entered. The choices are English and Metric. The default setting is English.

\section{Units Results}

Results may be displayed in different units. Changing the units in which results are displayed using the Result Tools floating palette is described in Getting Started. This section will describe the various unit settings in detail.

\begin{tabular}{|lll|}
\hline Result Tools: Untilled & \\
Result Type: & \multicolumn{1}{c|}{ Deterministic } \\
& \multicolumn{1}{|c|}{ Units } \\
Unit System: & English \\
Time Period: & Default \\
Perf. Table: & Default \\
Cost Table: & M\$(Cap), M\$Mr(0\&M) \\
& Revenue & - \\
Cost Year: & 1996 \\
Inflation Ctrl: & Constant & \\
\hline \hline
\end{tabular}

The Result Tools floating palette 


\section{Result Type}

The Result Type option determines the type of values displayed in the result tables. The choices available are Deterministic, Mean, Median (50th percentile), 2.5 percentile, 97.5 percentile, and Standard Deviation. The default setting is Deterministic.

\section{Unit System}

The Unit System option determines the unit system in which result values are displayed. The choices available are English and Metric. The default setting is English.

\section{Time Period}

The Time Period option determines the time period for which result values are displayed. The choices available are Default, Max Hourly and Annual Avg. The default setting is Default.

\section{Performance Table}

The Perf. Table option determines the units in which values are displayed on performance result screens. The choices available are Default, \% Total, mass/kWh, and mass/Btu in. The default setting is Default.

NOTE: The \% Total unit change can be used to determine the volume percent and weight percent of the components of the flue gas. This is possible when viewing the "Gas Summary" result table for any control technology.

\section{Cost Table}

The Cost Table option determines the units in which values are displayed on cost result screens. The choices available are $\mathbf{M} \$(C a p), \mathbf{M} \$ \mathbf{y r}(\mathbf{O} \& \mathbf{M})$ and $\$ / \mathbf{k W}(\mathrm{Cap})$, mills/kWh(O\&M). The default setting is $\mathbf{M} \$(C a p), \mathbf{M} \$ \mathbf{y r}(\mathbf{O} \& \mathbf{M})$.

\section{Cost Year}

The Cost Year option determines the year for which values are displayed on cost result screens. You may choose any year between 1977 and 1998. The default setting is 1996.

\section{Inflation Control}

The Inflation Ctrl option determines the method by which inflation is calculated for cost result screens. The choices available are Constant and Current. The default setting is Constant. 


\section{Working with Graphs}

\section{Graph Chooser}

The table and diagram results displayed on the Get Results screens are all deterministic values; that is, uncertainties are not taken into consideration. Probabilistic results (with uncertainties taken into consideration) can be displayed in graphical format as a supplement to every deterministic value shown.

The graph chooser window opens when any value displayed on a result screen is double-clicked. The figure below shows the initial graph window.

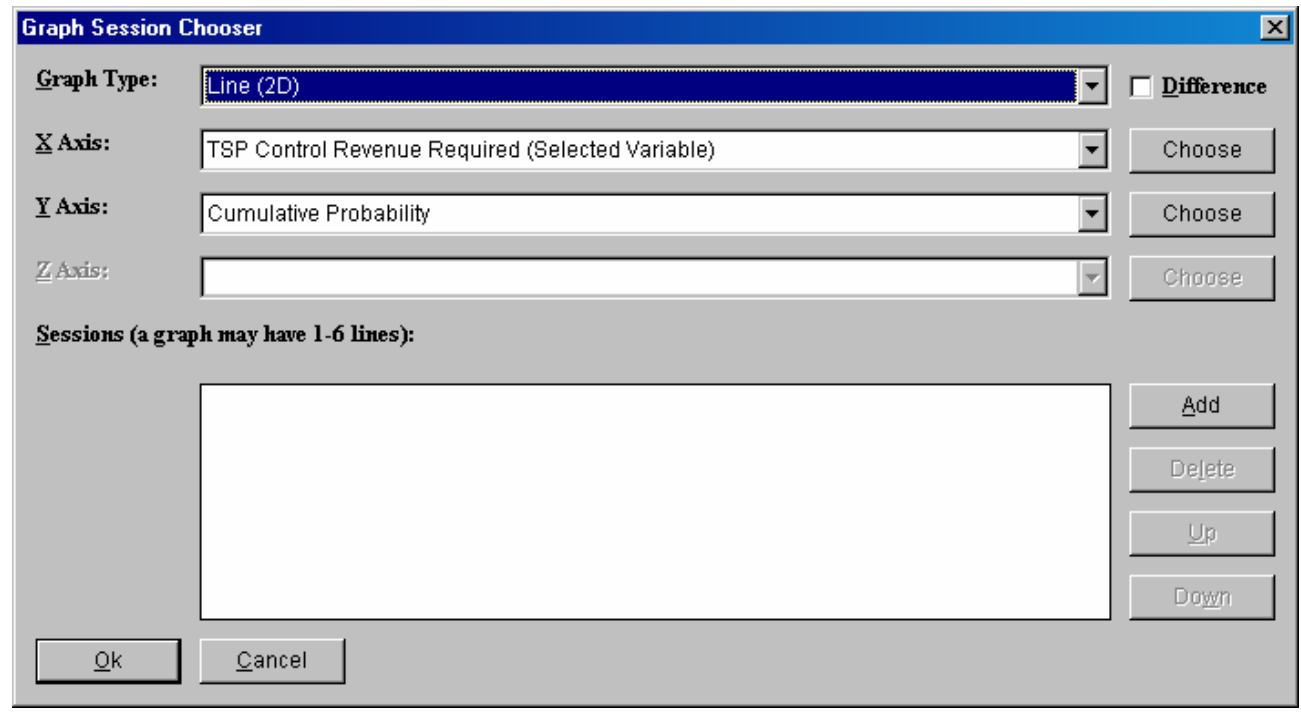

The graph chooser window

The graph chooser window contains several drop-down menus, a check box, and a few buttons. Each menu begins in a default state, producing a cumulative probability distribution (CDF) graph of the particular result variable double-clicked. These dropdown menus can be modified to produce many different types of graphs. These will be described in the following sections.

To view the standard CDF graph, select the menu items as they appear in the figure above:

- Graph Type: Line (2D)

- X Axis: (Selected Variable) 
- Y Axis: Cumulative Probability

The graph type and details that will be displayed can be modified later if the initial graph is not what was desired.

\section{Graph Type}

\begin{tabular}{|c|c|c|}
\hline Graph Type: & Line (2D) & $\nabla$ \\
\hline & Line (2D) & \\
\hline X Axis: & $\begin{array}{l}\text { Scatter (2D) } \\
\text { Scatter (3D) }\end{array}$ & \\
\hline$\underline{Y}$ Axis: & Tape (3D) & \\
\hline
\end{tabular}

Graph type selection menu

The Graph Type drop-down menu contains multiple types of graphs. Line (2D) and Scatter (2D) can be selected initially with the line graph as the default option. Additional options are available after the graph opens. The line graph connects the $\mathrm{x}$ $\mathrm{y}$ data points consecutively with line segments. The scatter graph displays the $\mathrm{x}-\mathrm{y}$ data points with markers instead of line segments. Because the IECM generates sorted $\mathrm{x}-\mathrm{y}$ data with $\mathrm{x}$ values always increasing, the two graphs will appear very similar. The only difference is the use of line segments and data markers.

\section{$\mathrm{X}$ Axis}

\begin{tabular}{|c|c|c|}
\hline X Axis: & Gross Electrical Output & $\checkmark$ \\
\hline \multirow{2}{*}{ Y Axis: } & TSP Control Revenue Required (Selected Variable) & \\
\hline & Gross Electrical Output & \\
\hline
\end{tabular}

$X$ Axis variable selection menu

The $\mathbf{X}$ Axis drop-down menu allows you to select the independent variable. The menu initially contains only one item - the variable you double-clicked. This is the "selected variable" as shown in the figure above. If the Choose button immediately to the right of the drop-down menu is clicked, any input or result variable that exists in the IECM can be selected (see Variable Chooser on page 375).

\section{Y Axis}

\begin{tabular}{|c|c|c|}
\hline Y Axis: & Cumulative Probability & 7 \\
\hline$\underline{Z}$ A Axis: & Cumulative Probability & \\
\hline
\end{tabular}

Y Axis variable selection menu

The Y Axis drop-down menu allows you to select the dependent variable. The menu initially contains only two items - "Cumulative Probability" and the variable you double-clicked. The second item is the "selected variable" as shown in the figure above. "Cumulative Probability" is the default option. If the Choose button immediately to the right of the drop-down menu is clicked, any input or result variable that exists in the IECM can be selected (see Variable Chooser).

\section{Z Axis}

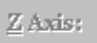


The $\mathbf{Z}$ Axis drop-down menu allows you to select an additional variable. This option is currently unavailable.

\section{Variable Chooser}

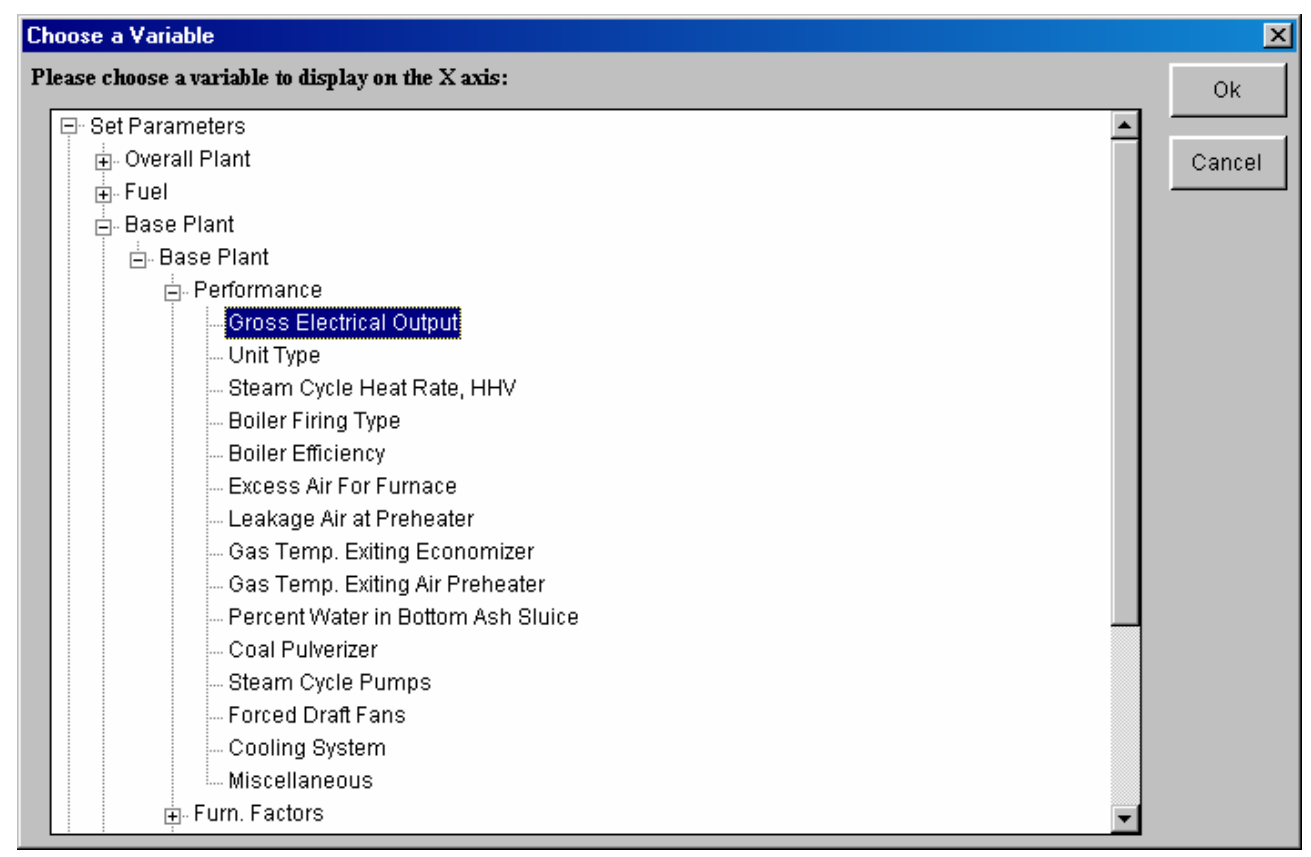

All the IECM variables are available through the Choose buttons.

Clicking the Choose button immediately to the right of the axis drop down menus in the graph chooser window opens the variable chooser window, as shown above. All the input variables listed in the IECM are included in this window. The variables are nested according to input or result variable, technology type, and technology suboption. These match the navigation tabs used in the IECM. Every variable is present in the same pattern as the IECM screens themselves.

Select a variable and click $\mathbf{O k}$ to place the variable in the $\mathrm{X}$-axis drop-down list. The variable chosen will be added to the drop down menu. For best results, select a variable that has a probabilistic function defined; in other words; the variable must be probabilistic in order to represent multiple values. Input variables in the IECM can be associated with uncertainty functions. Result variables must be a direct result of one or more input variables with uncertainty functions assigned. For more information on assigning uncertainty functions to input variables, see Uncertainty Distributions . 


\section{Selecting Multiple Sessions}

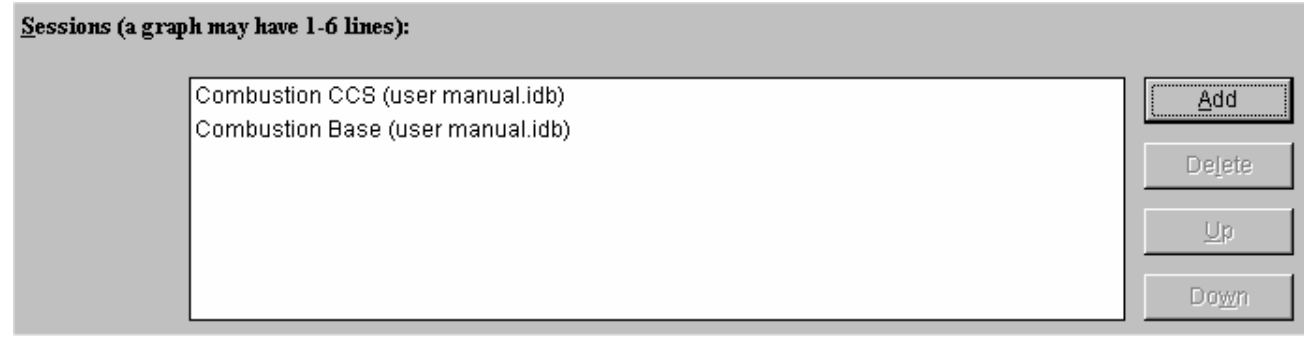

Multiple session selection area

The graph chooser window allows the same variable(s) from multiple sessions to be displayed on the same graph. The sessions you may select to graph simultaneously are listed in the graph chooser window. The order of these can be changed by using the Up and Down buttons on the right side of the window. Database files listed can be removed by using the Delete button on the right side of the window.

The default is to display only the variable(s) from the current session. As demonstrated in the figure above, only additional sessions are listed in the white area. All graphs displayed will use the X, Y, and Z variables selected in the graph selection window.

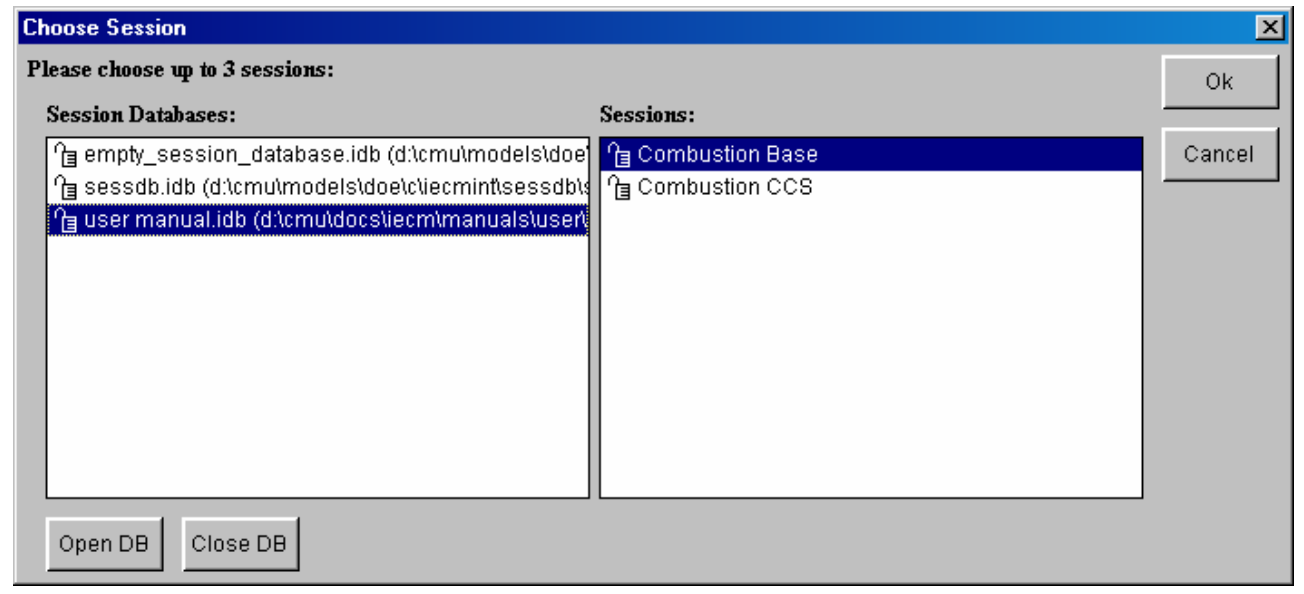

Choose session window

To add additional session to your graph, use the Add button immediately to the right of this area. A session chooser window will be displayed as shown in the figure above. Up to five additional sessions can be selected. The sessions may come from multiple session database files. For more information on session databases, see Session Database Files .

The sessions you add will be reflected in the graph chooser window. All those shown will be displayed in a graph when you click the Ok button on the graph chooser window. 


\section{Difference Graphs}

\begin{tabular}{|c|c|c|c|}
\hline \multicolumn{3}{|c|}{ Graph Session Chooser } & \multirow[b]{2}{*}{$\sqrt{\square}$ Difference } \\
\hline Graph Type: & Line (2D) & $\nabla$ & \\
\hline X Axis: & Gross Electrical Output & $\nabla$ & Choose \\
\hline Y Axis: & Cumulative Probability & 7 & Choose \\
\hline$\underline{Z}$ Axis: & & $\nabla$ & Choose \\
\hline \multicolumn{4}{|c|}{ 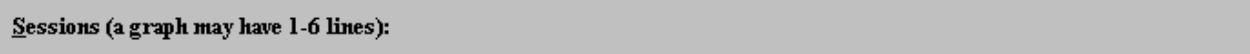 } \\
\hline & Combustion CCS (user manual.idb) & & Add \\
\hline & Combustion Base (user manual.idb) & & \\
\hline & & & Delete \\
\hline & & & $\underline{U} p$ \\
\hline & & & Down \\
\hline$\underline{\mathrm{O} k}$ & Cancel & & \\
\hline
\end{tabular}

The graph chooser window can be used to display the difference in a variable across multiple sessions

The graphing window can also display the difference between the currently selected variable and the same variable in one to five other sessions. The result is a unique method of examining differences between key results across different modeling sessions.

The first step to graphing difference graphs is the click the Difference check box at the top of the graph chooser window. The next step is to select other sessions to compare with the current session. This is described in Selecting Multiple Sessions on page 376. Finally, click the Ok button at the bottom of the graph chooser window.

\section{Graph Window}

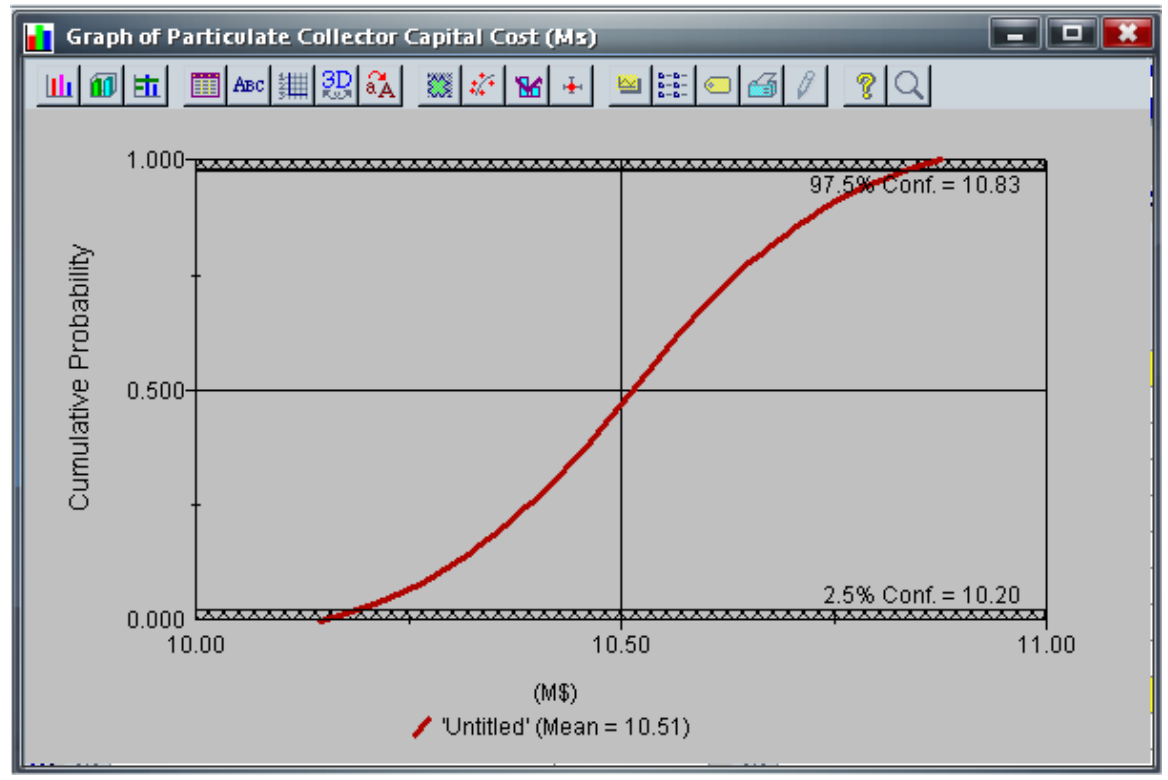

Graph window using all default conditions 
The graph window is a very powerful and versatile tool for viewing data results. The variables selected earlier are represented on the axes. Graph option buttons are provided above the graph, allowing you to change the appearance and style of the variables being graphed. These are described in a separate help document distributed with the IECM.
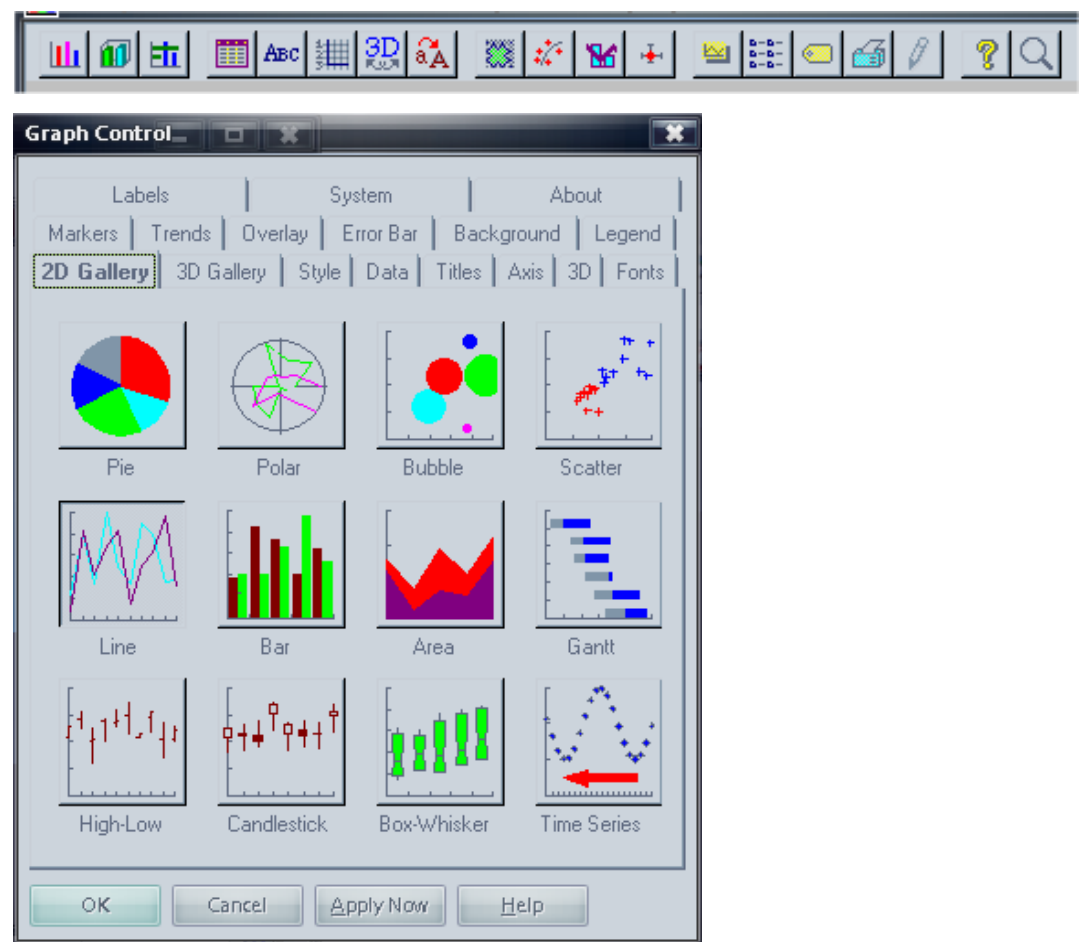

Graph controls can be accessed from any button on the graph window, or any tab from within the graph control window itself. The two methods are synonymous.

Each button at the top of the graph window opens the same graph control window, but with a particular tab selected. The figure above shows the row of buttons in the graph window and the graph control window that opens when one of the buttons is clicked. Consult the graphing help file for more detailed descriptions of the graph option buttons. The graphing help file is distributed with the IECM software and is accessible from the graph control window (see the help button on the lower right of the figure above).

NOTE: Right-clicking the graph window will also open the graph control window.

\section{Importing and Exporting Graphs}

If a graph window is active, you may use the Windows copy function (press Ctrl-C) to copy the graph to the clipboard. Both the data and the graph will be placed on the clipboard at the same time.

Because the clipboard contains both data and graph information, it is not certain in which format Windows will paste the graph into an application. Windows may paste a Bitmap image, a Windows Metafile image, or a data list of $x-y$ values taken from the graph. By default, graphics programs will typically paste the graph information and word processing programs will paste the data information. To determine how the 


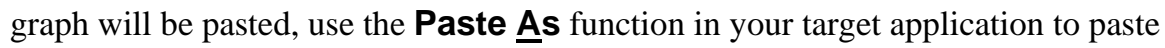
the graph.

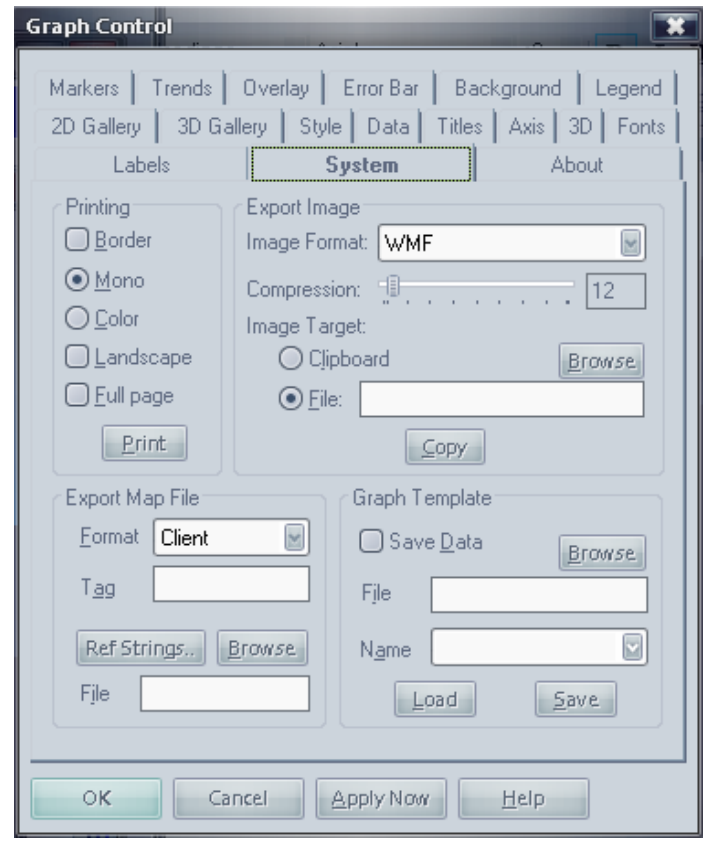

The "System" tab in the graph control window allows data to be imported and saved in any method.

Full control of importing and exporting is accomplished through the "System" tab in the graph control window, as shown in the figure above. For more detailed information, please consult the graph window help file.

\section{Graph Window Help}

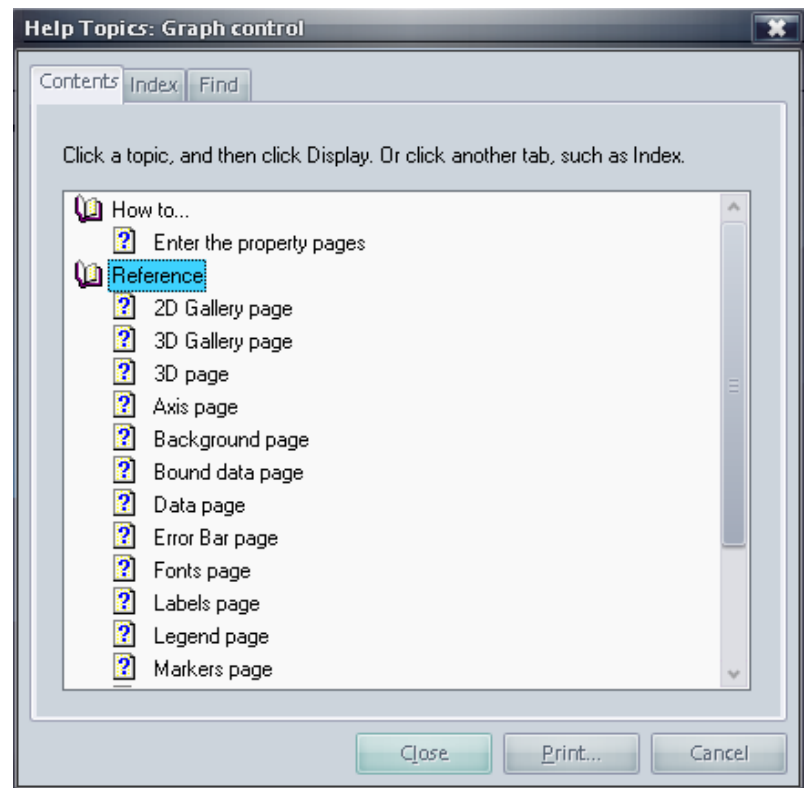

Detailed Help File Window 
Detailed graph help is available by clicking the $\mathscr{P}$ button on the graph window. Clicking this button brings up the help file as shown in the figure above. This detailed help is not reproduced here. 


\section{Running a Probabilistic Analysis}

\section{Uncertainty Analysis}

As noted in the introduction, a unique feature of the IECM is its ability to analyze uncertainties probabilistically. You may assign probability distributions to any input parameter, including calculated parameters. The combined effect of all uncertain parameters is then calculated. This chapter describes again how to specify input probability distributions, and how to set several additional parameters needed to conduct a probabilistic analysis.

Even after probabilistic values have been set you do not have to use them. Probabilistic analysis can be turned on or off individually for technologies or input types or all at once. Turning the probabilistic calculations on and off for particular portions of the plant allows you to evaluate the major sources of uncertainty.

\section{Uncertainty Distributions}

The entry of uncertainty distributions is covered briefly in Getting Started This section gives a more detailed description of the process.

\section{Uncertainty Parameters}

Each uncertainty distribution requires one or more parameters. The table below lists the parameters and numerical value limits required for each distribution type.

\begin{tabular}{||l|l|l|l|l||}
\hline \hline Function & Operator & min or mean & mode & max or sdev \\
\hline \hline Normal, Half- & $*$ & $\mathrm{x}>=0$ & $\mathrm{~N} / \mathrm{A}$ & $\mathrm{x}>0$ \\
normal(s) & + & $\mathrm{x}$ & $\mathrm{N} / \mathrm{A}$ & $\mathrm{x}>0$ \\
\hline \hline LogNormal & $*$ & $\mathrm{x}>0$ & $\mathrm{~N} / \mathrm{A}$ & $\mathrm{x}>=1$ \\
& + & $\mathrm{x}>0$ & $\mathrm{~N} / \mathrm{A}$ & $\mathrm{x}>=1$ \\
\hline \hline Uniform & $*$ & $\mathrm{x}>=0$ & $\mathrm{~N} / \mathrm{A}$ & $\mathrm{x}>=0$ \\
& + & $\mathrm{x}$ & $\mathrm{N} / \mathrm{A}$ & $\mathrm{x}$ \\
\hline \hline Triangular & $*$ & $\mathrm{x}>=0$ & $\mathrm{x}>=0$ & $\mathrm{x}>=0$ \\
& + & $\mathrm{x}$ & $\mathrm{x}$ & $\mathrm{x}$ \\
\hline \hline Fractiles & $*$ & $\mathrm{x}>=0$ & $\mathrm{~N} / \mathrm{A}$ & $\mathrm{N} / \mathrm{A}$ \\
\hline
\end{tabular}




\begin{tabular}{||l|l|l|l|l||} 
& + & N/A & N/A & N/A \\
\hline \hline Wedge & $*$ & $\mathrm{x}>=0$ & N/A & $\mathrm{x}>=0$ \\
& + & $\mathrm{x}$ & N/A & $\mathrm{x}$ \\
\hline \hline
\end{tabular}

\section{Distribution Types}

Several types of probability distributions are provided with the IECM. Brief descriptions of each uncertainty distribution are included in the model when the uncertainty editor is selected; the information required, and additional notes, appear below. Distributions that are easiest to use are designated with a dagger $(\dagger)$. Consult a standard statistics reference for additional information.

\section{None}

None represents no uncertainty.

\section{Normal Distributions}

†Normal (mean, stddev) returns a continuous, normal Gaussian probability distribution with the specified mean and the standard deviation, stddev.

†Neghalf_Normal (mean, stddev) returns the lower half of a normal Gaussian probability distribution with the specified mean and the standard deviation, stddev.

†Half_Normal (mean, stddev) returns the upper half of a normal Gaussian probability distribution with the specified mean and the standard deviation, stddev.

This bell-shaped distribution is often assumed in statistical analysis as the basis for unbiased measurement errors. The normal distribution has infinite tails; however, over 99 percent of all values of the normal distribution lie within plus or minus three standard deviations of the mean. Thus, when used to represent uncertainty in physical quantities which much be greater than zero, the standard deviation should not be more than about 20 or 30 percent of the mean.

\section{Lognormal Distribution}

Lognormal (median, gsdev) returns a continuous lognormal probability distribution with the specified median and the geometric standard deviation, gsdev. The geometric standard deviation must be 1 or greater.

This distribution is usually used to represent uncertainty in physical quantities which must be positive values that are positively skewed, such as the ambient concentration of a pollutant. This distribution may be appropriate when uncertainties are expressed on a multiplicative order-of-magnitude basis (e.g., factor of 2) or when there is a probability of obtaining extreme large values.

\section{Uniform Distribution}

†Uniform ( $\min , \max$ ) returns a continuous probability distribution in which every value between $\min$ and $\max$ has an equal chance of occurring.

Use this when you are able to specify a finite range of possible values, but are unable to decide which values in the range are more likely to occur than others. The use of the uniform distribution is also a signal that the details about uncertainty in the variable are not known. It is useful for screening studies. 


\section{Triangular Distribution}

†Triangular (min, mode, max) returns a continuous, triangular probability distribution bounded by $\min$ and $\max$ and with the specified mode.

Use this when you are able to specify both a finite range of possible values and a "most likely" (mode) value. The triangle distribution may be symmetric or skewed. Like the uniform distribution, this distribution indicates that additional details about uncertainty are not yet known. The triangle distribution is excellent for screening studies.

\section{Fractiles}

Fractiles. If $\mathrm{n}$ is the number of elements in the list $\mathrm{L}$, Fractiles $(\mathbf{L})$ returns a continuous probability distribution where the first element is the $0 \%$ fractile, the second is the $1 /(n-1)$ fractile, the third is the $2 /(n-1)$ fractile, and so on. (The values must be enclosed in square-brackets to register as a "list.")

This distribution looks like a histogram for large sample sizes and can be used to represent any arbitrary data or judgment about uncertainties in a parameter, when the parameter is continuous. It explicitly shows detail of the uncertainties. It is used in the IECM Model to represent all trace species data in the default databases. The finite range of possible values is divided into subintervals. Within each subinterval, the values are sampled uniformly according to a specified frequency for each subinterval.

\section{Wedge Distribution}

†Wedge (min, $\max$ ) returns a continuous wedge-shaped probability distribution increasing linearly from $\min$ to $\max$.

Use this when you are able to specify a finite range of possible values. The wedge distribution increases linearly from zero probability at the minimum value to the maximum probability at the maximum value. Like the uniform distribution, this distribution indicates that additional details about uncertainty are not yet known. This is a special case of the triangular distribution described below.

\section{Configuring Uncertainty in Results}

Some uncertainty parameters may be changed while results are displayed. These are modified using the Uncertainty Tools Floating Palette

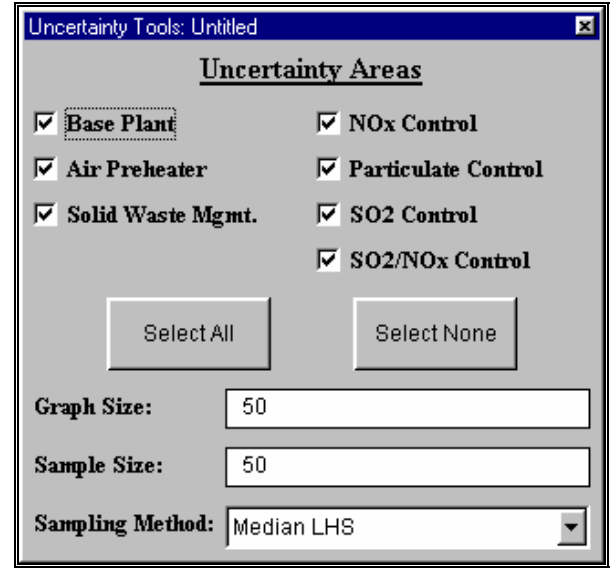

The Uncertainty Tools floating palette 


\section{Uncertainty Areas}

You may choose technology or technologies for which you would like results with uncertain values by clicking the box to the left of each technology. You may select all or none by clicking the buttons at the bottom of the palette.

\section{Graph Size}

The sample size determines the number of possible data points used to draw a graph. This parameter determines how many of the total samples to use for the graph. This value cannot exceed the sample size.

\section{Sample Size}

You can also specify the number of samples used with the sampling method. This is the number of iterations performed in a probabilistic analysis. The appropriate sample size depends on the number and types of uncertainty distributions that are specified, and on the accuracy with which the distribution is to be estimated (especially the tails of the distribution). A sample size of 100 is the default. The maximum is 200. The calculation time and memory requirements are proportional to this value.

\section{Sampling Methods}

Input and output variables are related to each other by model definitions defined for each variable. These relationships are generally referred to as the "decision tree." The model uses this decision tree to determine which input variables must be calculated to specify the output variable. Only those input variables necessary to specify the output variable value are calculated.

Since each input variable can be expressed as a non-singular distribution, a method of sampling the inputs must be determined. Several methods are available in the model, ranging from a deterministic or single "best guess" value to a completely random sampling of each input distribution. The sampling methods all produce sets of values for the inputs. These sets together form the "sampling space."

\section{Deterministic Evaluation}

Output values can be determined by using the most probable value for each input. This method is frequently referred to as the "best guess."

Input variables can be treated deterministically either by specifying only a single value, or by selecting the "Off" option for the "Uncertainty Distribution" pane. This option forces all uncertain parameters to be evaluated deterministically. Selecting the "Off" option forces each uncertainty function used in the decision tree to be evaluated using its expected value. This option overrides any particular uncertainty distribution types.

\section{Monte Carlo}

Monte Carlo is the simplest and best-known sampling method. It draws values at random from the uncertainty distribution of each input variable in the decision tree. For a particular sampling run, each input variable is randomly sampled once. The random samples from each input result in one final output value. This process is repeated $m$ times and results in a final solution set. This set can then be evaluated with standard statistical techniques to determine the mean, precision, and confidence. 
This method has the advantage of providing an easy method of determining the precision for a specific number of samples using standard statistical techniques. However, it suffers from requiring a large number of samples for a given precision. It also has the drawback of substantial noise in the resulting distribution. For these reasons, Latin Hypercube sampling is preferred as the model default.

\section{Latin Hypercube}

Latin Hypercube is a stratified sampling method that divides the sampling space into equally probable intervals, or strata. For each input variable, the method samples each interval in a random order. When the samples from each input variable are combined, one resultant output is determined. This process is repeated $m$ times, forming a final result of $m$ output values. These $m$ output values contain the uncertainty of the output variable, based on all the uncertainties of the entire set of input variables. The value $m$ is referred to as the sample size.

The model contains two variations of Latin Hypercube sampling: Random and Median. Random Latin Hypercube (RLH) samples each strata randomly, while the Median Latin Hypercube (MLH) samples each strata by its median value. (See: Diwekar, U.M. and J.R. Kalagnanam, (1997) "Efficient Sampling Technique for Optimization under Uncertainty,” AIChE Journal, Vol. 43, No. 2, pp. 440-7.) Median Latin Hypercube is the default sampling method.

Both forms of Latin Hypercube have the advantage of sampling more uniformly over the input distributions relative to Monte Carlo sampling, resulting in less noise in the final distribution. Another advantage is the reduced number of samples that must be taken to satisfy a given precision. Latin Hypercube has the drawback that the precision is more difficult to calculate using statistical methods. Finally, the output is random but not independent.

\section{Hammersley}

A new sampling technique has been added to the IECM which is more efficient than either the Monte Carlo or Latin-Hypercube sampling techniques. It is called the Hammersley sequence sampling technique. (See: Diwekar, U.M. and J.R.

Kalagnanam, (1997) "Efficient Sampling Technique for Optimization under Uncertainty,” AIChE Journal, Vol. 43, No. 2, pp. 440-7.) The sampling method is loosely based on the Monte Carlo method. However, instead of using a random number generator, it uses a quasi-random number generator based on Hammersley points to uniformly sample a unit hypercube. These points are an optimal design for placing $\mathrm{n}$ points on a k-dimensional hypercube. The sample points are then inverted over a cumulative probability distribution to define the sample set for any uncertainty variable.

Hammersley has the advantage of high precision and consistent behavior in addition to better computational efficiency. The method reduces the number of samples required relative to the other sampling methods for calculating uncertainty by a factor of 2 to 100. The actual sample reduction varies with the uncertainty function being sampled. 



\section{Appendix A - Introduction to Uncertainty Analysis}

\section{Uncertainty Analysis}

The following section is provided as a means of introducing uncertainty analysis as a tool for model design and operation. However, you should consult standard statistical and other texts (e.g., Morgan and Henrion, Uncertainty, Cambridge Press, 1990) to develop a more complete understanding of the subject.

\section{Introduction}




\section{Philosophy of Uncertainty Analysis}

The classical approach to probability theory requires that estimates for probability distributions be based on empirical data. However, in many practical cases, the available data may not be available or relevant to the problem at hand. Thus, statistical manipulation of data may be an insufficient basis for estimating uncertainty. Engineering analysis or judgments about the data may be required.

An alternative approach is the "Bayesian" view. It differs in how probability distributions are interpreted. The probability of an outcome is your "degree of belief" that the outcome will occur, based on all of the relevant information you currently have about the system. Thus, the probability distribution may be based on empirical data and/or other considerations, such as your own technically-informed judgments. The assessment of uncertainties requires thought about all possible outcomes and their likelihood, not just the "most likely" outcome. The advantage to thinking systematically and critically about uncertainties is the likelihood of anticipating otherwise overlooked problems, or identifying potential payoffs that might otherwise be overlooked.

\section{Types of Uncertain Quantities}

There are a number of types of uncertainty to consider when developing a probability distribution for a variable. Some of these are summarized briefly here.

Statistical error is associated with imperfections in measurement techniques. Statistical analysis of test data is thus one method for developing a representation of uncertainty in a variable.

Empirical measurements also involve systematic error. The mean value of a quantity may not converge to the "true" mean value because of biases in measurement and procedures. Such biases may arise from imprecise calibration, faulty reading of meters, and inaccuracies in the assumptions used to infer the actual quantity of interest from the observed readings of other quantities. Estimating the possible magnitude of systematic error may involve an element of engineering judgment.

Variability can be represented as a probability distribution. Some quantities are variable over time. For example, the composition of a coal (or perhaps a sorbent) may vary over time.

Uncertainty may also arise due to lack of actual experience with a process. This type of uncertainty often cannot be treated statistically, because it requires predictions about something that has yet to be built or tested. This type of uncertainty can be represented using technical estimates about the range and likelihood of possible outcomes. These judgments may be based on a theoretical foundation or experience with analogous systems.

\section{Encoding Uncertainties as Probability Distributions}

As indicated in the previous sections, there are two fundamental approaches for encoding uncertainty in terms of probability distributions. These include statistical estimation techniques and engineering judgments. A combination of both methods may be appropriate in many practical situations. For example, a statistical analysis of measured test data for a new emission control technology may be a starting point for thinking about uncertainties in a hypothetical commercial scale system. You must then consider the effect that systematic errors, variability, or uncertainties about 
scaling-up the process might have on interpreting test results for commercial-scale design applications.

\section{Statistical Techniques}

Statistical estimation techniques involve estimating probability distributions from available data. The fit of data to a particular probability distribution function can be evaluated using various statistical tests. For example, the cumulative probability distribution of a set of data may be plotted on "probability" paper. If the data plot as a straight line, then the distribution is normal. Procedures for fitting probability distribution functions are discussed in many standard texts on probability and are not reviewed here.

Such procedures can be utilized to obtain distribution functions for many of the power plant parameters in the IECM when data are available for operating plants. In other cases, especially where data are limited, expert technical judgments may be necessary to develop appropriate distribution functions for model parameters. The emphasis of the discussion below is on the situations where statistical analysis alone may be insufficient.

\section{Judgments about Uncertainties}

In making judgments about a probability distribution for a quantity, there are a number of approaches (heuristics) that people use which psychologists have observed. Some of these can lead to biases in the probability estimate. Three of the most common are briefly summarized.

Availability: The probability experts assign to a particular possible outcome may be linked to the ease (availability) with which they can recall past instances of the outcome. For example, if tests have yielded high sorbent utilization, it may be easier to imagine obtaining a high sorbent utilization in the future than obtaining lower utilization. Thus, one tends to expect experts to be biased toward outcomes they have recently observed or can easily imagine, as opposed to other possible outcomes that have not been observed in tests.

Representativeness: has also been termed the "law of small numbers." People may tend to assume that the behavior they observe in a small set of data must be representative of the behavior of the system, which may not be completely characterized until substantially more data are collected. Thus, one should be cautious in inferring patterns from data with a small number of samples.

Anchoring and adjustment: involves using a natural starting point as the basis for making adjustments. For example, an expert might choose to start with a "best guess" value, which represents perhaps an average or most likely (modal) value, and then make adjustments to the best guess to achieve "worst" and "best" outcomes as bounds. The "worst" and "best" outcomes may be intended to represent a 90 percent probability range for the variable. However, the adjustment from the central "best guess" value to the extreme values is often insufficient, with the result that the probability distribution is too tight and biased toward the central value. This phenomenon is overconfidence, because the expert's judgment reflects less uncertainty in the variable than it should. The "anchor" can be any value, not just a central value. For example, if an expert begins with a "worst" case value, the entire distribution may be biased toward that value. 
Motivational Bias: Judgments also may be biased for other reasons. One common concern is motivational bias. This bias may occur for reasons such as:

- a person may want to influence a decision to go a certain way;

- the person may perceive that they will be evaluated based on the outcome and might tend to be conservative in their estimates;

- the person may want to suppress uncertainty that they actually believe is present in order to appear knowledgeable or authoritative; and

- the expert has taken a strong stand in the past and does not want to appear to contradict himself by producing a distribution that lends credence to alternative views.

\section{Designing an Elicitation Protocol}

Studies of uncertainty judgment show that the most frequent problem encountered is overconfidence. Knowledge of how people make judgments about probability distributions can be used to design a procedure for eliciting these judgments. The appropriate procedure depends on the background of the expert and the quantity for which the judgment is being elicited. For example, if you have some prior knowledge about the shape of the distribution for the quantity, then it may be appropriate to ask you to think about extreme values of the distribution and then to draw the distribution yourself. On the other hand, if you have little statistical background, it may be more appropriate to ask you a series of questions. For example, you might be asked the probability of obtaining a value less than or equal to some value $\mathrm{x}$, and then the question is repeated for a few other values of $\mathrm{x}$. Your judgment can then be graphed by an elicitor, who would review the results of the elicitation with you to see if you are comfortable with your answers.

To overcome the typical problem of overconfidence, consider extreme high or low values before asking about central values of the distribution. In general, experts' judgments about uncertainties tend to improve when:

- the expert is forced to consider how things could turn out differently than expected (e.g., high and low extremes); and

- the expert is asked to list reasons for obtaining various outcomes.

While the development of expert judgments may be flawed in some respects, it does permit a more robust analysis of uncertainties in a process when limited data are available. Furthermore, in many ways, the assessment of probability distributions is qualitatively no different than selecting single "best guess" values for use in a deterministic estimate. For example, a "best guess" value often represents a judgment about the single most likely value that one expects to obtain. The "best guess" value may be selected after considering several possible values. The types of heuristics and biases discussed above may play a similar role in selecting the value. Thus, even when only a single "best guess" number is used in an analysis, a seasoned engineer usually has at least a "sense" for "how good that number really is." This may be why engineers are usually able to make judgments about uncertainties, because they implicitly make these types of judgments routinely. 


\section{A Non-technical Example}

To illustrate the process of defining a subjective probability distribution, let's turn to a simple example of eating lunch in a cafeteria. How long does it take from the time you enter the cafeteria to the time you pay the cashier? Assume that you enter at 12:05 p.m. on a weekday and that you purchase your entire meal at the cafeteria. The answer you give may depend on your recent experiences in the cafeteria. Think about the shortest possible time that it could take (suppose nobody else is getting lunch) or the longest possible time (everyone shows up at the same time). What is the probability that it will take 2 minutes or less? 45 minutes or less? Is the probability that it takes 10 minutes or less greater than 50 percent? etc. After asking yourself a number of questions such as these, it should be possible to draw a distribution for your judgment regarding the time require to obtain and purchase lunch at the cafeteria. Such a distribution might take the form of a fractile distribution giving the probabilities of different waiting times to purchase lunch. For example, your evaluation may conclude that there is only a 1 percent (1 in 100) chance it will take one minute or less, a 60 percent chance of 1 to 10 minutes, a 25 percent likelihood of 10 to 15 minutes, and a 14 percent chance of up to 25 minutes. These probability intervals can be drawn as a histogram and translated into a fractile distribution for a probabilistic analysis.

\section{A Technical Example}

A second example focuses on a performance parameter for an advanced pollution control system. This parameter has an important effect on system performance and cost.

The example focuses on an assessment of uncertainty in the performance of an innovative emission control system for coal-fired power plants. In this system, a chemical sorbent circulates between a fluidized bed reactor, where $\mathrm{SO}_{2}$ in the flue gas is removed by chemical reaction with the sorbent, and a regenerator, in which $\mathrm{SO}_{2}$ is evolved in a reaction of the sulfated sorbent with methane. There is no commercial experience with this system; the largest test unit has been sized to handle $100 \mathrm{scfm}$ of flue gas. Furthermore, the test units have used batch, rather than continuous, regeneration.

One of the key parameters affecting the performance and cost of this system is the regeneration efficiency, which is defined as the fraction of the spent sorbent which is converted for reuse. In small-scale tests in which the regeneration efficiency has been estimated, the efficiency was found to be roughly 30 to 50 percent. In a more recent test, the regeneration efficiency was not measured due to instrumentation difficulties; however, it may have been lower than the previously obtained values. Regeneration residence times were typically greater than 30 minutes.

A detailed modeling study of the regenerator estimated that a properly sized and designed unit, coupled with heating of the sorbent to a sufficiently high reaction temperature, would result in a regeneration efficiency of just over 99 percent at a 30 minute residence time.

A potential problem that may be occurring in the test units is that regenerated sorbent in the regenerator may be reabsorbing some of the evolved $\mathrm{SO}_{2}$. However, this was not considered in the modeling study of the regenerator.

Based on this information, it appears that it may be possible to achieve the design target of over 99 percent regeneration efficiency. Clearly, however, it is possible that the actual efficiency may be substantially less than this target value. As a worst case, we might consider the known test results as a lower bound. Thus, there is a small 
chance the regeneration efficiency may be less than 50 percent. We expect the regeneration efficiency to tend toward the target value of 99.2 percent. Thus, to represent the expectation that the efficiency will be near the target value, but may be substantially less, we can use a negatively skewed distribution. In this case, we assume a triangle with a range from, say, 50 to 99.2 percent with a mode also at 99.2 percent. The triangle in this case gives us a distribution with a mean of about 83 percent and a median of about 85 percent. This type of triangular distribution, in which a minimum, maximum, and modal value are specified, is often a convenient way of expressing uncertainty distributions when a little information is available. 


\section{Appendix B - Technical Support}

\section{Reaching Technical Support}

Questions, issues or concerns regarding the Integrated Environmental Control Model should be directed to:

\section{Carnegie Mellon University}

BERKENPAS, MICHAEL B.

Office: Baker Hall 128B

Location: Pittsburgh, PA 15213

Phone: (412) 268-1088

FAX: (412) 268-1089

Email: mikeb@cmu.edu

Web: www.iecm-online.com/support.html 


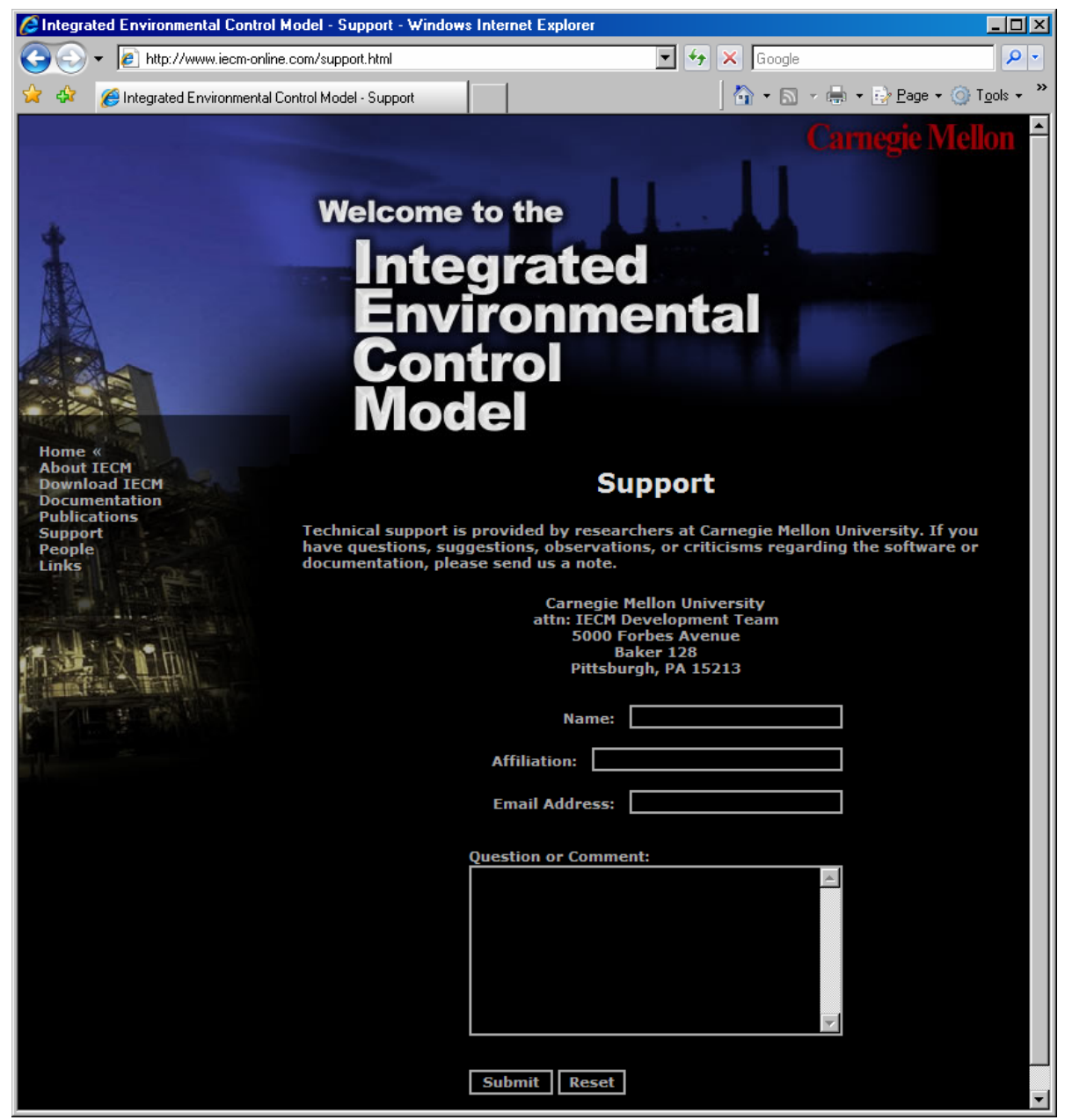




\section{Glossary of Terms}





\section{Index}

